Final Report

FHWA/IN/JTRP - 2000/18

\title{
THE EXAMINATION OF INFRA-RED TECHNIQUES FOR INSPECTION OF STEEL STRUCTURES
}

\author{
By \\ Vachirapun Trakulyingyong \\ and \\ Mark D. Bowman \\ School of Civil Engineering \\ Purdue University \\ Joint Transportation Research Program \\ Project Number: C-36-56BV \\ File Number: 7-4-47 \\ SPR-2203 \\ Conducted in Cooperation with the \\ Indiana Department of Transportation \\ and the \\ U.S. Department of Transportation \\ Federal Highway Administration
}

The contents of this report reflect the views of the authors, who are responsible for the facts and the accuracy of the data presented herein. The contents do not necessarily reflect the official views or policies of the Indiana Department of Transportation or the Federal Highway Administration at the time of publication. This report does not constitute a standard, specification, or regulation.

Purdue University

West Lafayette, IN 47906

December 2001 


\section{TECHNICAL SUMMARY}

\section{INTRODUCTION}

Component inspection is a key task that should be performed to insure continued structural integrity. Clearly, early detection of damage is critical to maintain safe operation of highway bridge structures whose failure can lead to the loss of life or property. Inspection is required both during initial manufacturing to insure that the new structure is free of unacceptable anomalies, and later to detect service-induced damage. The safe operating life concept is based on the assumption that flaws may develop in the structure when it is used for some period of time. This initial flaw will grow to a size that may cause severe damage or even collapse of the structure. In general, the initial crack size assumptions are based on inspection capabilities (i.e., the largest crack that could go undetected.) Thus, inspection limits, which are associated with various inspection procedures, have a direct influence on investigating the structural integrity and determining the safe operating life.

Non-destructive evaluation (NDE) is one of the best methods to evaluate the integrity of new and old structures. The results of the NDE inspection are used to evaluate the suitability of an object of interest. Moreover, the ideal inspection method should be simple to apply, accurate, and reliable. Research in the NDE field has increased dramatically in recent years as scientists and engineers have sought to develop new inspection methods to help field engineers ensure structural integrity for both new and old structures. Especially for the infra-red technique, increasing developments in the infra-red technology suggest further applications for this promising inspection method. The primary objective of this project is to investigate the capability, sensitivity, and limitations of fatigue crack detection in steel structures using the infra-red thermography technique.

After an in-depth review of various infra-red techniques, a specific infra-red system was selected to detect cracks in steel bridge members. To evaluate the sensitivity 
and performance of the infra-red inspection equipment, experiments were conducted in both the laboratory and under actual field conditions. Fatigue cracks in the selected laboratory specimens and in members evaluated in the field were inspected using the infra-red thermography technique. All data from experiments were examined to investigate the performance of this technique and develop the suitable recommendation for using this technique to detect cracks in steel bridge members and structural components.

\section{FINDINGS}

The feasibility and general practicality of using infra-red inspection techniques to detect fatigue cracks in steel highway bridge structures was assessed. Control specimens were tested in the Kettelhut Structural Engineering Laboratory to evaluate the many variables that influence infra-red sensitivity. Based on these tests, the optimal sensing controls were established for the infra-red system used in this study. Infra-red inspection was then performed under actual field conditions to assess the impact field environmental conditions. Several observations from the investigation are summarized in the following:

1. The active infra-red inspection approach, where an external heat source is used to create a thermal variation across the region of interest, provided more reliable inspection results than the passive inspection approach, where the thermal variation is related to the variation in internal stress carried by the component being inspected.

2. Crack depth with respect to member thickness is an important factor affecting infra-red crack detection. Only through-thickness cracks can be detected clearly, with sharp distinction, by the infra-red camera utilized in this study.

3. Surface condition significantly affects the results obtained by infra-red inspection. Surfaces that are coated with a matte color improve the quality of the thermal images and increase the longest effective camera distance. Also, 
painting with a matte color reduces the effects of surface reflection and other spurious signals coming from a non-uniform specimen surface.

4. It is difficult to determine a unique set of optimum critical factor values, such as heating time, delay time, distance from infra-red camera to object, etc., for varied testing environments. Many of the factors are influenced by environmental conditions, such as the surface temperature and the reflectivity of the surface, and results in a change in the inspection system performance.

5. The smallest crack that can be distinctly and reliably detected with the infra-red system used in this project is larger than the smallest crack size that can be detected by an unaided human eye.

\section{IMPLEMENTATION}

Based on the results in this study and those reported in studies elsewhere, it is apparent that infra-red inspection can be used to detect fatigue cracks in steel bridge members. Even very small fatigue cracks were detected by the infra-red system in control specimens when tested under laboratory conditions. However, a number of challenges were encountered during the study which suggest that the infra-red system should not be implemented for field use at this time.

Some of the concerns encountered in use of the infra-red system included the large number of environment-sensitive critical factors that influenced equipment performance; the lack of compactness of the system, with several separate components needed to conduct the inspection; the need for frequent re-calibration of the infra-red camera; and the operator skill level required to utilize the infra-red system. The primary drawback, however, which is partially related to the limitations noted above, is that the smallest crack that could be reliably detected when using infra-red inspection is larger than that which can be detected with the unaided eye. 
In spite of the many limitations encountered in this study, infra-red inspection is still a promising application for fatigue-crack crack detection. However, additional development, probably in a commercial setting, needs to occur before the infra-red inspection method is viable for routine bridge inspection. 
TECHNICAL REPORT STANDARD TITLE PAGE

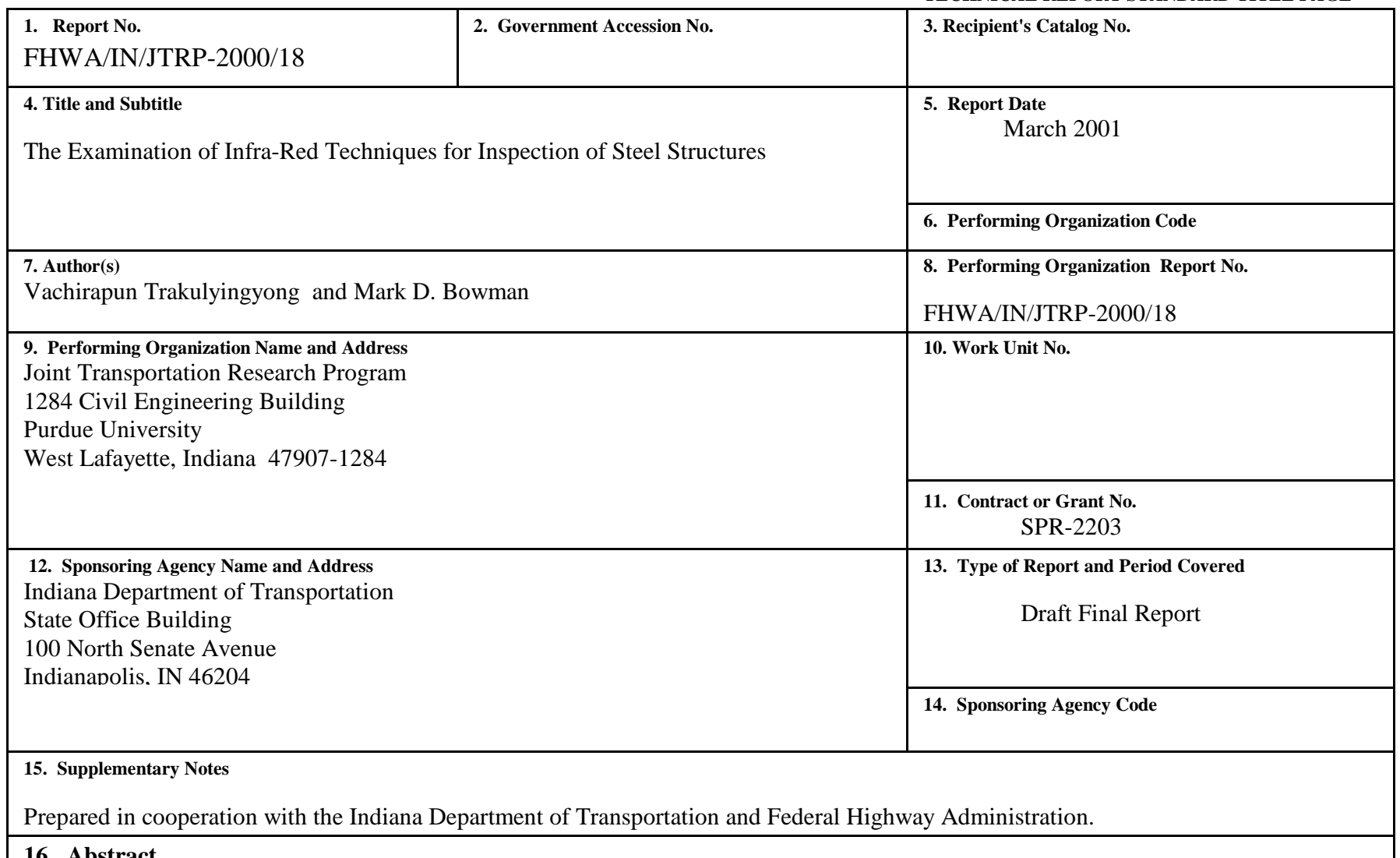

Infra-red thermography systems that have been developed over the last few years offer great potential to locate and discover flaws in steel highway bridge structures at a relatively early stage in their development. Under ideal conditions, the use of infra-red instrumentation should allow bridge inspection personnel to rapidly scan the structure and determine if a potential structural problem has developed. If a problem spot is located by the infra-red camera, then the trouble spot can be examined carefully to determine the need for corrective maintenance.

The primary purpose of this research study is to evaluate the accuracy and reliability of sensitive infra-red equipment for detecting fatigue cracks in steel highway bridge structures and components. The performance and sensitivity of one particular infra-red system was explored by conducting tests on two different specimen types in the laboratory, followed by a check of the equipment under field conditions. Crack detection sensitivity in the laboratory was evaluated using a center-hole test coupon geometry as well as a welded attachment plate detail. The test samples were subjected to cyclic loading to initiate and propagate a fatigue crack. Control variables for the infra-red system were then varied to evaluate the optimal conditions. The field tests were conducted to assess the equipment limitations and performance under field conditions. The detail inspected involved a vertical plate that was welded to the web of a beam member and used to attach transverse diaphragm cross-frame members; the diaphragm connection plate was selected for inspection because it was known that fatigue cracks had developed at the end of a number of the vertical plates.

It was found that infra-red inspection could be used successfully to detect fatigue cracks in steel bridge members and components if the crack had propagated through the thickness. Consequently, the crack size that could be reliably and consistently detected was not significantly different from that which could be detected from a careful visual inspection. Moreover, a number of difficulties were encountered when using infra-red inspection in the field. Limitations were encountered in the field related to mobility of the equipment, calibration requirements, operator skill level required, and the variable effects of environmental factors that influence the detection capabilities.

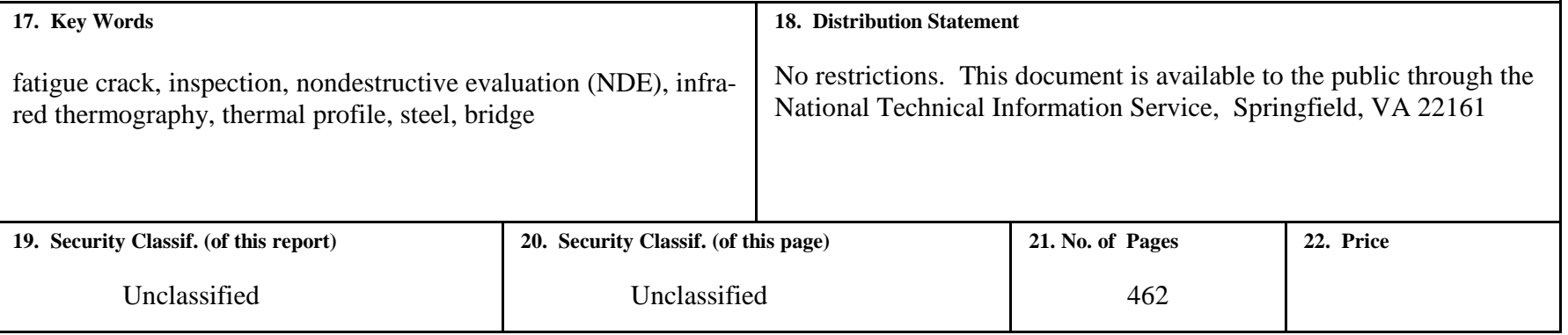




\section{ACKNOWLEDGEMENTS}

The research project was financially supported by the Federal Highway Administration and the Indiana Department of Transportation. The authors would like to express their grateful acknowledgments for sponsorship of this project.

The valuable suggestions and comments provided by the Study Advisory Committee are sincerely appreciated. The members of the Study Advisory Committee include the following: Dr. Tommy Nantung, Mr. James Karr, Mr. Donald Leonard, and Mr. William Dittrich of the Indiana Department of Transportation; Mr. Rick Drumm and Mr. Thomas Saad of the Federal Highway Administration; and Professor Adolph Altschaeffl and Professor Mark Bowman of Purdue University. Particular acknowledgement is given to Professor Adolph Altschaeffl, who provided encouragement and repeatedly suggested that the study be initiated.

Special acknowledgement is also due to several INDOT personnel who assisted in the experimental portion of the study. Although not all of these can be named individually, special thanks are due to Mr. Larry Decker and Mr. Mike Wink in the Crawfordsville District who assisted in coating some of the laboratory test specimens; and to Mr. James Mickler and Mr. James Karr who provided patient assistance in the field testing and inspection operations. Thanks are also due to Mr. Daniel Bazile of Stress Photonics, Inc. who provided assistance in the operation and use of the infrared camera and associated software. Sincere thanks are also extended to several individuals in the Kettelhut Laboratory at Purdue University, who have provided help for various aspects of the study. Among them are Mr. Harry Tidrick, Ms. Jodi Enderson, Mr. Santiago Pujol, and Mr. Ahmet Koray Tureyen. 


\section{TABLE OF CONTENTS}

Page

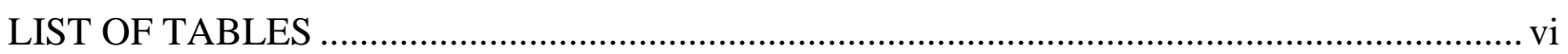

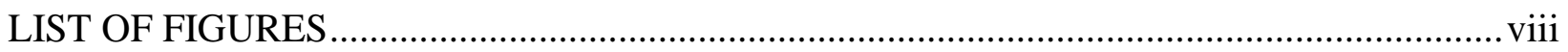

IMPLEMENTATION REPORT ..........................................................................

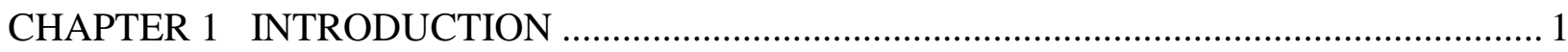

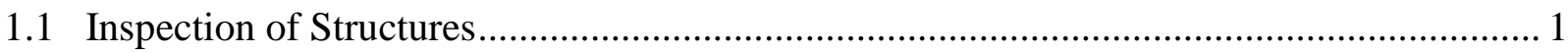

1.2 Motivation and Project Objective ........................................................................... 2

\section{CHAPTER 2 BACKGROUND}

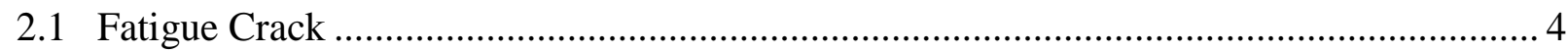

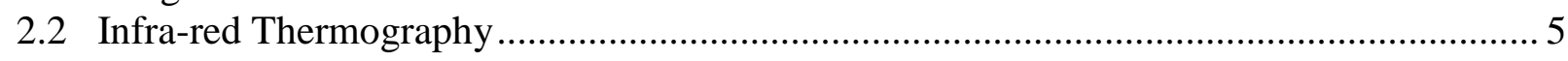

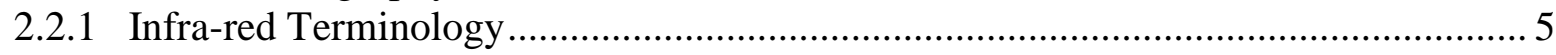

2.2.2 The Basic Concept of Infra-red Thermography Imaging .................................... 6

2.2.3 The Applications of Infra-red Thermography NDE Techniques ............................ 9

2.3 The Active Approach Infra-red Thermography NDE ............................................. 10

2.4 The Passive Approach Infra-red Thermography NDE ............................................. 13

CHAPTER 3 EXPERIMENTAL PROCEDURES ......................................................... 21

3.1 The Scope of Experimental Study ..................................................................... 21

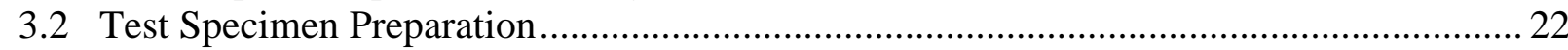

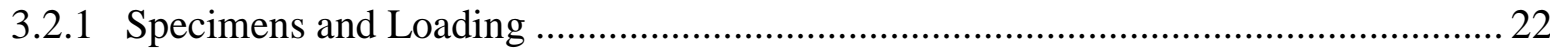

3.2.2 Test Specimen Surface Preparation.............................................................. 24

3.2.3 The Fatigue Crack Growth Characterization .................................................. 26

3.3 The Experimental Apparatus................................................................................... 28

3.3.1 The Projector (Heat Source) and Controller .................................................... 28

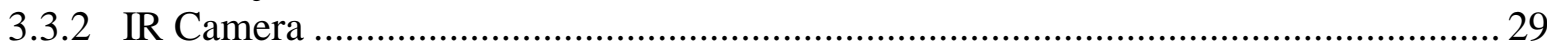

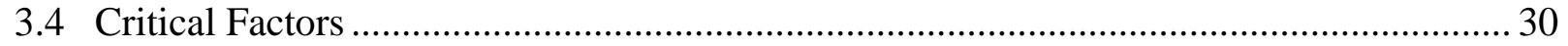

3.4.1 Critical Factors of the Passive Approach ........................................................... 31

3.4.2 Critical Factors of the Active Approach ........................................................... 32

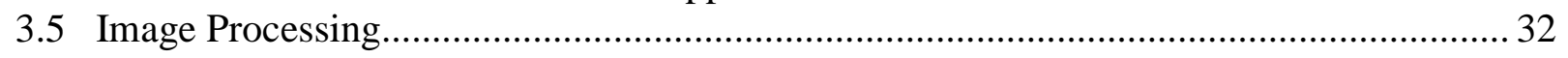

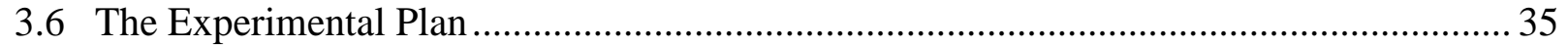

3.6.1 The Experimental Procedures for $\mathrm{CH}$ Test Series .............................................. 36

3.6.2 The Experimental Procedures for WD Test Series ........................................... 38

CHAPTER 4 DISCUSSION OF LABORATORY RESULTS ......................................... 75

4.1 Discussions of the Results from $\mathrm{CH}$ Test Series....................................................... 75 


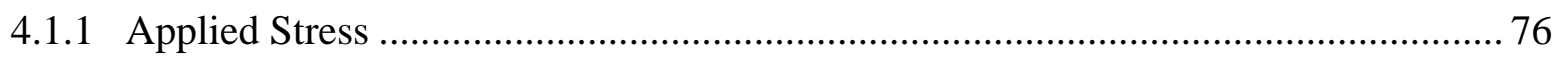

4.1.2 Distance from IR Camera to Test Specimen........................................................... 77

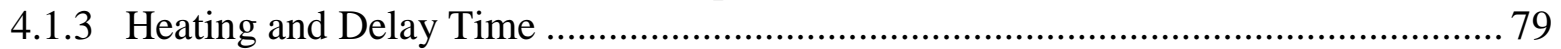

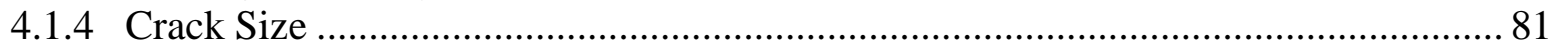

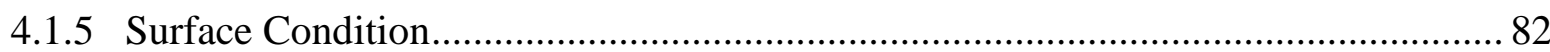

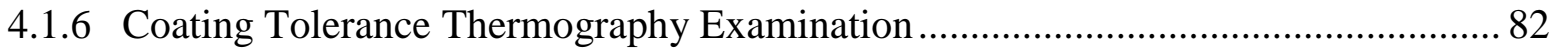

4.2 Discussions of the Results from WD Test Series............................................................. 83

4.2.1 Distance from IR Camera to Test Specimen............................................................. 84

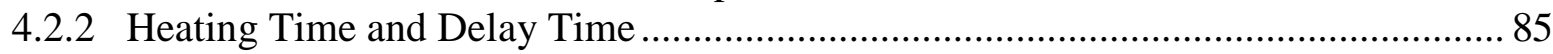

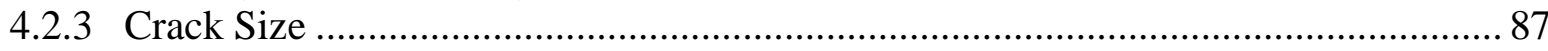

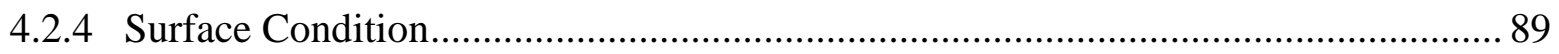

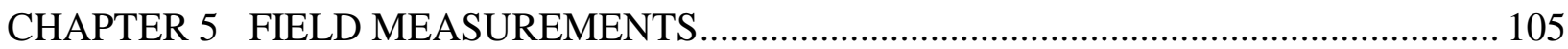

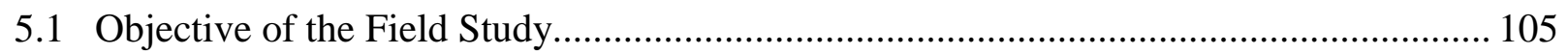

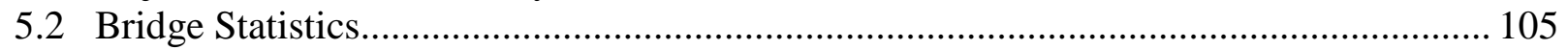

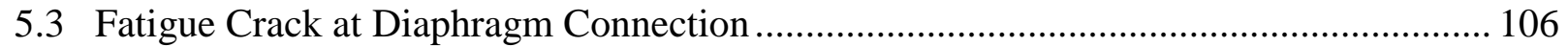

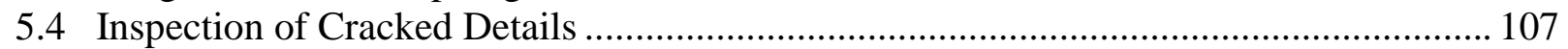

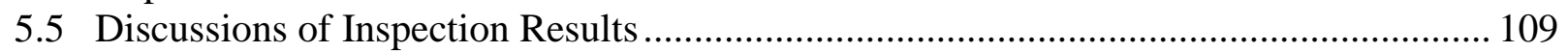

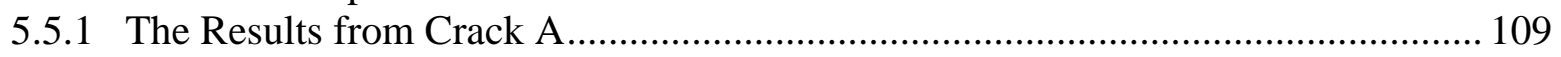

5.5.2 Results from Crack B and Crack C ................................................................. 110

5.6 General Observations from IR Field Inspection ........................................................... 111

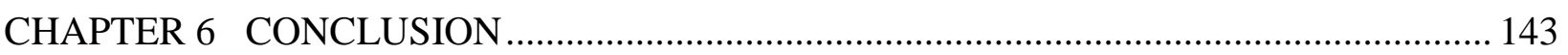

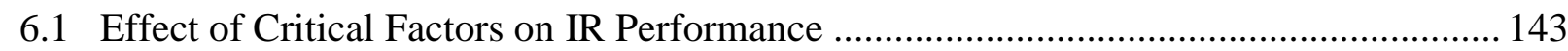

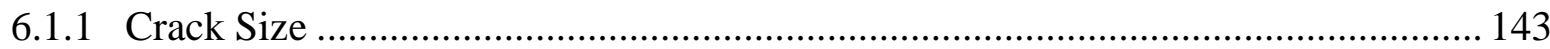

6.1.2 Distance from IR Camera to Specimen................................................................. 144

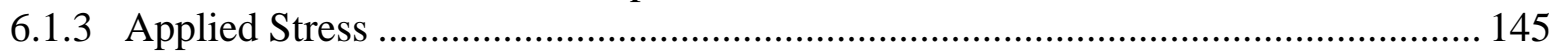

6.1.4 Heating Time and the Delay Time …………..................................................... 145

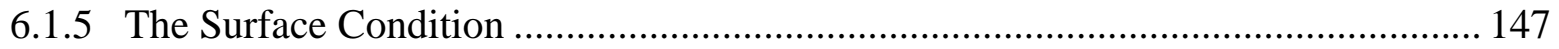

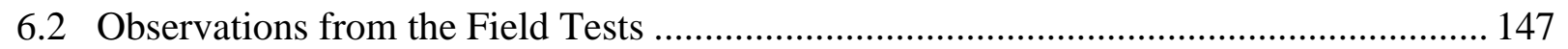

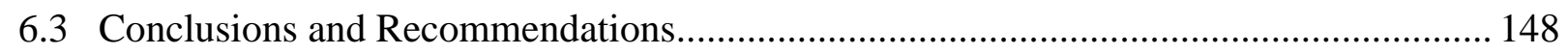

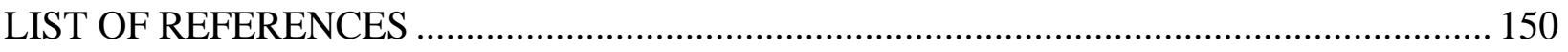

APPENDIX A LABORATORY EXPERIMENTAL RESULTS .............................................. 153

A.1 Experimental Results from CH Test Series............................................................... 153

A.2 Experimental Results from WD Test Series................................................................ 155

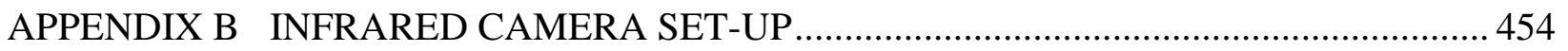

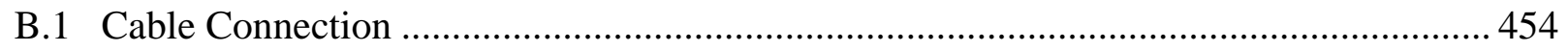

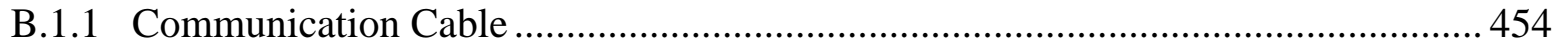

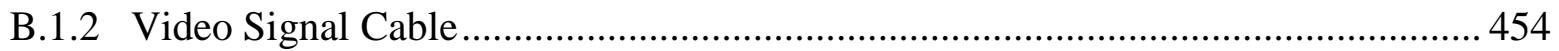




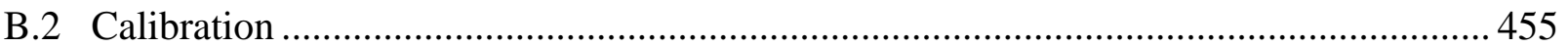

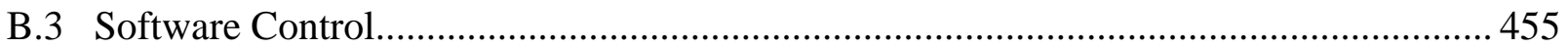

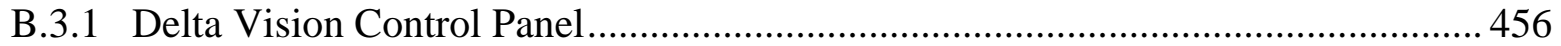

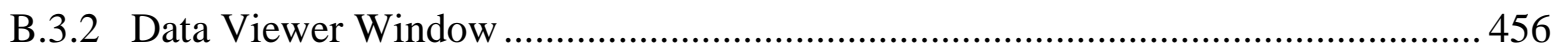

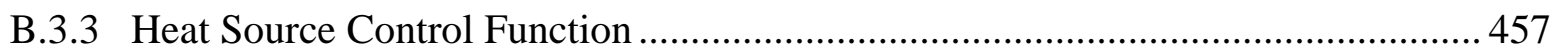

B.3.4 Image Control Function........................................................................................... 457 


\section{LIST OF TABLES}

\section{Page}

Table 3.1 Dimensions and cross-section areas of test specimens in $\mathrm{CH}$ test series

Table 3.2 Dimensions and cross-section areas of test specimens in WD test series.

Table 3.3 The minimum and maximum load for $\mathrm{CH}$ test series.....................40

Table 3.4 The minimum and maximum load for WD test series.................... 40

Table 3.5 Average emissivity values for various spray coatings on steel............. 41

Table 3.6 The emissivity values to these of various un-coated surfaces................42

Table 3.7 The transmission efficiency of energy in the infra-red range of the typical cylindrical lenses material.............................42

Table 5.1 The results of crack A from field test............................. 112

Table 5.2 The results of crack B from field test................................ 113

Table 5.3 The results of crack $\mathrm{C}$ from field test................................ 114

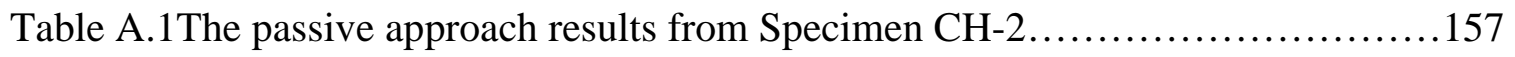

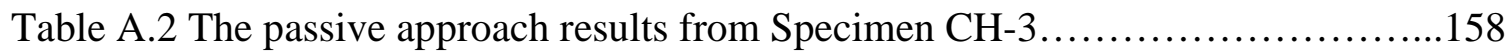

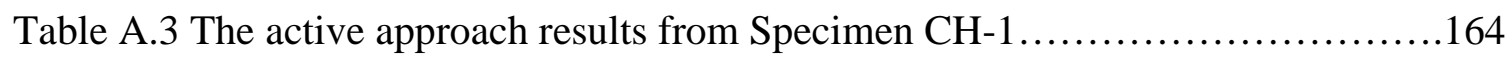

Table A.4 The active approach results from Specimen CH-2 ..................... 165

Table A.5 The active approach results from Specimen CH-3.......................167

Table A.6 The active approach results from Specimen WD-1..................... 174

Table A.7 The active approach results from Specimen WD-2 ..................... 177

Table A.8 The active approach results from Specimen WD-3 (tested under the enclosed laboratory condition). 180 
Table A.9 The active approach results from Specimen WD-4 (tested under

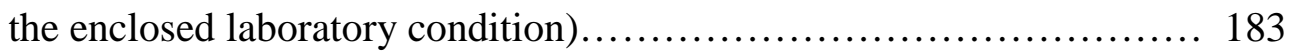




\section{LIST OF FIGURES}

Figure 2.1 Schematic representation of the fatigue crack formation, growth, and fracture.......................................... 15

Figure 2.2 Initiation and propagation portions of the fatigue life................. 15

Figure 2.3 Schematic representation of $\log \mathrm{da} / \mathrm{dN}-\log \Delta \mathrm{K}$ data $\ldots \ldots \ldots \ldots \ldots \ldots \ldots \ldots$

Figure 2.4 Electromagnetic spectrum.................................... 16

Figure 2.5 Graphical representation of the concept of the focal plane array camera....17

Figure 2.6 Heat transfer in an object with a defect depends on the geometry and material properties of the defect in relation to those of the object..... 17

Figure 2.7 Thermal method............................................. 18

Figure 2.8 The infra-red thermography NDE active approach.................... 18

Figure 2.9 Heat reflected from paint chips................................. 19

Figure 2.10 Experimental results showing the dependence of the image contrast on the angle between the heat source and the fatigue crack................19

Figure 2.11 Schematic view of elliptical hole in a large plate loaded with remote tensile stress...........................................20

Figure 3.1 Simple-detail test specimen dimensions (all units are in millimeter)......43

Figure 3.2 Weld-detail test specimen dimensions (all units are in millimeter)........44

Figure 3.3 Stress distribution around the notch tip...........................45

Figure 3.4 Fatigue strength of plates with transverse fillet welds..................45

Figure 3.5 The relationship between maximum stress in base plate and failure life .................................................46

Figure 3.6 The test specimen surface preparation............................47

Figure 3.7 Paint chip .................................................. 47 
Figure 3.8 Final crack size in $\mathrm{CH}$ test specimens............................ 48

Figure 3.9 Surface crack length versus number of loading cycles of Specimen CH-1..49

Figure 3.10 Surface crack length versus number of loading cycles of Specimen CH-2..50

Figure 3.11 Surface crack length versus number of loading cycles of Specimen CH-3...51

Figure 3.12 The graphic showing surface crack length (a) and through-thickness

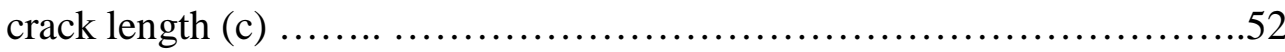

Figure 3.13 Crack in the weld (top) and crack in the member at the weld toe (bottom)

Figure 3.14 Crack at weld toe and crack in weld on Specimen WD-1................53

Figure 3.15 Surface in-weld crack length versus number of loading cycles of Specimen

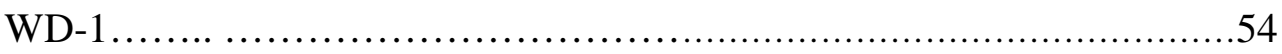

Figure 3.16 Surface weld toe crack length versus number of loading cycles of Specimen

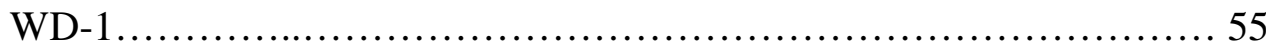

Figure 3.17 Through-thickness weld toe crack length versus number of loading cycles of

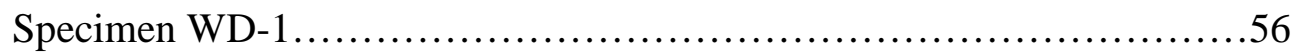

Figure 3.18 Surface weld toe crack length (back side) versus number of loading cycles of Specimen WD 1 .............................................. 57

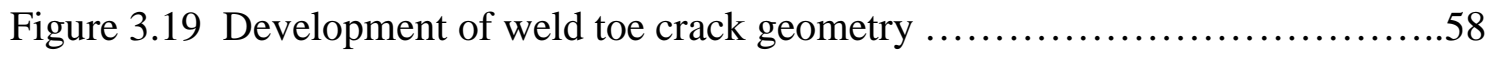

Figure 3.20 Crack at weld toe and crack in weld on Specimen WD-2 ................59

Figure 3.21 Surface in weld crack length versus number of loading cycles of Specimen

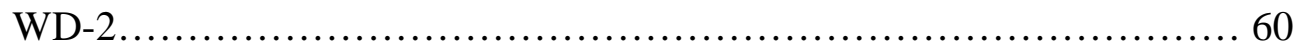

Figure 3.22 Surface weld toe crack length versus number of loading cycles of Specimen WD-2

Figure 3.23 Through-thickness weld toe crack length versus number of loading cycles of Specimen WD-2. .62

Figure 3.24 Surface weld toe crack length (back side) versus number of loading cycles of Specimen WD-2

Figure 3.25 Visible crack in Specimen WD-3 at 1,500,000 loading cycles............64

Figure 3.26 Visible crack in Specimen WD-3 at 1,600,000 loading cycles............64

Figure 3.27 Visible crack in Specimen WD-3 at 1,670,000 loading cycles............65

Figure 3.28 Visible crack in Specimen WD-3 at 1,735,550 loading cycles............65 
Figure 3.29 Surface failure of Specimen WD-3 ...............................66

Figure 3.30 Visible crack in Specimen WD-4 at 1,250,000 loading cycles............67

Figure 3.31 Visible crack in Specimen WD-4 at 1,840,000 loading cycles.............67

Figure 3.32 Surface failure of Specimen WD-4 ..............................68

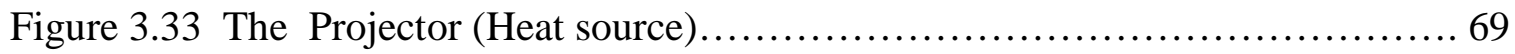

Figure 3.34 The IR camera and calibrate plates................................. 70

Figure 3.35 Schematic represents the concept of heating and delay time..............71

Figure 3.36 Setting up the camera to capture the thermal image of the test specimen... 72

Figure 3.37 The examples of thermal image (a), thermal intensity profile (b),

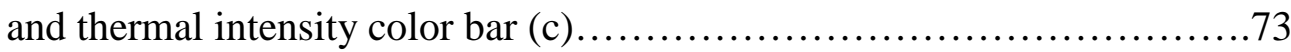

Figure 3.38 Theoretical schematic representing The coating tolerance thermography concept................................................. 74

Figure 4.1 Average thermal gradient versus delay time of Specimen CH-3 at 575,000 loading cycles..................................................... 90

Figure 4.2 The maximum thermal gradient versus delay time of Specimen CH-3 at 575,000 loading cycles.

Figure 4.3 The ratio of the maximum thermal gradient to average thermal gradient versus delay time of Specimen $\mathrm{CH}-3$ at 575,000 loading cycles.

Figure 4.4 Average thermal gradient versus delay time of Specimen WD-1 at $1,335,000$ loading cycles.

Figure 4.5 The maximum thermal gradient versus delay time of Specimen WD-1 at 1,335,000 loading cycles.

Figure 4.6 The ratio of the maximum thermal gradient at crack to the average thermal gradient versus delay time of Specimen WD-1 at 1,335,000 loading cycles. 95

Figure 4.7 Average thermal gradient versus delay time of Specimen WD-2 at $1,131,000$ loading cycles. 
Figure 4.8 The maximum thermal gradient versus delay time of Specimen

WD-2 at 1,131,000 loading cycles.

Figure 4.9 The ratio of the maximum thermal gradient at crack to the average thermal gradient versus delay time of Specimen WD-2 at 1,131,000 loading cycles.

Figure 4.10 Average thermal gradient versus delay time of Specimen WD-3 (tested in laboratory condition) at 1,735,550 loading cycles

Figure 4.11 The maximum thermal gradient versus delay time of Specimen WD-3 (tested in laboratory condition) at 1,735,550 loading cycles.

Figure 4.12 The ratio of the maximum thermal gradient at crack to the average thermal gradient versus delay time of Specimen WD-3 (tested in laboratory condition) at 1,735,550 loading cycles

Figure 4.13 Average thermal gradient versus delay time of Specimen WD-4 (tested under laboratory condition) at 1,845,500 loading cycles 102

Figure 4.14 The maximum thermal gradient versus delay time of Specimen WD-4 (tested under laboratory condition) at 1,845,500 loading cycles 103

Figure 4.15 The ratio of the maximum thermal gradient at crack to the average thermal gradient versus delay time of Specimen WD-4 (tested under laboratory condition) at 1,845,500 loading cycles 104

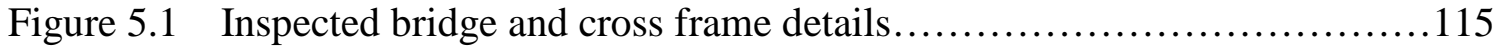

Figure 5.2 Crack at weld under connection between cross frame and girder web.....116

Figure 5.3 Drilled hole used as crack arrester at weld connection (left) and two

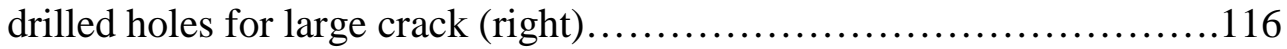

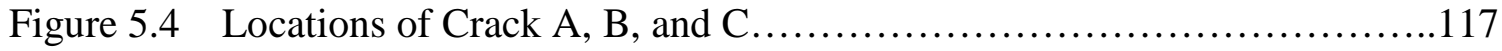

Figure 5.5 Crack A (large crack) ....................................... 118

Figure 5.6 Crack B (small crack) on detail side of girder web.....................119

Figure 5.7 Crack C (intermediate crack) on detail side of girder web...............119

Figure 5.8 Inspection of crack at connection detail between cross frame and girder web 
Figure 5.9 Inspection of cracks A, B, and C on the opposite side

Figure 5.10 Inspection of crack A on detail side (IR camera at the same level as the crack)

Figure 5.11 Inspection of cracks B and C on the detail side (IR camera was set directly under the cross frame).

Figure 5.12 Thermal images of crack A (clear side). The heating time is 30 seconds.

The delay time is 1 second.

Figure 5.13 Thermal images of crack A (clear side). The heating time is 30 seconds.

The delay time is 3 seconds.

Figure 5.14 Thermal images of crack A (clear side). The heating time is 30 seconds.

The delay time is 6 seconds.

Figure 5.15 Thermal images of crack A (clear side). The heating time is 30 seconds.

The delay time is 9 seconds.

Figure 5.16 Thermal images of crack A (detail side). The heating time is 90 seconds.

The delay time is 1 second.

Figure 5.17 Thermal images of crack A (detail side). The heating time is 90 seconds.

The delay time is 3 seconds.

Figure 5.18 Thermal images of crack A (detail side). The heating time is 90 seconds.

The delay time is 6 seconds.

Figure 5.19 Thermal images of crack A (detail side). The heating time is 90 seconds.

The delay time is 9 seconds.

Figure 5.20 Thermal images of crack A (detail side). The heating time is 90 seconds.

The delay time is 1 second.

Figure 5.21 Thermal images of crack A (detail side). The heating time is 90 seconds.

The delay time is 3 seconds.

Figure 5.22 Thermal images of crack A (detail side). The heating time is 90 seconds.

The delay time is 6 seconds.

Figure 5.23 Thermal images of crack A (detail side). The heating time is 90 seconds.

The delay time is 9 seconds. 
Figure 5.24 Thermal images of crack B (detail side). The heating time is 120 seconds.

Figure 5.25 Thermal intensity profile along the line across the fatigue crack shown in Figure 5.20.

Figure 5.26 Thermal images of crack B (plain side). The heating time is 120 seconds..137

Figure 5.27 Thermal images of crack C (detail side). The heating time is 90 seconds.

The delay time is 1 second.

Figure 5.28 Thermal images of crack C (detail side). The heating time is 90 seconds.

The delay time is 3 seconds.

Figure 5.29 Thermal images of crack C (detail side). The heating time is 90 seconds.

The delay time is 6 seconds.

Figure 5.30 Thermal images of crack C (detail side). The heating time is 90 seconds.

The delay time is 9 seconds.

Figure 5.31 Thermal images of crack C (plain side). The heating time is 120 seconds..142

Figure A.1 Thermal images of unpainted Specimen CH-2 (using the passive approach) .

Figure A.2 Thermal intensity profiles along the line across the fatigue crack shown in Figure A.1. 188

Figure A.3 Thermal images of Specimen $\mathrm{CH}-2$ (using the passive approach).... 190

Figure A.4 Thermal images of unpainted Specimen CH-3 (using the passive approach) at 400,000 loading cycles with various stresses.

Figure A.5 The thermal intensity profile along the line across the fatigue crack shown in Figure A.4. 194

Figure A.6 Thermal images of unpainted Specimen CH-3 (using the passive approach) at 500,000 loading cycles with various stresses.

Figure A.7 The thermal intensity profile along the line across the fatigue crack shown in Figure A.6. 198

Figure A.8 Thermal images of Specimen $\mathrm{CH}-3$ (using the passive approach) at 500,000 loading cycles with various stresses 
Figure A.9 Thermal images of unpainted Specimen CH-1 taken at the various distances (no load is applied to the specimen) .................... 202

Figure A.10 Thermal intensity profile along the line across the fatigue crack shown in Figure A.9. .............................................. 203

Figure A.11 Thermal images of unpainted Specimen $\mathrm{CH}-2$ taken at the various distances (using passive approach at $144.8 \mathrm{MPa}$ ) .................. 204

Figure A.12 Thermal intensity profile along the line across the fatigue crack shown

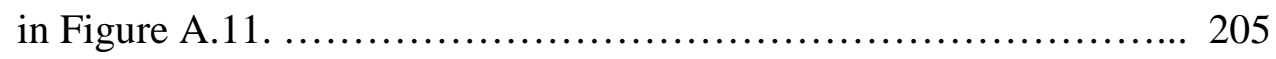

Figure A.13 Thermal images of unpainted Specimen CH-3 (at 550,000 loading cycles) taken at the various distances (using passive approach at 137.9 MPa) . 206

Figure A.14 Thermal intensity profile along the line across the fatigue crack shown in Figure A.13 . ................................................207

Figure A.15 Thermal images of Specimen CH-3 (at 550,000 loading cycles) taken at the various distances (no load is applied to the specimen)........... 208

Figure A.16 Thermal images of Specimen CH-3 (at 550,000 loading cycles) taken at the various distances (using passive approach at $137.9 \mathrm{MPa}$ ).......... 209

Figure A.17 Thermal images of Specimen CH-1 (using the active approach and heating time is 30 seconds) . .................................210

Figure A.18 Thermal intensity profile along the line across the fatigue crack shown in Figure A.17.

Figure A.19 Thermal images of Specimen CH-1 (using the active approach and heating time is 60 seconds)

Figure A.20 Thermal intensity profile along the line across the fatigue crack shown in Figure A.19.

Figure A.21 Thermal images of Specimen CH-1 (using the active approach and heating time is 90 seconds) .

Figure A.22 Thermal intensity profile along the line across the fatigue crack shown in Figure A.21. 
Figure A.23 Thermal images of Specimen $\mathrm{CH}-1$ (using the active approach and heating time is 120 seconds) .

Figure A.24 Thermal intensity profile along the line across the fatigue crack shown in Figure A.23.

Figure A.25 Thermal images of unpainted Specimen CH-2 (using the active approach and heating time is 30 seconds) .

Figure A.26 Thermal intensity profile along the line across the fatigue crack shown in Figure A.25.

Figure A.27 Thermal images of unpainted Specimen $\mathrm{CH}-2$ (using the active approach and heating time is 60 seconds)

Figure A.28 Thermal intensity profile along the line across the fatigue crack shown in Figure A.27.

Figure A.29 Thermal images of unpainted Specimen 2 (using the active approach and heating time is 90 seconds).

Figure A.30 Thermal intensity profile along the line across the fatigue crack shown in Figure A.29.

Figure A.31 Thermal images of unpainted Specimen $\mathrm{CH}-2$ (using the active approach and heating time is 120 seconds) .

Figure A.32 Thermal intensity profile along the line across the fatigue crack shown in Figure A.31. 225

Figure A.33 Thermal images of Specimen CH-2 (using the active approach and heating time is 30 seconds). .

Figure A.34 Thermal intensity profile along the line across the fatigue crack shown in Figure A.33.

Figure A.35 Thermal images of Specimen CH-2 (using the active approach and heating time is 60 seconds).

Figure A.36 Thermal intensity profile along the line across the fatigue crack shown in Figure A.35. 
Figure A.37 Thermal images of Specimen $\mathrm{CH}-2$ (using the active approach and heating time is 90 seconds) .

Figure A.38 Thermal intensity profile along the line across the fatigue crack shown in Figure A.3.

Figure A.39 Thermal images of Specimen $\mathrm{CH}-2$ (using the active approach and heating time is 120 seconds)

Figure A.40 Thermal intensity profile along the line across the fatigue crack shown in Figure A.39.

Figure A.41 Thermal images of Specimen CH-3 (using the active approach and heating time is 15 seconds) at 450,000 loading cycles.

Figure A.42 Thermal intensity profile along the line across the fatigue crack shown in Figure A.41.

Figure A.43 Thermal images of Specimen CH-3 at 450,000 loading cycles 3 (using the active approach and heating time is 30 seconds).... .236

Figure A.44 Thermal intensity profile along the line across the fatigue crack shown in Figure A.43.

Figure A.45 Thermal images of Specimen CH-3 at 450,000 loading cycles 3 (using the active approach and heating time is 45 seconds).......... 238

Figure A.46 Thermal intensity profile along the line across the fatigue crack shown in Figure A.45.

Figure A.47 Thermal images of Specimen CH-3 at 450,000 loading cycles (using the active approach and heating time is 60 seconds). 240

Figure A.48 Thermal intensity profile along the line across the fatigue crack shown in Figure A.47.

Figure A.49 Thermal images of Specimen CH-3 at 450,000 loading cycles (using the active approach and heating time is 90 seconds). 242

Figure A.50 Thermal intensity profile along the line across the fatigue crack shown in Figure A.49. 
Figure A.51 Thermal images of Specimen CH-3 at 450,000 loading cycles (using the active approach and heating time is 120 seconds)

Figure A.52 Thermal intensity profile along the line across the fatigue crack shown in Figure A.51.

Figure A.53 Thermal images of Specimen CH-3 at 500,000 loading cycles (using the active approach and heating time is 15 seconds)

Figure A.54 Thermal intensity profile along the line across the fatigue crack shown in Figure A.53.

Figure A.55 Thermal images of Specimen CH-3 at 500,000 loading cycles (using the active approach and heating time is 30 seconds). .248

Figure A.56 Thermal intensity profile along the line across the fatigue crack shown in Figure A.55

Figure A.57 Thermal images of Specimen CH-3 at 500,000 loading cycles (using the active approach and heating time is 45 seconds).... 250

Figure A.58 Thermal intensity profile along the line across the fatigue crack shown in Figure A.57

Figure A.59 Thermal images of Specimen 3 at 500,000 loading cycles (using the active approach and heating time is 60 seconds).

Figure A.60 Thermal intensity profile along the line across the fatigue crack shown in Figure A.59... 253

Figure A.61 Thermal images of Specimen CH-3 at 500,000 loading cycles (using the active approach and heating time is 90 seconds).

Figure A.62 Thermal intensity profile along the line across the fatigue crack shown in Figure A.61.

Figure A.63 Thermal images of Specimen CH-3 at 500,000 loading cycles (using the active approach and heating time is 120 seconds).............. 256

Figure A.64 Thermal intensity profile along the line across the fatigue crack shown in Figure A.63 
Figure A.65 Thermal images of unpainted Specimen CH-3 at 550,000 loading cycles (using the active approach and heating time is 15 seconds)........ 258

Figure A.66 Thermal intensity profile along the line across the fatigue crack

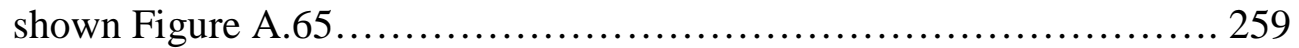

Figure A.67 Thermal images of unpainted Specimen CH-3 at 550,000 loading cycles (using the active approach and heating time is 30 seconds).......260

Figure A.68 Thermal intensity profile along the line across the fatigue crack shown in Figure A.67........................................ 261

Figure A.69 Thermal images of unpainted Specimen CH-3 at 550,000 loading cycles (using the active approach and heating time is 45 seconds)........ 262

Figure A.70 Thermal intensity profile along the line across the fatigue crack shown in Figure A.69.......................................... 263

Figure A.71 Thermal images of unpainted Specimen CH-3 at 550,000 loading cycles (using the active approach and heating time is 60 seconds)....... 264

Figure A.72 Thermal intensity profile along the line across the fatigue crack shown

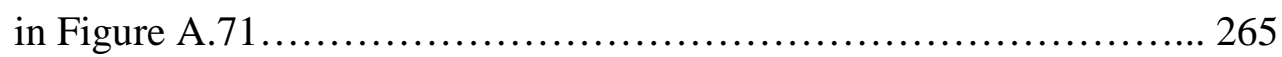

Figure A.73 Thermal images of unpainted Specimen CH-3 at 550,000 loading cycles (using the active approach and heating time is 90 seconds)....... 266

Figure A.74 Thermal intensity profile along the line across the fatigue crack

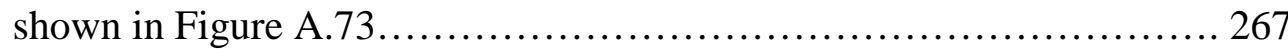

Figure A.75 Thermal images of Specimen CH-3 at 550,000 loading cycles (using the active approach and heating time is 15 seconds).................. 268

Figure A.76 Thermal intensity profile along the line across the fatigue crack shown in Figure A.75....................................... 269

Figure A.77 Thermal images of Specimen CH-3 at 550,000 loading cycles (using the active approach and heating time is 30 seconds) ................ 270

Figure A.78 Thermal intensity profile along the line across the fatigue crack shown in Figure A.77 
Figure A.79 Thermal images of Specimen 3 at 550,000 loading cycles (using the active approach and heating time is 45 seconds)................ 272

Figure A.80 Thermal intensity profile along the line across the fatigue crack shown in Figure A.79......................................... 273

Figure A.81 Thermal images of Specimen CH-3 at 550,000 loading cycles (using the active approach and heating time is 60 seconds) .................. 274

Figure A.82 Thermal intensity profile along the line across the fatigue crack shown in Figure A.81 ............................................. 275

Figure A.83 Thermal images of Specimen CH-3 at 550,000 loading cycles (using the active approach and heating time is 90 seconds) ...................276

Figure A.84 Thermal intensity profile along the line across the fatigue crack shown in Figure A.83 .................................... 277

Figure A.85 Thermal images of unpainted Specimen $\mathrm{CH}-1$ taken at various distances

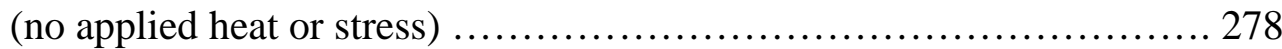

Figure A.86 Thermal images of unpainted Specimen $\mathrm{CH}-1$ (using active approach and heating time is 30 seconds). The distance between IR camera and specimen is $450 \mathrm{~mm}$.

Figure A.87 Thermal intensity profile along the line across the fatigue crack shown in Figure A.86. 280

Figure A.88 Thermal images of unpainted Specimen CH-1 (using active approach and heating time is 30 seconds). The distance between IR camera and specimen is $525 \mathrm{~mm}$.

Figure A.89 Thermal intensity profile along the line across the fatigue crack shown in Figure A.88 282

Figure A.90 Thermal images of unpainted Specimen CH-1 (using active approach and heating time is 30 seconds). The distance between IR camera and specimen is $600 \mathrm{~mm}$.

Figure A.91 Thermal intensity profile along the line across the fatigue crack shown in Figure A.90. 
Figure A.92 Thermal images of unpainted Specimen CH-1 (using active approach and heating time is 30 seconds). The distance between IR camera and specimen is $675 \mathrm{~mm}$.

Figure A.93 Thermal intensity profile along the line across the fatigue crack shown in Figure A.92.

Figure A.94 Thermal images of Specimen CH-1 (no applied stress or heat).

The distance between IR camera and specimen is $150 \mathrm{~mm}$

Figure A.95 Thermal images of Specimen CH-1 (using active approach and heating time is 30 seconds). The distance between IR camera and specimen is $150 \mathrm{~mm}$. 288

Figure A.96 Thermal intensity profile along the line across the fatigue crack shown in Figure A.95

Figure A.97 Thermal images of Specimen 1 (using active approach and heating time is 30 seconds). The distance between IR camera and specimen is $225 \mathrm{~mm}$.

Figure A.98 Thermal intensity profile along the line across the fatigue crack shown in Figure A.97.

Figure A.99 Thermal images of Specimen CH-1 (using active approach and heating time is 30 seconds). The distance between IR camera and specimen is $300 \mathrm{~mm}$.

Figure A.100 Thermal intensity profile along the line across the fatigue crack shown in Figure A.99.

Figure A.101 Thermal images of Specimen CH-1 (using active approach and heating time is 30 seconds). The distance between IR camera and specimen is $375 \mathrm{~mm}$.

Figure A.102 Thermal intensity profile along the line across the fatigue crack shown in Figure A.101. 
Figure A.103 Thermal images of Specimen CH-1 (using active approach and heating time is 30 seconds). The distance between IR camera and specimen is $450 \mathrm{~mm}$.

Figure A.104 Thermal intensity profile along the line across the fatigue crack shown in Figure A.103.

Figure A.105 Thermal images of Specimen CH-1 (using active approach and heating time is 30 seconds). The distance between IR camera and specimen is $525 \mathrm{~mm}$

Figure A.106 Thermal intensity profile along the line across the fatigue crack shown in Figure A.105.

Figure A.107 Thermal images of Specimen CH-1 (using active approach and heating time is 30 seconds). The distance between IR camera and specimen is $675 \mathrm{~mm}$.

Figure A.108 Thermal intensity profile along the line across the fatigue crack shown in Figure A.107

Figure A.109 Thermal images of Specimen CH-1 (using active approach and heating time is 30 seconds). The distance between IR camera and specimen is $825 \mathrm{~mm}$.

Figure A.110 Thermal intensity profile along the line across the fatigue crack shown in Figure A.109. 303

Figure A.111 Thermal images of Specimen CH-1 (using active approach and heating time is 30 seconds). The distance between IR camera and specimen is $975 \mathrm{~mm}$. 304

Figure A.112 Thermal intensity profile along the line across the fatigue crack shown in Figure A.111. 305

Figure A.113 Thermal images of Specimen CH-1 (using active approach and heating time is 30 seconds). The distance between IR camera and specimen is $1050 \mathrm{~mm}$ 
Figure A.114 Thermal intensity profile along the line across the fatigue crack shown in Figure A.113.

Figure A.115 Thermal images of unpainted Specimen CH-2 (using the passive approach and heating time is 30 seconds). The distance between IR camera and specimen is $150 \mathrm{~mm}$.

Figure A.116 Thermal intensity profile along the line across the fatigue crack shown in Figure A.115. 309

Figure A.117 Thermal images of unpainted Specimen CH-2 (using active approach and heating time is 30 seconds) The distance between IR camera and specimen is $225 \mathrm{~mm}$.

Figure A.118 Thermal intensity profile along the line across the fatigue crack shown in Figure A.117.

Figure A.119 Thermal images of unpainted Specimen CH-2 (using active approach and heating time is 30 seconds). The distance between IR camera and specimen is $300 \mathrm{~mm}$.

Figure A.120 The thermal intensity profile along the line across the fatigue crack shown in Figure A.119.

Figure A.121 Thermal images of unpainted Specimen CH-2 (using the active approach and heating time is 30 seconds). The distance between IR camera and specimen is $375 \mathrm{~mm}$..

Figure A.122 Thermal intensity profile along the line across the fatigue crack shown in Figure A.121.

Figure A.123 Thermal images of Specimen CH-3 (using the active approach and heating time is 30 seconds) at 500,000 loading cycles. The distance between IR camera and test specimen is $150 \mathrm{~mm}$. 316

Figure A.124 Thermal intensity profile along the line across the fatigue crack shown in Figure A.123 
Figure A.125 Thermal images of Specimen CH-3 (using the active approach and heating time is 30 seconds) at 500,000 loading cycles. The distance between IR camera and test specimen is $225 \mathrm{~mm}$.................... 318

Figure A.126 Thermal intensity profile along the line across the fatigue crack shown in Figure A.125.......................................... 319

Figure A.127 Thermal images of Specimen 3 (using the active approach and heating time is 30 seconds) at 500,000 loading cycles. The distance between IR camera and test specimen is $300 \mathrm{~mm}$.

Figure A.128 Thermal intensity profile along the line across the fatigue crack shown in Figure A.127.

Figure A.129 Thermal images of Specimen CH-3 (using the active approach and heating time is 30 seconds) at 500,000 loading cycles. The distance between IR camera and test specimen is $375 \mathrm{~mm}$.

Figure A.130 Thermal intensity profile along the line across the fatigue crack shown in Figure A.129.

Figure A.131 Thermal images of Specimen 3 (using the active approach and heating time is 30 seconds) at 550,000 loading cycles. The distance between IR camera and test specimen is $150 \mathrm{~mm}$.

Figure A.132 Thermal intensity profile along the line across the fatigue crack shown in Figure A.131.

Figure A.133 Thermal images of Specimen 3 (using the active approach and heating time is 30 seconds) at 550,000 loading cycles. The distance between IR camera and test specimen is $225 \mathrm{~mm}$ 326

Figure A.134 Thermal intensity profile along the line across the fatigue crack shown in Figure A.133

Figure A.135 Thermal images of Specimen CH-3 (using the active approach and heating time is 30 seconds) at 550,000 loading cycles. The distance between IR camera and test specimen is $300 \mathrm{~mm}$ 
Figure A.136 Thermal intensity profile along the line across the fatigue crack shown in Figure A.135

Figure A.137 Thermal images of Specimen $\mathrm{CH}-3$ (using the active approach and heating time is 30 seconds) at 550,000 loading cycles. The distance between IR camera and test specimen is $375 \mathrm{~mm}$

Figure A.138 Thermal intensity profile along the line across the fatigue crack shown in Figure A.137

Figure A.139 Thermal images of Specimen CH-3 (using the active approach and heating time is 30 seconds) at 550,000 loading cycles. The distance between IR camera and test specimen is $450 \mathrm{~mm}$.

Figure A.140 Thermal intensity profile along the line across the fatigue crack shown in Figure A.139

Figure A.141 Thermal images of Specimen CH-3 (using the active approach and heating time is 30 seconds) at 550,000 loading cycles. The distance between IR camera and test specimen is $525 \mathrm{~cm}$.

Figure A.142 Thermal intensity profile along the line across the fatigue crack shown in Figure A.141

Figure A.143 Thermal images of Specimen $\mathrm{CH}-3$ (using the active approach and heating time is 30 seconds) at 550,000 loading cycles. The distance between IR camera and test specimen is $600 \mathrm{~mm}$

Figure A.144 Thermal intensity profile along the line across the fatigue crack shown in Figure A.143

Figure A.145 Thermal images of Specimen CH-3 (using active approach and heating time is 30 seconds) at 550,000 loading cycles. The distance between IR camera and specimen is $675 \mathrm{~mm}$

Figure A.146 Thermal intensity profile along the line across the fatigue crack shown in Figure A.145 
Figure A.147 Thermal images of unpainted Specimen CH-3 (using active approach and heating time is 30 seconds) at 550,000 loading cycles. The distance between IR camera and specimen is $150 \mathrm{~mm}$..................... 340

Figure A.148 Thermal intensity profile along the line across the fatigue crack shown in Figure A.147

Figure A.149 Thermal images of unpainted Specimen CH-3 (using active approach and heating time is 30 seconds) at 550,000 loading cycles. The distance between IR camera and specimen is $225 \mathrm{~mm}$..

Figure A.150 Thermal intensity profile along the line across the fatigue crack shown in Figure A.149. 343

Figure A.151 Thermal images of unpainted Specimen CH-3 (using active approach and heating time is 30 seconds) at 550,000 loading cycles. The distance between IR camera and specimen is $300 \mathrm{~mm}$..

Figure A.152 Thermal intensity profile along the line across the fatigue crack shown in Figure A.151.

Figure A.153 Thermal images of unpainted Specimen CH-3 (using active approach and heating time is 30 seconds) at 550,000 loading cycles. The distance between IR camera and specimen is $375 \mathrm{~mm}$..

Figure A.154 Thermal intensity profile along the line across the fatigue crack shown in Figure A.153.

Figure A.155 Thermal images of unpainted Specimen CH-3 (using active approach and heating time is 30 seconds) at 550,000 loading cycles. The distance between IR camera and specimen is $450 \mathrm{~mm}$..

Figure A.156 Thermal intensity profile along the line across the fatigue crack shown in Figure A.155.

Figure A.157 Thermal images of unpainted Specimen CH-3 at 550,000 loading cycles (heating time is 30 seconds). The initial specimen temperature is $20^{\circ} \mathrm{C}$ 
Figure A.158 Thermal intensity profile along the line across the fatigue crack shown in figure A.157. 351

Figure A.159 Thermal images of unpainted Specimen CH-3 at 550,000 loading cycles (heating time is 30 seconds). The initial specimen temperature is $30^{\circ}$

Figure A.160 Thermal intensity profile along the line across the fatigue crack shown in figure A.159.

Figure A.161 Thermal images of unpainted Specimen CH-3 at 550,000 loading cycles (heating time is 30 seconds). The initial specimen temperature is $40^{\circ} \mathrm{C}$.

Figure A.162 Thermal images of Specimen CH-3 at 550,000 loading cycles (heating time is 30 seconds). The initial specimen temperature is $20^{\circ} \mathrm{C}$. .355

Figure A.163 Thermal intensity profile along the line across the fatigue crack shown in figure A.162. 356

Figure A.164 Thermal images of Specimen CH-3 at 550,000 loading cycles (heating time is 30 seconds). The initial specimen temperature is $30^{\circ} \mathrm{C}$

Figure A.165 Thermal intensity profile along the line across the fatigue crack shown in figure A.164.

Figure A.166 Thermal images of Specimen CH-3 at 550,000 loading cycles (heating time is 30 seconds). The initial specimen temperature is $40^{\circ} \mathrm{C}$.

Figure A.167 The thermal intensity profile along the line across the fatigue crack shown in figure A.166.

Figure A.168 Effects of paint anomalies when in-plane heat flows from top to bottom

Figure A.169 Effects of paint anomalies when in-plane heat flows from bottom to top. 362

Figure A.170 Effects of paint anomalies are minimized using the thermal gradient subtraction process (Figure A.169(c) is subtracted with figure A.169(c)). 
Figure A.171 Effects of cracks when in-plane heat flows from top to bottom......... 364

Figure A.172 Effects of cracks when in-plane heat flows from bottom to top. ........365

Figure A.173 Effects of cracks are augmented using the thermal gradient subtraction process (Figure A.172(c) is subtracted with

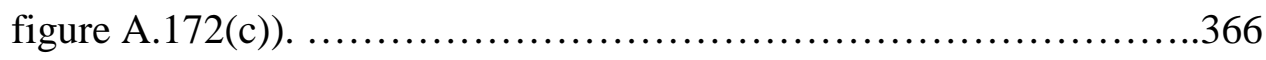

Figure A.174 Thermal images of the Specimen WD-1 at 250,000 loading cycles. Heat is applied at the attached plate. The heating time is 30 seconds.........367

Figure A.175 Thermal intensity profile along the line across the fatigue crack shown in Figure A.174.

Figure A.176 Top-heated thermal images of the Specimen WD-1 at 250,000

loading cycles. The heating time is 30 seconds.

Figure A.177 Thermal intensity profile along the line across the fatigue crack shown in Figure A.176.

Figure A.178 Top-heated thermal images of the Specimen WD-1 at 1,320,000 loading cycles. The heating time is 30 seconds....

Figure A.179 Thermal intensity profile along the line across the fatigue crack shown in Figure A.178. 375

Figure A.180 Thermal images of the Specimen WD-1 at 1,320,000 loading cycles. Heat is applied at the attached plate. The heating time is 30 seconds... 377

Figure A.181 Thermal intensity profile along the line across the fatigue crack shown in Figure A.180.

Figure A.182 Top-heated thermal images of the Specimen WD-1 at 1,335,000 loading cycles. The heating time is 30 seconds. The delay time is 1 second. 381

Figure A.183 Top-heated thermal images of the Specimen WD-1 at 1,335,000 loading cycles. The heating time is 30 seconds. The delay time is 3 seconds. .382 
Figure A.184 Top-heated thermal images of the Specimen WD-1 at 1,335,000 loading cycles. The heating time is 30 seconds. The delay time is 6 seconds.

Figure A.185 Top-heated thermal images of the Specimen WD-1 at 1,335,000 loading cycles. The heating time is 30 seconds. The delay time is 9 seconds.

Figure A.186 Top-heated Thermal images of the Specimen WD-1 at 1,335,000 loading cycles. The heating time is 60 seconds. The delay time is 1 second.

Figure A.187 Top-heated thermal images of the Specimen WD-1 at 1,335,000 loading cycles. The heating time is 60 seconds. The delay time is 3 seconds. .386

Figure A.188 Top-heated thermal images of the Specimen WD-1 at 1,335,000 loading cycles. The heating time is 60 seconds. The delay time is 6 seconds.

Figure A.189 Top-heated thermal images of the Specimen WD-1 at 1,335,000 loading cycles. The heating time is 60 seconds. The delay time is 9 seconds.

Figure A.190 Top-heated thermal images of the Specimen WD-1 at 1,335,000 loading cycles. The heating time is 90 seconds. The delay time is 1 second.

Figure A.191 Top-heated thermal images of the Specimen WD-1 at 1,335,000 loading cycles. The heating time is 90 seconds. The delay time is 3 seconds.

Figure A.192 Top-heated Thermal images of the Specimen WD-1 at 1,335,000 loading cycles. The heating time is 90 seconds. The delay time is 6 seconds. 
Figure A.193 Top-heated thermal images of the Specimen WD-1 at 1,335,000 loading cycles. The heating time is 90 seconds. The delay time is 9 seconds.

Figure A.194 Top-heated thermal images of the Specimen WD-1 at 1,335,000 loading cycles. The heating time is 30 seconds. The delay time is 1 second

Figure A.195 Top-heated thermal images of the Specimen WD-1 at 1,335,000 loading cycles. The heating time is 30 seconds. The delay time is 3 seconds.

Figure A.196 Top-heated thermal images of the Specimen WD-1 at 1,335,000 loading cycles. The heating time is 30 seconds. The delay time is 6 seconds.

Figure A.197 Top-heated thermal images of the Specimen WD-1 at 1,335,000 loading cycles. The heating time is 30 seconds. The delay time is 9 seconds.

Figure A.198 Top-heated thermal images of the Specimen WD-2 at 1,110,000 loading cycles. The heating time is 30 seconds.

Figure A.199 Thermal intensity profile along the line across the fatigue crack shown in Figure A.198 .399

Figure A.200 Top-heated thermal images of the Specimen WD-2 at 1,131,000 loading cycles. The heating time is 30 seconds. The delay time is 1 second.

Figure A.201 Top-heated thermal images of the Specimen WD-2 at 1,131,000 loading cycles. The heating time is 30 seconds. The delay time is 3 seconds. .402

Figure A.202 Top-heated thermal images of the Specimen WD-2 at 1,131,000 loading cycles. The heating time is 30 seconds. The delay time is 6 seconds. 
Figure A.203 Top-heated thermal images of the Specimen WD-2 at 1,131,000 loading cycles. The heating time is 30 seconds. The delay time is 9 seconds. 404

Figure A.204 Top-heated thermal images of the Specimen WD-2 at 1,131,000 loading cycles. The heating time is 60 seconds. The delay time is 1 second.

Figure A.205 Top-heated thermal images of the Specimen WD-2 at 1,131,000 loading cycles. The heating time is 60 seconds. The delay time is 3 seconds. .406

Figure A.206 Top-heated thermal images of the Specimen WD-2 at 1,131,000 loading cycles. The heating time is 60 seconds. The delay time is 6 seconds.

Figure A.207 Top-heated thermal images of the Specimen WD-2 at 1,131,000 loading cycles. The heating time is 60 seconds. The delay time is 9 seconds. 408

Figure A.208 Top-heated thermal images of the Specimen WD-2 at 1,131,000 loading cycles. The heating time is 90 seconds. The delay time is 1 second.

Figure A.209 Top-heated thermal images of the Specimen WD-2 at 1,131,000 loading cycles. The heating time is 90 seconds. The delay time is 3 seconds.

Figure A.210 Top-heated thermal images of the Specimen WD-2 at 1,131,000 loading cycles. The heating time is 90 seconds. The delay time is 6 seconds.

Figure A.211 Top-heated thermal images of the Specimen WD-3 (coated with real color) at $1,735,550$ loading cycles. The heating time is 30 seconds. The delay time is 1 second. 
Figure A.212 Top-heated thermal images of the Specimen WD-3 (coated with real color) at $1,735,550$ loading cycles. The heating time is 30 seconds. The delay time is 3 seconds.

Figure A.213 Top-heated thermal images of the Specimen WD-3 (coated with real color) at $1,735,550$ loading cycles. The heating time is 30 seconds. The delay time is 6 seconds.

Figure A.214 Top-heated thermal images of the Specimen WD-3 (coated with real color) at $1,735,550$ loading cycles. The heating time is 30 seconds. The delay time is 9 seconds.

Figure A.215 Top-heated thermal images of the Specimen WD-3 (coated with real color) at $1,735,550$ loading cycles. The heating time is 60 seconds. The delay time is 1 second.

Figure A.216 Top-heated thermal images of the Specimen WD-3 (coated with real color) at 1,735,550 loading cycles. The heating time is 60 seconds. The delay time is 3 seconds.

Figure A.217 Top-heated thermal images of the Specimen WD-3 (coated with real color) at $1,735,550$ loading cycles. The heating time is 60 seconds. The delay time is 6 seconds.

Figure A.218 Top-heated thermal images of the Specimen WD-3 (coated with real color) at $1,735,550$ loading cycles. The heating time is 60 seconds. The delay time is 9 seconds.

Figure A.219 Top-heated thermal images of the Specimen WD-3 (coated with real color) at 1,735,550 loading cycles. The heating time is 90 seconds. The delay time is 1 second.

Figure A.220 Top-heated thermal images of the Specimen WD-3 (coated with real color) at $1,735,550$ loading cycles. The heating time is 90 seconds. The delay time is 3 seconds. 
Figure A.221 Top-heated thermal images of the Specimen WD-3 (coated with real color) at $1,735,550$ loading cycles. The heating time is 90 seconds. The delay time is 6 seconds.

Figure A.222 Top-heated thermal images of the Specimen WD-3 (coated with real color) at 1,735,550 loading cycles. The heating time is 90 seconds. The delay time is 9 seconds.

Figure A.223 Top-heated thermal images of the Specimen WD-3 (coated with real color and tested in outdoor condition) at 1,735,550 loading cycles. The heating time is 30 seconds.

Figure A.224 Thermal intensity profile along the line across the fatigue crack shown in Figure A.223.

Figure A.225 Top-heated thermal images of the Specimen WD-3 (coated with real color and tested in outdoor condition) at 1,735,550 loading cycles. The heating time is 60 seconds.

Figure A.226 Thermal intensity profile along the line across the fatigue crack shown in Figure A.225.

Figure A.227 Top-heated thermal images of the Specimen WD-3 (coated with real color and tested in outdoor condition) at 1,735,550 loading cycles.

The heating time is 90 seconds. .428

Figure A.228 Thermal intensity profile along the line across the fatigue crack shown in Figure A.227.

Figure A.229 Top-heated thermal images of the Specimen WD-4 (coated with real color) at 1,845,500 loading cycles. The heating time is 30 seconds. The delay time is 1 second.

Figure A.230 Top-heated thermal images of the Specimen WD-4 (coated with real color) at $1,845,500$ loading cycles. The heating time is 30 seconds. The delay time is 3 seconds. 
Figure A.231 Top-heated thermal images of the Specimen WD-4 (coated with real color) at $1,845,500$ loading cycles. The heating time is 30 seconds. The delay time is 6 seconds.

Figure A.232 Top-heated thermal images of the Specimen WD-4 (coated with real color) at $1,845,500$ loading cycles. The heating time is 30 seconds. The delay time is 9 seconds.

Figure A.233 Top-heated thermal images of the Specimen WD-4 (coated with real color) at 1,845,500 loading cycles. The heating time is 60 seconds. The delay time is 1 second.

Figure A.234 Top-heated thermal images of the Specimen WD-4 (coated with real color) at 1,845,500 loading cycles. The heating time is 60 seconds. The delay time is 3 seconds.

Figure A.235 Top-heated thermal images of the Specimen WD-4 (coated with real color) at $1,845,500$ loading cycles. The heating time is 60 seconds. The delay time is 6 seconds.

Figure A.236 Top-heated thermal images of the Specimen WD-4 (coated with real color) at $1,845,500$ loading cycles. The heating time is 60 seconds. The delay time is 9 seconds.

Figure A.237 Top-heated thermal images of the Specimen WD-4 (coated with real color) at $1,845,500$ loading cycles. The heating time is 90 seconds. The delay time is 1 second.

Figure A.238 Top-heated thermal images of the Specimen WD-4 (coated with real color) at 1,845,500 loading cycles. The heating time is 90 seconds. The delay time is 3 seconds.

Figure A.239 Top-heated thermal images of the Specimen WD-4 (coated with real color) at $1,845,500$ loading cycles. The heating time is 90 seconds. The delay time is 6 seconds. 
Figure A.240 Top-heated thermal images of the Specimen WD-4 (coated with real color) at $1,845,500$ loading cycles. The heating time is 90 seconds.

The delay time is 9 seconds.

Figure A.241 Top-heated thermal images of the Specimen WD-4 (coated with real color and tested in outdoor condition) at 1,845,500 loading cycles.

The heating time is 30 seconds.

Figure A.242 Thermal intensity profile along the line across the fatigue crack shown in Figure A.241. .

Figure A.243 Top-heated thermal images of the Specimen WD-4 (coated with real color and tested in outdoor condition) at 1,845,500 loading cycles. The heating time is 60 seconds.

Figure A.244 Thermal intensity profile along the line across the fatigue crack shown in Figure A.243.

Figure A.245 Top-heated thermal images of the Specimen WD-4 (coated with real color and tested in outdoor condition) at 1,845,500 loading cycles.

The heating time is 90 seconds. 446

Figure A.246 Thermal intensity profile along the line across the fatigue crack shown in Figure A.245.

Figure A.247 Top-heated hermal images of the Specimen WD-1 at 1,336,000 loading cycles. The camera is at $450 \mathrm{~mm}$. from specimen.

The heating time is 30 seconds. The delay time is 1 second.... 448

Figure A.248 Top-heated thermal images of the Specimen WD-1 at 1,336,000 loading cycles. The camera is at $525 \mathrm{~mm}$. from specimen. The heating time is 30 seconds. The delay time is 1 second. .449

Figure A.249 Top-heated thermal images of the Specimen WD-2 at 1,133,000 loading cycles. The camera is at $450 \mathrm{~mm}$. from specimen. The heating time is 30 seconds. The delay time is 1 second. 450 
Figure A.250 Top-heated thermal images of the Specimen WD-2 at 1,133,000 loading cycles. The camera is at $525 \mathrm{~mm}$. from specimen. The heating time is 30 seconds. The delay time is 1 second.

Figure A.251 Top-heated thermal images of the Specimen WD-3 at 1,739,550 loading cycles. The camera is at $450 \mathrm{~mm}$. from specimen.

The heating time is 30 seconds. The delay time is 1 second. .452

Figure A.252 Top-heated thermal images of the Specimen WD-3 at 1,739,550 loading cycles. The camera is at $525 \mathrm{~mm}$. from specimen. The heating time is 30 seconds. The delay time is 1 second.............453

Figure B.1 Cable connection to control IR camera.............................455

Figure B.2 Calibration window........................................460

Figure B.3 Calibration set up Figure B.4 The DeltaVision Control Panel............460

Figure B.4 The DeltaVision Control Panel.................................. 461

Figure B.5 The Data Viewer Window Figure.............................. 461

Figure B.6 Thermal intensity profile....................................462 


\section{IMPLEMENTATION REPORT}

Component inspection is a crucial task that is performed to insure the continued integrity of highway bridge structures. Early detection of damage is critical to maintain the safe operation of bridge structures whose failure can lead to the loss of life or property. In general, the initial crack size assumptions used in a crack propagation safety assessment are based on inspection capabilities (i.e., the largest crack that could go undetected.) Thus, inspection limits have a direct influence on investigating the structural integrity and determining the safe operating life.

Non-destructive evaluation (NDE) is one of the best methods to evaluate the integrity of new and old bridge structures. In NDE, the results of the test or inspection are used to evaluate the suitability of the object of interest. The ideal inspection method, of course, should be simple to apply, accurate, and reliable. New innovations and developments in NDE inspection methods continue to be explored to develop optimal inspection methods. Research and continued developments in infra-red technology suggest that further applications for this promising inspection method are possible.

The primary purpose of this research is to explore the overall suitability of using infra-red thermography methods for detecting fatigue cracks in steel highway bridge components and structures. To perform this evaluation, an infra-red systems was purchased to evaluate the crack detection capabilities for three different detail types. The experimental evaluation involved a number of control specimens that were tested in the Kettelhut Structural Engineering Laboratory as well as a structural detail in a highway bridge. Cyclic loading was utilized to initiate and propagate fatigue cracks in specimens with geometries that produced a significant stress raiser. The two laboratory specimen geometries involved flat plate dog-bone type coupons with details that contained either a central hole or a transversely welded attachment plate. The field test involved the inspection of the end portions of a vertical plate that was used for a diaphragm connection and was welded to the web of the primary beam members. The laboratory tests were used to evaluate optimal test conditions and to assess the overall crack detection capabilities of

the infra-red system under "ideal" laboratory conditions, while the field test was used to 
evaluate the suitability of the infra-red system under more difficult environmental conditions.

Several important observations from the experimental evaluation are summarized in the following:

1. The crack depth with respect to member thickness is an important factor affecting crack detection by infra-red inspection. Only through-thickness cracks can be detected reliably and distinctly by the infra-red camera utilized in this study.

2. The smallest crack that can be reliably detected with the system used in this project is larger than the smallest crack size that can be detected by the unaided human eye.

3. The results of the infra-red inspection were influenced significantly by environmental conditions, such as surface temperature, ambient light and surface coating. Surfaces painted with a matte color improved the quality of the thermal images and increased the longest effective camera distance. Moreover, fatigue cracks can be detected more easily when coated with a dark matte surface rather than when covered with a glossy-surface.

Based on the observations and conclusions from the study described herein, the following recommendations for implementing the research are provided:

1. Based on the results in this study it is apparent that infra-red inspection can be used to detect fatigue cracks in steel bridge members. Even very small fatigue cracks were detected by infra-red in control specimens when tested under laboratory conditions. However, a number of challenges were encountered in both the laboratory and the field testing that suggest that an infra-red inspection should not be implemented for field use at this time.

2. A significant disadvantage of the infra-red crack detection system used in this study is that it requires both physical space and considerable time to calibrate properly before use. The calibration should be performed in an enclosed space 


\section{xxxviii}

that has as little light as possible, which is often difficult to attain under field conditions. Therefore, the present infra-red crack detection system is not well suited for field use. The ideal system should be a portable unit combining the active heat source, the infra-red camera, the controller, and computer together in one module.

3. The smallest crack size detectable by the active or passive infra-red inspection approach with the system used in this project is larger than the smallest crack size typically detectable by the unaided human eye.

4. In spite of the limitations, crack detection by infra-red thermography is still believed to be viable for certain applications, including highway bridge inspection. However, many challenges need to be addressed before infra-red inspection is feasible for routine field inspection. Equipment portability, calibration requirements, range of use, and required skill-level of the operator are some of the primary concerns that need to be addressed to improve usability and reliability of infra-red inspection. Most of these issues are probably best addressed by commercial development before implementation is practical. 


\section{CHAPTER 1 \\ INTRODUCTION}

\section{$\underline{1.1 \text { Inspection of Structures }}$}

Component inspection is a key task that should be performed to insure continued structural integrity. Clearly, early detection of damage is critical to maintain safe operation of the structures whose failure can lead to the loss of life or property. Inspection is required both during initial manufacturing to insure that the new structure is free of unacceptable anomalies, and later in life to detect service-induced damage. The safe operating life concept is based on the assumption that the flaws may develop in the structure when it is used for some period of time. This initial flaw will grow to a size that causes the failure. In general, the initial crack size assumptions are based on inspection capabilities (i.e. the largest crack that could go undetected.) Thus, inspection limits have a direct influence on investigating the structural integrity and determining the safe operating life (Liu, 1995).

Non-destructive evaluation (NDE) is one of the best methods to evaluate the integrity of new and old structures (Gibson, 1998). The NDE implies that the results of the test or inspection are used to evaluate the suitability of the object of interest. This interpretative aspect is a more comprehensive description of the process. The ideal inspection method should be simple to apply, accurate, and reliable. Research in the NDE field has increased dramatically in recent years as scientists and engineers have sought to develop new inspection methods to help field engineers ensure structural integrity for both new and old structures. Especially for the infra-red technique, increasing developments in 
the infra-red technology suggest further applications for this promising inspection method (Grover, 1995).

\subsection{Motivation and Project Objective}

As the infrastructure in the United States ages, the need to develop accurate and reliable non-destructive evaluation methods continues to grow. Such inspection techniques should be accurate, quick, and safe for use by the operator. Infra-red technology is able to meet these criteria. In the 1970's, infra-red technology, which was owned by the military and used primarily for night vision and in the military operations, became available to civilians. Since that time, a variety of non-contact and non-destructive infra-red inspection methods have been developed. In general terms, infra-red inspection techniques can be described as methods in which images of the thermal energy of an object are captured, recorded, and used to reveal information about the internal structure of that object.

Infra-red technology has been used to locate flaws in concrete bridge decks, to evaluate structural and mechanical components of aircraft, to find leaks in the buried pipelines and tanks, as well as to monitor and locate problems in industrial processes, such as steel production and the chemical plants (Jonaz, 1996). In addition, this technique has been developed to inspect large steel bridge structures and locate the fatigue cracks that are invisible to the naked eyes (Gibson, 1998). Some research institutions and companies are developing and refining the technology that will allow cracks in a steel member to be located and identified (Chen,1995).

The objective of this work is to investigate the capability, sensitivity, and limitation of the infra-red thermography NDE technique for the fatigue crack inspection in the steel highway bridge structures. The ultimate aim of this study is to be able to evaluate the performance of using infra-red technique to detect fatigue cracking in the steel structural details. For the purpose of evaluating these possibilities, two experimental series 
(the experiments on the simple-detail specimens and the test specimens developed to stimulate the typical structural details) were conducted.

An overview of this report is as follows. Chapter 2 presents the necessary background materials needed to understand the concepts of fatigue crack generation, crack detection by infra-red thermography method, and some terminology in the field of the infra-red thermography. Chapter 3 presents the experimental plan, procedures for specimen preparation, experimental apparatus, and the sequence of the experimental procedures chosen to investigate the capability, sensitivity, and limitation of the fatigue crack inspection using infra-red thermography. This chapter also narrows the objective into a specific plan for investigation. In Chapter 4, the results of all experimental studies are presented. Finally, discussions and conclusions are presented in Chapters 5 and 6, respectively. 


\section{CHAPTER 2}

\section{BACKGROUND}

The fundamental concepts involved in fatigue crack generation and fatigue crack inspection by NDE techniques based on the infra-red thermography approaches are described in this Chapter.

\section{$\underline{2.1}$ Fatigue Crack}

The fatigue crack is associated with cyclic load persistently applied to the structures. As shown in Figure 2.1, the fatigue process consists of three stages: crack nucleation, stable crack growth, and final fracture. The pre-existing crack could have occurred from the material or the manufacturing defects, prior service (initiated by fatigue or environmental attack), or by mechanical damage.

The fatigue life of a component is made up of initiation and propagation stages as illustrated schematically in Figure 2.2. The size of the crack at the transition from initiation to propagation is usually unknown and often depends on the point of view of analyst and the size of the component being analyzed (Surich, 1991).

Many factors influence the rate of the fatigue crack growth, including the material chemistry (or metallurgy), the microstructure, the type of product (plate, extrusions, forging), residual stresses, and batch to batch variations in material processing. Also, environmental conditions and loading history have a significant influence on the crack growth rate. Loading variables include the magnitude and sign 
(tension or compression) of the applied load, the mean stress level, the sequence of load applications, and the occurrence of overloads or underloads. Other important factors include the type of environment (e.g., salt water, humidity, etc.), temperature, and the frequency and shape of the loading cycle in a given environment.

The important characteristics of the fatigue crack are fracture toughness and the fatigue crack threshold described in the following. As the stress intensity factor reaches a critical value, $\mathrm{K}_{\mathrm{c}}$, unstable fracture occurs. This critical value of the stress intensity factor is known as the fracture toughness of the material. The fracture toughness can be considered the limiting value of the stress intensity just as the yield stress might be considered the limiting value of the applied stress. The fracture toughness depends on both temperature and the specimen thickness. When collected over a wide range of crack growth rate, da/dN - $\Delta \mathrm{K}$ curves for many materials have the sigmoidal shape as shown in Figure 2.3. A vertical asymptote is observed when $\Delta \mathrm{K}_{\max }=\Delta \mathrm{K}=\Delta \mathrm{K}_{\mathrm{c}}$. Fracture occurs at that point. There may also be an asymptote at low $\Delta \mathrm{K}$ levels, designated as the fatigue threshold stress intensity factor, $\Delta K_{\text {th }}$. Below the value of the fatigue threshold stress intensity factor, fatigue crack growth does not occur or occur at a rate too slow to measure (Schijive, 1996).

\subsection{Infra-red Thermography}

\subsubsection{Infra-red Terminology}

The Infra-red terminology, which is used to define infra-red systems and components, originates from fields of electronics, optics, and physics. Descriptions can appear complex and therefore be a distraction from an appreciation of the system 
capabilities and its suitability for an application (Paul, 1995). Listed below are a number of terms that should be useful for understanding infra-red thermography.

- Infra-red Wavelength The electromagnetic spectrum whose wavelengths (about $10^{-6}$ and $10^{-3} \mathrm{~m}$.) are between the visible and microwave wavelengths (see Figure 2.4).

- Thermal Emissivity Thermal emissivity is the heat transfer mechanism that makes use of the electromagnetic waves emitted from a source. While these electromagnetic waves are in both the visible and invisible ranges, most of the heat transfer is accomplished by invisible infra-red rays. Thermal emissivity is defined as the ratio of the heat emitted from the object to that of a black body at the same temperature. This numerical value is used to express the capability of an object to emit the heat of the object.

- Black Body An ideal thermal radiator emitting and absorbing all possible thermal radiation at a given temperature, hence having an emissivity of 1 .

- Thermal conductivity The capability of the material to propagate the heat throughout the object. Thermal conductivity is the significant mechanism by which heat can be transmitted from the point of higher temperature to a point of lower temperature.

- Focal plane array (FPA) FPA is an array in the IR camera that contains the group of the detectors, which typically has more than one vertical row and one horizontal line of detectors together (Stress Photonics, 1999). In this project, the IR camera contains 256 lines and 256 rows of detectors. The focal plane is that plane where the image is focused. The concept of "array" is graphically presented in Figure 2.5.

\subsubsection{The Basic Concept of Infra-red Thermography Imaging}

Infra-red thermography imaging is a mapping of the temperature distribution on the surface of the object. It is used for safe, non-contact, rapid inspection of the large areas of materials for subsurface defects. 
Defects in a nontransparent materials such as metals or composites can be detected using a variety of methods, such as X-ray and acoustic inspection. Although these techniques can yield the excellent results, they can involve the hazardous sensing technologies (X-rays), tends to time-consuming, and they may require the sensor to come into contact with device under test (Gibson, 1998). Thermography, and IR thermography in particular, is an attractive alternative. It is safe and yields the results faster than some of the other techniques (Douglas, 1996). Thermography-based NDE techniques are founded on principles of heat transfer in solids. The technique has recently begun to gain a wide interest, spurred by advances in IR detectors and imaging systems.

The terms in the following discussion are defined in Figure 2.6. Thermography imaging uses thermal energy as a probe that reveals the internal condition of the objects. When a non-uniform object is heated, thermal energy propagates throughout the object via the heat conductivity (in solids) or radiation (in voids). The spatial distribution of the thermal conductivity inside the object can significantly affect this propagation, and thus the object's volume and surface temperature distributions.

The object is characterized by the following parameters.

- object characteristics:

- Object thickness, T

- Thermal conductivity, $\mathrm{a}_{\mathrm{ob}}$

- Surface emissivity, $\Phi$

- defect characteristics:

- Defect thickness, $\mathrm{t}$

- Defect diameter, d

- Thermal conductivity at defect, $a_{\text {def }}$

The temperature distribution in the object depends on these parameters and also on the object's geometry and the time history of heating/cooling. Figure 2.6 illustrates a case where heat is applied to (or removed from) the side of the object opposite to the observation side. Heat can also be applied to (or removed from) the other side. If there is no defect in the object, the thermal gradient should be "smooth" like the 
graphic shown in Figure 2.6. But, if there is a defect in the object, it will cause the anomaly in the thermal gradient due to the different thermal conductivity at that area.

Thermography imaging can detect defects (e.g., voids or cracks) because they have the thermal conductivity different (usually lower) than that of the surrounding material. Thermal conductivity of material can also be locally changed in regions that have been machined or heat-treated. These changes are frequently greater, and thus easier to detect, than the changes in other properties of the materials. For example, the thermal conductivity of steel decreases by a factor of 2 during the hardening, which is nearly two orders of magnitude greater than the change in the ultrasound velocity in steel during hardening (Jonaz, 1996).

Thermal flow will take place in substances whenever the temperature levels differ. The heat energy always flows from the substance at the higher temperature level to that at the lower temperature level. The flow of the thermal energy will continue in this direction until the temperature levels are even. An increase in the temperature difference between two locations will produce an increased rate of the thermal flow. Thermal gradient or temperature gradient is the difference of temperature between two points a unit distance apart. The amount of heat being conducted through a body is proportional to the cross-sectional area, the difference in the temperature between the measuring points, and the thermal conductivity. It is inversely proportional to the distance or length between the measuring points (Jonaz, 1996).

The thermal contrast, the difference between temperatures at various points of an object, determines the visibility of the subsurface defect. The thermal contrast increases with the difference between the thermal conductivity of a defect and that of the bulk material of the object. A thermal scan will produce an image of the temperature distribution across the object. The manner in which the heat is transferred through the object depends on the properties of that object. For example, a flaw that would impede the transfer of forces through the member will also interrupt the flow of heat through the member. The impedance of the heat flow and the resulting thermal images are used to locate the defect because the heat flow is impeded at the defect due to the different thermal conductivity, and this impeded heat causes a high thermal contrast in the object and an anomaly in the thermal image. A leak in an underground pipe or 
tank can be located by obtaining the thermograph of the ground surrounding the pipe or tank. Detectable subsurface temperature changes are visible in the thermal image and can be used to pin point the location where the fluid has saturated the soil surrounding the leak (Gibson, 1998).

To detect a defect in an object, it is in some cases sufficient to observe the steady-state temperature distribution without actively changing the temperature. Usually, however, the object must be heated or cooled to induce the significant internal heat transfer. Several methods have been developed to improve the thermal contrast and to facilitate the quantitative characterization of defects (Chen, 1995; Cramer, 1996; Cramer, 1992; Lesniak, 1992; Lesniak, 1995; Lesniak, 1996; Lesniak, 1997; Lesniak, 1998) Some of these are described below.

-Pulse Heating (Chen, 1995; Cramer, 1996; Cramer, 1992) A single pulse of heat is applied to the viewed side of the object and the time evolution of the temperature distribution is observed. and a deviation from that slope at the position of the defect is observed. This approach is also used in this project.

-Thermal wave (Lesniak, 1992; Lesniak, 1995; Lesniak, 1996; Lesniak, 1997; Lesniak, 1998) A periodic pattern of the heating generates a thermal wave that travel across the object as shown in Figure 2.7. The "scattering" of this wave by the defect causes the anomaly of the wave's amplitude and phase at the defect position, compared with those in an object without the defect, and the defect can be detected.

\subsubsection{The Applications of Infra-red Thermography NDE Techniques}

The infra-red thermography NDE techniques can be described as either active or passive approach. An active approach infra-red thermography requires the use of the external heat source to produce the desired image. In many cases a thermal pulse is applied to the test specimen and the flow of the heat through the object is monitored. Using the principle of the heat transfer as described in the previous section, the flaw in 
the object can be detected. A defect in the object will disrupt the heat flow in the object and cause the anomaly in the image. Such method has been developed for the inspection of the aging aircraft (Cramer, 1996). Lesniak $(1996,1997)$ shows the application of this method to detect crack in girder developed to simulate the real bridge details. In addition, steel manufacturers have incorporated active thermography techniques to locate flaws and inclusions during the fabrication of steel products (Chen, 1995). In this case, because the material is at an elevated temperature, the application of cold water to the hot steel causes the thermal pulse. Generally, a thermal pulse is applied using a uniform pulse application of heat.

In contrast, a passive approach is one that does not require the use of an additional heat source to obtain the desired thermal image. For example, the use of the infra-red thermography for the bridge deck inspection is a passive approach. The image is taken at ambient temperature and the temperature differential across the deck indicates the presence of a defect (Maser, 1990). Passive techniques are also employed to find leaks in tanks or pipelines. The inspection of manufacturing processes and electrical systems is also accomplished using passive evaluation methods (Chen, 1995). The small temperature increase that accompanies a malfunction can be detected in a thermal image, and the proper maintenance can be performed before a catastrophic failure occurs. Thermal Stress Analysis (TSA) is a passive approach that has been developed to create a thermal image of the temperature variations caused by the stress concentration generated by the defects in an object (Lesniak, 1998). The details of both active and passive approach are described in the following sections.

\subsection{The Active Approach Infra-red Thermography NDE}

The infra-red thermography NDE active approach is an inspection method that has been developed using the concept of the impeded heat transfer at the defects. This method requires the projector to apply heat to the structure (see Figure 2.8). 
Furthermore, this system can developed to be sensitive to the structural flaws, but not sensitive to the paint chips, debris, reflective paint. In other word, cracks developed underneath the coating can be detected without being mistaken for paint chip and debris. This approach is called “The Coating Tolerant Thermography Approach” (Lesniak, 1996; Lesniak, 1997). To achieve these goals, the optimal heat source, infra-red camera, imaging techniques and instrumentation have to be developed.

Theoretically, The thermal gradient is constant at locations not near a flaw and non-constant at a flaw. In addition, the gradient can be assigned a sign to indicate the direction of heat flow, i.e., if the thermal gradient of the heat that flows from left to right is assigned to be positive, the thermal gradient of the heat that flows from right to left is negative. The IR camera is used to capture an image of the thermal flow, and any perturbation in the flow is used to signal the defects.

However, the flow of heat may be perturbed by the presence of the surface flaw, such as a paint chip. In order to distinguish between a structural flaw and a nonstructural flaw, further attention has to be paid to the components of the thermal image. In general, the thermal intensity (I), which is the part captured by the IR camera, can be broken down into two components, the emissivity $(\Phi)$ and the photo flux reflection $(\varepsilon)$, as shown in Equation 2.2 (Lesniak, 1996; Lesniak, 1997). The photo flux reflection is the portion of the image that is sensitive to debris, paint chips and reflections because it is the portion coming only from the reflection part. This component depends on the surface condition, color of the object, other light condition, etc. It doesn't represent the thermal distribution in the object. Therefore, it can not reveal the internal condition of the object. However, the sign of this component of the gradient is independent of the direction of the applied heat source. This is due to the fact that the direction of the applied heat will not affect the heat reflected from the surface defects (Lesniak, 1996; Lesniak, 1997). (See Figure 2.9)

$$
\mathrm{I}_{(\mathrm{x}, \mathrm{y})}=\Phi_{(\mathrm{x}, \mathrm{y})}+\varepsilon_{(\mathrm{x}, \mathrm{y})}
$$

When heat is flowing from the left, the gradient is positive (as defined) because the heat builds up behind the crack on the left. When heat is flowing from the right, the gradient changes sign becoming negative because now heat builds up behind 
the crack on the right side. Only a true structural flaw has this characteristic. Thermal gradient caused by paint chips or reflection changes on the surface of the structure does not conduct direction sensitivity. From Figure 2.9, as a material is heated from left (Figure 2.9 (left)), the region under the paint edge is uniformly heated because there is no flaw in the structure. On the left edge of the paint chip in Figure 2.9 (left), the thermal differential due to the reflection is apparently cold on the left (on the paint) and apparently hot on the right (on the bare surface). Similarly, if heat conducts from right (Figure 2.9 (right)), the area under the left edge is heated uniformly and the left side of the edge (painted area) remains apparently cold and the right side stays apparently hot. Therefore, the gradient from the reflection part is independent of the direction of the heat flow. Hence, by subtracting images heated from the left and right, the effects caused by photo flux reflection are effectively canceled. This is the backbone concept of coating tolerant thermography.

The emissivity components refer to the part of the image that is associated with the structural flaws. This component can reveal the internal condition of the objects and depends on the thermal distribution in the object. It is this component that is dependent on the direction in which the heat is applied. The build up of heat on one side of the crack will determine the sign of the thermal gradient, and the sign of the thermal gradient of this component will change when the direction of the applied heat changes. Since the sign of the thermal gradient varies when heat is applied to opposite sides of a crack, subtracting the images taken from opposite sides leads to enhance the image. Therefore, the dependence of the sign of the thermal gradient on the heat flow direction is the most important factor that can distinguish the structural flaw from the non-structural flaw. It is this behavior that allows coating tolerant thermography to work.

At this point in the development of the technique an emissivity gradient has the same effect as a structural defect. The fundamental principle behind Coating Tolerant Thermography is that only the thermal spatial derivative of a true structural anomaly will change the sign with opposing heat flow.

There are several parameters that affect the thermal contrast in the thermal image. They include the heating time (the length of time of heat application), the distance from the IR camera to the specimen, etc. These parameters are outlined in a related study 
in which technology is being investigated for using in finding the fatigue cracks in thin metal sheet with the application commonly found in the aerospace industry (Chen, 1995).

The effects of the orientation of the heat source relative the fatigue crack on the thermal contrast are worth nothing (Cramer, 1992). It was found that the optimum thermal contrast was obtained when the heat source was oriented perpendicular to the crack. As angle between the alignment of the heat source and the plane perpendicular to the fatigue crack increases, the thermal contrast decreases (see Figure 2.10). Increasing this angle from zero (heat source is perpendicular to the crack) to 10 degrees resulted in a 20 percent reduction in the thermal contrast. When the angle is increased to 45 degrees, the degradation of the thermal contrast is 80 percent.

\subsection{The Passive Approach Infra-red Thermography NDE}

Thermoelastic Stress Analysis (TSA) is a passive approach in which a thermal image of the stress field surrounding the crack is captured and recorded. As a structure is repetitively loaded, heat is produced. A differential thermography infra-red camera is used to measure the magnitude of the temperature change on the surface of the specimen due to the stress concentration. The data from thermal image can be related to the stress distribution in the material surrounding the fatigue crack.

- Stress concentration at the crack tip The formal definition of the stress field at the crack tip lies in the behavior of the linear elastic crack trip stress field. Although fatigue crack stress analysis is beyond the scope of this project, it is worth mentioning because it will clarify how the stress concentration develops at the crack tip. The nature of the crack trip stresses for the linear elastic behavior may be indicated by examining the limiting behavior of the elliptical notch located in a large plate loaded with remote tension stress $(\sigma)$ as shown in Figure 2.11. From theory of elasticity, the tensile stress at the root of the major axis is given by Equation 2.3 (Tada, 1973). 


$$
\sigma_{\text {tip }}=\sigma *\left(1+2 *(a / \rho)^{1 / 2}\right)
$$

Here $\mathrm{a}$ and $\mathrm{c}$ are the major and minor axes of the elliptical notch, $\sigma$ is the remotely applied tension stress, and $\rho$ is the notch radius of curvature. Now, defining a crack as the limiting case when the elliptical notch radius ( $\rho)$ approaches zero, the normal stress at the crack is given by Equation 2.4.

$$
\sigma_{\text {tip }}=\lim _{\rho \rightarrow 0}\left(1+2 *(\mathrm{a} / \rho)^{1 / 2}\right) * \sigma=\infty
$$

Note that this simple estimate for the crack tip stress indicates that the crack tip stress is "square root singular", i.e., the stress approaches infinity in the special manner (Borek, 1982). The fact that all elastic crack problems have this characteristic square root singularity leads to the formal definition of the stress intensity factor $(\mathrm{K})$. Based on this definition of the stress intensity factor, the crack tip stress and deformation can be derived and easily founded in the textbook about the fracture mechanics (Borek, 1982; Barsoum, 1977).

It is obvious that no real material can withstand infinite stresses, however, and plastic zone will occur at the actual crack tips. This large stress zone is confined to a fairly small region and causes a change in the surface temperature due to the thermoplastic effects.

-Thermoelastic effects When the volume is changed by a load (a force applied to an object), that object will become slightly warmer or slightly cooler. This phenomenon is known as the thermoelastic effect (Stress Photonics, 1999).

Thermoelastic temperature variations are quite small, on the order of $0.001^{\circ} \mathrm{C}\left(1^{\circ} \mathrm{mK}\right)$, and can be practically measured only with the exquisite sensitivity of modern infra-red detectors and sophisticated signal-processing electronics (Stress Photonics, 1999). The challenge in the development of this method lies in finding a way to take the data from the thermal images and quantify the stress intensity factors. The process that was developed relies on an understanding of fundamental stress features that are presented surrounding a crack in a plate. This task is beyond the scope of this project, and can be found in a technical paper on the thermoplastic stress analysis (Harwood, 1991; Hucker, 1992; Kovalenko, 1969). 


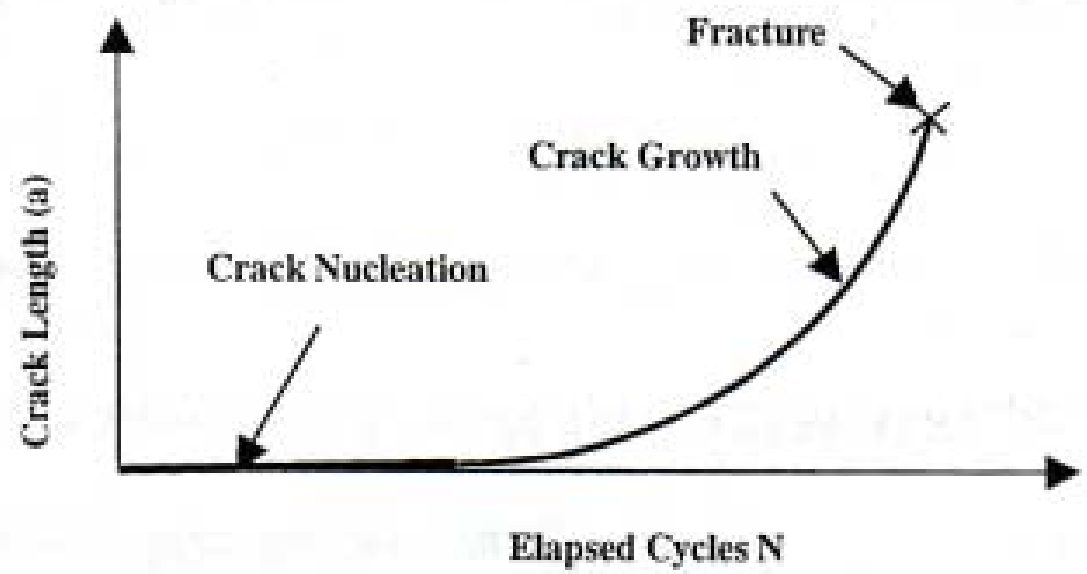

Figure 2.1 Schematic representation of the fatigue crack formation, growth, and fracture (Surich, 1991)

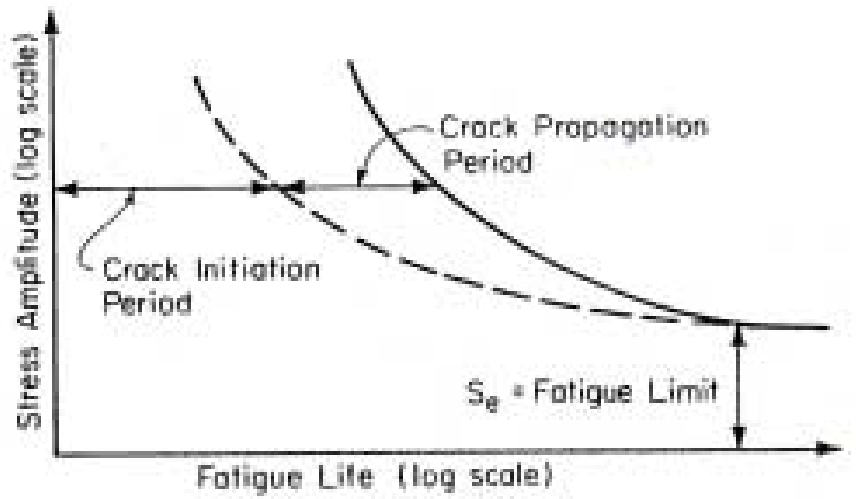

Figure 2.2 Initiation and propagation portions of the fatigue life (Surich, 1991) 


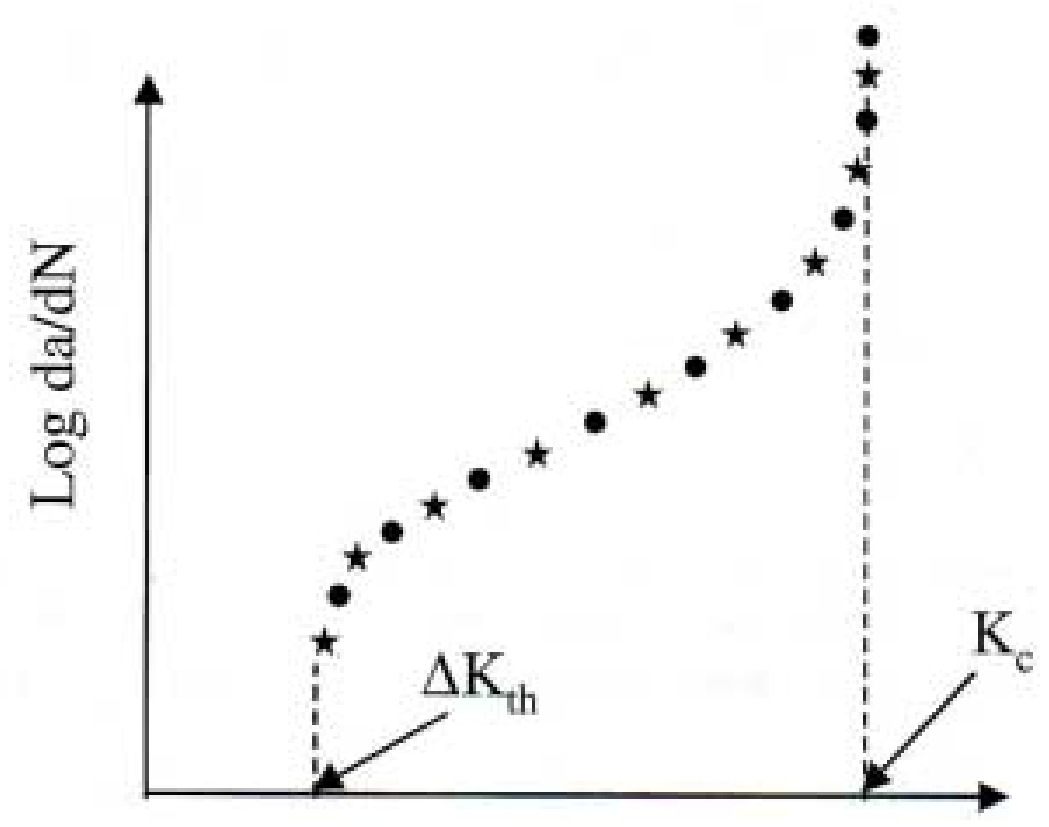

Figure 2.3 Schematic representation of $\log \mathrm{da} / \mathrm{dN}-\log \Delta \mathrm{K}$ data (Schijive, 1996).

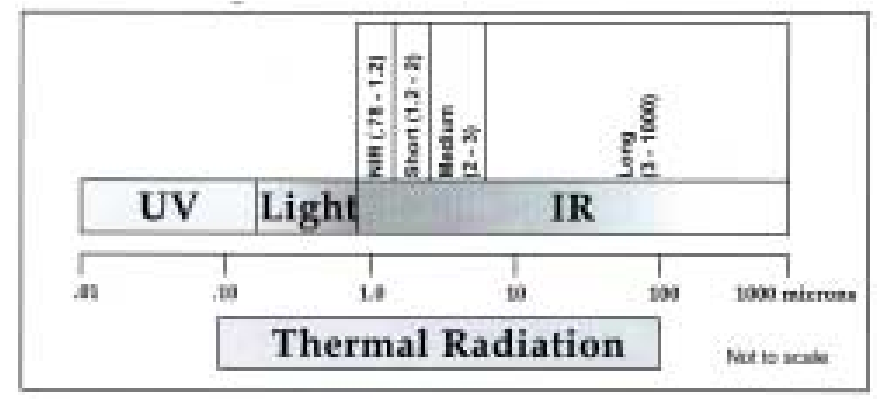

Figure 2.4 Electromagnetic spectrum (Gibson, 1998) 


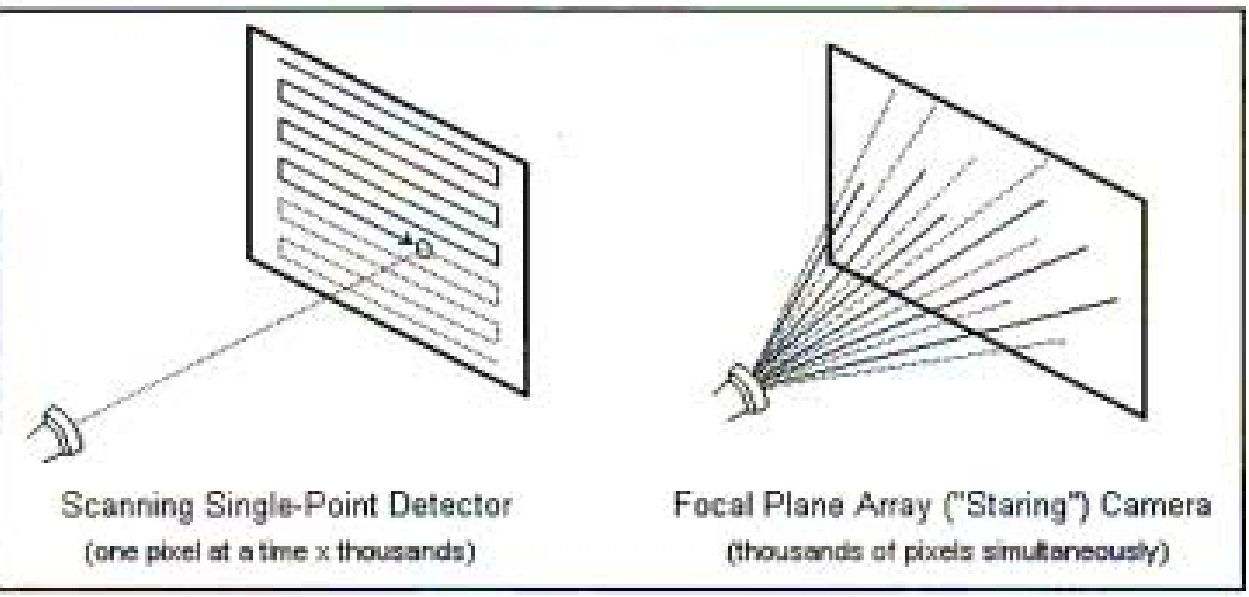

Figure 2.5 Graphical representation of the concept of the focal plane array camera (Stress Photonics, 1999)

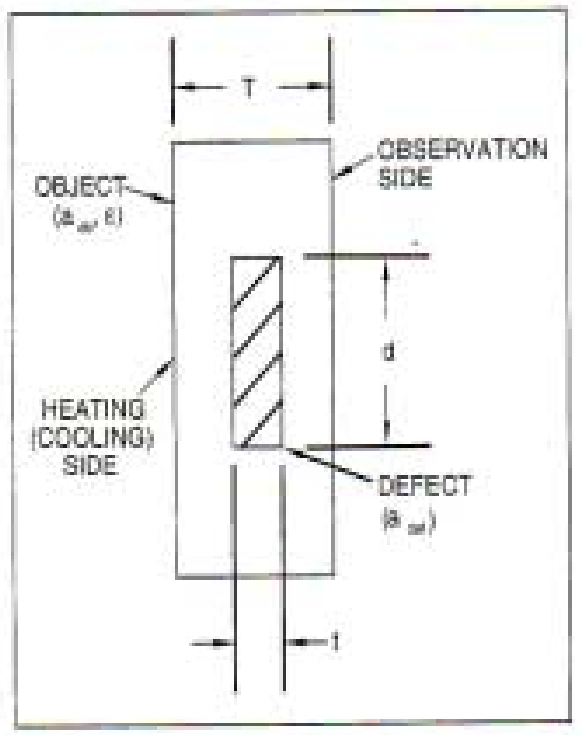

a) Defect in the object

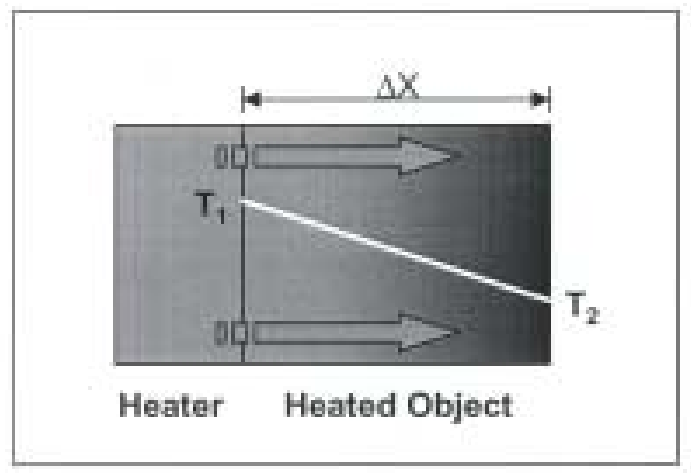

b) Thermal gradient

Figure 2.6 Heat transfer in an object with a defect depends on the geometry and material properties of the defect in relation to those of the object (Gibson, 1998) 


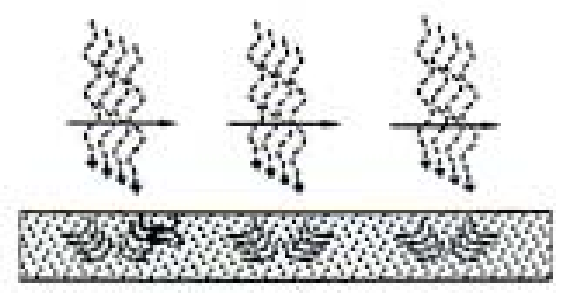

Figure 2.7 Thermal method (Lesniak, 1996)

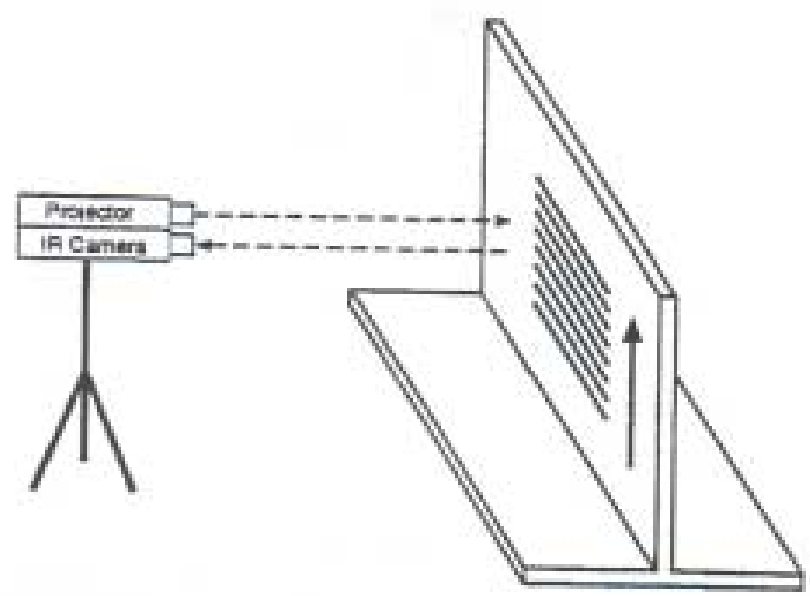

Figure 2.8 The infra-red thermography NDE active approach (Lesniak, 1996) 

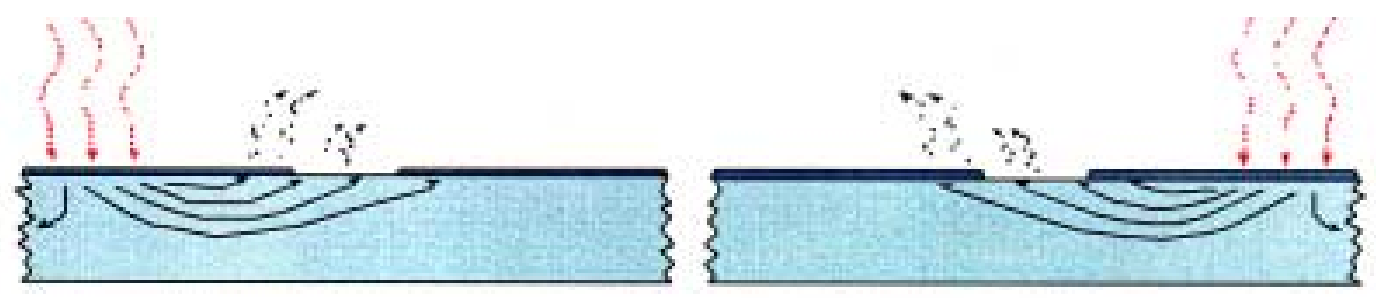

Figure 2.9 Heat reflected from paint chips (Lesniak, 1997)

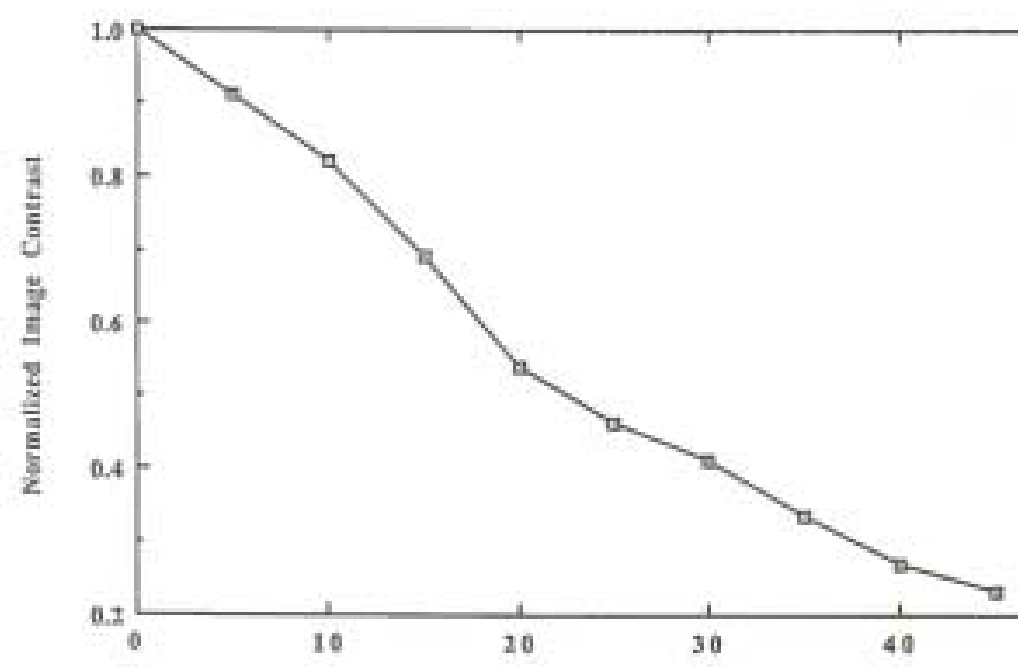

Figure 2.10 Experimental results showing the dependence of the image contrast on the angle between the heat source and the fatigue crack (Cramer, 1992). 


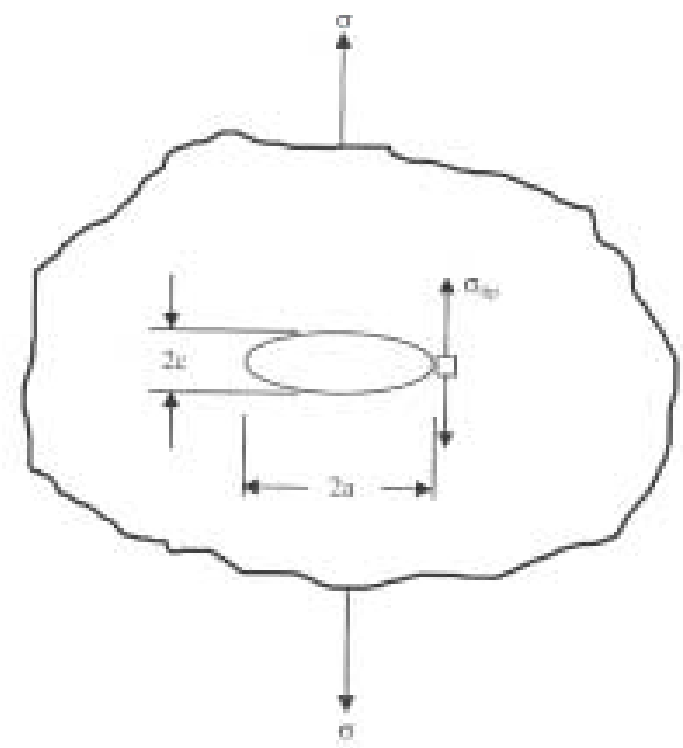

Figure 2.11 Schematic view of elliptical hole in a large plate loaded with remote tensile stress (Anderson, 1995). 


\section{CHAPTER 3 \\ EXPERIMENTAL PROCEDURES}

\subsection{The Scope of Experimental Study}

The first experimental series examined the general performance of using the infra-red thermography technique to detect fatigue cracking in simple-detail specimens. The effects of several critical factors, such as heating time, delay time, and the distance from IR camera to test specimen were examined. Both active and passive crack-detection approaches were examined. The numerous experiments were performed to vary the critical factors so that the optimum values of these critical factors could be determined.

The second experimental series examined the applicability of infra-red thermography NDE techniques for particular structural details. The specimens were subjected to cyclic loading and periodically inspected to detect the onset of fatigue cracking. A set of specimens was developed to model a typical welded structural details. Inspections were performed in both the laboratory and in outdoor conditions. The optimum values of the critical effects obtained from the first experimental series were used. 


\subsection{Test Specimen Preparation}

\subsubsection{Specimens and Loading}

There are two sets of test specimens in this project. The first set involves the set of circular-hole test specimen, and the second set utilizes the typical weld detail. The purpose of the center-hole $(\mathrm{CH})$ test series was to examine the influence of the critical variables. It is well known that the center-hole causes a significant stress concentration that will eventually lead to fatigue cracking. The welded detail (WD) test series was conducted to examine the applicability of the IR method for a more realistic structural detail. The geometry of the $\mathrm{CH}$ and WD specimens are shown in Figure 3.1 and 3.2, respectively. Critical dimensions for individual test specimens are provided in Table 3.1 and 3.2 for $\mathrm{CH}$ and WD specimens, respectively.

\section{- Cyclic Load Applied to CH Test Series}

To generate a fatigue crack in the $\mathrm{CH}$ test specimens, a cyclic load was applied to the test specimens. The cyclic gross section stress in the test specimens was designed to vary from 6.89 $\mathrm{MPa}$ to $144.75 \mathrm{MPa}$ (1 ksi to $21 \mathrm{ksi}$ ) in the form of Haver sine. Because the test specimens have slightly different dimensions, the cyclic load was adjusted as shown in Table 3.3 to produce the same values of the gross section stress in every test specimen. The loading frequency was $1.5 \mathrm{~Hz}$.

To ensure fatigue crack development and growth, the range in the stress intensity factor, $\Delta \mathrm{K}$, should be greater than the fatigue crack threshold stress intensity factor range, $\Delta \mathrm{K}_{\mathrm{th}}$. There is an empirical formula to approximately predict this threshold value for steel as shown in equation 3.1 (Barsom, 1977). 


$$
\Delta \mathrm{K}_{\mathrm{th}} /\left(\sigma_{\mathrm{ys}} 2 / 3 * \rho^{1 / 2}\right)=5
$$

where $\sigma_{\mathrm{ys}}=$ yield strength $(248.22 \mathrm{MPa}$ assumed for $A 36)$

$$
\rho=\text { notch radius of curvature }
$$

From equation 3.1,

$$
\begin{aligned}
\Delta \mathrm{K}_{\mathrm{th}} / \rho^{1 / 2} & =5 * 248.2^{2 / 3} \\
& =197.47 \mathrm{MPa}
\end{aligned}
$$

For an elliptical notch, the stress at the tip calculation is shown in Figure 3.3. For the circular hole (radius of curvature $=$ diameter of the hole), the maximum stress (at position $r=\rho / 2$ and $\theta=0$ ) can be calculated as the followings (substitute $r=\rho / 2$ and $\theta$ $=0$ in equation for calculating $\sigma y$ in Figure 3.3)

$$
\begin{aligned}
\Delta \sigma_{\max } & =\left(2 / \pi^{1 / 2}\right) *\left(\Delta \mathrm{K}_{\mathrm{I}} / \rho^{1 / 2}\right) \\
& =\left(2 / \pi^{1 / 2}\right) * 197.47 \\
& =222.82 \mathrm{MPa}
\end{aligned}
$$

Therefore, the minimum stress required to generate the crack is 222.82 $\mathrm{MPa}$. Relate the remote stress (cyclic stress varying from 6.89 $\mathrm{MPa}$ to $144.75 \mathrm{MPa}$ ) and the local concentration of stress.

$$
\begin{aligned}
& \Delta \sigma_{\text {local }}=\mathrm{K}_{\mathrm{t}} *\left(\Delta \sigma_{\text {remote }}\right) \\
& \text { where } \mathrm{K}_{\mathrm{t}}=\text { stress concentration factor }(2.58 \text { for the geometry like test } \\
& \text { specimen used in this work (Peterson, 1974)) } \\
& \Delta \sigma_{\text {local }, \text { applied }}=2.58 *(144.75-6.89) \\
& =355.68 \mathrm{MPa}>222.82 \mathrm{MPa}
\end{aligned}
$$

From the previous calculations, it is obvious that stress range is large enough so that the fatigue cracks will develop in test specimen.

\section{- Cyclic Load Applied to WD Test Series}

The relationship between failure life $\left(\mathrm{N}_{\mathrm{f}}\right)$ and applied stress in the base plate for plates with transverse fillet welds is illustrated in Figure 3.4 (the modified 
Goodman diagram.) By using the Goodman diagram for a zero - to - tension loading, an $\mathrm{S}-\mathrm{N}$ type diagram can be developed. The $\log \mathrm{S}$ versus $\log \mathrm{N}$ diagram for this curve is illustrated in Figure 3.5.

According to the relationship in Figure 3.5, for a failure life equal to 600,000 cycles, the corresponding maximum stress in base plate is $161.55 \mathrm{MPa}(23.43$ $\mathrm{ksi}$ ). Therefore, to achieve this failure life, the load is applied to the test specimen to produce the cyclic stress in the base plate that varies from 6.895 $\mathrm{MPa}$ to $165.48 \mathrm{MPa}(1$ ksi to $24 \mathrm{ksi}$ ). The loading frequency is $1.7 \mathrm{~Hz}$. Based on this failure life, a visible crack is estimated to develop at about 400,000 loading cycles.

However, specimen WD-1 failed at 1,336,550 cycles, which was more than the failure life previously predicted. Consequently, to decrease the failure life, the maximum stress was increased to $179.27 \mathrm{MPa}(26 \mathrm{ksi})$ for Specimens WD-2 and WD-3. Because all test specimens have the slightly different dimensions, the cyclic load was adjusted as shown in Table 3.4 to produce the same values of stress $(6.895 \mathrm{MPa}$ to 179.27 $\mathrm{MPa})$.

\subsubsection{Test Specimen Surface Preparation}

In general, the IR camera detects two types of reaction from an object: emissivity and reflection. Emissivity depends solely on the thermal distribution of the specimen and reflection depends on the surface condition of object, color of the object, light condition, etc. Only the emissivity part can reveal the internal condition of the object. Therefore, the effects from the reflection in the results should be minimized. To do this, the specimens were painted to have uniform color. The uniform color on the specimen eliminates the effect of reflection from the non-uniform color surface. Krylon Ultra Flat Black paint was used to eliminate this effect, and it provided good emissivity in the infra-red spectrum (Gibson, 1998). 
The infra-red camera collects radiation emitted from the surface of an object undergoing periodic loading or an object subjected to the application of heat. The qualities of the image and thermal data depend on the efficiency of radiation emission (emissivity, e), which must be high, and uniform. Although signals can be obtained from bare surfaces, they are enhanced, with a corresponding improvement in sensitivity, when a surface is sprayed with a matte paint. The matte paint also reduces the risk of picking up spurious reflected signals. Before applying any coating, the test-object surface was descaled and degreased. The surface should be reasonably smooth, but may be abraded. The surface was sprayed lightly, making several passes, until it was evenly covered.

A good paint typically increases emissivity to between 0.9 and 0.95 , approaching a perfect emissivity of 1.0. But high emissivity is not the sole criterion for the choice of paint (Gibson, 1998). It should also emit uniformly over a wide angle of view, have a good thermal conductivity, and be easy to apply and remove. Any coating should be applied uniformly, since unevenness may produce variations in emissivity and in thermoelastic signal. Thick coatings may attenuate the emissivity signal. Figure 3.6 illustrates the test specimen surface after suitable preparation. For comparative purposes, the emissivity values for uncoated surfaces are shown in Table 3.5.

Paint does not need to be black to be a good emitter, and not all black paints are good emitters. Although flat black paint is the most commonly used coating for thermal stress analysis, it is not the color so much as the emissivity that affects the image quality. A flat paint, no matter what the color, is superior to other finishes or bare metal. Table 3.6 shows average emissivity values for various spray coatings on steel (values are similar for other metals).

From Figure 3.6, it is obvious that the reflection from prepared specimen is much less than the reflection from unprepared specimen. All specimens in the $\mathrm{CH}$ test series and specimen WD-1 and WD-2 in WD test series were painted with black matte color. The purposes of using black matte paint was not only to improve the emissivity and reduce the reflection effect, but also investigate the capability of crack detection under the matte coat. The paint was removed while applying load to specimen and reapplied again before capturing the thermal image in order to detect the crack growth. 
Specimens WD-3 and WD-4 were painted with coating used in the bridge structures in order to investigate the crack detection capability for actual coating used in the field. The specimens were painted by the Indiana Department of Transportation in conjunction with a separate bridge painting project. The procedures for applying this coat are as follows:

- $\quad$ step \# 1 Lightly blasted to remove oil film

- $\quad$ step \# 2 Apply primer coat (zinc base) 5 mils thickness

- $\quad$ step \# 3 Apply intermediate coat (epoxy) 6 mils thickness

- $\quad$ step \# 4 Apply finish top coat (polyurethane) 4 mils thickness

Although the results from Lesniak $(1996,1997)$ demonstrated that the active approach could detect cracks under paint in girders developed to simulate real bridge details, the experimental procedures in those works were not realistic because test specimen was painted after a visible crack (50 mm in length) was developed. Therefore, they could not attest that the IR approach was able to detect cracks before visual detection. To obtain more realistic results for specimens WD-3 and WD-4, the paint that had been applied to specimen initially was not removed during the loading stage in order to investigate the crack detection capability.

For coating tolerant thermography examination, the specimen was prepared to have the uneven coating by making the $25 \mathrm{~mm}$. X $25 \mathrm{~mm}$. (1in. x 1 in. ) no-painted area on the painted specimen as shown in Figure 3.7.

\subsubsection{The Fatigue Crack Growth Characterization}

In addition to IR inspection, visual inspection was used to detect the fatigue crack growth. The fatigue crack size was periodically recorded along with the corresponding number of loading cycles. 


\section{- Crack Growth in CH Test Specimens}

Specimens $\mathrm{CH}-1$ and $\mathrm{CH}-2$ in this set were cyclically loaded until significant crack sizes developed. Both active and passive inspection approaches were performed to investigate the sensitivity and capability of these approaches. The cyclic loading in Specimen $\mathrm{CH}-1$ was stopped when a $18.2 \mathrm{~mm}$. (0.64 in) through-thickness fatigue crack developed on both sides of the center hole. A similar crack growth characterization was observed in Specimen CH-3.

The cyclic loading in Specimen $\mathrm{CH}-2$ was stopped when small corner crack (3.2 mm. (0.125 in) in length) develop on one side of the center hole. The crack had not penetrated through the specimen. Figure 3.8 illustrates the crack geometry in specimen 1,2, and 3 at the end of the test. Crack growth data from the test specimens are

presented in Figures 3.9 to 3.11. Two different crack growth orientations were measured as shown in 3.12.

\section{- Crack Growth in WD Series Test Specimens}

In weld details, there are two suspicious areas in which cracks frequently develop: within the weld at a discontinuity and at the weld toe. Test data on weld details have demonstrated that fatigue cracks typically commence at some initial discontinuity in the weld (porosity, trapped slag, etc.) or at a weld periphery (weld toe), which is transverse to the direction of the stress reversal. Figure 3.13 illustrates both of these types of cracking.

Cracks in Specimen WD-1 were of both crack types: in-weld crack and crack at the weld toe as illustrated in Figure 3.14. An in-weld crack was first observed at 500,000 loading cycles, and crack at the weld toe was first detected at 800,000 loading cycles. The specimen failed at 1,336,550 cycles. The relationship between crack length and number of loading cycles of in-weld crack is shown in Figure 3.15 to Figure 3.18. Initially, the crack at the weld toe of Specimen WD-1 was semi-elliptical. Then it grew 
and transformed into corner crack, and eventually became a through-thickness crack. Figure 3.19 shows the development of crack geometry at weld toe.

Specimen WD-2 developed cracks both in the weld and at the weld toe as illustrated in Figure 3.20. The weld crack was first observed at 300,000 loading cycles, and the crack at the weld toe was first observed at 500,000 loading cycles. The specimen failed at 1,133,300 cycles. The weld toe crack in Specimen WD-2 exhibited the same behavior as the critical weld toe crack in specimen WD-1 (transformed from a partial crack to a corner crack, and finally to a through-thickness crack.) The relationship between crack length and number of loading cycles for the crack surfaces of Specimen WD-2 in specimen 2 are shown in Figure 3.21 to Figure 3.24.

The relationship between crack length and number of loading cycles of Specimen WD-3 and WD-4 could not be traced because paint had not been removed from specimen surfaces. Figure 3.25 to Figure 3.32 show visible cracks in Specimen WD-3 and WD-4. Some part of weld toe crack in Specimen WD-3 and WD-4 was first visible at 1,300,000 and 1,250,000 cycles by observing a hair-line break on paint, respectively. This visible part of crack on Specimen WD-3 and WD-4 went thorough specimen's thickness at 1,735,500 and 1,840,000 cycles, respectively. Specimen WD-3 failed at $1,742,500$ cycles and Specimen WD-4 failed at 1,875,000 cycles.

\subsection{The Experimental Apparatus}

\subsubsection{The Projector (Heat Source) and Controller}

Heat source is an important factor affecting the active approach IR crack detection. Appropriate heat source is accomplished with a full-field, continuously emitted 
heat source. It was found that the pattern consisting of the stripe line of light could produce the optimum thermal gradient (Chen, 1995; Cramer, 1996; Cramer, 1992; Lesniak, 1992; Lesniak, 1995; Lesniak, 1996; Lesniak, 1997; Lesniak, 1998).

In this work, a quart-T3 halogen lamp is used as heat source. It consumes about $500 \mathrm{~W}$ at 120 volts and emits most of its energy in the near infra-red (below $3 \mu \mathrm{m}$ ) that does not significantly conflict with the sensitivity range of a typical IR camera $(3 \mu \mathrm{m}$ - $5 \mu \mathrm{m}$ and $8 \mu \mathrm{m}-12 \mu \mathrm{m}$ ) (Hocking, 1997). The projector parses radiation from the line source into one stripe line of light via a 1-in-by-2-in Plano cylindrical convex lenses (focus length $=80 \mathrm{~cm}$ ). Lenses are made from $B K 7$ glass, which can take high temperature and has high efficiency (90\%) in transmission for the energy near the infrared range when compared with the other types of materials - see Table 3.7 (Hocking, 1997). Controller is the device used to control the pattern and period of heat application (heating time and delay time as explained in Section 3.4.2). See Figure 3.33 for heat source and controller.

\subsubsection{IR Camera}

An IR camera captures thermal images by sensing electromagnetic wave, which its wavelength is in the range from 3 to $15 \mu \mathrm{m}$ (Hocking, 1997). The ideal camera is one that is not expensive, highly sensitive to temperature change, and provides high resolution. IR camera used to capture thermal images in this work can detect the temperature change of approximately $0.1^{\circ} \mathrm{C}$. A differential thermography camera that captured 434 frames per second was chosen in this project because it can measure small oscillation in temperature change at a surface of material occurring when in-plane heat flows. See Figure 3.34 for IR camera and calibrate plates. Both IR camera and Controller can be set up, controlled, and calibrated by DeltaTherm software, developed by StressPhotonic, Inc. (see Appendix B for camera and software controlling). 
The IR Camera Specifications are as follows (StressPhotonics, Inc., 1999):

Frame Rate: 434 frames/s

- Specimen Temperature: $0^{\circ} \mathrm{C}$ to $50^{\circ} \mathrm{C}$ (unlimited temperature range with accessories)

- Thermal Resolution (spatial uniformity): $0.1^{\circ} \mathrm{C}$

- $\quad$ Array: $128 \times 128 \mathrm{InSb}, 3-5 \mu \mathrm{m}$ sensitivity

- Lens: $50 \mathrm{~mm}$ diameter

- $\quad$ Focus Range: $15 \mathrm{~cm}$ to $80 \mathrm{~cm}$

- Cooling Systems: Liquid Nitrogen

- $\quad$ Overall Size: 12 in. long, 7 in. wide, 9 in. high $(30 \mathrm{~cm}$ long, $18 \mathrm{~cm}$ wide, $23 \mathrm{~cm}$ high)
Weight (dry): $8 \mathrm{lb} .(4 \mathrm{~kg})$
Video Outputs: NTSC

\subsection{Critical Factors}

Many factors influence the IR crack inspection. Included among these factors are crack size, camera distance, applied stress magnitude, heating time and delay time, and the surface condition. The investigation plans of these factors are discussed in the following sections. 


\subsubsection{Critical Factors of The Passive Approach}

- Applied stress:

According to thermoelastic stress theory, applying stress to specimen can slightly change surface temperature. Stress is concentrated along the fatigue crack length and at a crack tip due to the irregularities and the plastic zone deformation. All these stress concentrations can be detected by IR camera due to the stress-surface temperature interrelation. However, it is not practical to generate a high stress level on real bridge components. As a result, a minimum required stress level that makes crack detectable is investigated in this work.

- Distance from IR camera to specimen:

The thermal image taken from the shorter camera distance generates the more comprehensive and crack-detectable thermal images (Cramer, 1996). But, practically, IR camera can not be placed up close to bridge structure in the field because of accessibility restriction. The longest effective camera distance is an important information used to set up the camera to detect crack in the field. As a result, the longest effective camera distance is investigated in this work.

- Fatigue crack size:

The main purpose to investigate the crack-size effect is the attempts to find the "clear-cut" smallest detectable crack size, which can be detected by IR camera.

- Surface condition:

Another critical factor investigated in this project is surface condition. The reflection effects, generally making thermal image results worse, substantially depend on 
surface condition. Both unpainted specimen and specimen painted with matte color (used to reduce reflection) are investigated in this project.

\subsubsection{Critical Factors of The Active Approach}

In addition to fatigue crack size, distance from IR camera to test specimen, and surface condition, the heating time - delay time are important factors for active approach.

- Heating - delay time:

The heating time is the period of heat-application time, and the delay time is the period of time from the moment that the heat source is turned off to the moment that the thermal image is captured. The graphical interpretation of heating and delay time is illustrated in Figure 3.35. The optimum heating time and delay time are investigated in this work.

\section{$\underline{3.5 \text { Image Processing }}$}

The thermal image of the suspected area is taken while the test specimen is loaded or heated up for the passive and active approaches, respectively. A graphical representation of the IR camera set up (position) is illustrated in Figure 3.36.

The active approach uses the concept of impeded heat flow to detect a crack. As a result, heat should flow in the appropriate portions of details that may contain a crack. Heat is applied perpendicular to the specimen surface, and the thermal image is 
captured in the same alignment (Figure 3.36a). For the WD test series, the cracks typically develop in the weld or at the weld toe. The radiated area should be in a position that lets most of the heat flow through the part containing a crack. Therefore, heat should flow through the weld in order to detect an in-weld crack, and through the base plate in order to detect a weld toe crack.

Figure 3.36b (left) and Figure 3.36b (right) illustrate the method used to detect cracks at weld toes and within the weld, respectively. In Figure 3.36b (left), heat is applied directly to a part of the member that one suspects contains a crack in order to avoid heat flow obstruction by an in-weld crack before reaching the weld toe crack.

From Figure 3.13, the majority of an in-weld crack is in the fillet weld. Consequently, the heat level has to be high enough so that some part of it flows through the fillet. As a result, the radiated area should be close to the suspicious weld, but not directly on the fillet weld. Heat should be applied to the smaller part joining the suspected details because it will be confined to flow through the desired area.

After thermal images are captured, thermal intensity values are calculated. Figure 3.37 illustrates an example of a typical thermal image collected for the center-hole test specimen. The thermal intensity profile and corresponding color bar are also shown.

The thermal intensity color bar is a legend of the relative thermal intensities within the image. Different color schemes can reveal different details within an image. The numbers on this bar are the arbitrary values. The relationship between the numbers on the color bar and the exact value of specimen temperature has not been developed, yet. As a present, it represents only the relative difference of the temperature within the object: the higher number on the color bar represents the higher temperature in the object (Stress Photonics, 1999).

Another test that was performed in this work is the coating tolerance thermogrphy. In this test, heat was applied in one direction and the first thermal image was captured. Next, the heat-application direction was reversed and a second thermal image was captured. The thermal gradient of both images were calculated and subtracted from each other to find the net difference. Because the emissivity signs are different, the emissivity thermal contrast, representing a structural flaw, was augmented. On the other 
hand, the reflection thermal contrast, which is not dependent on heat flow direction, was minimized. Simply stated, taking the difference of the two images magnifies the effects of a structural flaw and washes out the effects of a paint chip (Lesniak, 1996; Lesniak, 1997). It is in this way that the system remains sensitive to the structural flaws and insensitive to surface defects and reflections. Equations 3.2 and 3.3 (Lesniak, 1997) represent the concept of the coating tolerant thermography approach.

$$
\begin{gathered}
I_{x}^{1}(x, y)=\Delta \Phi_{x}^{1}(x, y)+\varepsilon_{x}(x, y) \\
I_{x}^{2}(x, y)=\Delta \Phi_{x}^{2}(x, y)+\varepsilon_{x}(x, y) \\
Q(x, y)=I_{x}^{1}(x, y)-I_{x}^{2}(x, y)=\Delta \Phi_{x}^{1}(x, y)-\Delta \Phi_{x}^{2}(x, y)
\end{gathered}
$$

$I, \Phi$, and $\varepsilon$ are thermal intensity, emissivity component, and reflection component, respectively. Equation 3.2 represents thermal gradient from two thermal images that have the opposite heat flow directions. The raised number 1 and 2 represent the different signs due to the different heat flow directions, and the lowered alphabet $\mathrm{x}$ and $\Delta$ represent the gradient terms. It should be noted that only the reflection component is independent of heat flow direction. Equation 3.3 represents the results when a leftheated thermal image is subtracted with right-heated thermal image. The reflection component is eliminated, and only the emissivity component remains. Thus, the internal condition of the object can be revealed without the influence from a non-structural flaw. The schematic in Figure 3.38 theoretically shows the thermal intensity data in terms of thermal gradient and the concept of the coating tolerant theromgraphy. The experimental results of these analyses are described in Chapter 4.

A crack is easier to detect when thermal intensity data are presented in the gradient form (Lesniak, 1997). At this time, unfortunately, the conventional program that can effectively and readily calculate the thermal gradient at the specific point has not been completely developed, yet. In this project, the thermal gradient is calculated from 
the simplest mathematical differentiation, i.e., calculating the ratio of the difference of thermal intensity values of two adjacent pixels with respect to the distance between those two pixels.

\subsection{The Experimental Plan}

The experimental procedures used to examine the critical factor effects are presented in this section. Specimens $\mathrm{CH}-1, \mathrm{CH}-2$, and $\mathrm{CH}-3$ were cyclically loaded until the different crack sizes developed. Both active and passive approaches were performed on Specimens $\mathrm{CH}-1$ and $\mathrm{CH}-2$ with the final crack sizes. For Specimen $\mathrm{CH}-3$, the IR inspections were performed at a number of specific intervals during the loading stage. All critical factors mentioned in Section 3.4 were varied to investigate their relative influence. For Specimen CH-3, the inspection intervals are as the following:

- For the first 200,000 cycles, the inspection interval $=50,000$ cycles.

- After 200,000 cycles, the inspection interval $=25,000$ cycles.

The critical factors were varied in each specimen experiment to examine their effects on IR crack detection. The coating tolerant thermography approach was also performed. The $\mathrm{CH}$ test series were tested under the enclosed laboratory condition, and the paint was repeatedly applied and removed when capturing the thermal image in order to trace the crack growth.

The applicability of IR crack detection on structural details was investigated using the WD test series. The inspections were performed periodically while being in the loading stage with variation of the critical factors. The critical factor optimum values used in WD test series were based on those of the $\mathrm{CH}$ test series. 


\subsubsection{The Experimental Procedures for CH Test Series}

- The Passive Approach Experimental Procedures

- Applied stress examination The objective of this examination is to find the optimum effective range of applied stress. Specimens $\mathrm{CH}-1$ and $\mathrm{CH}-2$, containing the large and small pre-existing crack respectively, were subjected to an applied stress varying from 144.8 $\mathrm{MPa}$ to $227.5 \mathrm{MPa}$ in steps of $20.7 \mathrm{MPa}$ (21 ksi to $33 \mathrm{ksi}$ in steps of $3 \mathrm{ksi}$ ). A lower applied stress was used in Specimen $\mathrm{CH}-3$. The applied stress varied from 34.5 MPa to 206.9 MPa in steps of $34.5 \mathrm{MPa}$ (5 ksi to $30 \mathrm{ksi}$ in steps of $5 \mathrm{ksi}$ ). Specimen CH-3 passive approach was performed while test specimen was in the loading stage. The distance from IR camera to the test specimen was $150 \mathrm{~mm}$. (6 in.).

- Distance from IR camera to test specimen examination The objective of this examination is to determine the longest effective camera distance. The distance from the IR camera to the specimen surface was increased from $15 \mathrm{~cm}$, in steps of $7.5 \mathrm{~cm}$, until reaching the longest effective distance. This examination was performed after the crack had been detected at the $15-\mathrm{cm}$ camera distance. The stress level was a constant value that was able to make the crack detectable at a $15-\mathrm{cm}$ camera distance.

- Crack size examination The objective of this examination is to find the smallest detectable crack size. The passive approach was performed periodically while the specimen was subjected to a load. Then, with the load applied, the "clear - cut" minimum detectable fatigue crack size was investigated.

\section{- Surface condition examination:}

Reduced surface reflection should, theoretically, improve the thermal image detected and improve the measured thermal distribution. Therefore, specimens with 
unpainted surfaces and specimens painted with a black matte color were tested to investigate surface condition effects.

- The Active Approach Experimental Procedures

To investigate crack size and surface condition effects using the active approach, with procedures somewhat analogous to those of passive approach, three other experimental procedures were also performed.

- The heating time - delay time examination The objective of this examination is to find the optimum heating time and delay time. For Specimens $\mathrm{CH}-1$ and $\mathrm{CH}-2$, the heating time were 30,60, 90, and 120 seconds, and the delay time were 1 , 3, 6, and 9 seconds for each heating time. The distance from IR camera to test specimen was $15 \mathrm{~cm}$ (6 in.), and heat source was at the same position as IR camera.

The heating time for Specimen $\mathrm{CH}-3$ was refined from those of Specimens CH-1 and CH-2 by adding a 15-second and 45-second heating time The 120second heating time was not utilized because the Specimen $\mathrm{CH}-1$ and $\mathrm{CH}-2$ results show that cracks could only be detected with a heating time shorter than 120 seconds. The distance from IR camera to test specimen was $15 \mathrm{~cm}$ (6 in.), and the heat source was at the same position as IR camera.

- Distance from IR camera to test specimen examination The same concepts as those of the passive approach were used. The distance from the IR camera to the test specimen was increased from $15 \mathrm{~cm}$, in steps of $7.5 \mathrm{~cm}$, until reaching the longest effective distance. The heating time and the delay time used in this examination were the period making crack detectable at a $15-\mathrm{cm}$ camera distance. The heat source was at the same position as IR camera.

- The coating tolerant thermography examination The results of specimens containing crack and artificially $25 \mathrm{~mm}$ x $25 \mathrm{~mm}$ paint chip (Figure 3.7) were 
compared. Heat was applied at the top and bottom of both specimens. Camera distance was $30 \mathrm{~cm}$ (12 in.), and the heat source was located at the same position as IR camera. The heating time and delay time was 60 seconds and 6 seconds, respectively.

\subsubsection{The Experimental Procedures for WD test series}

The $\mathrm{CH}$ test results demonstrate that the active approach is more promising than the passive approach because the passive approach requires a stress usually higher than the service-level stress developed in real bridge structures. It is difficult to generate this high stress level in real structures, such as bridges, etc. Consequently, only the active inspection approach was further investigated in WD test series.

For Specimen WD-1, heating times were 30, 60, and 90 seconds, and delay times were $1,3,6$, and 9 seconds. IR camera was at $15 \mathrm{~cm}$ (6 in.) from the test specimen. Once a crack could be detected at this distance, then the camera distance was increased from $15 \mathrm{~cm}$ in steps of $7.5 \mathrm{~cm}$ until reaching the longest effective distance. All parameters were defined using the optimum values from the $\mathrm{CH}$ test results. The procedures used for image capture, which are described in Section 3.5, were employed to detect both in-weld cracks and cracks at weld toe. For Specimens WD-2, WD-3, and WD-4, the experimental procedures were analogous to those of Specimen WD-1. Specimens WD-1 and WD-2 were tested only under enclosed laboratory condition, but Specimens WD-3 and WD-4 (which were painted with a glossy INDOT specification color) were tested under both outdoor and enclosed laboratory conditions to investigate the surface condition effects. 
Table 3.1 Dimensions and cross-sectional areas of specimens in $\mathrm{CH}$ test series

\begin{tabular}{|c|c|c|c|c|c|}
\hline Specimen & $\begin{array}{c}\text { Thickness } \\
(\mathrm{mm} .)\end{array}$ & $\begin{array}{c}\text { Center width } \\
(\mathrm{mm} .)\end{array}$ & $\begin{array}{c}\text { Hole Diameter } \\
(\mathrm{mm} .)\end{array}$ & $\begin{array}{c}\text { Area (net) } \\
\left(\mathrm{mm}^{2}\right)\end{array}$ & $\begin{array}{c}\text { Area (gross) } \\
\left(\mathrm{mm}^{2}\right)\end{array}$ \\
\hline CH-1 & 7.82 & 75.87 & 12.78 & 493.36 & 593.30 \\
\hline CH-2 & 7.81 & 75.82 & 12.73 & 492.73 & 592.15 \\
\hline CH-3 & 7.81 & 75.89 & 12.75 & 493.12 & 592.70 \\
\hline
\end{tabular}

Table 3.2 Dimensions and cross-sectional areas of specimens in WD test series

\begin{tabular}{|c|c|c|c|}
\hline Specimen & $\begin{array}{c}\text { Center width } \\
(\mathrm{mm} .)\end{array}$ & $\begin{array}{c}\text { Thickness } \\
(\mathrm{mm} .)\end{array}$ & $\begin{array}{c}\text { Area } \\
\left(\mathrm{mm} .^{2}\right)\end{array}$ \\
\hline WD-1 & 75.81 & 7.89 & 598.14 \\
\hline WD-2 & 75.96 & 7.89 & 599.32 \\
\hline WD-3 & 75.23 & 7.89 & 593.56 \\
\hline
\end{tabular}


Table 3.3 The minimum and maximum loads for $\mathrm{CH}$ test specimens

\begin{tabular}{|c|c|c|c|c|}
\cline { 2 - 5 } \multicolumn{1}{c|}{} & \multicolumn{2}{c|}{ Minimum } & \multicolumn{2}{c|}{ Maximum } \\
\hline Specimen & $\begin{array}{c}\text { Load } \\
(\mathrm{kN})\end{array}$ & $\begin{array}{c}\text { Stress (net) } \\
(\mathrm{MPa})\end{array}$ & $\begin{array}{c}\text { Load } \\
(\mathrm{kN})\end{array}$ & $\begin{array}{c}\text { Stress (net) } \\
(\mathrm{MPa})\end{array}$ \\
\hline $\mathrm{CH}-1$ & 4.09 & 8.29 & 85.88 & 174.07 \\
\hline $\mathrm{CH}-2$ & 4.08 & 8.28 & 85.71 & 173.96 \\
\hline $\mathrm{CH}-3$ & 4.08 & 8.28 & 85.79 & 173.98 \\
\hline
\end{tabular}

Table 3.4 The minimum and maximum load for WD specimens

\begin{tabular}{|c|c|c|}
\hline Specimen & $\begin{array}{c}\text { Minimum load } \\
(\mathrm{kN})\end{array}$ & $\begin{array}{c}\text { Maximum load } \\
(\mathrm{kN})\end{array}$ \\
\hline WD-1 & 4.12 & 98.98 \\
\hline WD-2 & 4.13 & 107.43 \\
\hline WD-3 & 4.09 & 106.41 \\
\hline
\end{tabular}


Table 3.5 The emissivity values to these of various uncoated surfaces (Hocking, 1997).

\begin{tabular}{|c|c|}
\hline Material and Finish & Emissivity (e) \\
\hline Aluminum, polished & 0.12 \\
\hline Aluminum, natural & 0.46 \\
\hline Aluminum, sand blasted & 0.24 \\
\hline Aluminum, chromatic acid anodized & 0.05 \\
\hline Mild Steel, polished & 0.07 \\
\hline Mild Steel, natural & 0.39 \\
\hline Mild Steel, sand blasted & 0.43 \\
\hline Mild Steel, oxidized & 0.79 \\
\hline
\end{tabular}


Table 3.6 Average emissivity values for various spray coatings on steel (Hocking, 1997).

\begin{tabular}{|c|c|}
\hline Paint type & Emissivity (e) \\
\hline Krylon ultra flat black & 0.95 \\
\hline Nextel black paint & 0.93 \\
\hline Nextel white paint & 0.90 \\
\hline
\end{tabular}

Table 3.7 The transmission efficiency of energy in the infra-red range of the typical cylindrical lenses material (Hocking, 1997)

\begin{tabular}{|c|c|}
\hline Material type & $\begin{array}{c}\text { Transmission efficiency of energy } \\
\text { in the infra-red range }\end{array}$ \\
\hline Fused silica (IR grade) & $88 \%$ \\
\hline Fused silica (UV grade) & $80 \%$ \\
\hline Quartz & $75 \%$ \\
\hline Calcium Fluoride & $75 \%$ \\
\hline
\end{tabular}




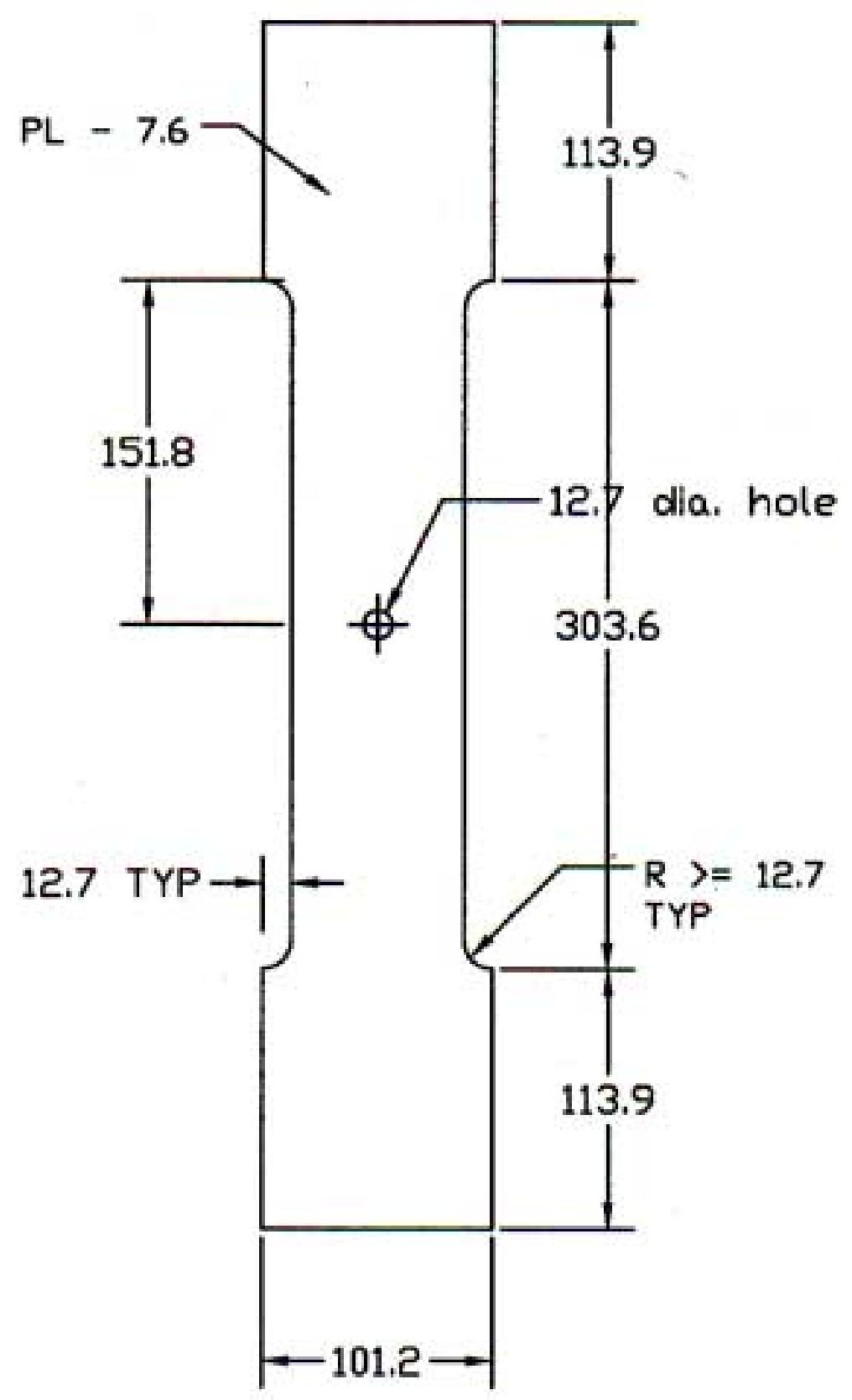

Figure 3.1 Simple-detail test specimen dimensions (all units are in millimeter) 

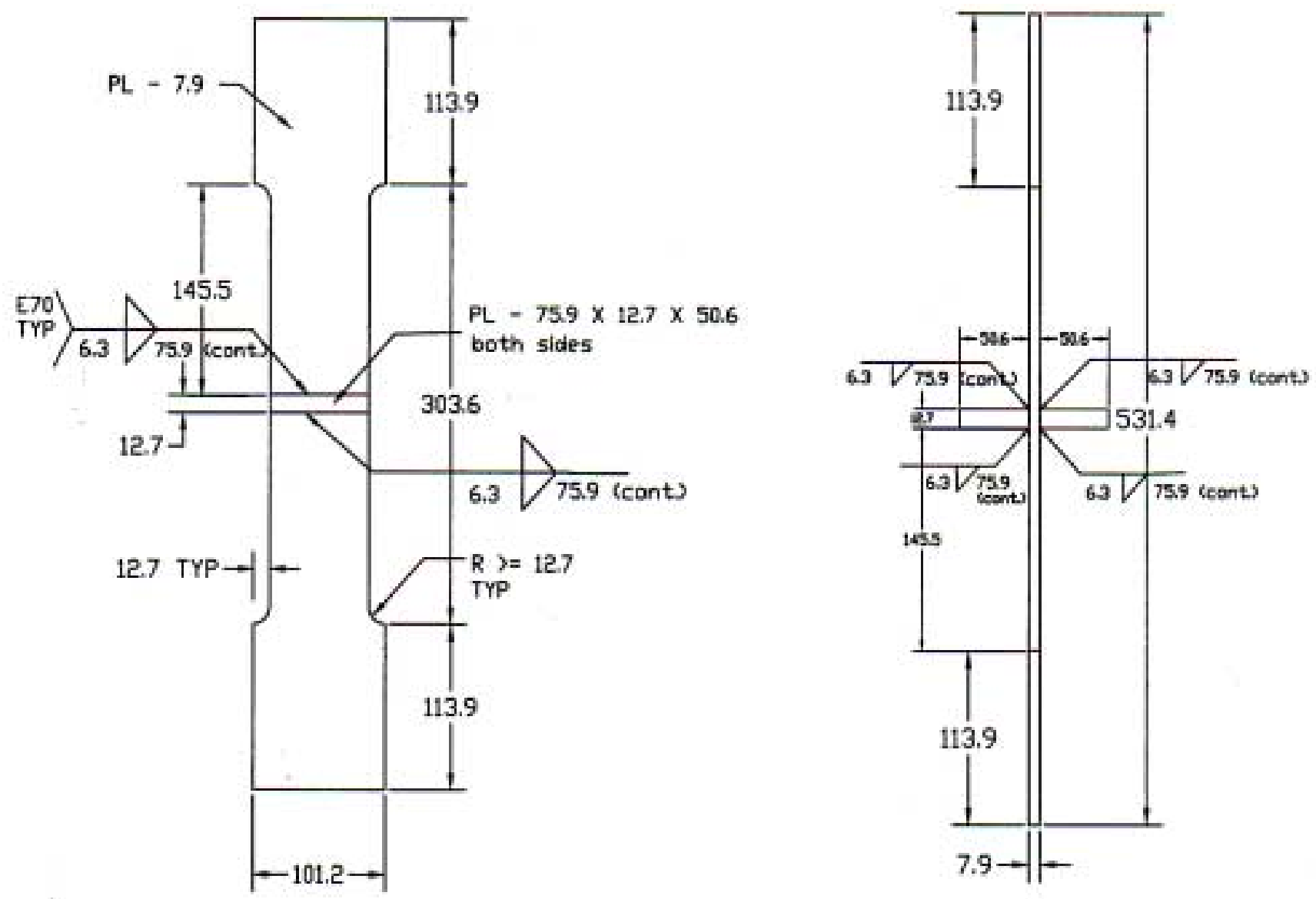

Figure 3.2 Weld-detail test specimen dimensions (all units are in millimeter) 


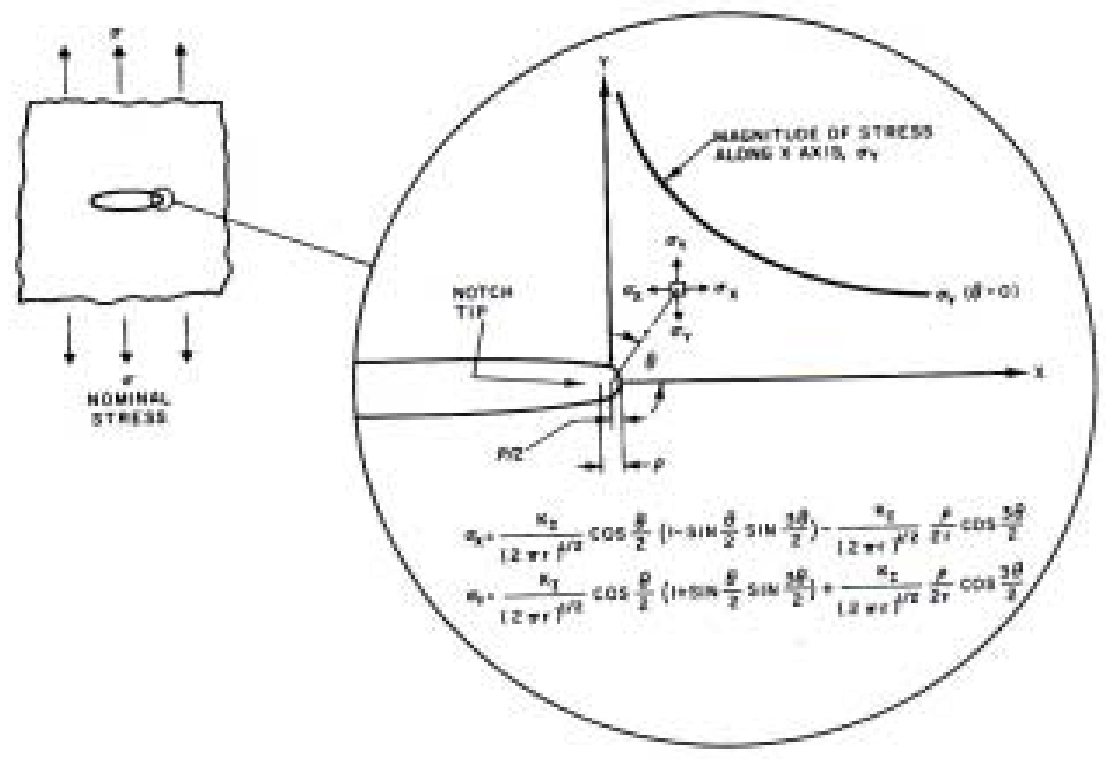

Figure 3.3 Stress distribution around the notch tip (Barsoum, 1977)

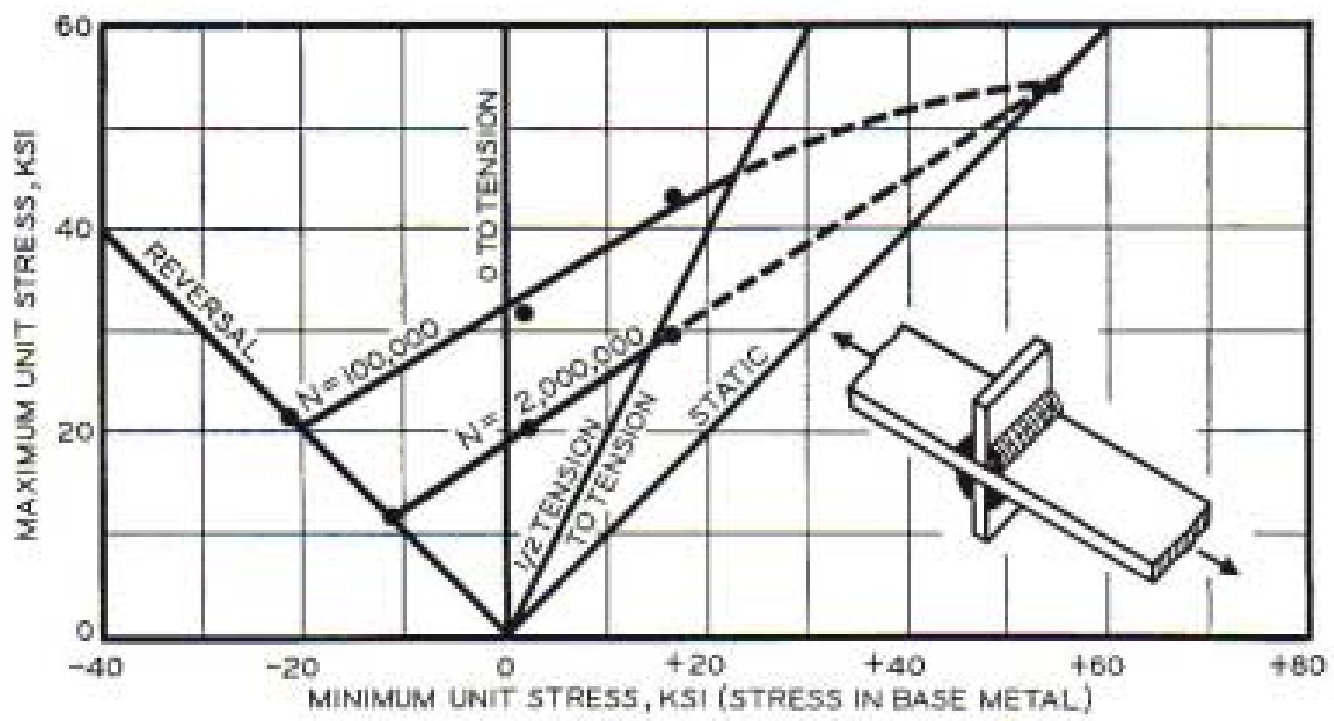

Figure 3.4 Fatigue strength of plates with transverse fillet welds (Munse, 1964). 


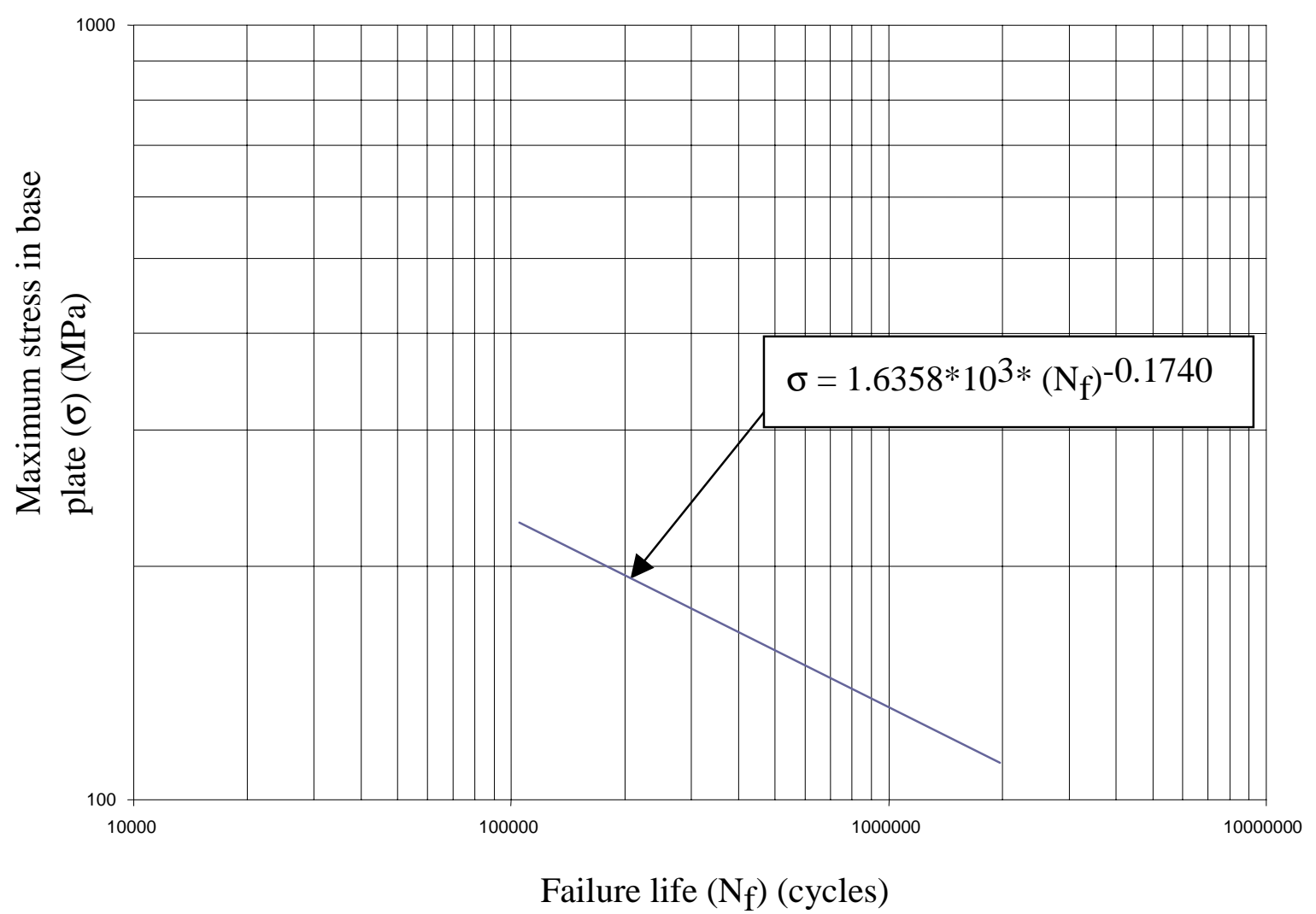

Figure 3.5 The relationship between maximum stress in base plate and failure life. 


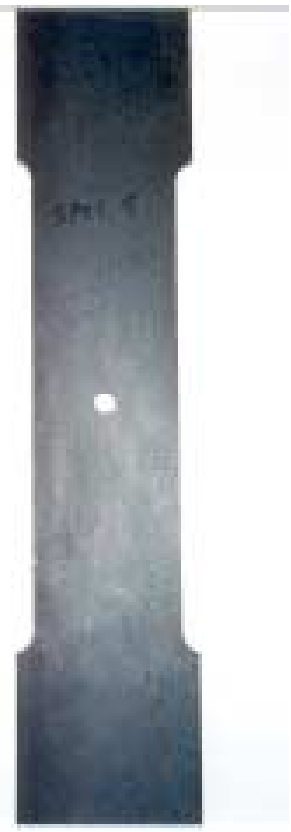

a) specimen with no paint

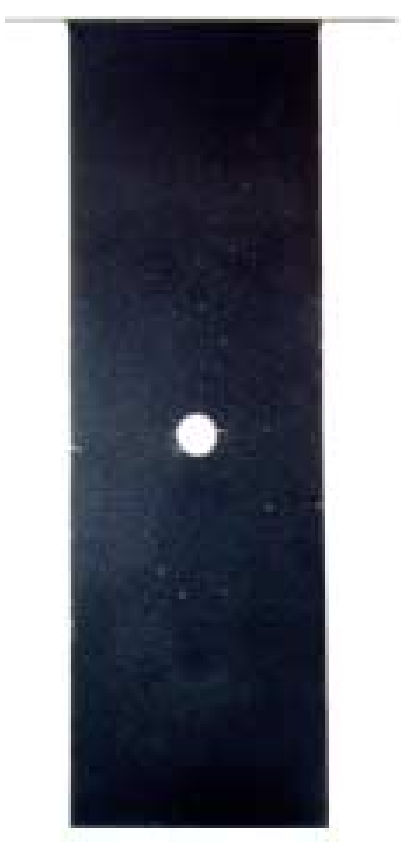

b) painted specimen

Figure 3.6 The test specimen surface preparation

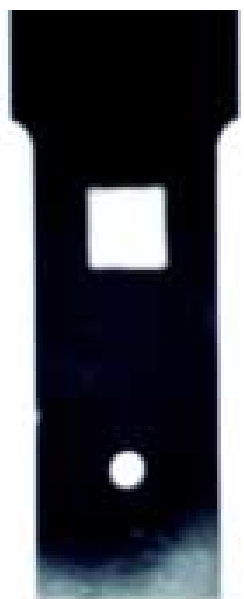

Figure 3.7 Paint chip 

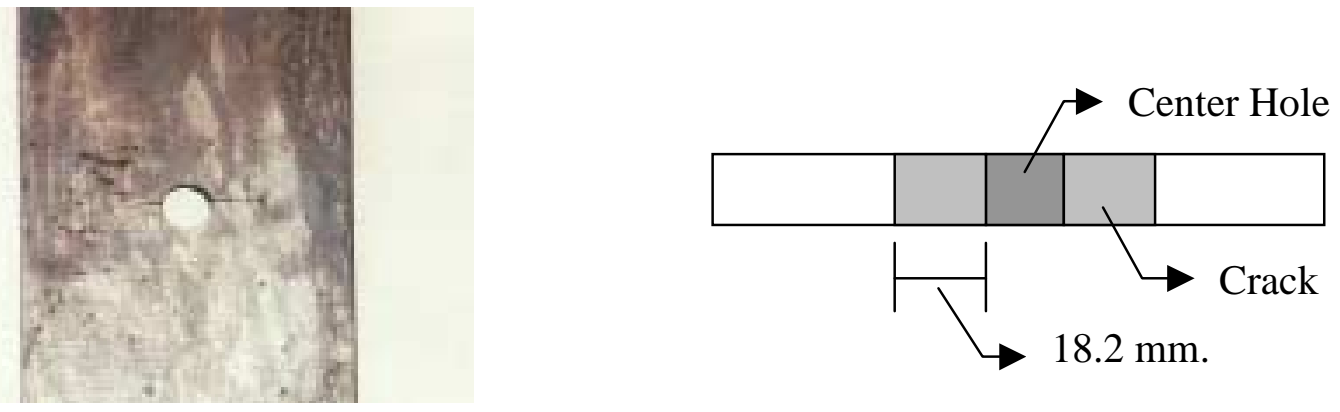

a) Specimen $\mathrm{CH}-1$
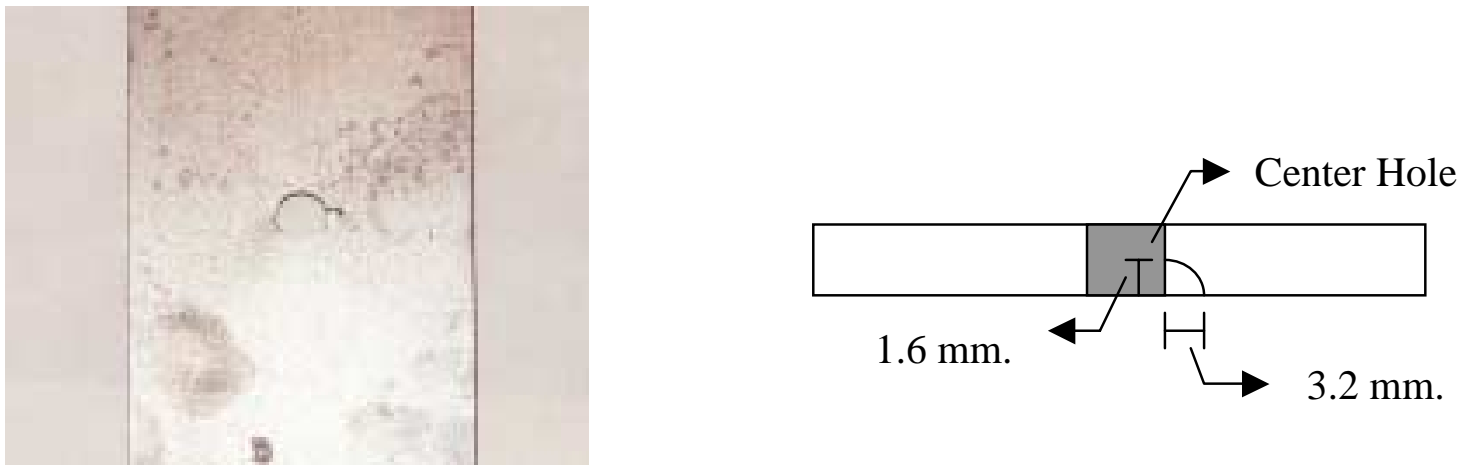

b) Specimen $\mathrm{CH}-2$
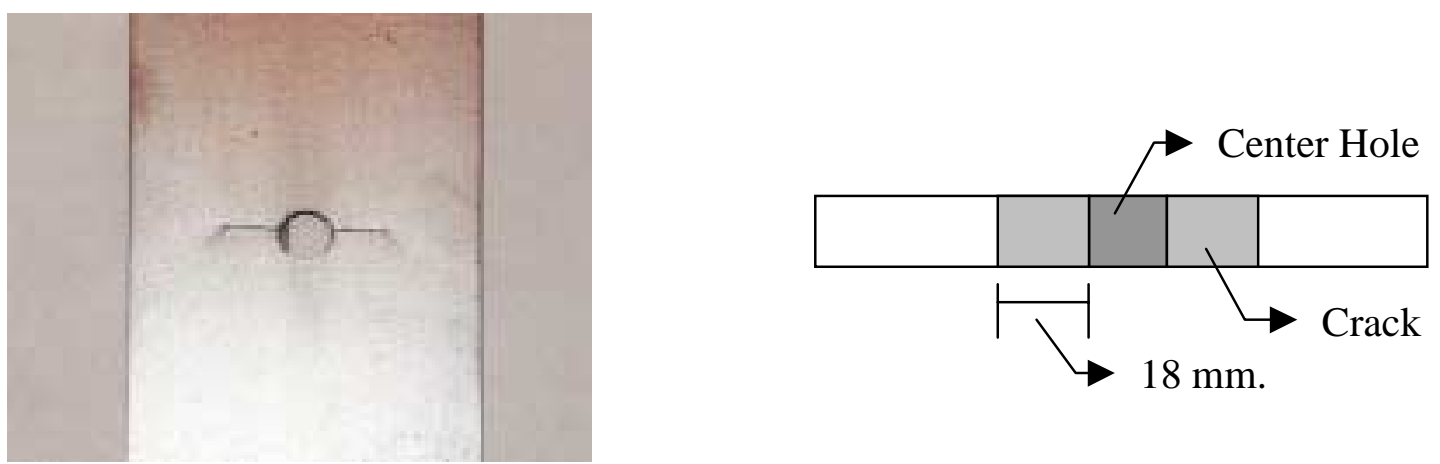

c) Specimen $\mathrm{CH}-3$

Figure 3.8 Final crack size in $\mathrm{CH}$ test specimens 


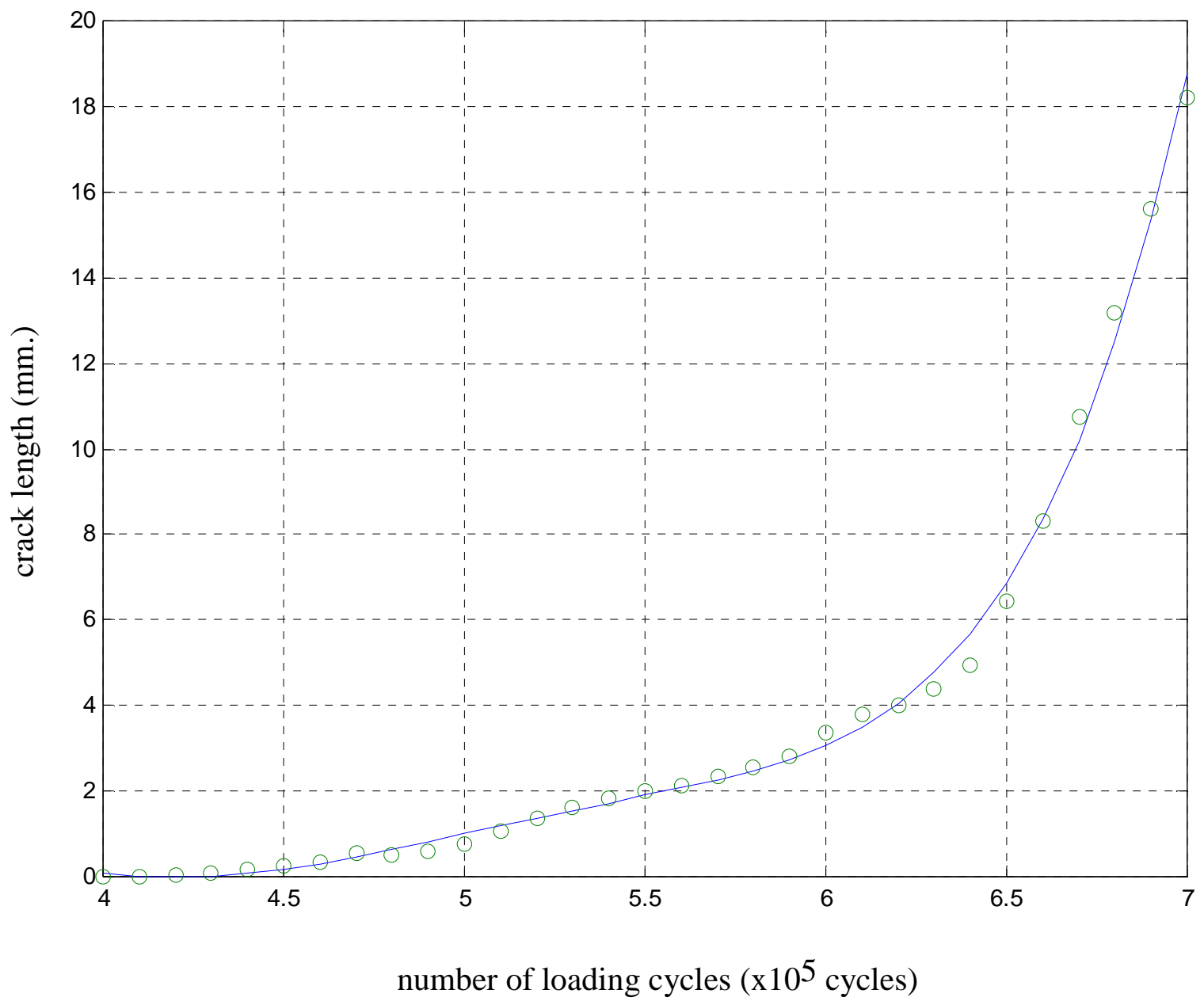

Figure 3.9 Surface crack length versus number of loading cycles of Specimen $\mathrm{CH}-1$ 


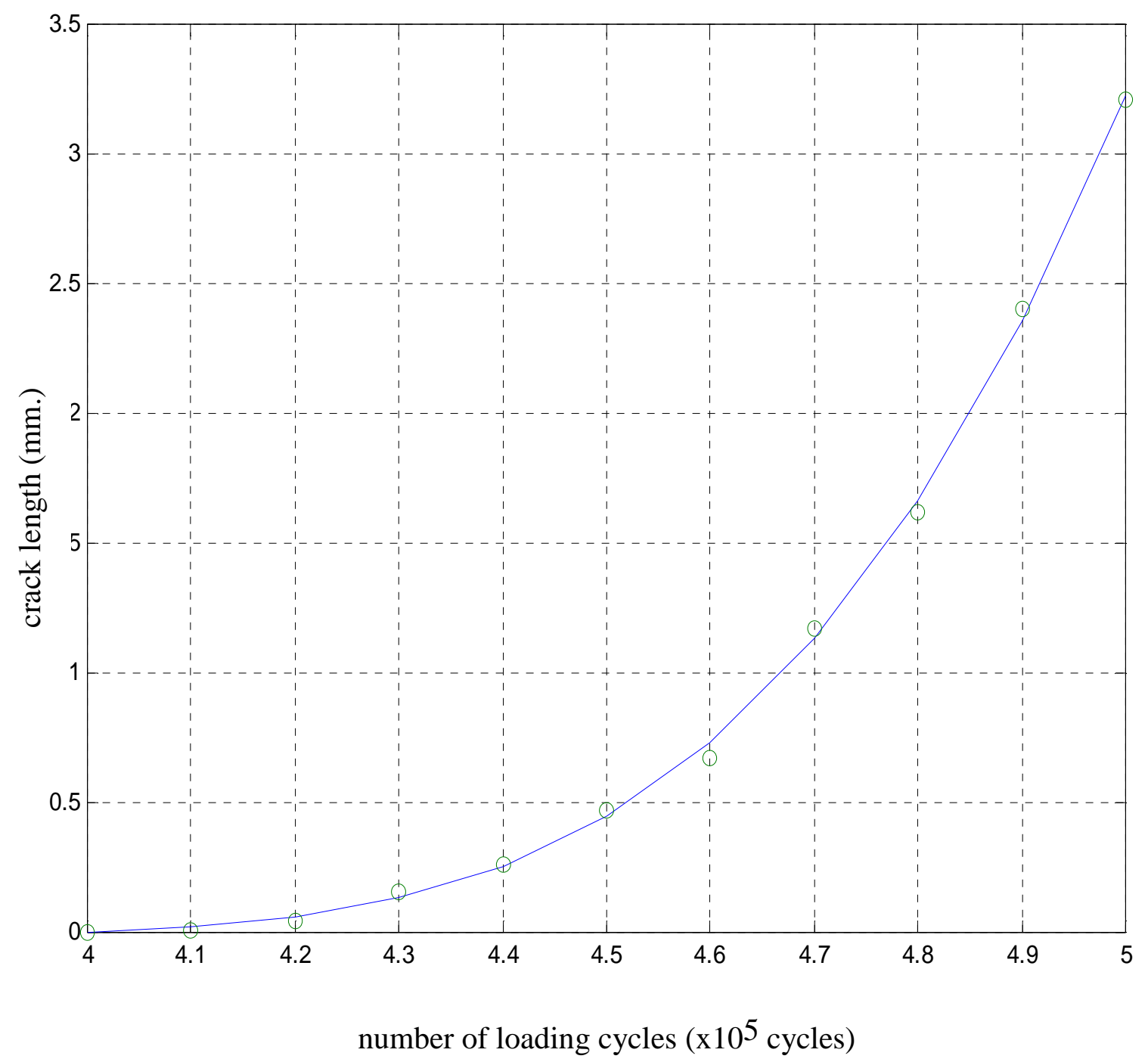

Figure 3.10 Surface crack length versus number of loading cycles of Specimen $\mathrm{CH}-2$ 


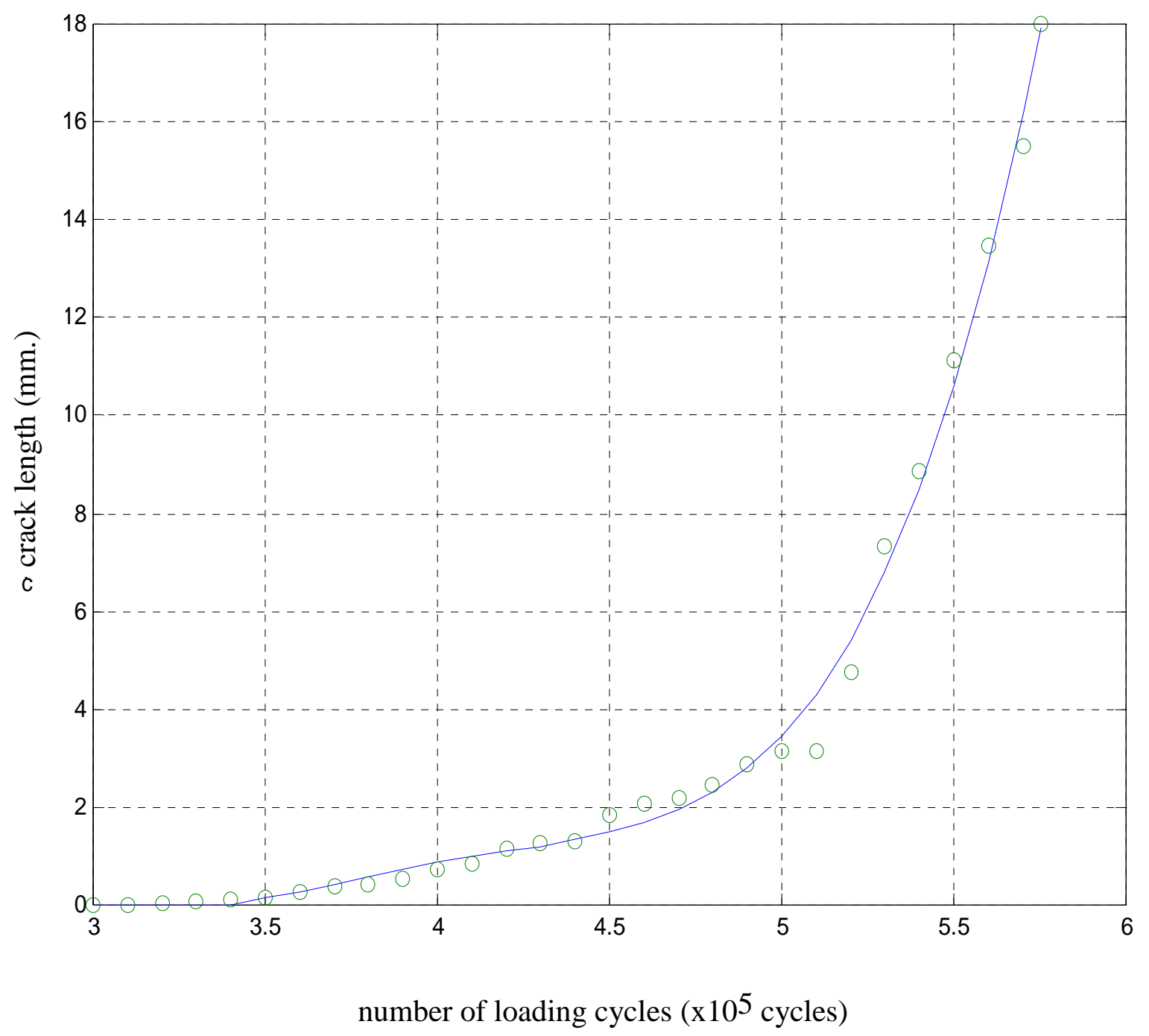

Figure 3.11 Surface crack length versus number of loading cycles of Specimen CH-3 


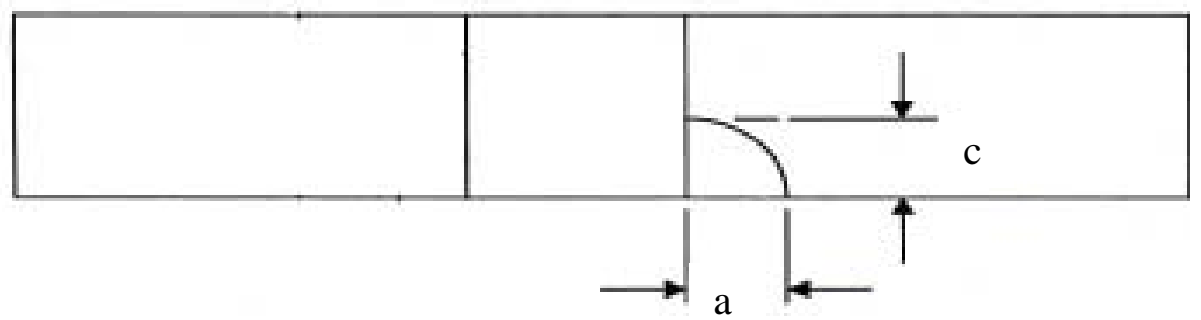

Figure 3.12 The graphic showing surface crack length (a) and throughthickness crack length (c)
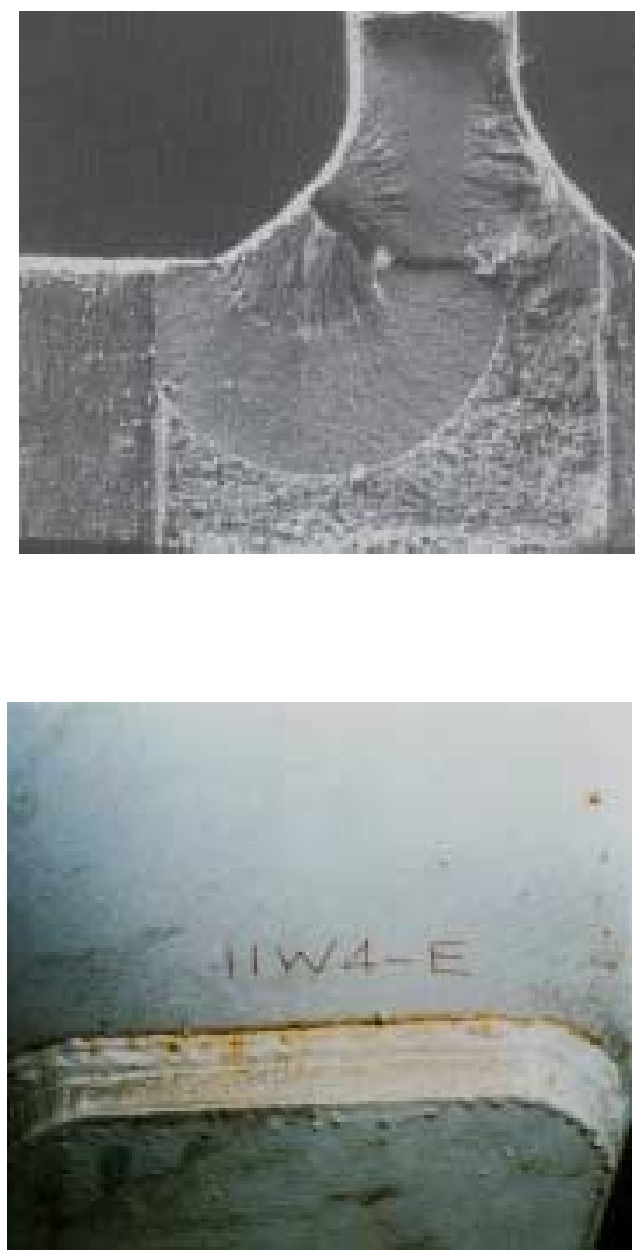

Figure 3.13 Crack in the weld (top) and crack in the member at the weld toe (bottom) (Sung, 1993). 


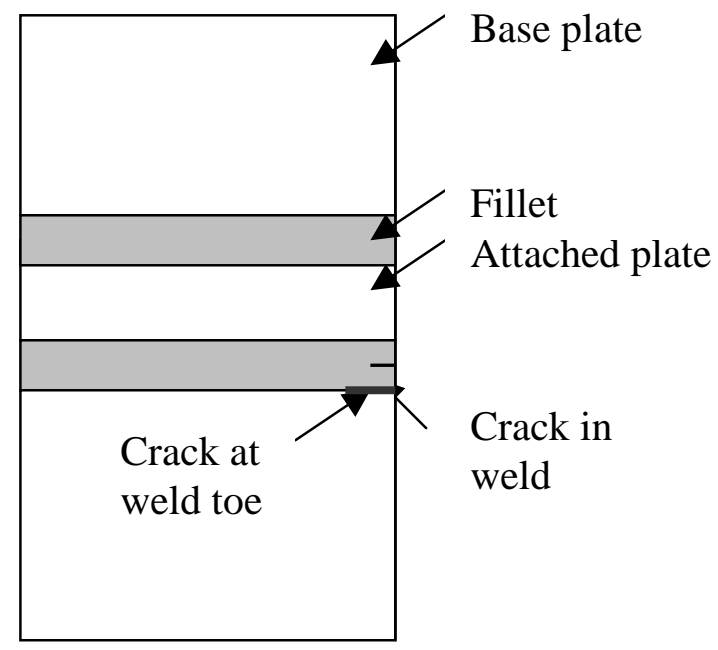

a) Location where crack started

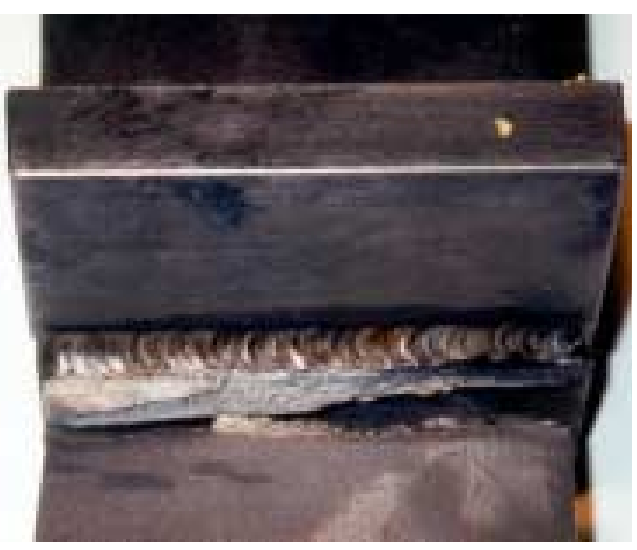

b) Front view of failed specimen

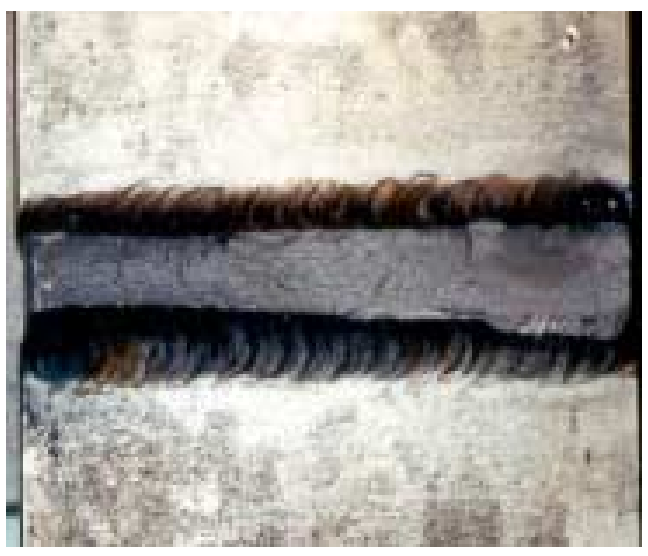

c) Failure surface

Figure 3.14 Crack at weld toe and crack in weld on Specimen WD-1 


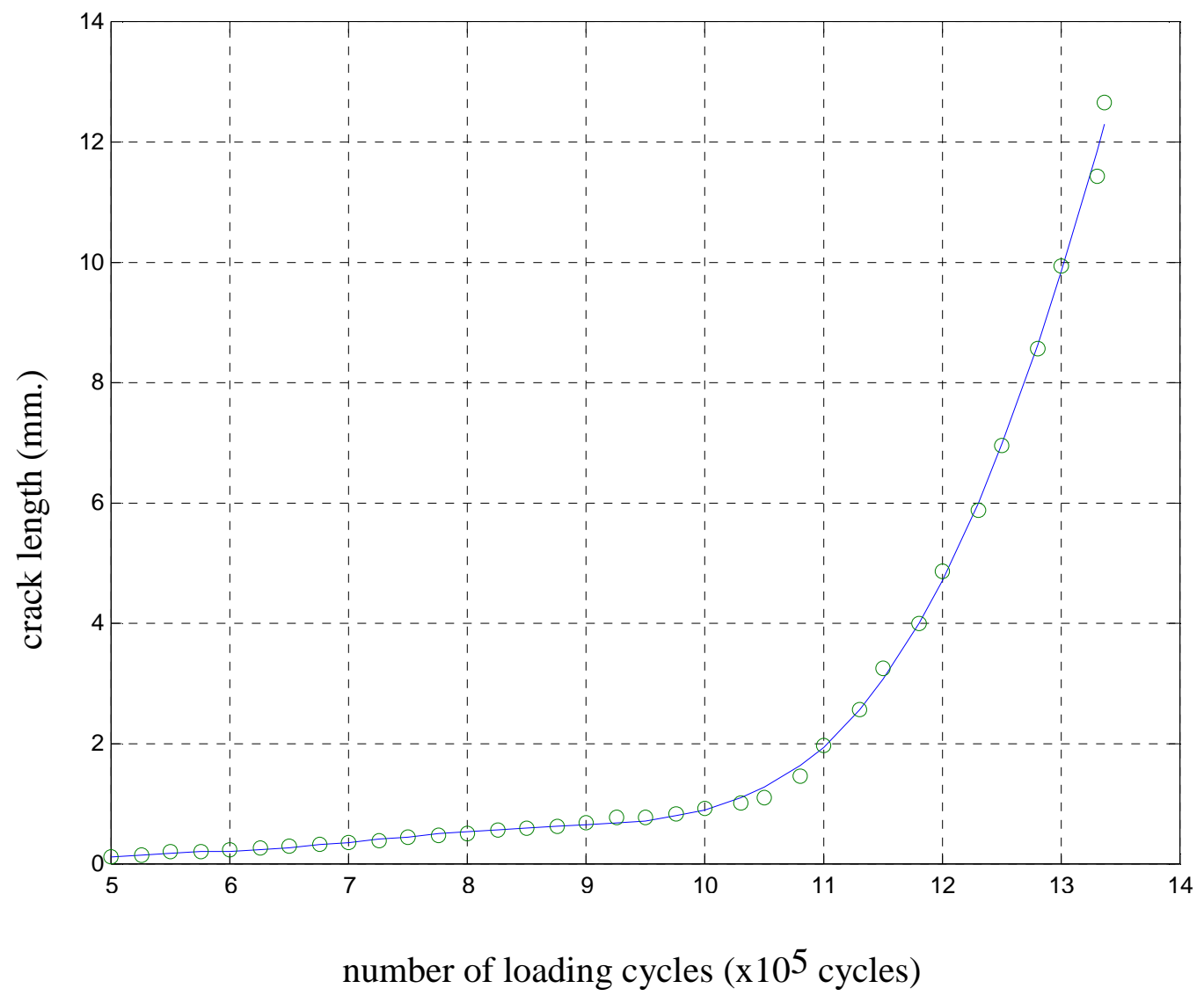

Figure 3.15 Surface in-weld crack length versus number of loading cycles of Specimen WD-1 


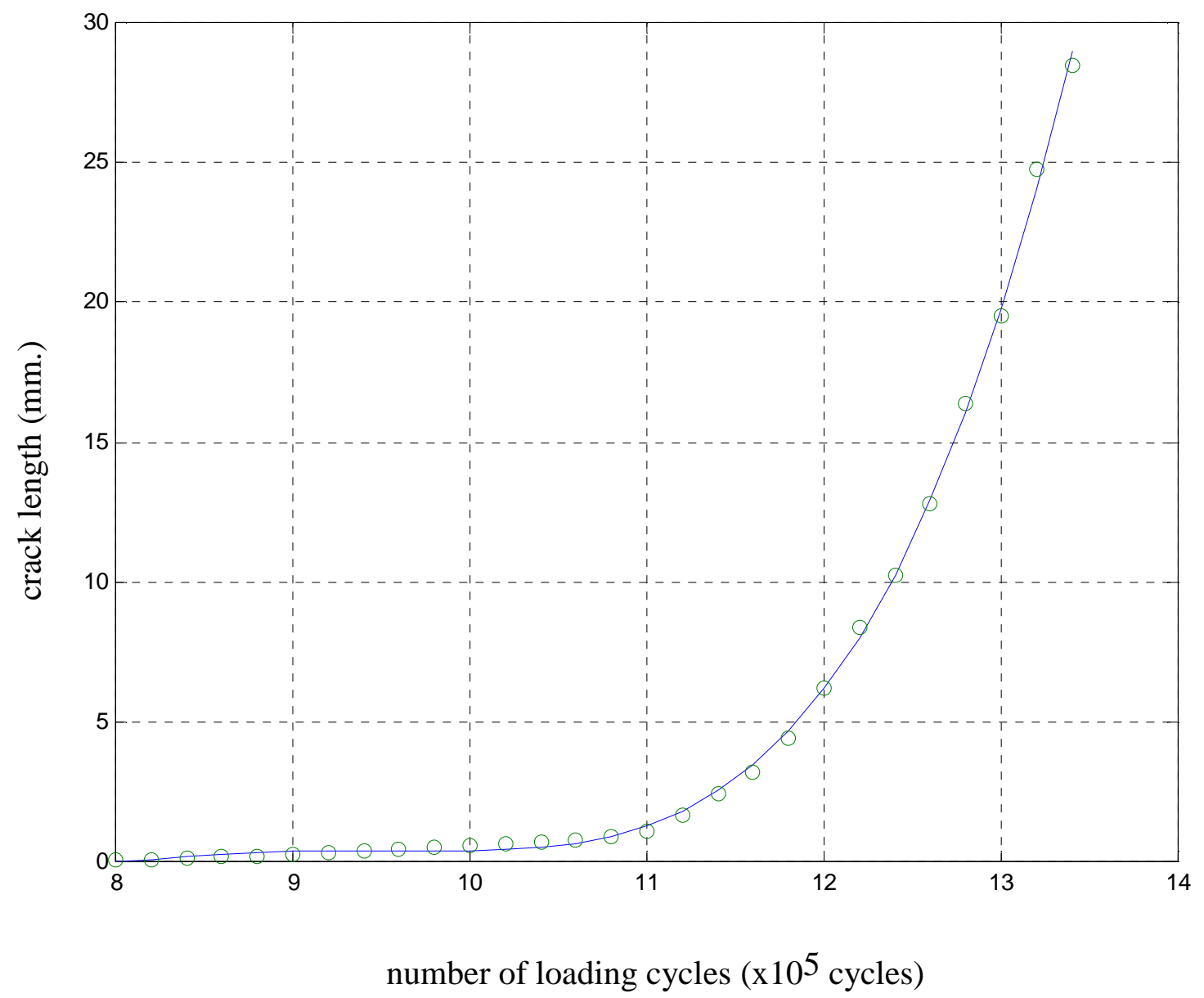

Figure 3.16 Surface weld toe crack length versus number of loading cycles of Specimen WD-1 


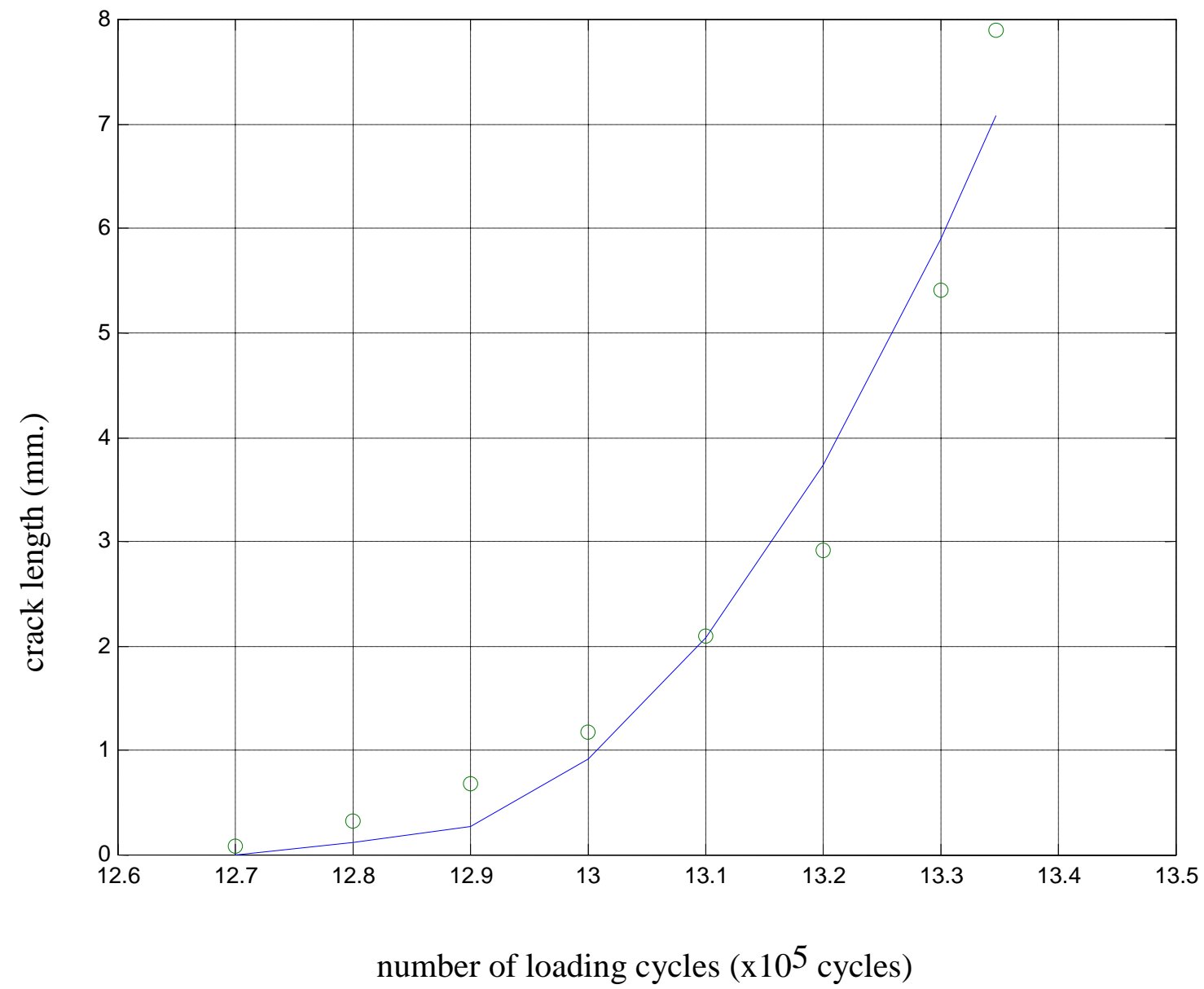

Figure 3.17 Through-thickness weld toe crack length versus number of loading cycles of Specimen WD-1 


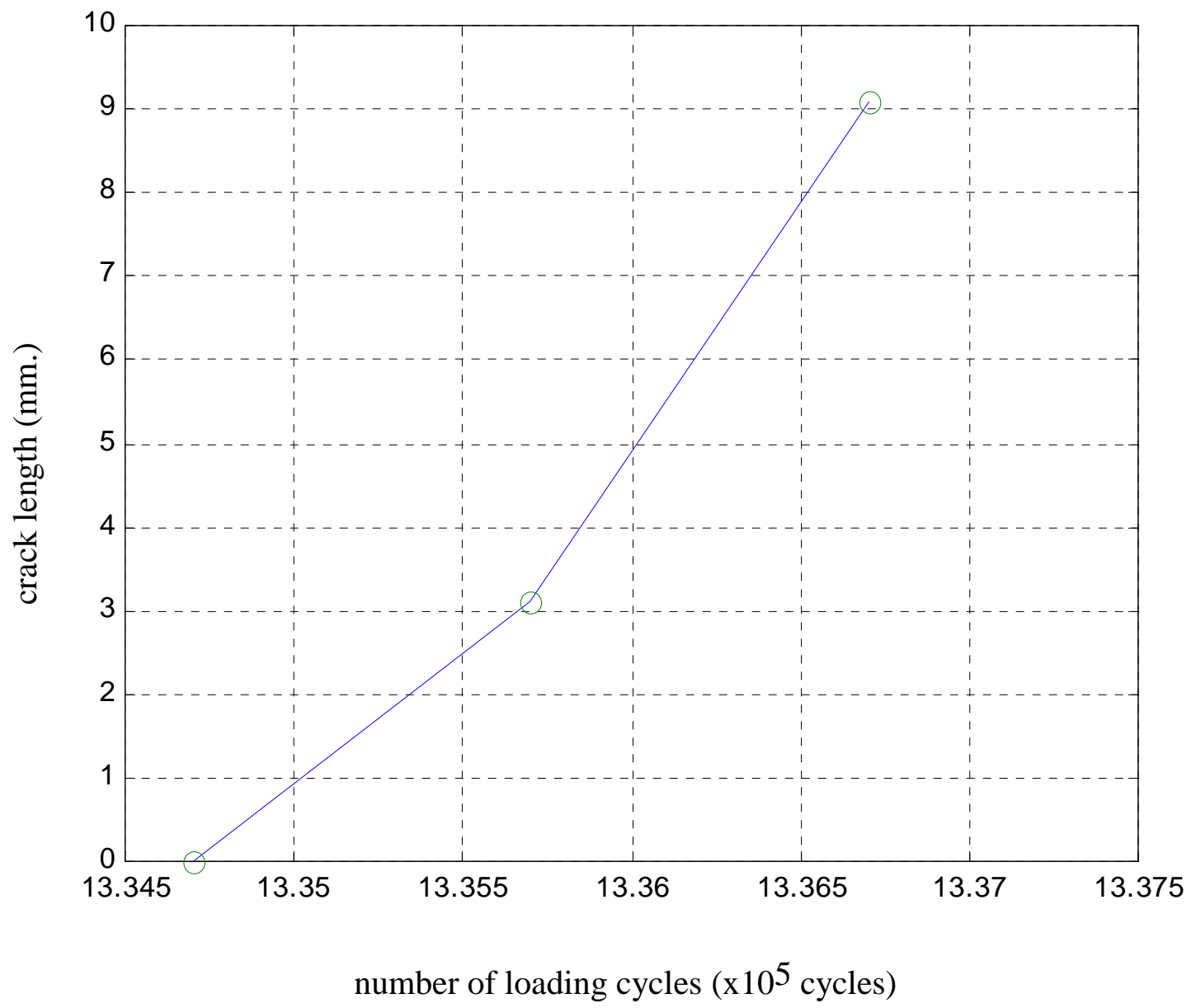

Figure 3.18 Surface weld toe crack length (back side) versus number of loading cycles of Specimen WD-1 

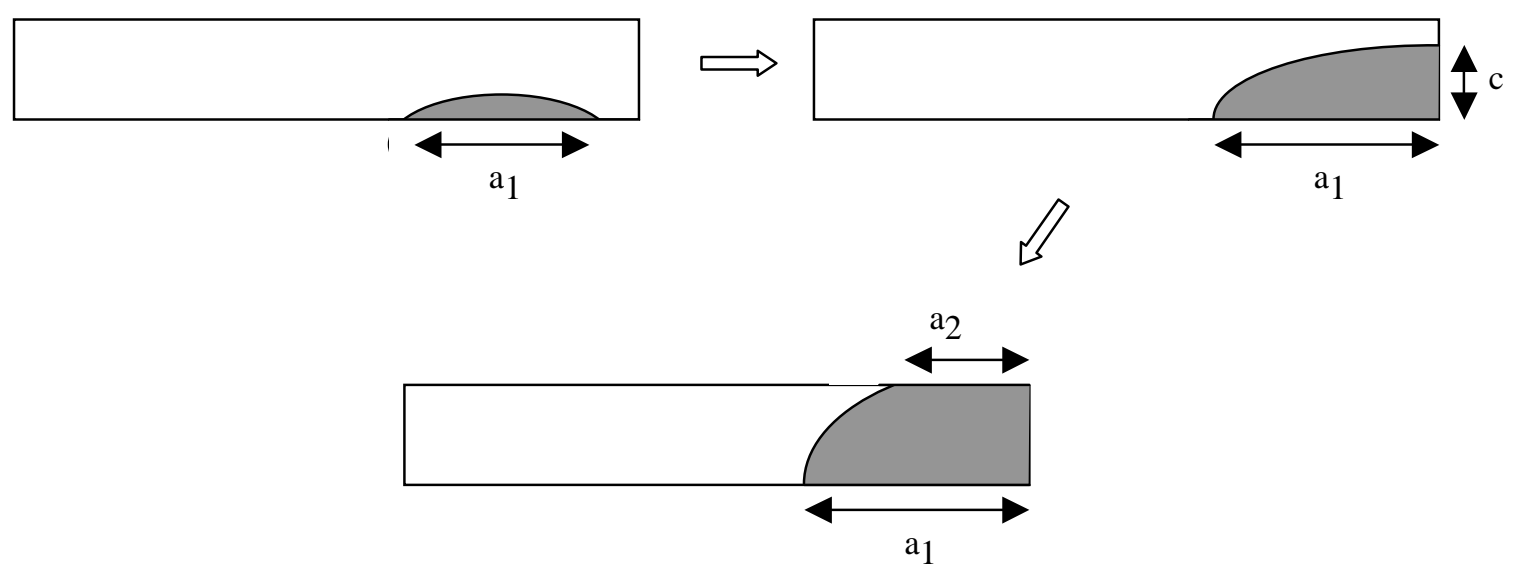

Figure 3.19 Development of weld toe crack geometry 


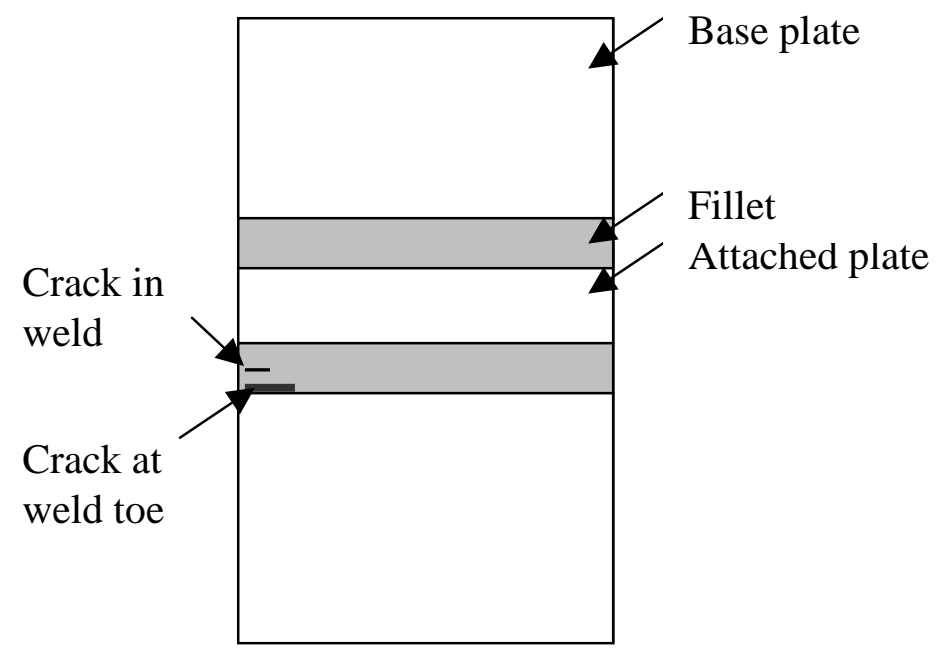

a) Location where crack started

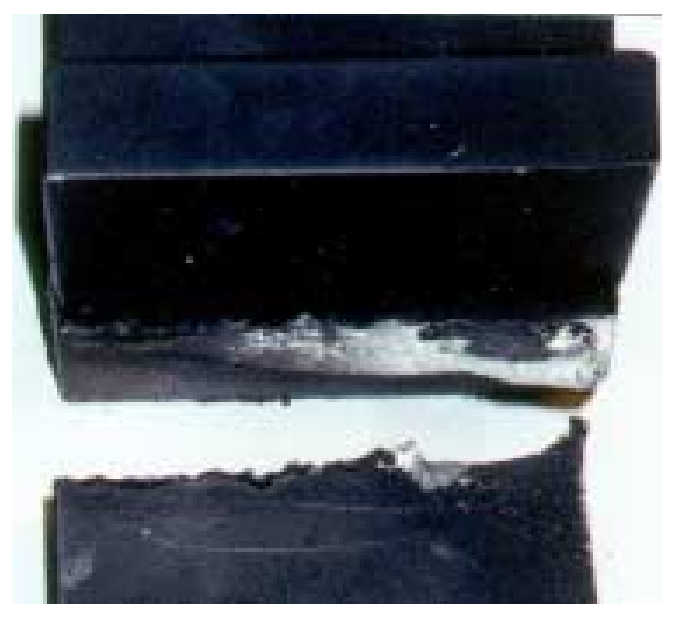

b) Front view of failed specimen

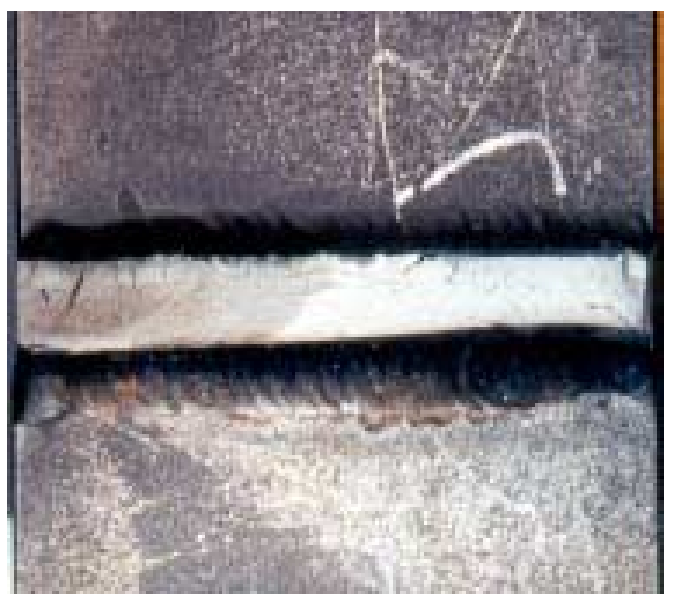

c) Failure surface

Figure 3.20 Crack at weld toe and crack in weld on Specimen WD-2 


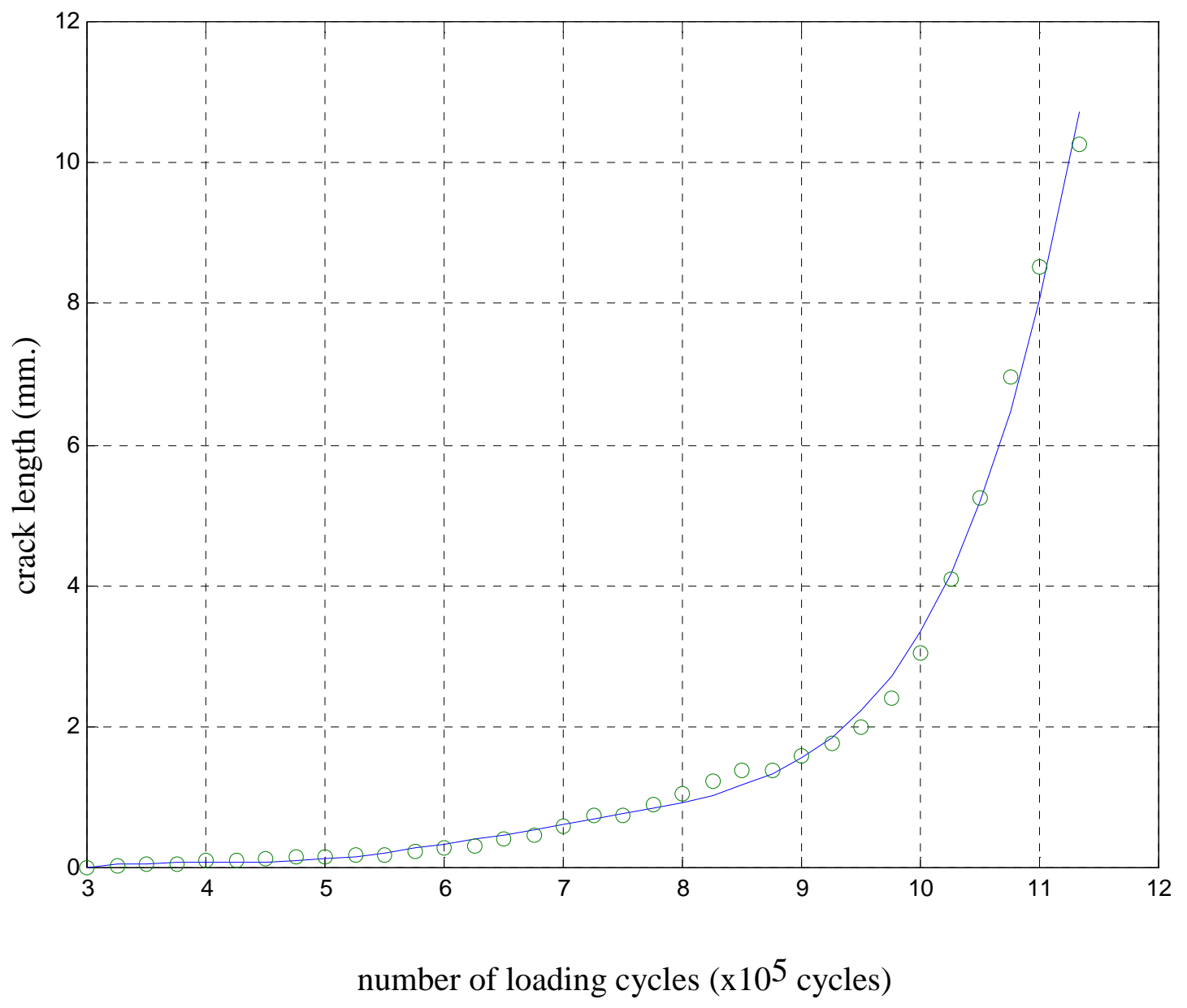

Figure 3.21 Surface in-weld crack length versus number of loading cycles of Specimen WD-2 


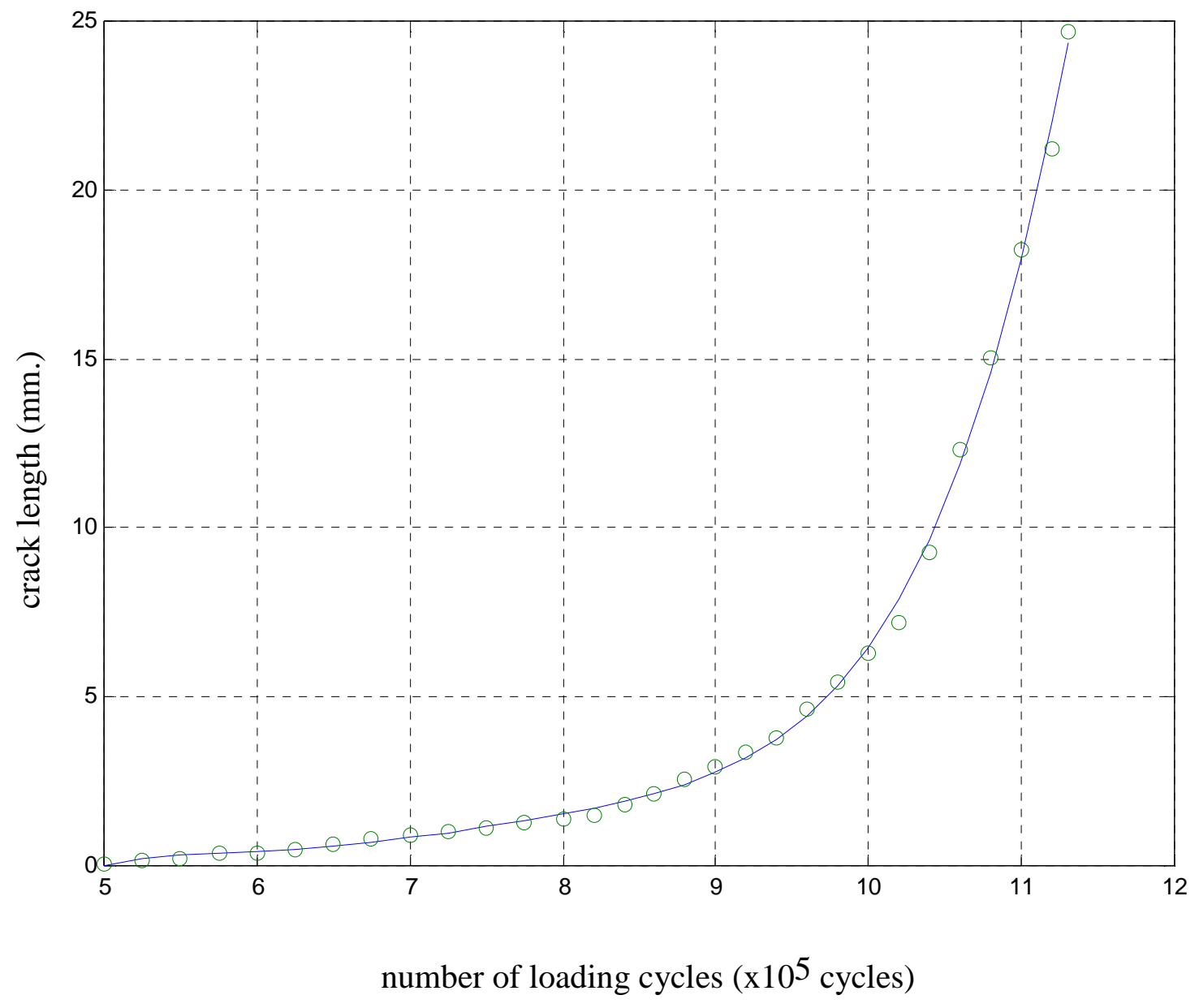

Figure 3.22 Surface weld toe crack length versus number of loading cycles of Specimen WD-2 


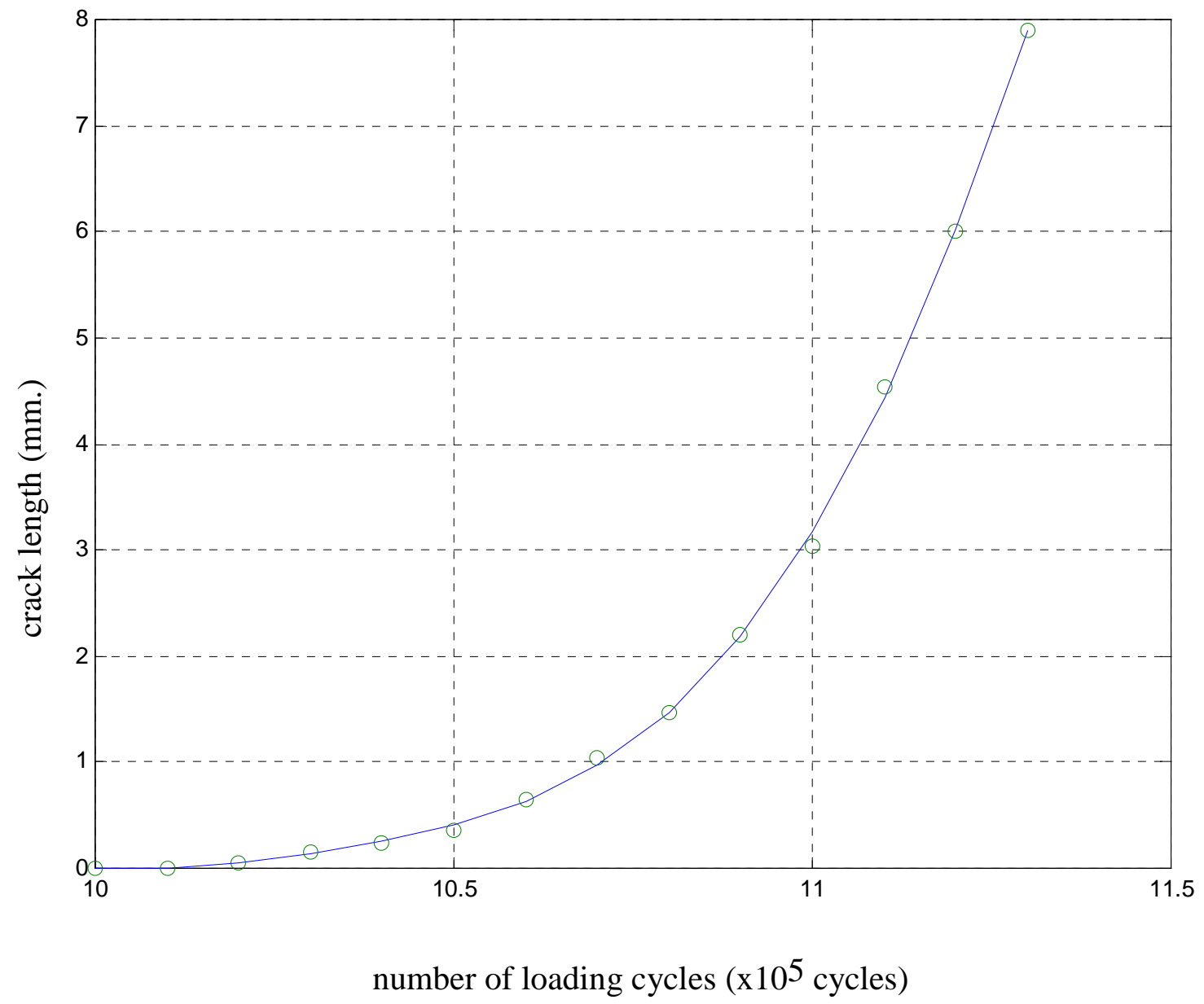

Figure 3.23 Through-thickness weld toe crack length versus number of loading cycles of Specimen WD-2 


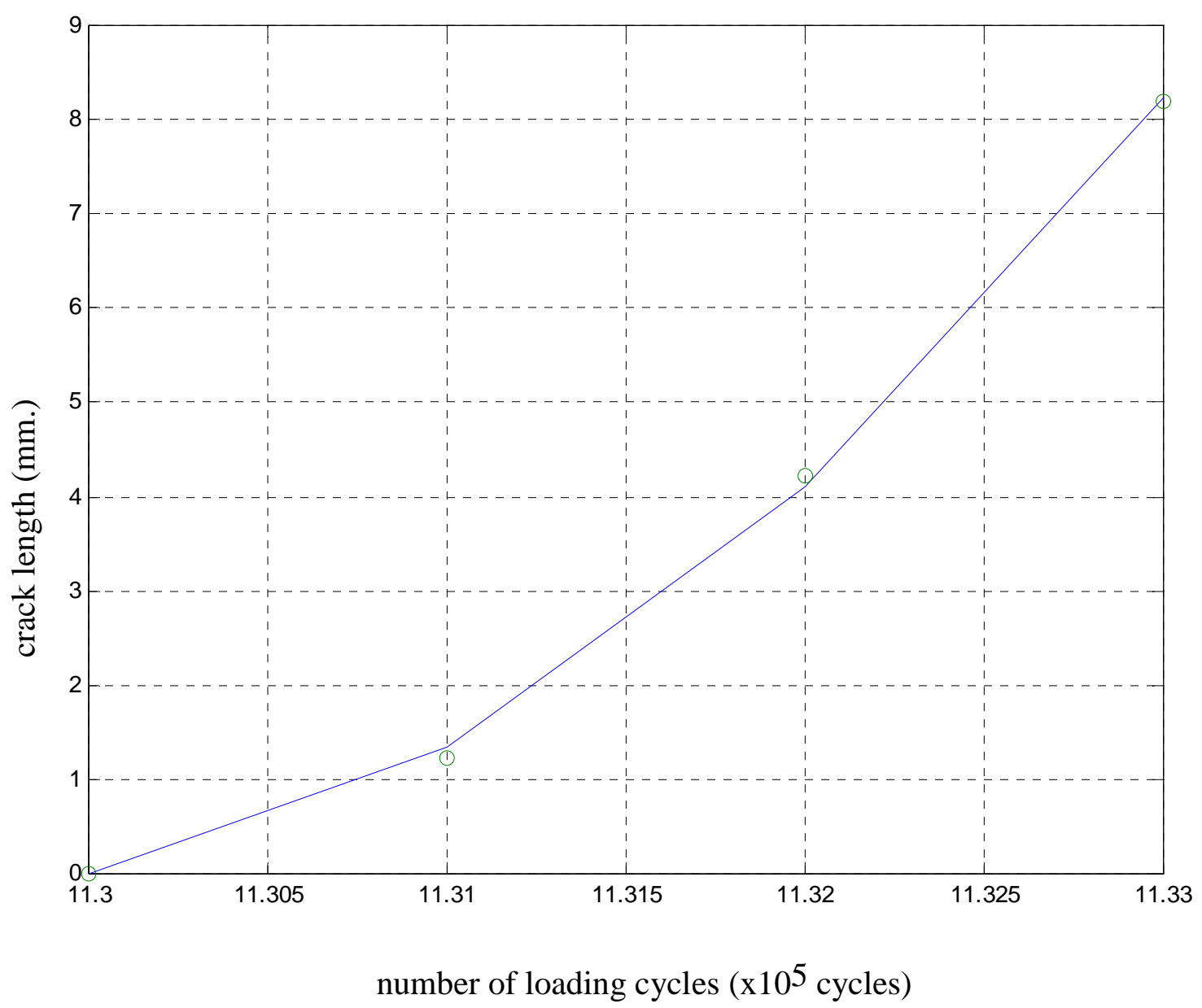

Figure 3.24 Surface weld toe crack length (back side) versus number of loading cycles of Specimen WD-2 


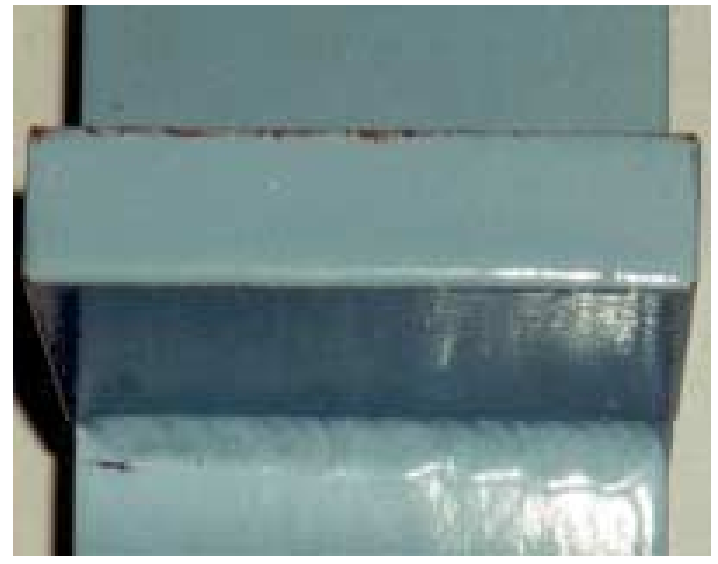

a) $3 / 8$ in. surface crack

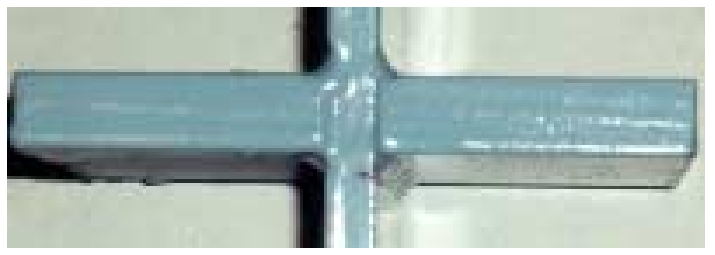

b) $1 / 16$ in. through-thickness crack

Figure 3.25 Visible crack in Specimen WD-3 at 1,500,000 loading cycles

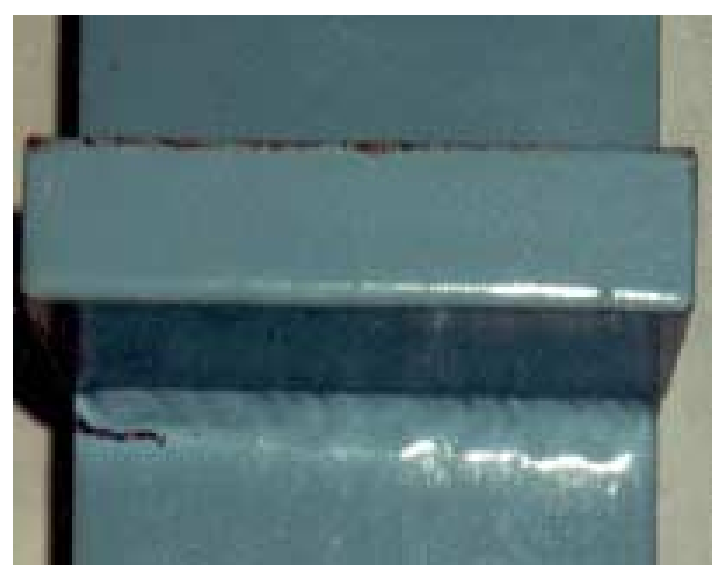

a) $4 / 8$ in. surface crack

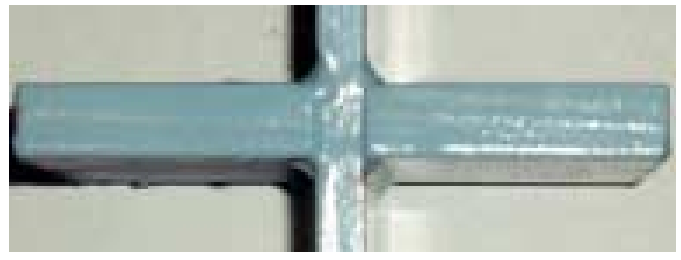

Figure 3.26 Visible crack in Specimen WD-3 at 1,600,000 loading cycles 


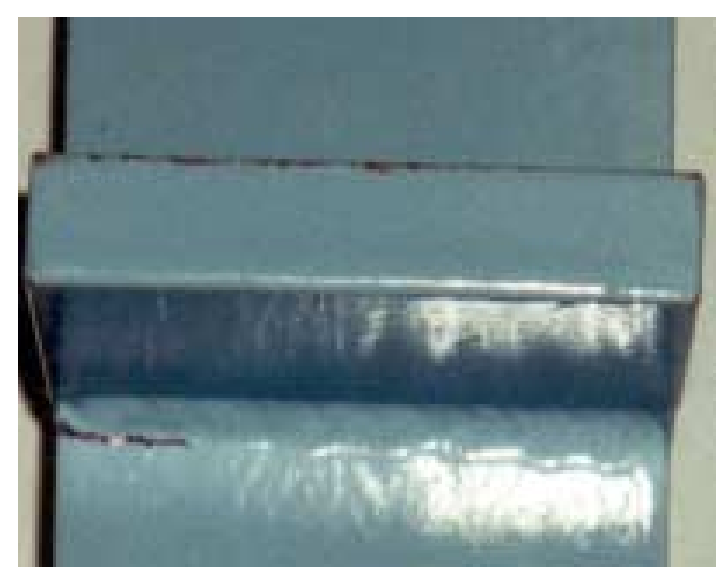

a) $5 / 8$ in. surface crack

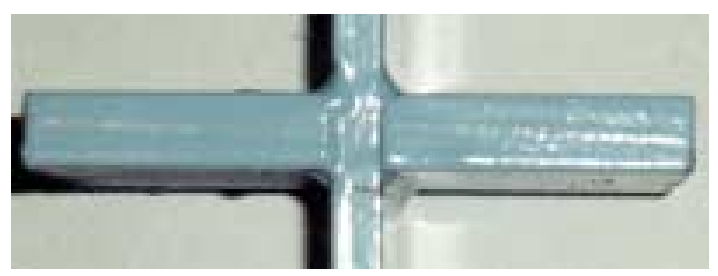

b) $3 / 16$ in. through-thickness crack

Figure 3.27 Visible crack in Specimen WD-3 at 1,670,000 loading cycles

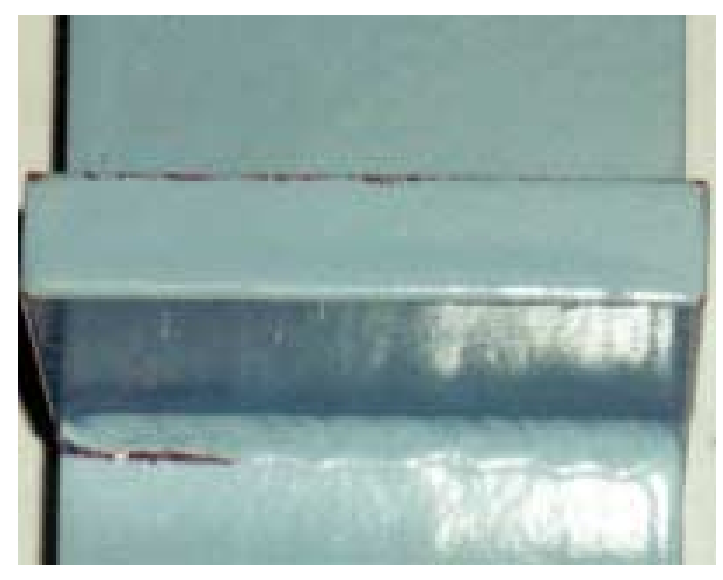

a) $7 / 8$ in. surface crack

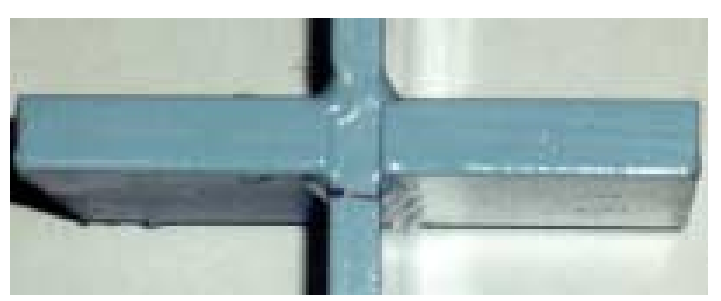

b) $5 / 16$ in. through-thickness crack

Figure 3.28 Visible crack in Specimen WD-3 at 1,735,550 loading cycles 


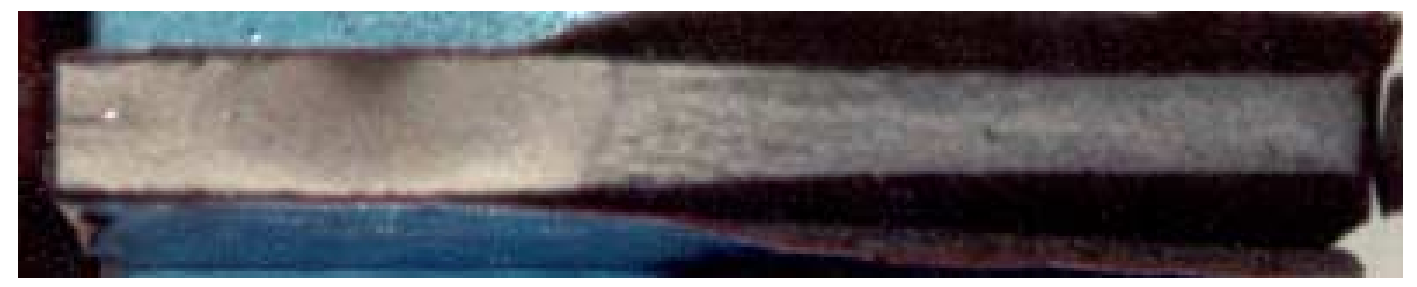

Figure 3.29 Surface failure of Specimen WD-3 


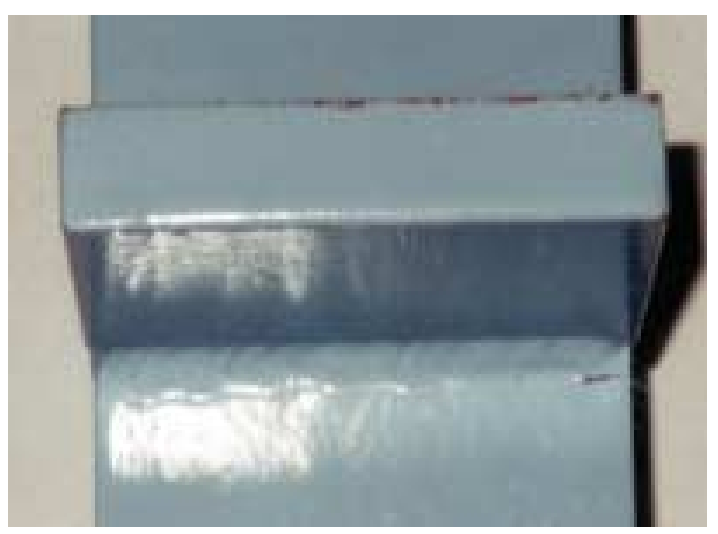

a) $3 / 8$ in. surface crack

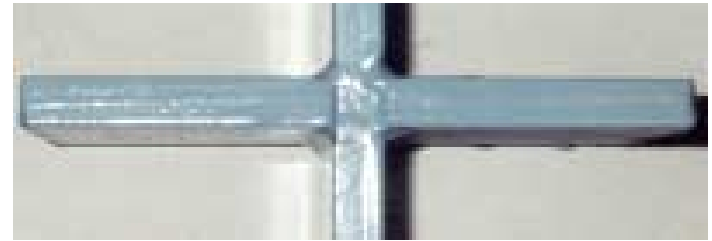

b) $1 / 16$ in. through-thickness crack

Figure 3.30 Visible crack in Specimen WD-4 at 1,250,000 loading cycles

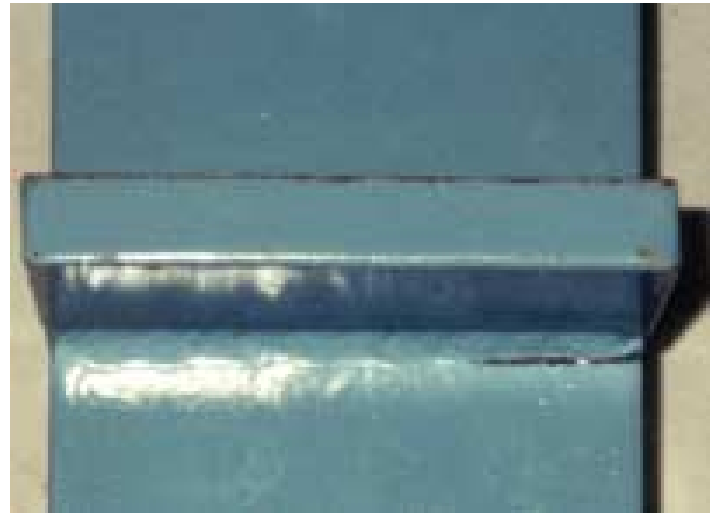

a) $3 / 8$ in. surface crack

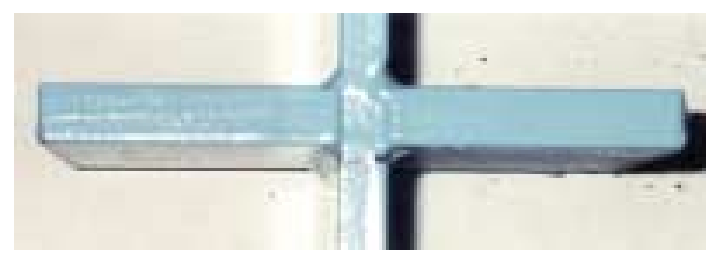

b) $1 / 16$ in. through-thickness crack

Figure 3.31 Visible crack in Specimen WD-4 at 1,840,000 loading cycles 


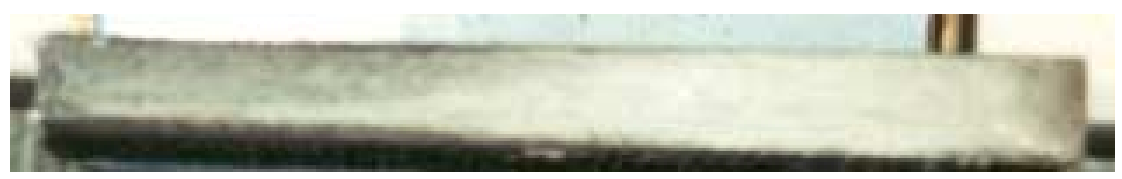

Figure 3.32 Surface failure of Specimen WD-4 


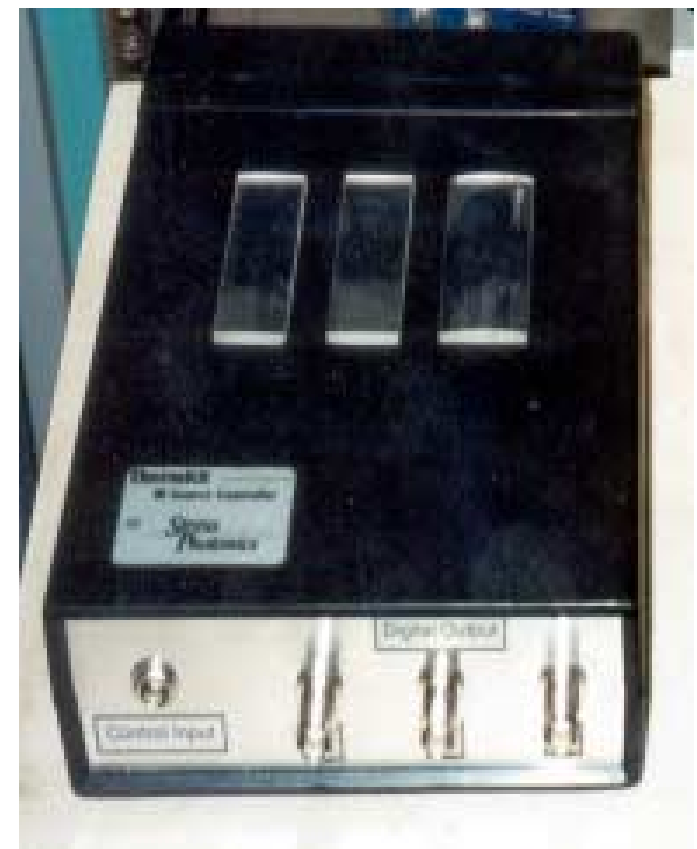

a) Controller and cylindrical lenses

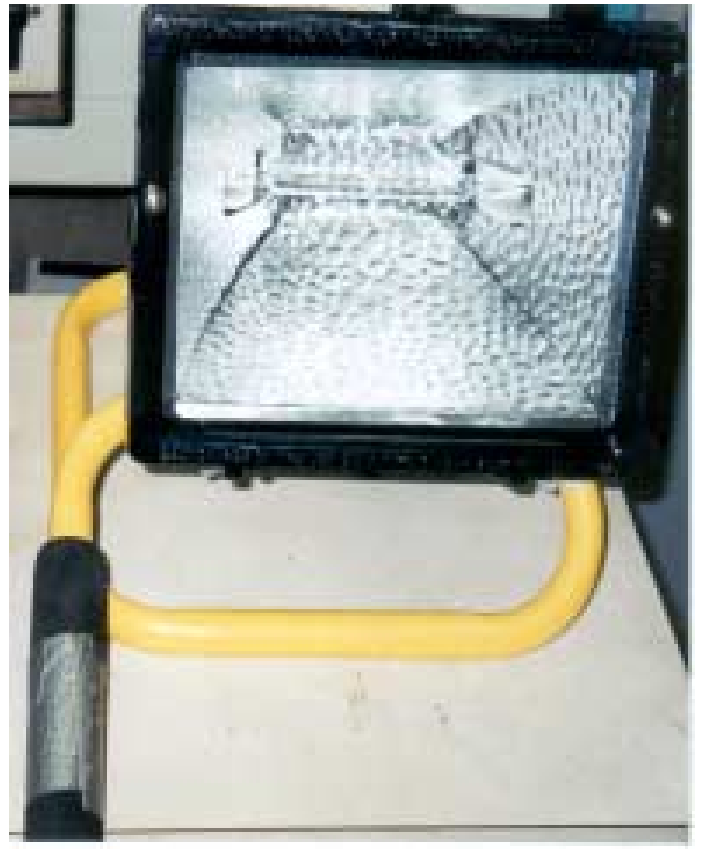

b) Halogen lamp

Figure 3.33 The Projector (Heat Source) 


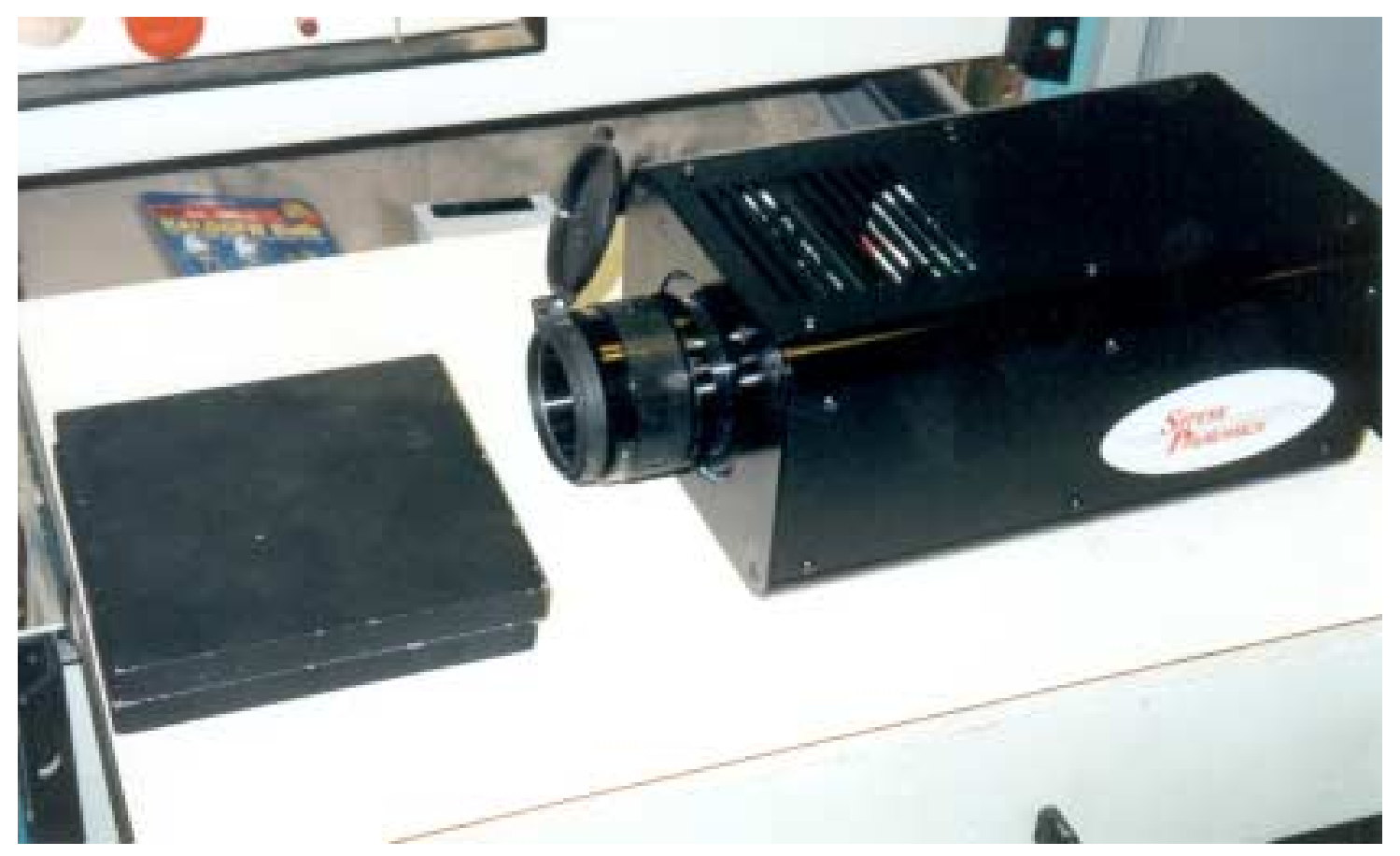

Figure 3.34 The IR camera and calibrate plates 
Level of heat applied to test specimen (\%)

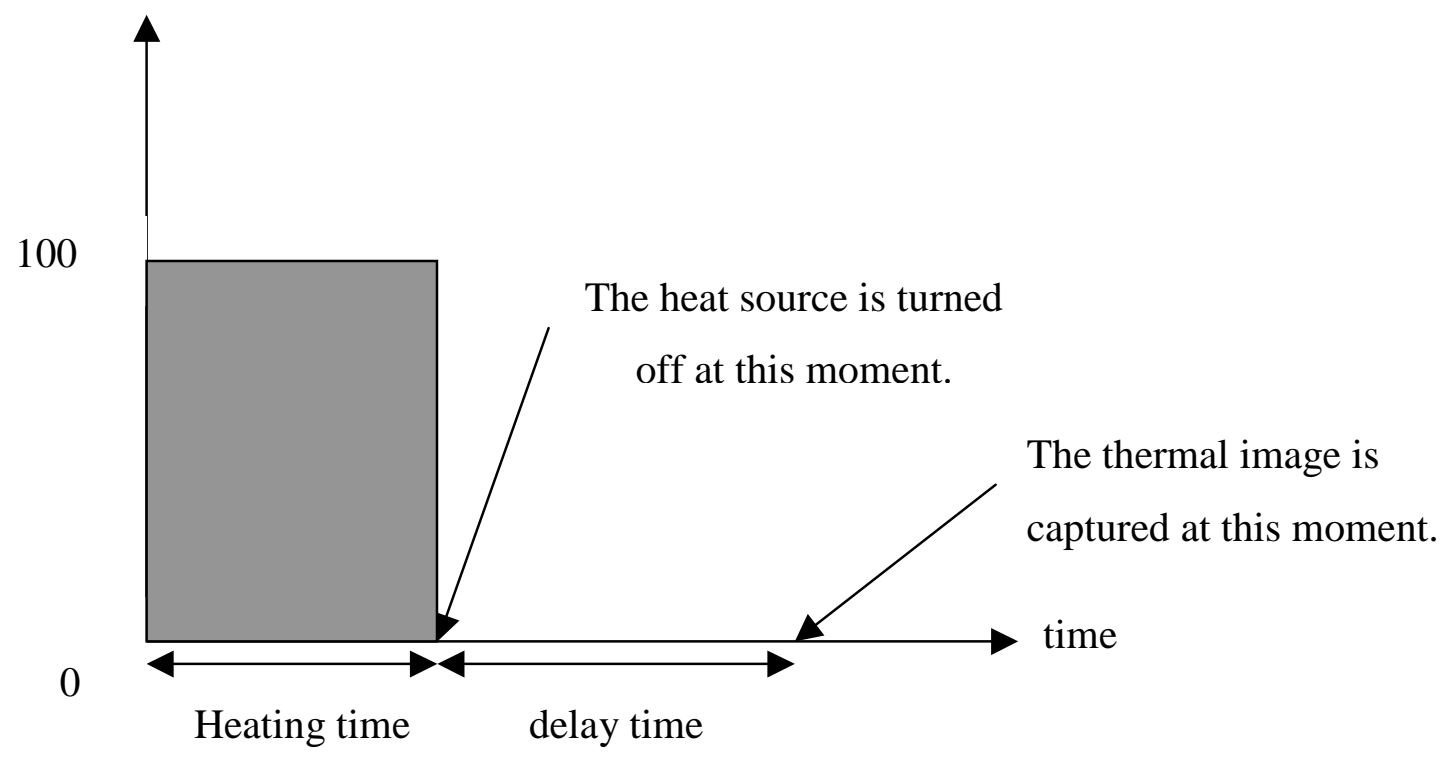

Figure 3.35 Schematic represents the concept of heating and delay time 


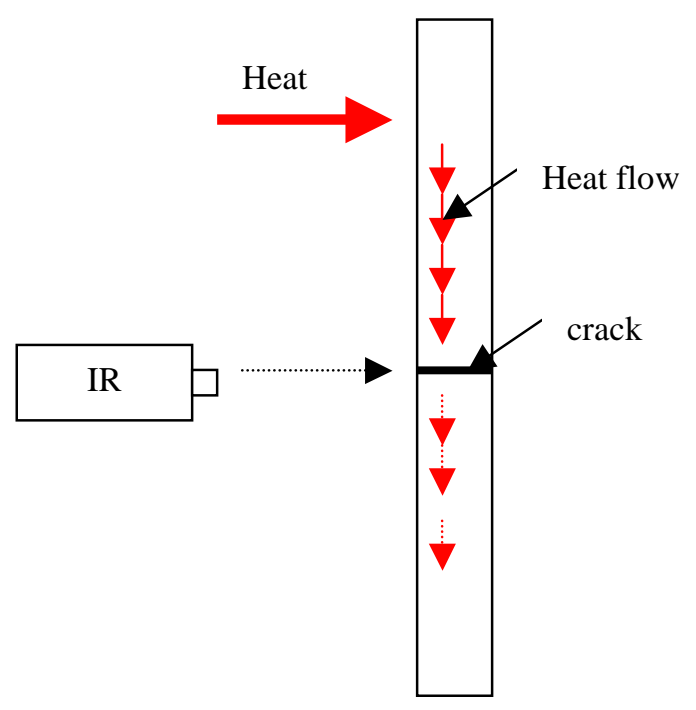

a) $\mathrm{CH}$ test series
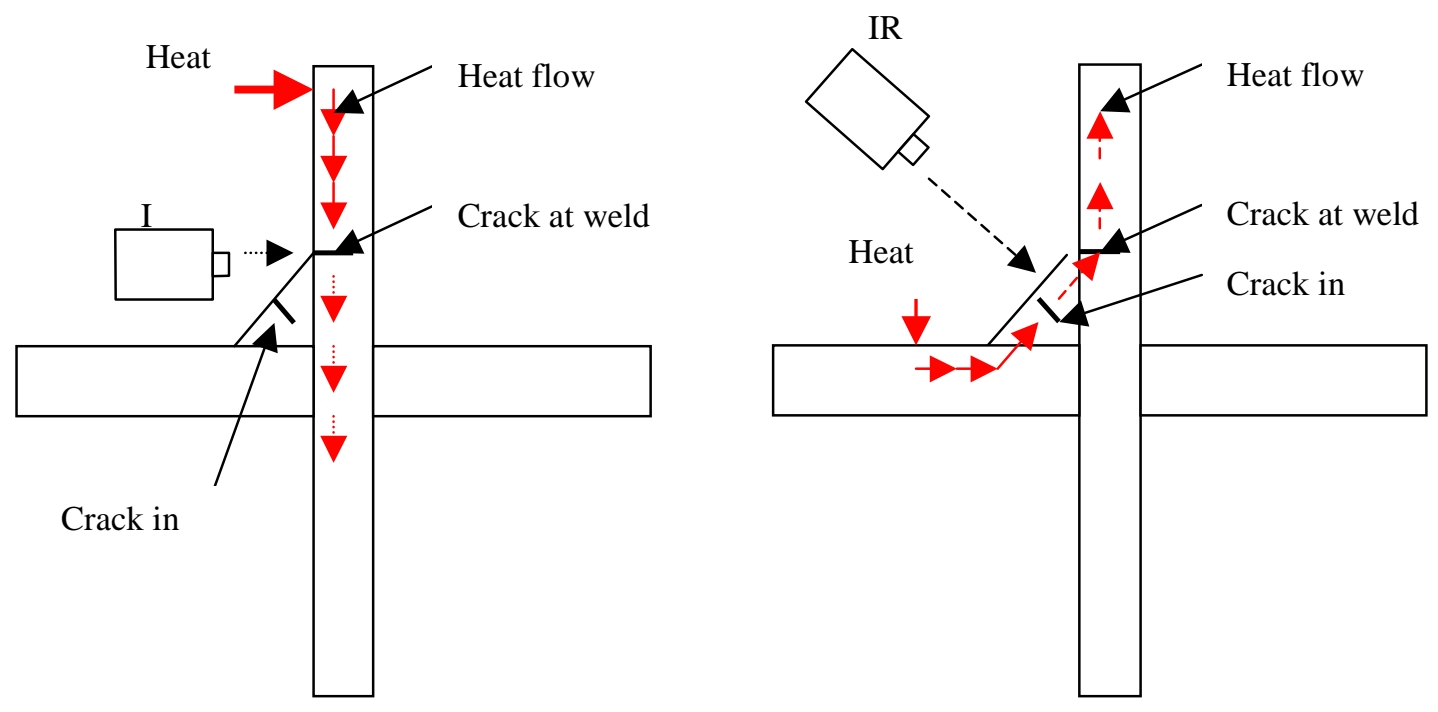

b) WD test seris

Figure 3.36 Setting up the camera to capture the thermal image of the test specimen 


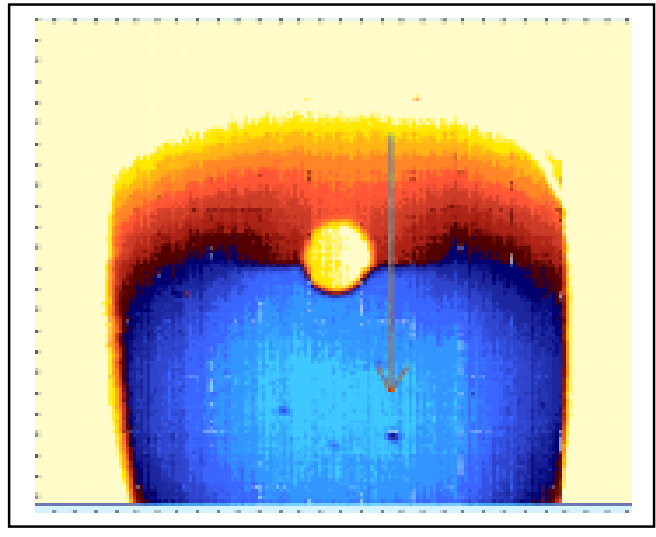

a)

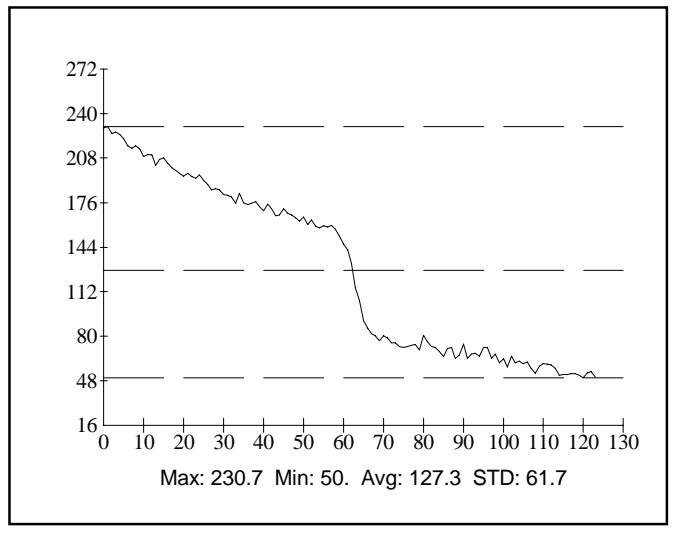

b)

\begin{tabular}{|l|}
\hline 264.0 \\
248.0 \\
232.0 \\
216.0 \\
200.0 \\
184.0 \\
168.0 \\
152.0 \\
136.0 \\
120.0 \\
104.0 \\
88.0 \\
72.0 \\
56.0 \\
40.0 \\
24.0 \\
\end{tabular}

c)

Figure 3.37 The examples of thermal image (a), thermal intensity profile (b), and thermal intensity color bar (c) 
I

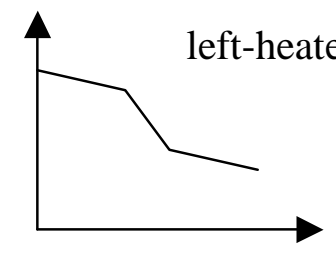

distance

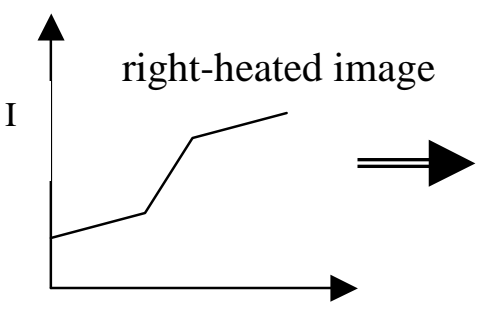

distance

left-heated image
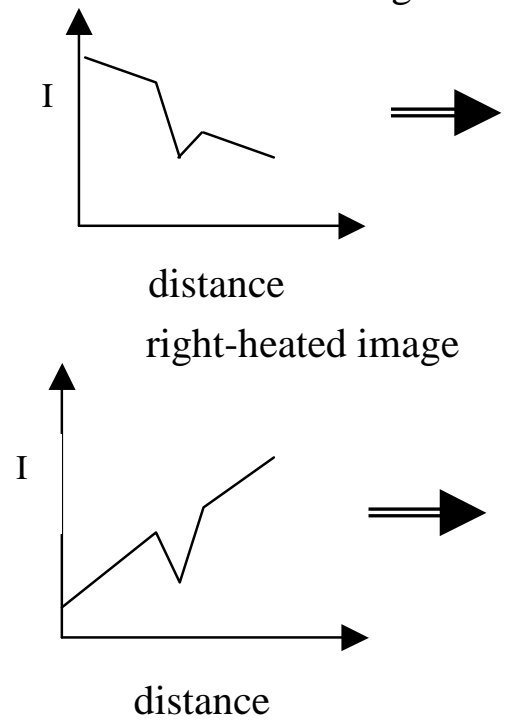

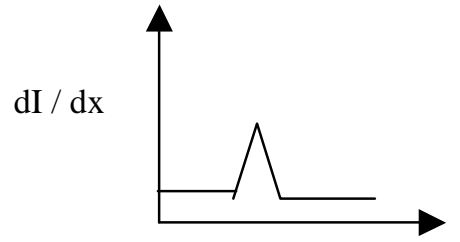

distance
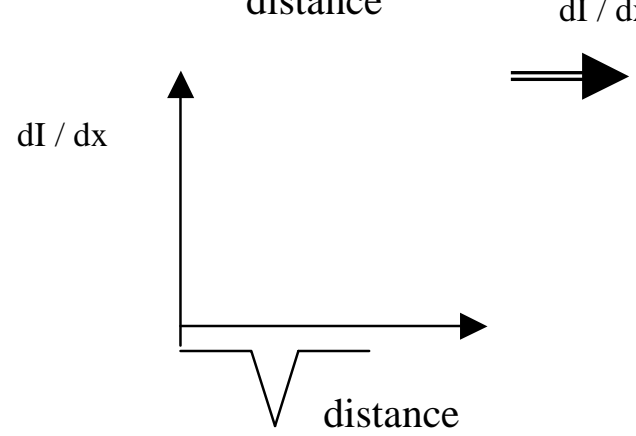

a) data from crack results after subtraction

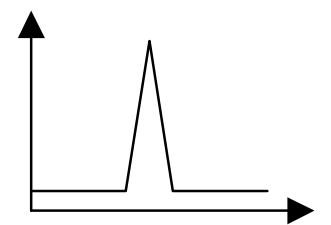

distance

$\mathrm{dI} / \mathrm{dx}$

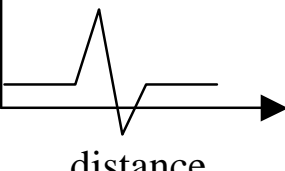

results after subtraction

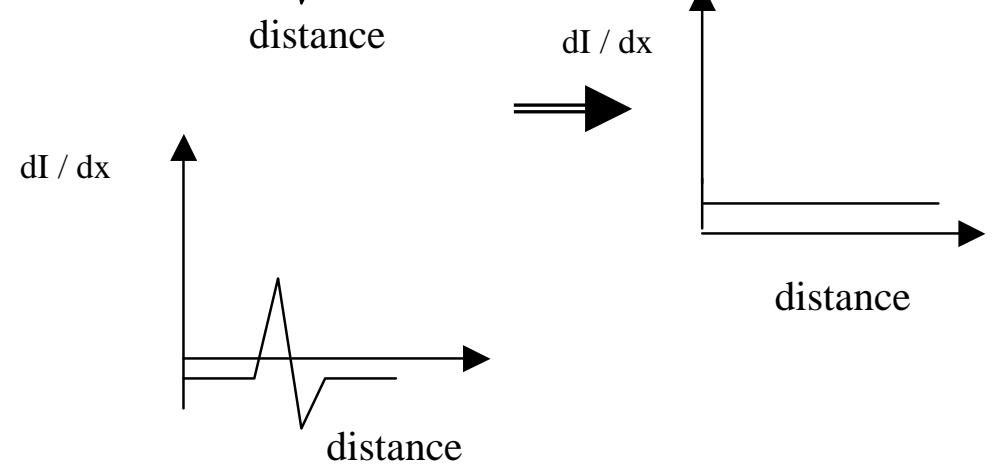

b) data from paint chip

Figure 3.38 Theoretical schematic representing the coating tolerance thermography concept 


\section{CHAPTER 4}

\section{DISCUSSION OF LABORATORY RESULTS}

In this chapter, the effectiveness and performance of an IR system for

detection of fatigue cracks in the WD and $\mathrm{CH}$ test specimens are discussed. Based on several tests conducted under laboratory conditions, a number of observations are achieved. These observations are discussed in the following sections.

\subsection{Discussions of The Results from $\mathrm{CH}$ test series}

A number of passive approach and active approach tests were performed on $\mathrm{CH}$ series test specimens under enclosed laboratory conditions by varying the critical factors described in Section 3.4. Many factors influence IR crack inspection. Included among these factors are crack size, camera distance, applied stress magnitude, heating time, delay time, and surface condition (unpainted and matte-painted specimen). 


\subsubsection{Applied Stress}

\section{The reflection contrast effect}

A crack sometimes can be detected through the influence of either factor. For example, the crack in the unpainted Specimen CH-2 (Figures A.1 to A.2) could be detected only when the applied stress levels was 144.8 MPa and 165.5 MPa (21 ksi and $24 \mathrm{ksi}$, respectively). However, the crack could not be detected for painted Specimen CH2 (Figure A.3) at any stress level. Therefore, it is believed that the crack in the unpainted Specimen $\mathrm{CH}-2$ was detected only because reflected light from the crack surfaces at particular stress levels make it visible through IR inspection.

Typically, cracks are detected in the passive IR approach at locations of stress concentration. An increase in the stress level causes an increased crack-tip stress concentration effect and makes the crack more distinguishable from the center-hole stress concentration. For example, note the increased presence of white shading for increasing stress levels shown in Figure A.8 for Specimen CH-3. However, the unpainted Specimen $\mathrm{CH}-2$ results, as described earlier, did not demonstrate this.

\section{A minimum required stress level}

There is a minimum value of stress that makes a crack detectable by IR inspection. Generally, an elevated applied stress level will make a crack more detectable.

The Specimen CH-3 passive-approach results are presented in Figure A.4 to Figure A.8. The applied stress levels were varied from $0 \mathrm{MPa}$ to $206.9 \mathrm{MPa}$ in steps of $34.5 \mathrm{MPa}(0 \mathrm{ksi}$ to $30 \mathrm{ksi}$ in steps of $5 \mathrm{ksi}$ ). Figure A.6 to Figure A.8 illustrate the passive-approach results at 500,000 loading cycles. In Figure A.8, a crack could be detected only with an applied stress level greater than $137.9 \mathrm{MPa}(20 \mathrm{ksi})$. It can be 
noticed in the figures that the influence of stress distribution around the center hole and near the crack tip can be observed from the white pixels in the thermal image.

Figure A.8a to Figure A.8d can be used to verify these observations. Both center-hole and crack-tip stress concentrations increased as the applied stress level increased, but they could not be detected distinguishably with stress level less than 137.9 MPa (20 ksi). With stress levels greater than 137.9 MPa (Figure A.8e thru Figure A.8g), a crack-tip stress concentration could be detected distinguishably from a center-hole stress concentration by observing the high white pixel concentration at the crack-tip vicinity.

The stress intensity factor is an important variable used to represent the stress distribution in the crack tip vicinity. An increased in the stress intensity value yields an increased stress concentration (Barsom, 1977). The Specimen CH-2 stress intensity factor is less than that of Specimen $\mathrm{CH}-3$ at the same applied stress level because the crack in Specimen CH-3 was deeper than that of Specimen $\mathrm{CH}-2$. This stress-intensity-factor difference leads to the stress concentration difference and, consequently, makes the crack in Specimen $\mathrm{CH}-3$ detectable by stress concentration effects, but not for crack in Specimen CH-2. However, with stress levels lower than 137.9 $\mathrm{MPa}$, the Specimen $\mathrm{CH}-3$ crack-tip stress concentration was so low that it could not be

distinguished from a center-hole stress concentration and, as a result, a crack could not be detected.

\subsubsection{Distance from IR Camera to Test Specimen}

\section{Longest effective camera distance}

The effective camera distance increased as crack size increased. The longest effective camera distances of $\mathrm{CH}$ test series are $22.5 \mathrm{~cm}$ and $90 \mathrm{~cm}$ for the passive and active approaches, respectively. 
Effective camera distance by an impeded heat flow and by the reflection contrast effect

The longest effective camera distance of a specimen with a crack detected by an impeded heat flow or stress concentration effect is longer than that of unpainted specimens detected by the reflection contrast effect.

The active approach results from painted Specimen $\mathrm{CH}-3$ are illustrated in Figures A.123 to A.156. Cracking was detected by an impeded heat flow that resulted in a definite and considerable drop in the thermal intensity profile. Unpainted Specimen $\mathrm{CH}-2$ results are illustrated in Figure A.115 to Figure A.122. For Specimen CH-2, however, the thermal profile was believed to be influenced by the reflection contrast effect.

The anomaly on the unpainted Specimen $\mathrm{CH}-2$ thermal images was not caused by an impeded heat flow. Instead, it is believed to be caused by the reflection contrast effect of a non-uniform surface because of its unusual thermal intensity profile characteristic. The thermal contrast caused by an impeded heat flow demonstrates a definite and sudden drop in the thermal intensity profile at the crack front. In other words, when a crack is encountered and the thermal contrast level drops, then the thermal contrast level does not return to the same intensity level on the other side of the crack. (See Figures A.77 and A.78 for examples of thermal contrast caused by an impeded heat flow).

Compare unpainted Specimen $\mathrm{CH}-2$ and painted Specimen $\mathrm{CH}-3$ results at comparable crack lengths (see Figures A.115 to A.122 and Figures A.123 to A.130, respectively). The Specimen $\mathrm{CH}-2$ crack could not be detected at a distance greater than $15 \mathrm{~cm}$ from the specimen. However, the comparable Specimen $\mathrm{CH}-3$ crack (detected by an impeded heat flow) could be detected up to $30 \mathrm{~cm}$. Thus, it can be concluded that a crack detected by an impeded heat flow can be detected at a distance further away from the surface than a comparable crack detected by the reflection contrast method. 


\subsubsection{Heating and Delay Time}

\section{$\underline{\text { Heating time and delay time variations }}$}

There is no significant effect from variations in the heating time and delay time on through-thickness IR crack detection. The results for Specimen $\mathrm{CH}-1$ are illustrated in Figures A.17 to A.24. The fatigue crack could be detected clearly from a considerable drop on thermal intensity profile without any inconsistency, as the heating time and delay time were varied. This influence, however, is not true for cracks which are only partially through-thickness and, therefore, it can not be concluded that the heating time and delay time variation has no effect on IR crack detection. The effects of variations in the heating time and delay time are presented for the WD test results.

\section{$\underline{\text { Reflection contrast effect }}$}

The unpainted and matte-painted Specimen $\mathrm{CH}-2$ active-approach results are illustrated in Figures A.25 to A.32 and Figures A.33 to A.40, respectively. Cracks could be detected successfully from the unpainted specimen. However, cracks could not be detected from the painted specimen, although the same heating time and delay time were used. This result indicates that, in the case of unpainted specimens, cracks were possibly detected by reflection contrast, and not by an impeded heat flow, because, as explained in Section 4.1.2, the thermal intensity profile does not show a thermal contrast caused by an impeded heat flow.

\section{Minimum required heating time and delay time}

Cracks could not be detected with the heating time shorter than a minimum required period. The Specimen $\mathrm{CH}-3$ results are illustrated in Figures A.41 to A.84. A crack could not be detected with a 15-second heating time. However, cracks 
could be detected with any heating time more than 30 seconds, and the delay time variation did not significantly affect the results. However, the delay time variation numerically affects the thermal gradient value as described in the following section.

Nevertheless, it can not be concluded that the heating time and delay time variation has no effect on IR crack detection. These effects are obvious for the complicated details. The WD and field test results in particular demonstrate this observation.

$\underline{\text { Relationships between heating time, delay time, and thermal gradient }}$

The relations between the heating time, the delay time, and the thermal gradient of Specimen CH-3 are illustrated in Figures 4.1 to 4.3. Figures 4.1 and 4.2 show that a longer heating time produces a higher average thermal gradient and a higher maximum thermal gradient. Moreover, Figure 4.3 indicates that there is an "optimum" delay time causing the maximum thermal gradient. Some "clear-cut" criterion to define a crack is attempted by observing the ratio of the maximum thermal gradient to an average value. These ratios vary from 7.8 to 14.5 as shown in Figure 4.3.

\section{$\underline{\text { Initial surface temperature }}$}

The higher the initial surface temperature, the more difficult it becomes to detect the thermal gradient. Figures A.157 to A.167 are the thermal images of Specimen CH-3 with the different surface temperatures. The thermal gradient of the lower-surfacetemperature specimen was more suitable for IR crack detection than that of the higher initial surface temperature, for the same heating time and delay time. The higher initial surface temperature required a longer heating time to make the thermal gradient detectable. It is also evident that a black matte paint can make the thermal gradient more detectable (compare Figures A.166 to A.170 and Figures A.171 to A.176). 


\subsubsection{Crack Size}

\section{Crack depth}

Crack depth significantly affects IR crack detection. The examples are shown in the Specimen CH-2 results (Figures A.33 to A.40) and Specimen CH-3 results (Figures A.53 to A.54). Although their crack lengths at the time were comparable, only the crack in Specimen CH-3 could be detected.

Crack geometry plays an important role in the process of impeding heat flow. For example, although they had comparable crack lengths, the crack geometries of the two specimens were different. The crack in Specimen CH-3 was a through-thickness crack but the crack in Specimen $\mathrm{CH}-2$ was a partial crack with a 1.6-mm depth $(20 \%$ of member thickness). Consequently, the heat flow in Specimen $\mathrm{CH}-3$ was more impeded than that of Specimen $\mathrm{CH}-2$, resulting in a distinct thermal contrast in Specimen $\mathrm{CH}-3$ that was easier to detect than that of Specimen $\mathrm{CH}-2$. However, when the crack is not through-thickness, then the heat can flow around the partial-depth crack and result in a less distinctive thermal contrast.

\section{$\underline{\text { Smallest detectable crack }}$}

The smallest detectable crack was a 3.1-mm through-thickness crack (Specimen CH-3 at 500,000 loading cycles). Compare Figures A.41 through A.52 with Figures A.53 through A.64 (Specimen CH-3 at 450,000 and 500,000 loading cycles, respectively). In Figures A.53 through A.64, the crack could be detected initially from a sudden drop in the thermal gradient and the thermal line boundary on both sides of the center hole, as observed in the thermal image. Similar indications could not be observed in Figures A.41 through A.52. Consequently, the 3.1-mm long crack, as measured on the 
specimen surface, was first detected by IR with a change in the thermal gradient at 500,000 loading cycles.

\subsubsection{Surface Condition}

The results indicate that surfaces painted with a matte color tend to improve the quality of the thermal images and increase the effective detectable camera distance. Painting with a matte color reduces the surface-reflection effects and other spurious signals coming from the non-uniform specimen surface.

The unpainted and matte-painted active-approach results of Specimen $\mathrm{CH}$ 3 are shown in Figures A.65 to A.74 and Figures A.75 to A.84, respectively. Cracks could be detected in the painted specimens only. Moreover, the cracks could be detected at a camera distance of up to $60 \mathrm{~cm}$.

The Specimen $\mathrm{CH}-3$ passive approach results are illustrated in Figures A.13 to A.16. When painted specimen results are compared to unpainted specimen results, it is observed that cracks in painted specimen can be detected by the IR camera at a greater distance than that of an unpainted specimen.

\subsubsection{Coating Tolerance Thermography Examination}

The thermal gradient of the heat flowing from bottom to top is assigned to be positive. The results of a specimen containing a paint chip are illustrated in Figures A.168 to A.169. From both Figure A.168 (top-heated thermal images) and Figure A.169 (bottom-heated thermal images), the paint chip can be detected from the considerable "jump" and "drop" of the thermal gradient, respectively. These observations are the same in both top-heated and bottom-heated thermal images. Therefore, the paint chip thermal contrast does not depend on heat flow direction, and they are minimized when subtracting the bottom-heated thermal gradient profile with the top-heated thermal gradient profile as shown in Figure A.194. 
Structural-flaw thermal contrasts are different from those contrasts of non-structural flaws. In Figure A.171, heat was applied at the top of a cracked specimen. The crack could be detected from the considerable "drop" of the thermal gradient along the defined line crossing a crack. In Figure A.172, heat was applied at the bottom of the same specimen. Unlike the top-heated results, the crack could be detected from the substantial "jump" of the thermal gradient with the different sign compared to that of top-heated case.

Therefore, it is evident that the crack thermal contrast depends on the heat flow direction. As a result, it is augmented when the bottom-heated thermal gradient is subtracted with the top-heated thermal gradient as shown in Figure A.173. Conclusively, it should be noted that the concept of thermal gradient subtraction in the coating tolerant thermography method can distinguish structural flaws from non-structural flaws.

\subsection{Discussions of The Results from WD Test Series}

The results from the $\mathrm{CH}$ test series exhibited two significant results. First,

the thermal images from unpainted specimens give worse results when compared with those of a matte coated specimen surface. Second, the minimum value of stress that makes crack detectable is often much higher than the service-level stress in a real structure. Consequently, the passive inspection approach is not a promising approach to use for crack detection in an actual structure. As a result, the passive approach and performing experiments on unpainted specimens were not conducted in WD test series.

A number of active approach testes were performed in the WD test series under the enclosed laboratory test condition by varying the inspected critical factors. Many factors influence the IR crack inspection. Included among these factors are crack size, camera distance, applied stress magnitude, heating time and delay time, and the surface condition (matte-painted surfaces of Specimens WD-1 and WD-2 and glossy- 
painted surfaces of Specimens WD-3 and WD-4). Specimens WD-3 and WD-4 were also tested under outdoor conditions. Each of these factor effects is discussed in the following sections.

\subsubsection{Distance from IR Camera to Test specimen}

The effective camera distance increased as crack size increased. The longest effective camera distance in the WD test series was $45.0 \mathrm{~cm}$ under enclosed laboratory conditions.

\subsubsection{Heating Time and Delay Time}

\section{A potential crack indication}

The thermal images of Specimen WD-1 containing partial-thickness weld toe cracks shorter than $2.1 \mathrm{~cm}$, are shown in Figures A.174 to A.177. For these thermal images, cracks could not be detected with any combination heating time and delay time.

The thermal images of Specimen WD-1 containing a partial-thickness weld toe crack, between $2.1 \mathrm{~cm}$ and $2.4 \mathrm{~cm}$ long, (depth was between $3.8 \mathrm{~mm}$. and the full member thickness) are shown in Figures A.178 to A.181. For these thermal images and those of Specimen WD-2 containing a partial-thickness crack, between $2 \mathrm{~cm}$ and 2.2 cm long, (depth was between $4.1 \mathrm{~mm}$. and the full member thickness) as shown in Figures A.198 to A.199, a potential crack indication could be observed from the slower heat flow rate in a suspected area when compared with the surrounding area. Although a considerable drop in the thermal intensity profile was not evident initially, with more 
loading cycles, the considerable drop was observed in the thermal intensity profile in this suspected area. The laboratory results of Specimens WD-3 and WD-4 agreed with those of Specimens WD-1 and WD-2.

\section{A through-thickness crack thermal contrast}

The sudden and considerable drop in the thermal intensity profile was first observed when the crack became through-thickness. The thermal images of Specimen WD-1, WD-2, WD-3, and WD-4 (tested under the enclosed laboratory condition) containing through-thickness weld toe cracks are shown in Figures A.182 to A.197, Figures A.200 to A.210, Figures A.211 to A.222, and Figures A.229 to A.240, respectively. From these thermal images it can be observed that the fatigue crack could be detected clearly from the sudden and considerable drop in the thermal intensity profile.

\section{$\underline{\text { Heating time and delay time variations }}$}

There is no significant effect from variations in the heating time and delay time on through-thickness crack detection. The thermal images of Specimens WD-1 and WD-2 containing through-thickness weld toe cracks (Figures A.182 to A.197 and Figures A.200 to A.210, respectively) demonstrate that variations in the heating time and delay time did not significantly affect IR crack detection. The Specimen WD-3 and WD-4 laboratory results showed an agreement with those of Specimens WD-1 and WD-2.

However, it should be noted that the variations of the heating time and delay time affect IR partial-thickness crack detection. Consider, for example, the thermal images of Specimens WD-1 and WD-2 containing partial weld toe cracks (Figures A.178 to A.181 and Figures A.198 to A.199, respectively). The longer delay time decreased the thermal gradient values at the crack and resulted in an image close to that of an unflawed area. As a result, the difference between the temperatures at points in front of a crack and behind a crack decreases for longer delay time because the heat flow is not completely 
impeded. Consequently, a potential crack indication is difficult to detect for long delay times when the crack penetrates only a portion of the thickness.

\section{$\underline{\text { Relationship between the heating time, delay time, and thermal gradient }}$}

The relationships between the heating time, delay time, and thermal gradient of Specimens WD-1, WD-2, WD-3, and WD-4 are shown in Figures 4.4 to 4.15. In Figures 4.4, 4.7, 4.10, and 4.13, the average thermal gradient (temperature per unit length) is plotted versus the delay time. The average thermal gradient is determined by computing the slope of the thermal response for each of the recorded pixel results. In Figures 4.5, 4.8, 4.11, and 4.14, the maximum thermal gradient is plotted versus the delay time; this value is the one that represents the greatest change in the temperature. In Figures 4.6, 4.9, 4.12, and 4.15, the ratio of the maximum to average thermal gradient is plotted versus the delay time. The purpose of this comparison is to evaluate if a correlation exits between the change in the thermal gradient and the presence of the fatigue crack. The ratios of the maximum thermal gradient to the average values of Specimens WD-1, WD-2, WD-3, and WD-4 vary from 7.8 to 12.2.

Longer heating times tend to produce the higher maximum thermal

gradient and average thermal gradient. However, a longer delay time yields a lower thermal gradient value.

It is difficult to find a unique set of optimum heating time and delay time values for any particular testing environment. Many of the factors, such as surface temperature, the power and pattern of the heat source, the sensitivity of the IR camera, and the test environment are inter-related. The multiple variable influences and the complex interaction of the various variables make it very difficult to establish a unique set of optimum conditions. 


\subsubsection{Crack Size}

\section{$\underline{\text { Partial crack }}$}

The first potential crack indication in Specimen WD-1 occurred at the weld toe, and it was visually evident at 1,320,000 loading cycles (see Figures A.178 to A.181). Although, a considerable drop on thermal intensity profile was not yet evident, a potential crack indication could be observed by considering the heat flow rate with respect to the delay time. Apparently, the heat flow rate in the suspected area was lower than that of surrounding area. After additional loading cycles were applied, a crack developed at the suspected area.

Only a weld toe crack was found by the IR camera for Specimen WD-2. The first potential crack indication was observed at 1,110,000 loading cycles (Figures A.198 to A.199) with the slower heat flow rate in the suspected area compared to that of the surrounding area. With more loading cycles, a crack developed in this suspected area and resulted in a definite IR indication. The Specimen WD-3 and WD-4 laboratory results showed an agreement with those of Specimens WD-1 and WD-2.

A partial-through-thickness crack can be detected from the heat flow rate with respect to the delay time. The heat flow rate of the cracked area is lower than that of an uncracked area. Nevertheless, a potential crack indication can be obtained at some specific crack depth with respect to specimen thickness. Both weld toe cracks for Specimen WD-1 and WD-2 showed potential crack indications at crack depths of $3.8 \mathrm{~mm}$ and $4.1 \mathrm{~mm}$, respectively (48.8\% and $52.6 \%$ of Specimen WD-1 and WD-2 thickness, respectively). The partial crack sizes in Specimen WD-3 and WD-4 could not be traced because, at that time, they did not break the surface paint.

Fatigue cracks also developed in the weld metal away from the weld toe. The longest surface length of in-weld cracks for Specimens WD-1 and WD-2 were 1.22 $\mathrm{cm}$ and $1 \mathrm{~cm}$, respectively. Based on crack length to depth measurements for fatigue 
cracks in beam members with welded, partial length cover plates Hassan et al. (1996) observed that the length-to-depth ratio of the fatigue cracks were 4 to 1 . Based on this assumed length-to-depth crack ratio, the in-weld crack depths of Specimens WD-1 and WD-2 would be $3.05 \mathrm{~mm}$ (38.4\% of Specimen WD-1 thickness) and $2.6 \mathrm{~mm}(33.3 \%$ of Specimen WD-2 thickness), respectively. However, these cracks could not be detected by IR inspection.

It should be noted that a partial thickness crack can often be detected from the slower heat flow rate at a depth of more than $50 \%$ of specimen thickness. The heat flow is completely impeded in the case of a through-thickness crack, resulting in a sudden drop in the thermal intensity profile. Unlike the through-thickness crack result, heat flow is only partially impeded in a partial-through thickness crack. Although partially impeded heat flow will not cause the distinct drop in the thermal intensity profile, it will produce a reduced heat flow rate, which can be observed with respect to the delay time.

\section{Through-thickness crack}

Specimens WD-1, WD-2, WD-3, and WD-4 (which were all tested under enclosed laboratory conditions) produced a clear drop in the thermal intensity profile when the crack became through-thickness. The sudden and considerable drop in the thermal intensity profile for the through-thickness-crack thermal images is illustrated in the following thermal images: Figures A.182 to A.197, Figures A.200 to A.210, Figures A.211 to A.222, and Figures A.229 to A.240 for Specimens WD-1, WD-2, WD-3, and WD-4, respectively. 


\subsubsection{Surface condition}

The IR thermal image results for matte coated Specimens WD-1 and WD2 are not significantly different from those of Specimens WD-3 and WD-4 with a glossy coating, when the tests were performed under enclosed laboratory conditions. However, the results from matte coated specimens were notably different from those of glossy coated specimens when the tests were performed outdoors.

The enclosed laboratory results of Specimens WD-1 and WD-2, shown in Figures A.182 to A.197 and Figures A.200 to A.210, respectively, agreed with those of Specimens WD-3 and WD-4 (Figures A.211 to A.222 and Figures A.229 to A.240, respectively). However, the outdoor results of Specimens WD-3 and WD-4, as shown in Figures A.223 to A.228 and Figures A.241 to A.246, respectively, were notably different from results obtained in the laboratory. For the laboratory results, both potential crack indications and clear drop on the thermal intensity profile could be obtained. However, the outdoor results did not show any distinct crack indication. These results indicate that, when tested outdoors, glossy paint affects the IR crack inspection. 


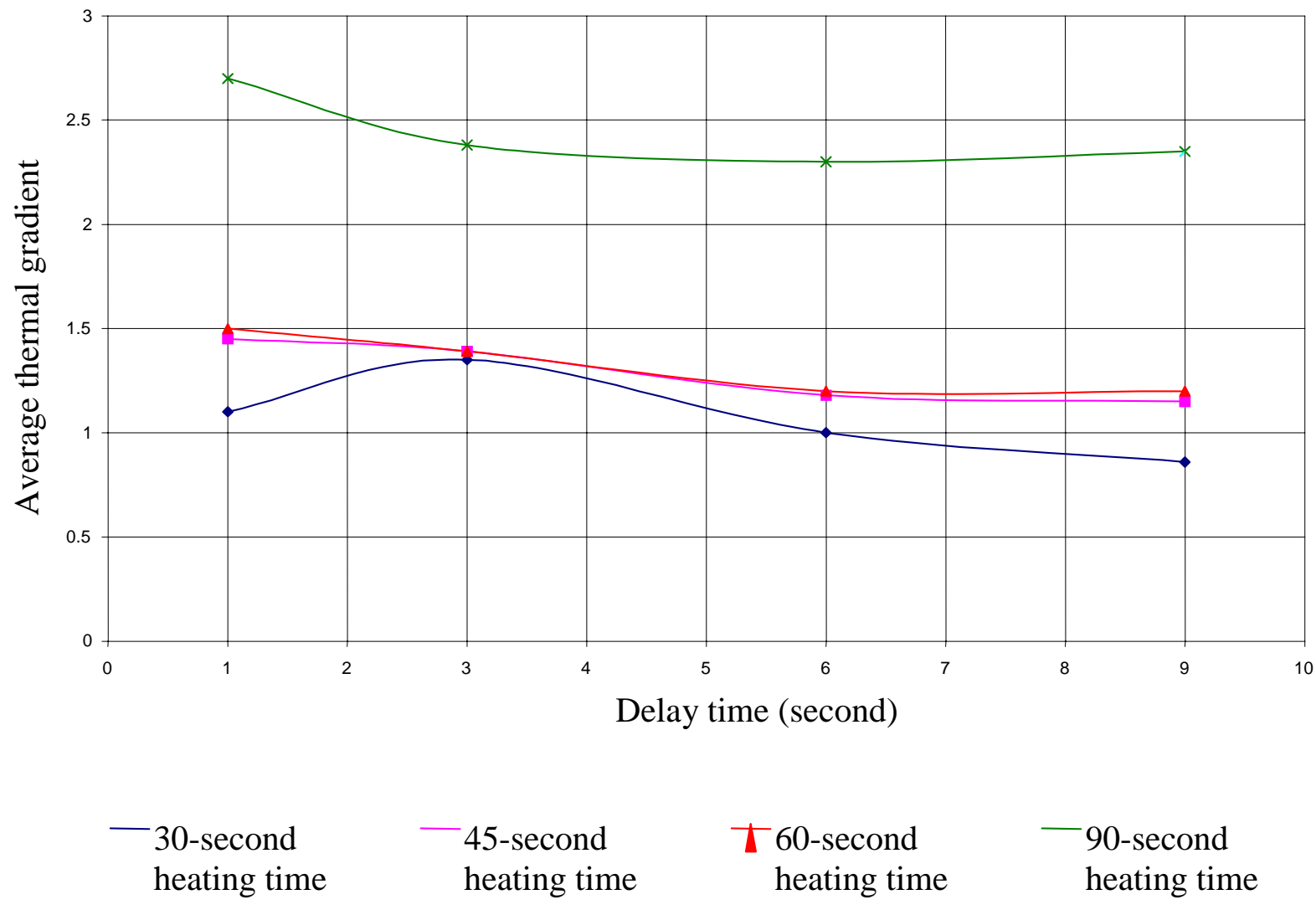

Figure 4.1 Average thermal gradient versus delay time of Specimen $\mathrm{CH}-3$ at 575,000 loading cycles. 


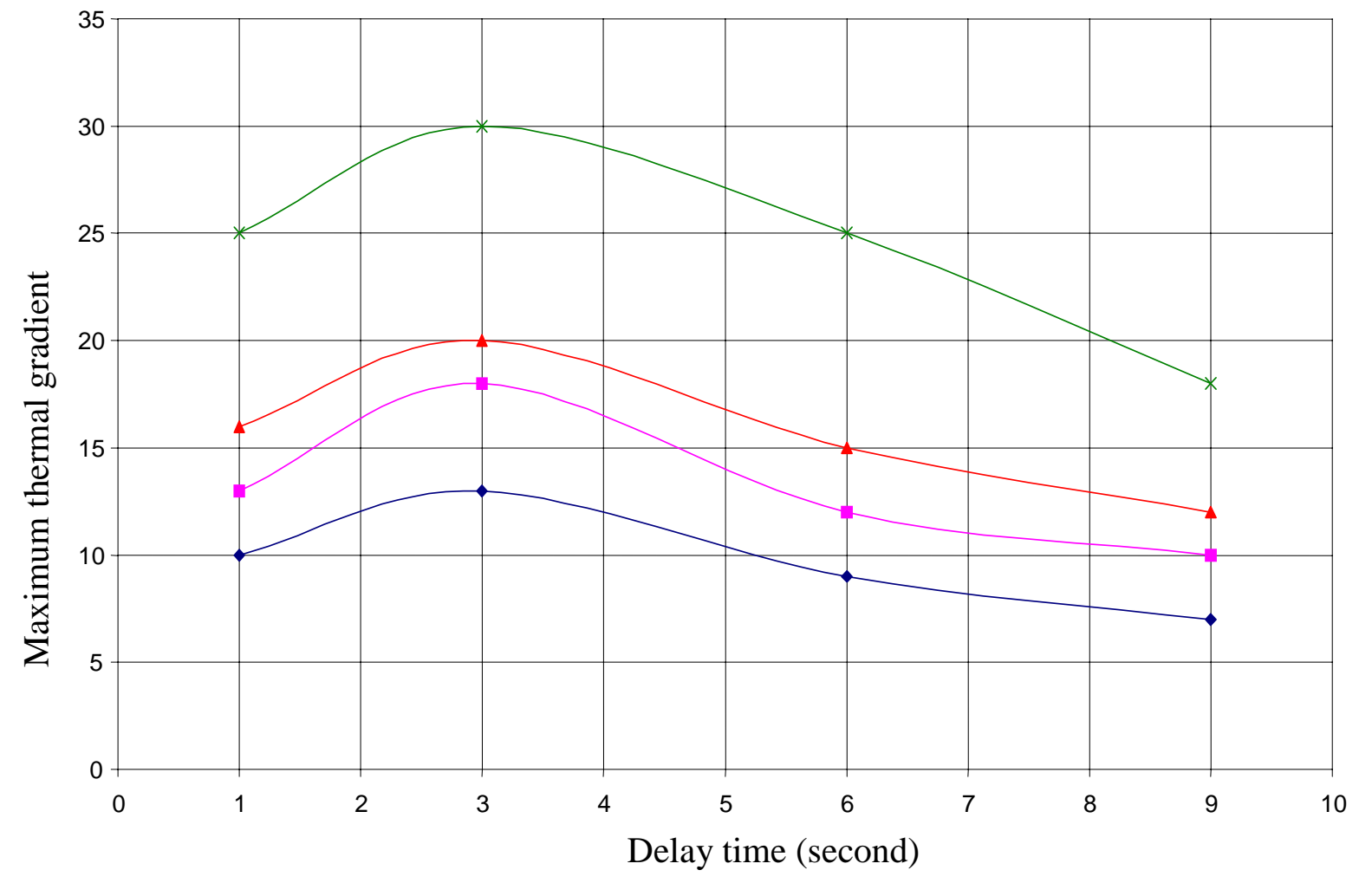

$\begin{array}{llll}-30 \text {-second } & \text { 45-second } & 60 \text {-second } & -90 \text {-second } \\ \text { heating time } & \text { heating time } & \text { heating time } & \text { heating time }\end{array}$

Figure 4.2 The maximum thermal gradient versus delay time of Specimen $\mathrm{CH}$ 3 at 575,000 loading cycles. 


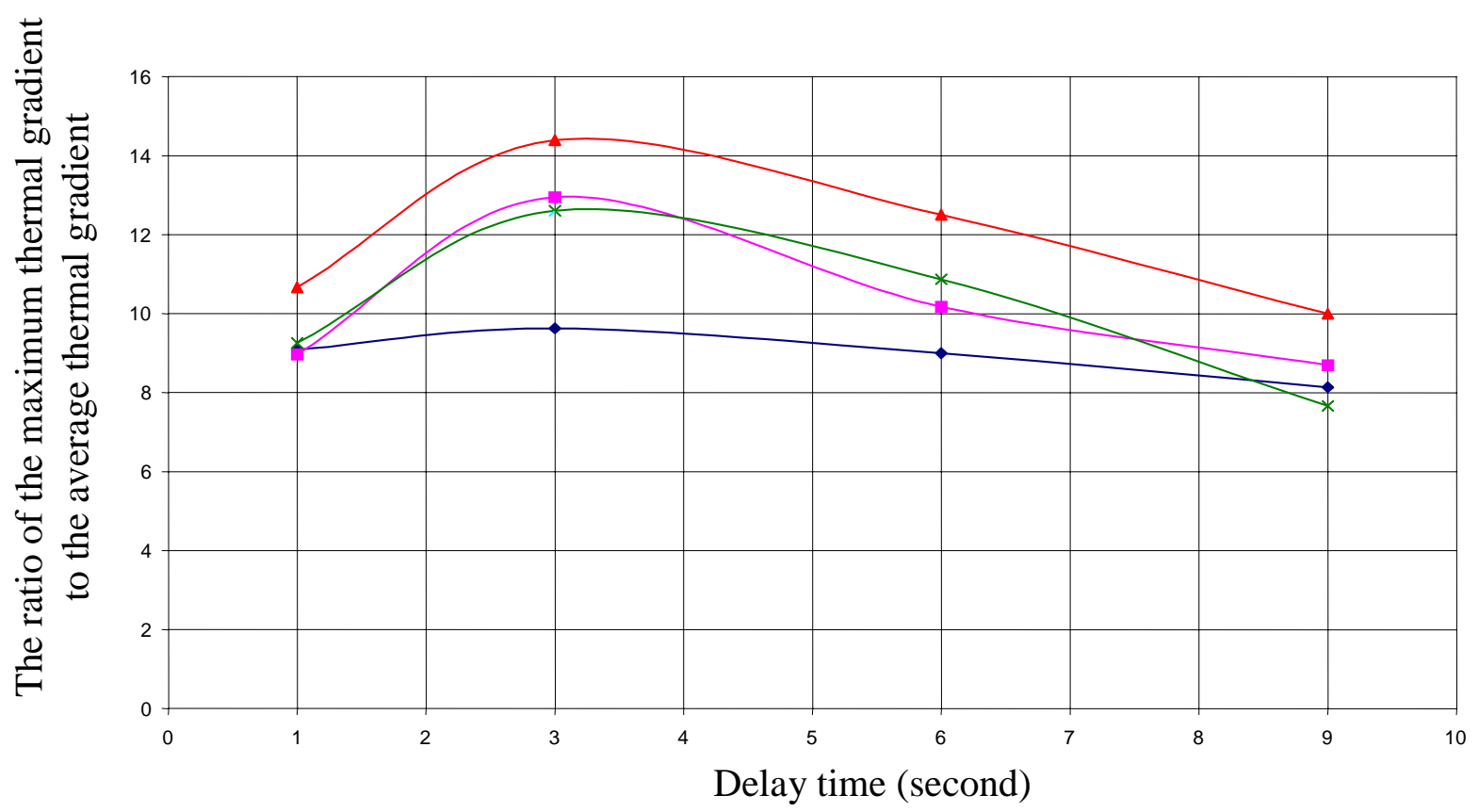

$\begin{array}{llll}-30 \text {-second } & -45 \text {-second } & 60 \text {-second } & -90 \text {-second } \\ \text { heating time } & \text { heating time } & \text { heating time } & \text { heating time }\end{array}$

Figure 4.3 The ratio of the maximum thermal gradient to average thermal gradient versus delay time of Specimen $\mathrm{CH}-3$ at 575,000 loading cycles. 


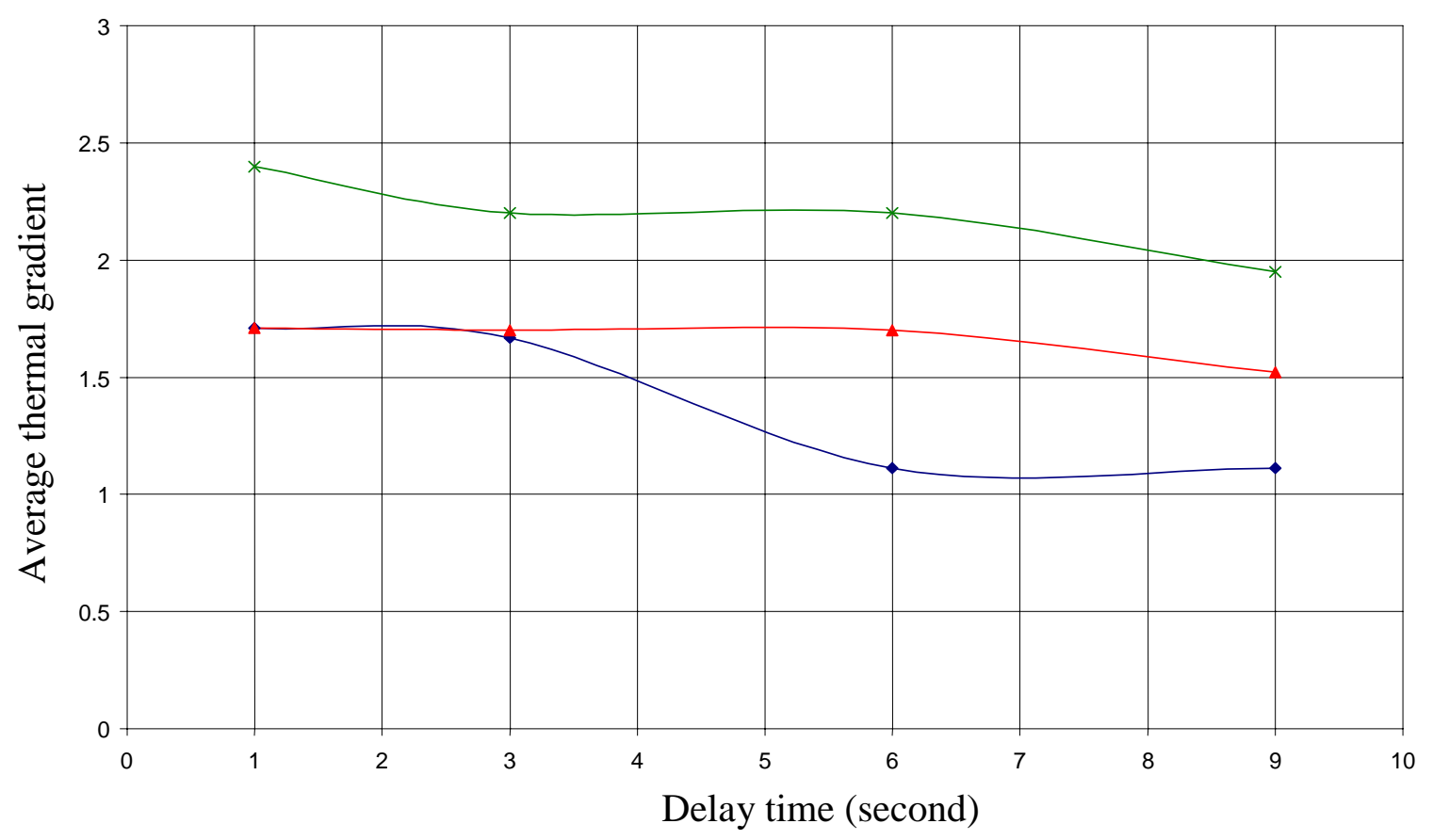

$\begin{array}{lll}30 \text {-second } & 60 \text {-second } & 90 \text {-second } \\ \text { heating time } & \text { heating time } & \text { heating time }\end{array}$

Figure 4.4 Average thermal gradient versus delay time of Specimen WD-1 at $1,335,000$ loading cycles. 


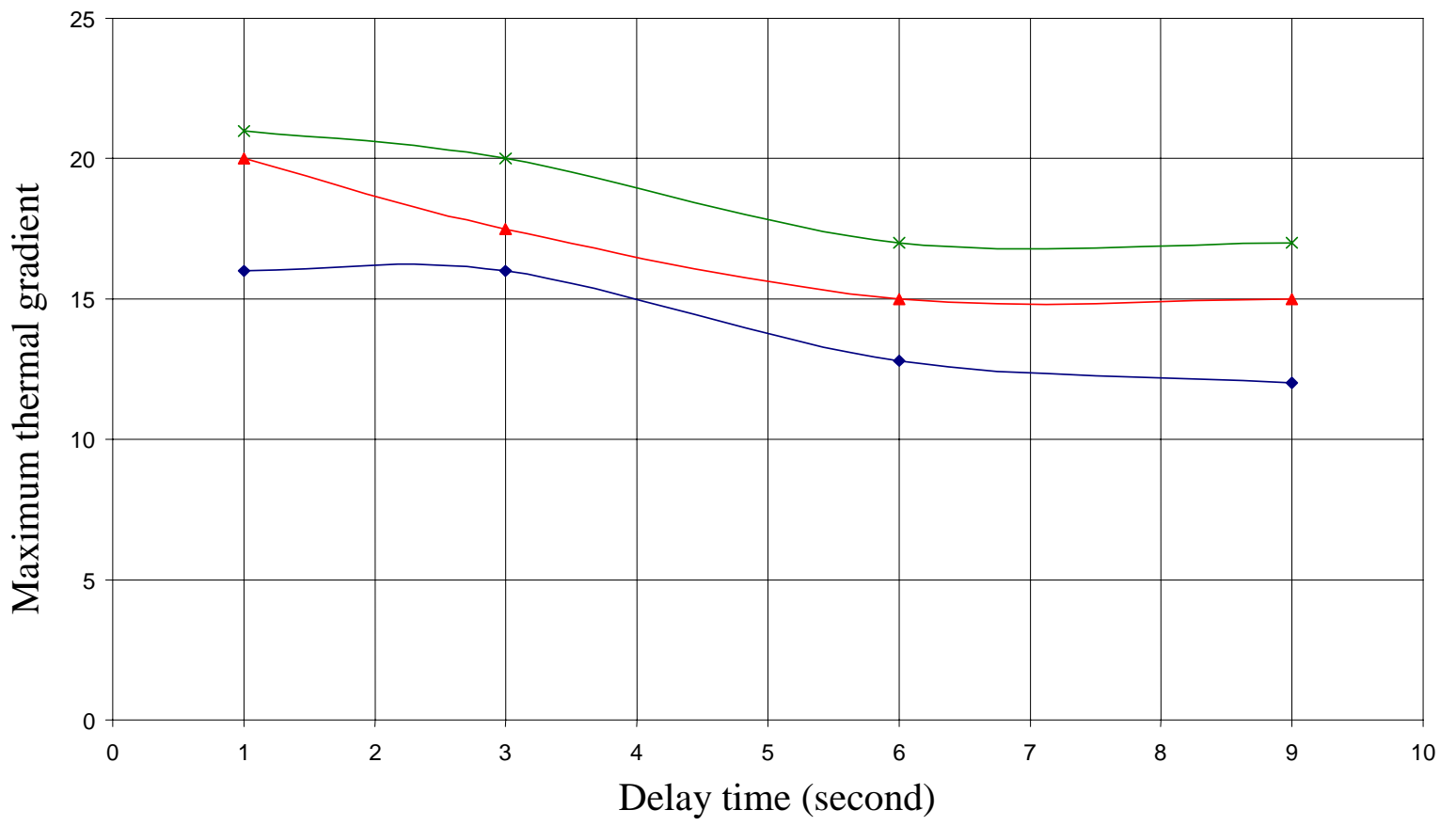

\begin{tabular}{|c|}
\hline $\begin{array}{l}\text { 30-second } \\
\text { heating time }\end{array}$ \\
\hline
\end{tabular}

Figure 4.5 The maximum thermal gradient versus delay time of Specimen WD-1 at $1,335,000$ loading cycles. 


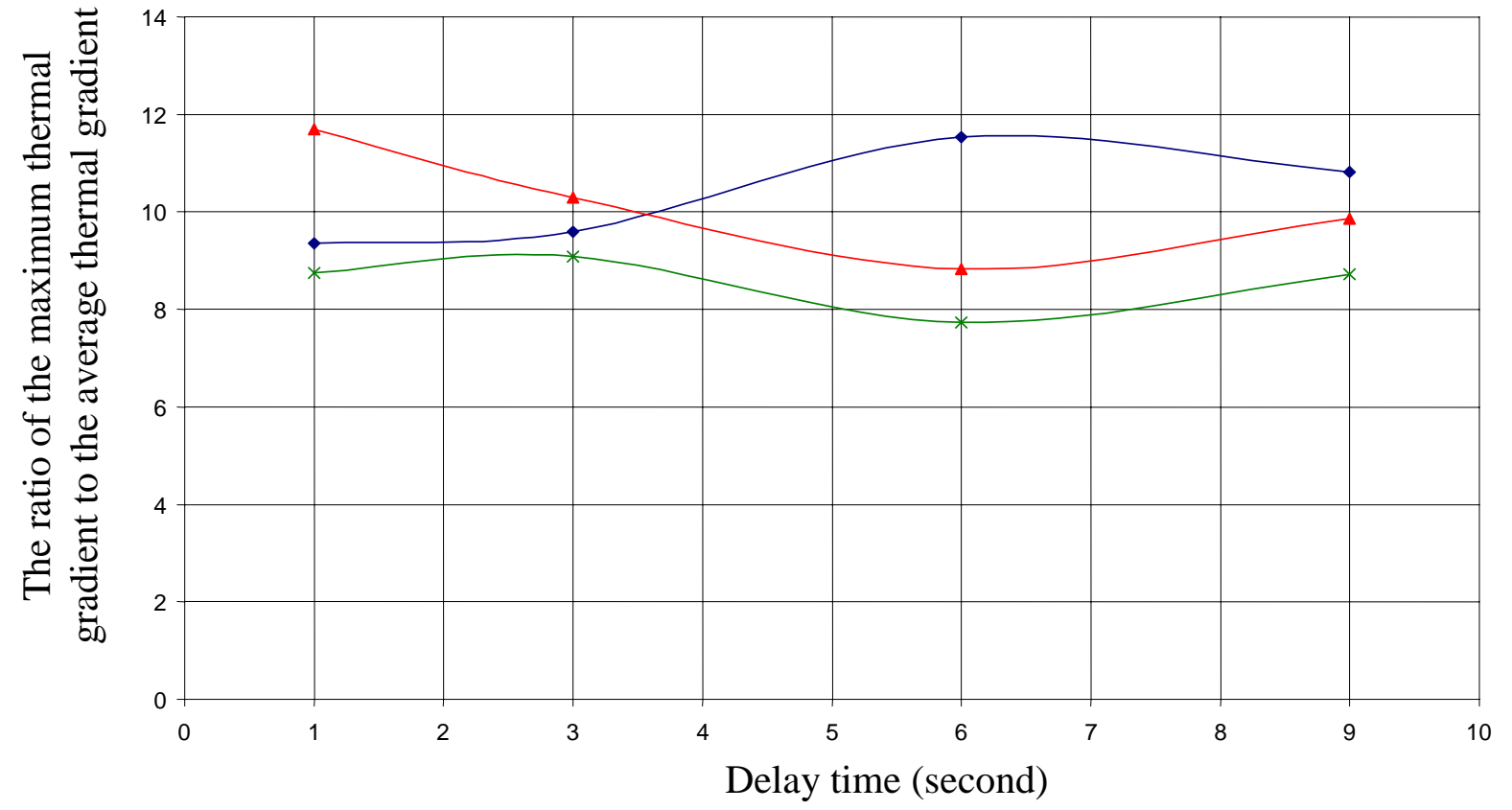

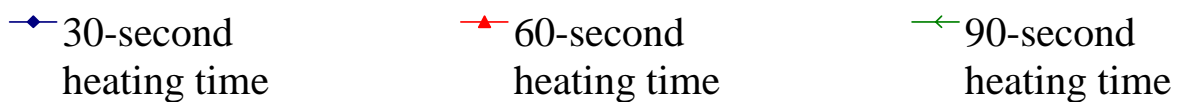

Figure 4.6 The ratio of the maximum thermal gradient at crack to the average thermal gradient versus delay time of Specimen WD-1 at 1,335,000 loading cycles. 


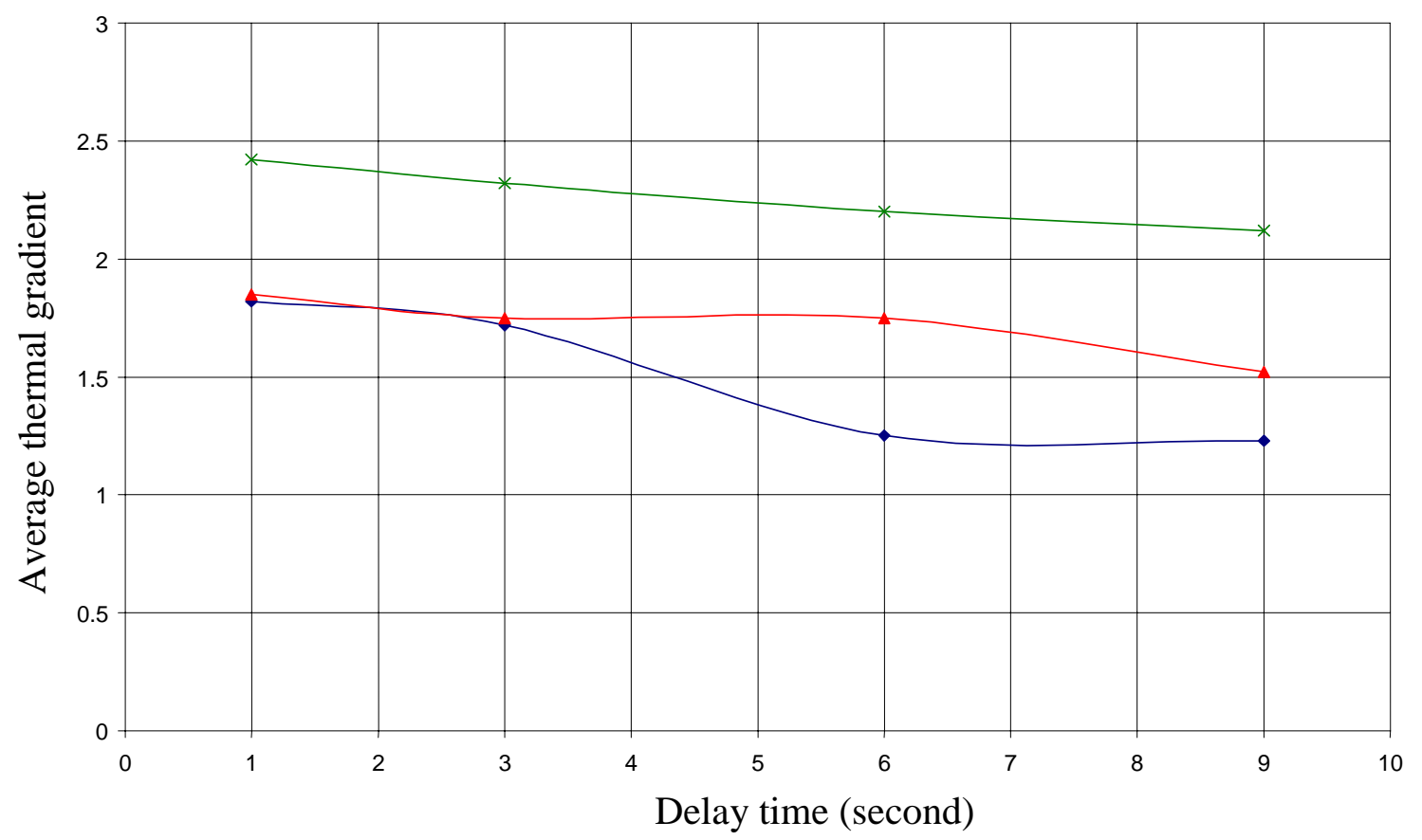

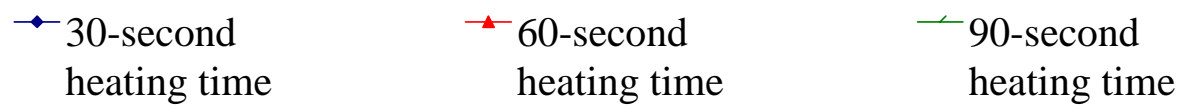

Figure 4.7 Average thermal gradient versus delay time of Specimen WD-2 at $1,131,000$ loading cycles. 


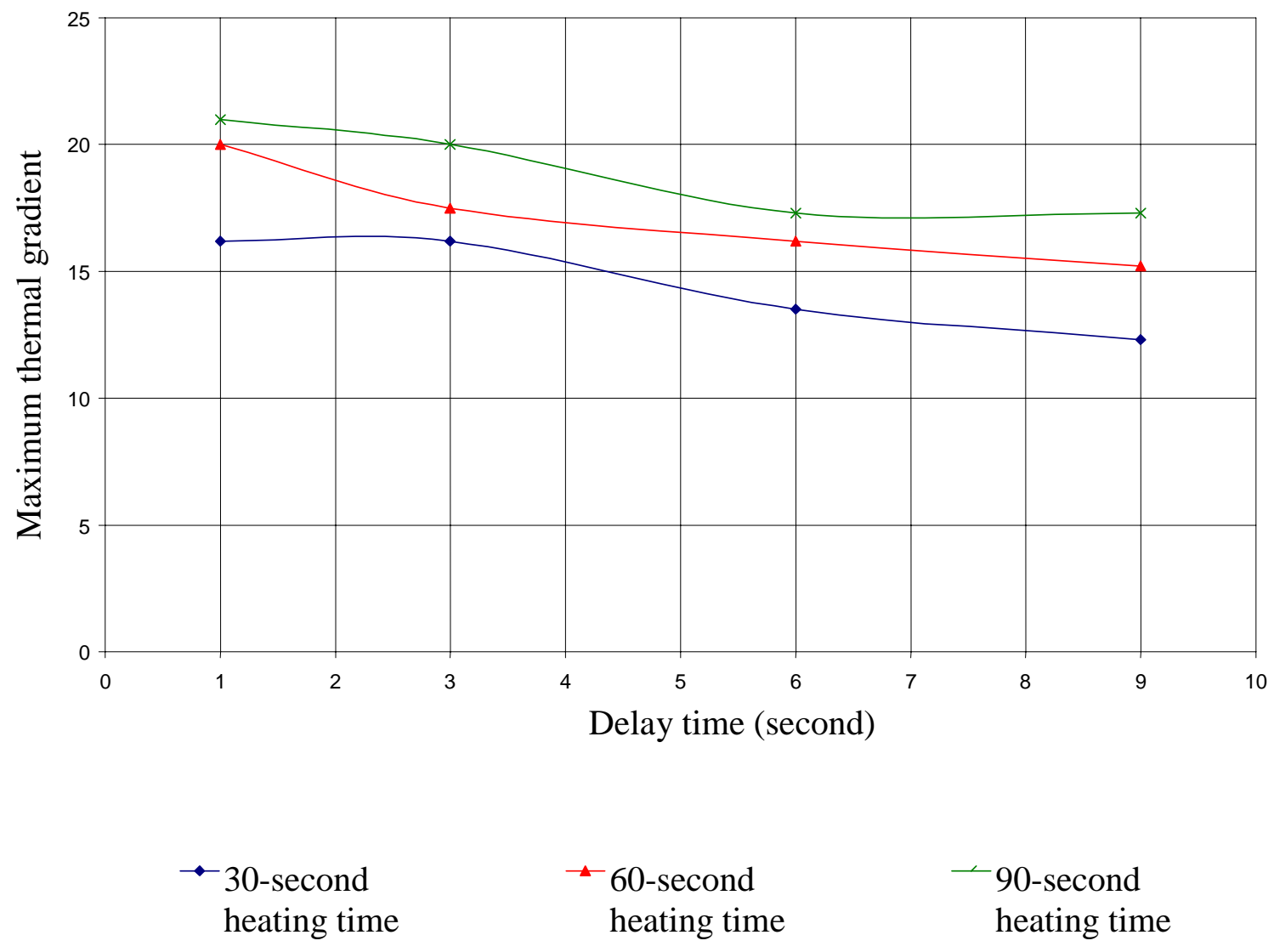

Figure 4.8 The maximum thermal gradient versus delay time of Specimen WD2 at 1,131,000 loading cycles. 


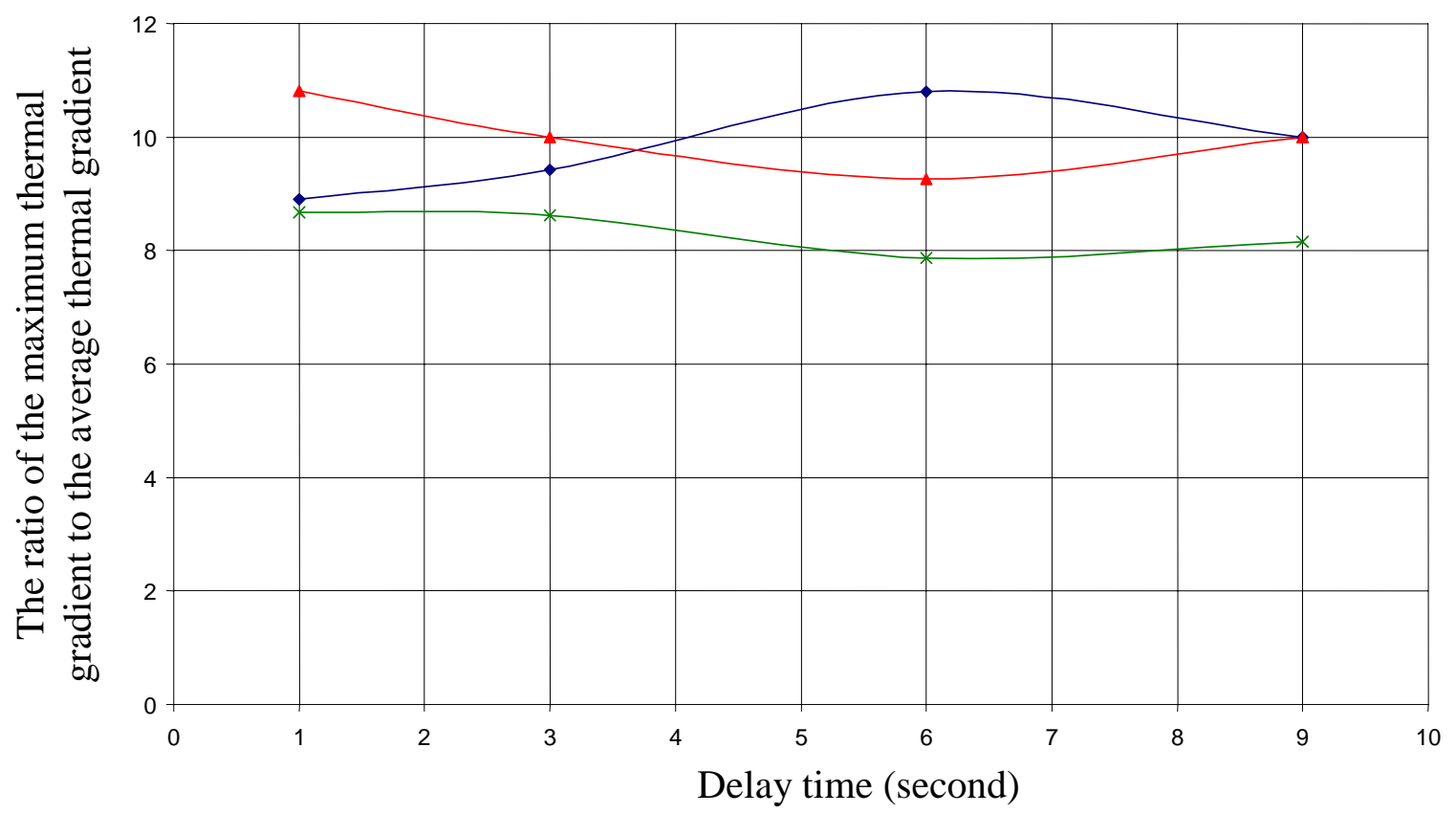

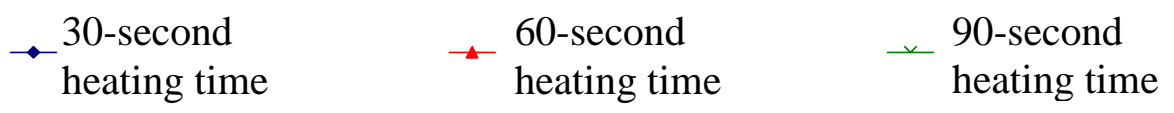

Figure 4.9 The ratio of the maximum thermal gradient at crack to the average thermal gradient versus delay time of Specimen WD-2 at 1,131,000 loading cycles. 


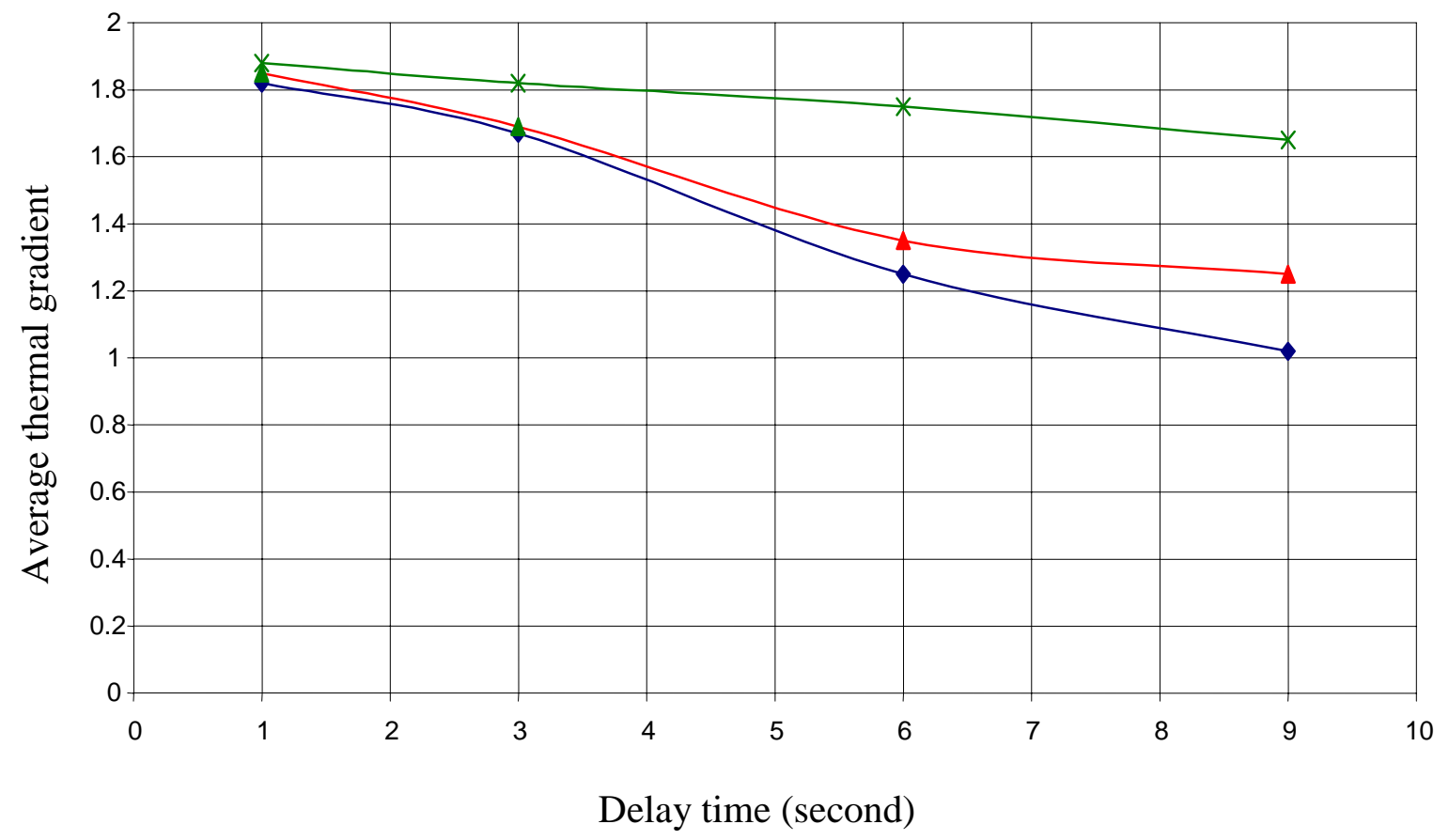
$\rightarrow-\begin{aligned} & \text { 30-second heating } \\ & \text { time }\end{aligned} \rightarrow \begin{aligned} & 60 \text {-second heating } \\ & \text { time }\end{aligned} \rightarrow \begin{aligned} & 90 \text {-second heating } \\ & \text { time }\end{aligned}$

Figure 4.10 Average thermal gradient versus delay time of Specimen WD-3 (tested under laboratory condition) at 1,735,550 loading cycles. 


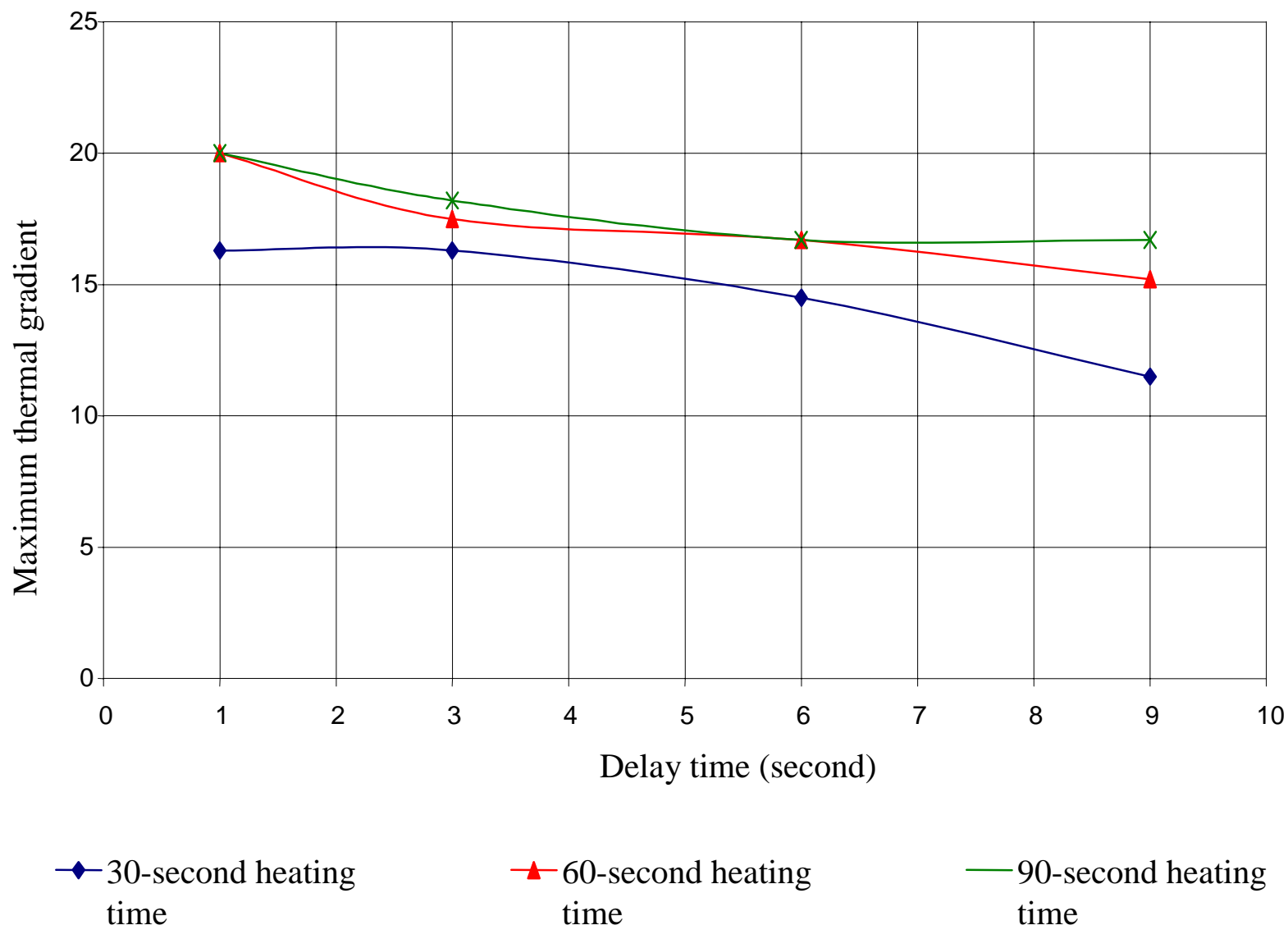

Figure 4.11 The maximum thermal gradient versus delay time of Specimen WD-3 (tested under laboratory condition) at 1,735,550 loading cycles. 


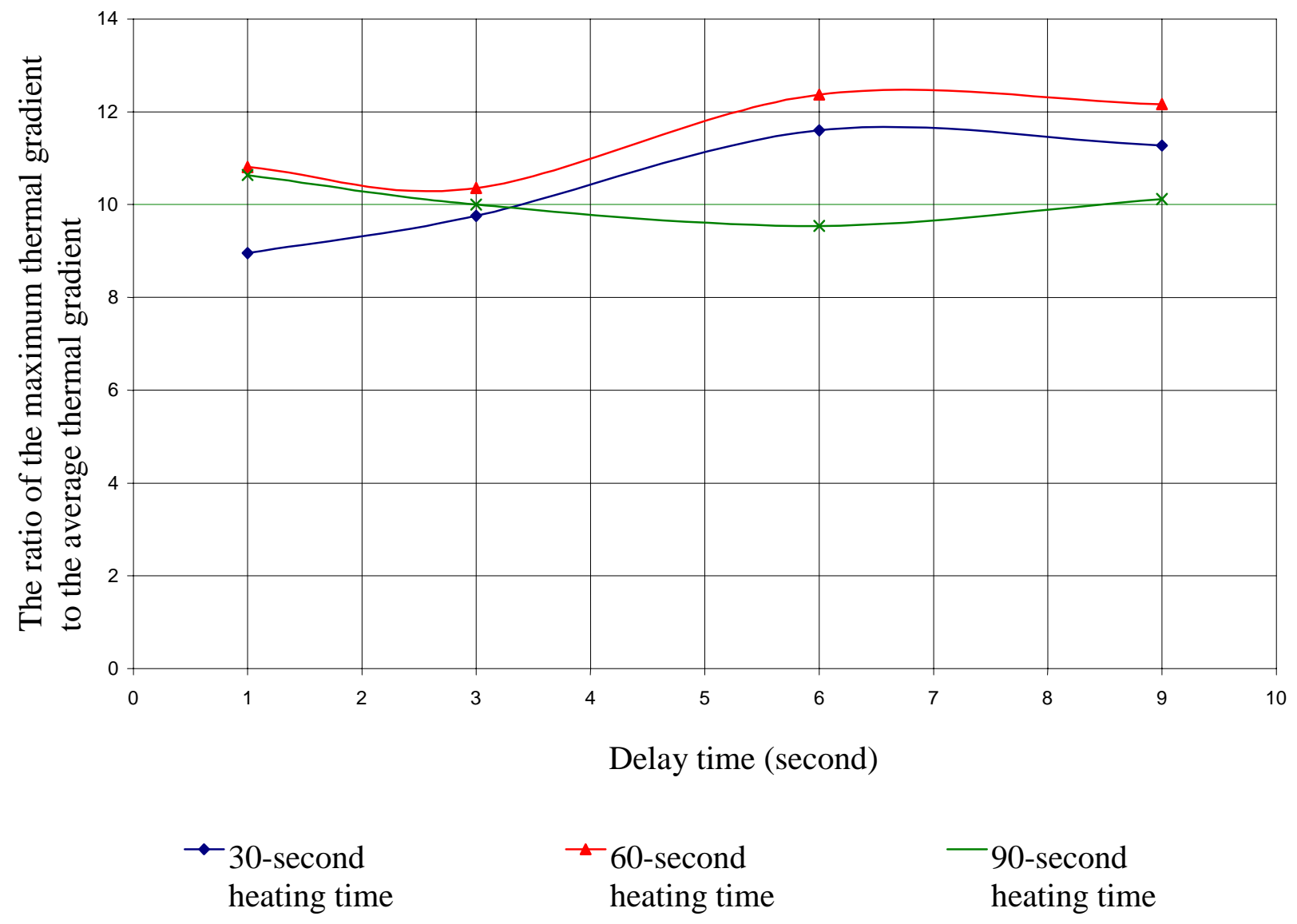

Figure 4.12 The ratio of the maximum thermal gradient at crack to the average thermal gradient versus delay time of Specimen WD-3 (tested under laboratory condition) at 1,735,550 loading cycles. 


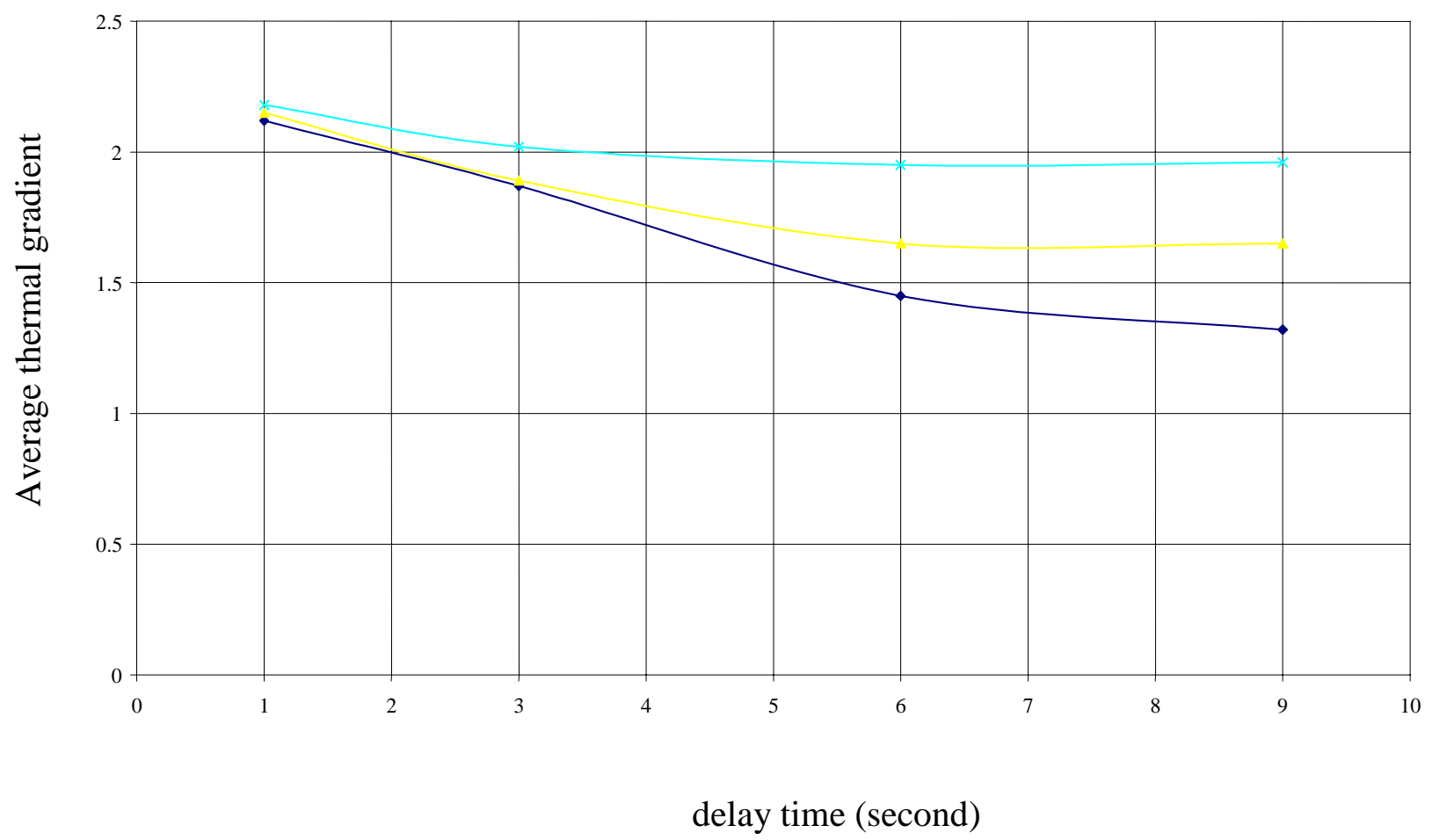

- 30-second heating time $\quad 60$-second heating time $\quad * 90$-second heating time

Figure 4.13 Average thermal gradient versus delay time of Specimen WD-4 (tested under laboratory condition) at 1,845,500 loading cycles 


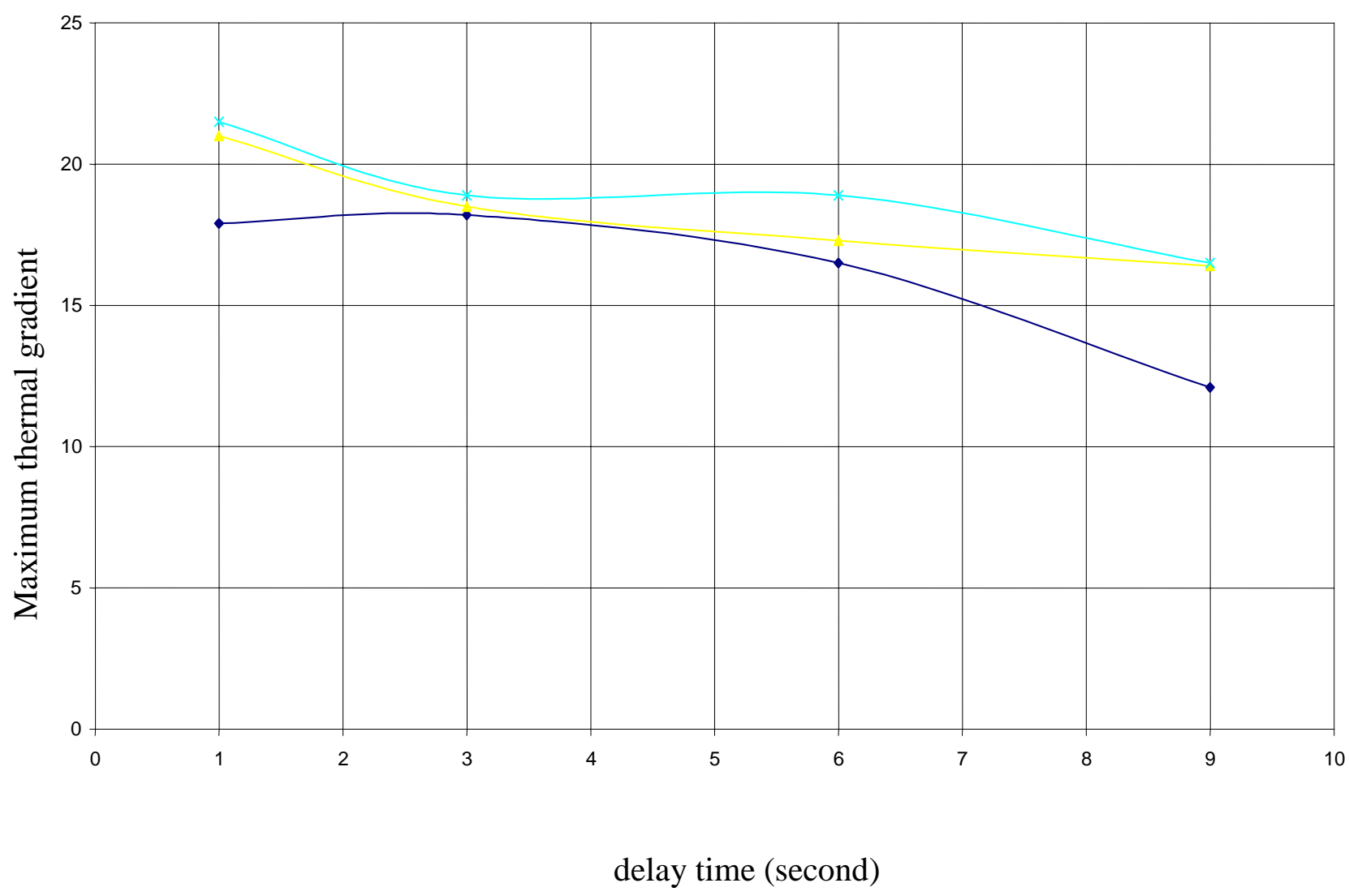

30-second heating time $\quad 60$-second heating time ${ }^{*} 90$-second heating time

Figure 4.14 The maximum thermal gradient versus delay time of Specimen WD-4 (tested under laboratory condition) at 1,845,500 loading cycles 


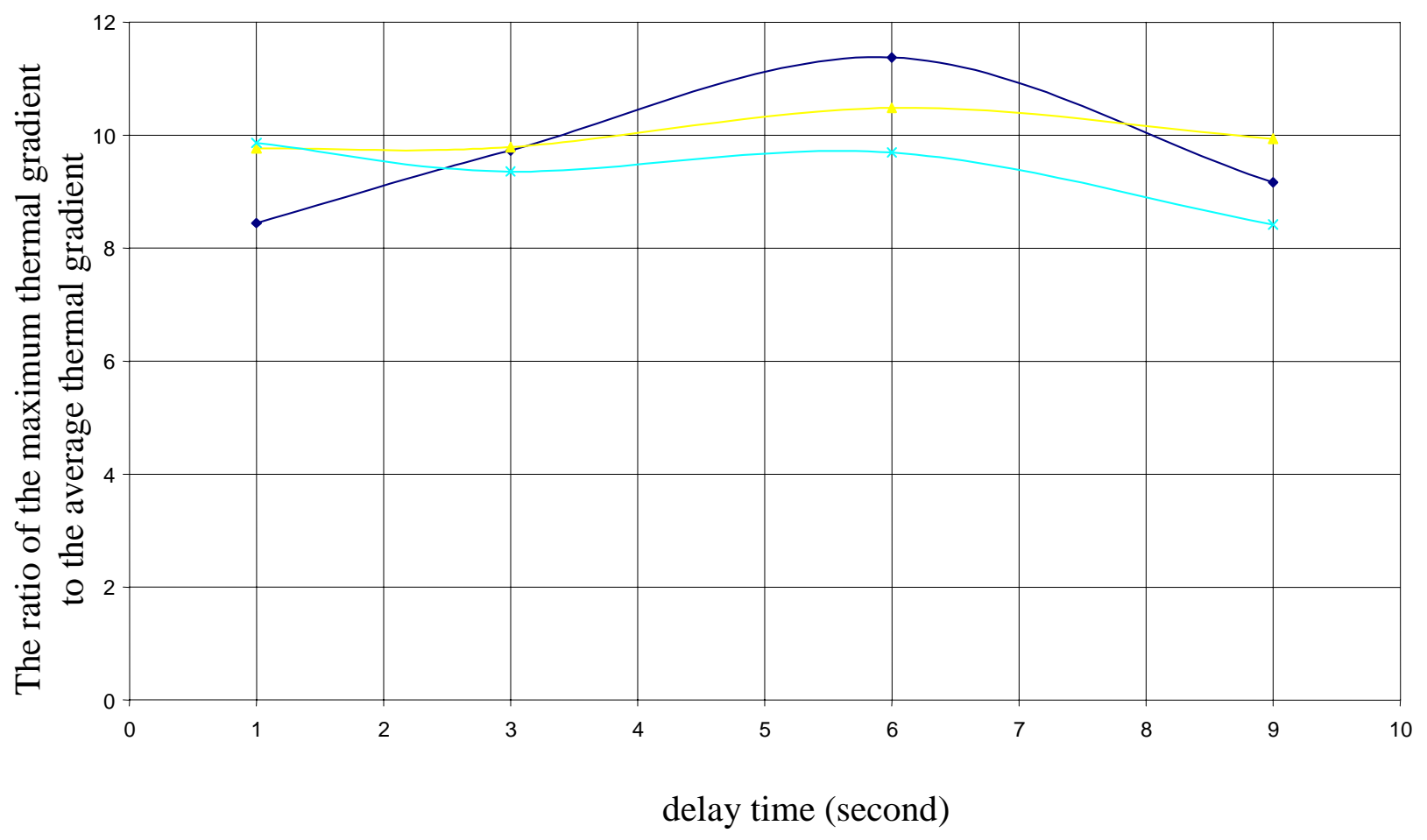

$\rightarrow$ 30-second heating time $\quad 60$-second heating time $\quad * 90$-second heating time

Figure 4.15 The ratio of the maximum thermal gradient at crack to the average thermal gradient versus delay time of Specimen WD-4 (tested under laboratory condition) at 1,845,500 loading cycles 


\section{CHAPTER 5}

\section{FIELD MEASUREMENTS}

\section{$\underline{5.1 \text { Objective of the Field Study }}$}

The objective of the field measurement phase of the study was to investigate the use of the active approach to detect fatigue cracks in steel bridge structures. Unlike the laboratory, under field conditions there are many factors that affect the performance of the active approach such as sunlight, weather conditions, surface

conditions, accessibility to the structure, etc. These factors can not be simulated reliably and accurately in the laboratory.

\subsection{Bridge Statistics}

The field measurements were performed on a typical steel-girder bridge with an 8" composite concrete deck. This bridge (Bridge I65-112-2431) was built in 1974 and is located near the intersection of I-65 and New York street on the east side of Indianapolis. The end spans of the three-span continuous structure carry I-65 over the north and south bound exit ramps, while the middle span passes over a pair of railroad tracks. The bridge has 22 built-up welded plate girders that are $127 \mathrm{~cm}$ (50 in) deep, with 
an overall width of 49.18 meters for 8 lanes of traffic - four northbound and four southbound on three separate bridge decks. For each girder, the bridge has three continuous spans with span lengths of 17.91, 38.55, and 31.27 meters, respectively.

Lateral stability was provided by 24 WF 68 diaphragms at the abutments and the interior piers. Cross-frame diaphragm elements were used along the span. The cross diaphragm connection was the detail of interest in the field inspection and evaluation reported herein. The cross-frame diaphragm was built by bolting an assembly of single angle members to a vertical plate that was welded directly to the web of the beam members. The vertical plate was terminated about $50 \mathrm{~mm}$ short of the girder flanges, creating a gap between the end of the attachment plate and girder flange. The bridge was designed in accordance with 1973 AASHTO specification. The girder, cross frame, and cross frame connection details is illustrated in Figure 5.1.

\section{$\underline{5.3 \text { Fatigue Crack at Diaphragm Connection }}$}

Diaphragms often develop cracking in the girder/beam web at the end of vertical connection plates where there is a gap between the diaphragm connection plate and the flange. Cracks develop around the weld at the bottom of the vertical plate at the connection with the diaphragm due to the stress concentration induced by the irregular geometry and bending stress induced by the rotational restraint due to the diaphragm (Kennert, 1992). Out-of-plane distortion is a main cause of the fatigue-induced crack in this type of detail. Typically, the girder web just below the diaphragm connection cracks from the out-of-plane bending caused by the transverse member elastic rotation. When unsymmetrical load is applied to the girder, the twisting displacement mode is induced. But, at the location of the diaphragm, the twisting is restrained. Therefore, the relative twisting movement of girder web between the location of the diaphragm and the other locations occur and out-of-plane bending stress is induced (Kennert, 1992). This type of crack is in category C' according to 1994 AASHTO specification. INDOT has found that 
this cracking has occurred in many bridges where the X-braces are not back-to-back. The rocking action of the X-bracing also has a push and pull action on the girder webs, which increases the probability of cracks developing.

The bridge inspection revealed that several fatigue cracks could be detected visually in the girder web at the diaphragm cross-frame connection. Some details were found with a small u-shape crack around the weld at the bottom of the vertical plate, but was not visible on the opposite side of the web. Moreover, in a number of details a large fatigue crack was found at the bottom of the vertical attachment plate weld and appeared on the both sides of the web. The crack sizes vary approximately from $25 \mathrm{~mm}$ to $100 \mathrm{~mm}$ in length. The large cracks can be detected clearly from rust seeping out of the crack line. The small cracks, on the other hand, can be detected by breaking of the paint on the surface. An example of one of the diaphragm connection fatigue cracks is illustrated in Figure 5.2.

While the team from Purdue University was inspecting the I-65 bridge, another group from INDOT was repairing the diaphragm connections with large fatigue cracks. A hole-drilling procedure was used to remove the end of the fatigue cracks. A magnetic drill with a coring bit was used to remove a small portion of the girder web that contained the crack tip.

Although the drilled hole still leaves a stress concentration in the web, it is significantly less severe than that due to the crack tip. With a proper reduction in the stress concentration, crack propagation will be terminated. An example of the drilled repair is illustrated in Figure 5.3.

\section{$\underline{5.4 \text { Inspection of Cracked Details }}$}

The active-approach inspections were performed on three cracks (cracks $\mathrm{A}, \mathrm{B}$, and C) of different sizes. The location of the diaphragm web cracks that were 
examined is shown in the plan view in Figure 5.4. Crack $\mathrm{A}$ is the largest of the three cracks examined. It is located near mid span at the bottom of the vertical attachment plate on the first girder (the outmost girder). The crack was roughly 100-mm.-long and was visible on both sides of girder web. Crack B, the smallest of the cracks, is a u-shaped crack at the bottom of the vertical attachment plate on the third girder. It appeared to be 50-mm.-long u-shaped crack on the detail side (the girder web side attached to the cross frame) of girder web, but the crack was not visible on the opposite side (the girder web side not attached to the cross frame) of girder web. Finally, Crack $\mathrm{C}$ was an intermediate length crack at the bottom of the vertical attachment plate on the fifth girder. It appeared as a 70-mm-long u-shaped crack on the detail side of the girder web, but was not visible on the opposite side. Cracks A, B, and C are illustrated in Figures 5.5 to 5.7, respectively. Figure 5.8 shows how the IR crack inspection was performed using a bucket truck.

The inspections were performed on both sides of girder web. For inspection on the opposite side, the IR camera was positioned perpendicular to the girder web and heat was applied on either side of a potential crack, as shown in Figure 5.9.

For the detail side inspection, the IR camera had to be positioned in an inclined direction with respect to crack alignment due to the geometry restriction. For Crack A inspection, the IR camera was set at the same level as the crack. The inclined angle was measured on the horizontal plane and the inspection was performed on the left side and the right side of the cross frame. Because cracks B and $\mathrm{C}$ are $\mathrm{u}$-shaped and they do not extend as a line crack on both sides of weld, the IR camera was set directly under the cross frame. Consequently, the inclined angle was varied in the vertical plane. Figures 5.10 and 5.11 illustrate the IR camera set up for inspecting cracks on the detail side. The field inspection results are summarized in Tables 4.1 to 4.3. Also, some relevant thermal images are shown in Figures 5.12 to 5.31 . 


\section{$\underline{5.5 \text { Discussions of Inspection Results }}$}

The heating time and delay time used in capturing each thermal image was varied in order to get the best results. The thermal contrast can be captured best if the thermal image is captured in the perpendicular direction (Chen, 1995). Moreover, the results from the laboratory test indicate that the closer the IR camera is positioned to the inspected area, the more likely cracking shows in the thermal image. Therefore, the IR camera was positioned in the perpendicular direction and as close to the inspected area as possible. The ambient temperature during inspection varied from $23.3{ }^{\circ} \mathrm{C}-26.7^{\circ} \mathrm{C}$.

\subsubsection{The results from Crack A}

Crack $\mathrm{A}$ is the large crack at the bottom weld of the vertical stiffener on the outside girder. It appeared as a 100-mm-long horizontal line crack on both sides of the girder web. The IR camera was positioned at $450 \mathrm{~mm}$. from the girder web in the perpendicular direction. The back side thermal images of crack A are shown in Figures 5.12 to 5.15 . The 30-second heating time was used first with the delay times of $1,3,6$, and 9 seconds. The crack could be detected from the orange horizontal line in the thermal image and the considerable drop on the thermal profile. Monitoring with a longer heating time was not undertaken because the crack could be detected at this heating time. The

effects of delay time are not obvious in this experiment. Although the 9-second delay time gave the most obvious crack in thermal image, the crack could be detected from the other thermal images captured with the different delay times.

Heating time of 30 seconds, 60 seconds, and 90 seconds were used with delay times of $1,3,6$, and 9 seconds. The IR camera was positioned at $600 \mathrm{~mm}$. from the girder web in an inclined direction. The crack could not be detected from the thermal 
image captured with 30-second and 60-second heating times, but it could be detected from the sharp boundary line between the high and low temperature zones for the 90second delay time. The detail side thermal images of crack A are shown in Figures 5.16 to 5.23.The substantial drop on the thermal profile due to the crack can be observed in some of figures. The results from the left side and right side of the cross frame shows an agreement that the crack could be seen only from thermal images captured with 6-second and 9-second delay times (see Figures 5.18, 5.19, 5.22, and 5.23). Therefore, it was observed that the delay time will have a significant effect on crack detection if the thermal image is captured from the web surface on the detail side at an inclined angle.

\subsubsection{Results from Cracks B and Crack C}

Crack B and Crack C are u-shaped cracks at the bottom weld of the transverse stiffeners on girder number 3 and 5, respectively. They are 50-mm. and 70$\mathrm{mm}$. long cracks appearing only on the detail side of girder web. Because of the crack shape, the IR camera was set directly under the cross frame in order to get as close to the crack at the bottom weld as possible. When comparing the detail side results from Crack C (Figures 5.27 to 5.30) to the detail side results from Crack B (Figures 5.24 and 5.25), the u-shape thermal contrast line in the thermal image and the considerable drop on the thermal intensity profile can be observed only in the results from Crack $\mathrm{C}$, although the same heating time and delay time are used. Therefore, these results confirm that crack size is an important factor affecting the performance of crack detection when using the IR camera. Cracks could be detected clearly from thermal images captured with 6-second and 9-second delay times. Therefore, it can be stated that the delay time will have the significant effect on the crack detection if the thermal image is captured from the detail surface. 


\section{$\underline{5.6 \text { General Observations from IR Field Inspection }}$}

The results from the field test show that, with the IR camera used in this project, the smallest crack detectable by the IR camera is larger than the smallest crack detectable by the unaided human eye. The results from the field test, similar to the results from laboratory, demonstrate that the crack depth is an important factor affecting crack detection. Through-thickness cracks can be detected clearly by the IR camera. However, cracks, which are not fully through the thickness, are not easily detected when using he IR camera. The surface and light conditions substantially affected on the results. A heating time longer than that which was used in laboratory test was used to create thermal contrast. This was necessary due to the elevated surface temperature of the girder web and because of heat reflected back as a result of glossy girder web surface.

The main disadvantage evident from the field test is that this IR crack detection system requires both physical space and time to calibrate properly before use. The calibration should be performed in an enclosed space that has as little light as possible, which is difficult to achieve under typical field conditions. Therefore, the present IR crack detection system is not well suited for field use. The ideal system should be a portable unit combining heat source, IR camera, and computer together in one module. 
Table 5.1 Inspection results for Crack A

\begin{tabular}{|c|c|c|c|c|c|c|c|c|}
\hline \multirow[t]{2}{*}{ Crack A } & \multirow{2}{*}{$\begin{array}{c}\text { Types of } \\
\text { investigation }\end{array}$} & \multirow{2}{*}{$\begin{array}{l}\text { Distance from } \\
\text { IR camera to } \\
\text { test specimen } \\
\quad(\mathrm{mm} .)\end{array}$} & \multirow{2}{*}{$\begin{array}{l}\text { Heating } \\
\text { time } \\
\text { (second) }\end{array}$} & \multicolumn{4}{|c|}{$\begin{array}{l}\text { Delay Time } \\
\text { (Second) }\end{array}$} & \multirow[t]{2}{*}{ Reference } \\
\hline & & & & 1 & 3 & 6 & 9 & \\
\hline $\begin{array}{c}\text { Thermal image from back } \\
\text { side }\end{array}$ & Active approach & $\begin{array}{c}450 \\
\text { (perpendicular) }\end{array}$ & 30 & $\mathrm{D}$ & $\mathrm{D}$ & $\mathrm{D}$ & $\mathrm{D}$ & $5.12-5.15$ \\
\hline \multirow{3}{*}{$\begin{array}{c}\text { Thermal image from detail } \\
\text { side (left side of cross } \\
\text { frame) }\end{array}$} & \multirow{3}{*}{ Active approach } & \multirow{3}{*}{$\begin{array}{c}600 \\
\text { (10-degree incline) }\end{array}$} & 30 & ND & ND & ND & ND & \multirow[t]{3}{*}{$5.16-5.19$} \\
\hline & & & 60 & ND & ND & ND & ND & \\
\hline & & & 90 & $\mathrm{D}$ & $\mathrm{D}$ & $\mathrm{D}$ & $\mathrm{D}$ & \\
\hline \multirow{3}{*}{$\begin{array}{l}\text { Thermal image from detail } \\
\text { side (right side of cross } \\
\text { frame) }\end{array}$} & \multirow{3}{*}{ Active approach } & \multirow{3}{*}{$\begin{array}{c}600 \\
(10 \text {-degree incline })\end{array}$} & 30 & ND & ND & ND & ND & \multirow[t]{3}{*}{$5.20-5.23$} \\
\hline & & & 60 & ND & ND & ND & ND & \\
\hline & & & 90 & $\mathrm{D}$ & $\mathrm{D}$ & $\mathrm{D}$ & $\mathrm{D}$ & \\
\hline
\end{tabular}

Note: $\mathrm{D}=$ Crack can be detected by IR

$\mathrm{ND}=$ Crack can not be detected by IR 
Table 5.2 Inspection results for Crack B

\begin{tabular}{|c|c|c|c|c|c|c|c|c|}
\hline \multirow[t]{2}{*}{ Crack B } & \multirow[t]{2}{*}{$\begin{array}{c}\text { Types of } \\
\text { investigation }\end{array}$} & \multirow{2}{*}{$\begin{array}{l}\text { Distance from } \\
\text { IR camera to } \\
\text { test specimen } \\
\quad(\mathrm{mm} .)\end{array}$} & \multirow{2}{*}{\begin{tabular}{|c} 
Heating \\
time \\
(second)
\end{tabular}} & \multicolumn{4}{|c|}{$\begin{array}{c}\text { Delay } \\
\text { Time } \\
\text { (Second) }\end{array}$} & \multirow[t]{2}{*}{ Reference } \\
\hline & & & & 1 & 3 & 6 & 9 & \\
\hline \multirow{4}{*}{$\begin{array}{c}\text { Thermal image from back } \\
\text { side }\end{array}$} & \multirow{4}{*}{ Active approach } & \multirow{4}{*}{$\begin{array}{c}450 \\
\text { (perpendicular) }\end{array}$} & 30 & ND & ND & ND & ND & \multirow[t]{4}{*}{5.26} \\
\hline & & & 60 & ND & ND & ND & ND & \\
\hline & & & 90 & ND & ND & ND & ND & \\
\hline & & & 120 & ND & ND & ND & ND & \\
\hline \multirow{4}{*}{$\begin{array}{l}\text { Thermal image from detail } \\
\text { side }\end{array}$} & \multirow{4}{*}{ Active approach } & \multirow{4}{*}{$\begin{array}{c}450 \\
\text { (30 degree incline) }\end{array}$} & 30 & ND & ND & ND & ND & \multirow[t]{4}{*}{$5.24-5.25$} \\
\hline & & & 60 & ND & ND & ND & ND & \\
\hline & & & 90 & ND & ND & ND & ND & \\
\hline & & & 120 & ND & ND & ND & ND & \\
\hline
\end{tabular}

Note: $\mathrm{D}=$ Crack can be detected by IR

$\mathrm{ND}=$ Crack can not be detected by IR 
Table 5.3 Inspection results for Crack C

\begin{tabular}{|c|c|c|c|c|c|c|c|c|}
\hline \multirow[t]{2}{*}{ Crack C } & \multirow[t]{2}{*}{$\begin{array}{c}\text { Types of } \\
\text { investigation }\end{array}$} & \multirow{2}{*}{$\begin{array}{l}\text { Distance from } \\
\text { IR camera to } \\
\text { test specimen } \\
\quad(\mathrm{mm} .)\end{array}$} & \multirow{2}{*}{$\begin{array}{c}\text { Heating } \\
\text { time } \\
\text { (second) }\end{array}$} & \multicolumn{4}{|c|}{$\begin{array}{c}\text { Delay } \\
\text { Time } \\
\text { (Second) }\end{array}$} & \multirow[t]{2}{*}{ Reference } \\
\hline & & & & 1 & 3 & 6 & 9 & \\
\hline \multirow{4}{*}{$\begin{array}{c}\text { Thermal image from back } \\
\text { side }\end{array}$} & \multirow{4}{*}{ Active approach } & \multirow{4}{*}{$\begin{array}{c}450 \\
\text { (perpendicular) }\end{array}$} & 30 & ND & ND & ND & ND & \multirow[t]{4}{*}{5.31} \\
\hline & & & 60 & ND & ND & ND & $\mathrm{ND}$ & \\
\hline & & & 90 & ND & ND & ND & ND & \\
\hline & & & 120 & ND & ND & ND & $\mathrm{ND}$ & \\
\hline \multirow{3}{*}{$\begin{array}{l}\text { Thermal image from detail } \\
\text { side }\end{array}$} & \multirow{3}{*}{ Active approach } & \multirow{3}{*}{$\begin{array}{c}450 \\
(30 \text { degree incline })\end{array}$} & 30 & ND & ND & ND & ND & \multirow[t]{3}{*}{$5.27-5.30$} \\
\hline & & & 60 & ND & ND & ND & $\mathrm{ND}$ & \\
\hline & & & 90 & $\mathrm{D}$ & $\mathrm{D}$ & $\mathrm{D}$ & $\mathrm{D}$ & \\
\hline
\end{tabular}

Note: $\mathrm{D}=$ Crack can be detected by IR

$\mathrm{ND}=$ Crack can not be detected by IR 


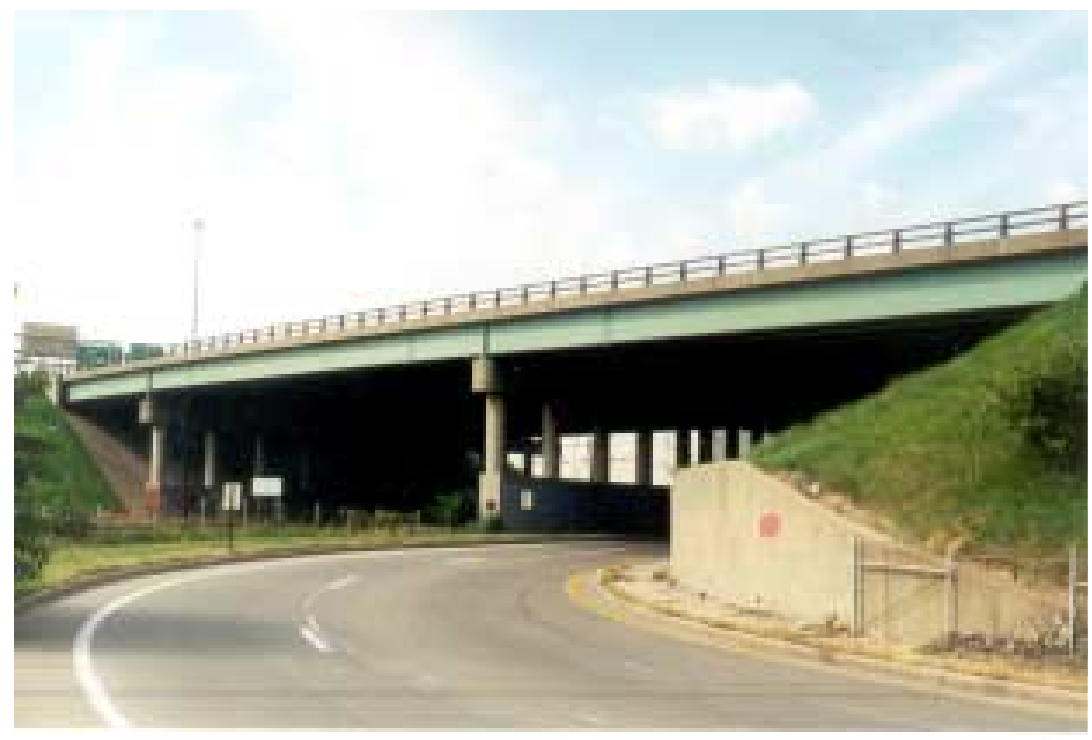

a) Inspected bridge

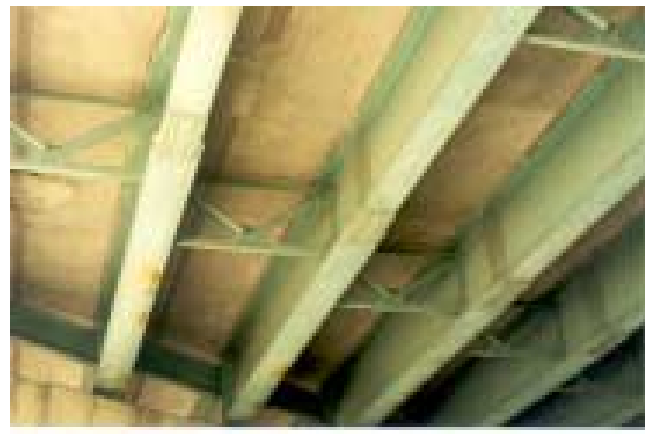

b) Cross frame

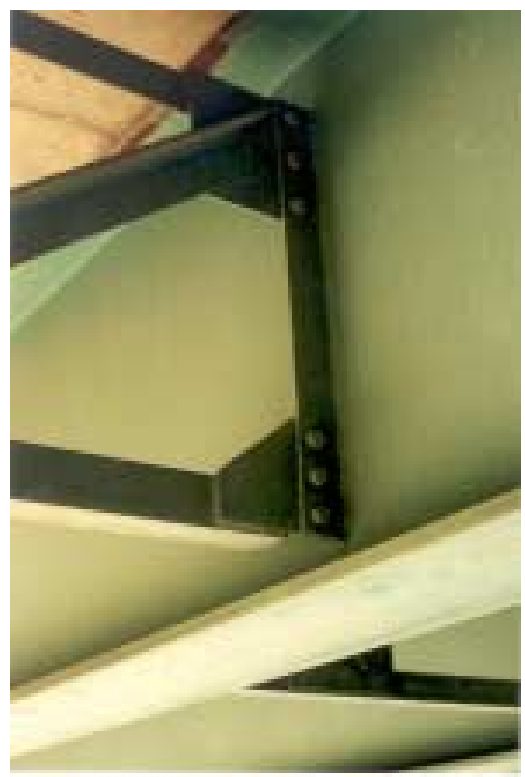

c) The connection between cross

frame and girder web

Figure 5.1 Inspected bridge and cross frame details. 


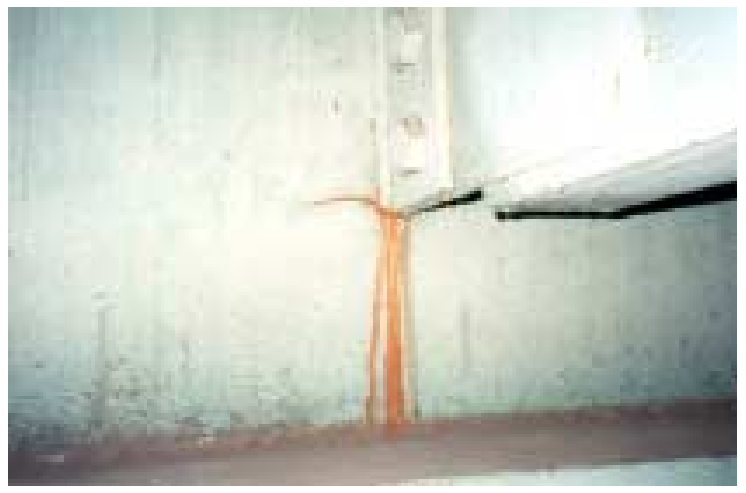

Figure 5.2 Fatigue crack in beam web at cross-frame attachment plate weld
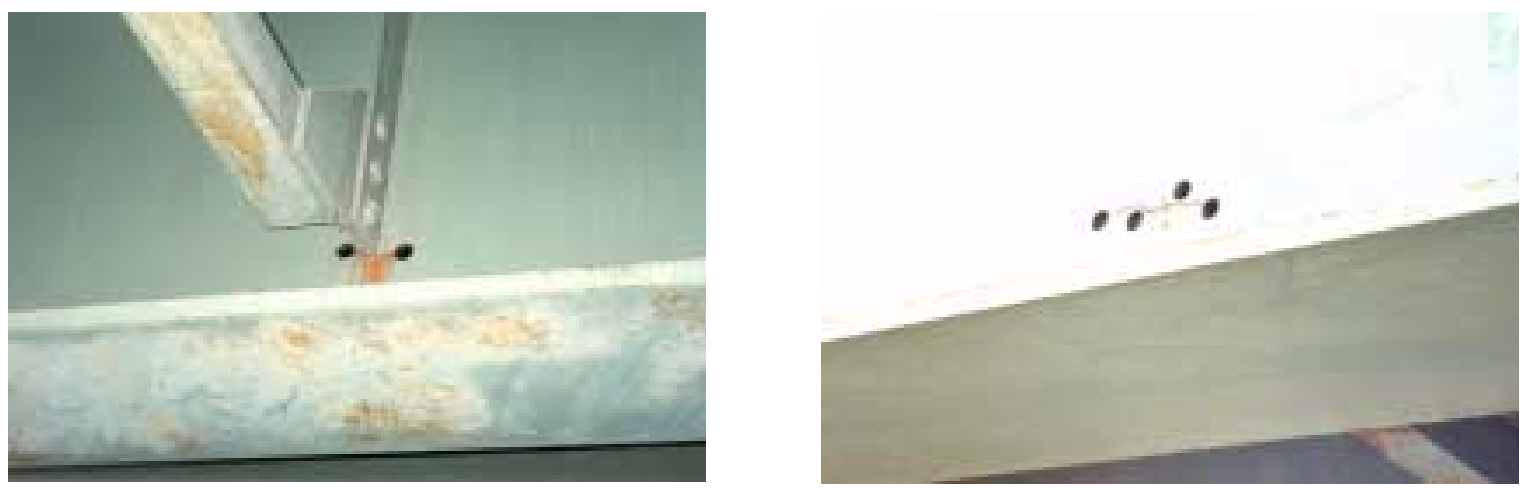

Figure 5.3 Drilled holes used as a crack arrester, at weld connection (left) and two drilled holes for large crack (right) 


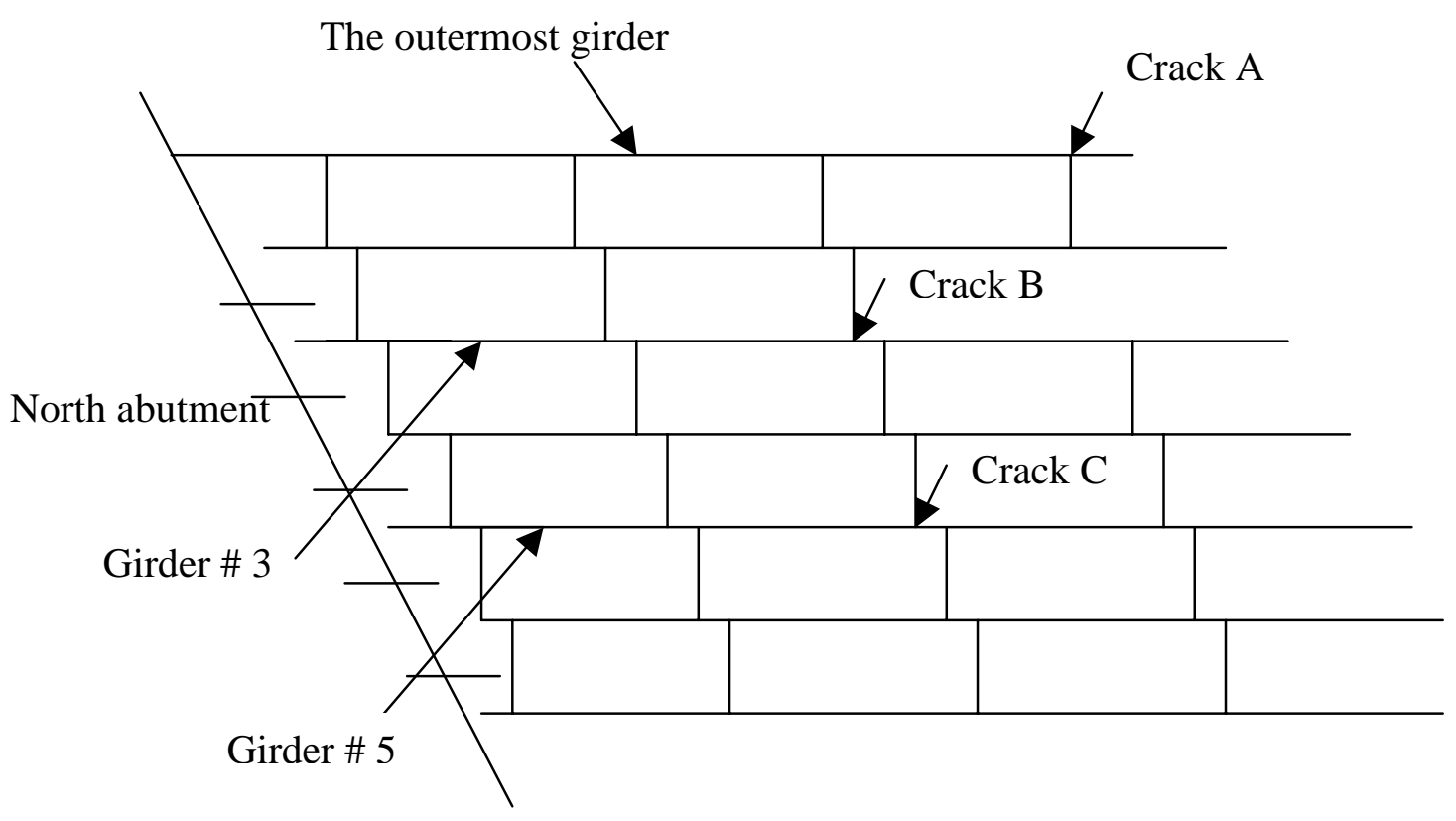

Figure 5.4 Locations of Crack A, B, and C 


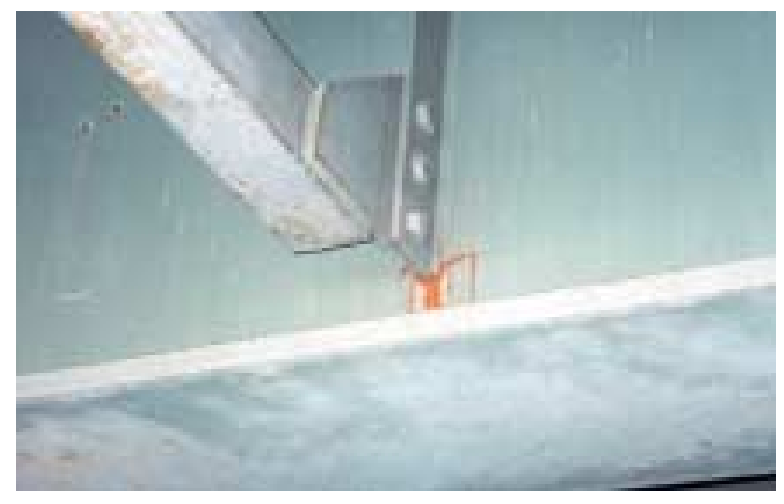

a) Crack $A$ on detail side

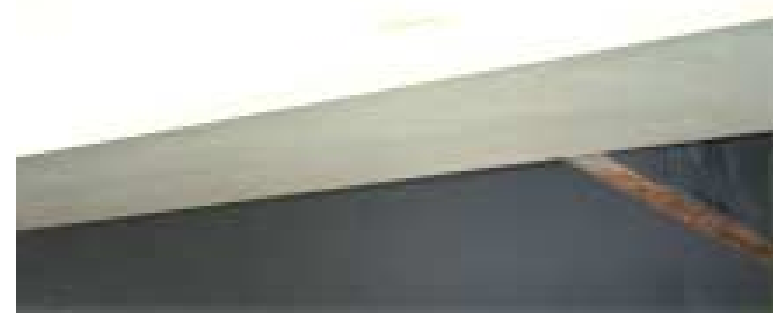

b) Crack A on opposite side

Figure 5.5 Crack A (large crack) 


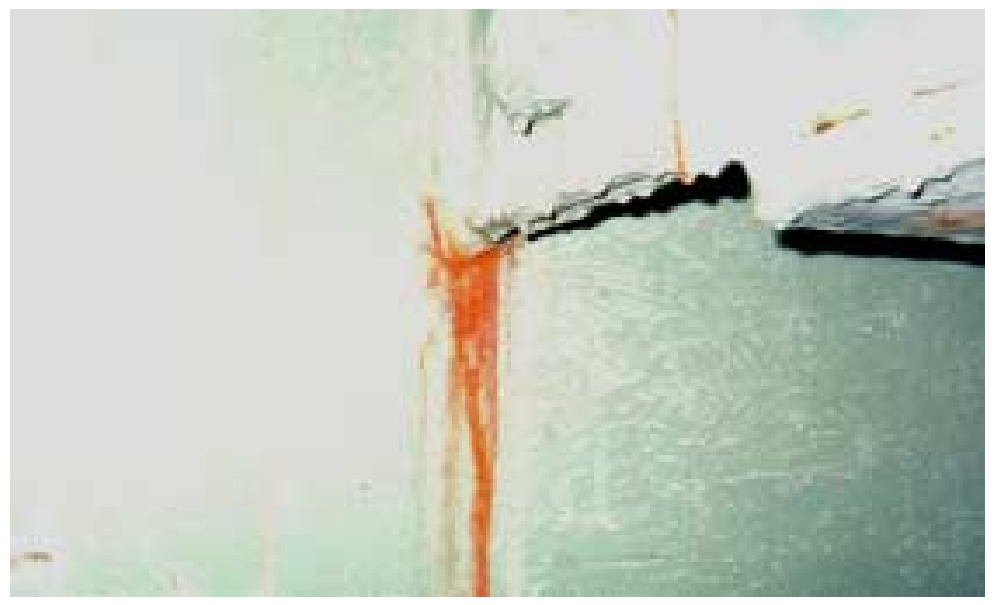

Figure 5.6 Crack B (small crack ) on detail side of girder web

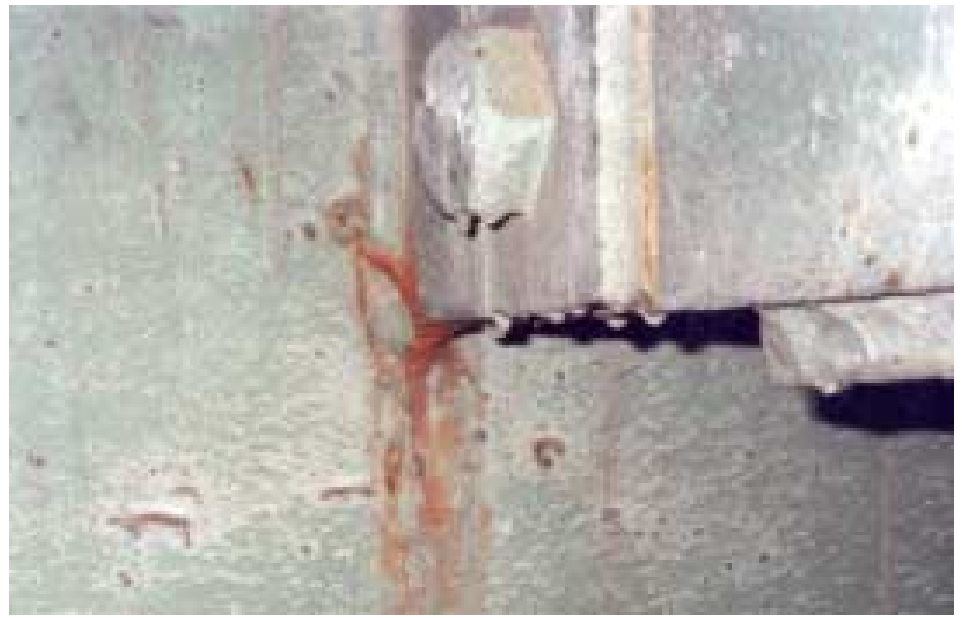

Figure 5.7 Crack C (intermediate crack) on detail side of girder web 


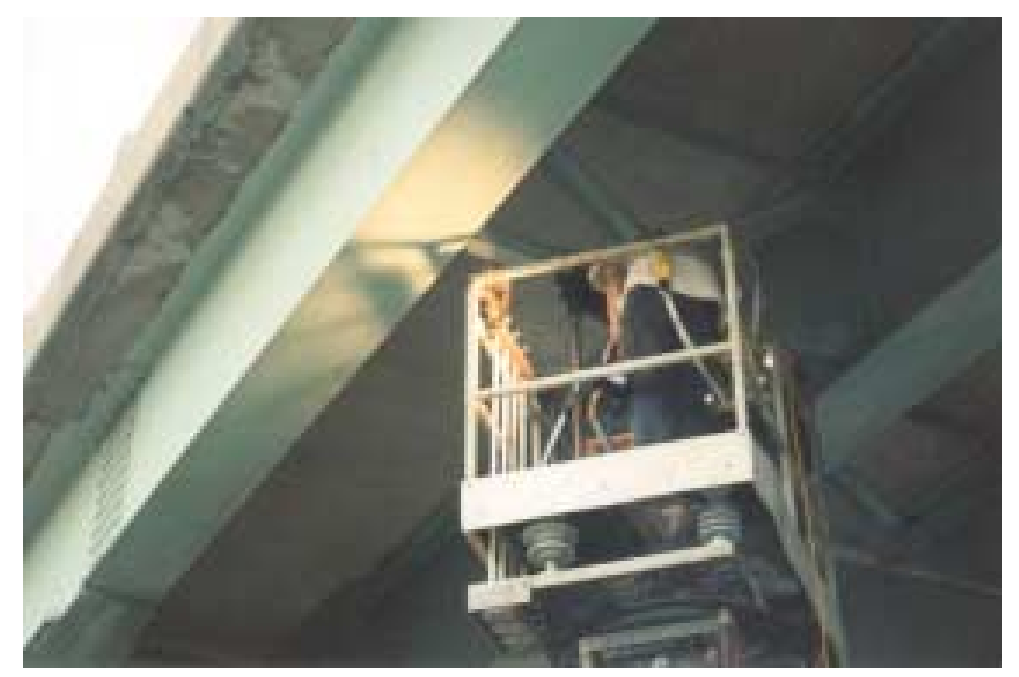

Figure 5.8 Inspection of cross frame to girder web connection detail 


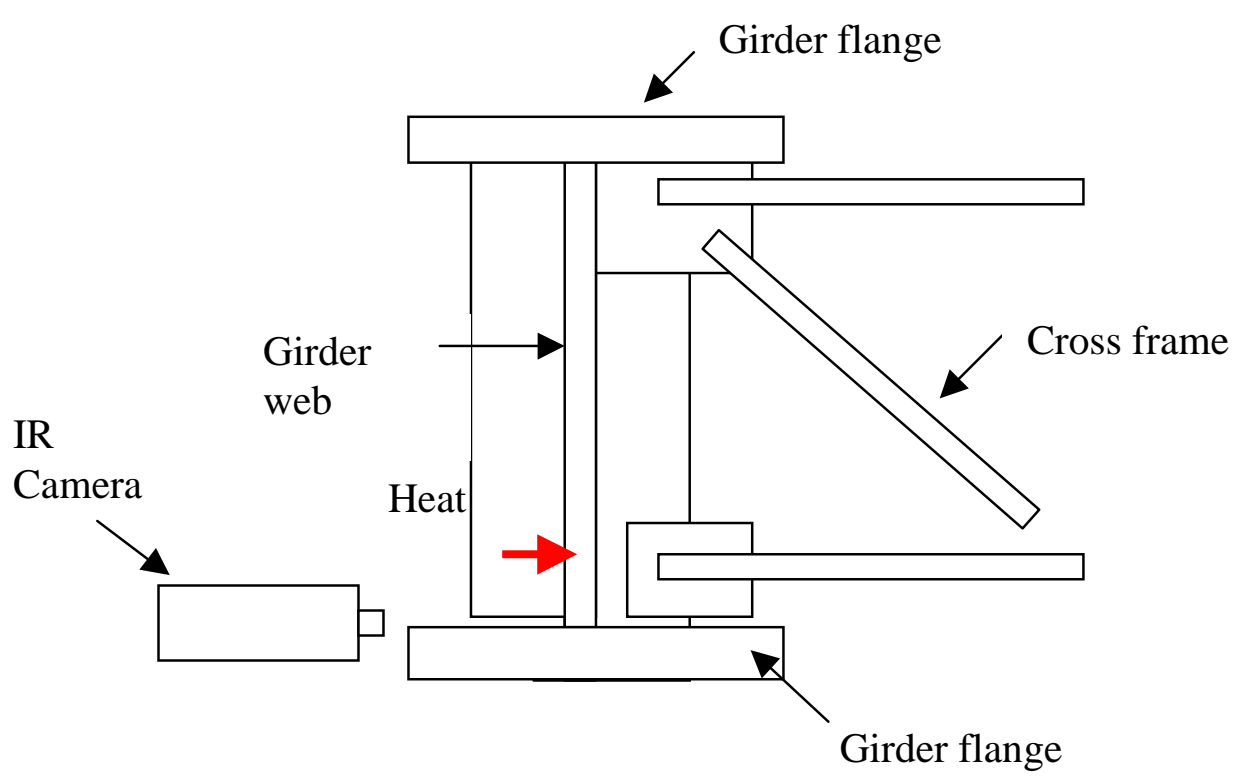

Figure 5.9 Inspection of cracks A, B, and C on the opposite side.

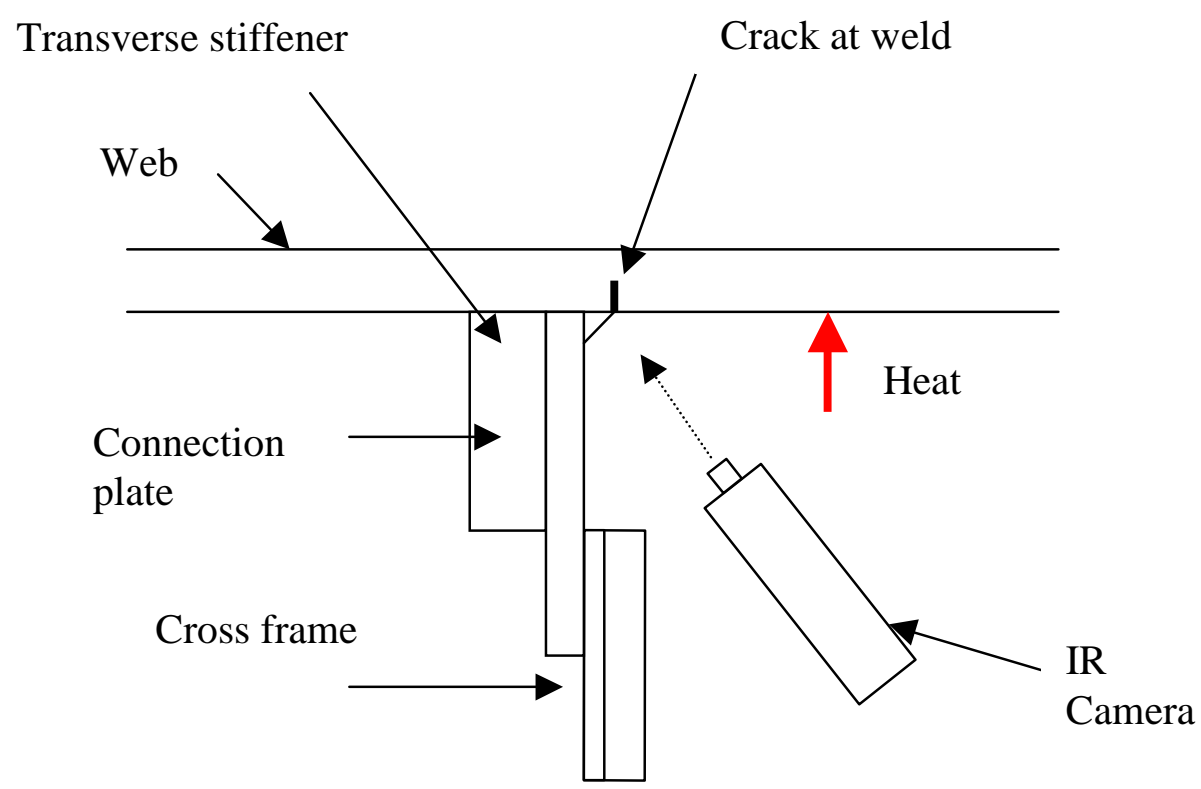

Figure 5.10 Inspection of crack A on detail side (IR camera at the same level as the crack). 


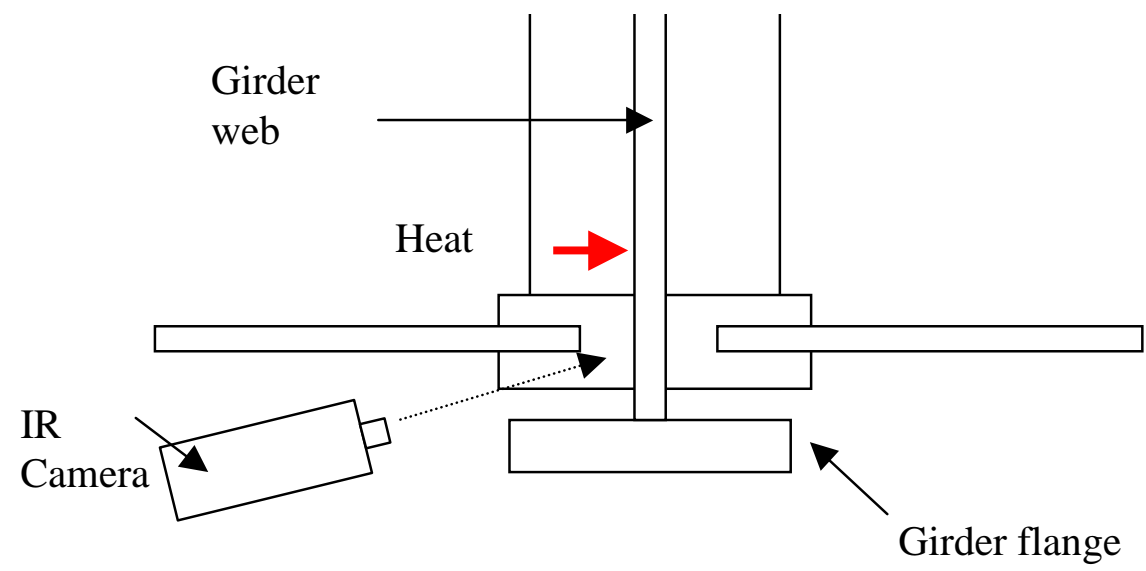

Figure 5.11 Inspection of cracks B and C on the detail side (IR camera was set directly under the cross frame). 


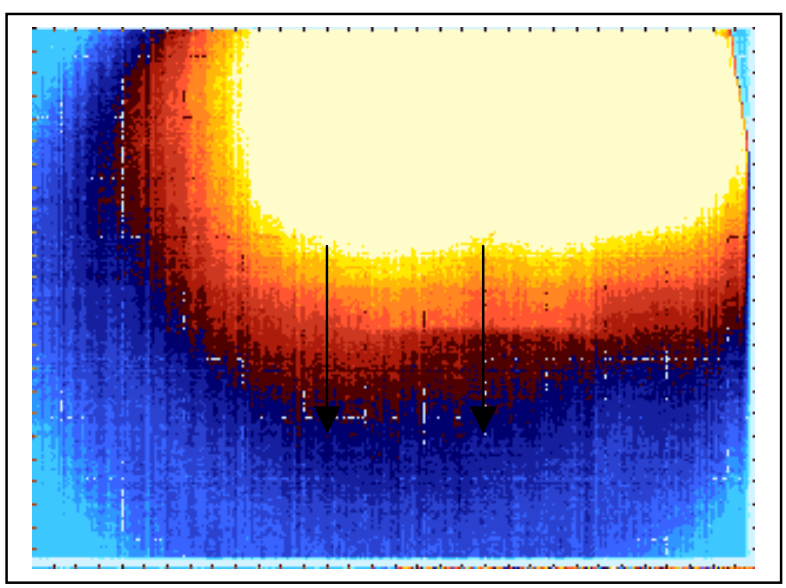

a) Thermal image
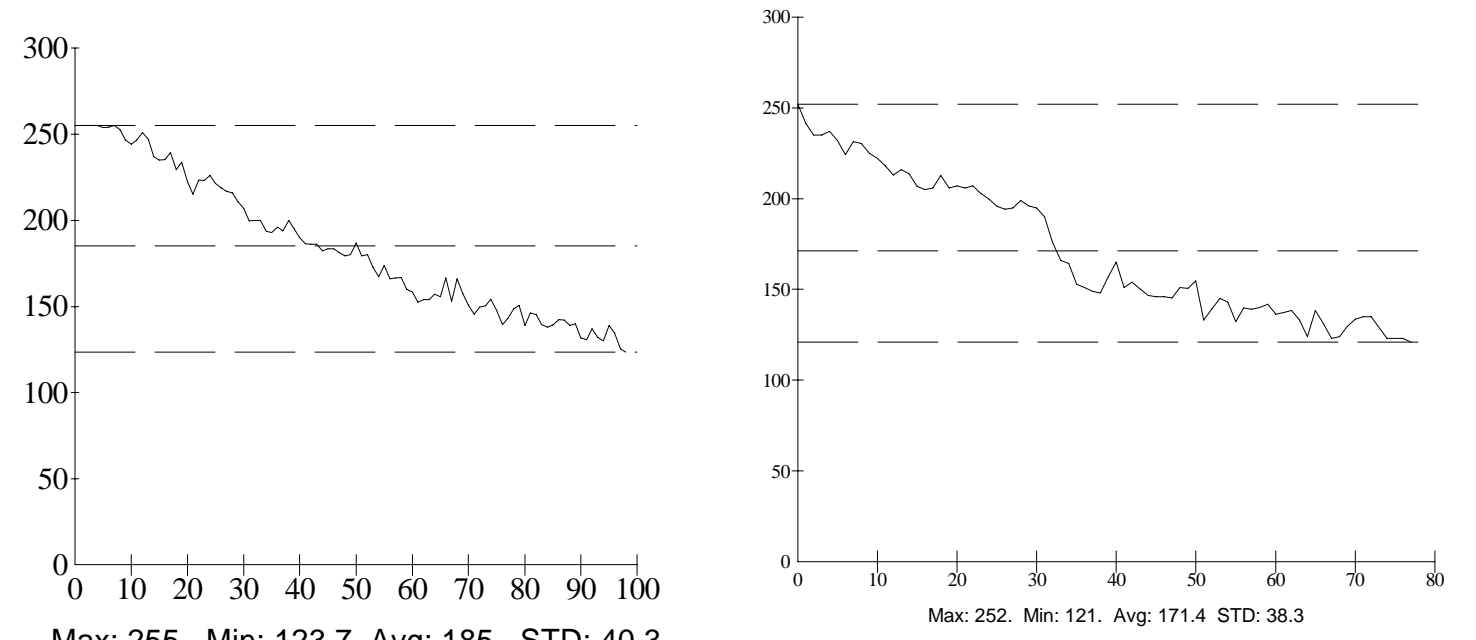

Max: 255. Min: 123.7 Avg: 185. STD: 40.3

b) Thermal profile from the left line

c) Thermal profile from the right line

Figure 5.12 Thermal images of crack A (opposite side) with 30-second heating time and 1-second delay time. 


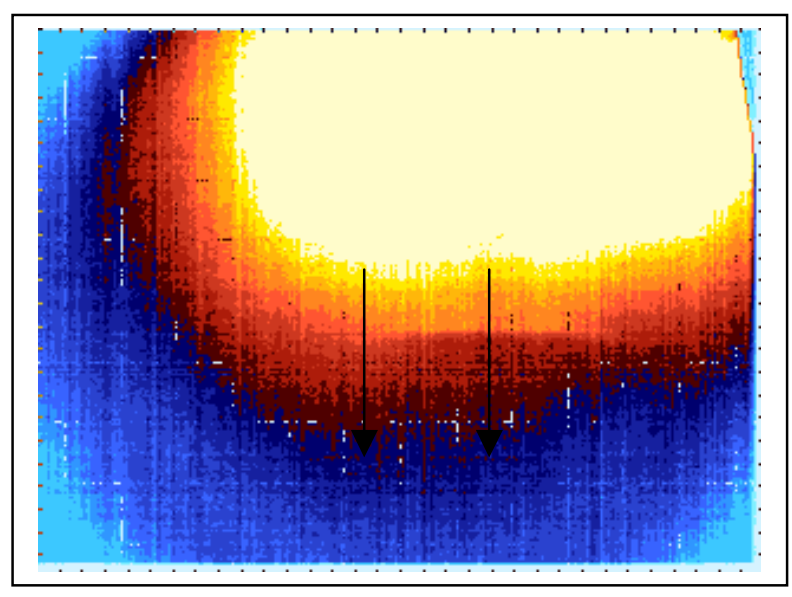

a) Thermal image

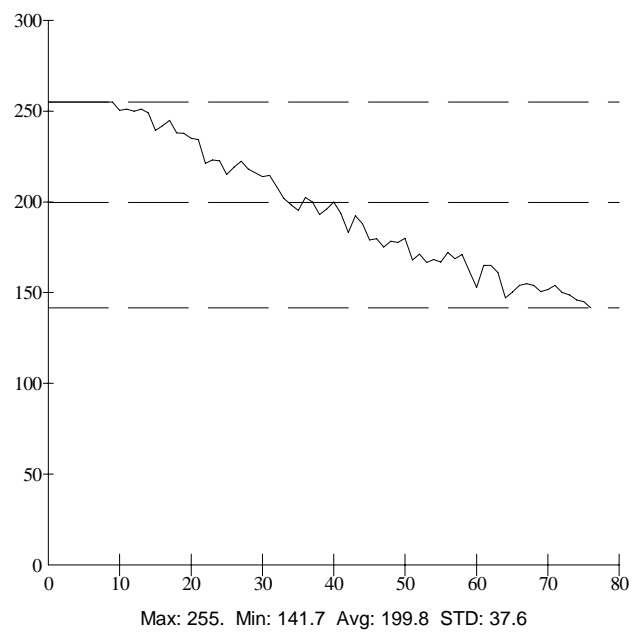

b) Thermal profile from the left line

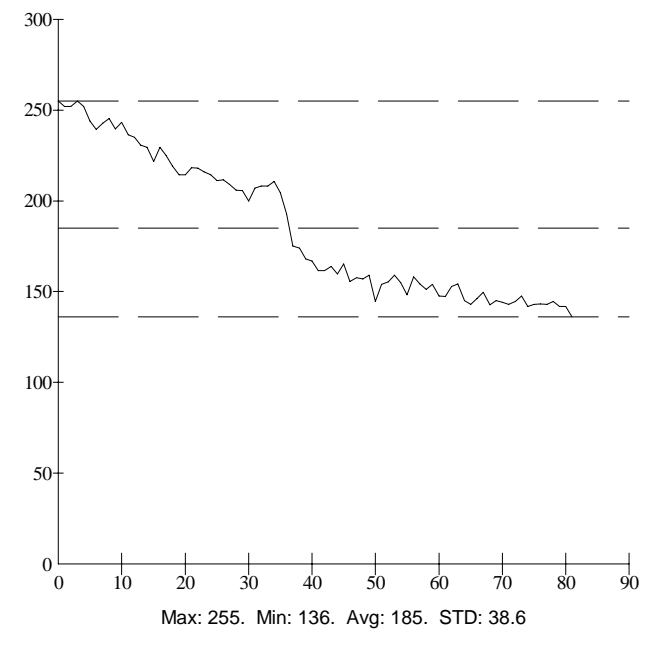

c) Thermal profile from the right line

Figure 5.13 Thermal images of crack A (opposite side) with 30-second heating time and 3 -second delay time. 


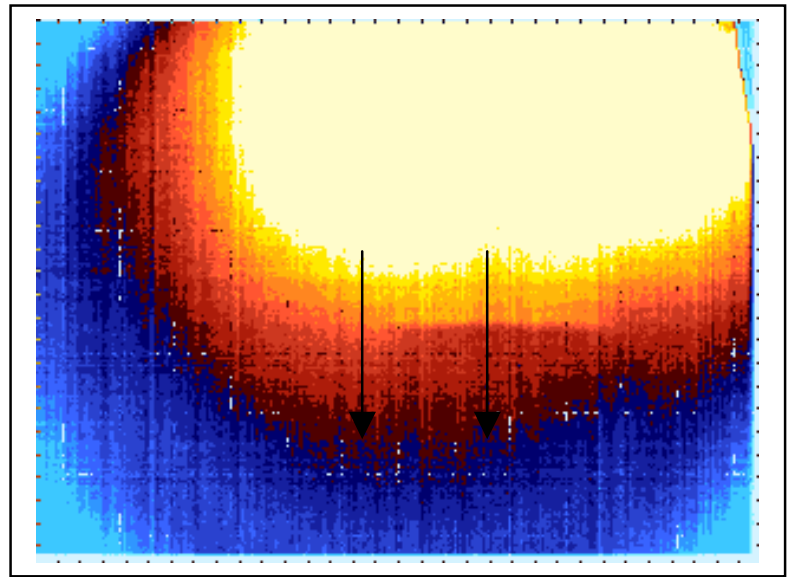

a) Thermal image

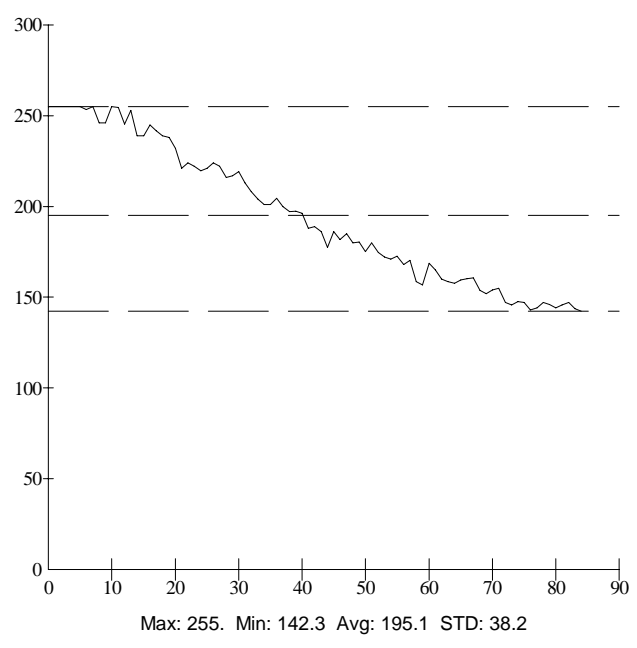

b) Thermal profile from the left line

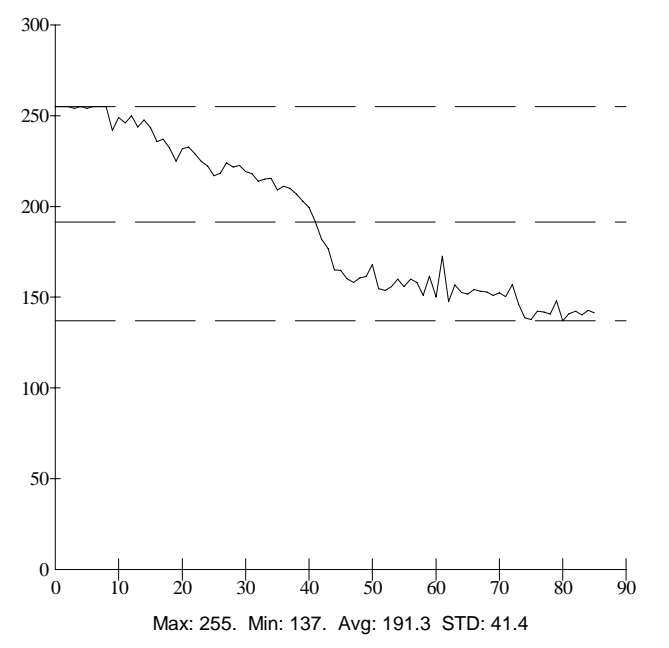

c) Thermal profile from the right line

Figure 5.14 Thermal images of crack A (opposite side) with 30-second heating time and 6-second delay time. 


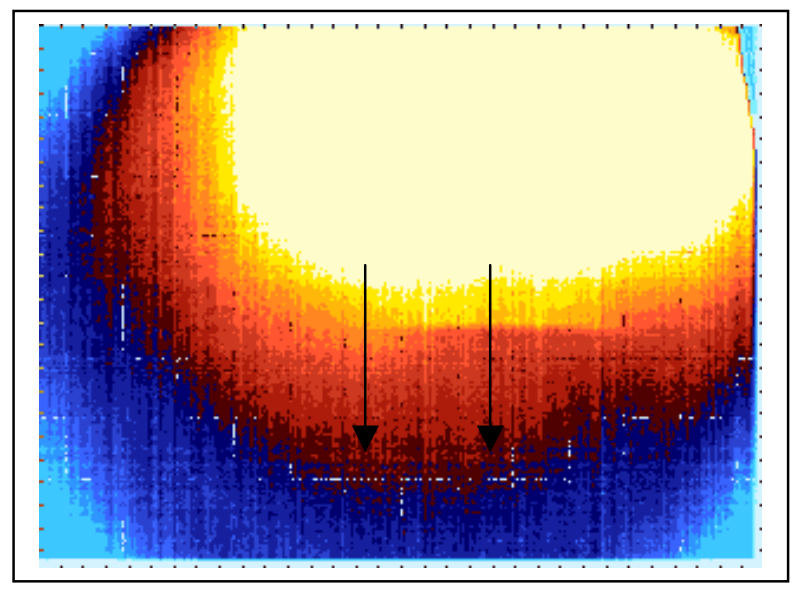

a) Thermal image

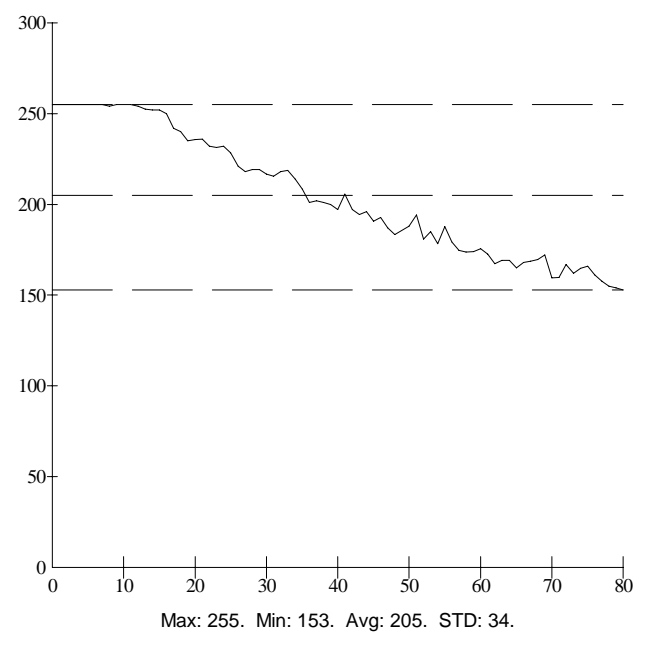

b) Thermal profile from the left line

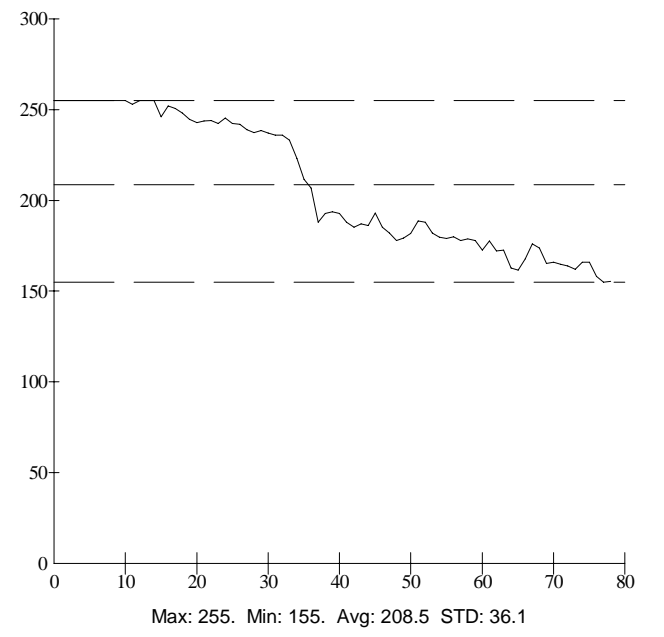

c) Thermal profile from the right line

Figure 5.15 Thermal images of crack A (opposite side) with 30-second heating time and 9-second delay time. 


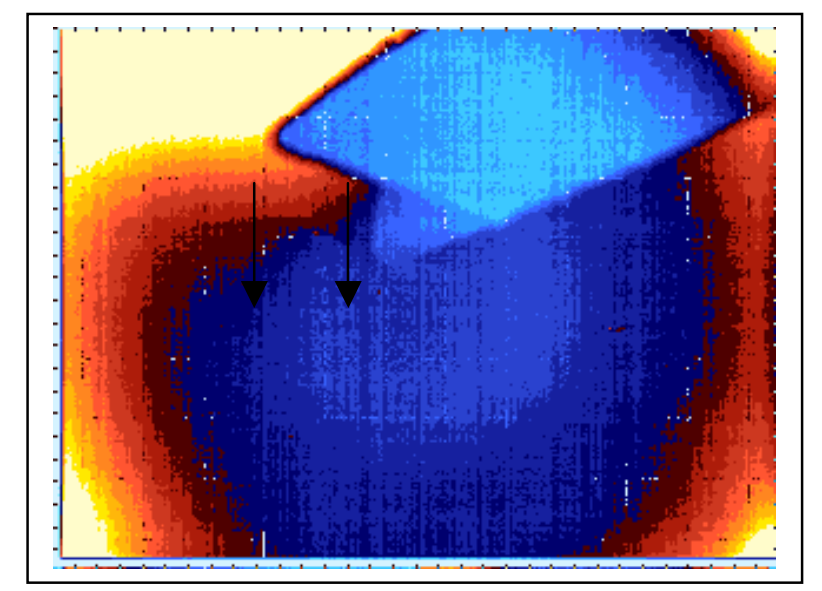

a) Thermal

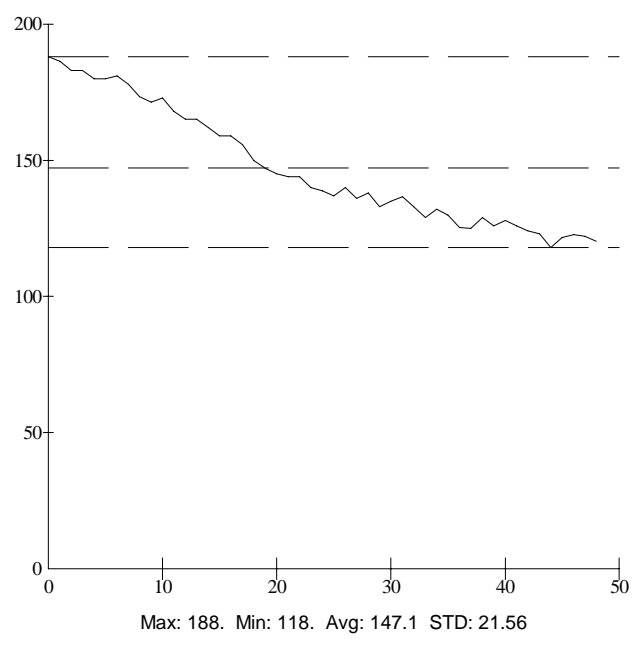

b) Thermal profile from the left line

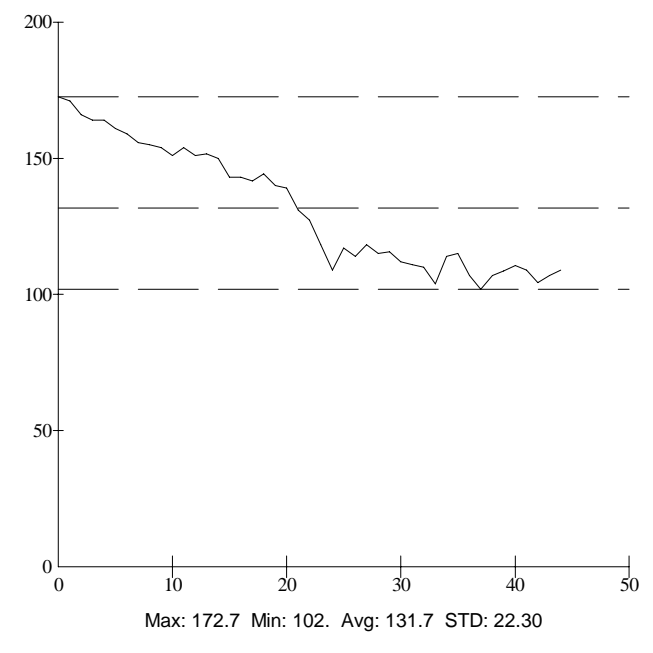

c) Thermal profile from the right line

Figure 5.16 Left-side thermal images of crack A (detail side) with 90-second heating time and 1-second delay time. 


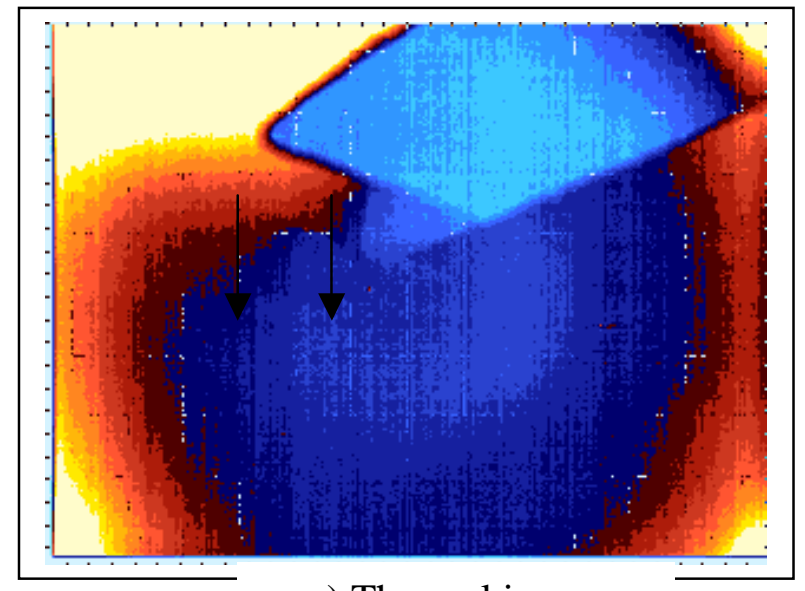

a) Thermal image

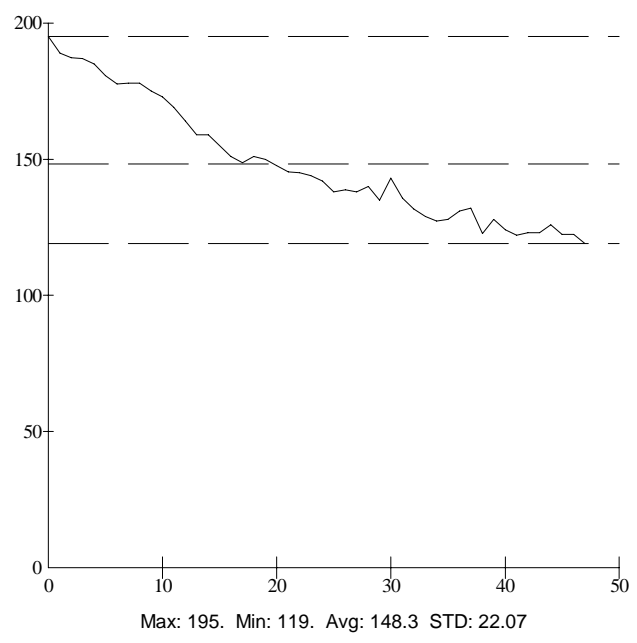

b) Thermal profile from the left line

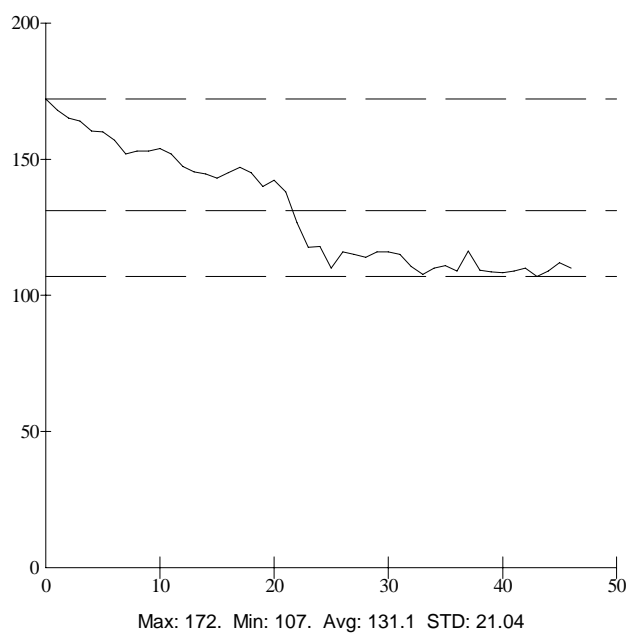

c) Thermal profile from the right line

Figure 5.17 Left-side thermal images of crack A (detail side) with 90-second heating time and 3 -second delay time. 


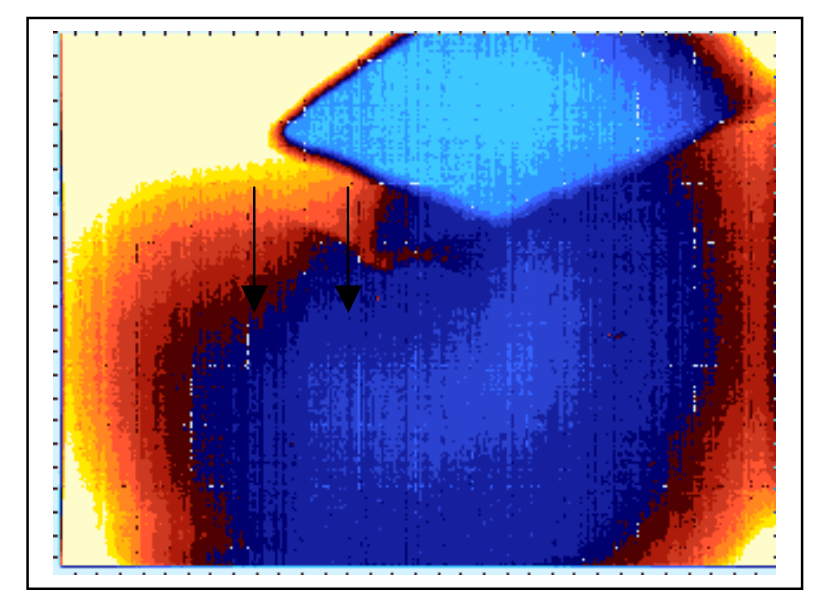

a) Thermal image

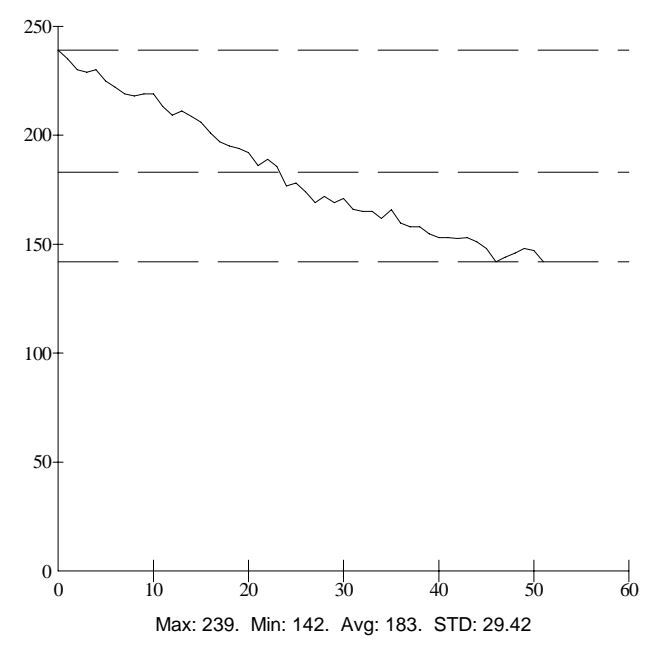

b) Thermal profile from the left line

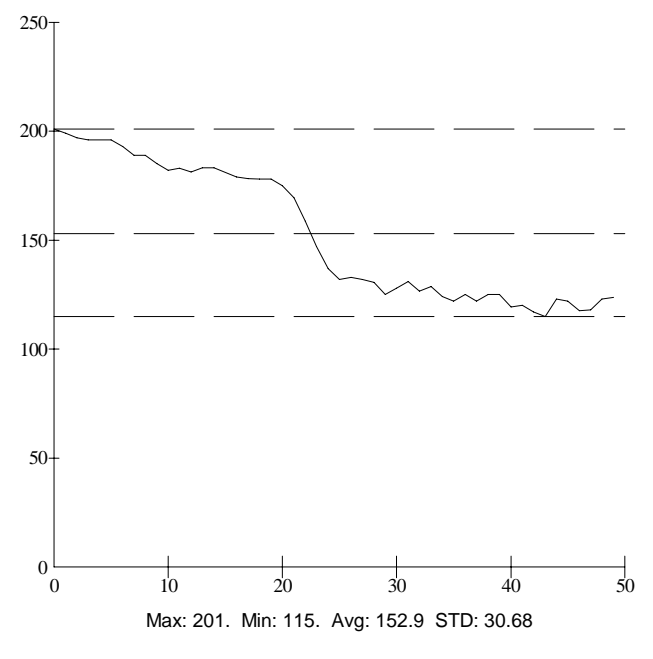

c) Thermal profile from the right line

Figure 5.18 Left-side thermal images of crack A (detail side) with 90-second heating time and 6-second delay time. 


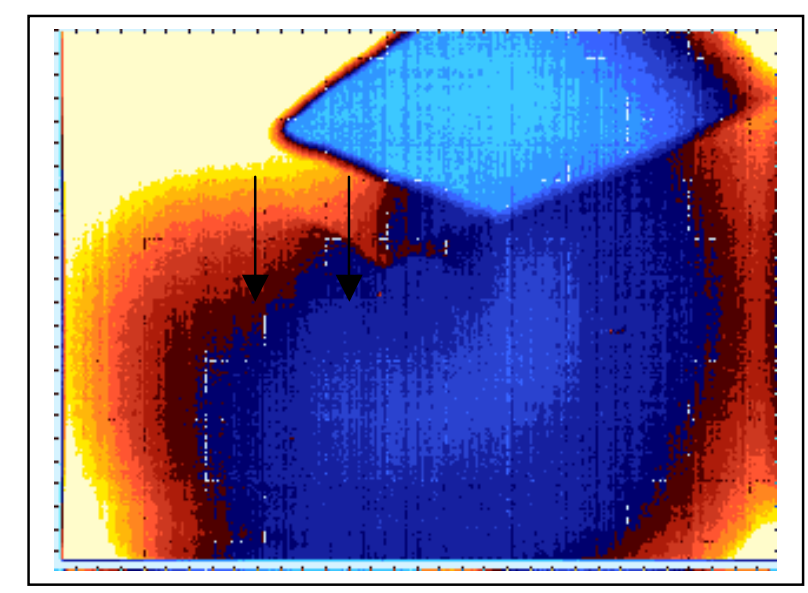

a) Thermal image

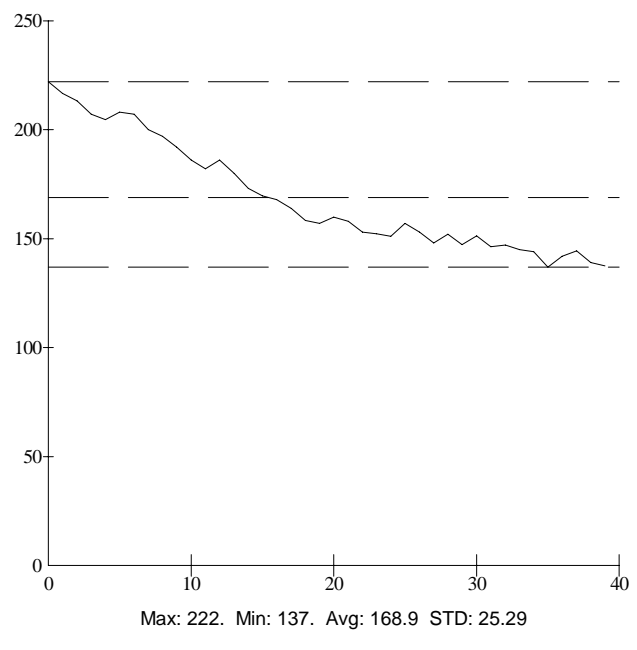

b) Thermal profile from the left line

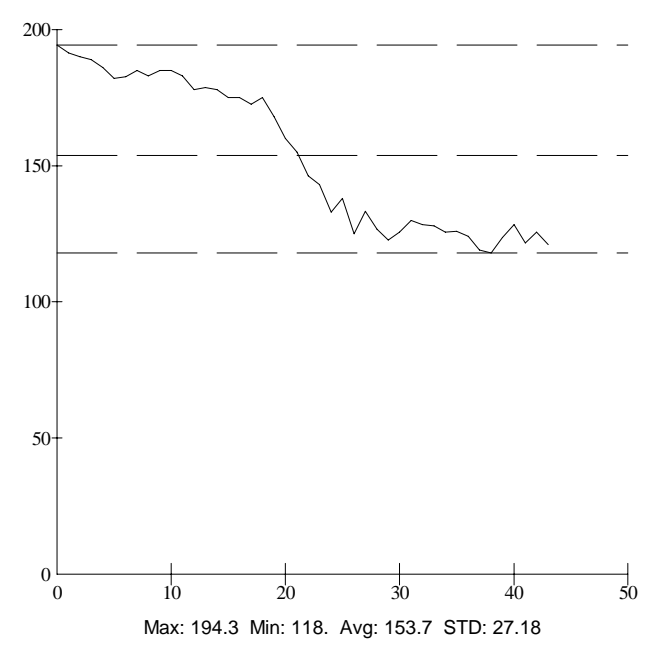

c) Thermal profile from the right line

Figure 5.19 Left-side thermal images of crack A (detail side) with 90-second heating time and 9-second delay time. 


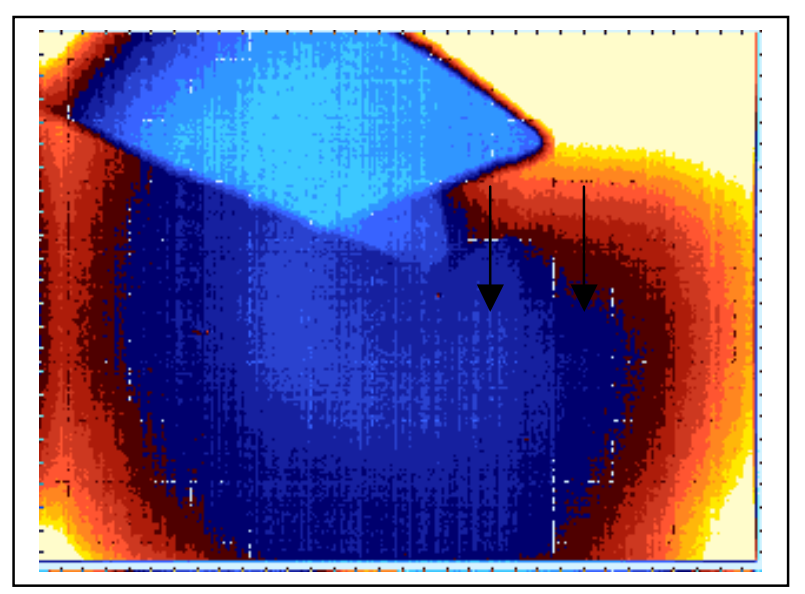

a) Thermal image
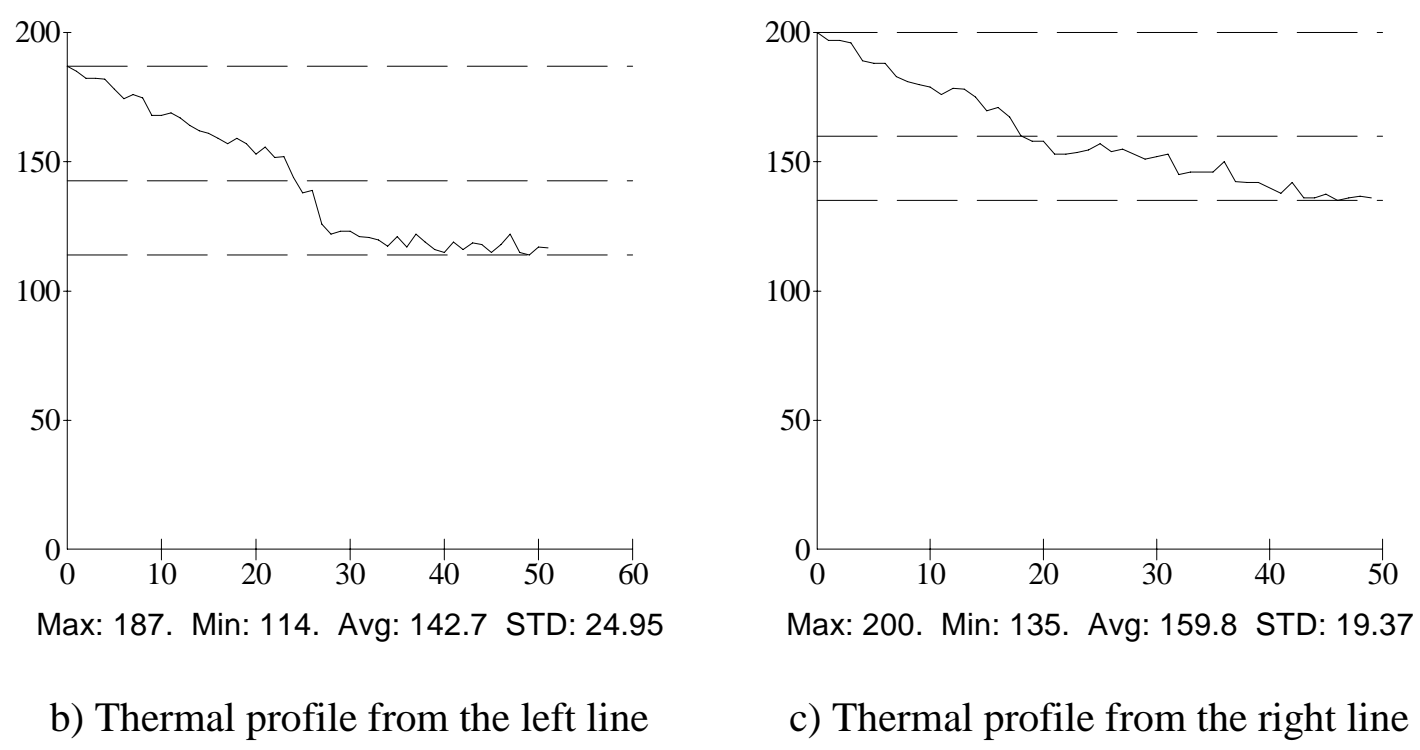

Figure 5.20 Right-side hermal images of crack A (detail side) with 90-second heating time and 1-second delay time. 


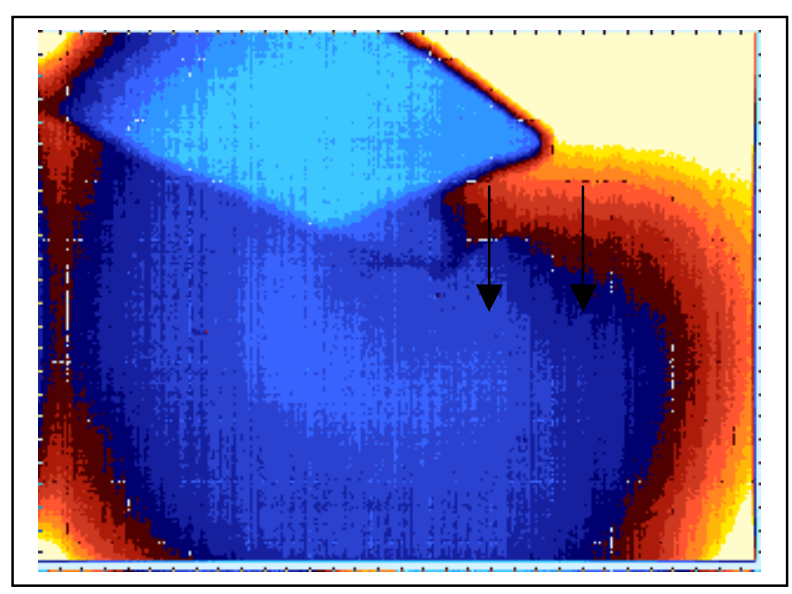

a) Thermal image

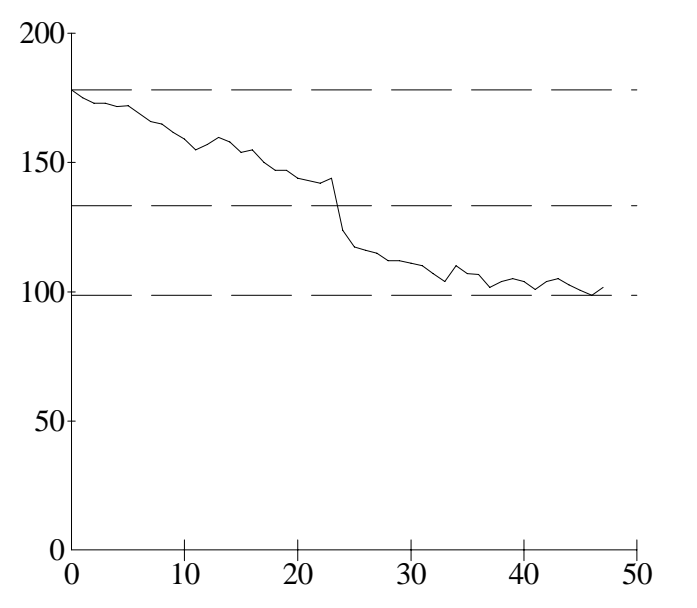

Max: 178. Min: 98.7 Avg: 133.3 STD: 27.31

b) Thermal profile from the left line

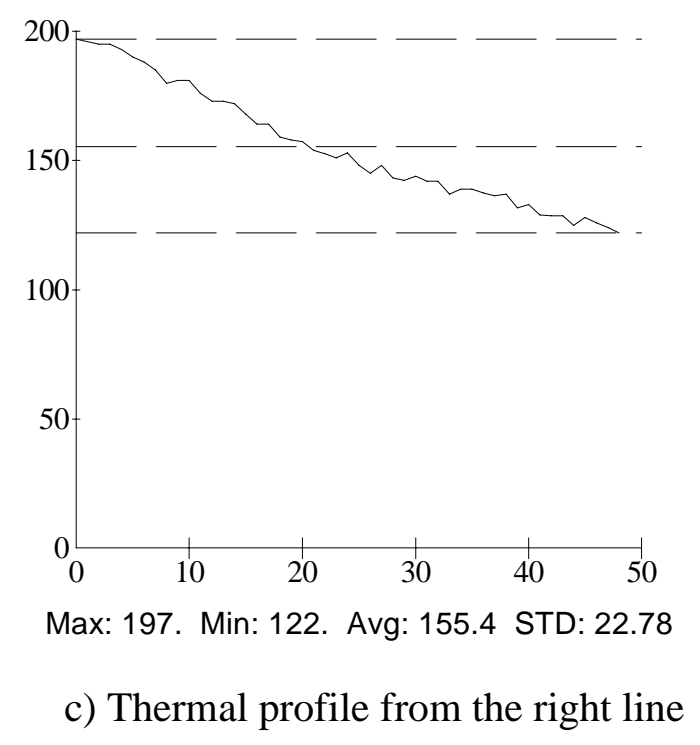

c) Thermal profile from the right line

Figure 5.21 Right-side thermal images of crack A (detail side) with 90-second heating time and 3-second delay time. 


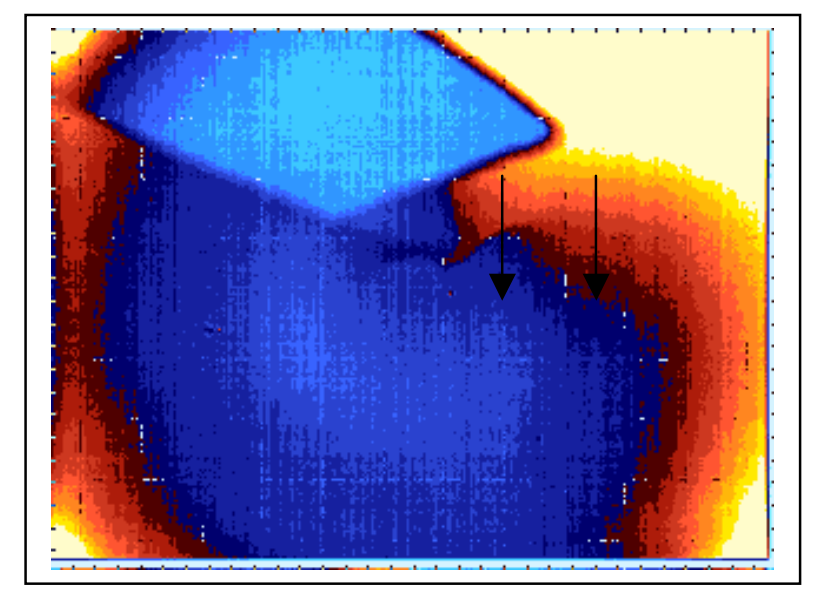

a) Thermal image

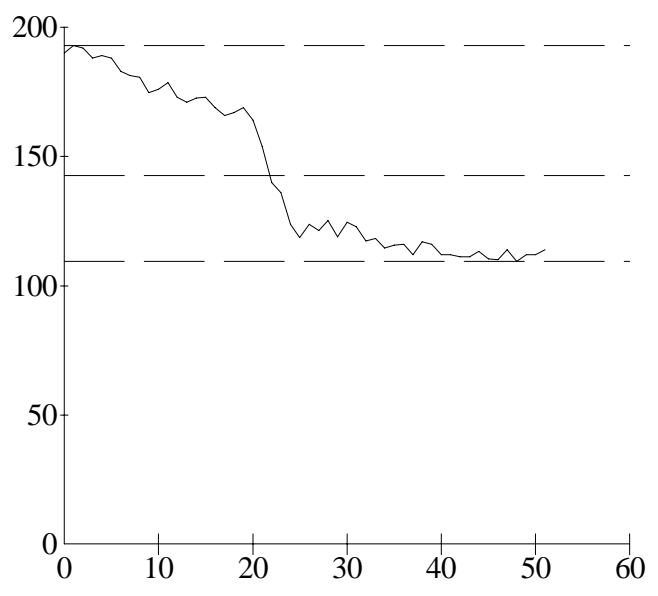

Max: 193. Min: 109.3 Avg: 142.6 STD: 30.61

b) Thermal profile from the left line

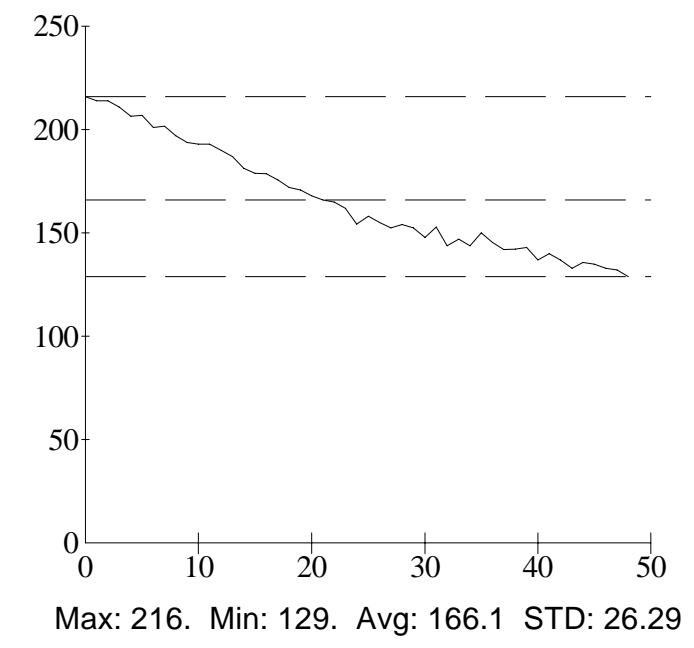

c) Thermal profile from the right line

Figure 5.22 Right-side thermal images of crack A (detail side) with 90-second heating time and 6-second delay time. 


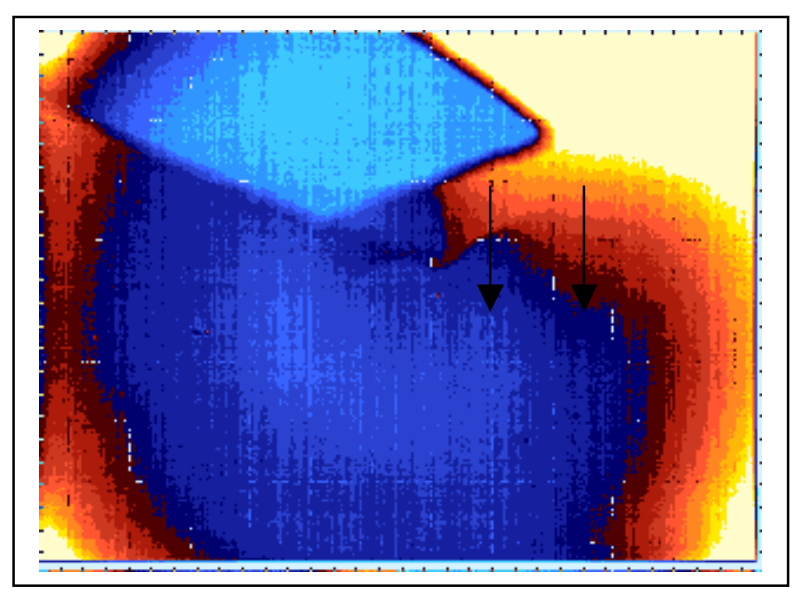

a) Thermal image
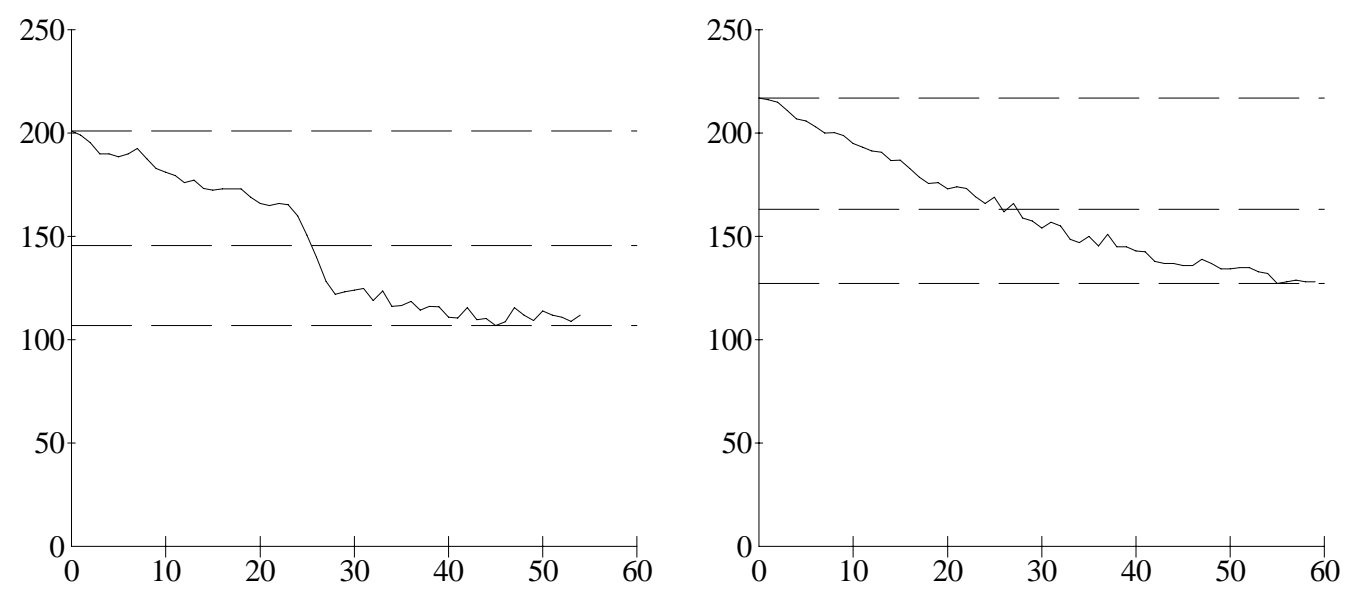

Max: 201. Min: 107. Avg: 145.6 STD: 32.6

b) Thermal profile from the left line

Figure 5.23 Right-side thermal images of crack A (detail side) with 90-second heating time and 9-second delay time. 


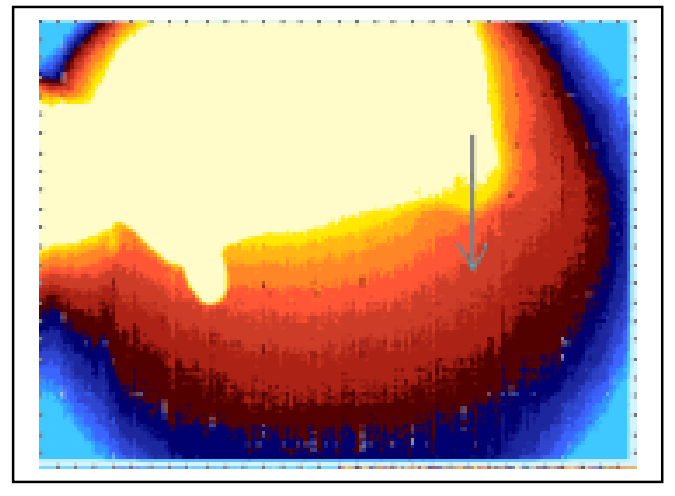

a) 1-second delay time

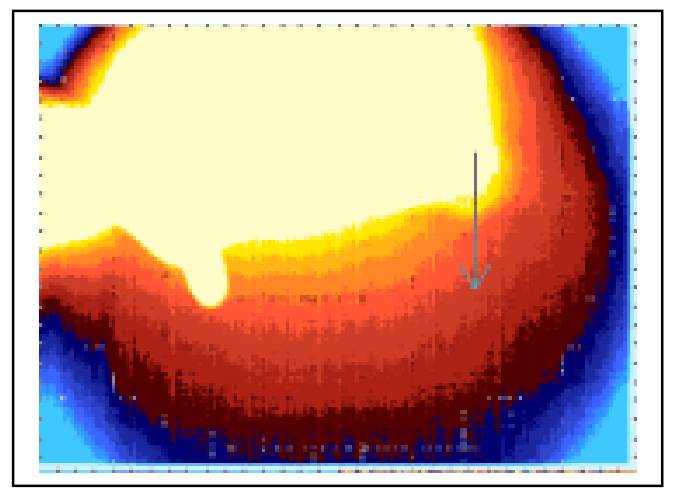

c) 6-second delay time

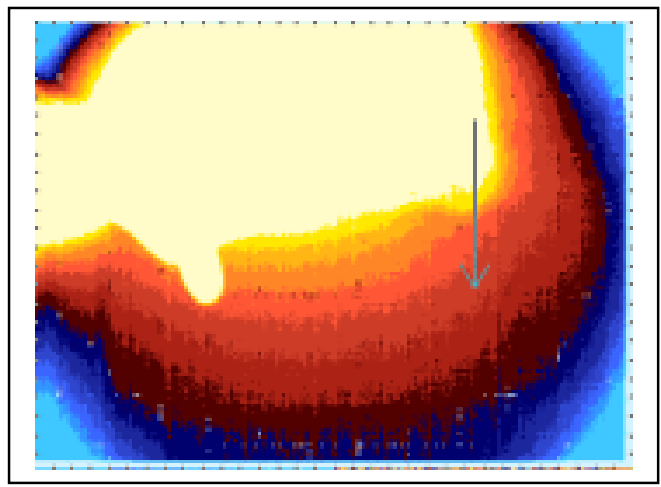

b) 3-second delay time

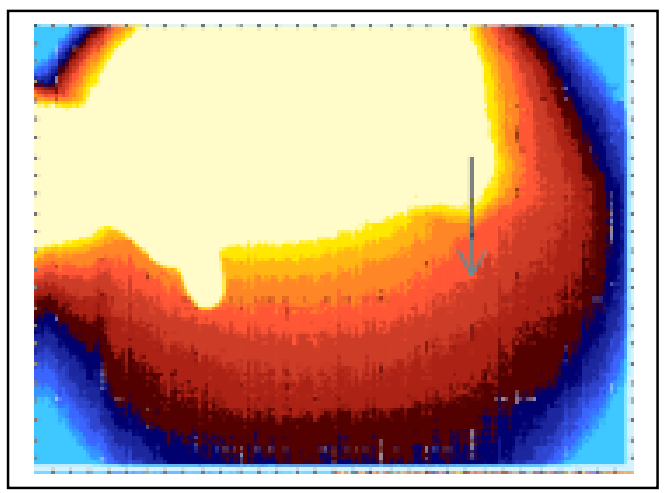

d) 9-second delay time

Figure 5.24 Thermal images of crack B (detail side) with 120-second heating time. 


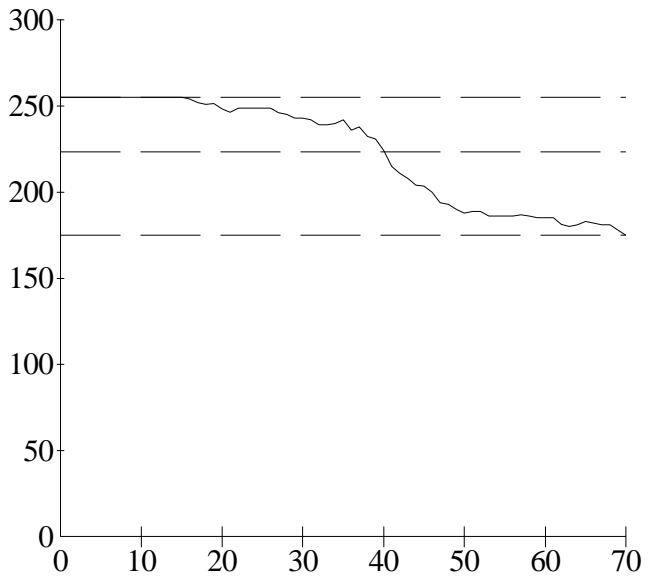

Max: 255. Min: 175. Avg: 223.2 STD: 30.32

a) 1-second delay time

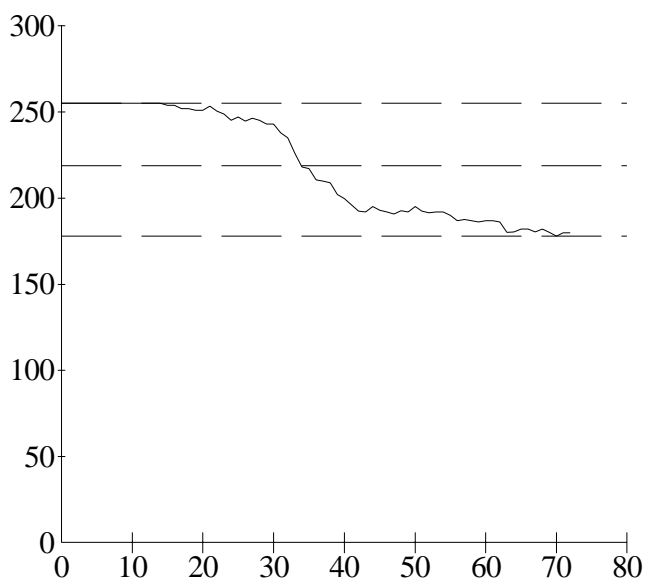

Max: 255. Min: 178. Avg: 218.8 STD: 30.55

c) 6-second delay time

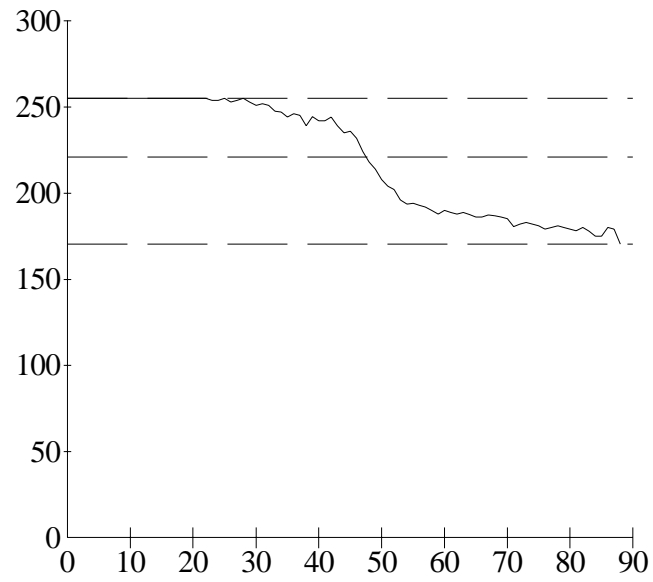

Max: 255. Min: 170.3 Avg:221.1 STD: 32.5

b) 3-second delay time

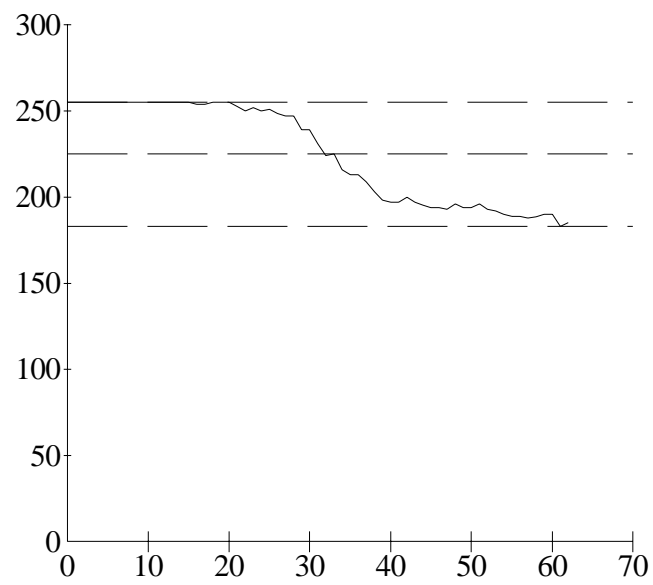

Max: 255. Min: 183. Avg:225.2 STD: 28.40 d) 9-second delay time

Figure 5.25 Thermal intensity profile along the line across the fatigue crack shown in Figure 5.24. 


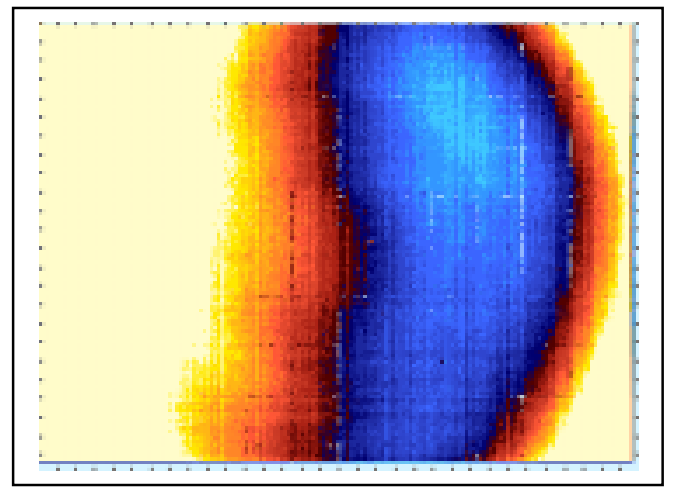

a) 1-second delay time

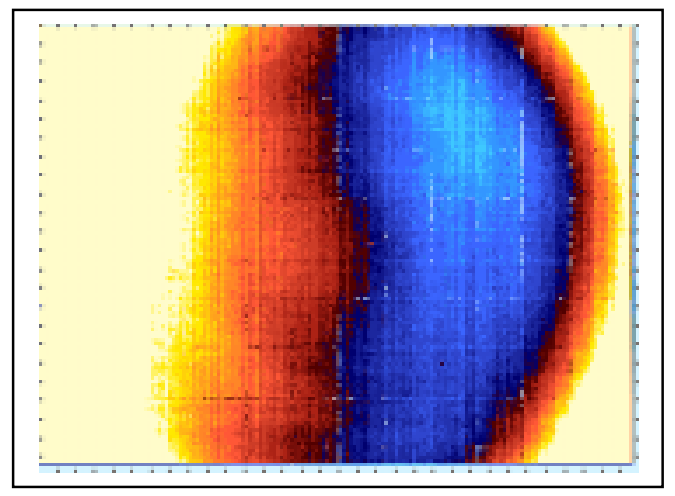

c) 6-second delay time

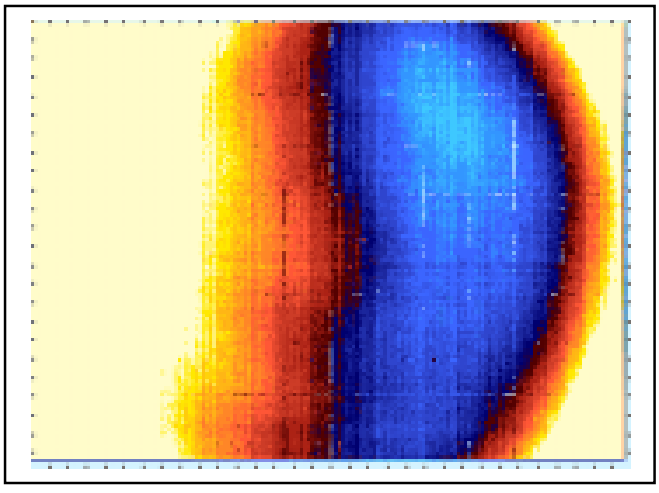

b) 3-second delay time

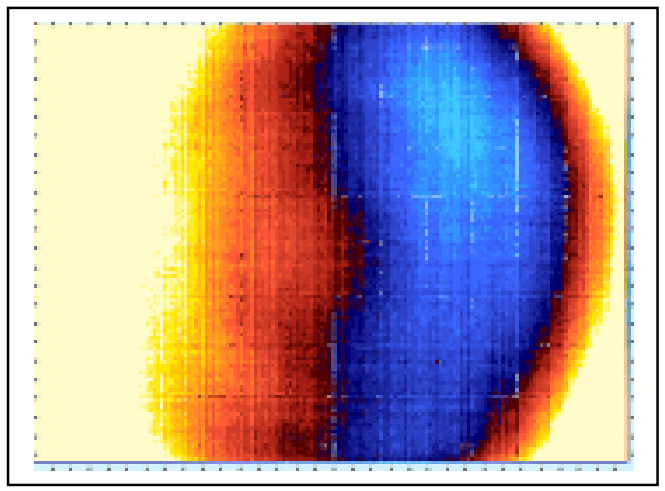

d) 9-second delay time

Figure 5.26 Thermal images of crack B (back side) with 120-second heating time. 


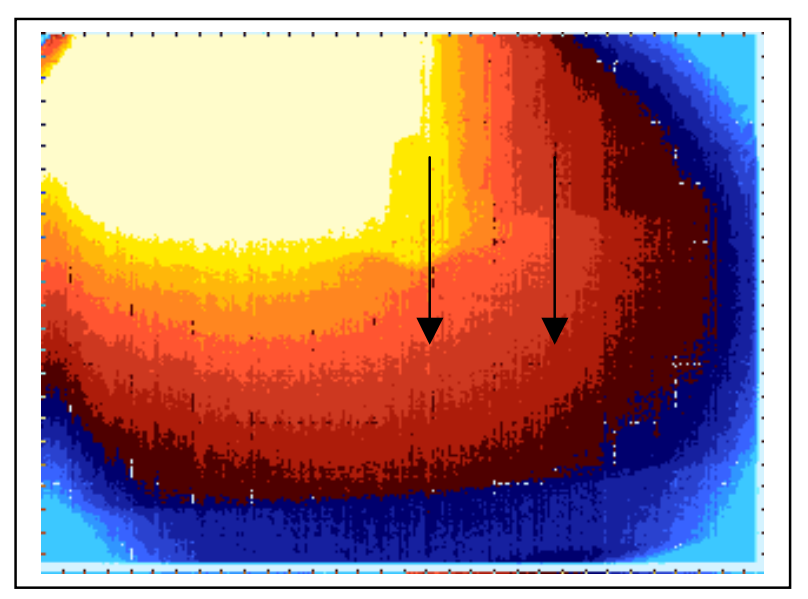

a) Thermal image

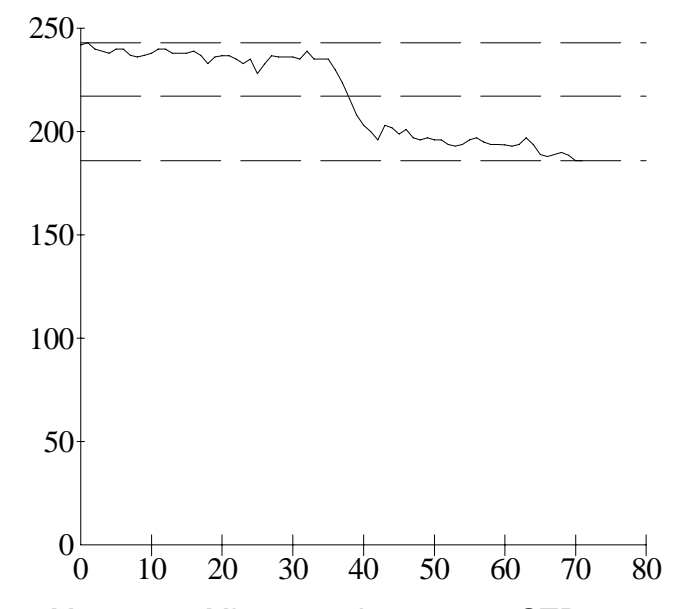

Max: 243. Min: 186. Avg: 217.2 STD: 20.88

b) Thermal profile from the left line

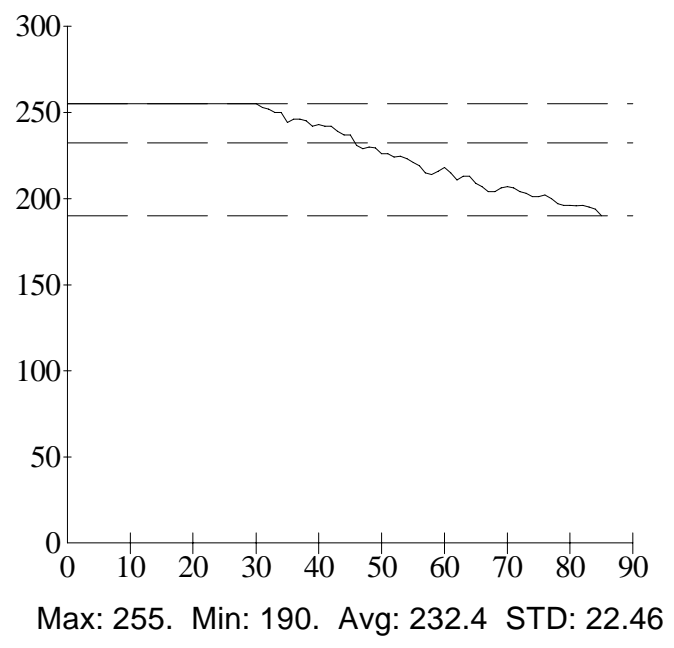

c) Thermal profile from the right line

Figure 5.27 Thermal images of crack C (detail side) with 90-second heating time and 1-second delay time. 


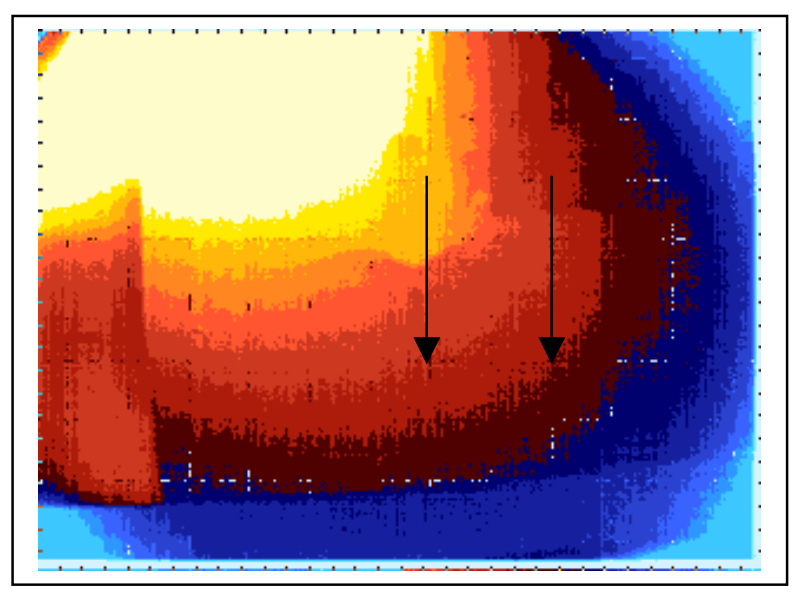

a) Thermal image
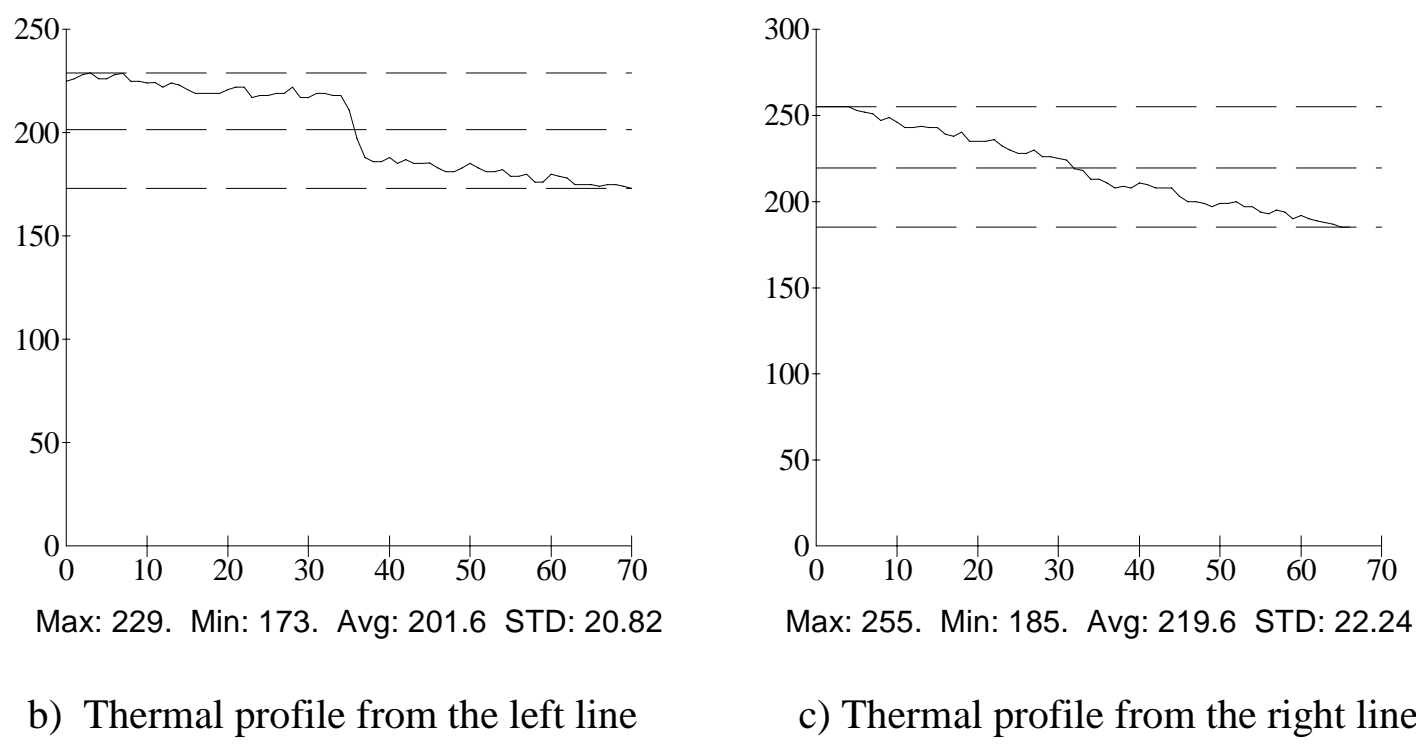

Max: 255. Min: 185. Avg:219.6 STD: 22.24

c) Thermal profile from the right line

Figure 5.28 Thermal images of crack C (detail side) with 90-second heating time and 3-second delay time. 


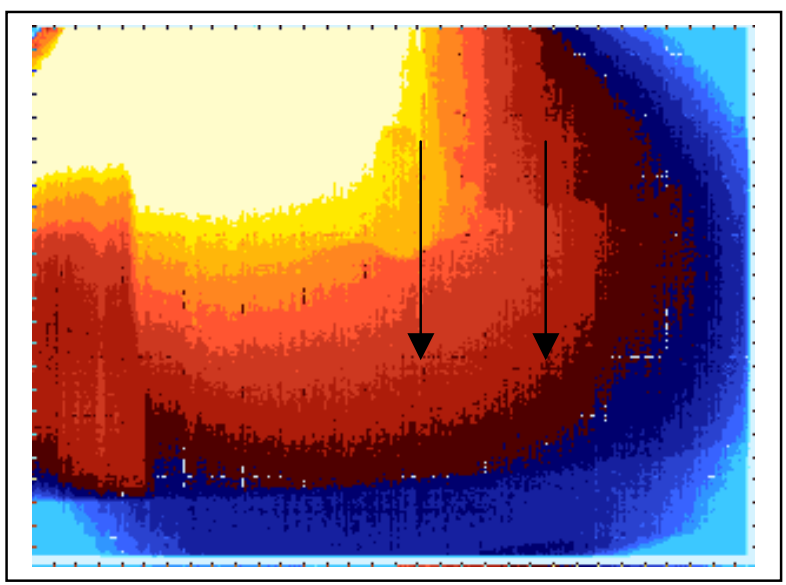

a) Thermal image
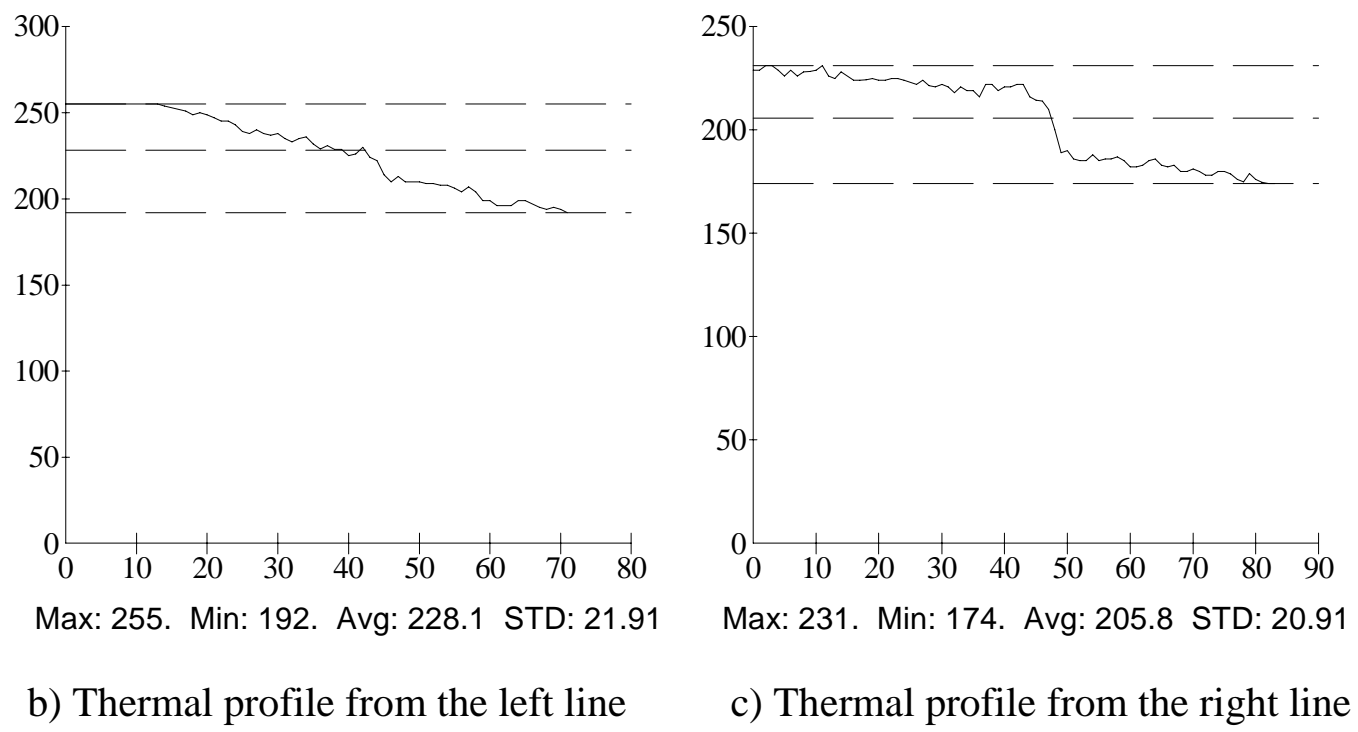

b) Thermal profile from the left line

Figure 5.29 Thermal images of crack C (detail side) with 90-second heating time and 6-second delay time. 


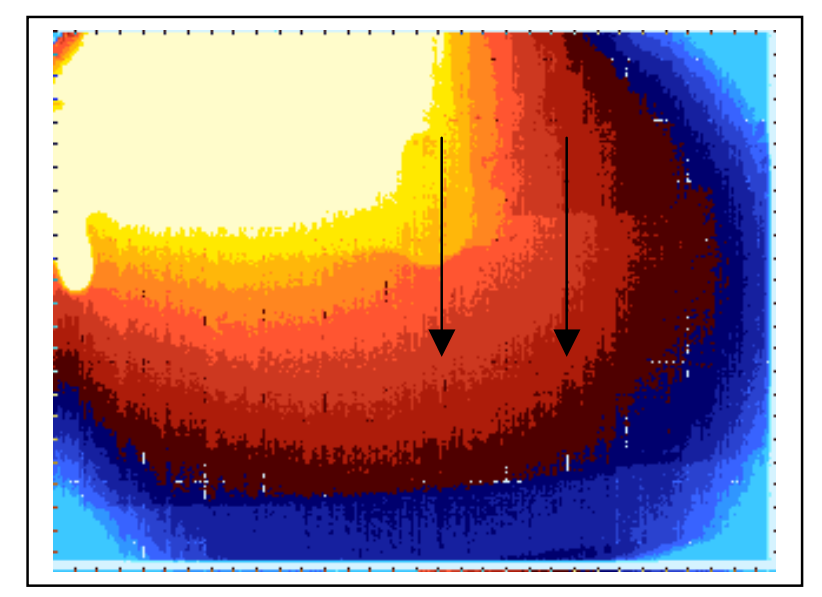

a) Thermal image

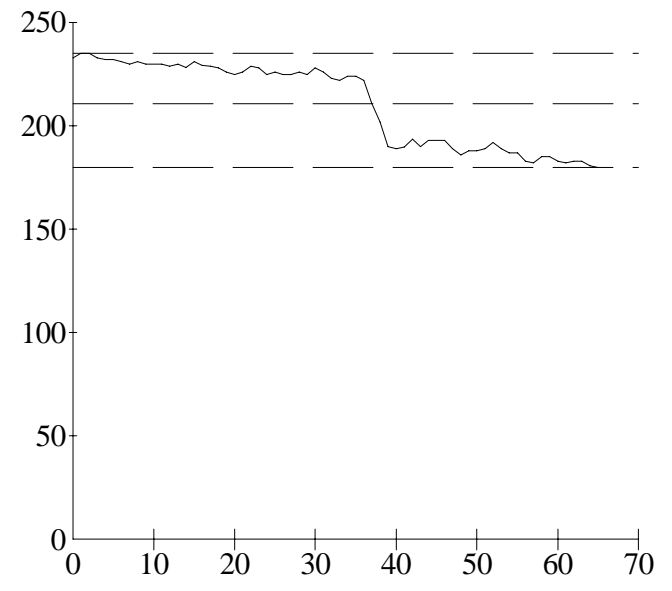

Max: 235. Min: 180. Avg:210.7 STD: 20.29

b) Thermal profile from the left line

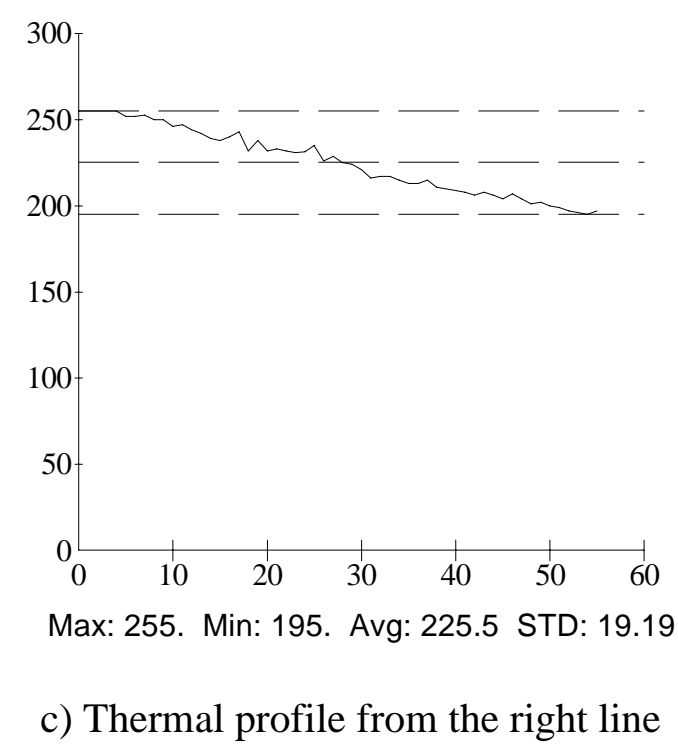

Figure 5.30 Thermal images of crack C (detail side) with 90-second heating time and 9-second delay time. 


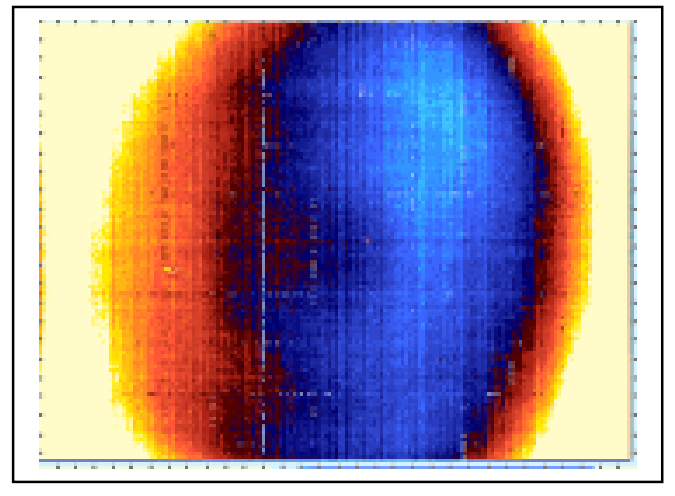

a) 1-second delay time

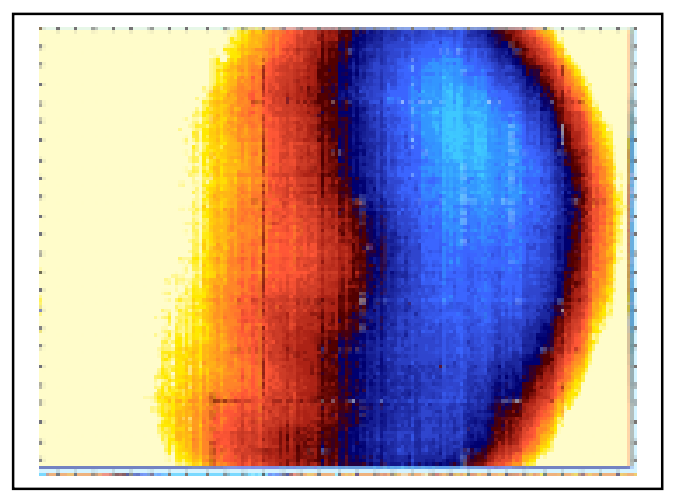

c) 6-second delay time

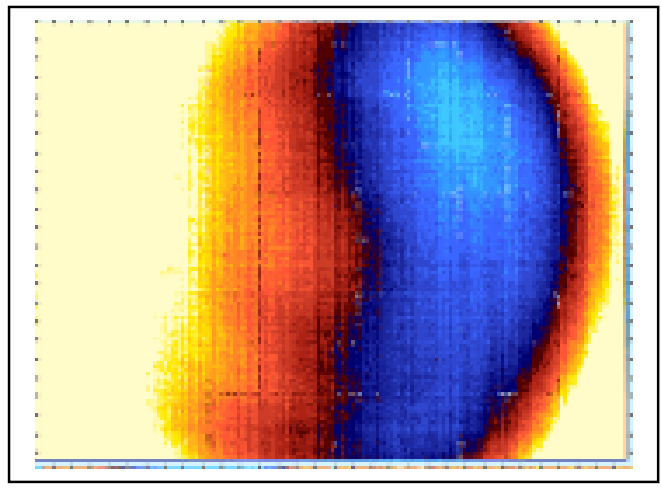

b) 3-second delay time

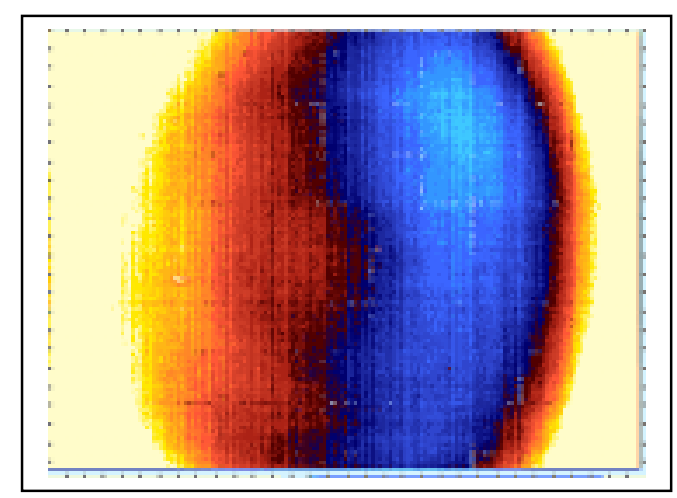

d) 9-second delay time

Figure 5.31 Thermal images of crack C (detail side) with 120-second heating time. 


\section{CHAPTER 6}

\section{CONCLUSION}

This study has evaluated the effectiveness and performance of an infrared sensor to detect the onset of fatigue cracking in steel bridge members. Based upon experimental observations of tests conducted in the laboratory using controlled specimens and tests performed in the field on a bridge structure in Indianapolis, a number of general trends were noted and some conclusions were formulated. Those observations are summarized in the following section.

\section{$\underline{6.1 \text { Effect of Critical Factors on IR Performance }}$}

A number of factors influence the inspection performance using IR system. Included among these factors are crack size, camera distance, applied stress magnitude, heating time and delay time, and the surface condition. Each of these factors is discussed.

\subsubsection{Crack Size}

1. The crack depth with respect to member thickness is an important factor affecting IR crack detection. For the passive approach, the different crack depths yield the different stress intensity factors 
although they are at the same length. For the active approach, regardless of crack length, the higher the ratio of crack depth to the member thickness, the more the heat flow is impeded, and the easier a crack can be detected.

2. A considerable drop in thermal intensity profile is evident only after a crack becomes through-thickness. A shallow crack generally can not be detected.

3. The smallest crack that can be detected by active or passive approach with the system used in this project is larger than the smallest crack size that can be detected by an unaided human eye.

\subsubsection{Distance from IR Camera to Specimen}

1. There is a limitation of the longest effective distance in both active and passive approaches. The longest effective distance of active approach is longer than the longest effective distance of passive approach for the same crack size.

2. A crack detected by the effects of the impeded heat flow (the effects from the emissivity) can be detected up to the distance longer than crack detected by the effects of the contrast reflection at cracked surface. In other words, the longest effective distance of active approach is longer than the longest effective distance of passive approach for the same crack size. 
3. Matte and glossy surfaces yield the same effective distance when performing a test under enclosed laboratory condition, but the effective distance from matte surface is significantly longer than that of glossy surface at the same crack length, heating time, and delay time when tested outdoors because of the disturbance from reflection.

\subsubsection{Applied Stress}

1. There is a minimum value of stress that makes crack detectable. A more elevated applied stress level makes crack more detectable.

2. The effect of the stress concentration due to crack is not distinguishable from the effects of the stress concentration due to the surrounding irregular geometry (rivet hole, weld, etc.) when applied stress is lower than the minimum value.

3. The minimum value of stress that makes crack detectable is often much higher than the service-level stress in a real structure. Consequently, the passive inspection approach is not a promising approach to use for crack detection in real structure.

6.1.4 Heating time and the delay time

1. The initial temperature and initial thermal distribution of the specimen significantly affects the active approach. If the initial temperature of the specimen is elevated relative to the calibration plate, the crack is difficult to detect when using the active approach. 
2. A minimum required heating time is needed to make a crack detectable. A crack can not be detected if the heating period is less than this minimum time.

3. For a through-thickness crack, a heating time longer than the minimum required heating time has no negative effect on an active approach IR crack detection. The ratio of the maximum thermal gradient at the crack to the average thermal gradient does not considerably change as heating time changes.

4. For a through-thickness crack, the longer the heating time, the higher the thermal contrast due to impeded heat flow.

5. For a through-thickness cracks, a crack generally can not be detected for any delay time if the heating time is less than the minimum required heating time. For a heating time longer than the minimum required period, then a variation in the delay time has no significant effects on the crack detection.

6. In case of very a shallow crack (a crack depth less than $50 \%$ of member thickness), the crack generally can not be detected. In the case of an intermediate depth crack (a crack that is not-throughthickness, but with more depth than $50 \%$ of the member thickness), the thermal image often produces a potential crack indication with a slower heat flow rate compared with that from the surrounding area.

7. For a partial-thickness crack or a crack on a non-plain surface, a combination of heating time and delay time has significant effects on the crack detection capability. 
8. A difference in the delay time leads to a difference in the maximum thermal gradient at crack. Moreover, an optimum delay time produces a maximum value of thermal gradient at the crack.

\subsubsection{The Surface Condition}

1. Surfaces painted with a matte color improve the quality of the thermal images and increases the longest effective camera distance. Painting with a matte color reduces the effects of surface reflection and other spurious signals coming from the non-uniform specimen surface.

2. Results from matte specimens are not significantly different from results from glossy specimens when tests are performed under the enclosed laboratory condition. However, the results from matte specimens are different from the results from glossy specimens when tests are performed under an outdoor condition. It is believed that the difference in the results observed for specimens with glossy surface and matte surface conditions are due to significant variations in the amount of light reflected by the two surfaces.

\section{$\underline{6.2 \text { Observations from The Field Test }}$}

1. The smallest crack detectable by IR camera in the field is larger than the smallest crack detectable by the unaided human eye. 
2. The results from the field test, similar to the results from laboratory, demonstrate that the crack depth is an important factor affecting crack detection.

3. Only through-thickness cracks can be detected clearly in the field by IR camera utilized in this study.

4. The surface and light conditions substantially affected the IR results. A heating time longer than that used in laboratory test was required to create a detectable thermal contrast. This was necessary due to the heat reflection and the elevated surface temperature of the girder web.

\section{$\underline{6.3 \text { Conclusions and Recommendations }}$}

1. It is difficult to find a unique set of optimum critical factor values, such as heating time, delay time, distance from IR camera to object, etc., for any particular testing environments. Many of the factors, such as the surface temperature of object, the power and pattern of heat source, the sensitivity of IR camera, the testing environmental are inter-related, and the interaction effects makes it very difficult to establish a unique set of optimum conditions.

2. The significant disadvantage evident of IR crack detection system used in this study is that it requires both physical space and time to calibrate properly before use. The calibration should be performed in an enclosed space that has as little light as possible, which is difficult to attain under field conditions. Therefore, the present IR crack detection system is not well suited for field use. The ideal system should be a 
portable unit combining heat source, IR camera, and computer together in one module.

3. The smallest crack size detectable by active or passive approach with the system used in this project is larger than the smallest crack size detectable by an unaided human eye.

4. In this project, the smallest crack detectable in laboratory and field condition is $1.25 \mathrm{~cm}$ and $70 \mathrm{~mm}$, respectively. However, the capability of detecting a small crack depends on the camera sensitivity. By improving the camera's sensitivity, smaller cracks can be detected.

5. The concept of crack detection by IR thermography approach is still believed to be viable for certain application. The results from this project prove cracks can be detected by the IR thermography approach. Portability of the equipment is a significant problem for field use. Also, it is believed that the performance of the IR system could be improved if the sensitivity of IR camera was increased. 


\section{LIST OF REFERENCES}

AASHTO LRFD Bridge Design Specifications, American Association of State Highway and Transportation Officials, First Edition, 1994.

A. F. Liu, Structural Life Assessment Methods, ASM International, 1998.

Anderson, T. L., Fracture Mechanics: Fundamentals and Applications, CRC Press, 1995.

Bannatine, J. A., Corner, J. J., and Handrock, J. L., Fundamentals of Metal Fatigue Analysis, Prentice Hall, 1990.

Barsom, J. M. and Rolfe, S. T., Fracture and Fatigue Control in Structures: Applications of Fracture Mechanics, Prentice-Hall, Inc., 1977.

Borek, D.R., Elementary Engineering Fracture Mechanics, $3^{\text {rd }}$ edition, Martinous Nijhoff Publishers, 1982.

Burleigh, Douglas D., Practical Aspects of Thermal nondestructive evaluation, Thermosense XVII, Orlando, D. Burleigh and J. Spicer, Editors, Proc. SPIE Vol. 2766, pp. 158-163, April, 1996.

Chen, John, Novel Applications of Thermal Imaging in the Steel Industry, Thermosense XVII, Orlando, Sharon A. Semanovich, Editor, Proc. SPIE Vol. 2473, pp. 289-294, April, 1995.

Cramer, K.E. and Winfree, W. P., Thermal Characterization of Defects in Aircraft Structures via Spatially Controlled Heat Application, Thermosense XVIII, Orlando, D. Burleigh and J. Spicer, Editors, Proc. SPIE Vol. 2766, pp. 202-217, April, 1996.

Cramer, K.E. and Winfree, W. P., Thermographic Imaging of Cracks in Thin Metal Sheets, Thermosense XIV, Orlando, D. Burleigh and J. Spicer, Editors, Proc. SPIE Vol. 1682, pp. 162-170, April, 1992.

Gibson, T. W., Seeing in the Dark, Invention and Technology, July 1998, pp.47-54.

Grover, Paul, Infrared can warn of impending disaster, National Engineer, V 99, n 4 April, 1995, pp. 27-30. 
Harwood, N. and Cummings, W. M., Thermoelastic stress analysis, Bristol-Hilger, 1991.

Hassan, A.F. and Bowman, M.D., Fatigue Strength of Tapered Partial-length Cover Plates, Ph.D. Thesis, School of Civil Engineering, Purdue University, 1996.

Hocking, Colin, Back to Basics, Infrared Equipment Technology, Technical Information, American Society of Non-Destructive Testing, September, 1997.

Hucker, S. A., A boundary element approach to thermoelastic crack problems, Master Thesis, School of Aeronautics and Astronautics, Purdue University, 1992.

Jonaz, Miroslaw, Using termography of nondestructive testing of materials, Sensor, v 12, October 1995, pp. 31-34.

Kennert R. White, John Minor, and Kenneth N. Derucer, Bridge Maintenance, Inspection, and Evaluation, Second Edition, Marecl Dekker, Inc., 1992.

Kovalenko, A. D., Thermoelasticity: Basic theory and applications, Groningen, WoltersNoordhoff, 1969.

Lesniak, J.R. and Boyce, B.R., Forced Diffusion Thermography, SPIE Nondestructive Inspection of Aging Aircraft, San Diego, Micheal T. Valley, Nancy K. Del Grande and Albert S. Kobayashi, Editors, Proc. SPIE Vol. 1682, PP. 222-233, 1992.

Lesniak, J. R. and Boyce, B. R., Differential Thermography Applied to Structural Intergrity Assesment, Thermosense XVII, Orlando, Sharon A. Semanovich, Editor, Proc. SPIE Vol. 2473, pp. 179-189, April, 1995.

Lesniak, J. R. and Bazile, D.J., Forced-Diffusion Thermography Technique and Projector Design. Thermosense XIV, Orlando, D. Burleigh and J. Spicer, Editors, Proc. SPIE Vol. 2766, pp. 210-217, April, 1996.

Lesniak, J. R. and Bazile, D.J., Structural Integrity Assessment via Coating Tolerant Forced Diffusion Thermography, SPIE Aging Infrastructure Conference, Pheonix, December, 1996.

Lesniak, J. R. and Bazile, D.J., Structural Integrity Assessment via Coating Tolerant Forced Diffusion Thermography, ASCE Structural Congress XV, Portland, Leon Kemper, Jr. and Colin A. Brown, Editors, pp. 924-928, April 1997.

Lesniak, J. R. and Bazile, D.J., Theory and application of thermography, Thermosense XX, Orlando, D. Burleigh and J. Spicer, Editors, Proc. SPIE Vol. 2775, pp. 155-162, April, 1998. 
Luong, M. P., Infrared thermography for fatigue in metals, Thermosense XIV, Orlando, K. Eklund, Editor, Proc. SPIE Vol. 1682, pp. 222-233, Jan., 1992.

Maser, K. R., Roddis, T. J., and W. M. Kim., Principle of thermography and radar for bridge deck assessment. Journal of Transportation ngineering, Vol 116, Sep-Oct 1990, pp. 583-601.

Munse, W. H. and Grover, La Motte., Fatigue of Welded Steel Structures, Welding Research Council, 1964.

Murakami, Y., Stress Intensity Factors Handbook, Pergamon Press, 1987.

Peterson, R. E., Stress Concentration Factors, Wiley, 1974.

StressPhotonics, Inc., Reference Manual for DeltaTherm Software, DeltaTherm Software package, Nov., 1999.

Schijive, Johnson, Fatigue Crack Growth Under Variable-Amplitude Loading, ASM Handbook, Vol. 19, Fatigue and Fracture, 1996, pp. 110-133.

Standard Specifications for Highway Bridges, American Association of State Highway and Transportation Officials, Twelfth Edition, 1977.

Sung H. Park, Bridge Rehabilitation and Replacement, John Wiley \& Sons, Inc., 1993.

Surich, S., Fatigue of Materials, Cambridge University Press, 1991.

Tada, G., Paris, P., and Irwin, G., The Stress Analysis of Cracks Handbook, Del Research Corporation, Hellertown, PA, 1973. 
APPENDICES 


\section{APPENDIX A \\ LABORATORY EXPERIMENTAL RESULTS}

\section{A.1 Experimental Results from CH Test Series}

The experimental results from $\mathrm{CH}$ test series are summarized in Tables A.1 to A.5. The following notations are used in all tables.

$$
\begin{aligned}
\mathrm{D}= & \text { crack could be detected with IR camera } \\
\mathrm{ND}= & \text { crack could not be detected with IR camera } \\
\mathrm{X}= & \text { the experiment was not performed because a crack could not be } \\
& \text { detected } 15 \mathrm{~cm} \text { or more from specimen surface. }
\end{aligned}
$$

Significant thermal images from both passive and active approaches are shown in the following tables and figures. The surface condition, testing condition, and camera distance are described for each specimen. If there is no additional description, the specimen is at $15 \mathrm{~cm}$ from IR camera, painted with black matte color, and tested under the enclosed laboratory conditions. The presentation of the results is noted below.

\section{The effects of applied stress}

The results from Specimens $\mathrm{CH}-2$ and $\mathrm{CH}-3$ are illustrated in Figure A.1 to Figure A.8. 
The effects of distance from the IR camera to the specimen using the passive approach

The results from Specimen $\mathrm{CH}-1$ are illustrated in Figure A.9 to Figure A.10. The results from Specimen CH-2 are illustrated in Figure A.11 to Figure A.12. And the results from Specimen CH-3 are illustrated in Figure A.13 to Figure A.16.

The effects of heating time and delay time

The results from Specimen CH-1 are illustrated in Figure A.17 to Figure A.24. The results from Specimen CH-2 are illustrated in Figure A.25 to Figure A.40. And the results from Specimen CH-3 are illustrated in Figure A.41 to Figure A.84.

The effects of the distance from the IR camera to the specimen using the active approach

The results from Specimen CH-1 are illustrated in Figure A.85 to Figure A.114. The results from Specimen CH-2 are illustrated in Figure A.115 to Figure A.122. And the results from Specimen CH-3 are illustrated in Figure A.123 to Figure A.156.

The effects of initial surface temperature on the active approach

The results are illustrated in Figure A.157 to Figure A.167.

The results from Coating Tolerance Thermography approach

The results are illustrated in Figure A.168 to Figure A.173. 


\section{A.2 Experimental Results from WD Test Series}

The experimental results from the WD test series are summarized in Tables A.6 to A.9. Only top-heated thermal images are presented, because cracking could not be detected from a bottom-heated thermal image, due to limitations on IR camera positioning. The following notation is used in all tables.

$\mathrm{D} \quad=$ crack could be detected with IR camera

$\mathrm{ND}=$ crack could not be detected with IR camera

$\mathrm{X}=$ the experiment was not performed because crack could not be detected at $15 \mathrm{~cm}$ or more from the specimen surface.

The surface condition, testing condition, and camera distance are described for each specimen. If there is no additional description, the specimen surface is located $15 \mathrm{~cm}$ from the IR camera, painted with black matte color, and tested under enclosed laboratory conditions. Specimen gripping was adjusted to position the cracks in Specimen WD-1, WD-2, WD-3, and WD-4 at the bottom side of the welded plate for convenience in capturing the thermal images. Consequently, cracks in the thermal images appear in a different positions from the cracks shown in Chapter 3.

The effects of heating time and delay time

The results from Specimen WD-1 are illustrated in Figure A.174 to Figure A.197. The results from Specimen WD-2 are illustrated in Figure A.198 to Figure A.210. The results from Specimen WD-3 are illustrated in Figure A.211 to Figure A.228, and the results from Specimen WD-4 are illustrated in Figure A.229 to Figure A.246. 
The effects of the distance from the IR camera to the specimen

The results from Specimens WD-1, WD-2, WD-3, and WD-4 are illustrated in Figure A.247 to Figure A.252. Only the 1-second-delay-time results are presented because there was no significant difference observed between the results with various (different) delay times. 
Table A.1 The passive approach results from Specimen $\mathrm{CH}-2$

\begin{tabular}{|c|c|c|c|c|c|c|c|c|c|}
\hline \multirow{2}{*}{$\begin{array}{l}\text { Visible crack length (mm.) } \\
\text { and number of loading } \\
\text { cycles }\end{array}$} & \multirow[t]{2}{*}{$\begin{array}{c}\text { Types of } \\
\text { investigation }\end{array}$} & \multirow{2}{*}{$\begin{array}{l}\text { Distance from } \\
\text { IR camera to } \\
\text { test specimen } \\
\quad(\mathrm{mm} .)\end{array}$} & \multicolumn{6}{|c|}{$\begin{array}{l}\text { Stress } \\
(\mathrm{MPa})\end{array}$} & \multirow[t]{2}{*}{ Figure } \\
\hline & & & 0 & 144.8 & 165.5 & 186.2 & 206.9 & 227.5 & \\
\hline \multirow{4}{*}{$\begin{array}{l}3.2 \mathrm{~mm} \text { @ } 500,000 \text { cycles } \\
\text { (initial surface temperature } \\
=32.1^{\circ} \mathrm{C} \text { ) }\end{array}$} & \multirow[t]{4}{*}{$\begin{array}{c}\text { Passive approach } \\
\text { (unpainted specimen) }\end{array}$} & 150 & $\mathrm{D}$ & $\mathrm{D}$ & $\mathrm{D}$ & ND & ND & ND & $\begin{array}{l}\text { A.1 - } \\
\text { A. } 2\end{array}$ \\
\hline & & 225 & ND & ND & ND & $X$ & $X$ & $X$ & \multirow[t]{3}{*}{$\begin{array}{l}\text { A.11 - } \\
\text { A.12 }\end{array}$} \\
\hline & & 300 & ND & ND & ND & $X$ & $X$ & $X$ & \\
\hline & & 375 & ND & ND & ND & $X$ & $X$ & $X$ & \\
\hline \multirow{2}{*}{$\begin{array}{c}3.2 \mathrm{~mm} \text {. } @ 500,000 \text { cycles } \\
\text { (initial surface temperature } \\
=32.4^{\circ} \mathrm{C} \text { ) }\end{array}$} & \multirow{2}{*}{$\begin{array}{l}\text { Passive approach } \\
\text { (specimen was } \\
\text { painted with } \\
\text { black matte color) }\end{array}$} & 150 & ND & ND & ND & ND & ND & ND & A. 3 \\
\hline & & $\begin{array}{c}\text { Not shorter than } \\
225\end{array}$ & $X$ & $X$ & $X$ & $X$ & $X$ & $X$ & $X$ \\
\hline
\end{tabular}


Table A.2 The passive approach results from Specimen CH-3

\begin{tabular}{|c|c|c|c|c|c|c|c|c|c|}
\hline \multirow{2}{*}{$\begin{array}{l}\text { Visible crack length }(\mathrm{cm} .) \\
\text { and number of loading } \\
\text { cycles }\end{array}$} & \multirow[t]{2}{*}{$\begin{array}{c}\text { Types of } \\
\text { investigation }\end{array}$} & \multirow{2}{*}{$\begin{array}{l}\text { Distance from } \\
\text { IR camera to } \\
\text { test specimen } \\
\quad(\mathrm{mm} .)\end{array}$} & \multicolumn{6}{|c|}{$\begin{array}{l}\text { Stress } \\
(\mathrm{MPa})\end{array}$} & \multirow[t]{2}{*}{ Figure } \\
\hline & & & 34.5 & 68.9 & 103.4 & 137.9 & 172.5 & 207 & \\
\hline \multirow{4}{*}{$\begin{array}{c}\text { Crack length was less } \\
\text { than } 2.1 \mathrm{~mm} \text { and } \\
\text { number of loading } \\
\text { cycles were less } \\
\text { than } 475,000 \text { cycles } \\
\text { (inspect @ } \\
\text { every } 25,000 \text { cycles) } \\
\text { (initial surface temperature } \\
=29.3^{\circ} \mathrm{C} \text { ) }\end{array}$} & \multirow[t]{4}{*}{$\begin{array}{c}\text { Passive approach } \\
\text { (unpainted specimen) }\end{array}$} & 150 & ND & ND & ND & ND & ND & ND & $\begin{array}{l}\text { A. } 4- \\
\text { A. } 5\end{array}$ \\
\hline & & 225 & $\mathrm{X}$ & $\mathrm{X}$ & $X$ & $\mathrm{X}$ & $\mathrm{X}$ & $\mathrm{X}$ & \multirow[t]{3}{*}{$\mathrm{X}$} \\
\hline & & 300 & $\mathrm{X}$ & $\mathrm{X}$ & $\mathrm{X}$ & $\mathrm{X}$ & $X$ & $\mathrm{X}$ & \\
\hline & & 375 & $\mathrm{X}$ & $X$ & $X$ & $\mathrm{X}$ & $X$ & $X$ & \\
\hline \multirow{4}{*}{$\begin{array}{c}3.1 \mathrm{~mm} \text {. @ 500,000 cycles } \\
\left.=29.5^{\circ} \mathrm{C}\right)\end{array}$} & \multirow{4}{*}{$\begin{array}{c}\text { Passive approach } \\
\text { (unpainted specimen) }\end{array}$} & 150 & ND & ND & ND & $\mathrm{D}$ & $\mathrm{D}$ & $\mathrm{D}$ & \multirow[t]{4}{*}{ A.6-A.7 } \\
\hline & & 225 & $\mathrm{X}$ & $X$ & $\mathrm{X}$ & ND & ND & ND & \\
\hline & & 300 & $\mathrm{X}$ & $\mathrm{X}$ & $\mathrm{X}$ & ND & ND & ND & \\
\hline & & 375 & $X$ & $X$ & $X$ & ND & ND & ND & \\
\hline
\end{tabular}


Table A.2 (continued) The passive approach results from Specimen CH-3

\begin{tabular}{|c|c|c|c|c|c|c|c|c|c|}
\hline \multirow{2}{*}{$\begin{array}{c}\text { Visible crack length (mm.) } \\
\text { and number of loading } \\
\text { cycles }\end{array}$} & \multirow[t]{2}{*}{$\begin{array}{c}\text { Types of } \\
\text { investigation }\end{array}$} & \multirow{2}{*}{$\begin{array}{l}\text { Distance from } \\
\text { IR camera to } \\
\text { test specimen } \\
\quad(\mathrm{mm} .)\end{array}$} & \multicolumn{6}{|c|}{$\begin{array}{l}\text { Stress } \\
(\mathrm{MPa})\end{array}$} & \multirow[t]{2}{*}{ Figure } \\
\hline & & & 34.5 & 68.9 & 103.4 & 137.9 & 172.5 & 207 & \\
\hline \multirow{4}{*}{$\begin{array}{c}6.8 \mathrm{~mm} \text { @ } 525,000 \text { cycles } \\
\text { (initial surface temperature } \\
=29.9^{\circ} \mathrm{C} \text { ) }\end{array}$} & \multirow{4}{*}{$\begin{array}{c}\text { Passive approach } \\
\text { (unpainted specimen) }\end{array}$} & 150 & ND & ND & ND & $\mathrm{D}$ & $\mathrm{D}$ & $\mathrm{D}$ & \multirow[t]{4}{*}{$\begin{array}{c}\text { Not } \\
\text { shown }\end{array}$} \\
\hline & & 225 & $\mathrm{X}$ & $\bar{X}$ & $\mathrm{X}$ & ND & ND & ND & \\
\hline & & 300 & $\mathrm{X}$ & $\mathrm{X}$ & $\mathrm{X}$ & ND & ND & ND & \\
\hline & & 375 & $\mathrm{X}$ & $\mathrm{X}$ & $\mathrm{X}$ & ND & ND & ND & \\
\hline \multirow{4}{*}{$\begin{array}{c}11.1 \mathrm{~mm} . @ 550,000 \text { cycles } \\
\text { (initial surface temperature } \\
=30.3^{\circ} \mathrm{C} \text { ) }\end{array}$} & \multirow{4}{*}{$\begin{array}{c}\text { Passive approach } \\
\text { (unpainted specimen) }\end{array}$} & 150 & ND & ND & ND & $\mathrm{D}$ & $\mathrm{D}$ & $\mathrm{D}$ & \multirow{4}{*}{$\begin{array}{l}\text { Not showr } \\
\text { A.13-A.14 }\end{array}$} \\
\hline & & 225 & $\bar{X}$ & $X$ & $X$ & ND & $\mathrm{D}$ & $\mathrm{D}$ & \\
\hline & & 300 & $\mathrm{X}$ & $\mathrm{X}$ & $\mathrm{X}$ & ND & $\mathrm{ND}$ & ND & \\
\hline & & 375 & $\mathrm{X}$ & $\mathrm{X}$ & $\mathrm{X}$ & ND & ND & ND & \\
\hline
\end{tabular}


Table A.2 (continued) The passive approach results from Specimen CH-3

\begin{tabular}{|c|c|c|c|c|c|c|c|c|c|}
\hline \multirow{2}{*}{$\begin{array}{c}\text { Visible crack length (mm.) } \\
\text { and number of loading } \\
\text { cycles }\end{array}$} & \multirow[t]{2}{*}{$\begin{array}{c}\text { Types of } \\
\text { investigation }\end{array}$} & \multirow{2}{*}{$\begin{array}{l}\text { Distance from } \\
\text { IR camera to } \\
\text { test specimen } \\
(\mathrm{mm} .)\end{array}$} & \multicolumn{6}{|c|}{$\begin{array}{l}\text { Stress } \\
(\mathrm{MPa})\end{array}$} & \multirow[t]{2}{*}{ Figure } \\
\hline & & & 34.5 & 68.9 & 103.4 & 137.9 & 172.5 & 207 & \\
\hline \multirow{4}{*}{$\begin{array}{c}18.2 \mathrm{~mm} \text { @ } 575,000 \text { cycles } \\
\text { (initial surface temperature } \\
=29.5^{\circ} \mathrm{C} \text { ) }\end{array}$} & \multirow{4}{*}{$\begin{array}{c}\text { Passive approach } \\
\text { (unpainted specimen) }\end{array}$} & 150 & ND & ND & ND & $\mathrm{D}$ & $\mathrm{D}$ & D & \multirow[t]{4}{*}{$\begin{array}{c}\text { Not } \\
\text { shown }\end{array}$} \\
\hline & & 225 & X & $X$ & X & ND & D & D & \\
\hline & & 300 & $X$ & $X$ & $\mathrm{X}$ & ND & ND & $\mathrm{ND}$ & \\
\hline & & 375 & $\mathrm{X}$ & $\mathrm{X}$ & $\mathrm{X}$ & ND & ND & $\mathrm{ND}$ & \\
\hline
\end{tabular}


Table A.2 (continued) The passive approach results from Specimen CH-3

\begin{tabular}{|c|c|c|c|c|c|c|c|c|c|}
\hline \multirow{2}{*}{$\begin{array}{c}\text { Visible crack length (mm.) } \\
\text { and number of loading } \\
\text { cycles }\end{array}$} & \multirow[t]{2}{*}{$\begin{array}{c}\text { Types of } \\
\text { investigation }\end{array}$} & \multirow{2}{*}{$\begin{array}{l}\text { Distance from } \\
\text { IR camera to } \\
\text { test specimen } \\
\quad(\mathrm{mm} .)\end{array}$} & \multicolumn{6}{|c|}{$\begin{array}{l}\text { Stress } \\
(\mathrm{MPa})\end{array}$} & \multirow[t]{2}{*}{ Figure } \\
\hline & & & 34.5 & 68.9 & 103.4 & 137.9 & 172.5 & 207 & \\
\hline \multirow{4}{*}{$\begin{array}{c}\text { Crack length was less } \\
\text { than } 3 \mathrm{~mm} \text { and } \\
\text { number of loading } \\
\text { cycles were less } \\
\text { than } 475,000 \text { cycles } \\
\text { (inspect @ } \\
\text { every } 25,000 \text { cycles) } \\
\text { (initial surface temperature } \\
=29.7^{\circ} \mathrm{C} \text { ) }\end{array}$} & \multirow{4}{*}{$\begin{array}{l}\text { Passive approach } \\
\text { (specimen was } \\
\text { painted with } \\
\text { black matte color) }\end{array}$} & 150 & ND & ND & ND & ND & ND & ND & \multirow[t]{4}{*}{$\begin{array}{c}\text { Not } \\
\text { shown }\end{array}$} \\
\hline & & 225 & $\mathrm{X}$ & $\mathrm{X}$ & $\mathrm{X}$ & $\mathrm{X}$ & $\mathrm{X}$ & $\mathrm{X}$ & \\
\hline & & 300 & $\mathrm{X}$ & $\mathrm{X}$ & $\mathrm{X}$ & $\mathrm{X}$ & $\mathrm{X}$ & $X$ & \\
\hline & & 375 & $\mathrm{X}$ & $\mathrm{X}$ & $\mathrm{X}$ & $\mathrm{X}$ & $\mathrm{X}$ & $\mathrm{X}$ & \\
\hline \multirow{4}{*}{$\begin{array}{c}3.1 \mathrm{~mm} \text {. @ 500,000 cycles } \\
\text { (initial surface temperature } \\
=29.5^{\circ} \mathrm{C} \text { ) }\end{array}$} & \multirow{4}{*}{$\begin{array}{l}\text { Passive approach } \\
\text { (specimen was } \\
\text { painted with } \\
\text { black matte color) }\end{array}$} & 150 & ND & ND & ND & $\mathrm{D}$ & $\mathrm{D}$ & $\mathrm{D}$ & \multirow[t]{4}{*}{ Not shown } \\
\hline & & 225 & $\mathrm{X}$ & $\mathrm{X}$ & $\mathrm{X}$ & ND & ND & ND & \\
\hline & & 300 & $\mathrm{X}$ & $\mathrm{X}$ & $\mathrm{X}$ & ND & ND & ND & \\
\hline & & 375 & $\mathrm{X}$ & $\mathrm{X}$ & $\mathrm{X}$ & $\mathrm{ND}$ & ND & ND & \\
\hline
\end{tabular}


Table A.2 (continued) The passive approach results from Specimen $\mathrm{CH}-3$

\begin{tabular}{|c|c|c|c|c|c|c|c|c|c|}
\hline \multirow{2}{*}{$\begin{array}{l}\text { Visible crack length (mm.) } \\
\text { and number of loading } \\
\text { cycles }\end{array}$} & \multirow[t]{2}{*}{$\begin{array}{c}\text { Types of } \\
\text { investigation }\end{array}$} & \multirow{2}{*}{$\begin{array}{l}\text { Distance from } \\
\text { IR camera to } \\
\text { test specimen } \\
(\mathrm{mm} .)\end{array}$} & \multicolumn{6}{|c|}{$\begin{array}{l}\text { Stress } \\
(\mathrm{MPa})\end{array}$} & \multirow[t]{2}{*}{ Figure } \\
\hline & & & 34.5 & 68.9 & 103.4 & 137.9 & 172.5 & 207 & \\
\hline \multirow{4}{*}{$\begin{array}{c}6.8 \mathrm{~mm} \text {. } @ 525,000 \text { cycles } \\
\text { initial surface temperature } \\
\left.=28.3{ }^{\circ} \mathrm{C}\right)\end{array}$} & \multirow{4}{*}{$\begin{array}{l}\text { Passive approach } \\
\text { (specimen was } \\
\text { painted with } \\
\text { black matte color) }\end{array}$} & 150 & ND & ND & ND & $\mathrm{D}$ & $\mathrm{D}$ & $\mathrm{D}$ & \multirow[t]{4}{*}{$\begin{array}{c}\text { Not } \\
\text { shown }\end{array}$} \\
\hline & & 225 & $\mathrm{X}$ & $\mathrm{X}$ & $\mathrm{X}$ & ND & ND & ND & \\
\hline & & 300 & $\mathrm{X}$ & $\mathrm{X}$ & $\mathrm{X}$ & ND & ND & ND & \\
\hline & & 375 & $\mathrm{X}$ & $\mathrm{X}$ & $\mathrm{X}$ & ND & ND & ND & \\
\hline \multirow{4}{*}{$\begin{array}{c}11.1 \mathrm{~mm} . @ 550,000 \text { cycles } \\
\text { (initial surface temperature } \\
=29.8^{\circ} \mathrm{C} \text { ) }\end{array}$} & \multirow{4}{*}{$\begin{array}{l}\text { Passive approach } \\
\text { (specimen was } \\
\text { painted with } \\
\text { black matte color) }\end{array}$} & 150 & ND & ND & ND & $\mathrm{D}$ & $\mathrm{D}$ & $\mathrm{D}$ & A. 8 \\
\hline & & 225 & $\mathrm{X}$ & $X$ & $\mathrm{X}$ & ND & $\mathrm{D}$ & $\mathrm{D}$ & \multirow[t]{3}{*}{$\begin{array}{l}\text { A.15- } \\
\text { A.16 }\end{array}$} \\
\hline & & 300 & $\mathrm{X}$ & $X$ & $X$ & ND & ND & ND & \\
\hline & & 375 & $\mathrm{X}$ & $X$ & $X$ & ND & ND & ND & \\
\hline
\end{tabular}


Table A.2 (continued) The passive approach results from Specimen CH-3

\begin{tabular}{|c|c|c|c|c|c|c|c|c|c|}
\hline \multirow{2}{*}{$\begin{array}{l}\text { Visible crack length }(\mathrm{cm} .) \\
\text { and number of loading } \\
\text { cycles }\end{array}$} & \multirow[t]{2}{*}{$\begin{array}{c}\text { Types of } \\
\text { investigation }\end{array}$} & \multirow{2}{*}{$\begin{array}{l}\text { Distance from } \\
\text { IR camera to } \\
\text { test specimen } \\
\quad(\mathrm{mm} .)\end{array}$} & \multicolumn{6}{|c|}{$\begin{array}{l}\text { Stress } \\
(\mathrm{MPa})\end{array}$} & \multirow[t]{2}{*}{ Figure } \\
\hline & & & 34.5 & 68.9 & 103.4 & 137.9 & 172.5 & 207 & \\
\hline \multirow{4}{*}{$\begin{array}{c}18.2 \mathrm{~mm} \text {. } @ 575,000 \text { cycles } \\
\text { (initial surface temperature } \\
=29.8^{\circ} \mathrm{C} \text { ) }\end{array}$} & \multirow{4}{*}{$\begin{array}{l}\text { Passive approach } \\
\text { (specimen was } \\
\text { painted with } \\
\text { black matte color) }\end{array}$} & 150 & ND & ND & ND & $\mathrm{D}$ & $\mathrm{D}$ & $\mathrm{D}$ & \multirow[t]{4}{*}{$\begin{array}{c}\text { Not } \\
\text { shown }\end{array}$} \\
\hline & & 225 & $\mathrm{X}$ & $\mathrm{X}$ & $\mathrm{X}$ & ND & $\mathrm{D}$ & $\mathrm{D}$ & \\
\hline & & 300 & $\mathrm{X}$ & $\mathrm{X}$ & $\mathrm{X}$ & ND & ND & ND & \\
\hline & & 375 & $\mathrm{X}$ & $\mathrm{X}$ & $\mathrm{X}$ & ND & ND & ND & \\
\hline
\end{tabular}


Table A.3 The active approach results from Specimen $\mathrm{CH}-1$

\begin{tabular}{|c|c|c|c|c|c|c|c|c|}
\hline \multirow{2}{*}{$\begin{array}{l}\text { Visible crack length (mm.) } \\
\text { and number of loading } \\
\text { cycles }\end{array}$} & \multirow[t]{2}{*}{$\begin{array}{c}\text { Types of } \\
\text { investigation }\end{array}$} & \multirow{2}{*}{$\begin{array}{l}\text { Distance from } \\
\text { IR camera to } \\
\text { test specimen } \\
\quad(\mathrm{mm} .)\end{array}$} & \multirow{2}{*}{$\begin{array}{l}\text { Heating } \\
\text { time } \\
\text { (second) }\end{array}$} & \multicolumn{4}{|c|}{$\begin{array}{l}\text { Delay } \\
\text { Time } \\
\text { (second) }\end{array}$} & \multirow[t]{2}{*}{ Figure } \\
\hline & & & & 1 & 3 & 6 & 9 & \\
\hline \multirow{16}{*}{$\begin{array}{c}18.2 \mathrm{~mm} . @ 700,000 \\
\text { (initial surface temperature } \\
=24.8^{\circ} \mathrm{C} \text { ) }\end{array}$} & \multirow{16}{*}{$\begin{array}{c}\text { Active approach } \\
\text { (specimen was } \\
\text { painted with black } \\
\text { matte color) }\end{array}$} & \multirow{4}{*}{150} & 30 & $\mathrm{D}$ & $\mathrm{D}$ & $\mathrm{D}$ & $\mathrm{D}$ & \multirow{4}{*}{$\begin{array}{c}\text { A. } 17 \text { - } \\
\text { A. } 24\end{array}$} \\
\hline & & & 60 & $\mathrm{D}$ & $\mathrm{D}$ & $\mathrm{D}$ & $\mathrm{D}$ & \\
\hline & & & 90 & $\mathrm{D}$ & $\mathrm{D}$ & $\mathrm{D}$ & $\mathrm{D}$ & \\
\hline & & & 120 & $\mathrm{D}$ & $\mathrm{D}$ & $\mathrm{D}$ & $\mathrm{D}$ & \\
\hline & & 225 & 30 & $\mathrm{D}$ & $\mathrm{D}$ & $\mathrm{D}$ & $\mathrm{D}$ & \multirow{12}{*}{$\begin{array}{l}\text { A. } 95 \\
\text { A. } 114\end{array}$} \\
\hline & & 300 & 30 & $\mathrm{D}$ & $\mathrm{D}$ & $\mathrm{D}$ & $\mathrm{D}$ & \\
\hline & & 375 & 30 & $\mathrm{D}$ & $\mathrm{D}$ & $\mathrm{D}$ & $\mathrm{D}$ & \\
\hline & & 450 & 30 & $\mathrm{D}$ & $\mathrm{D}$ & $\mathrm{D}$ & $\mathrm{D}$ & \\
\hline & & 525 & 30 & $\mathrm{D}$ & $\mathrm{D}$ & $\mathrm{D}$ & $\mathrm{D}$ & \\
\hline & & 600 & 30 & $\mathrm{D}$ & $\mathrm{D}$ & $\mathrm{D}$ & $\mathrm{D}$ & \\
\hline & & 675 & 30 & $\mathrm{D}$ & $\mathrm{D}$ & $\mathrm{D}$ & $\mathrm{D}$ & \\
\hline & & 750 & 30 & $\mathrm{D}$ & $\mathrm{D}$ & $\mathrm{D}$ & $\mathrm{D}$ & \\
\hline & & 825 & 30 & $\mathrm{D}$ & $\mathrm{D}$ & $\mathrm{D}$ & $\mathrm{D}$ & \\
\hline & & 900 & 30 & $\mathrm{D}$ & $\mathrm{D}$ & $\mathrm{D}$ & $\mathrm{D}$ & \\
\hline & & 975 & 30 & $\mathrm{D}$ & $\mathrm{D}$ & $\mathrm{D}$ & $\mathrm{D}$ & \\
\hline & & 1050 & 30 & ND & ND & ND & ND & \\
\hline
\end{tabular}


Table A.4 The active approach results from Specimen $\mathrm{CH}-2$

\begin{tabular}{|c|c|c|c|c|c|c|c|c|}
\hline \multirow{2}{*}{$\begin{array}{l}\text { Visible crack length (mm.) } \\
\text { and number of loading } \\
\text { cycles }\end{array}$} & \multirow[t]{2}{*}{$\begin{array}{c}\text { Types of } \\
\text { investigation }\end{array}$} & \multirow{2}{*}{$\begin{array}{l}\text { Distance from } \\
\text { IR camera to } \\
\text { test specimen } \\
\quad(\mathrm{mm} .)\end{array}$} & \multirow{2}{*}{$\begin{array}{l}\text { Heating } \\
\text { time } \\
\text { (second) }\end{array}$} & \multicolumn{4}{|c|}{$\begin{array}{c}\text { Delay Time } \\
\text { (Second) }\end{array}$} & \multirow[t]{2}{*}{ Figure } \\
\hline & & & & 1 & 3 & 6 & 9 & \\
\hline \multirow{7}{*}{$\begin{array}{c}3.2 \mathrm{~mm} . @ 500,000 \\
\text { (initial surface temperature } \\
=26.7^{\circ} \mathrm{C} \text { ) }\end{array}$} & \multirow{7}{*}{$\begin{array}{c}\text { Active approach } \\
\text { (unpainted specimen) }\end{array}$} & \multirow[t]{4}{*}{150} & 30 & $\mathrm{D}$ & $\mathrm{D}$ & $\mathrm{D}$ & $\mathrm{D}$ & \multirow{4}{*}{$\begin{array}{l}\text { A.25 - } \\
\text { A.32 }\end{array}$} \\
\hline & & & 60 & $\mathrm{D}$ & $\mathrm{D}$ & $\mathrm{D}$ & $\mathrm{D}$ & \\
\hline & & & 90 & $\mathrm{D}$ & $\mathrm{D}$ & $\mathrm{D}$ & $\mathrm{D}$ & \\
\hline & & & 120 & $\mathrm{D}$ & $\mathrm{D}$ & $\mathrm{D}$ & $\mathrm{D}$ & \\
\hline & & 225 & 30 & ND & ND & ND & ND & \multirow{3}{*}{$\begin{array}{l}\text { A. } 115 \\
\text { A.122 }\end{array}$} \\
\hline & & 300 & 30 & ND & ND & $\mathrm{ND}$ & ND & \\
\hline & & 375 & 30 & ND & ND & ND & ND & \\
\hline
\end{tabular}


Table A.4 (continued) The active approach results from Specimen CH-2

\begin{tabular}{|c|c|c|c|c|c|c|c|c|}
\hline \multirow{2}{*}{$\begin{array}{l}\text { Visible crack length (mm.) } \\
\text { and number of loading } \\
\text { cycles }\end{array}$} & \multirow[t]{2}{*}{$\begin{array}{c}\text { Types of } \\
\text { investigation }\end{array}$} & \multirow{2}{*}{$\begin{array}{l}\text { Distance from } \\
\text { IR camera to } \\
\text { test specimen } \\
\quad(\mathrm{mm} .)\end{array}$} & \multirow{2}{*}{$\begin{array}{l}\text { Heating } \\
\text { time } \\
\text { (second) }\end{array}$} & \multicolumn{4}{|c|}{$\begin{array}{c}\text { Delay Time } \\
\text { (Second) }\end{array}$} & \multirow[t]{2}{*}{ Figure } \\
\hline & & & & 1 & 3 & 6 & 9 & \\
\hline \multirow{7}{*}{$\begin{array}{c}3.2 \mathrm{~mm} . @ 500,000 \\
\text { (initial surface temperature } \\
=26.4{ }^{\circ} \mathrm{C} \text { ) }\end{array}$} & \multirow{7}{*}{$\begin{array}{c}\text { Active approach } \\
\text { (specimen was } \\
\text { painted with black } \\
\text { matte color) }\end{array}$} & \multirow[t]{4}{*}{150} & 30 & ND & ND & ND & ND & \multirow{4}{*}{$\begin{array}{l}\text { A.33 - } \\
\text { A.40 }\end{array}$} \\
\hline & & & 60 & ND & ND & ND & ND & \\
\hline & & & 90 & ND & ND & ND & ND & \\
\hline & & & 120 & ND & ND & ND & ND & \\
\hline & & 225 & 30 & $\mathrm{X}$ & $\mathrm{X}$ & $\mathrm{X}$ & $\mathrm{X}$ & \multirow[t]{3}{*}{$X$} \\
\hline & & 300 & 30 & $\mathrm{X}$ & $\mathrm{X}$ & $\mathrm{X}$ & $\mathrm{X}$ & \\
\hline & & 375 & 30 & $\mathrm{X}$ & $\mathrm{X}$ & $\mathrm{X}$ & $X$ & \\
\hline
\end{tabular}


Table A.5 The active approach results from Specimen CH-3

\begin{tabular}{|c|c|c|c|c|c|c|c|c|}
\hline \multirow{2}{*}{$\begin{array}{l}\text { Visible crack length (mm.) } \\
\text { and number of loading } \\
\text { cycles }\end{array}$} & \multirow[t]{2}{*}{$\begin{array}{c}\text { Types of } \\
\text { investigation }\end{array}$} & \multirow{2}{*}{$\begin{array}{l}\text { Distance from } \\
\text { IR camera to } \\
\text { test specimen } \\
\quad(\mathrm{mm} .)\end{array}$} & \multirow{2}{*}{$\begin{array}{l}\text { Heating } \\
\text { time } \\
\text { (second) }\end{array}$} & \multicolumn{4}{|c|}{$\begin{array}{c}\text { Delay Time } \\
\text { (Second) }\end{array}$} & \multirow[t]{2}{*}{ Figure } \\
\hline & & & & 1 & 3 & 6 & 9 & \\
\hline \multirow{6}{*}{$\begin{array}{l}\text { Crack length was less } \\
\text { than } 2.1 \mathrm{~mm} \text {. and number } \\
\text { of loading cycles are } \\
\text { less than } 475,000 \text { cycles } \\
\text { (average initial surface } \\
\text { temperature }=22.4^{\circ} \mathrm{C} \text { ) }\end{array}$} & \multirow{6}{*}{$\begin{array}{c}\text { Active approach } \\
\text { (specimen was painted } \\
\text { with matte black color) }\end{array}$} & \multirow[t]{5}{*}{150} & 15 & ND & ND & ND & ND & \multirow{5}{*}{$\begin{array}{l}\text { A.41 - } \\
\text { A.52 }\end{array}$} \\
\hline & & & 30 & ND & ND & ND & ND & \\
\hline & & & 45 & ND & ND & ND & ND & \\
\hline & & & 60 & ND & ND & ND & ND & \\
\hline & & & 90 & ND & ND & ND & ND & \\
\hline & & $\begin{array}{c}\text { Not shorter than } \\
225\end{array}$ & 30 & ND & ND & ND & ND & $\begin{array}{c}\text { Not } \\
\text { shown }\end{array}$ \\
\hline \multirow{9}{*}{$\begin{array}{c}3.1 \mathrm{~mm} . @ 500,000 \\
\text { (initial surface temperature } \\
=35.4^{\circ} \mathrm{C} \text { ) }\end{array}$} & \multirow{9}{*}{$\begin{array}{c}\text { Active approach } \\
\text { (specimen was painted } \\
\text { with matte black color) }\end{array}$} & \multirow[t]{5}{*}{150} & 15 & $\mathrm{D}$ & $\mathrm{D}$ & $\mathrm{D}$ & $\mathrm{D}$ & \multirow{5}{*}{$\begin{array}{c}\text { A.53 - } \\
\text { A.64 }\end{array}$} \\
\hline & & & 30 & $\mathrm{D}$ & $\mathrm{D}$ & $\mathrm{D}$ & $\mathrm{D}$ & \\
\hline & & & 45 & $\bar{D}$ & $\mathrm{D}$ & $\mathrm{D}$ & $\mathrm{D}$ & \\
\hline & & & 60 & $\mathrm{D}$ & $\mathrm{D}$ & $\mathrm{D}$ & $\mathrm{D}$ & \\
\hline & & & 90 & $\mathrm{D}$ & $\mathrm{D}$ & $\mathrm{D}$ & $\mathrm{D}$ & \\
\hline & & 225 & 30 & $\bar{D}$ & $\mathrm{D}$ & $\mathrm{D}$ & $\mathrm{D}$ & \multirow{4}{*}{$\begin{array}{l}\text { A.123- } \\
\text { A. } 130\end{array}$} \\
\hline & & 300 & 30 & $\mathrm{D}$ & $\mathrm{D}$ & $\mathrm{D}$ & $\mathrm{D}$ & \\
\hline & & 375 & 30 & $\mathrm{D}$ & $\mathrm{D}$ & $\mathrm{D}$ & $\mathrm{D}$ & \\
\hline & & 450 & 30 & ND & ND & ND & ND & \\
\hline
\end{tabular}


Table A.5 (continued) The active approach results from Specimen CH-3

\begin{tabular}{|c|c|c|c|c|c|c|c|c|}
\hline \multirow{2}{*}{$\begin{array}{c}\text { Visible crack length (mm.) } \\
\text { and number of loading } \\
\text { cycles }\end{array}$} & \multirow[t]{2}{*}{$\begin{array}{c}\text { Types of } \\
\text { investigation }\end{array}$} & \multirow{2}{*}{$\begin{array}{l}\text { Distance from } \\
\text { IR camera to } \\
\text { test specimen } \\
(\mathrm{mm} .)\end{array}$} & \multirow{2}{*}{$\begin{array}{l}\text { Heating } \\
\text { time } \\
\text { (second) }\end{array}$} & \multicolumn{4}{|c|}{$\begin{array}{l}\text { Delay Time } \\
\text { (Second) }\end{array}$} & \multirow[t]{2}{*}{ Figure } \\
\hline & & & & 1 & 3 & 6 & 9 & \\
\hline \multirow{10}{*}{$\begin{array}{c}6.8 \mathrm{~mm} . @ 525,000 \\
\text { (initial surface temperature } \\
=35.5^{\circ} \mathrm{C} \text { ) }\end{array}$} & \multirow{10}{*}{$\begin{array}{c}\text { Active approach } \\
\text { (specimen was painted } \\
\text { with matte black color) }\end{array}$} & \multirow[t]{5}{*}{150} & 15 & D & D & $\mathrm{D}$ & D & \multirow{10}{*}{$\begin{array}{c}\text { Not } \\
\text { shown }\end{array}$} \\
\hline & & & 30 & $\mathrm{D}$ & $\mathrm{D}$ & $\mathrm{D}$ & $\mathrm{D}$ & \\
\hline & & & 45 & $\mathrm{D}$ & $\mathrm{D}$ & $\mathrm{D}$ & $\mathrm{D}$ & \\
\hline & & & 60 & D & D & $\mathrm{D}$ & D & \\
\hline & & & 90 & D & D & D & D & \\
\hline & & 225 & 30 & $\mathrm{D}$ & D & D & $\mathrm{D}$ & \\
\hline & & 300 & 30 & D & D & D & D & \\
\hline & & 375 & 30 & $\mathrm{D}$ & $\mathrm{D}$ & $\mathrm{D}$ & $\mathrm{D}$ & \\
\hline & & 450 & 30 & ND & ND & ND & ND & \\
\hline & & 525 & 30 & ND & ND & ND & ND & \\
\hline
\end{tabular}


Table A.5 (continued) The active approach results from Specimen CH-3

\begin{tabular}{|c|c|c|c|c|c|c|c|c|}
\hline \multirow{2}{*}{$\begin{array}{l}\text { Visible crack length (mm.) } \\
\text { and number of loading } \\
\text { cycles }\end{array}$} & \multirow[t]{2}{*}{$\begin{array}{c}\text { Types of } \\
\text { investigation }\end{array}$} & \multirow{2}{*}{$\begin{array}{l}\text { Distance from } \\
\text { IR camera to } \\
\text { test specimen } \\
\quad(\mathrm{mm} .)\end{array}$} & \multirow{2}{*}{$\begin{array}{l}\text { Heating } \\
\text { time } \\
\text { (second) }\end{array}$} & \multicolumn{4}{|c|}{$\begin{array}{c}\text { Delay Time } \\
\text { (Second) }\end{array}$} & \multirow[t]{2}{*}{ Figure } \\
\hline & & & & 1 & 3 & 6 & 9 & \\
\hline \multirow{12}{*}{$\begin{array}{c}11.1 \mathrm{~mm} . @ 550,000 \\
\text { (initial surface temperature } \\
=25.9^{\circ} \mathrm{C} \text { ) }\end{array}$} & \multirow{12}{*}{$\begin{array}{c}\text { Active approach } \\
\text { (specimen was painted } \\
\text { with matte black color) }\end{array}$} & \multirow[t]{5}{*}{150} & 15 & $\mathrm{D}$ & $\mathrm{D}$ & $\mathrm{D}$ & $\mathrm{D}$ & \multirow{5}{*}{$\begin{array}{l}\text { A. } 75- \\
\text { A. } 84\end{array}$} \\
\hline & & & 30 & $\mathrm{D}$ & $\mathrm{D}$ & $\mathrm{D}$ & $\mathrm{D}$ & \\
\hline & & & 45 & $\mathrm{D}$ & $\mathrm{D}$ & $\mathrm{D}$ & $\mathrm{D}$ & \\
\hline & & & 60 & $\mathrm{D}$ & $\mathrm{D}$ & $\mathrm{D}$ & $\mathrm{D}$ & \\
\hline & & & 90 & $\mathrm{D}$ & $\mathrm{D}$ & $\mathrm{D}$ & $\mathrm{D}$ & \\
\hline & & 225 & 30 & $\mathrm{D}$ & $\mathrm{D}$ & $\mathrm{D}$ & $\mathrm{D}$ & \multirow{7}{*}{$\begin{array}{l}\text { A.131 - } \\
\text { A.146 }\end{array}$} \\
\hline & & 300 & 30 & $\mathrm{D}$ & $\mathrm{D}$ & $\mathrm{D}$ & $\mathrm{D}$ & \\
\hline & & 375 & 30 & $\mathrm{D}$ & $\mathrm{D}$ & $\mathrm{D}$ & $\mathrm{D}$ & \\
\hline & & 450 & 30 & $\mathrm{D}$ & $\mathrm{D}$ & $\mathrm{D}$ & $\mathrm{D}$ & \\
\hline & & 525 & 30 & $\mathrm{D}$ & $\mathrm{D}$ & $\mathrm{D}$ & $\mathrm{D}$ & \\
\hline & & 600 & 30 & $\mathrm{D}$ & $\mathrm{D}$ & $\mathrm{D}$ & $\mathrm{D}$ & \\
\hline & & 675 & 30 & ND & ND & ND & ND & \\
\hline
\end{tabular}


Table A.5 (continued) The active approach results from Specimen $\mathrm{CH}-3$

\begin{tabular}{|c|c|c|c|c|c|c|c|c|}
\hline \multirow{2}{*}{$\begin{array}{l}\text { Visible crack length (mm.) } \\
\text { and number of loading } \\
\text { cycles }\end{array}$} & \multirow[t]{2}{*}{$\begin{array}{c}\text { Types of } \\
\text { investigation }\end{array}$} & \multirow{2}{*}{$\begin{array}{l}\text { Distance from } \\
\text { IR camera to } \\
\text { test specimen } \\
\quad(\mathrm{mm} .)\end{array}$} & \multirow{2}{*}{$\begin{array}{l}\text { Heating } \\
\text { time } \\
\text { (second) }\end{array}$} & \multicolumn{4}{|c|}{$\begin{array}{c}\text { Delay Time } \\
\text { (Second) }\end{array}$} & \multirow[t]{2}{*}{ Figure } \\
\hline & & & & 1 & 3 & 6 & 9 & \\
\hline \multirow{16}{*}{$\begin{array}{c}18.2 \mathrm{~mm} . @ 575,000 \\
\text { (initial surface temperature } \\
=27.1^{\circ} \mathrm{C} \text { ) }\end{array}$} & \multirow{16}{*}{$\begin{array}{c}\text { Active approach } \\
\text { (specimen was painted } \\
\text { with matte black color) }\end{array}$} & \multirow[t]{5}{*}{150} & 15 & $\mathrm{D}$ & D & D & D & \multirow{16}{*}{$\begin{array}{c}\text { Not } \\
\text { shown }\end{array}$} \\
\hline & & & 30 & $\mathrm{D}$ & D & $\mathrm{D}$ & $\mathrm{D}$ & \\
\hline & & & 45 & $\mathrm{D}$ & D & $\mathrm{D}$ & $\mathrm{D}$ & \\
\hline & & & 60 & $\mathrm{D}$ & D & $\mathrm{D}$ & $\mathrm{D}$ & \\
\hline & & & 90 & $\mathrm{D}$ & $\mathrm{D}$ & $\mathrm{D}$ & $\mathrm{D}$ & \\
\hline & & 225 & 30 & $\mathrm{D}$ & D & D & D & \\
\hline & & 300 & 30 & $\mathrm{D}$ & $\mathrm{D}$ & $\mathrm{D}$ & $\mathrm{D}$ & \\
\hline & & 375 & 30 & $\mathrm{D}$ & $\mathrm{D}$ & $\mathrm{D}$ & $\mathrm{D}$ & \\
\hline & & 450 & 30 & $\mathrm{D}$ & $\mathrm{D}$ & $\mathrm{D}$ & $\mathrm{D}$ & \\
\hline & & 525 & 30 & $\mathrm{D}$ & $\mathrm{D}$ & $\mathrm{D}$ & $\mathrm{D}$ & \\
\hline & & 600 & 30 & $\mathrm{D}$ & $\mathrm{D}$ & $\mathrm{D}$ & $\mathrm{D}$ & \\
\hline & & 675 & 30 & D & D & D & D & \\
\hline & & 750 & 30 & $\mathrm{D}$ & $\mathrm{D}$ & $\mathrm{D}$ & $\mathrm{D}$ & \\
\hline & & 825 & 30 & $\mathrm{D}$ & D & $\mathrm{D}$ & $\mathrm{D}$ & \\
\hline & & 900 & 30 & D & D & D & D & \\
\hline & & 975 & 30 & ND & ND & ND & ND & \\
\hline
\end{tabular}


Table A.5 (continued) The active approach results from Specimen CH-3

\begin{tabular}{|c|c|c|c|c|c|c|c|c|}
\hline \multirow{2}{*}{$\begin{array}{l}\text { Visible crack length (mm.) } \\
\text { and number of loading } \\
\text { cycles }\end{array}$} & \multirow[t]{2}{*}{$\begin{array}{c}\text { Types of } \\
\text { investigation }\end{array}$} & \multirow{2}{*}{$\begin{array}{l}\text { Distance from } \\
\text { IR camera to } \\
\text { test specimen } \\
\quad(\mathrm{mm} .)\end{array}$} & \multirow{2}{*}{$\begin{array}{l}\text { Heating } \\
\text { time } \\
\text { (second) }\end{array}$} & \multicolumn{4}{|c|}{$\begin{array}{l}\text { Delay Time } \\
\text { (Second) }\end{array}$} & \multirow[t]{2}{*}{ Figure } \\
\hline & & & & 1 & 3 & 6 & 9 & \\
\hline \multirow{6}{*}{$\begin{array}{l}\text { Crack length was less } \\
\text { than } 2.1 \mathrm{~mm} \text {. and number } \\
\text { of loading cycles are } \\
\text { less than } 475,000 \text { cycles } \\
\text { (average initial surface } \\
\text { temperature }=24.4^{\circ} \mathrm{C} \text { ) }\end{array}$} & \multirow{6}{*}{$\begin{array}{c}\text { Active approach } \\
\text { (unpainted specimen) }\end{array}$} & \multirow[t]{5}{*}{150} & 15 & ND & ND & ND & ND & \multirow{5}{*}{$\begin{array}{c}\text { Not } \\
\text { shown }\end{array}$} \\
\hline & & & 30 & ND & ND & ND & ND & \\
\hline & & & 45 & ND & ND & ND & ND & \\
\hline & & & 60 & ND & ND & ND & ND & \\
\hline & & & 90 & ND & ND & ND & ND & \\
\hline & & $\begin{array}{c}\text { Not shorter than } \\
225\end{array}$ & 30 & $\mathrm{X}$ & $\mathrm{X}$ & $\bar{X}$ & $\bar{X}$ & $X$ \\
\hline \multirow{6}{*}{$\begin{array}{c}3.1 \mathrm{~mm} . @ 500,000 \text { cycles } \\
\text { (initial surface temperature } \\
=25.3^{\circ} \mathrm{C} \text { ) }\end{array}$} & \multirow{6}{*}{$\begin{array}{c}\text { Active approach } \\
\text { (unpainted specimen) }\end{array}$} & \multirow[t]{5}{*}{150} & 15 & ND & ND & ND & ND & \multirow{5}{*}{$\begin{array}{l}\text { Not } \\
\text { shown }\end{array}$} \\
\hline & & & 30 & ND & ND & ND & ND & \\
\hline & & & 45 & ND & ND & ND & ND & \\
\hline & & & 60 & ND & ND & ND & ND & \\
\hline & & & 90 & ND & ND & ND & ND & \\
\hline & & $\begin{array}{c}\text { Not shorter than } \\
225\end{array}$ & $\mathrm{X}$ & $\mathrm{X}$ & $\mathrm{X}$ & $\mathrm{X}$ & $\mathrm{X}$ & $X$ \\
\hline
\end{tabular}


Table A.5 (continued) The active approach results from Specimen CH-3

\begin{tabular}{|c|c|c|c|c|c|c|c|c|}
\hline \multirow{2}{*}{$\begin{array}{l}\text { Visible crack length (mm.) } \\
\text { and number of loading } \\
\text { cycles }\end{array}$} & \multirow[t]{2}{*}{$\begin{array}{c}\text { Types of } \\
\text { investigation }\end{array}$} & \multirow{2}{*}{$\begin{array}{l}\text { Distance from } \\
\text { IR camera to } \\
\text { test specimen } \\
\quad(\mathrm{mm} .)\end{array}$} & \multirow{2}{*}{$\begin{array}{l}\text { Heating } \\
\text { time } \\
\text { (second) }\end{array}$} & \multicolumn{4}{|c|}{$\begin{array}{c}\text { Delay time } \\
\text { (second) }\end{array}$} & \multirow[t]{2}{*}{ Figure } \\
\hline & & & & 1 & 3 & 6 & 9 & \\
\hline \multirow{6}{*}{$\begin{array}{c}6.8 \mathrm{~mm} . @ 525,000 \text { cycles } \\
\text { (initial surface temperature } \\
=25.2^{\circ} \mathrm{C} \text { ) }\end{array}$} & \multirow{6}{*}{$\begin{array}{c}\text { Active approach } \\
\text { (unpainted specimen) }\end{array}$} & \multirow[t]{5}{*}{150} & 15 & ND & ND & ND & ND & \multirow{5}{*}{$\begin{array}{c}\text { Not } \\
\text { shown }\end{array}$} \\
\hline & & & 30 & ND & ND & ND & ND & \\
\hline & & & 45 & ND & ND & ND & ND & \\
\hline & & & 60 & ND & ND & ND & ND & \\
\hline & & & 90 & ND & ND & ND & ND & \\
\hline & & $\begin{array}{c}\text { Not shorter than } \\
225\end{array}$ & 30 & $\mathrm{X}$ & $\mathrm{X}$ & $\mathrm{X}$ & $\mathrm{X}$ & $\begin{array}{c}\text { Not } \\
\text { shown }\end{array}$ \\
\hline \multirow{6}{*}{$\begin{array}{c}11.1 \mathrm{~mm} . @ 550,000 \text { cycles } \\
\text { (initial surface temperature } \\
=25.1^{\circ} \mathrm{C} \text { ) }\end{array}$} & \multirow{6}{*}{$\begin{array}{c}\text { Active approach } \\
\text { (unpainted specimen) }\end{array}$} & \multirow[t]{5}{*}{150} & 15 & ND & ND & ND & ND & \multirow{5}{*}{$\begin{array}{l}\text { A.65- } \\
\text { A.74 }\end{array}$} \\
\hline & & & 30 & ND & ND & ND & ND & \\
\hline & & & 45 & ND & ND & ND & ND & \\
\hline & & & 60 & ND & ND & ND & ND & \\
\hline & & & 90 & ND & ND & ND & ND & \\
\hline & & $\begin{array}{c}\text { Not shorter than } \\
225\end{array}$ & 30 & ND & ND & ND & ND & $\begin{array}{l}\text { A. } 147- \\
\text { A. } 156\end{array}$ \\
\hline
\end{tabular}


Table A.5 (continued) The active approach results from Specimen $\mathrm{CH}-3$

\begin{tabular}{|c|c|c|c|c|c|c|c|c|}
\hline \multirow{2}{*}{$\begin{array}{c}\text { Visible crack length (mm.) } \\
\text { and number of loading } \\
\text { cycles }\end{array}$} & \multirow[t]{2}{*}{$\begin{array}{c}\text { Types of } \\
\text { investigation }\end{array}$} & \multirow{2}{*}{$\begin{array}{l}\text { Distance from } \\
\text { IR camera to } \\
\text { test specimen } \\
\quad(\mathrm{mm} .)\end{array}$} & \multirow{2}{*}{$\begin{array}{l}\text { Heating } \\
\text { time } \\
\text { (second) }\end{array}$} & \multicolumn{4}{|c|}{$\begin{array}{c}\text { Delay time } \\
\text { (second) }\end{array}$} & \multirow[t]{2}{*}{ Figure } \\
\hline & & & & 1 & 3 & 6 & 9 & \\
\hline \multirow{6}{*}{$\begin{array}{c}18.2 \mathrm{~mm} . @ 575,000 \text { cycles } \\
\text { (initial surface temperature } \\
=24.8^{\circ} \mathrm{C} \text { ) }\end{array}$} & \multirow{6}{*}{$\begin{array}{c}\text { Active approach } \\
\text { (unpainted specimen) }\end{array}$} & \multirow[t]{5}{*}{150} & 15 & ND & ND & ND & ND & \multirow{5}{*}{$\begin{array}{c}\text { Not } \\
\text { shown }\end{array}$} \\
\hline & & & 30 & ND & $\mathrm{ND}$ & ND & ND & \\
\hline & & & 45 & ND & ND & ND & ND & \\
\hline & & & 60 & ND & ND & ND & ND & \\
\hline & & & 90 & ND & ND & ND & ND & \\
\hline & & \begin{tabular}{|c} 
Not shorter than \\
225
\end{tabular} & 30 & $\mathrm{X}$ & $\mathrm{X}$ & $X$ & $X$ & $X$ \\
\hline
\end{tabular}


Table A.6 The active approach results from Specimen WD-1

\begin{tabular}{|c|c|c|c|c|c|c|c|c|}
\hline \multirow{2}{*}{$\begin{array}{l}\text { Visible crack length (mm.) } \\
\text { and number of loading } \\
\text { cycles }\end{array}$} & \multirow[t]{2}{*}{$\begin{array}{c}\text { Types of } \\
\text { investigation }\end{array}$} & \multirow{2}{*}{$\begin{array}{l}\text { Distance from } \\
\text { IR camera to } \\
\text { test specimen } \\
\quad(\mathrm{mm} .)\end{array}$} & \multirow{2}{*}{$\begin{array}{l}\text { Heating } \\
\text { time } \\
\text { (second) }\end{array}$} & \multicolumn{4}{|c|}{$\begin{array}{c}\text { Delay Time } \\
\text { (Second) }\end{array}$} & \multirow[t]{2}{*}{ Figure } \\
\hline & & & & 1 & 3 & 6 & 9 & \\
\hline \multirow{4}{*}{$\begin{array}{l}\text { Crack length was less } \\
\text { than } 23 \mathrm{~mm} \text {. and number } \\
\text { of loading cycles were } \\
\text { less than } 1,330,000 \text { cycles } \\
\text { (average initial surface } \\
\text { temperature }=24.3^{\circ} \mathrm{C} \text { ) }\end{array}$} & \multirow{4}{*}{$\begin{array}{c}\text { Active approach } \\
\text { (specimen was painted } \\
\text { with matte black color) }\end{array}$} & \multirow[t]{3}{*}{150} & 30 & ND & ND & ND & ND & \multirow{3}{*}{$\begin{array}{l}\text { A.174 - } \\
\text { A.181 }\end{array}$} \\
\hline & & & 60 & ND & ND & ND & ND & \\
\hline & & & 90 & ND & ND & ND & ND & \\
\hline & & $\begin{array}{c}\text { Not shorter than } \\
225\end{array}$ & $\mathrm{X}$ & $\mathrm{X}$ & $\mathrm{X}$ & $\mathrm{X}$ & $\mathrm{X}$ & $\mathrm{X}$ \\
\hline \multirow{7}{*}{$\begin{array}{c}24.1 \mathrm{~mm} . @ 1,335,000 \\
\text { (initial surface temperature } \\
=25.5^{\circ} \mathrm{C} \text { ) }\end{array}$} & \multirow{7}{*}{$\begin{array}{c}\text { Active approach } \\
\text { (specimen was painted } \\
\text { with matte black color) }\end{array}$} & \multirow[t]{3}{*}{150} & 30 & $\mathrm{D}$ & $\mathrm{D}$ & $\mathrm{D}$ & $\mathrm{D}$ & \multirow{3}{*}{$\begin{array}{l}\text { A.182 - } \\
\text { A.197 }\end{array}$} \\
\hline & & & 60 & D & $\mathrm{D}$ & $\mathrm{D}$ & $\mathrm{D}$ & \\
\hline & & & 90 & D & D & $\mathrm{D}$ & D & \\
\hline & & 225 & 30 & $\mathrm{D}$ & $\mathrm{D}$ & $\mathrm{D}$ & $\mathrm{D}$ & \multirow[t]{4}{*}{ Not shown } \\
\hline & & 300 & 30 & $\mathrm{D}$ & $\mathrm{D}$ & $\mathrm{D}$ & $\mathrm{D}$ & \\
\hline & & 375 & 30 & ND & ND & ND & ND & \\
\hline & & 450 & 30 & ND & ND & ND & ND & \\
\hline
\end{tabular}


Table A.6 (continued) The active approach results from Specimen WD-1

\begin{tabular}{|c|c|c|c|c|c|c|c|c|}
\hline \multirow{2}{*}{$\begin{array}{l}\text { Visible crack length (mm.) } \\
\text { and number of loading } \\
\text { cycles }\end{array}$} & \multirow[t]{2}{*}{$\begin{array}{c}\text { Types of } \\
\text { investigation }\end{array}$} & \multirow{2}{*}{$\begin{array}{l}\text { Distance from } \\
\text { IR camera to } \\
\text { test specimen } \\
\quad(\mathrm{mm} .)\end{array}$} & \multirow{2}{*}{$\begin{array}{l}\text { Heating } \\
\text { time } \\
\text { (second) }\end{array}$} & \multicolumn{4}{|c|}{$\begin{array}{l}\text { Delay Time } \\
\text { (Second) }\end{array}$} & \multirow[t]{2}{*}{ Figure } \\
\hline & & & & 1 & 3 & 6 & 9 & \\
\hline \multirow{7}{*}{$\begin{array}{c}25.2 \mathrm{~mm} . @ 1,335,500 \\
\text { (initial surface temperature } \\
=25.8^{\circ} \mathrm{C} \text { ) }\end{array}$} & \multirow{7}{*}{$\begin{array}{c}\text { Active approach } \\
\text { (specimen was painted } \\
\text { with matte black color) }\end{array}$} & \multirow[t]{3}{*}{150} & 30 & $\mathrm{D}$ & $\mathrm{D}$ & $\mathrm{D}$ & $\mathrm{D}$ & \multirow[t]{3}{*}{ Not shown } \\
\hline & & & 60 & $\mathrm{D}$ & $\mathrm{D}$ & $\mathrm{D}$ & $\mathrm{D}$ & \\
\hline & & & 90 & $\mathrm{D}$ & $\mathrm{D}$ & $\mathrm{D}$ & $\mathrm{D}$ & \\
\hline & & 225 & 30 & $\mathrm{D}$ & $\mathrm{D}$ & $\mathrm{D}$ & $\mathrm{D}$ & \multirow[t]{4}{*}{ Not shown } \\
\hline & & 300 & 30 & $\mathrm{D}$ & $\mathrm{D}$ & $\bar{D}$ & $\mathrm{D}$ & \\
\hline & & 375 & 30 & $\mathrm{D}$ & $\mathrm{D}$ & $\mathrm{D}$ & $\mathrm{D}$ & \\
\hline & & 450 & 30 & ND & ND & ND & $\mathrm{ND}$ & \\
\hline
\end{tabular}


Table A.6 (continued) The active approach results from Specimen WD-1

\begin{tabular}{|c|c|c|c|c|c|c|c|c|}
\hline \multirow{2}{*}{$\begin{array}{l}\text { Visible crack length (mm.) } \\
\text { and number of loading } \\
\text { cycles }\end{array}$} & \multirow[t]{2}{*}{$\begin{array}{c}\text { Types of } \\
\text { investigation }\end{array}$} & \multirow{2}{*}{$\begin{array}{l}\text { Distance from } \\
\text { IR camera to } \\
\text { test specimen } \\
\quad(\mathrm{mm} .)\end{array}$} & \multirow{2}{*}{$\begin{array}{l}\text { Heating } \\
\text { time } \\
\text { (second) }\end{array}$} & \multicolumn{4}{|c|}{$\begin{array}{c}\text { Delay Time } \\
\text { (Second) }\end{array}$} & \multirow[t]{2}{*}{ Figure } \\
\hline & & & & 1 & 3 & 6 & 9 & \\
\hline \multirow{8}{*}{$\begin{array}{c}27.2 \mathrm{~mm} . @ 1,336,000 \\
\text { (initial surface temperature } \\
=26.1^{\circ} \mathrm{C} \text { ) }\end{array}$} & \multirow{8}{*}{$\begin{array}{c}\text { Active approach } \\
\text { (specimen was painted } \\
\text { with matte black color) }\end{array}$} & \multirow[t]{3}{*}{150} & 30 & $\mathrm{D}$ & $\mathrm{D}$ & $\mathrm{D}$ & $\mathrm{D}$ & \multirow[t]{3}{*}{ Not shown } \\
\hline & & & 60 & $\mathrm{D}$ & $\mathrm{D}$ & $\mathrm{D}$ & $\mathrm{D}$ & \\
\hline & & & 90 & $\mathrm{D}$ & $\mathrm{D}$ & $\mathrm{D}$ & $\mathrm{D}$ & \\
\hline & & 225 & 30 & $\mathrm{D}$ & $\mathrm{D}$ & $\mathrm{D}$ & $\mathrm{D}$ & \multirow[t]{5}{*}{ A. $247-$ A.248 } \\
\hline & & 300 & 30 & $\mathrm{D}$ & $\mathrm{D}$ & $\mathrm{D}$ & $\mathrm{D}$ & \\
\hline & & 375 & 30 & $\mathrm{D}$ & $\mathrm{D}$ & $\mathrm{D}$ & $\mathrm{D}$ & \\
\hline & & 450 & 30 & $\mathrm{D}$ & $\mathrm{D}$ & $\mathrm{D}$ & $\mathrm{D}$ & \\
\hline & & 525 & 30 & ND & ND & ND & ND & \\
\hline
\end{tabular}


Table A.7 The active approach results from Specimen WD-2

\begin{tabular}{|c|c|c|c|c|c|c|c|c|}
\hline \multirow{2}{*}{$\begin{array}{l}\text { Visible crack length (mm.) } \\
\text { and number of loading } \\
\text { cycles }\end{array}$} & \multirow[t]{2}{*}{$\begin{array}{c}\text { Types of } \\
\text { investigation }\end{array}$} & \multirow{2}{*}{$\begin{array}{l}\text { Distance from } \\
\text { IR camera to } \\
\text { test specimen } \\
\quad(\mathrm{mm} .)\end{array}$} & \multirow{2}{*}{$\begin{array}{l}\text { Heating } \\
\text { time } \\
\text { (second) }\end{array}$} & \multicolumn{4}{|c|}{$\begin{array}{l}\text { Delay Time } \\
\text { (Second) }\end{array}$} & \multirow[t]{2}{*}{ Figure } \\
\hline & & & & 1 & 3 & 6 & 9 & \\
\hline \multirow{4}{*}{$\begin{array}{l}\text { Crack length was less } \\
\text { than } 20 \mathrm{~mm} \text {. and number } \\
\text { of loading cycles were } \\
\text { less than } 1,130,000 \text { cycles } \\
\text { (average initial surface } \\
\text { temperature }=24.3^{\circ} \mathrm{C} \text { ) }\end{array}$} & \multirow{4}{*}{$\begin{array}{c}\text { Active approach } \\
\text { (specimen was painted } \\
\text { with matte black color) }\end{array}$} & \multirow[t]{3}{*}{150} & 30 & ND & ND & ND & ND & \multirow{3}{*}{$\begin{array}{l}\text { A.198 - } \\
\text { A.199 }\end{array}$} \\
\hline & & & 60 & ND & ND & ND & ND & \\
\hline & & & 90 & ND & ND & ND & ND & \\
\hline & & $\begin{array}{c}\text { Not shorter than } \\
225\end{array}$ & $\mathrm{X}$ & $\mathrm{X}$ & $X$ & $X$ & $\mathrm{X}$ & $X$ \\
\hline \multirow{7}{*}{$\begin{array}{c}21.2 \mathrm{~mm} . @ 1,131,000 \\
\text { (initial surface temperature } \\
=24.3^{\circ} \mathrm{C} \text { ) }\end{array}$} & \multirow{7}{*}{$\begin{array}{c}\text { Active approach } \\
\text { (specimen was painted } \\
\text { with matte black color) }\end{array}$} & 150 & 30 & $\mathrm{D}$ & $\mathrm{D}$ & $\mathrm{D}$ & $\mathrm{D}$ & \multirow{3}{*}{$\begin{array}{l}\text { A. } 200- \\
\text { A. } 210\end{array}$} \\
\hline & & & 60 & $\mathrm{D}$ & $\mathrm{D}$ & $\mathrm{D}$ & $\mathrm{D}$ & \\
\hline & & & 90 & $\mathrm{D}$ & $\mathrm{D}$ & $\mathrm{D}$ & $\mathrm{D}$ & \\
\hline & & 225 & 30 & $\mathrm{D}$ & $\mathrm{D}$ & $\mathrm{D}$ & $\mathrm{D}$ & \multirow[t]{4}{*}{ Not shown } \\
\hline & & 300 & 30 & $\mathrm{D}$ & $\mathrm{D}$ & $\mathrm{D}$ & $\mathrm{D}$ & \\
\hline & & 375 & 30 & ND & ND & ND & ND & \\
\hline & & A50 & 30 & $\mathrm{ND}$ & ND & ND & ND & \\
\hline
\end{tabular}


Table A.7 (continued) The active approach results from Specimen WD-2

\begin{tabular}{|c|c|c|c|c|c|c|c|c|}
\hline \multirow{2}{*}{$\begin{array}{l}\text { Visible crack length (mm.) } \\
\text { and number of loading } \\
\text { cycles }\end{array}$} & \multirow[t]{2}{*}{$\begin{array}{c}\text { Types of } \\
\text { investigation }\end{array}$} & \multirow{2}{*}{$\begin{array}{l}\text { Distance from } \\
\text { IR camera to } \\
\text { test specimen } \\
(\mathrm{mm} .)\end{array}$} & \multirow{2}{*}{$\begin{array}{l}\text { Heating } \\
\text { time } \\
\text { (second) }\end{array}$} & \multicolumn{4}{|c|}{$\begin{array}{l}\text { Delay Time } \\
\text { (Second) }\end{array}$} & \multirow[t]{2}{*}{ Figure } \\
\hline & & & & 1 & 3 & 6 & 9 & \\
\hline \multirow{7}{*}{$\begin{array}{c}22.1 \mathrm{~mm} . @ 1,132,000 \\
\text { (initial surface temperature } \\
=25.8^{\circ} \mathrm{C} \text { ) }\end{array}$} & \multirow{7}{*}{$\begin{array}{c}\text { Active approach } \\
\text { (specimen was painted } \\
\text { with matte black color) }\end{array}$} & \multirow[t]{3}{*}{150} & 30 & $\mathrm{D}$ & $\mathrm{D}$ & $\mathrm{D}$ & $\mathrm{D}$ & \multirow[t]{3}{*}{ Not shown } \\
\hline & & & 60 & $\mathrm{D}$ & $\mathrm{D}$ & $\mathrm{D}$ & $\mathrm{D}$ & \\
\hline & & & 90 & $\mathrm{D}$ & $\mathrm{D}$ & $\mathrm{D}$ & $\mathrm{D}$ & \\
\hline & & 225 & 30 & $\mathrm{D}$ & $\mathrm{D}$ & $\mathrm{D}$ & $\mathrm{D}$ & \multirow[t]{4}{*}{ Not shown } \\
\hline & & 300 & 30 & $\mathrm{D}$ & $\mathrm{D}$ & $\mathrm{D}$ & $\mathrm{D}$ & \\
\hline & & 375 & 30 & ND & ND & ND & ND & \\
\hline & & 450 & 30 & ND & ND & ND & ND & \\
\hline
\end{tabular}


Table A.7 (continued) The active approach results from Specimen WD-2

\begin{tabular}{|c|c|c|c|c|c|c|c|c|}
\hline \multirow{2}{*}{$\begin{array}{l}\text { Visible crack length (mm.) } \\
\text { and number of loading } \\
\text { cycles }\end{array}$} & \multirow[t]{2}{*}{$\begin{array}{c}\text { Types of } \\
\text { investigation }\end{array}$} & \multirow{2}{*}{$\begin{array}{l}\text { Distance from } \\
\text { IR camera to } \\
\text { test specimen } \\
\quad(\mathrm{mm} .)\end{array}$} & \multirow{2}{*}{$\begin{array}{l}\text { Heating } \\
\text { time } \\
\text { (second) }\end{array}$} & \multicolumn{4}{|c|}{$\begin{array}{l}\text { Delay Time } \\
\text { (Second) }\end{array}$} & \multirow[t]{2}{*}{ Figure } \\
\hline & & & & 1 & 3 & 6 & 9 & \\
\hline \multirow{8}{*}{$\begin{array}{c}24.4 \mathrm{~mm} . @ 1,133,000 \\
\text { (initial surface temperature } \\
=23.3^{\circ} \mathrm{C} \text { ) }\end{array}$} & \multirow{8}{*}{$\begin{array}{c}\text { Active approach } \\
\text { (specimen was painted } \\
\text { with matte black color) }\end{array}$} & \multirow[t]{3}{*}{150} & 30 & $\mathrm{D}$ & $\mathrm{D}$ & $\mathrm{D}$ & $\mathrm{D}$ & \multirow[t]{3}{*}{ Not shown } \\
\hline & & & 60 & $\mathrm{D}$ & $\mathrm{D}$ & $\mathrm{D}$ & $\mathrm{D}$ & \\
\hline & & & 90 & $\mathrm{D}$ & $\mathrm{D}$ & $\mathrm{D}$ & $\mathrm{D}$ & \\
\hline & & 225 & 30 & $\mathrm{D}$ & $\mathrm{D}$ & $\mathrm{D}$ & $\mathrm{D}$ & \multirow[t]{5}{*}{ A. $249-$ A. 250} \\
\hline & & 300 & 30 & $\mathrm{D}$ & $\mathrm{D}$ & $\mathrm{D}$ & $\mathrm{D}$ & \\
\hline & & 375 & 30 & $\mathrm{D}$ & $\mathrm{D}$ & $\mathrm{D}$ & $\mathrm{D}$ & \\
\hline & & 450 & 30 & $\mathrm{D}$ & $\mathrm{D}$ & $\mathrm{D}$ & $\mathrm{D}$ & \\
\hline & & 525 & 30 & ND & ND & ND & ND & \\
\hline
\end{tabular}


Table A.8 The active approach results from Specimen WD-3 (tested under the enclosed laboratory condition)

\begin{tabular}{|c|c|c|c|c|c|c|c|c|}
\hline \multirow{2}{*}{$\begin{array}{l}\text { Visible crack length (mm.) } \\
\text { and number of loading } \\
\text { cycles }\end{array}$} & \multirow[t]{2}{*}{$\begin{array}{c}\text { Types of } \\
\text { investigation }\end{array}$} & \multirow{2}{*}{$\begin{array}{l}\text { Distance from } \\
\text { IR camera to } \\
\text { test specimen } \\
\quad(\mathrm{mm} .)\end{array}$} & \multirow{2}{*}{$\begin{array}{l}\text { Heating } \\
\text { time } \\
\text { (second) }\end{array}$} & \multicolumn{4}{|c|}{$\begin{array}{l}\text { Delay Time } \\
\text { (Second) }\end{array}$} & \multirow[t]{2}{*}{ Figure } \\
\hline & & & & 1 & 3 & 6 & 9 & \\
\hline \multirow{4}{*}{$\begin{array}{l}\text { Crack length was less } \\
\text { than } 21.1 \mathrm{~mm} \text {. and number } \\
\text { of loading cycles were } \\
\text { less than } 1,730,000 \text { cycles } * \\
\text { (average initial surface } \\
\text { temperature }=21.2{ }^{\circ} \mathrm{C} \text { ) }\end{array}$} & \multirow{4}{*}{$\begin{array}{c}\text { Active approach } \\
\text { (specimen was painted } \\
\text { with real color used on } \\
\text { bridge structure) }\end{array}$} & \multirow[t]{3}{*}{150} & 30 & ND & ND & ND & ND & \multirow[t]{3}{*}{ Not shown } \\
\hline & & & 60 & ND & ND & ND & ND & \\
\hline & & & 90 & ND & ND & ND & ND & \\
\hline & & $\begin{array}{c}\text { Not shorter than } \\
225\end{array}$ & $\mathrm{X}$ & $X$ & $X$ & $\mathrm{X}$ & $X$ & $X$ \\
\hline \multirow{7}{*}{$\begin{array}{c}22.2 \mathrm{~mm} . @ 1,735,550 * \\
\text { (initial surface temperature } \\
=22.5^{\circ} \mathrm{C} \text { ) }\end{array}$} & \multirow{7}{*}{$\begin{array}{c}\text { Active approach } \\
\text { (specimen was painted } \\
\text { with real color used on } \\
\text { bridge structure) }\end{array}$} & \multirow[t]{3}{*}{150} & 30 & $\mathrm{D}$ & $\mathrm{D}$ & $\mathrm{D}$ & $\mathrm{D}$ & \multirow[t]{3}{*}{ A.211-A.222 } \\
\hline & & & 60 & $\mathrm{D}$ & $\mathrm{D}$ & $\mathrm{D}$ & $\mathrm{D}$ & \\
\hline & & & 90 & $\mathrm{D}$ & $\mathrm{D}$ & $\mathrm{D}$ & $\mathrm{D}$ & \\
\hline & & 225 & 30 & $\mathrm{D}$ & $\mathrm{D}$ & $\mathrm{D}$ & $\mathrm{D}$ & \multirow[t]{4}{*}{ Not shown } \\
\hline & & 300 & 30 & $\mathrm{D}$ & $\mathrm{D}$ & $\mathrm{D}$ & $\mathrm{D}$ & \\
\hline & & 375 & 30 & ND & ND & ND & ND & \\
\hline & & A50 & 30 & ND & ND & ND & ND & \\
\hline
\end{tabular}

* Crack could not be detected at any heating time or delay time when Specimen WD-3 was tested under the outdoor condition (see Figure A.223 to Figures A.228). 
Table A.8 (continued) The active approach results from Specimen WD-3 (tested under the enclosed laboratory condition)

\begin{tabular}{|c|c|c|c|c|c|c|c|c|}
\hline \multirow{2}{*}{$\begin{array}{l}\text { Visible crack length (mm.) } \\
\text { and number of loading } \\
\text { cycles }\end{array}$} & \multirow[t]{2}{*}{$\begin{array}{c}\text { Types of } \\
\text { investigation }\end{array}$} & \multirow{2}{*}{$\begin{array}{l}\text { Distance from } \\
\text { IR camera to } \\
\text { test specimen } \\
\quad(\mathrm{mm} .)\end{array}$} & \multirow{2}{*}{$\begin{array}{l}\text { Heating } \\
\text { time } \\
\text { (second) }\end{array}$} & \multicolumn{4}{|c|}{$\begin{array}{c}\text { Delay Time } \\
\text { (Second) }\end{array}$} & \multirow[t]{2}{*}{ Figure } \\
\hline & & & & 1 & 3 & 6 & 9 & \\
\hline \multirow{7}{*}{$\begin{array}{c}25.5 \mathrm{~mm} . @ 1,737,550 * \\
\text { (initial surface temperature } \\
=21.8^{\circ} \mathrm{C} \text { ) }\end{array}$} & \multirow{7}{*}{$\begin{array}{c}\text { Active approach } \\
\text { (specimen was painted } \\
\text { with real color used on } \\
\text { bridge structure) }\end{array}$} & \multirow[t]{3}{*}{150} & 30 & $\mathrm{D}$ & $\mathrm{D}$ & $\mathrm{D}$ & $\mathrm{D}$ & \multirow[t]{3}{*}{ Not shown } \\
\hline & & & 60 & D & D & $\mathrm{D}$ & $\mathrm{D}$ & \\
\hline & & & 90 & D & $\mathrm{D}$ & D & $\mathrm{D}$ & \\
\hline & & 225 & 30 & $\mathrm{D}$ & $\mathrm{D}$ & $\mathrm{D}$ & $\mathrm{D}$ & \multirow[t]{4}{*}{ Not shown } \\
\hline & & 300 & 30 & $\mathrm{D}$ & D & $\mathrm{D}$ & $\mathrm{D}$ & \\
\hline & & 375 & 30 & ND & ND & ND & ND & \\
\hline & & 450 & 30 & ND & ND & ND & ND & \\
\hline
\end{tabular}

* Crack could not be detected at any heating time or delay time when Specimen WD-3 was tested under the outdoor condition (see Figure A.223 to Figures A.228). 
Table A.8 (continued) The active approach results from Specimen WD-3 (tested under the enclosed laboratory condition)

\begin{tabular}{|c|c|c|c|c|c|c|c|c|}
\hline \multirow{2}{*}{$\begin{array}{l}\text { Visible crack length (mm.) } \\
\text { and number of loading } \\
\text { cycles }\end{array}$} & \multirow[t]{2}{*}{$\begin{array}{c}\text { Types of } \\
\text { investigation }\end{array}$} & \multirow{2}{*}{$\begin{array}{l}\text { Distance from } \\
\text { IR camera to } \\
\text { test specimen } \\
\quad(\mathrm{mm} .)\end{array}$} & \multirow{2}{*}{$\begin{array}{l}\text { Heating } \\
\text { time } \\
\text { (second) }\end{array}$} & \multicolumn{4}{|c|}{$\begin{array}{c}\text { Delay Time } \\
\text { (Second) }\end{array}$} & \multirow[t]{2}{*}{ Figure } \\
\hline & & & & 1 & 3 & 6 & 9 & \\
\hline \multirow{8}{*}{$\begin{array}{c}28.5 \mathrm{~mm} . @ 1,739,550 * \\
\text { (initial surface temperature } \\
=23.3^{\circ} \mathrm{C} \text { ) }\end{array}$} & \multirow{8}{*}{$\begin{array}{c}\text { Active approach } \\
\text { (specimen was painted } \\
\text { with real color used on } \\
\text { bridge structure) }\end{array}$} & \multirow[t]{3}{*}{150} & 30 & $\mathrm{D}$ & $\mathrm{D}$ & $\mathrm{D}$ & $\mathrm{D}$ & \multirow[t]{3}{*}{ Not shown } \\
\hline & & & 60 & $\mathrm{D}$ & $\mathrm{D}$ & $\mathrm{D}$ & $\mathrm{D}$ & \\
\hline & & & 90 & $\mathrm{D}$ & $\mathrm{D}$ & $\mathrm{D}$ & $\mathrm{D}$ & \\
\hline & & 225 & 30 & $\mathrm{D}$ & $\mathrm{D}$ & $\mathrm{D}$ & $\mathrm{D}$ & \multirow[t]{5}{*}{ A.251-A.252 } \\
\hline & & 300 & 30 & $\mathrm{D}$ & $\mathrm{D}$ & $\mathrm{D}$ & $\mathrm{D}$ & \\
\hline & & 375 & 30 & $\mathrm{D}$ & $\mathrm{D}$ & $\mathrm{D}$ & $\mathrm{D}$ & \\
\hline & & 450 & 30 & $\mathrm{D}$ & $\mathrm{D}$ & $\mathrm{D}$ & $\mathrm{D}$ & \\
\hline & & 525 & 30 & ND & ND & ND & ND & \\
\hline
\end{tabular}

* Crack could not be detected at any heating time or delay time when Specimen WD-3 was tested under the outdoor condition (see Figure A.223 to Figures A.228). 
Table A.9 The active approach results from Specimen WD-4 (tested under the enclosed laboratory condition)

\begin{tabular}{|c|c|c|c|c|c|c|c|c|}
\hline \multirow{2}{*}{$\begin{array}{l}\text { Visible crack length (mm.) } \\
\text { and number of loading } \\
\text { cycles }\end{array}$} & \multirow[t]{2}{*}{$\begin{array}{c}\text { Types of } \\
\text { investigation }\end{array}$} & \multirow{2}{*}{$\begin{array}{l}\text { Distance from } \\
\text { IR camera to } \\
\text { test specimen } \\
\quad(\mathrm{mm} .)\end{array}$} & \multirow{2}{*}{$\begin{array}{l}\text { Heating } \\
\text { time } \\
\text { (second) }\end{array}$} & \multicolumn{4}{|c|}{$\begin{array}{l}\text { Delay Time } \\
\text { (Second) }\end{array}$} & \multirow[t]{2}{*}{ Figure } \\
\hline & & & & 1 & 3 & 6 & 9 & \\
\hline \multirow{4}{*}{$\begin{array}{l}\text { Crack length was less } \\
\text { than } 18.8 \mathrm{~mm} \text {. and number } \\
\text { of loading cycles were } \\
\text { less than } 1,780,000 \text { cycles } * \\
\text { (average initial surface } \\
\text { temperature }=21.5{ }^{\circ} \mathrm{C} \text { ) }\end{array}$} & \multirow{4}{*}{$\begin{array}{c}\text { Active approach } \\
\text { (specimen was painted } \\
\text { with real color used on } \\
\text { bridge structure) }\end{array}$} & \multirow[t]{3}{*}{150} & 30 & ND & ND & ND & ND & \multirow[t]{3}{*}{ Not shown } \\
\hline & & & 60 & ND & ND & ND & ND & \\
\hline & & & 90 & ND & ND & ND & ND & \\
\hline & & $\begin{array}{c}\text { Not shorter than } \\
225\end{array}$ & $\mathrm{X}$ & $X$ & $X$ & $\mathrm{X}$ & $X$ & $X$ \\
\hline \multirow{7}{*}{$\begin{array}{c}18.8 \mathrm{~mm} . @ 1,780,00 * \\
\text { (initial surface temperature } \\
=23.6{ }^{\circ} \mathrm{C} \text { ) }\end{array}$} & \multirow{7}{*}{$\begin{array}{c}\text { Active approach } \\
\text { (specimen was painted } \\
\text { with real color used on } \\
\text { bridge structure) }\end{array}$} & \multirow[t]{3}{*}{150} & 30 & $\mathrm{D}$ & $\mathrm{D}$ & $\mathrm{D}$ & $\mathrm{D}$ & \multirow[t]{3}{*}{ Not shown } \\
\hline & & & 60 & $\mathrm{D}$ & $\mathrm{D}$ & $\mathrm{D}$ & $\mathrm{D}$ & \\
\hline & & & 90 & $\mathrm{D}$ & $\mathrm{D}$ & $\mathrm{D}$ & $\mathrm{D}$ & \\
\hline & & 225 & 30 & $\mathrm{D}$ & $\mathrm{D}$ & $\mathrm{D}$ & $\mathrm{D}$ & \multirow[t]{4}{*}{ Not shown } \\
\hline & & 300 & 30 & $\mathrm{D}$ & $\mathrm{D}$ & $\mathrm{D}$ & $\mathrm{D}$ & \\
\hline & & 375 & 30 & ND & ND & ND & ND & \\
\hline & & A50 & 30 & ND & ND & ND & ND & \\
\hline
\end{tabular}

* Crack could not be detected at any heating time or delay time when Specimen WD-4 was tested under the outdoor condition (see Figure A.241 to Figures A.246). 
Table A.9 (continued) The active approach results from Specimen WD-4 (tested under the enclosed laboratory condition)

\begin{tabular}{|c|c|c|c|c|c|c|c|c|}
\hline \multirow{2}{*}{$\begin{array}{l}\text { Visible crack length (mm.) } \\
\text { and number of loading } \\
\text { cycles }\end{array}$} & \multirow[t]{2}{*}{$\begin{array}{c}\text { Types of } \\
\text { investigation }\end{array}$} & \multirow{2}{*}{$\begin{array}{l}\text { Distance from } \\
\text { IR camera to } \\
\text { test specimen } \\
(\mathrm{mm} .)\end{array}$} & \multirow{2}{*}{$\begin{array}{l}\text { Heating } \\
\text { time } \\
\text { (second) }\end{array}$} & \multicolumn{4}{|c|}{$\begin{array}{l}\text { Delay Time } \\
\text { (Second) }\end{array}$} & \multirow[t]{2}{*}{ Figure } \\
\hline & & & & 1 & 3 & 6 & 9 & \\
\hline \multirow{7}{*}{$\begin{array}{c}22.2 \mathrm{~mm} . @ 1,845,500 * \\
\text { (initial surface temperature } \\
=21.8^{\circ} \mathrm{C} \text { ) }\end{array}$} & \multirow{7}{*}{$\begin{array}{c}\text { Active approach } \\
\text { (specimen was painted } \\
\text { with real color used on } \\
\text { bridge structure) }\end{array}$} & \multirow[t]{3}{*}{150} & 30 & $\mathrm{D}$ & $\mathrm{D}$ & $\mathrm{D}$ & $\mathrm{D}$ & \multirow[t]{3}{*}{ A. $229-$ A. 246} \\
\hline & & & 60 & $\mathrm{D}$ & $\mathrm{D}$ & $\mathrm{D}$ & $\mathrm{D}$ & \\
\hline & & & 90 & $\mathrm{D}$ & $\mathrm{D}$ & $\mathrm{D}$ & $\mathrm{D}$ & \\
\hline & & 225 & 30 & $\mathrm{D}$ & $\mathrm{D}$ & $\mathrm{D}$ & $\mathrm{D}$ & \multirow[t]{4}{*}{ Not shown } \\
\hline & & 300 & 30 & $\mathrm{D}$ & $\mathrm{D}$ & $\mathrm{D}$ & $\mathrm{D}$ & \\
\hline & & 375 & 30 & ND & ND & ND & ND & \\
\hline & & 450 & 30 & ND & ND & ND & ND & \\
\hline
\end{tabular}

* Crack could not be detected at any heating time or delay time when Specimen WD-4 was tested under the outdoor condition (see Figure A.241 to Figures A.246). 
Table A.9 (continued) The active approach results from Specimen WD-4 (tested under the enclosed laboratory condition)

\begin{tabular}{|c|c|c|c|c|c|c|c|c|}
\hline \multirow{2}{*}{$\begin{array}{l}\text { Visible crack length (mm.) } \\
\text { and number of loading } \\
\text { cycles }\end{array}$} & \multirow[t]{2}{*}{$\begin{array}{c}\text { Types of } \\
\text { investigation }\end{array}$} & \multirow{2}{*}{$\begin{array}{l}\text { Distance from } \\
\text { IR camera to } \\
\text { test specimen } \\
\quad(\mathrm{mm} .)\end{array}$} & \multirow{2}{*}{$\begin{array}{l}\text { Heating } \\
\text { time } \\
\text { (second) }\end{array}$} & \multicolumn{4}{|c|}{$\begin{array}{l}\text { Delay Time } \\
\text { (Second) }\end{array}$} & \multirow[t]{2}{*}{ Figure } \\
\hline & & & & 1 & 3 & 6 & 9 & \\
\hline \multirow{8}{*}{$\begin{array}{c}32.5 \mathrm{~mm} . @ 1,865,550 * \\
\text { (initial surface temperature } \\
=23.4{ }^{\circ} \mathrm{C} \text { ) }\end{array}$} & \multirow{8}{*}{$\begin{array}{c}\text { Active approach } \\
\text { (specimen was painted } \\
\text { with matte black color) }\end{array}$} & \multirow[t]{3}{*}{150} & 30 & $\mathrm{D}$ & $\mathrm{D}$ & $\mathrm{D}$ & $\mathrm{D}$ & \multirow[t]{3}{*}{ Not shown } \\
\hline & & & 60 & $\mathrm{D}$ & $\mathrm{D}$ & $\mathrm{D}$ & $\mathrm{D}$ & \\
\hline & & & 90 & $\mathrm{D}$ & $\mathrm{D}$ & $\mathrm{D}$ & $\mathrm{D}$ & \\
\hline & & 225 & 30 & $\mathrm{D}$ & $\mathrm{D}$ & $\mathrm{D}$ & $\mathrm{D}$ & \multirow[t]{5}{*}{ Not shown } \\
\hline & & 300 & 30 & $\mathrm{D}$ & $\mathrm{D}$ & $\mathrm{D}$ & $\mathrm{D}$ & \\
\hline & & 375 & 30 & $\mathrm{D}$ & $\mathrm{D}$ & $\mathrm{D}$ & $\mathrm{D}$ & \\
\hline & & 450 & 30 & $\mathrm{D}$ & $\mathrm{D}$ & $\mathrm{D}$ & $\mathrm{D}$ & \\
\hline & & 525 & 30 & ND & ND & ND & ND & \\
\hline
\end{tabular}

* Crack could not be detected at any heating time or delay time when Specimen WD-4 was tested under the outdoor condition (see Figure A.241 to Figures A.246). 


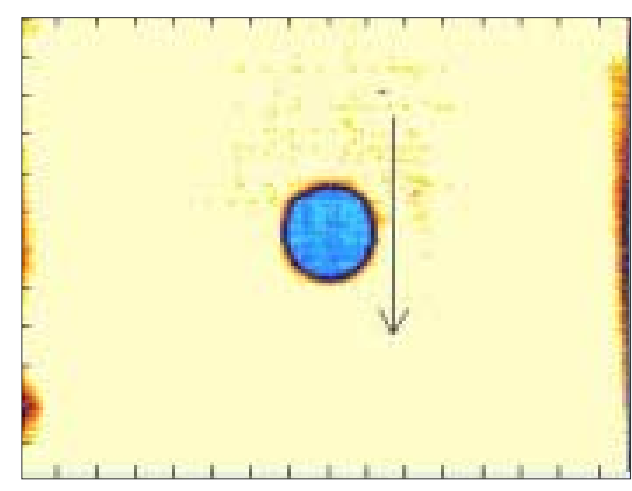

a) No applied load

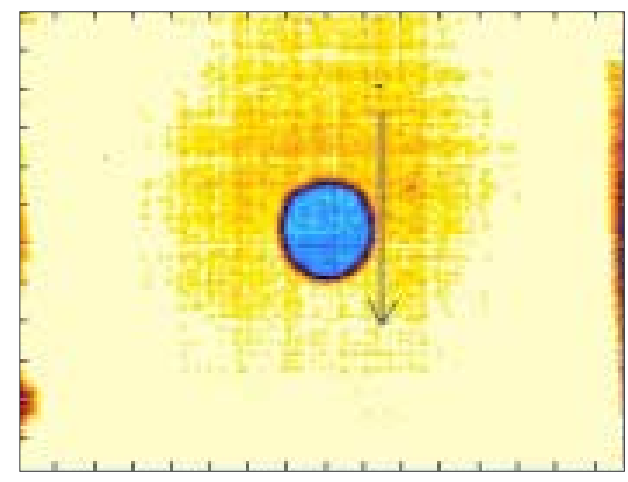

c) $165.5 \mathrm{MPa}$

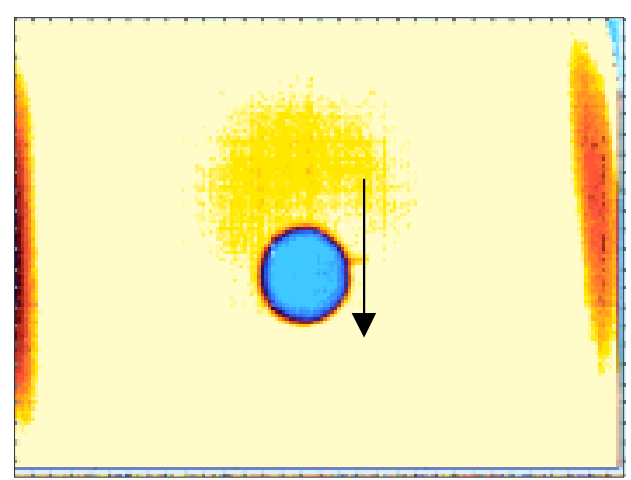

b) $144.8 \mathrm{MPa}$

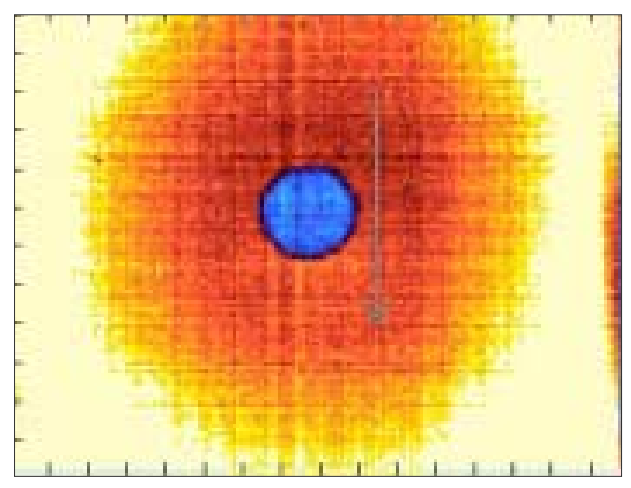

d) $186.2 \mathrm{MPa}$

Figure A.1 Thermal images of unpainted Specimen $\mathrm{CH}-2$ (using the passive approach). 


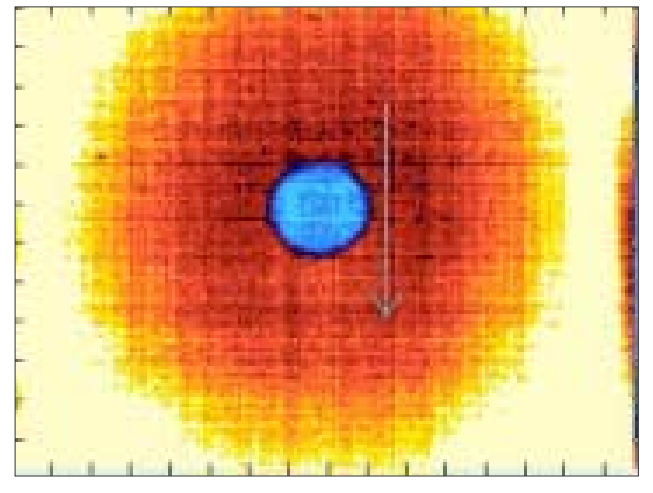

e) $206.9 \mathrm{MPa}$

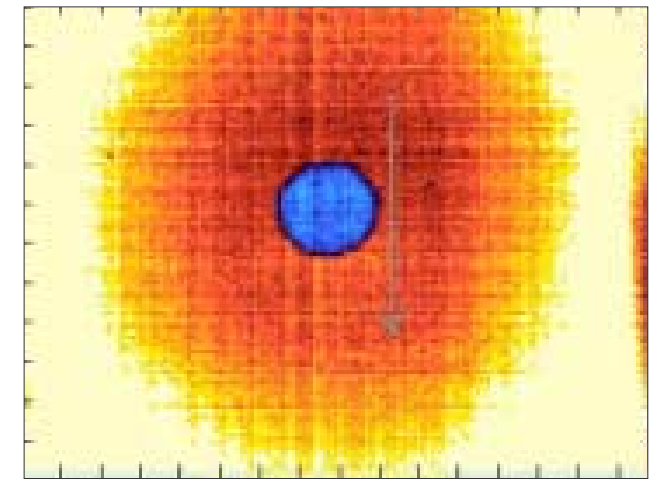

f) $227.5 \mathrm{MPa}$

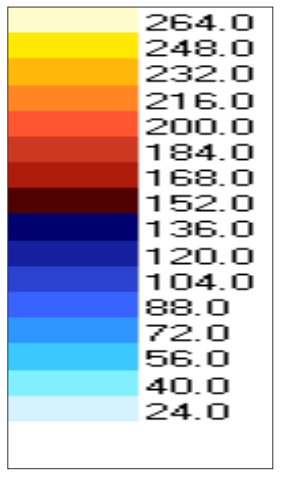

g) Thermal intensity color bar

Figure A.1 (continued) Thermal images of unpainted Specimen CH-2 (using the passive approach). 


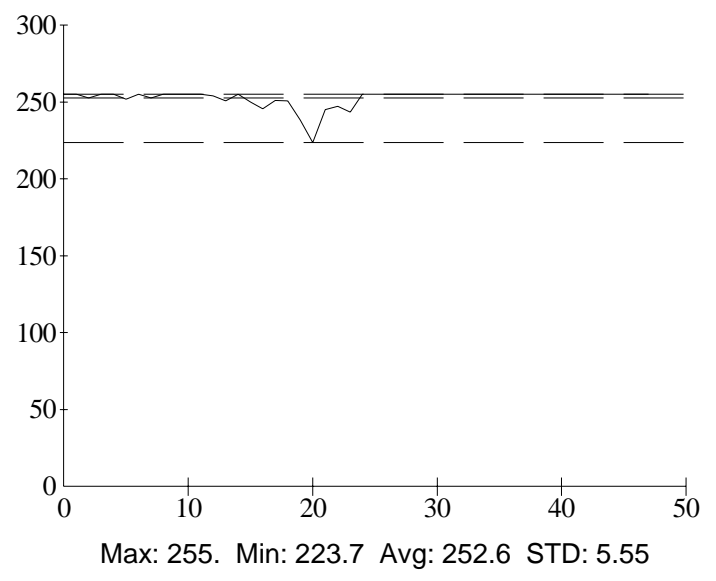

a) No applied load

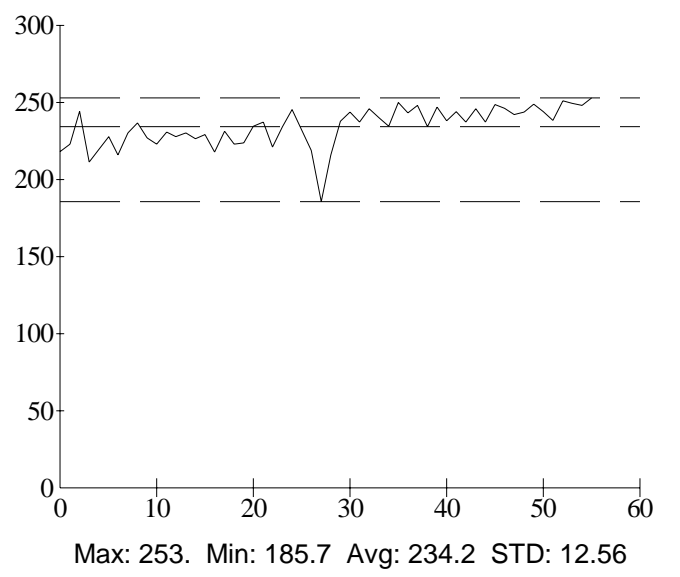

c) $165.5 \mathrm{MPa}$

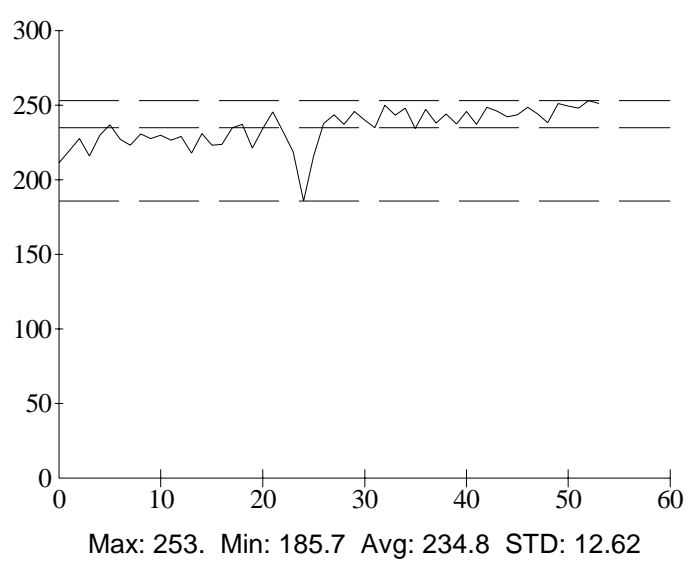

b) $144.8 \mathrm{MPa}$

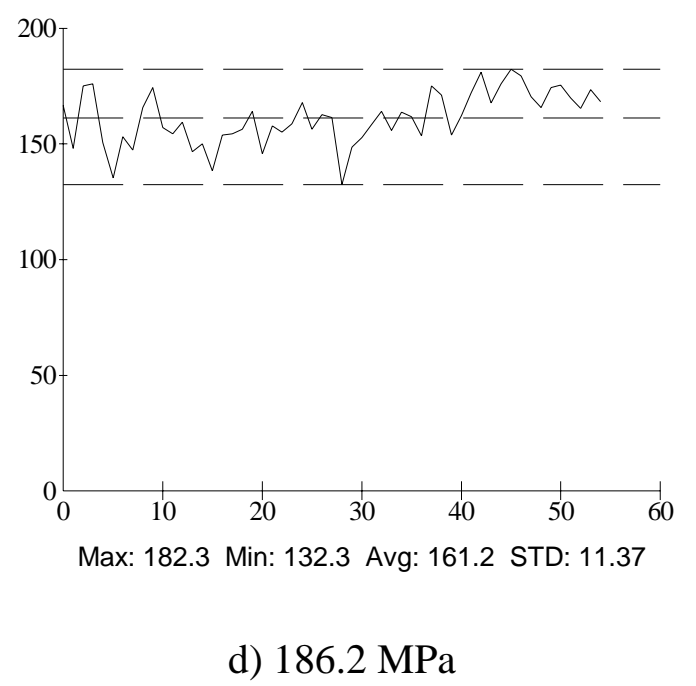

Figure A.2 Thermal intensity profiles along the line across the fatigue crack shown in Figure A.1. 

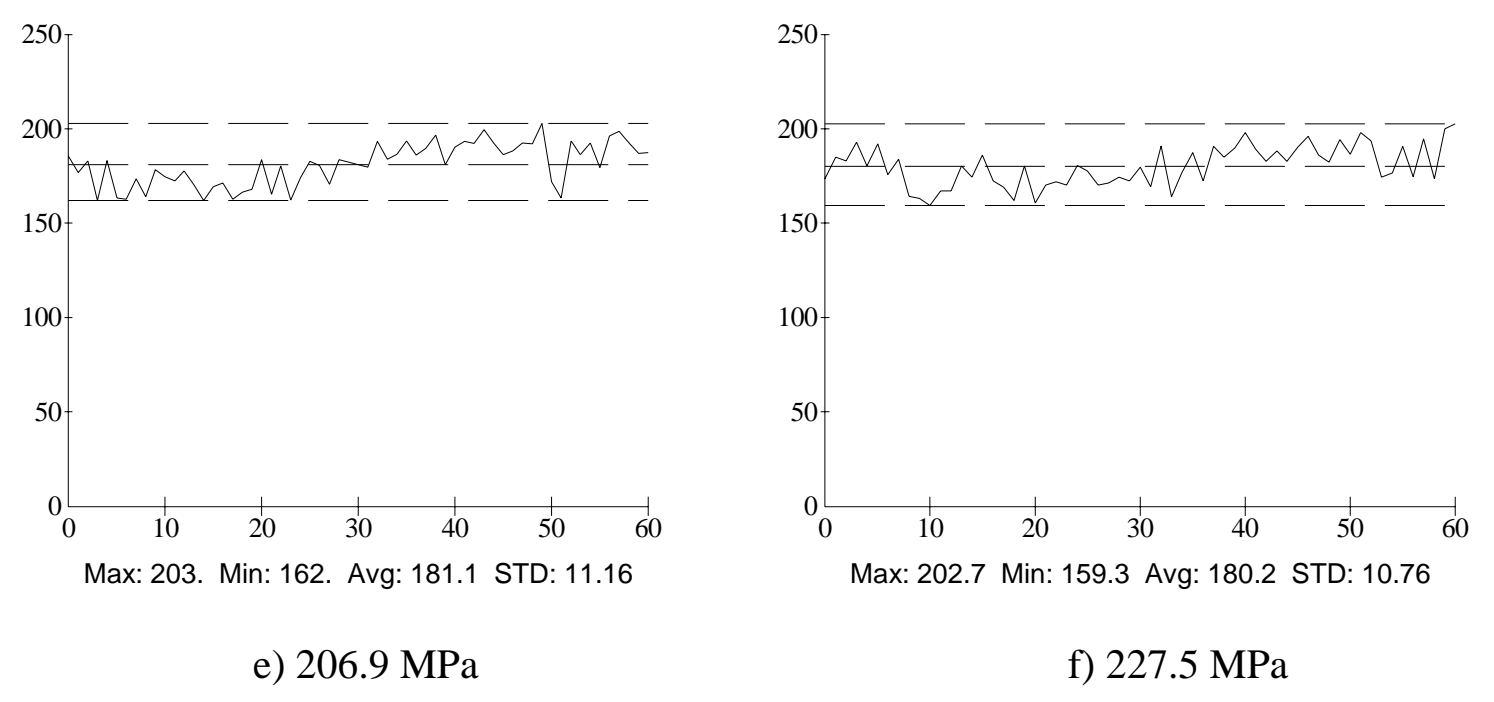

Figure A.2 (continued) The thermal intensity profiles along the line across the fatigue crack shown in Figure A.1. 


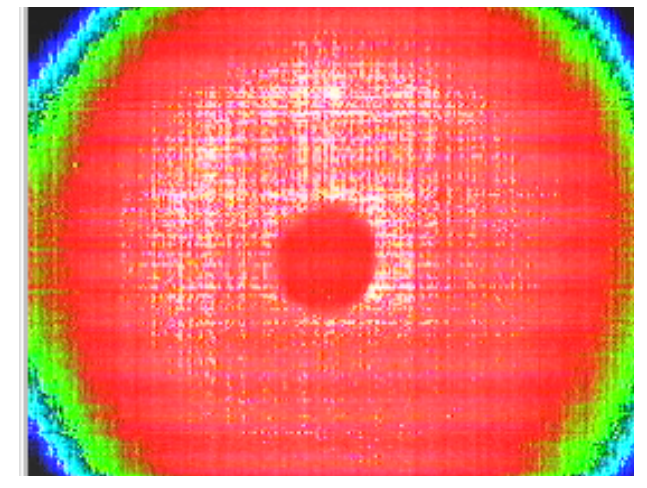

a) No applied load

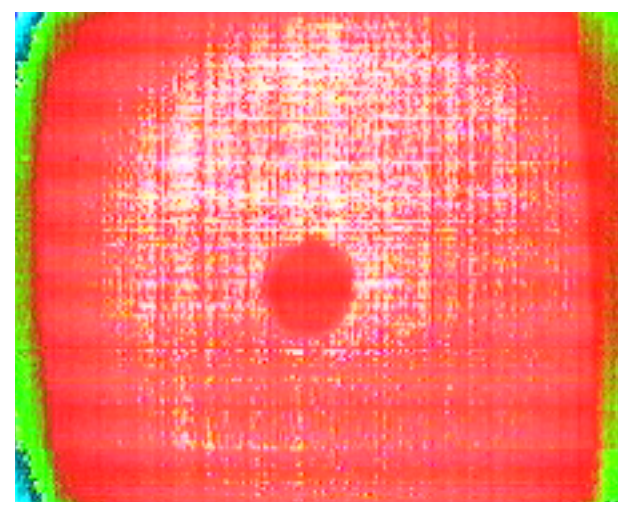

c) $165.5 \mathrm{MPa}$

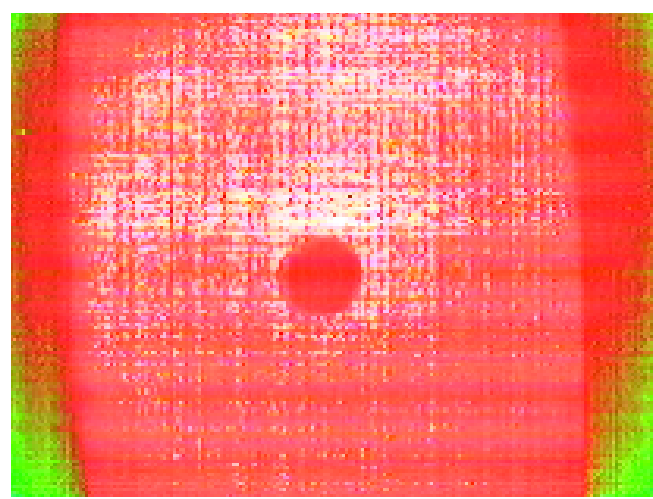

b) $144.8 \mathrm{MPa}$

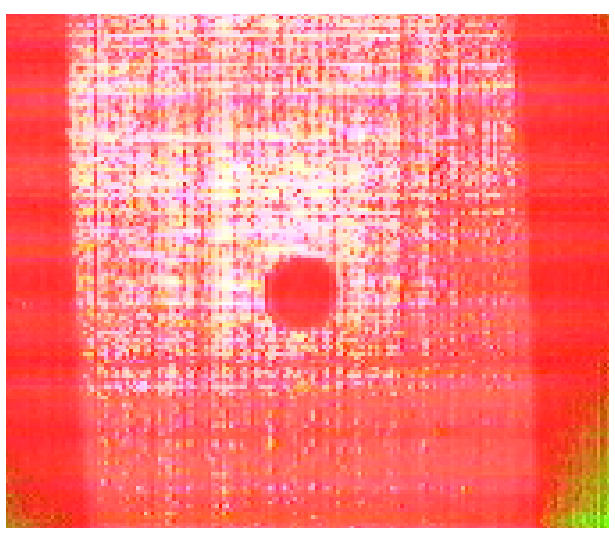

d) $186.2 \mathrm{MPa}$

Figure A.3 Thermal images of Specimen CH-2 (using the passive approach). 


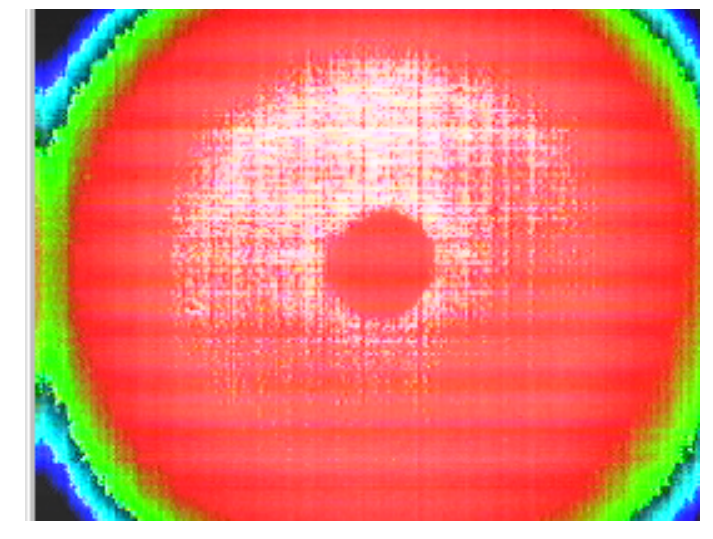

e) $206.9 \mathrm{MPa}$

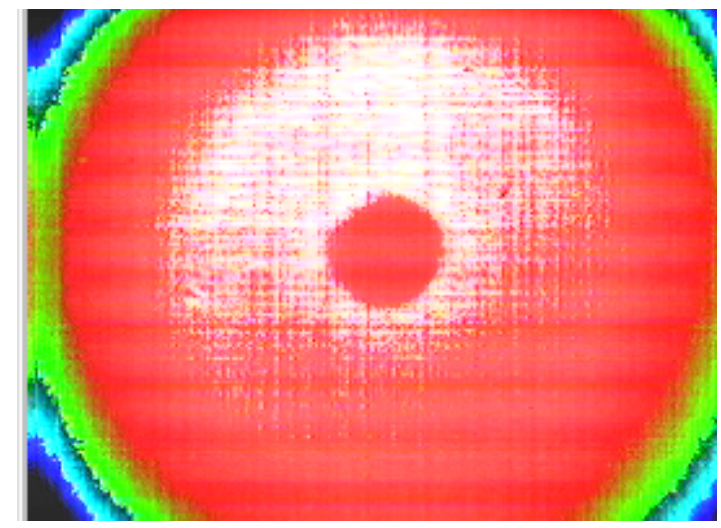

f) $227.5 \mathrm{MPa}$

Figure A.3 (continued) Thermal images of Specimen $\mathrm{CH}-2$ (using the passive approach). 


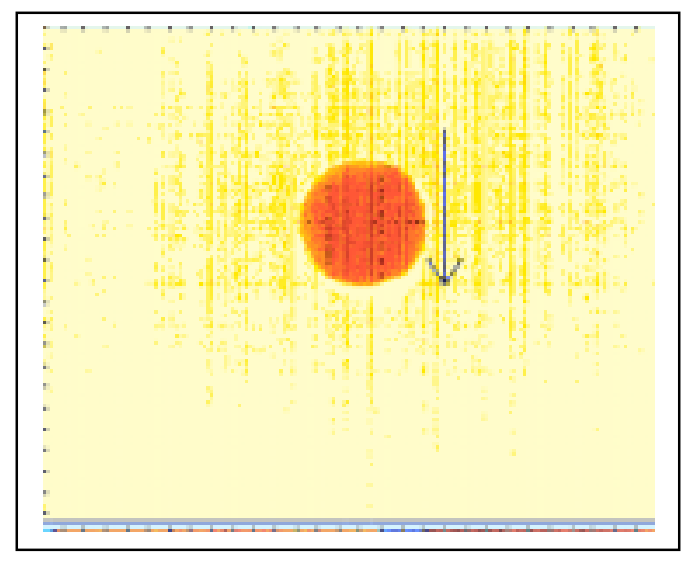

a) No applied load

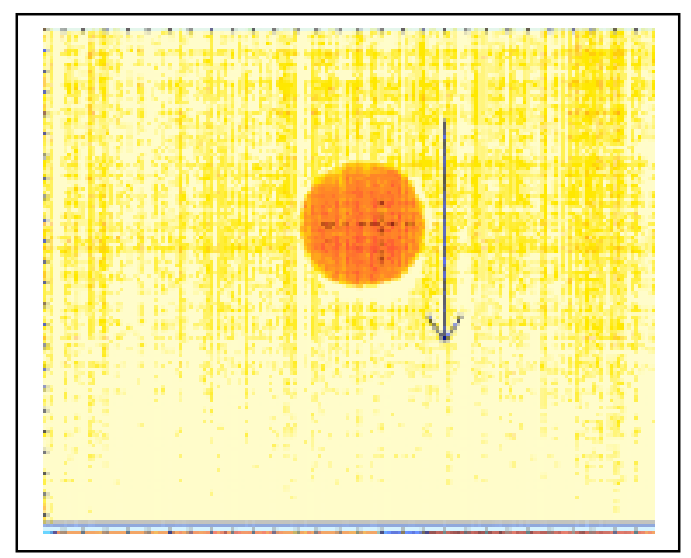

c) $68.9 \mathrm{MPa}$

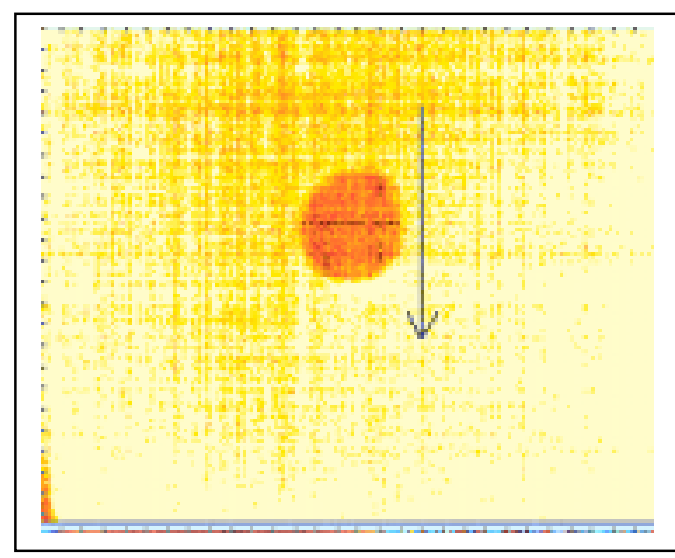

b) $34.5 \mathrm{MPa}$

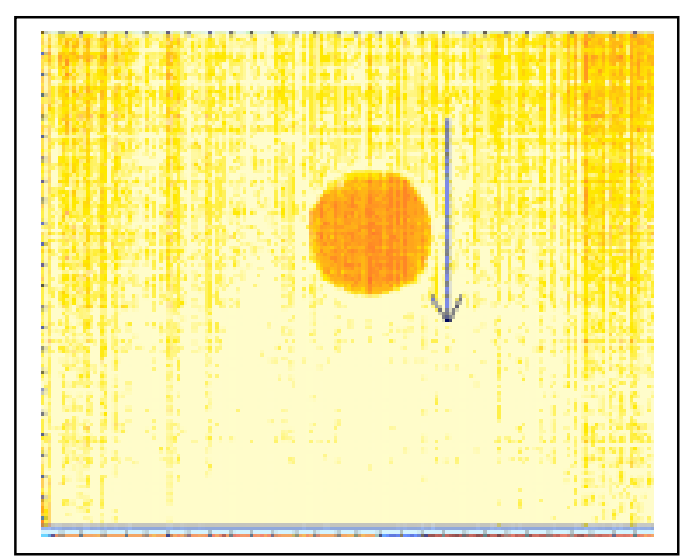

d) $103.4 \mathrm{MPa}$

Figure A.4 Thermal images of unpainted Specimen CH-3 (using the passive approach) at 400,000 loading cycles with various stresses. 


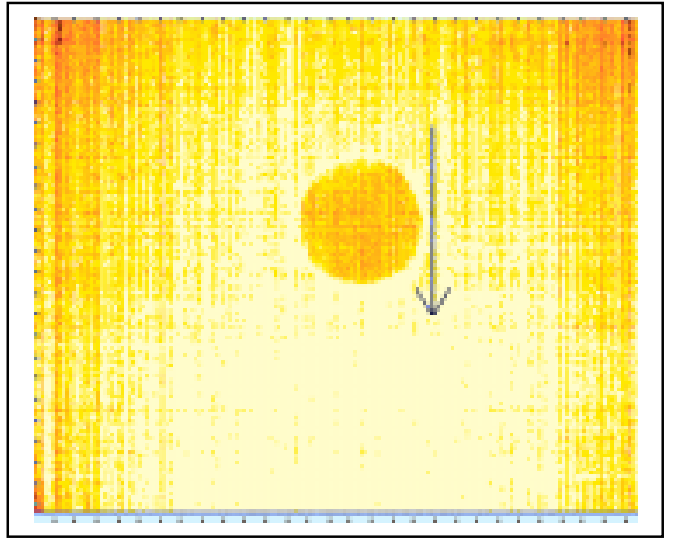

e) $137.9 \mathrm{MPa}$

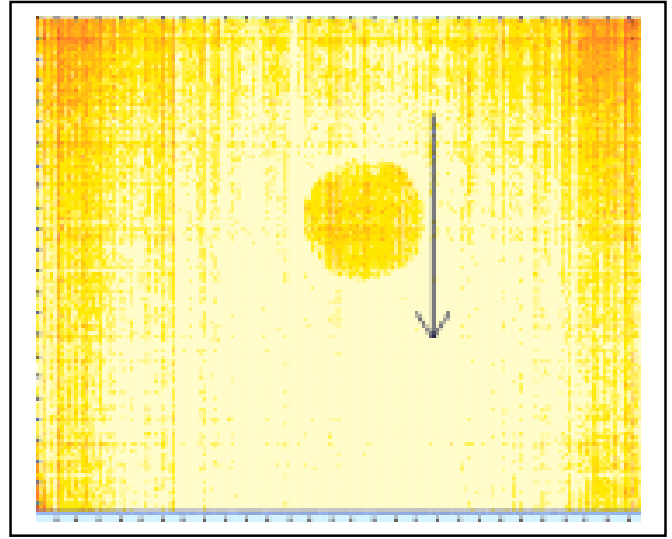

f) $172.5 \mathrm{MPa}$

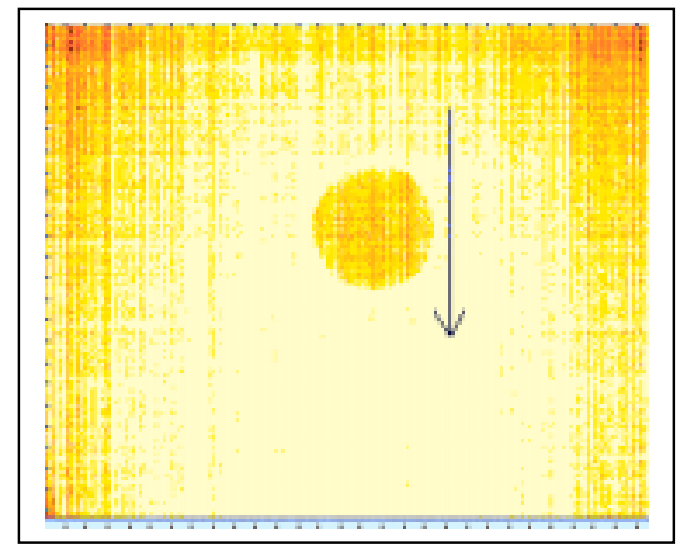

g) $207 \mathrm{MPa}$

Figure A.4 (continued) Thermal images of unpainted Specimen CH-3 (using the passive approach) at 400,000 loading cycles with various stresses. 


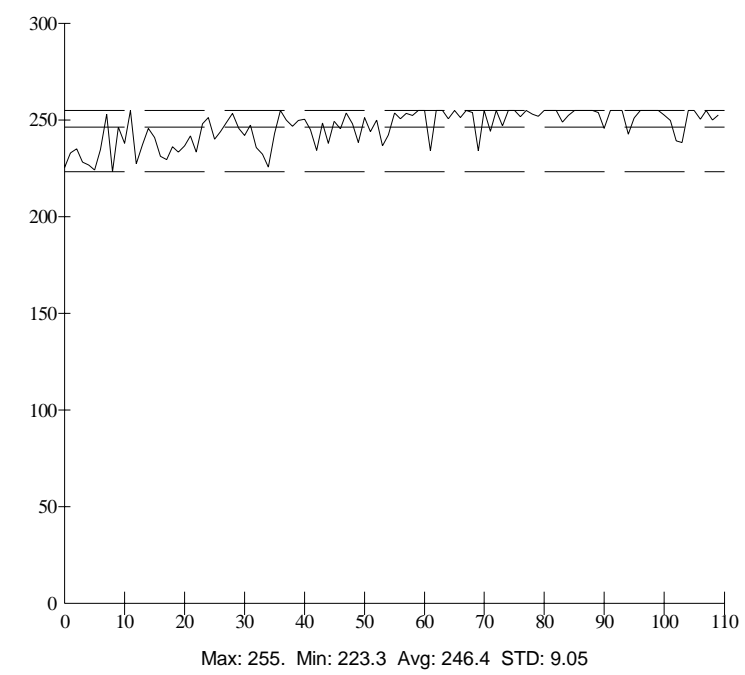

a) No applied load

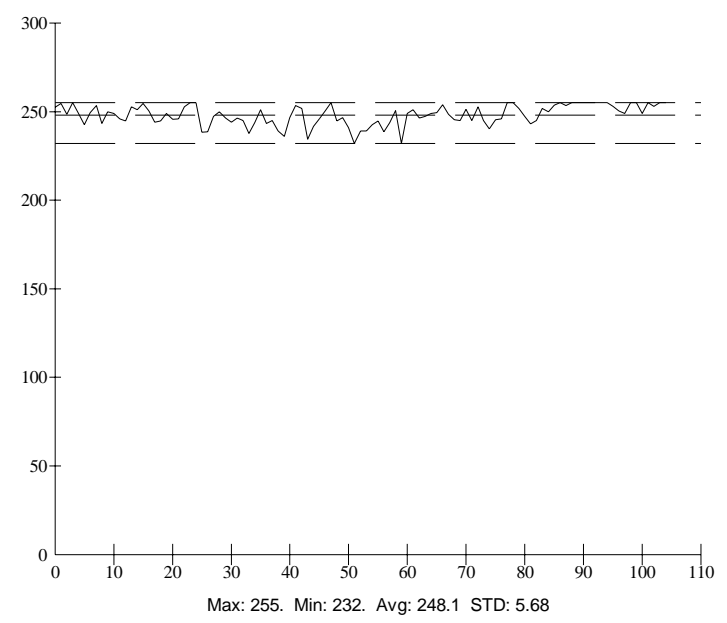

c) $68.9 \mathrm{MPa}$

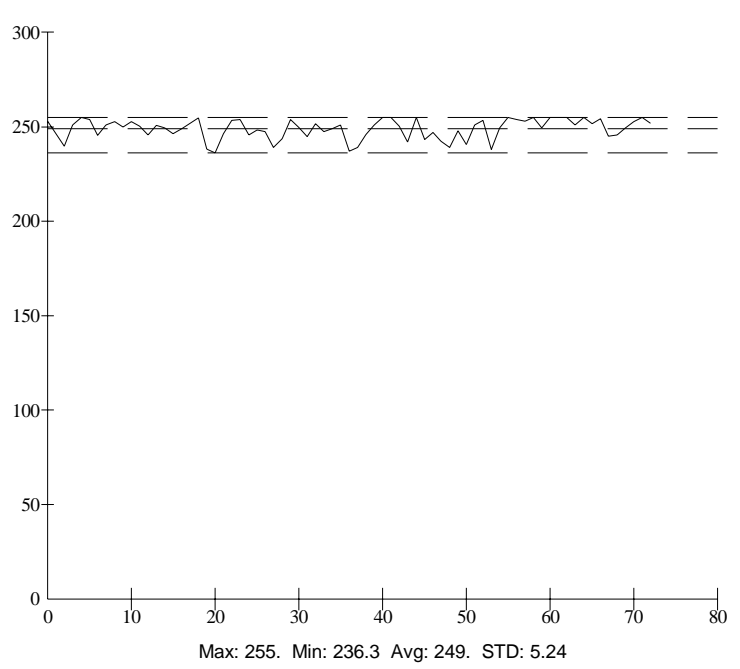

b) $34.5 \mathrm{MPa}$

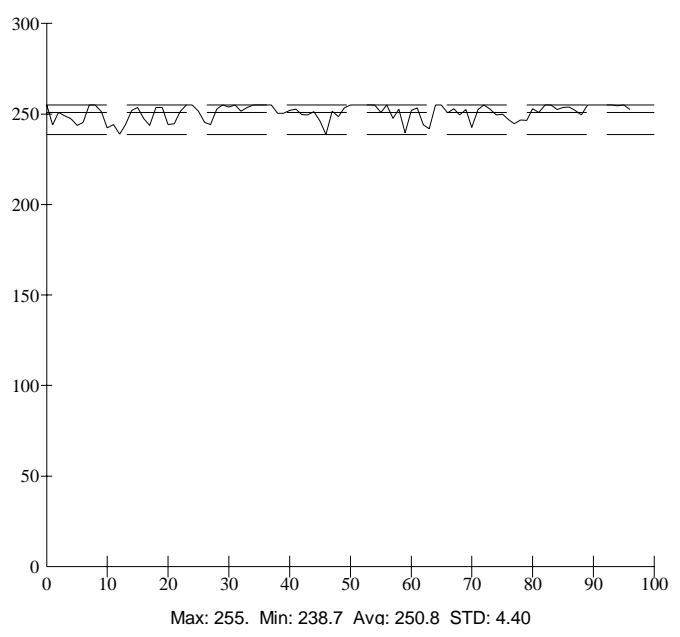

d) $103.4 \mathrm{MPa}$

Figure A.5 The thermal intensity profile along the line across the fatigue crack shown in Figure A.4. 

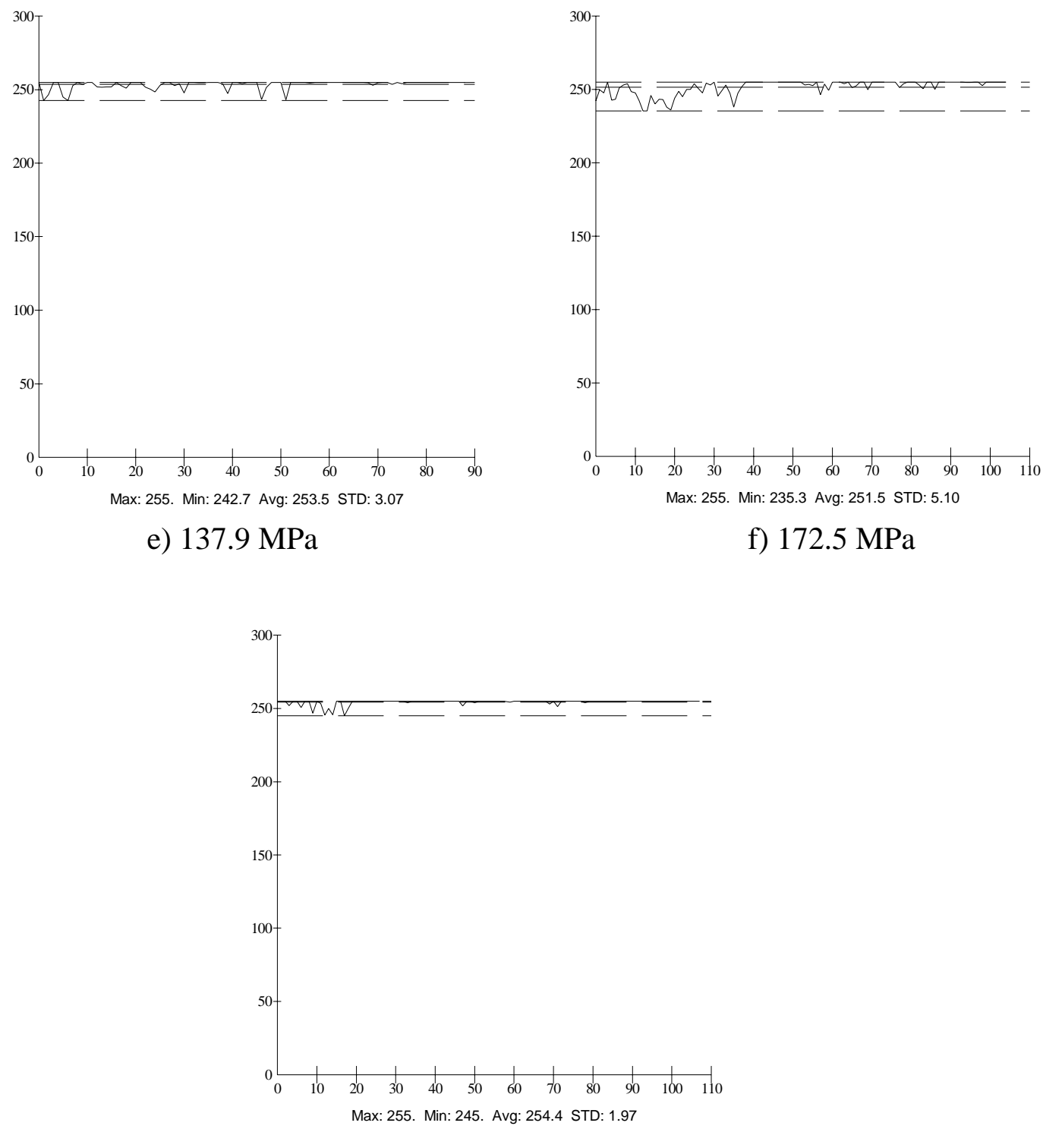

g) $207 \mathrm{MPa}$

Figure A.5 (continued) Thermal intensity profile along the line across the fatigue crack shown in Figure A.4. 


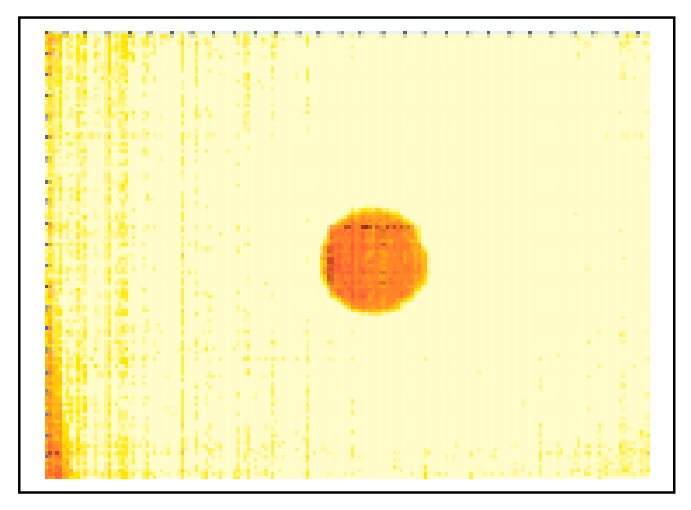

a) No applied load

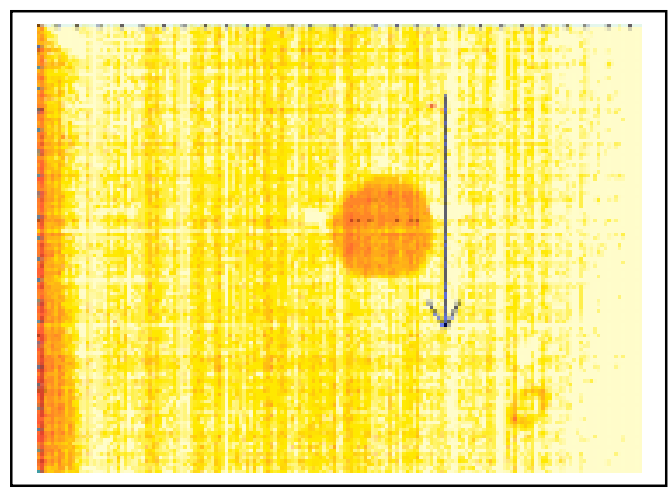

c) $68.9 \mathrm{MPa}$

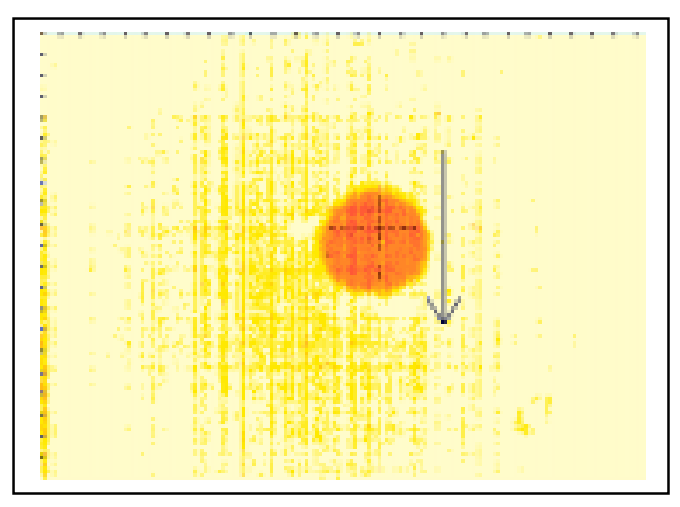

b) $34.5 \mathrm{MPa}$

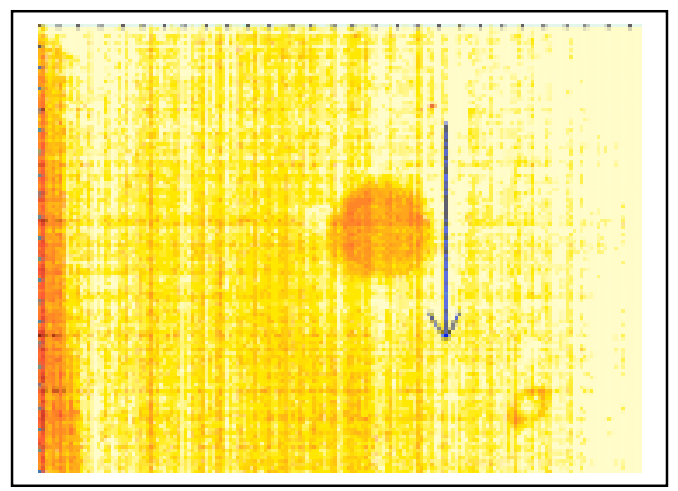

d) $103.4 \mathrm{MPa}$

Figure A.6 Thermal images of unpainted Specimen CH-3 (using the passive approach) at 500,000 loading cycles with various stresses. 


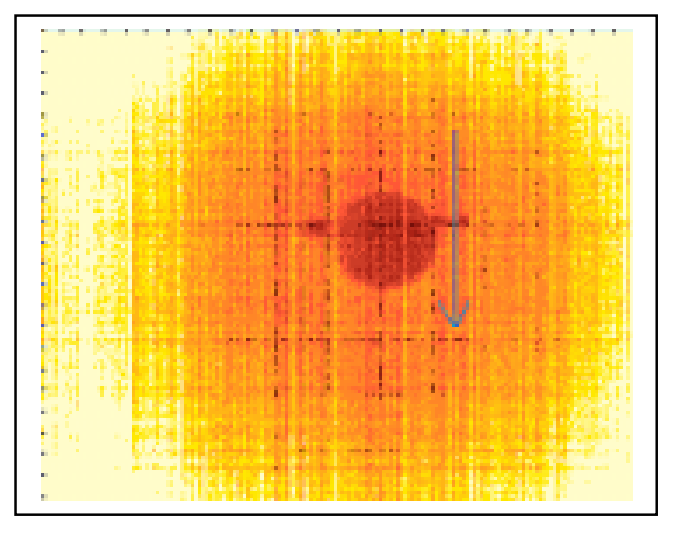

e) $137.9 \mathrm{MPa}$

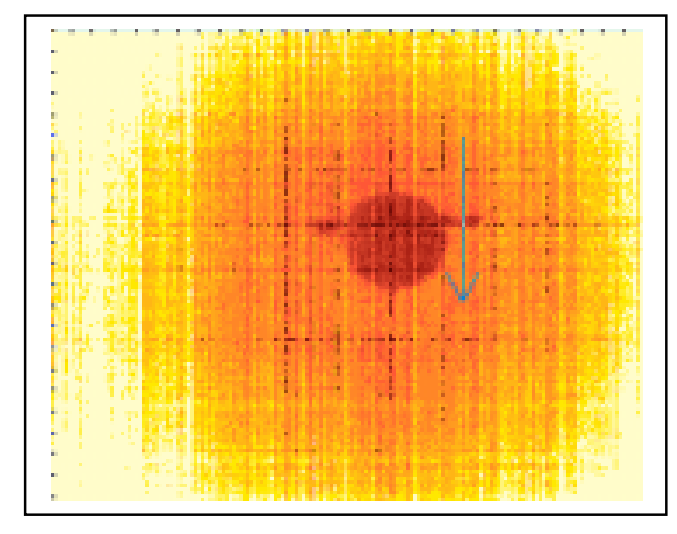

f) $172.5 \mathrm{MPa}$

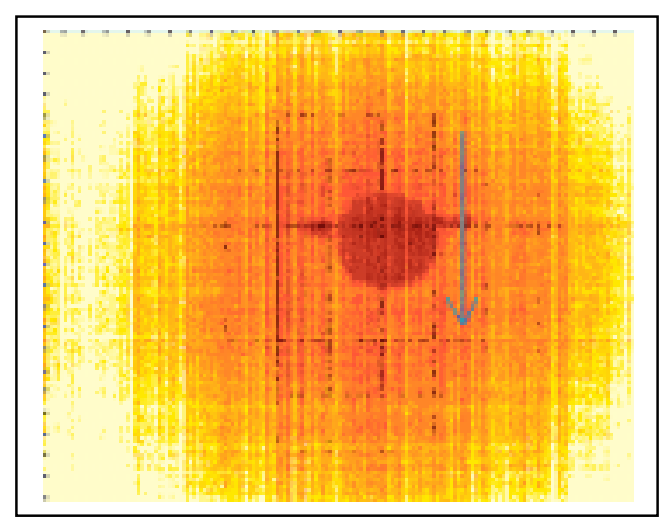

g) $207 \mathrm{MPa}$

Figure A.6 (continued) Thermal images of unpainted Specimen CH-3 (using the passive approach) at 500,000 loading cycles with various stresses. 


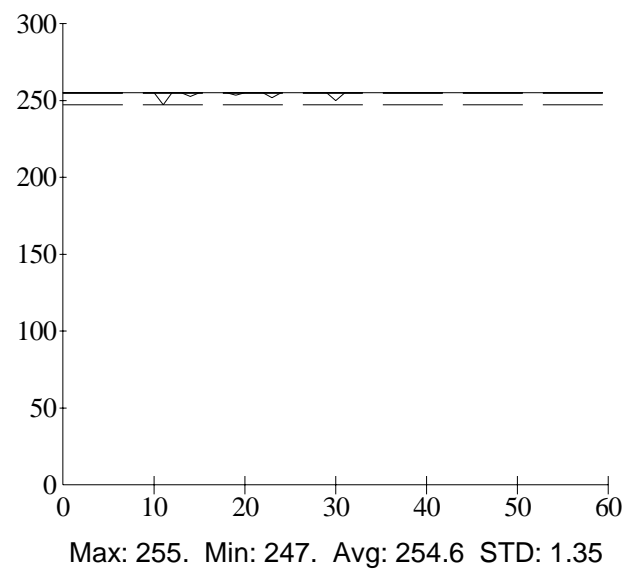

a) No applied load

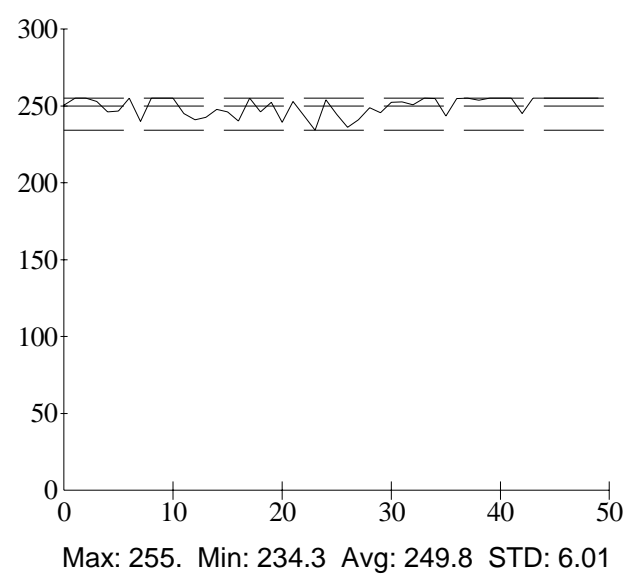

c) $68.9 \mathrm{MPa}$

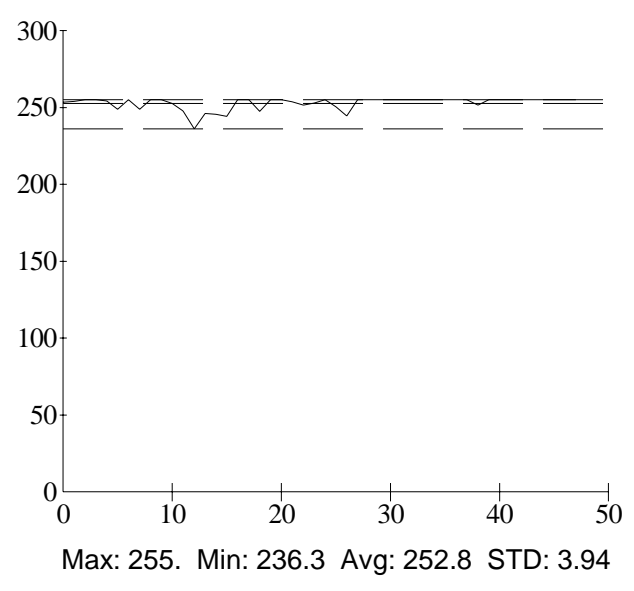

b) $34.5 \mathrm{MPa}$

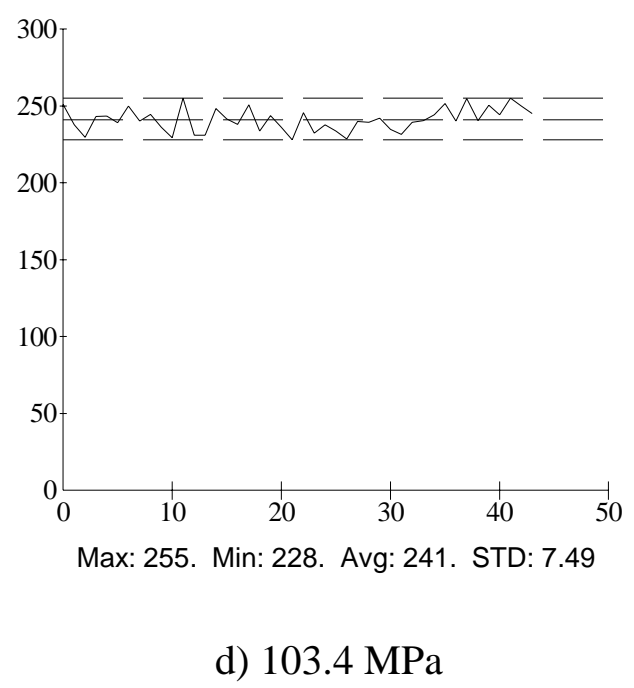

Figure A.7 The thermal intensity profile along the line across the fatigue crack shown in Figure A.6. 


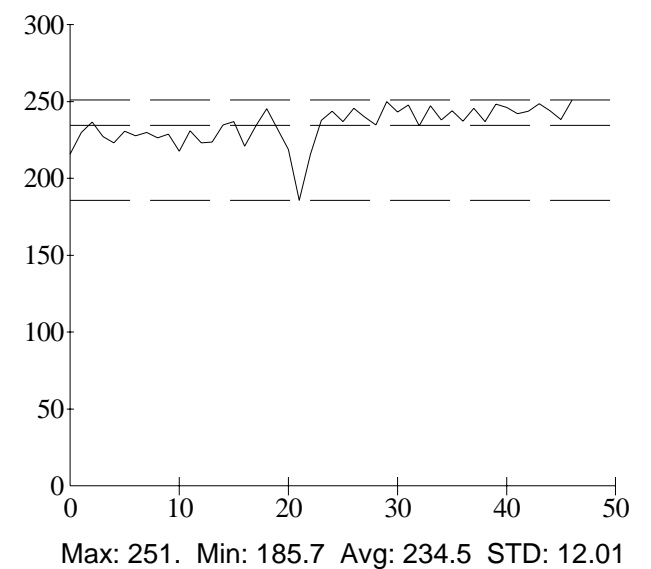

e) $137.9 \mathrm{MPa}$

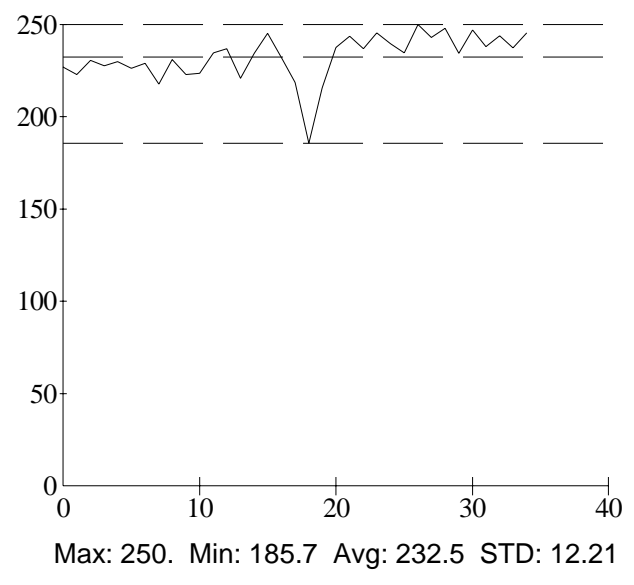

f) $172.5 \mathrm{MPa}$

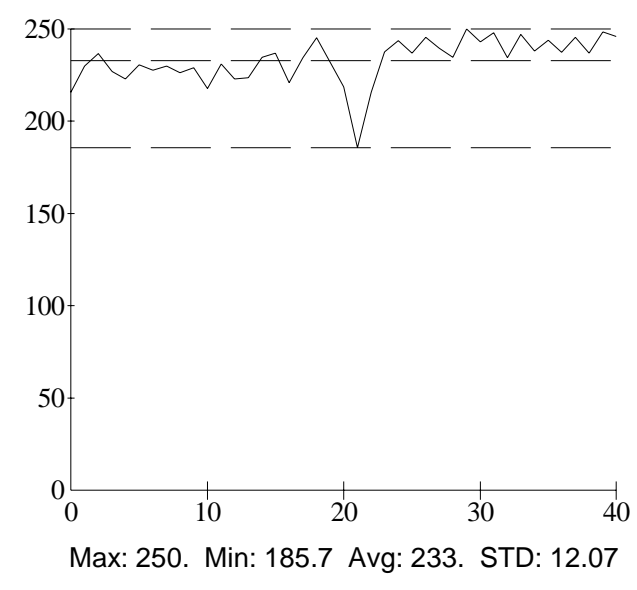

g) $207 \mathrm{MPa}$

Figure A.7 (continued) The thermal intensity profile along the line across the fatigue crack shown in Figure A.6. 


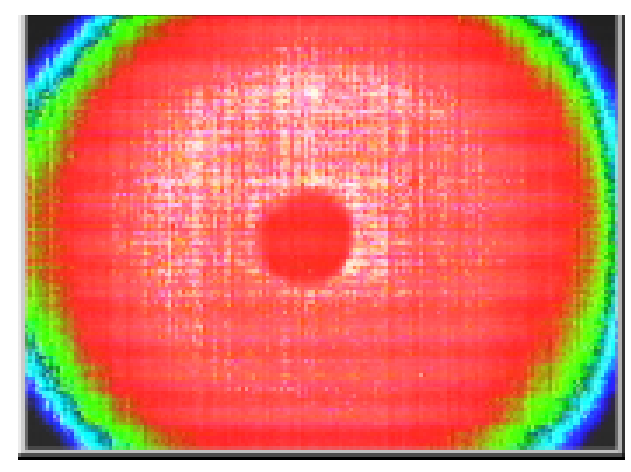

a) No applied load

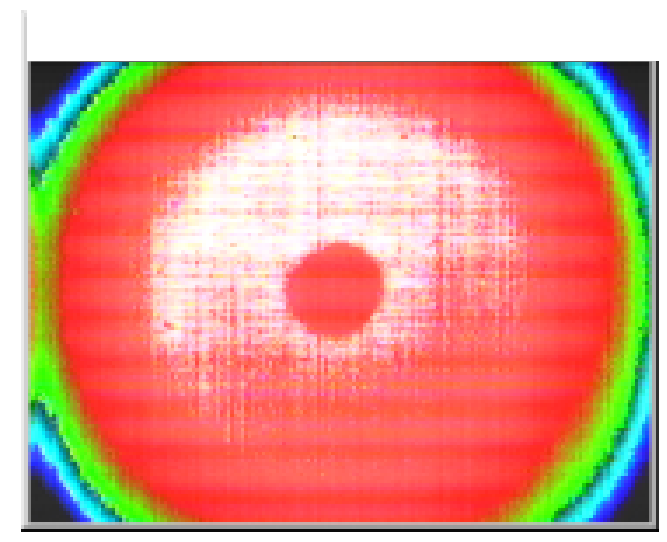

c) $68.9 \mathrm{MPa}$

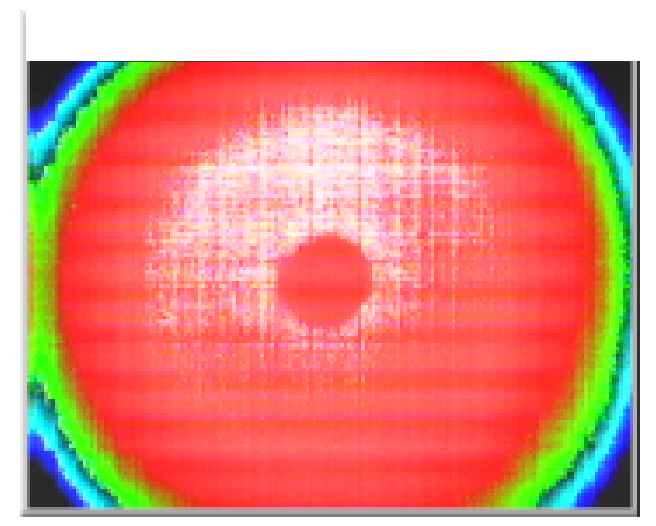

b) $34.5 \mathrm{MPa}$

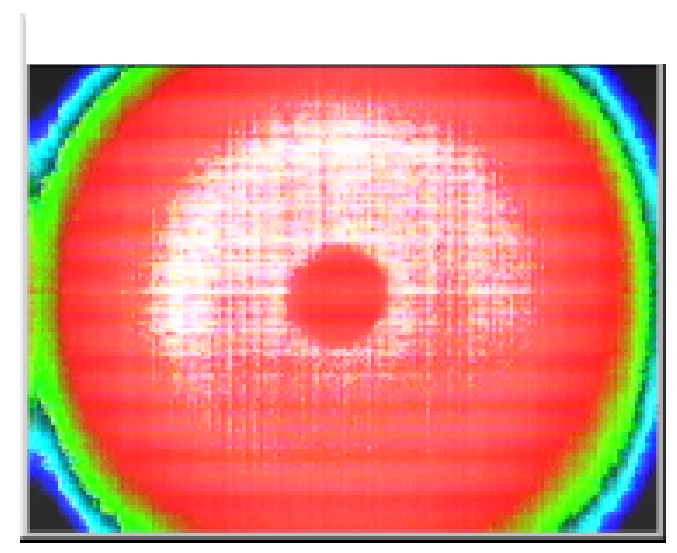

d) $103.4 \mathrm{MPa}$

Figure A.8 Thermal images of Specimen CH-3 (using the passive approach) at 500,000 loading cycles with various stresses. 


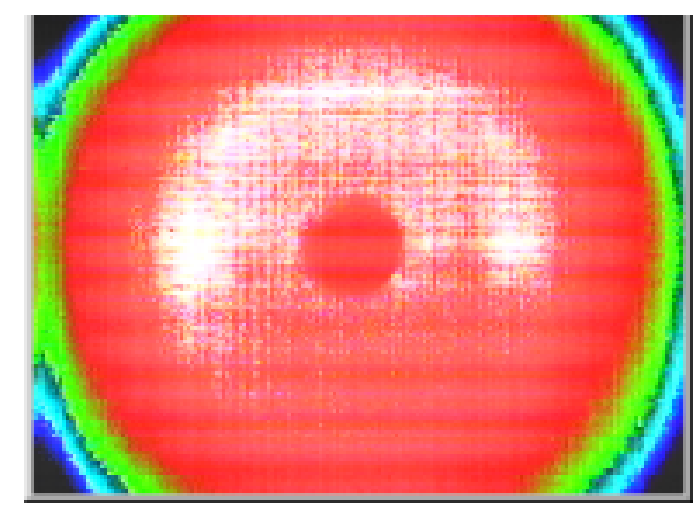

e) $137.9 \mathrm{MPa}$

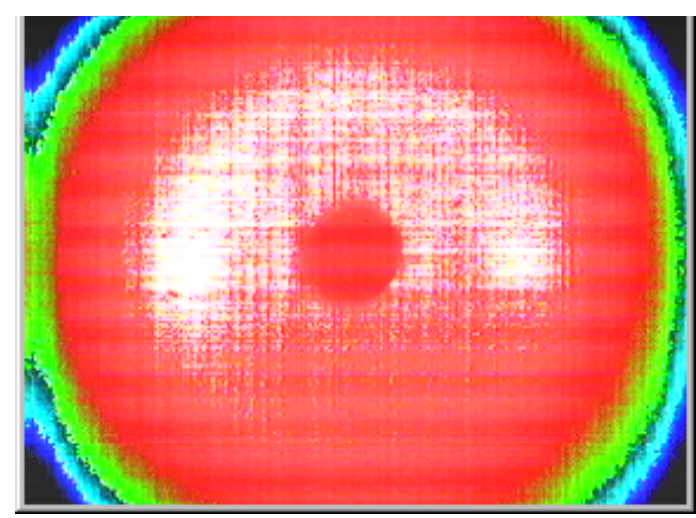

f) $172.5 \mathrm{MPa}$

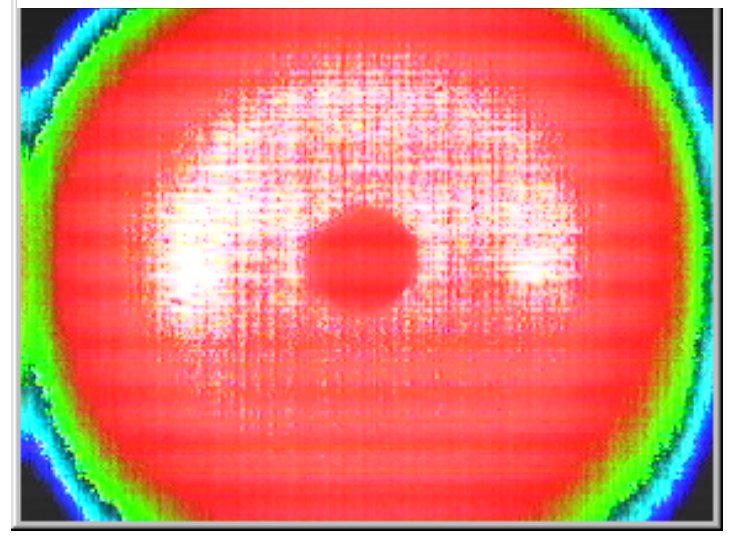

g) $207 \mathrm{MPa}$

Figure A.8 (continued) Thermal images of Specimen CH-3 (using the passive approach) at 500,000 loading cycles with various stresses. 


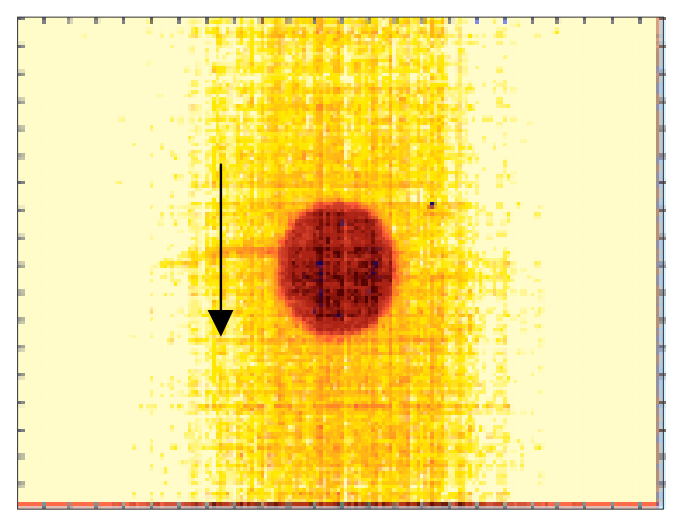

a) $150 \mathrm{~mm}$.

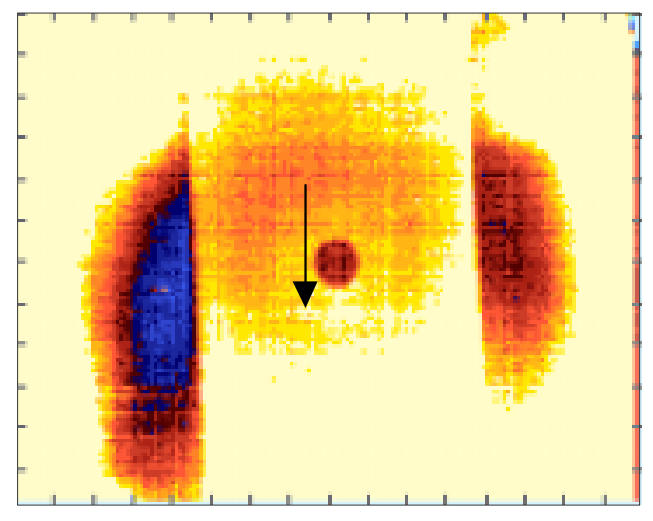

c) $300 \mathrm{~mm}$.

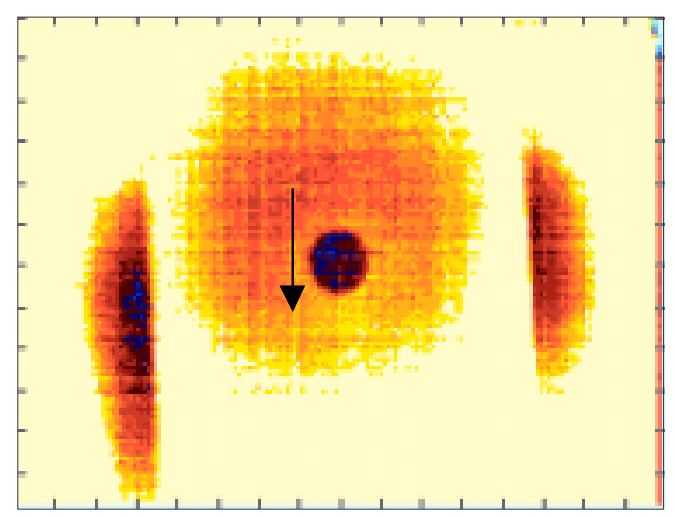

b) $225 \mathrm{~mm}$.

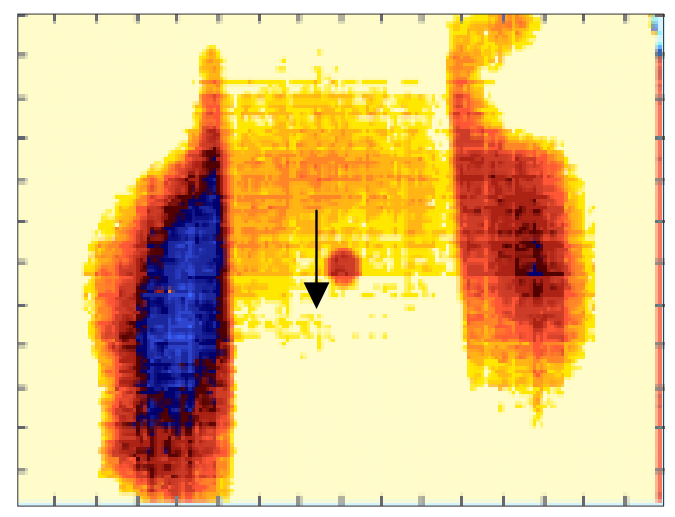

d) $375 \mathrm{~mm}$.

Figure A.9 Thermal images of unpainted Specimen $\mathrm{CH}-1$ taken at the various distances (no load is applied to the specimen). 


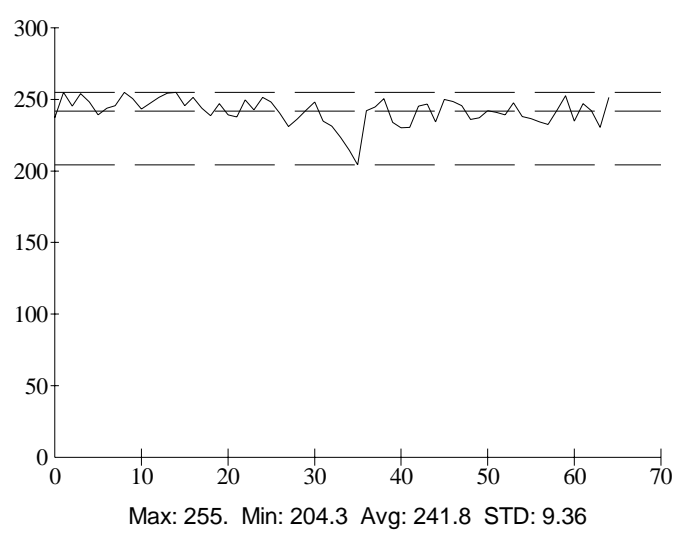

a) $150 \mathrm{~mm}$.

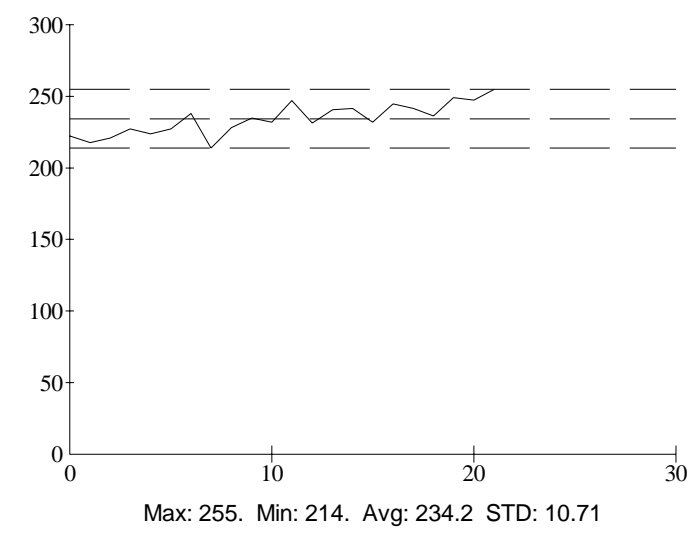

c) $300 \mathrm{~mm}$.

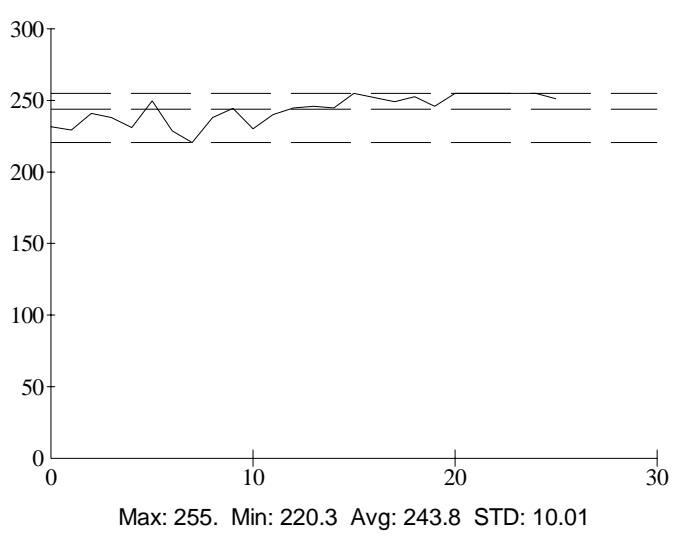

b) $225 \mathrm{~mm}$.

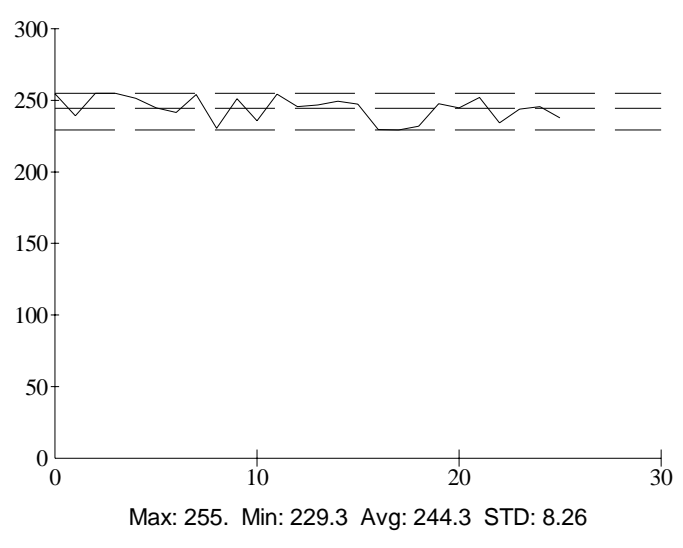

d) $375 \mathrm{~mm}$.

Figure A.10 Thermal intensity profile along the line across the fatigue crack shown in Figure A.9. 


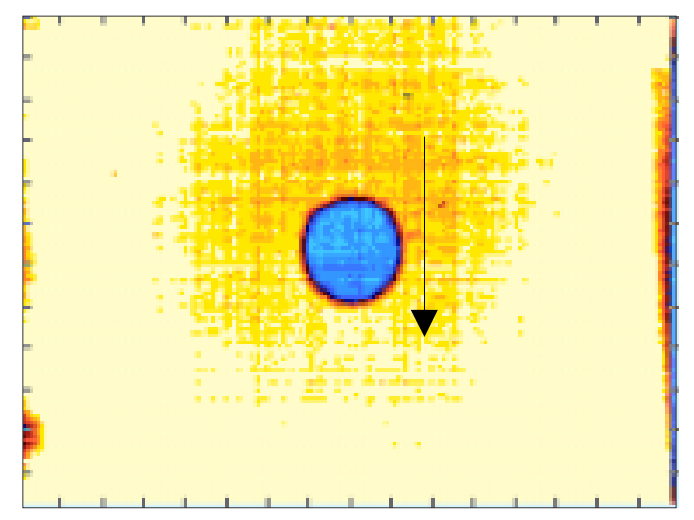

a) $150 \mathrm{~mm}$.

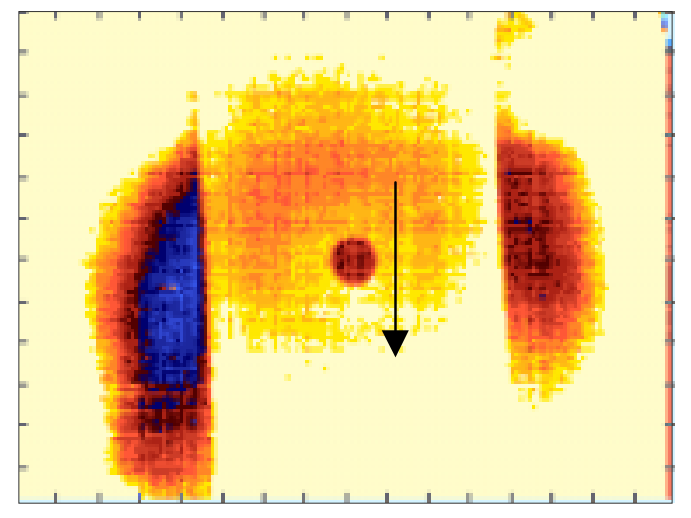

c) $300 \mathrm{~mm}$.

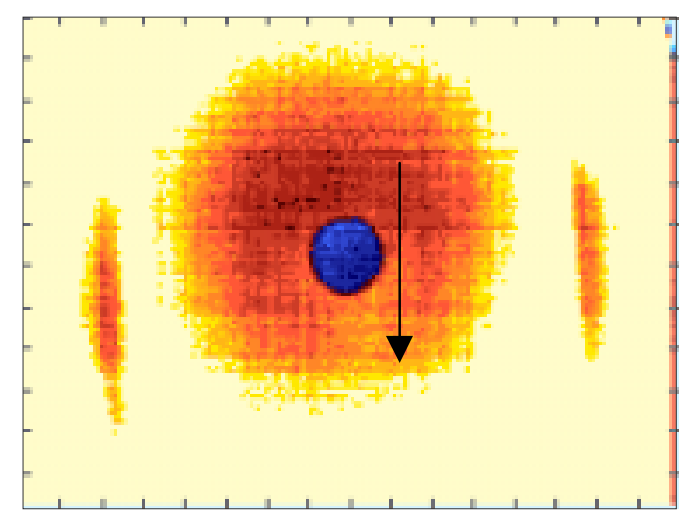

b) $275 \mathrm{~mm}$.

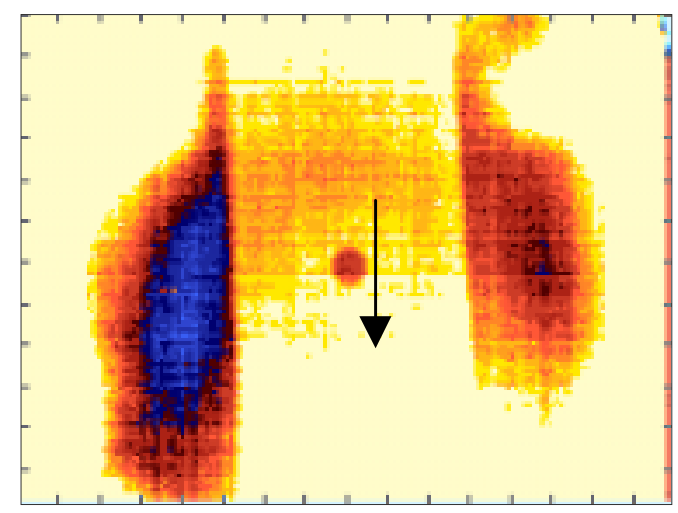

d) $375 \mathrm{~mm}$

Figure A.11 Thermal images of unpainted Specimen $\mathrm{CH}-2$ taken at the various distances (using passive approach at $144.8 \mathrm{MPa}$ ). 

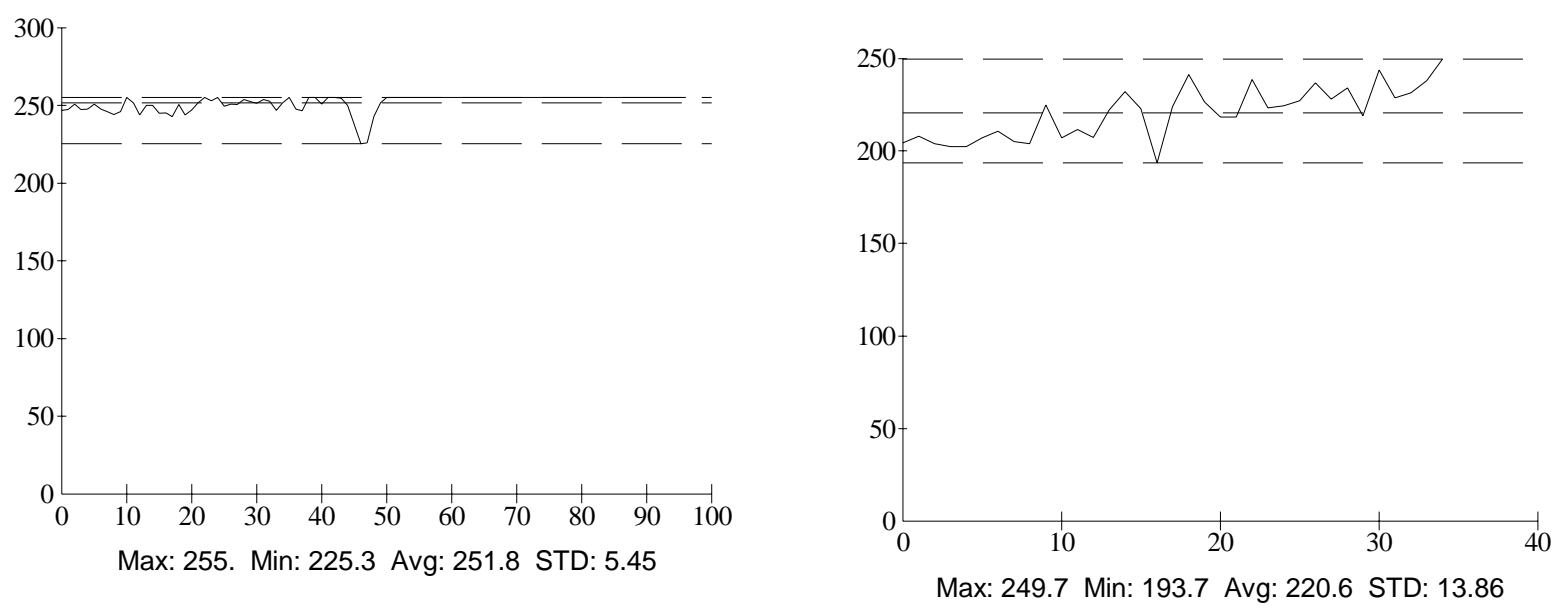

a) $150 \mathrm{~mm}$.
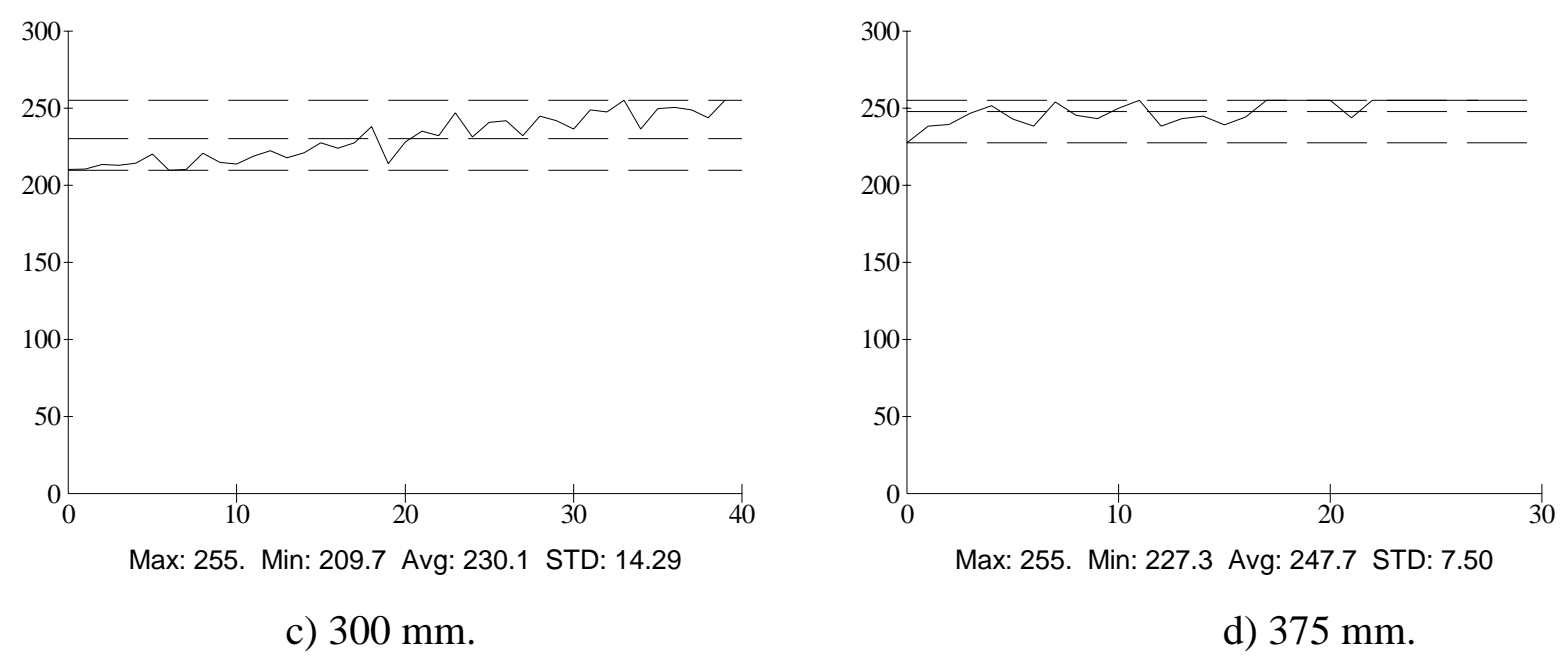

Figure A.12 Thermal intensity profile along the line across the fatigue crack shown in Figure A.11. 


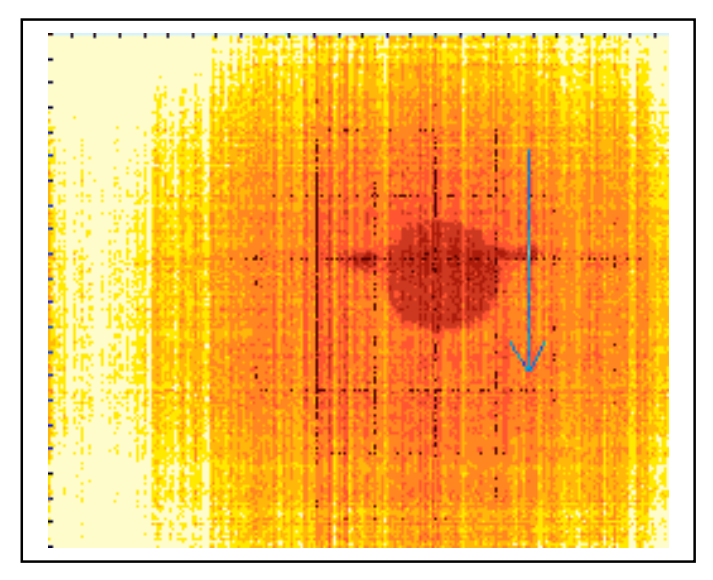

a) $150 \mathrm{~mm}$.

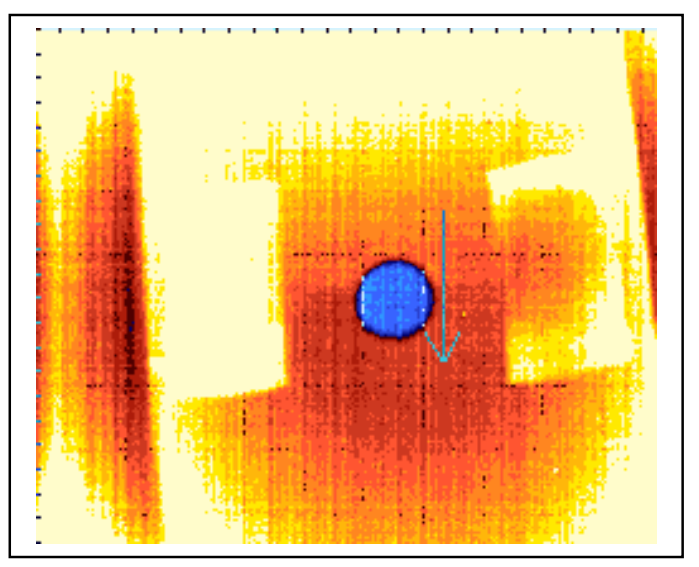

c) $300 \mathrm{~mm}$.

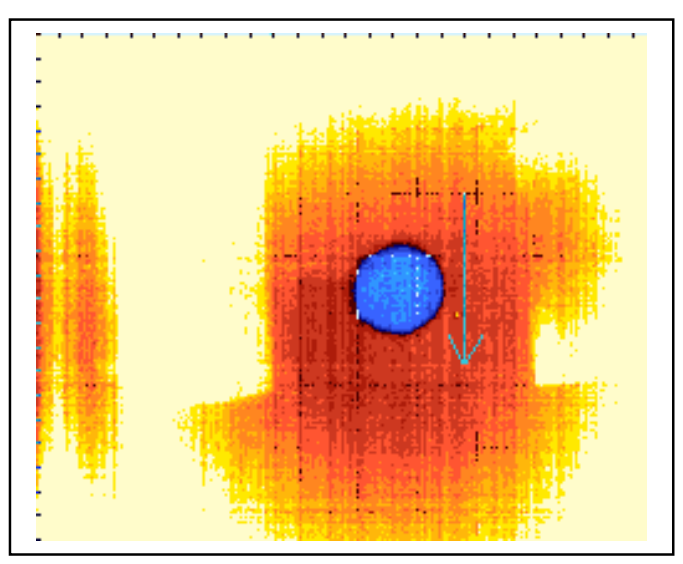

b) $225 \mathrm{~mm}$.

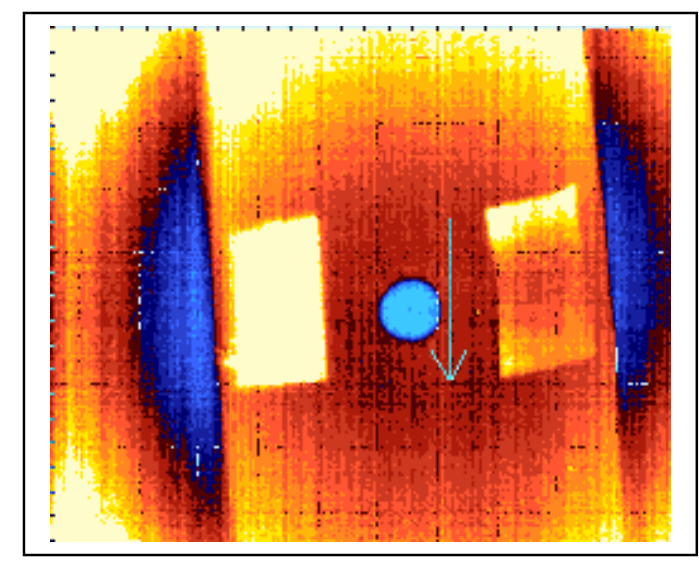

d) $375 \mathrm{~mm}$.

Figure A.13 Thermal images of unpainted Specimen CH-3 (at 550,000 loading cycles) taken at the various distances (using passive approach 137.9 MPa). 


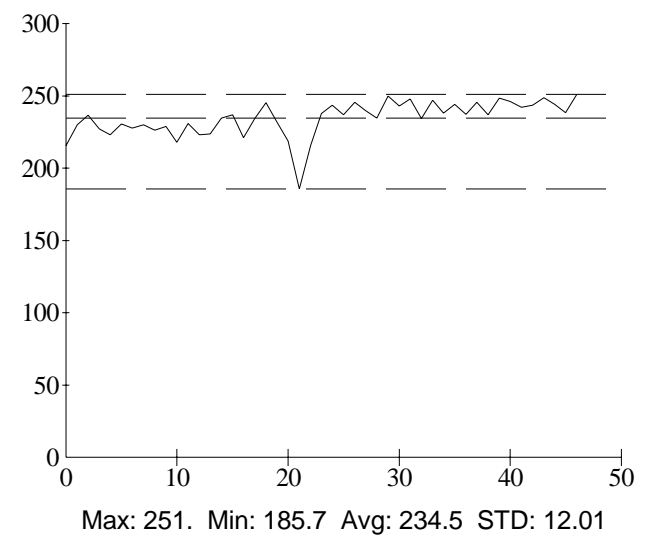

a) $150 \mathrm{~mm}$.

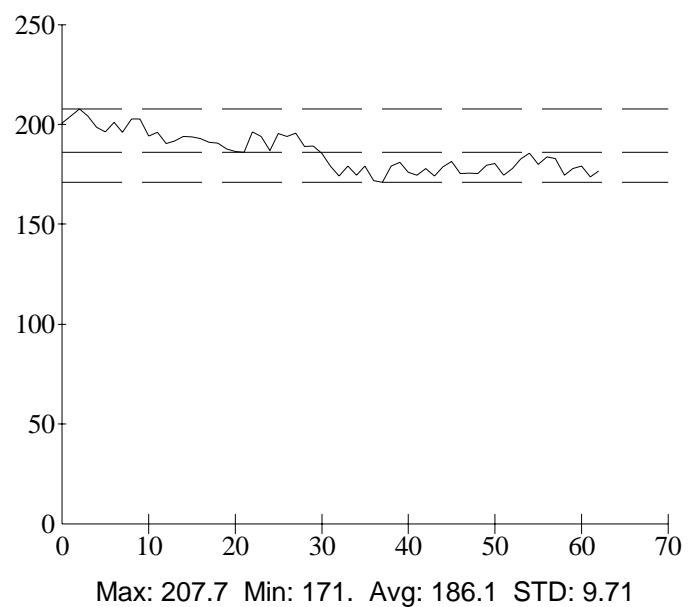

c) $300 \mathrm{~mm}$.

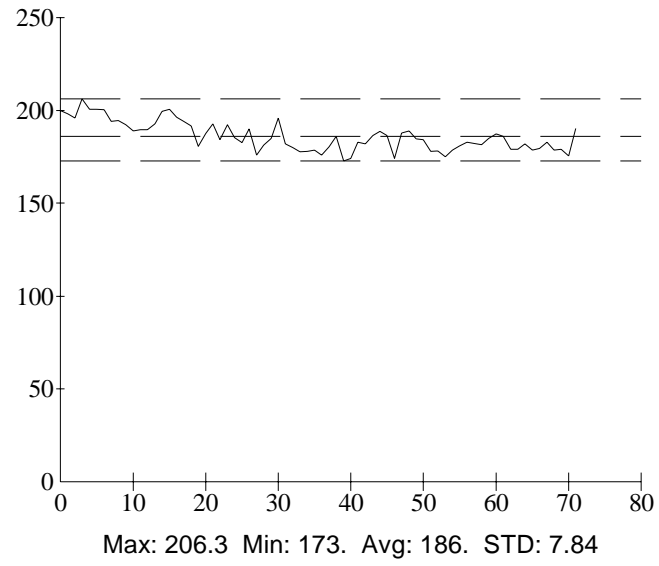

b) $225 \mathrm{~mm}$.

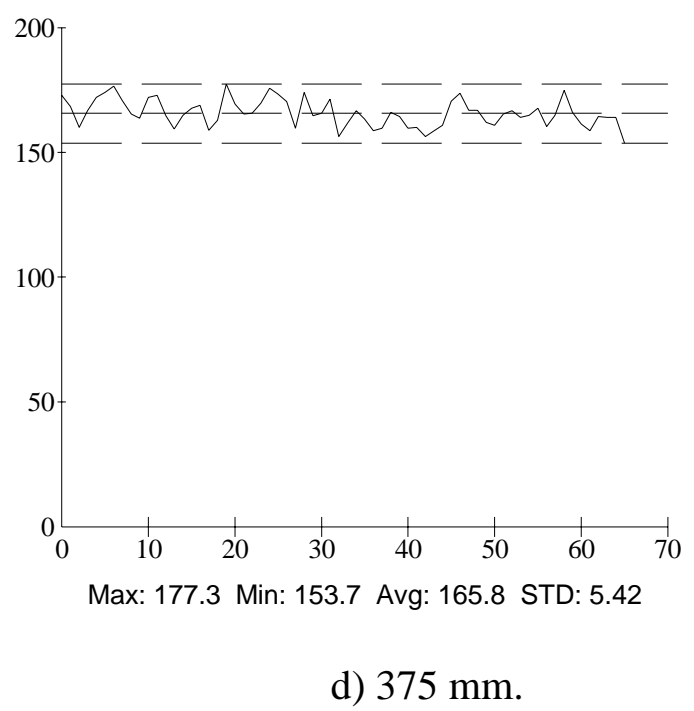

Figure A.14 Thermal intensity profile along the line across the fatigue crack shown in Figure A.13. 


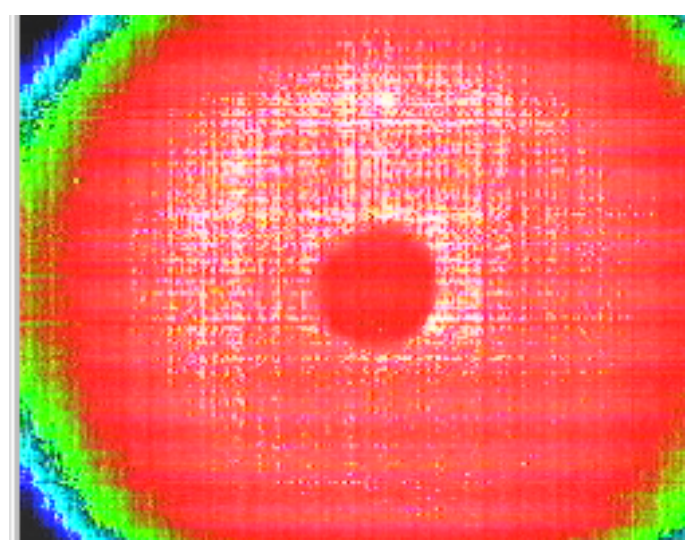

a) $150 \mathrm{~mm}$.

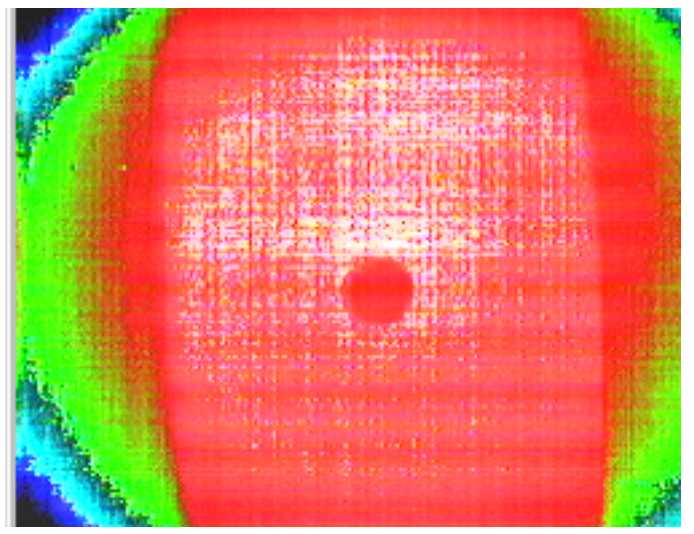

c) $300 \mathrm{~mm}$.

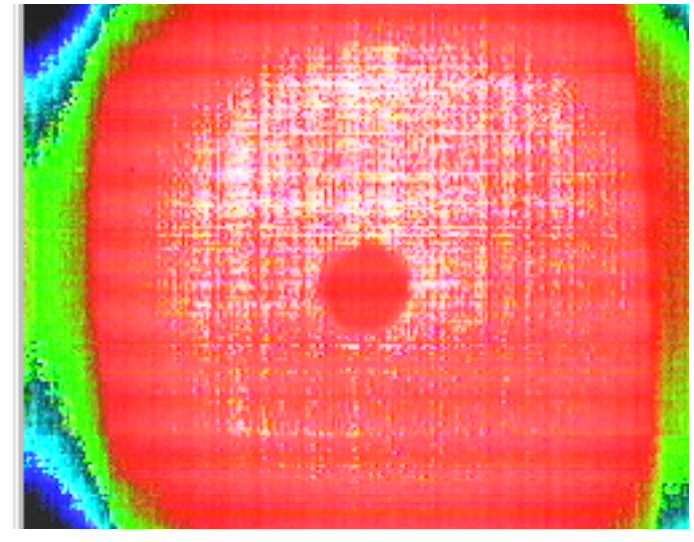

b) $225 \mathrm{~mm}$.

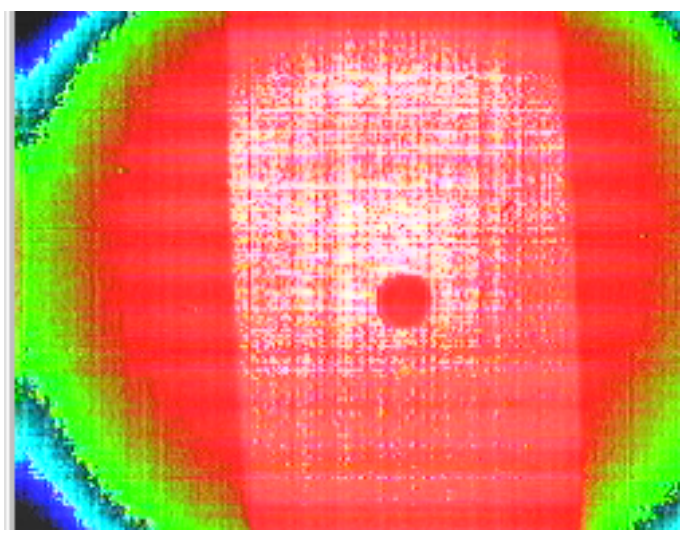

d) $375 \mathrm{~mm}$.

Figure A.15 Thermal images of Specimen CH-3 (at 550,000 loading cycles) taken at the various distances (no load is applied to the specimen). 


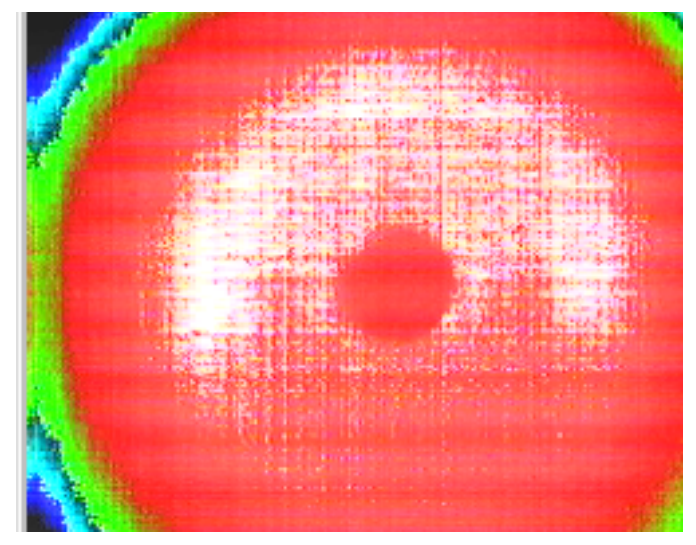

a) $150 \mathrm{~mm}$.

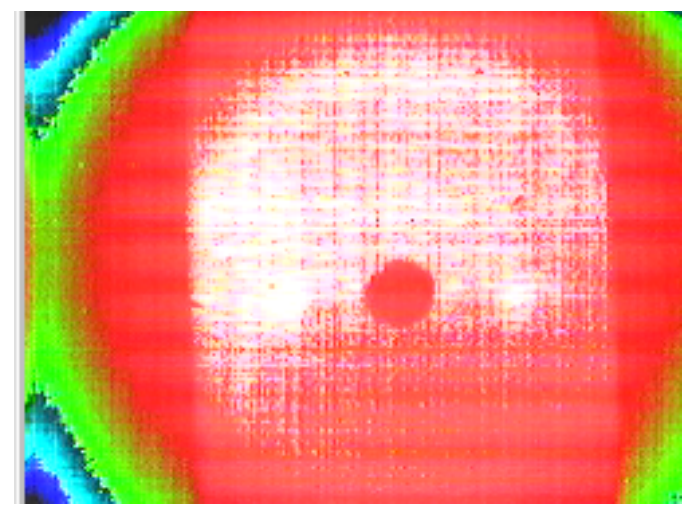

c) $300 \mathrm{~mm}$.

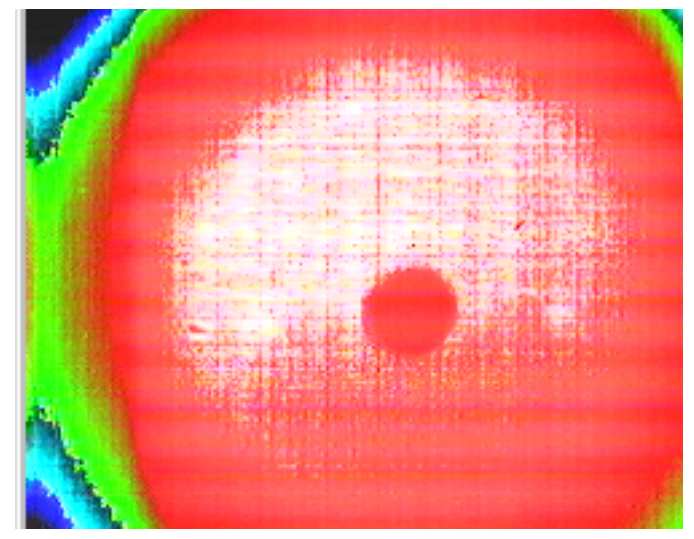

b) $225 \mathrm{~mm}$.

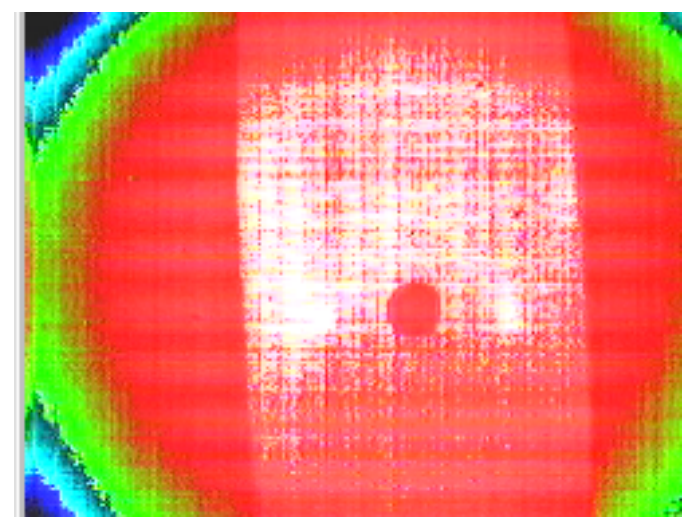

d) $375 \mathrm{~mm}$.

Figure A.16 Thermal images of Specimen CH-3 (at 550,000 loading cycles) taken at the various distances (using passive approach at 137.9 $\mathrm{MPa}$ ). 


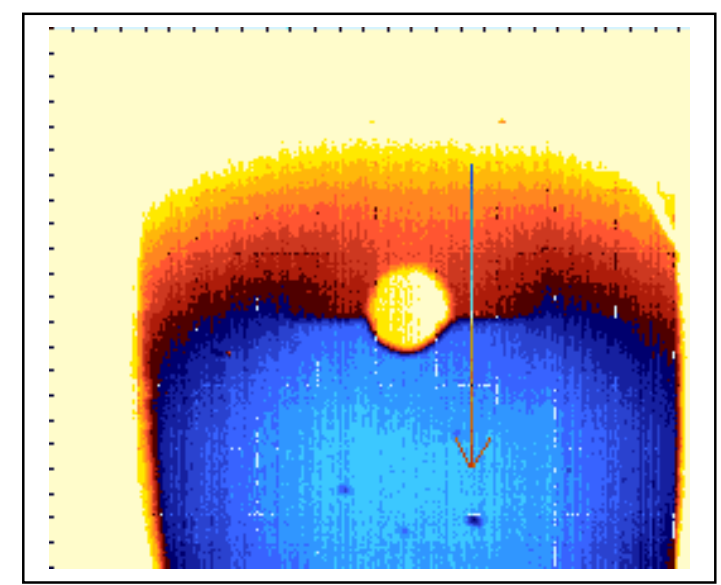

a) 1-second delay time

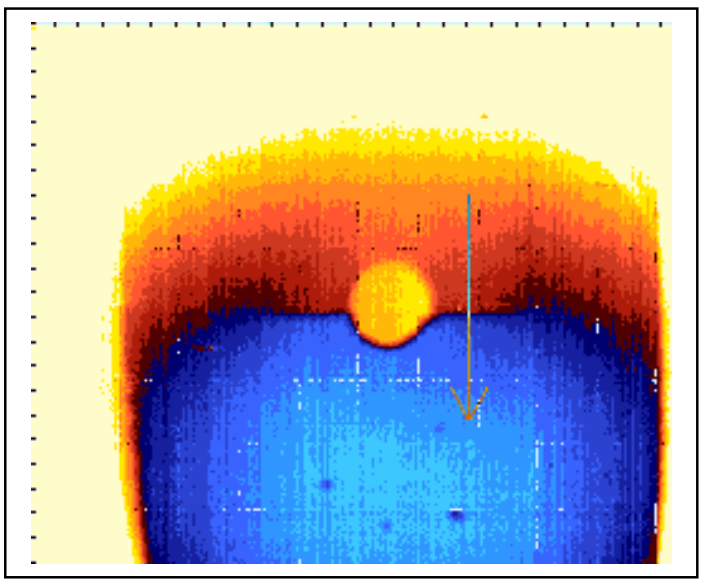

c) 6 second-delay time

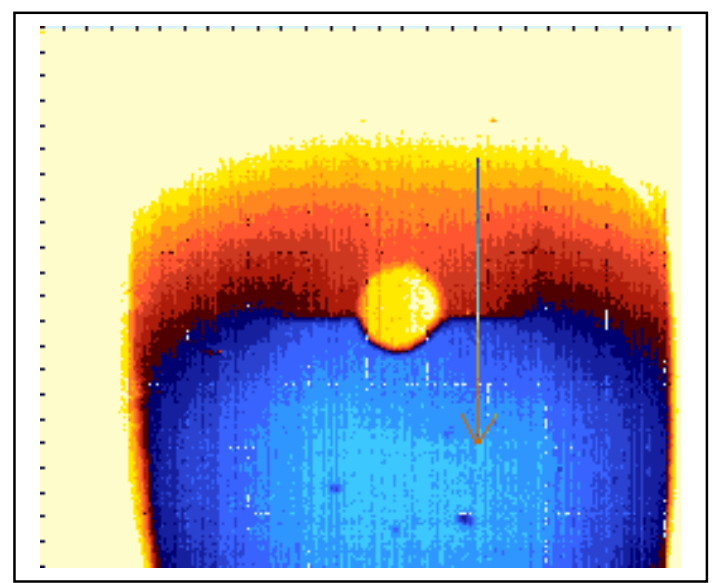

b) 3-second delay time

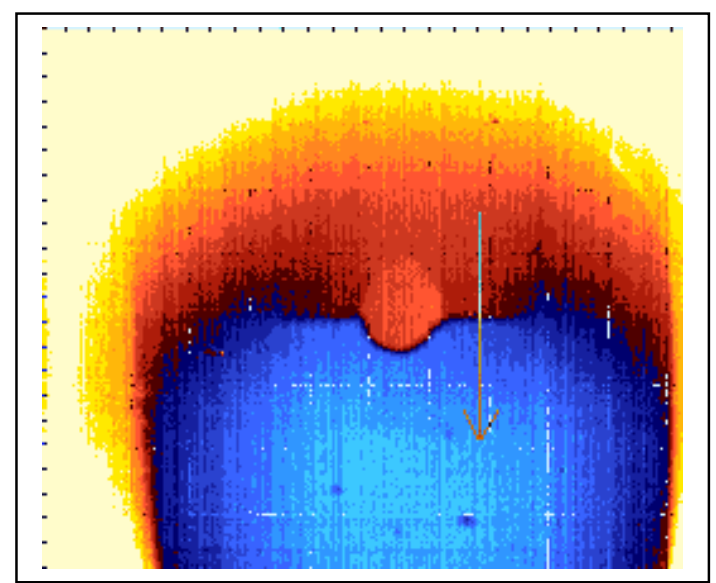

d) 9 second-delay time

Figure A.17 Thermal images of Specimen CH-1 (using the active approach and heating time is 30 seconds). 


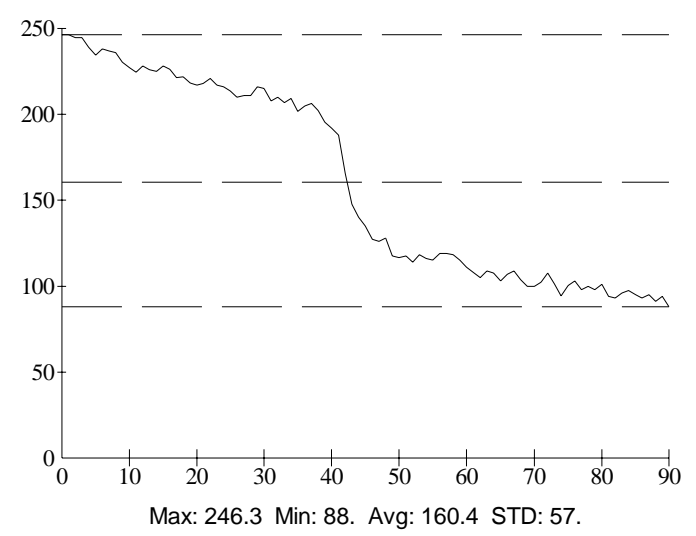

a) 1-second delay time

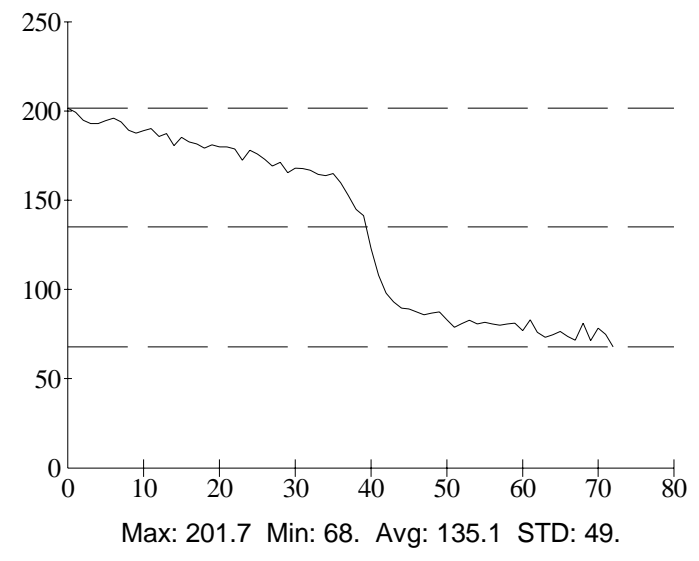

c) 6 second-delay time

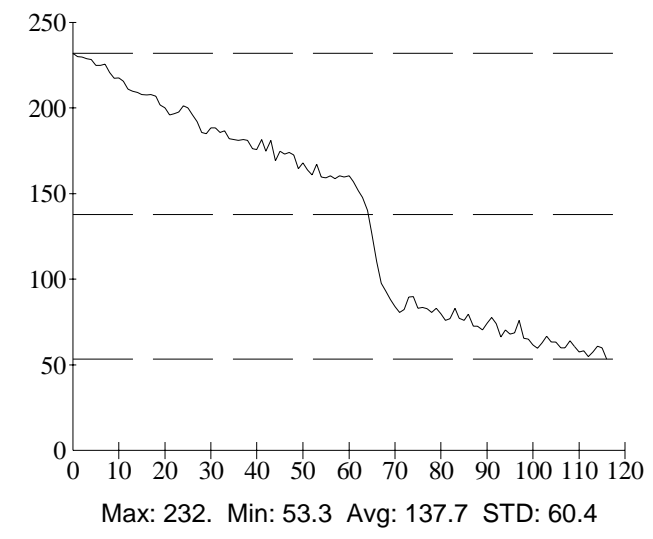

b) 3-second delay time

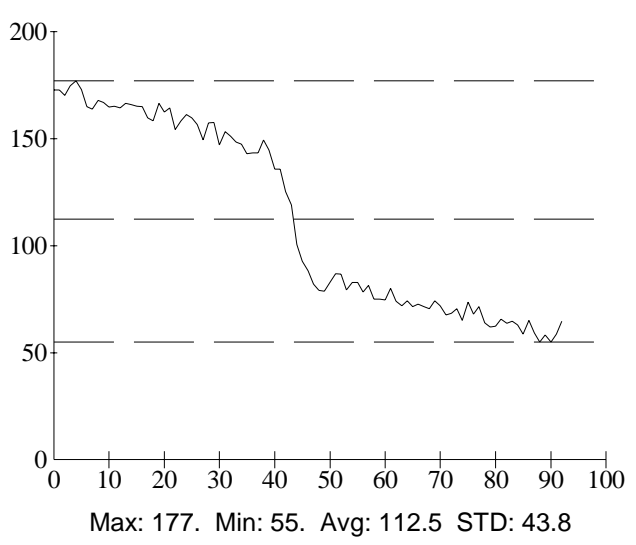

d) 9 second-delay time

Figure A.18 Thermal intensity profile along the line across the fatigue crack shown in Figure A.17. 


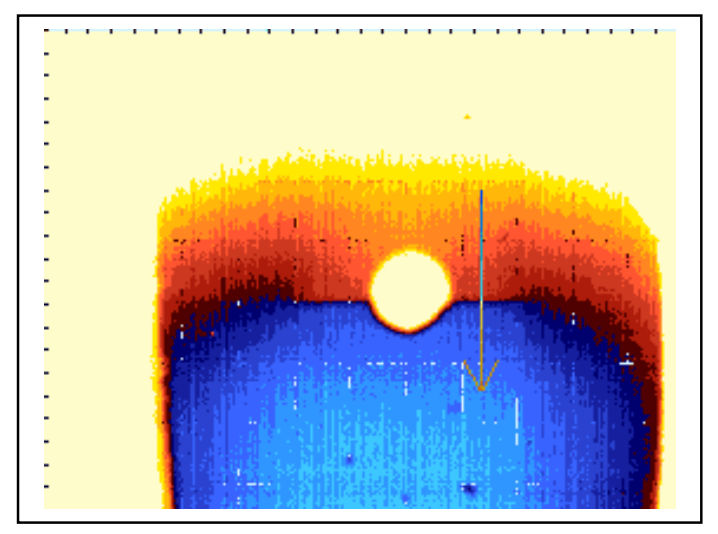

a) 1-second delay time

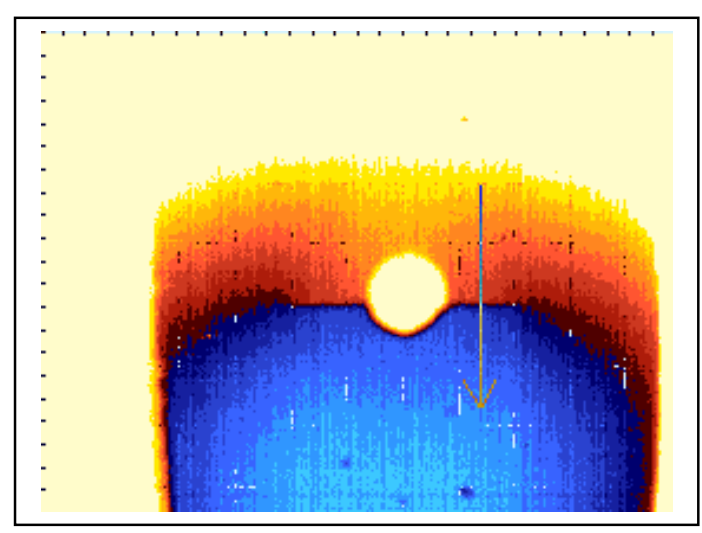

c) 6 second-delay time

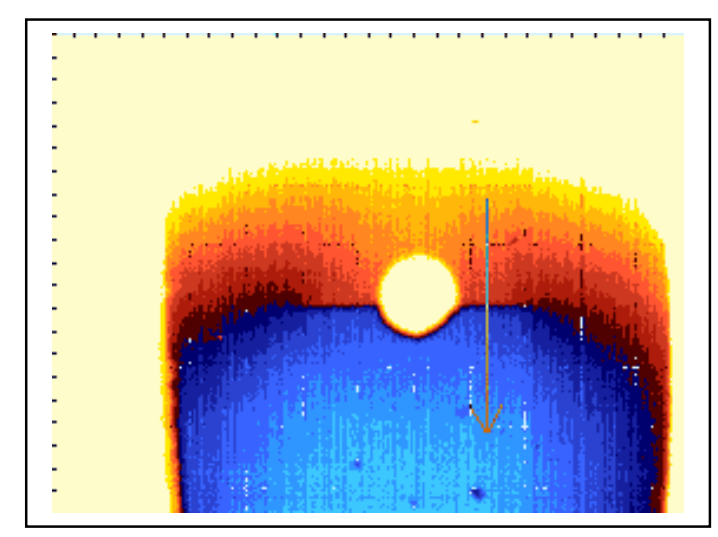

b) 3-second delay time

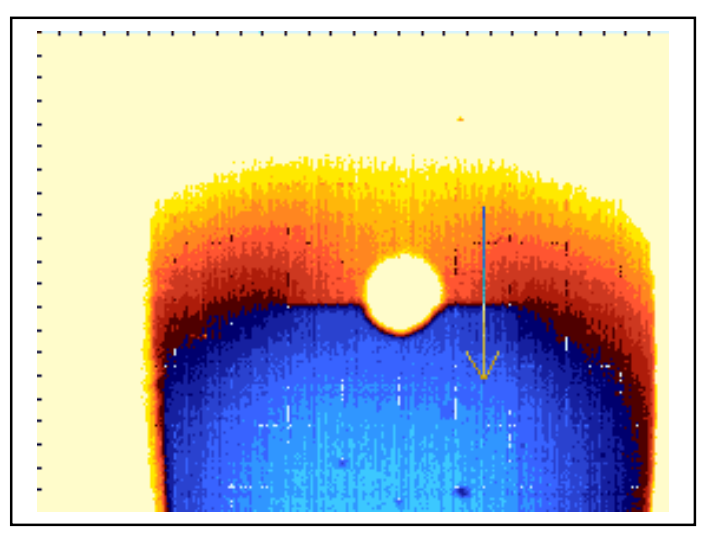

d) 9 second-delay time

Figure A.19 Thermal images of Specimen CH-1 (using the active approach and heating time is 60 seconds). 


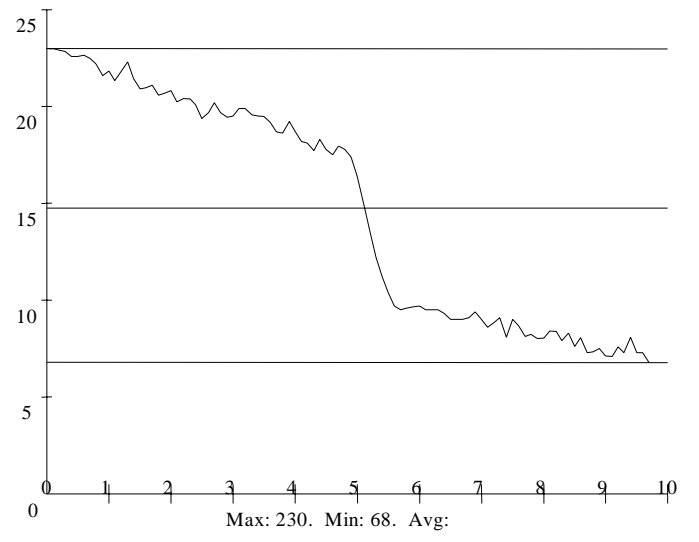

a) 1-second delay time

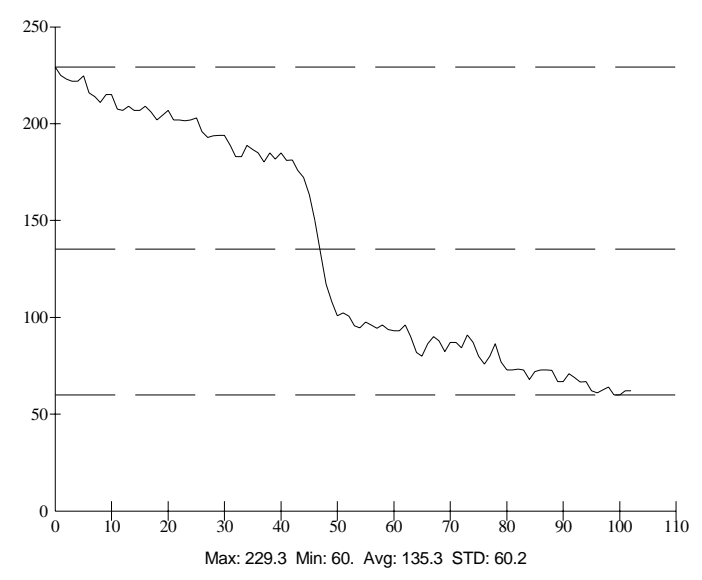

c) 6 second-delay time

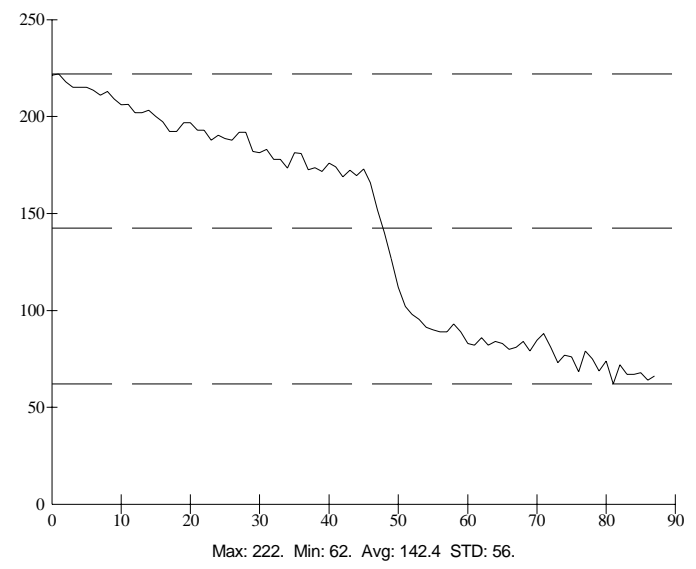

b) 3-second delay time

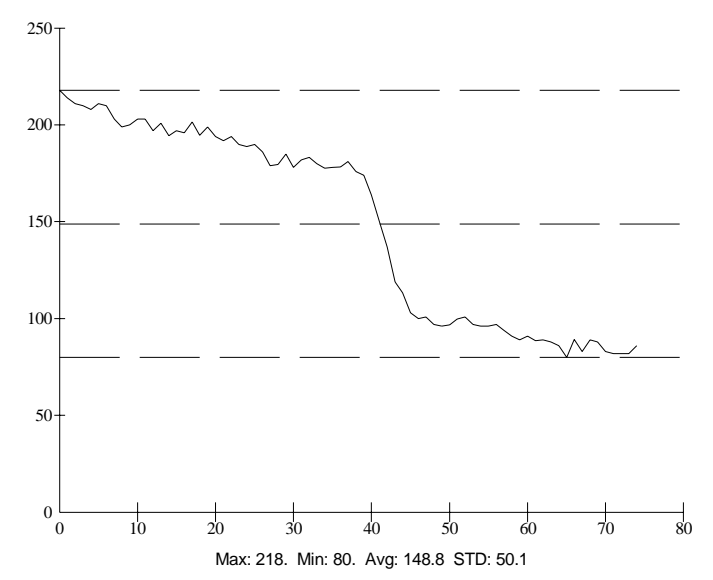

d) 9 second-delay time

Figure A.20 Thermal intensity profile along the line across the fatigue crack shown in Figure A.19. 


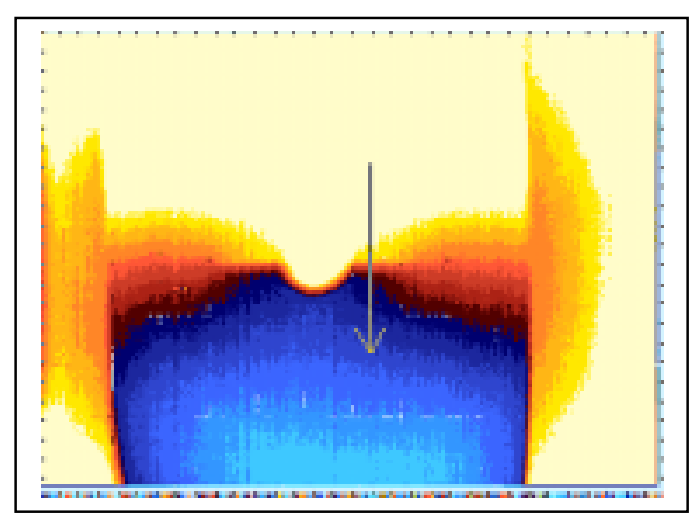

a) 1-second delay time

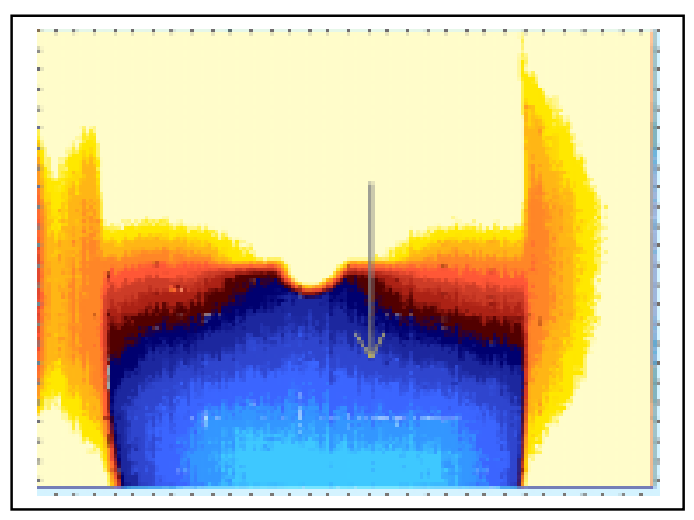

c) 6 second-delay time

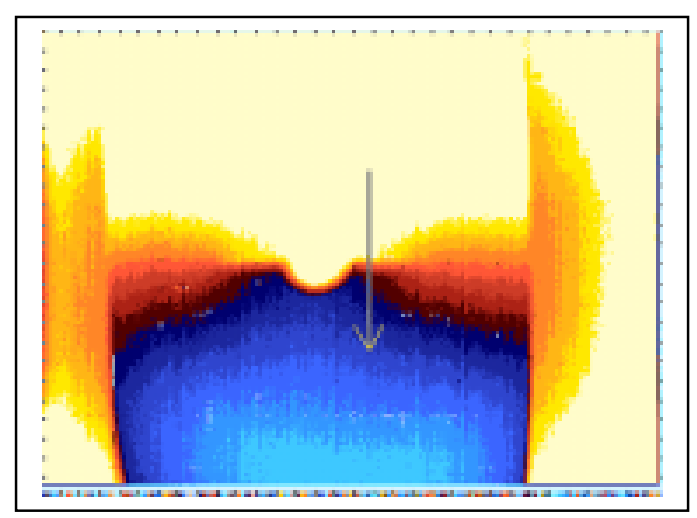

b) 3-second delay time

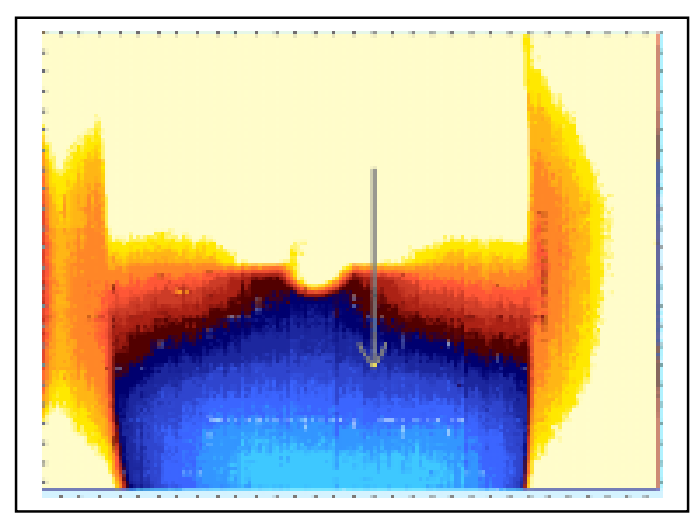

d) 9 second-delay time

Figure A.21 Thermal images of Specimen CH-1 (using the active approach and heating time is 90 seconds). 


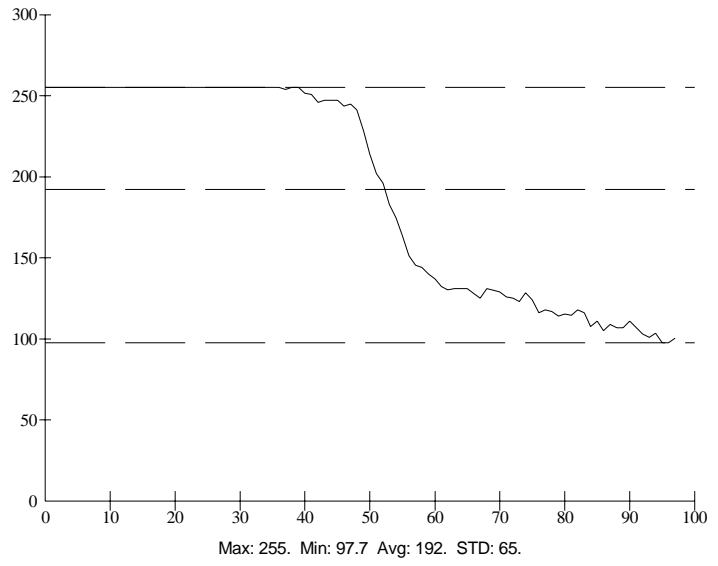

a) 1-second delay time

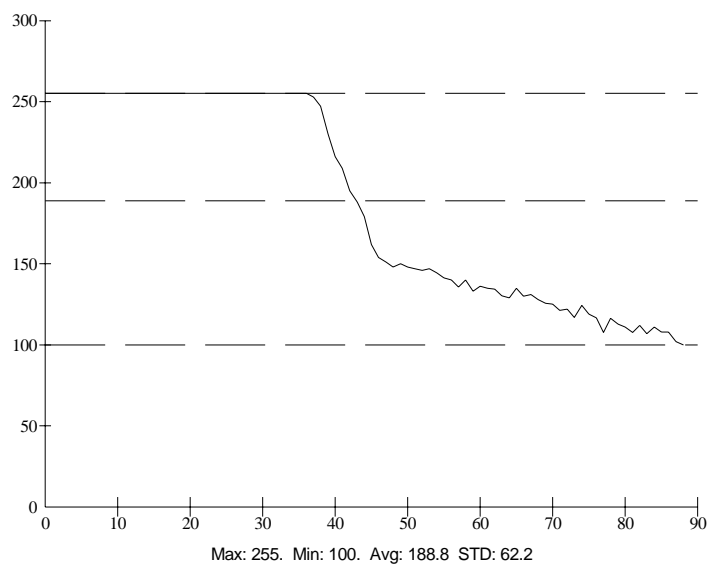

c) 6 second-delay time

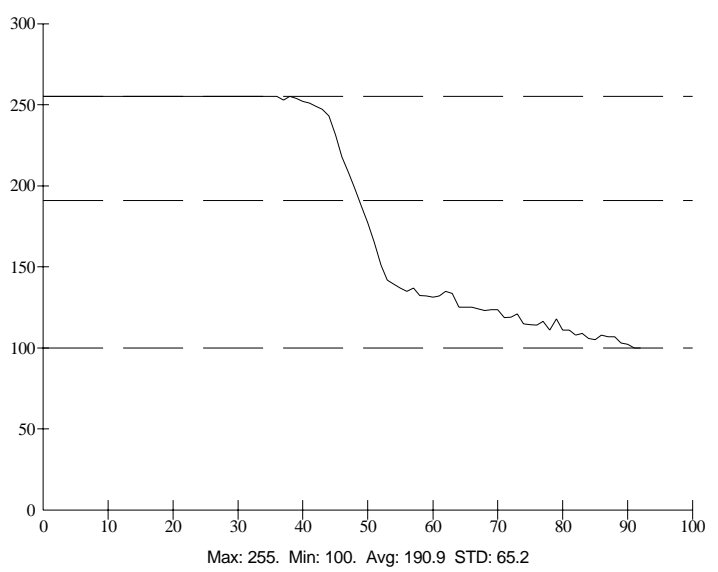

b) 3-second delay time

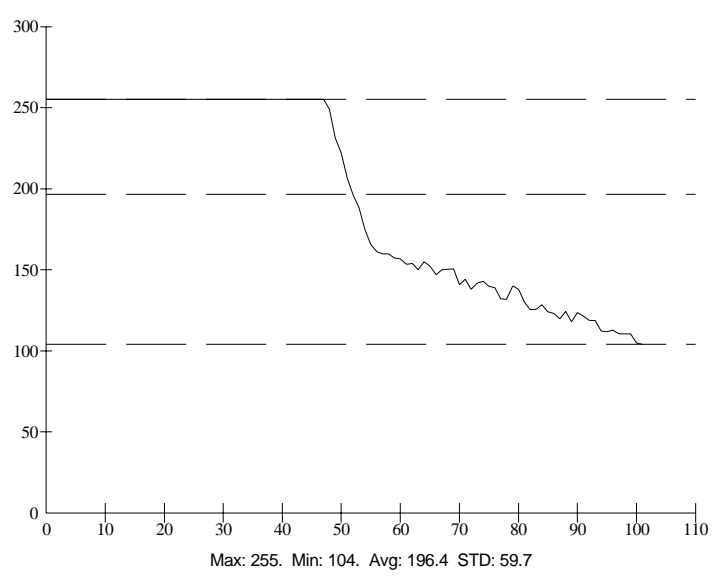

d) 9 second-delay time

Figure A.22 Thermal intensity profile along the line across the fatigue crack shown in Figure A.21. 


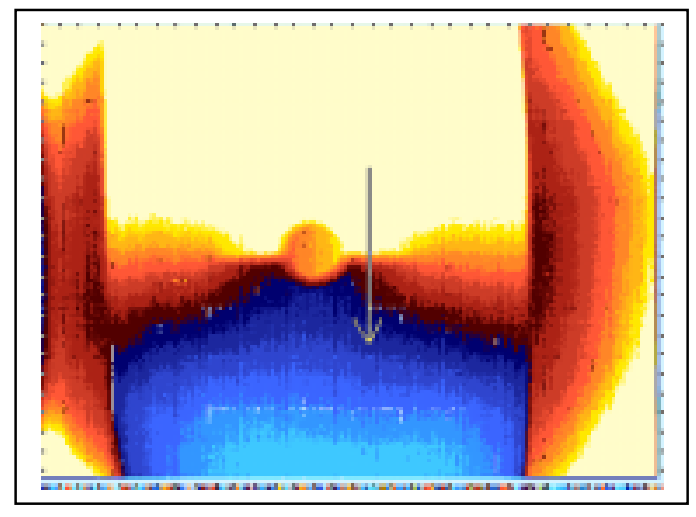

a) 1-second delay time

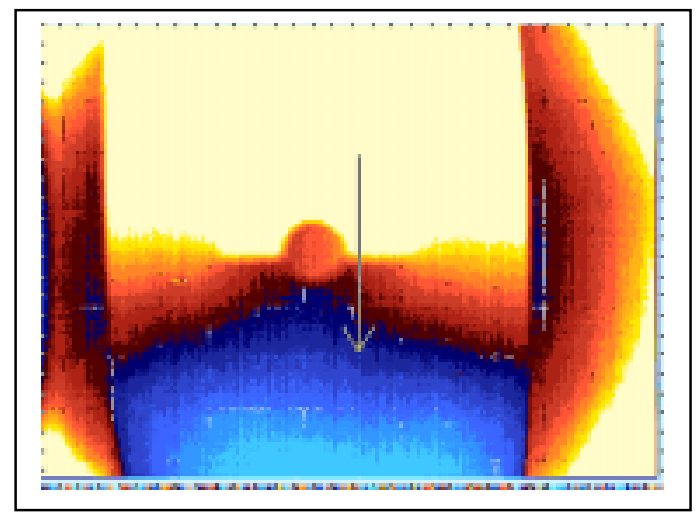

c) 6 second-delay time

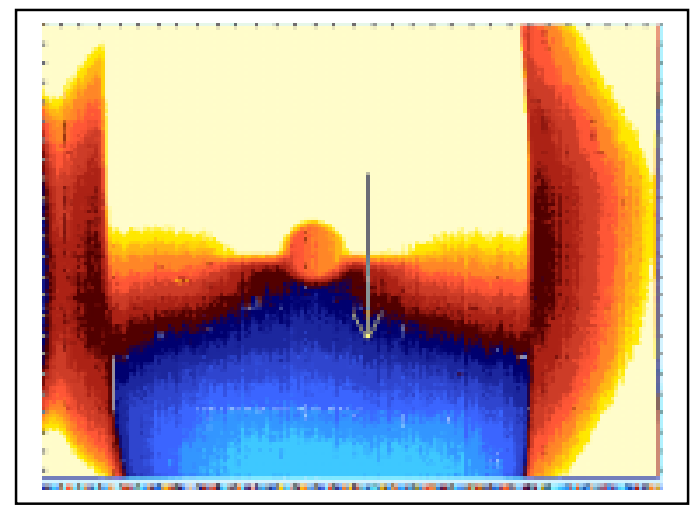

b) 3-second delay time

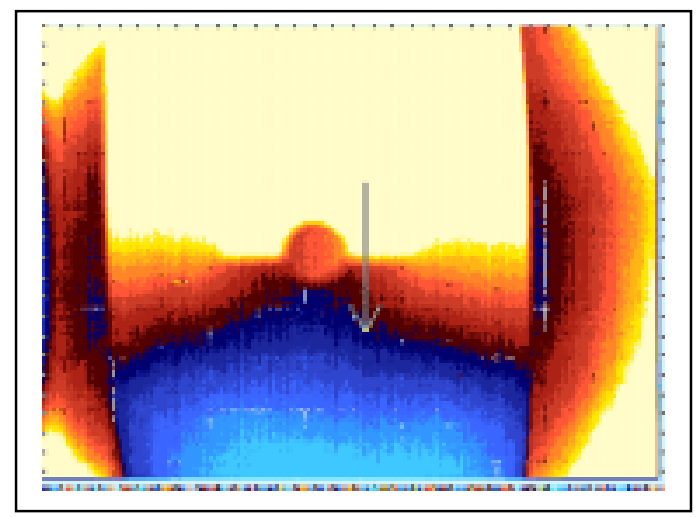

d) 9 second-delay time

Figure A.23 Thermal images of Specimen $\mathrm{CH}-1$ (using the active approach and heating time is 120 seconds). 


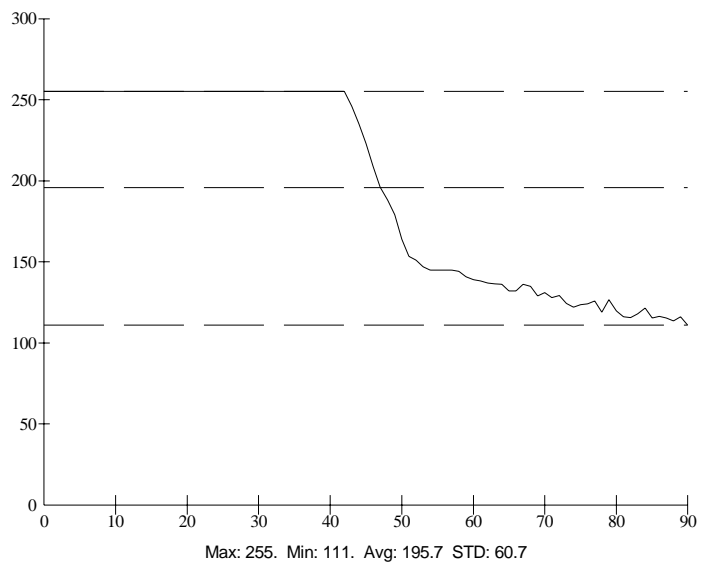

a) 1-second delay time

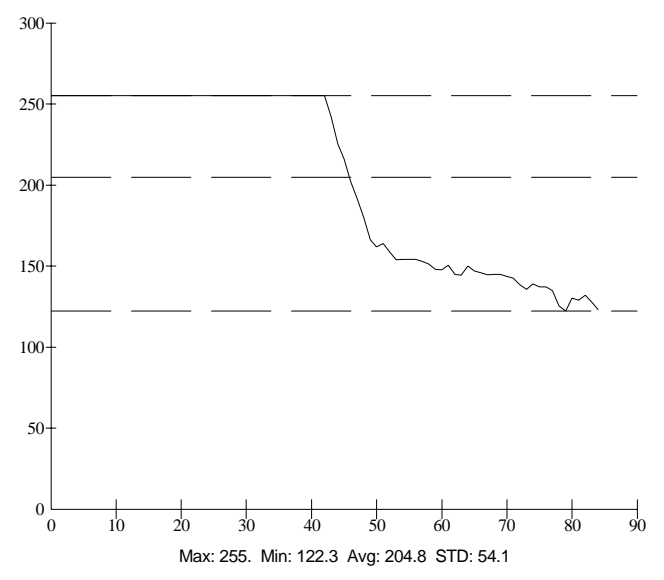

c) 3-second delay time

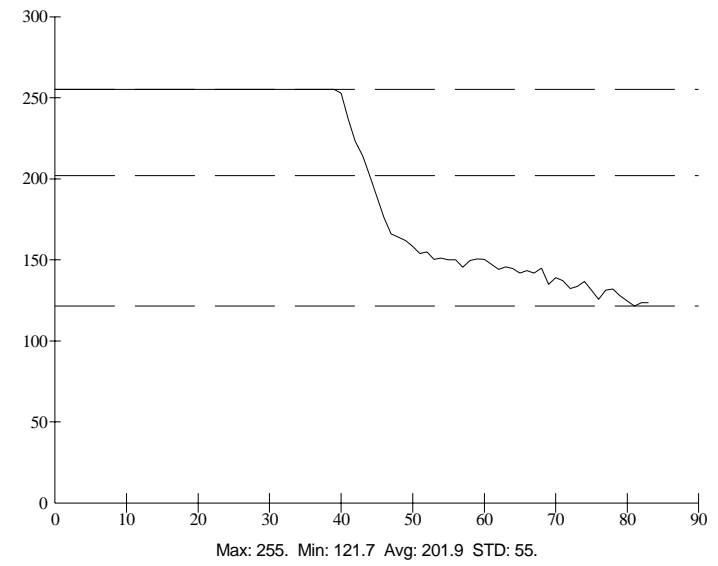

b) 3-second delay time

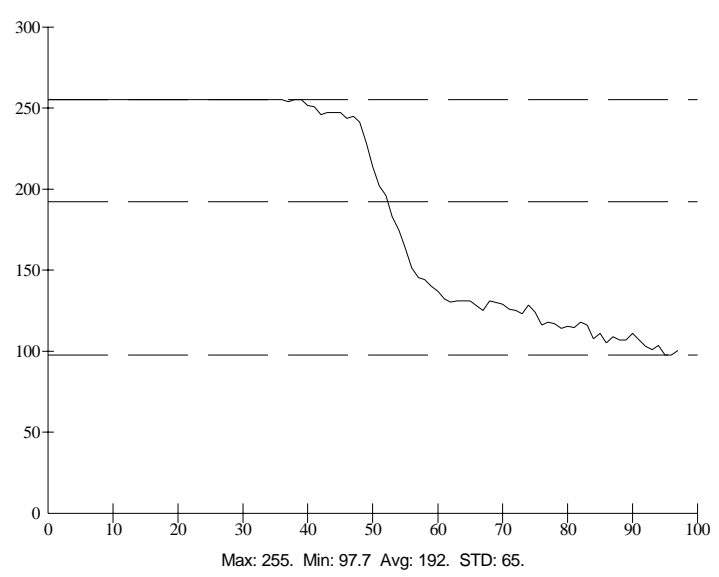

d) 9 second-delay time

Figure A.24 Thermal intensity profile along the line across the fatigue crack shown in Figure A.23. 


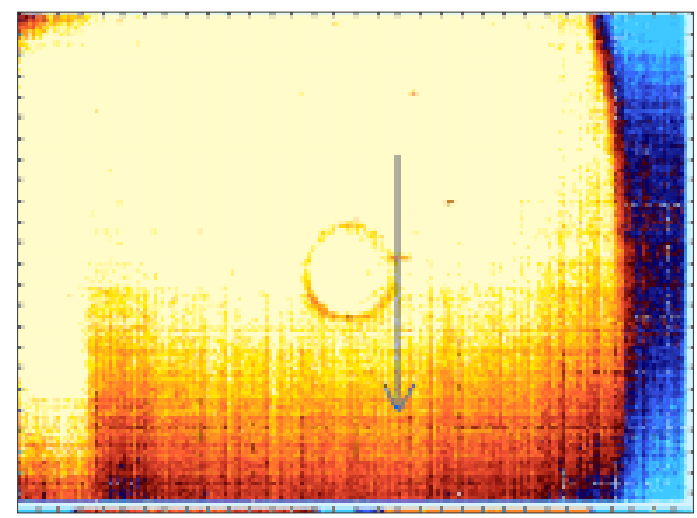

a) 1-second delay time

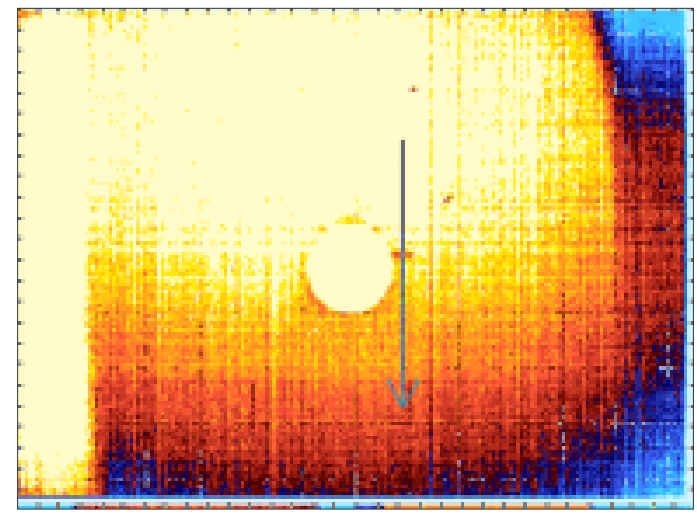

c) 6 second-delay time

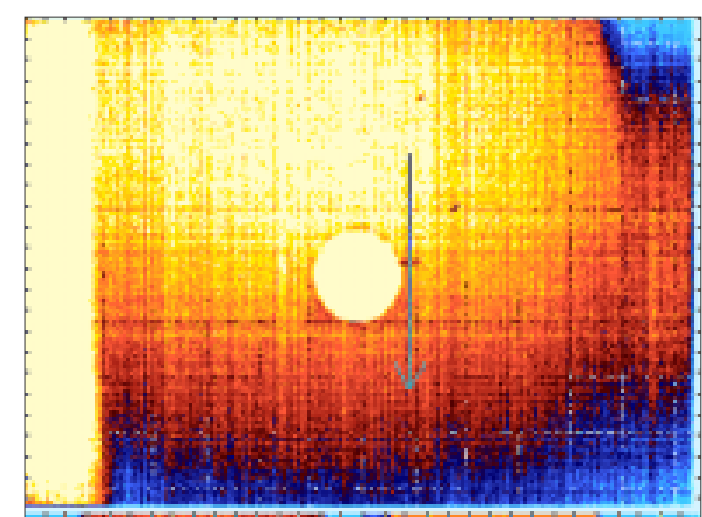

b) 3-second delay time

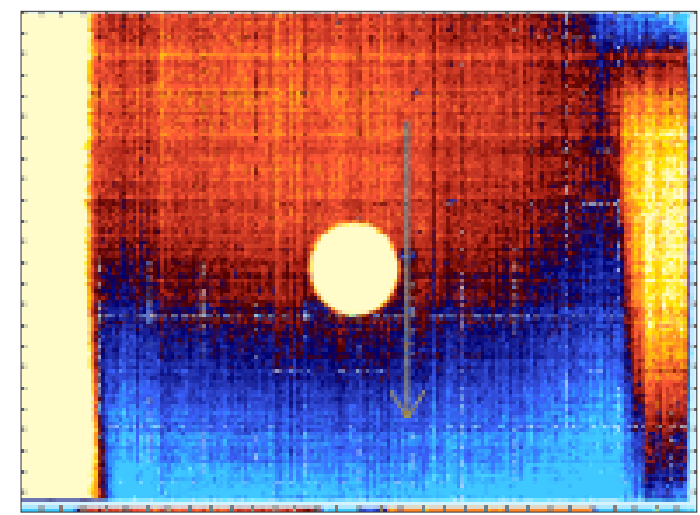

d) 9 second-delay time

Figure A.25 Thermal images of unpainted Specimen $\mathrm{CH}-2$ (using the active approach and heating time is 30 seconds). 


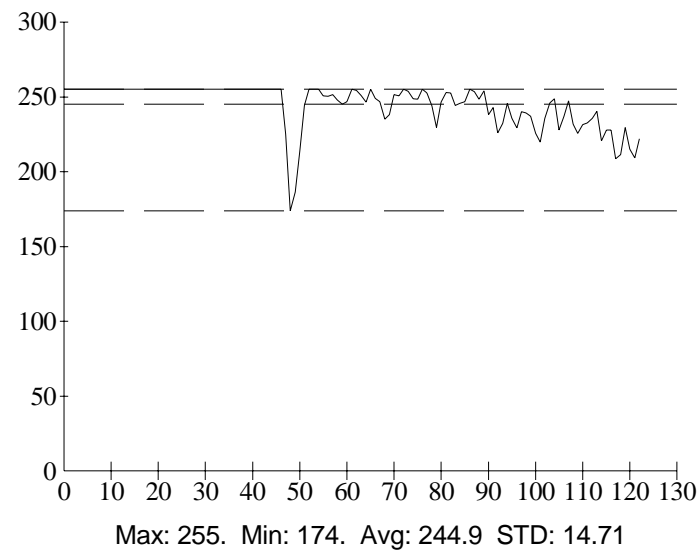

a) 1-second delay time

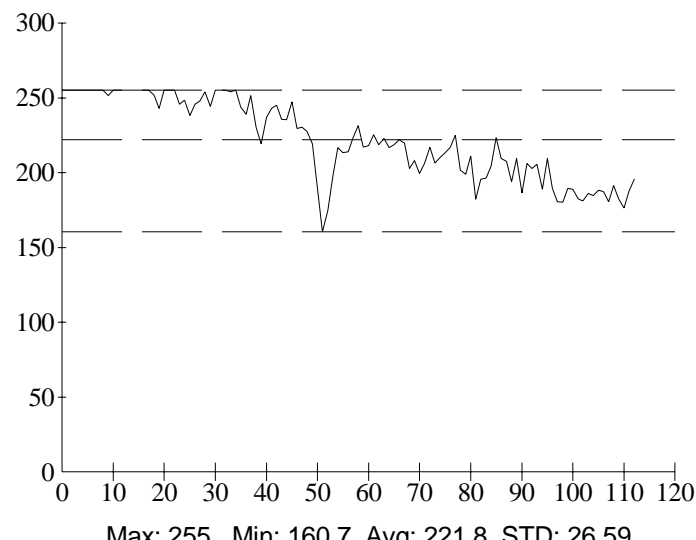

c) 6 second-delay time

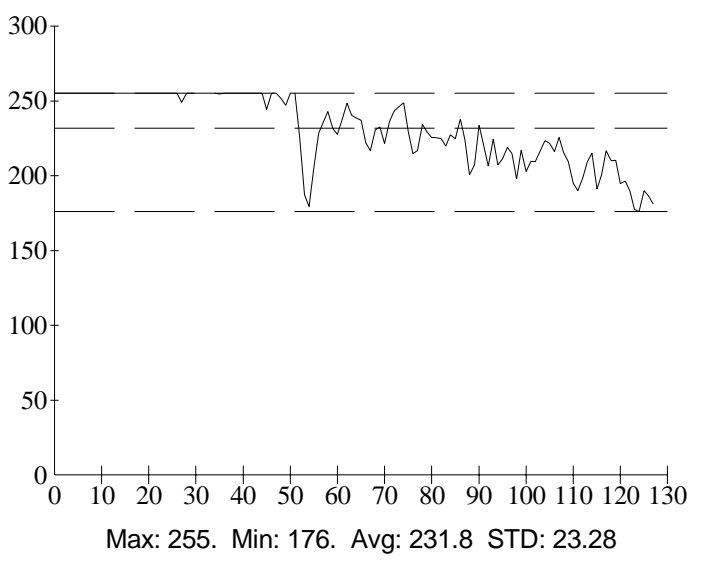

b) 3-second delay time

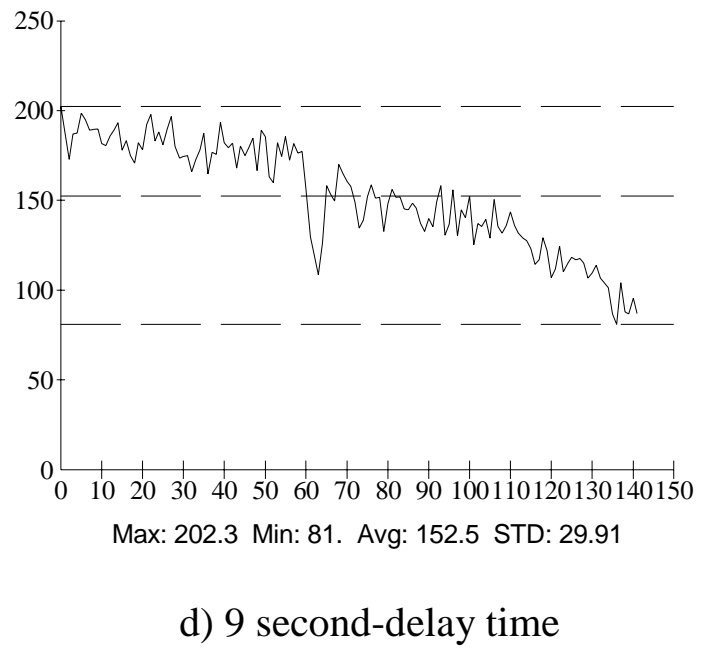

Figure A.26 Thermal intensity profile along the line across the fatigue crack shown in Figure A.25. 


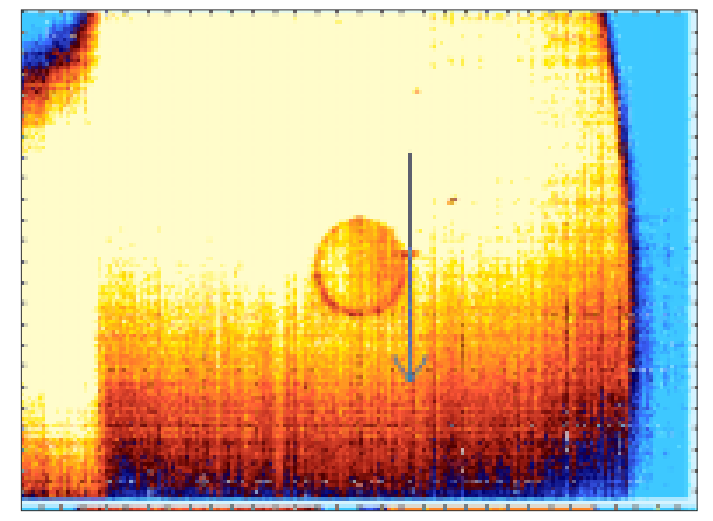

a) 1-second delay time

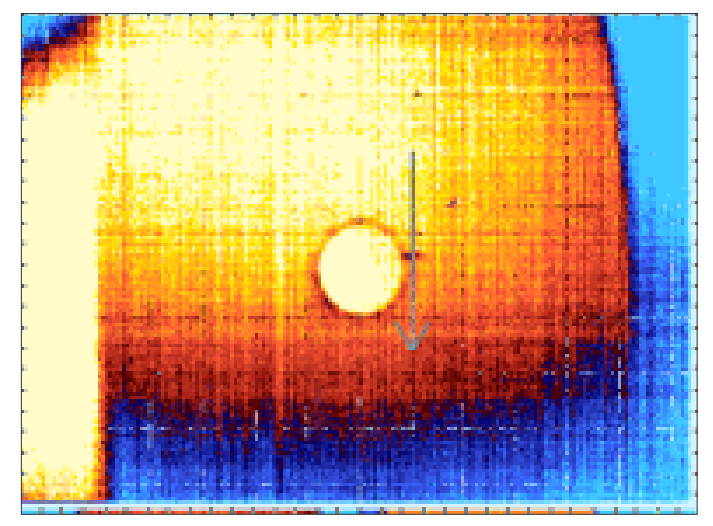

c) 6 second-delay time

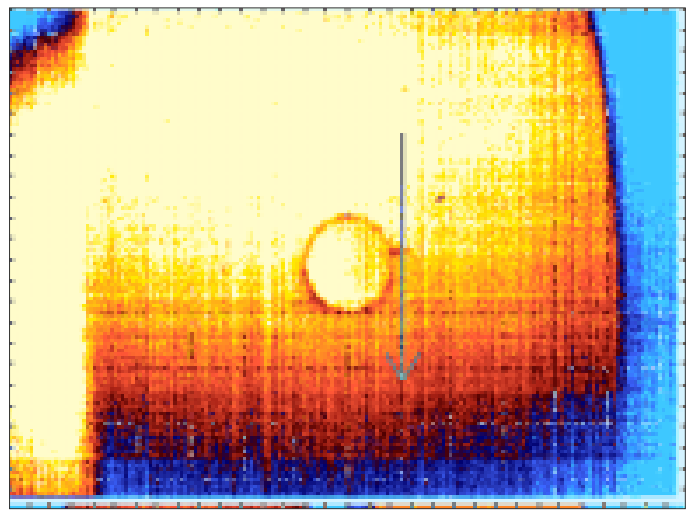

b) 3-second delay time

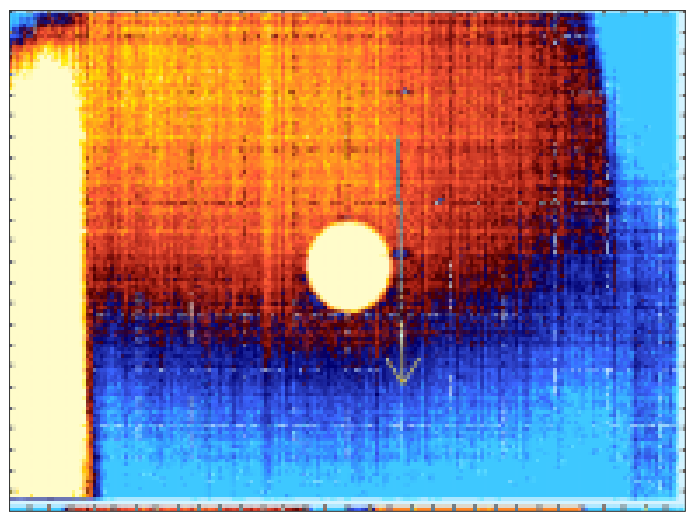

d) 9 second-delay time

Figure A.27 Thermal images of unpainted Specimen CH-2 (using the active approach and heating time is 60 seconds). 


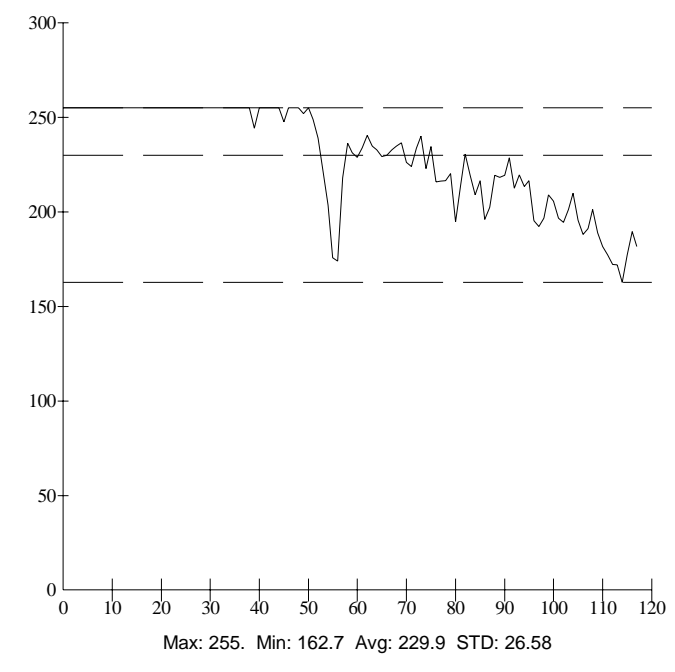

a) 1-second delay time

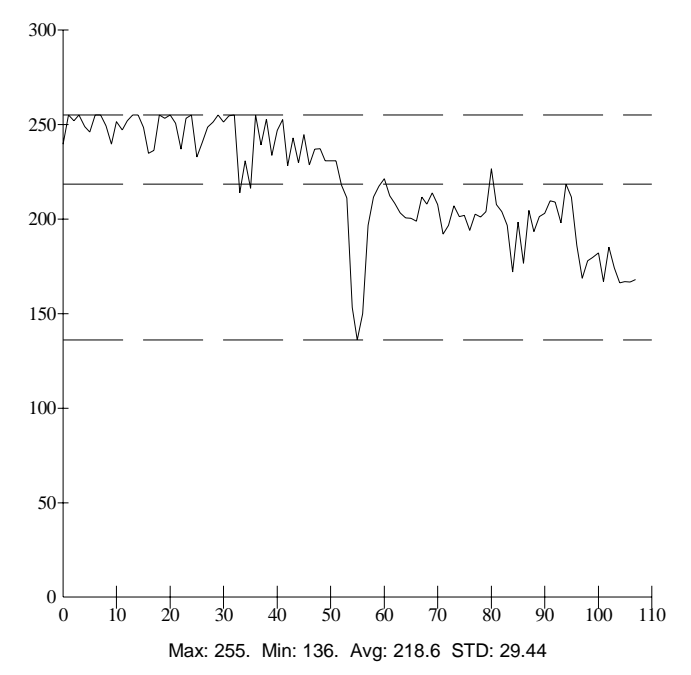

c) 6 second-delay time

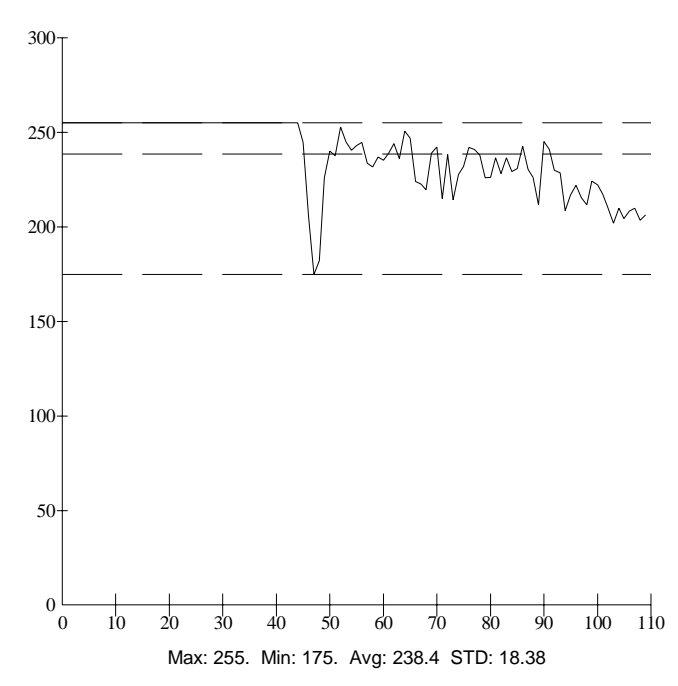

b) 3-second delay time

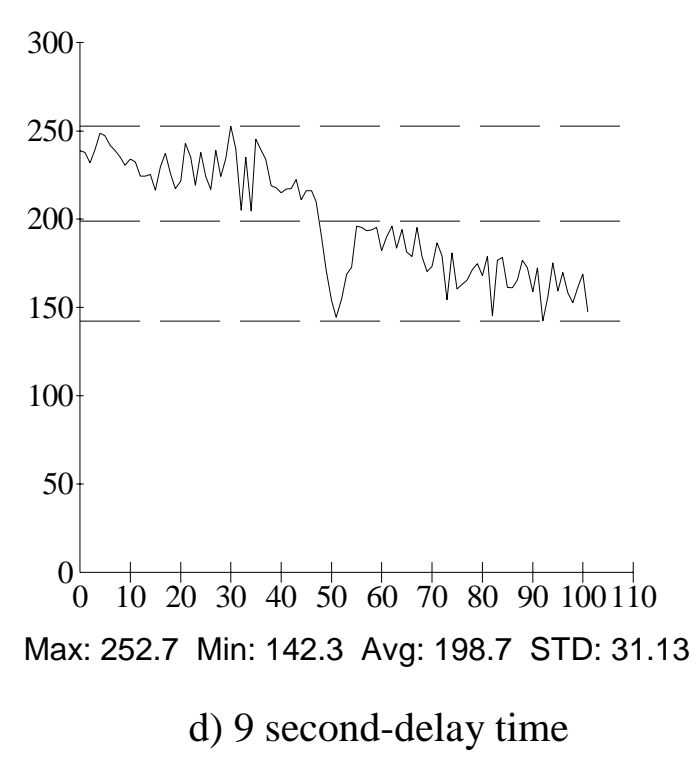

Figure A.28 Thermal intensity profile along the line across the fatigue crack shown in Figure A.27. 


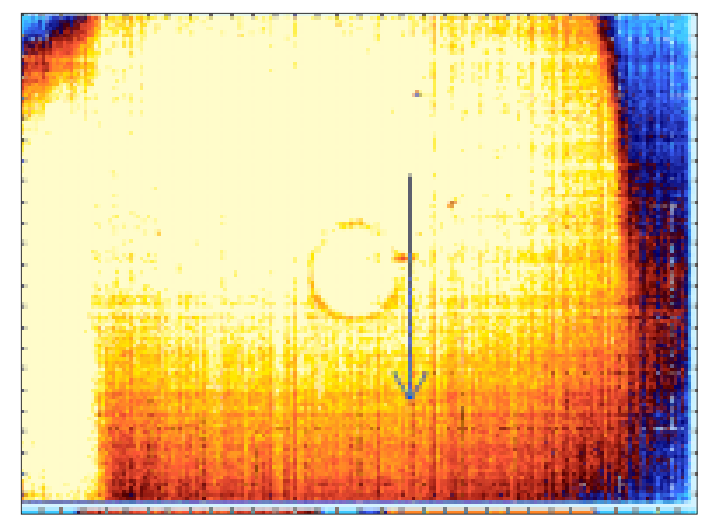

a) 1-second delay time

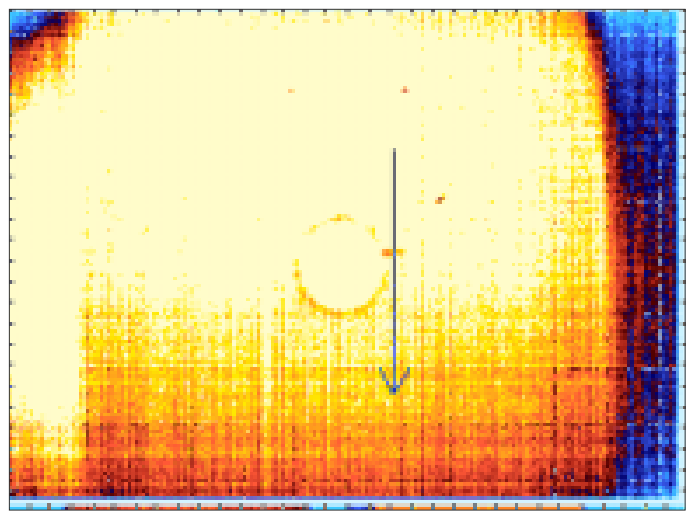

c) 6 second-delay time

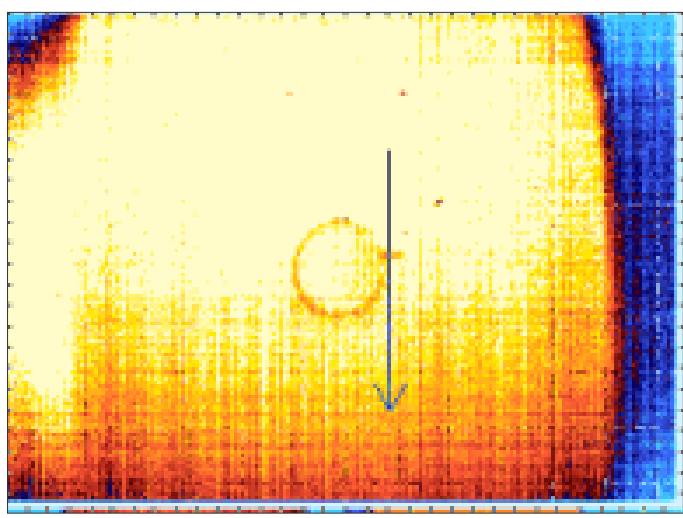

b) 3-second delay time

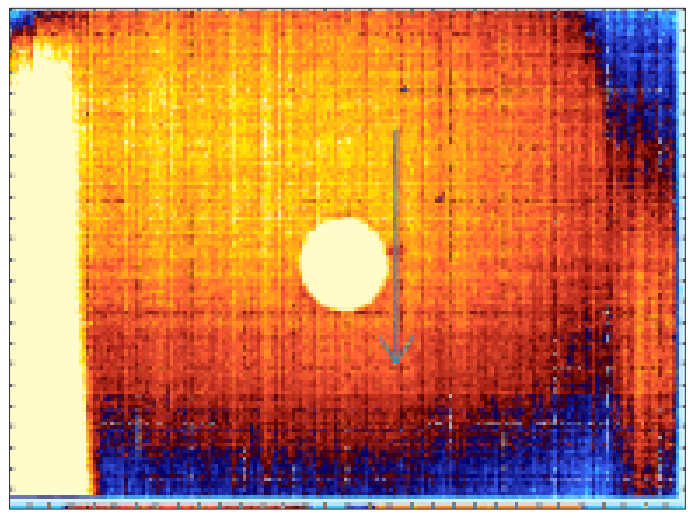

d) 9 second-delay time

Figure A.29 Thermal images of unpainted Specimen 2 (using the active approach and heating time is 90 seconds). 

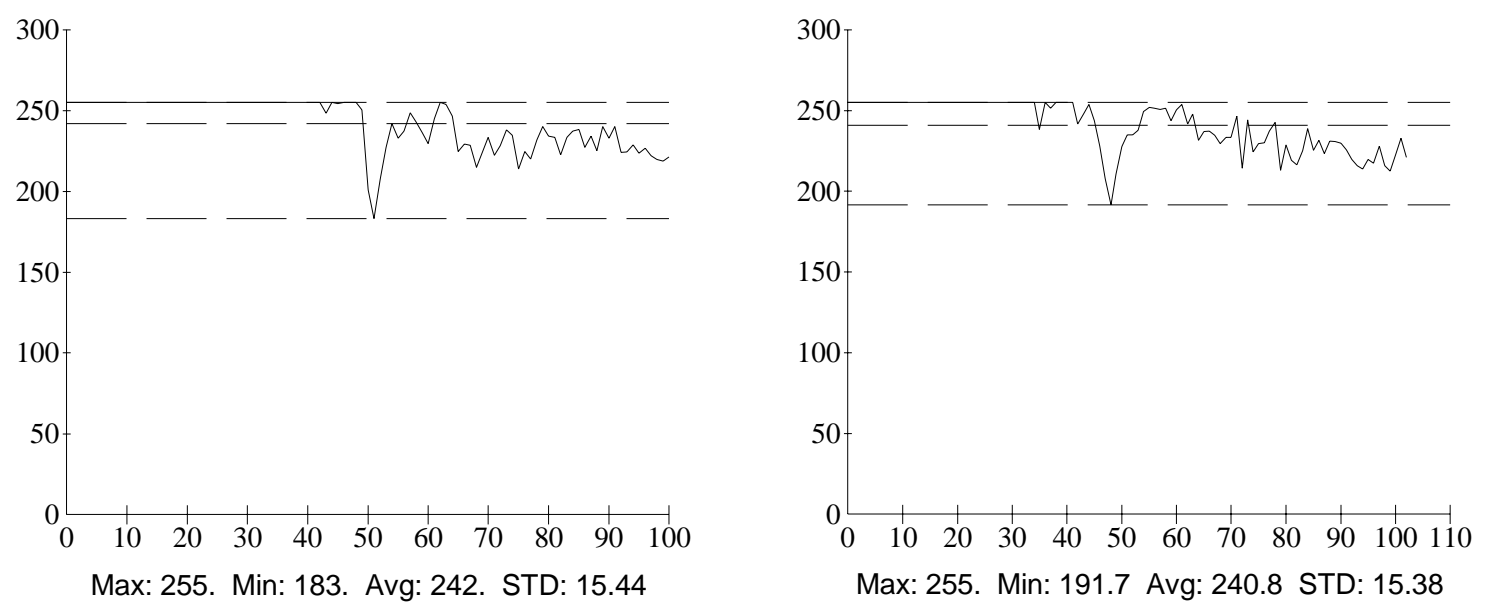

a) 1-second delay time

b) 3-second delay time
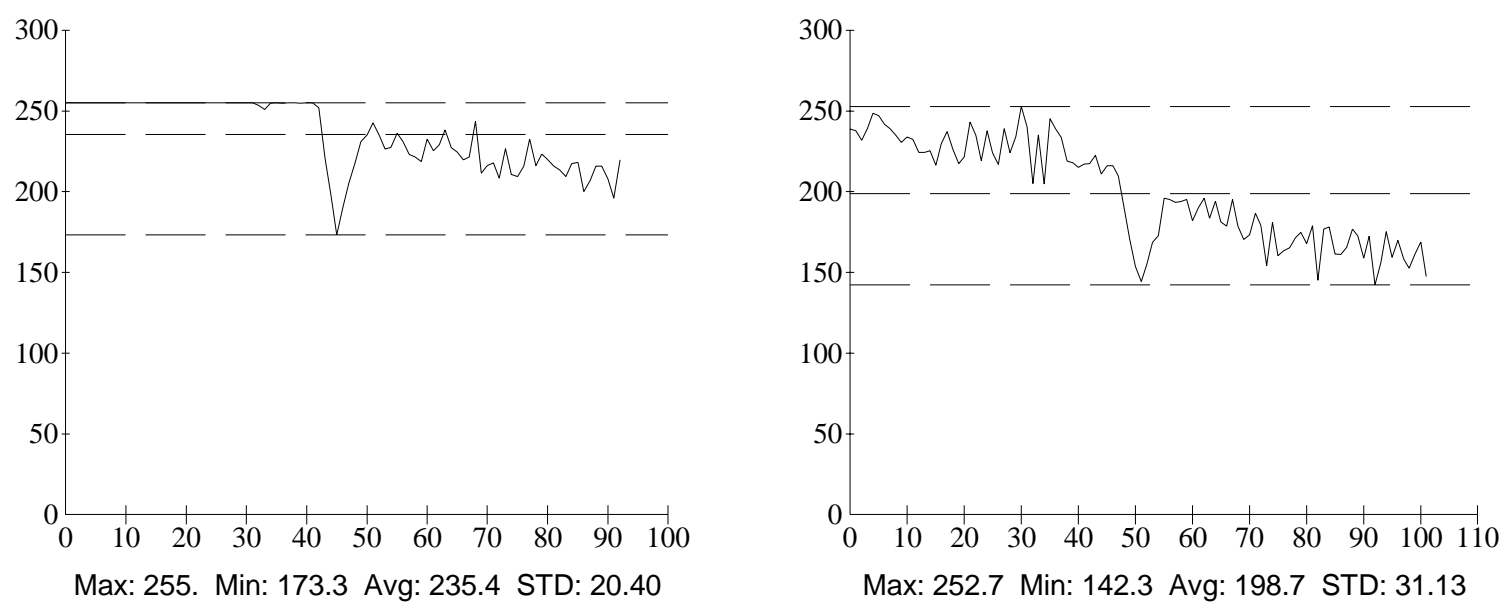

c) 6 second-delay time

d) 9 second-delay time

Figure A.30 Thermal intensity profile along the line across the fatigue crack shown in Figure A.29. 


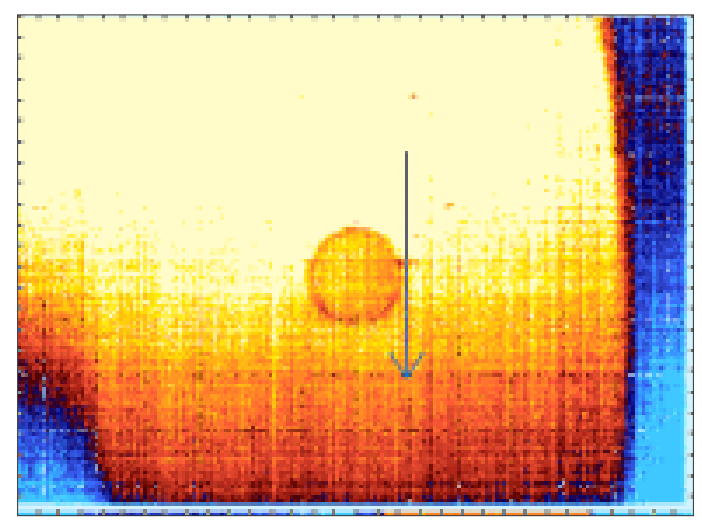

a) 1-second delay time

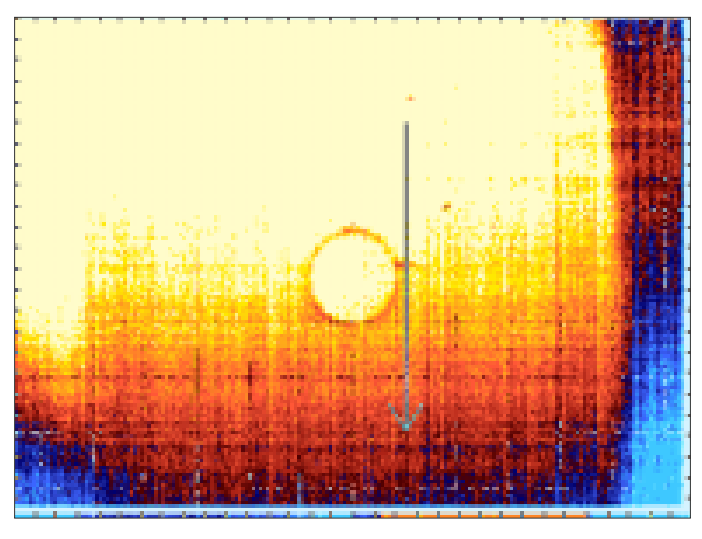

c) 6 second-delay time

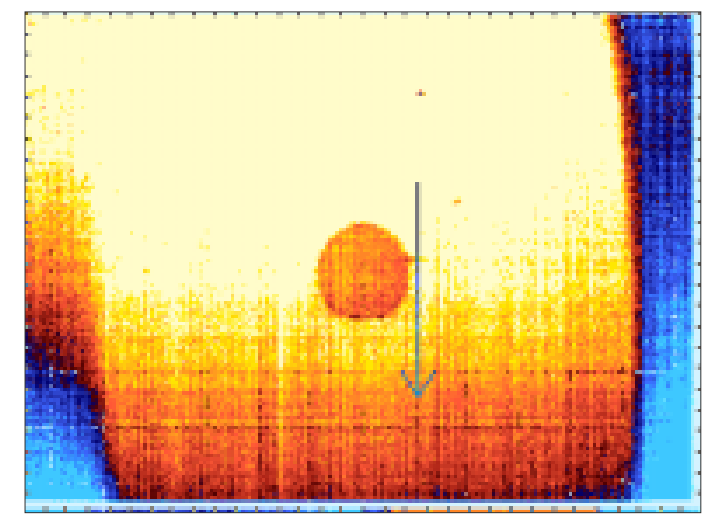

b) 3-second delay time

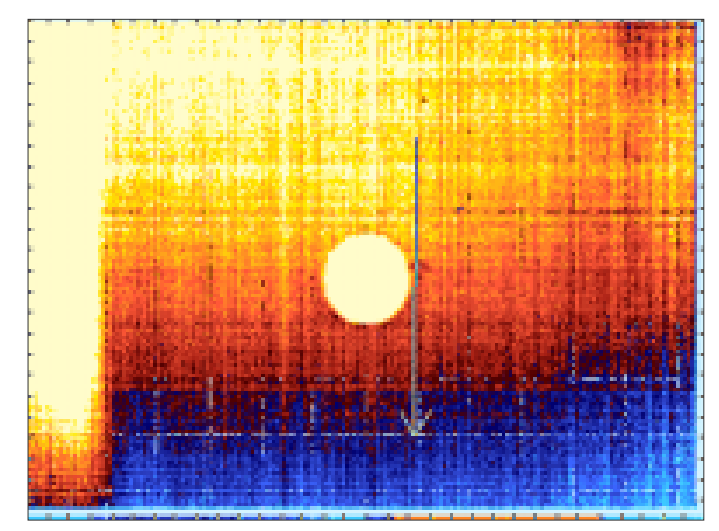

d) 9 second-delay time

Figure A.31 Thermal images of unpainted Specimen $\mathrm{CH}-2$ (using the active approach and heating time is 120 seconds). 


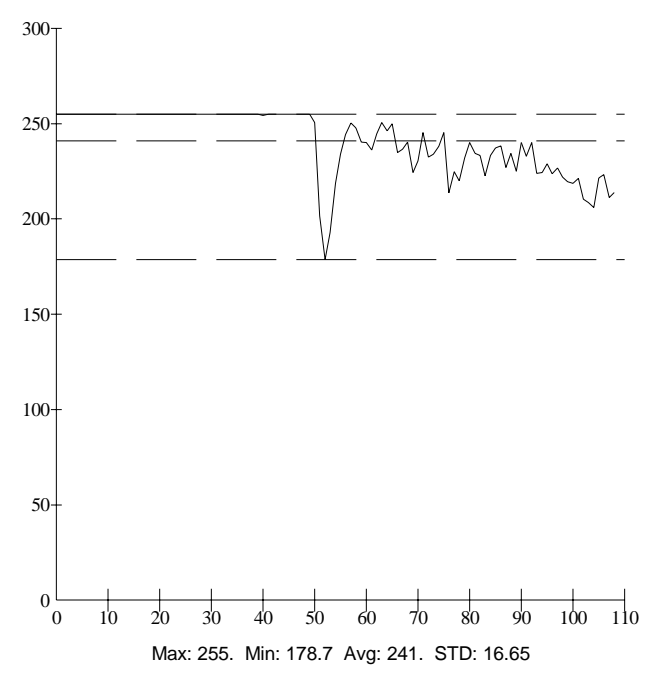

a) 1-second delay time

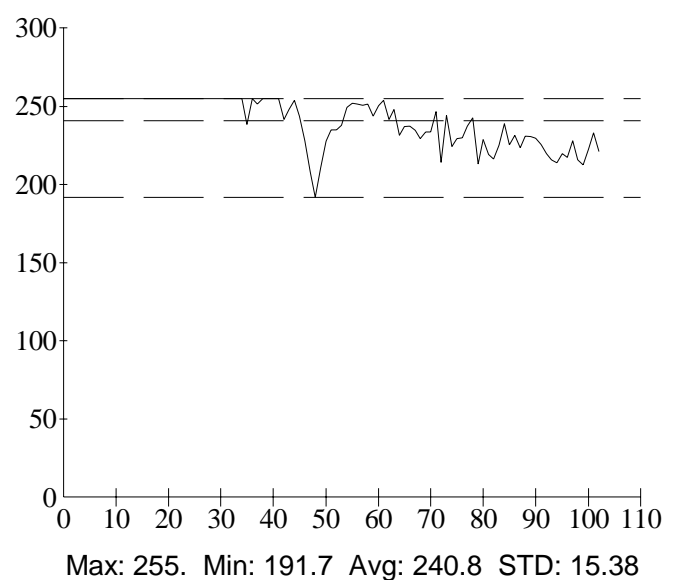

c) 6 second-delay time

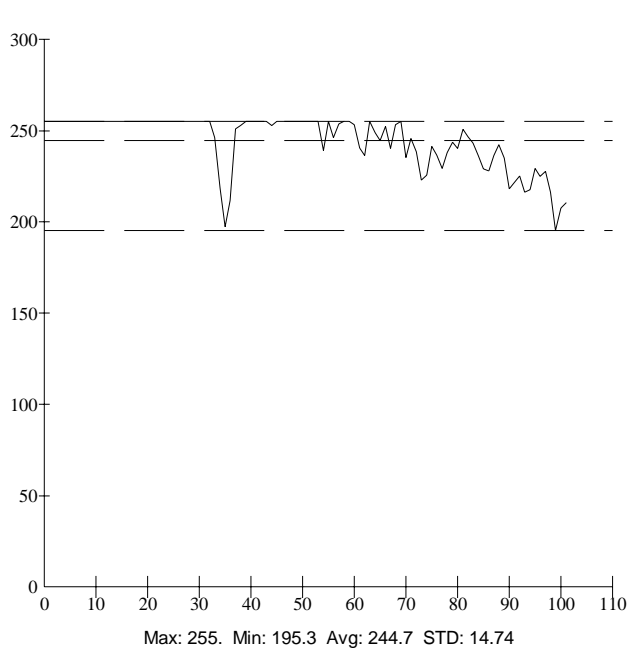

b) 3-second delay time

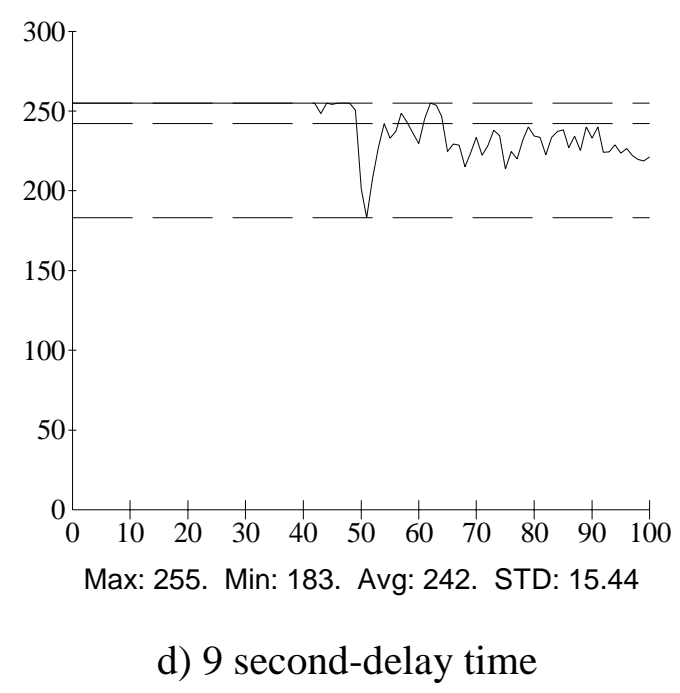

Figure A.32 Thermal intensity profile along the line across the fatigue crack shown in Figure A.31. 


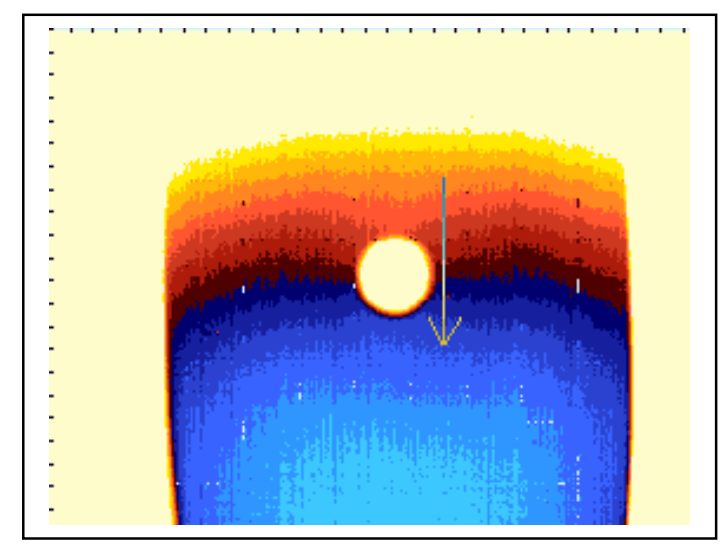

a) 1-second delay time

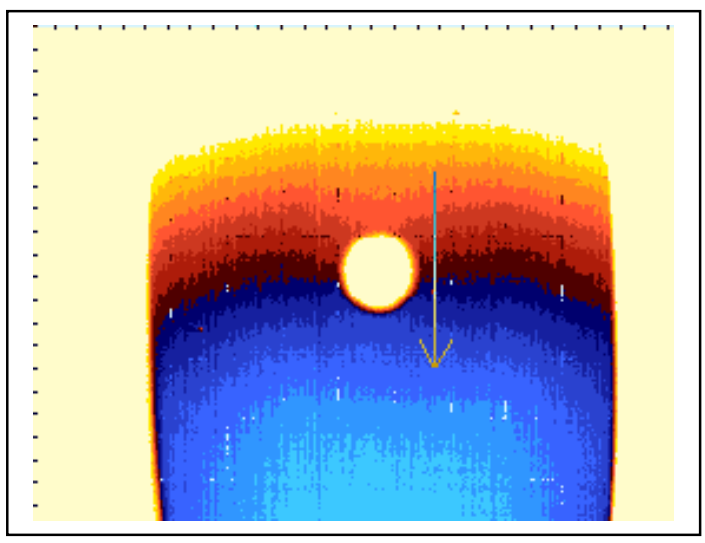

c) 6 second-delay time

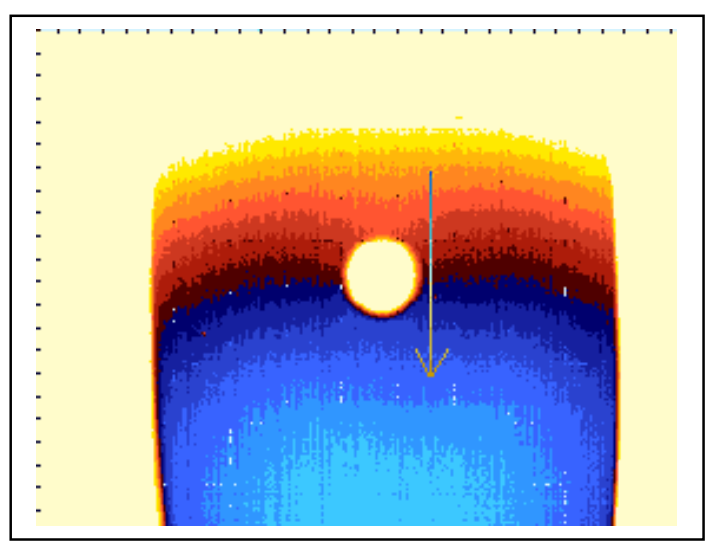

b) 3-second delay time

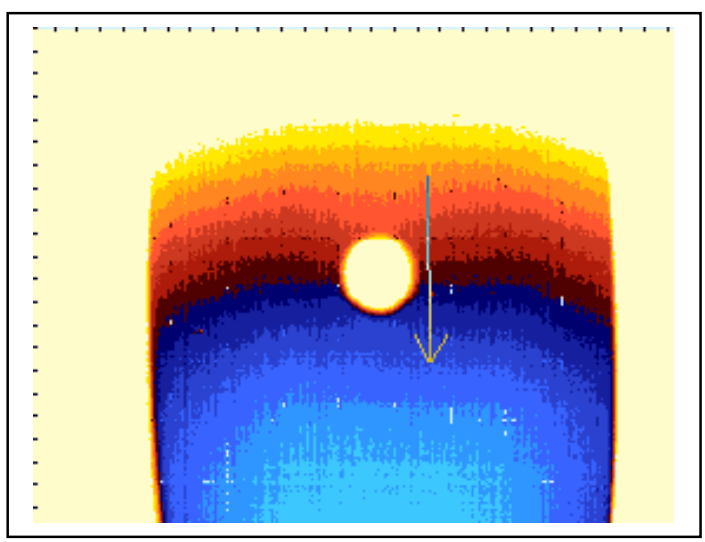

d) 9 second-delay time

Figure A.33 Thermal images of Specimen $\mathrm{CH}-2$ (using the active approach and heating time is 30 seconds). 


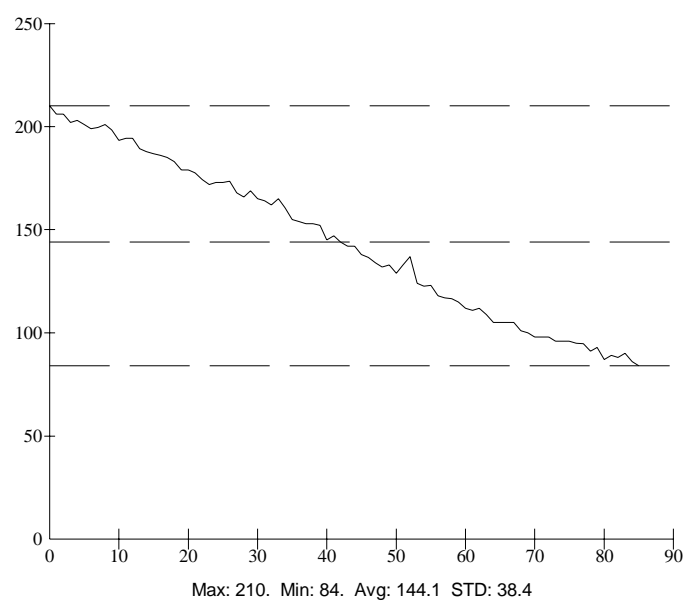

a) 1-second delay time

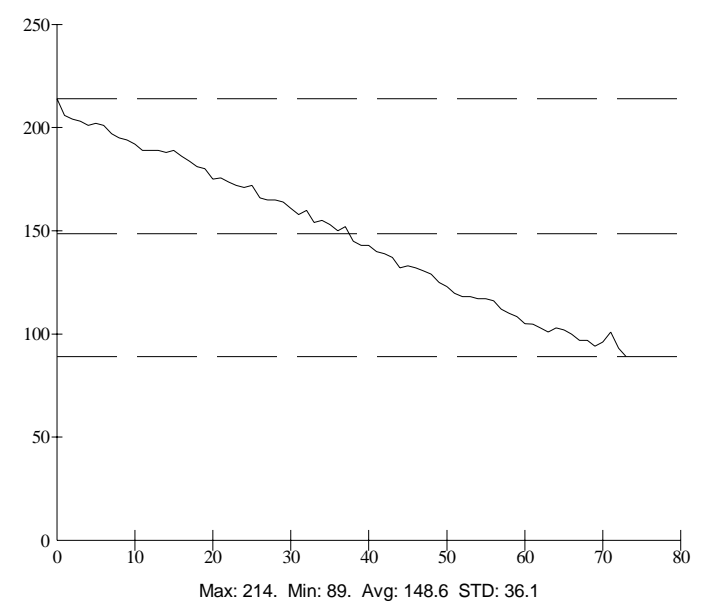

c) 6 second-delay time

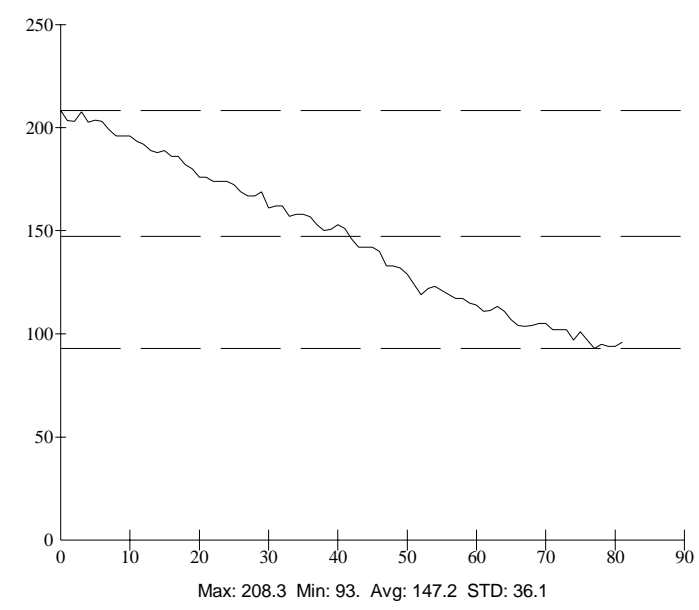

b) 3-second delay time

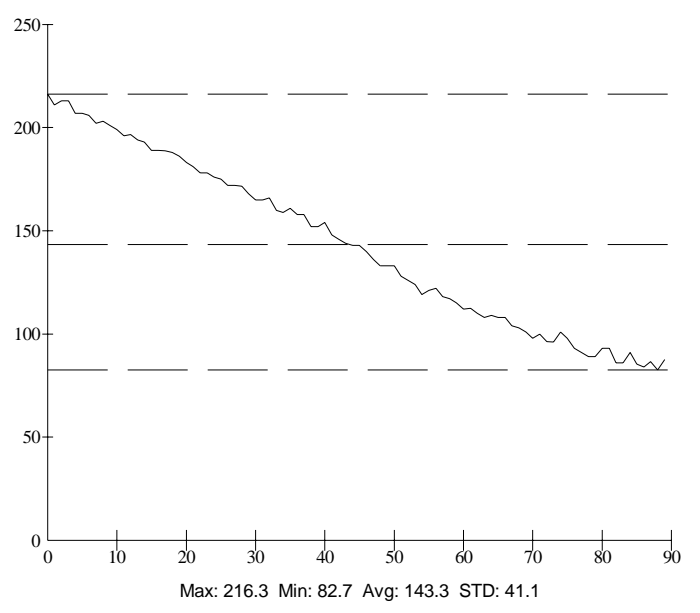

d) 9 second-delay time

Figure A.34 Thermal intensity profile along the line across the fatigue crack shown in Figure A.33. 


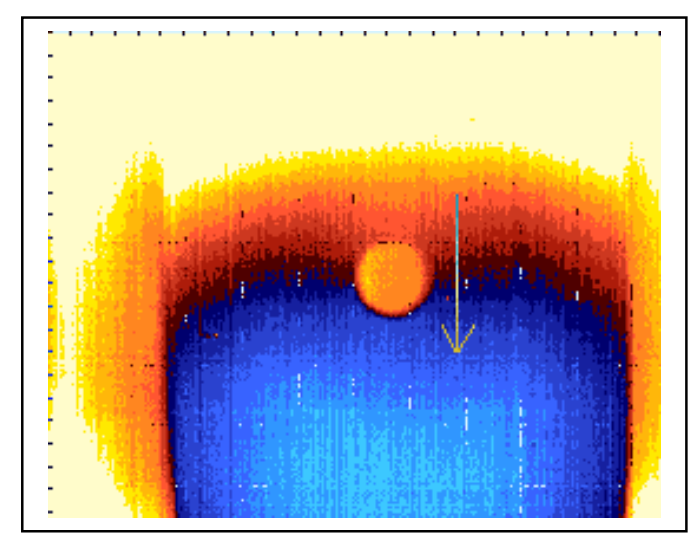

a) 1-second delay time

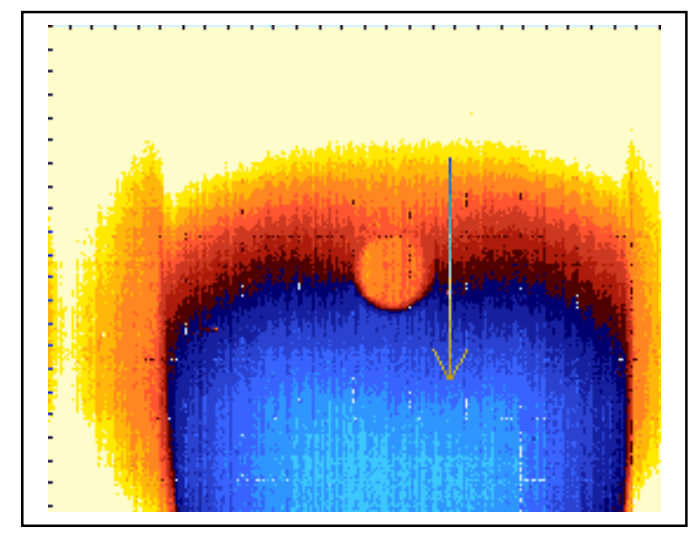

c) 6 second-delay time

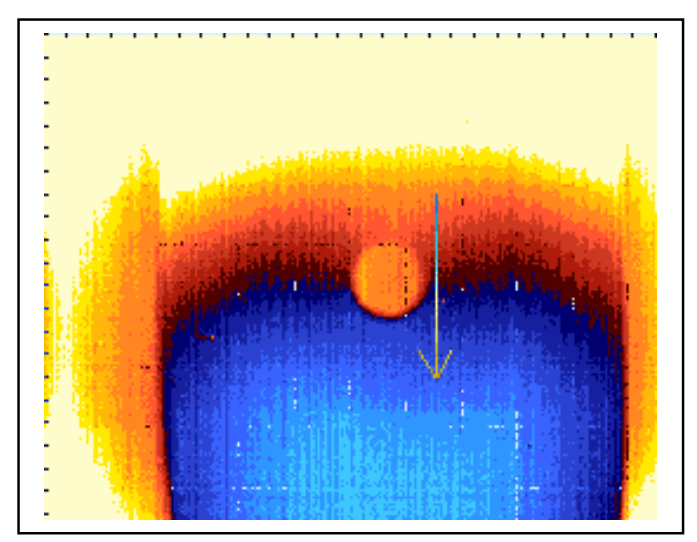

b) 3-second delay time

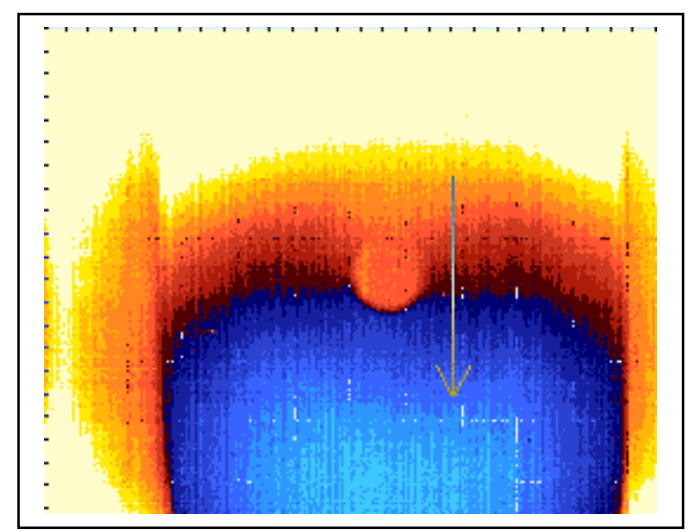

d) 9 second-delay time

Figure A.35 Thermal images of Specimen CH-2 (using the active approach and heating time is 60 seconds). 


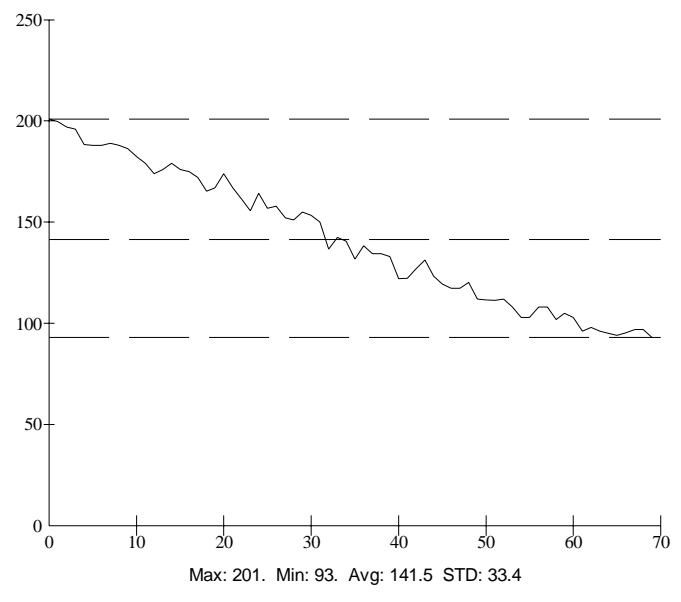

a) 1-second delay time

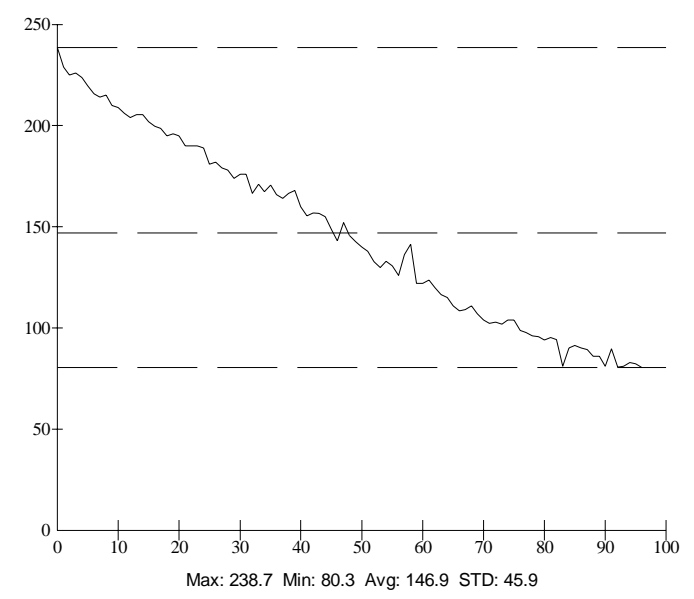

c) 6 second-delay time

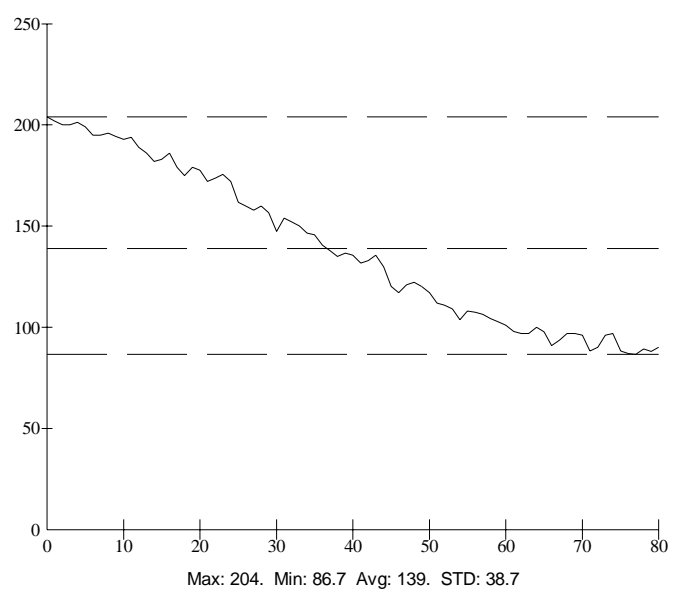

b) 3-second delay time

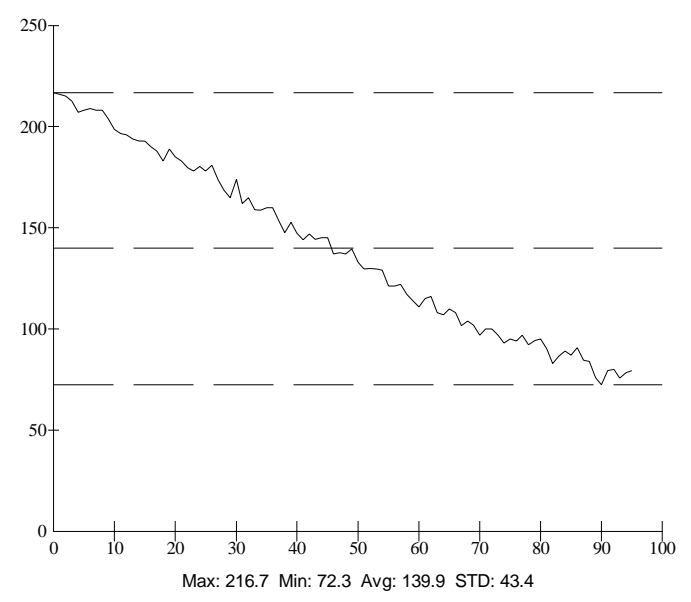

d) 9 second-delay time

Figure A.36 Thermal intensity profile along the line across the fatigue crack shown in Figure A.35. 


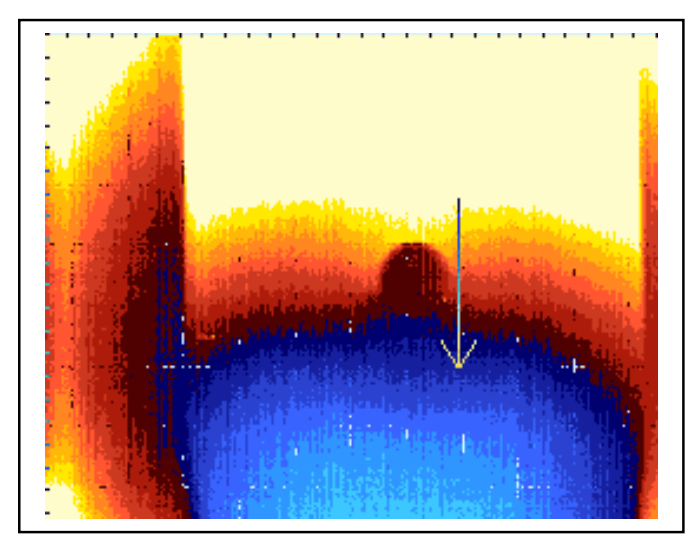

a) 1-second delay time

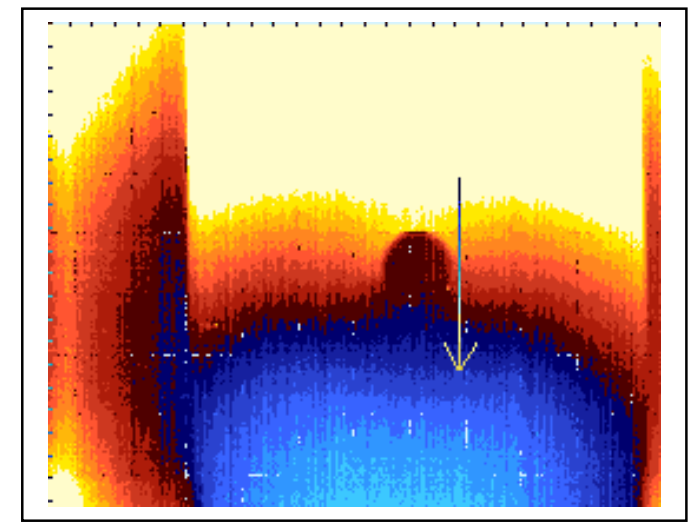

c) 6 second-delay time

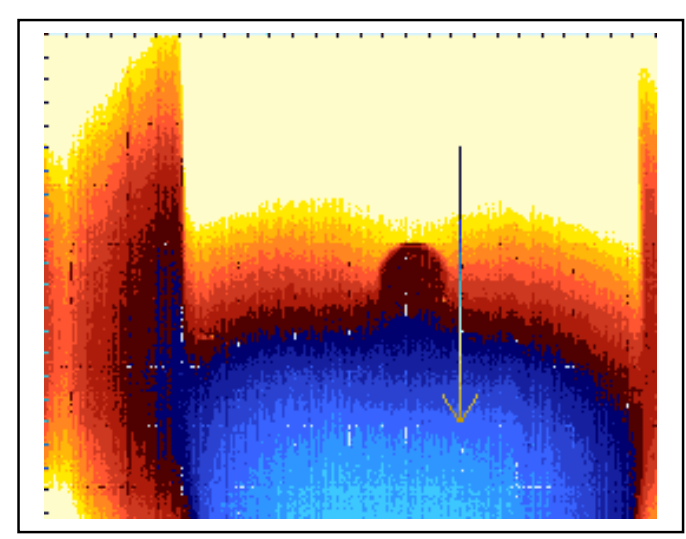

b) 3-second delay time

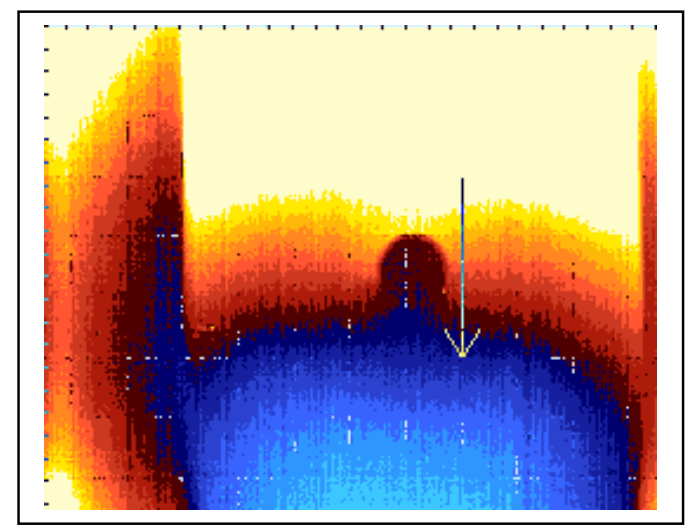

d) 9 second-delay time

Figure A.37 Thermal images of Specimen CH-2 (using the active approach and heating time is 90 seconds). 


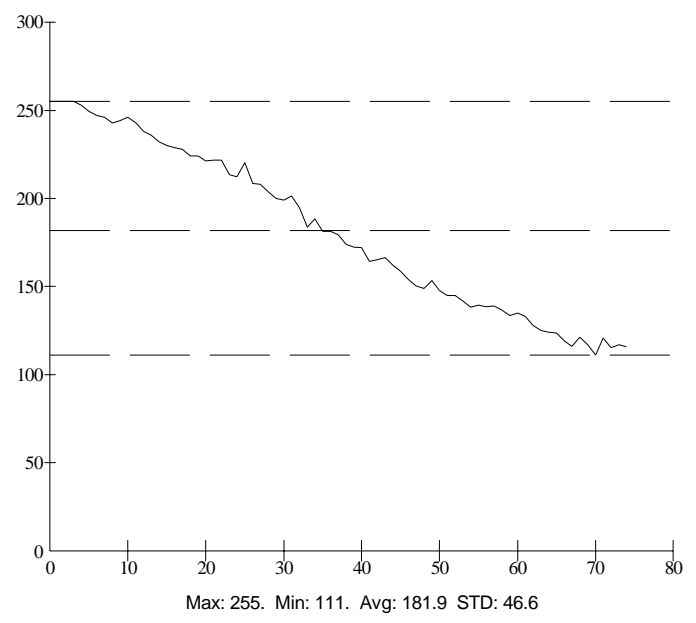

a) 1-second delay time

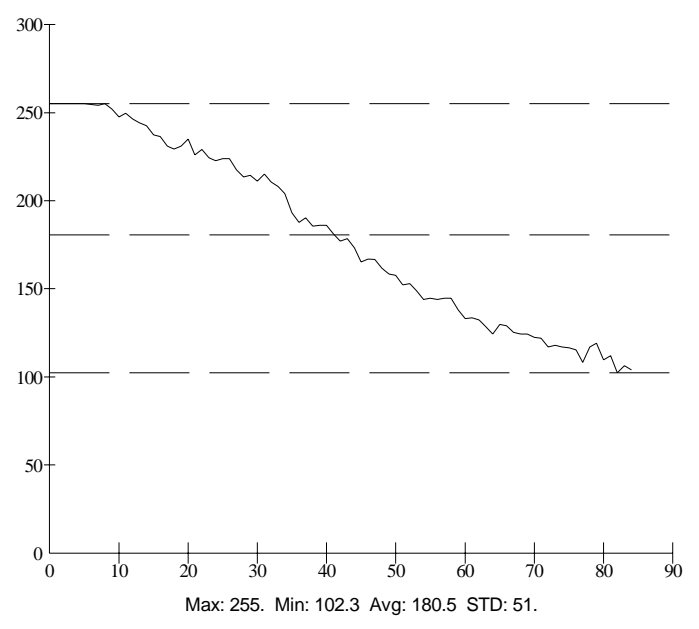

c) 6 second-delay time

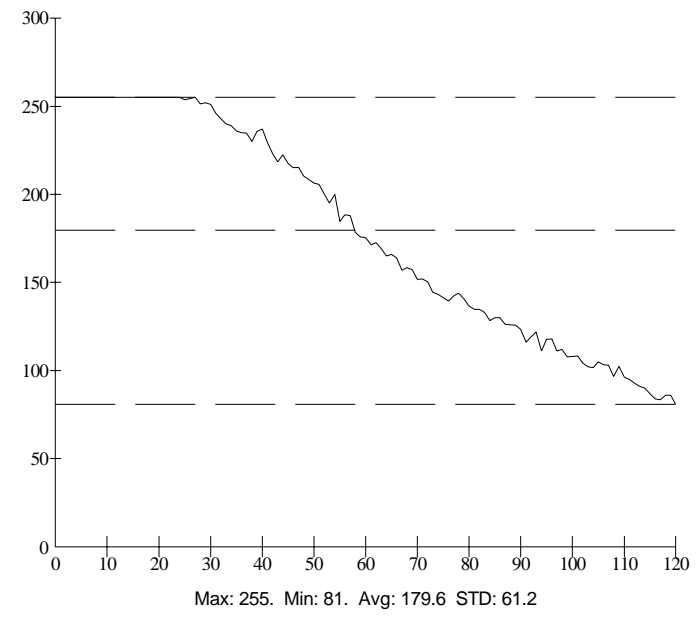

b) 3-second delay time

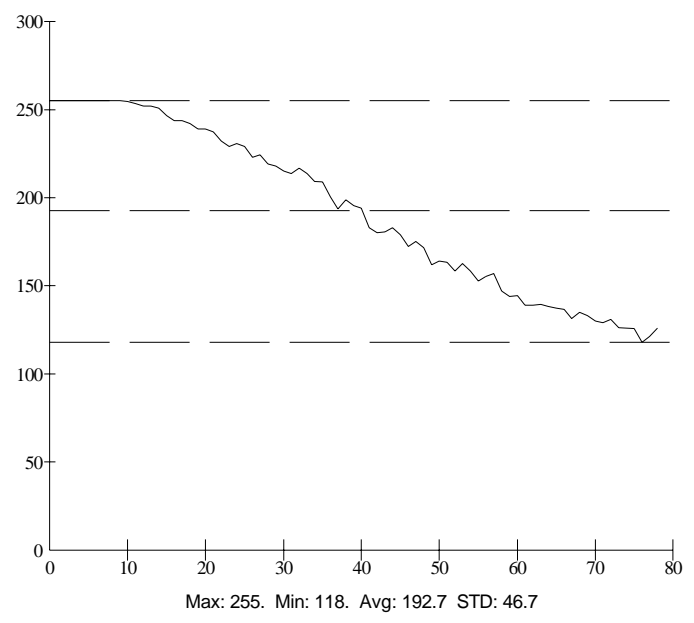

d) 9 second-delay time

Figure A.38 Thermal intensity profile along the line across the fatigue crack shown in Figure A.37. 


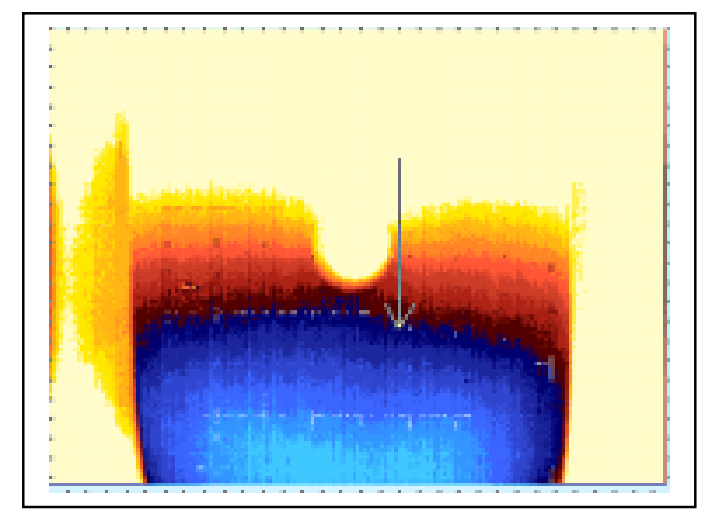

a) 1-second delay time

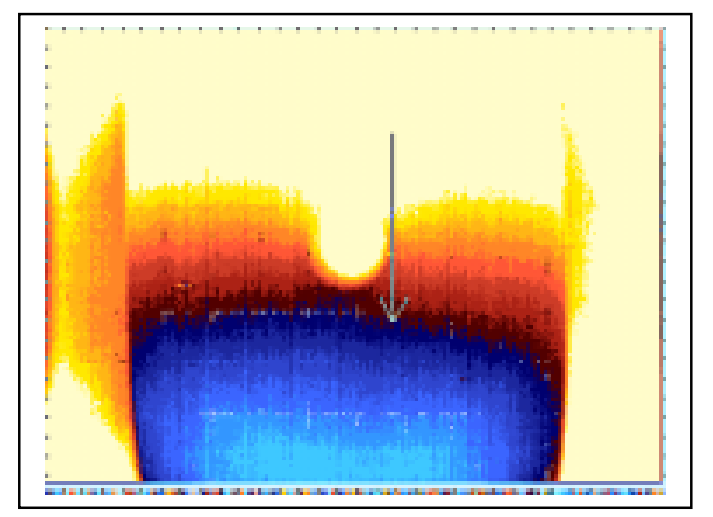

c) 6 second-delay time

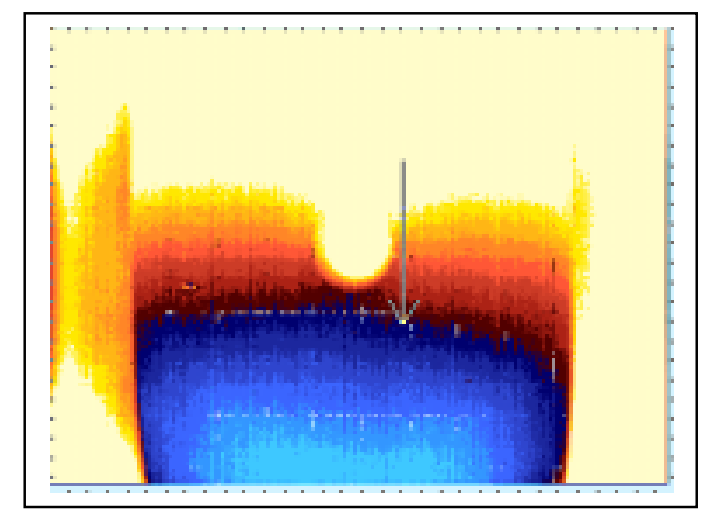

b) 3-second delay time

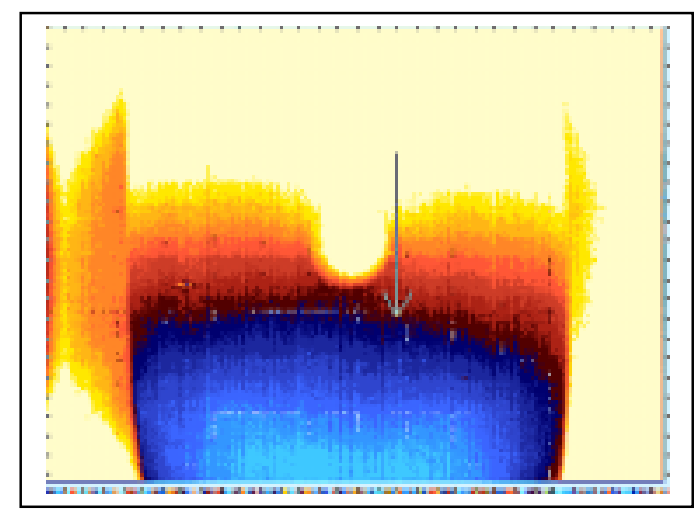

d) 9 second-delay time

Figure A.39 Thermal images of Specimen CH-2 (using the active approach and heating time is 120 seconds). 


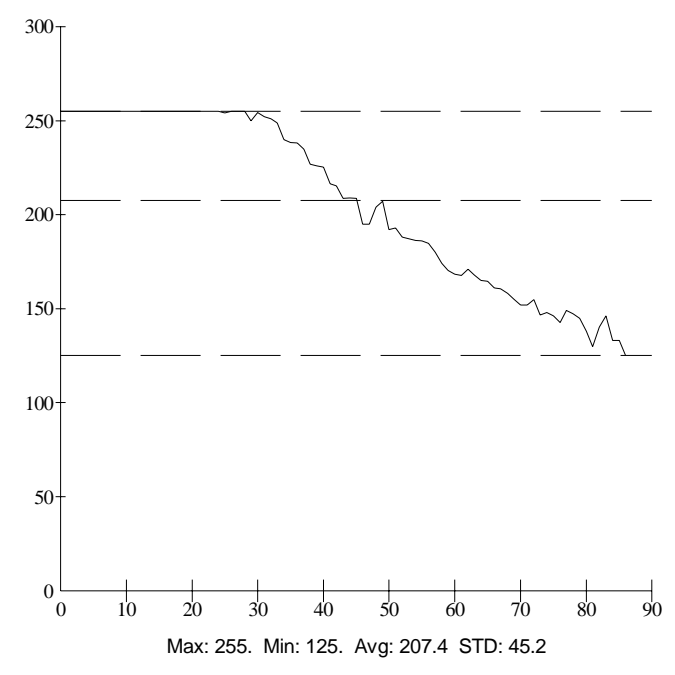

a) 1-second delay time

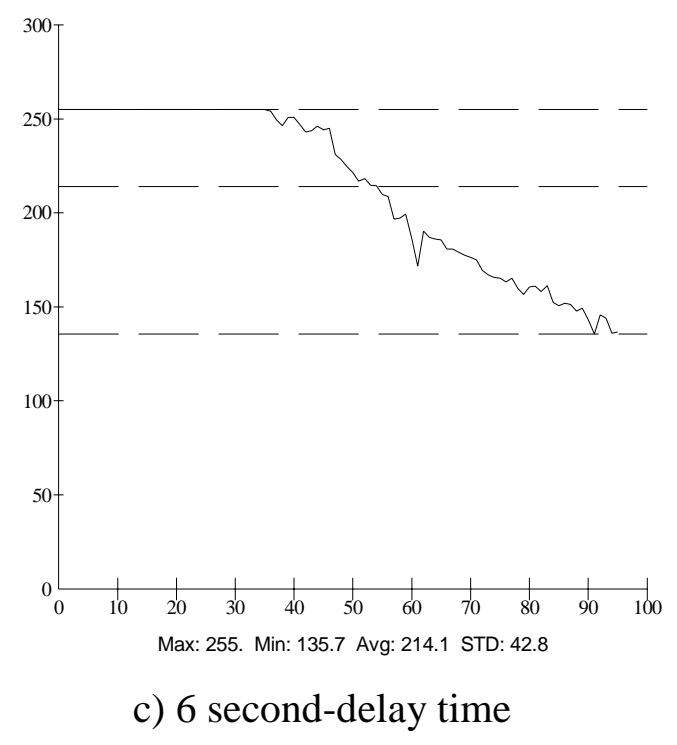

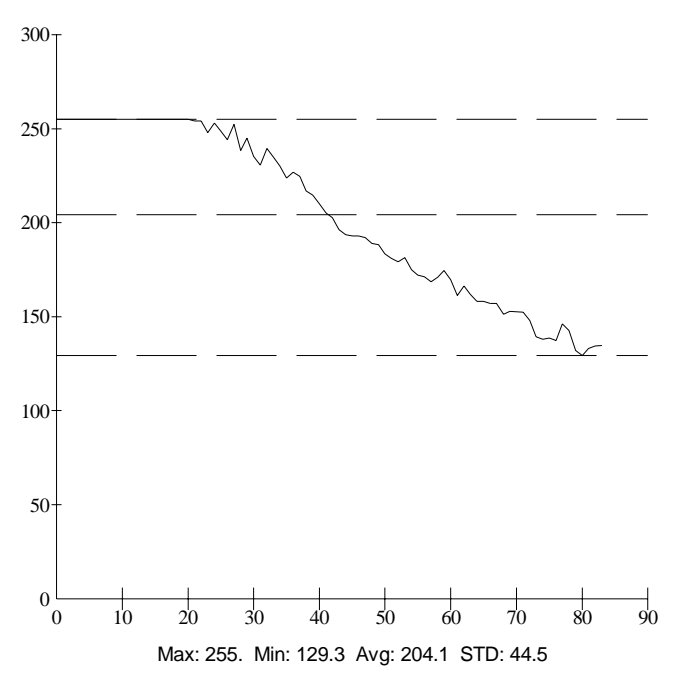

b) 3-second delay time

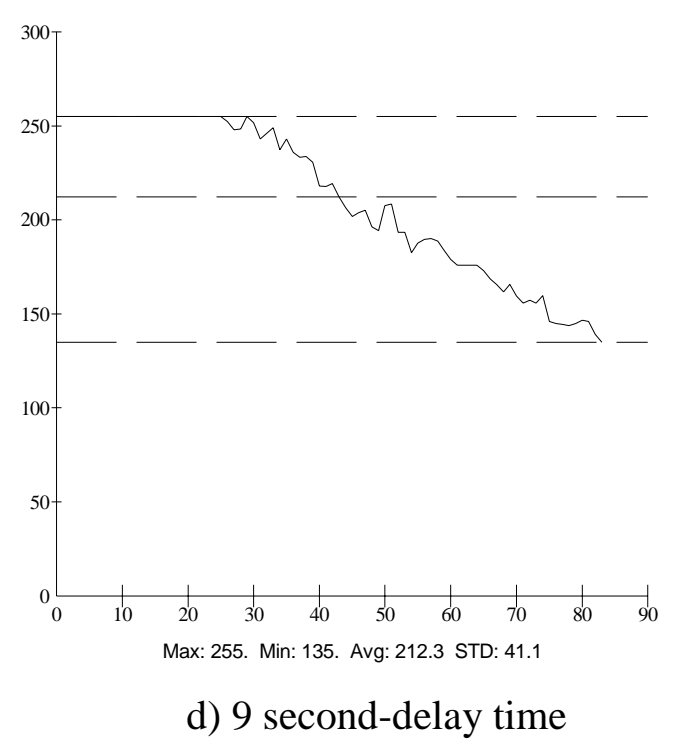

Figure A.40 Thermal intensity profile along the line across the fatigue crack shown in Figure A.39. 


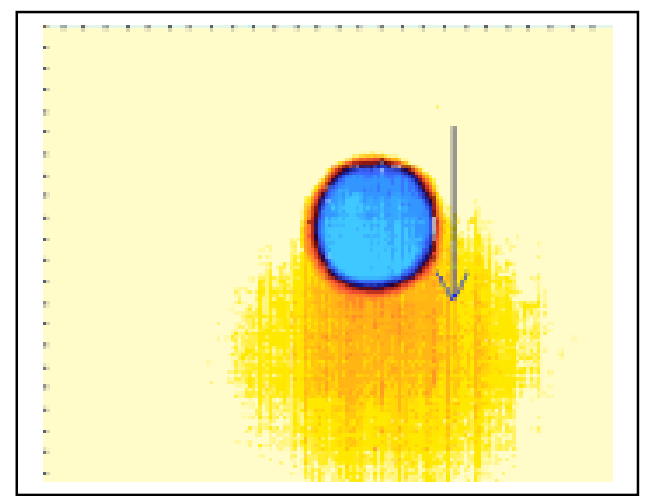

a) 1-second delay time

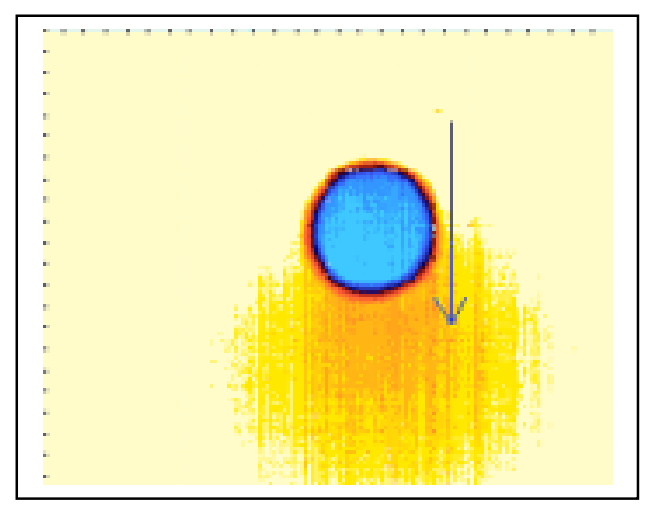

c) 6 second-delav time

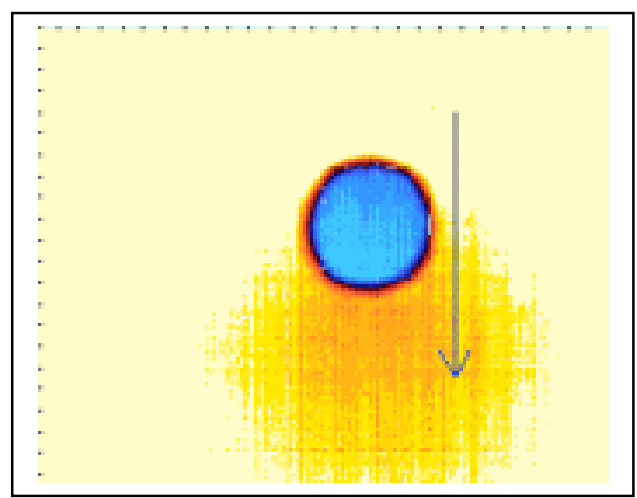

b) 3-second delay time

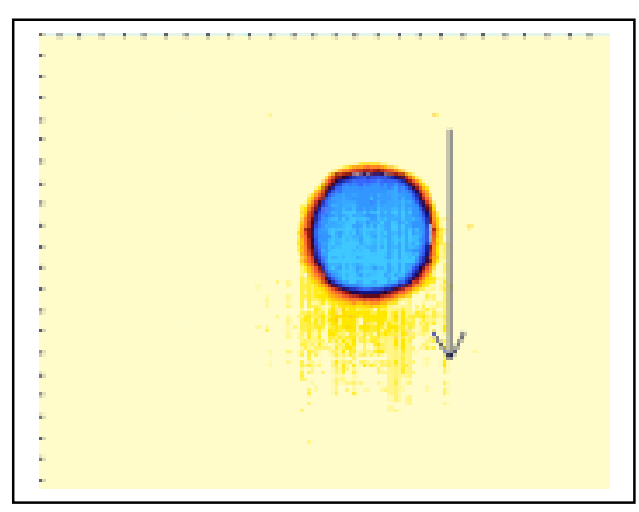

d) 9 second-delay time

Figure A.41 Thermal images of Specimen CH-3 (using the active approach and heating time is 15 seconds) at 450,000 loading cycles. 


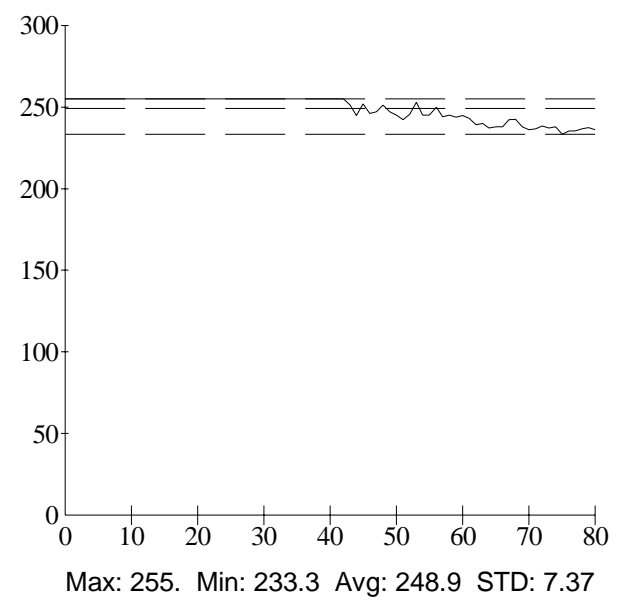

a) 1-second delay time

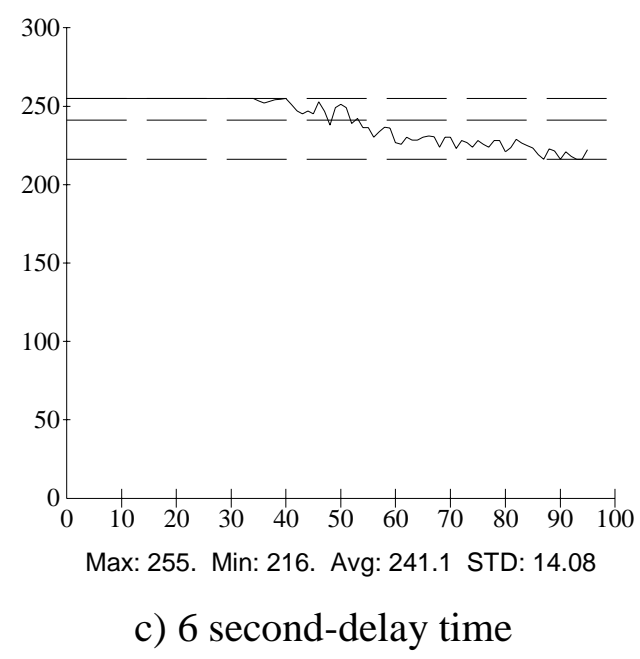

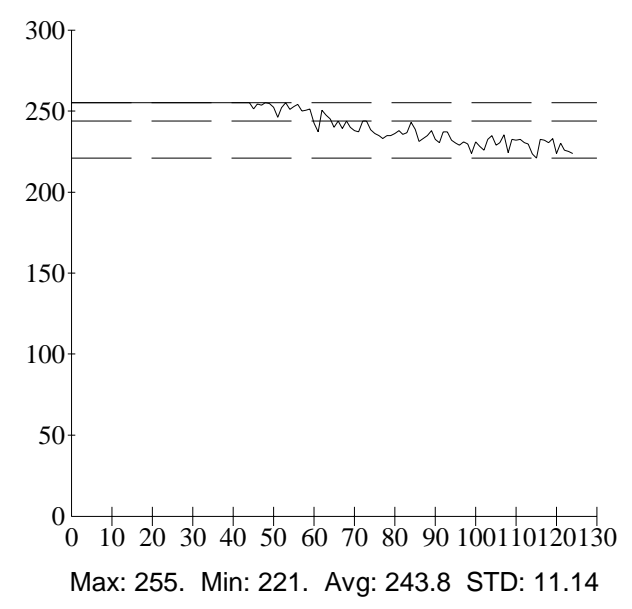

b) 3-second delay time

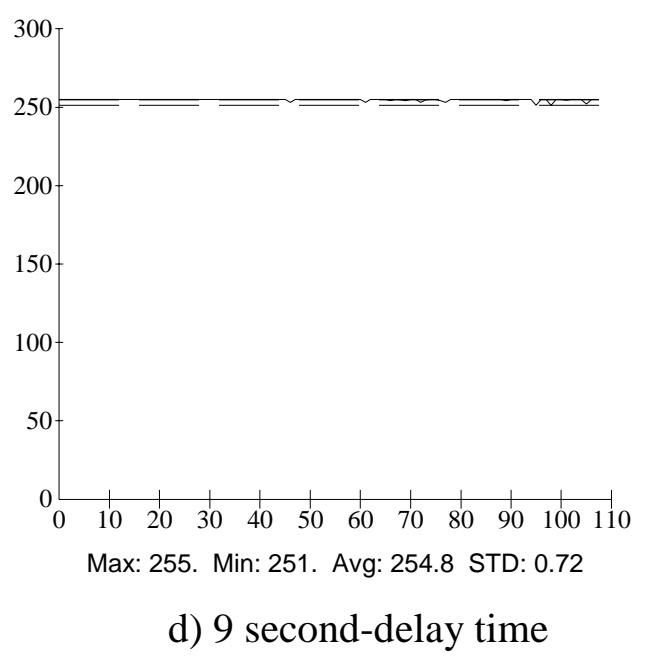

Figure A.42 Thermal intensity profile along the line across the fatigue crack shown in Figure A.41. 


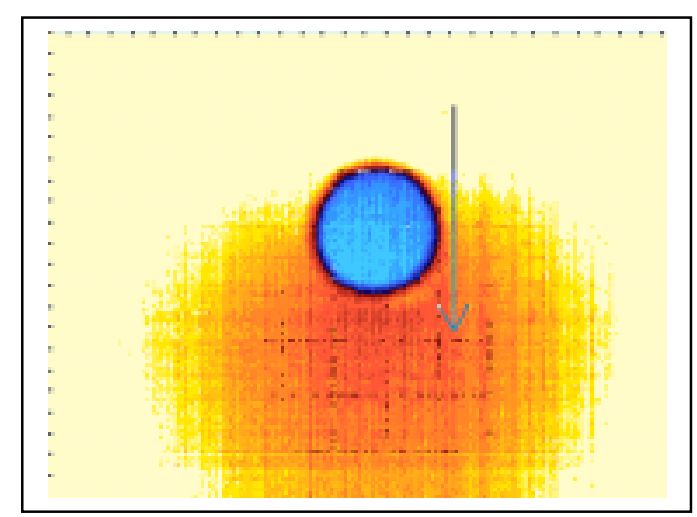

a) 1-second delay time

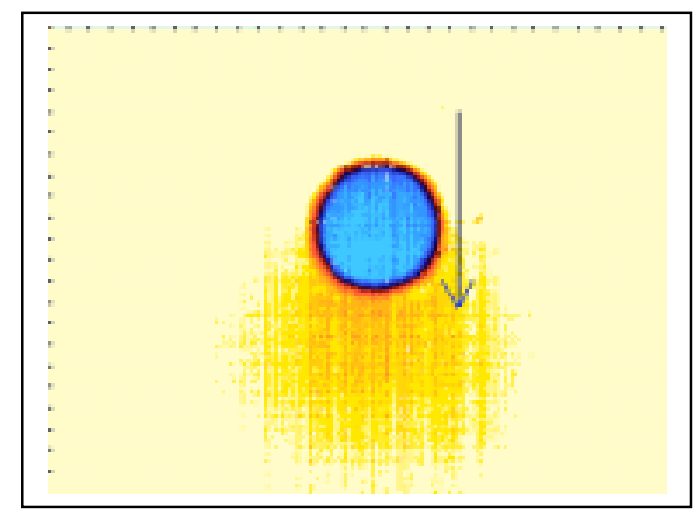

c) 6 second-delay time

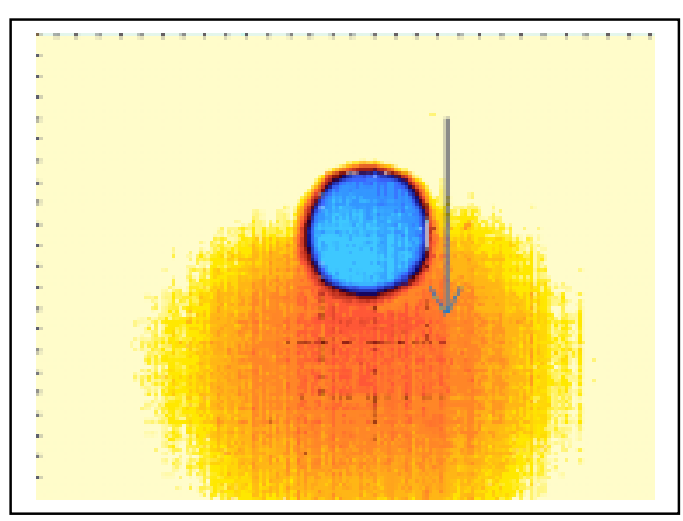

b) 3-second delay time

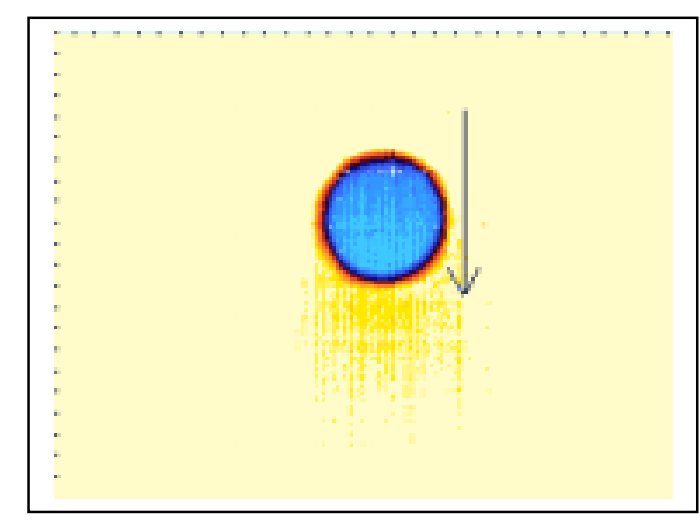

d) 9 second-delay time

Figure A.43 Thermal images of Specimen CH-3 at 450,000 loading cycles 3 (using the active approach and heating time is 30 seconds). 


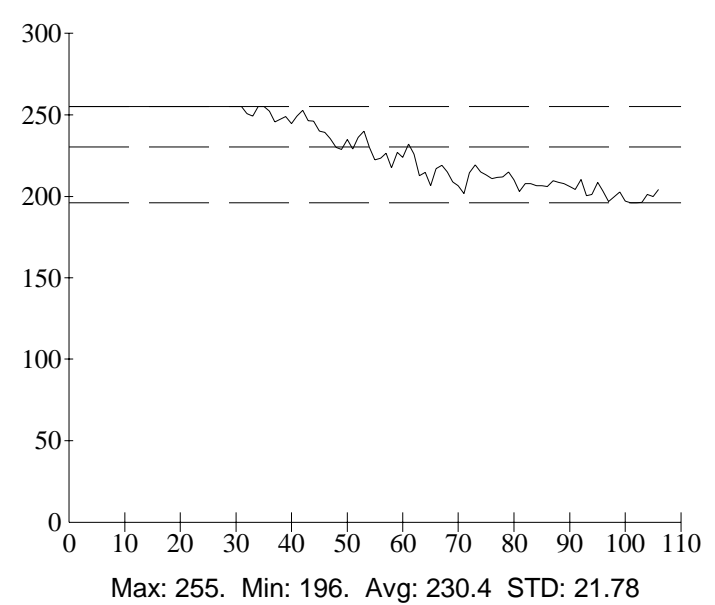

a) 1-second delay time

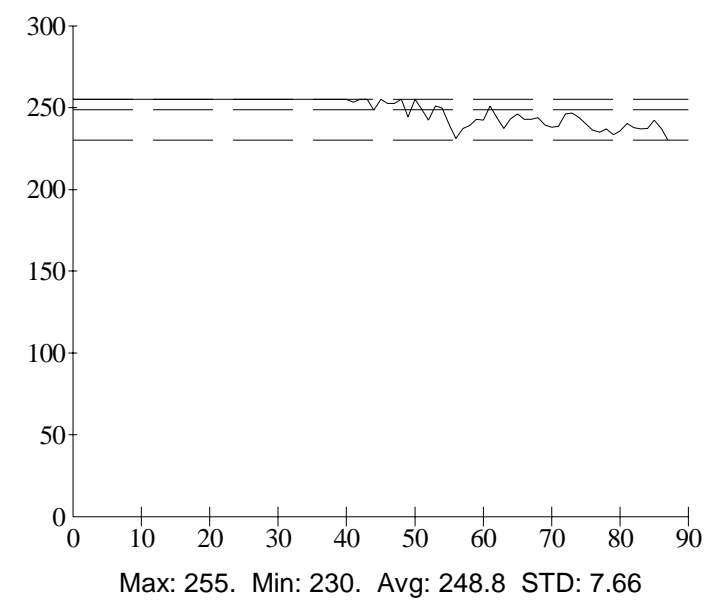

c) 6 second-delay time

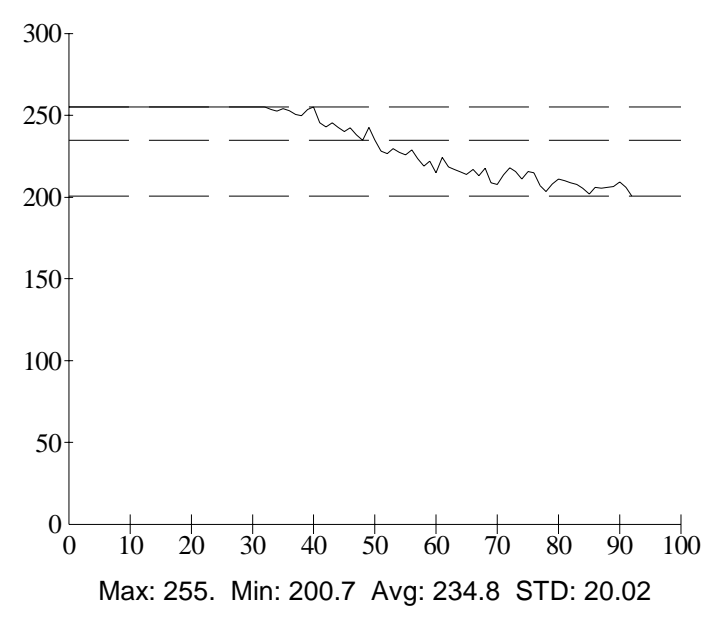

b) 3-second delay time

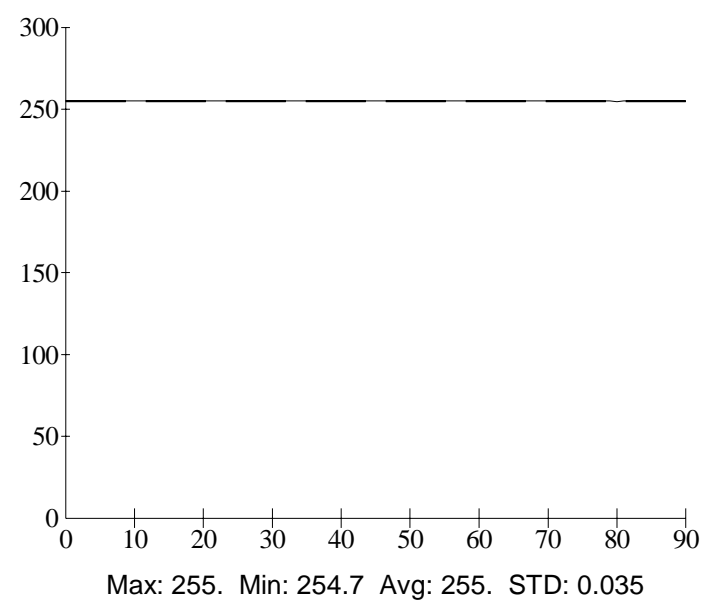

d) 9 second-delay time

Figure A.44 Thermal intensity profile along the line across the fatigue crack shown in Figure A.43. 


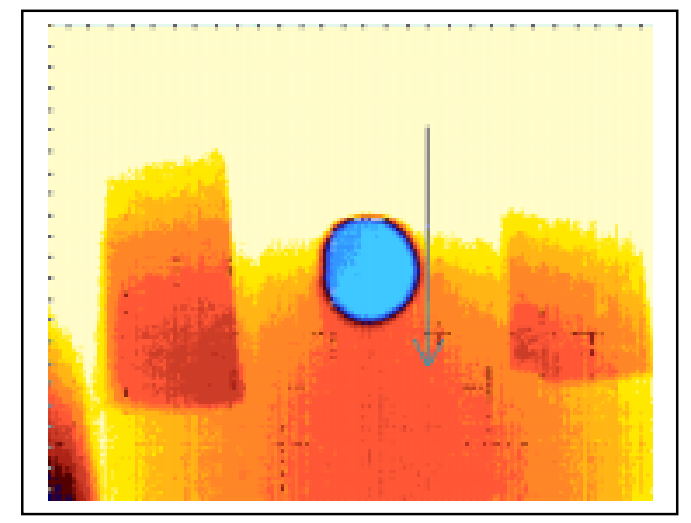

a) 1-second delay time

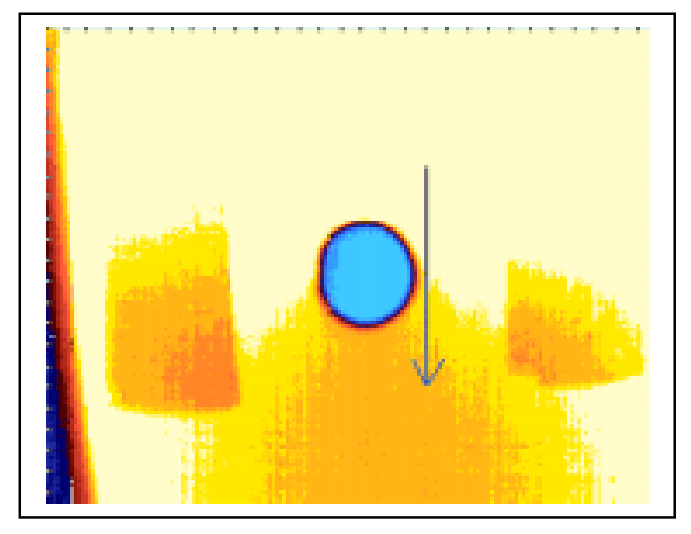

c) 6 second-delay time

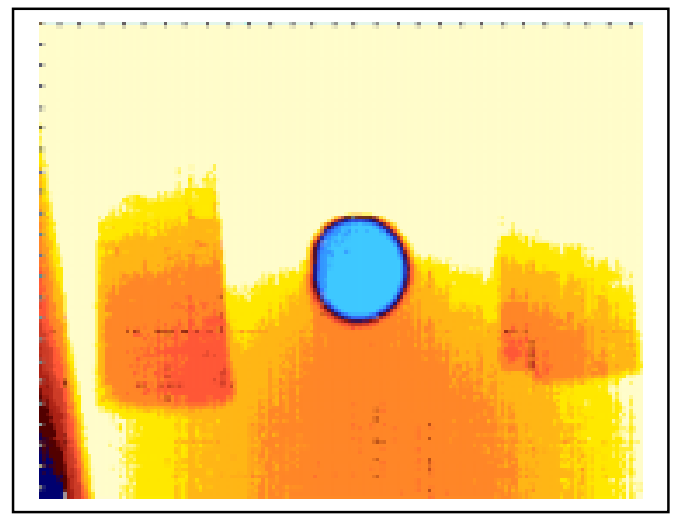

b) 3-second delay time

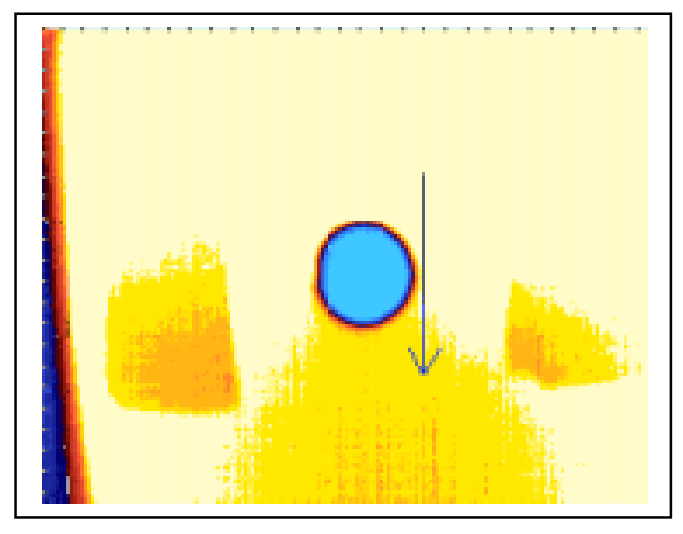

d) 9 second-delay time

Figure A.45 Thermal images of Specimen CH-3 at 450,000 loading cycles 3 (using the active approach and heating time is 45 seconds). 


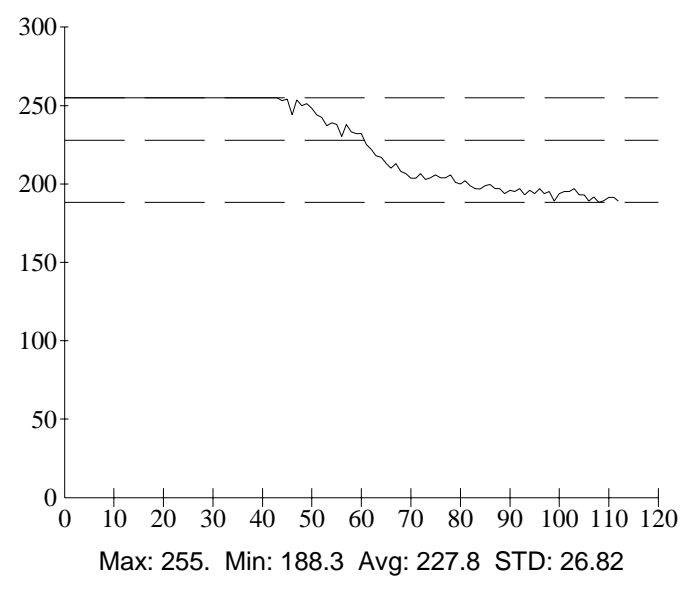

a) 1-second delay time

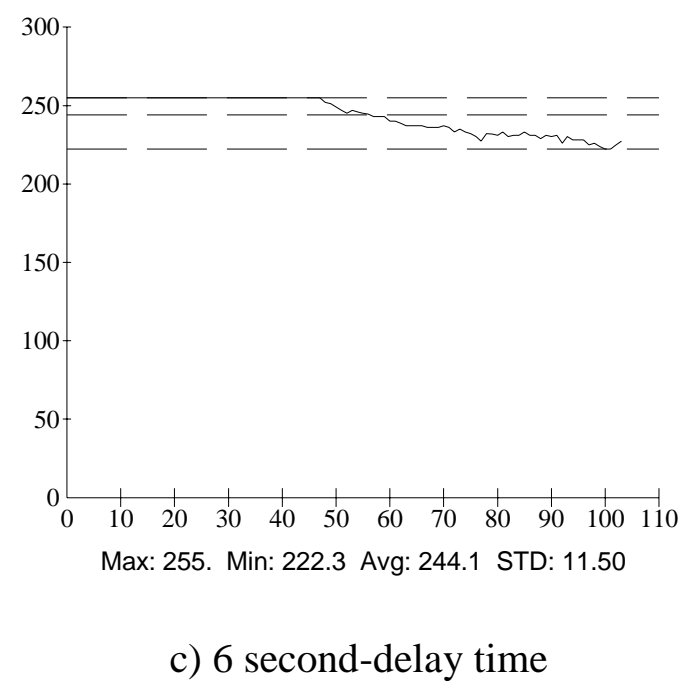

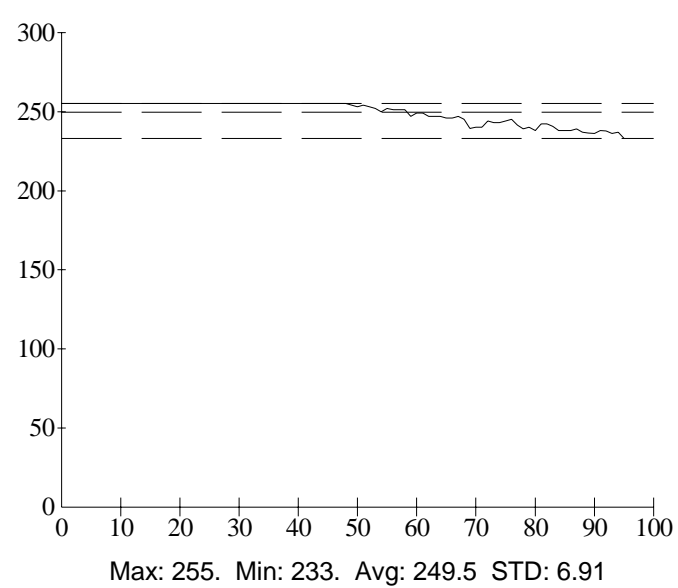

b) 3-second delay time

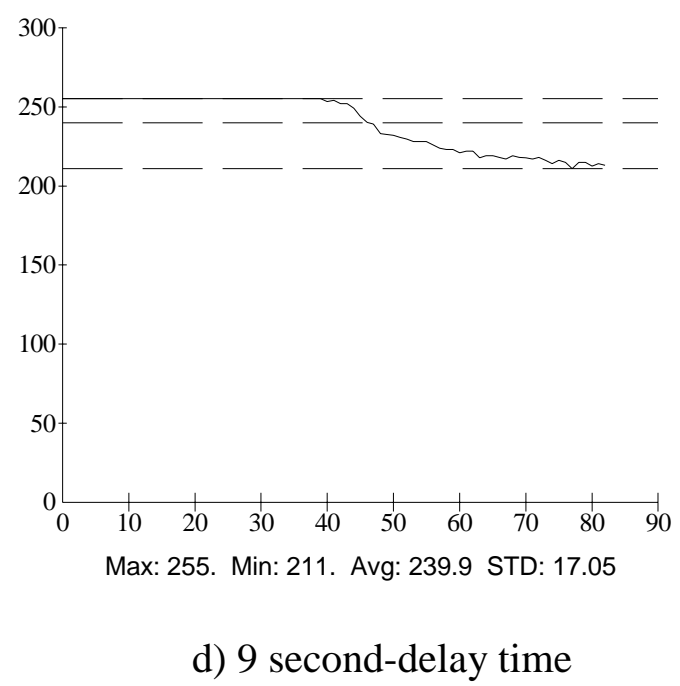

Figure A.46 Thermal intensity profile along the line across the fatigue crack shown in Figure A.45. 


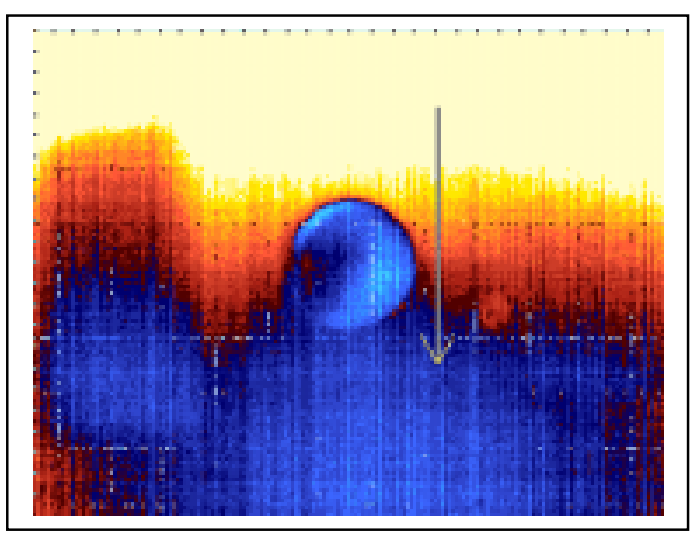

a) 1-second delay time

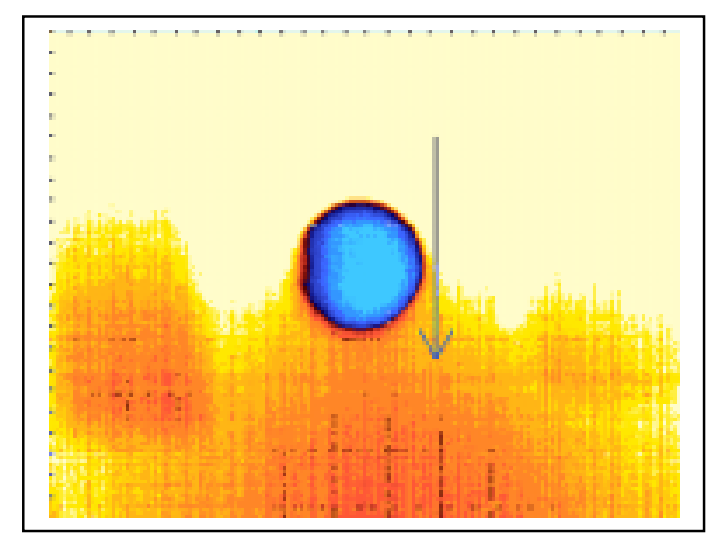

c) 6-second delay time

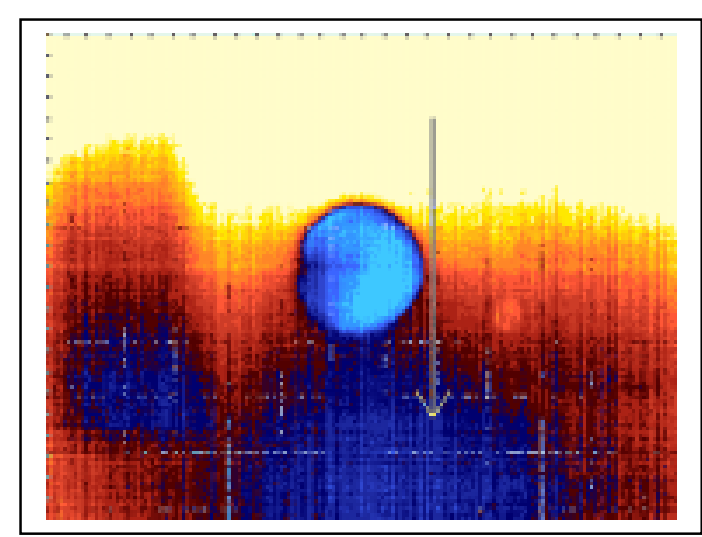

b) 3-second delay time

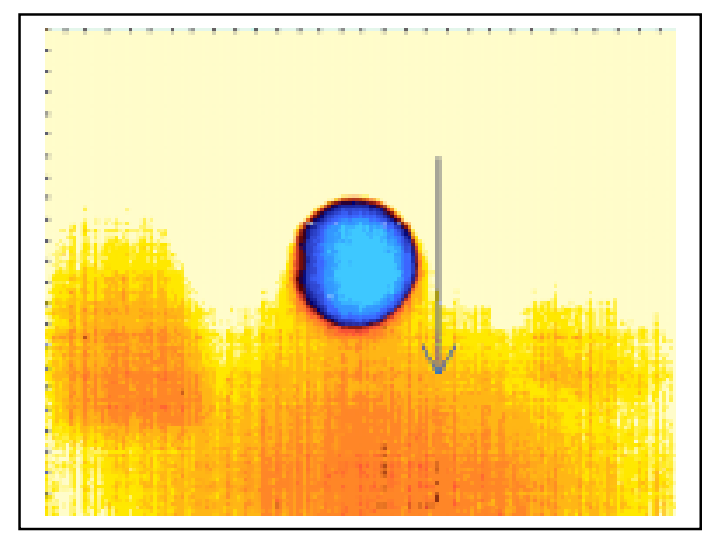

d) 9-second delay time

Figure A.47 Thermal images of Specimen CH-3 at 450,000 loading cycles (using the active approach and heating time is 60 seconds). 


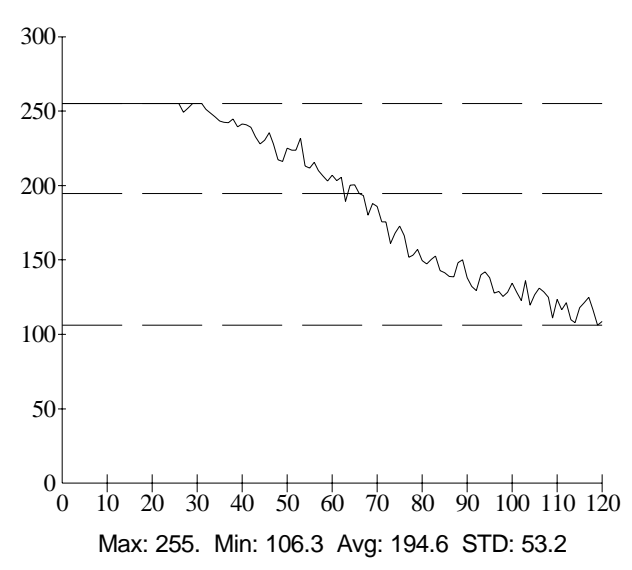

a) 1-second delay time

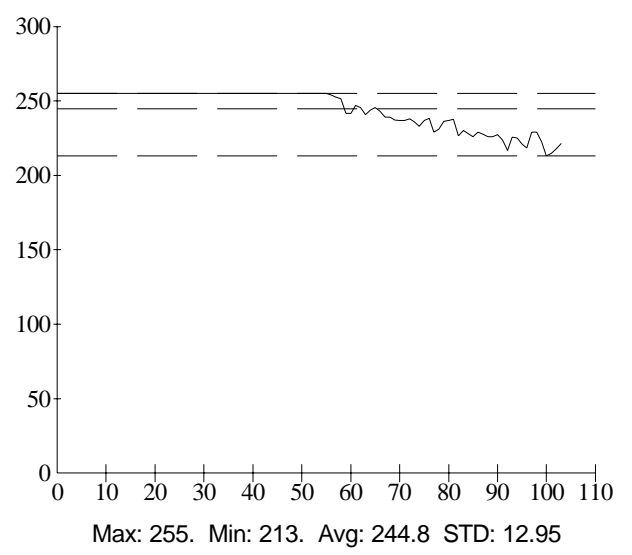

c) 6-second delay time

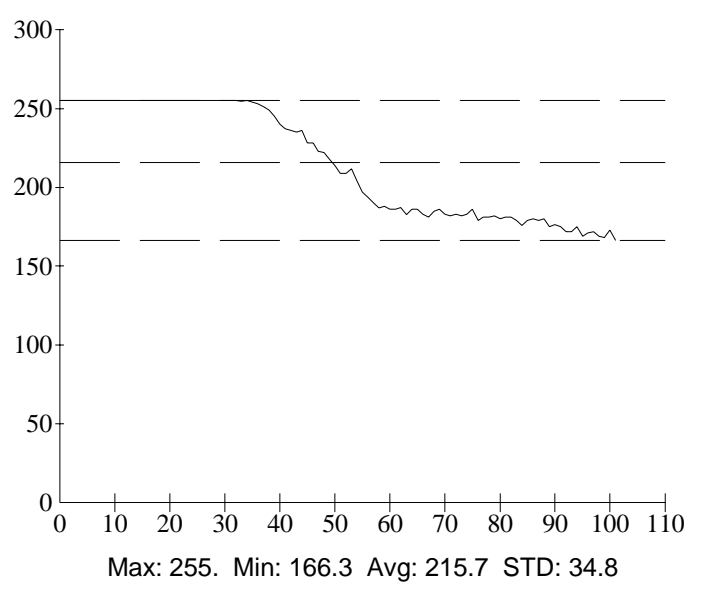

b) 3-second delay time

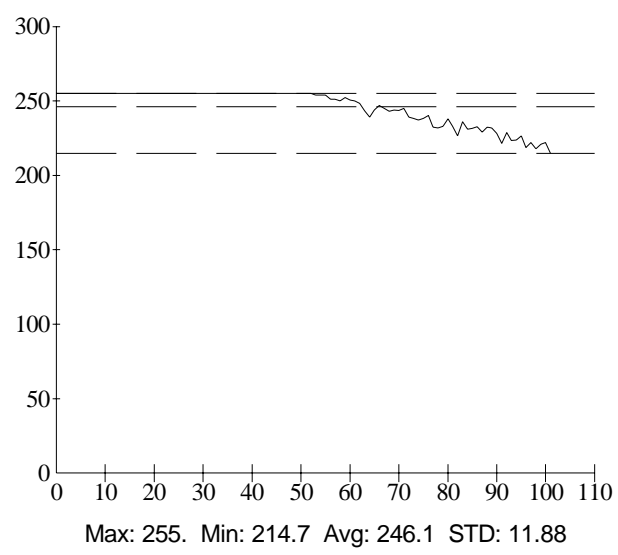

d) 9-second delay time

Figure A.48 Thermal intensity profile along the line across the fatigue crack shown in Figure A.47. 


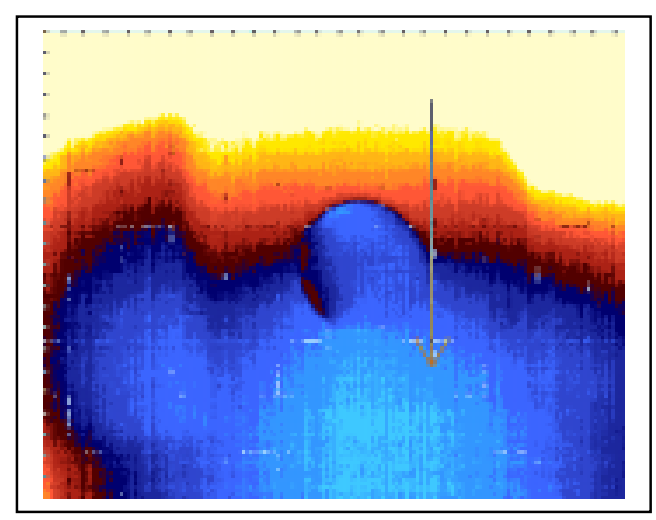

a) 1-second delay time

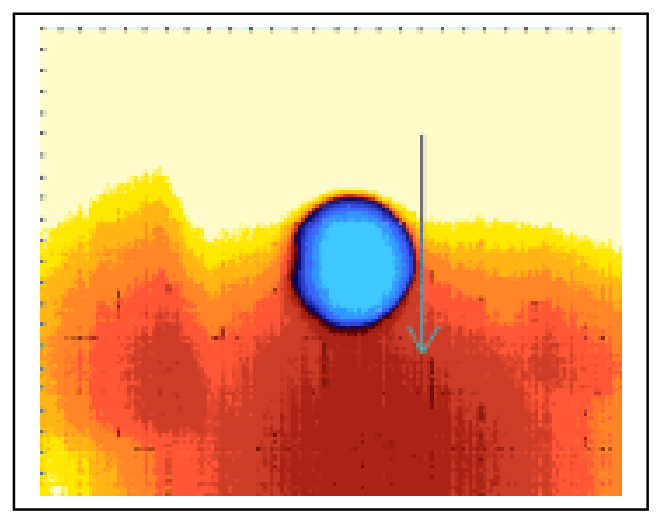

c) 6-second delay time

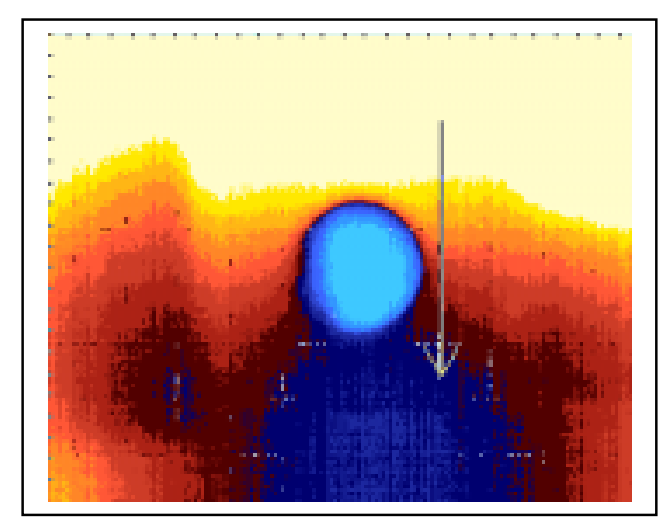

b) 3-second delay time

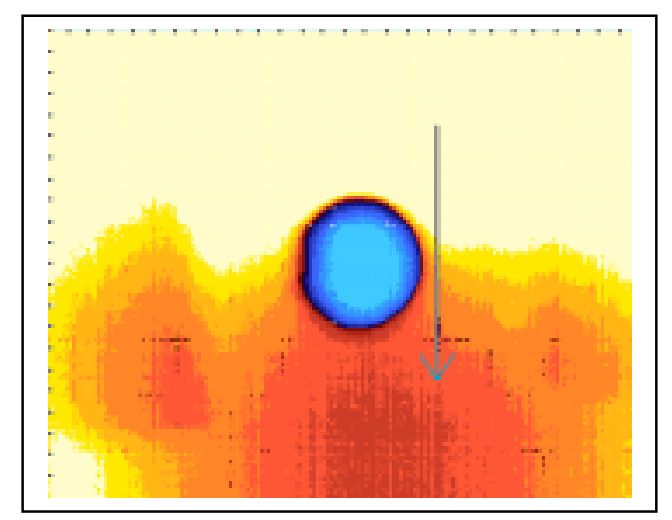

d) 9-second delay time

Figure A.49 Thermal images of Specimen CH-3 at 450,000 loading cycles (using the active approach and heating time is 90 seconds). 


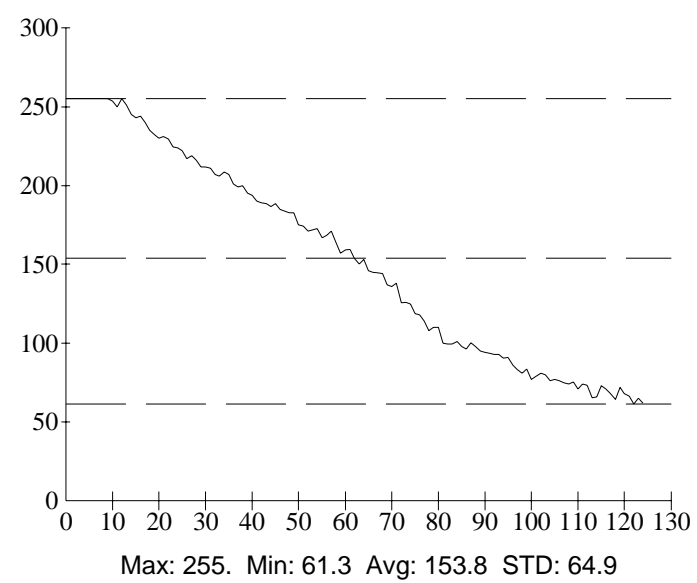

a) 1-second delay time

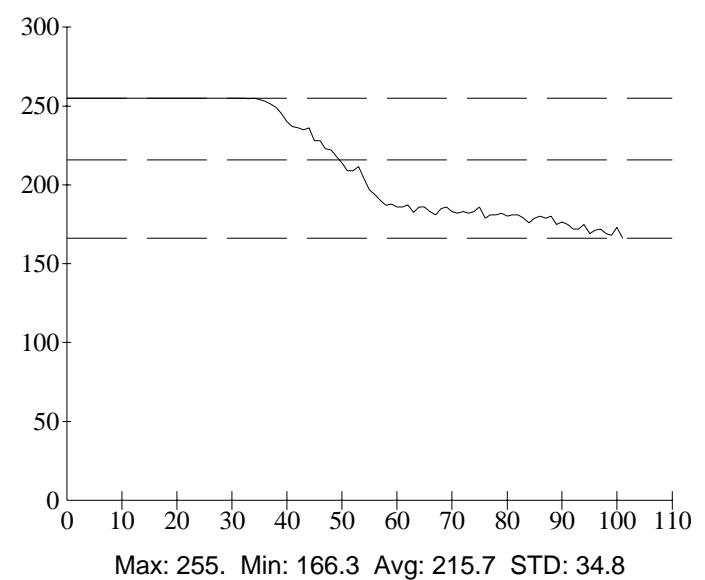

c) 6-second delay time

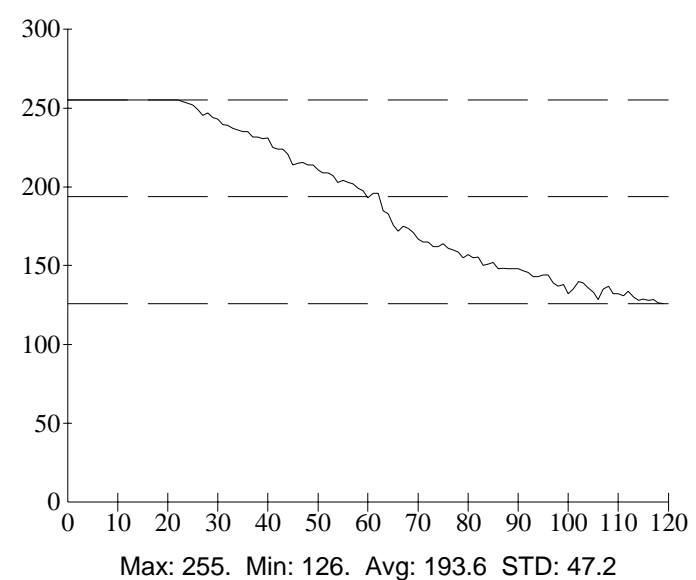

b) 3-second delay time

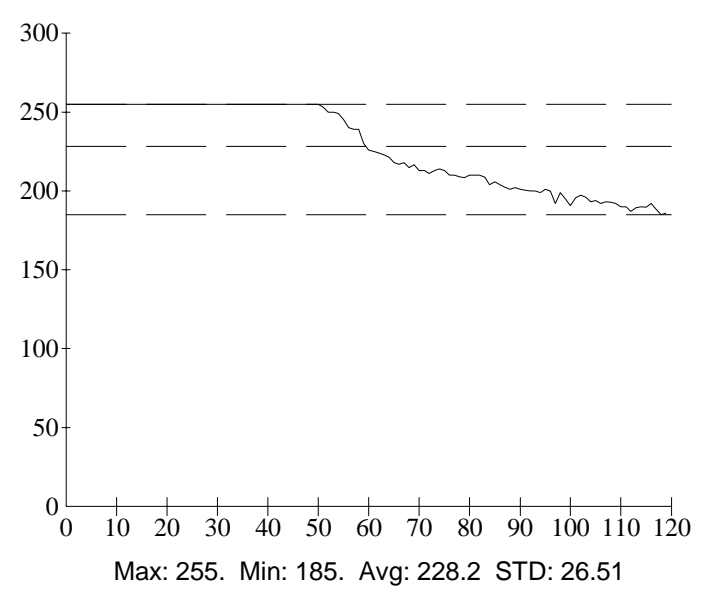

d) 9-second delay time

Figure A.50 Thermal intensity profile along the line across the fatigue crack shown in Figure A.49. 


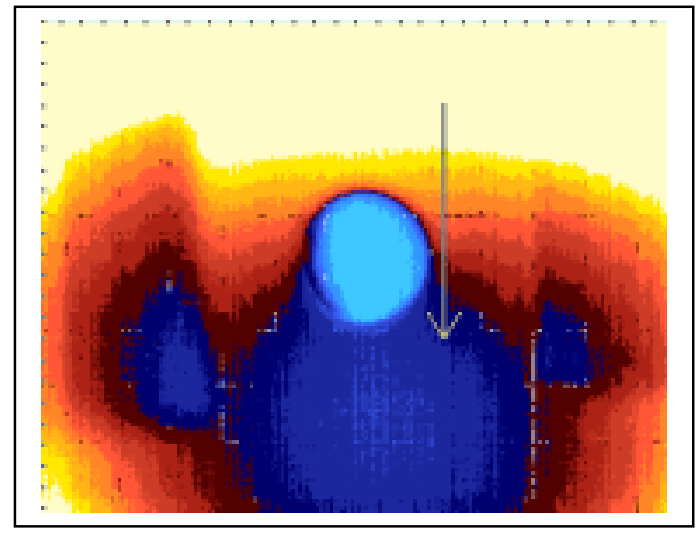

a) 1-second delay time

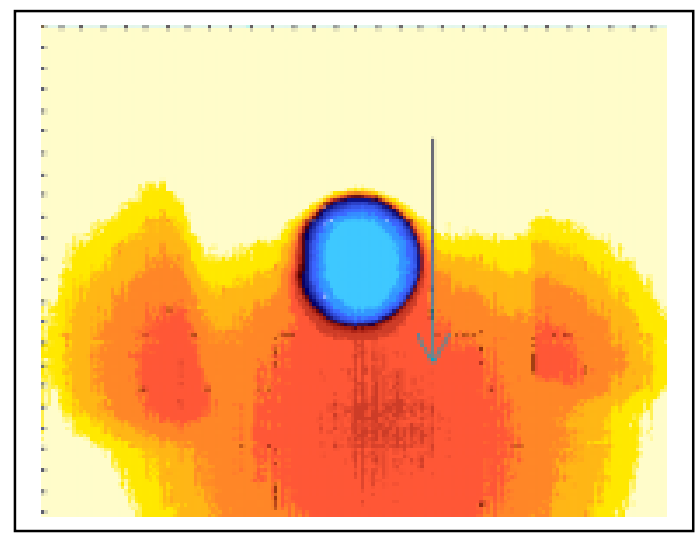

c) 6-second delay time

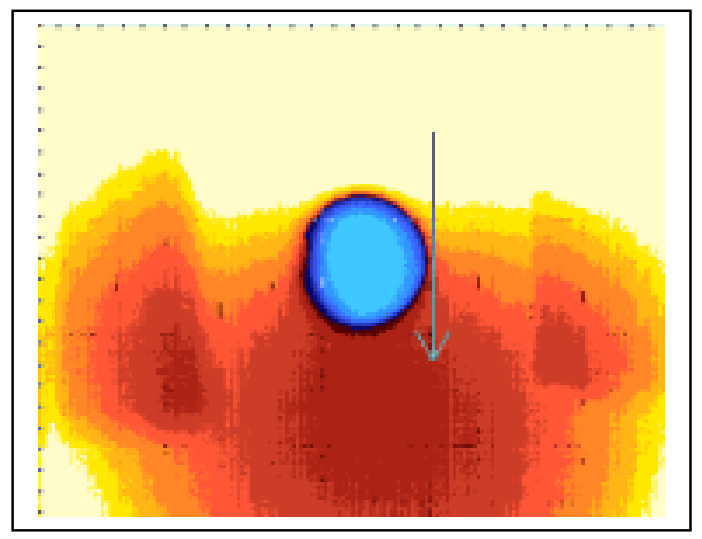

b) 3-second delay time

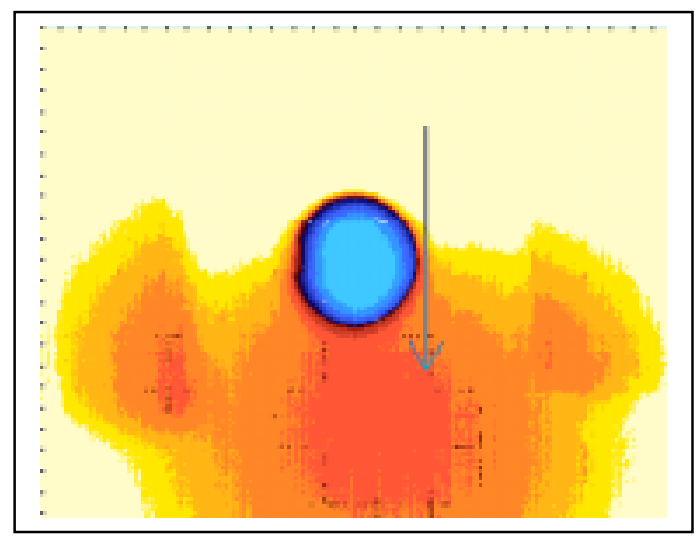

d) 9-second delay time

Figure A.51 Thermal images of Specimen CH-3 at 450,000 loading cycles (using the active approach and heating time is 120 seconds). 


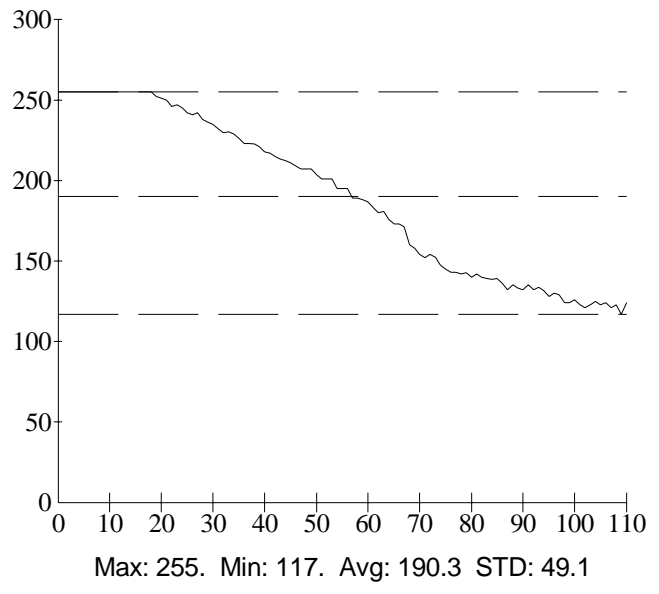

a) 1-second delay time

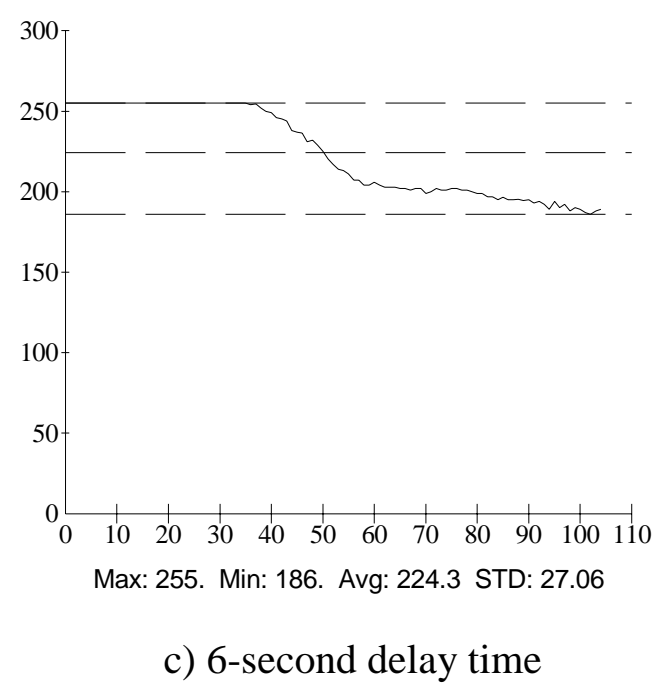

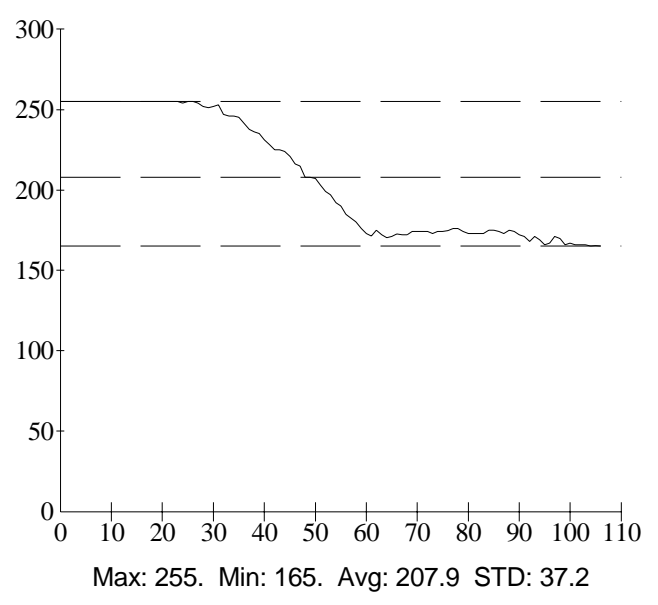

b) 3-second delay time

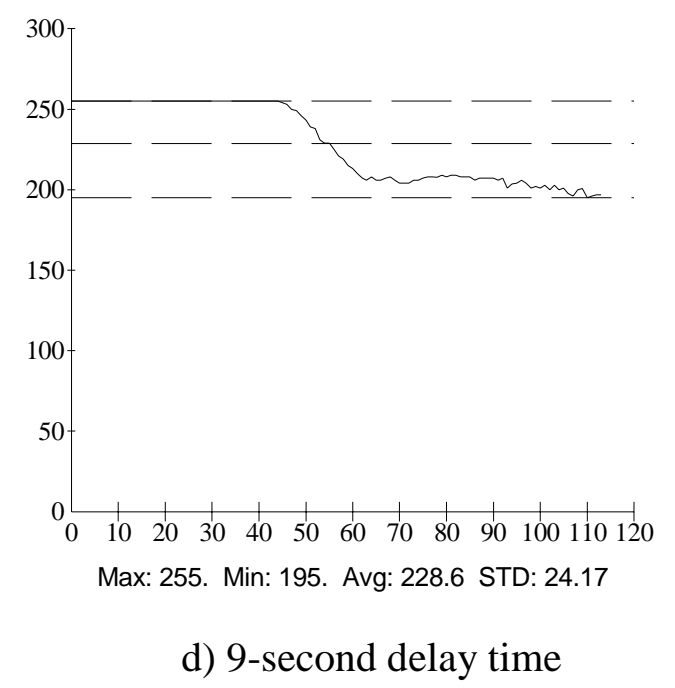

Figure A.52 Thermal intensity profile along the line across the fatigue crack shown in Figure A.51. 


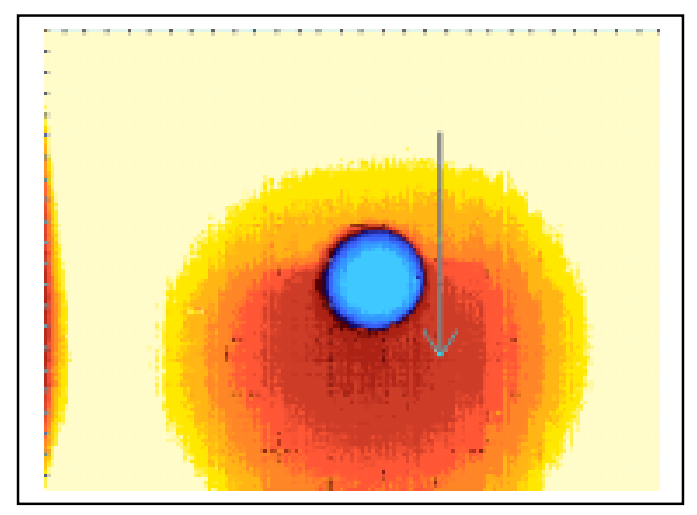

a) 1-second delay time

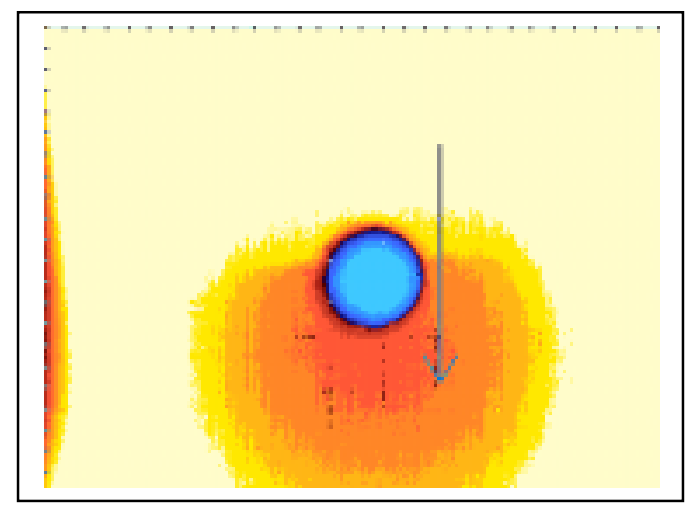

c) 6-second delay time

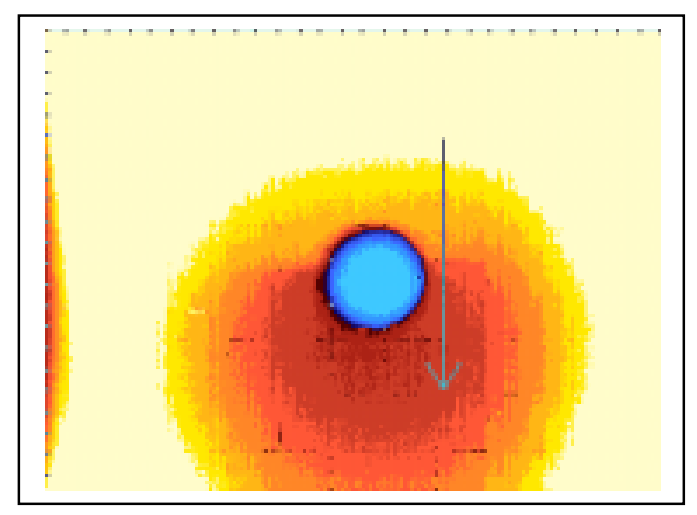

b) 3-second delay time

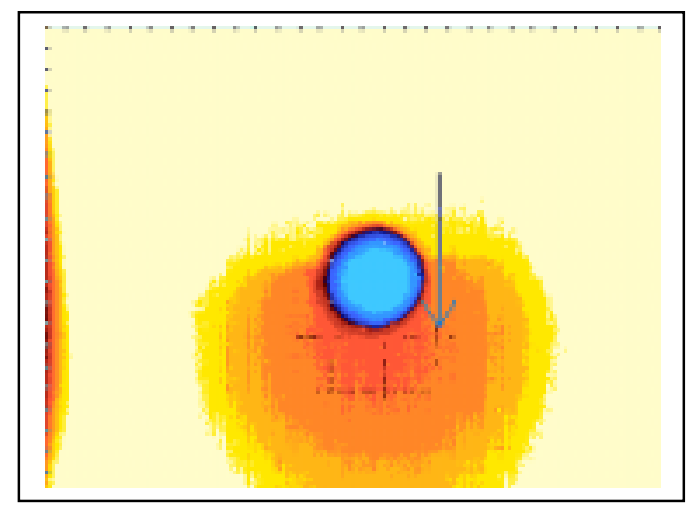

d) 9-second delay time

Figure A.53 Thermal images of Specimen CH-3 at 500,000 loading cycles (using the active approach and heating time is 15 seconds). 


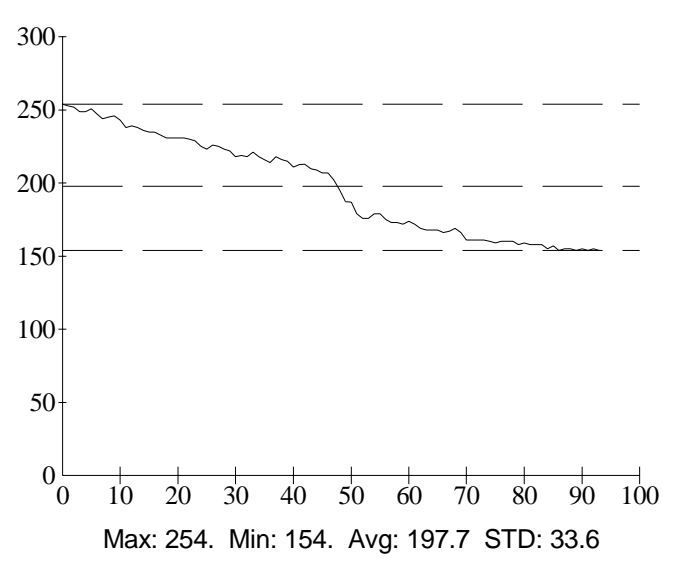

a) 1-second delay time

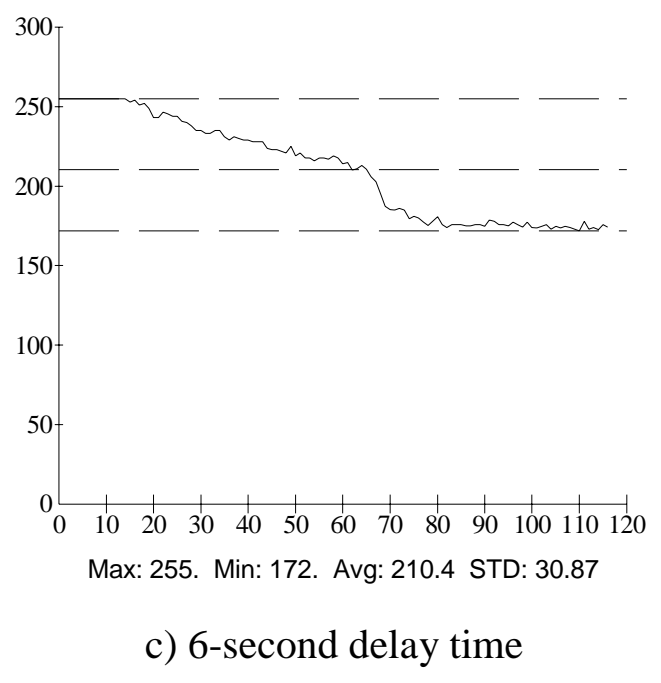

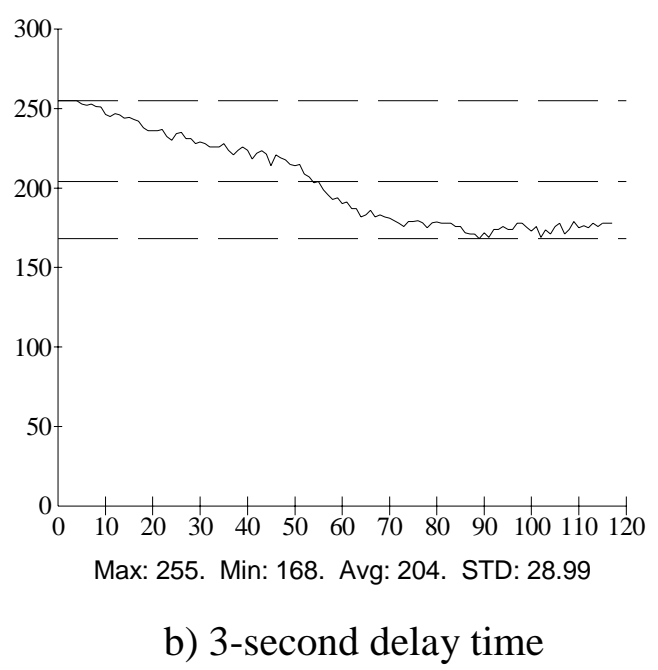

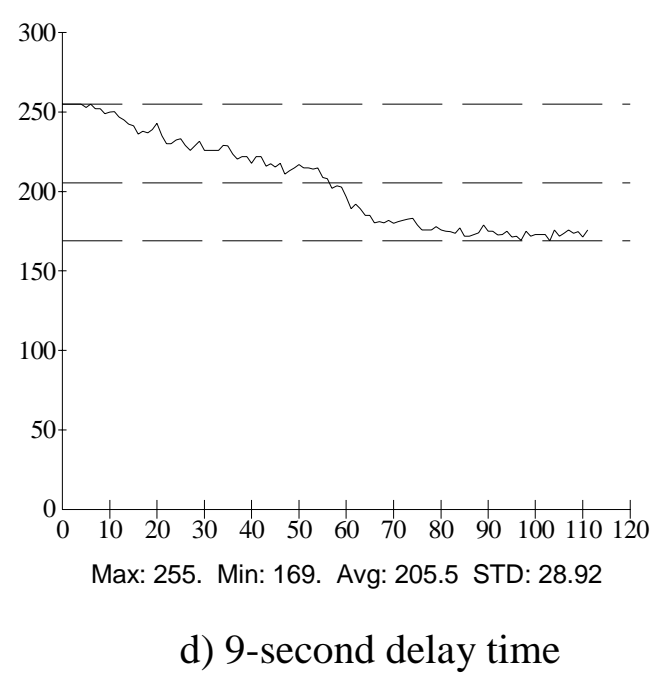

Figure A.54 Thermal intensity profile along the line across the fatigue crack shown in Figure A.53. 


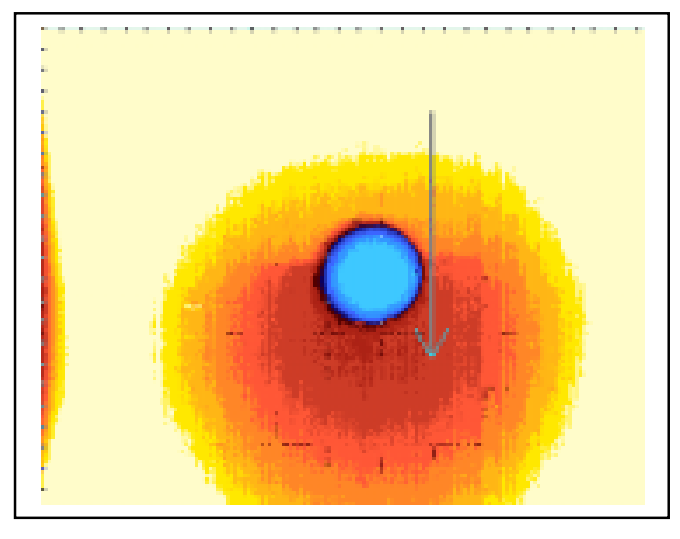

a) 1-second delay time

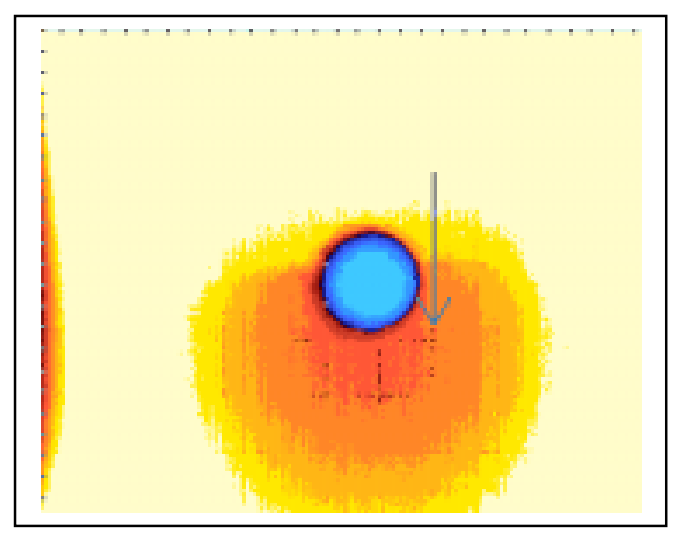

c) 6-second delay time

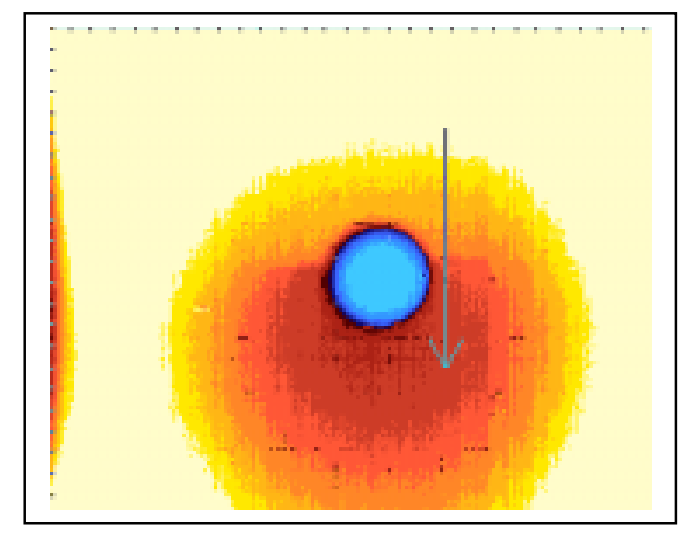

b) 3-second delay time

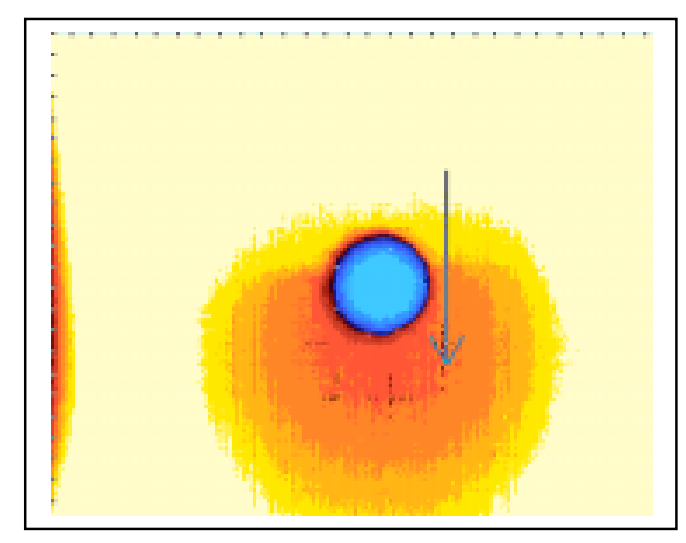

d) 9-second delay time

Figure A.55 Thermal images of Specimen CH-3 at 500,000 loading cycles (using the active approach and heating time is 30 seconds). 


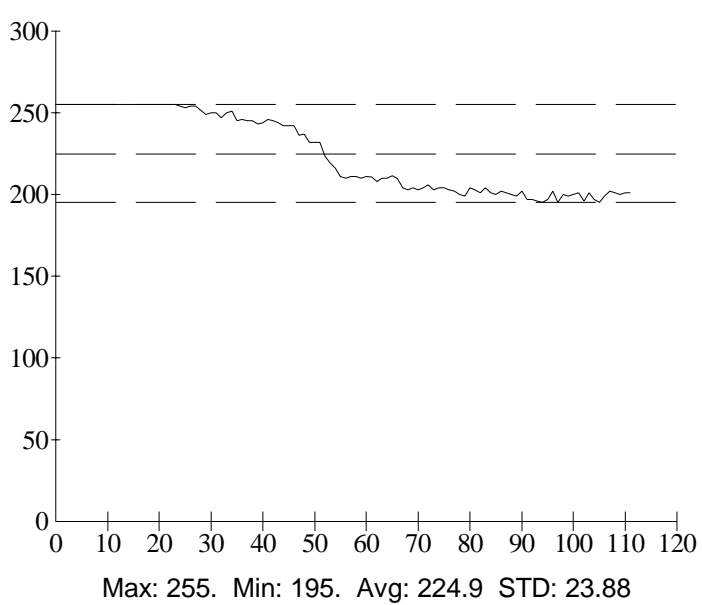

a) 1-second delay time

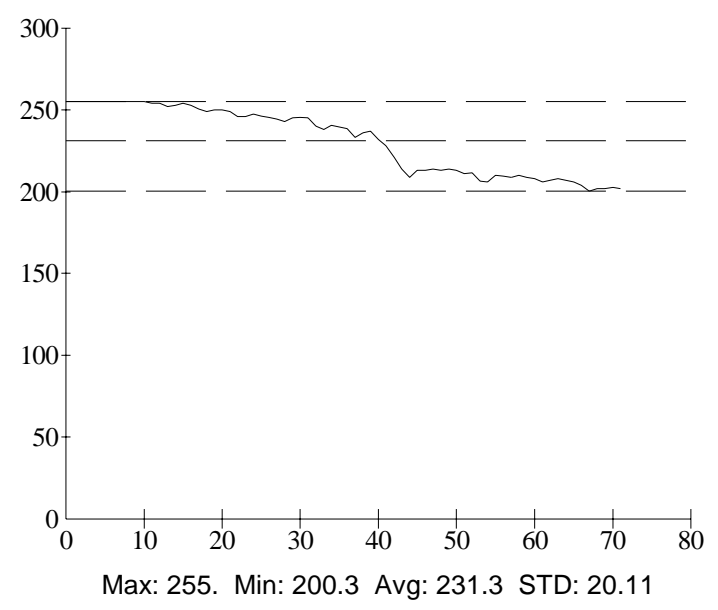

c) 6-second delay time

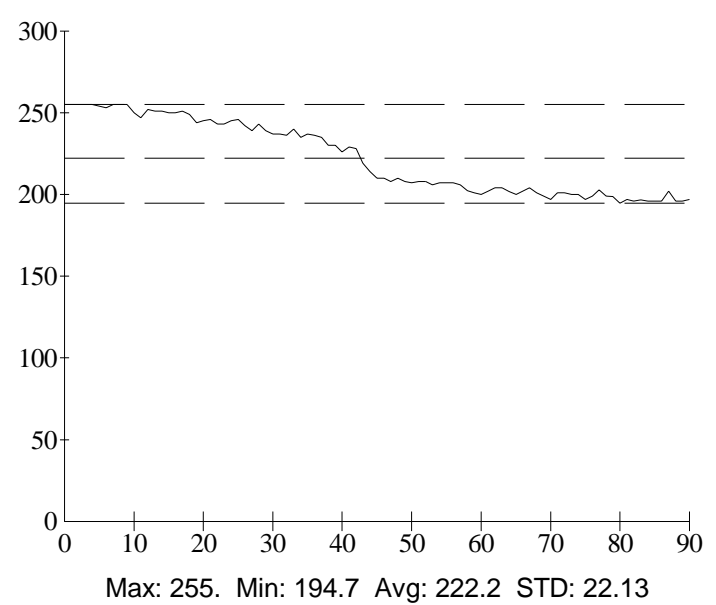

b) 3-second delay time

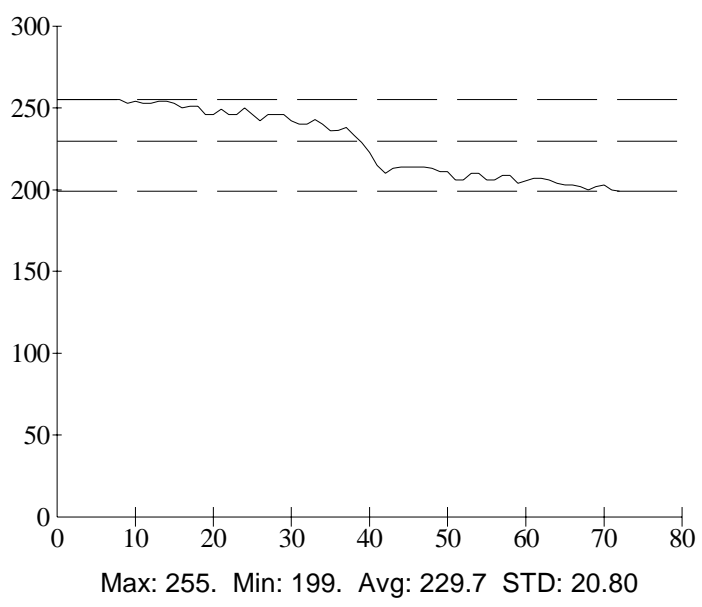

d) 9-second delay time

Figure A.56 Thermal intensity profile along the line across the fatigue crack shown in Figure A.55. 


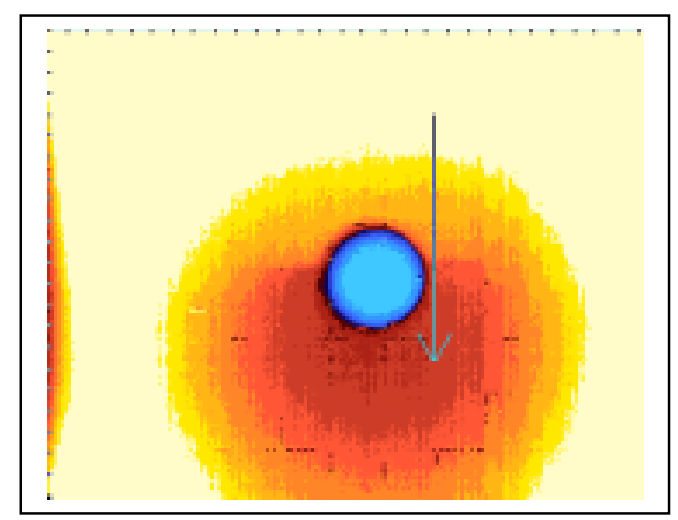

a) 1-second delay time

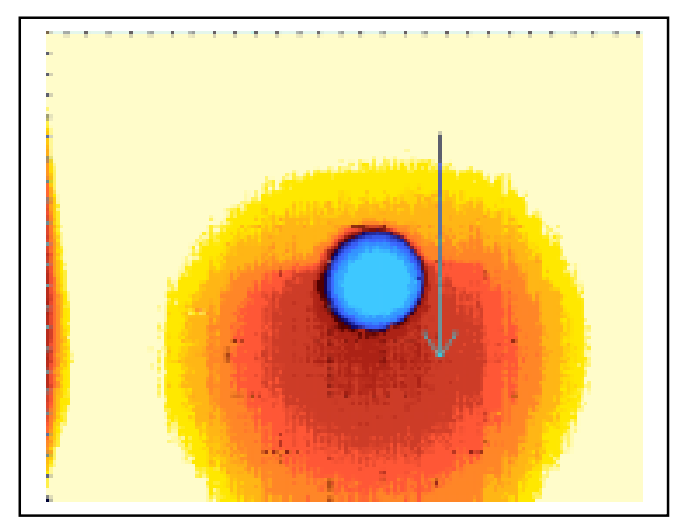

c) 6-second delay time

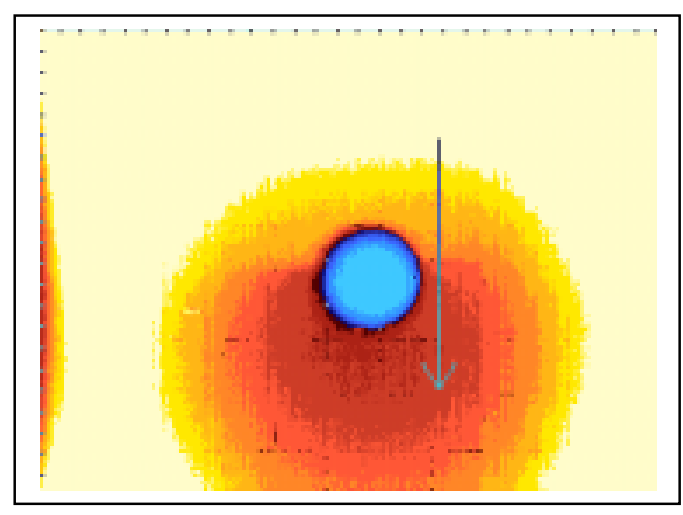

b) 3-second delay time

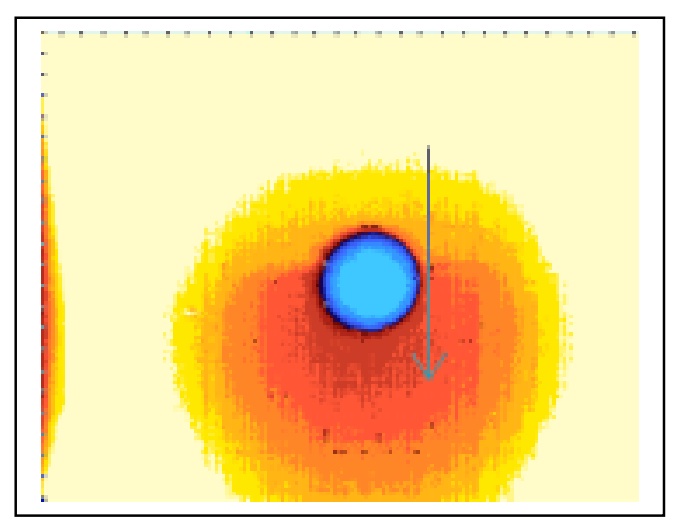

d) 9-second delay time

Figure A.57 Thermal images of Specimen CH-3 at 500,000 loading cycles (using the active approach and heating time is 45 seconds). 


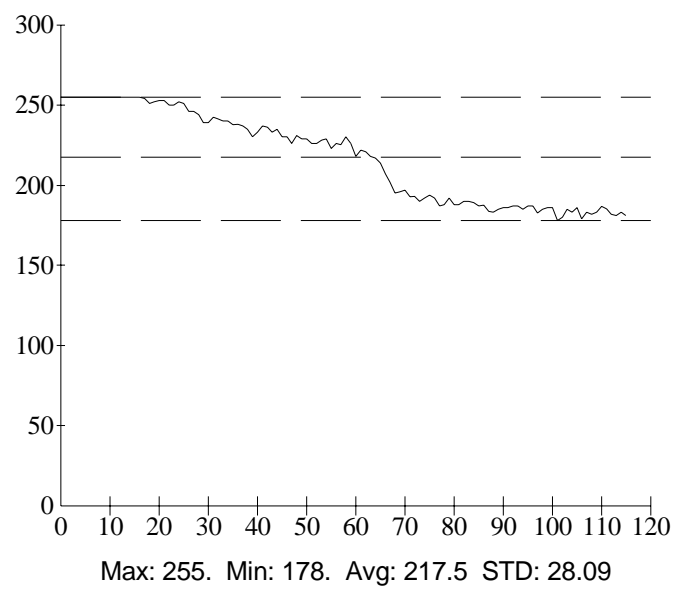

a) 1-second delay time

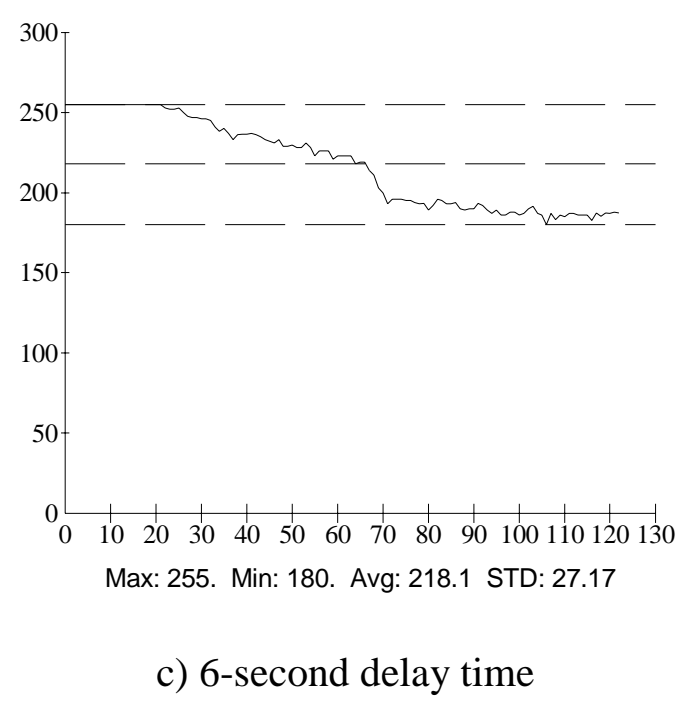

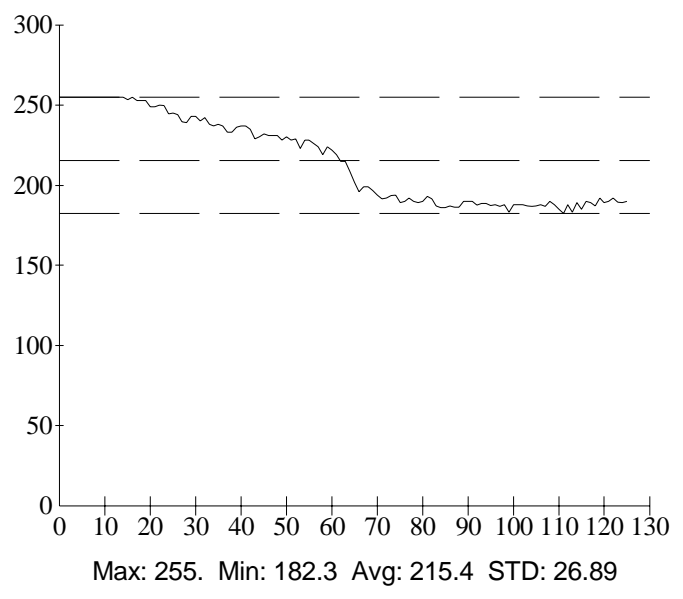

b) 3-second delay time

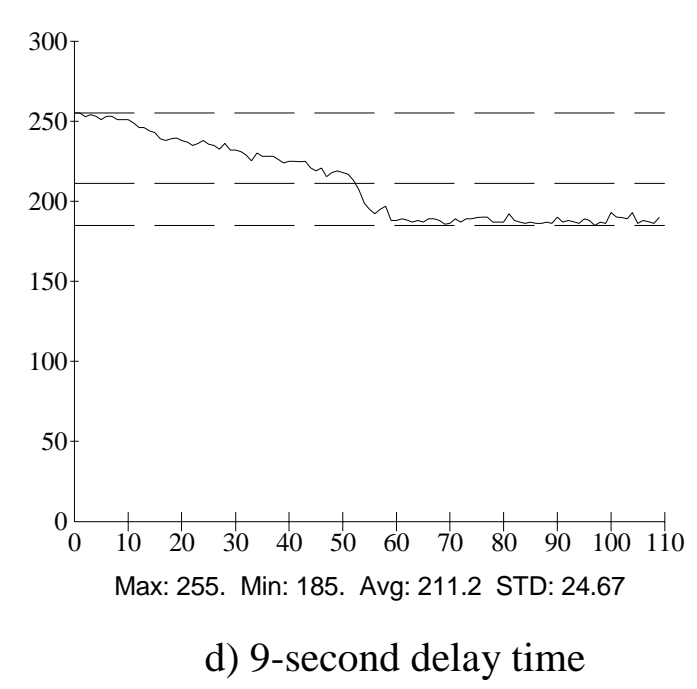

Figure A.58 Thermal intensity profile along the line across the fatigue crack shown in Figure A.57. 


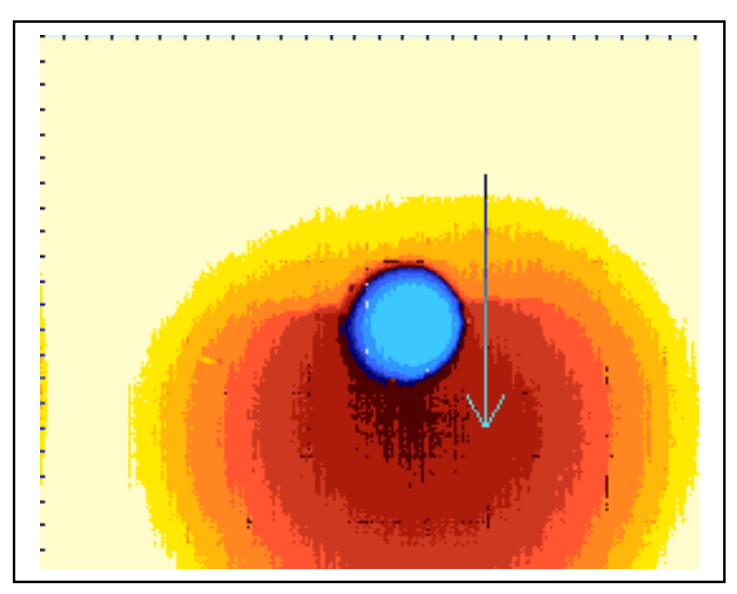

a) 1-second delay time

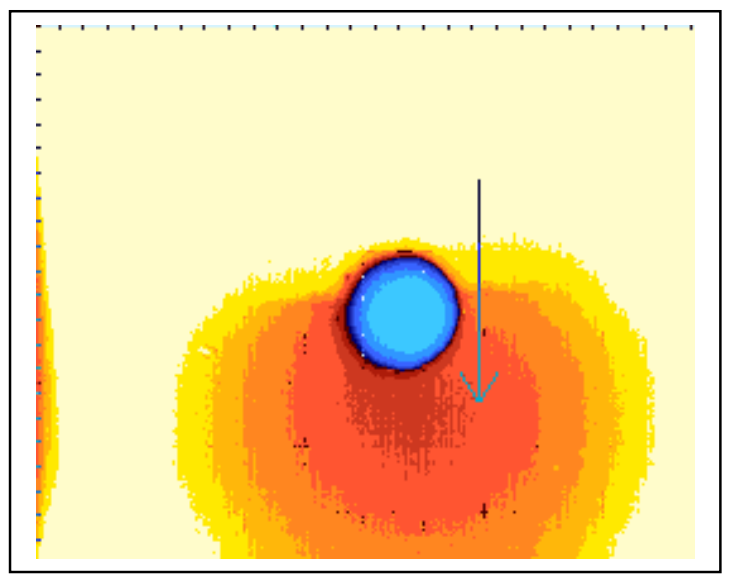

c) 6-second delay time

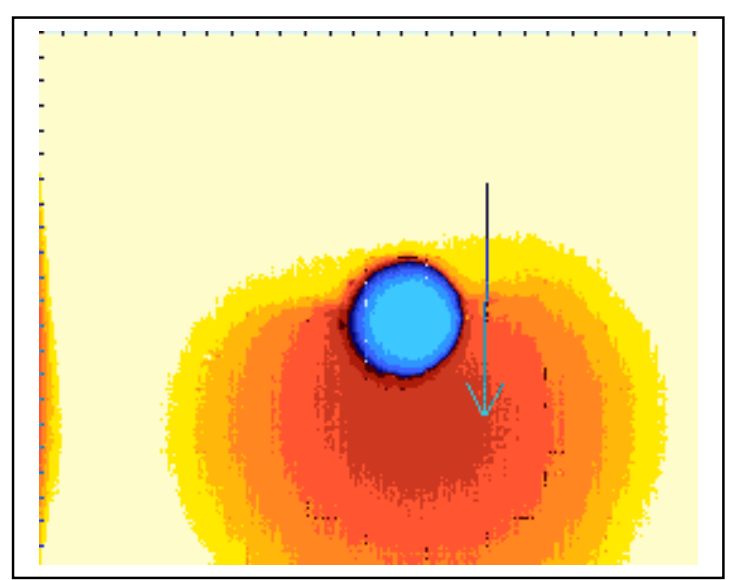

b) 3-second delay time

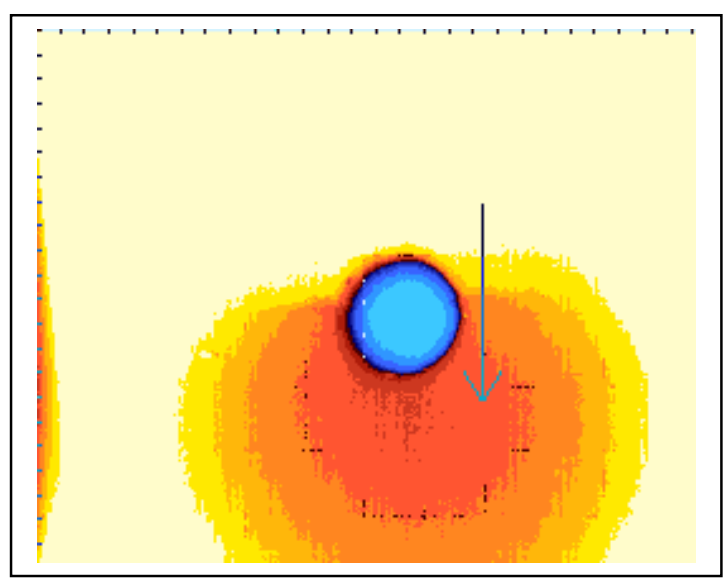

d) 9-second delay time

Figure A.59 Thermal images of Specimen 3 at 500,000 loading cycles (using the active approach and heating time is 60 seconds). 


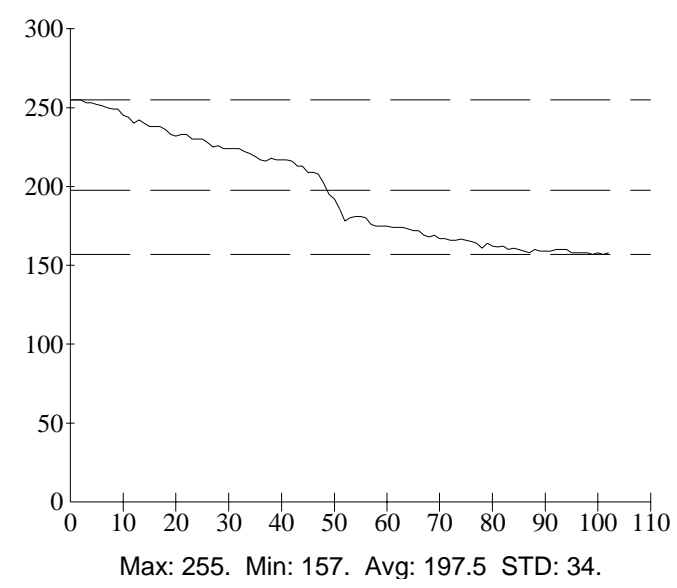

a) 1-second delay time

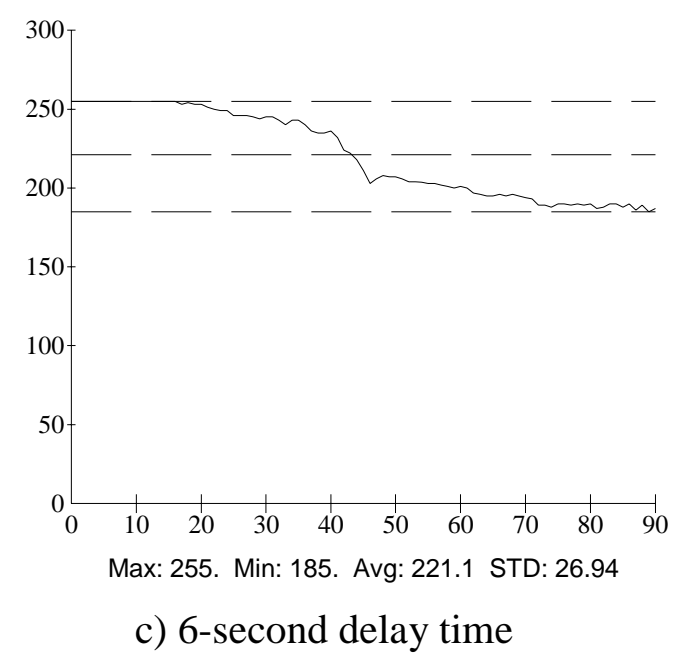

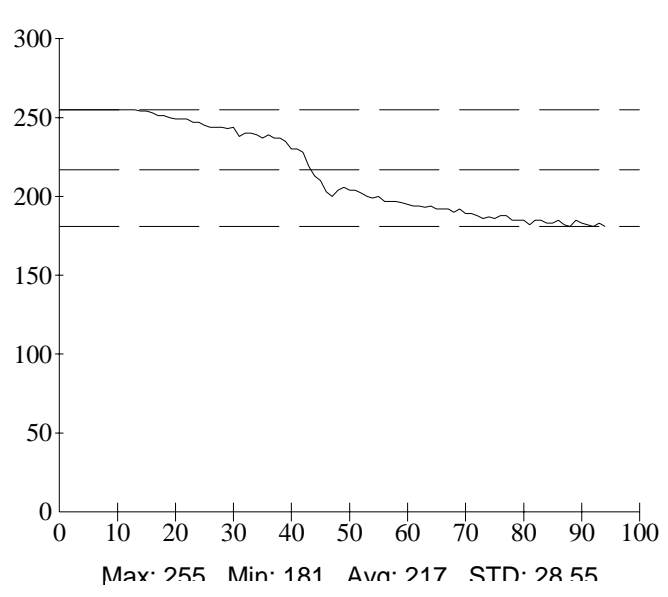

b) 3-second delay time

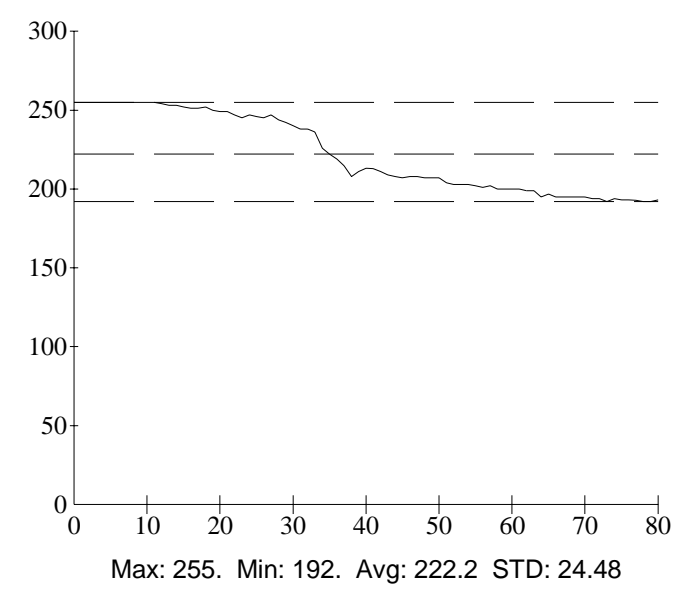

d) 9-second delay time

Figure A.60 Thermal intensity profile along the line across the fatigue crack shown in Figure A.59. 


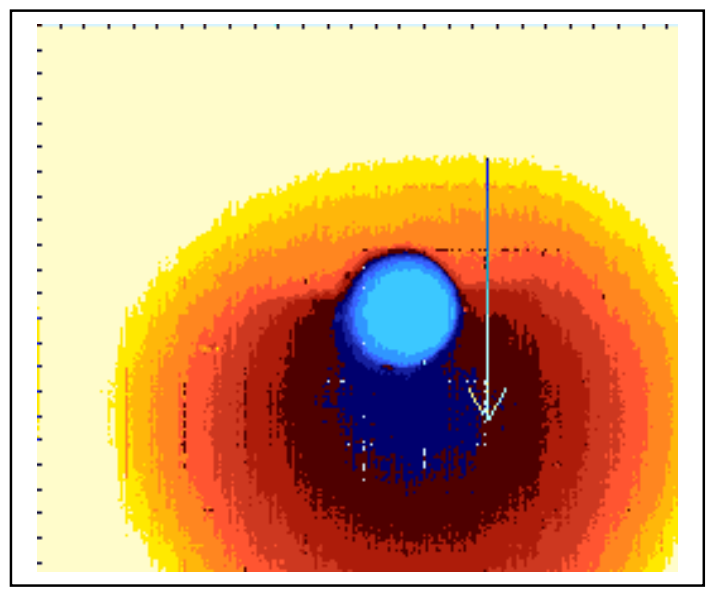

a) 1-second delay time

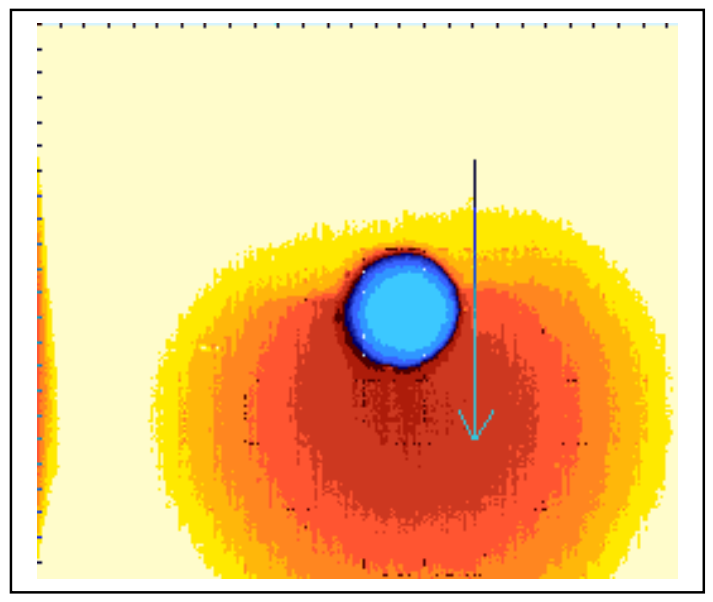

c) 6-second delay time

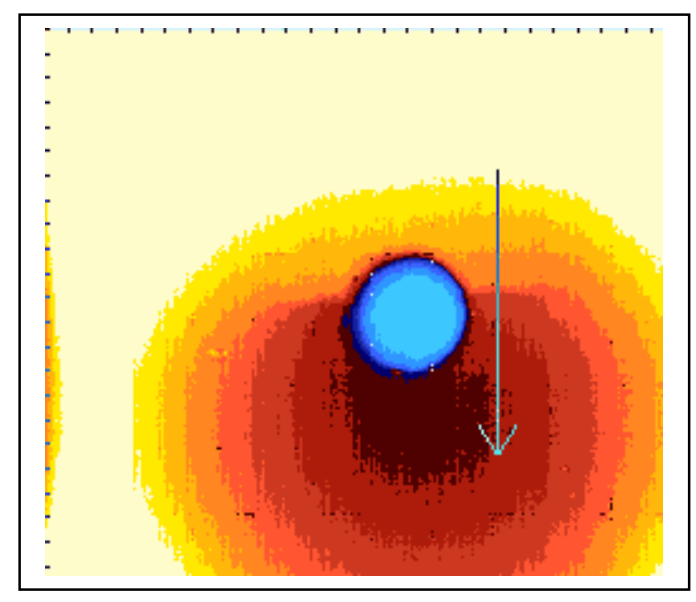

b) 3-second delay time

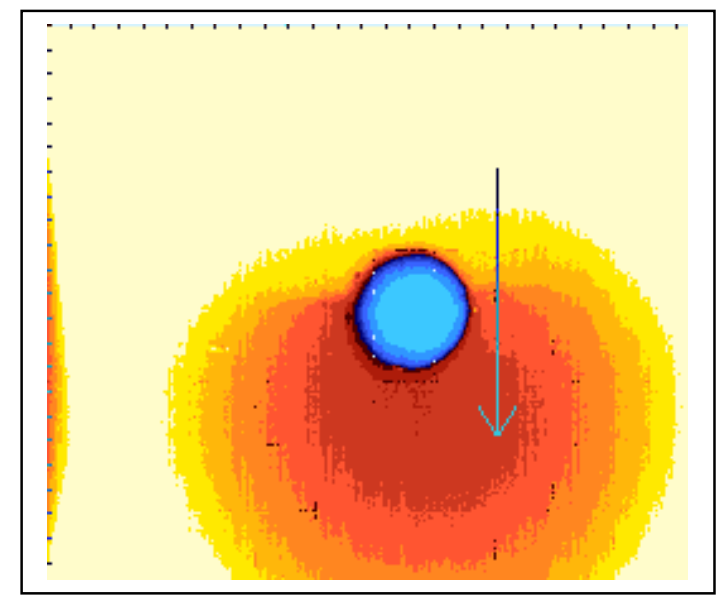

d) 9-second delay time

Figure A.61 Thermal images of Specimen CH-3 at 500,000 loading cycles (using the active approach and heating time is 90 seconds). 


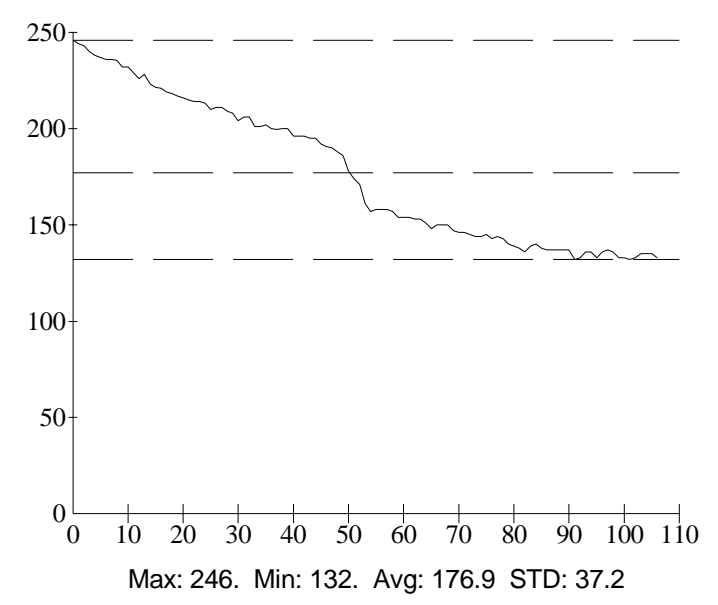

a) 1-second delay time

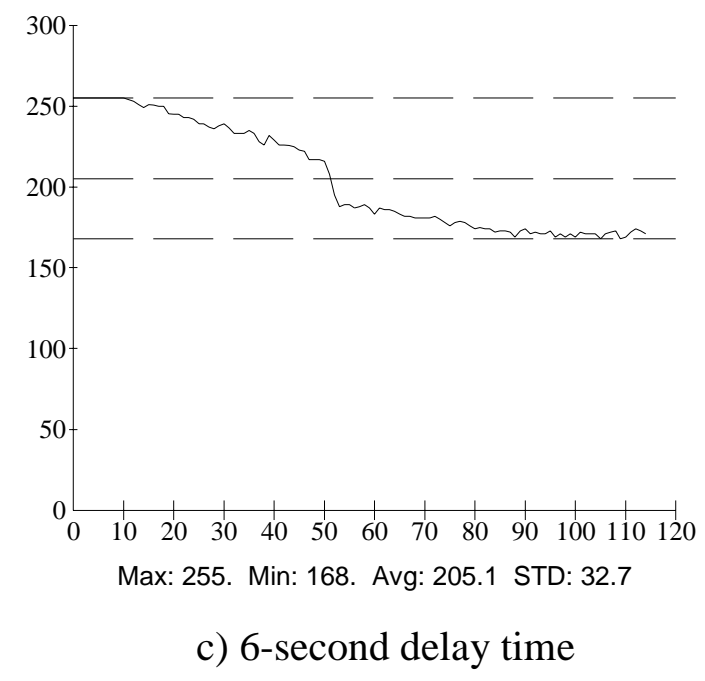

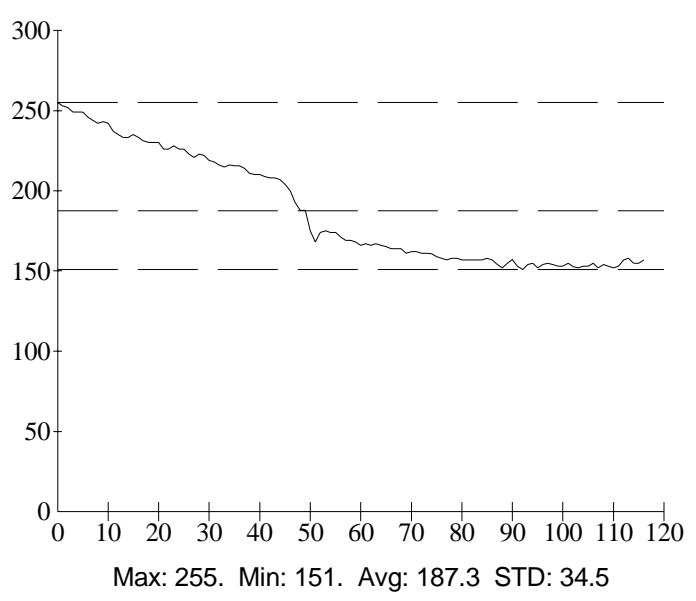

b) 3-second delay time

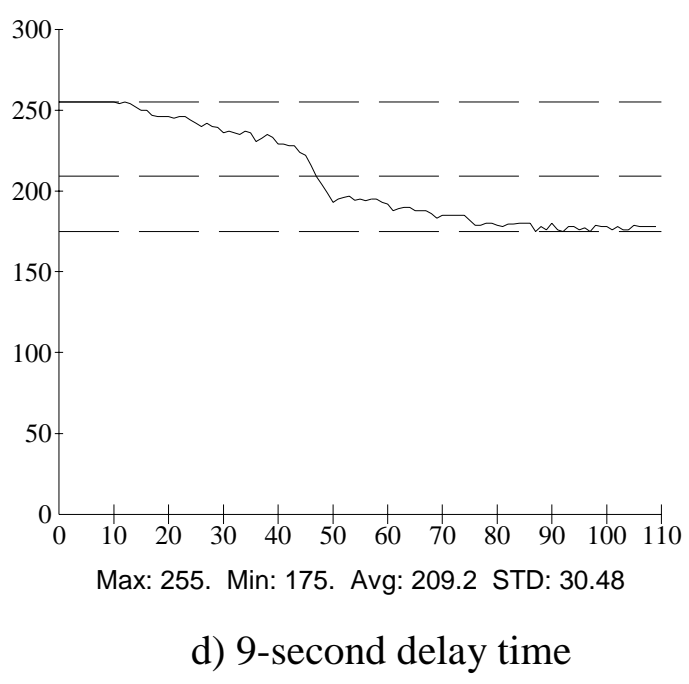

Figure A.62 Thermal intensity profile along the line across the fatigue crack shown in Figure A.61. 


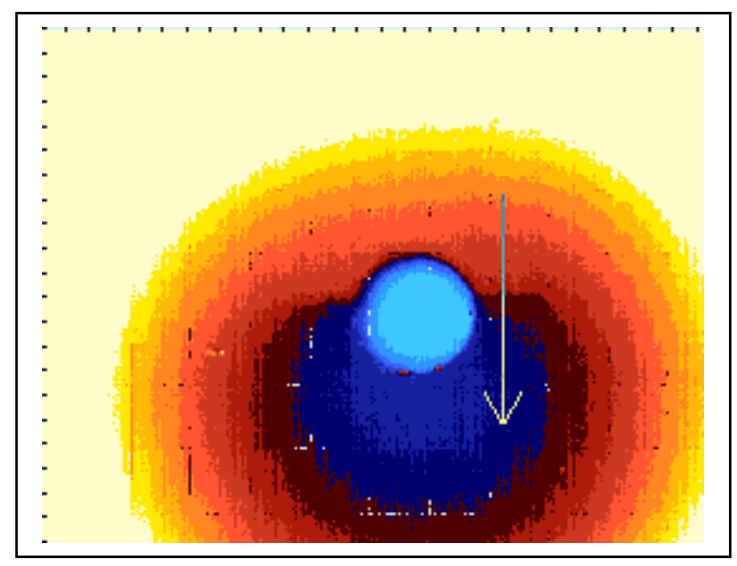

a) 1-second delay time

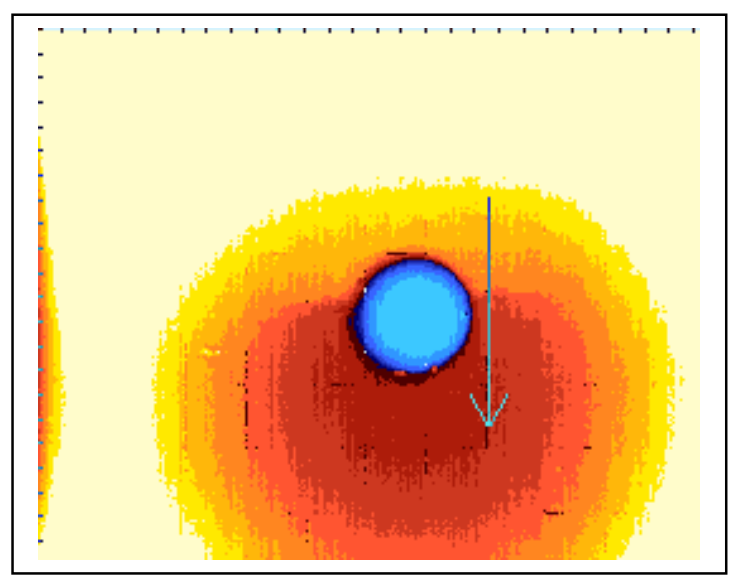

c) 6-second delay time

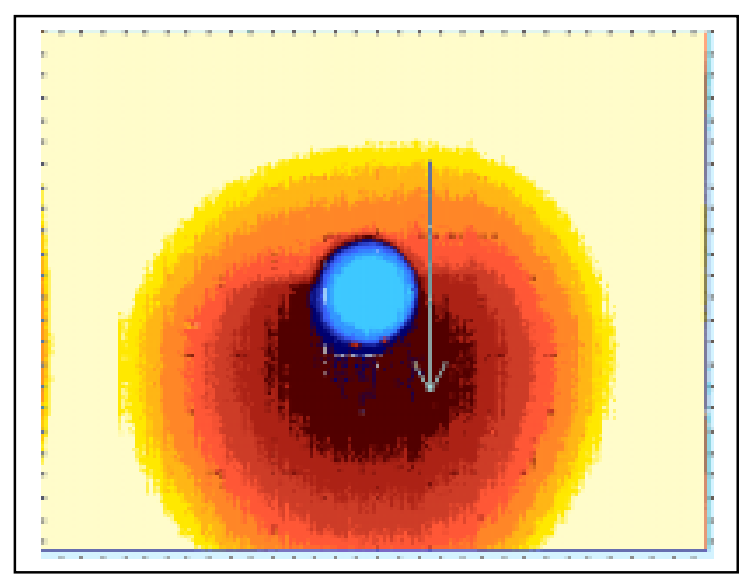

b) 3-second delay time

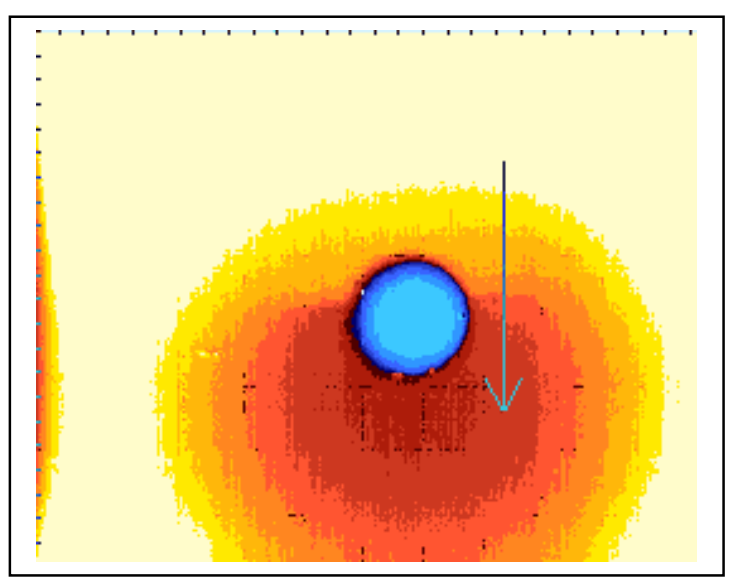

d) 9-second delay time

Figure A.63 Thermal images of Specimen CH-3 at 500,000 loading cycles (using the active approach and heating time is 120 seconds). 


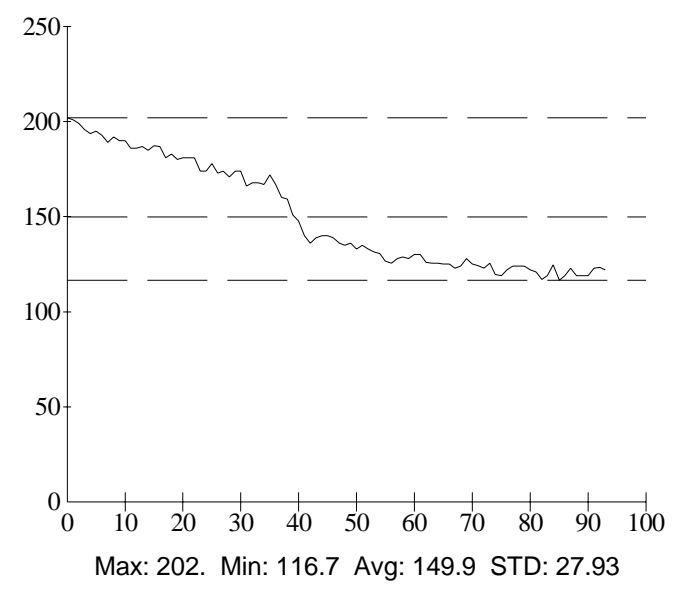

a) 1-second delay time

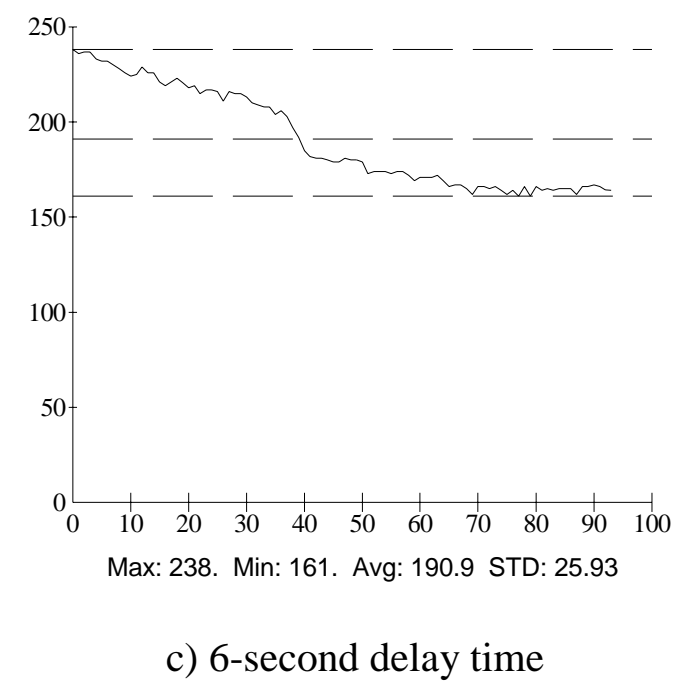

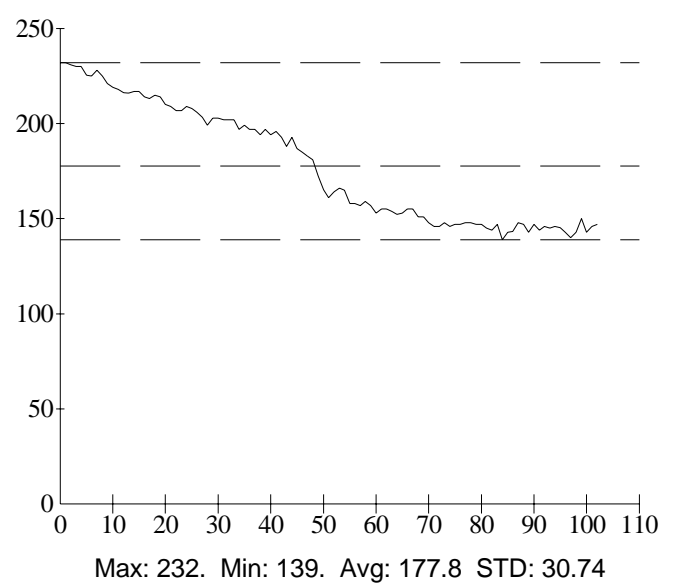

b) 3-second delay time

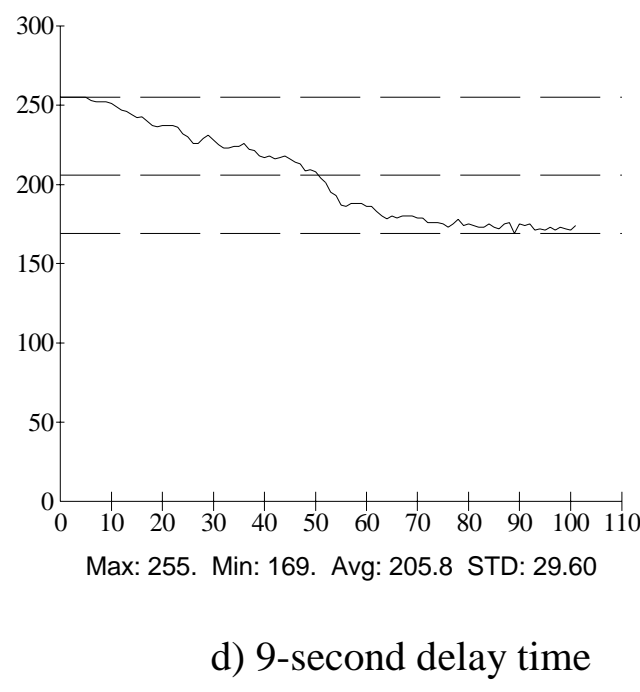

Figure A.64 Thermal intensity profile along the line across the fatigue crack shown in Figure A.63. 


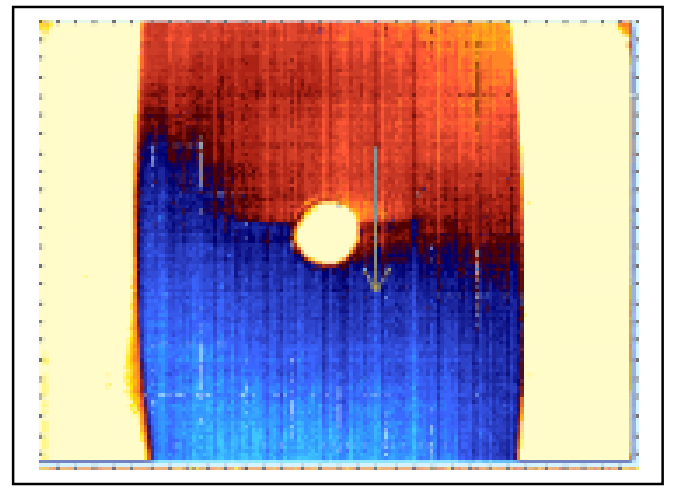

a) 1-second delay time

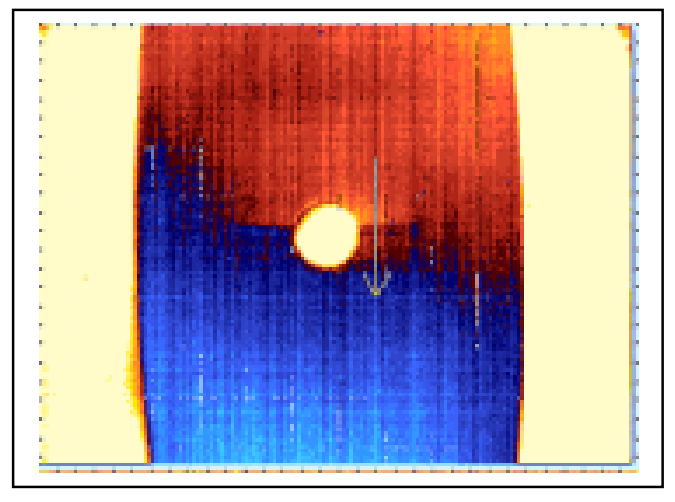

c) 6-second delay time

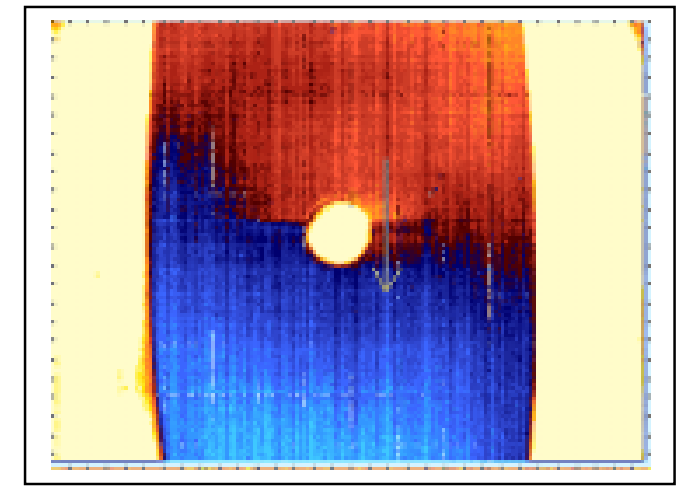

b) 3-second delay time

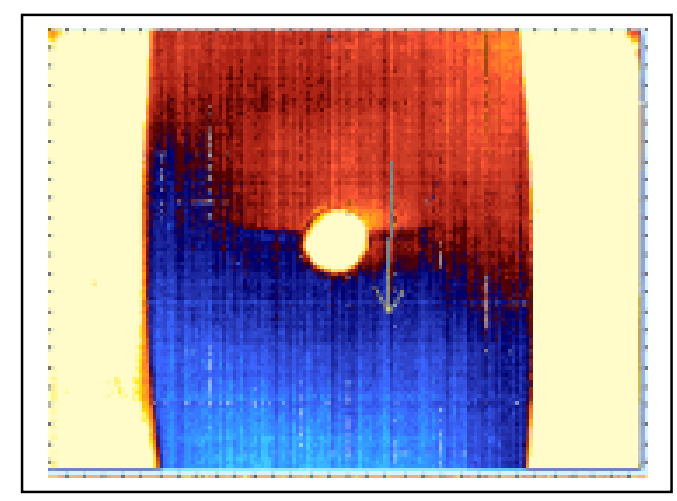

d) 9-second delay time

Figure A.65 Thermal images of unpainted Specimen CH-3 at 550,000 loading cycles (using the active approach and heating time is 15 seconds). 


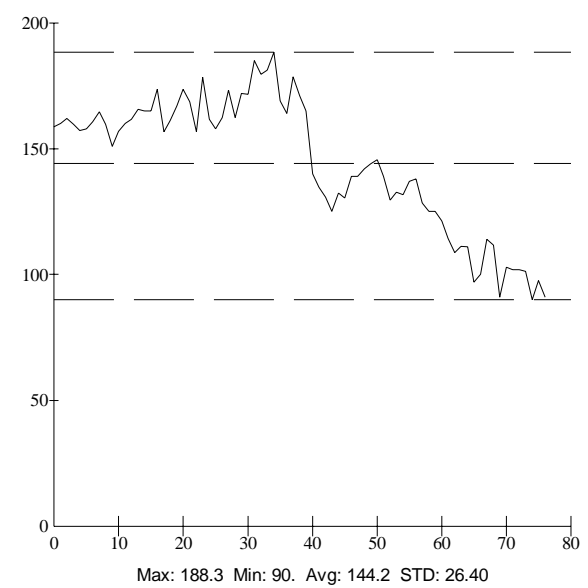

a) 1-second delay time

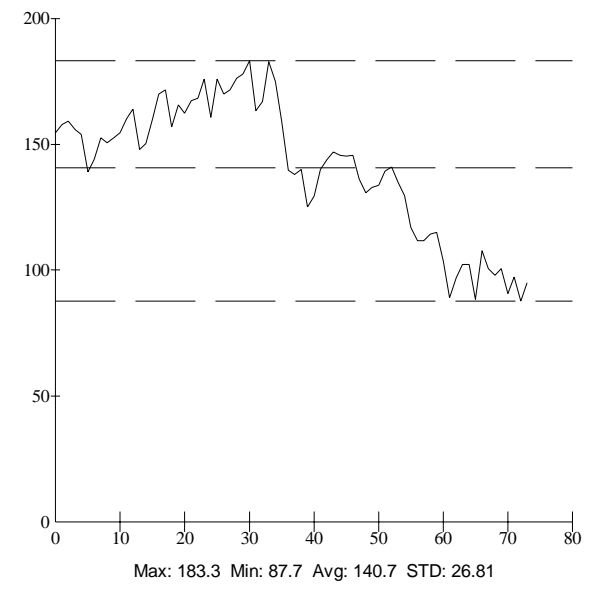

c) 6-second delay time

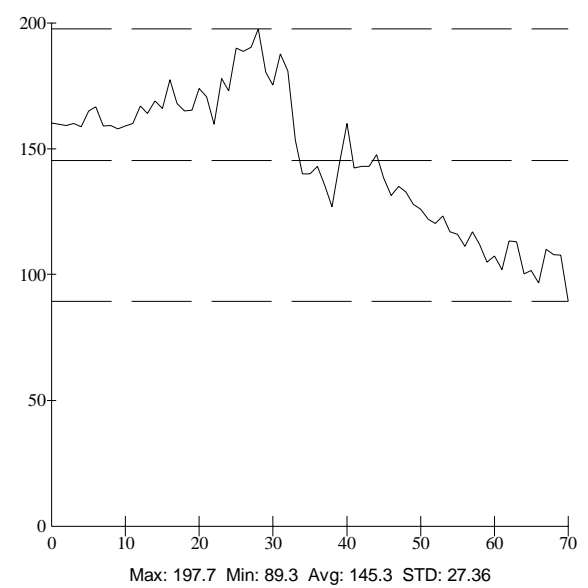

b) 3-second delay time

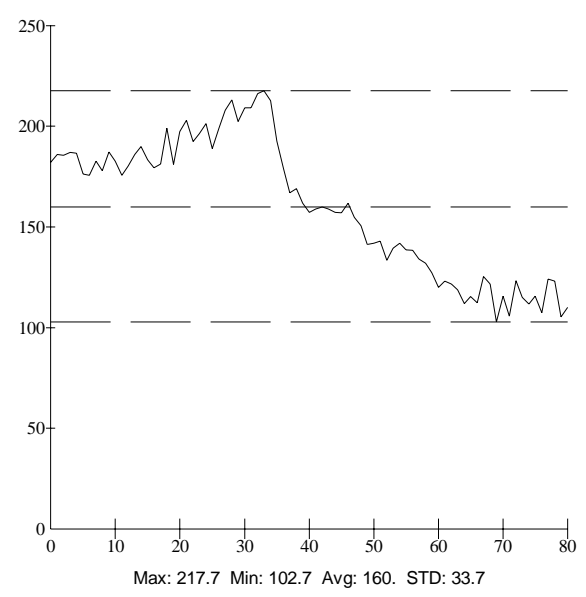

d) 9-second delay time

Figure A.66 Thermal intensity profile along the line across the fatigue crack shown Figure A.65. 


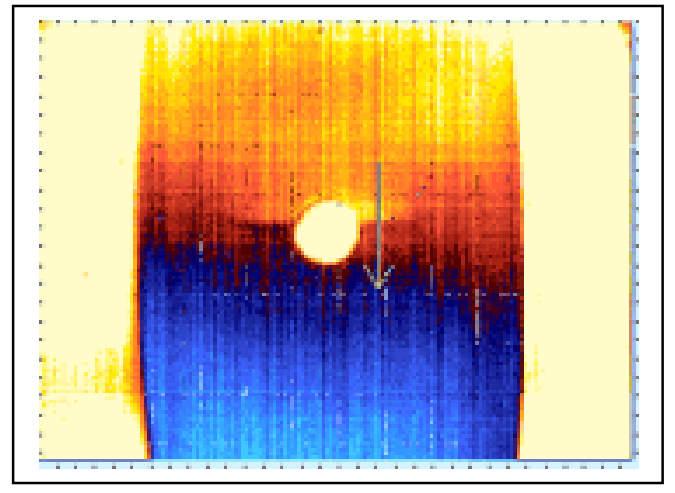

a) 1-second delay time

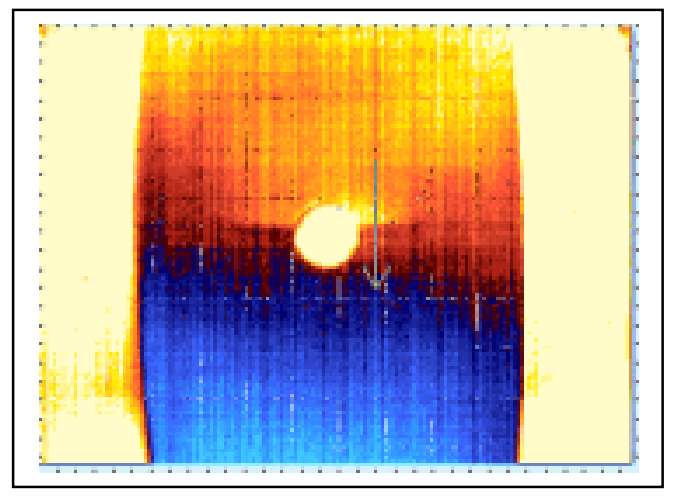

c) 6-second delay time

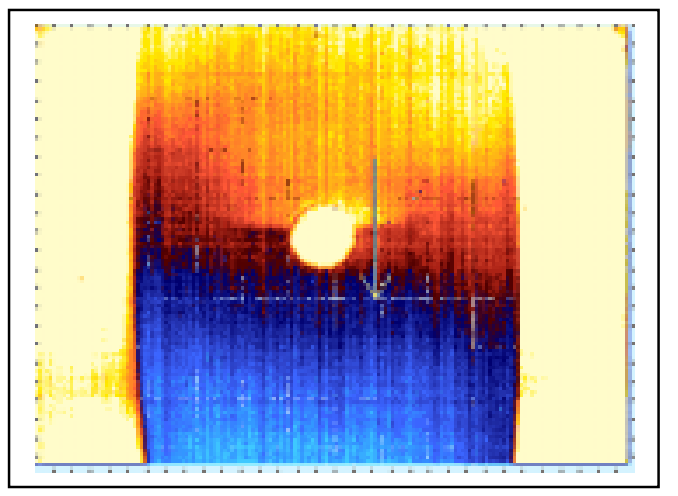

b) 3-second delay time

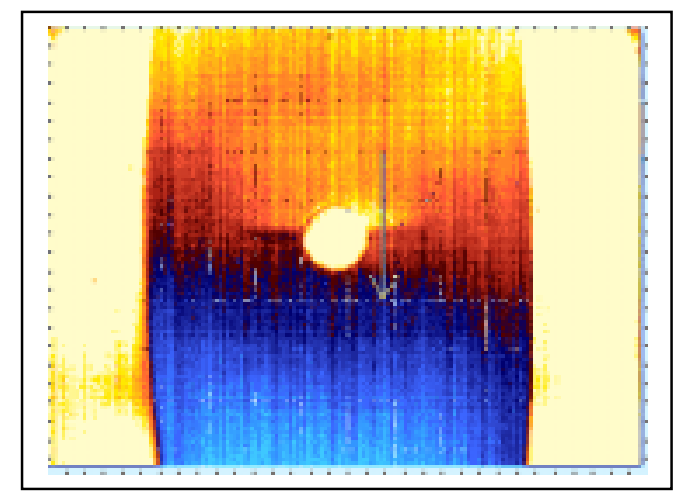

d) 9-second delay time

Figure A.67 Thermal images of unpainted Specimen CH-3 at 550,000 loading cycles (using the active approach and heating time is 30 seconds). 


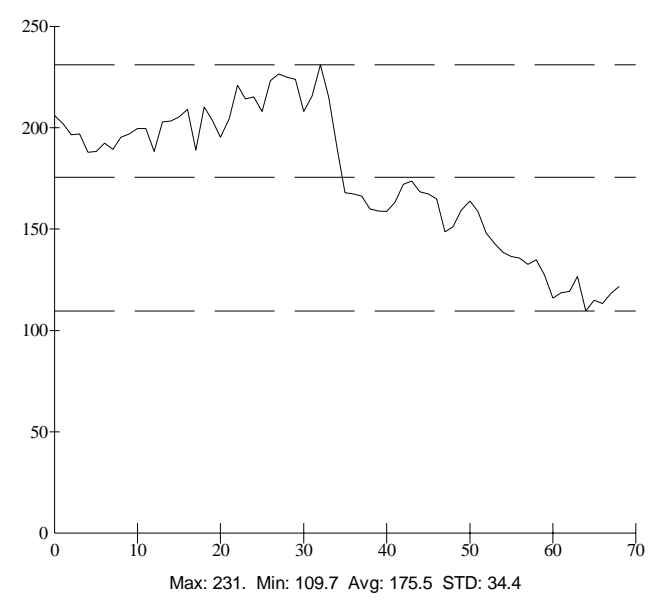

a) 1-second delay time

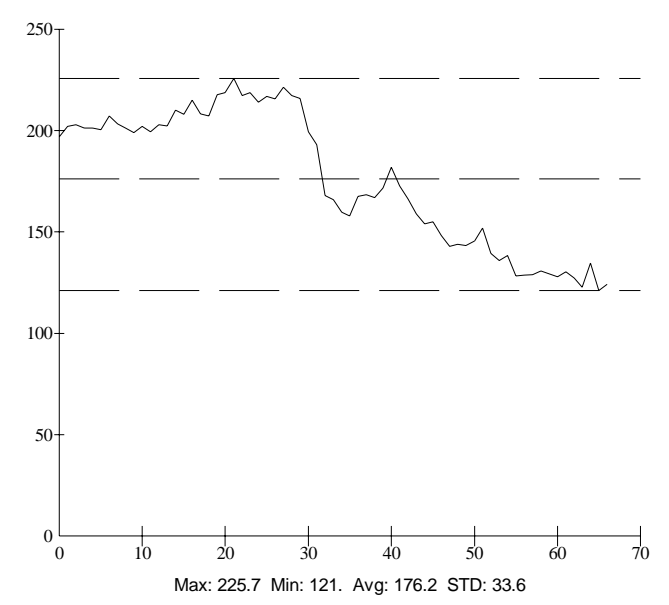

c) 6-second delay time

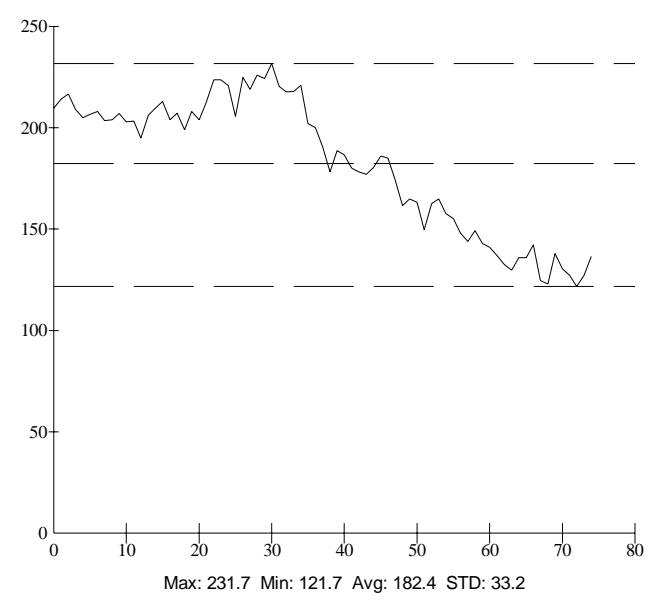

b) 3-second delay time

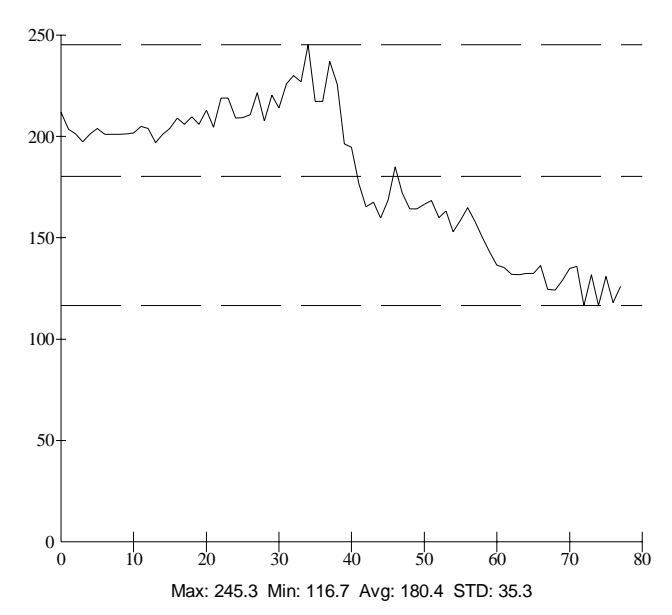

d) 9-second delay time

Figure A.68 Thermal intensity profile along the line across the fatigue crack shown in Figure A.67. 


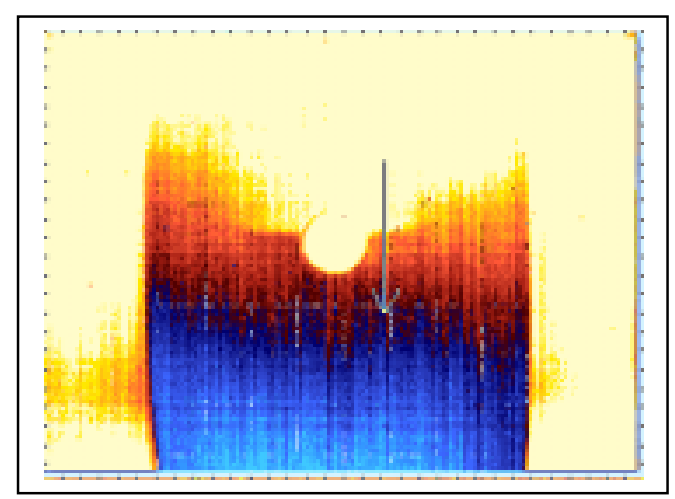

a) 1-second delay time

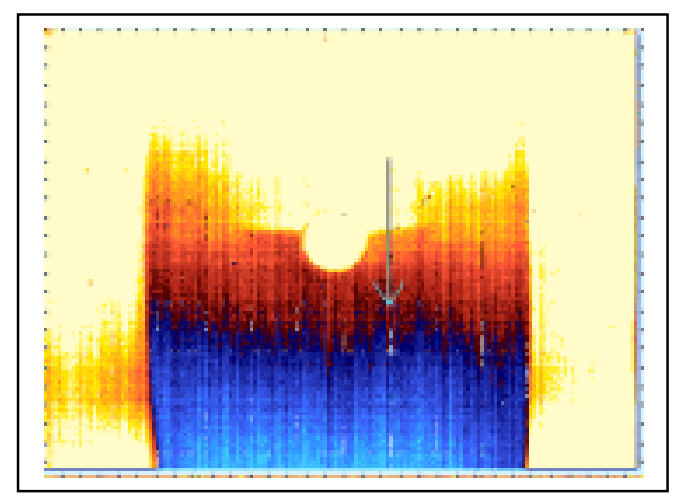

c) 6-second delay time

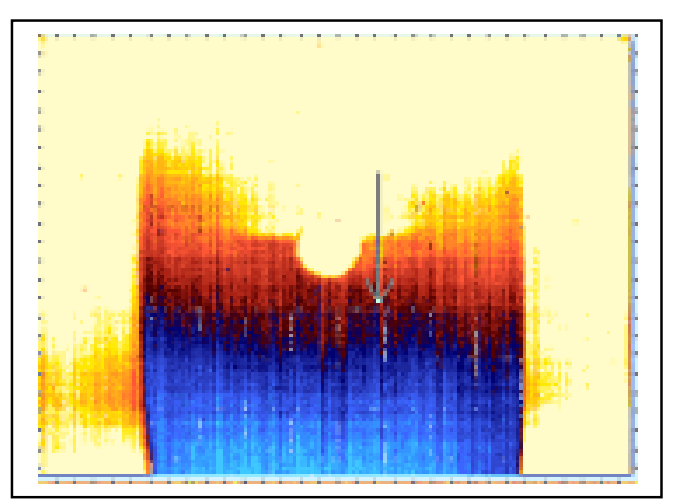

b) 3-second delay time

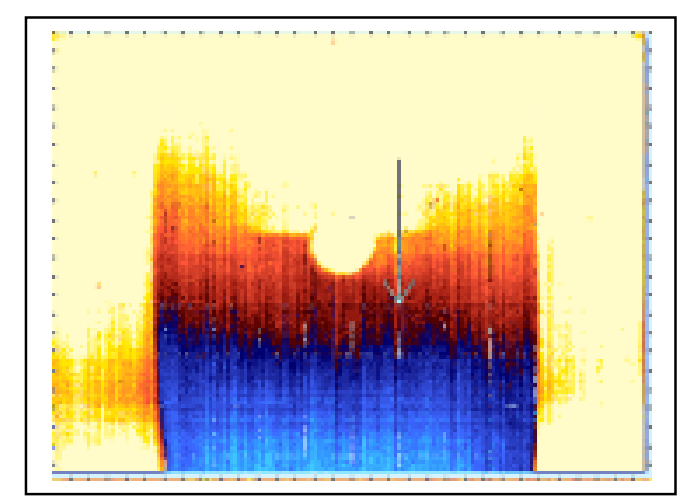

d) 9-second delay time

Figure A.69 Thermal images of unpainted Specimen CH-3 at 550,000 loading cycles (using the active approach and heating time is 45 seconds). 


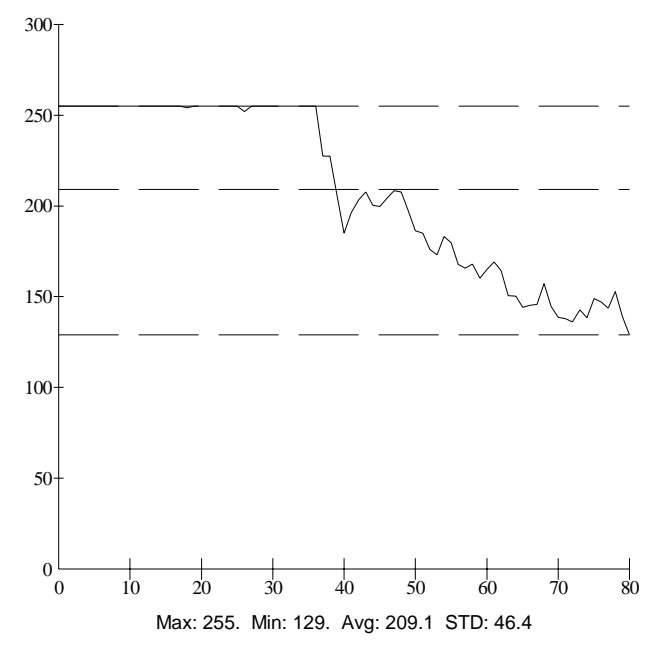

a) 1-second delay time

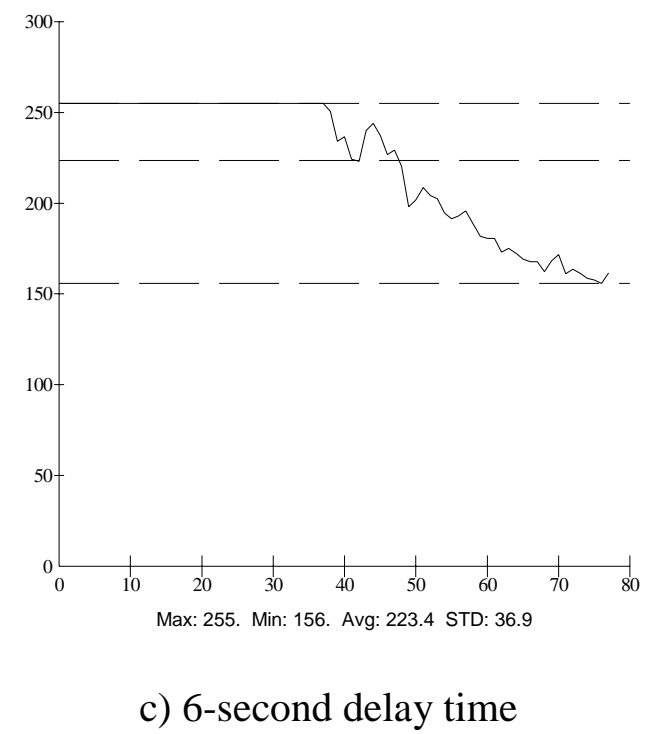

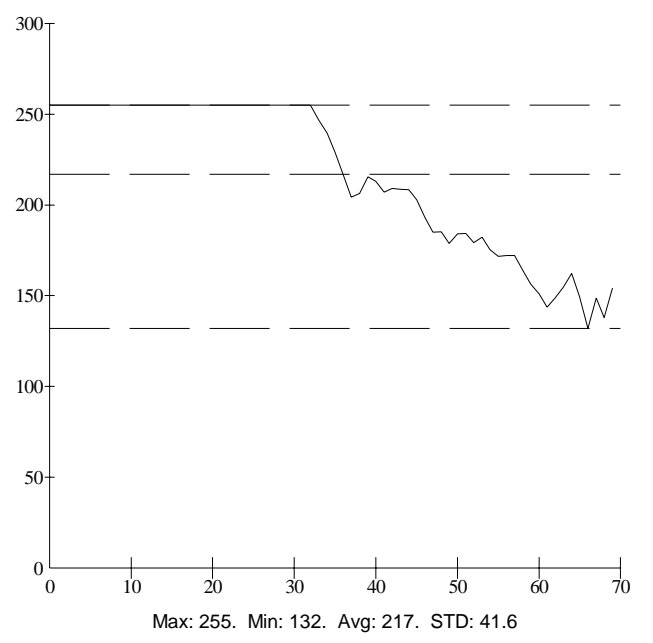

b) 3-second delay time

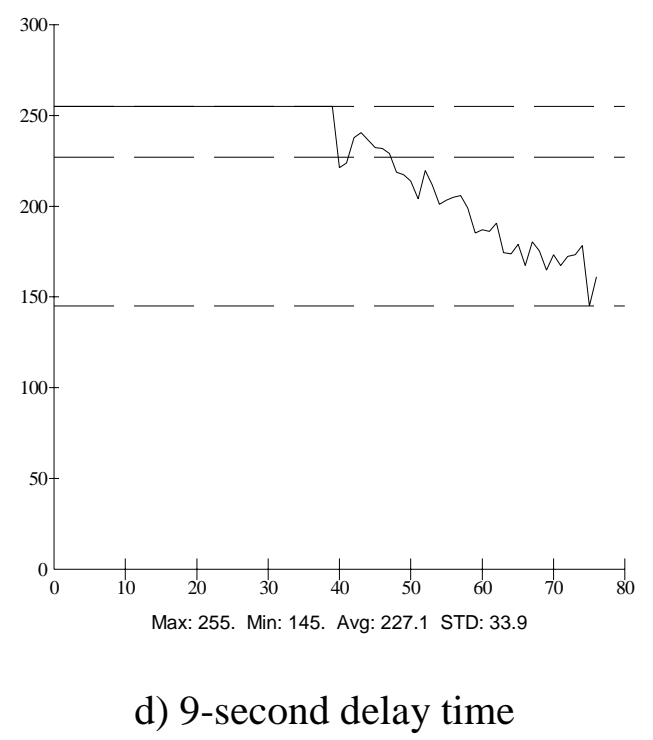

Figure A.70 Thermal intensity profile along the line across the fatigue crack shown in Figure A.69. 


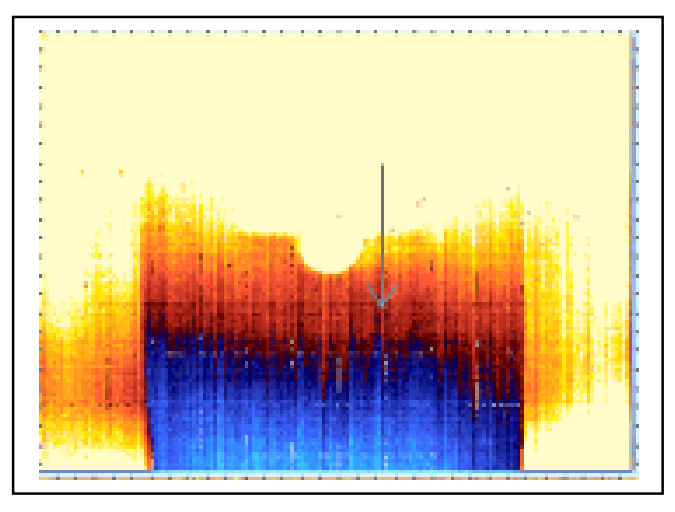

a) 1-second delay time

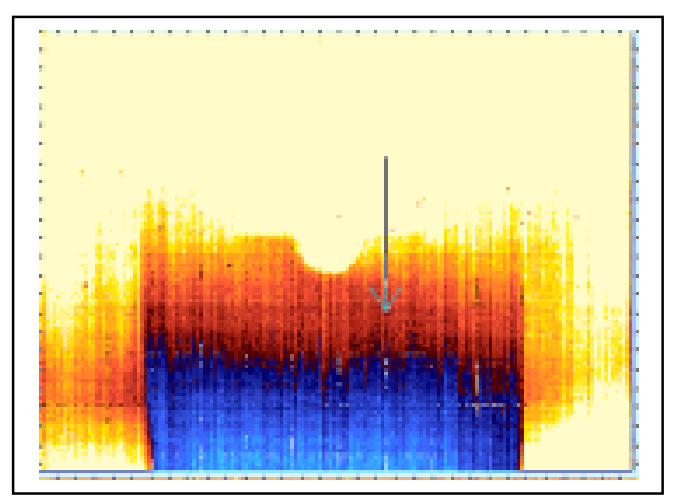

c) 6-second delay time

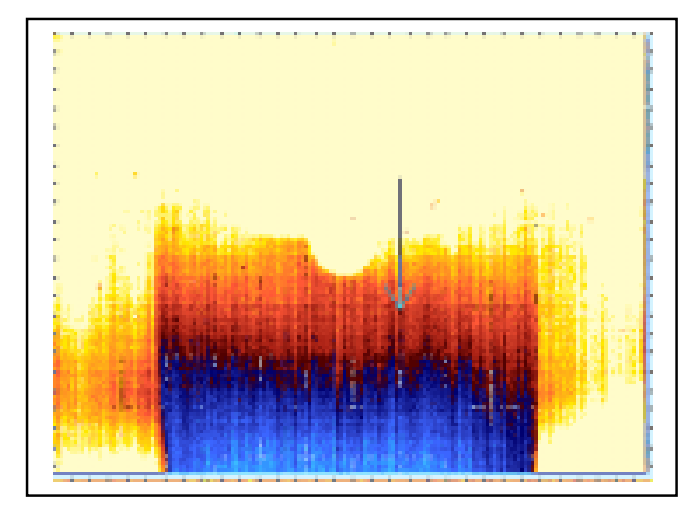

b) 3-second delay time

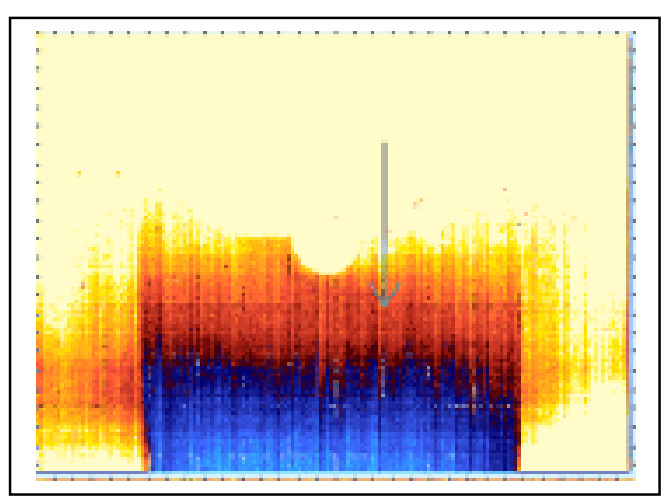

d) 9-second delay time

Figure A.71 Thermal images of unpainted Specimen CH-3 at 550,000 loading cycles 3 (using the active approach and heating time is 60 seconds). 


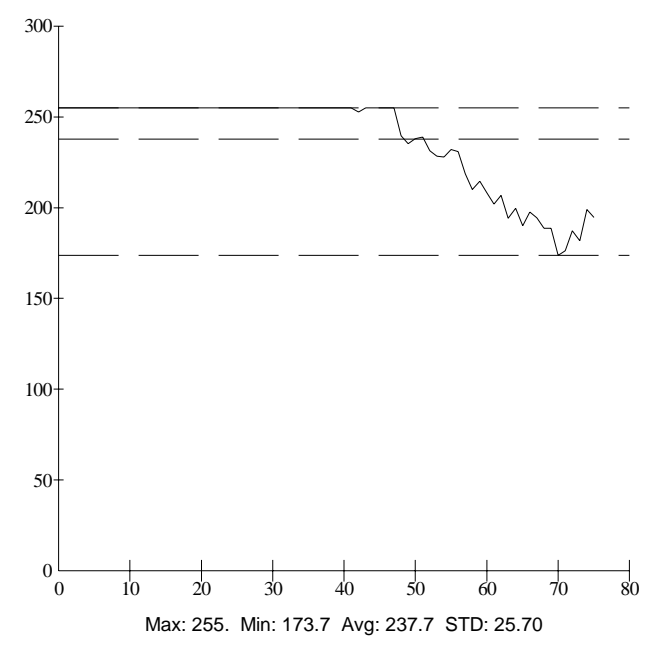

a) 1-second delay time

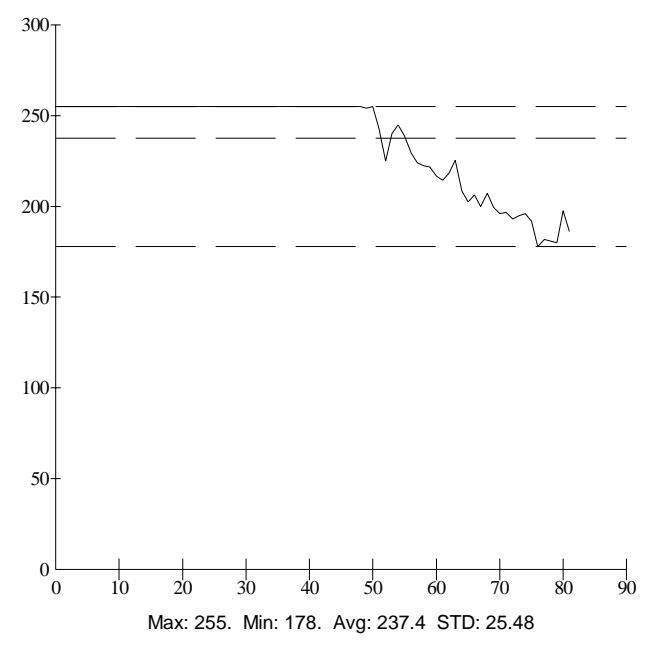

c) 6-second delay time

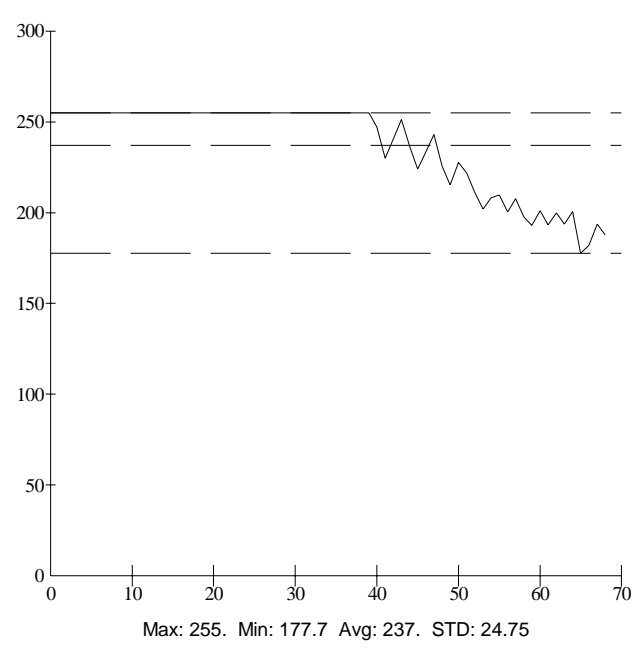

b) 3-second delay time

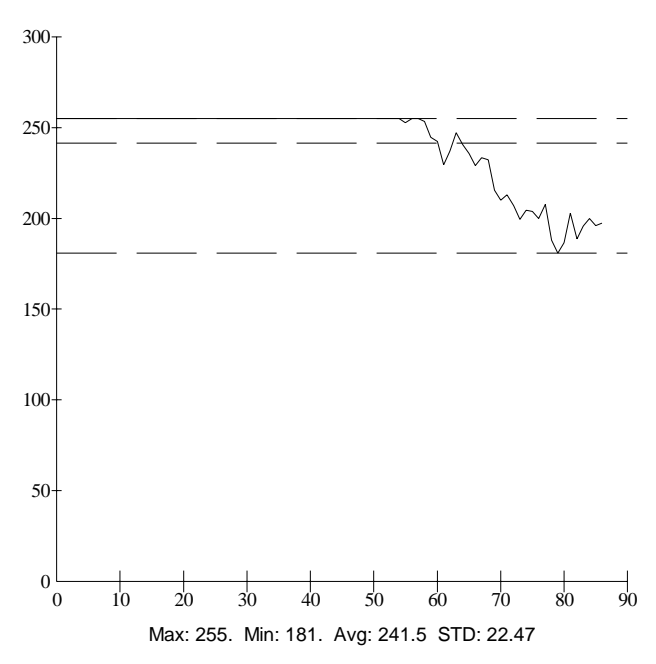

d) 9-second delay time

Figure A.72 Thermal intensity profile along the line across the fatigue crack shown in Figure A.71. 


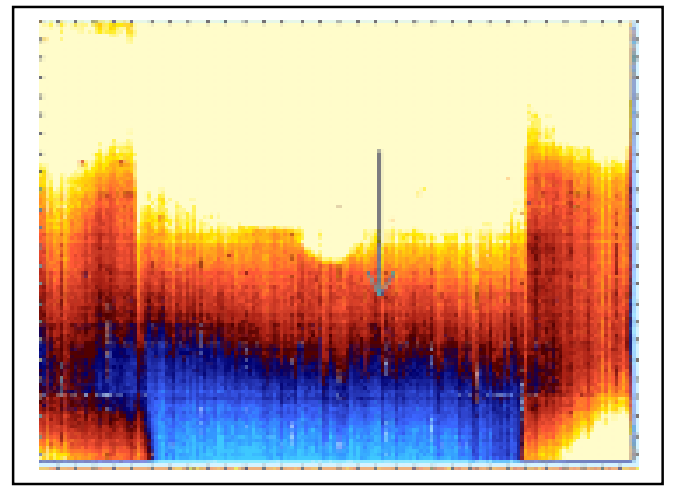

a) 1-second delay time

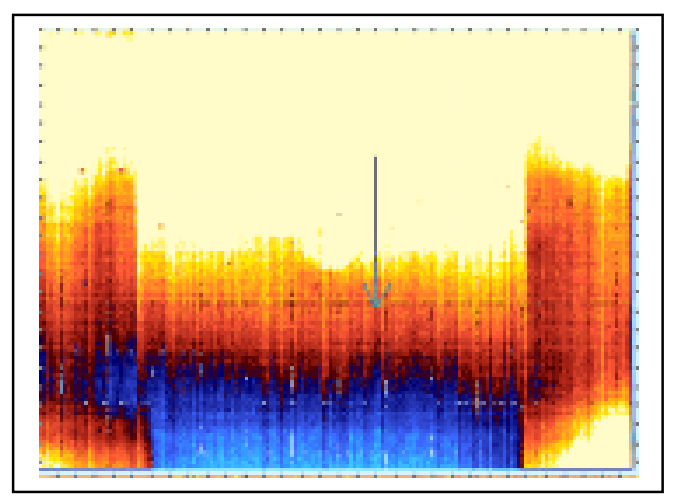

c) 6-second delay time

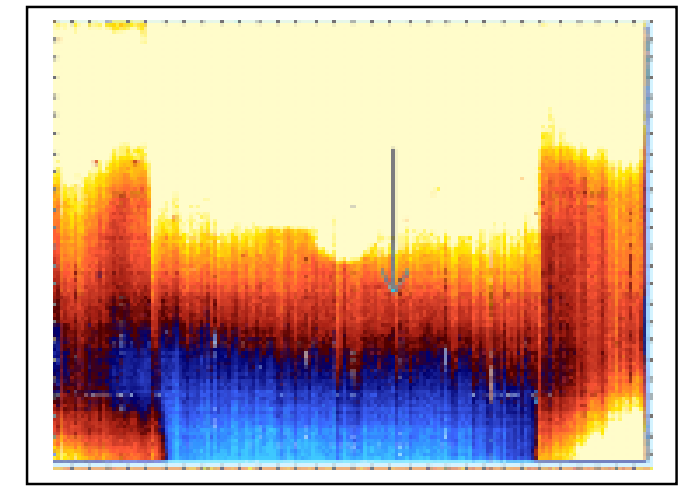

b) 3-second delay time

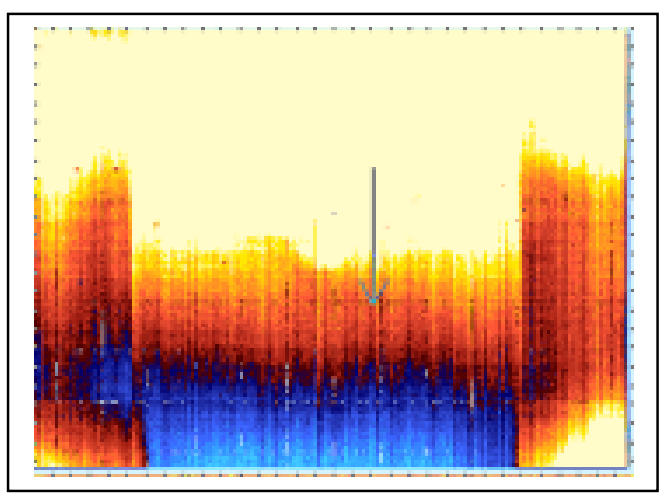

d) 9-second delay time

Figure A.73 Thermal images of unpainted Specimen CH-3 at 550,000 loading cycles (using the active approach and heating time is 90 seconds). 


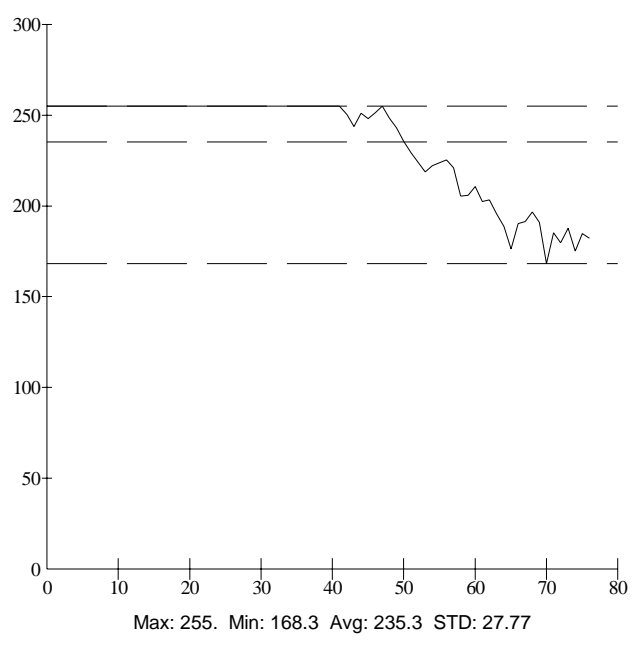

a) 1-second delay time

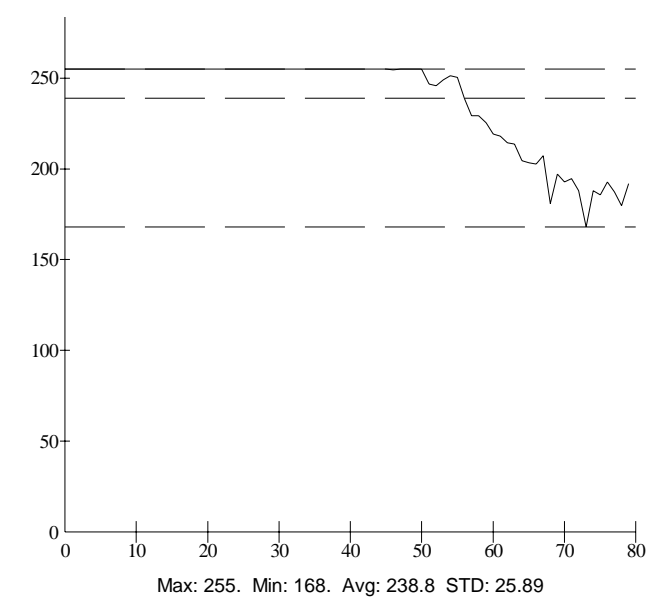

c) 6-second delay time

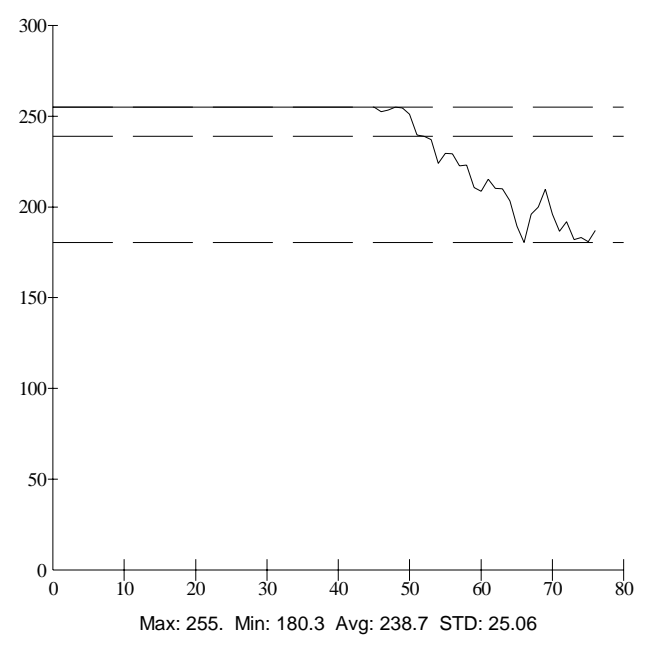

b) 3-second delay time

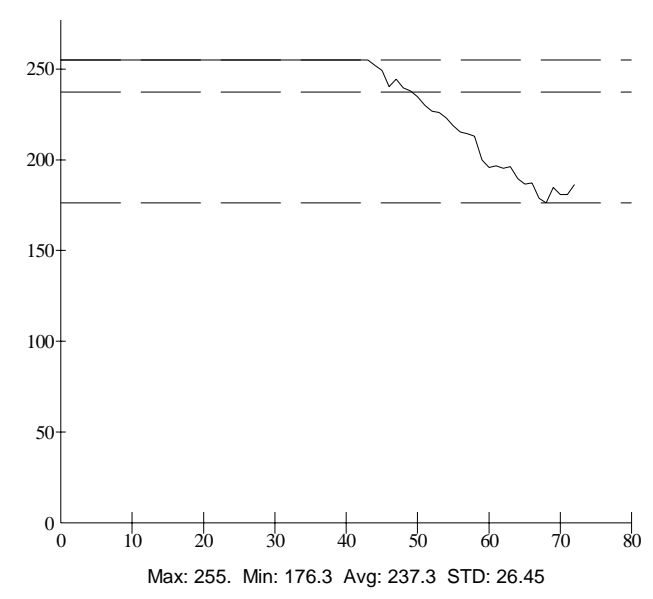

d) 9-second delay time

Figure A.74 Thermal intensity profile along the line across the fatigue crack shown in Figure A.73. 


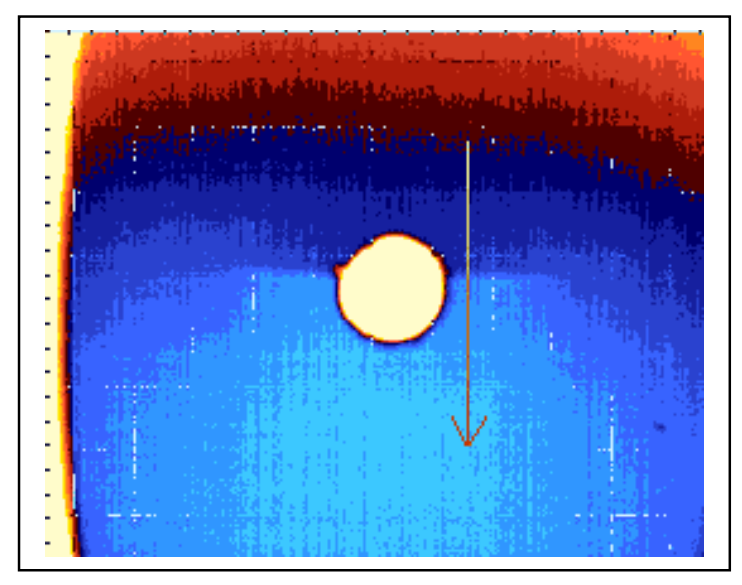

a) 1-second delay time

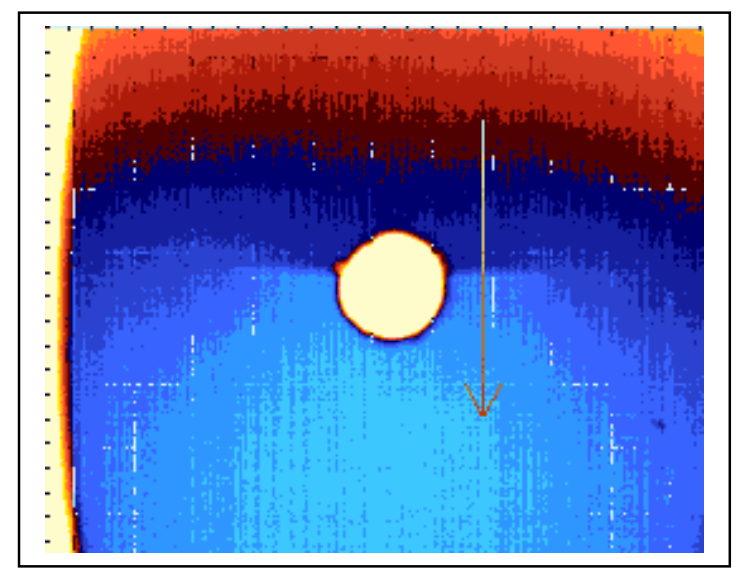

c) 6-second delay time

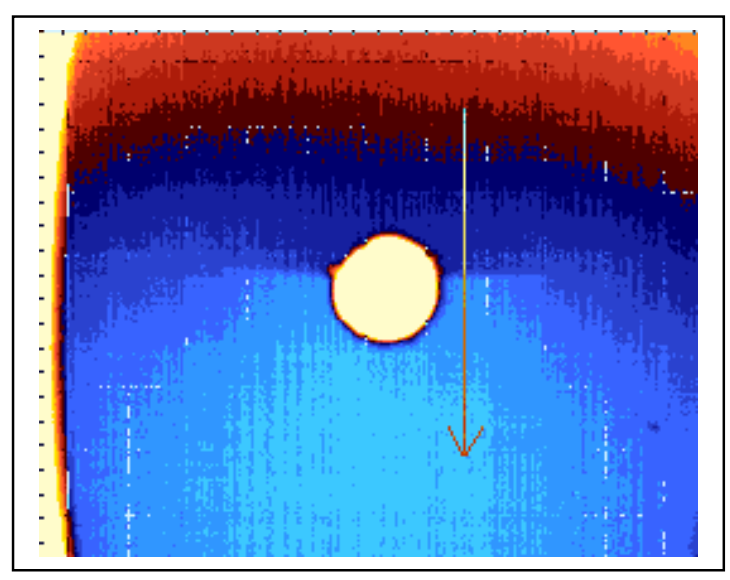

b) 3-second delay time

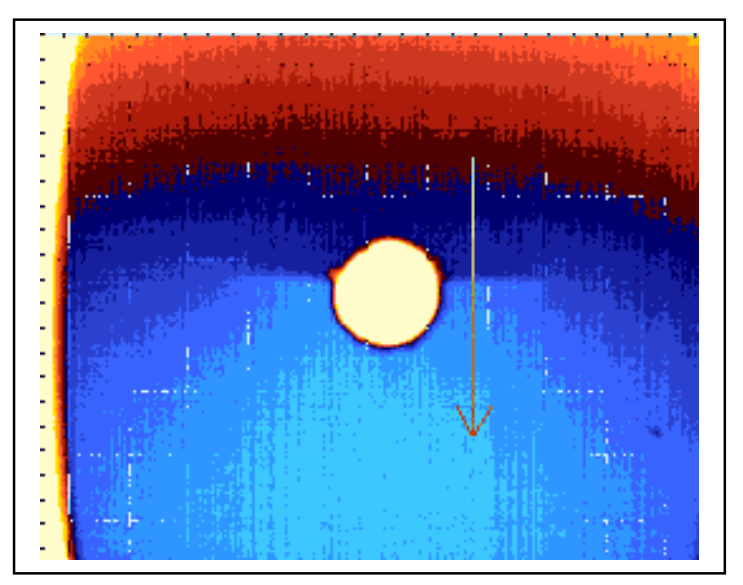

d) 9-second delay time

Figure A.75 Thermal images of Specimen CH-3 at 550,000 loading cycles (using the active approach and heating time is 15 seconds). 


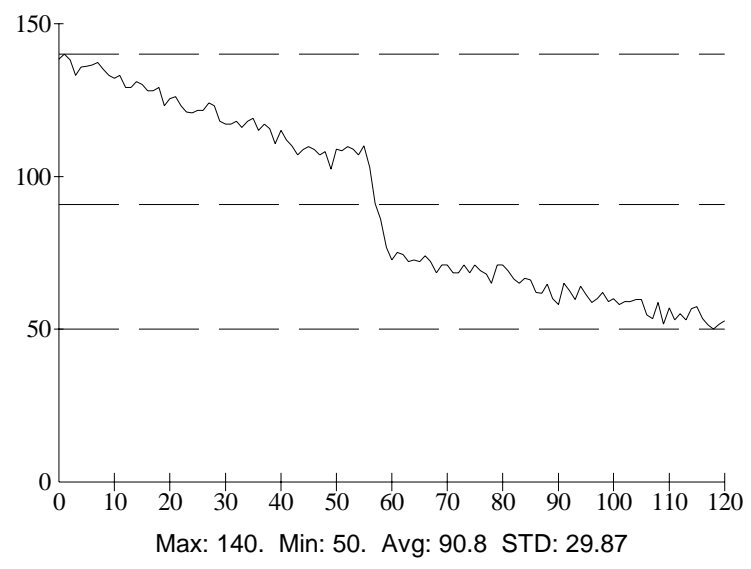

a) 1-second delay time

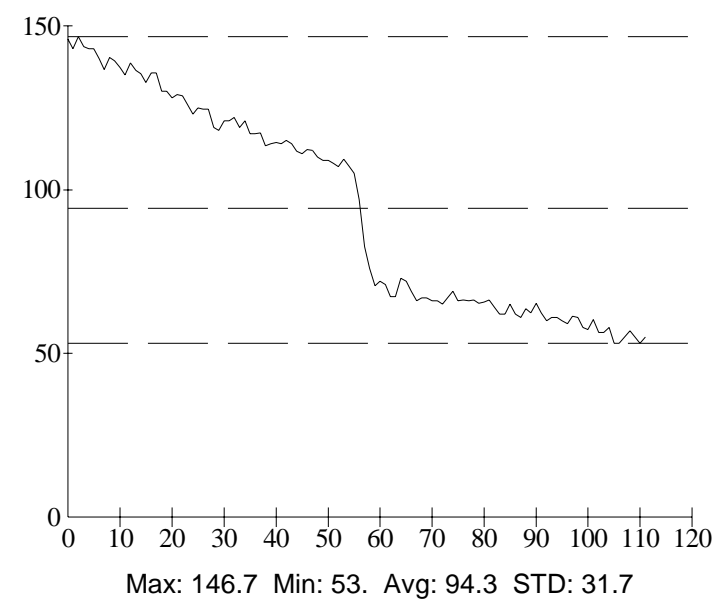

c) 6-second delay time

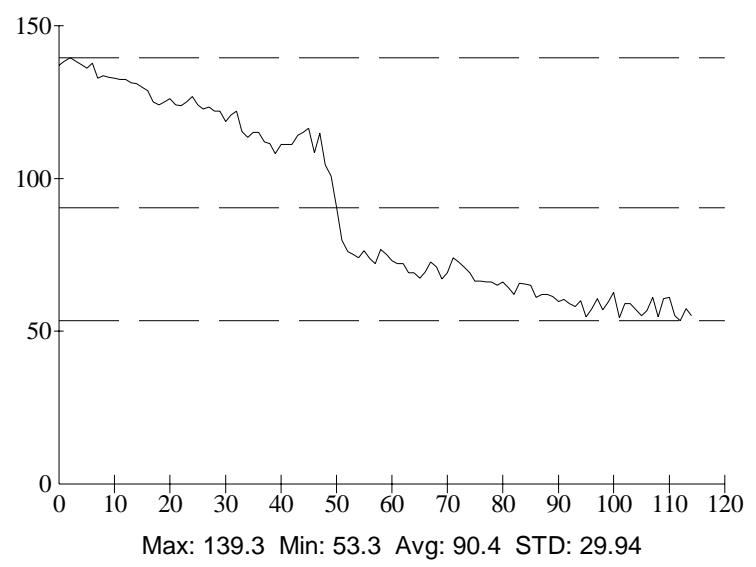

b) 3-second delay time

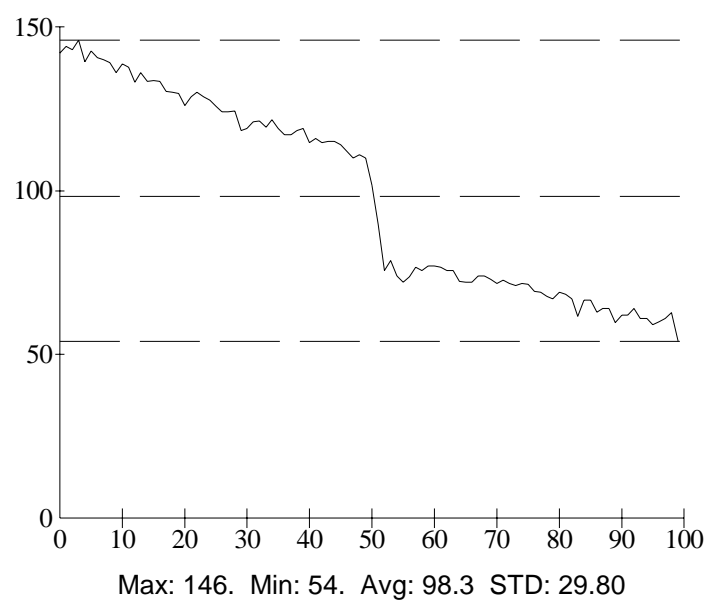

d) 9-second delay time

Figure A.76 Thermal intensity profile along the line across the fatigue crack shown in Figure A.75. 


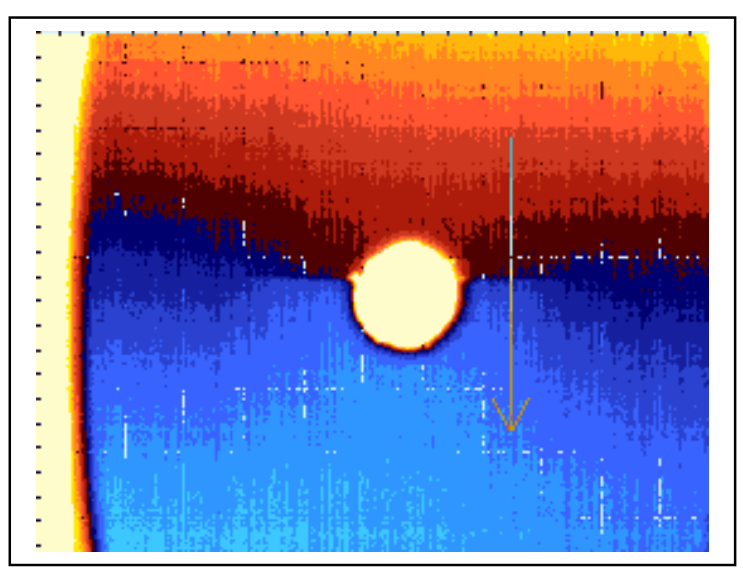

a) 1-second delay time

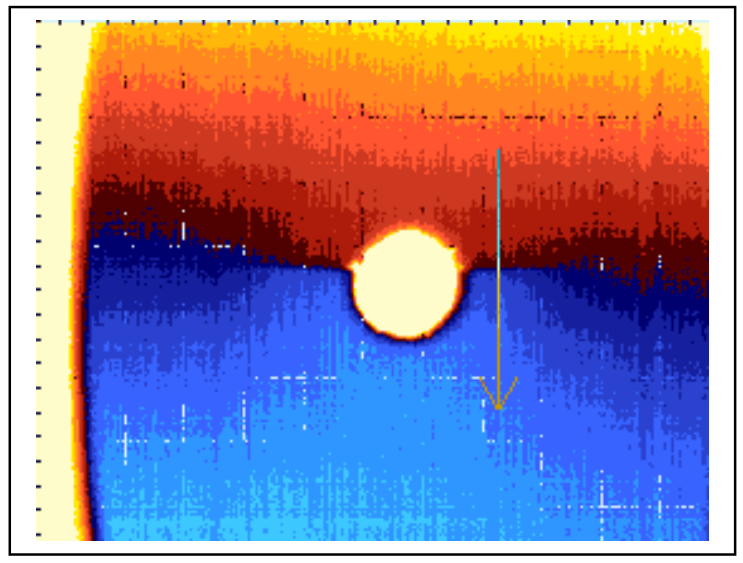

c) 6-second delay time

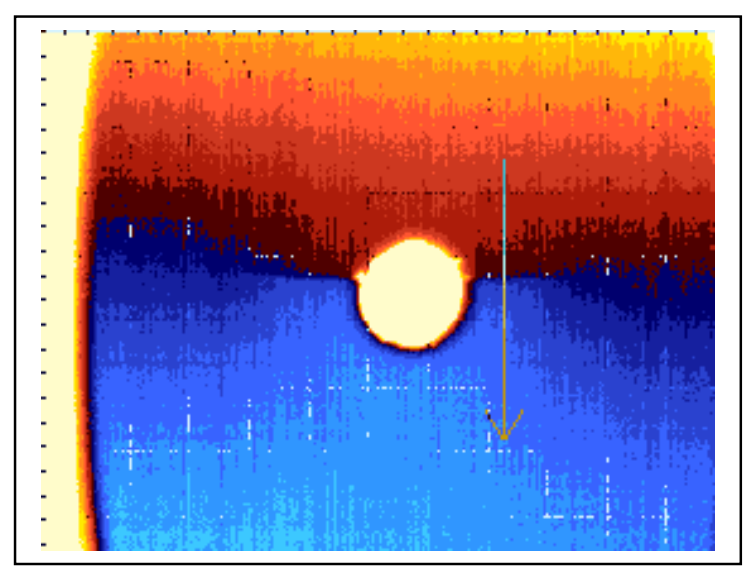

b) 3-second delay time

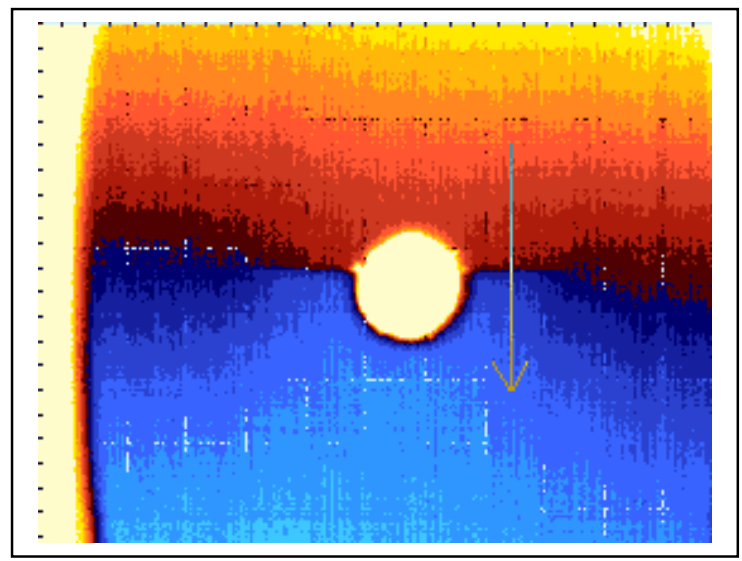

d) 9-second delay time

Figure A.77 Thermal images of Specimen CH-3 at 550,000 loading cycles (using the active approach and heating time is 30 seconds). 


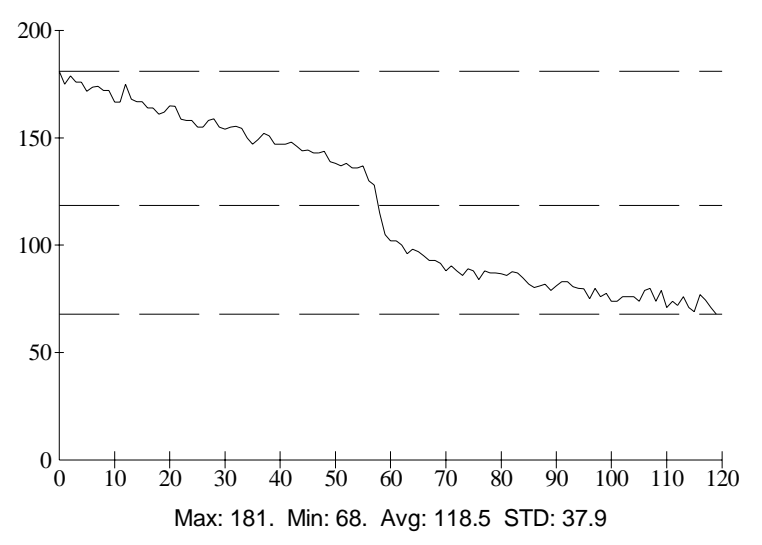

a) 1-second delay time

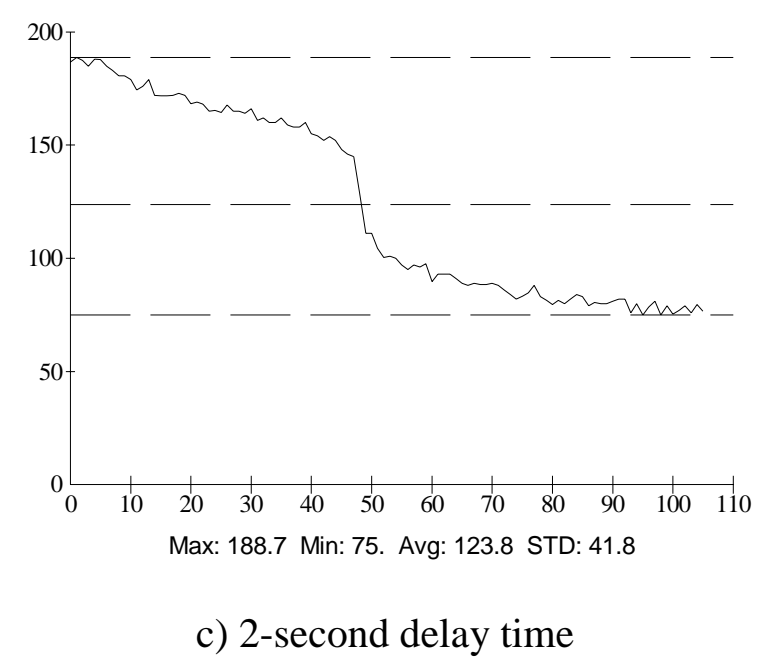

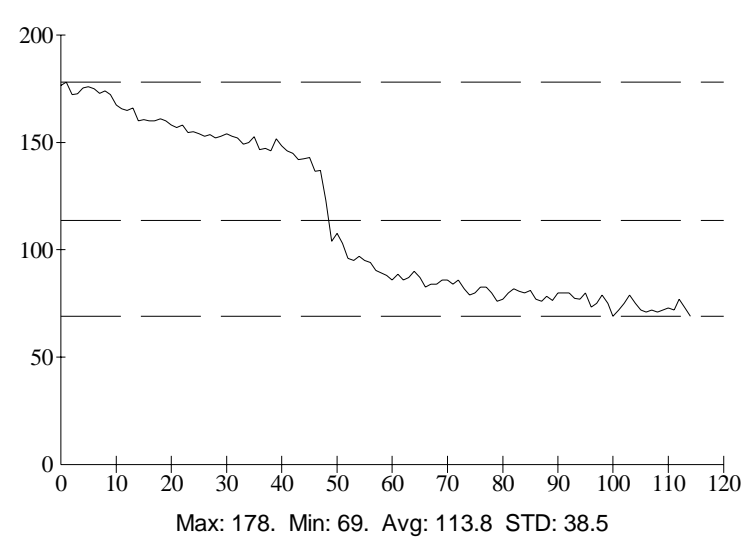

b) 2-second delay time

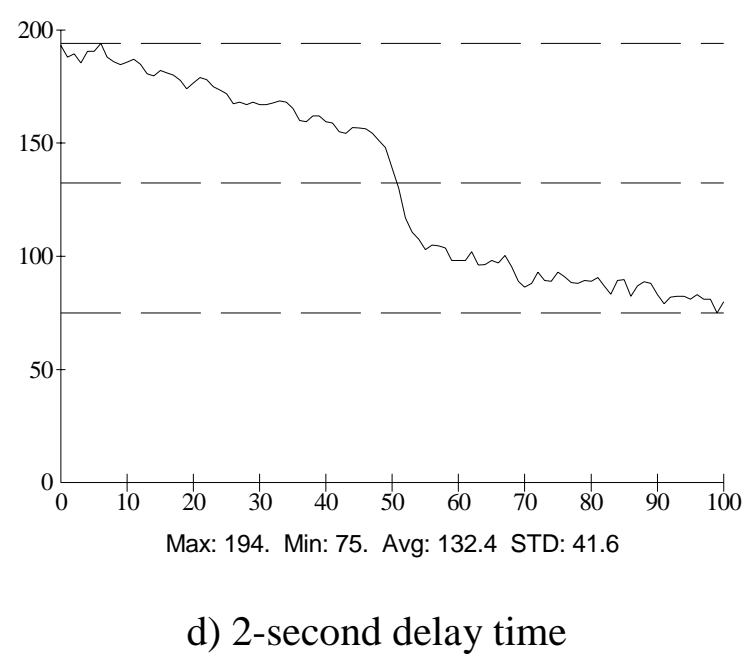

Figure A.78 Thermal intensity profile along the line across the fatigue crack shown in Figure A.77. 


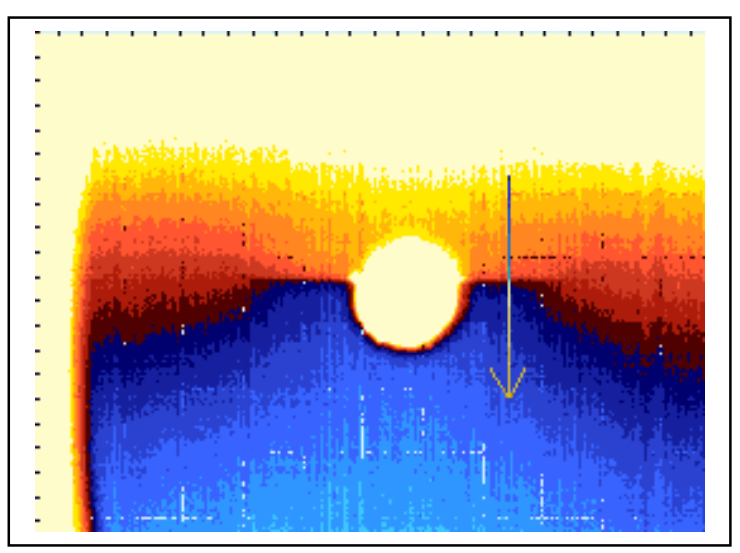

a) 1-second delay time

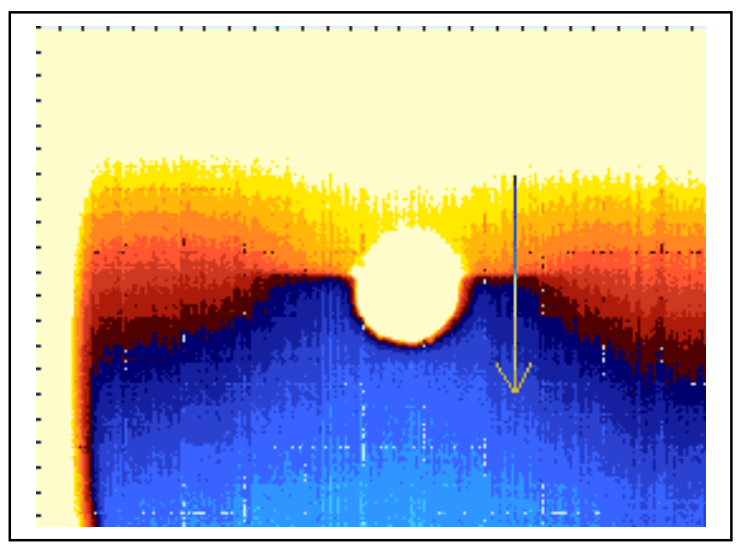

c) 6-second delay time

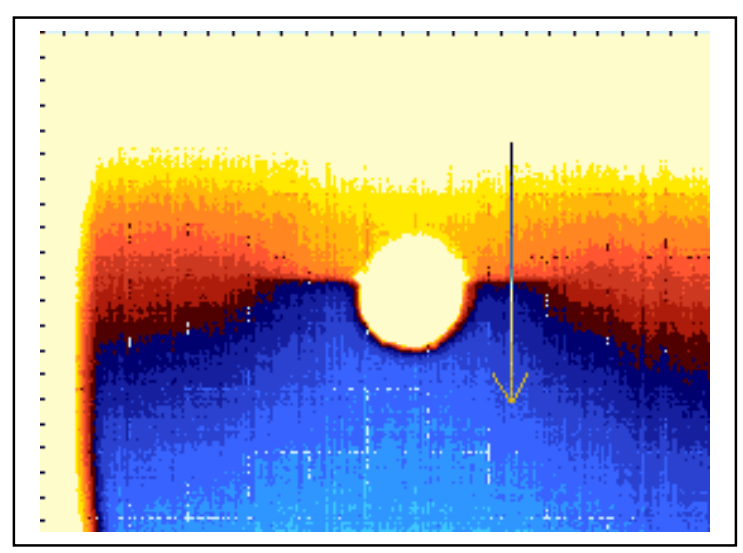

b) 3-second delay time

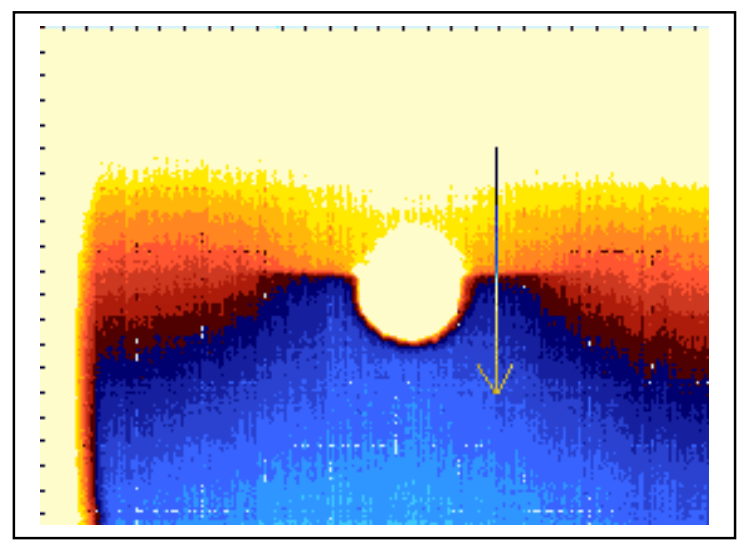

d) 9-second delay time

Figure A.79 Thermal images of Specimen 3 at 550,000 loading cycles (using the active approach and heating time is 45 seconds). 


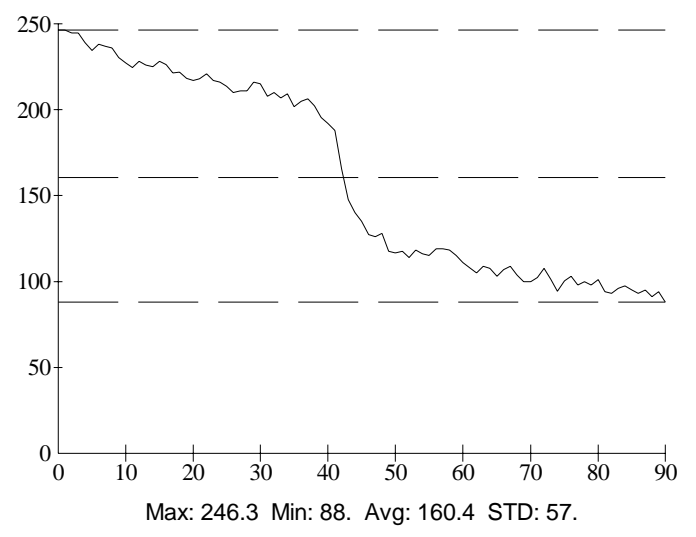

a) 1-second delay time

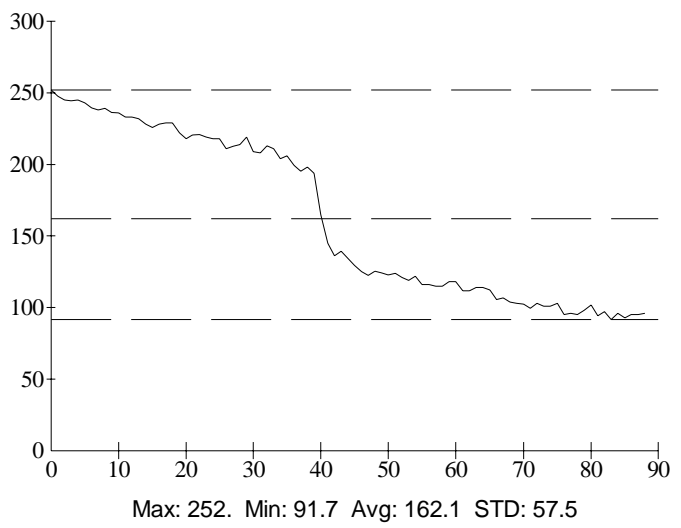

c) 6-second delay time

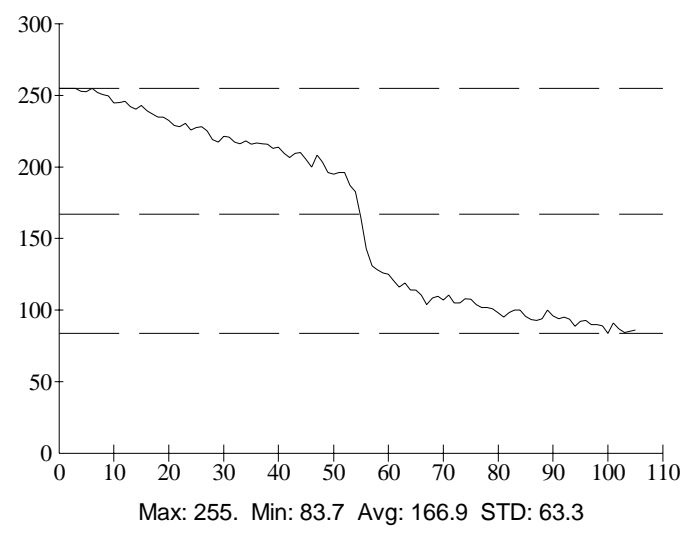

b) 3-second delay time

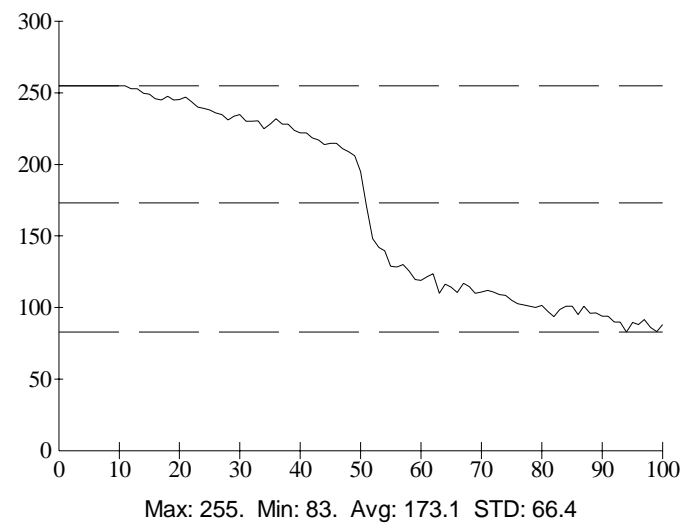

d) 9-second delay time

Figure A.80 Thermal intensity profile along the line across the fatigue crack shown in Figure A.79. 


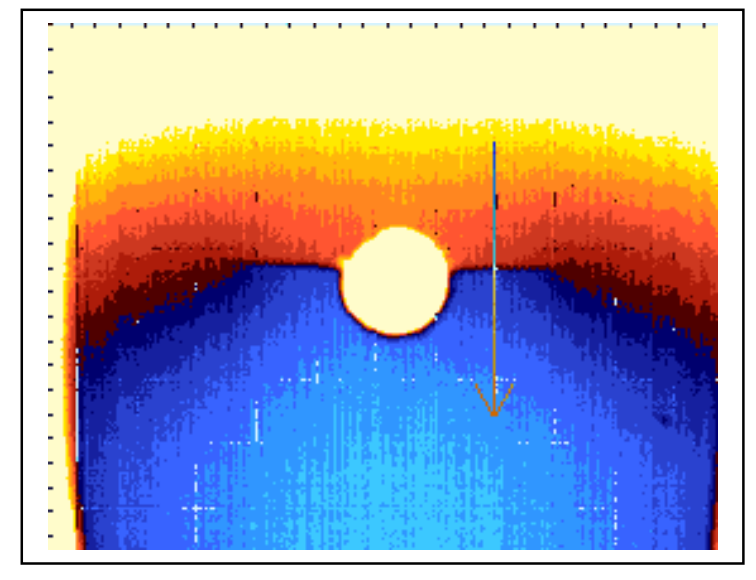

a) 1-second delay time

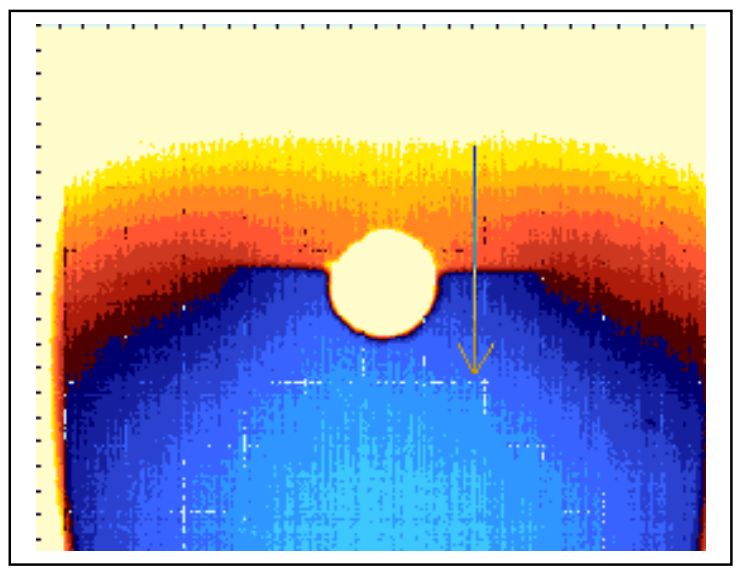

c) 6-second delay time

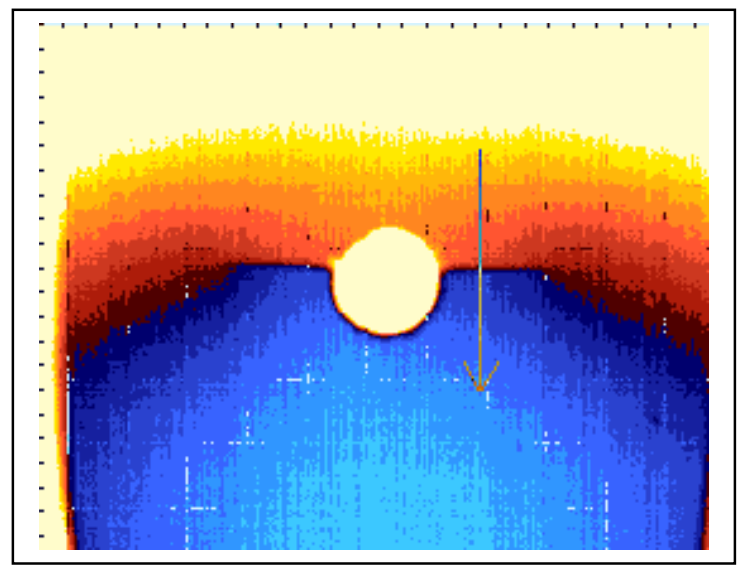

b) 3-second delay time

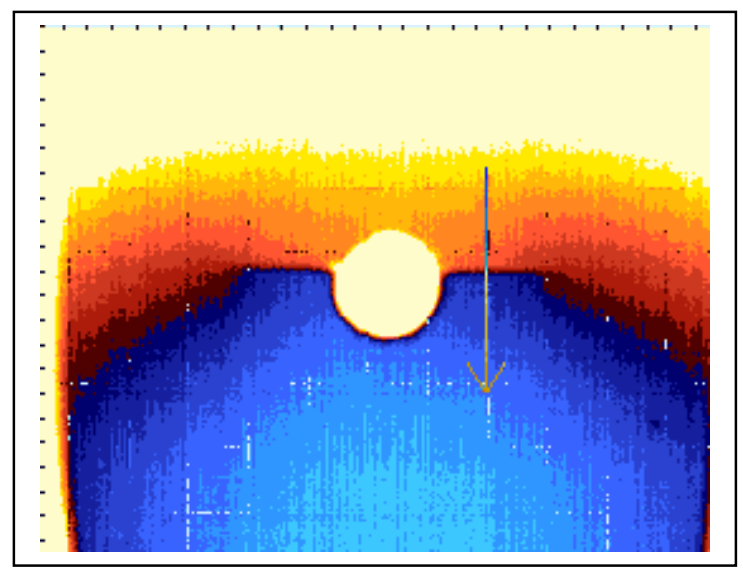

d) 9-second delay time

Figure A.81 Thermal images of Specimen CH-3 at 550,000 loading cycles (using the active approach and heating time is 60 seconds). 


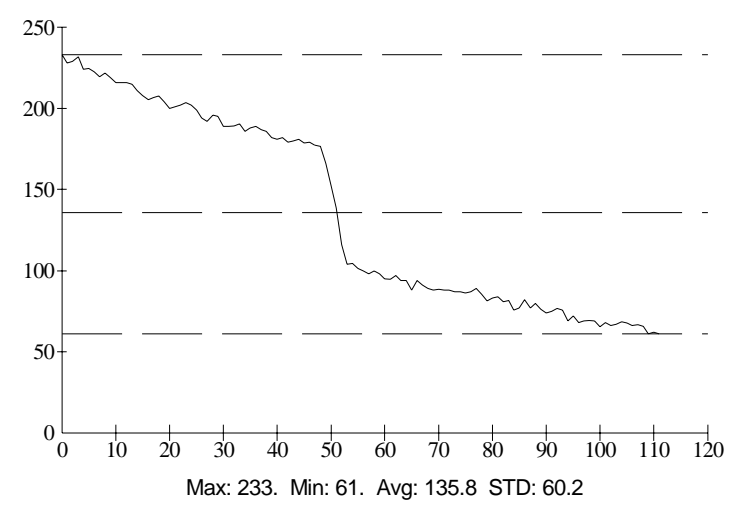

a) 1-second delay time

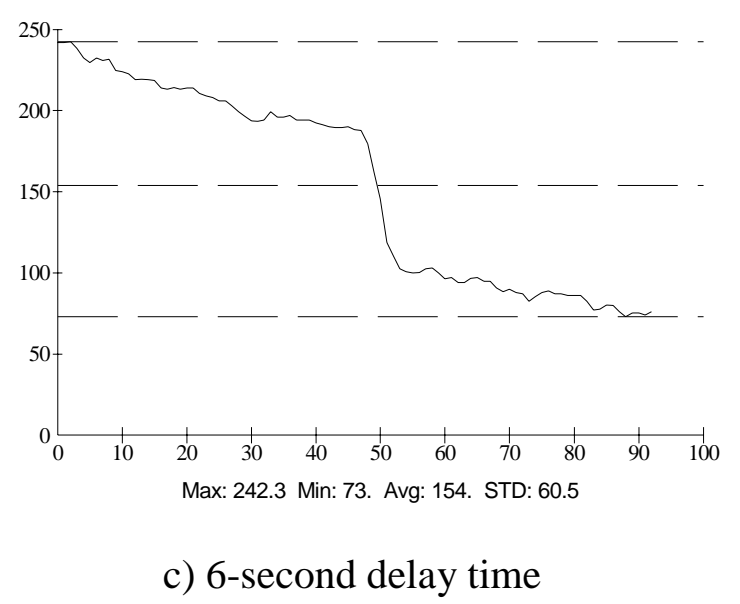

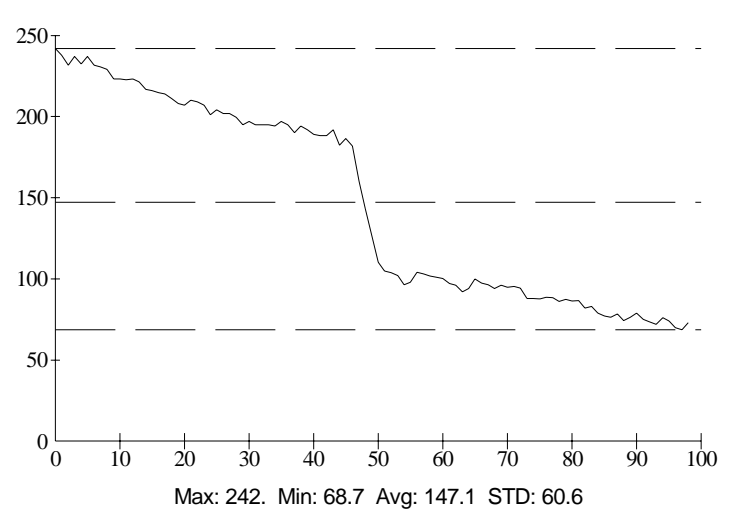

b) 3-second delay time

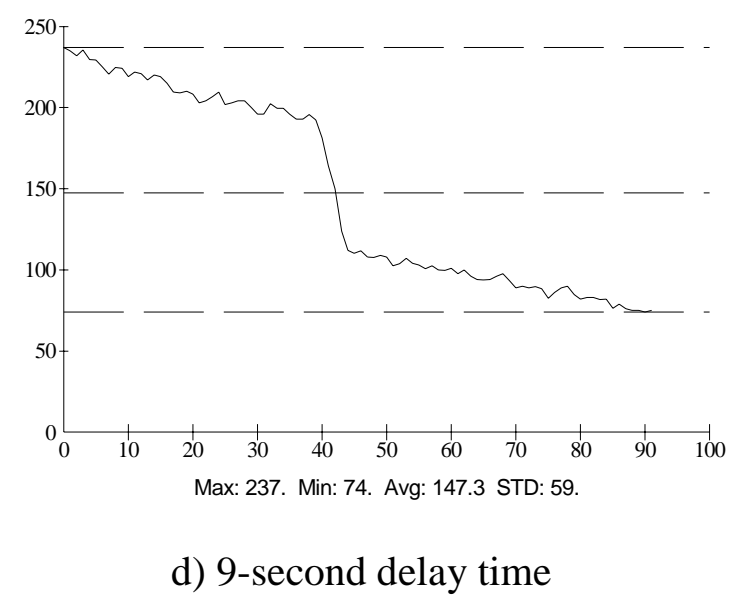

Figure A.82 Thermal intensity profile along the line across the fatigue crack shown in Figure A.81. 


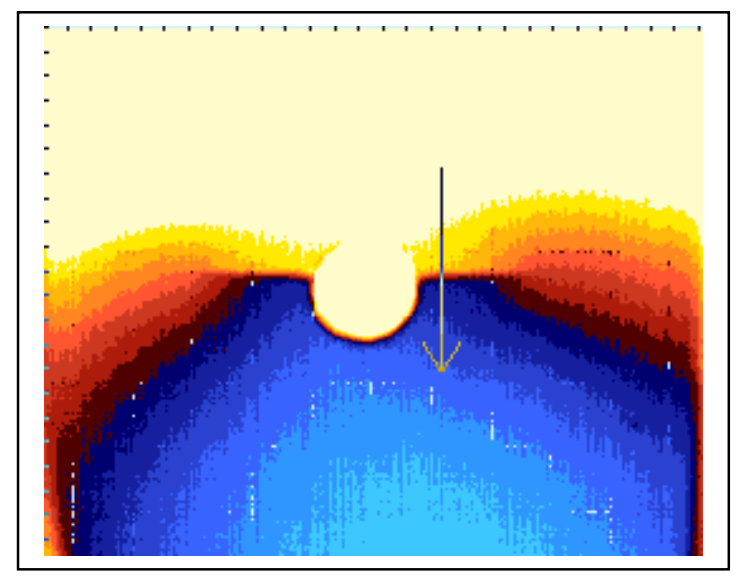

a) 1-second delay time

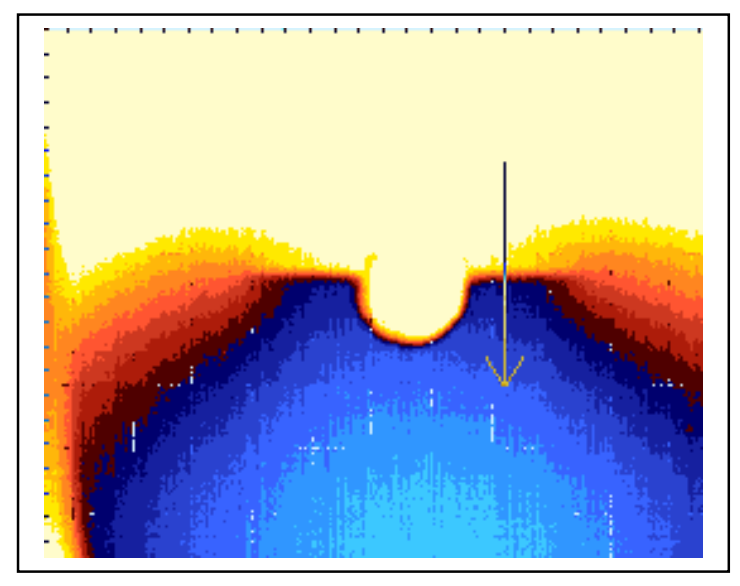

c) 6-second delay time

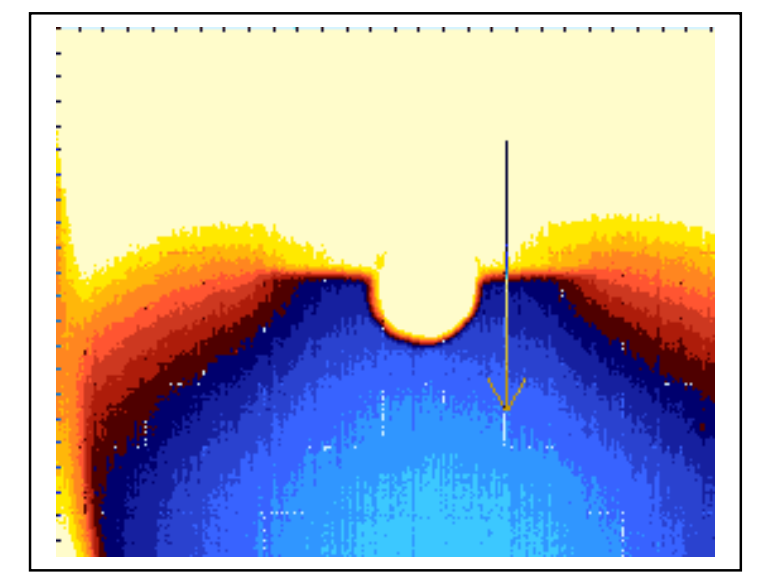

b) 3-second delay time

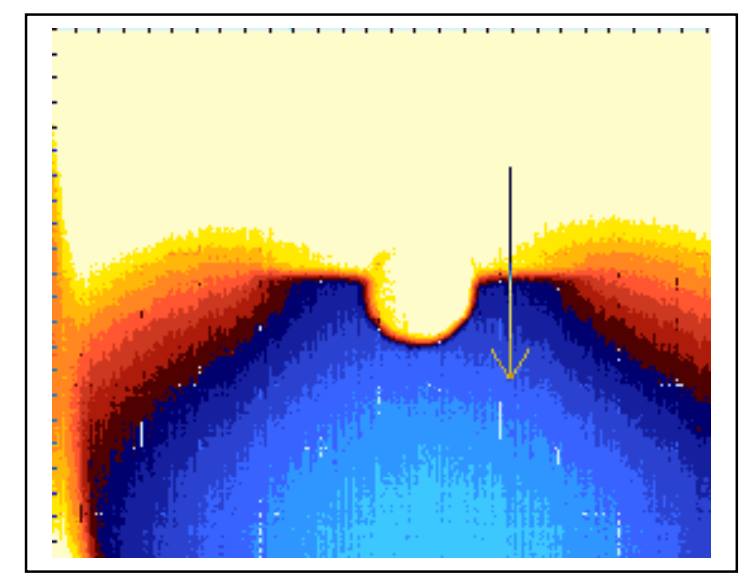

d) 9-second delay time

Figure A.83 Thermal images of Specimen CH-3 at 550,000 loading cycles (using the active approach and heating time is 90 seconds). 


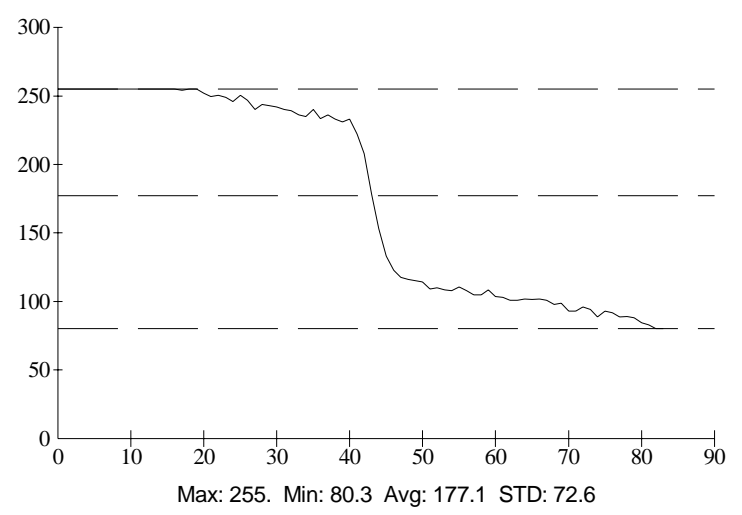

a) 1-second delay time

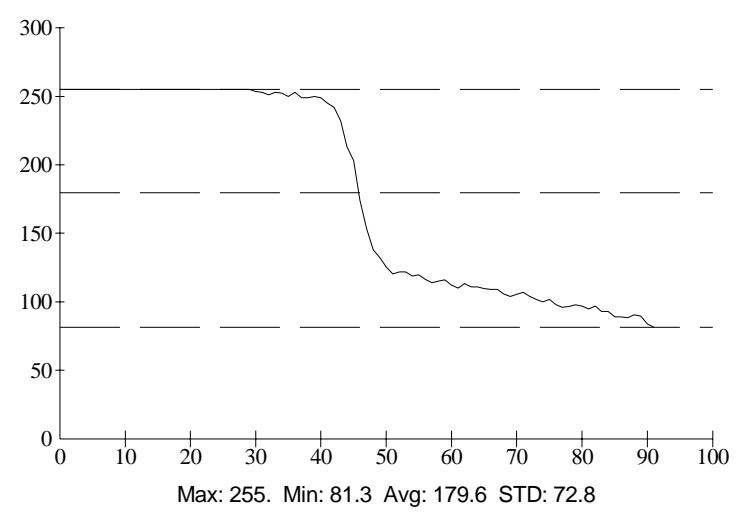

c) 6-second delay time

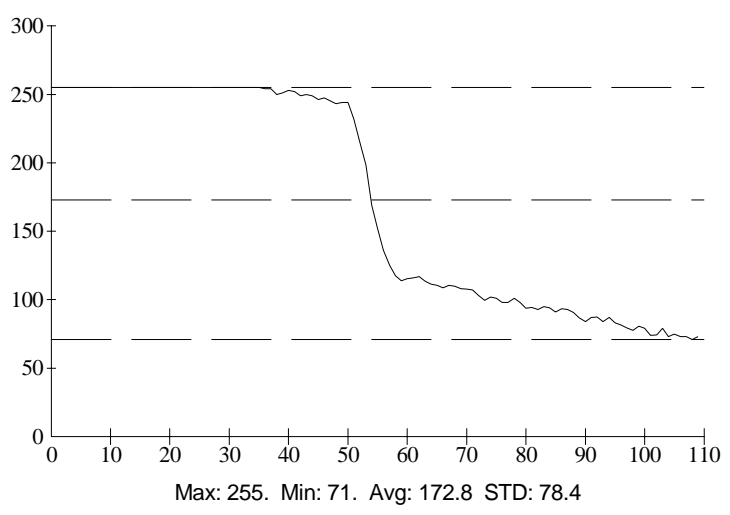

b) 3-second delay time

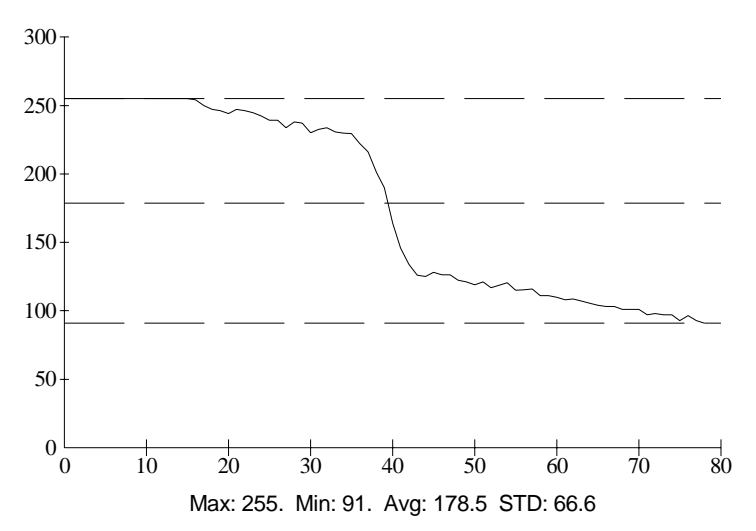

d) 9-second delay time

Figure A.84 Thermal intensity profile along the line across the fatigue crack shown in Figure A.83. 


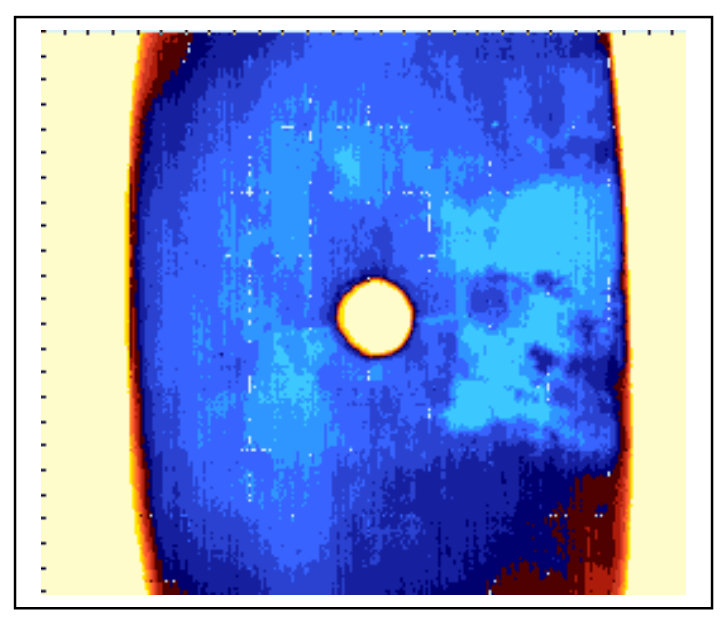

a) $150 \mathrm{~mm}$.

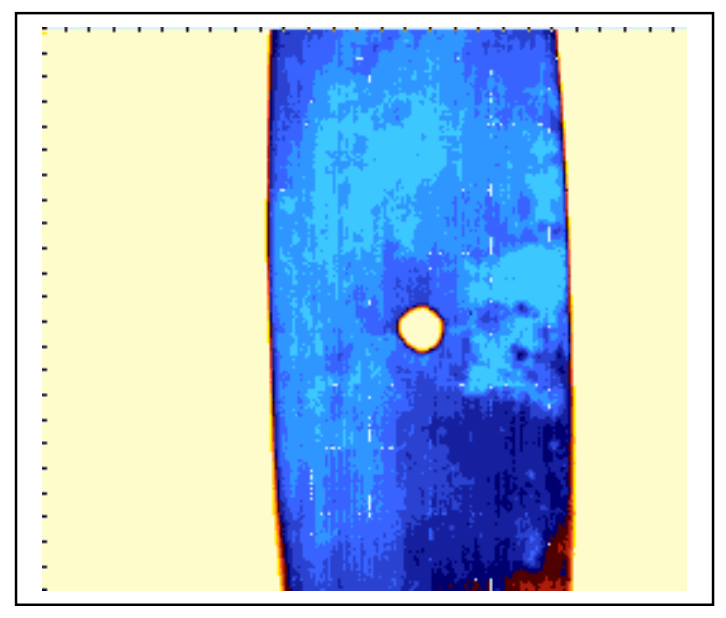

c) $300 \mathrm{~mm}$.

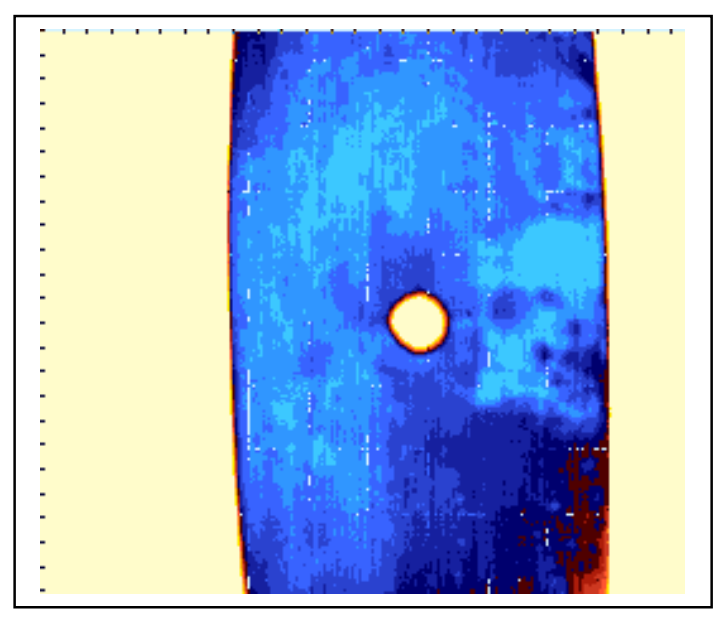

b) $225 \mathrm{~mm}$.

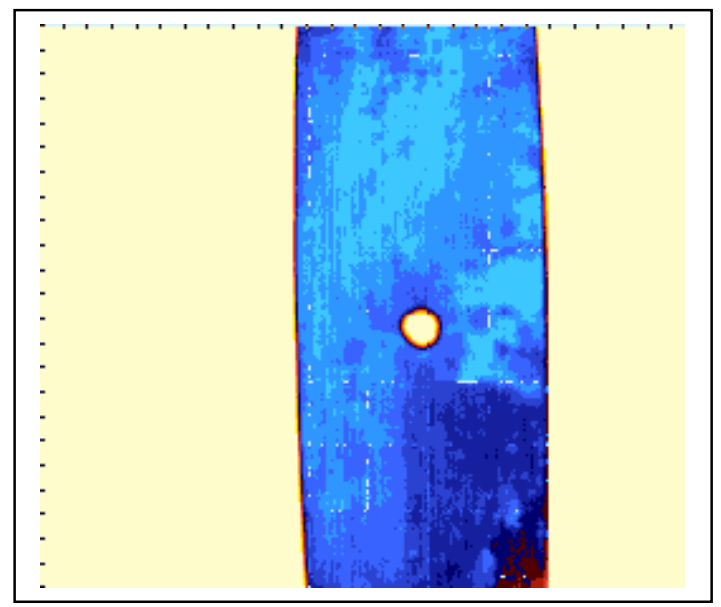

d) $375 \mathrm{~mm}$

Figure A.85 Thermal images of unpainted Specimen $\mathrm{CH}-1$ taken at various distances (no applied heat or stress). 


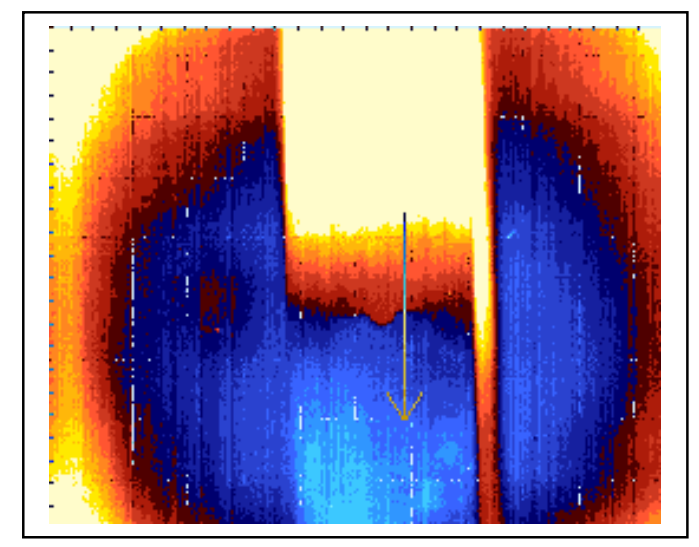

a) 1-second delay time

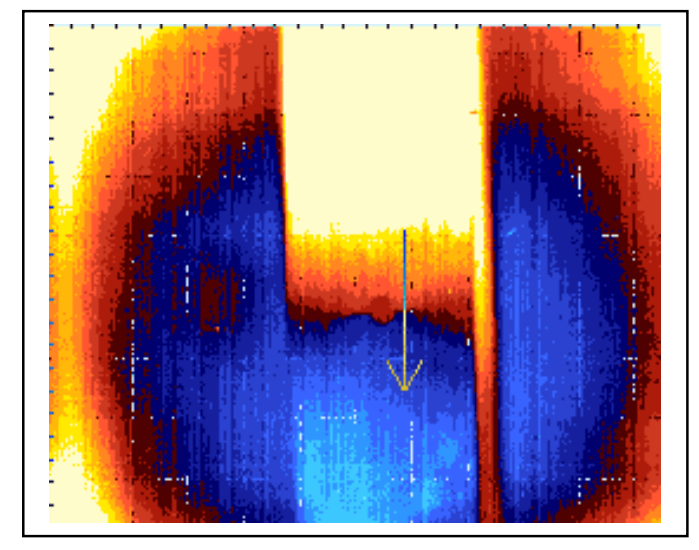

c) 6-second delay time

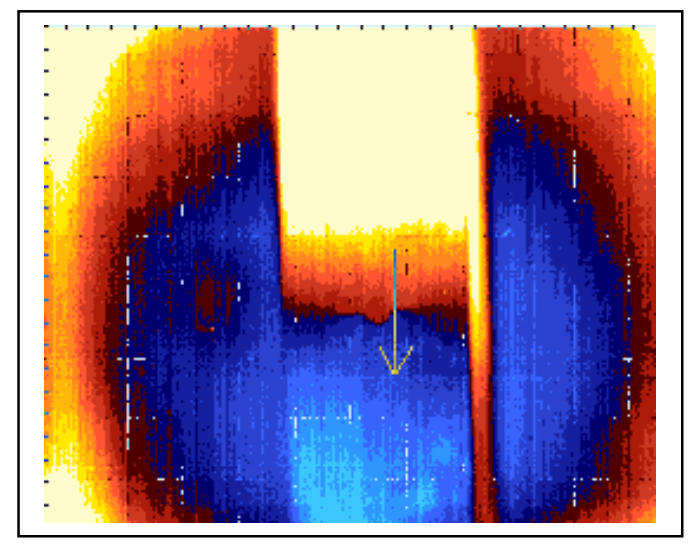

b) 3-second delay time

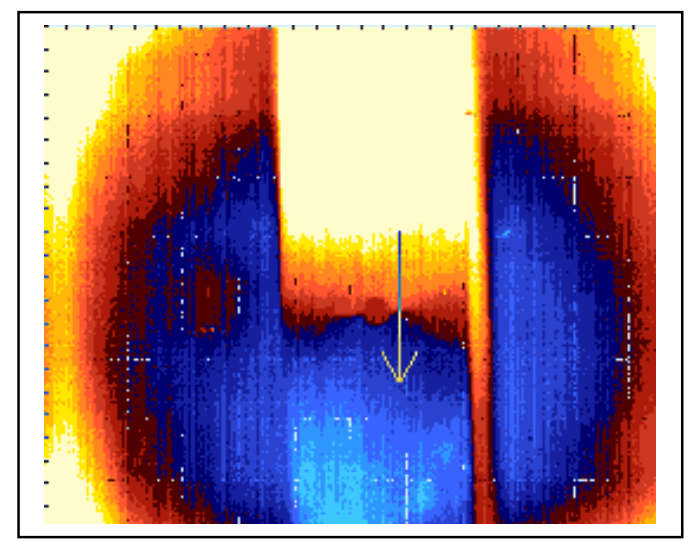

d) 9-second delay time

Figure A.86 Thermal images of unpainted Specimen CH-1 (using active approach and heating time is 30 seconds). The distance between IR camera and specimen is $450 \mathrm{~mm}$. 


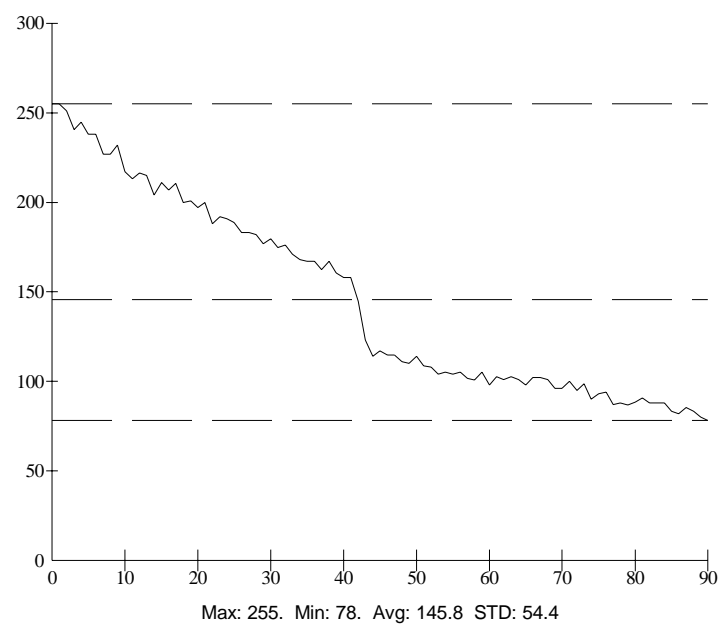

a) 1-second delay time

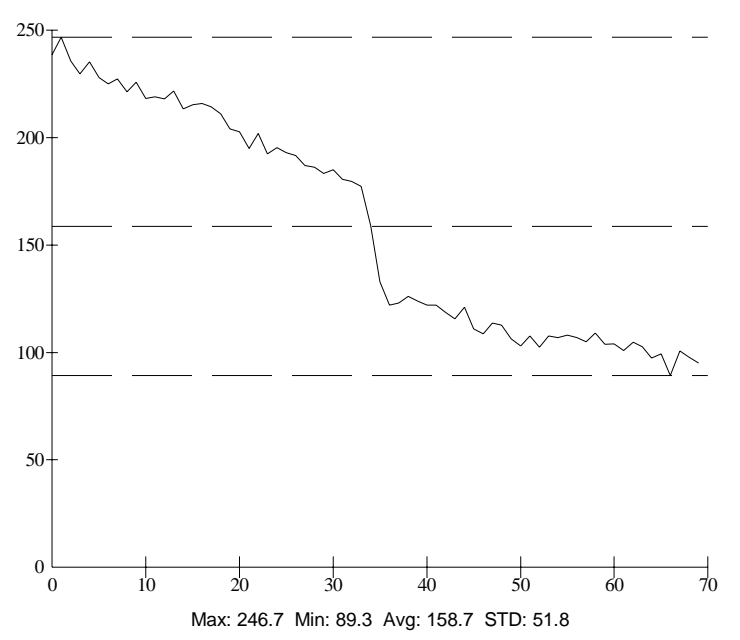

c) 6-second delay time

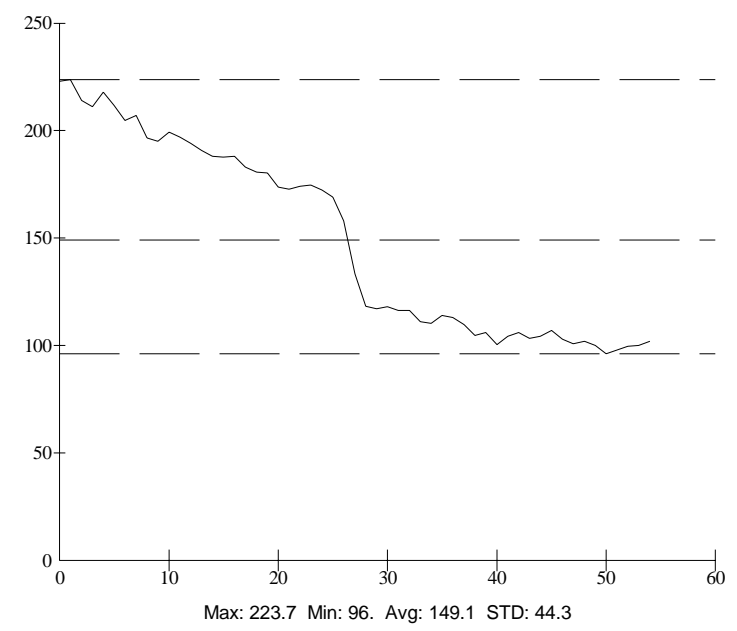

b) 3-second delay time

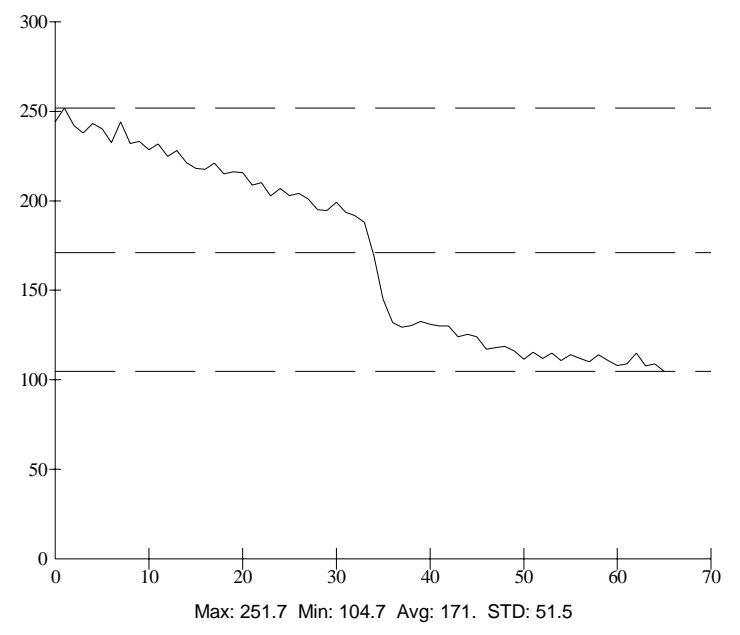

d) 9-second delay time

Figure A.87 Thermal intensity profile along the line across the fatigue crack shown in Figure A.86. 


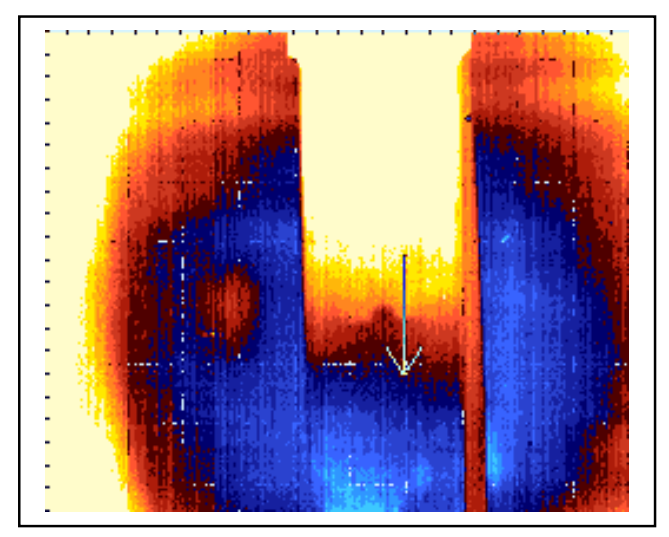

a) 1-second delay time

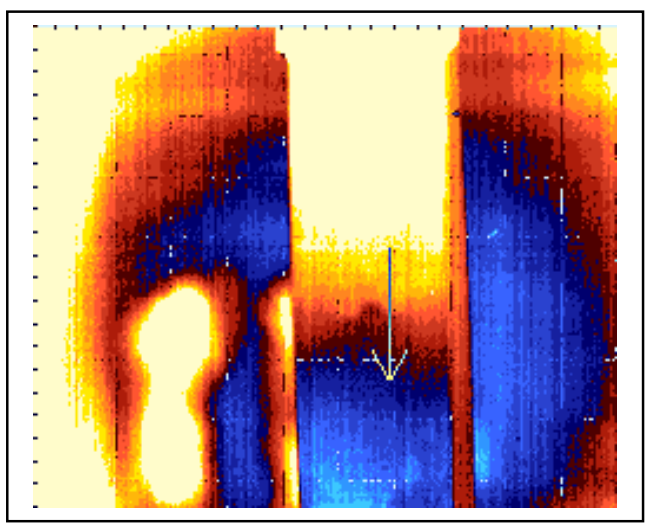

c) 6-second delay time

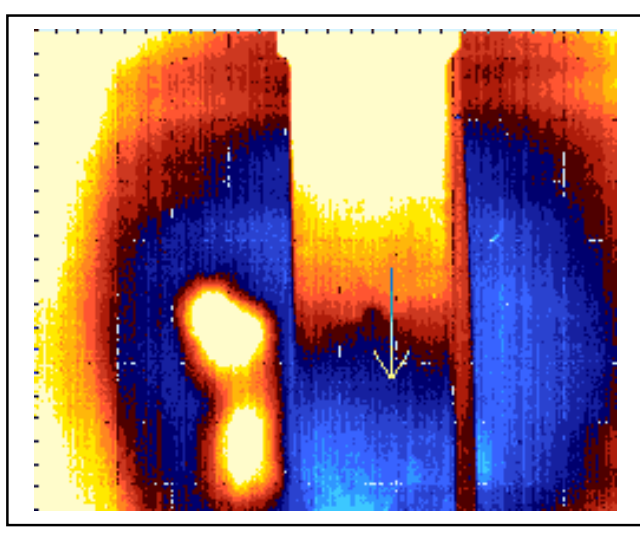

b) 3-second delay time

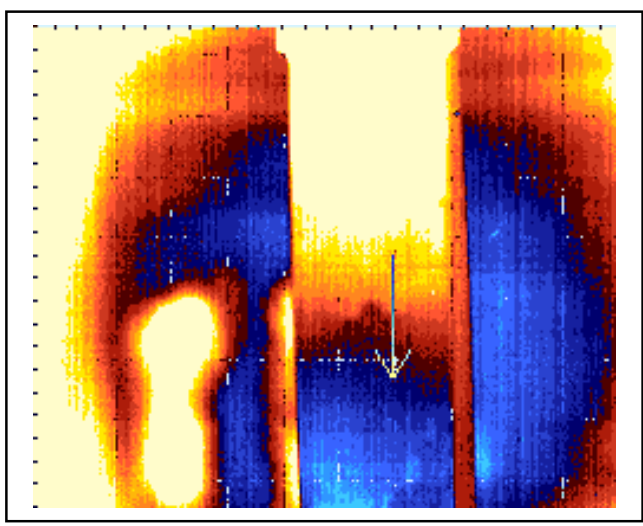

d) 9-second delay time

Figure A.88 Thermal images of unpainted Specimen $\mathrm{CH}-1$ (using active approach and heating time is 30 seconds). The distance between IR camera and specimen is $525 \mathrm{~mm}$. 


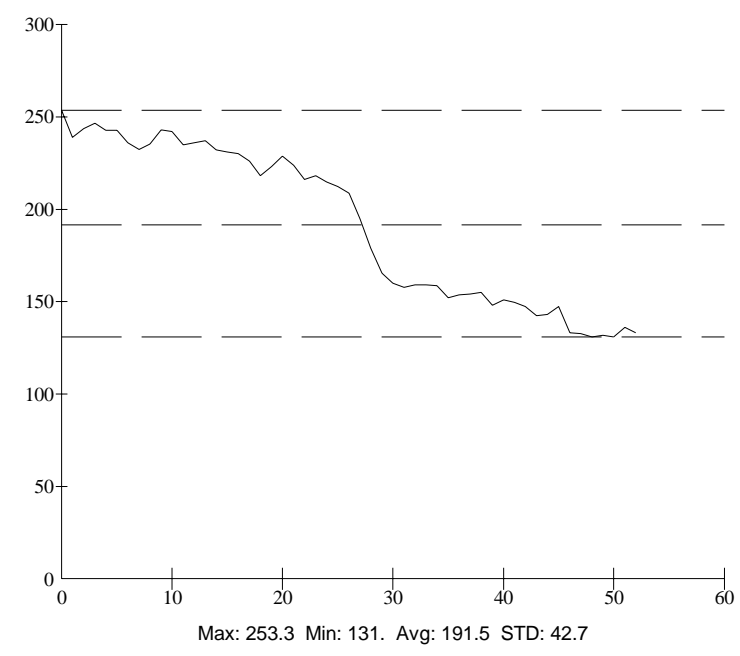

a) 1-second delay time

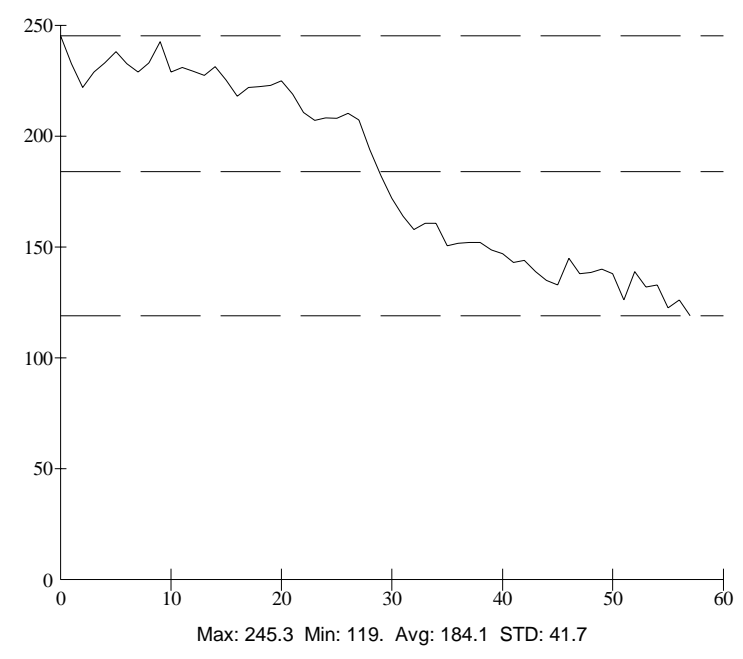

c) 6-second delay time

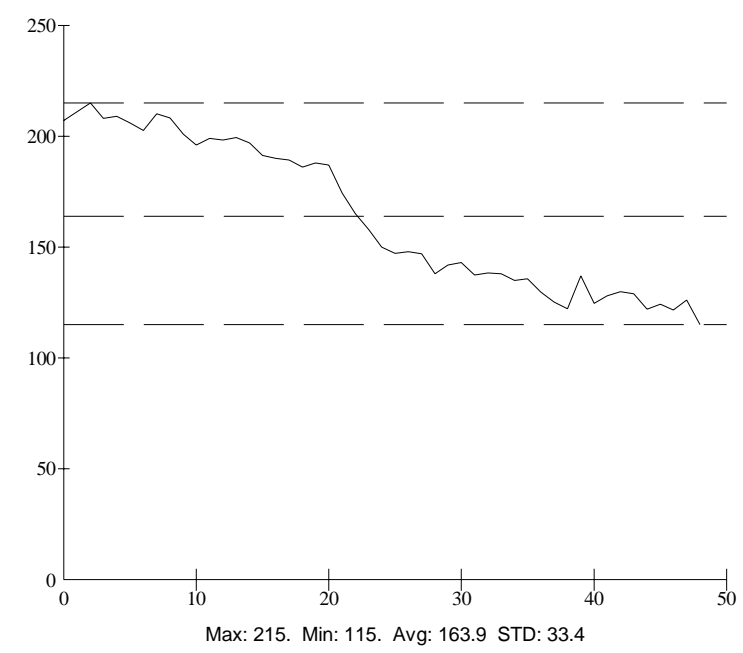

b) 3-second delay time

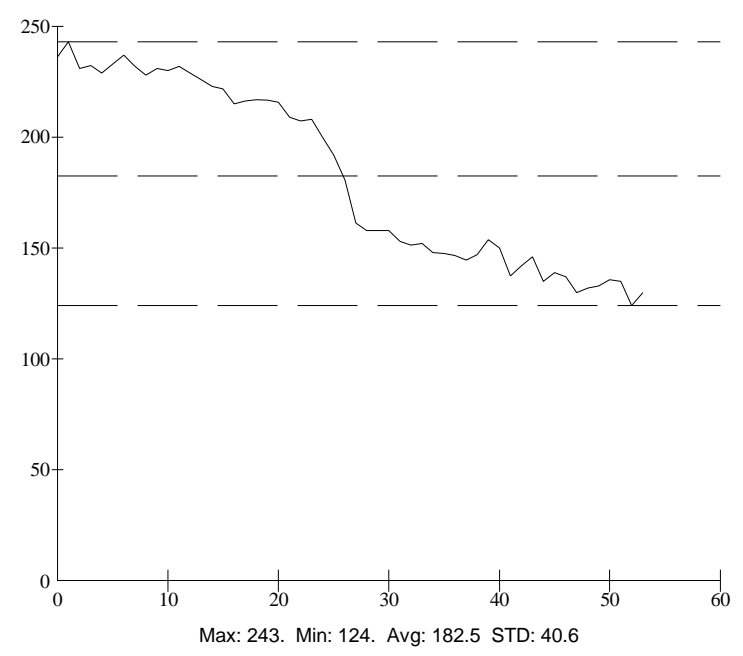

d) 9-second delay time

Figure A.89 Thermal intensity profile along the line across the fatigue crack shown in Figure A.88. 


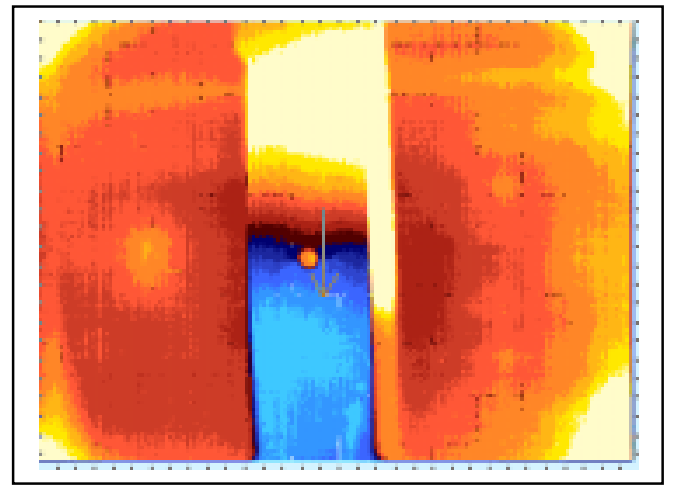

a) 1-second delay time

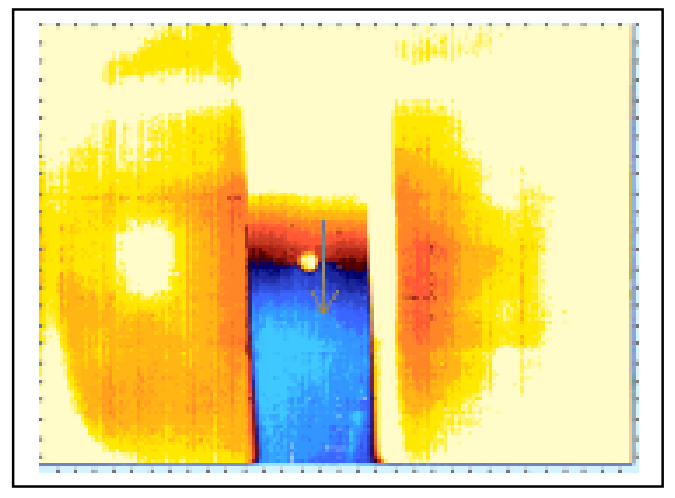

c) 6-second delay time

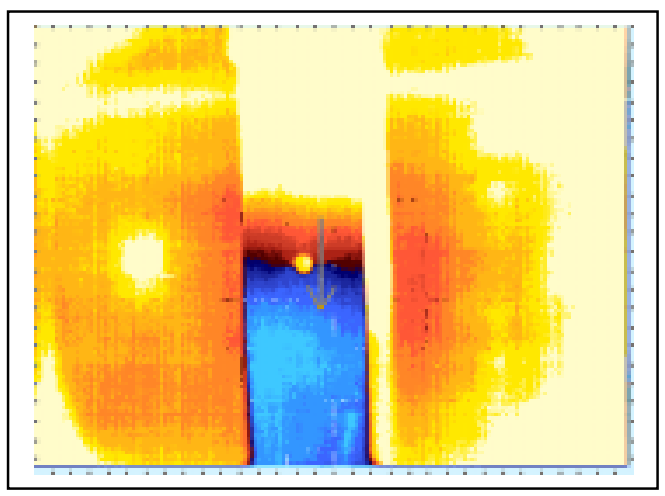

b) 3-second delay time

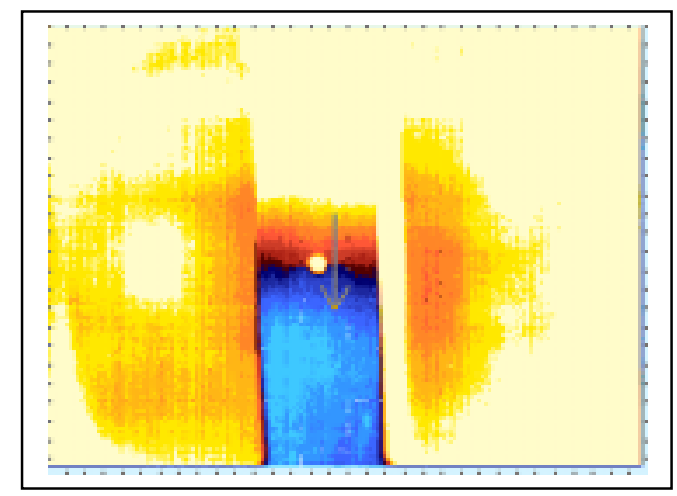

d) 9-second delay time

Figure A.90 Thermal images of unpainted Specimen CH-1 (using active approach and heating time is 30 seconds). The distance between IR camera and specimen is $600 \mathrm{~mm}$. 


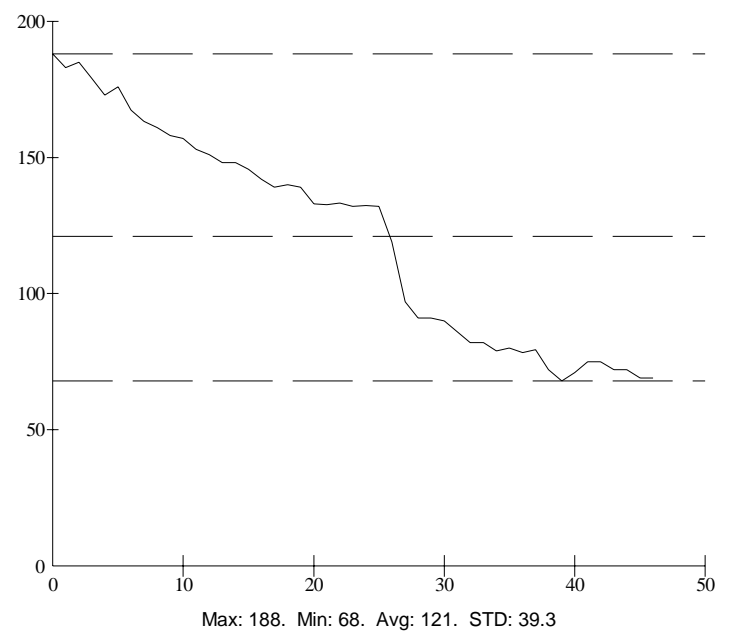

a) 1-second delay time

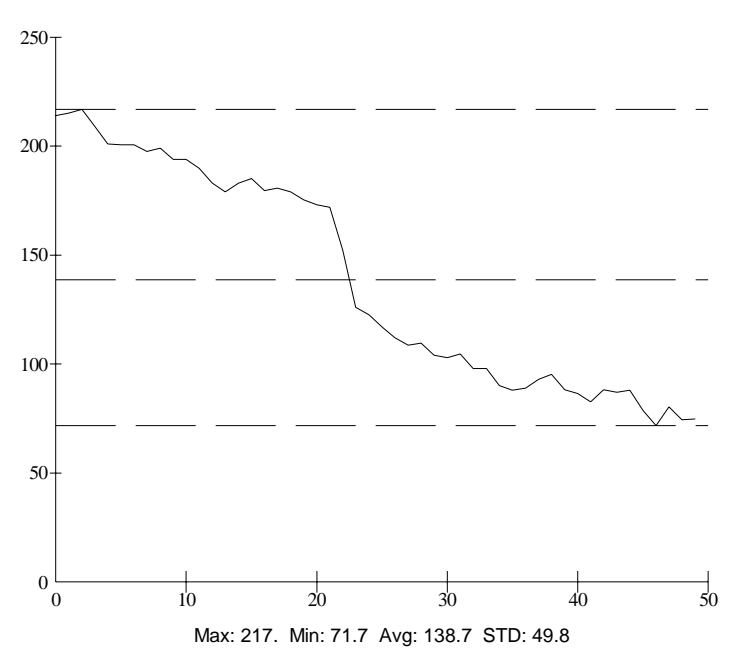

c) 6-second delay time

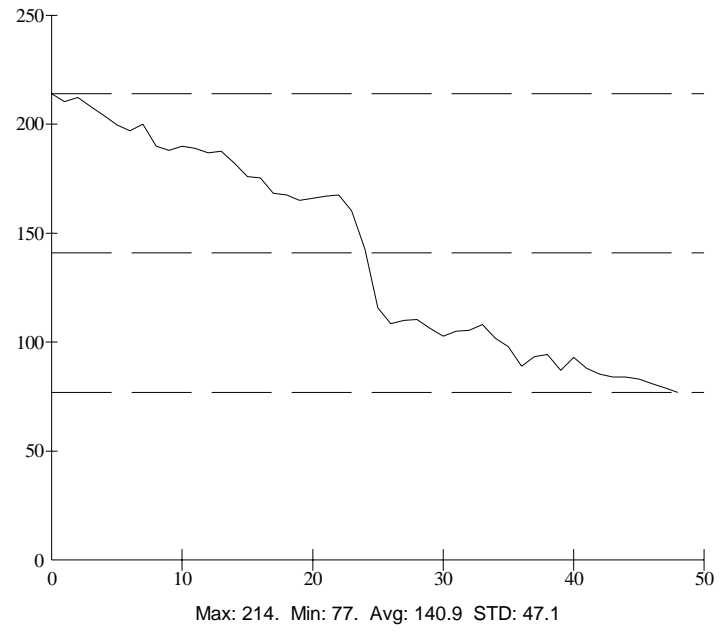

b) 3-second delay time

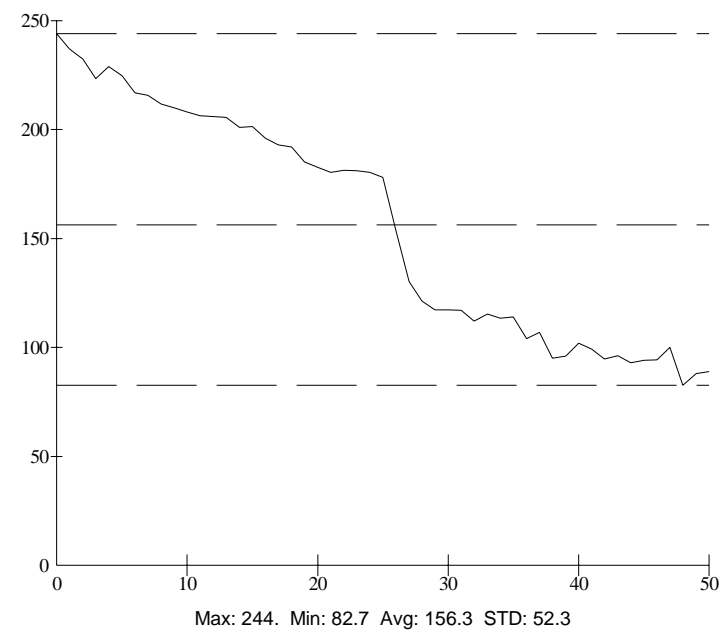

d) 9-second delay time

Figure A.91 Thermal intensity profile along the line across the fatigue crack shown in Figure A.90. 


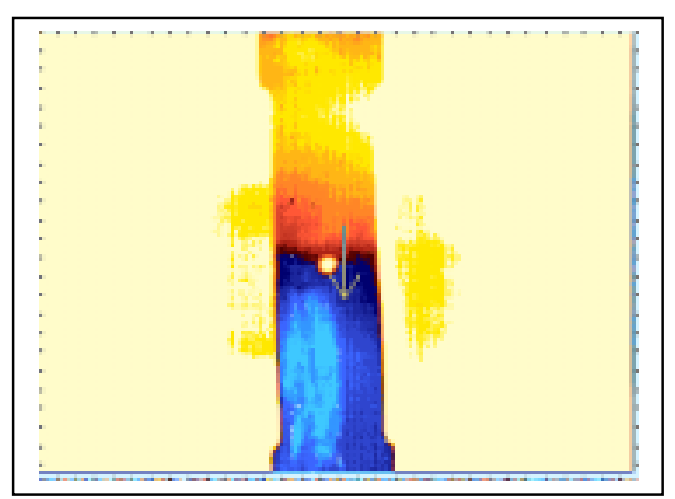

a) 1-second delay time

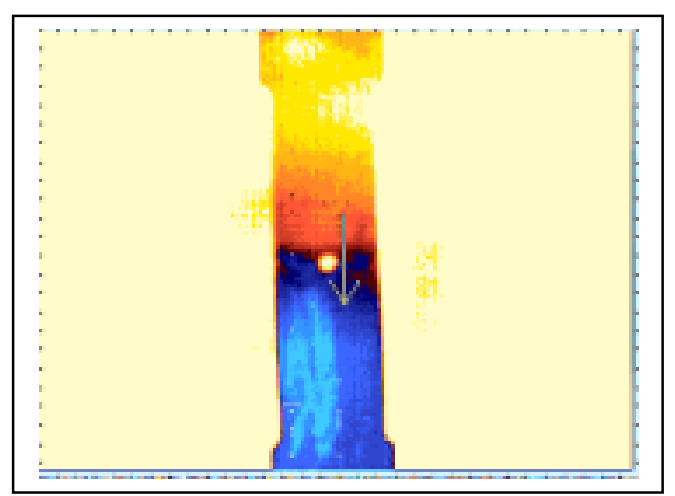

c) 6-second delay time

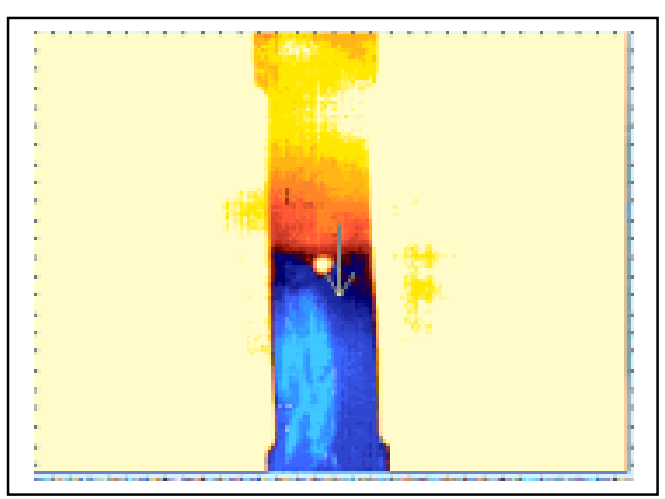

b) 3-second delay time

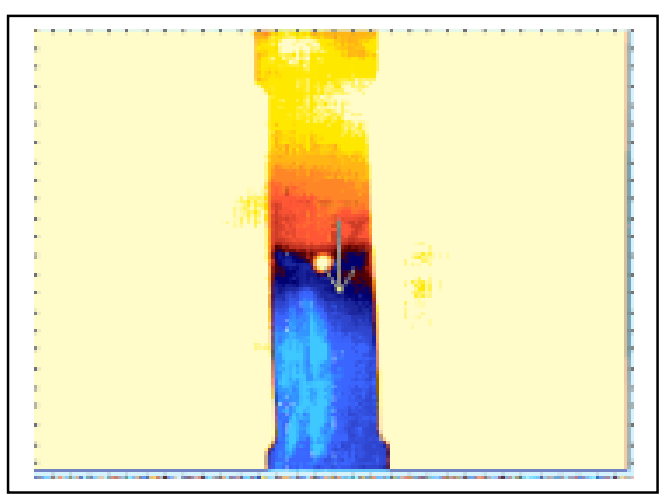

d) 9-second delay time

Figure A.92 Thermal images of unpainted Specimen CH-1 (using active approach and heating time is 30 seconds). The distance between IR camera and specimen is $675 \mathrm{~mm}$.. 


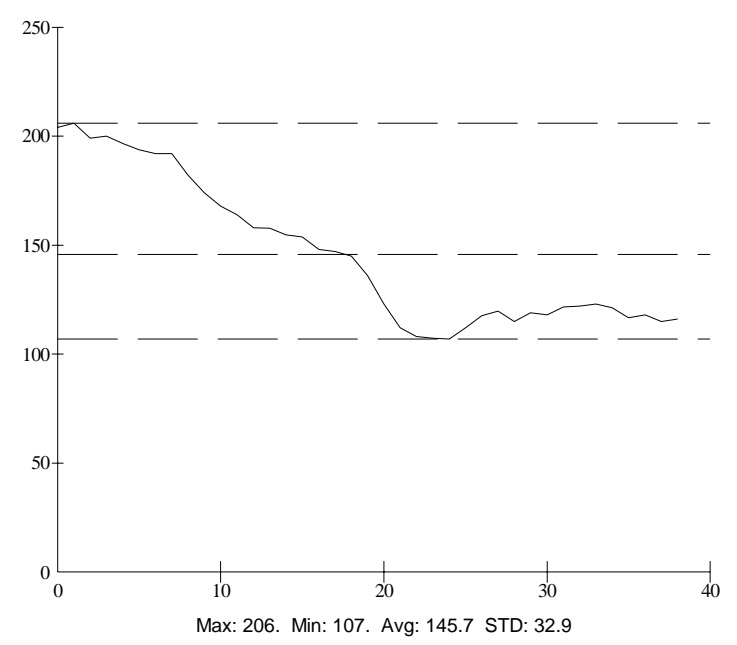

a) 1-second delay time

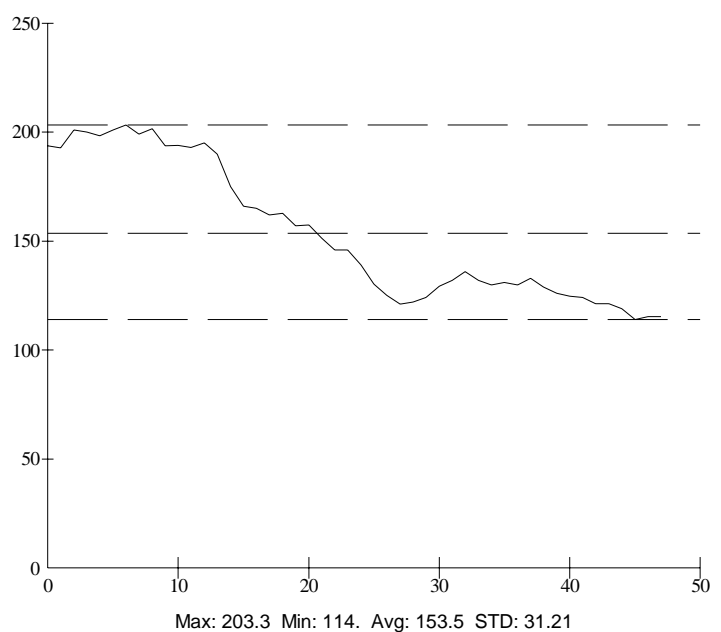

c) 6-second delay time

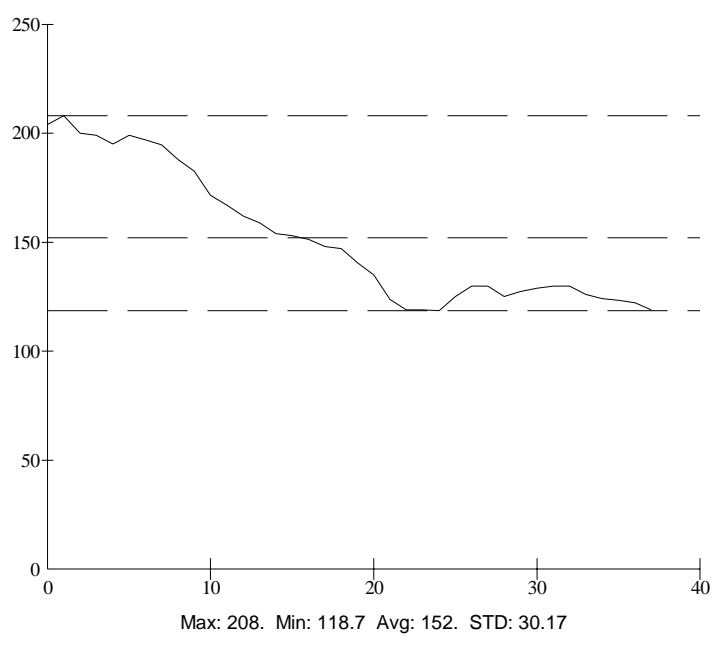

b) 3-second delay time

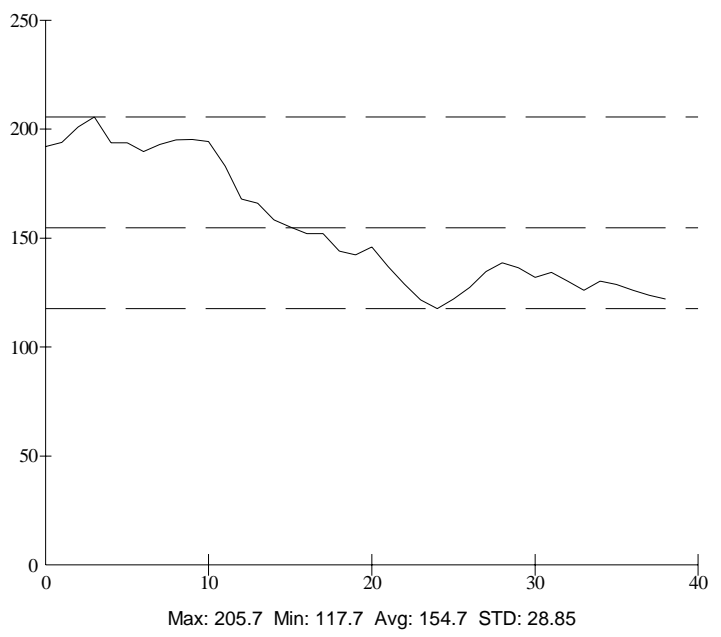

d) 9-second delay time

Figure A.93 Thermal intensity profile along the line across the fatigue crack shown in Figure A.92. 


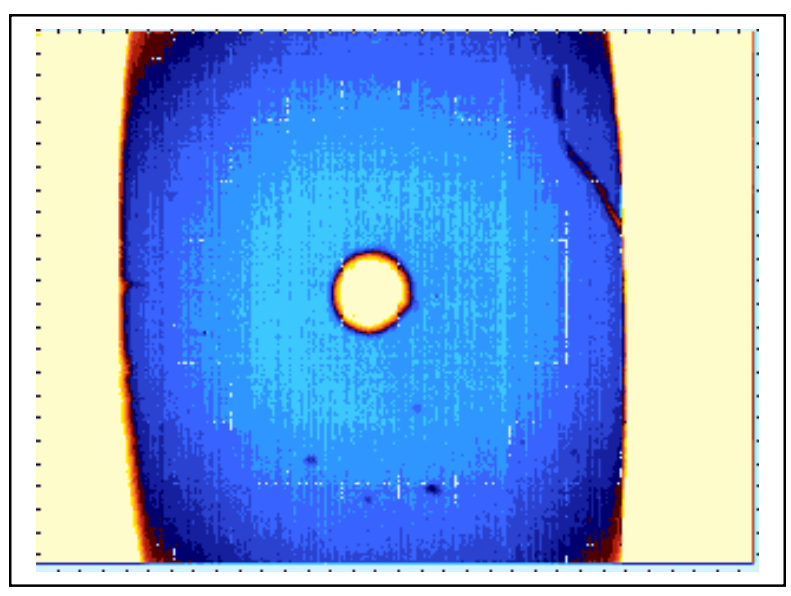

Figure A.94 Thermal images of Specimen $\mathrm{CH}-1$ (no applied stress or heat). The distance between IR camera and specimen is $150 \mathrm{~mm}$. 


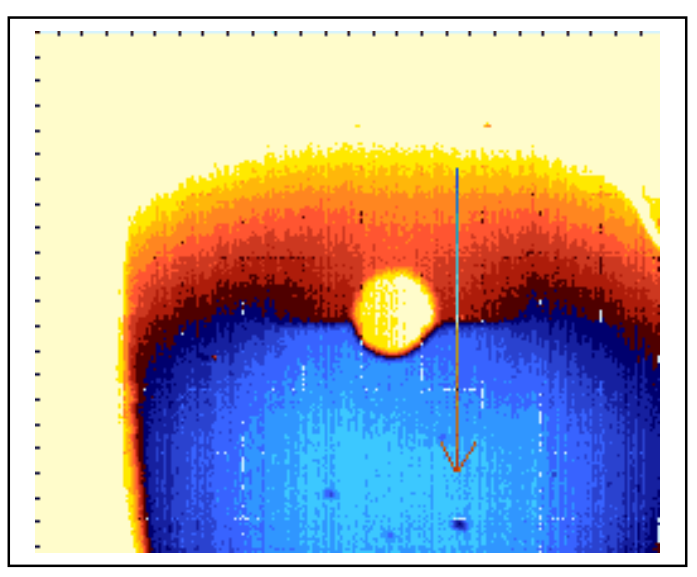

a) 1-second delay time

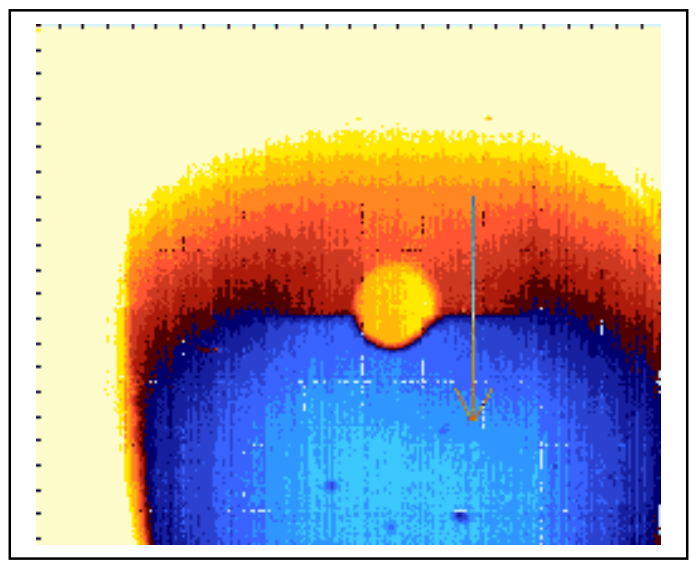

c) 6-second delay time

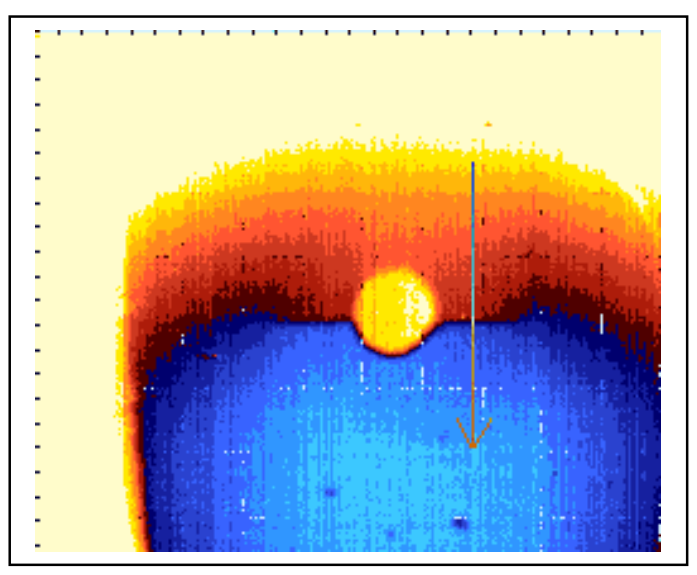

b) 3-second delay time

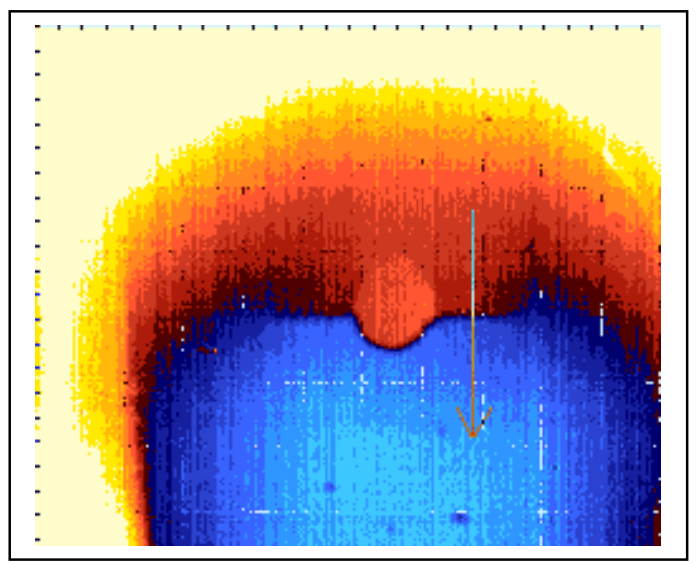

d) 9-second delay time

Figure A.95 Thermal images of Specimen $\mathrm{CH}-1$ (using active approach and heating time is 30 seconds). The distance between IR camera and specimen is $150 \mathrm{~mm}$.. 


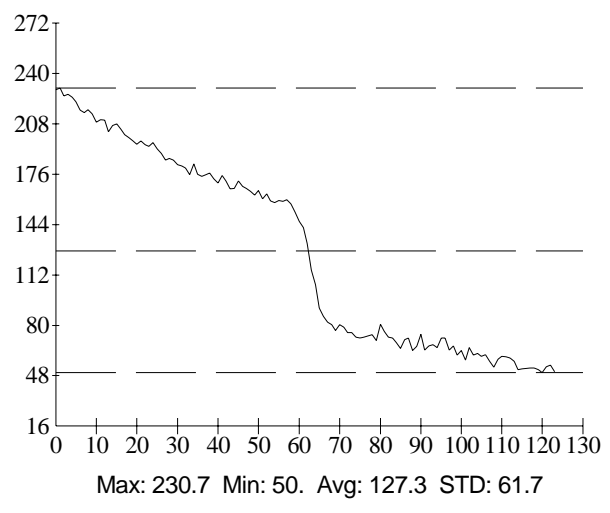

a) 1-second delay time

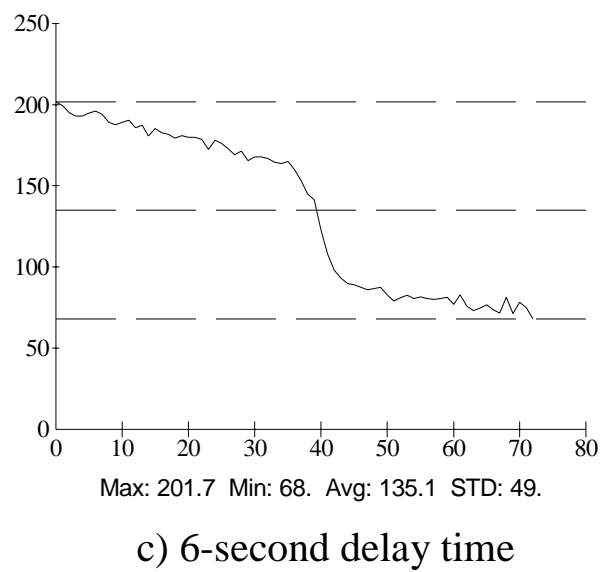

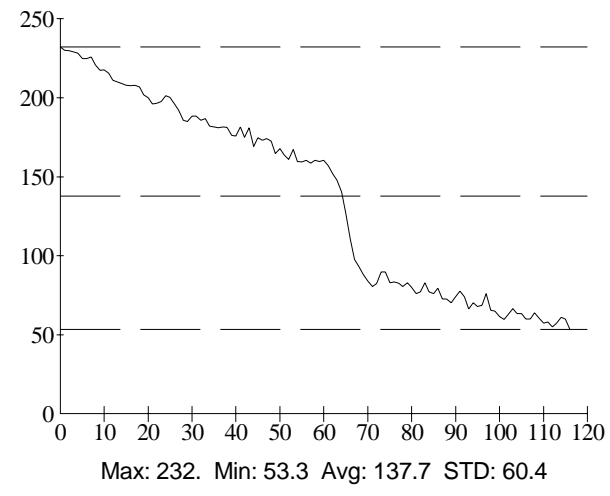

b) 3-second delay time

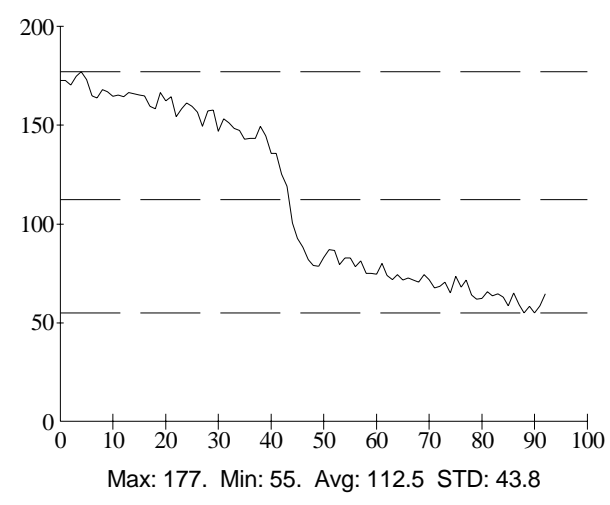

d) 9-second delay time

Figure A.96 Thermal intensity profile along the line across the fatigue crack shown in Figure A.95. 


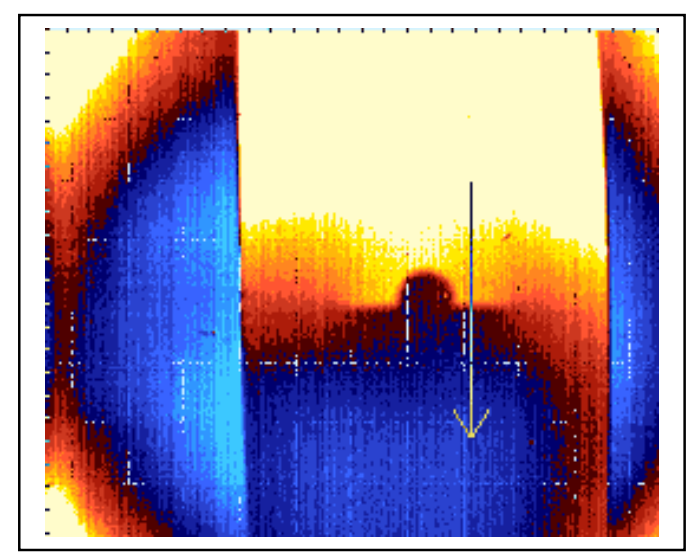

a) 1-second delay time

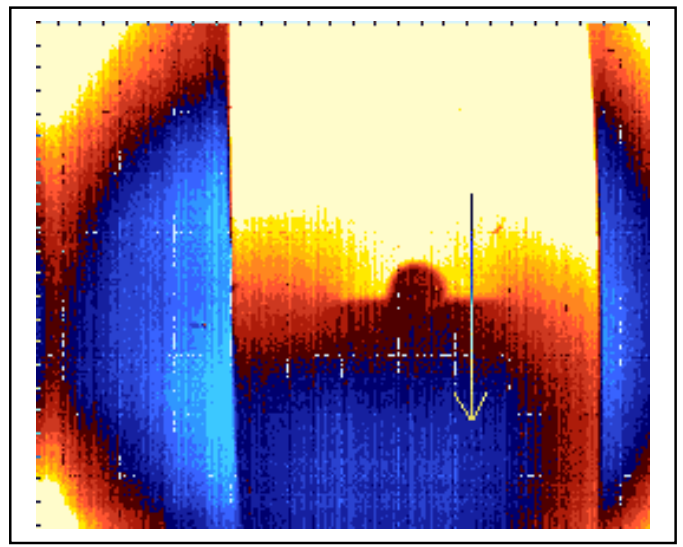

c) 6-second delay time

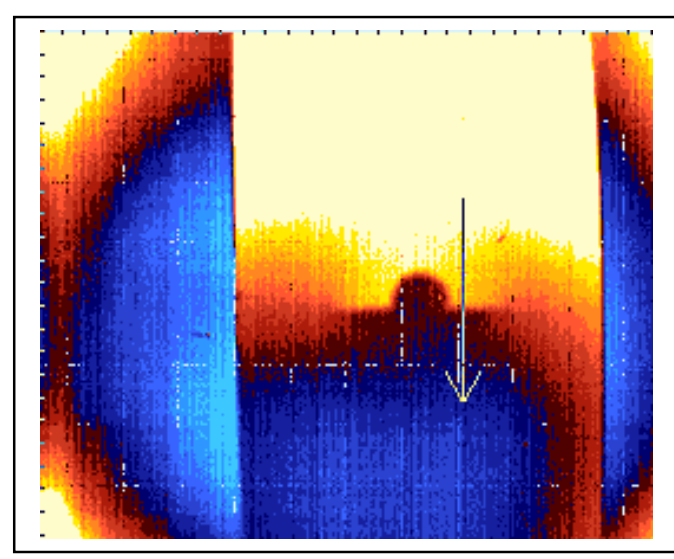

b) 3-second delay time

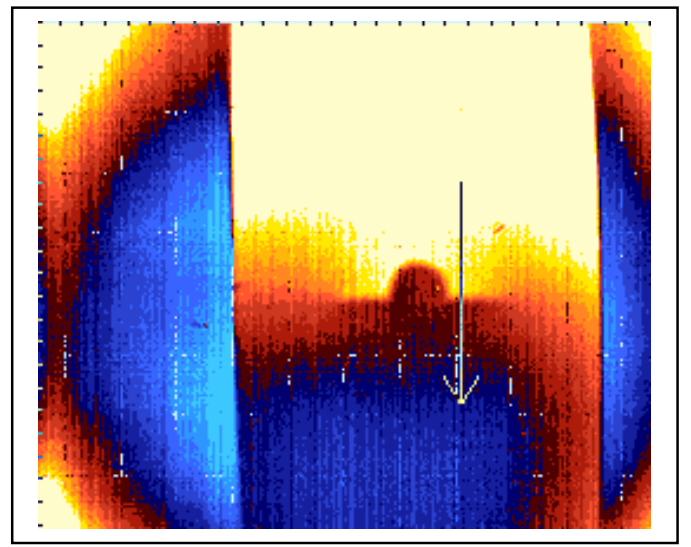

d) 9-second delay time

Figure A.97 Thermal images of Specimen 1 (using active approach and heating time is 30 seconds). The distance between IR camera and specimen is $225 \mathrm{~mm}$.. 


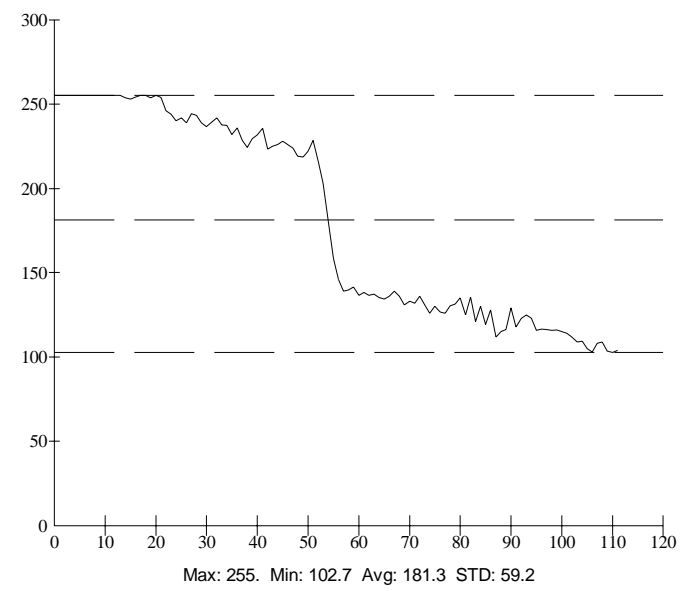

a) 1-second delay time

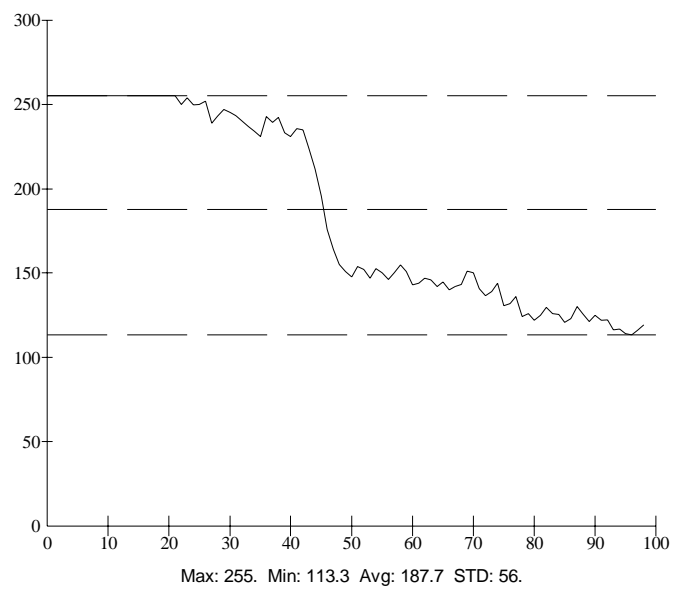

c) 6-second delay time

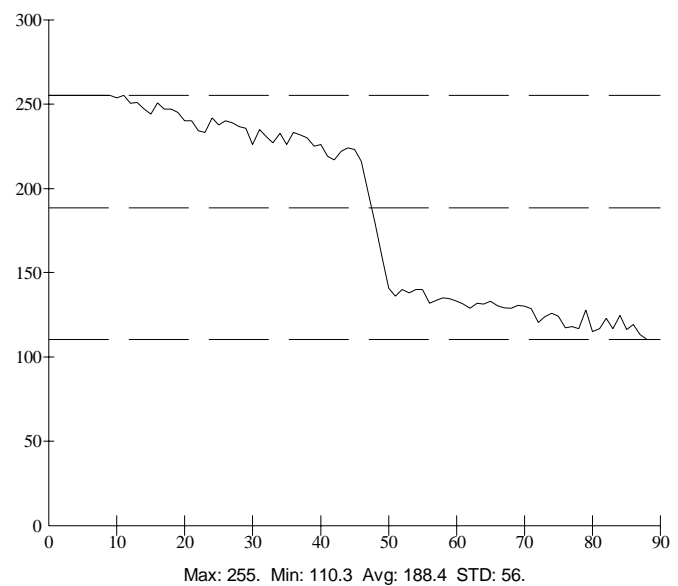

b) 3-second delay time

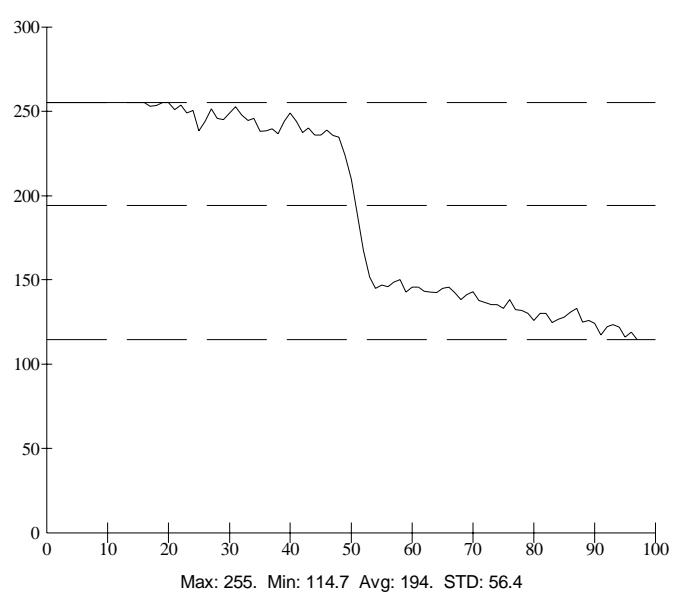

d) 9-second delay time

Figure A.98 Thermal intensity profile along the line across the fatigue crack shown in Figure A.97. 


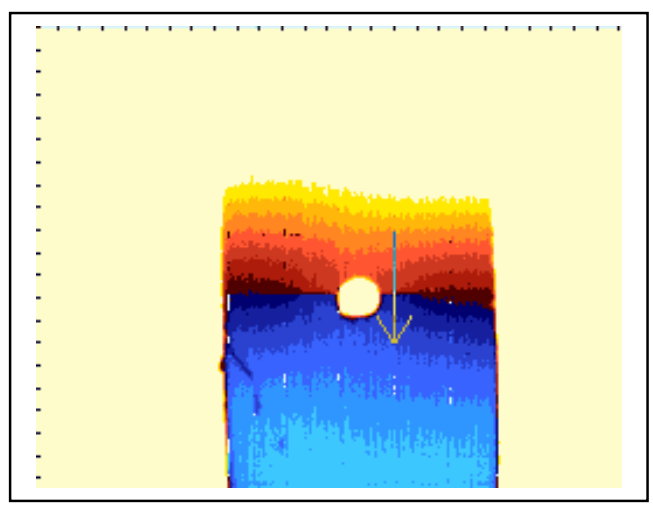

a) 1-second delay time

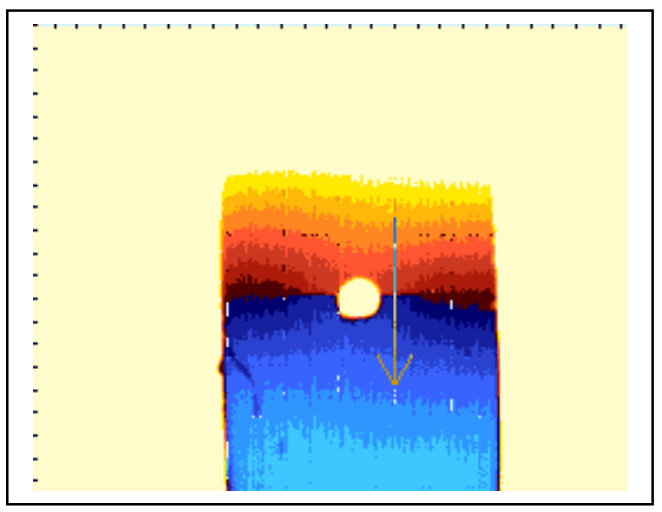

c) 6-second delay time

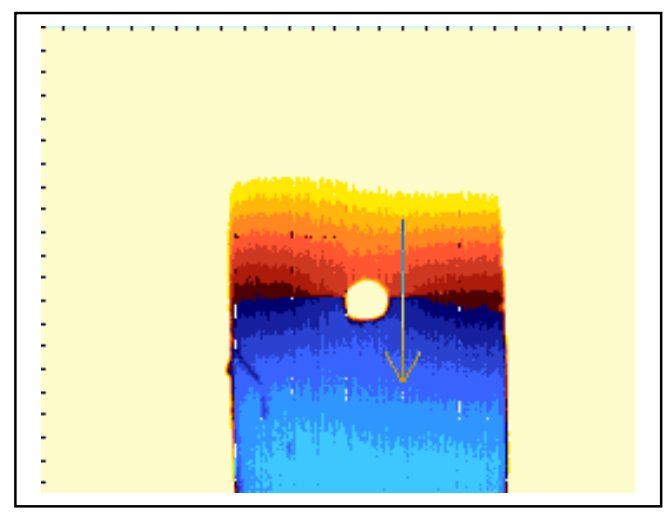

b) 3-second delay time

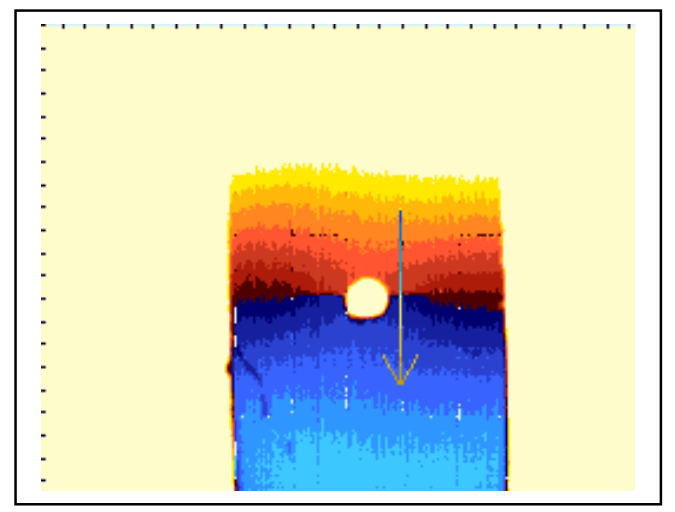

d) 9-second delay time

Figure A.99 Thermal images of Specimen CH-1 (using active approach and heating time is 30 seconds). The distance between IR camera and specimen is $300 \mathrm{~mm}$. . 


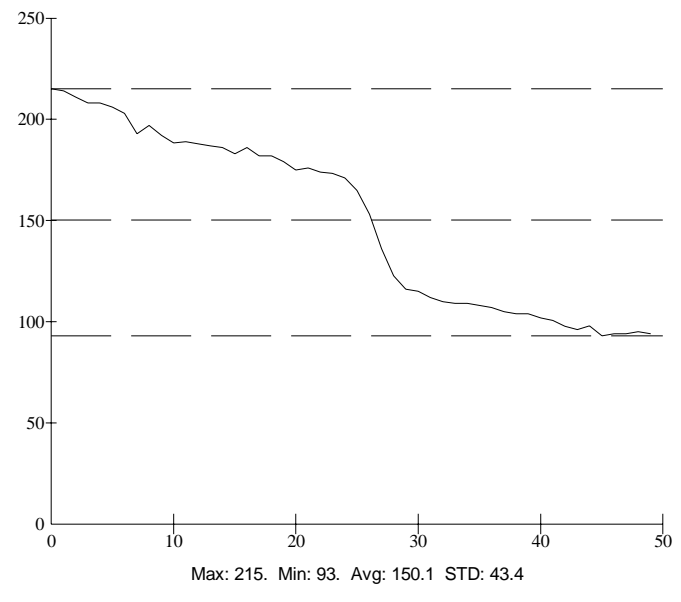

a) 1-second delay time

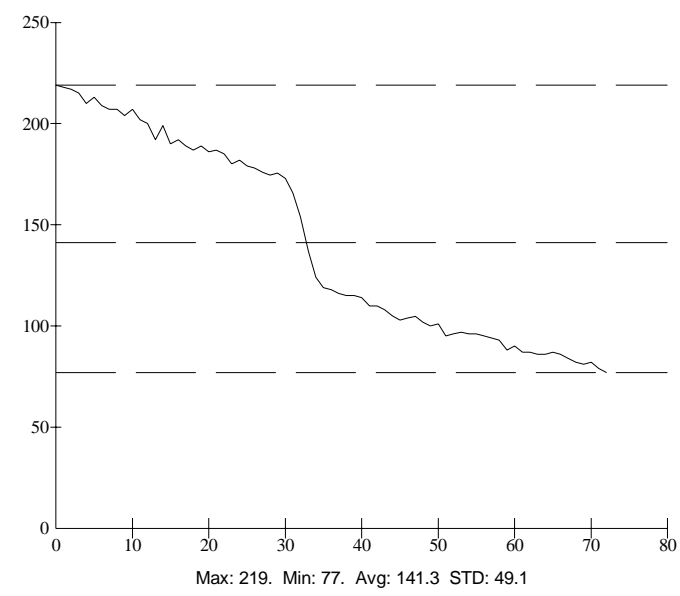

c) 6-second delay time

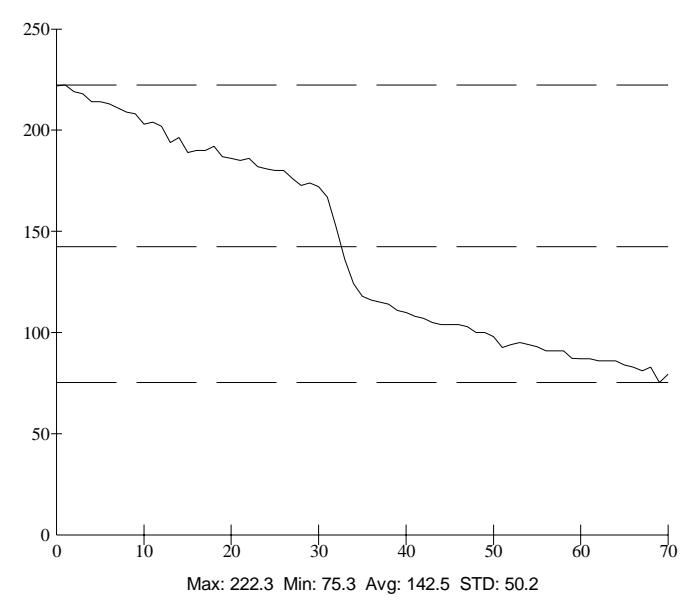

b) 3-second delay time

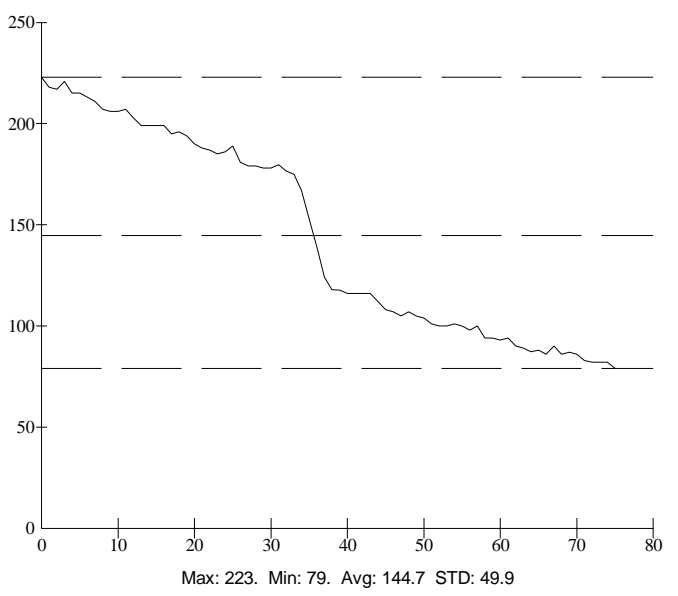

d) 9-second delay time

Figure A.100 Thermal intensity profile along the line across the fatigue crack shown in Figure A.99. 


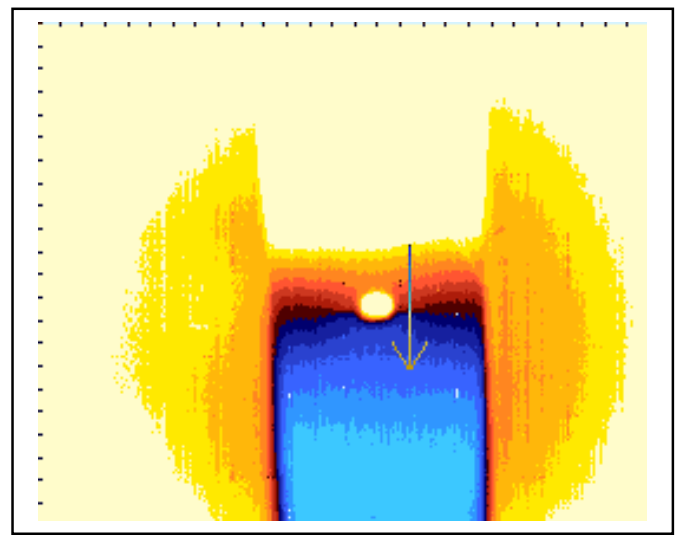

a) 1-second delay time

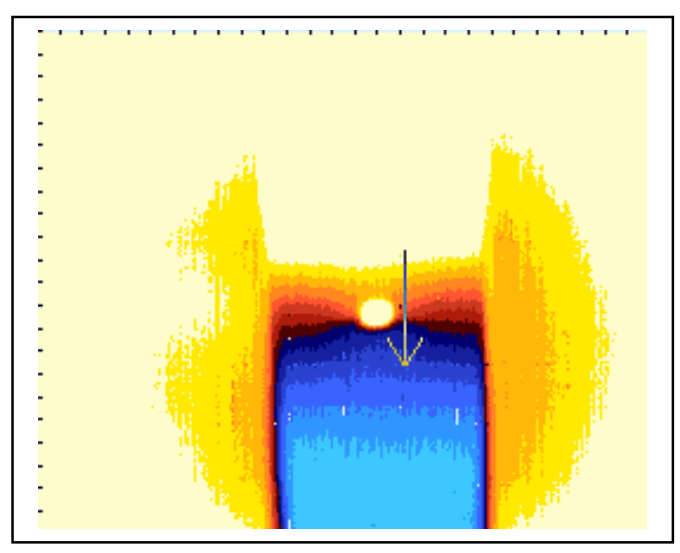

c) 6-second delay time

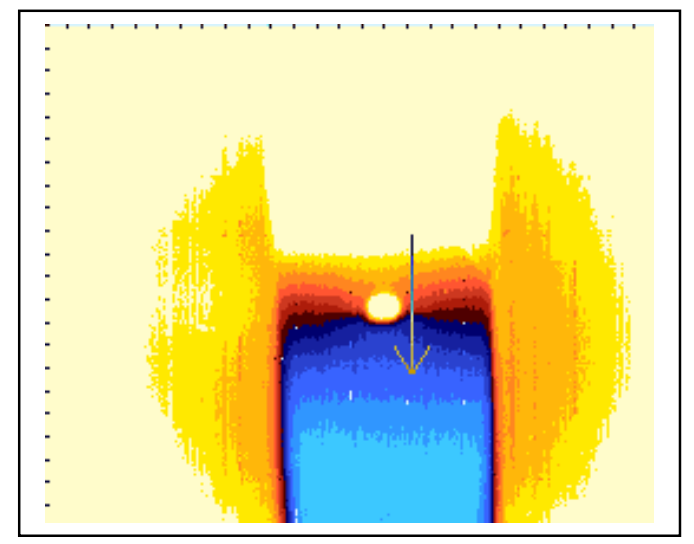

b) 3-second delay time

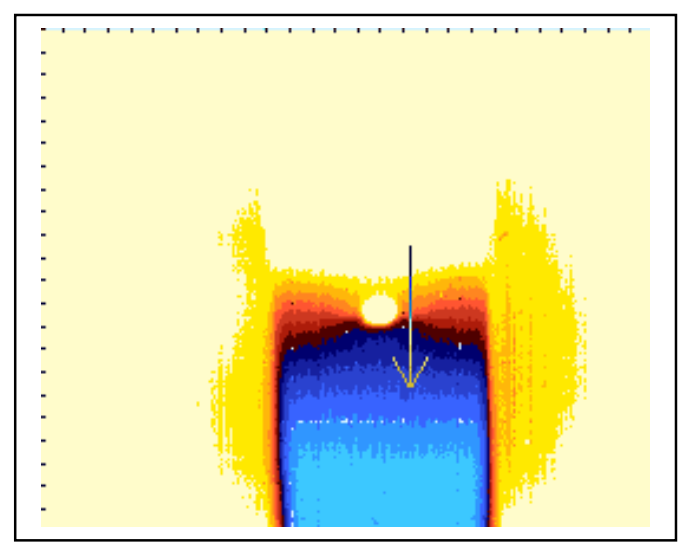

d) 9-second delay time

Figure A.101 Thermal images of Specimen CH-1 (using active approach and heating time is 30 seconds). The distance between IR camera and specimen is 375 mm.. 


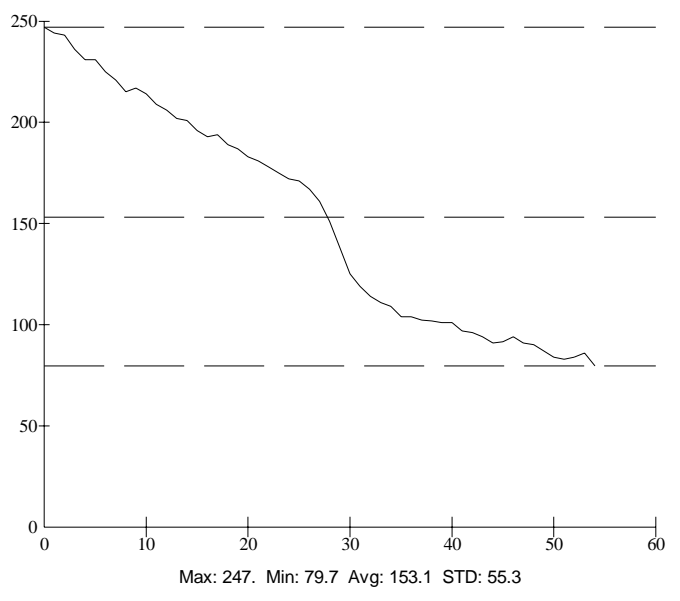

a) 1-second delay time

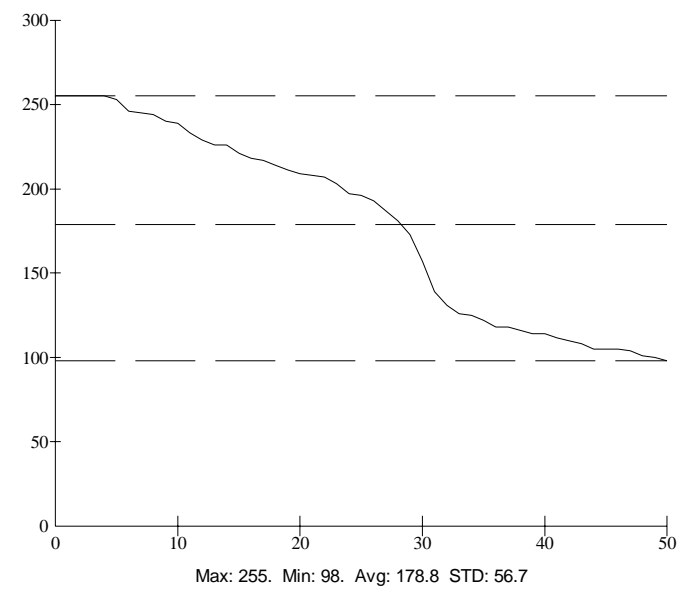

c) 6-second delay time

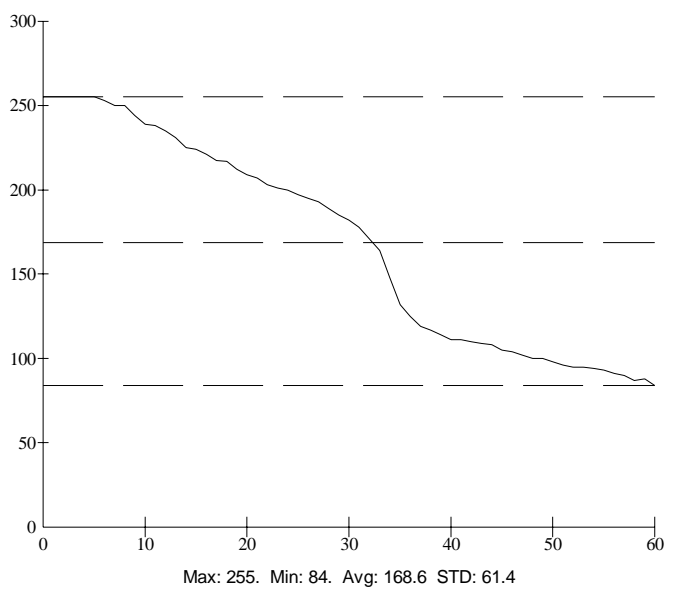

b) 3-second delay time

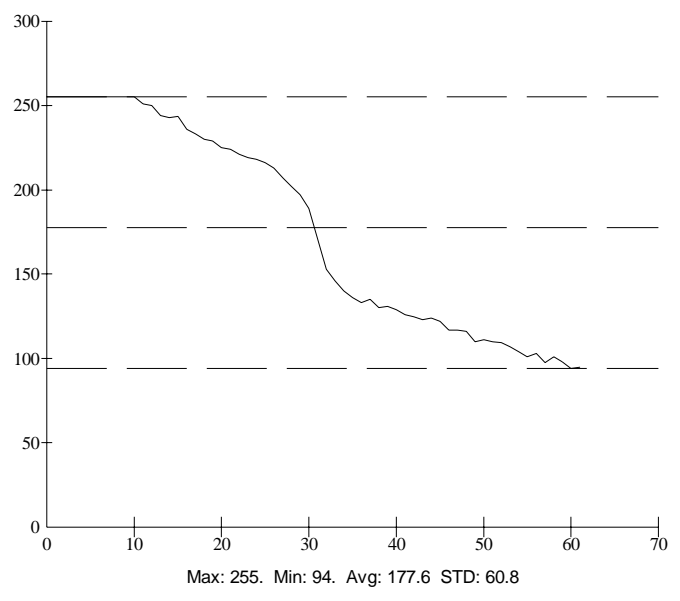

d) 9-second delay time

Figure A.102 Thermal intensity profile along the line across the fatigue crack shown in Figure A.101. 


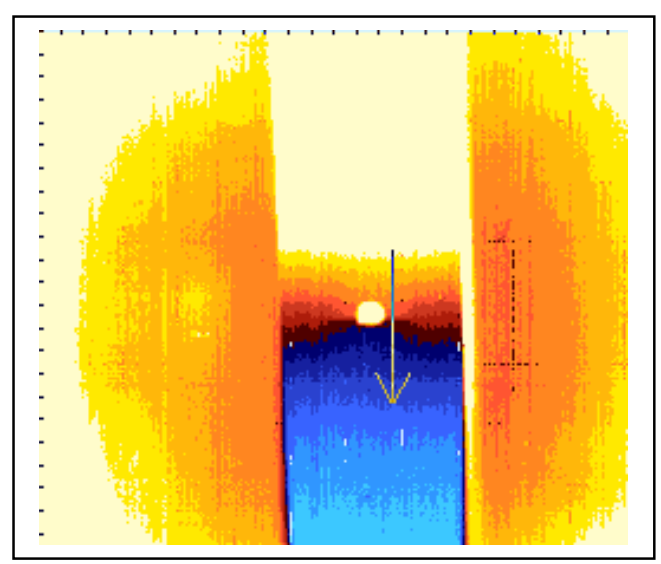

a) 1-second delay time

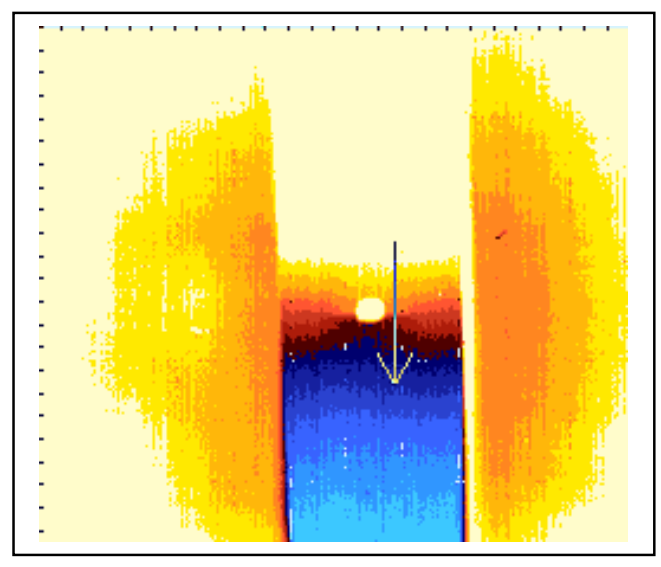

c) 6-second delay time

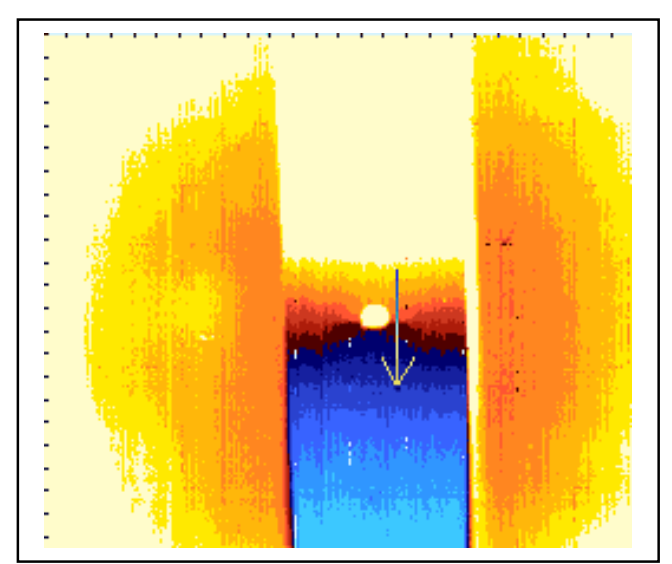

b) 3-second delay time

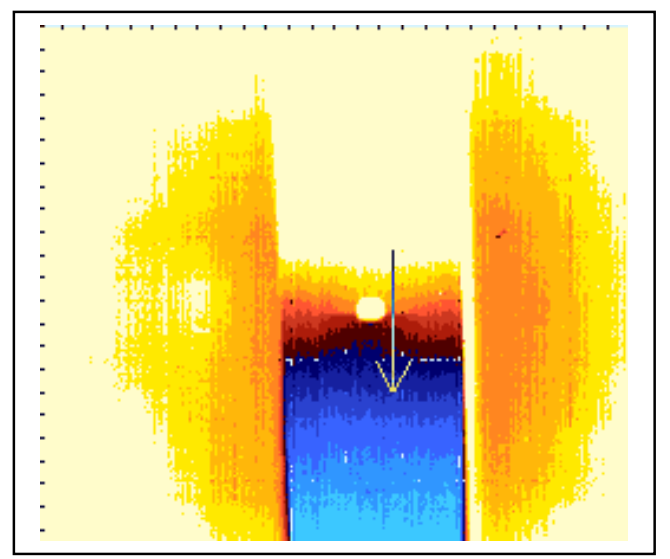

d) 9-second delay time

Figure A.103 Thermal images of Specimen CH-1 (using active approach and heating time is 30 seconds). The distance between IR camera and specimen is $450 \mathrm{~mm}$. 


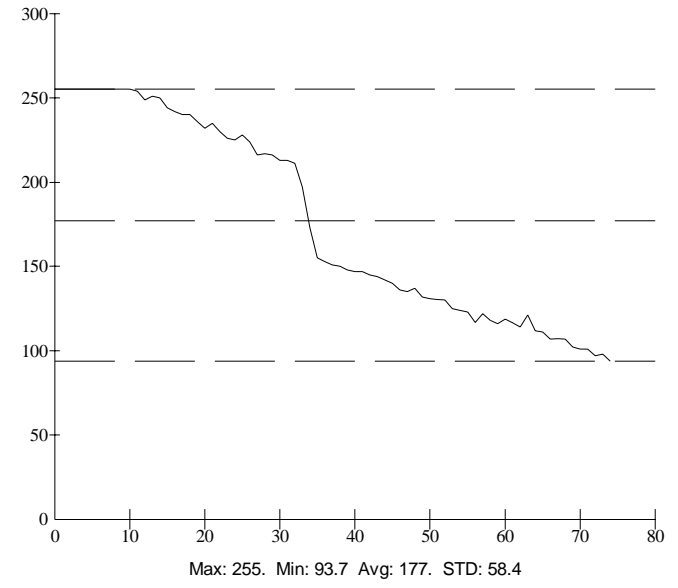

a) 1-second delay time

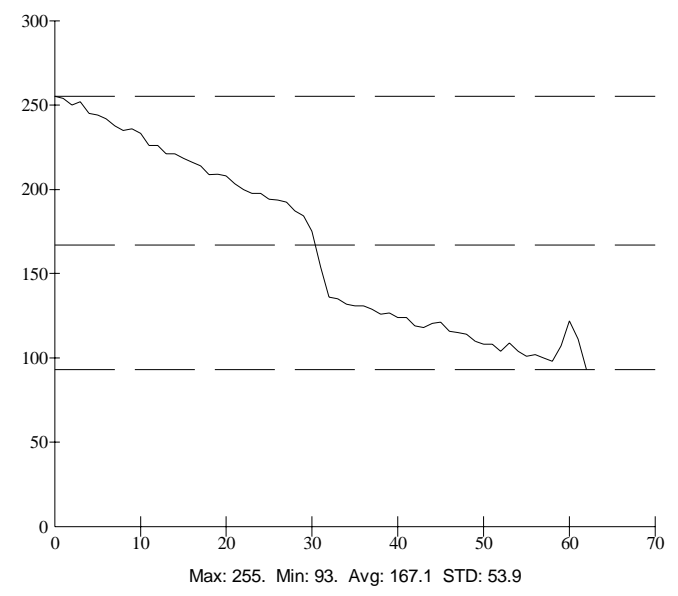

c) 6-second delay time

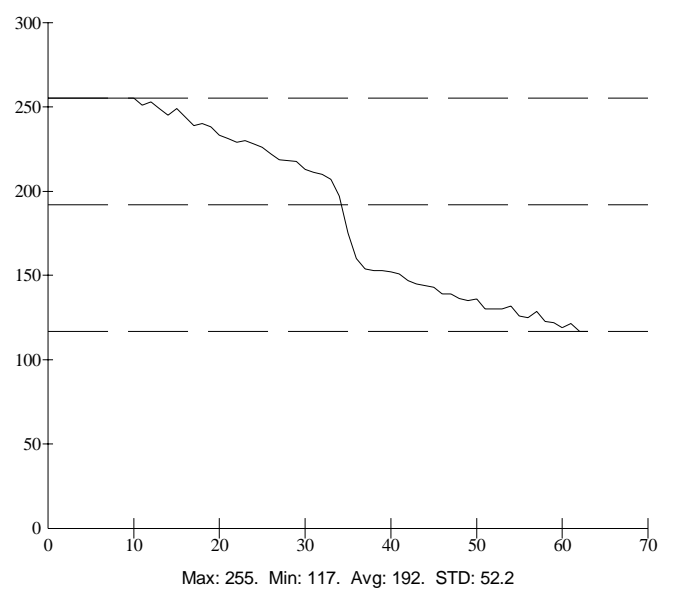

b) 3-second delay time

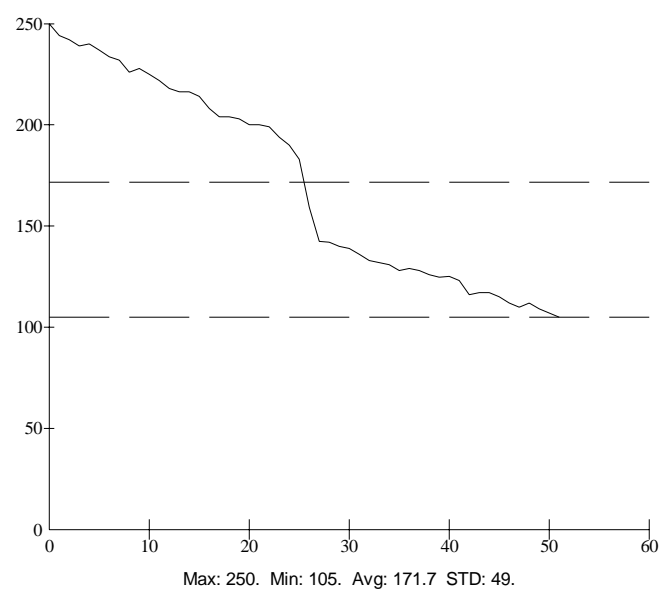

d) 9-second delay time

Figure A.104 Thermal intensity profile along the line across the fatigue crack shown in Figure A.103. 


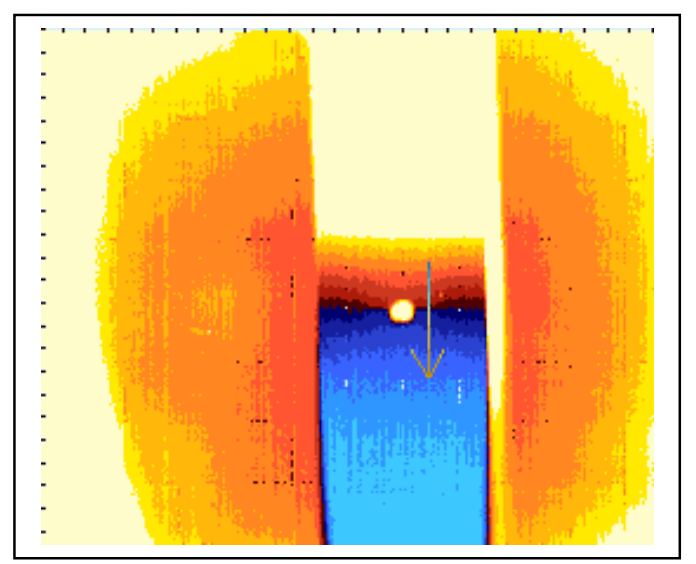

a) 1-second delay time

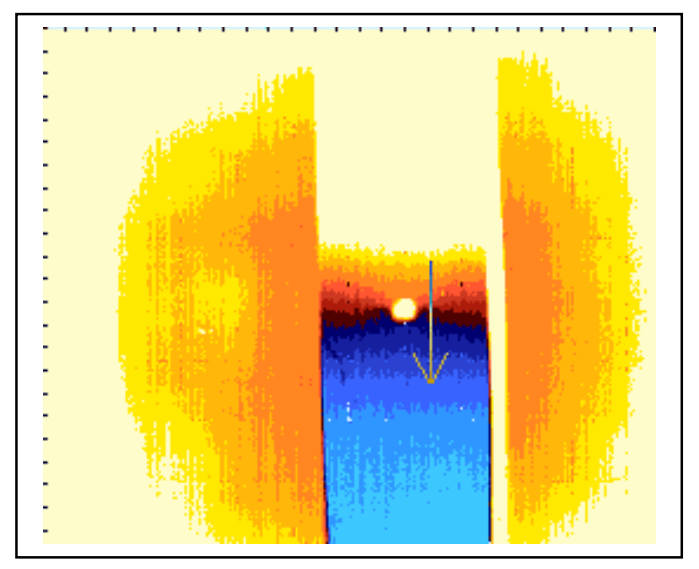

c) 6-second delay time

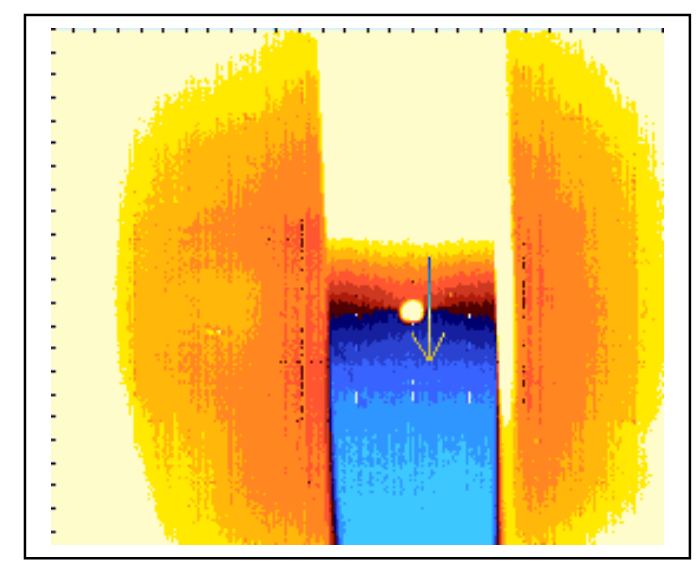

b) 3-second delay time

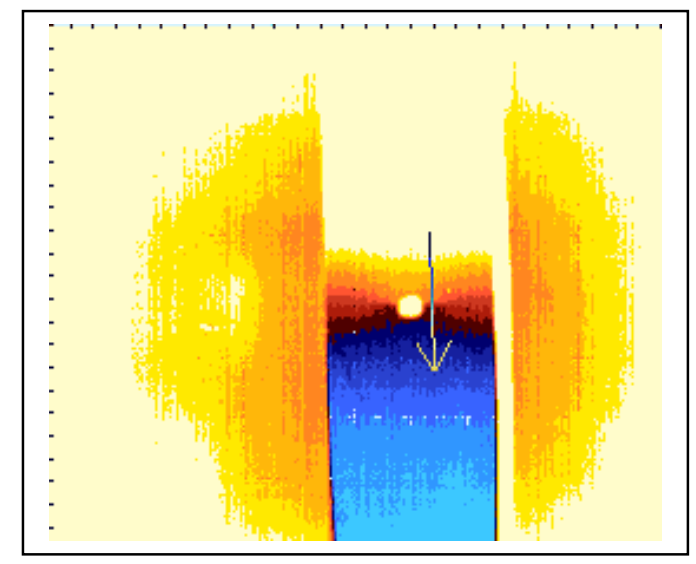

d) 9-second delay time

Figure A.105 Thermal images of Specimen CH-1 (using active approach and heating time is 30 seconds). The distance between IR camera and specimen is 525 mm.. 


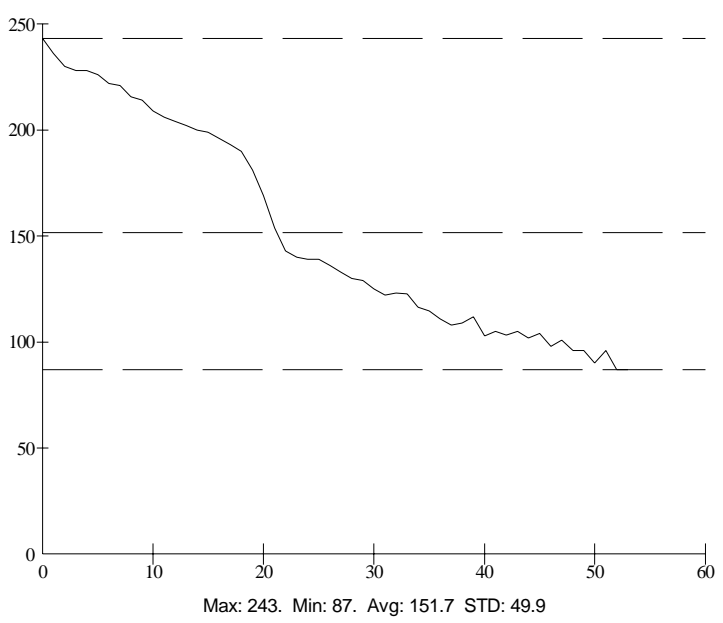

a) 1-second delay time

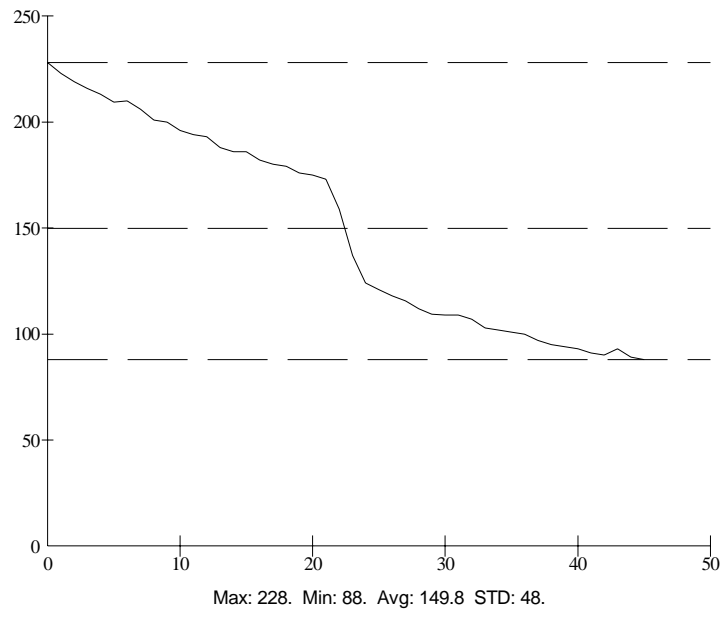

c) 6-second delay time

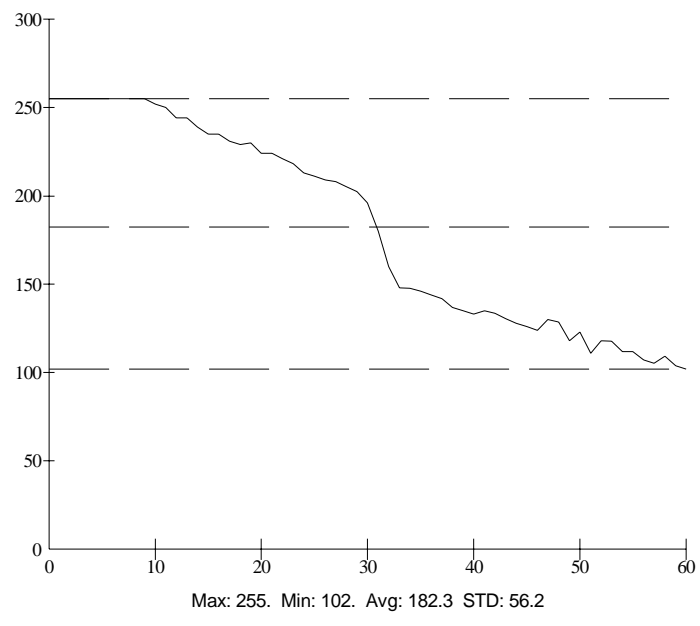

b) 3-second delay time

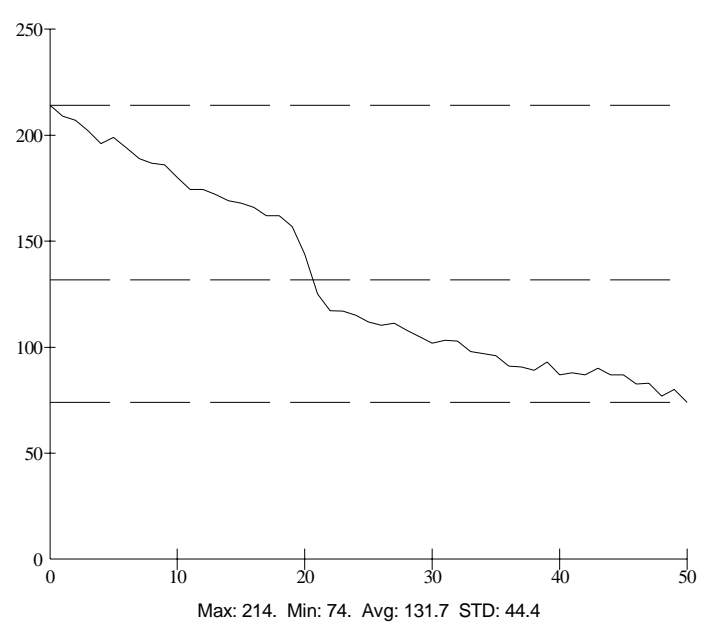

d) 9-second delay time

Figure A.106 Thermal intensity profile along the line across the fatigue crack shown in Figure A.105. 


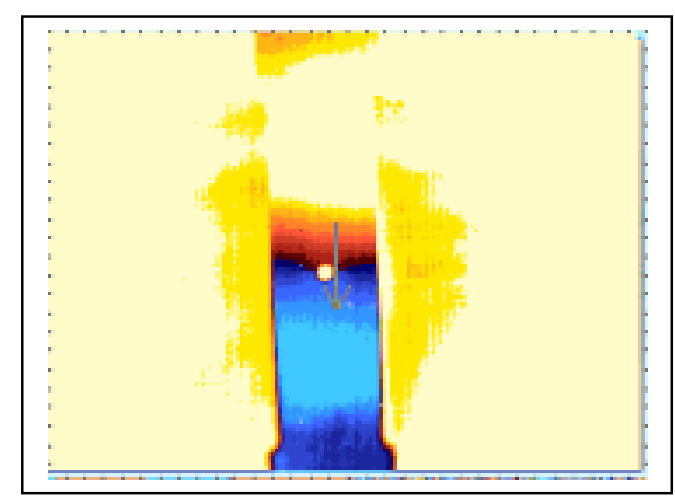

a) 1-second delay time

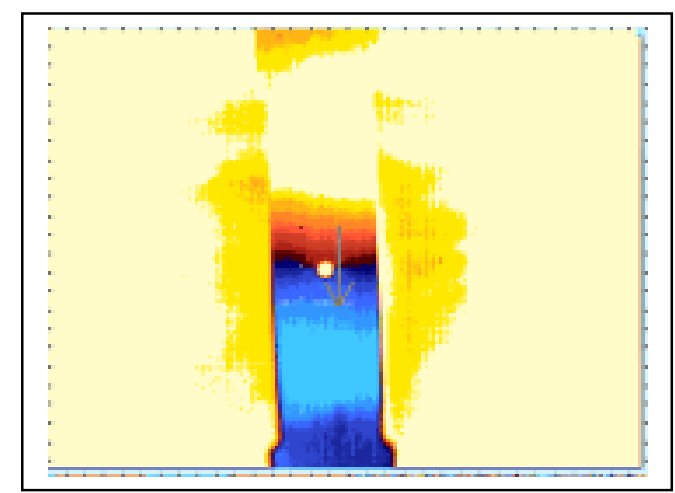

c) 6-second delay time

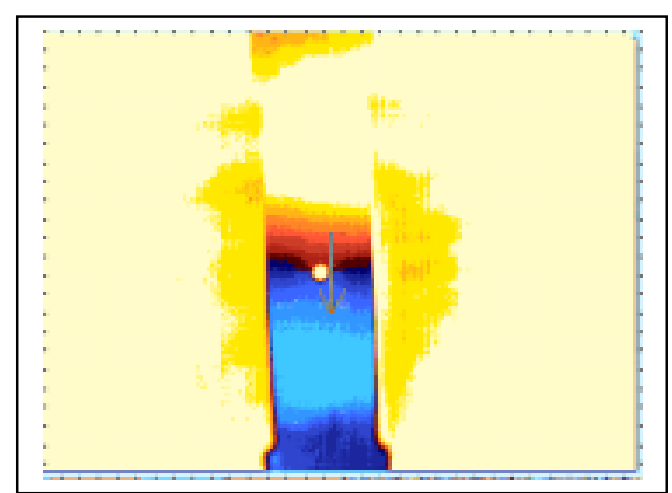

b) 3-second delay time

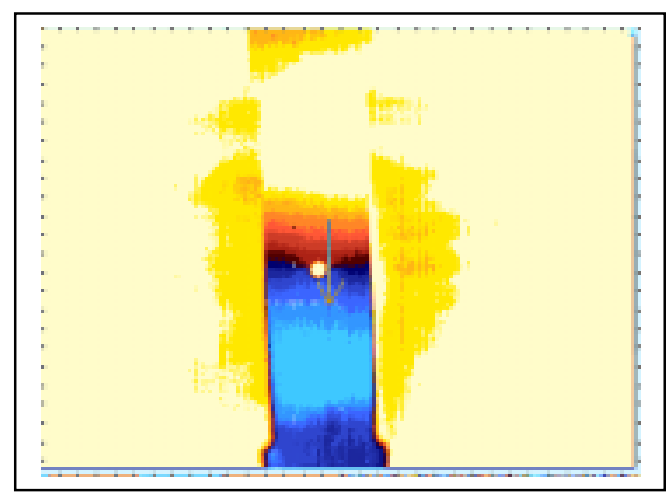

d) 9-second delay time

Figure A.107 Thermal images of Specimen $\mathrm{CH}-1$ (using active approach and heating time is 30 seconds). The distance between IR camera and specimen is 675 $\mathrm{mm}$. 


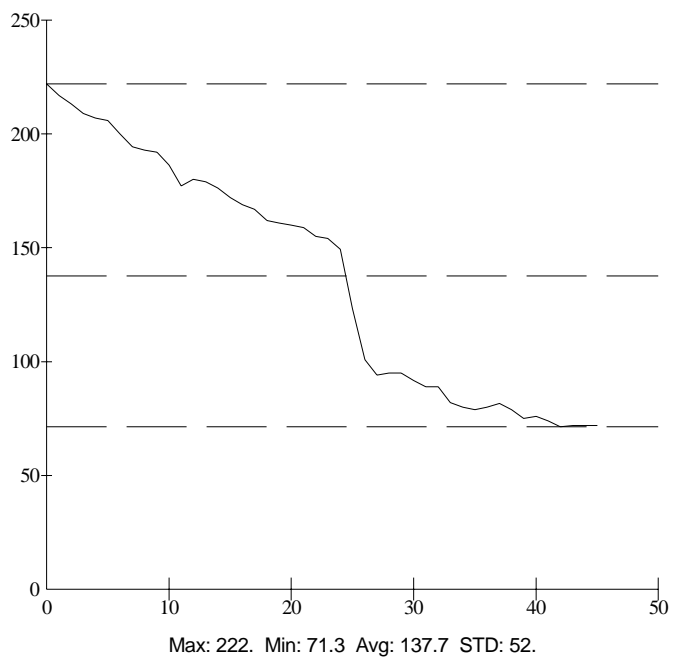

a) 1-second delay time

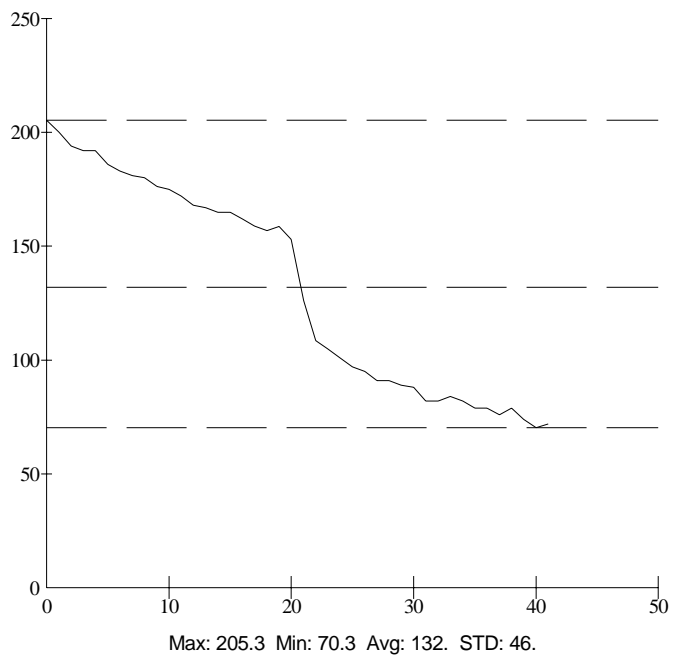

c) 6-second delay time

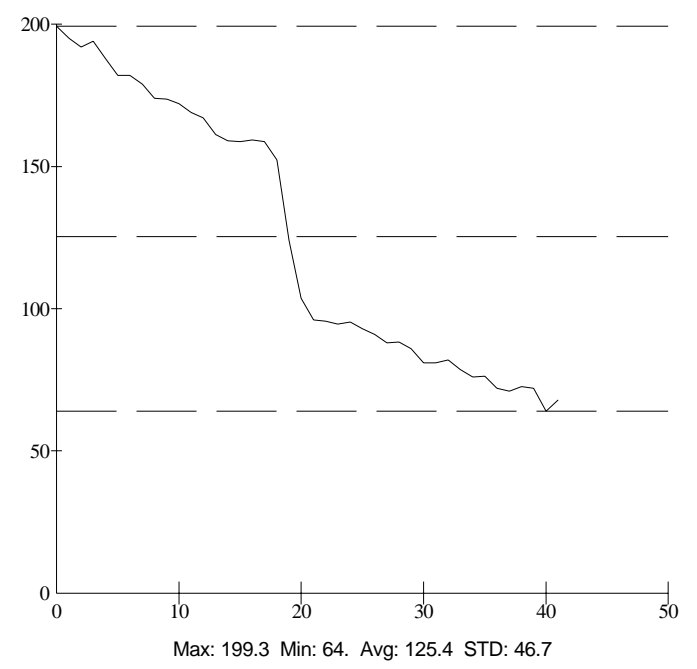

b) 3-second delay time

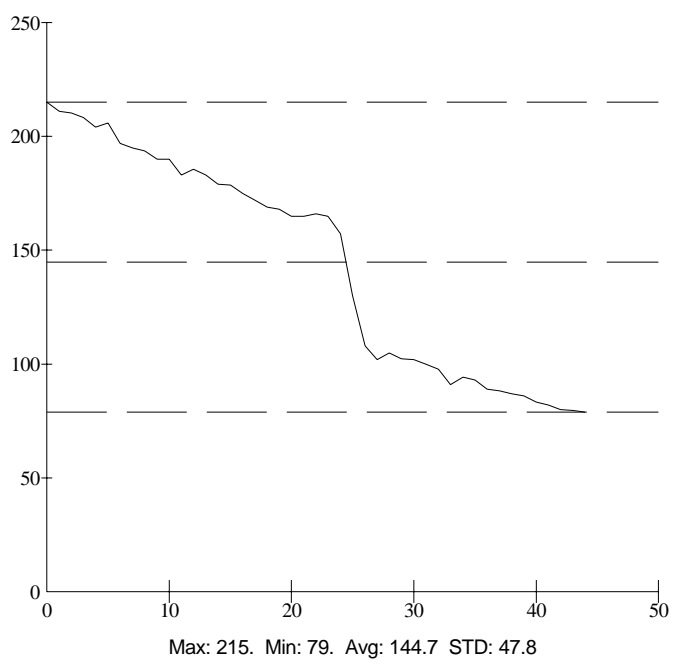

d) 9-second delay time

Figure A.108 Thermal intensity profile along the line across the fatigue crack shown in Figure A.107. 


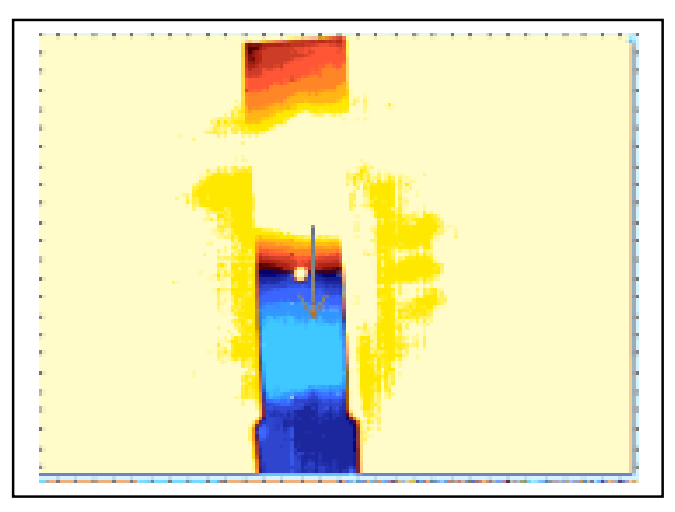

a) 1-second delay time

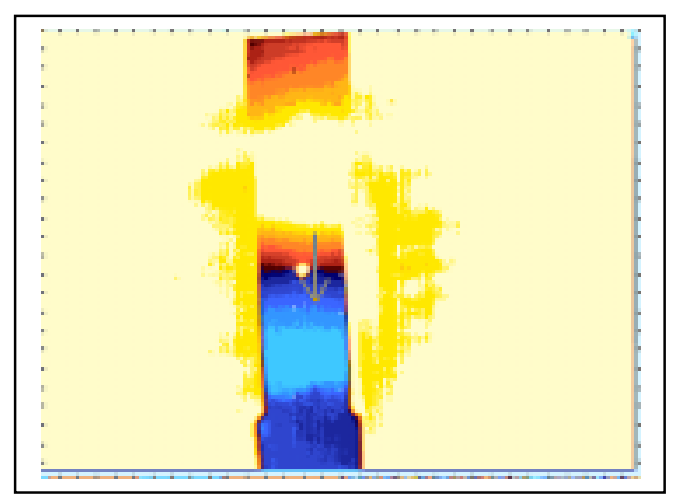

c) 6-second delay time

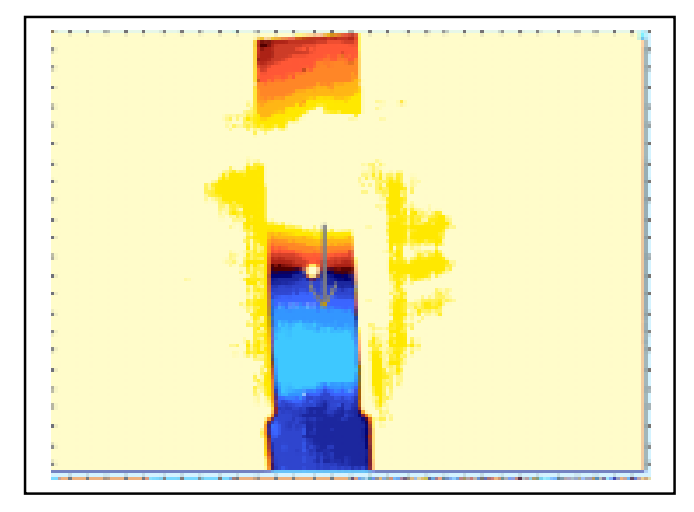

b) 3-second delay time

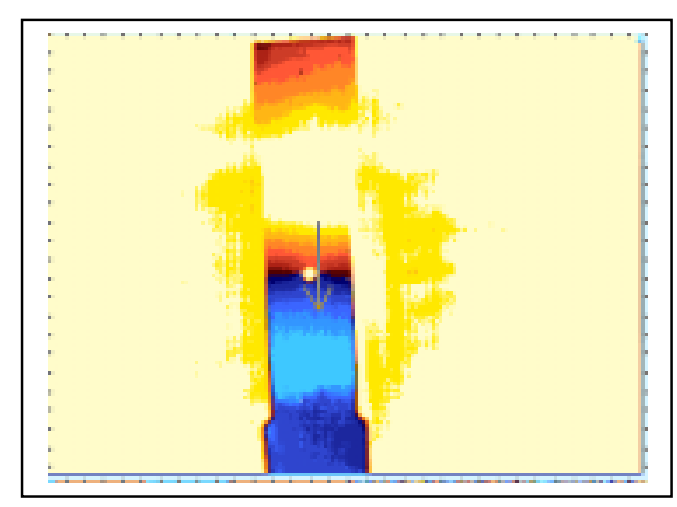

d) 9-second delay time

Figure A.109 Thermal images of Specimen CH-1 (using active approach and heating time is 30 seconds). The distance between IR camera and specimen is 825 mm.. 


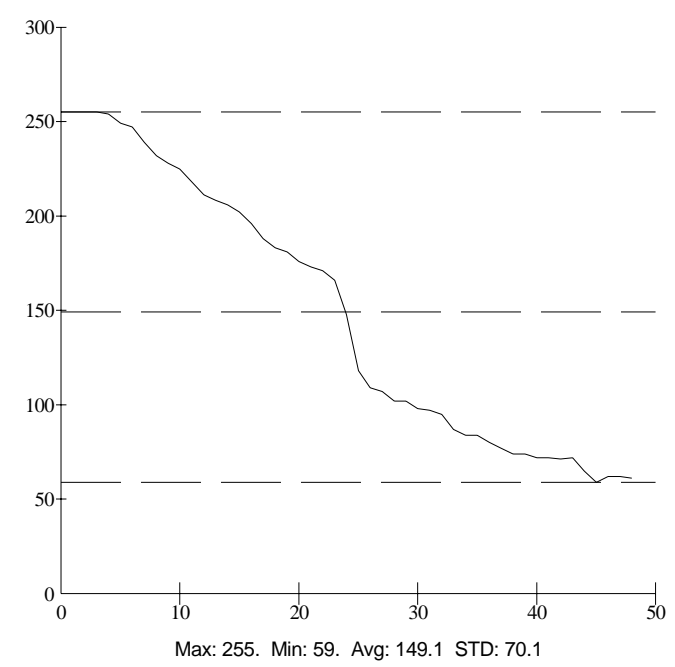

a) 1-second delay time

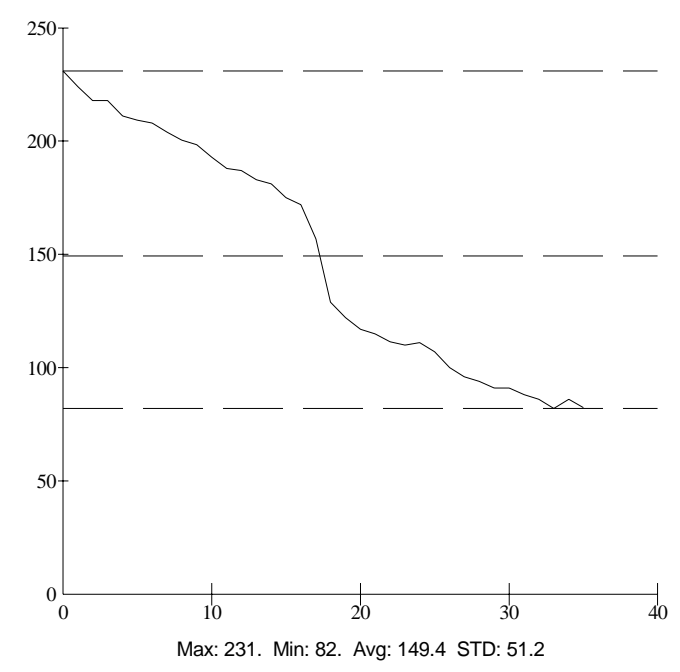

c) 6-second delay time

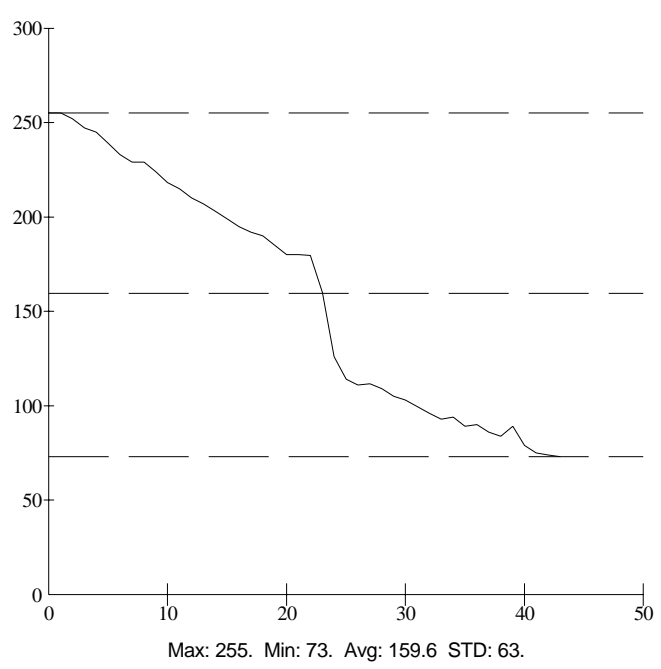

b) 3-second delay time

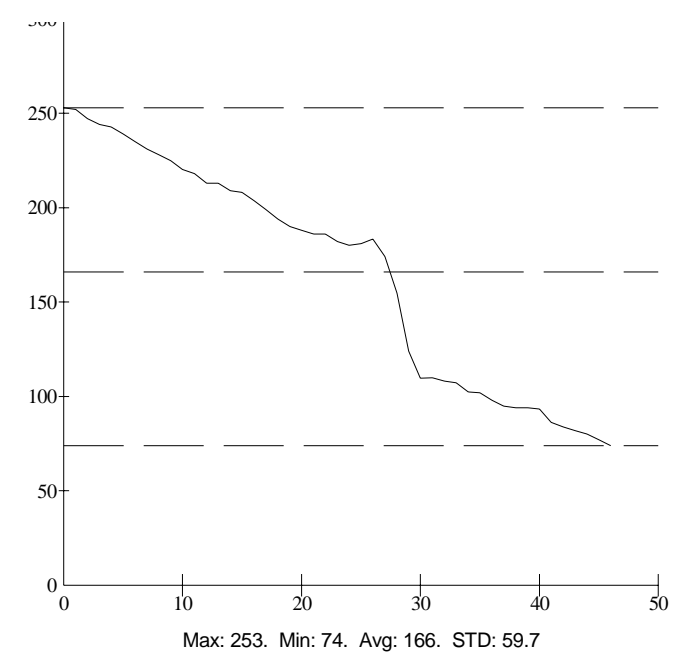

d) 9-second delay time

Figure A.110 Thermal intensity profile along the line across the fatigue crack shown in Figure A.109. 


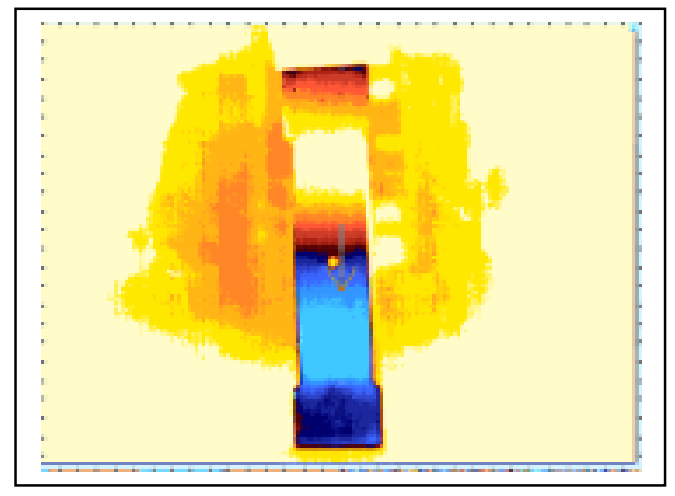

a) 1-second delay time

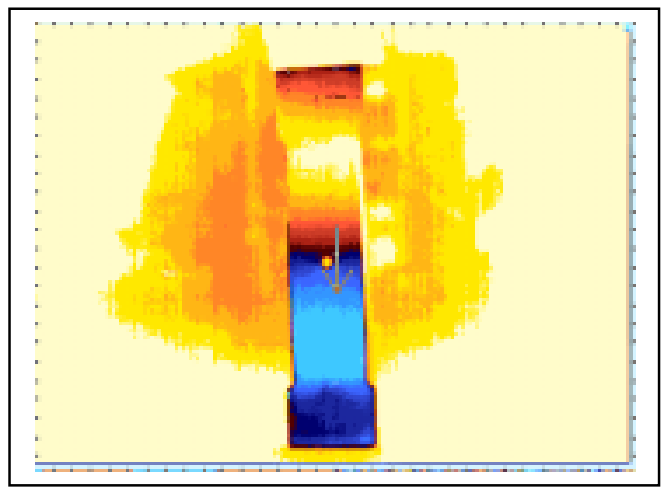

c) 6-second delay time

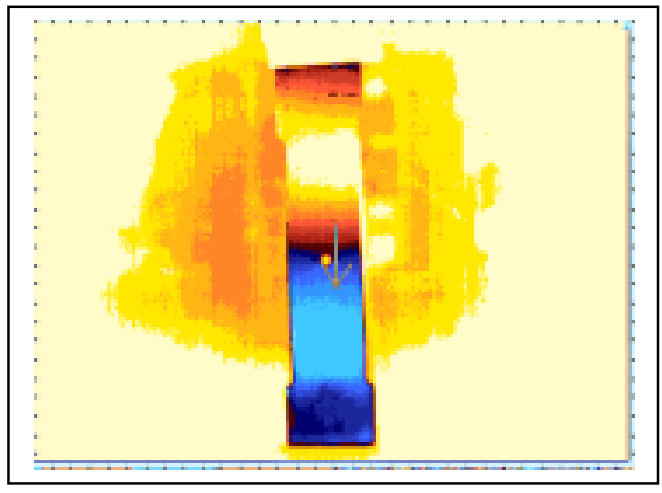

b) 3-second delay time

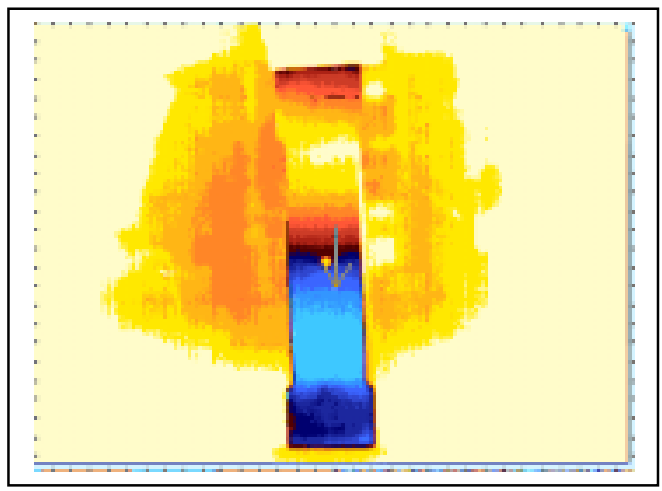

d) 9-second delay time

Figure A.111 Thermal images of Specimen CH-1 (using active approach and heating time is 30 seconds). The distance between IR camera and specimen is $975 \mathrm{~mm}$.. 


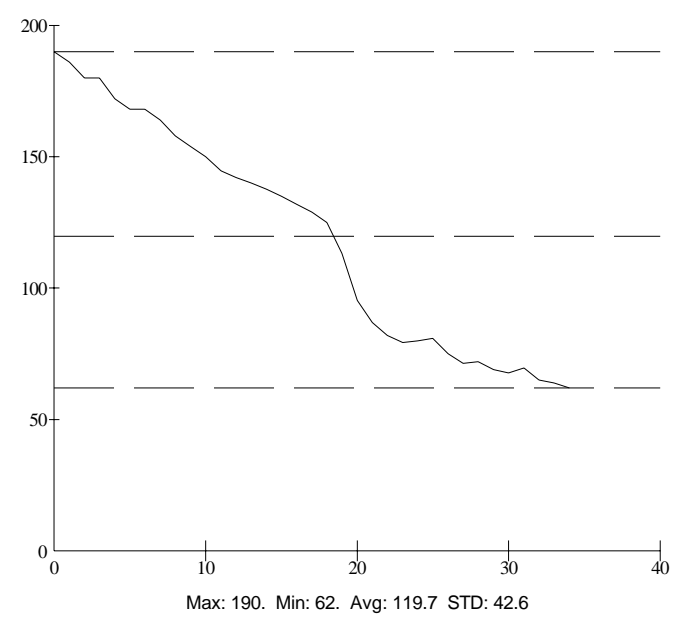

a) 1-second delay time

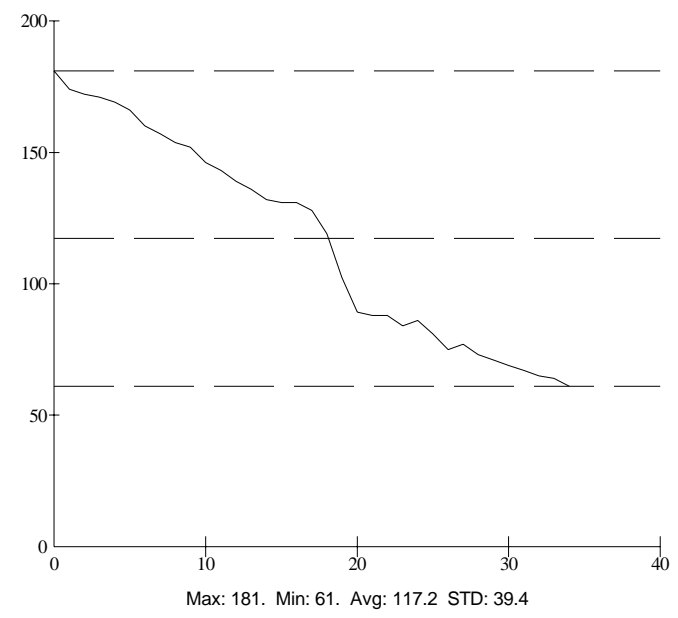

c) 6-second delay time

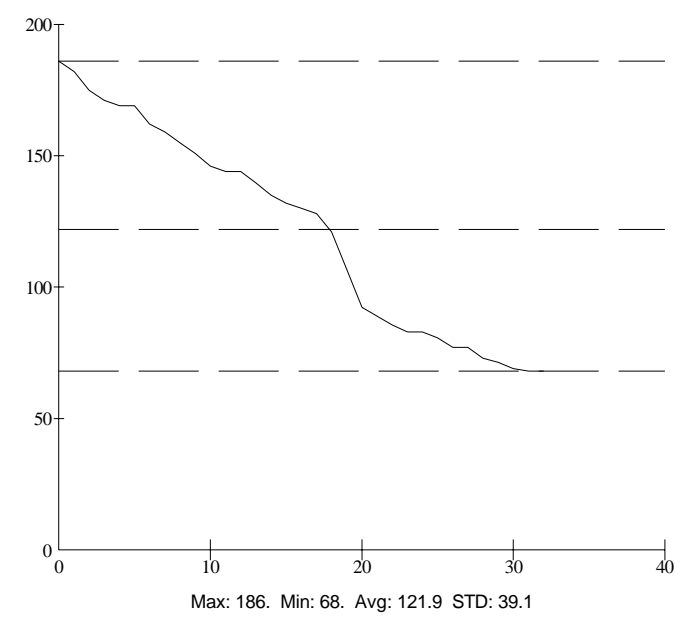

b) 3-second delay time

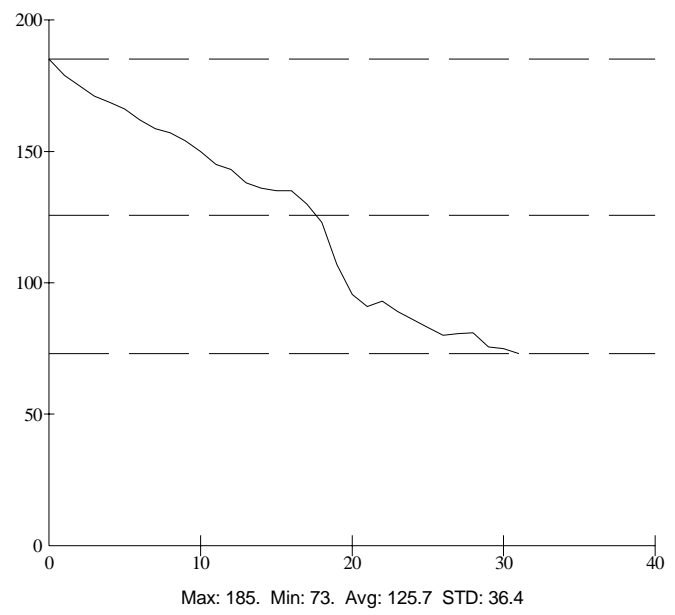

d) 9-second delay time

Figure A.112 Thermal intensity profile along the line across the fatigue crack shown in Figure A.111. 


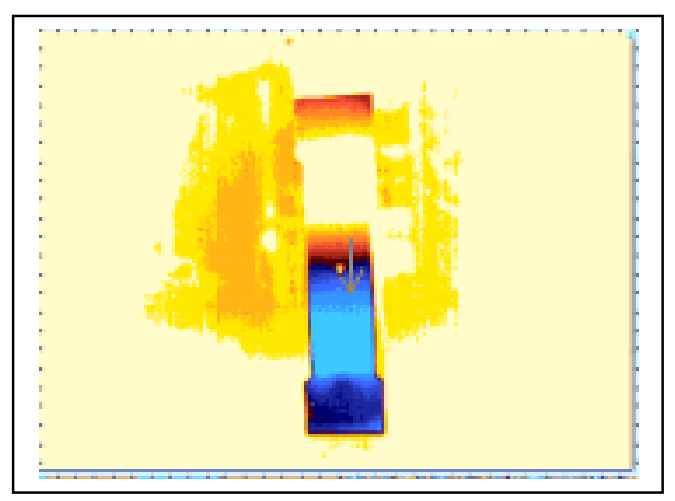

a) 1-second delay time

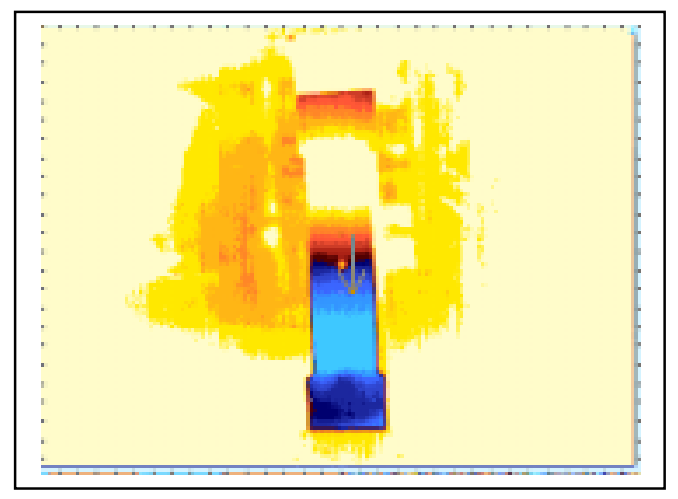

c) 6-second delay time

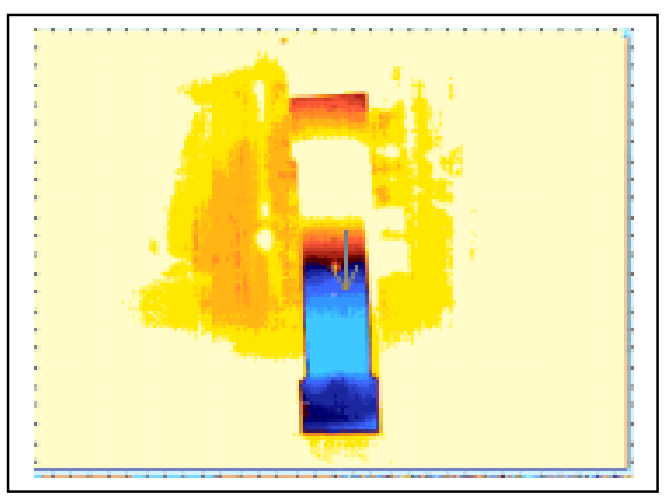

b) 3-second delay time

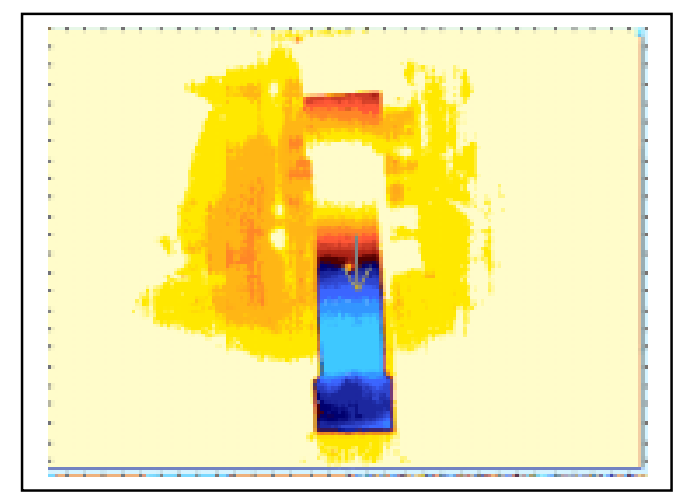

d) 9-second delay time

Figure A.113 Thermal images of Specimen CH-1 (using active approach and heating time is 30 seconds). The distance between IR camera and specimen is $1050 \mathrm{~mm}$. . 


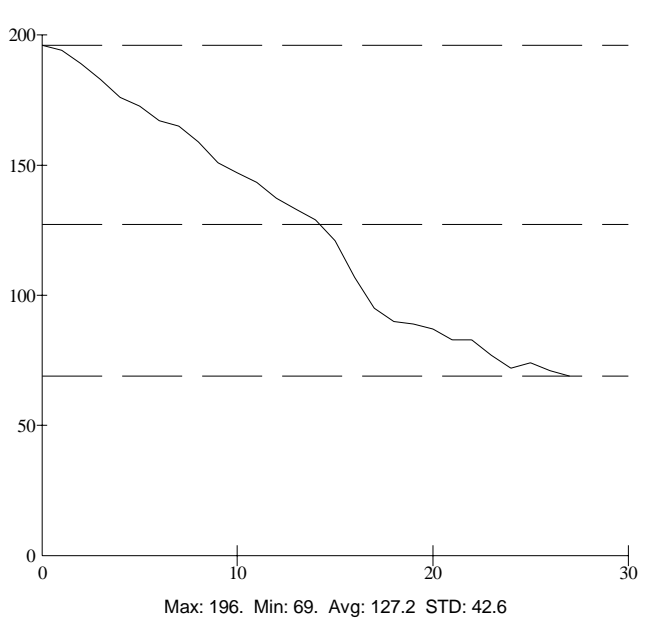

a) 1-second delay time

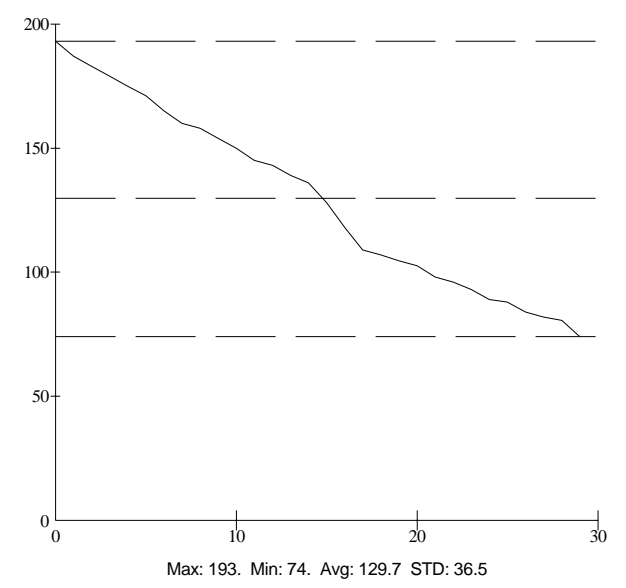

c) 6-second delay time

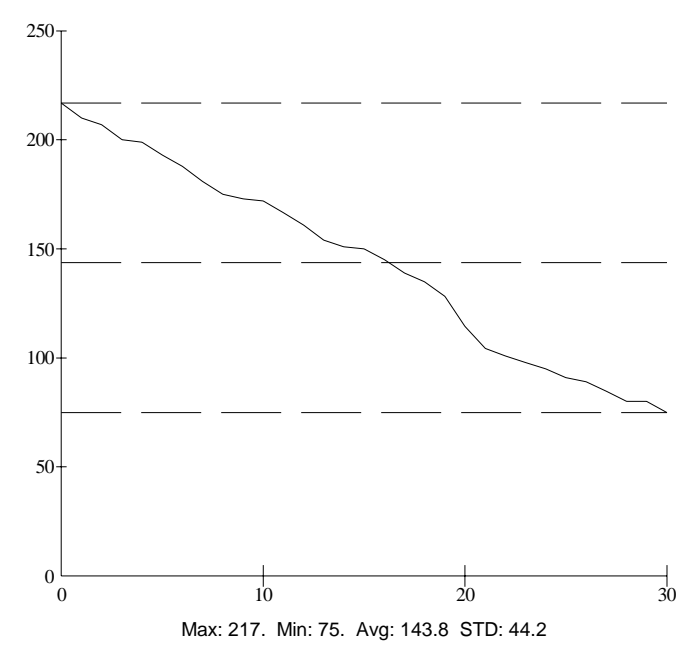

b) 3-second delay time

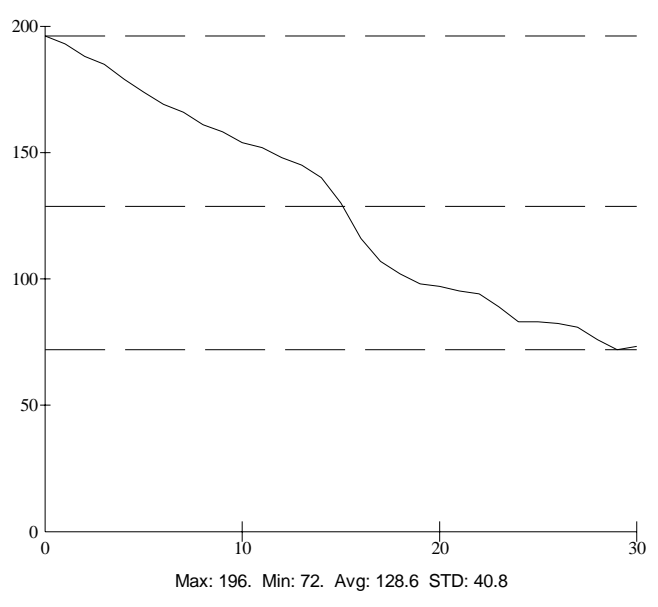

d) 9-second delay time

Figure A.114 Thermal intensity profile along the line across the fatigue crack shown in Figure A.113. 


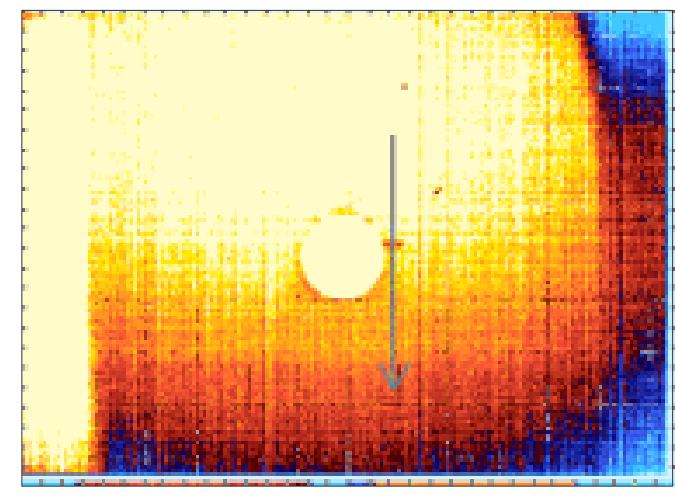

a) 1-second delay time

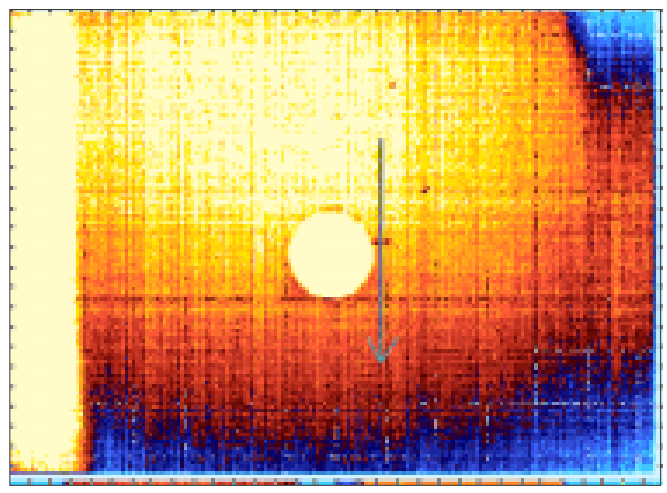

c) 6-second delay time

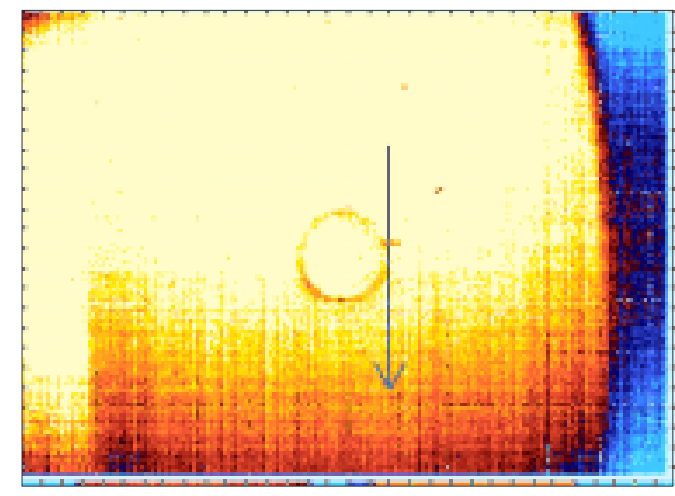

b) 3-second delay time

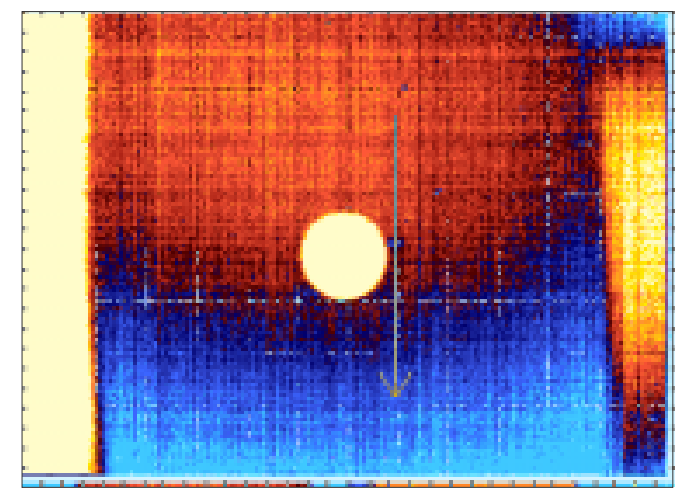

d) 9-second delay time

Figure A.115 Thermal images of unpainted Specimen CH-2 (using the passive approach and heating time is 30 seconds). The distance between IR camera and specimen is $150 \mathrm{~mm}$.. 


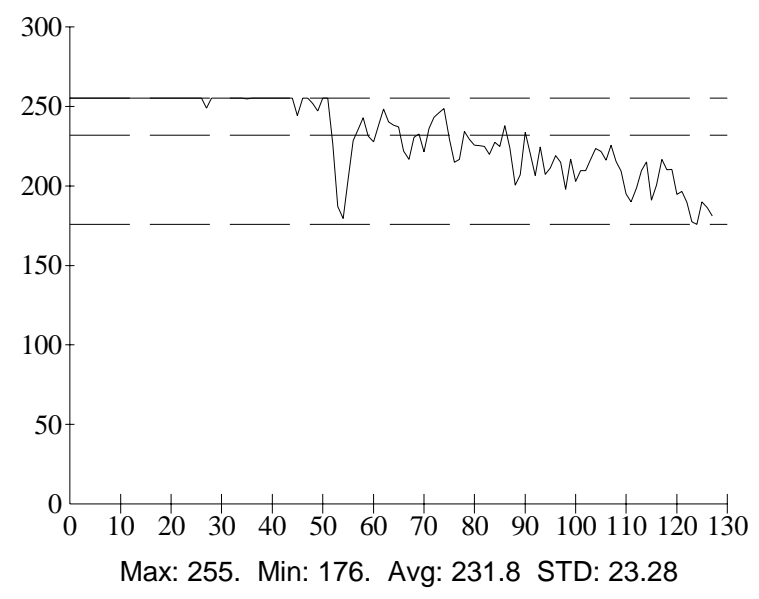

a) 1-second delay time

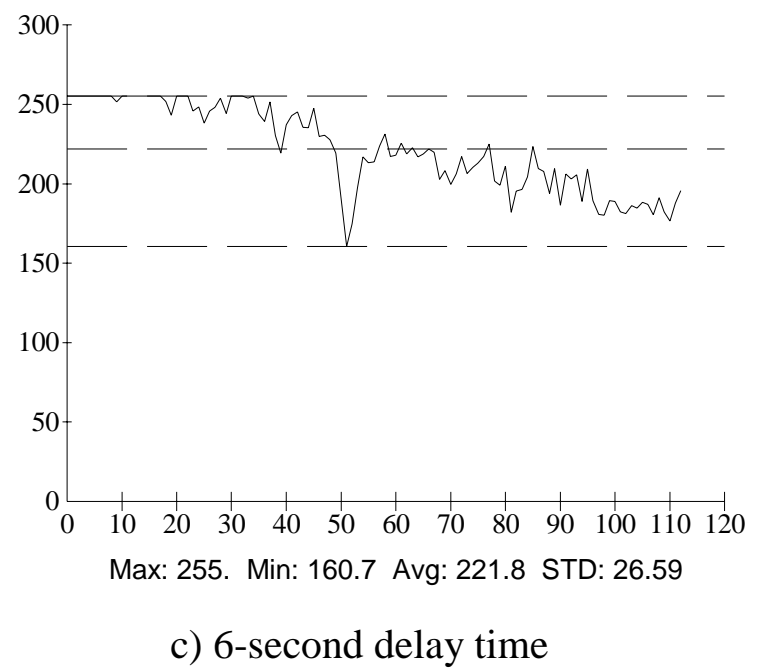

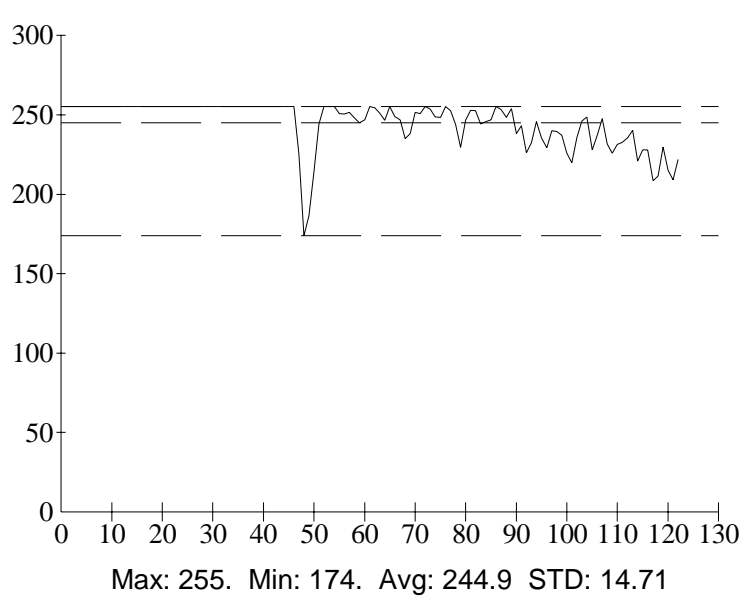

b) 3-second delay time

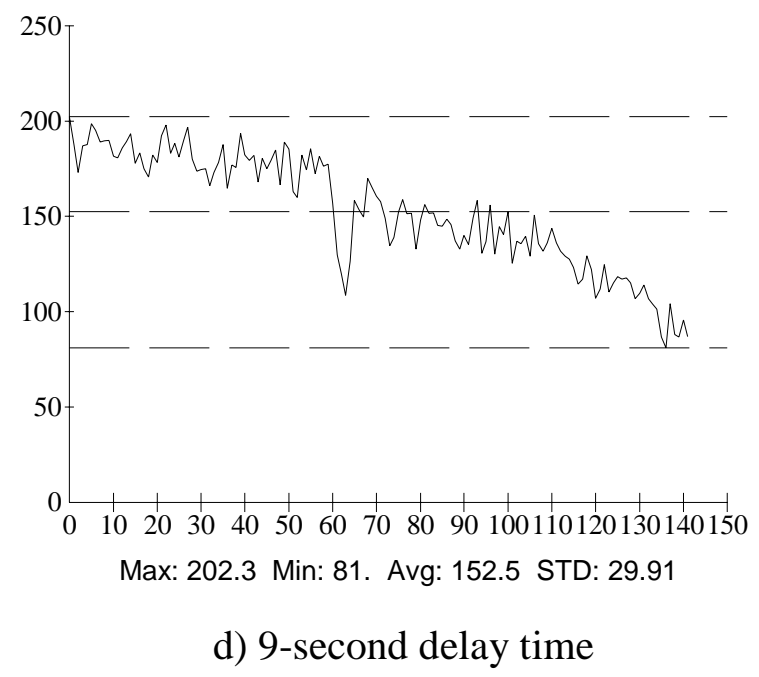

Figure A.116 Thermal intensity profile along the line across the fatigue crack shown in Figure A.115. 


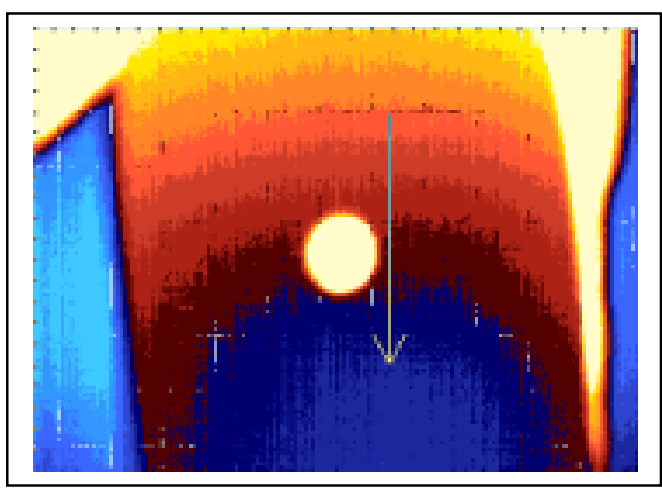

a) 1-second delay time

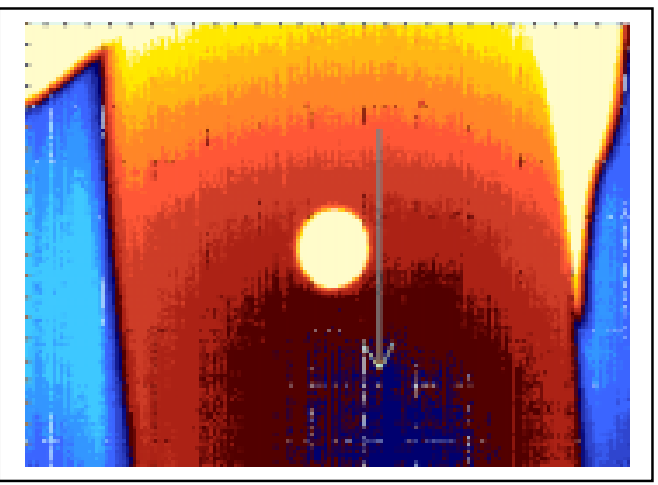

c) 6-second delay time

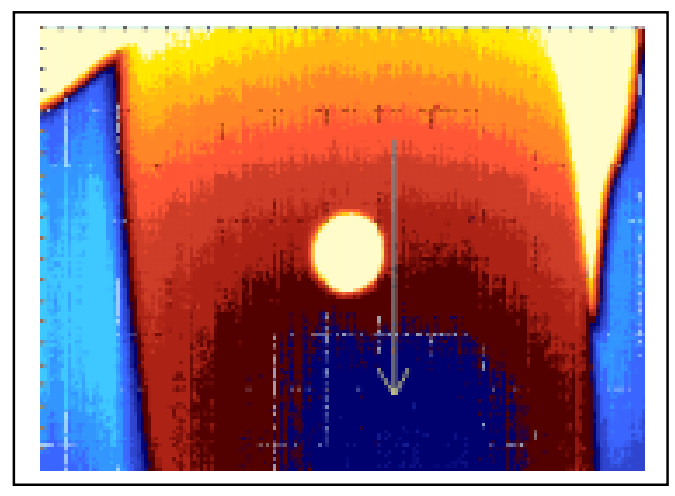

b) 3-second delay time

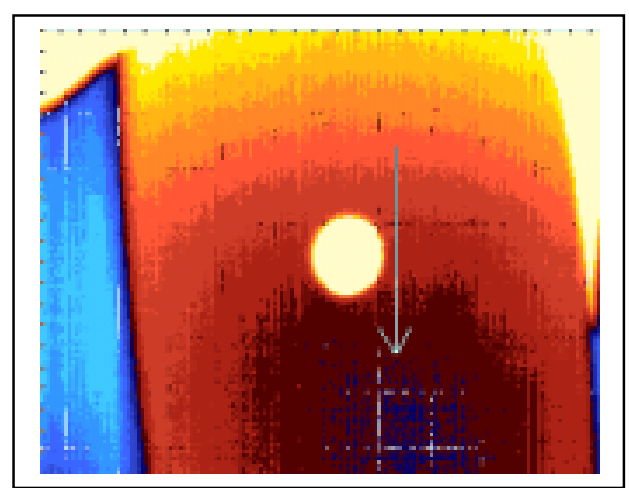

d) 9-second delay time

Figure A.117 Thermal images of unpainted Specimen CH-2 (using active approach and heating time is 30 seconds) The distance between IR camera and specimen is $225 \mathrm{~mm}$. 


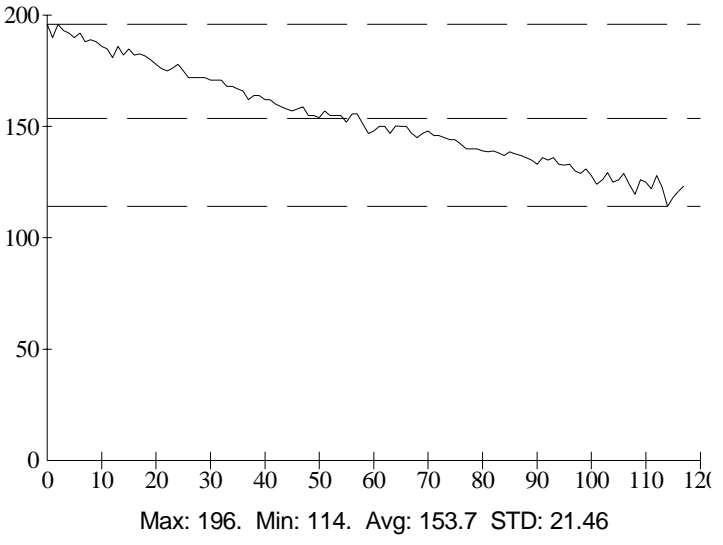

a) 1-second delay time

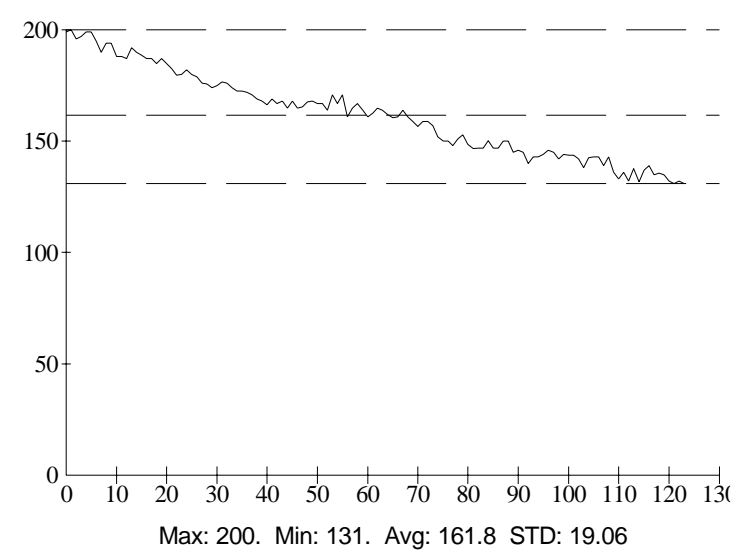

c) 6-second delay time

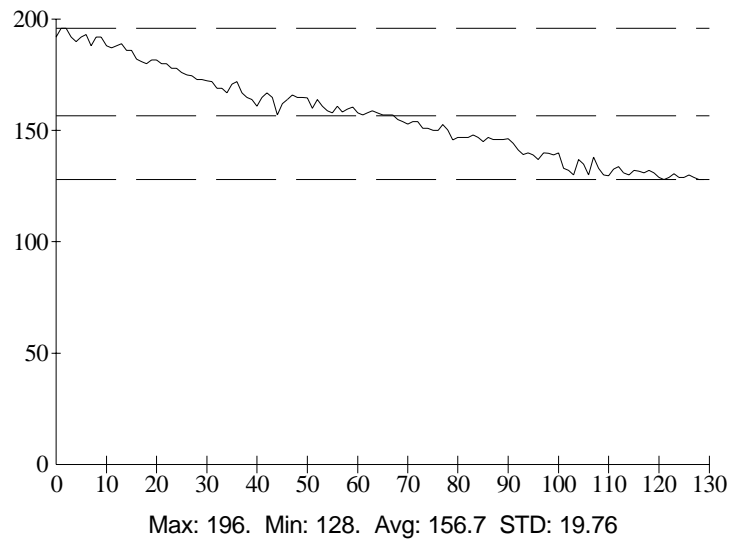

b) 3-second delay time

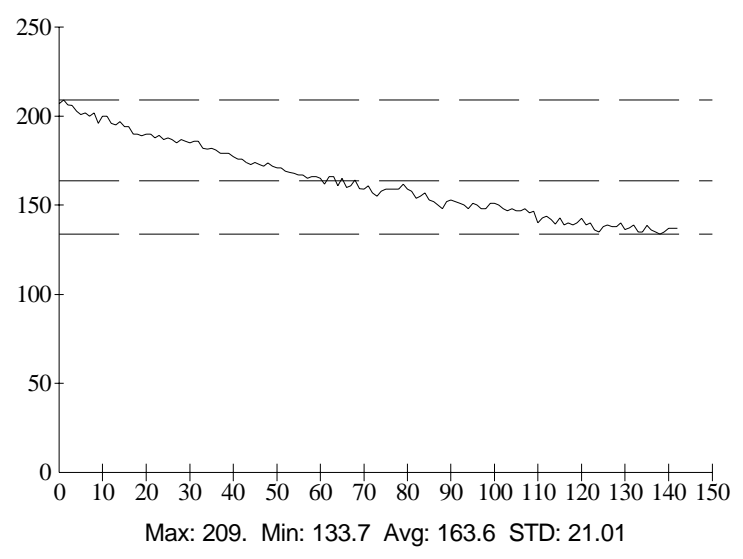

d) 9-second delay time

Figure A.118 Thermal intensity profile along the line across the fatigue crack shown in Figure A.117. 


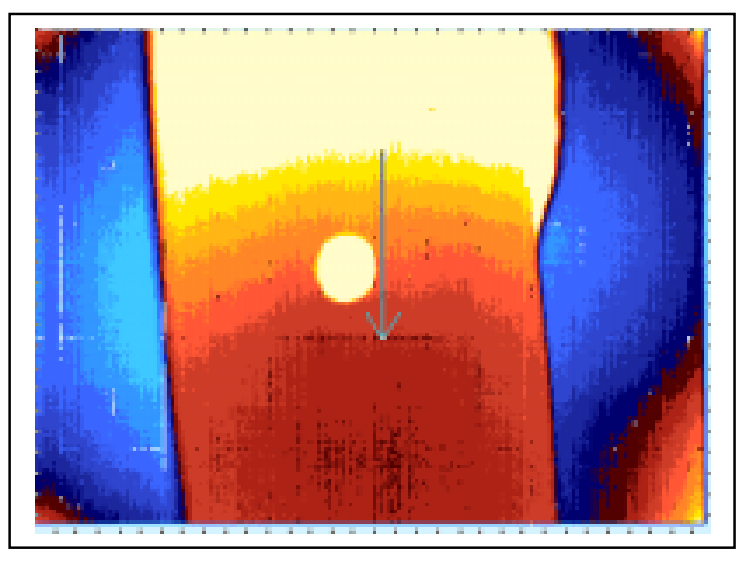

a) 1-second delay time

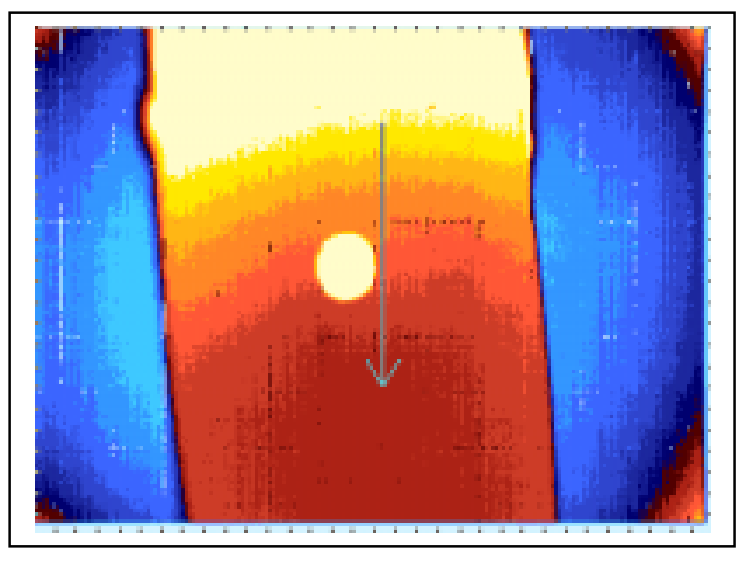

c) 6-second delay time

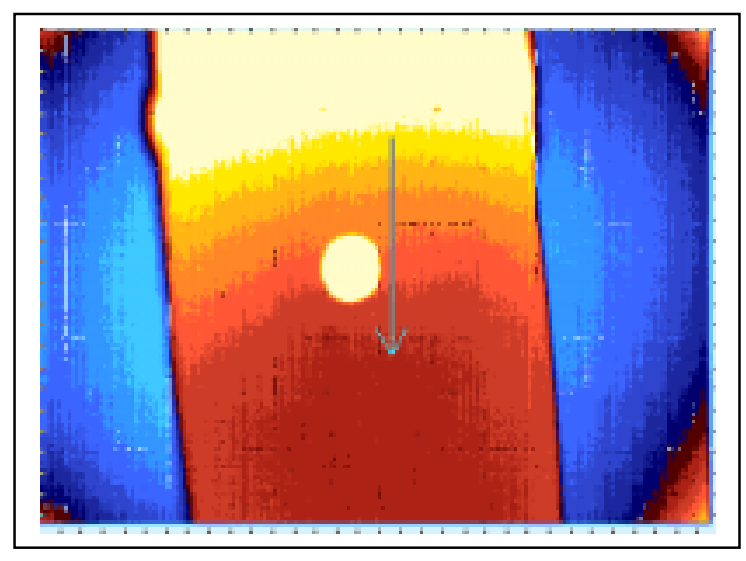

b) 3-second delay time

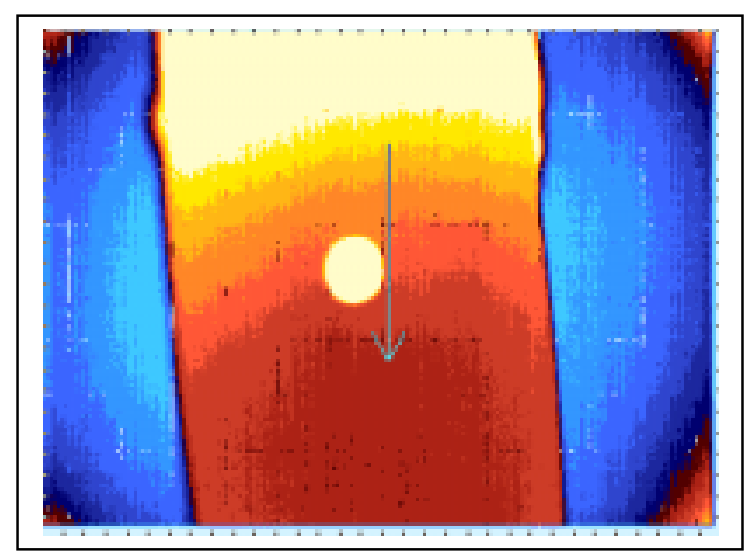

d) 9-second delay time

Figure A.119 Thermal images of unpainted Specimen CH-2 (using active approach and heating time is 30 seconds). The distance between IR camera and specimen is $300 \mathrm{~mm}$.. 


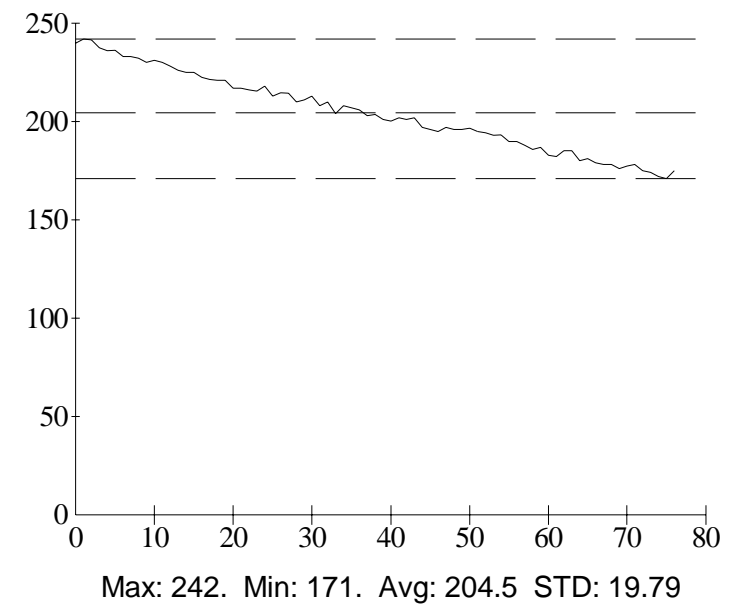

a) 1-second delay time

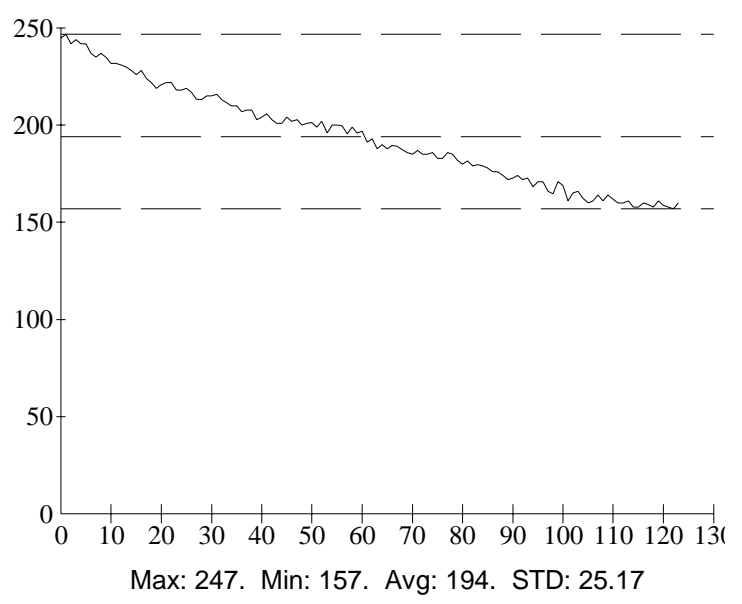

c) 6-second delay time

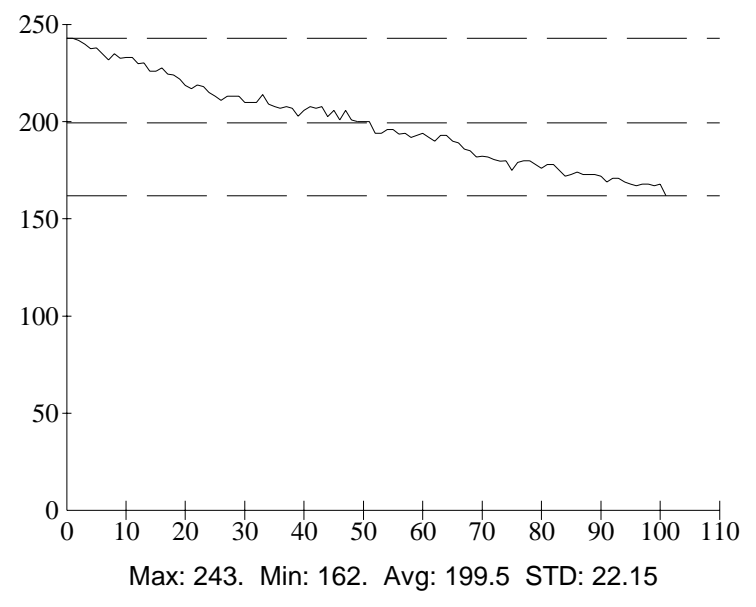

b) 3-second delay time

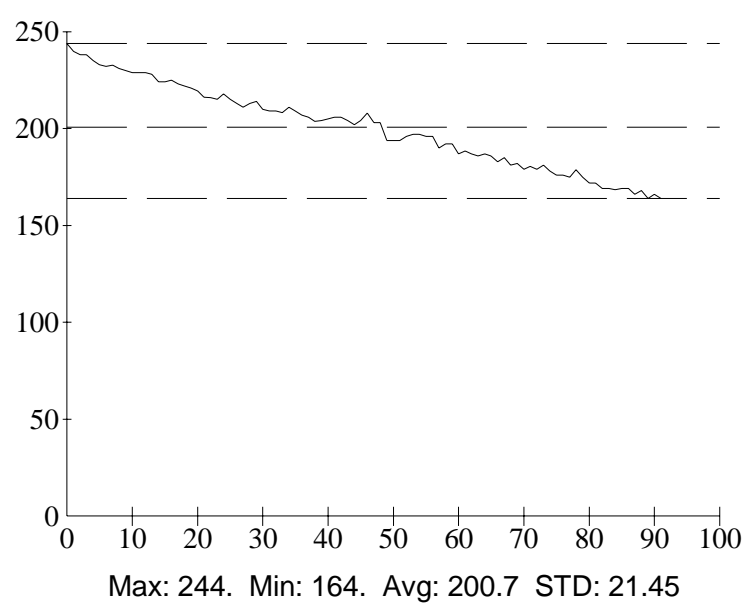

d) 9-second delay time

Figure A.120 The thermal intensity profile along the line across the fatigue crack shown in Figure A.119. 


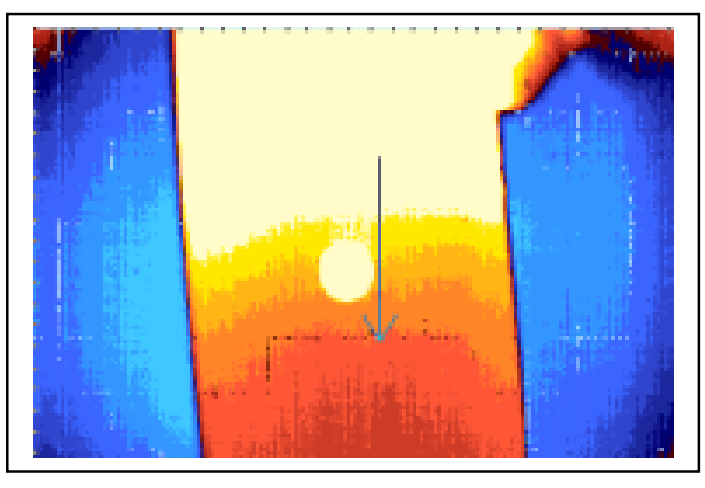

a) 1-second delay time

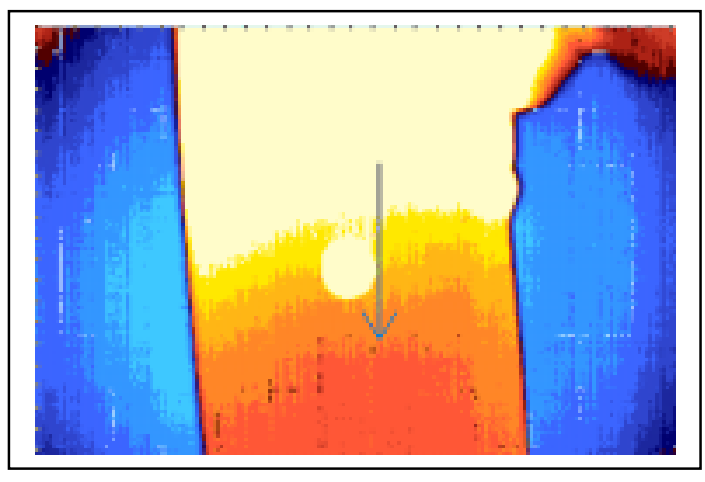

c) 6-second delay time

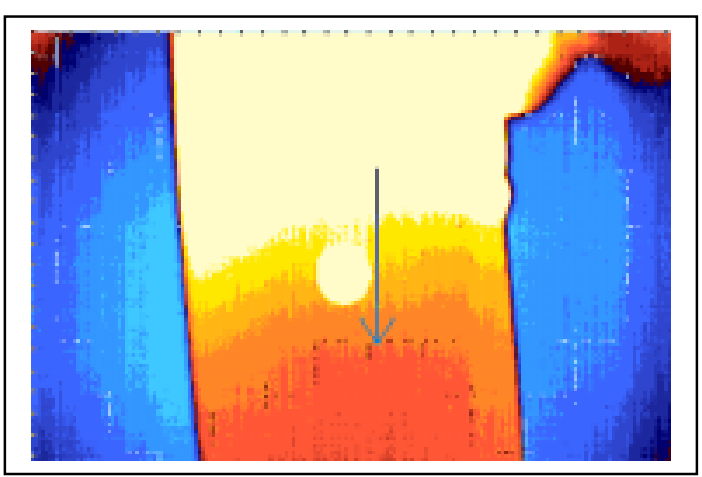

b) 3-second delay time

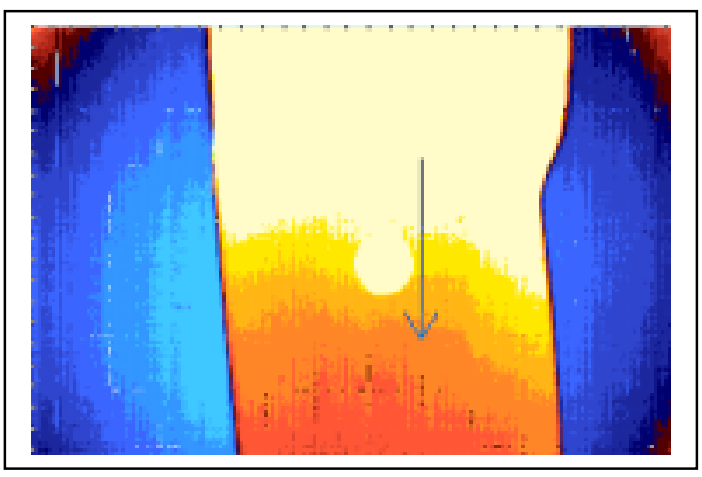

d) 9-second delay time

Figure A.121 Thermal images of unpainted Specimen $\mathrm{CH}-2$ (using the active approach and heating time is 30 seconds). The distance between IR camera and specimen is $375 \mathrm{~mm}$.. 


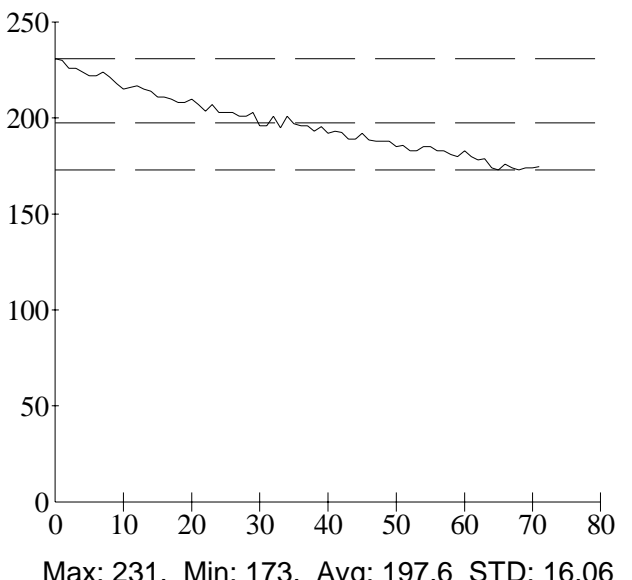

a) 1-second delay time

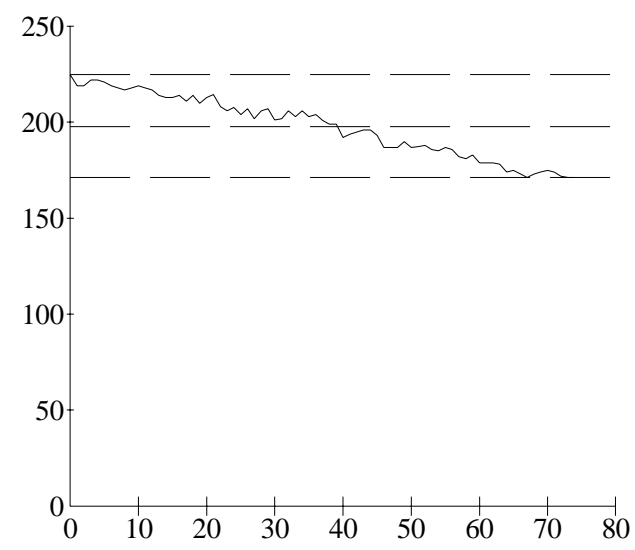

Max: 225. Min: 171.3 Avg: 197.7 STD: 16.09

c) 6-second delay time

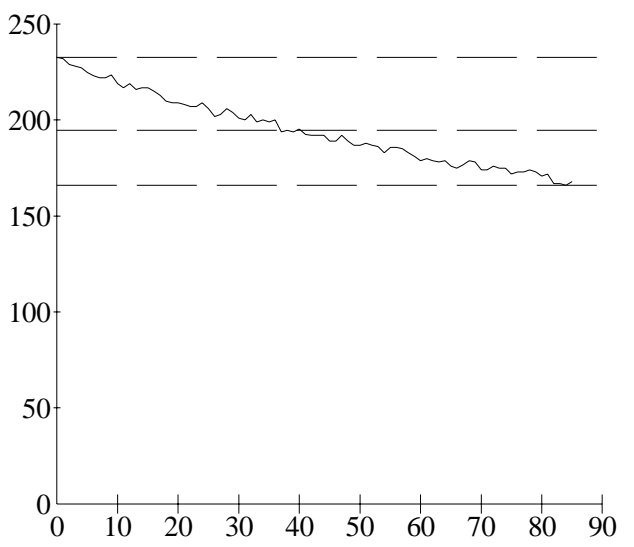

Max: 232.7 Min: 166. Avg: 194.8 STD: 18.23

b) 3-second delay time

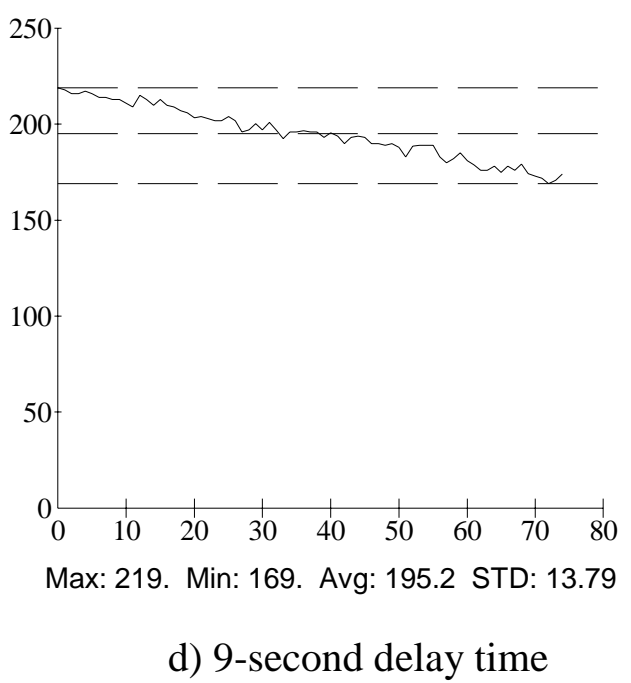

Figure A.122 Thermal intensity profile along the line across the fatigue crack shown in Figure A.121. 


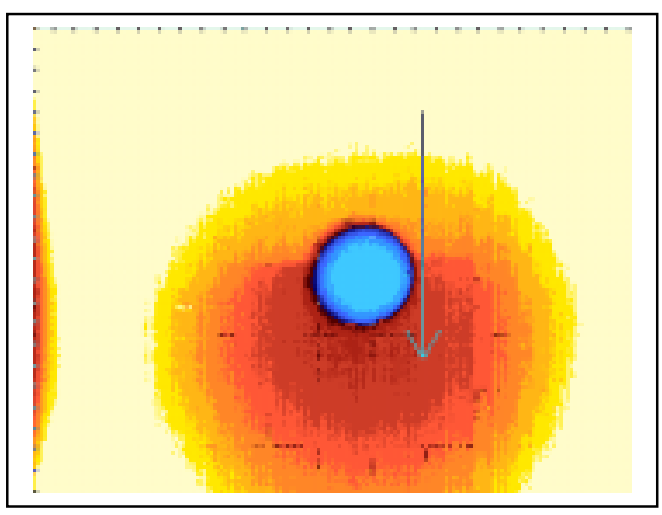

a) 1-second delay time

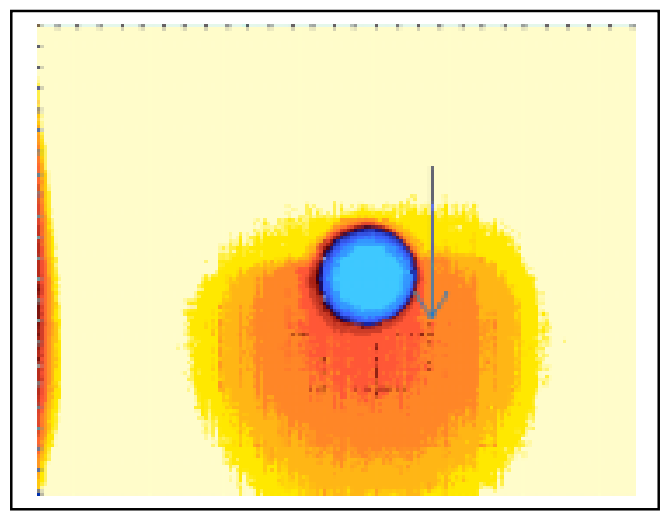

c) 6-second delay time

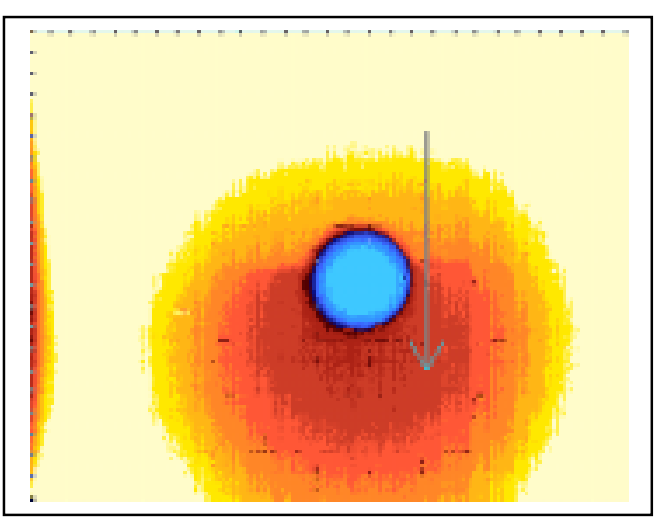

b) 3-second delay time

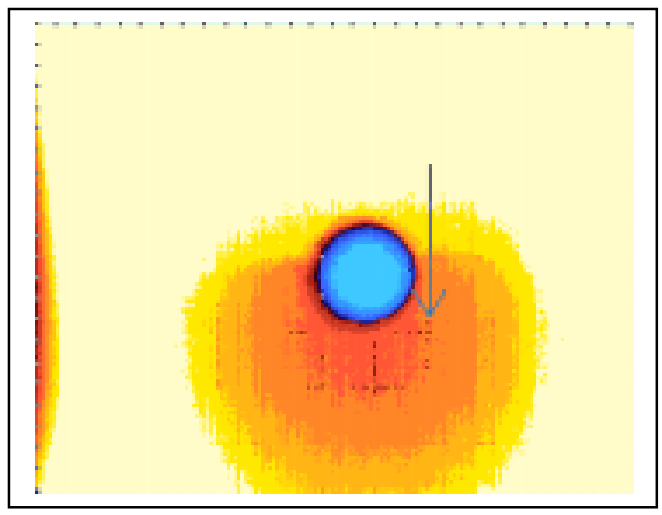

d) 9-second delay time

Figure A.123 Thermal images of Specimen CH-3 (using the active approach and heating time is 30 seconds) at 500,000 loading cycles. The distance between IR camera and test specimen is $150 \mathrm{~mm}$.. 


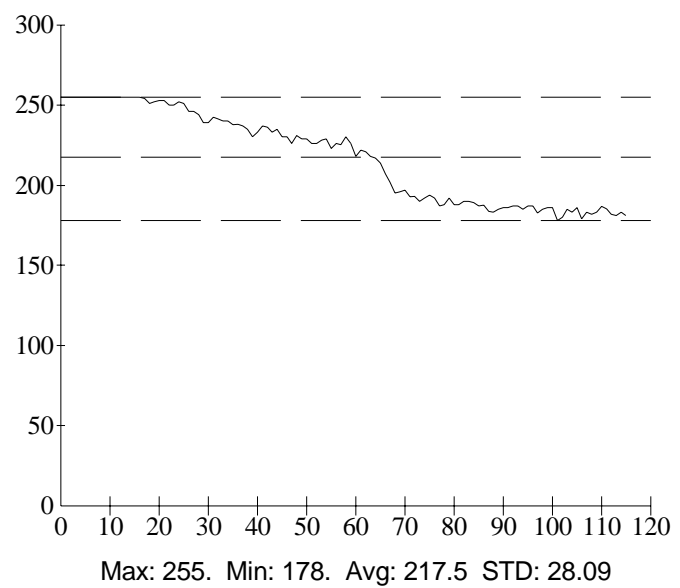

a) 1-second delay time

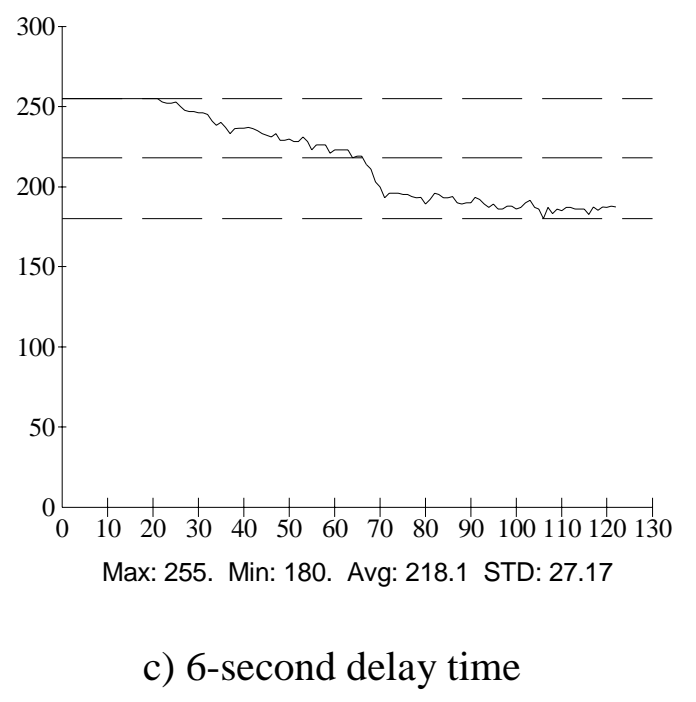

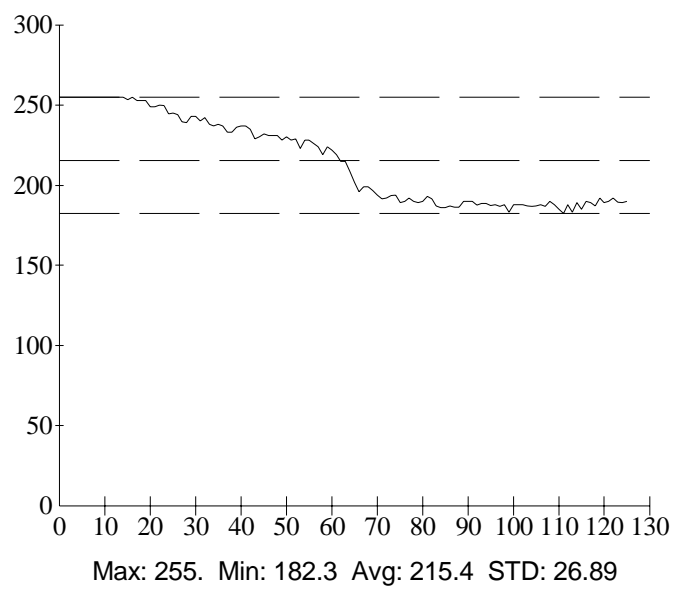

b) 3-second delay time

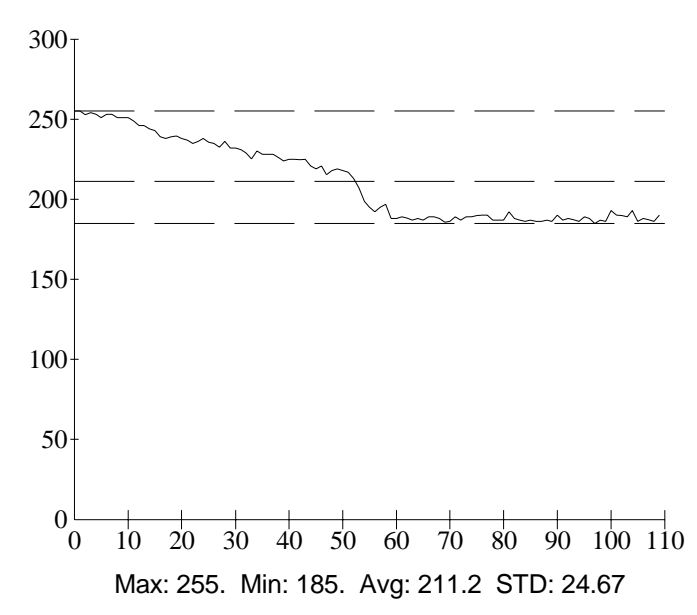

d) 9-second delay time

Figure A.124 Thermal intensity profile along the line across the fatigue crack shown in Figure A.123. 


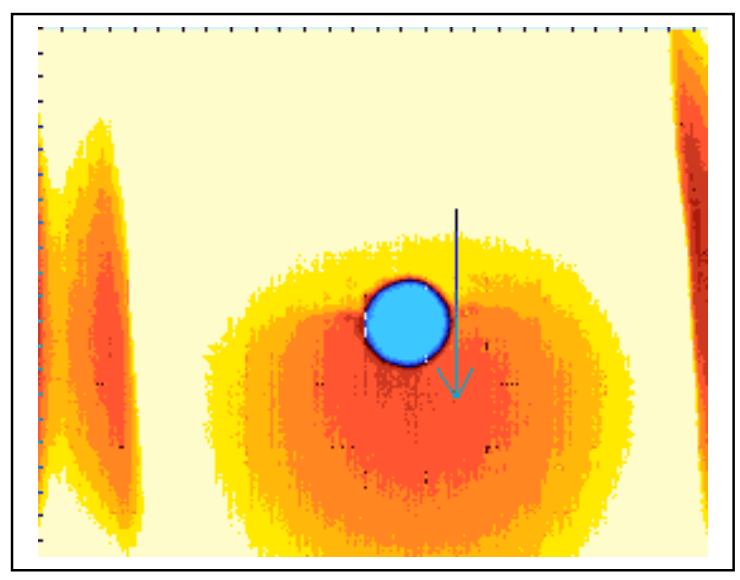

a) 1-second delay time

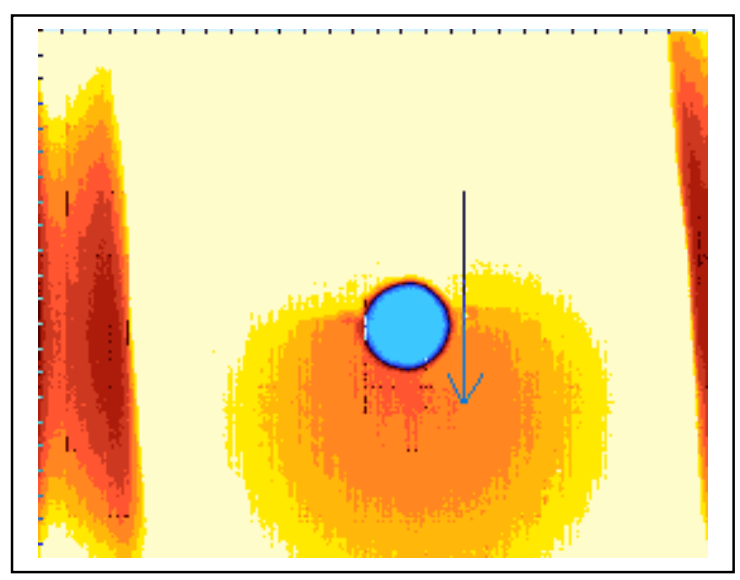

c) 6-second delay time

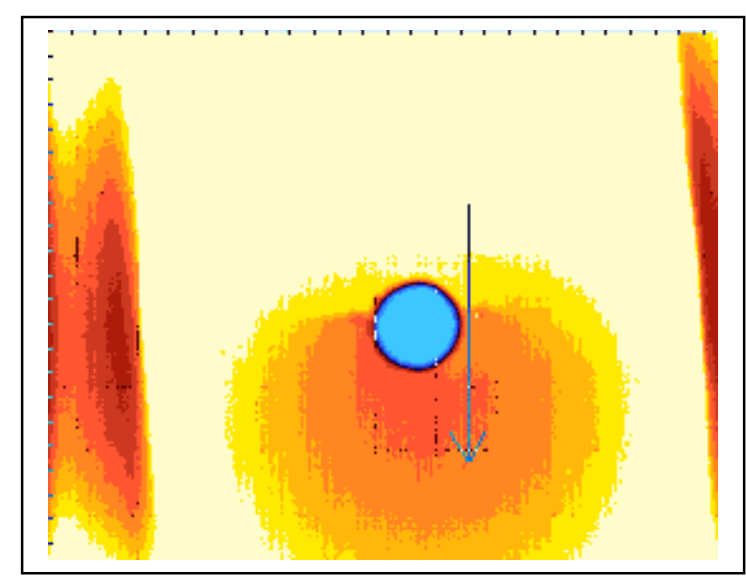

b) 3-second delay time

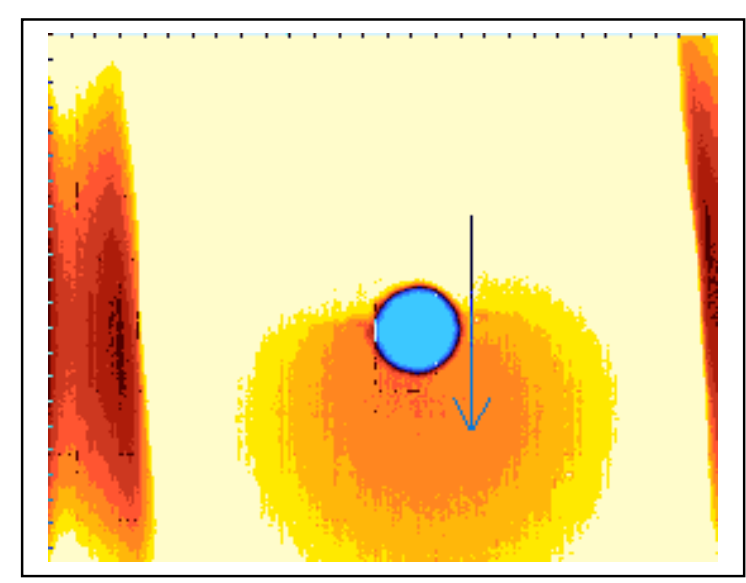

d) 9-second delay time

Figure A.125 Thermal images of Specimen $\mathrm{CH}-3$ (using the active approach and heating time is 30 seconds) at 500,000 loading cycles. The distance between IR camera and test specimen is $225 \mathrm{~mm}$.. 


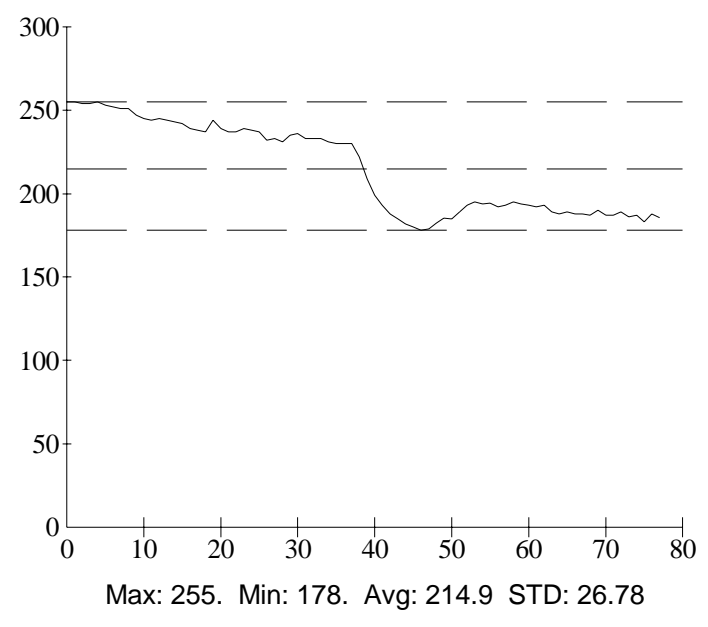

a) ) 1-second delay time

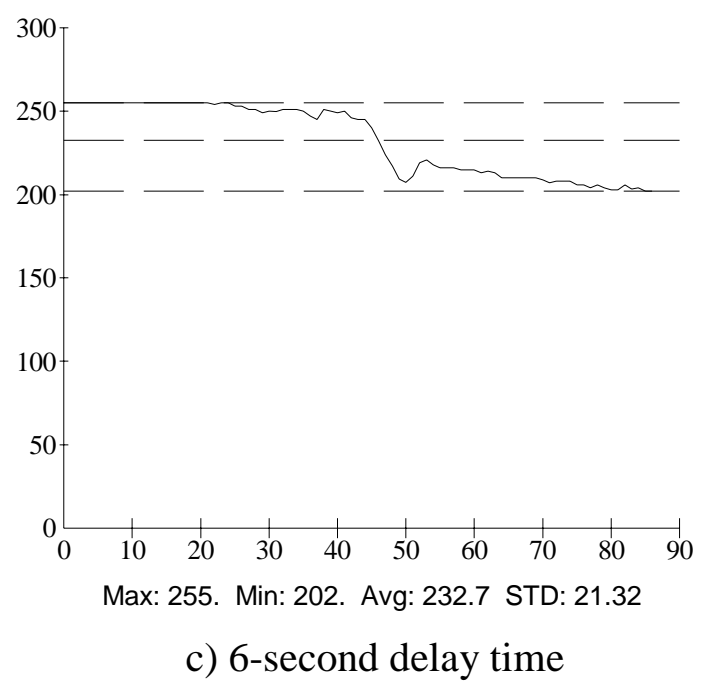

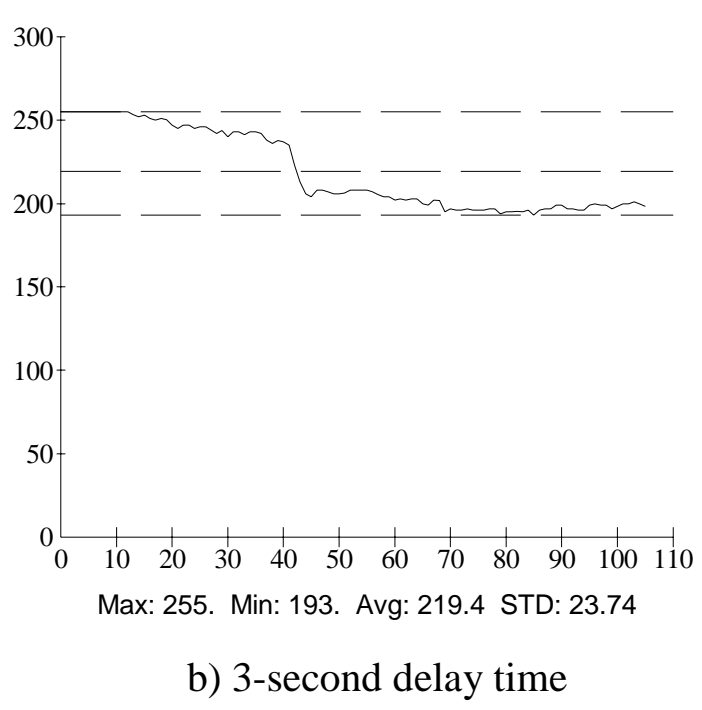

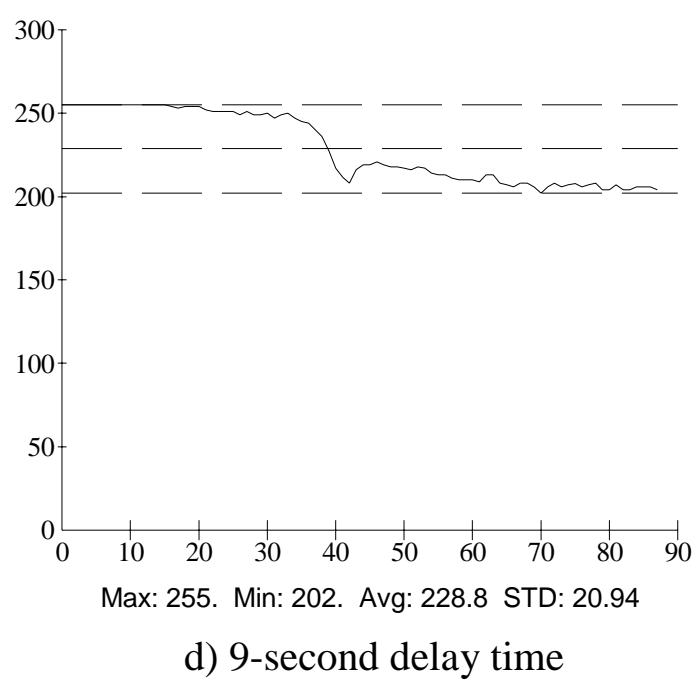

Figure A.126 Thermal intensity profile along the line across the fatigue crack shown in Figure A.125. 


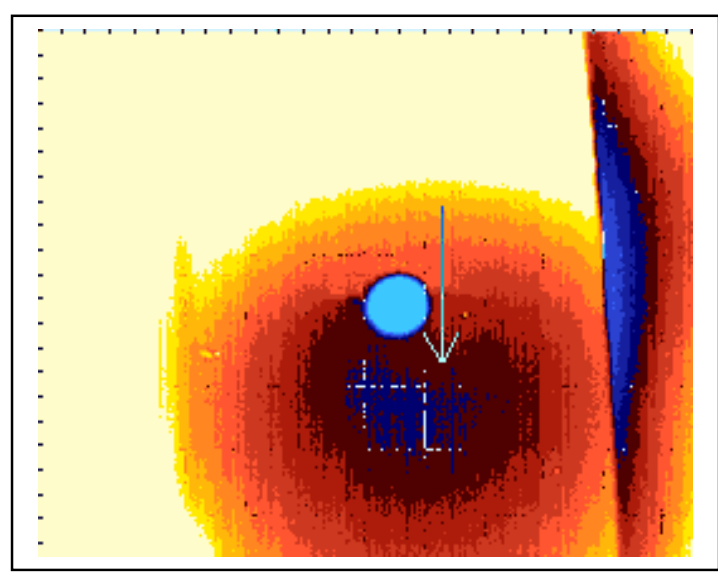

a) 1-second delay time

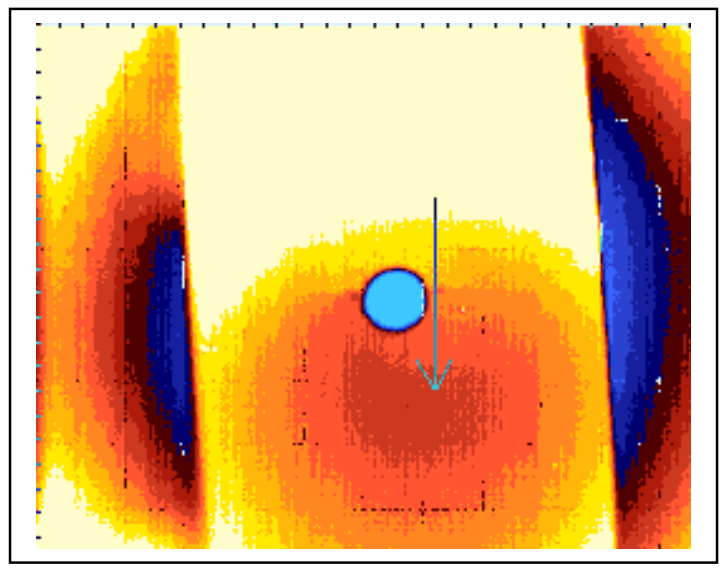

c) 6-second delay time

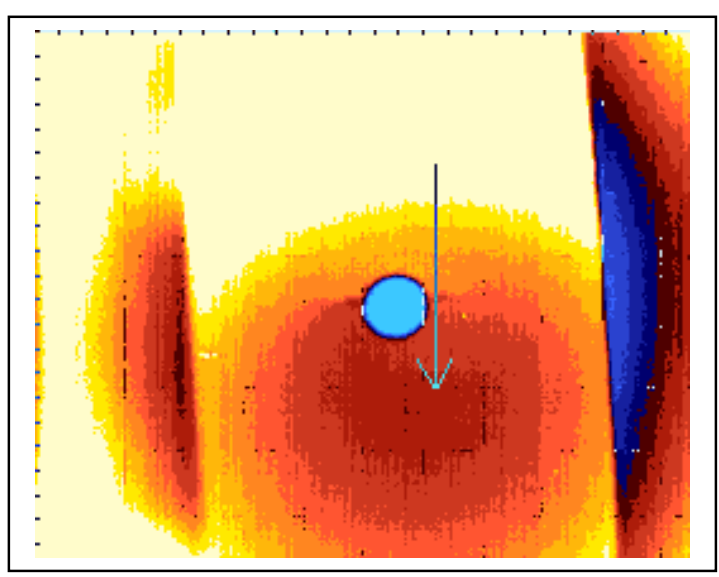

b) 3-second delay time

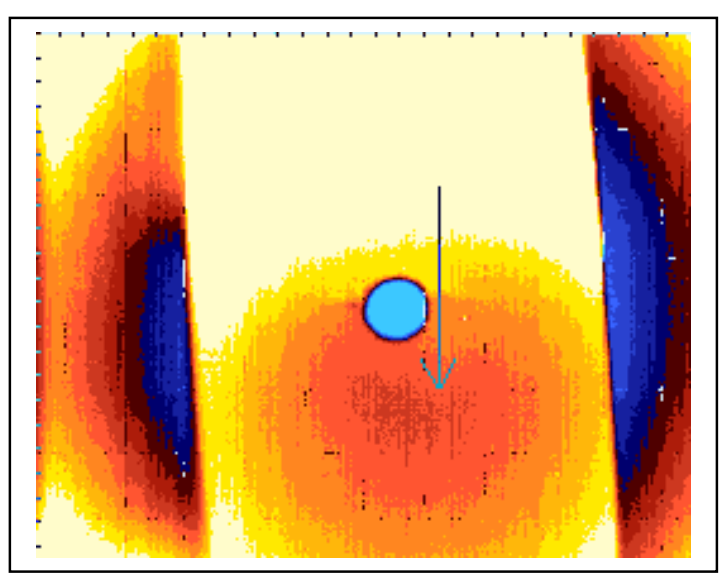

d) 9-second delay time

Figure A.127 Thermal images of Specimen 3 (using the active approach and heating time is 30 seconds) at 500,000 loading cycles. The distance between IR camera and test specimen is $300 \mathrm{~mm}$.. 


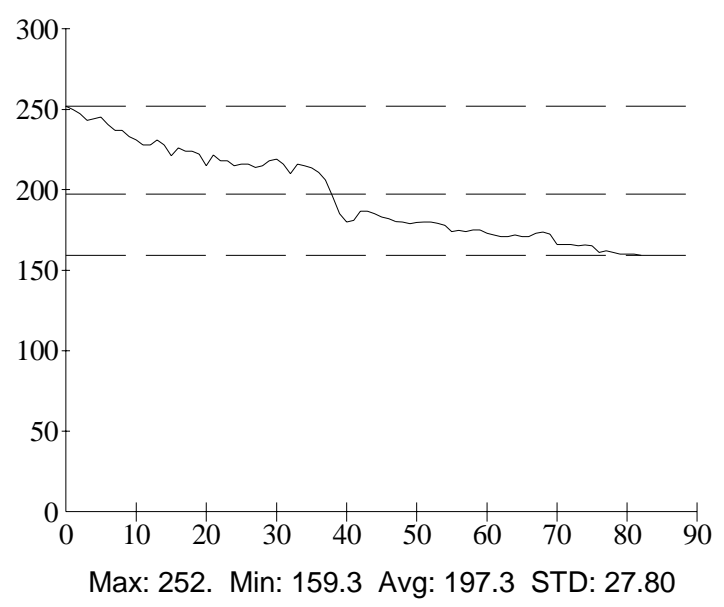

a) 1-second delay time

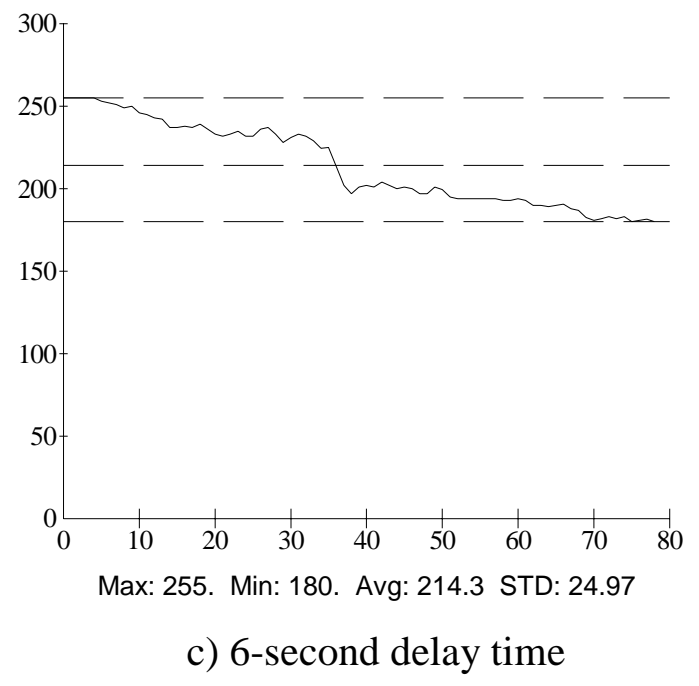

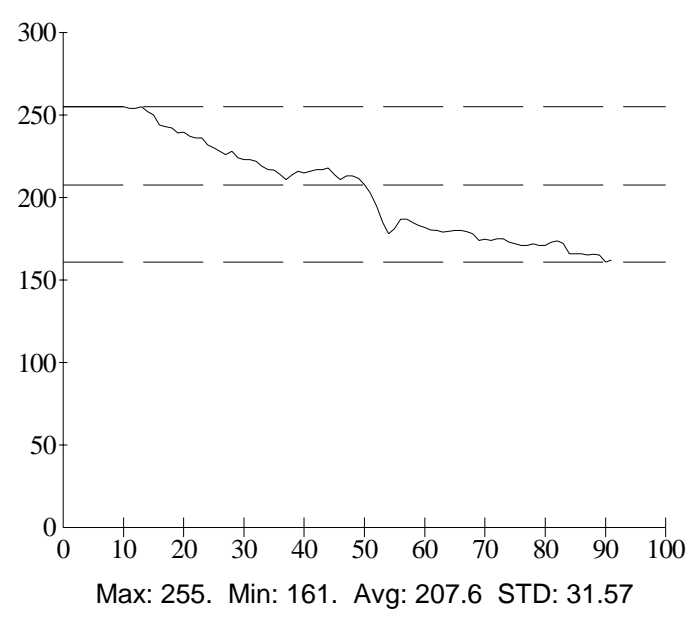

b) 3-second delay time

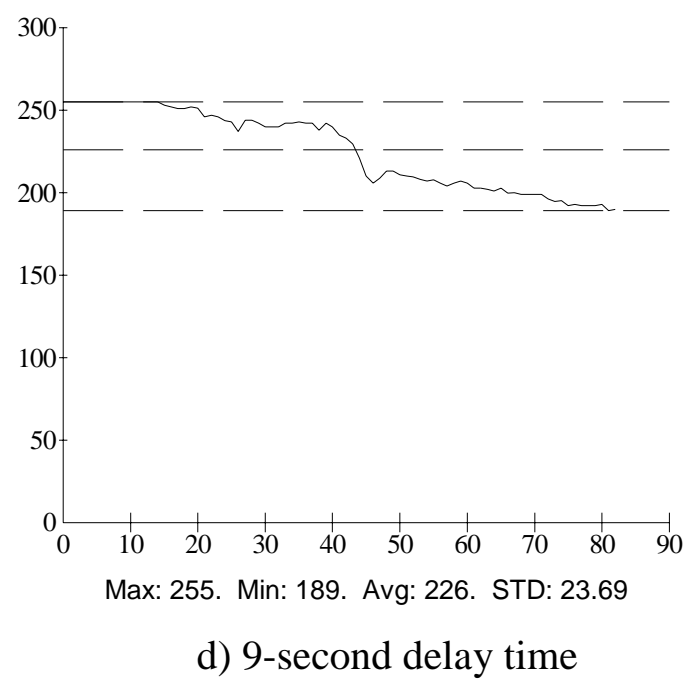

Figure A.128 Thermal intensity profile along the line across the fatigue crack shown in Figure A.127. 


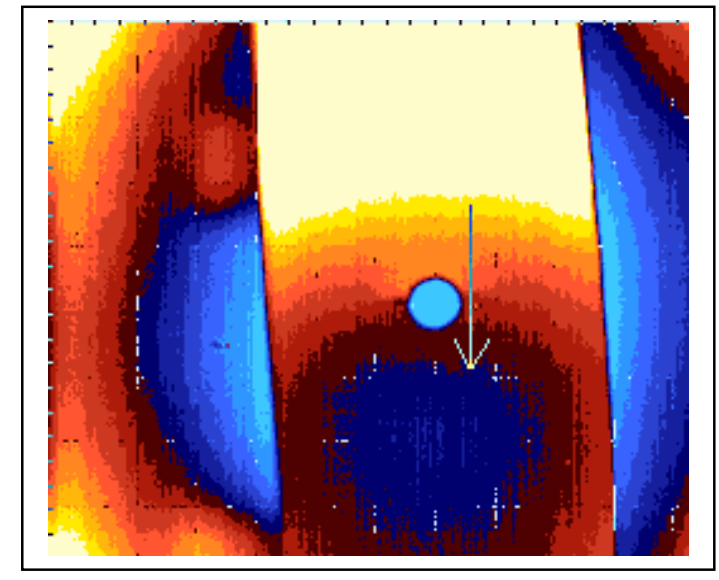

a) 1-second delay time

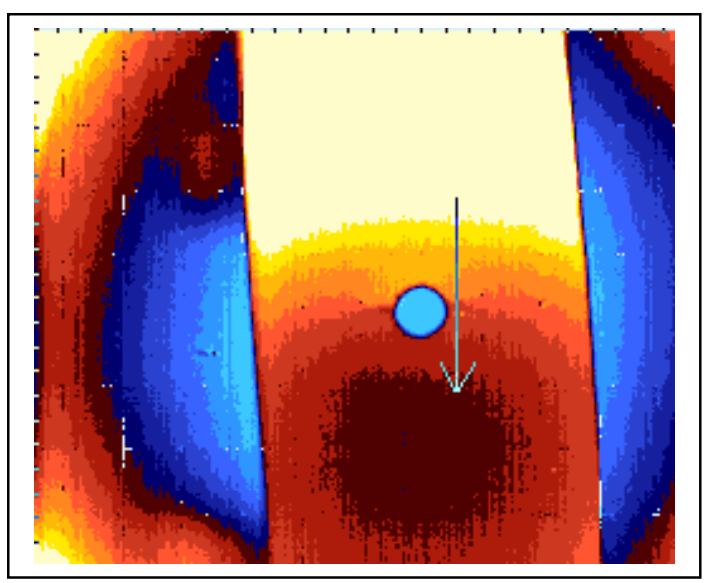

c) 6-second delay time

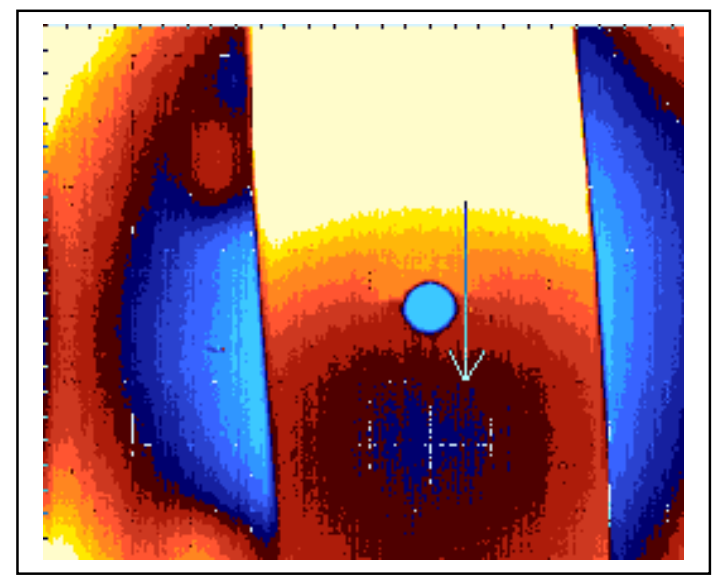

b) 3-second delay time

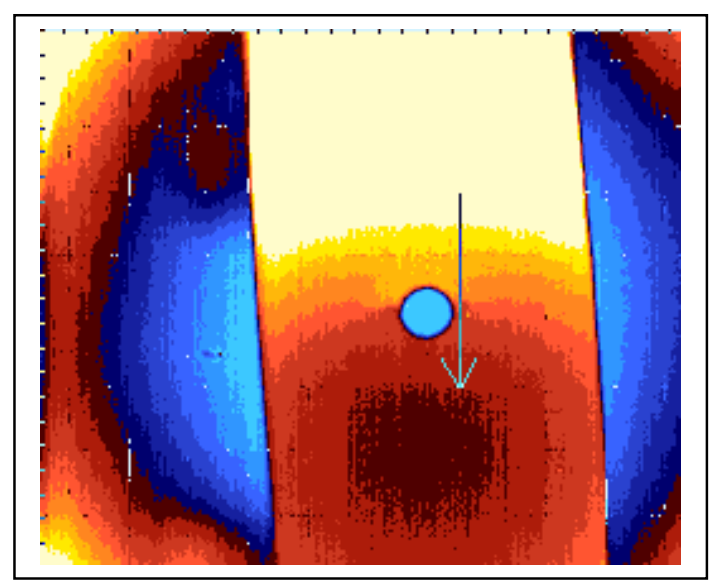

d) 9-second delay time

Figure A.129 Thermal images of Specimen $\mathrm{CH}-3$ (using the active approach and heating time is 30 seconds) at 500,000 loading cycles. The distance between IR camera and test specimen is $375 \mathrm{~mm}$. 


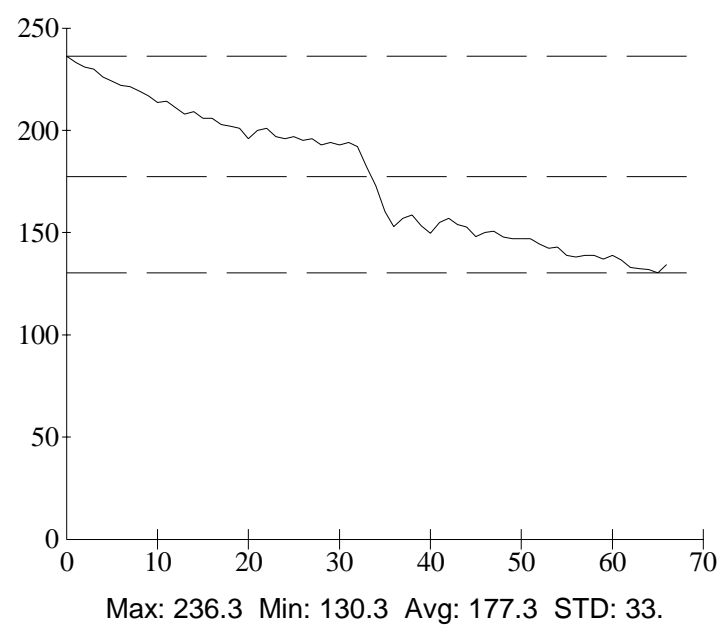

a) 1-second delay time

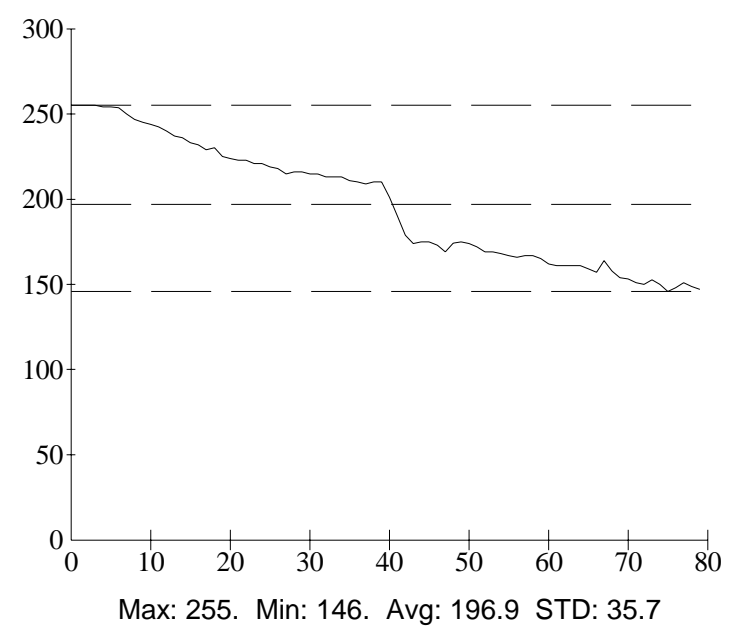

c) 6-second delay time

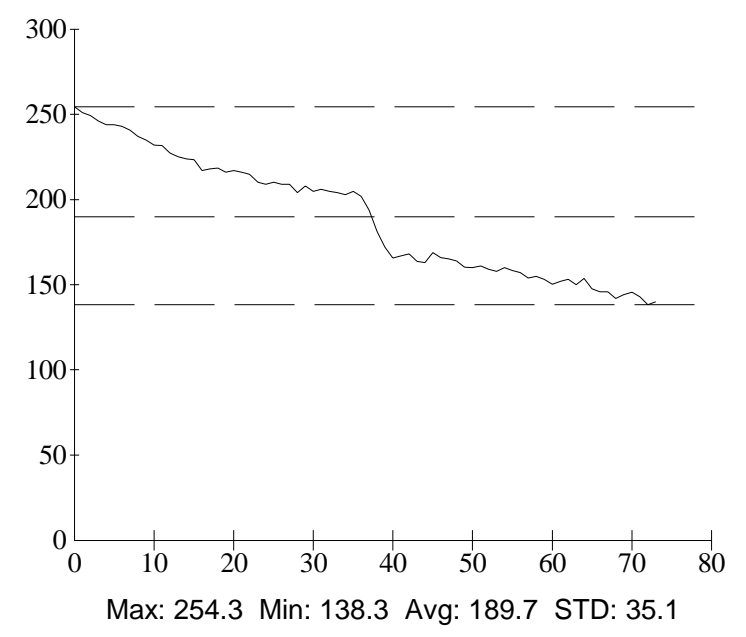

b) 3-second delay time

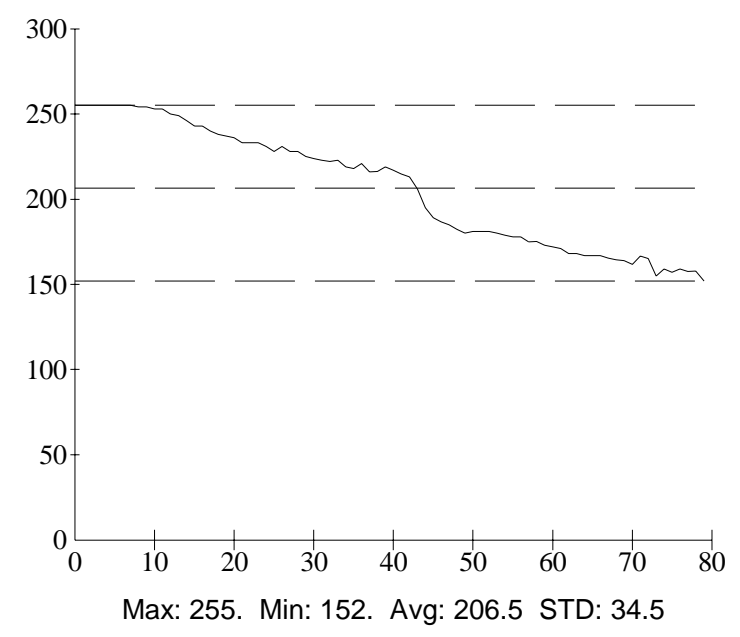

d) 9-second delay time

Figure A.130 Thermal intensity profile along the line across the fatigue crack shown in Figure A.129. 


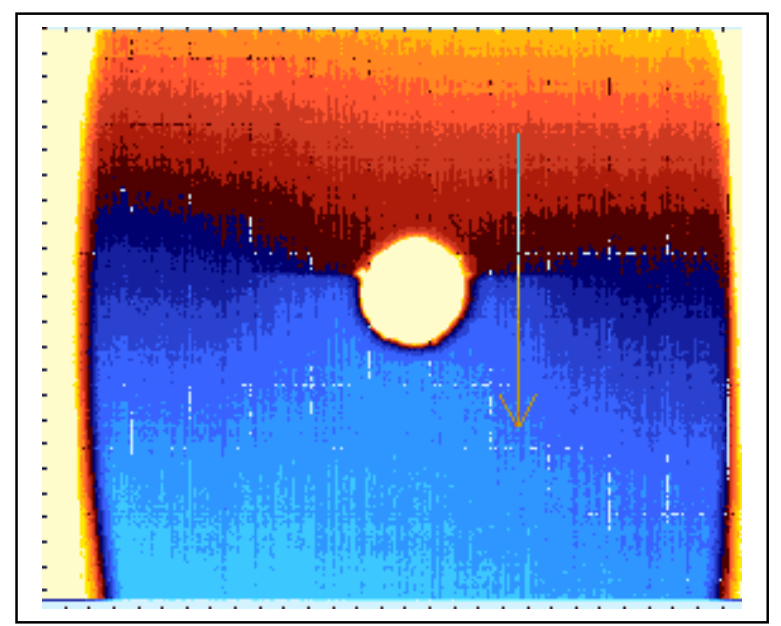

a) 1-second delay time

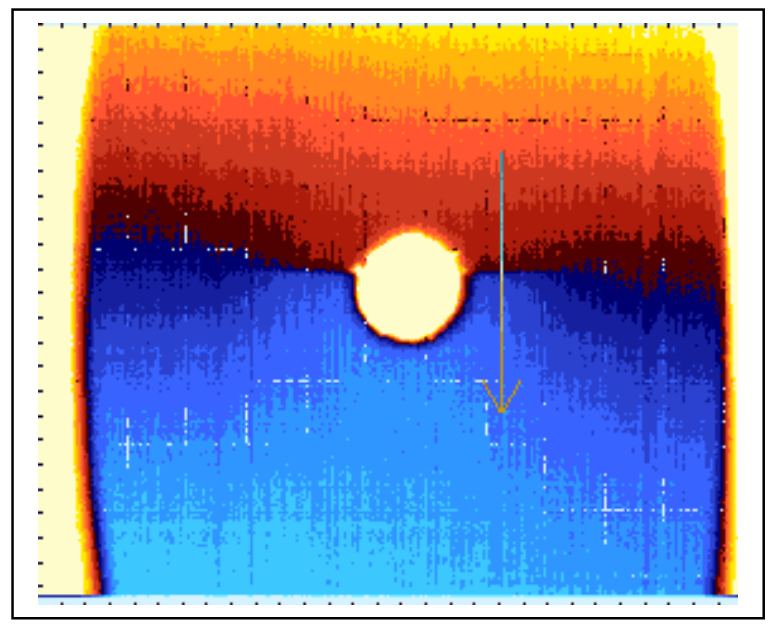

c) 6-second delay time

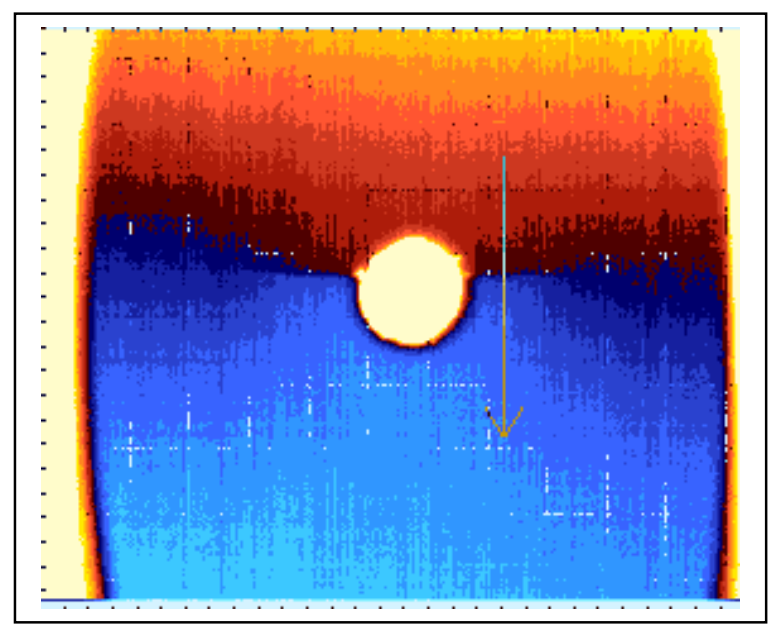

b) 3-second delay time

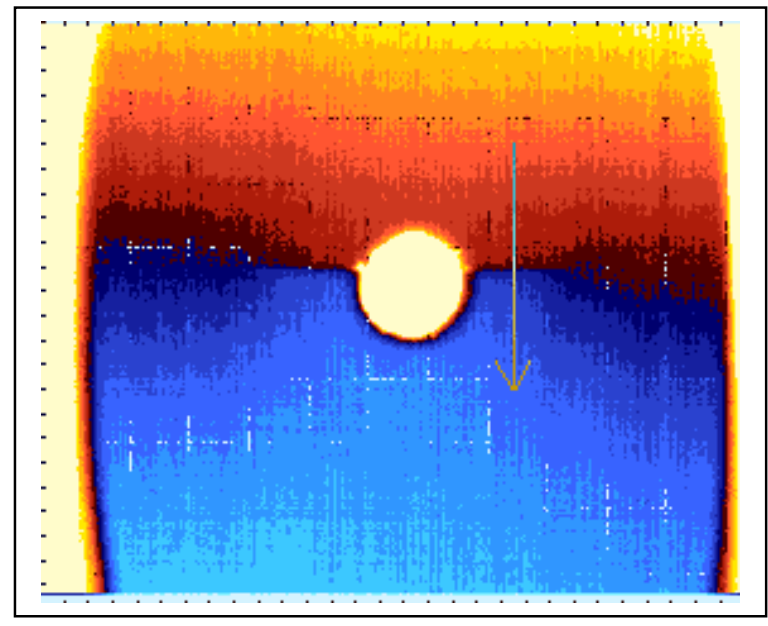

d) 9-second delay time

Figure A.131 Thermal images of Specimen 3 (using the active approach and heating time is 30 seconds) at 550,000 loading cycles. The distance between IR camera and test specimen is $150 \mathrm{~mm}$. 


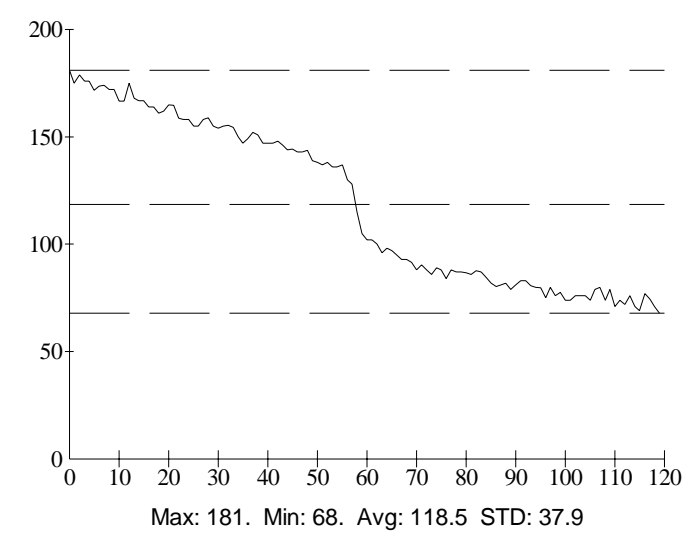

a) 1-second delay time

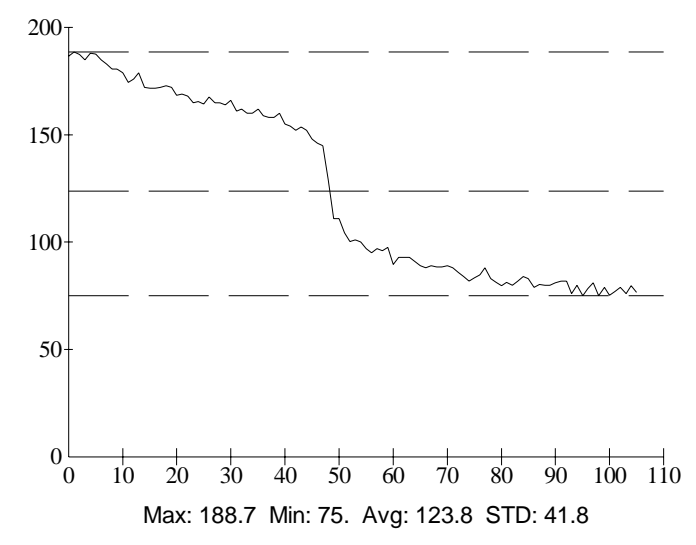

c) 6-second delay time

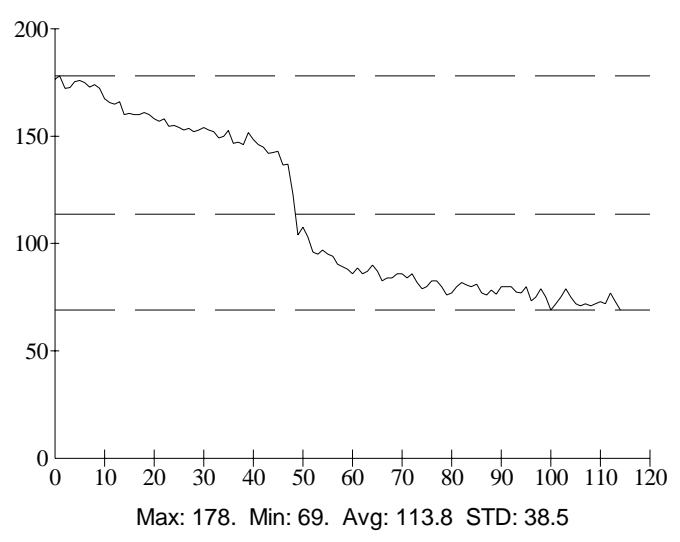

b) 3-second delay time

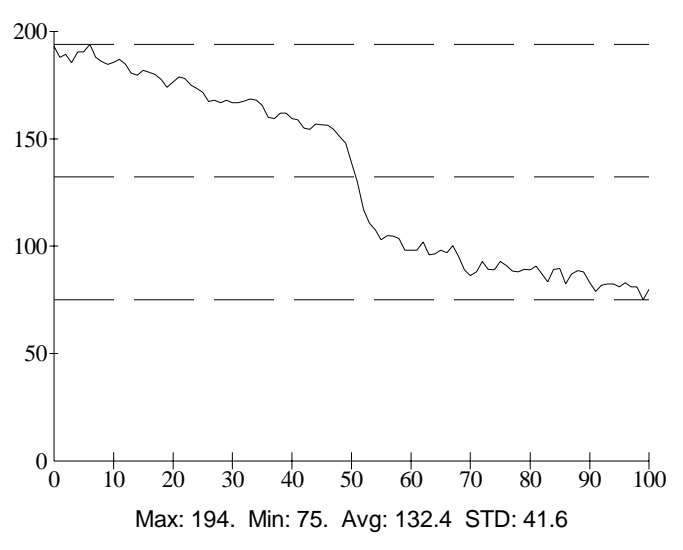

d) 9-second delay time

Figure A.132 Thermal intensity profile along the line across the fatigue crack shown in Figure A.131. 


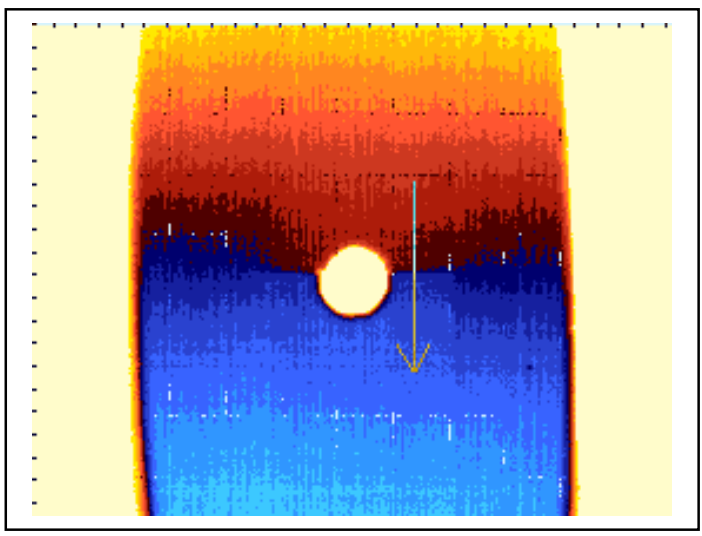

a) 1-second delay time

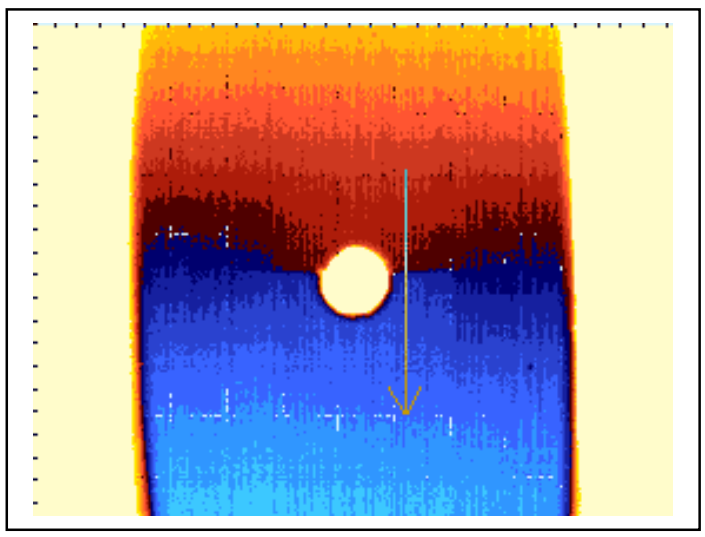

c) 6-second delay time

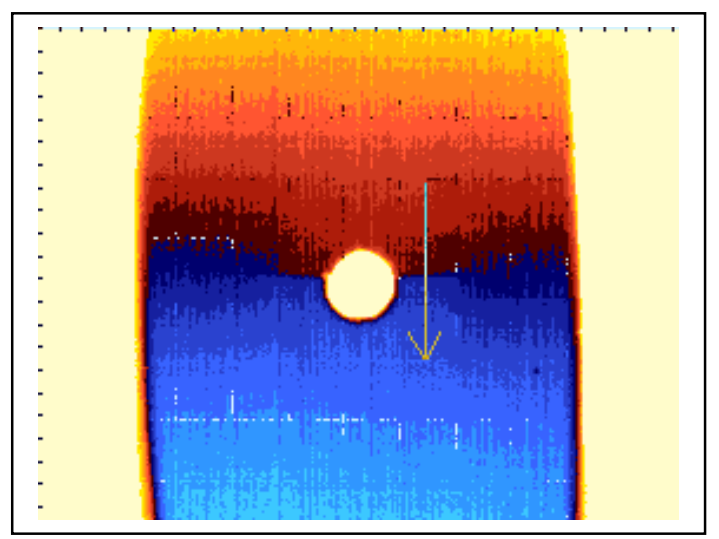

b) 3-second delay time

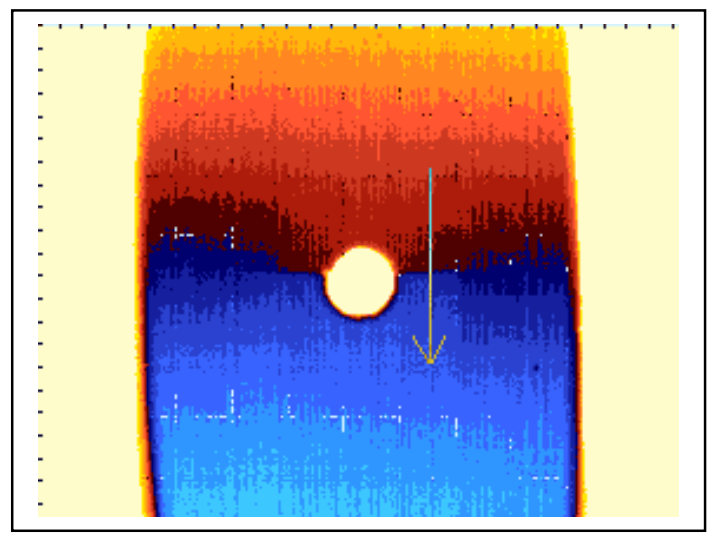

d) 9-second delay time

Figure A.133 Thermal images of Specimen 3 (using the active approach and heating time is 30 seconds) at 550,000 loading cycles. The distance between IR camera and test specimen is $225 \mathrm{~mm}$. 


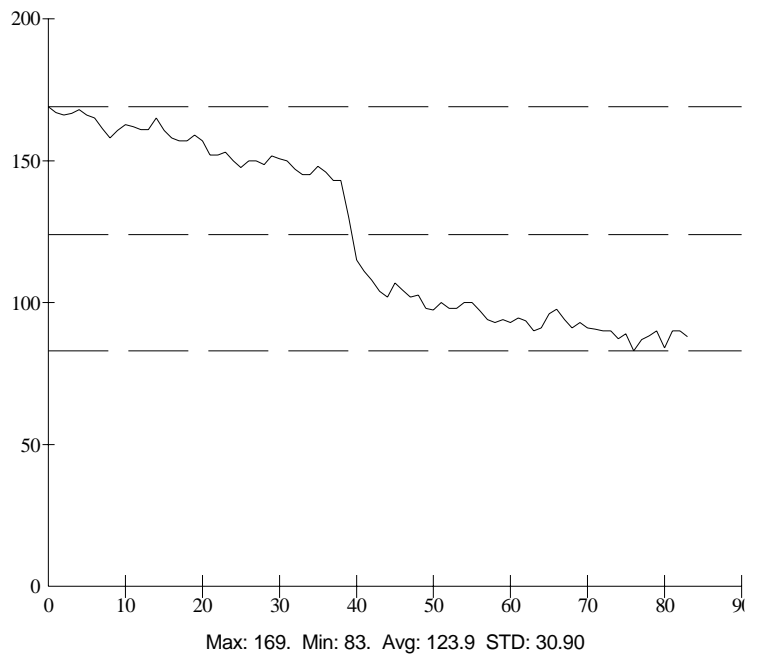

a) 1-second delay time

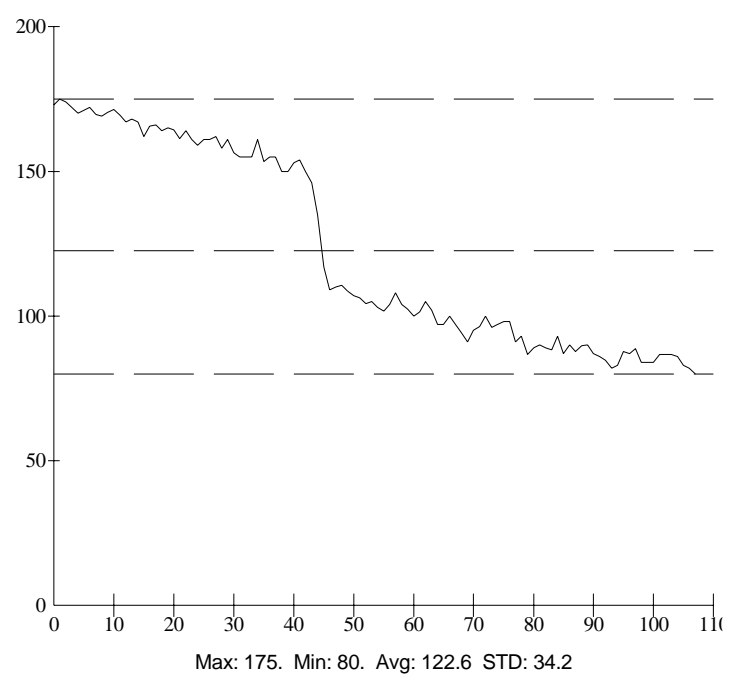

c) 6-second delay time

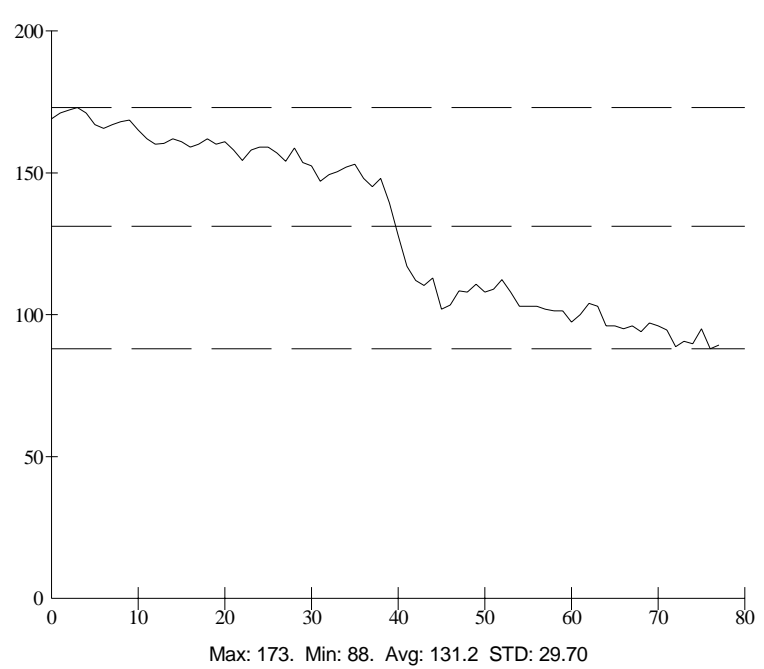

b) 3-second delay time

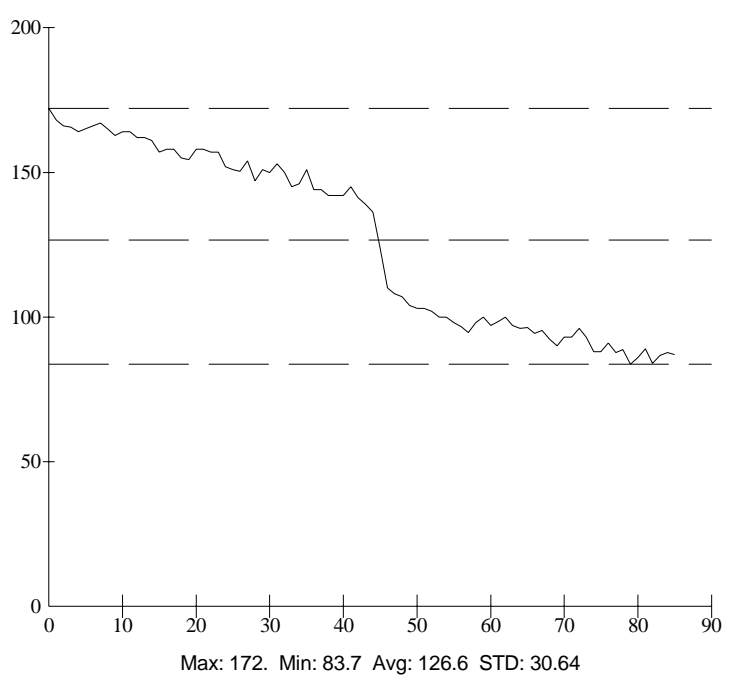

d) 9-second delay time

Figure A.134 Thermal intensity profile along the line across the fatigue crack shown in Figure A.133. 


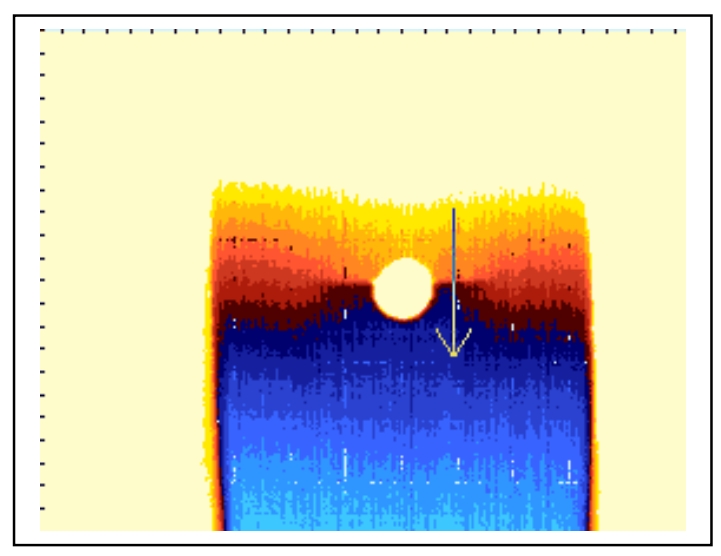

a) 1-second delay time

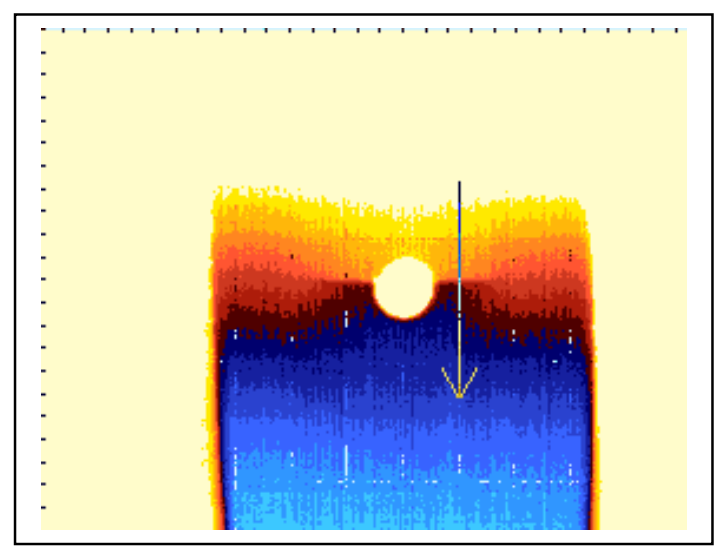

c) 6-second delay time

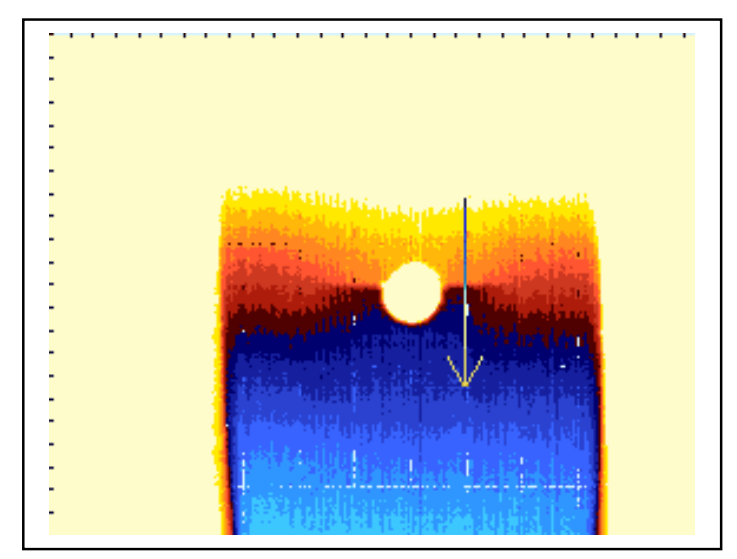

b) 3-second delay time

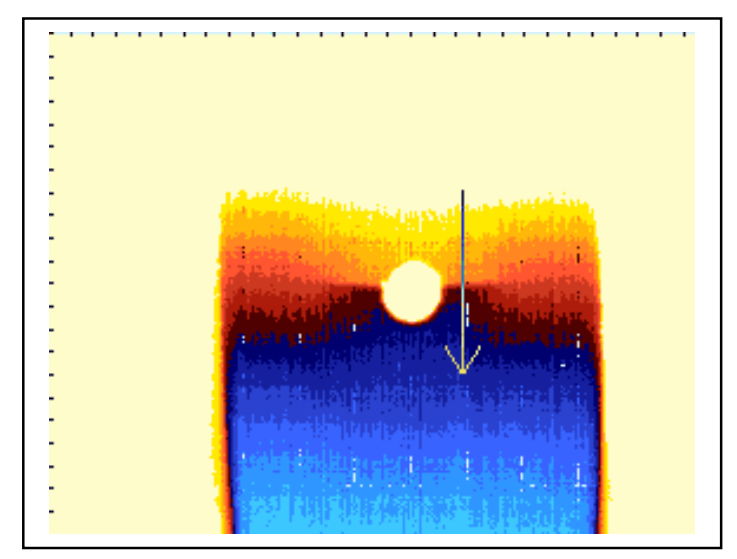

d) 9-second delay time

Figure A.135 Thermal images of Specimen $\mathrm{CH}-3$ (using the active approach and heating time is 30 seconds) at 550,000 loading cycles. The distance between IR camera and test specimen is $300 \mathrm{~mm}$. 


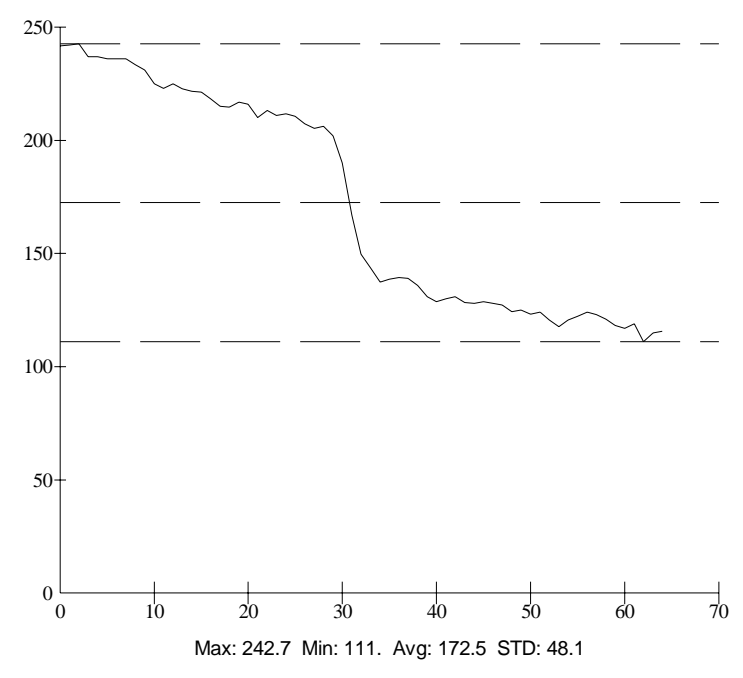

a) 1-second delay time

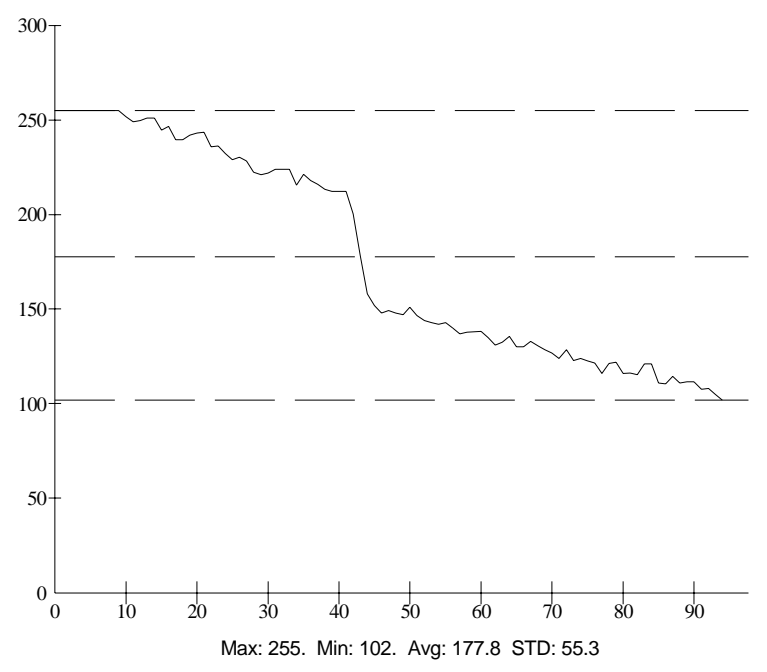

c) 6-second delay time

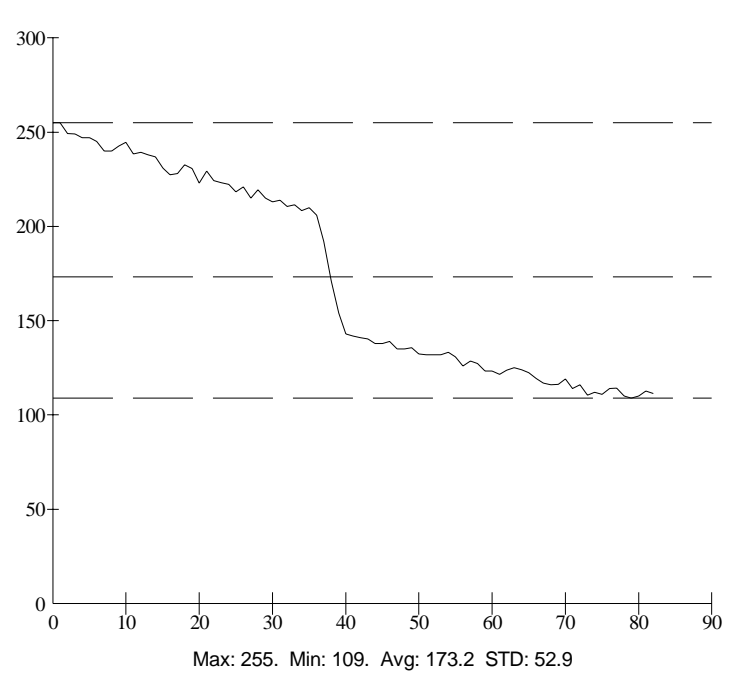

b) 3-second delay time

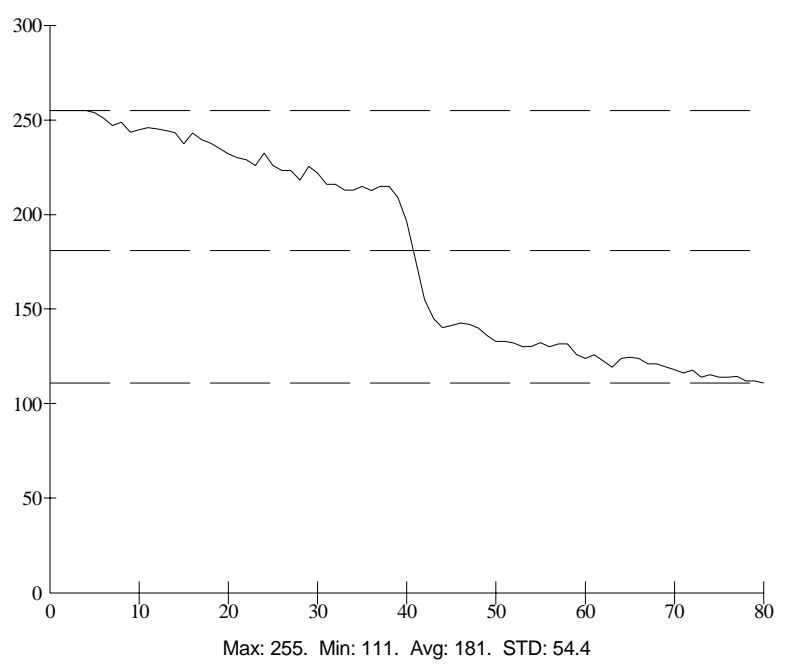

d) 9-second delay time

Figure A.136 Thermal intensity profile along the line across the fatigue crack shown in Figure A.135. 


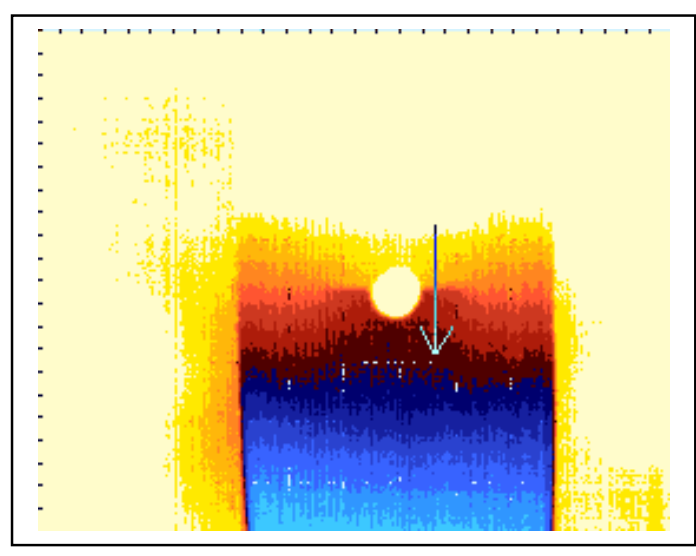

a) 1-second delay time

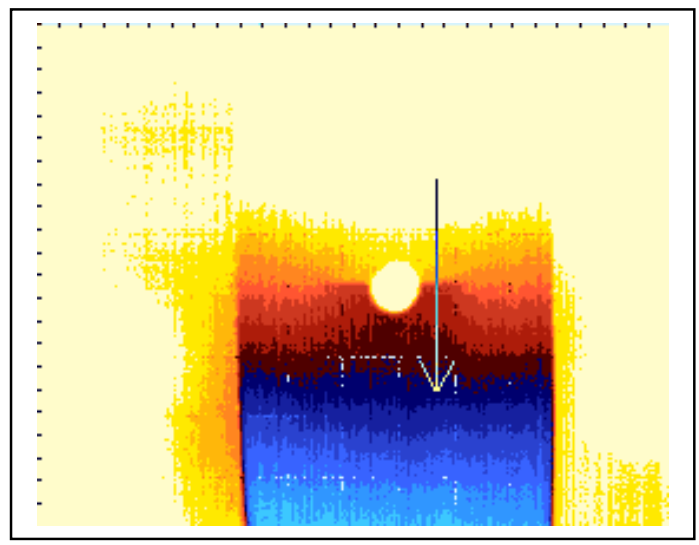

c) 6-second delay time

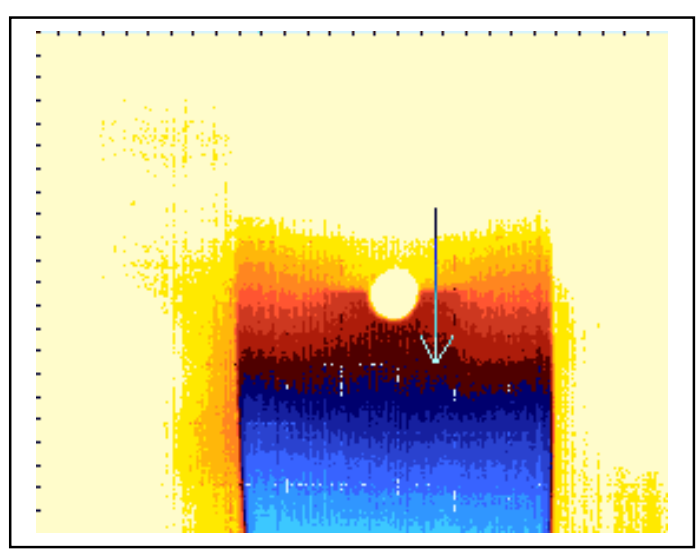

b) 3-second delay time

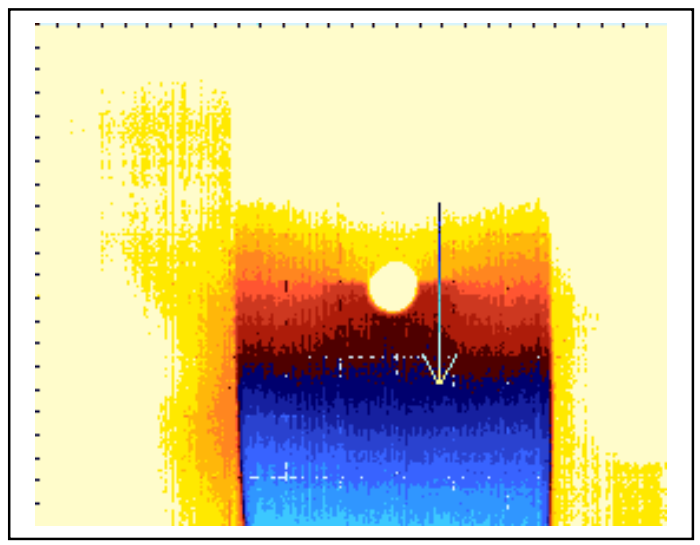

d) 9-second delay time

Figure A.137 Thermal images of Specimen $\mathrm{CH}-3$ (using the active approach and heating time is 30 seconds) at 550,000 loading cycles. The distance between IR camera and test specimen is $375 \mathrm{~mm}$. 


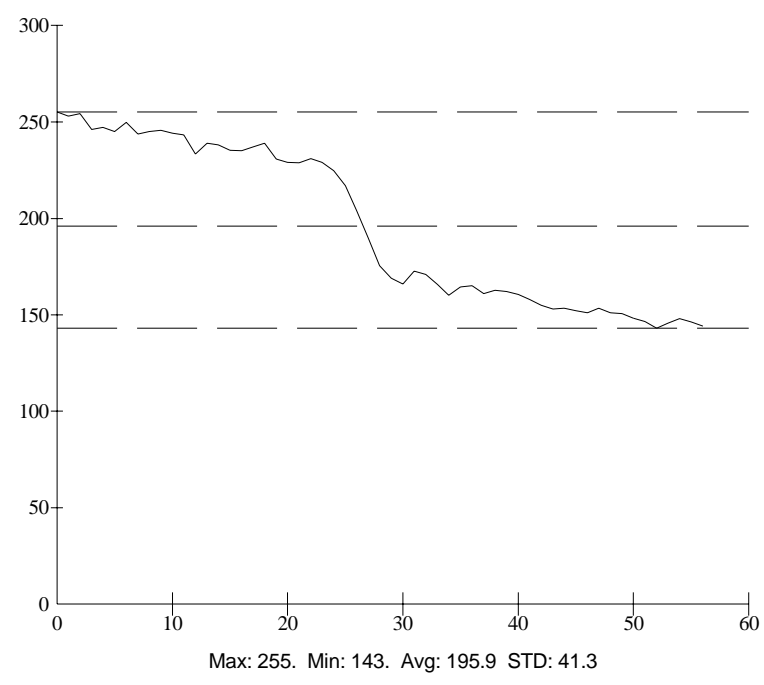

a) 1-second delay time

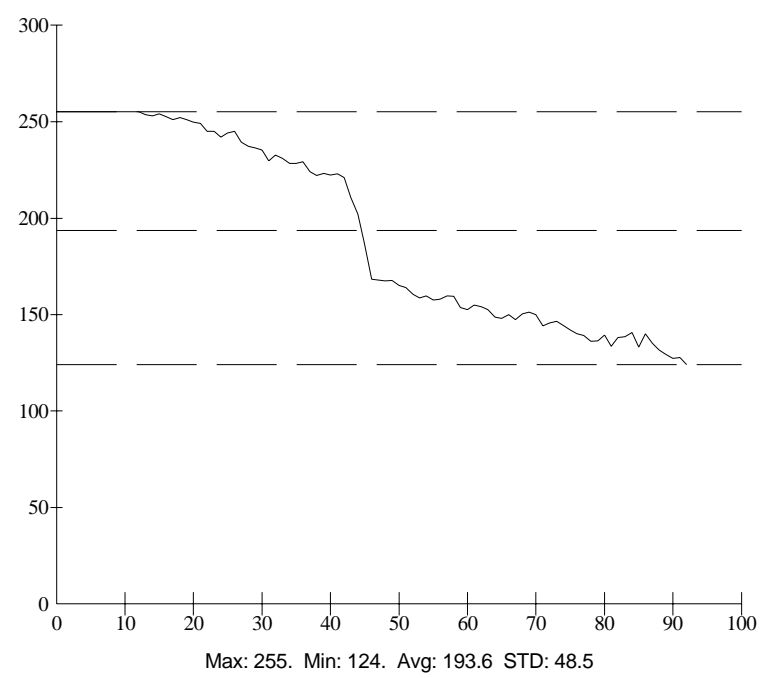

c) 6-second delay time

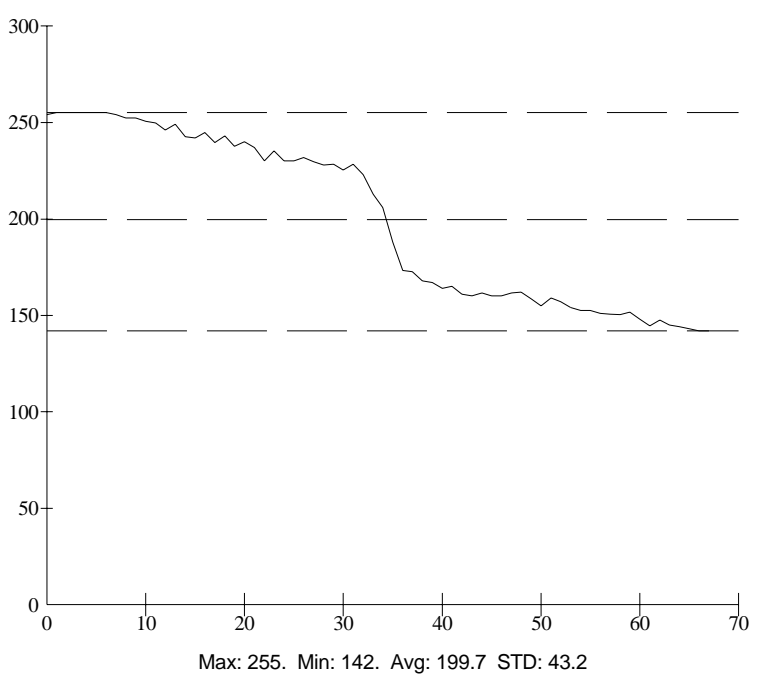

b) 3-second delay time

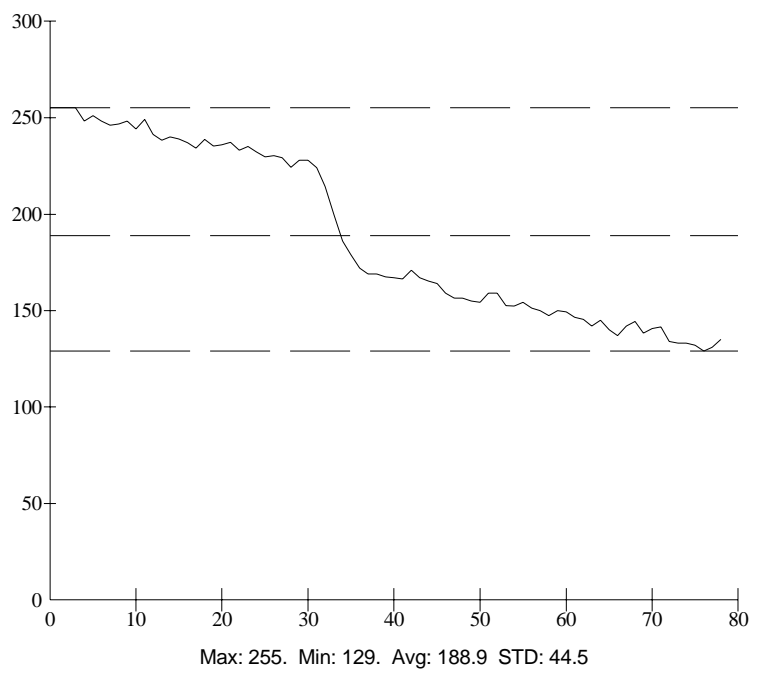

d) 9-second delay time

Figure A.138 Thermal intensity profile along the line across the fatigue crack shown in Figure A.137. 


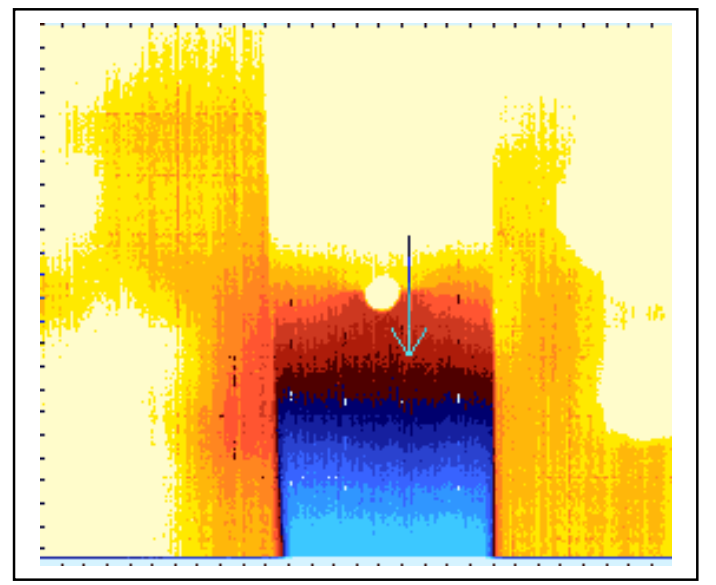

a) 1-second delay time

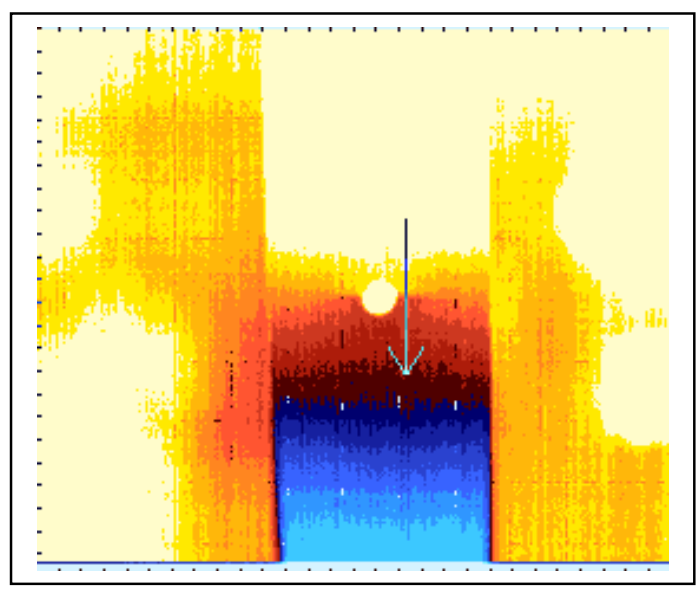

c) 6-second delay time

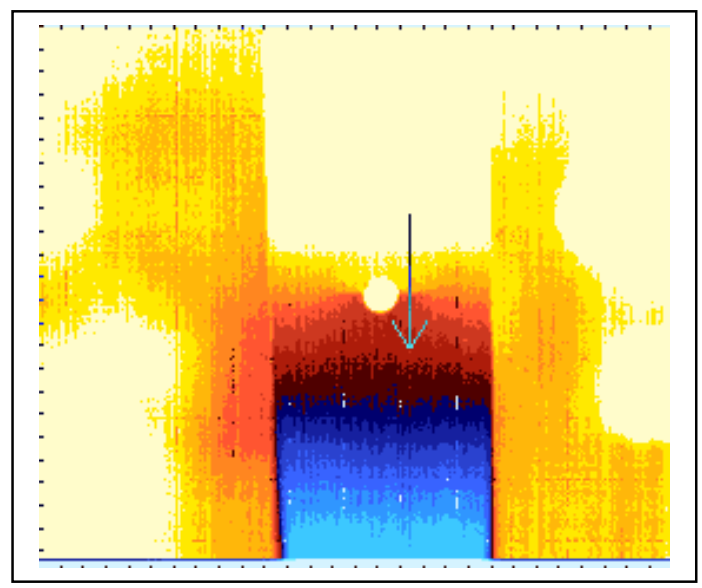

b) 3-second delay time

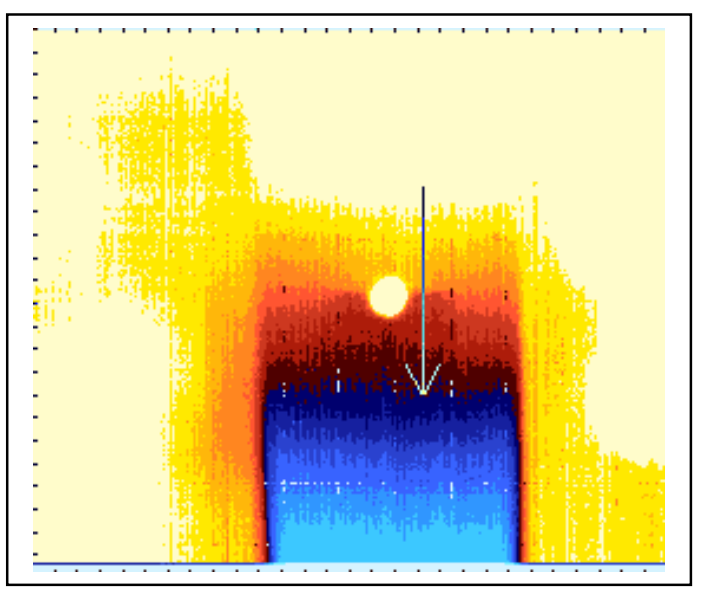

d) 9-second delay time

Figure A.139 Thermal images of Specimen $\mathrm{CH}-3$ (using the active approach and heating time is 30 seconds) at 550,000 loading cycles. The distance between IR camera and test specimen is $450 \mathrm{~mm}$. 


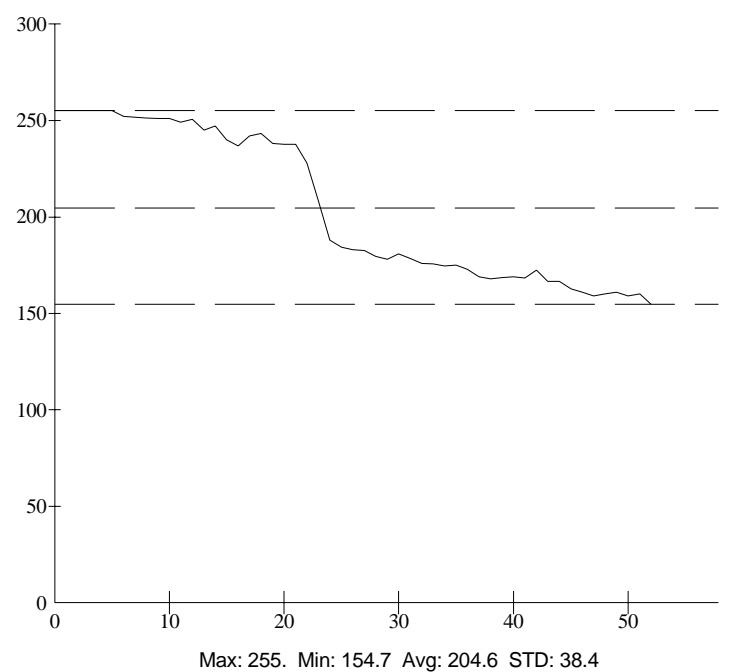

a) 1-second delay time

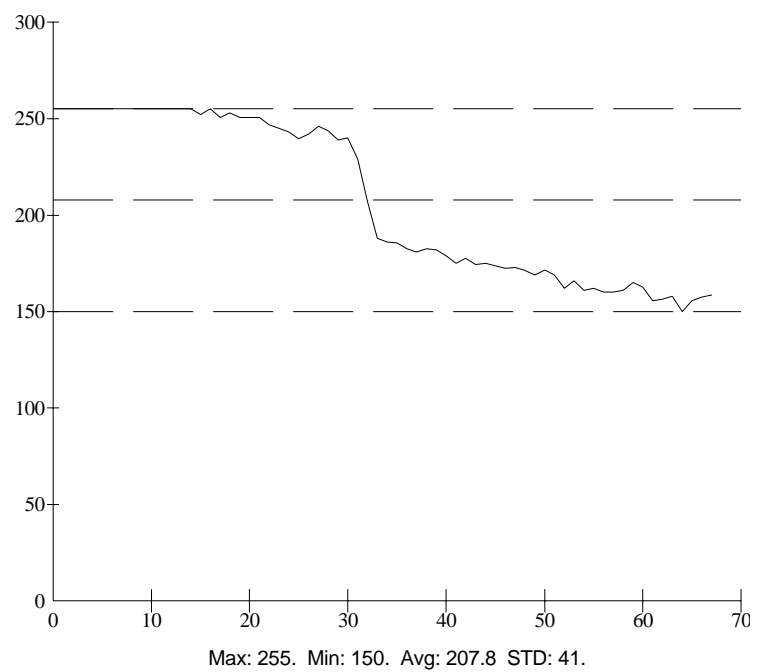

c) 6-second delay time

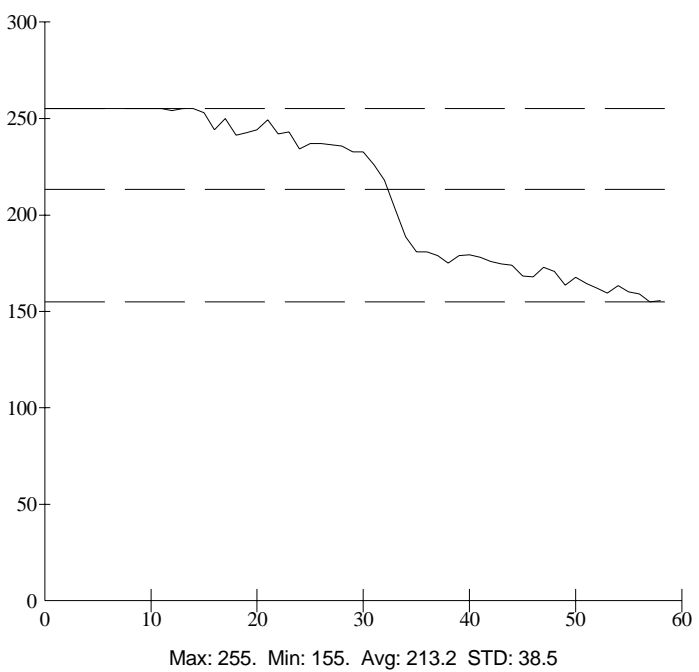

b) 3-second delay time

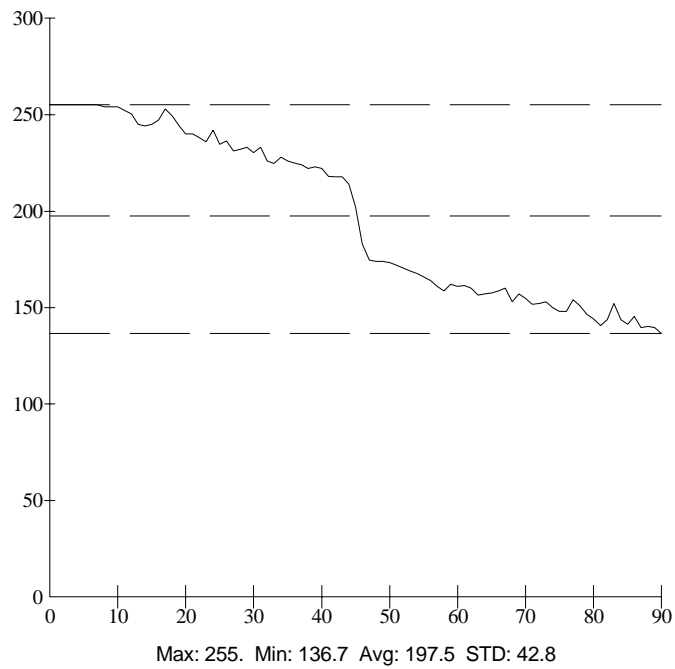

d) 9-second delay time

Figure A.140 Thermal intensity profile along the line across the fatigue crack shown in Figure A.139. 


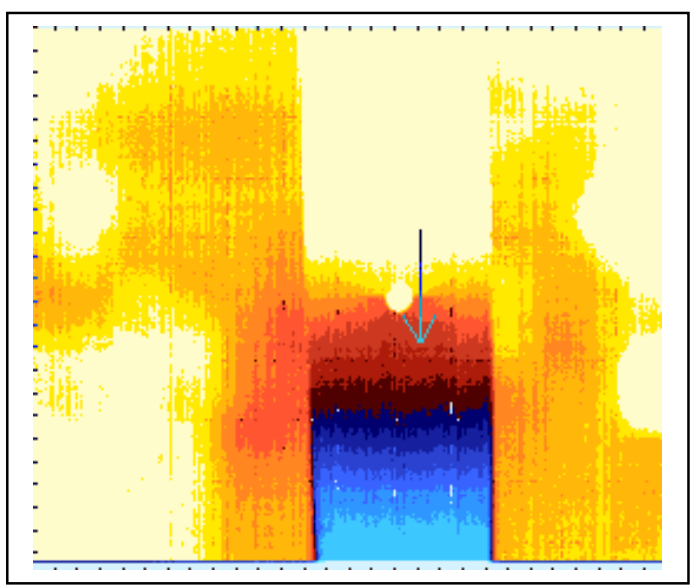

a) 1-second delay time

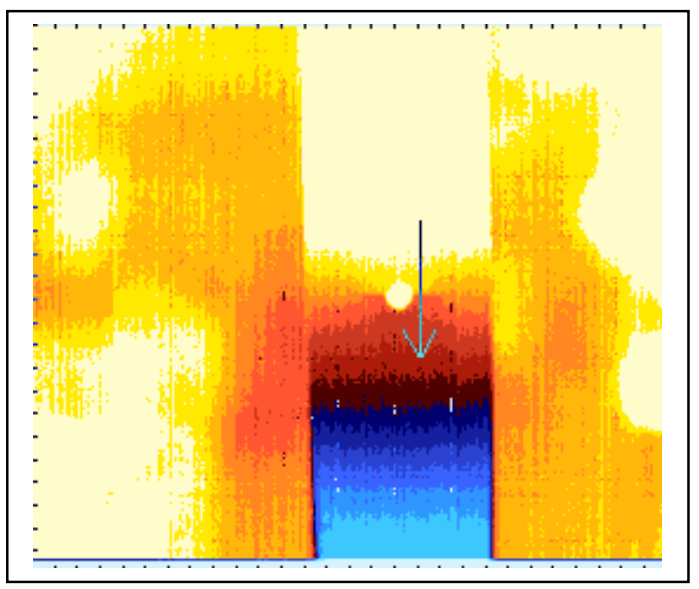

c) 6-second delay time

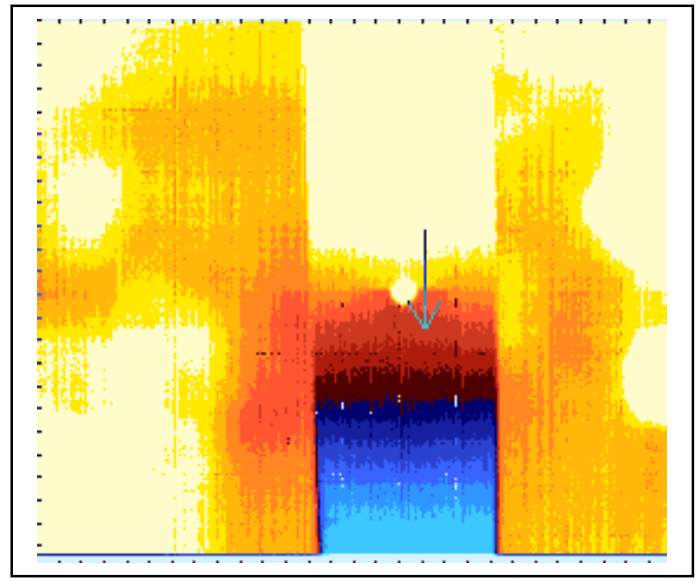

b) 3-second delay time

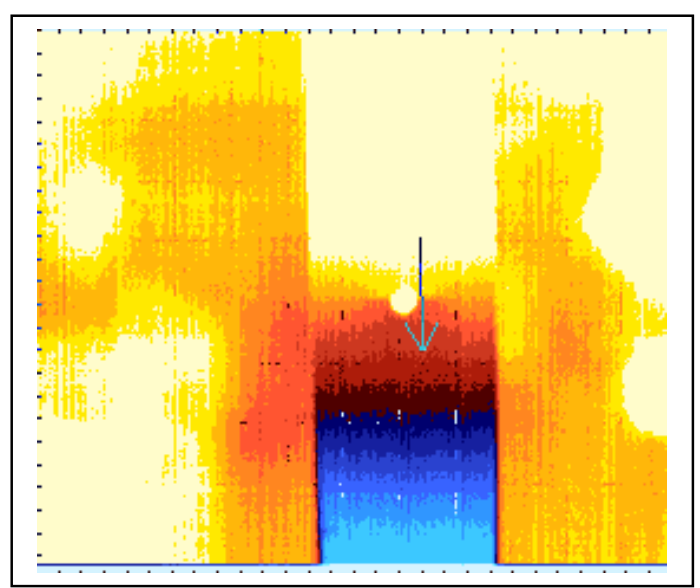

d) 9-second delay time

Figure A.141 Thermal images of Specimen CH-3 (using the active approach and heating time is 30 seconds) at 550,000 loading cycles. The distance between IR camera and test specimen is $525 \mathrm{~cm}$. 


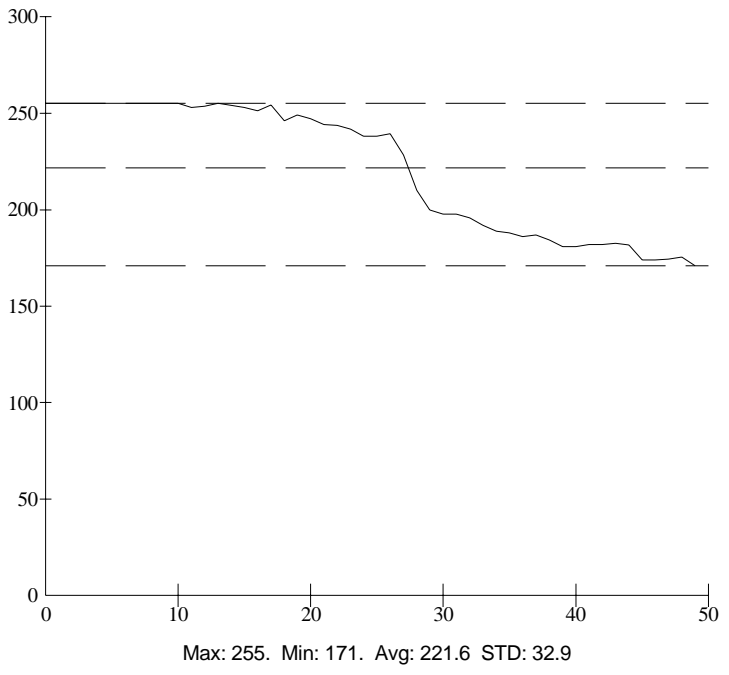

a) 1-second delay time

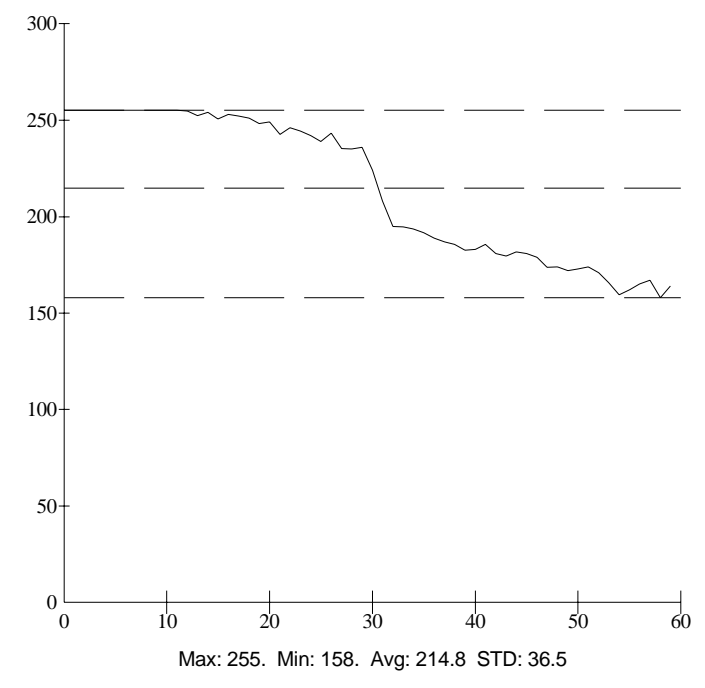

c) 6-second delay time

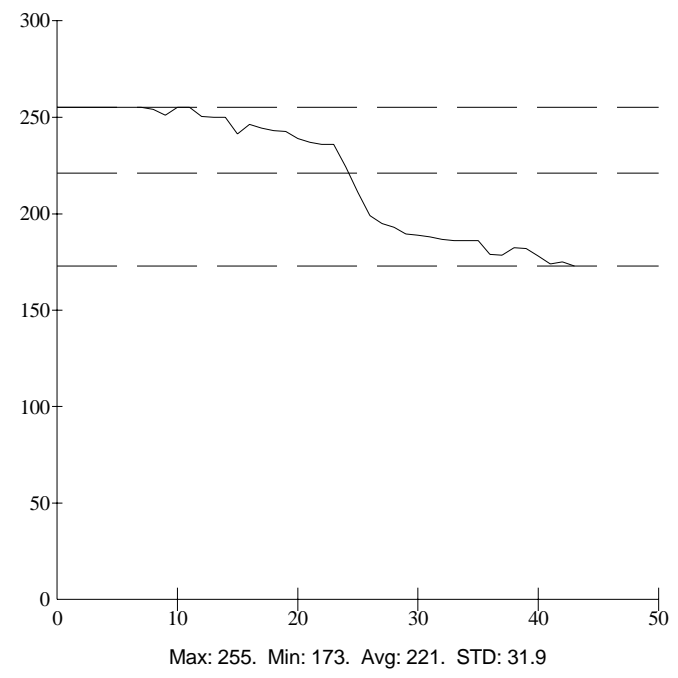

b) 3-second delay time

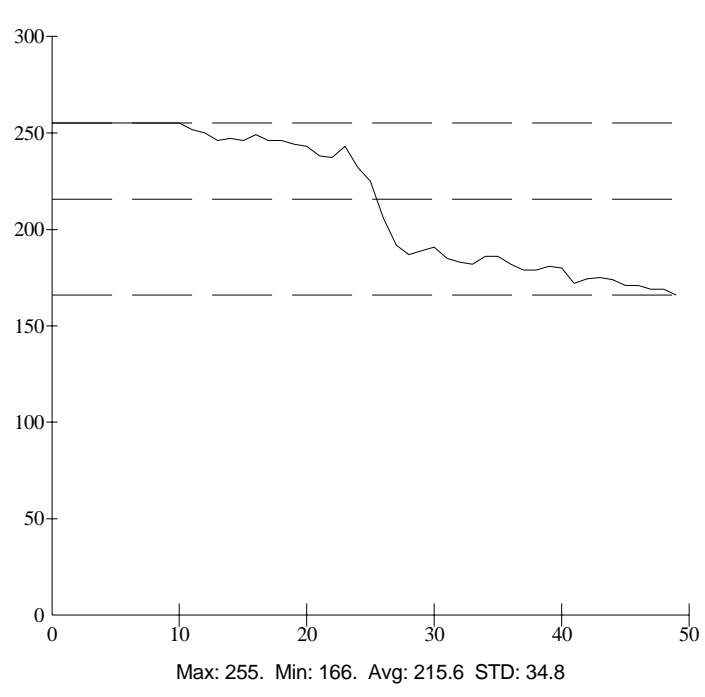

d) 9-second delay time

Figure A.142 Thermal intensity profile along the line across the fatigue crack shown in Figure A.141. 


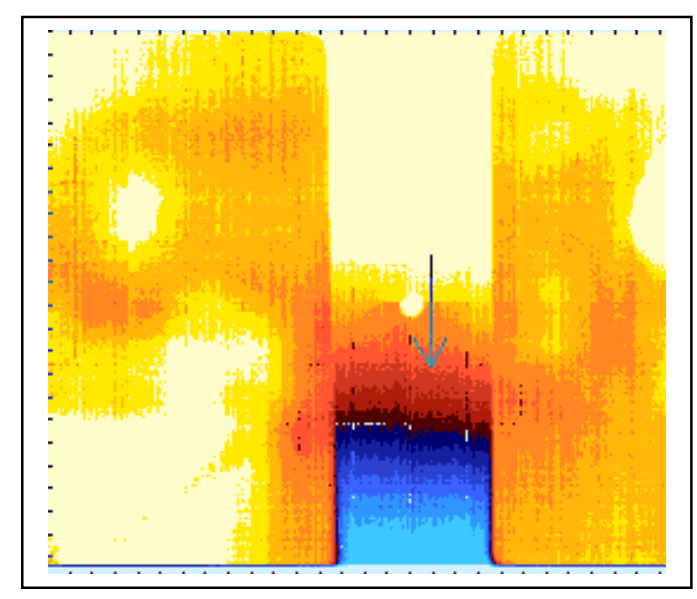

a) 1-second delay time

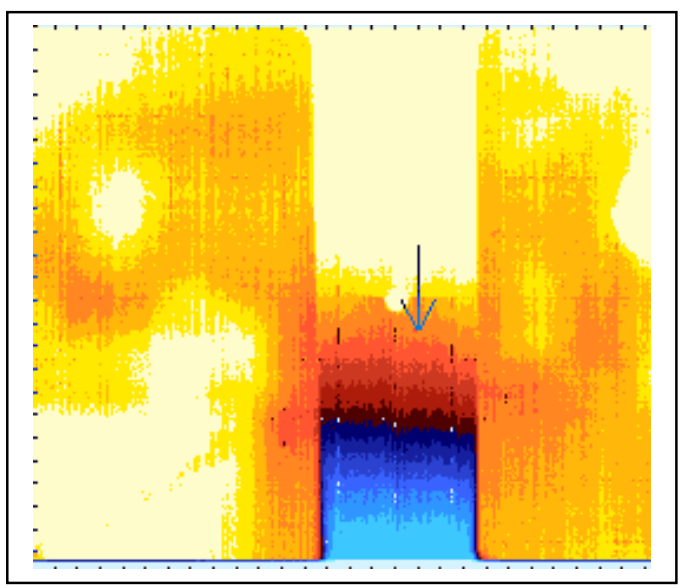

c) 6-second delay time

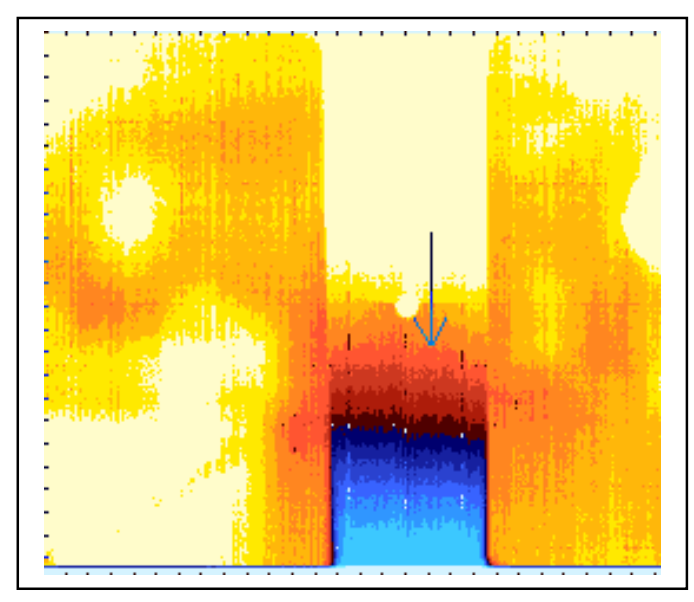

b) 3-second delay time

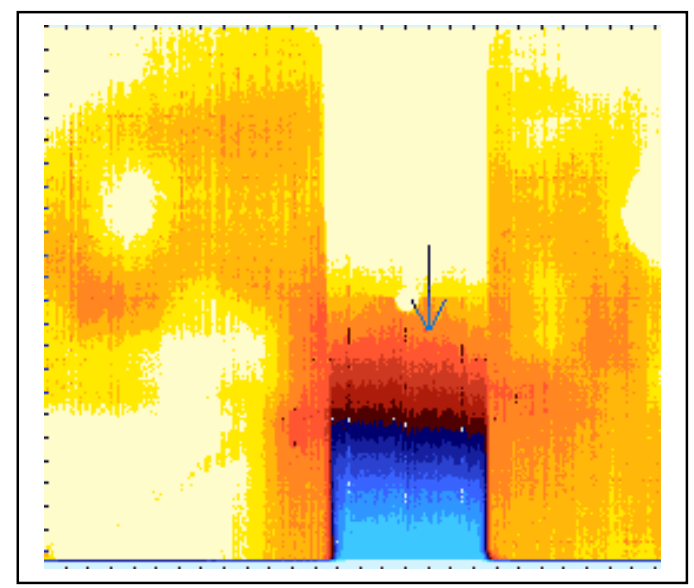

d) 9-second delay time

Figure A.143 Thermal images of Specimen CH-3 (using the active approach and heating time is 30 seconds) at 550,000 loading cycles. The distance between IR camera and test specimen is $600 \mathrm{~mm}$.. 


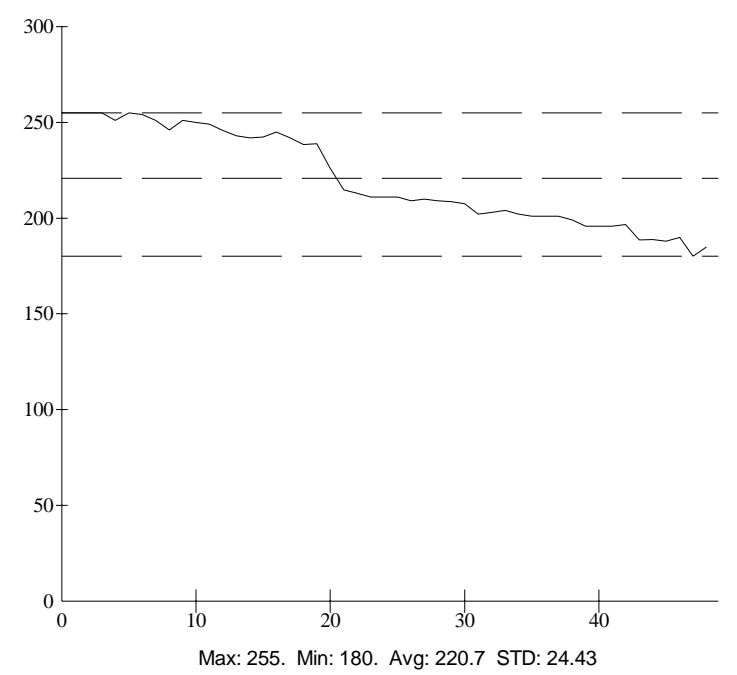

a) 1-second delay time

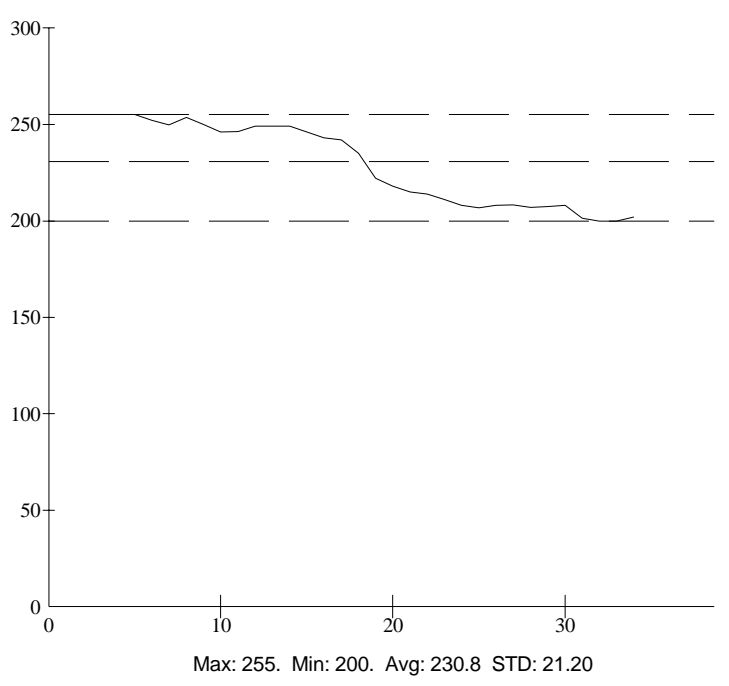

c) 6-second delay time

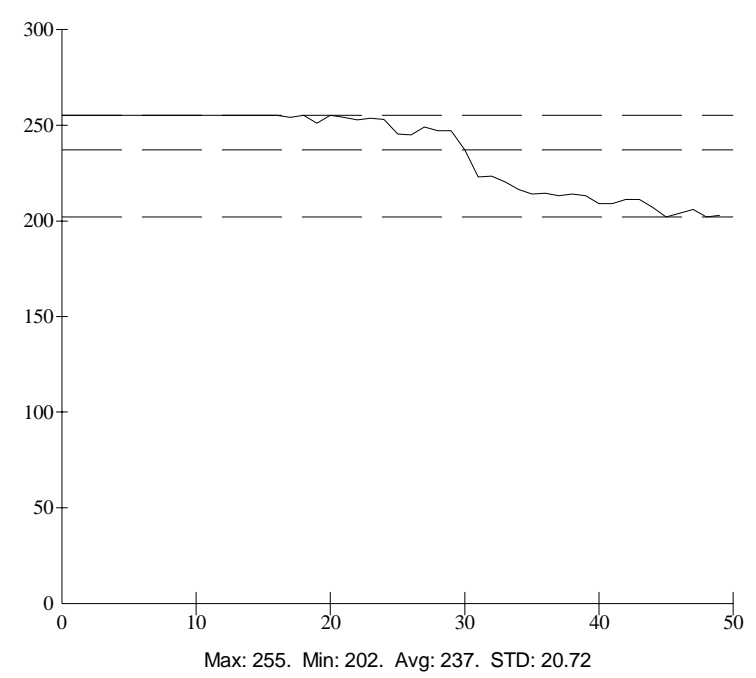

b) 3-second delay time

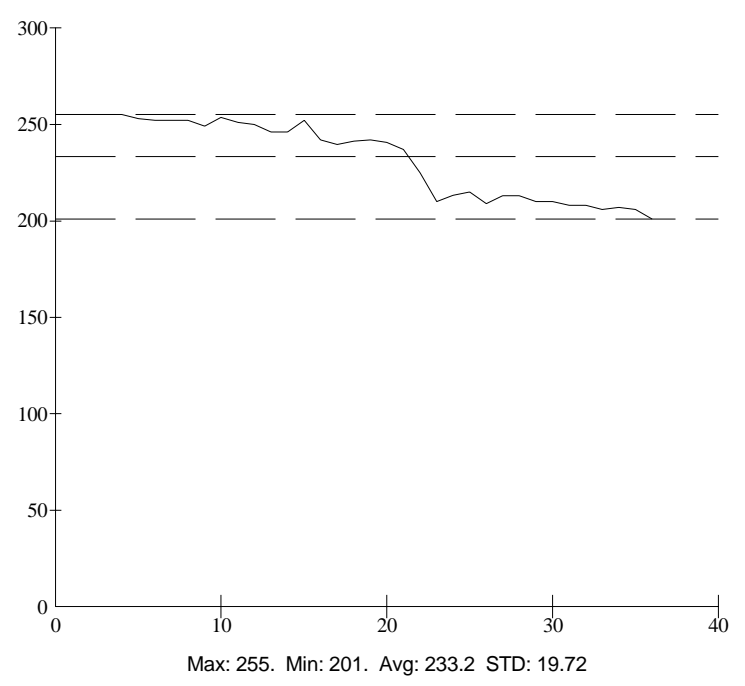

d) 9-second delay time

Figure A.144 Thermal intensity profile along the line across the fatigue crack shown in Figure A.143. 


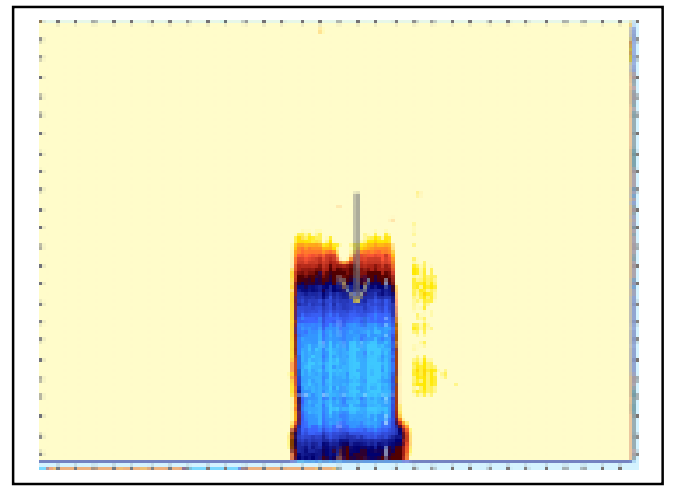

a) 1-second delay time

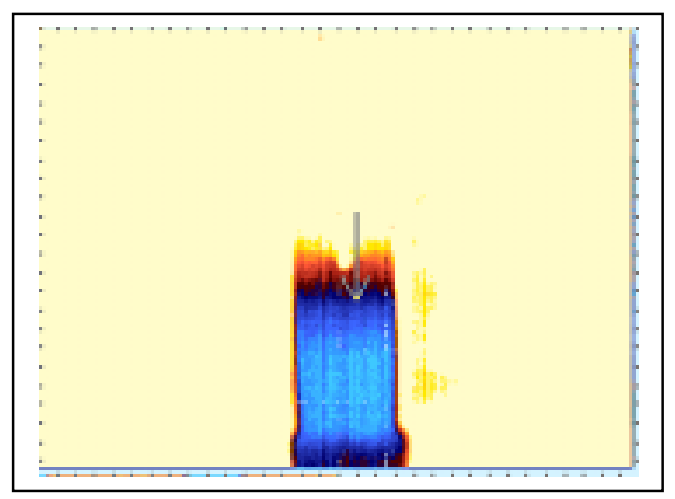

c) 6-second delay time

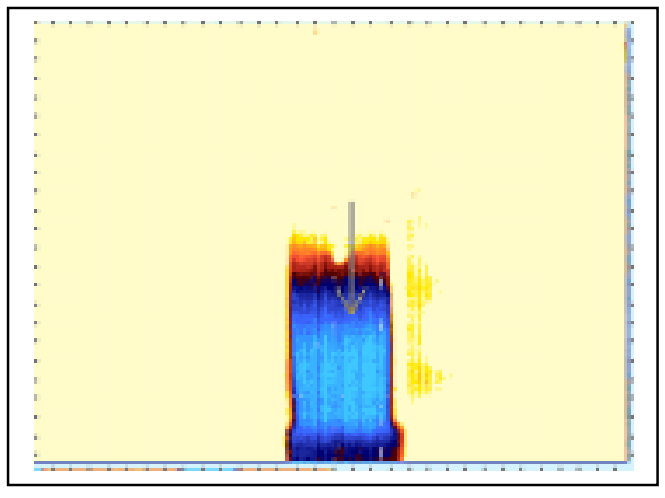

b) 3-second delay time

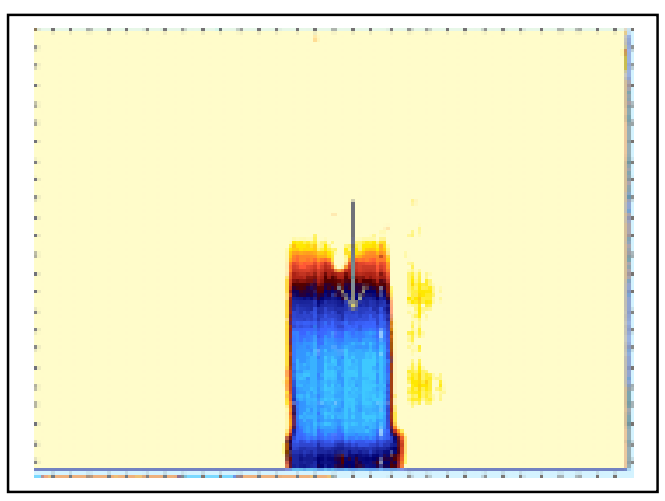

d) 9-second delay time

Figure A.145 Thermal images of Specimen CH-3 (using active approach and heating time is 30 seconds) at 550,000 loading cycles. The distance between IR camera and specimen is $675 \mathrm{~mm}$. 


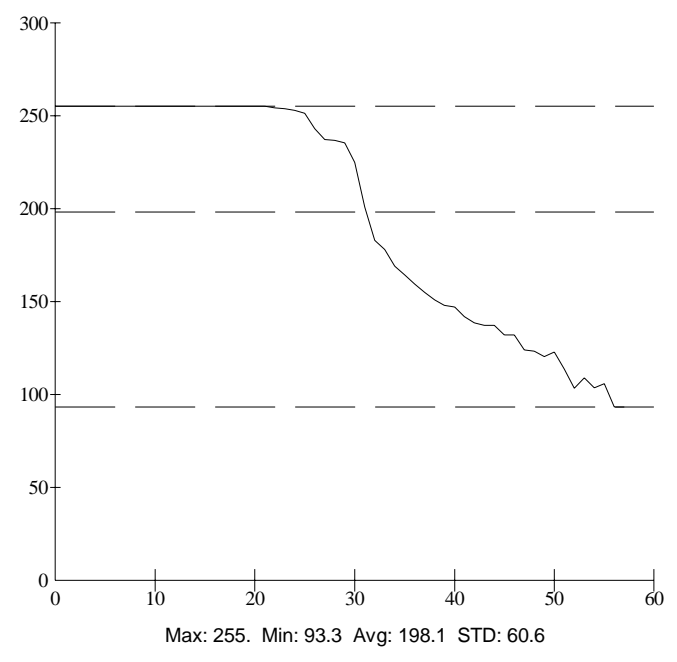

a) 1-second delay time

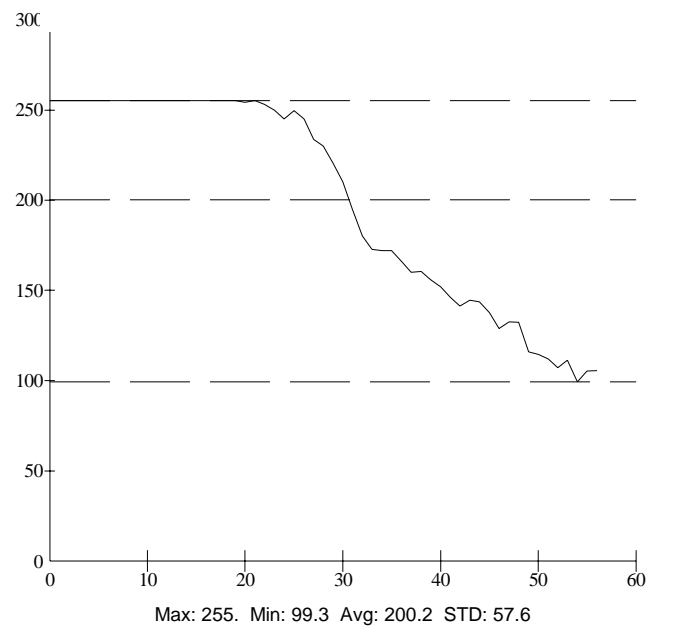

c) 6-second delay time

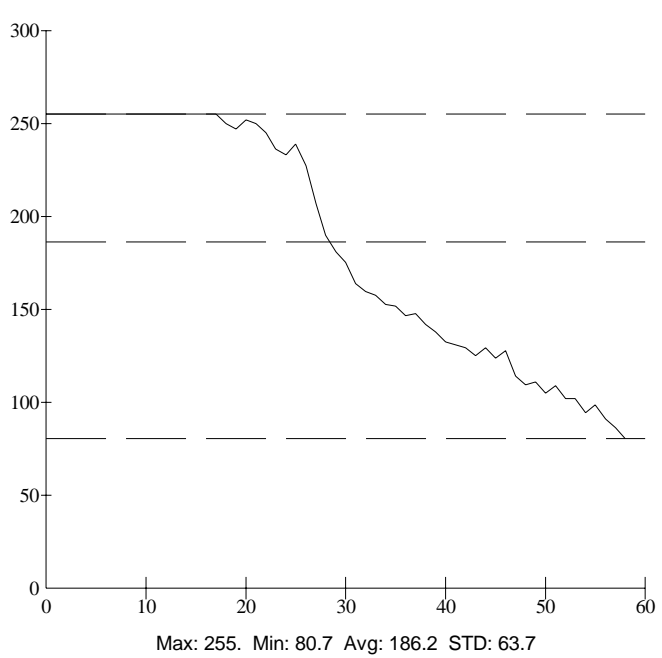

b) 3-second delay time

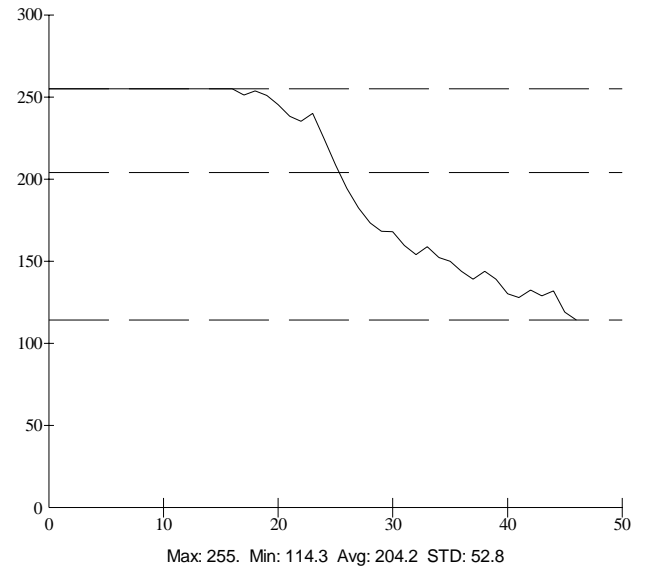

d) 9-second delay time

Figure A.146 Thermal intensity profile along the line across the fatigue crack shown in Figure A.145. 


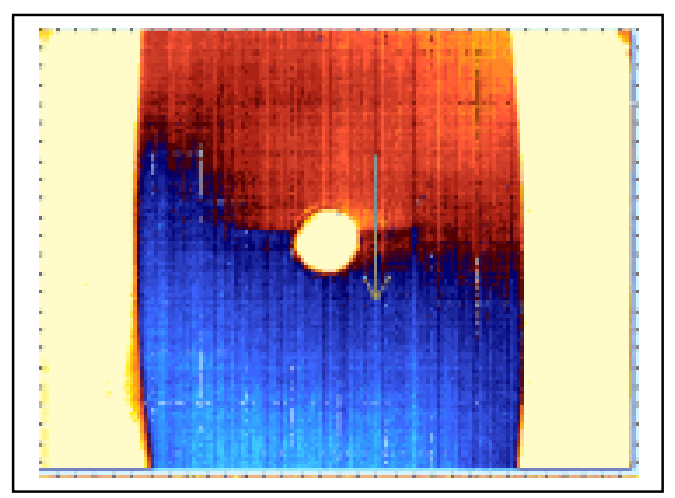

a) 1-second delay time

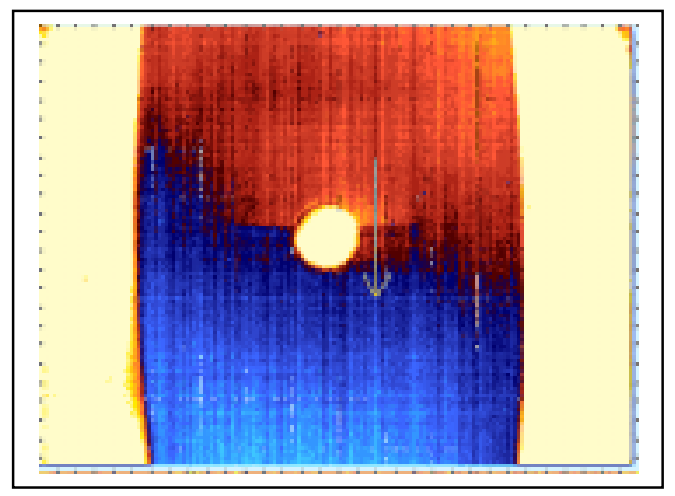

c) 6-second delay time

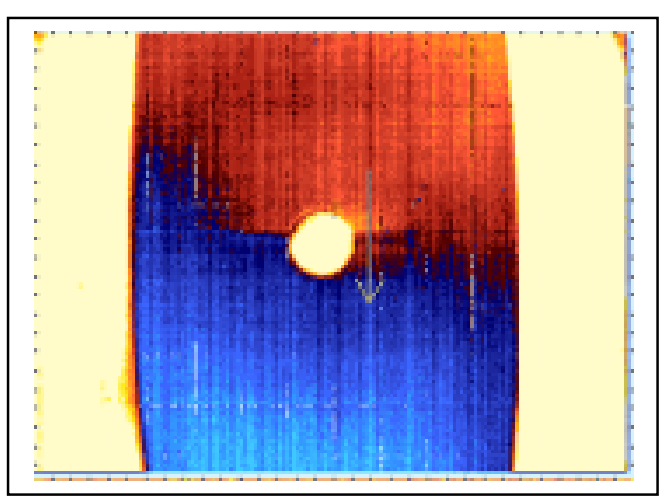

b) 3-second delay time

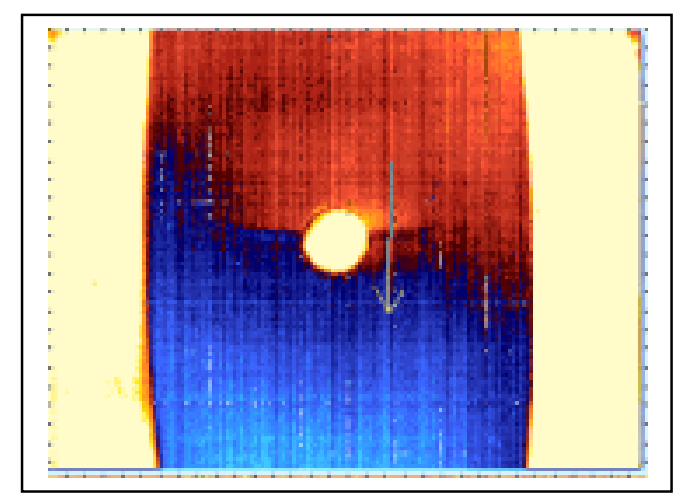

d) 9-second delay time

Figure A.147 Thermal images of unpainted Specimen CH-3 (using active approach and heating time is 30 seconds) at 550,000 loading cycles. The distance between IR camera and specimen is $150 \mathrm{~mm}$.. 


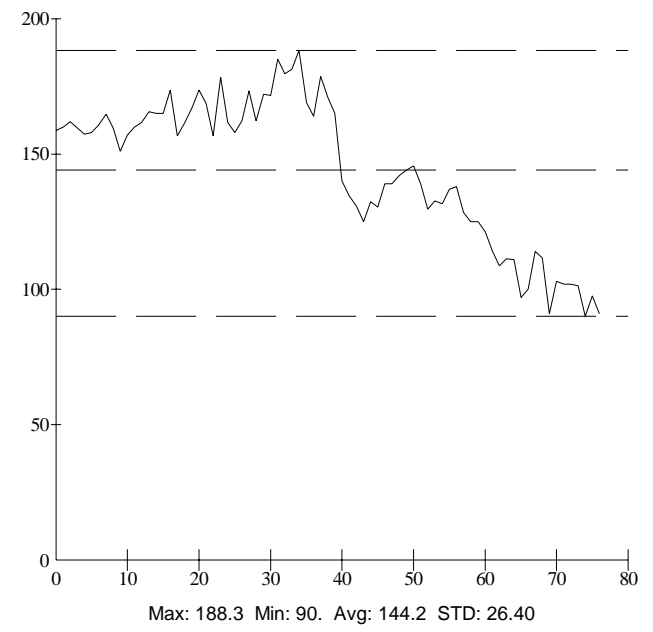

a) 1-second delay time

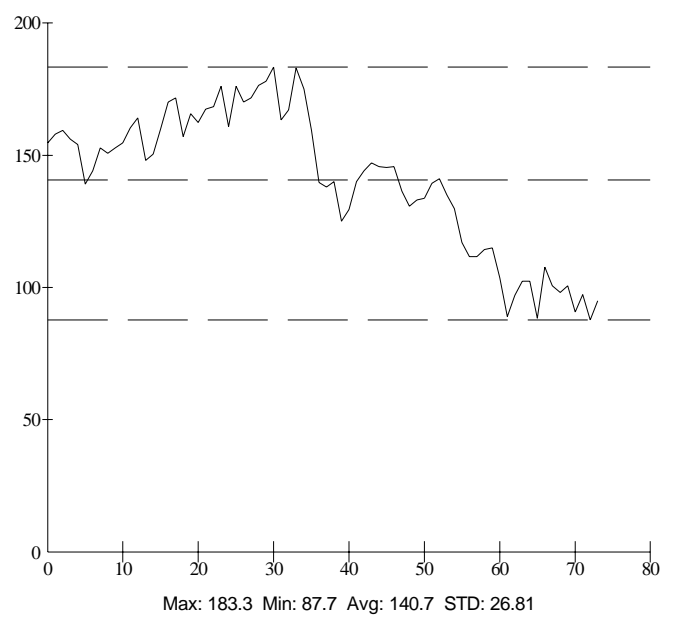

c) 6-second delay time

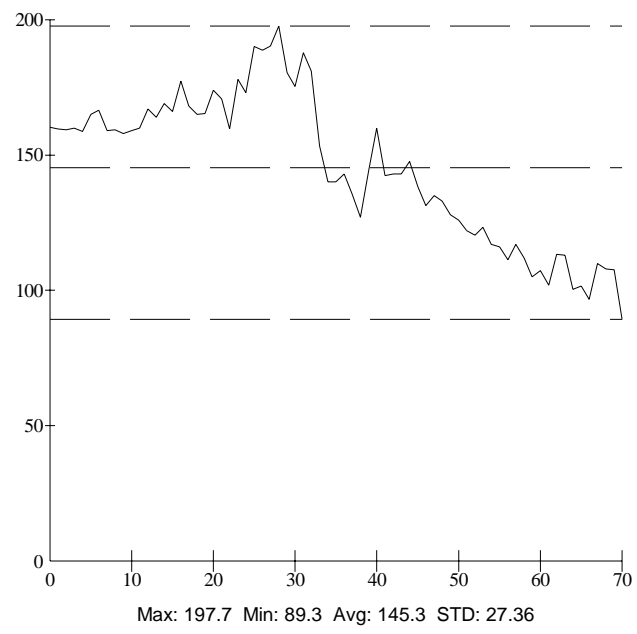

b) 3-second delay time

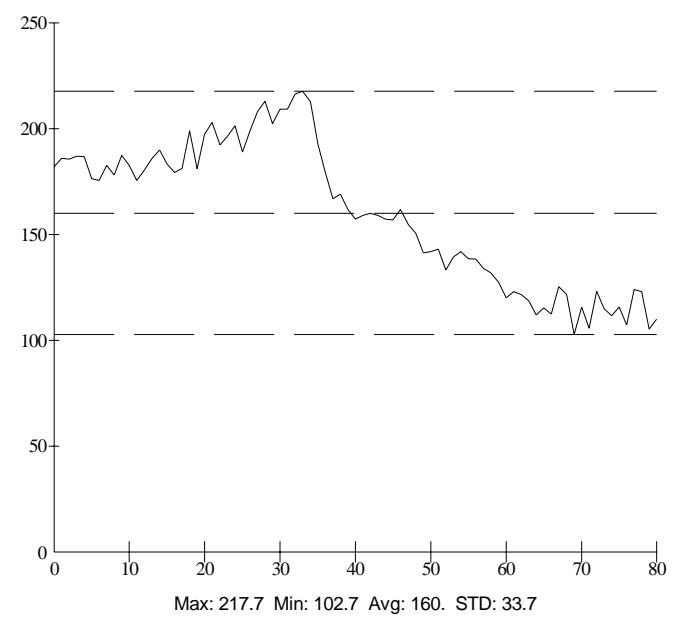

d) 9-second delay time

Figure A.148 Thermal intensity profile along the line across the fatigue crack shown in Figure A.147. 


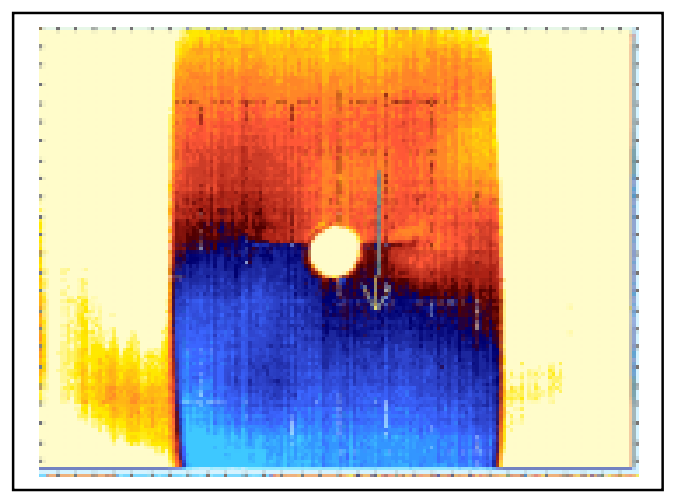

a) 1-second delay time

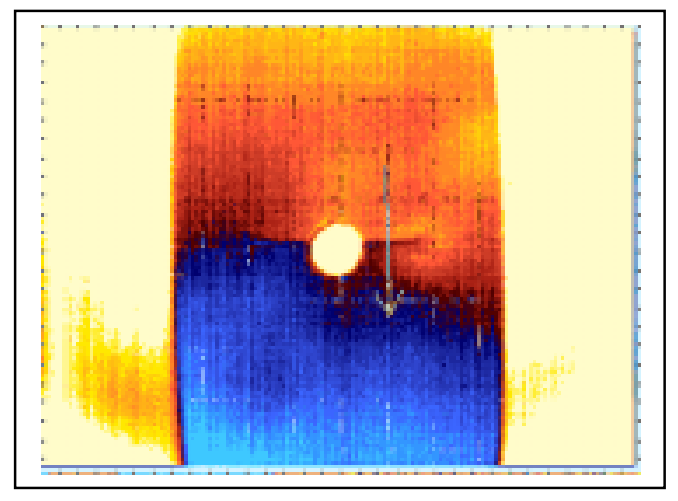

c) 6-second delay time

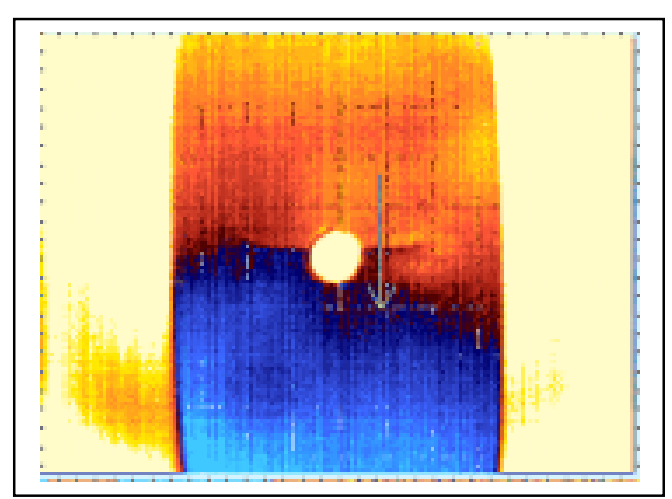

b) 3-second delay time

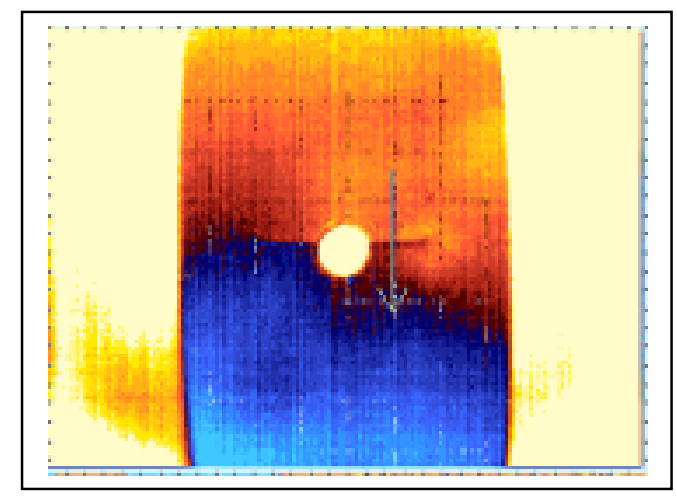

d) 9-second delay time

Figure A.149 Thermal images of unpainted Specimen CH-3 (using active approach and heating time is 30 seconds) at 550,000 loading cycles. The distance between IR camera and specimen is $225 \mathrm{~mm}$.. 


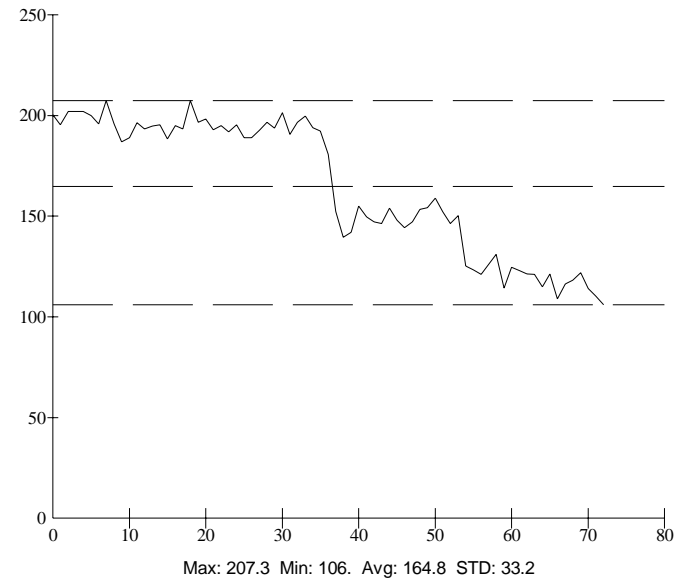

a) 1-second delay time

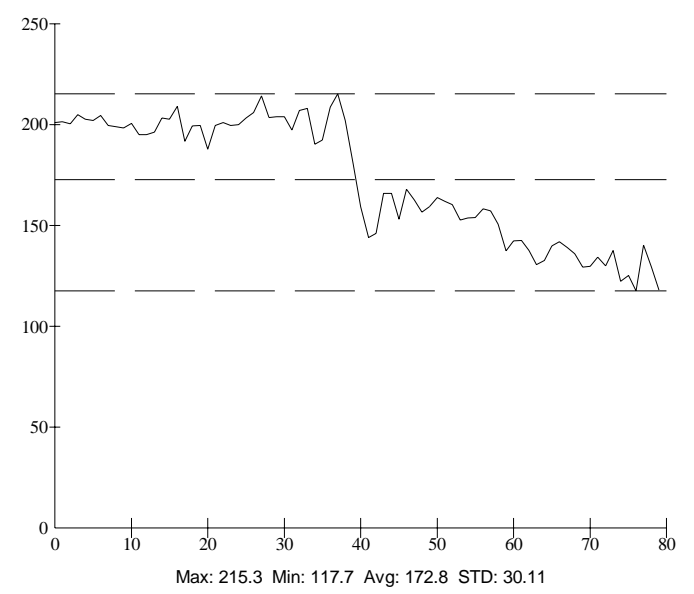

c) 6-second delay time

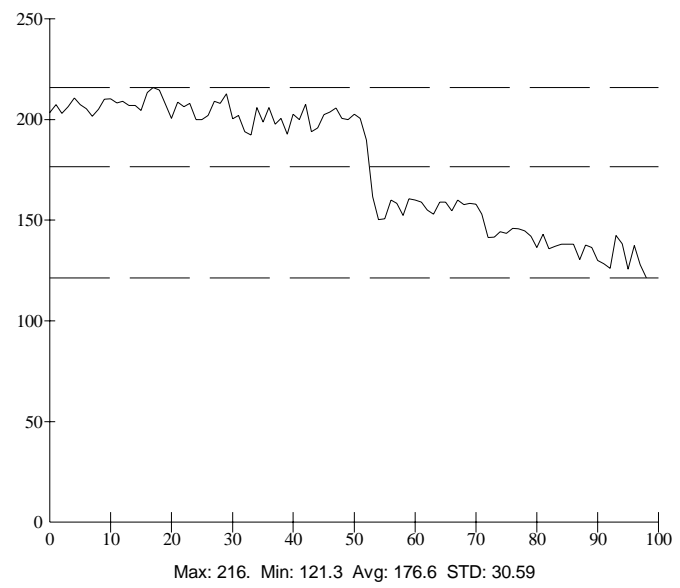

b) 3-second delay time

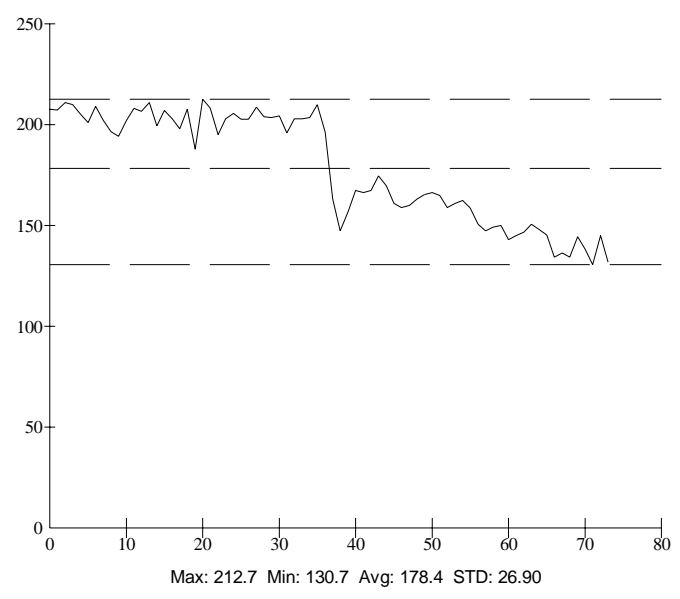

d) 9-second delay time

Figure A.150 Thermal intensity profile along the line across the fatigue crack shown in Figure A.149. 


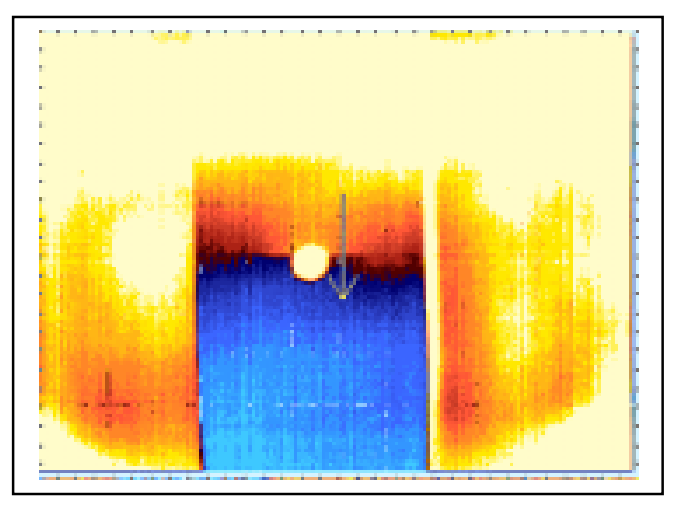

a) 1-second delay time

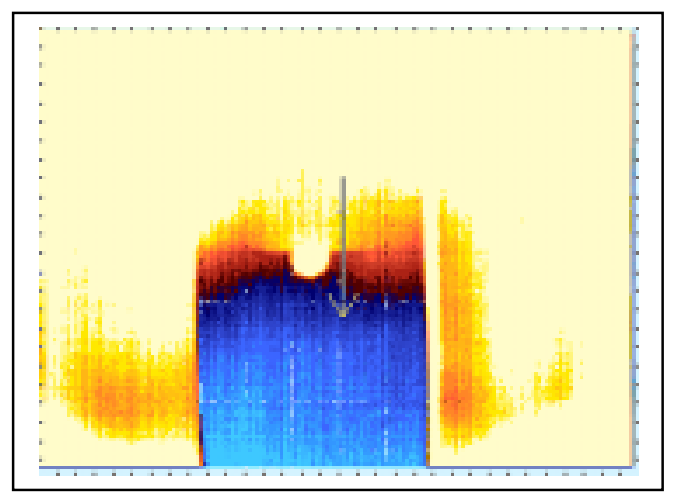

c) 6-second delay time

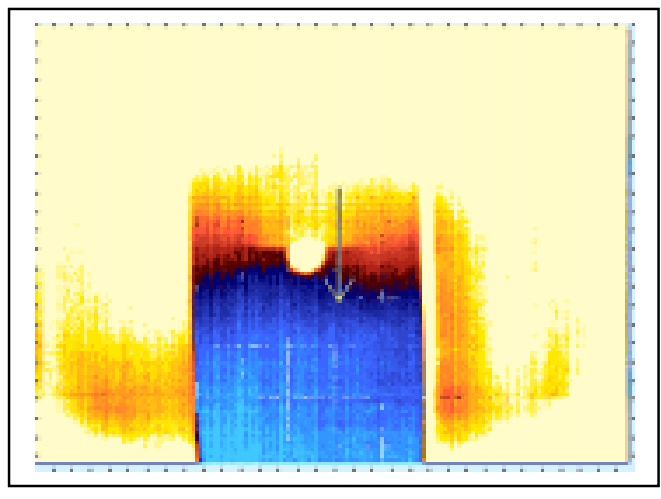

b) 3-second delay time

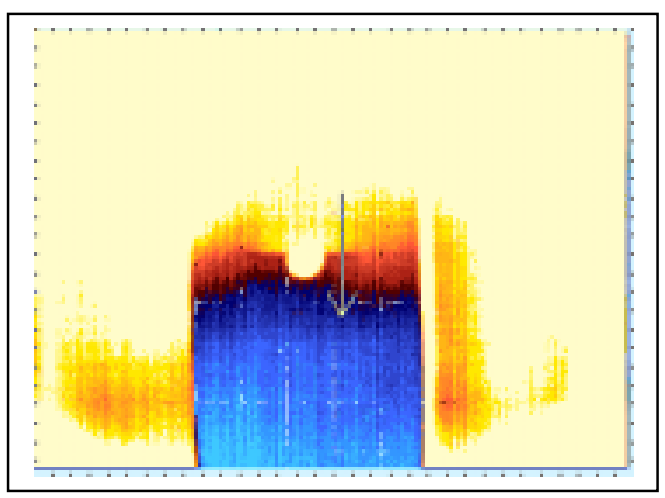

d) 9-second delay time

Figure A.151 Thermal images of unpainted Specimen $\mathrm{CH}-3$ (using active approach and heating time is 30 seconds) at 550,000 loading cycles. The distance between IR camera and specimen is $300 \mathrm{~mm}$.. 


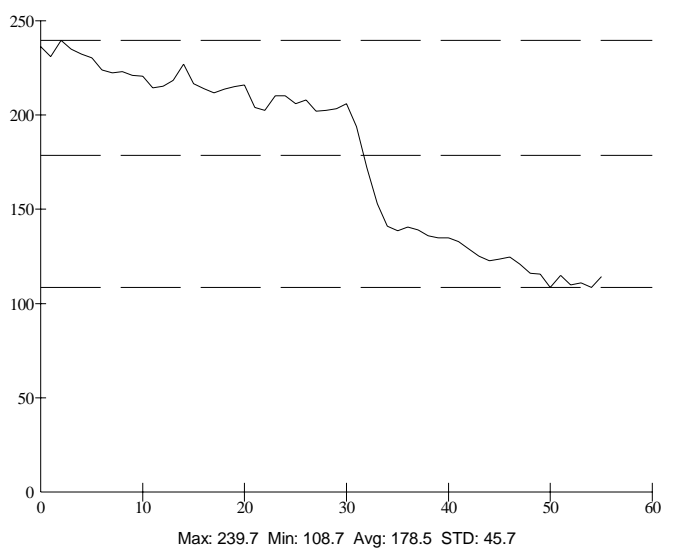

a) 1-second delay time

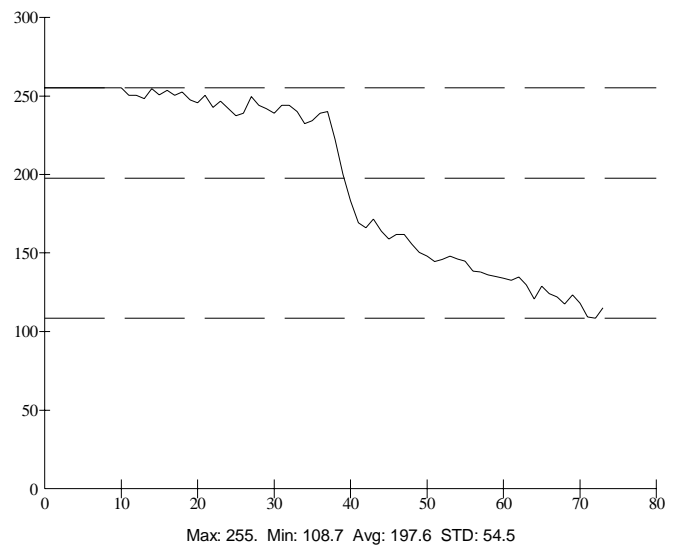

c) 6-second delay time

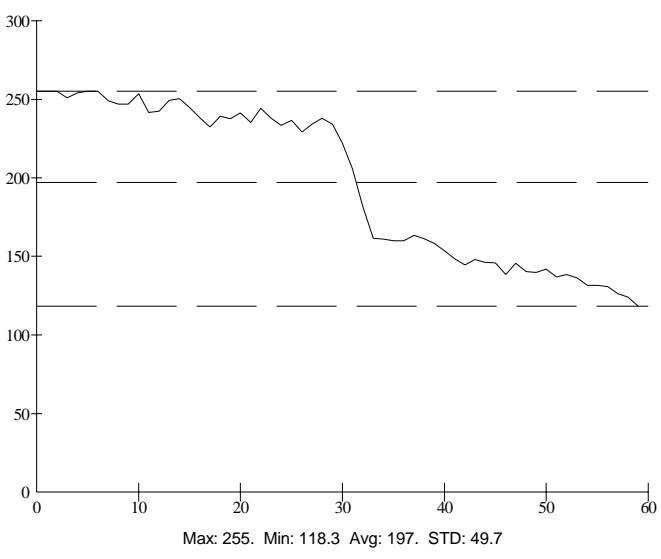

b) 3-second delay time

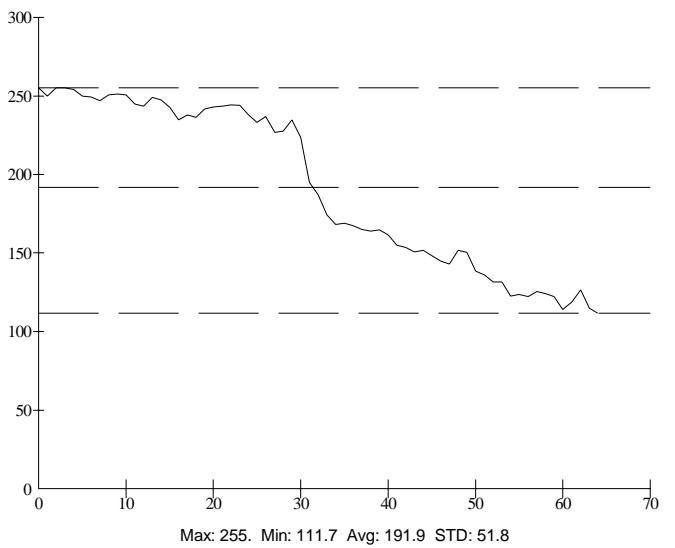

d) 9-second delay time

Figure A.152 Thermal intensity profile along the line across the fatigue crack shown in Figure A.151. 


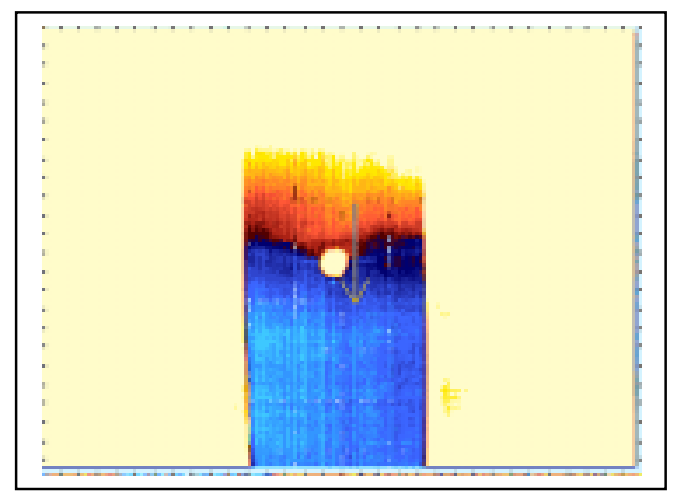

a) 1-second delay time

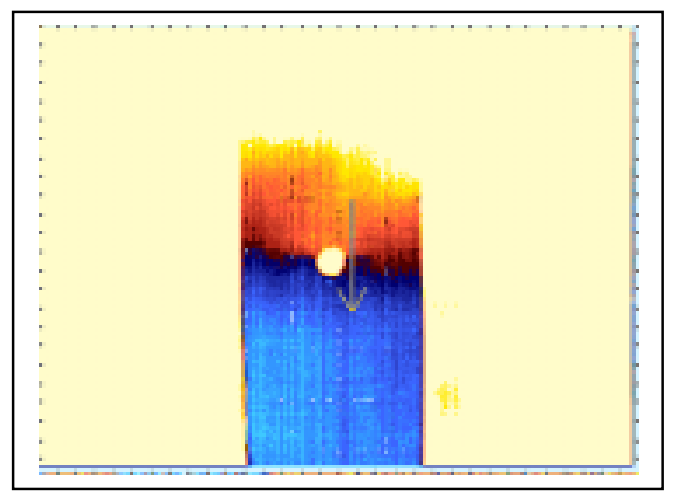

c) 6-second delay time

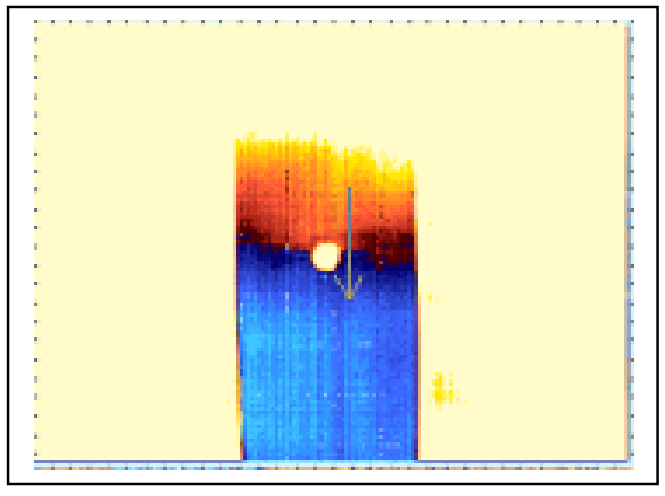

b) 3-second delay time

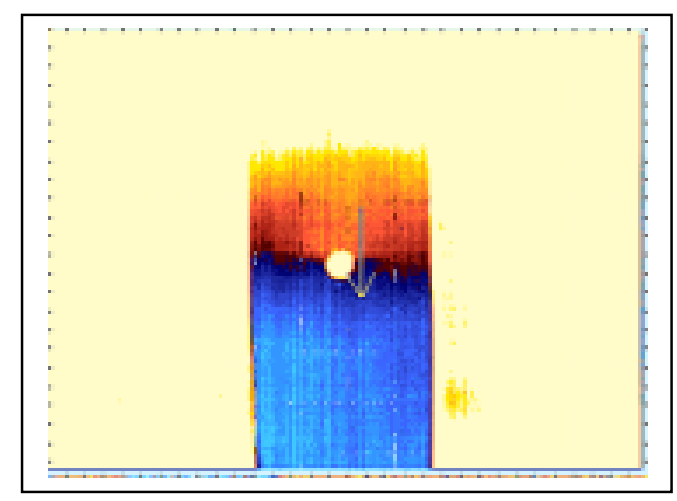

d) 9-second delay time

Figure A.153 Thermal images of unpainted Specimen CH-3 (using active approach and heating time is 30 seconds) at 550,000 loading cycles. The distance between IR camera and specimen is $375 \mathrm{~mm}$.. 


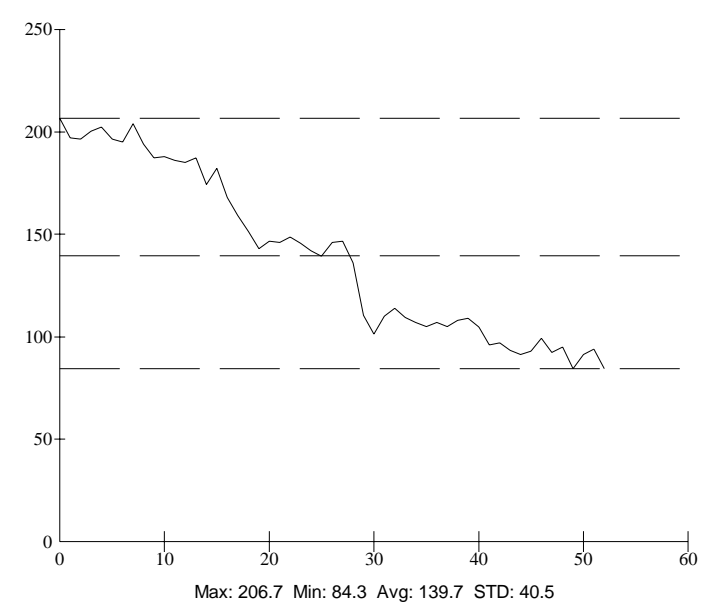

a) 1-second delay time

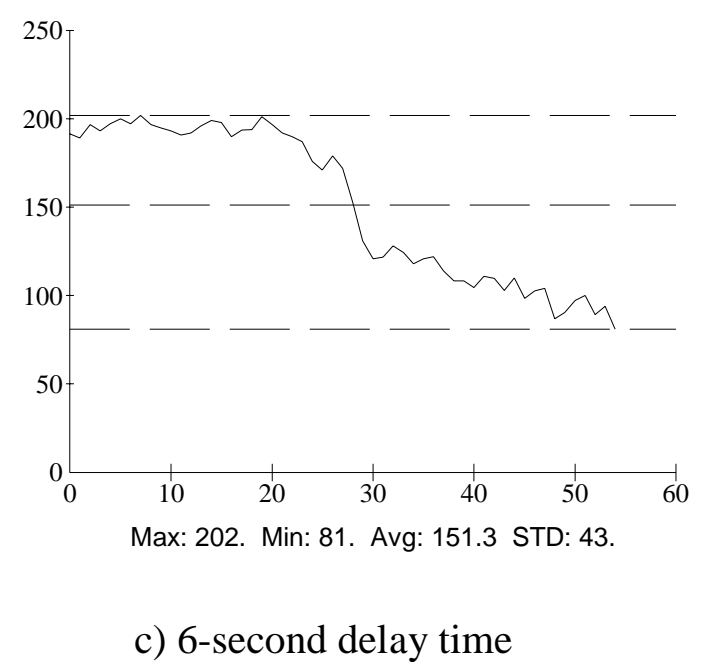

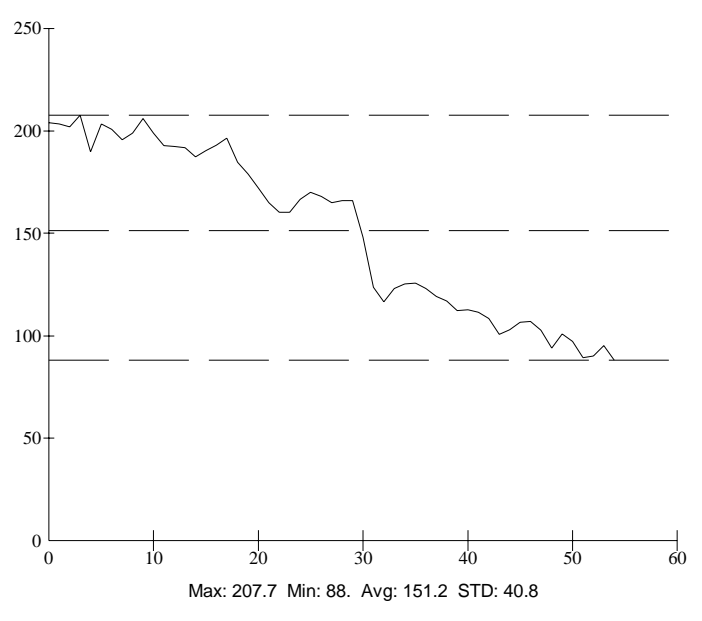

b) 3-second delay time

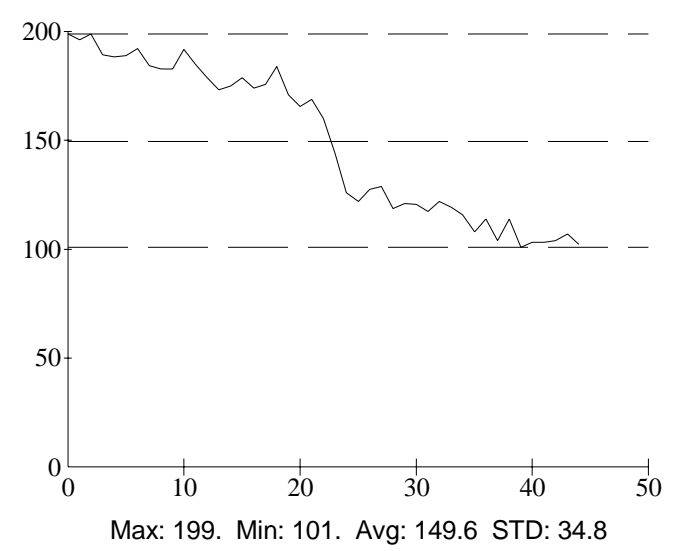

d) 9-second delay time

Figure A.154 Thermal intensity profile along the line across the fatigue crack shown in Figure A.153. 


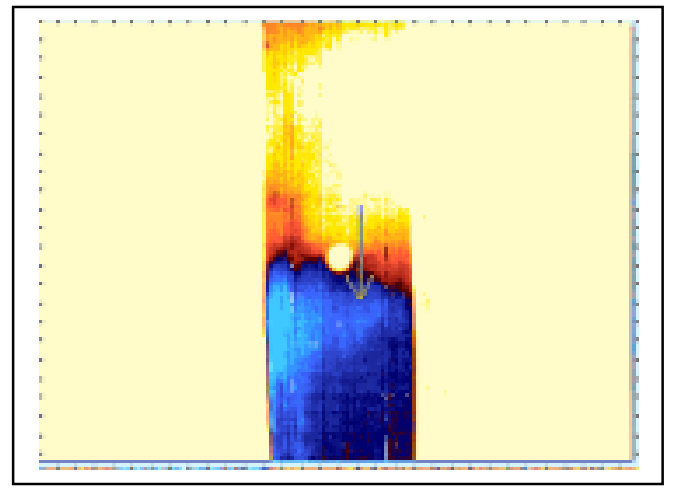

a) 1-second delay time

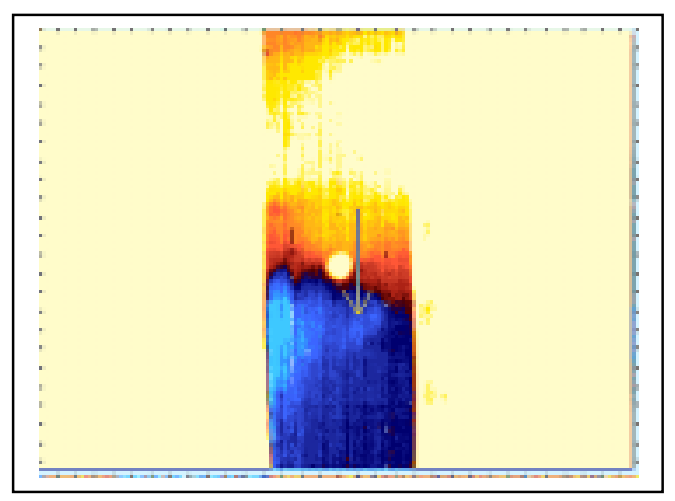

c) 6-second delay time

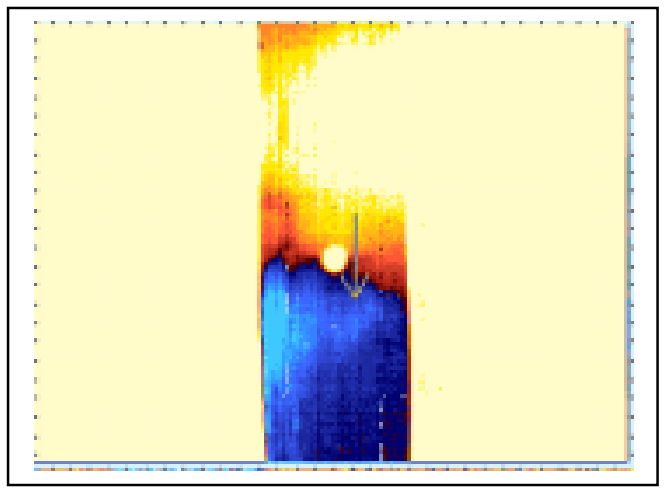

b) 3-second delay time

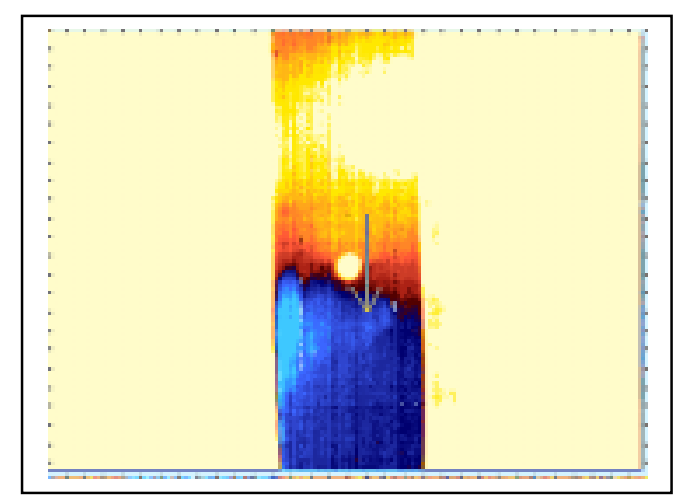

d) 9-second delay time

Figure A.155 Thermal images of unpainted Specimen $\mathrm{CH}-3$ (using active approach and heating time is 30 seconds) at 550,000 loading cycles. The distance between IR camera and specimen is $450 \mathrm{~mm}$.. 


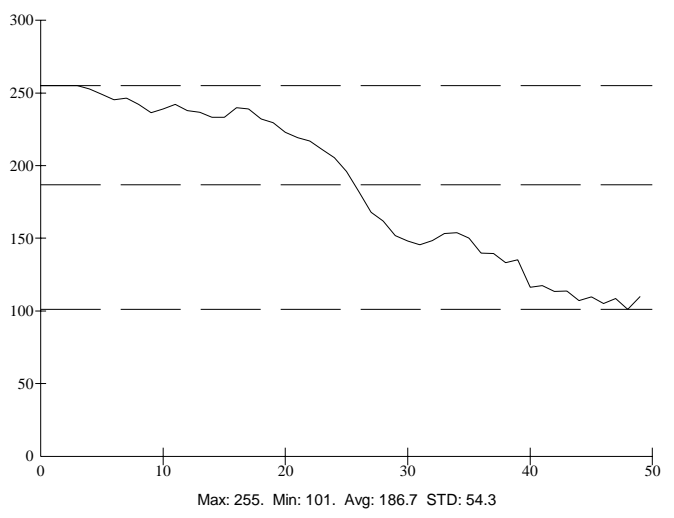

a) 1-second delay time

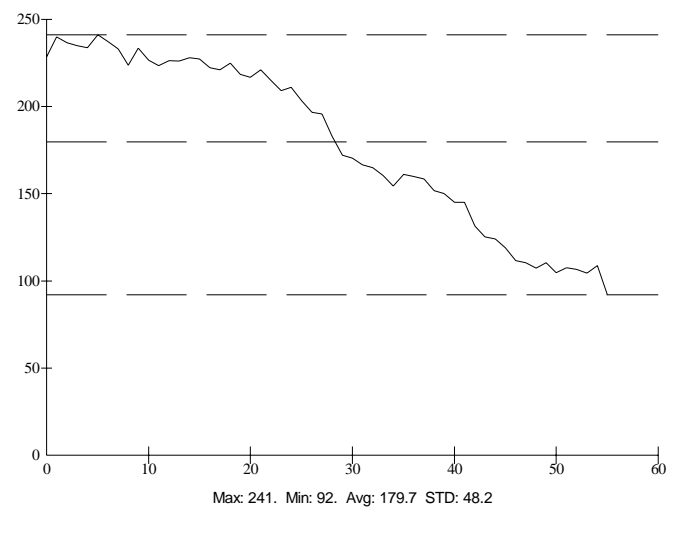

c) 6-second delay time

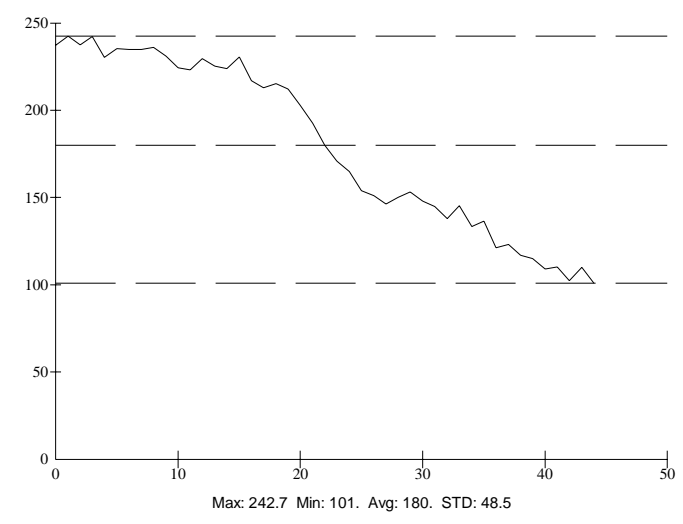

b) 3-second delay time

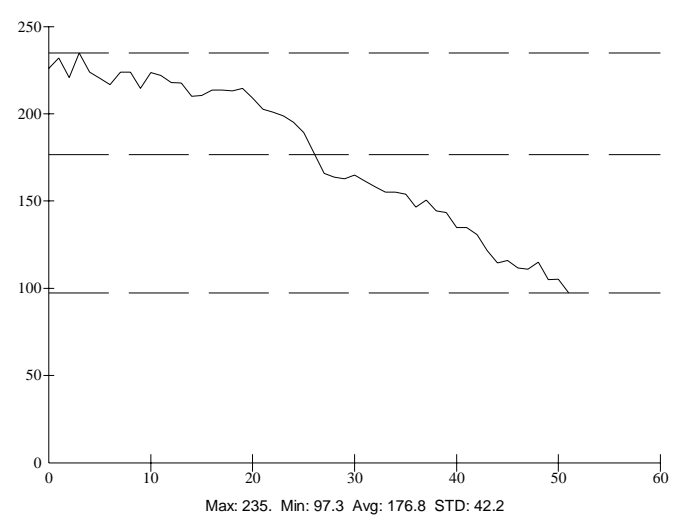

d) 9-second delay time

Figure A.156 Thermal intensity profile along the line across the fatigue crack shown in Figure A.155. 


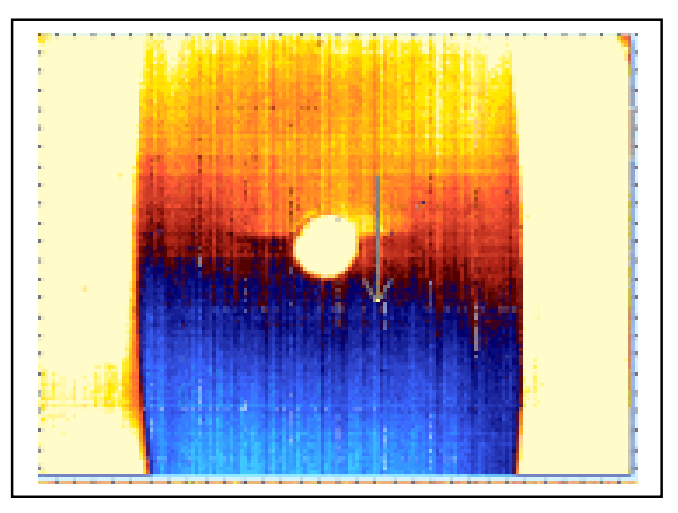

a) 1-second delay time

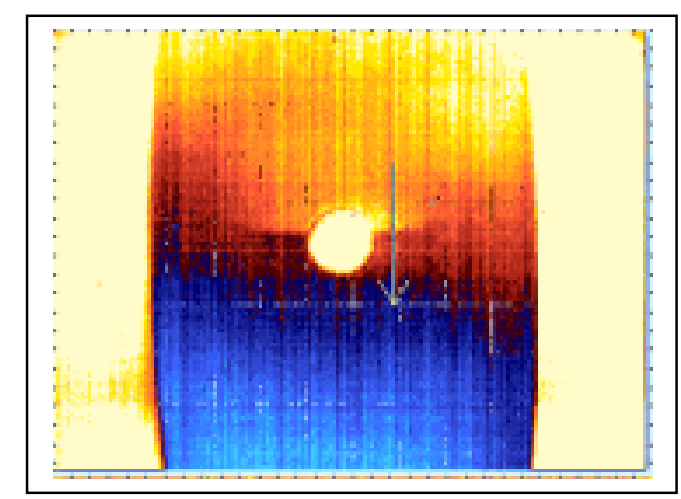

b) 3-second delay time

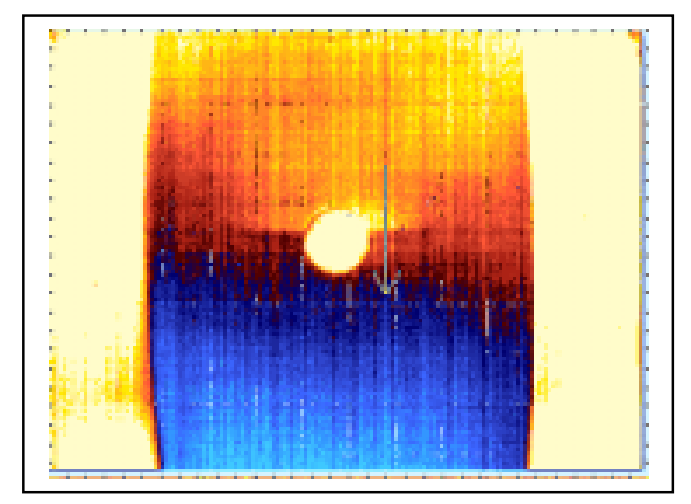

c) 6-second delay time

Figure A.157 Thermal images of unpainted Specimen CH-3 at 550,000 loading cycles (heating time is 30 seconds). The initial specimen temperature is $20^{\circ} \mathrm{C}$. 


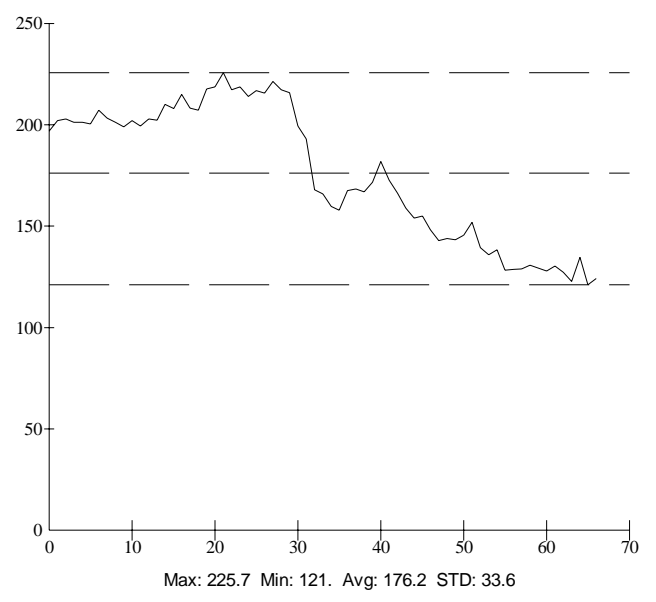

a) 1-second delay time

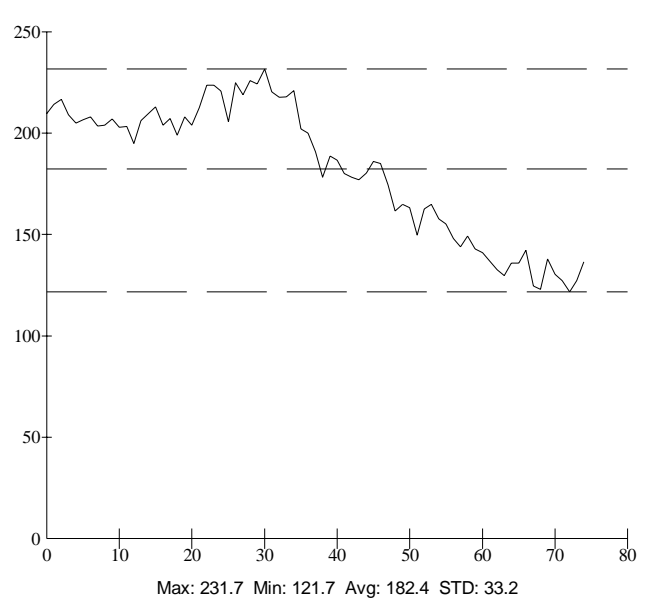

b) 3-second delay time

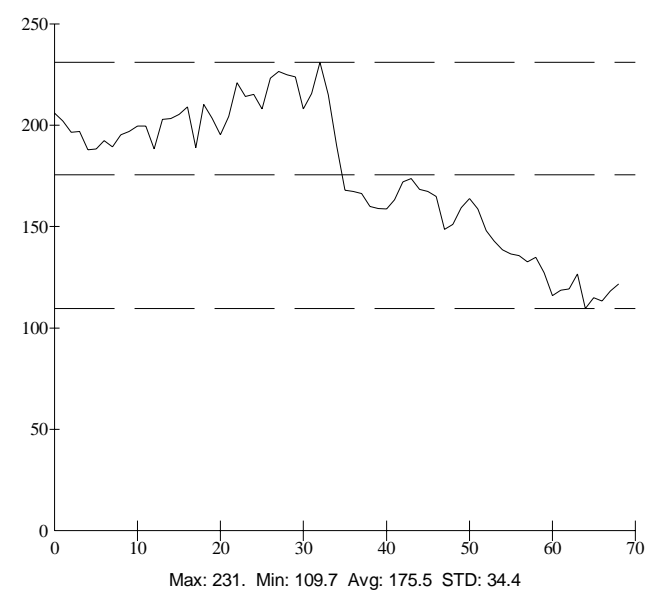

c) 6-second delay time

Figure A.158 Thermal intensity profile along the line across the fatigue crack shown in figure A.157. 


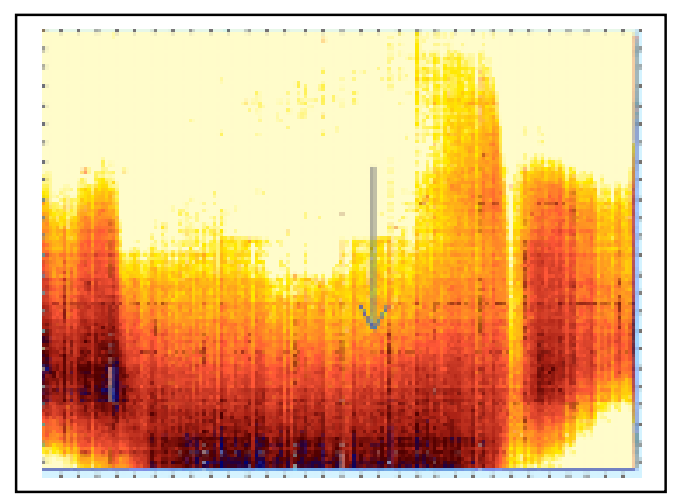

a) 1-second delay time

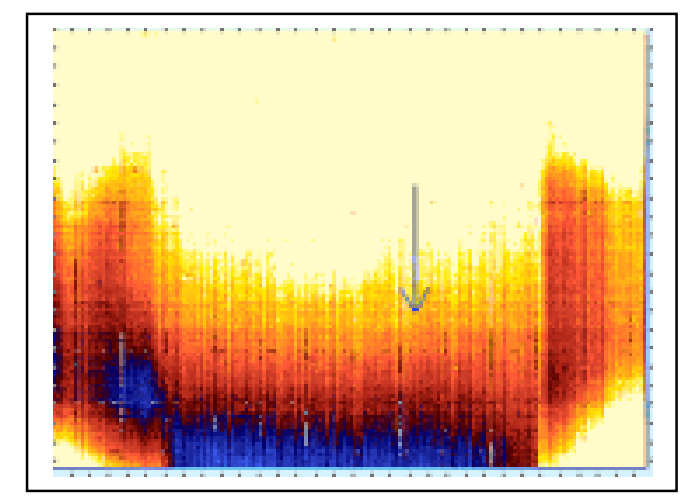

b) 3-second delay time

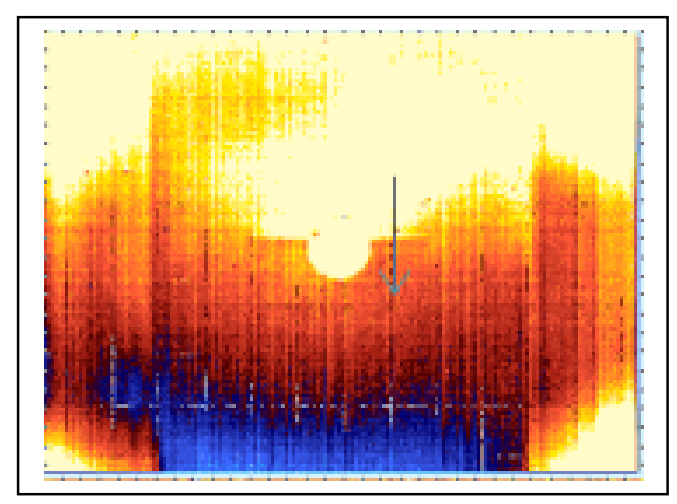

c) 6-second delay time

Figure A.159 Thermal images of unpainted Specimen CH-3 at 550,000 loading cycles (heating time is 30 seconds). The initial specimen temperature is $30^{\circ} \mathrm{C}$. 


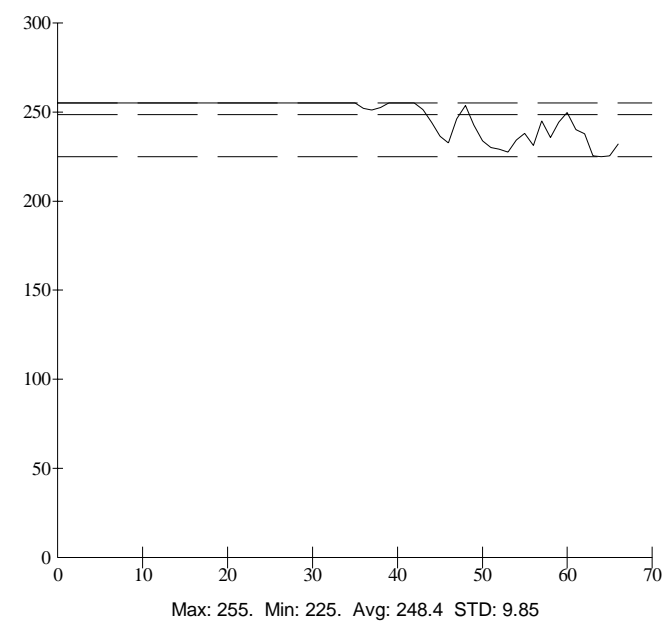

a) 1-second delay time

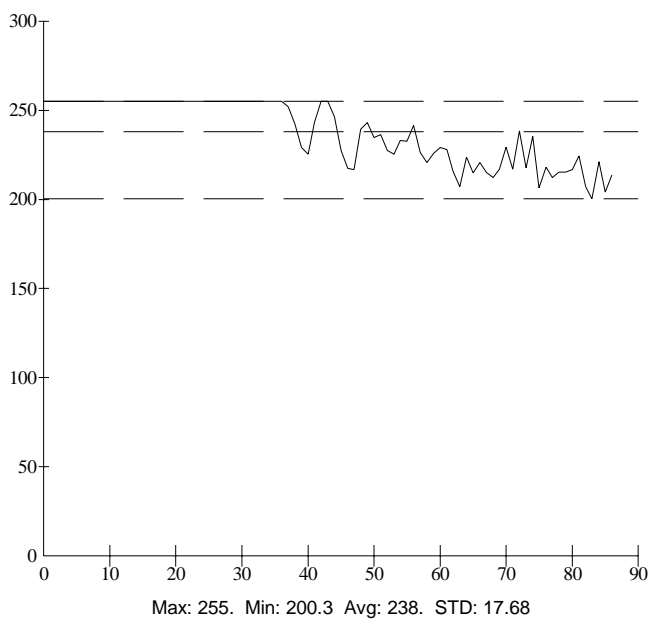

b) 3-second delay time

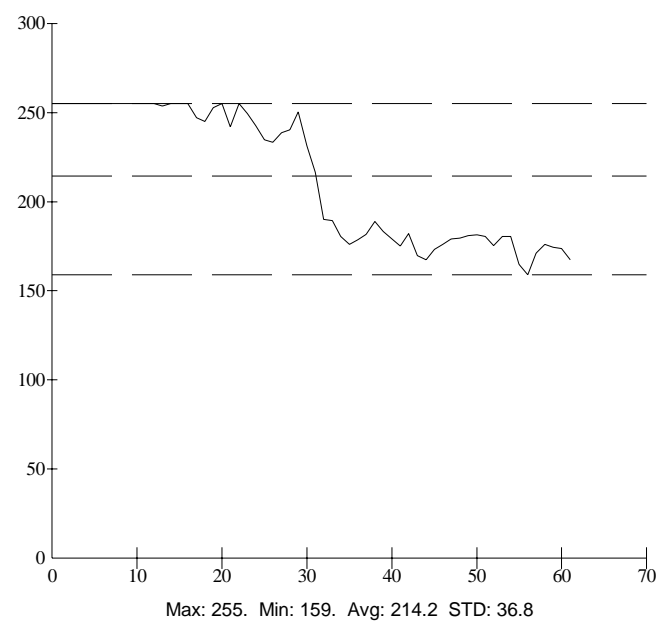

c) 6-second delay time

Figure A.160 Thermal intensity profile along the line across the fatigue crack shown in figure A.159. 


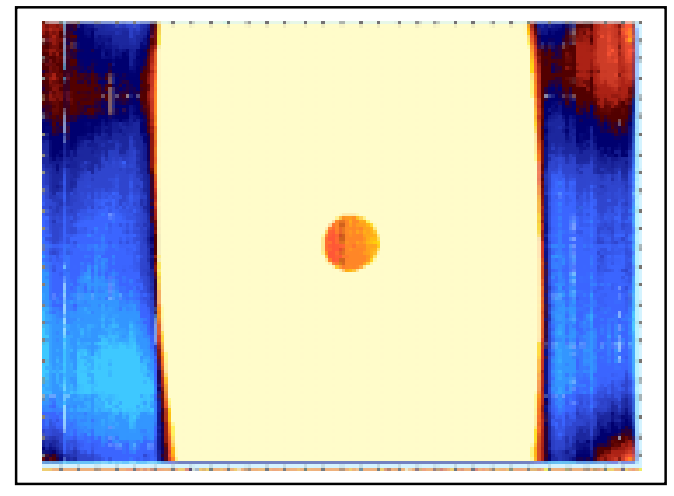

a) 1-second delay time

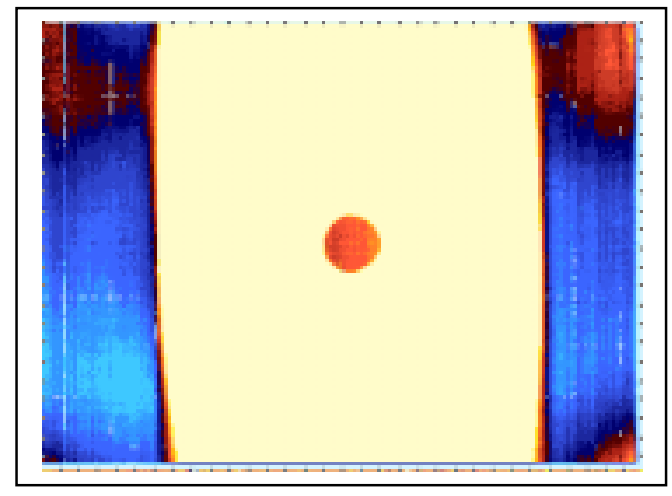

b) 3-second delay time

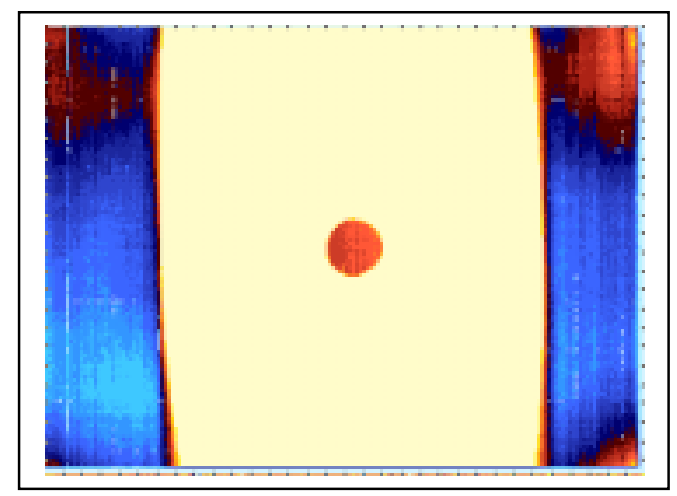

d) 6-second delay time

Figure A.161 Thermal images of unpainted Specimen CH-3 at 550,000 loading cycles (heating time is 30 seconds). The initial specimen temperature is $40{ }^{\circ} \mathrm{C}$. 


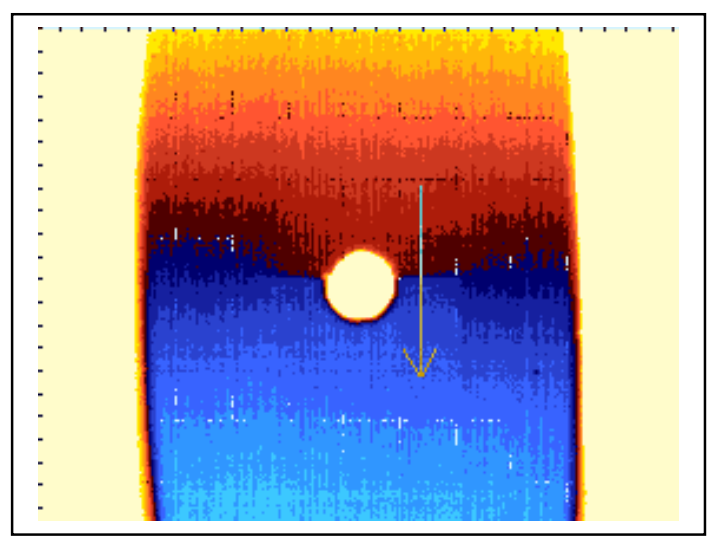

a) 1-second delay time

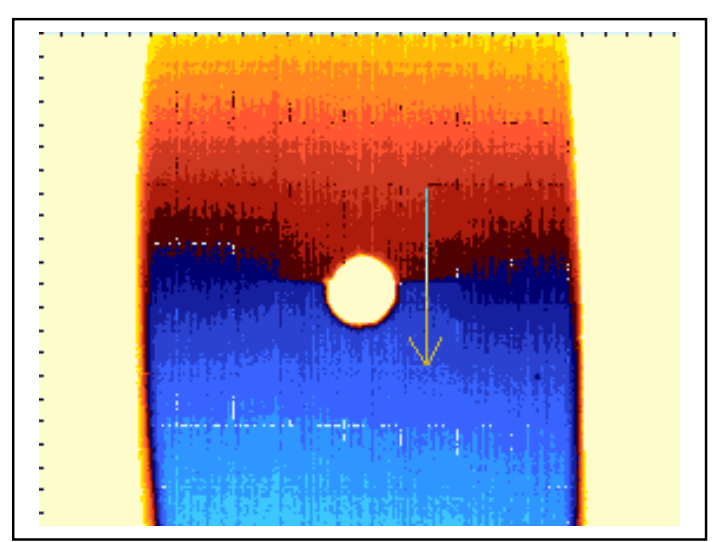

b) 3-second delay time

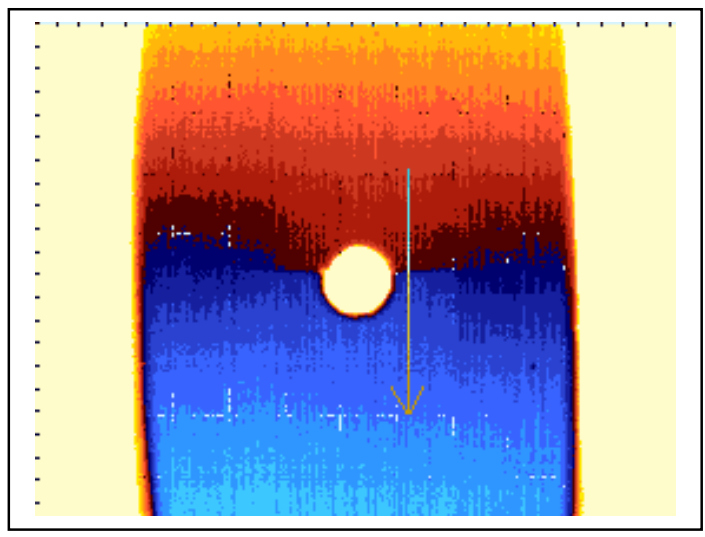

c) 6-second delay time

Figure A.162 Thermal images of Specimen CH-3 at 550,000 loading cycles (heating time is 30 seconds). The initial specimen temperature is $20^{\circ} \mathrm{C}$. 


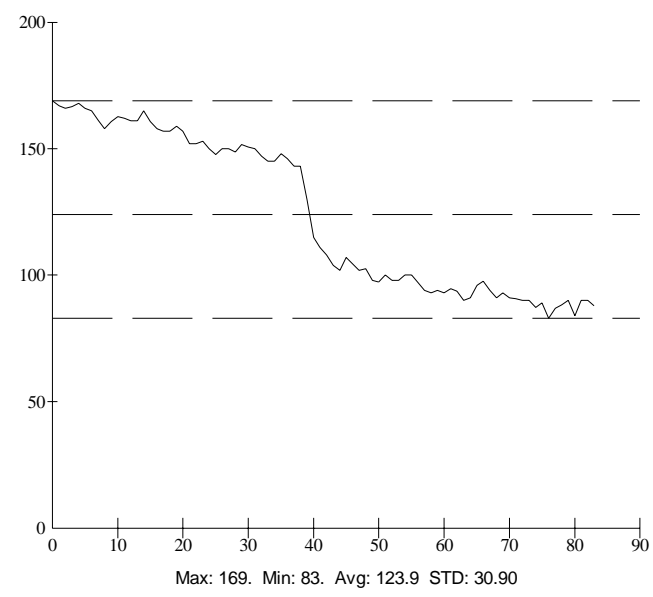

a) 1-second delay time

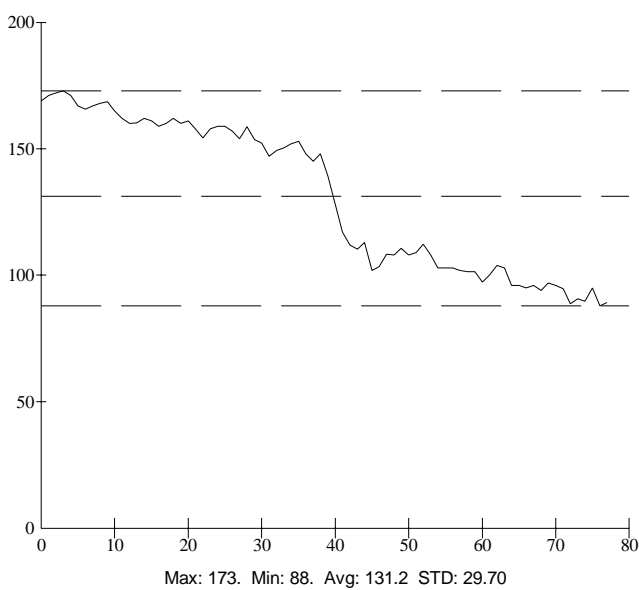

b) 3-second delay time

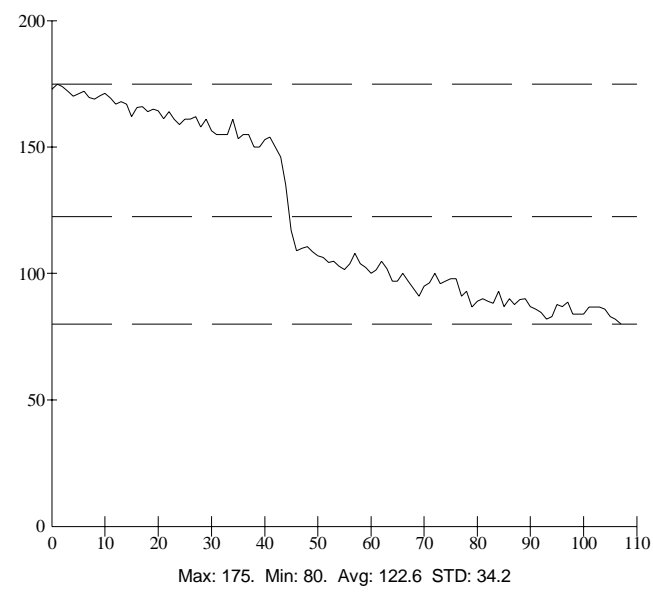

c) 6-second delay time

Figure A.163 Thermal intensity profile along the line across the fatigue crack shown in figure A.162. 


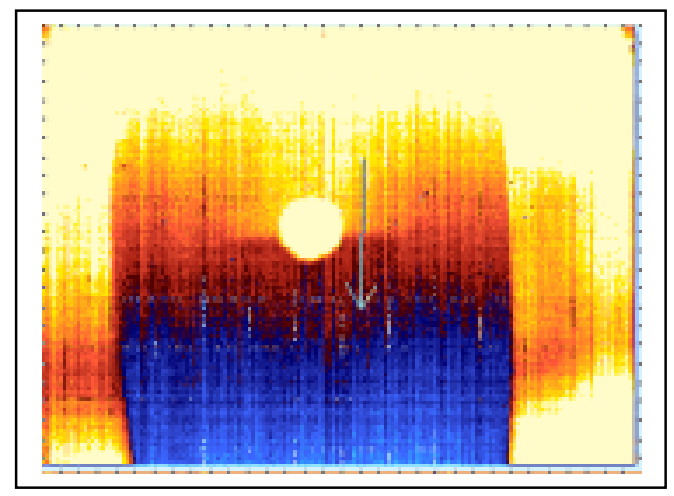

a) 1-second delay time

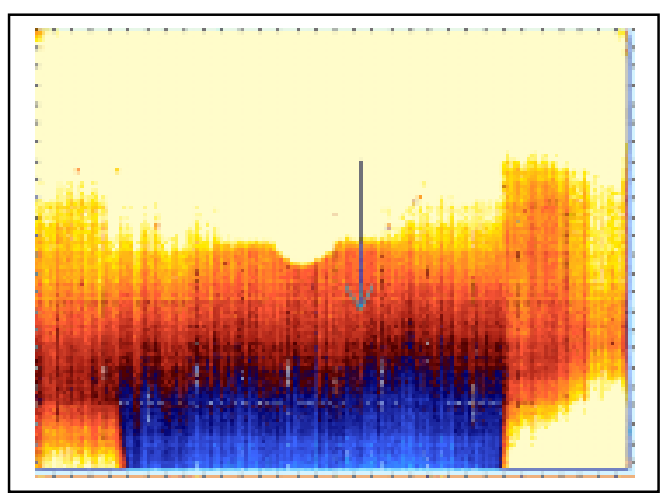

b) 3-second delay time

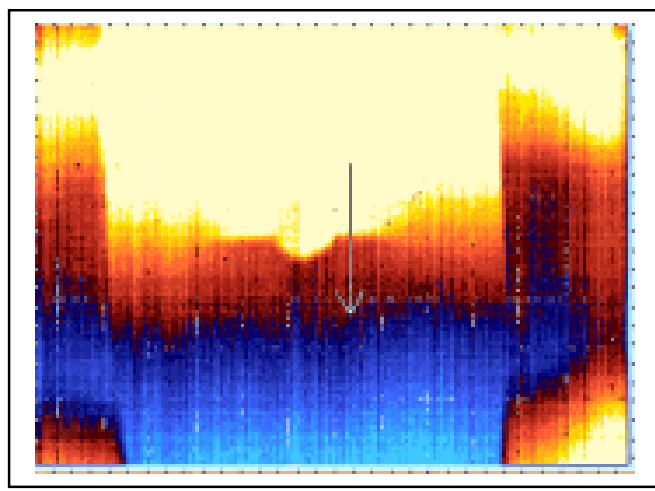

c) 6-second delay time

Figure A.164 Thermal images of Specimen CH-3 at 550,000 loading cycles (heating time is 30 seconds). The initial specimen temperature is $30^{\circ} \mathrm{C}$. 


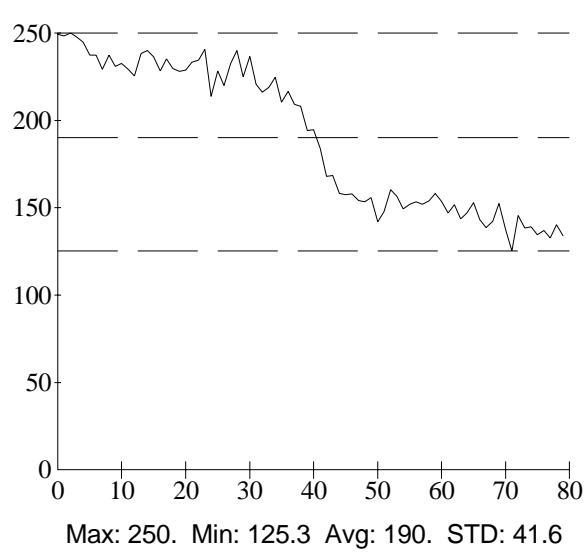

a) 1-second delay time

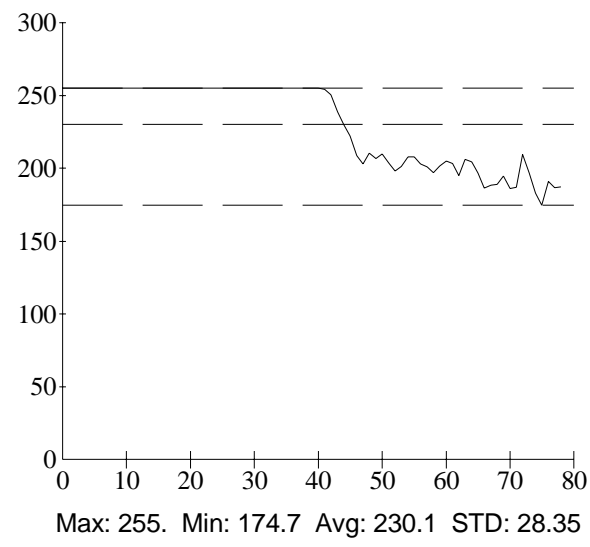

b) 3-second delay time

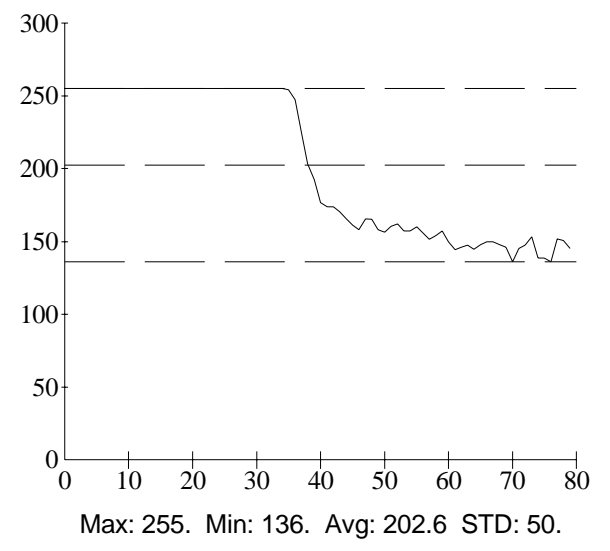

c) 6-second delay time

Figure A.165 Thermal intensity profile along the line across the fatigue crack shown in figure A.164. 


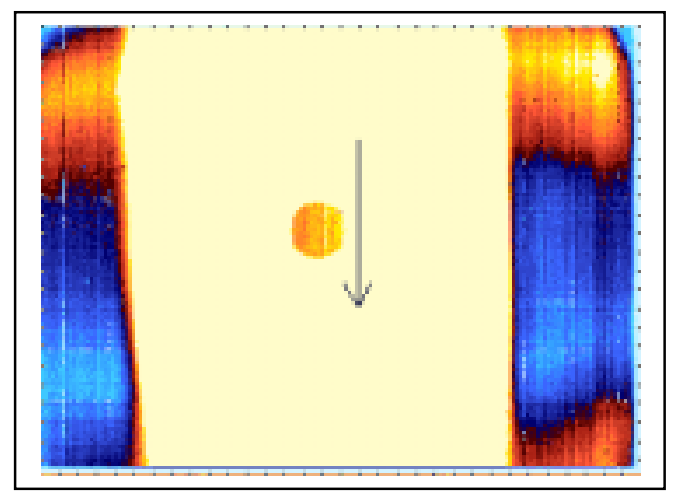

a) 1-second delay time

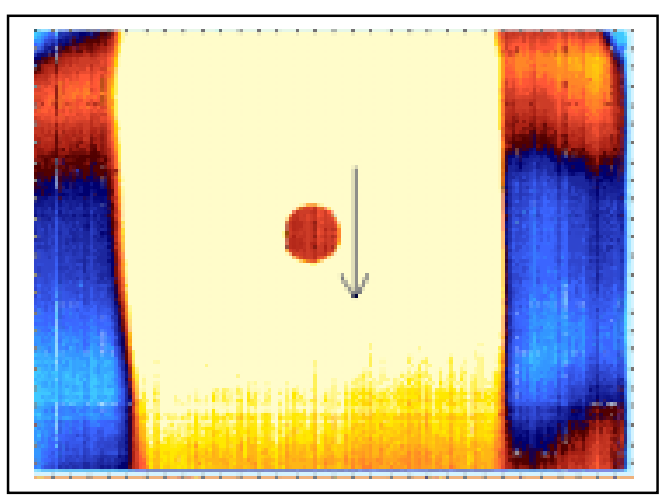

b) 3-second delay time

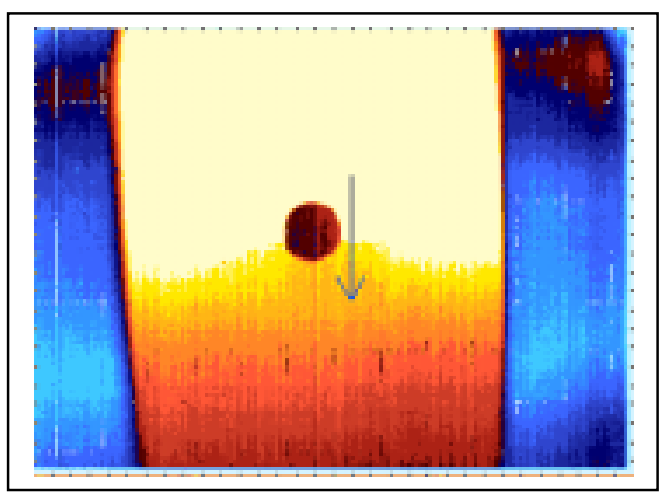

d) 6-second delay time

Figure A.166 Thermal images of Specimen CH-3 at 550,000 loading cycles (heating time is 30 seconds). The initial specimen temperature is $40^{\circ} \mathrm{C}$. 


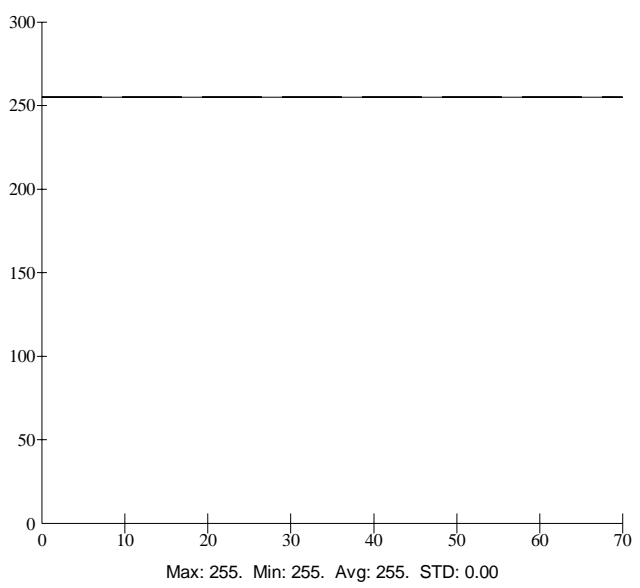

a) 1-second delay time

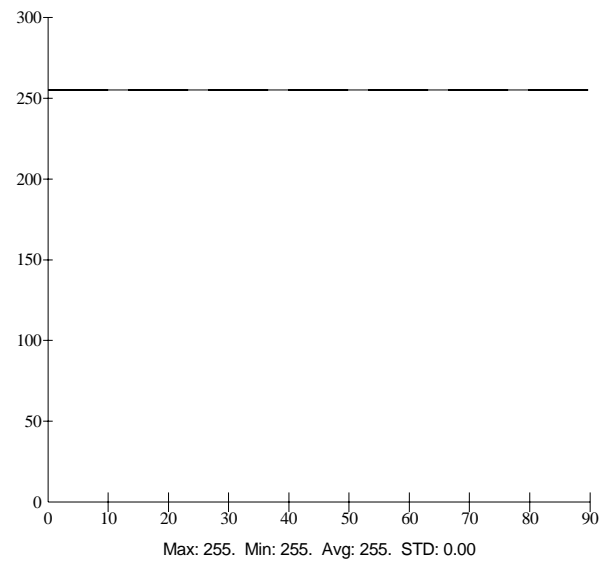

b) 3-second delay time

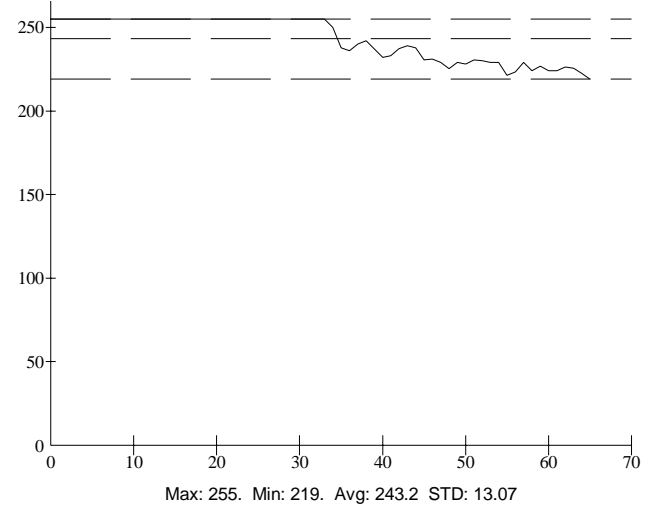

c) 6-second delay time

Figure A.167 The thermal intensity profile along the line across the fatigue crack shown in figure A.166. 
Thermal intensity

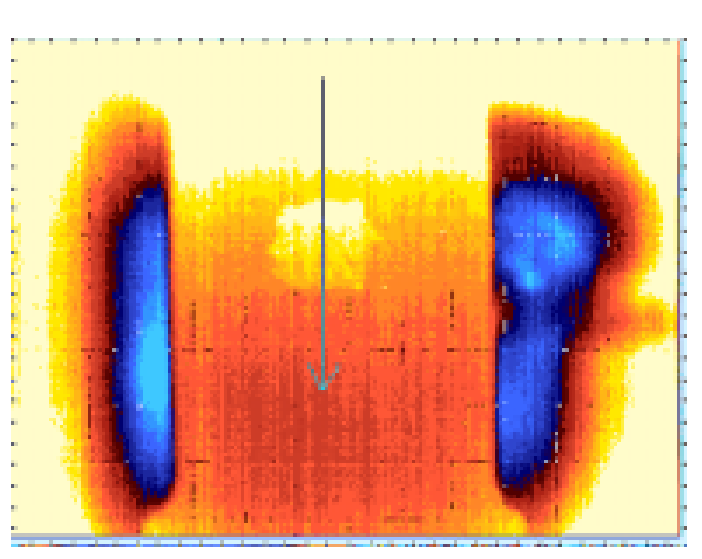

a) Top-heated thermal image
Thermal gradient

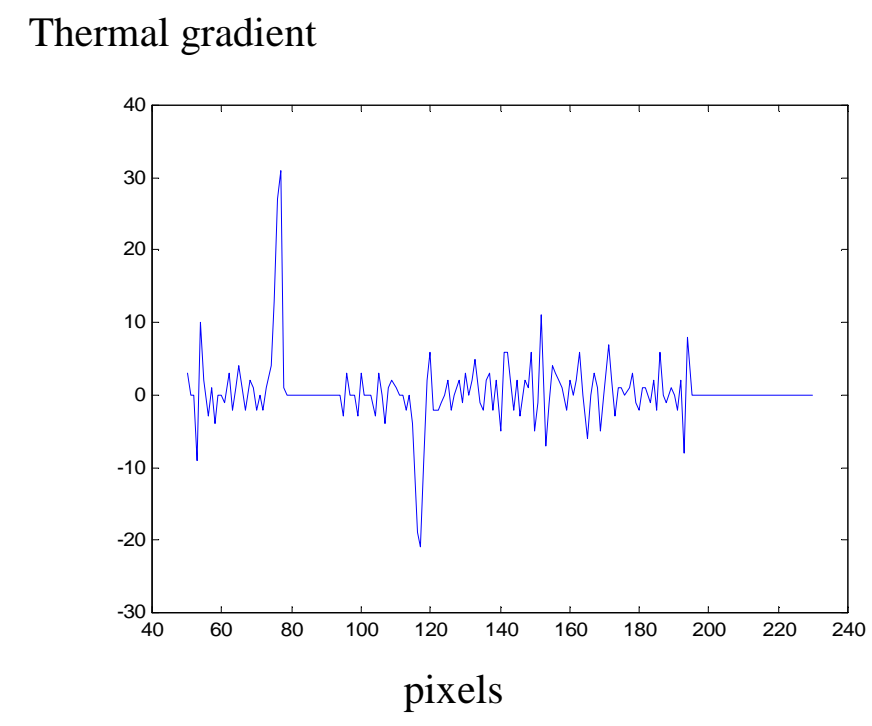

c) Thermal gradient profile

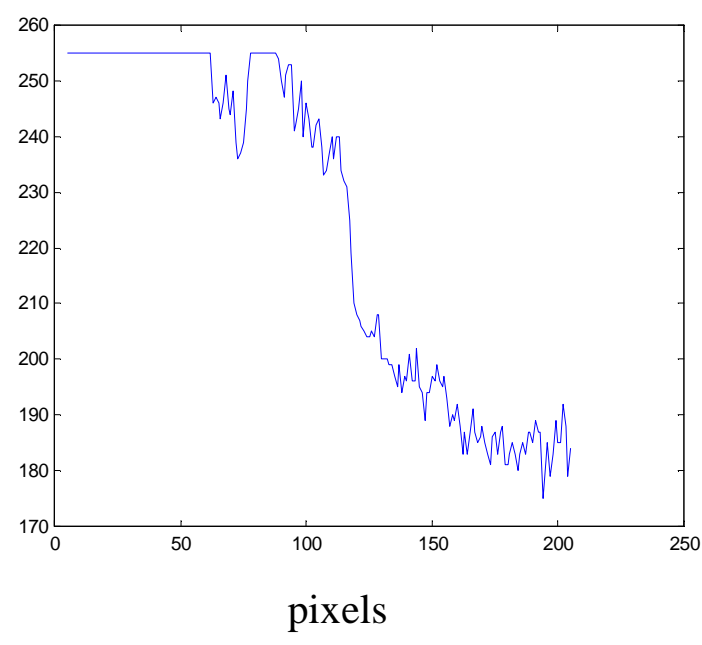

b) Thermal intensity profile
264.0

248.0

232.0

216.0

200.0

184.0

168.0

152.0

136.0

120.0

104.0

88.0

72.0

56.0

40.0

24.0

d) Thermal intensity color bar

Figure A.168 Effects of paint anomalies when in-plane heat flows from top to bottom. 
Thermal intensity

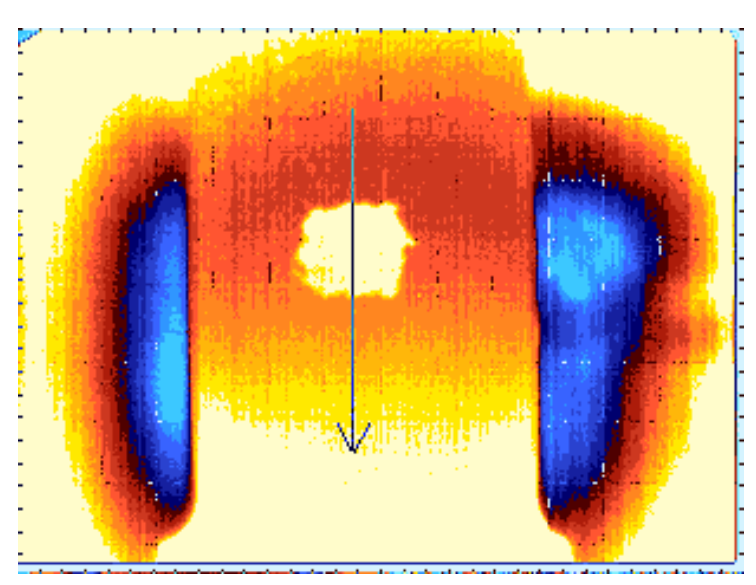

a) Bottom-heated thermal image

Thermal gradient

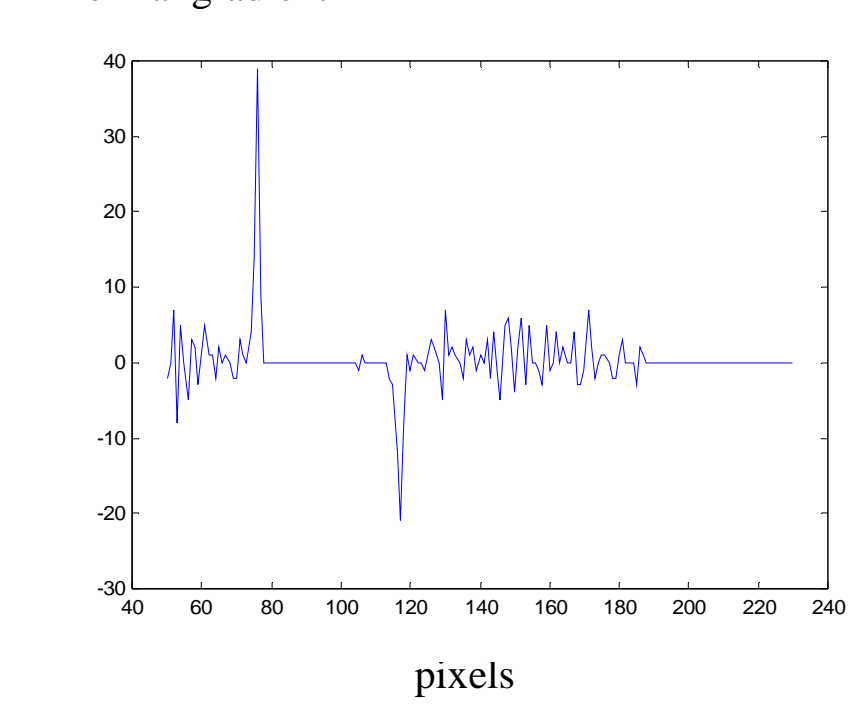

c) Thermal gradient profile

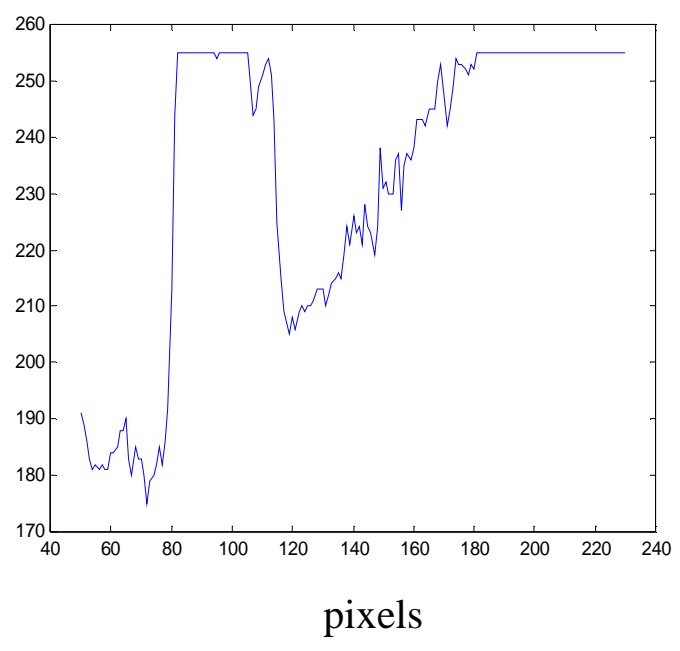

b) Thermal intensity profile
264.0

248.0

232.0

216.0

200.0

184.0

168.0

152.0

136.0

120.0

104.0

88.0

72.0

56.0

40.0

24.0

Figure A.169 Effects of paint anomalies when in-plane heat flows from bottom to top. 
Thermal gradient

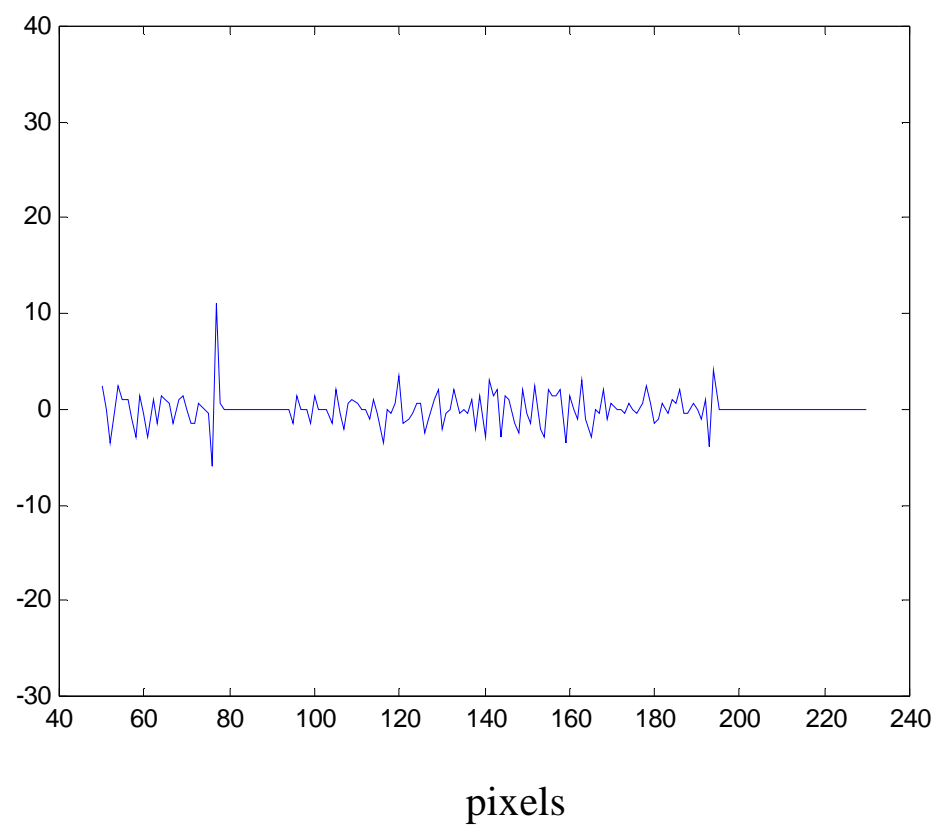

Figure A.170 Effects of paint anomalies are minimized using the thermal gradient subtraction process (Figure A.169(c) is subtracted with figure A.169(c)). 
Thermal intensity

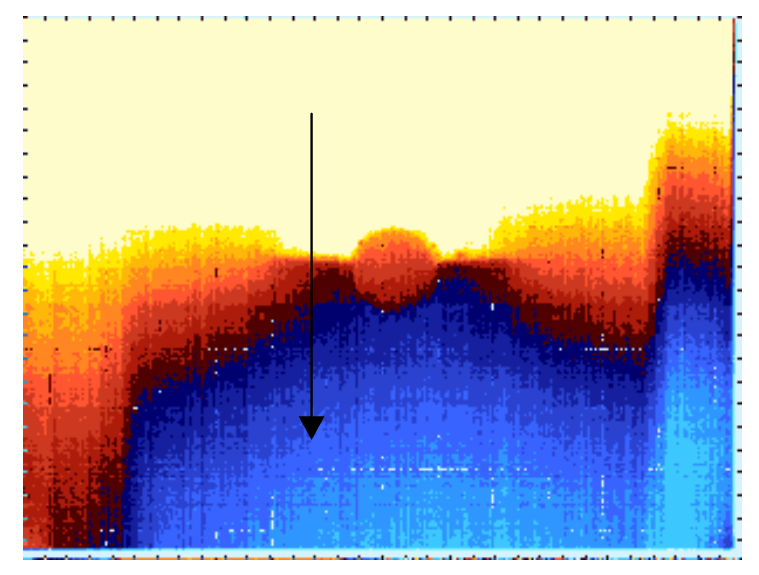

a) Top-heated thermal image

c) Thermal gradient profile
Thermal gradient

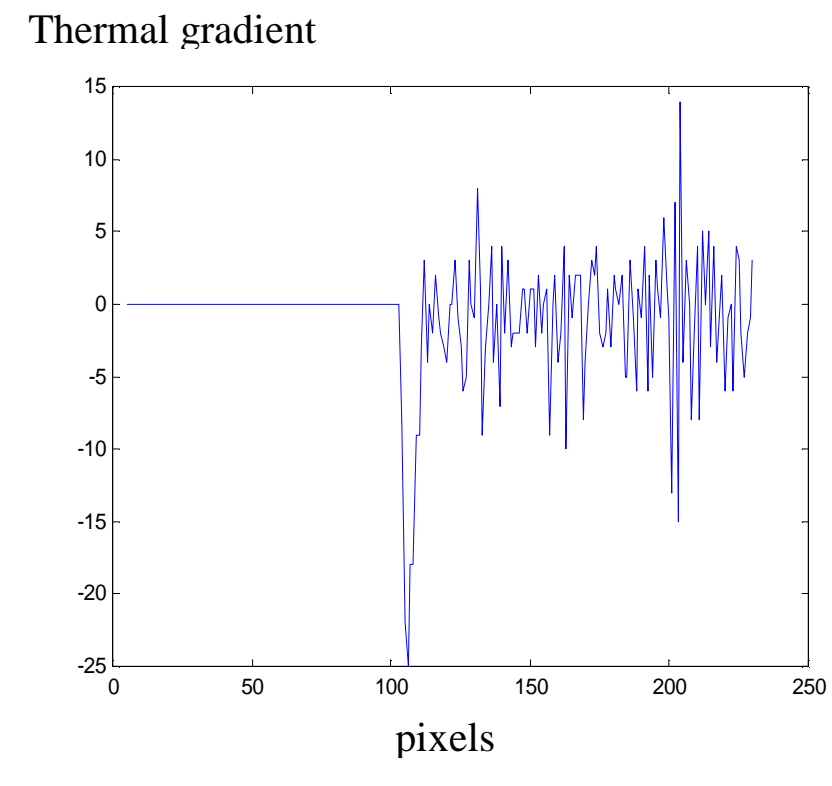

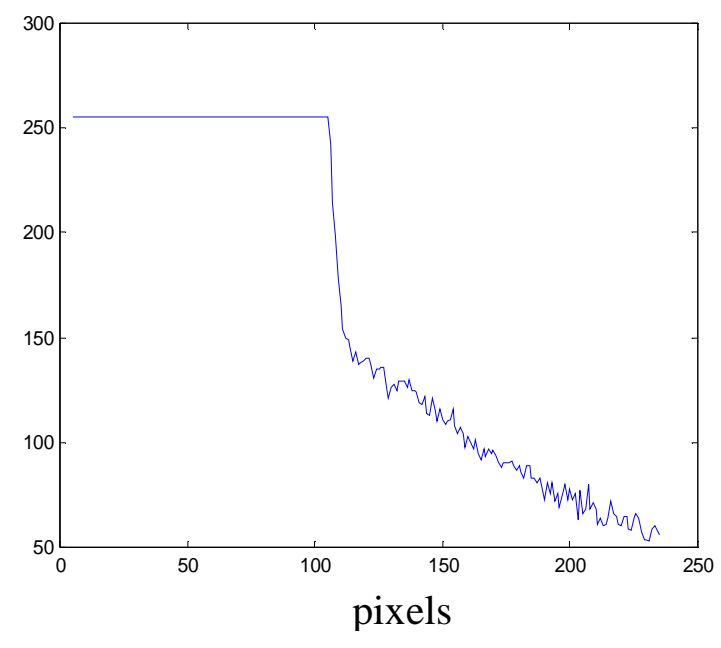

b) Thermal intensity profile

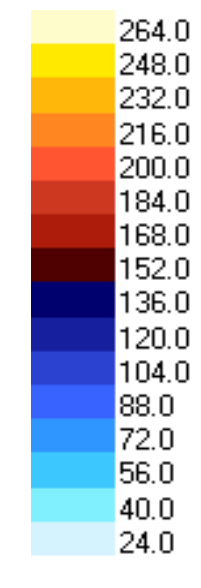

d) Thermal intensity color bar

Figure A.171 Effects of cracks when in-plane heat flows from top to bottom. 
Thermal intensity

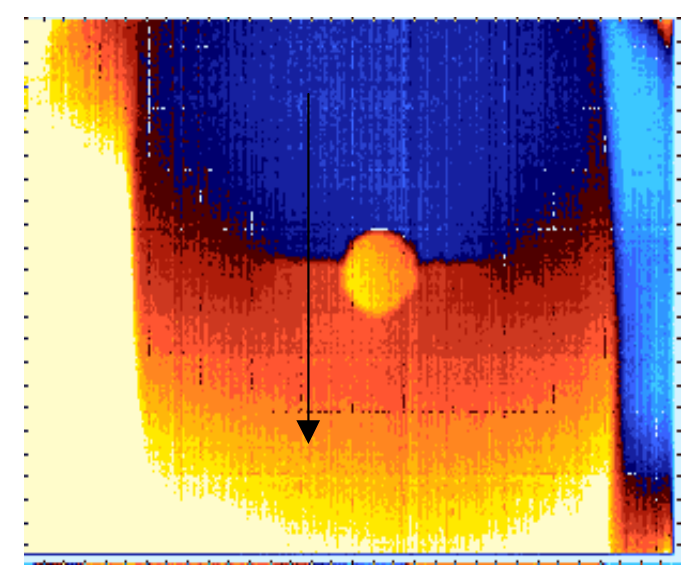

a) Bottom-heated thermal image

Thermal gradient

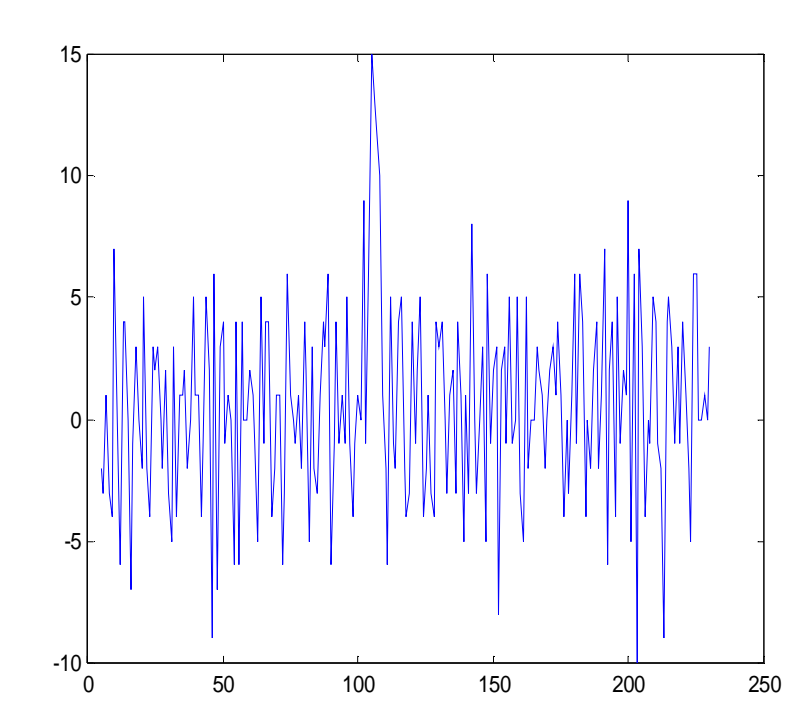

c) Thermal gradient profile

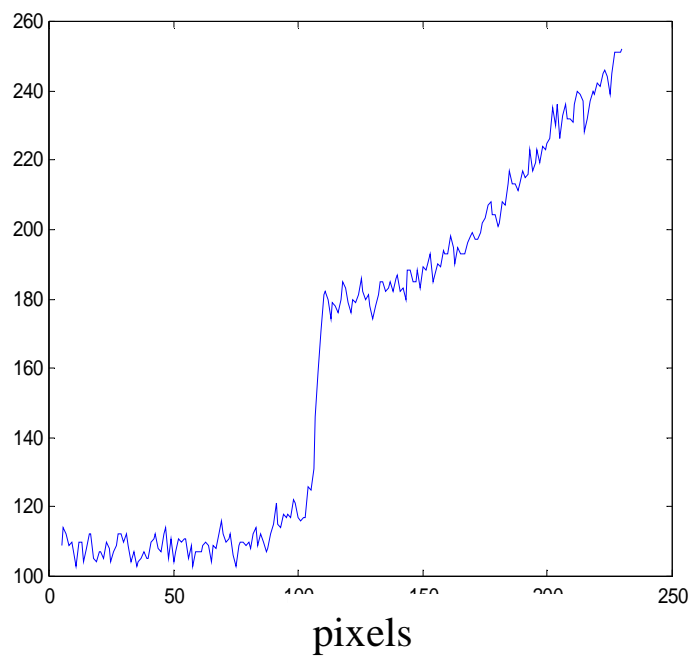

b) Thermal intensity profile

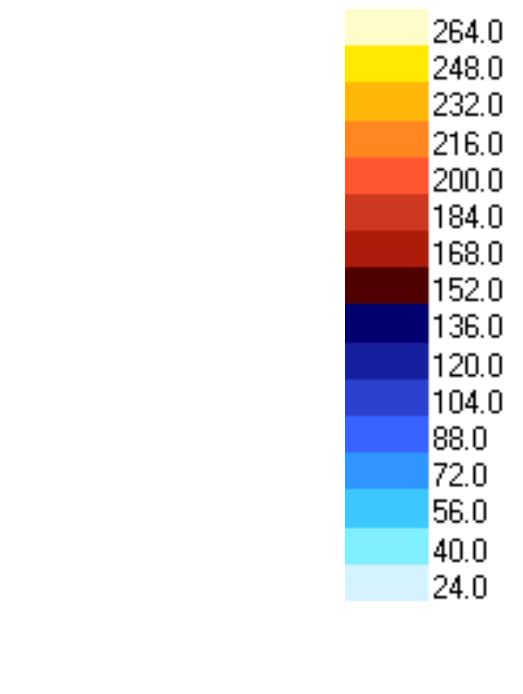

d) Thermal intensity color bar

Figure A.172 Effects of cracks when in-plane heat flows from bottom to top. 
Thermal gradient

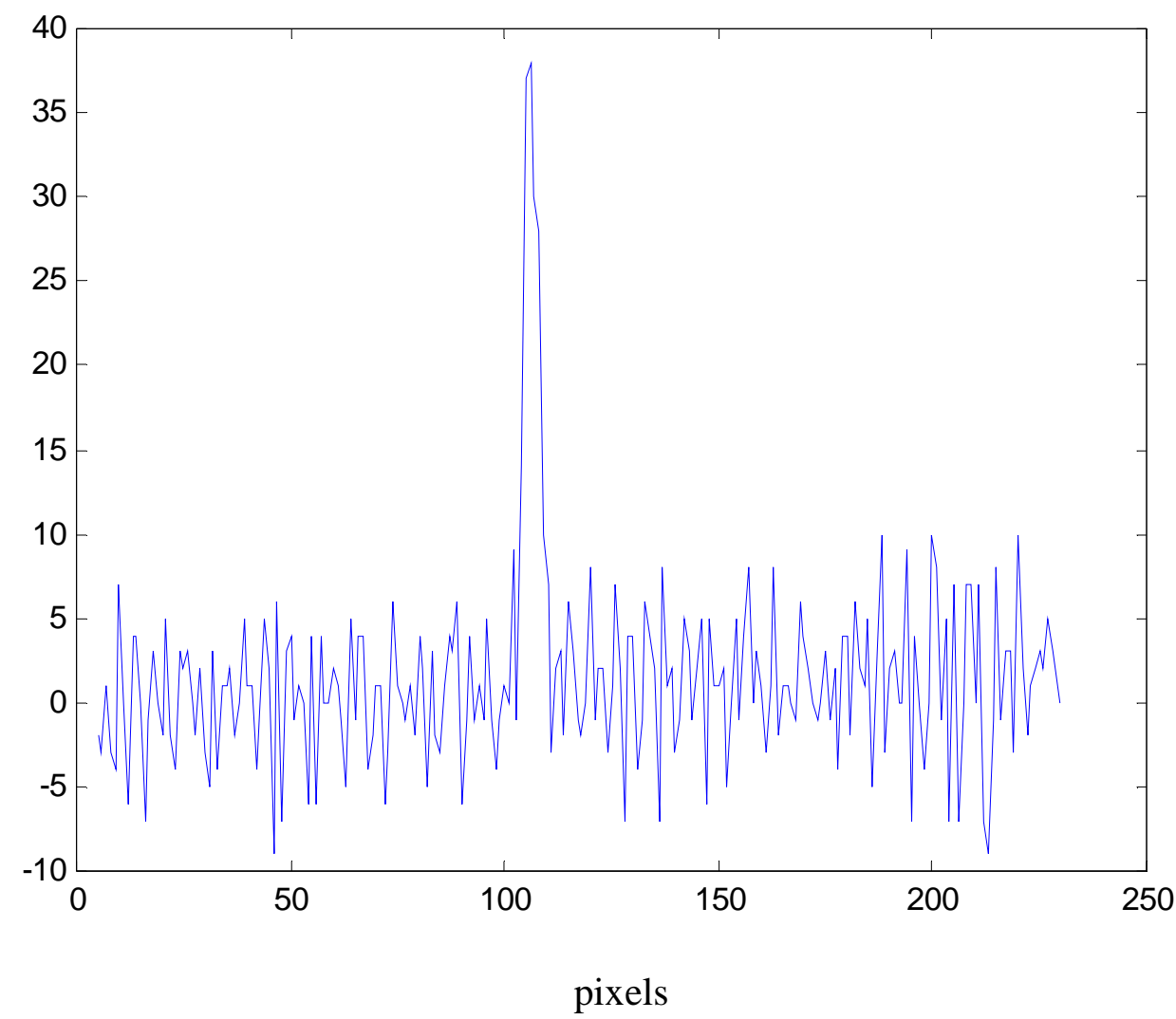

Figure A.173 Effects of cracks are augmented using the thermal gradient subtraction process (Figure A.172(c) is subtracted with figure A.172(c)). 


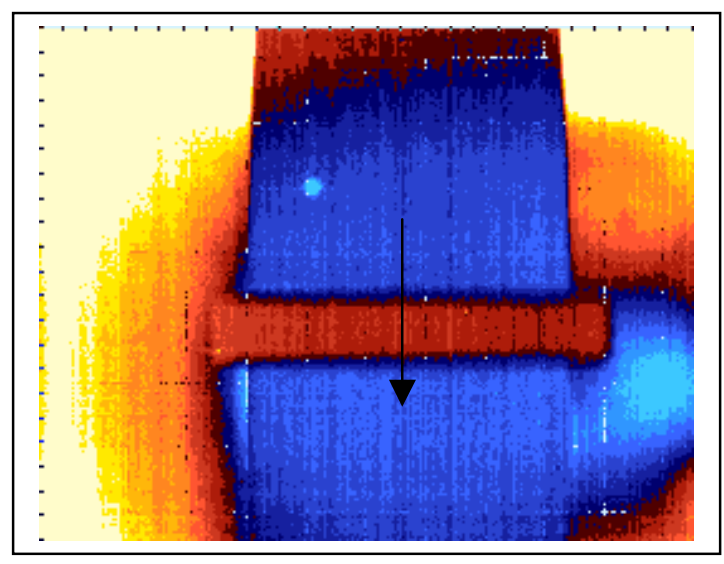

a) 1-second delay time

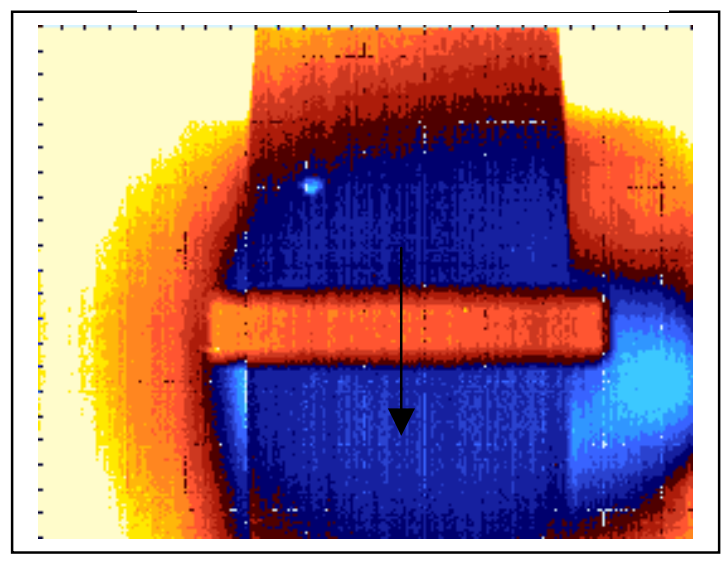

c) 6-second delay time

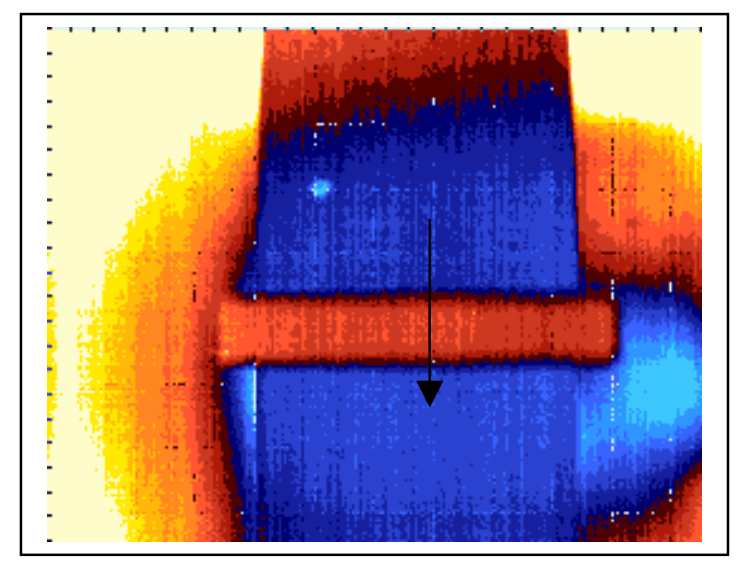

b) 3-second delay time

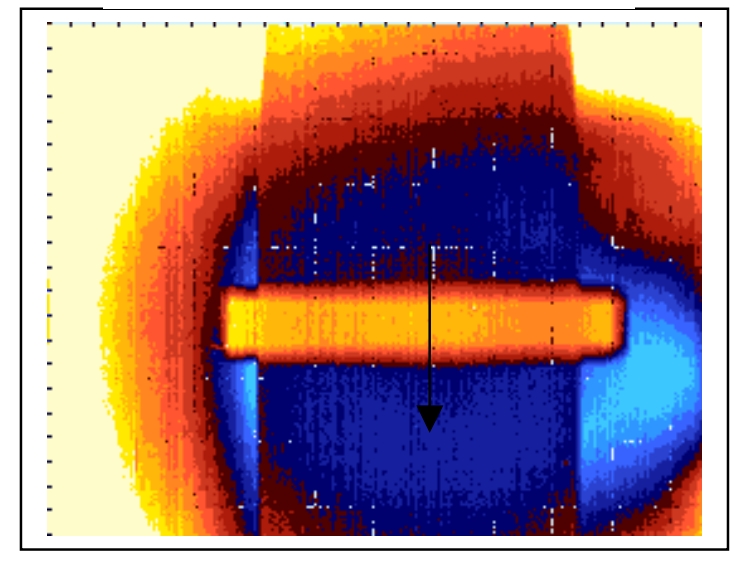

d) 9-second delay time

Figure A.174 Thermal images of the Specimen WD-1 at 250,000 loading cycles. Heat is applied at the attached plate. The heating time is 30 seconds. 


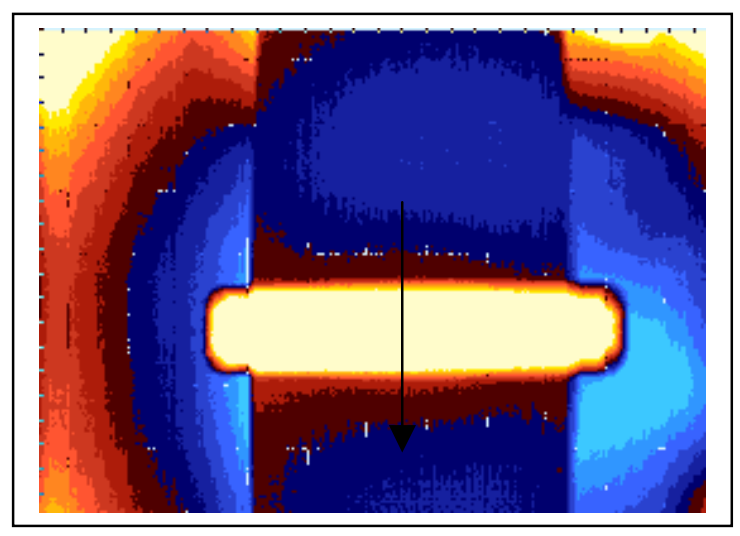

e) 12-second delay time

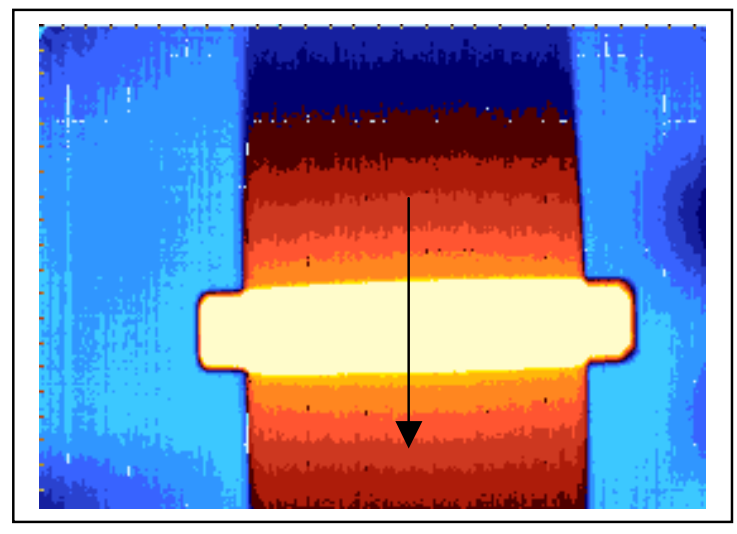

f) 15-second delay time

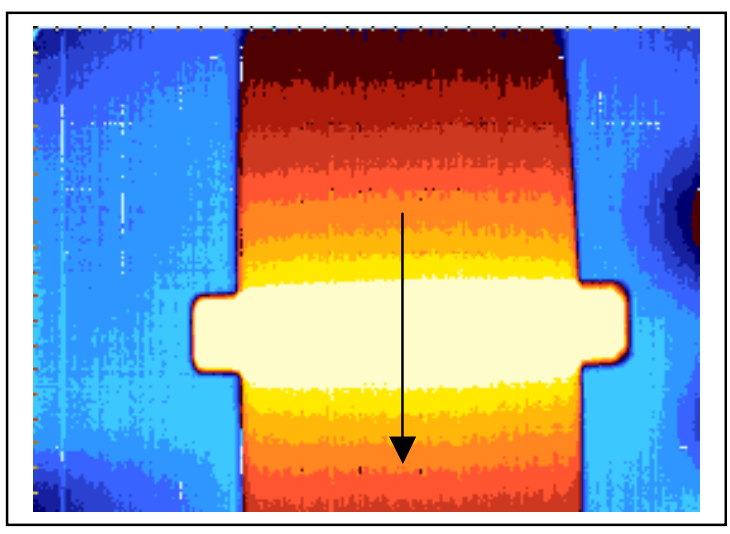

g) 18-second delay time

Figure A.174 (continued) Thermal images of the Specimen WD-1 at 250,000 loading cycles. Heat is applied at the attached plate. The heating time is 30 seconds. 


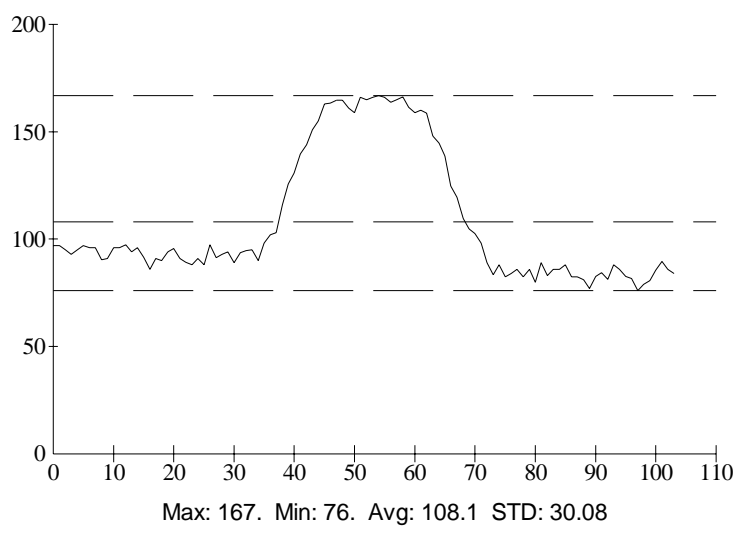

a) 1-second delay time

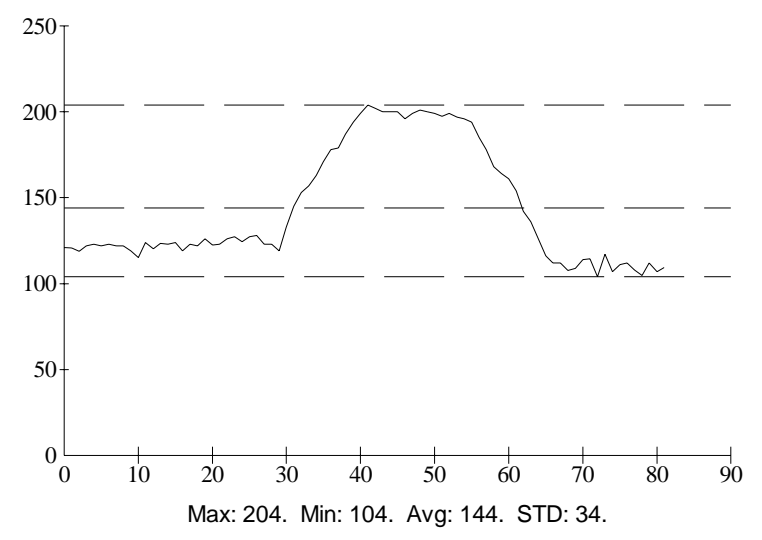

c) 6-second delay time

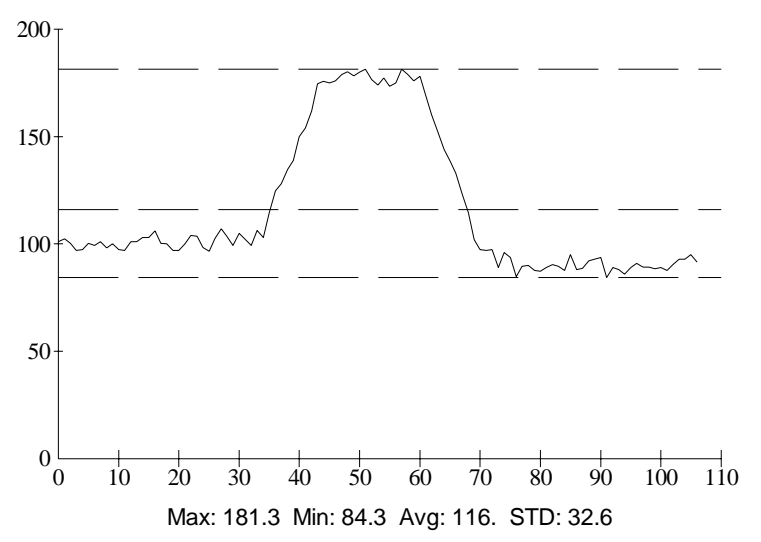

b) 3-second delay time

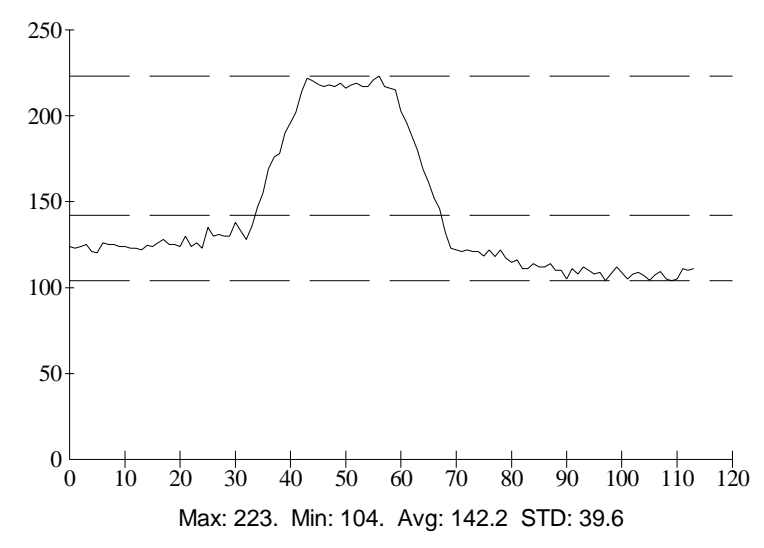

d) 9-second delay time

Figure A.175 Thermal intensity profile along the line across the fatigue crack shown in Figure A.174. 


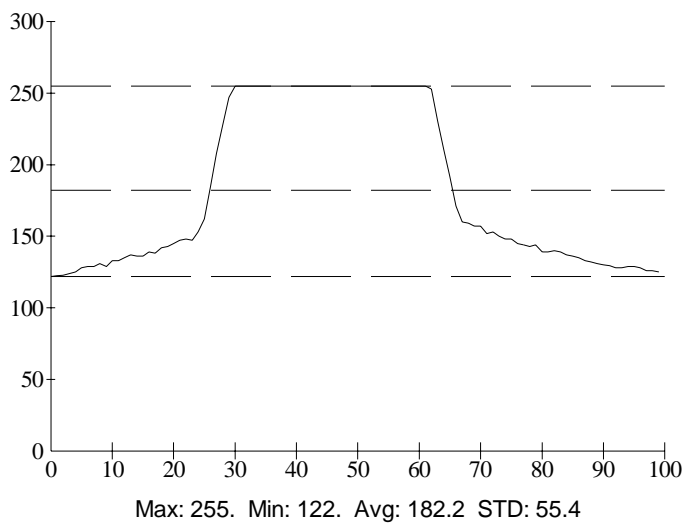

e) 12-second delay time

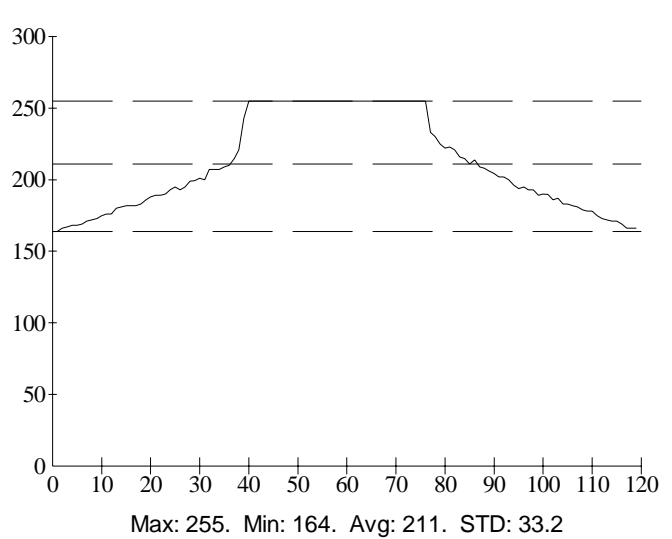

f) 15 -second delay time

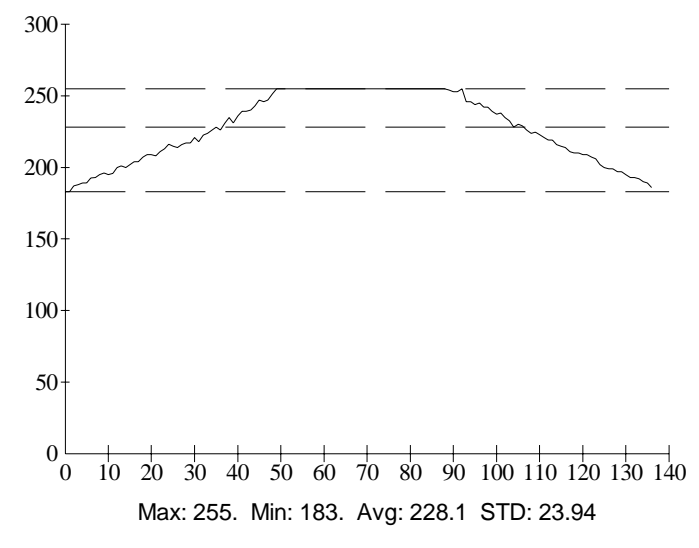

g) 18-second delay time

Figure A.175 (continued) Thermal intensity profile along the line across the fatigue crack shown in Figure A.174. 


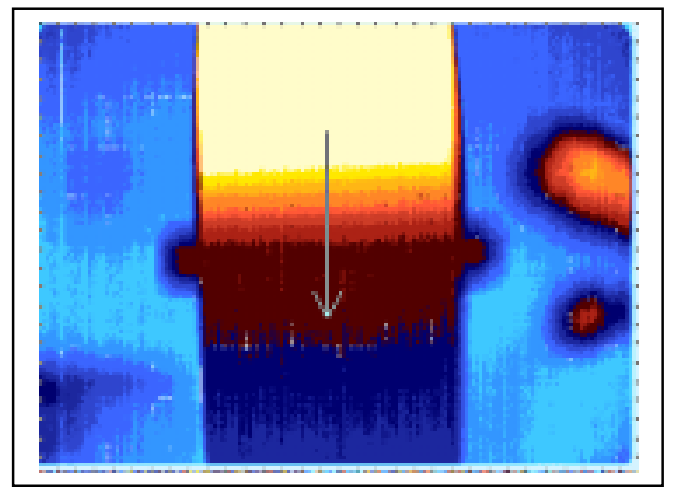

a) 1-second delay time

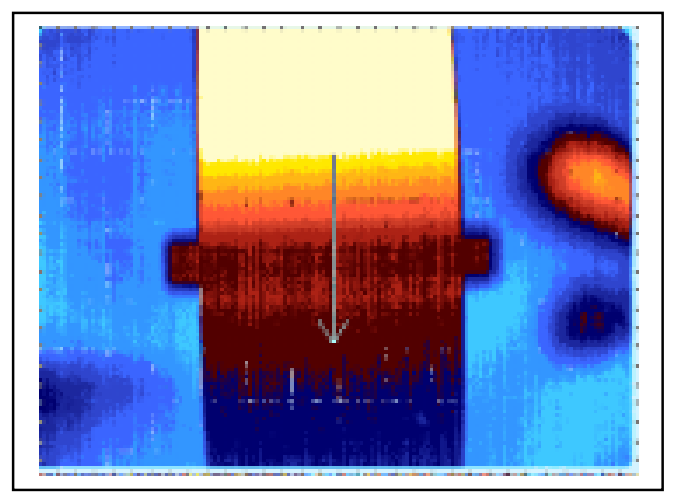

c) 6-second delay time

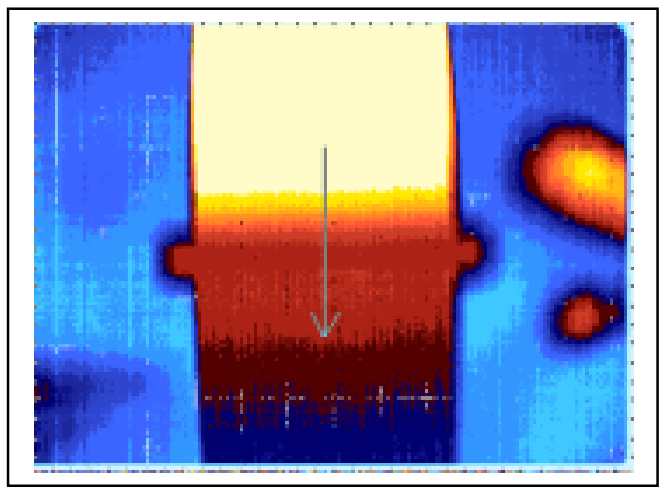

b) 3-second delay time

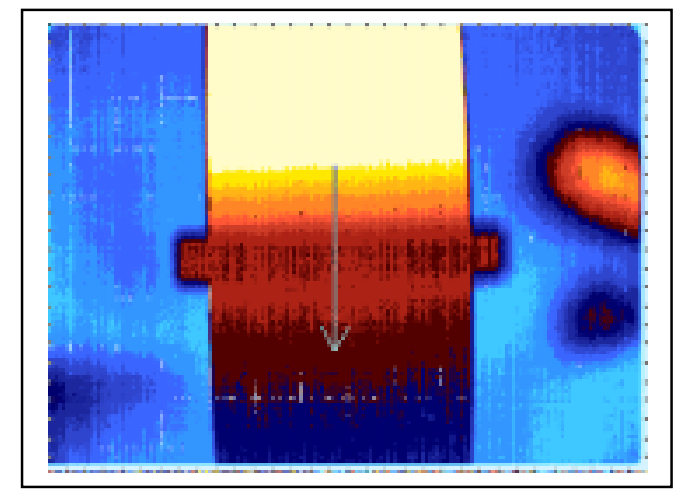

d) 9-second delay time

Figure A.176 Top-heated thermal images of the Specimen WD-1 at 250,000 loading cycles. The heating time is 30 seconds. 


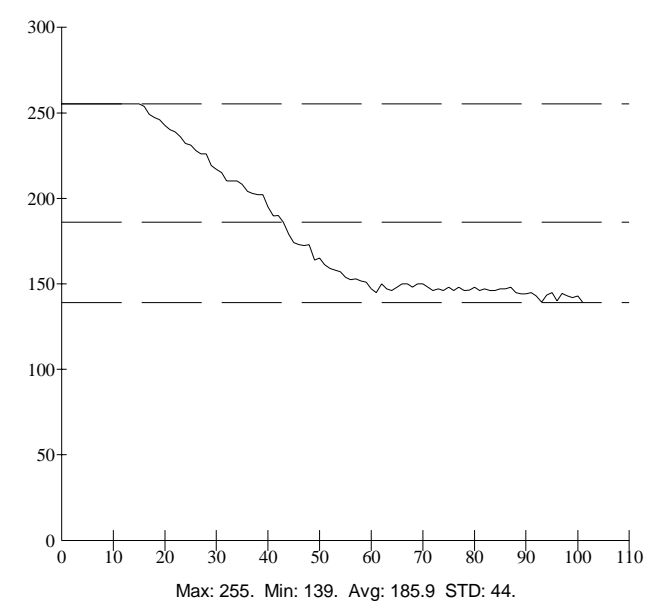

a) 1-second delay time

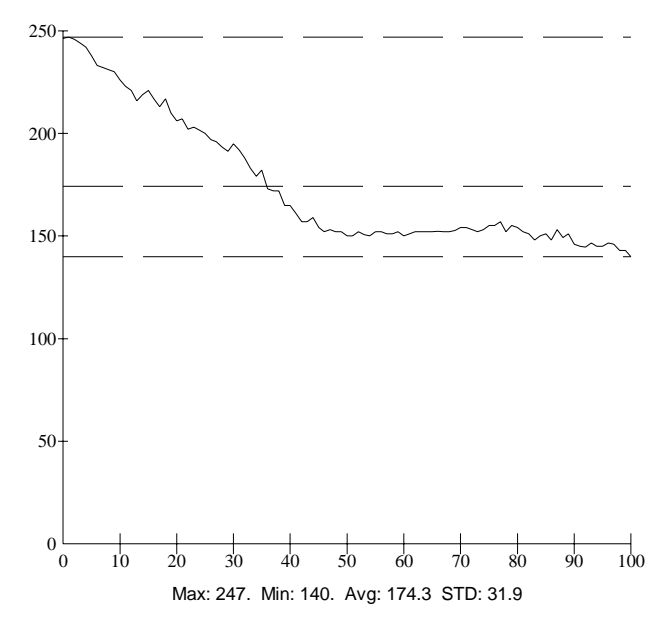

c) 6-second delay time

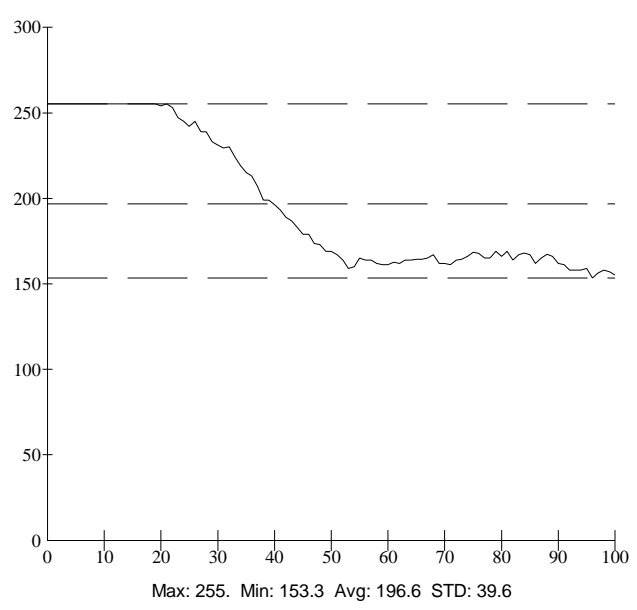

b) 3-second delay time

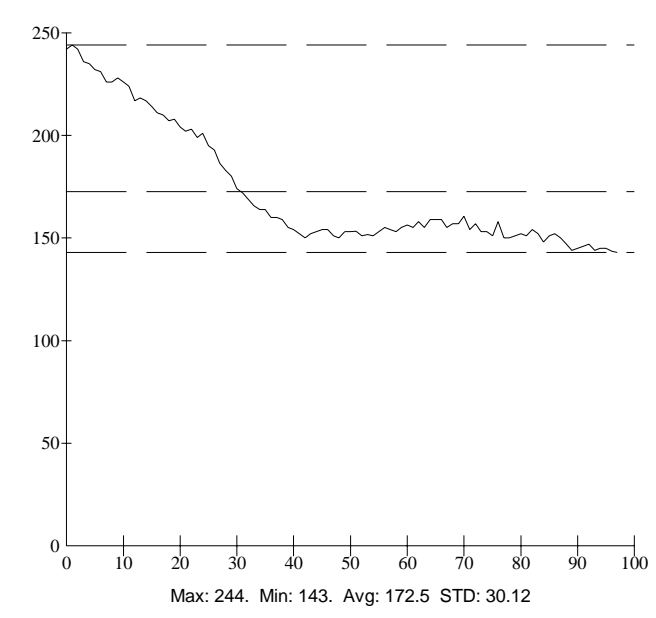

d) 9-second delay time

Figure A.177 Thermal intensity profile along the line across the fatigue crack shown in Figure A.176. 


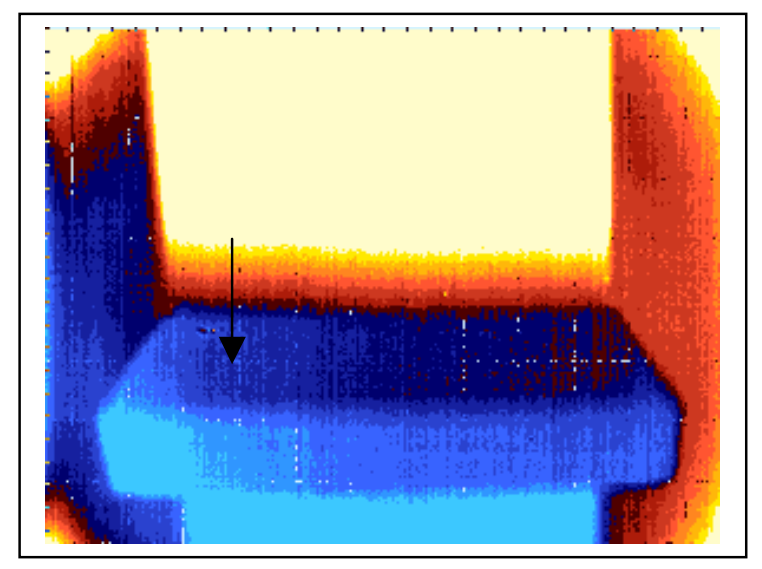

a) 1-second delay time

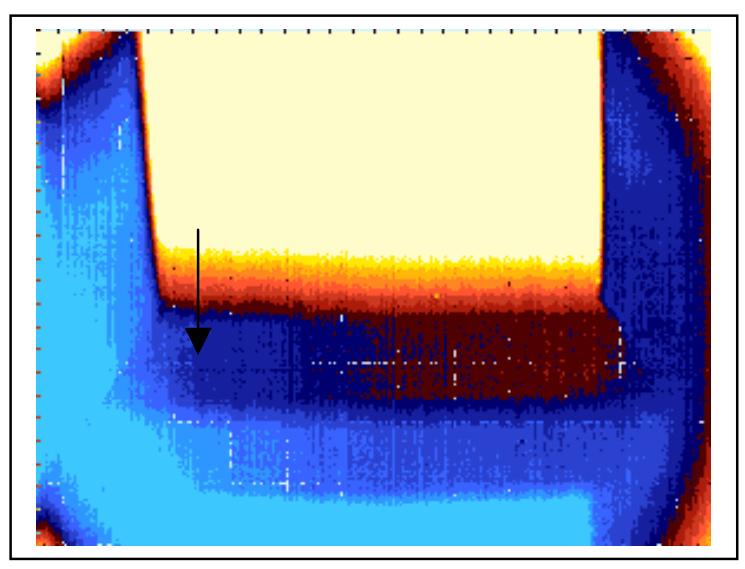

c) 6-second delay time

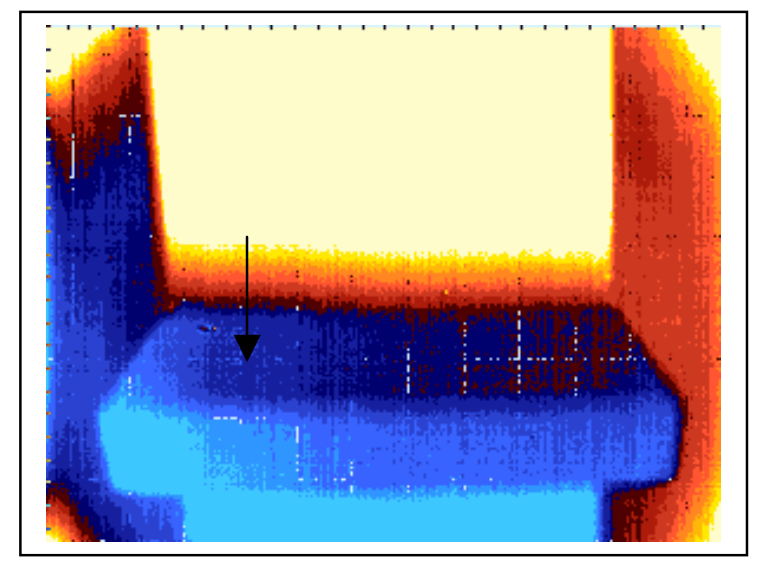

b) 3-second delay time

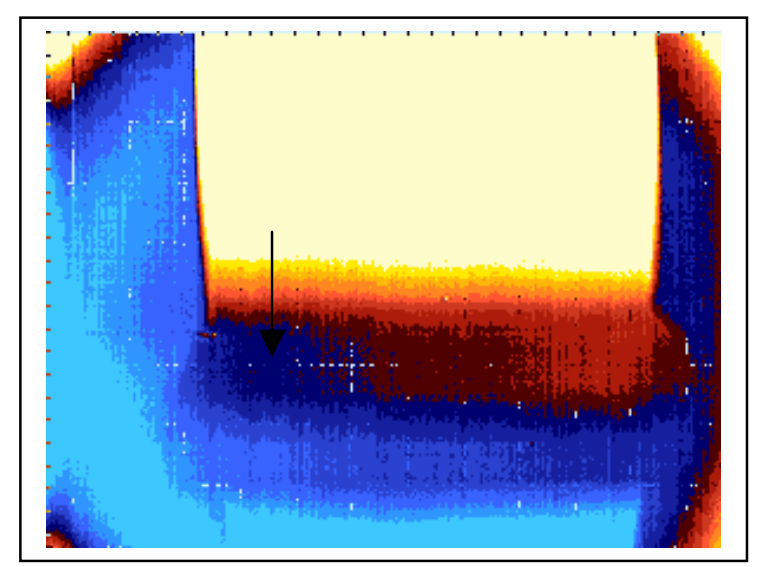

d) 9-second delay time

Figure A.178 Top-heated thermal images of the Specimen WD-1 at 1,320,000 loading cycles. The heating time is 30 seconds. 


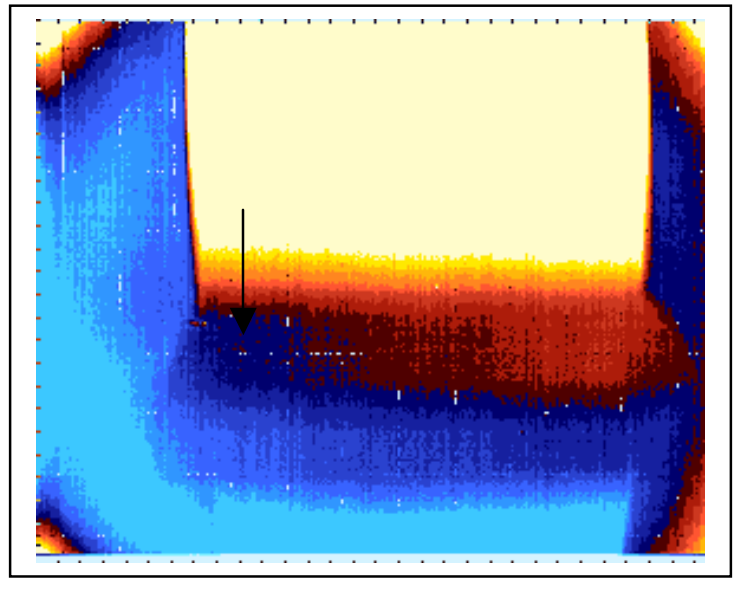

e) 12-second delay time

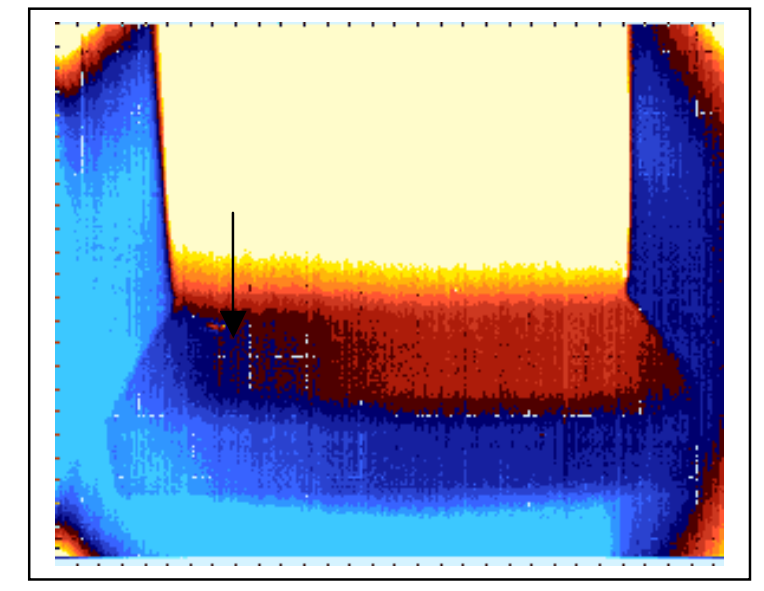

f) 15 -second delay time

Figure A.178 (continued) Top-heated thermal images of the Specimen WD-1 at $1,320,000$ loading cycles. The heating time is 30 seconds. 


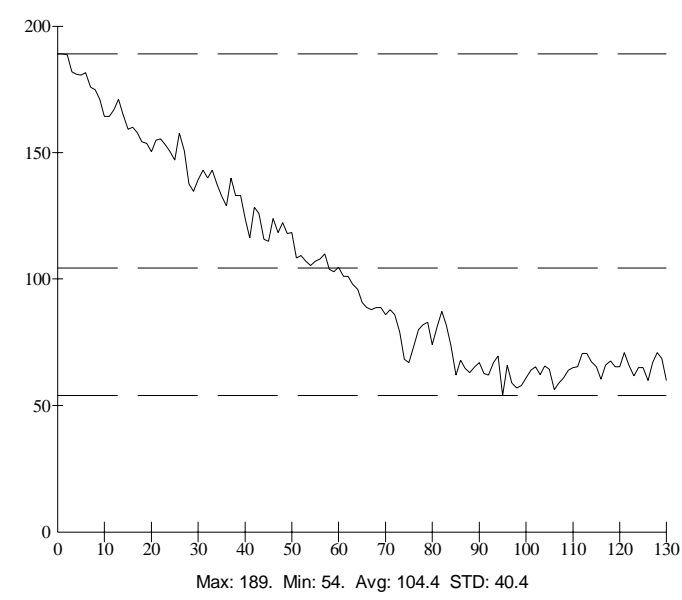

a) 1-second delay time

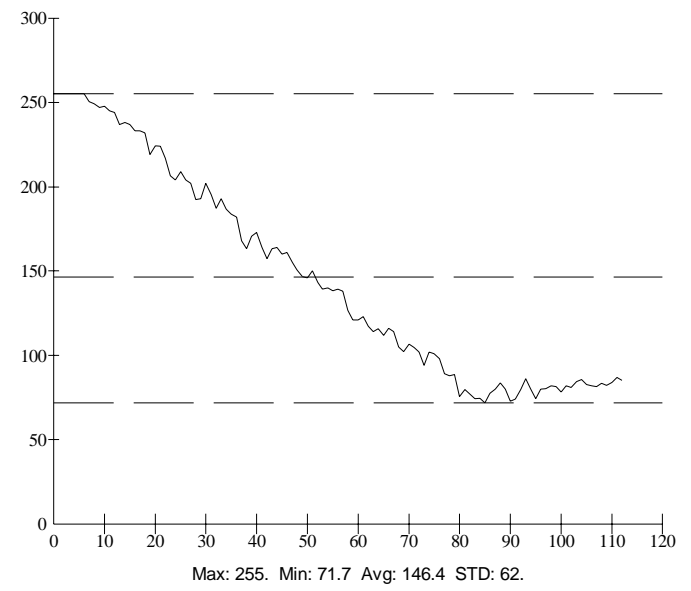

c) 6-second delay time

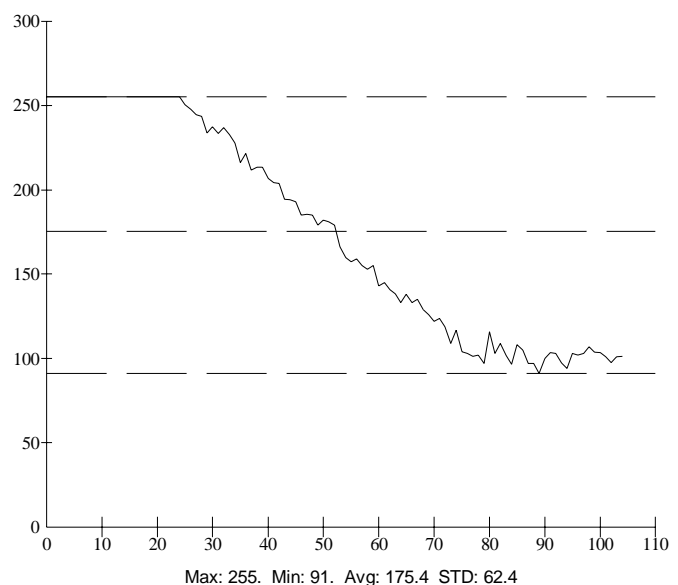

b) 3-second delay time

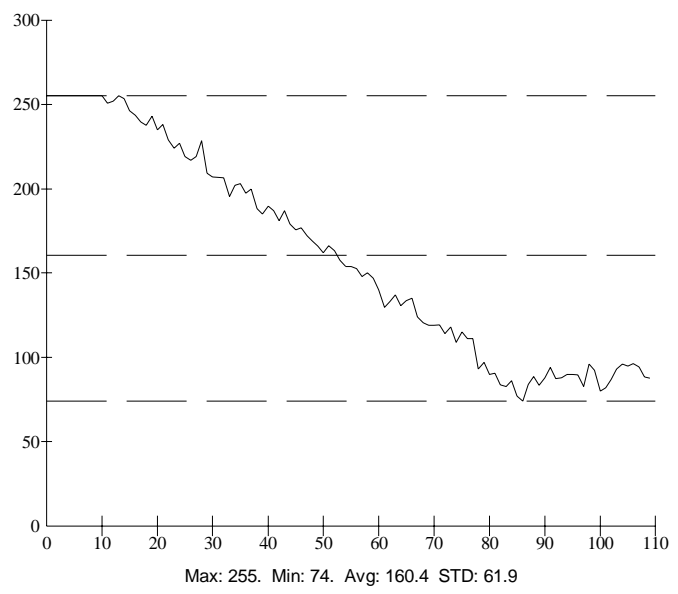

d) 9-second delay time

Figure A.179 Thermal intensity profile along the line across the fatigue crack shown in Figure A.178. 


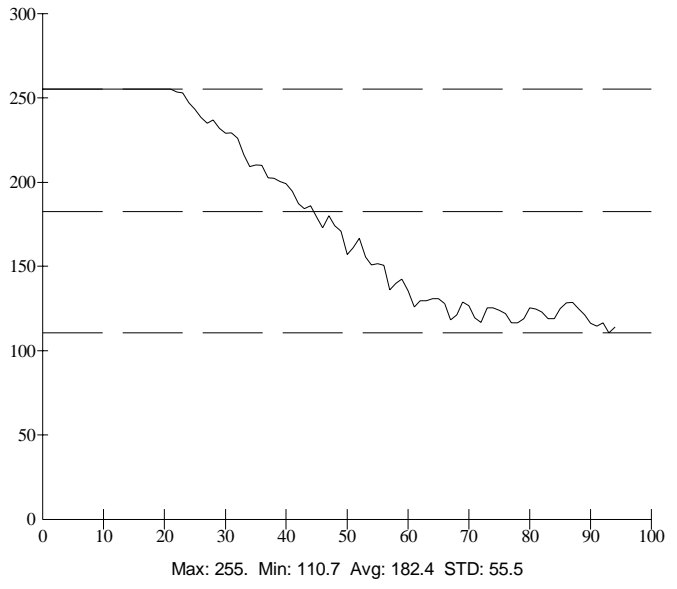

e) 12-second delay time

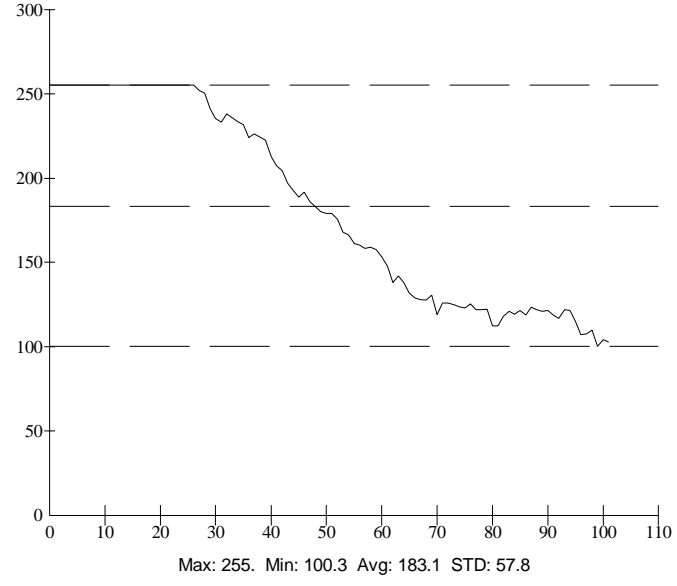

f) 15-second delay time

Figure A.179 (continued) Thermal intensity profile along the line across the fatigue crack shown in Figure A.178. 


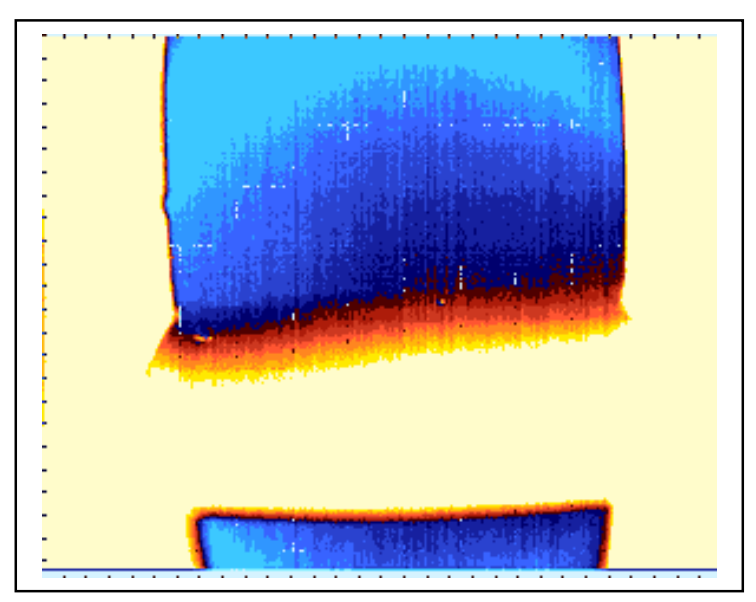

a) 1-second delay time

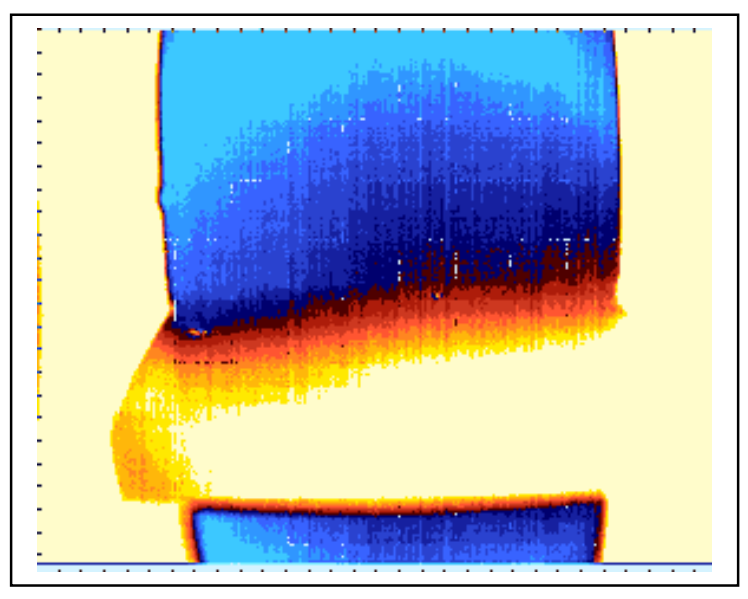

c) 6-second delay time

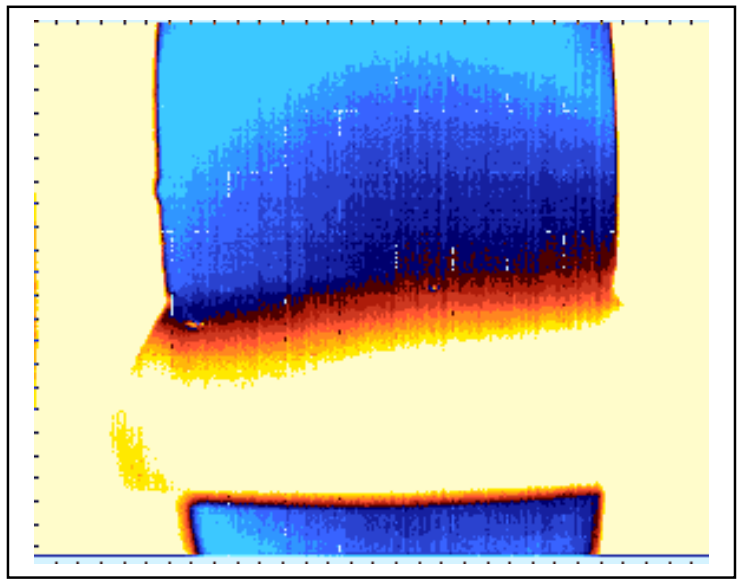

b) 3-second delay time

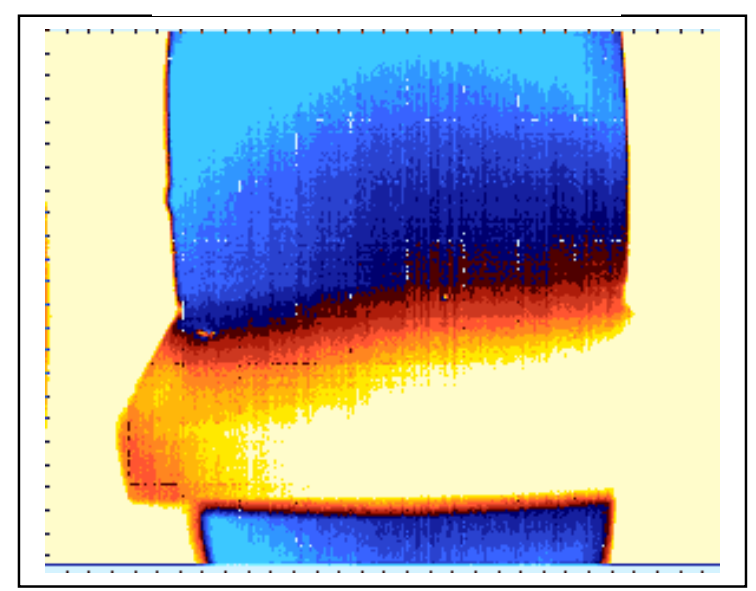

d) 9-second delay time

Figure A.180 Thermal images of the Specimen WD-1 at 1,320,000 loading cycles. Heat is applied at the attached plate. The heating time is 30 seconds. 


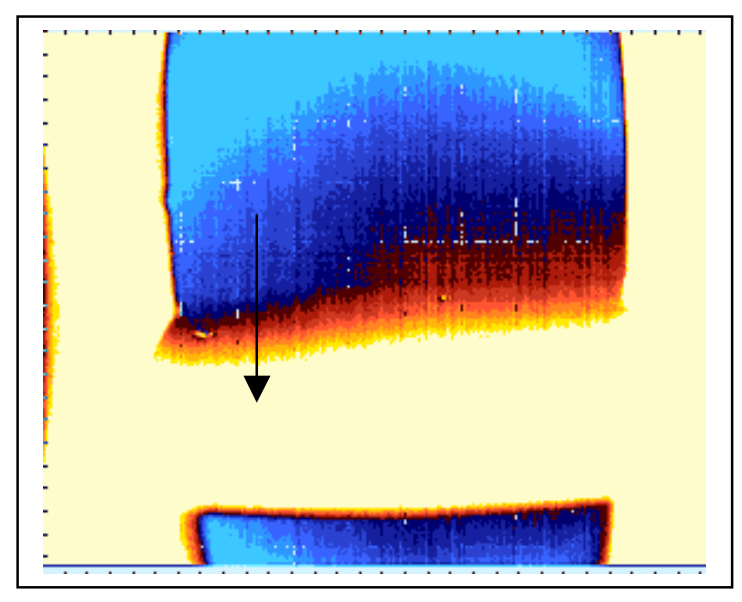

e) 12-second delay time

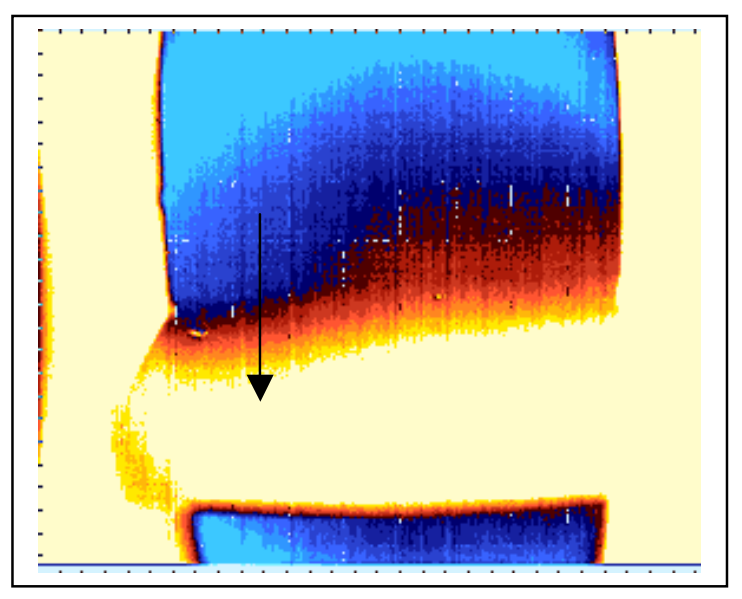

f) 15-second delay time

Figure A.180 (continued) Thermal images of the Specimen WD-1 at 1,320,000 loading cycles. Heat is applied at the top of the attached plate. The heating time is 30 seconds. 


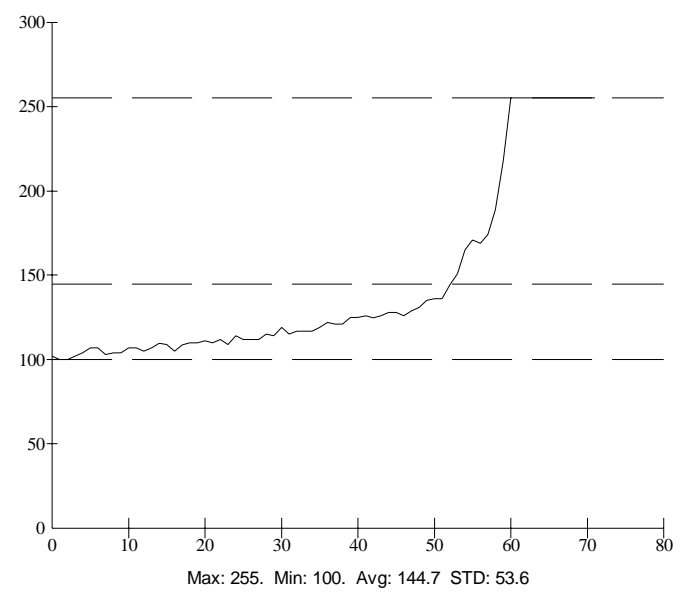

a) 1-second delay time

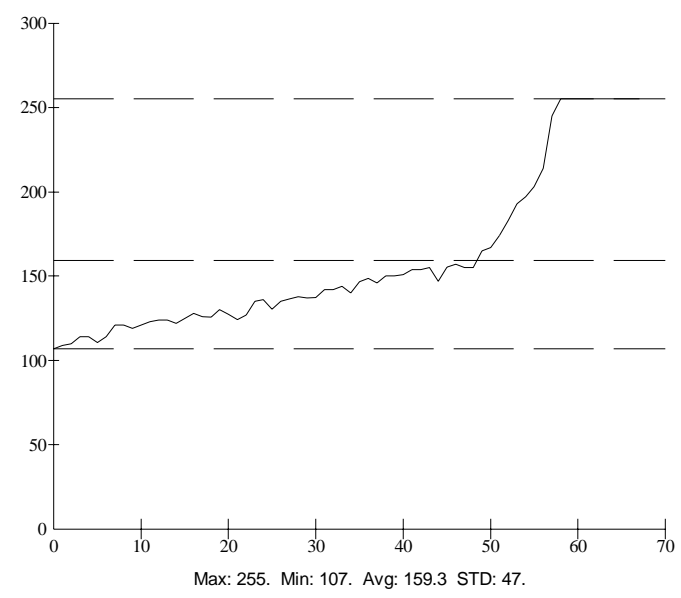

c) 6-second delay time

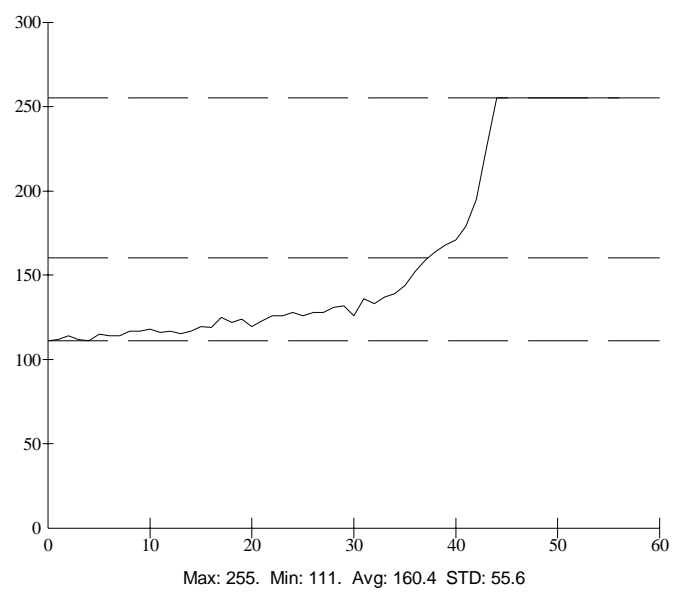

b) 3-second delay time

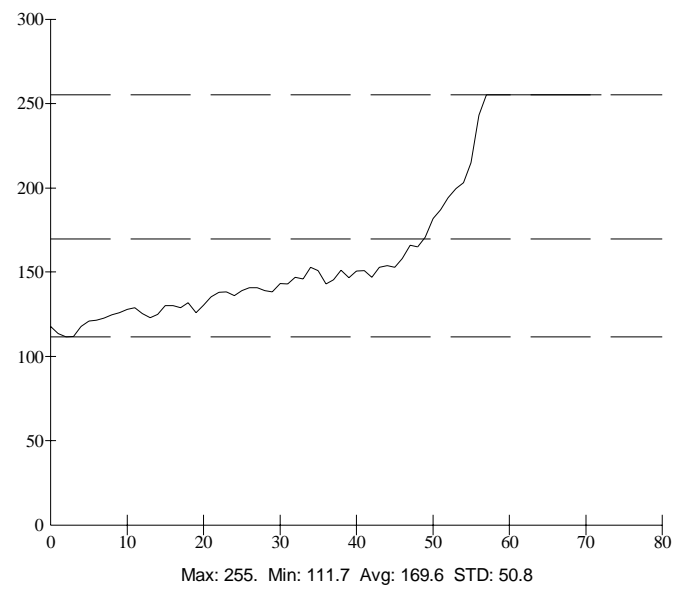

d) 9-second delay time

Figure A.181 Thermal intensity profile along the line across the fatigue crack shown in Figure A.180. 


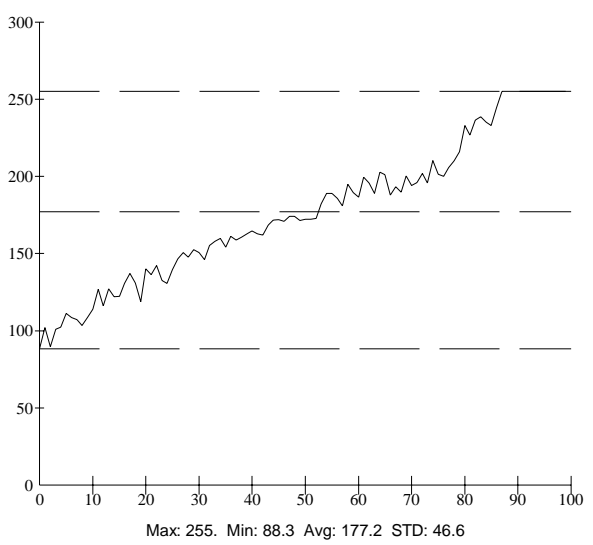

e) 12-second delay time

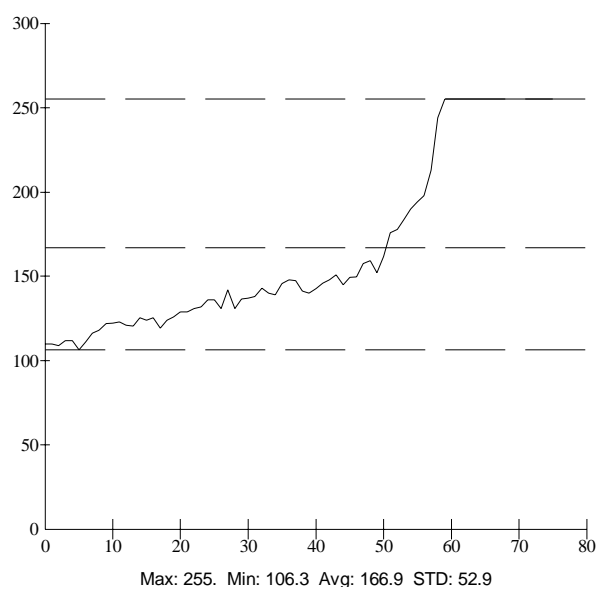

f) 15-second delay time

Figure A.181 (continued) Thermal intensity profile along the line across the fatigue crack shown in Figure A.180. 


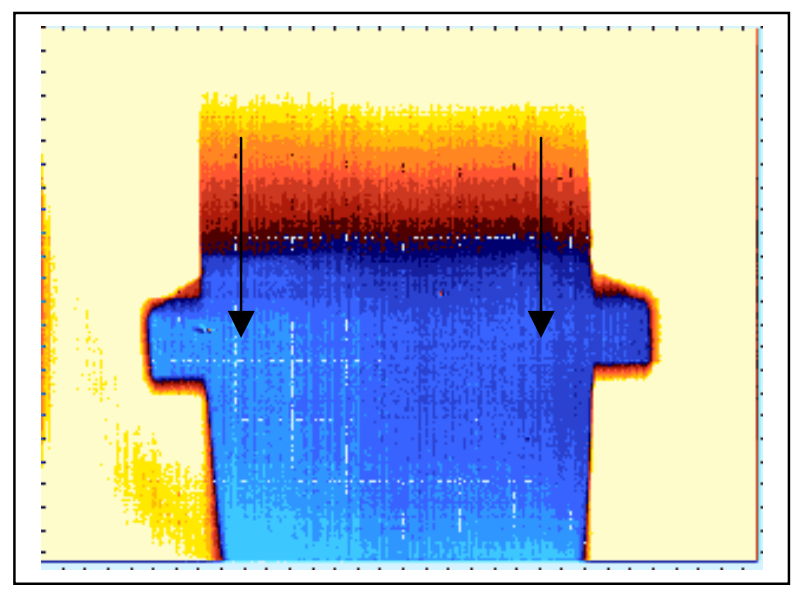

a) The thermal image
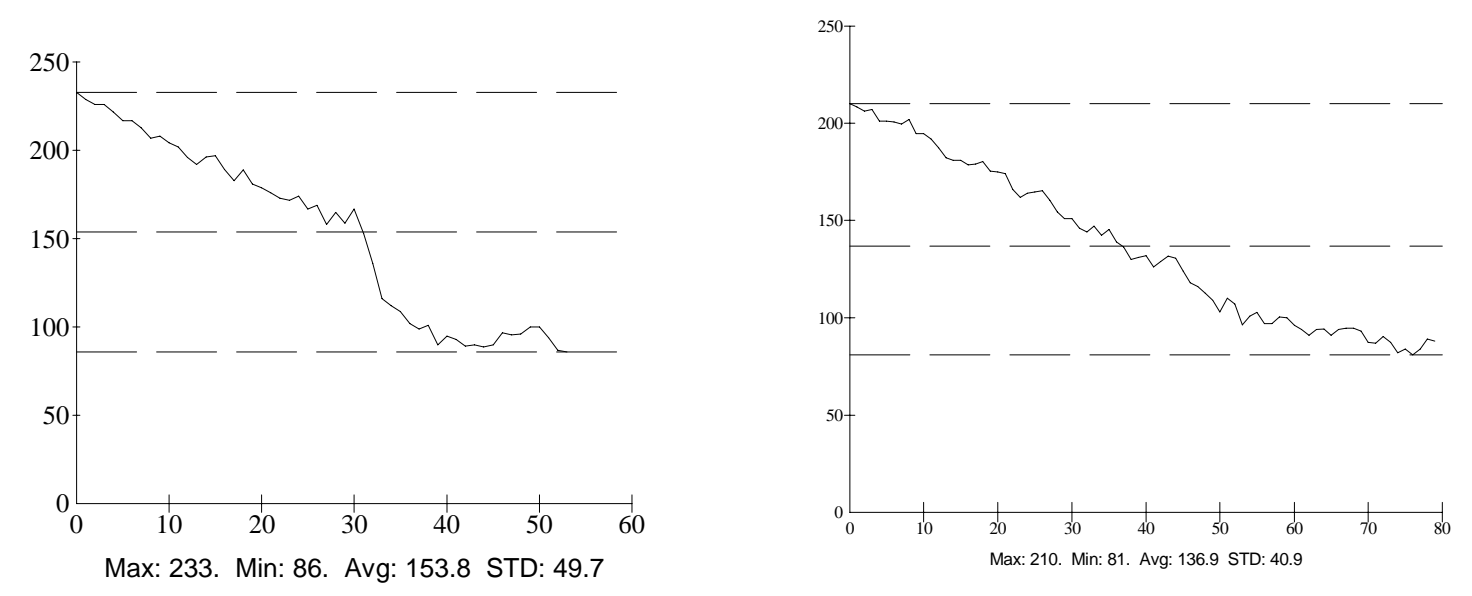

b) The thermal profile from the left line

c) The thermal profile from the right line

Figure A.182 Top-heated thermal images of the Specimen WD-1 at 1,335,000 loading cycles. The heating time is 30 seconds. The delay time is 1 second. 


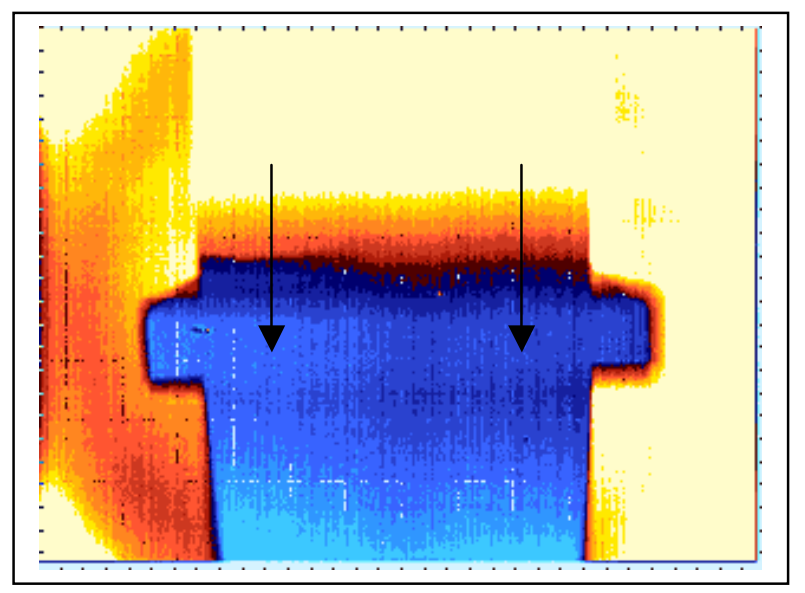

a) Thermal image

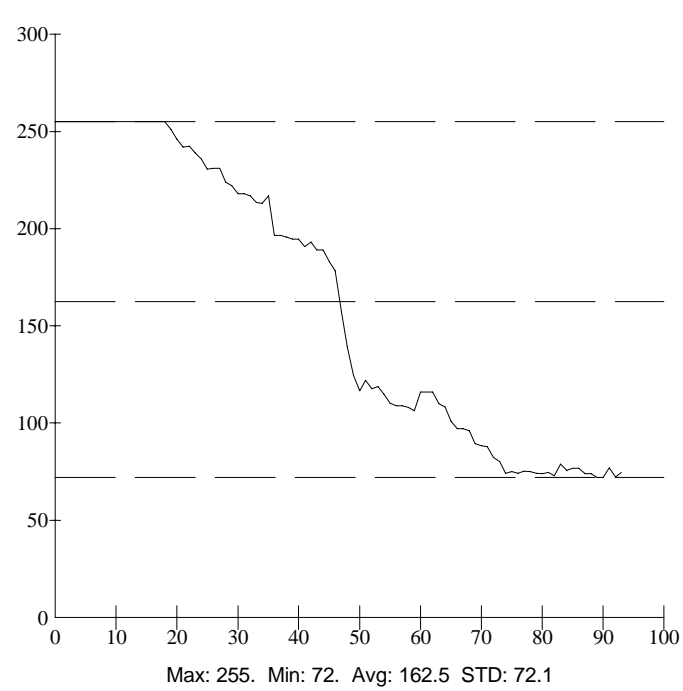

b) Thermal profile from the left line

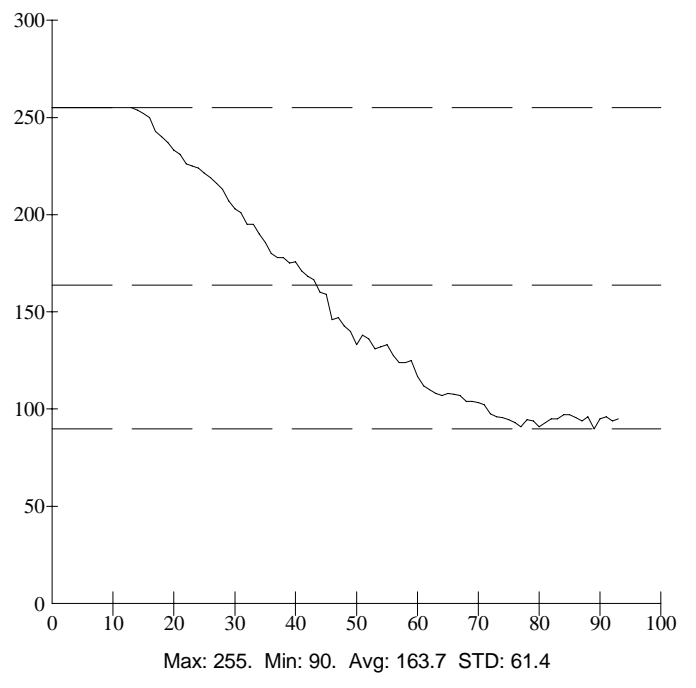

c) Thermal profile from the right line

Figure A.183 Top-heated thermal images of the Specimen WD-1 at 1,335,000 loading cycles. The heating time is 30 seconds. The delay time is 3 seconds. 


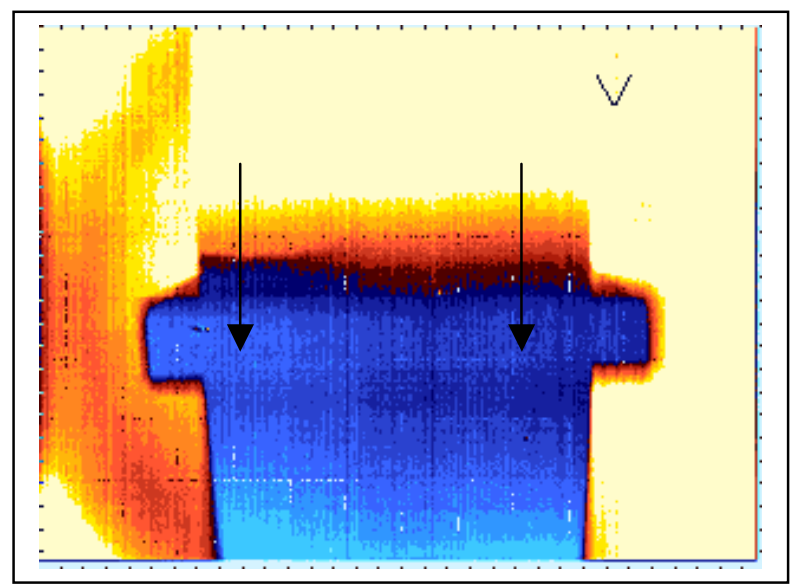

a) Thermal image

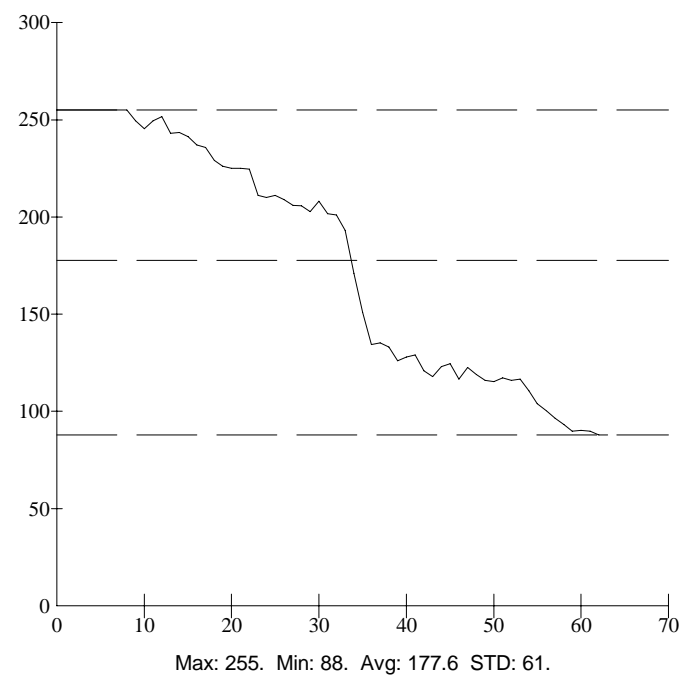

b) Thermal profile from the left line

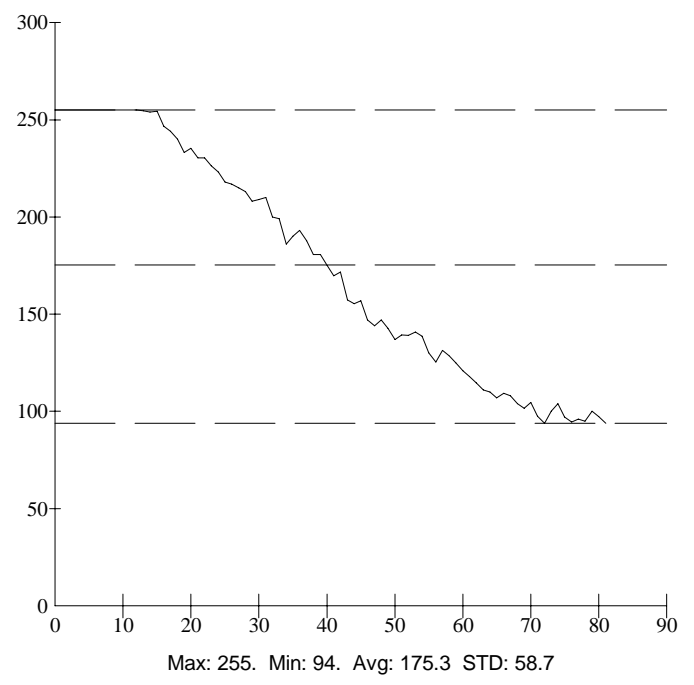

c) Thermal profile from the right line

Figure A.184 Top-heated thermal images of the Specimen WD-1 at 1,335,000 loading cycles. The heating time is 30 seconds. The delay time is 6 seconds. 


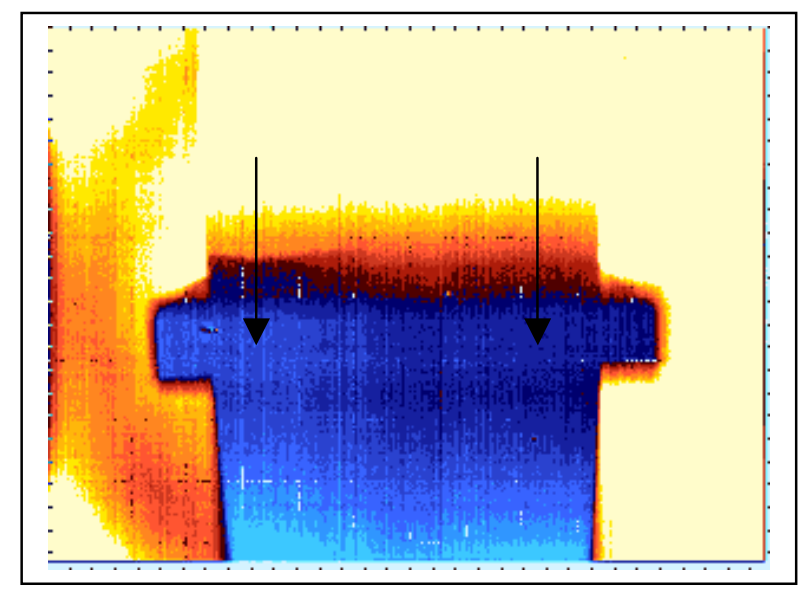

a) Thermal image

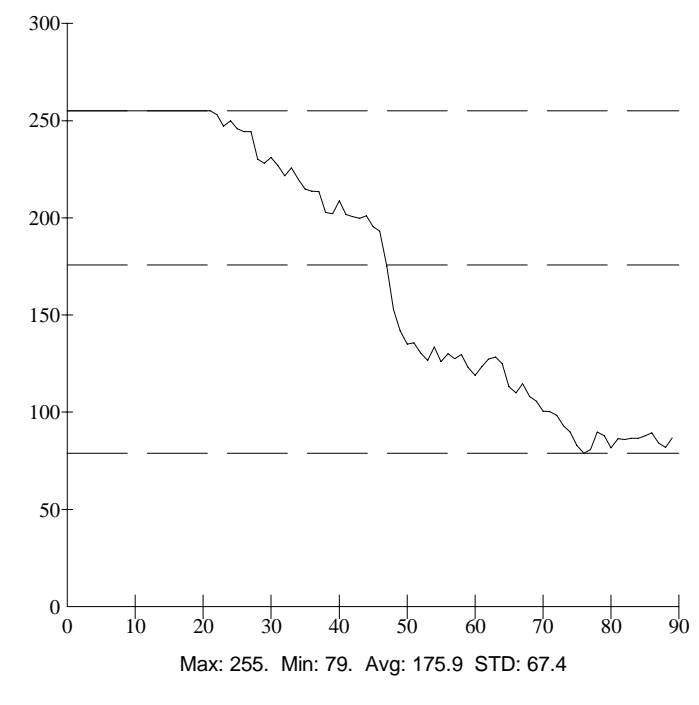

b) Thermal profile from the left line

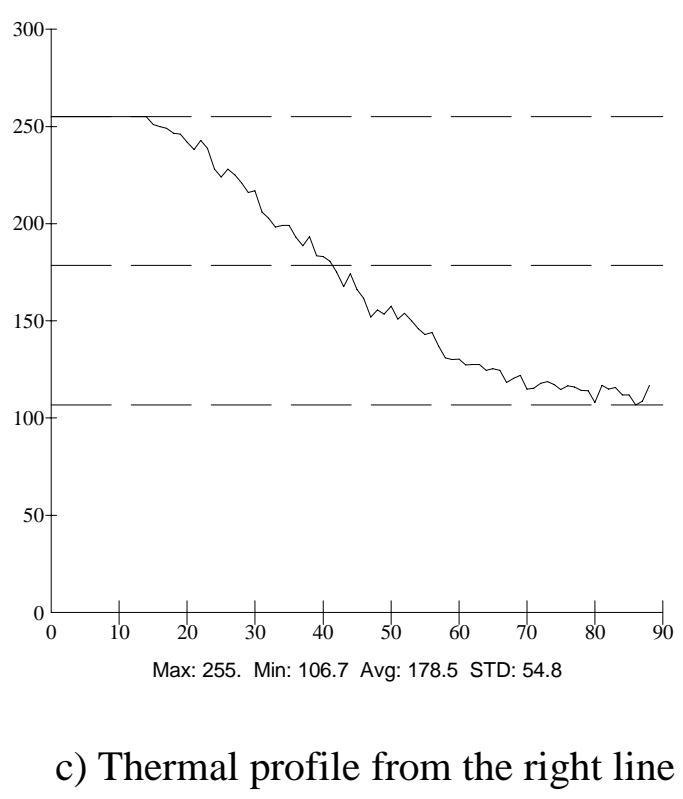

c) Thermal profile from the right line

Figure A.185 Top-heated thermal images of the Specimen WD-1 at 1,335,000 loading cycles. The heating time is 30 seconds. The delay time is 9 seconds. 


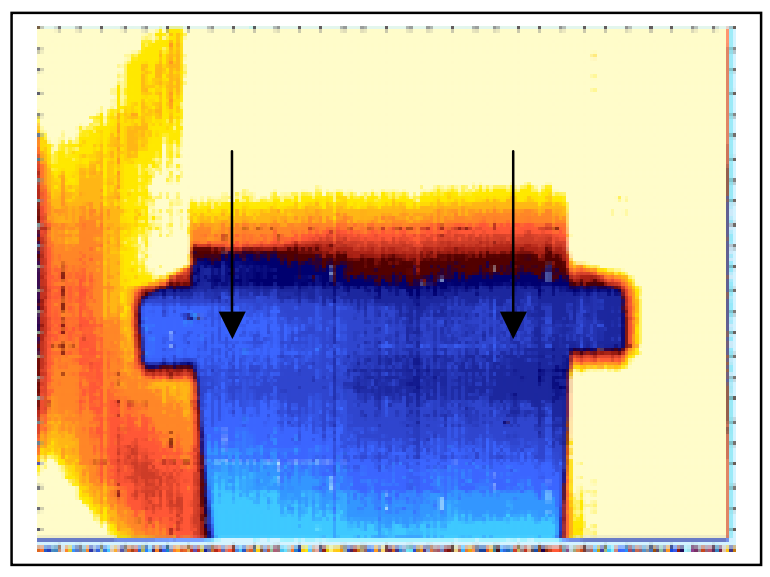

a) Thermal image
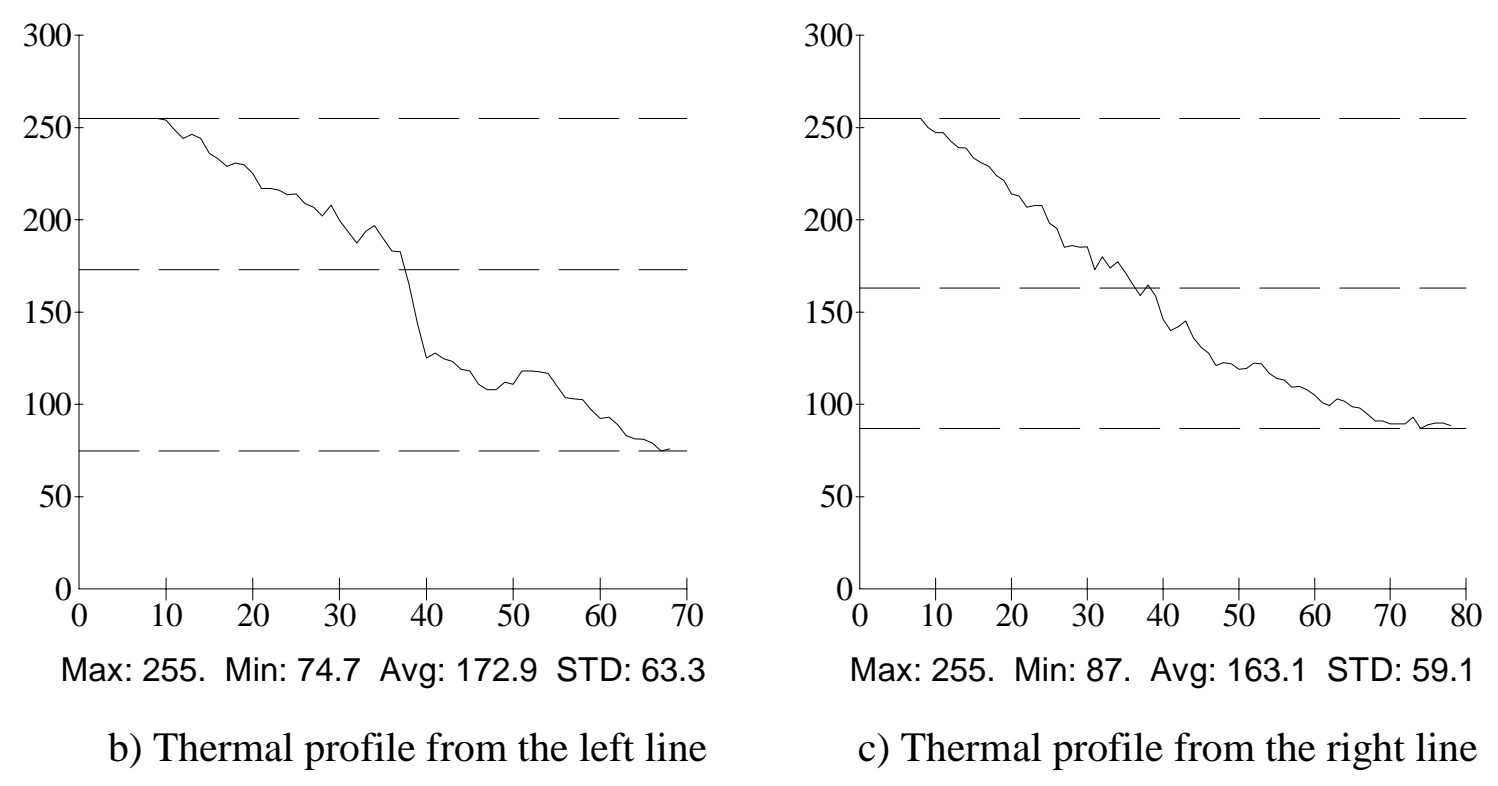

Figure A.186 Top-heated Thermal images of the Specimen WD-1 at 1,335,000 loading cycles. The heating time is 60 seconds. The delay time is 1 second. 


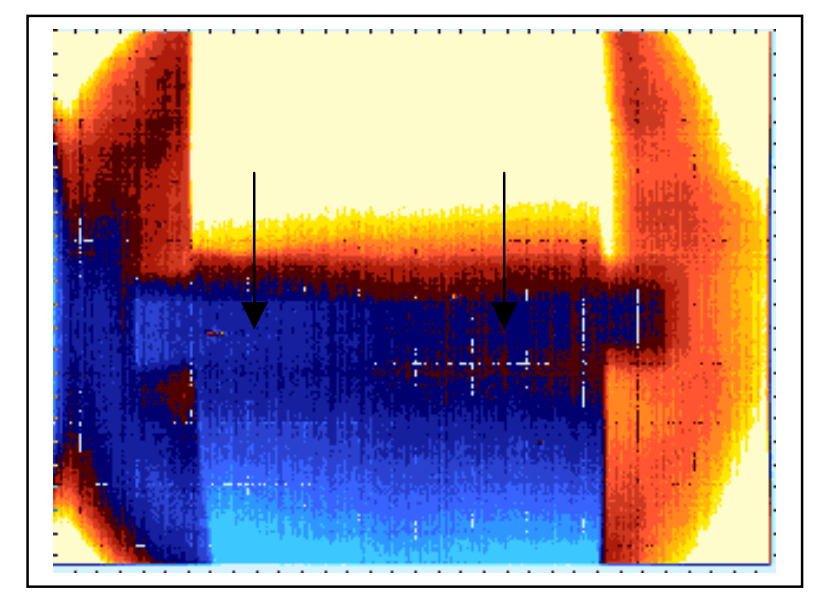

a) Thermal image
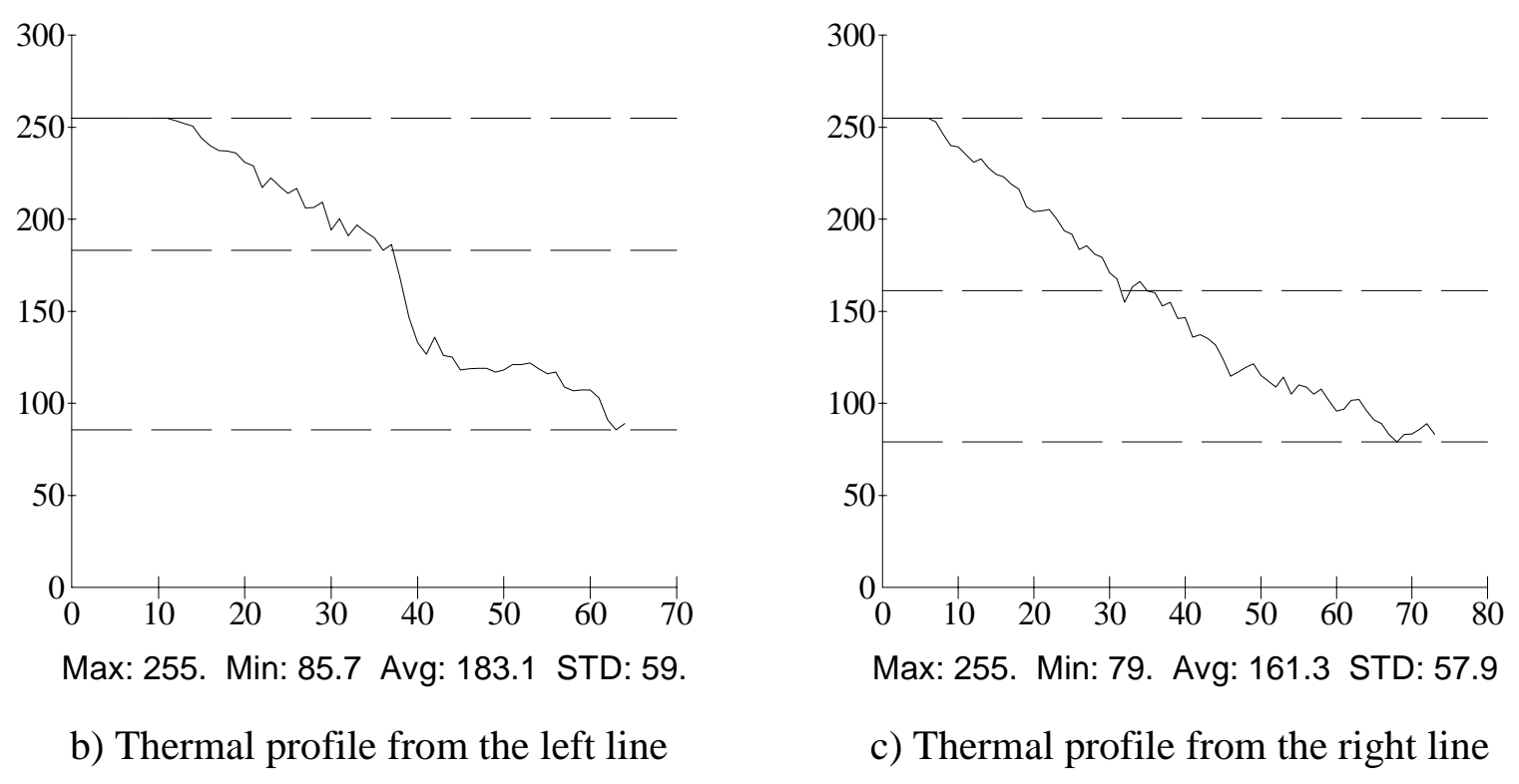

Figure A.187 Top-heated thermal images of the Specimen WD-1 at 1,335,000 loading cycles. The heating time is 60 seconds. The delay time is 3 seconds. 


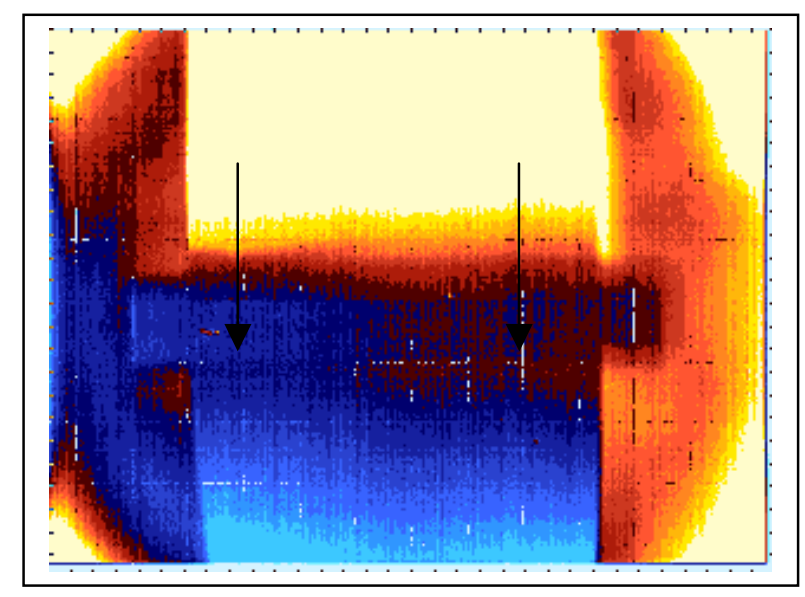

a) Thermal image

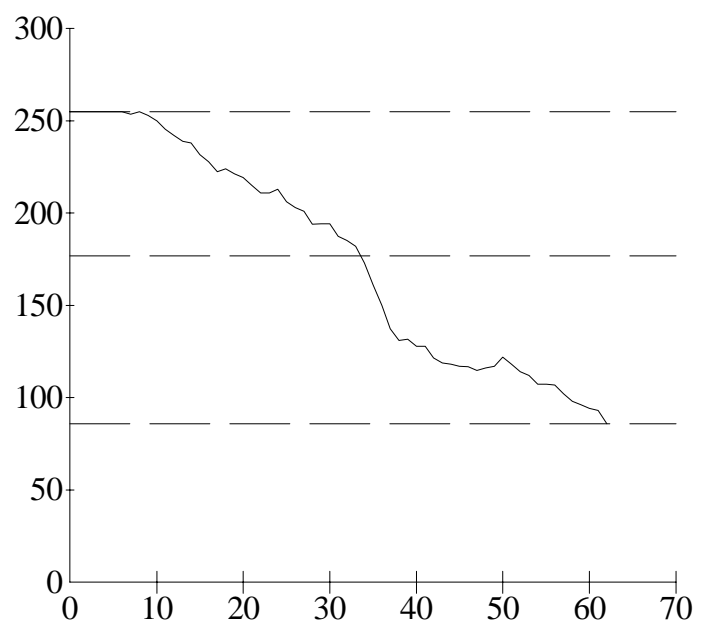

Max: 255. Min: 86. Avg: 176.8 STD: 58.2

b) Thermal profile from the left line

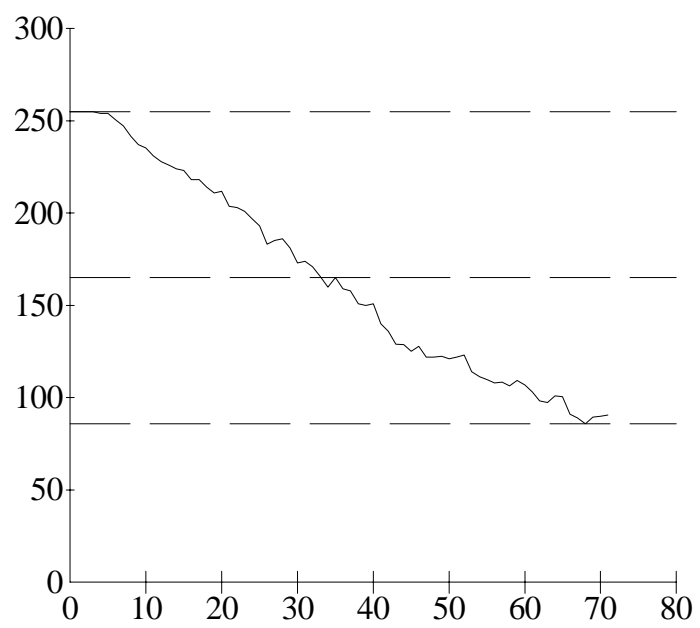

Max: 255. Min: 86. Avg: 165. STD: 54.8

c) Thermal profile from the right line

Figure A.188 Top-heated thermal images of the Specimen WD-1 at 1,335,000 loading cycles. The heating time is 60 seconds. The delay time is 6 seconds. 


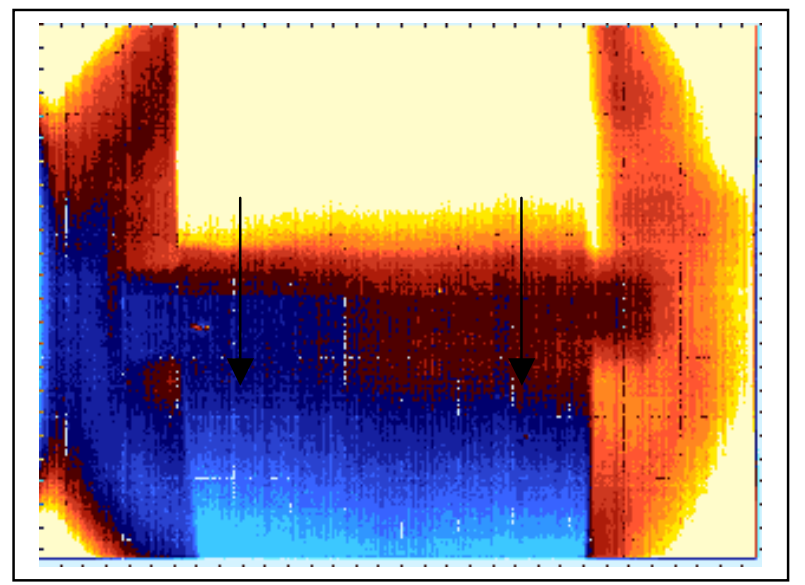

a) Thermal image
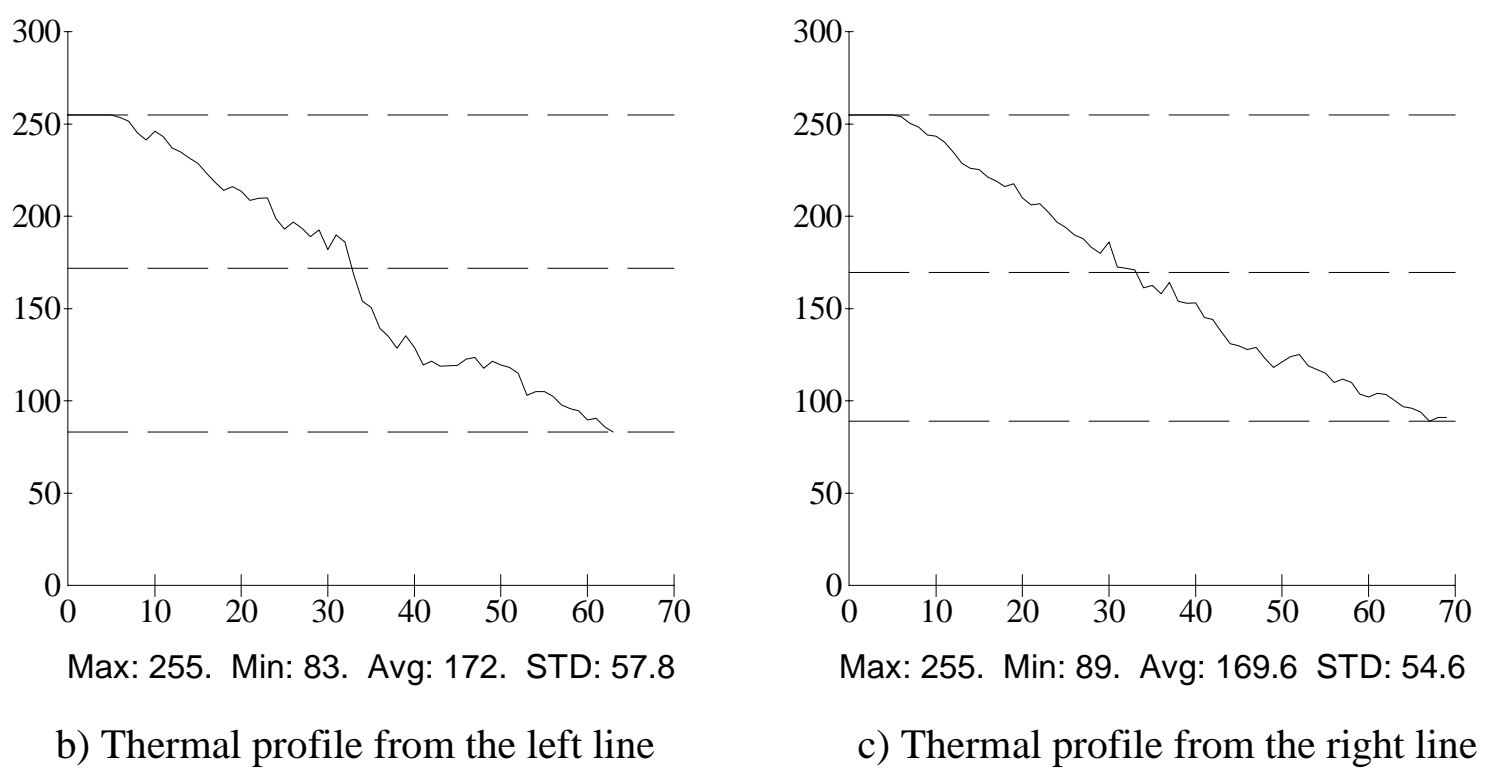

Figure A.189 Top-heated thermal images of the Specimen WD-1 at 1,335,000 loading cycles. The heating time is 60 seconds. The delay time is 9 seconds. 


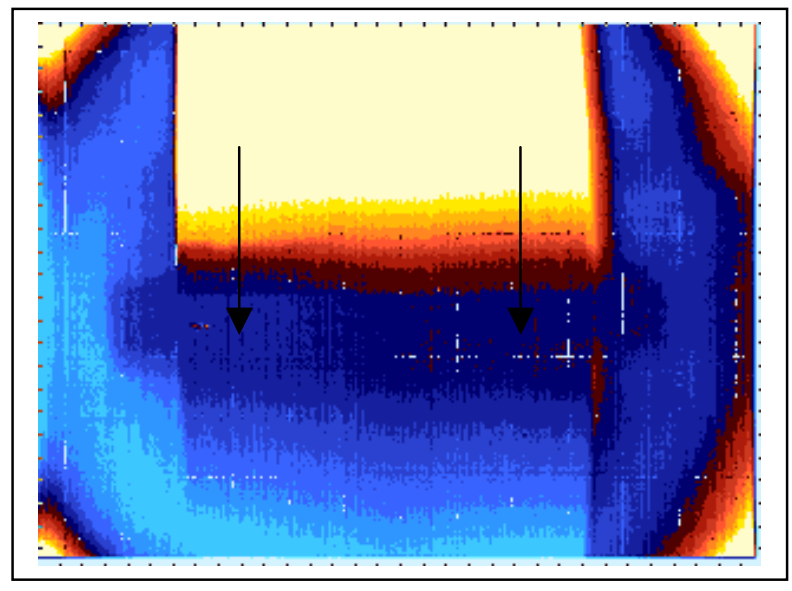

a) Thermal image

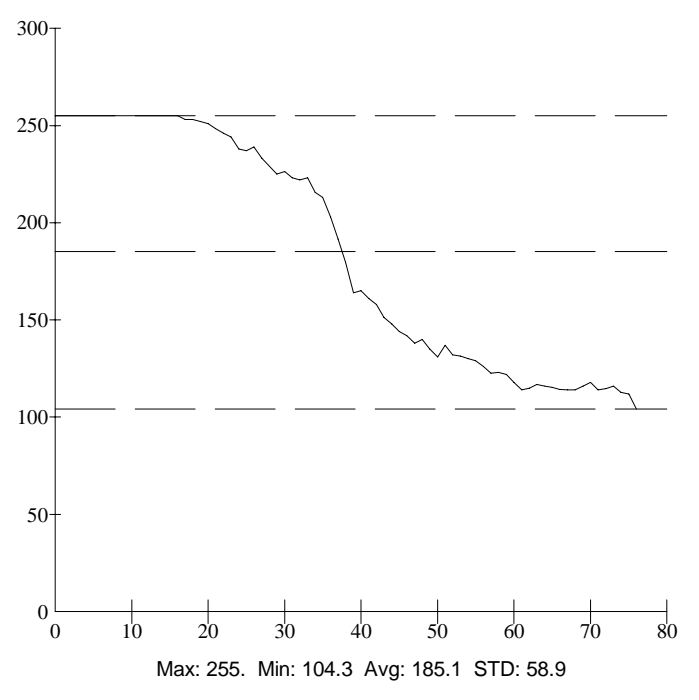

b) Thermal profile from the left line

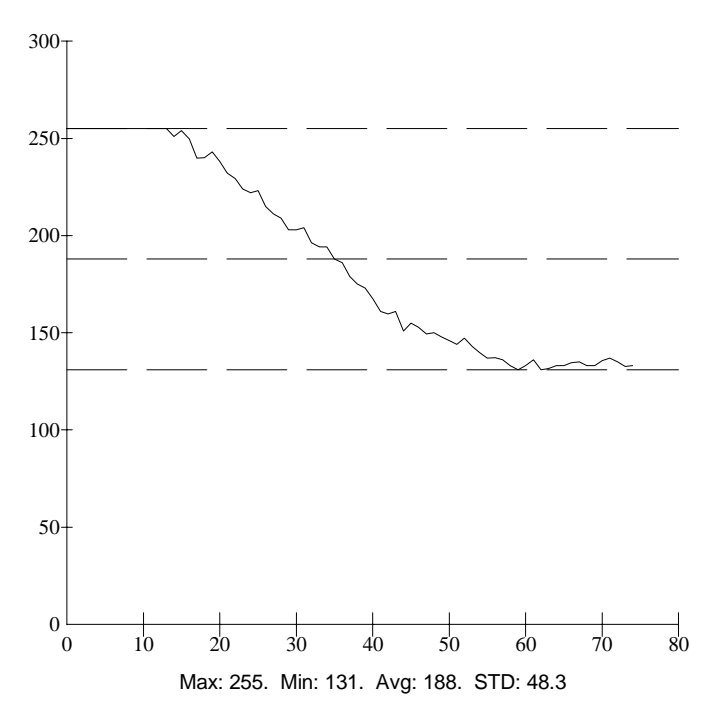

c) Thermal profile from the right line

Figure A.190 Top-heated thermal images of the Specimen WD-1 at 1,335,000 loading cycles. The heating time is 90 seconds. The delay time is 1 second. 


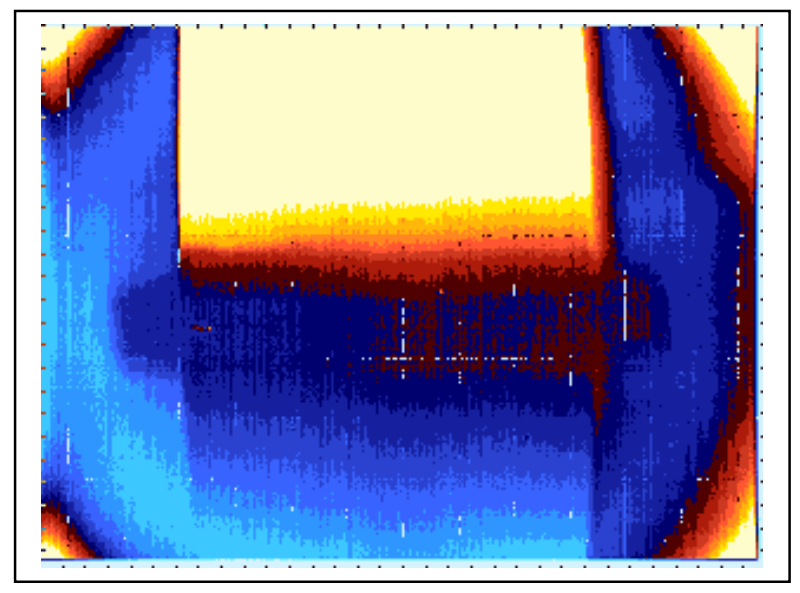

a) Thermal image

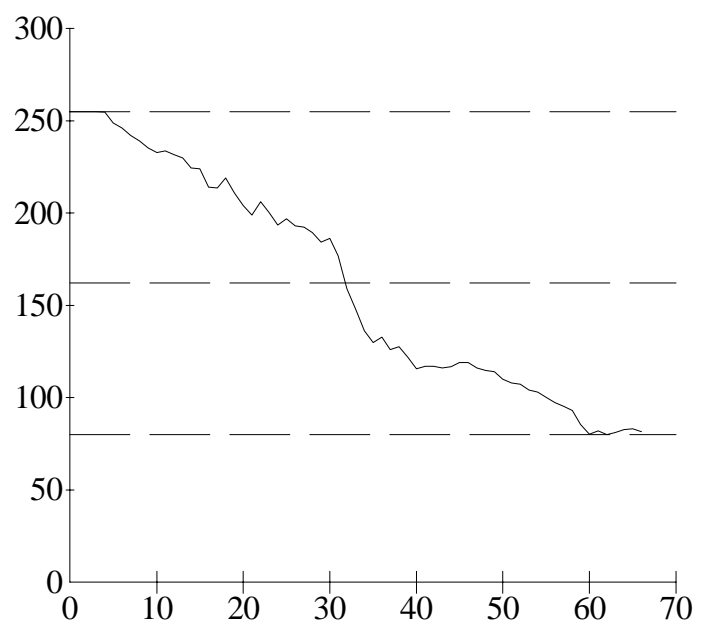

Max: 255. Min: 80. Avg: 162.1 STD: 59.6

b) Thermal profile from the left line

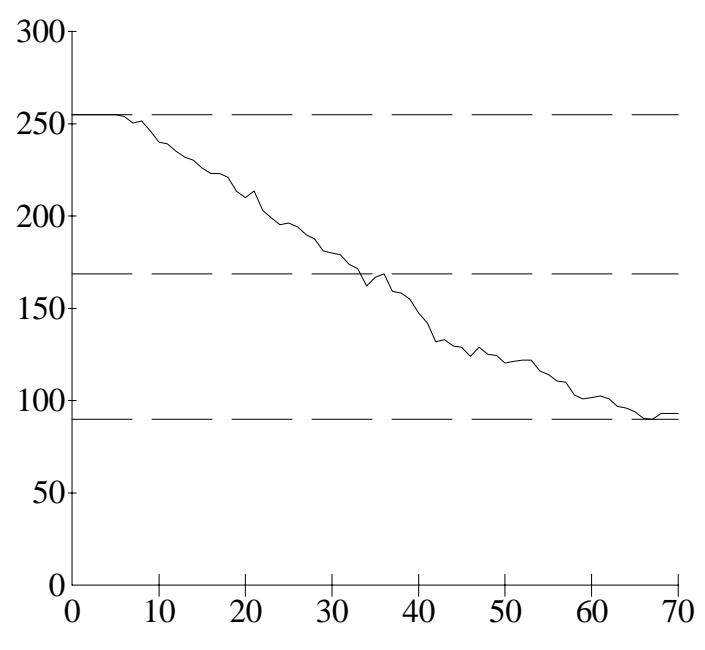

Max: 255. Min: 90. Avg: 168.5 STD: 55.8

c) Thermal profile from the right line

Figure A.191 Top-heated thermal images of the Specimen WD-1 at 1,335,000 loading cycles. The heating time is 90 seconds. The delay time is 3 seconds. 


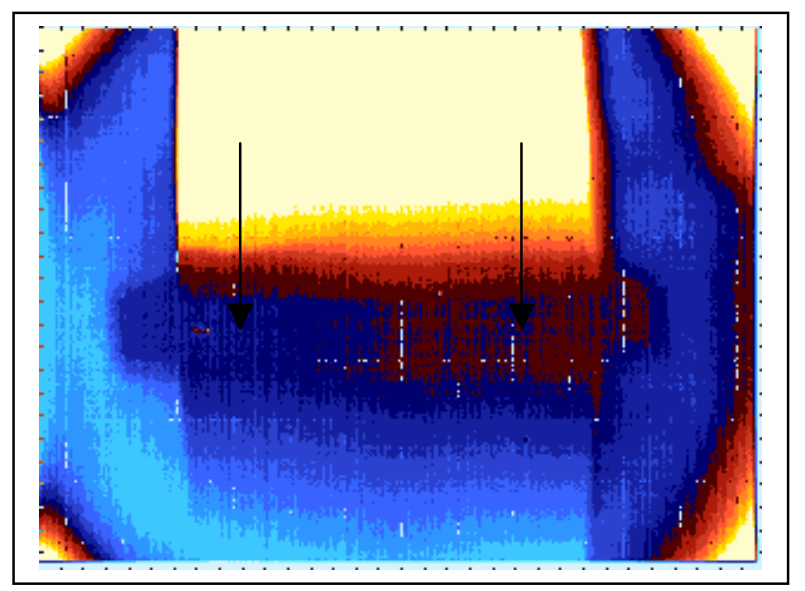

a) Thermal image
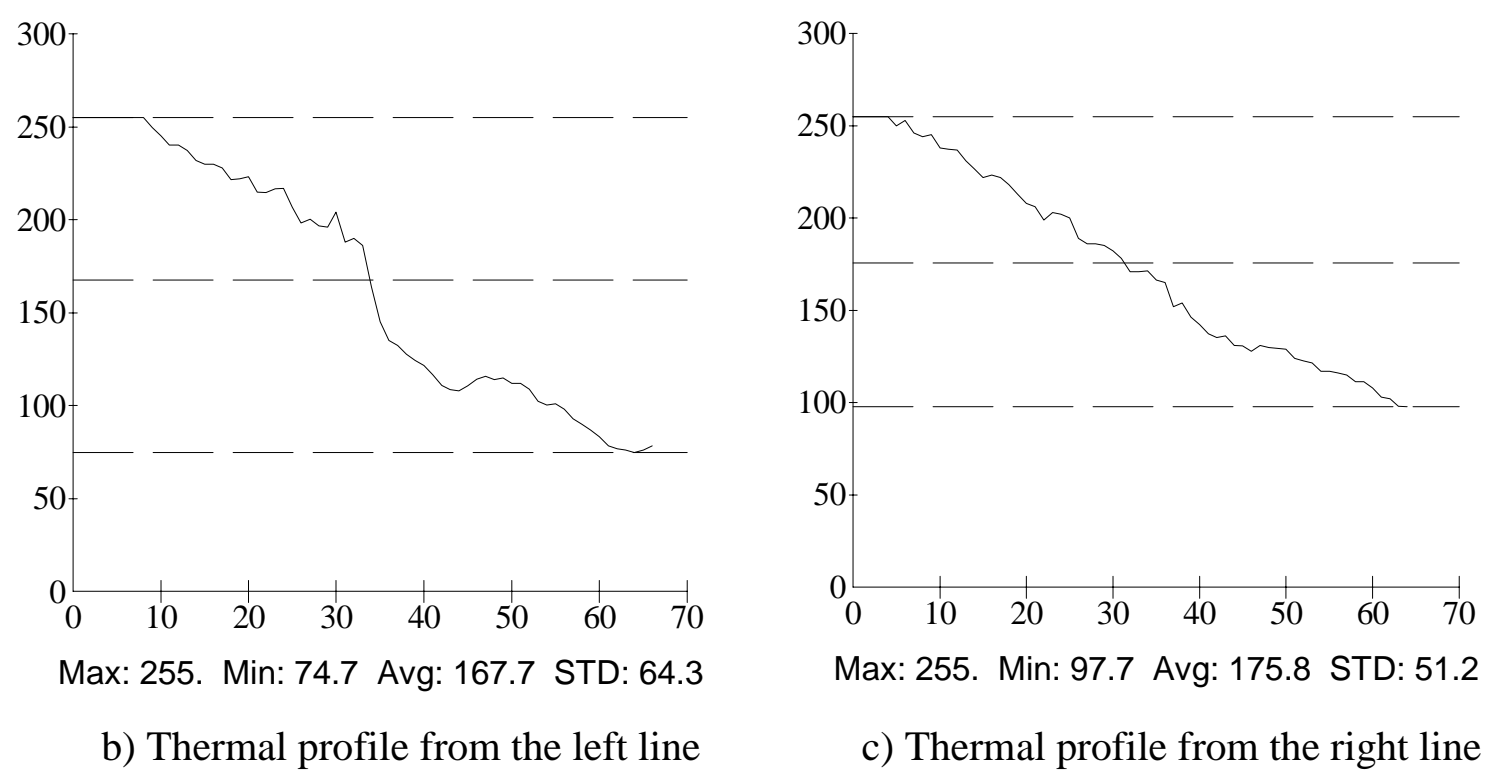

Figure A.192 Top-heated Thermal images of the Specimen WD-1 at 1,335,000 loading cycles. The heating time is 90 seconds. The delay time is 6 seconds. 


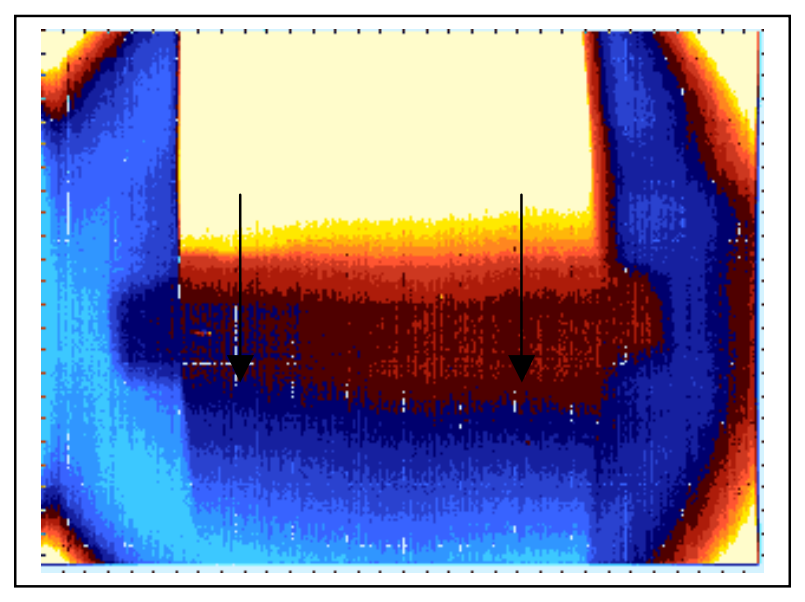

a) Thermal image

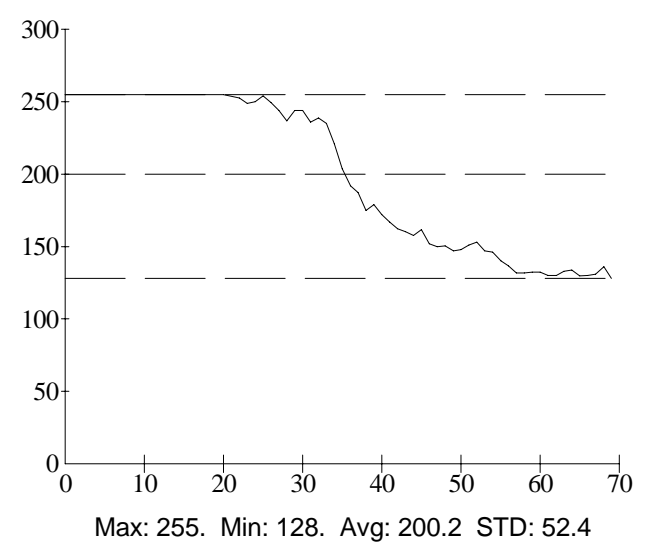

b) Thermal profile from the left line

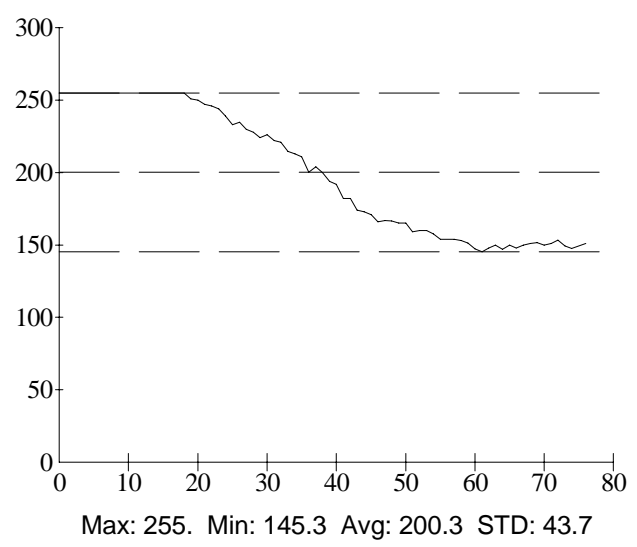

c) Thermal profile from the right line

Figure A.193 Top-heated thermal images of the Specimen WD-1 at 1,335,000 loading cycles. The heating time is 90 seconds. The delay time is 9 seconds. 


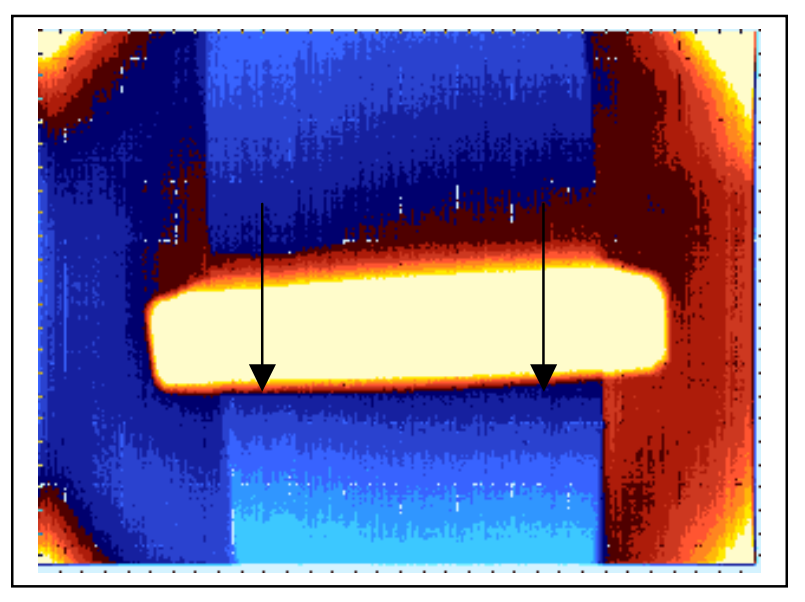

a) Thermal image

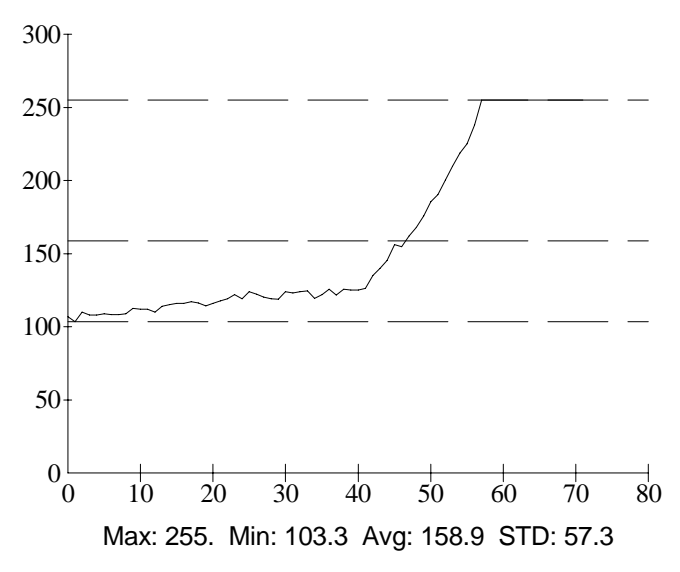

b) Thermal profile from the left line

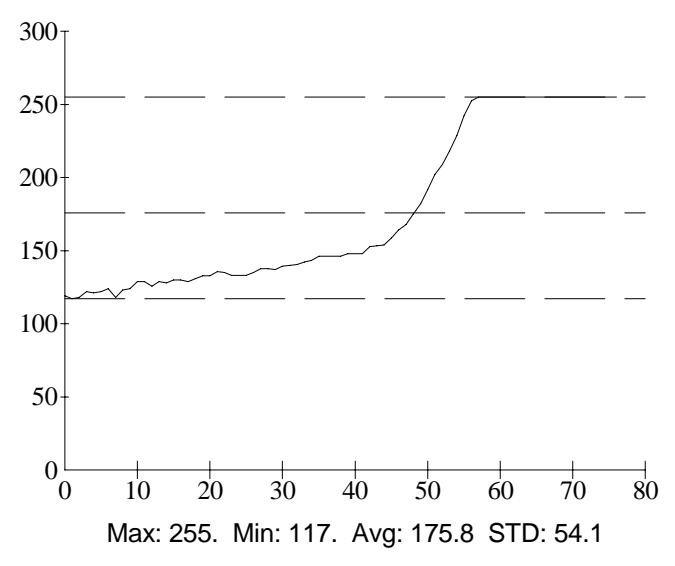

c) Thermal profile from the right line

Figure A.194 Top-heated thermal images of the Specimen WD-1 at 1,335,000 loading cycles. The heating time is 30 seconds. The delay time is 1 second. 


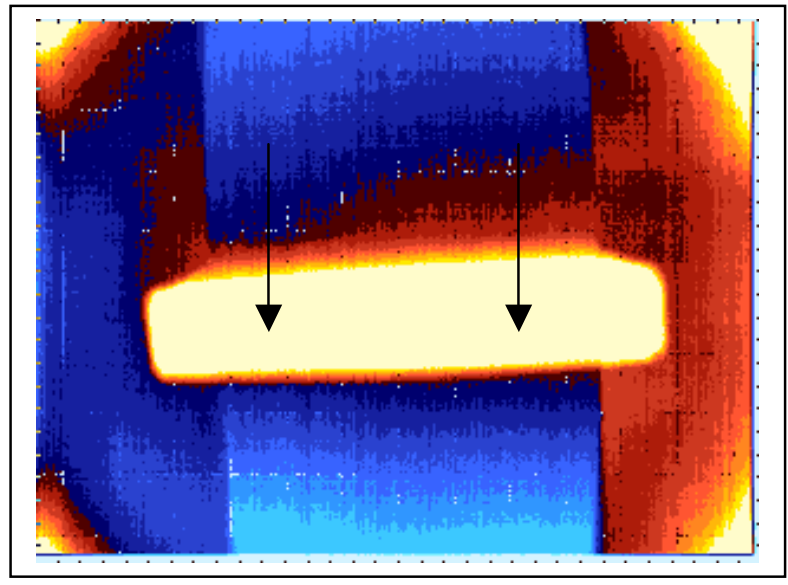

a) Thermal image

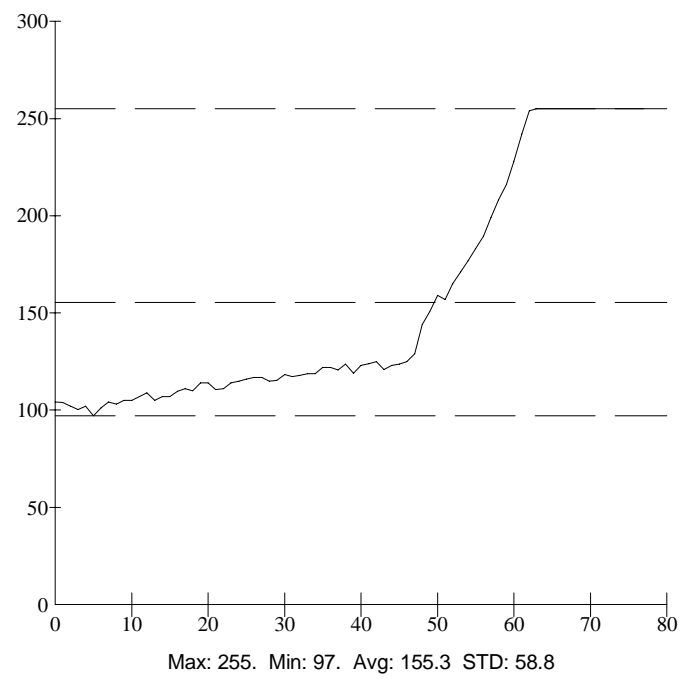

b) Thermal profile from the left line

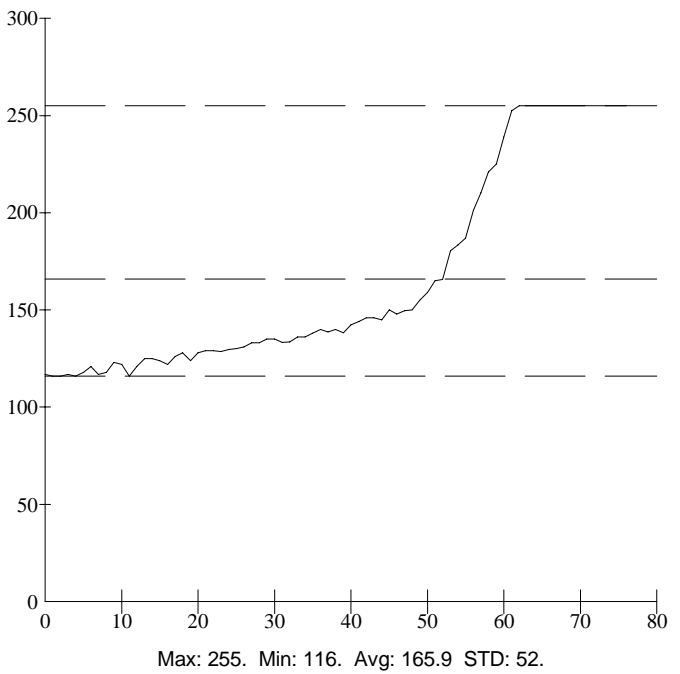

c) Thermal profile from the right line

Figure A.195 Top-heated thermal images of the Specimen WD-1 at 1,335,000 loading cycles. The heating time is 30 seconds. The delay time is 3 seconds. 


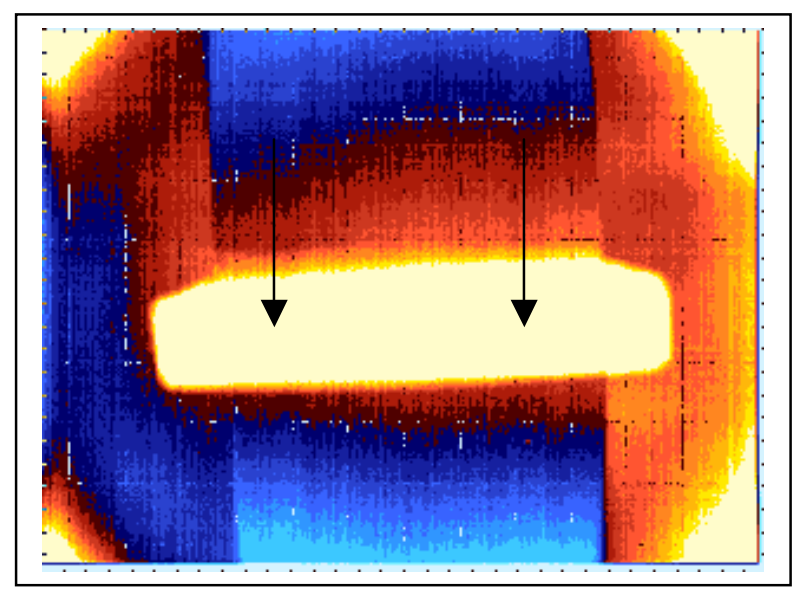

a) Thermal image

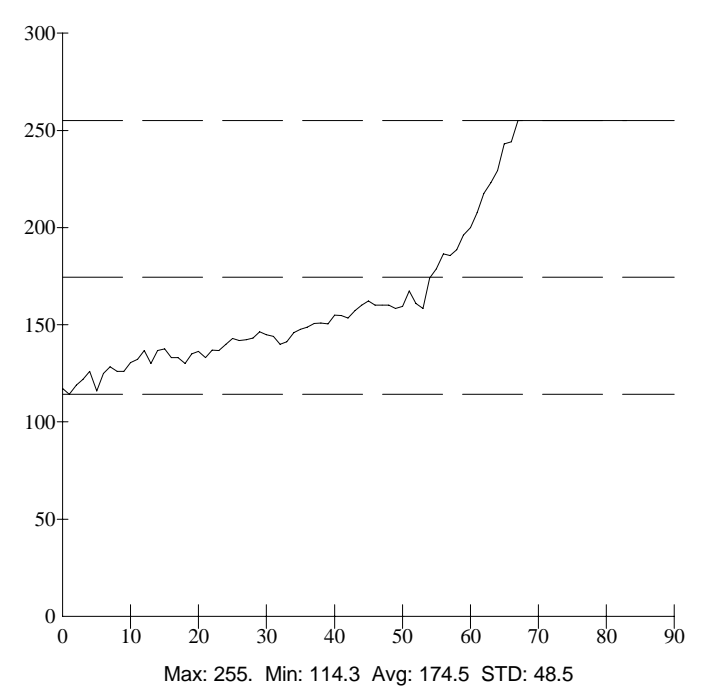

b) Thermal profile from the left line

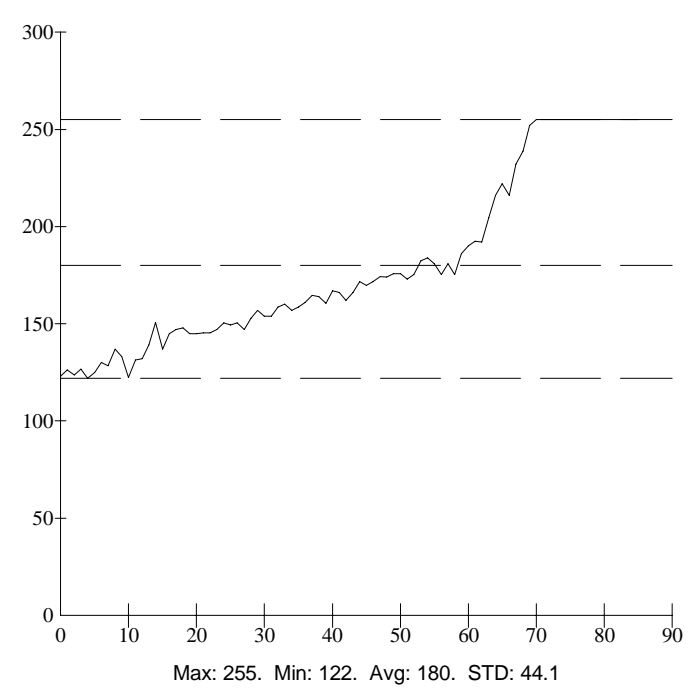

c) Thermal profile from the right line

Figure A.196 Top-heated thermal images of the Specimen WD-1 at 1,335,000 loading cycles. The heating time is 30 seconds. The delay time is 6 seconds. 


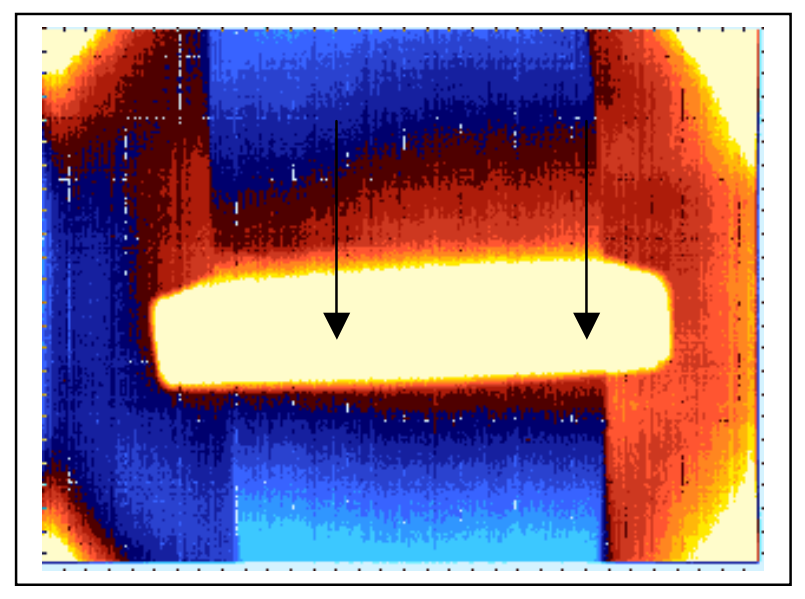

a) Thermal image

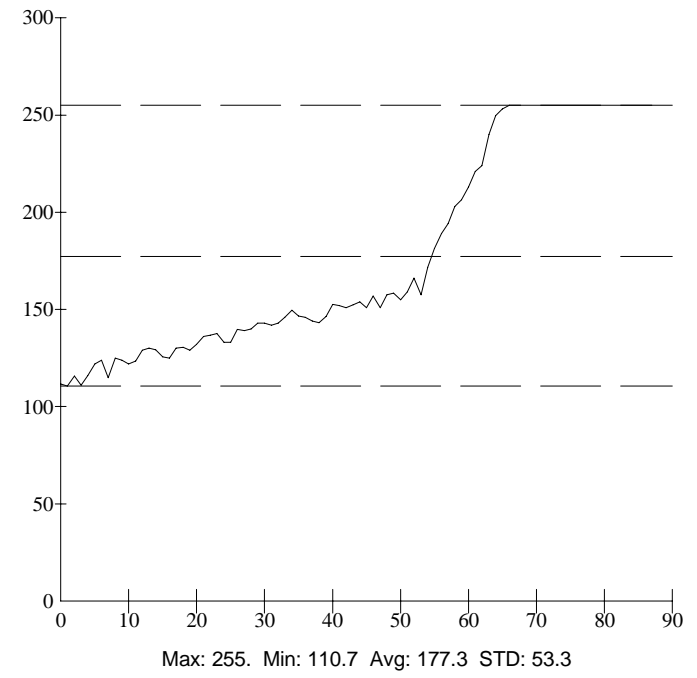

b) Thermal profile from the left line

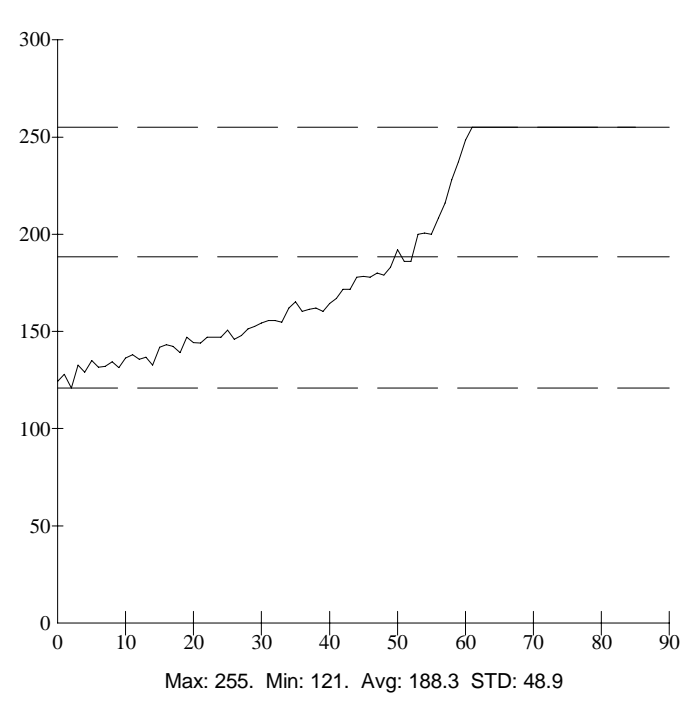

c) Thermal profile from the right line

Figure A.197 Top-heated thermal images of the Specimen WD-1 at 1,335,000 loading cycles. The heating time is 30 seconds. The delay time is 9 seconds. 


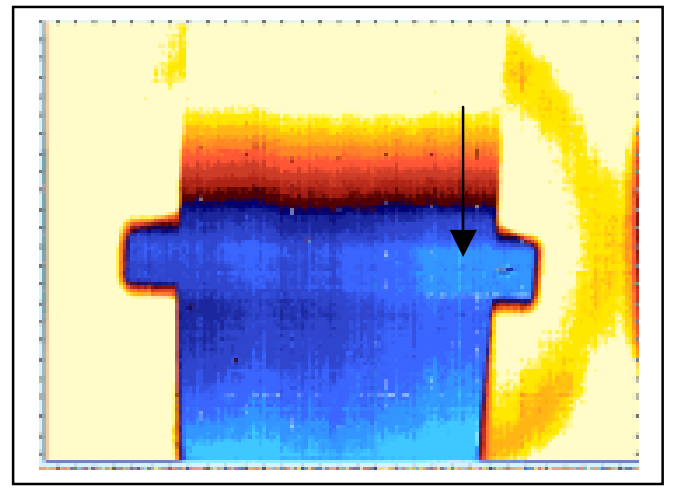

a) 1-second delay time

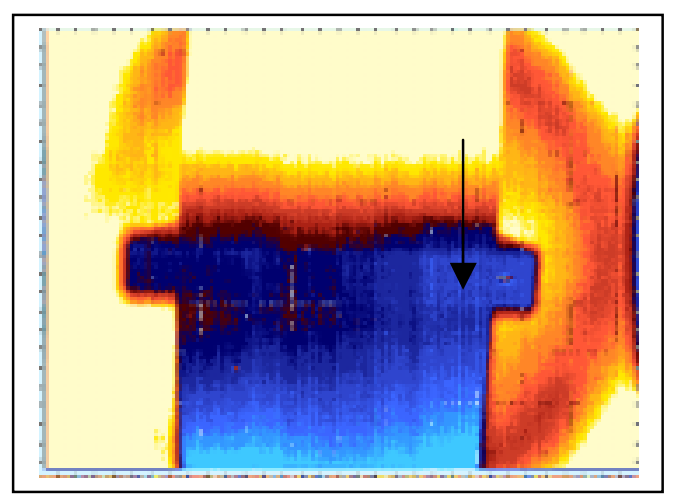

c) 6-second delay time

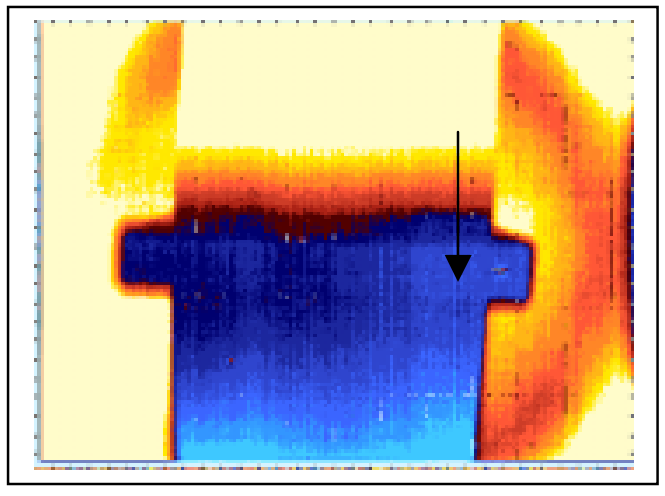

b) 3-second delay time

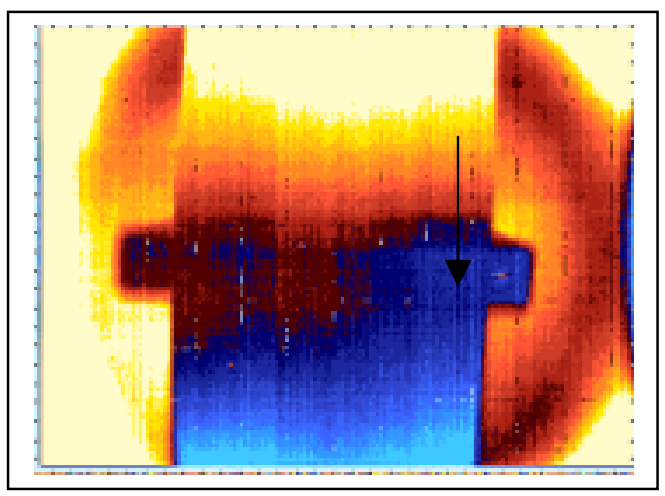

d) 9-second delay time

Figure A.198 Top-heated thermal images of the Specimen WD-2 at 1,110,000 loading cycles. The heating time is 30 seconds. 


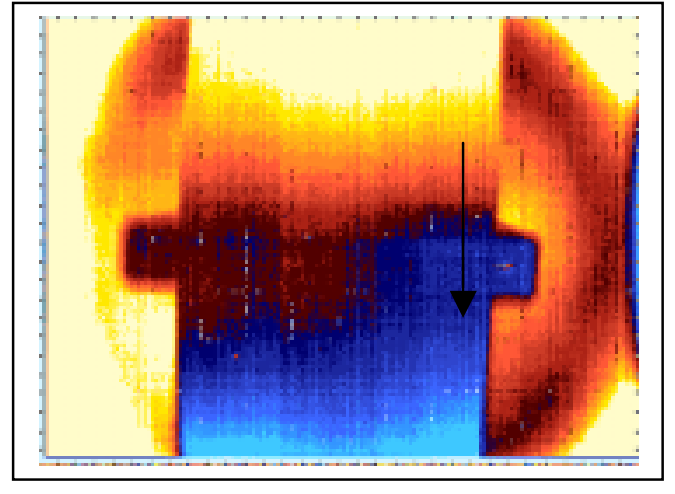

e) 12-second delay time

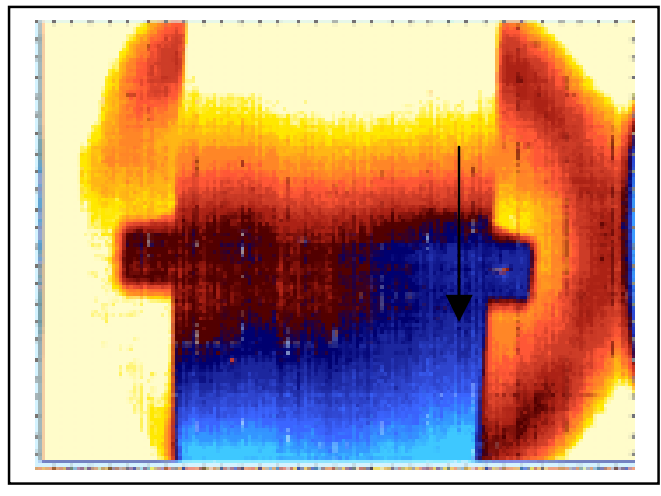

f) 15-second delay time

Figure A.198 (continued) Top-heated thermal images of the Specimen WD-2 at $1,110,000$ loading cycles. The heating time is 30 seconds. 


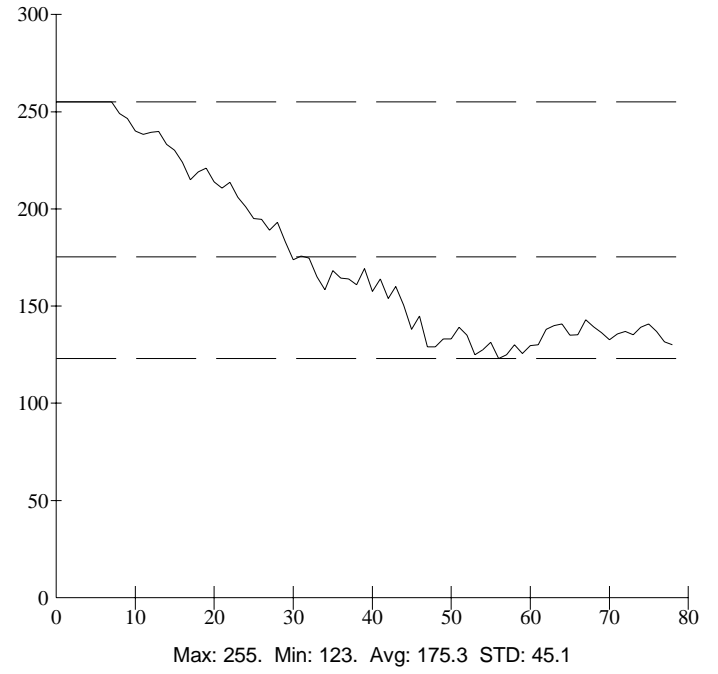

a) 1-second delay time

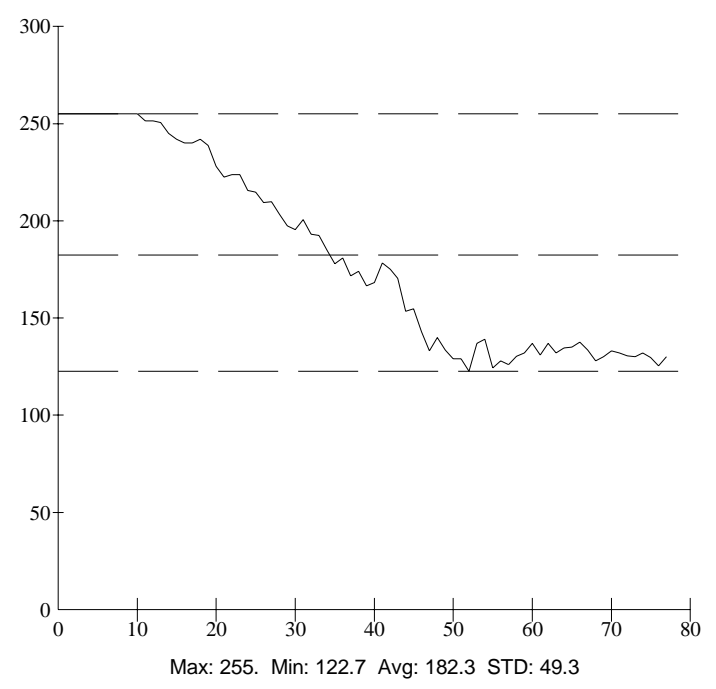

c) 6-second delay time

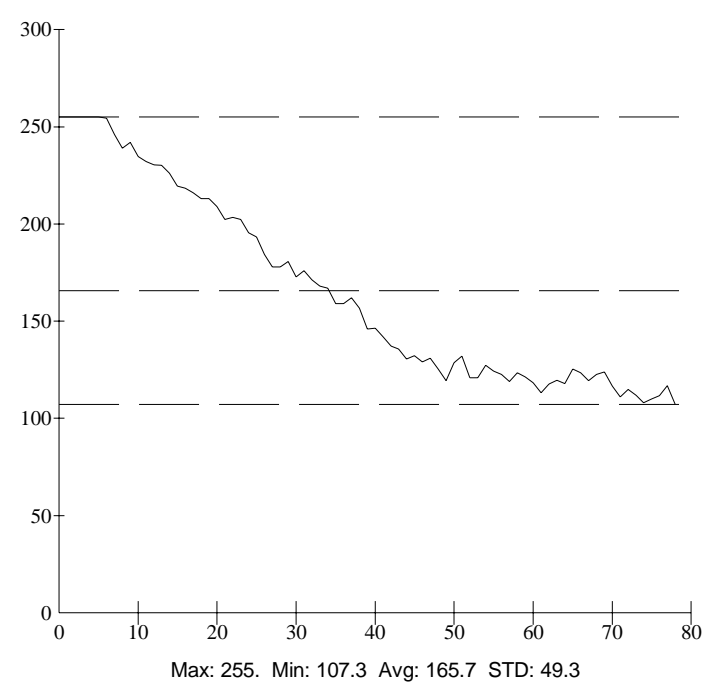

b) 3-second delay time

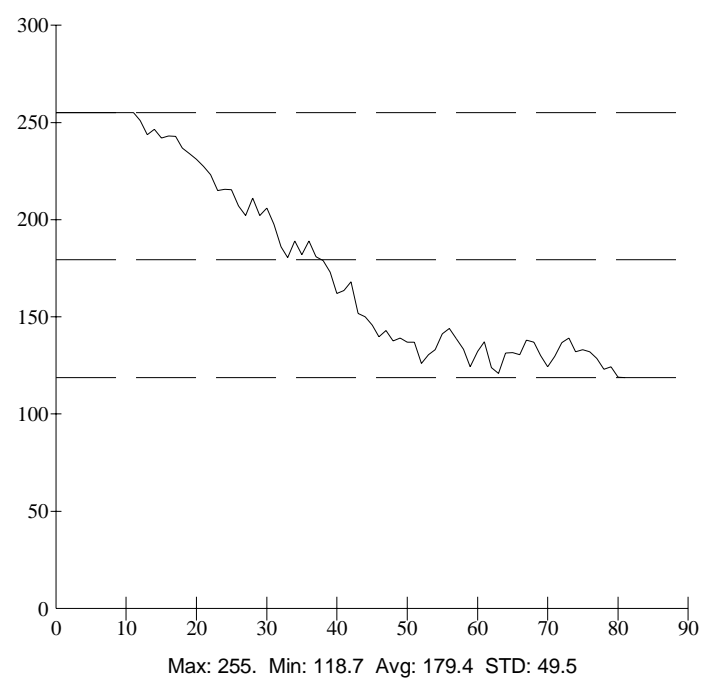

d) 9-second delay time

Figure A.199 Thermal intensity profile along the line across the fatigue crack shown in Figure A.198. 


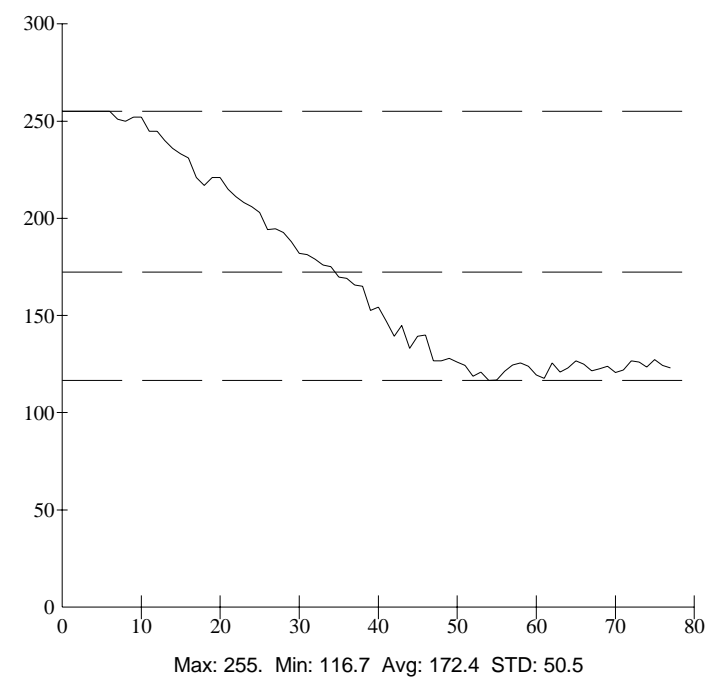

e) 12-second delay time

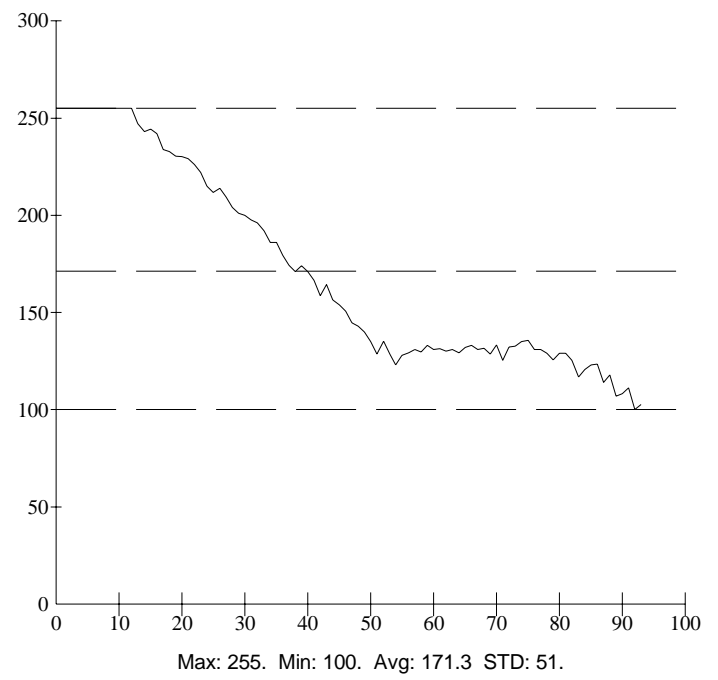

f) 15 -second delay time

Figure A.199 (continued) Thermal intensity profile along the line across the fatigue crack shown in Figure A.198. 


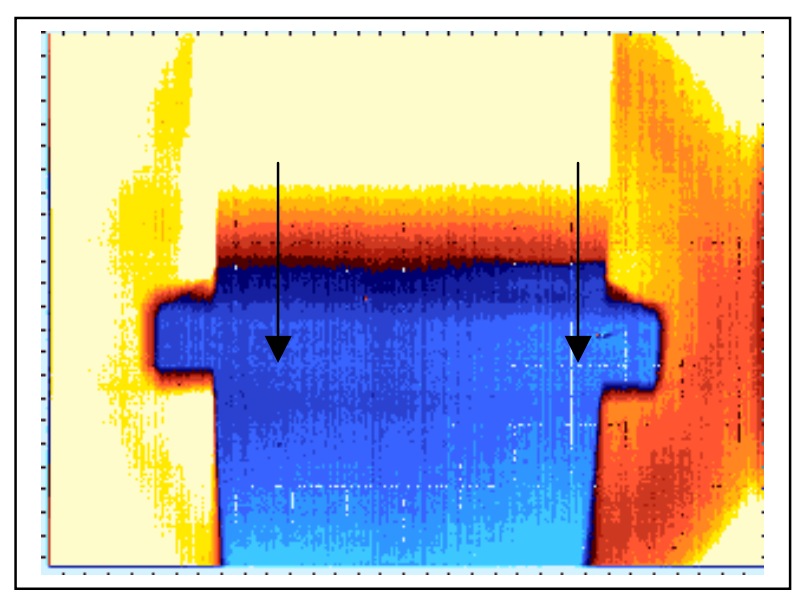

a) Thermal image

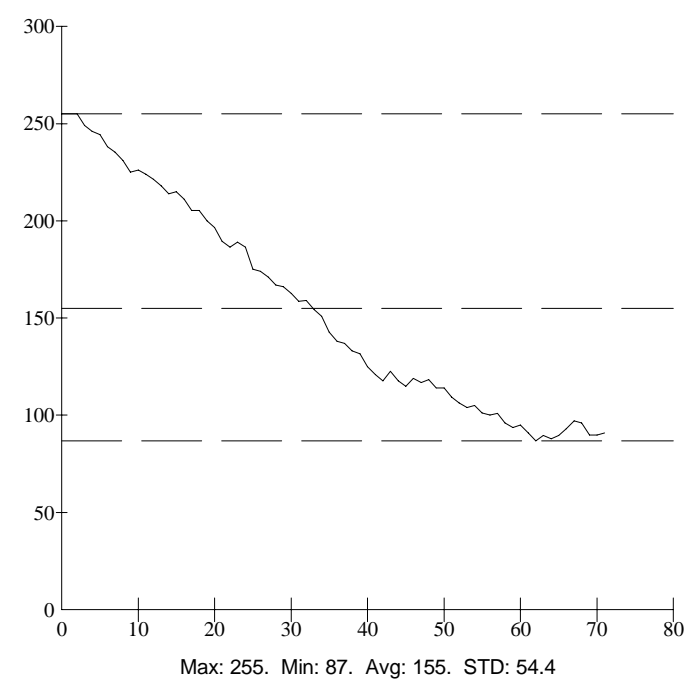

b) Thermal profile from the left line

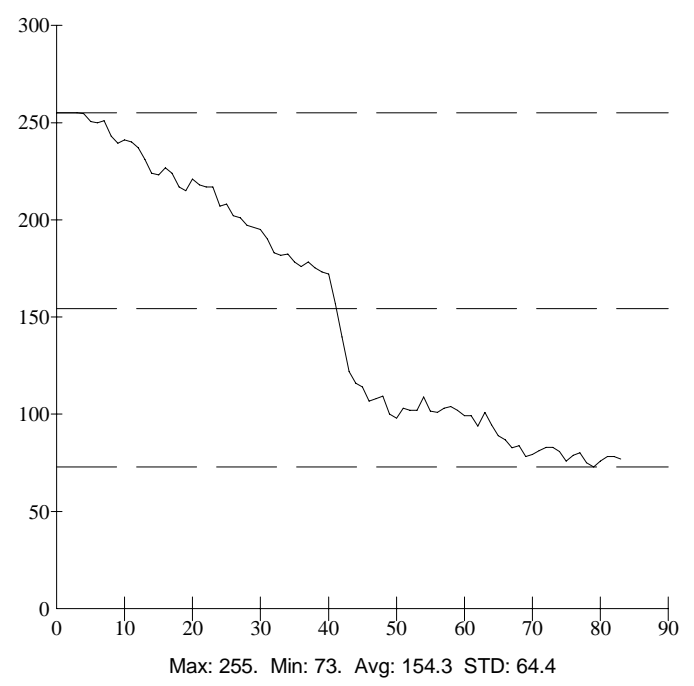

c) Thermal profile from the right line

Figure A.200 Top-heated thermal images of the Specimen WD-2 at 1,131,000 loading cycles. The heating time is 30 seconds. The delay time is 1 second. 


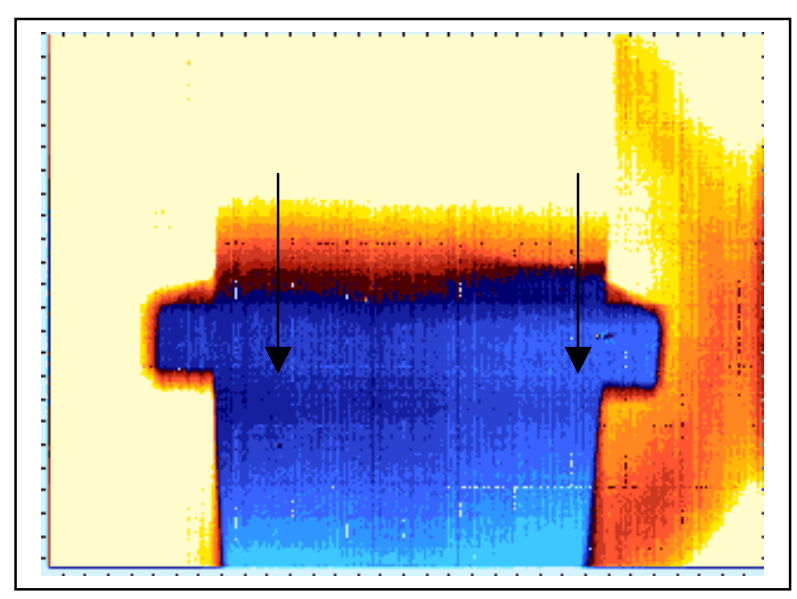

a) Thermal image

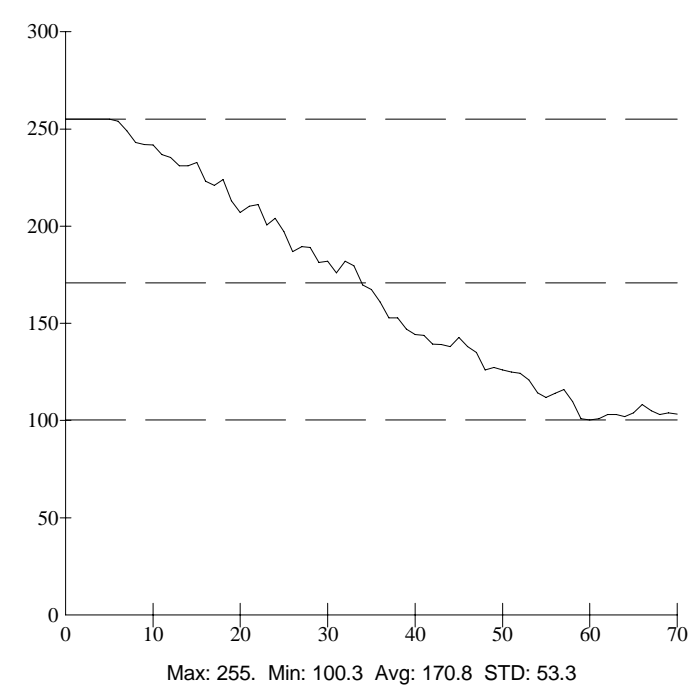

b) Thermal profile from the left line

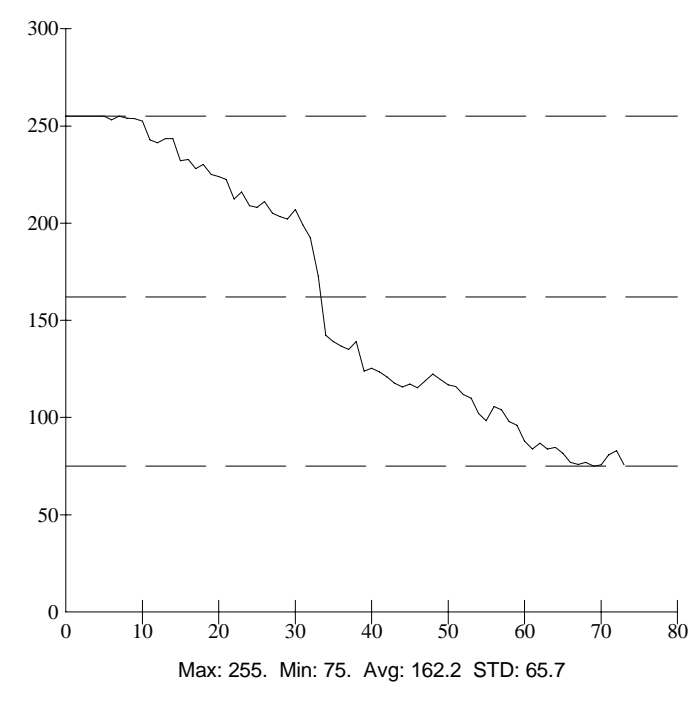

c) Thermal profile from the right line

Figure A.201 Top-heated thermal images of the Specimen WD-2 at 1,131,000 loading cycles. The heating time is 30 seconds. The delay time is 3 seconds. 


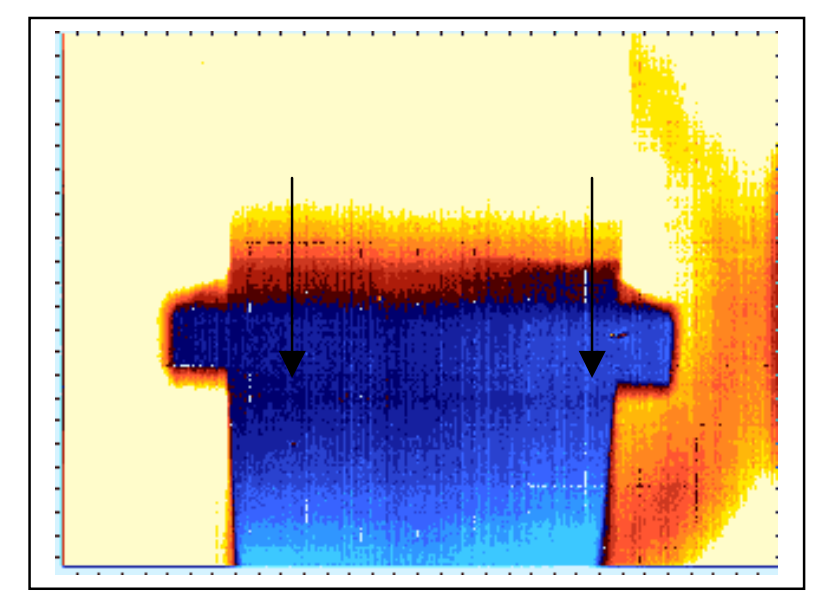

a) Thermal image

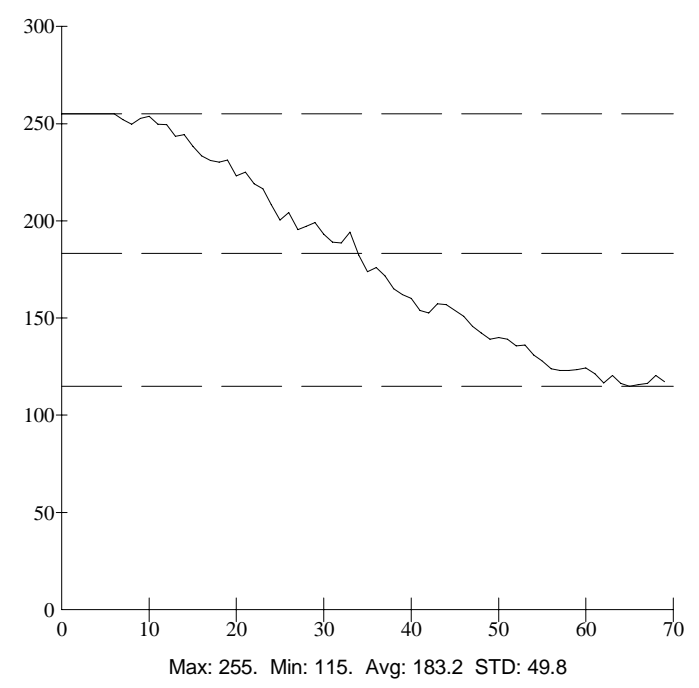

b) Thermal profile from the left line

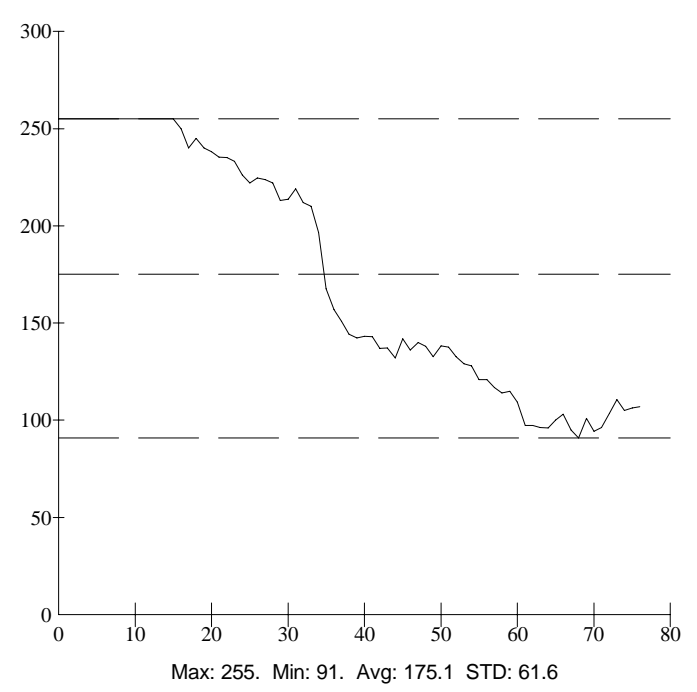

c) Thermal profile from the right line

Figure A.202 Top-heated thermal images of the Specimen WD-2 at 1,131,000 loading cycles. The heating time is 30 seconds. The delay time is 6 seconds. 


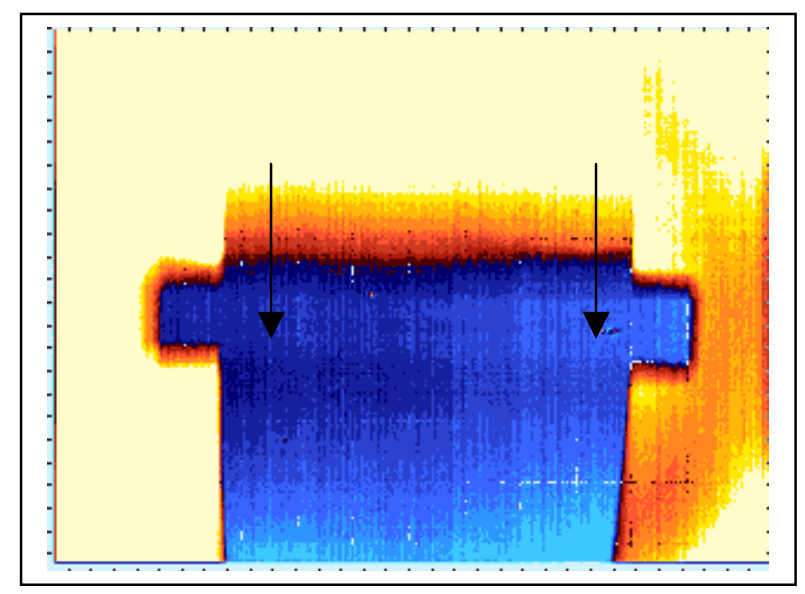

a) Thermal image

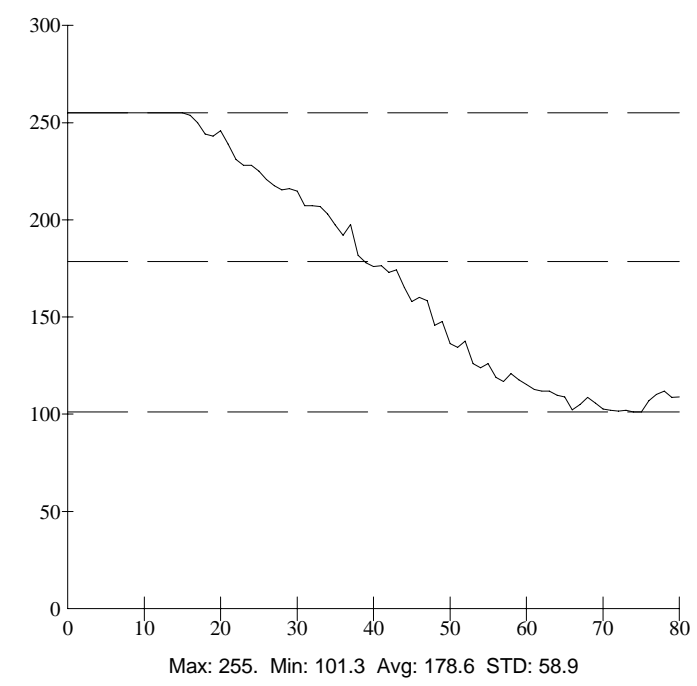

b) Thermal profile from the left line

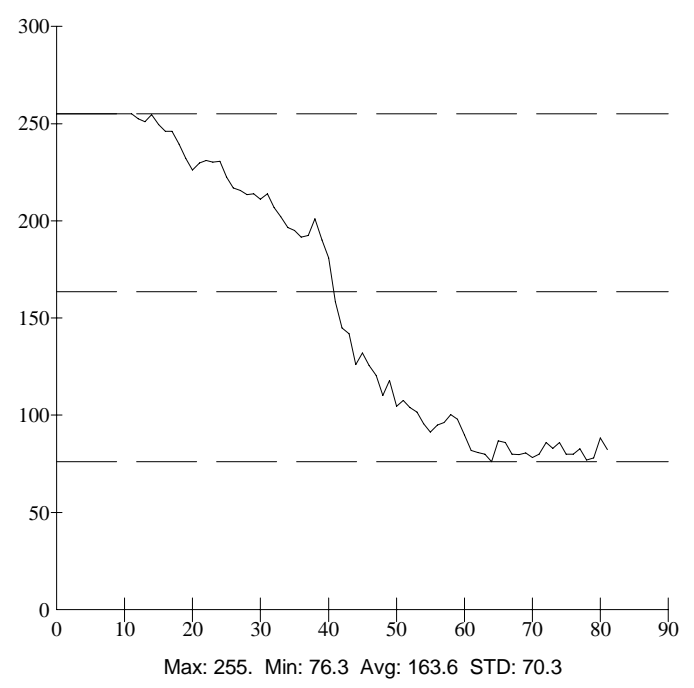

c) Thermal profile from the right line

Figure A.203 Top-heated thermal images of the Specimen WD-2 at 1,131,000 loading cycles. The heating time is 30 seconds. The delay time is 9 seconds. 


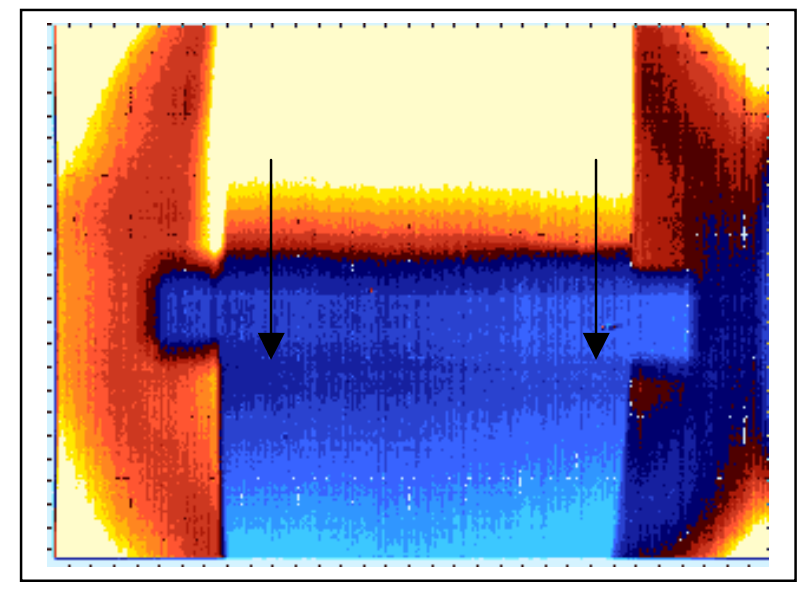

a) Thermal image

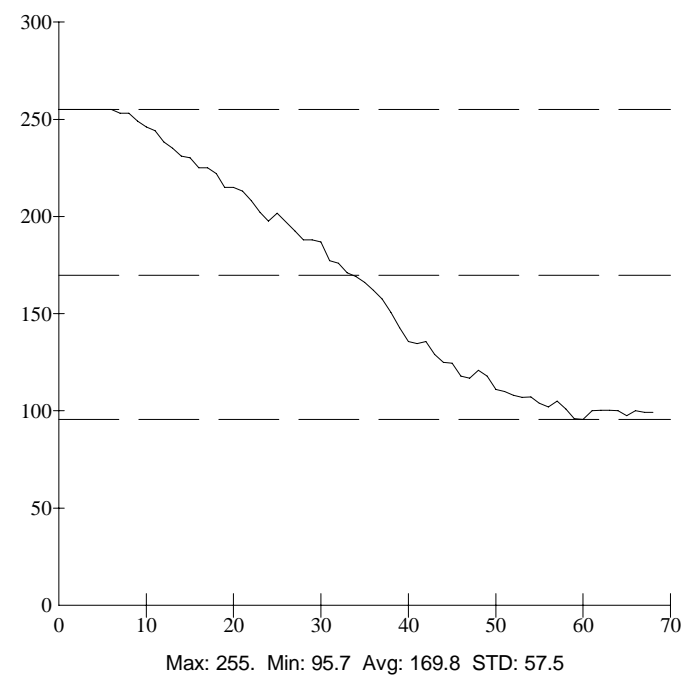

b) Thermal profile from the left line

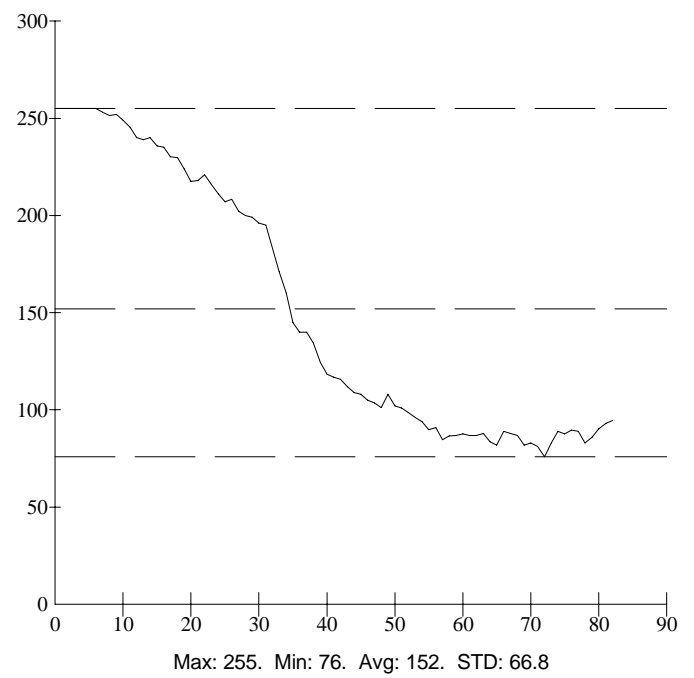

c) Thermal profile from the right line

Figure A.204 Top-heated thermal images of the Specimen WD-2 at 1,131,000 loading cycles. The heating time is 60 seconds. The delay time is 1 second. 


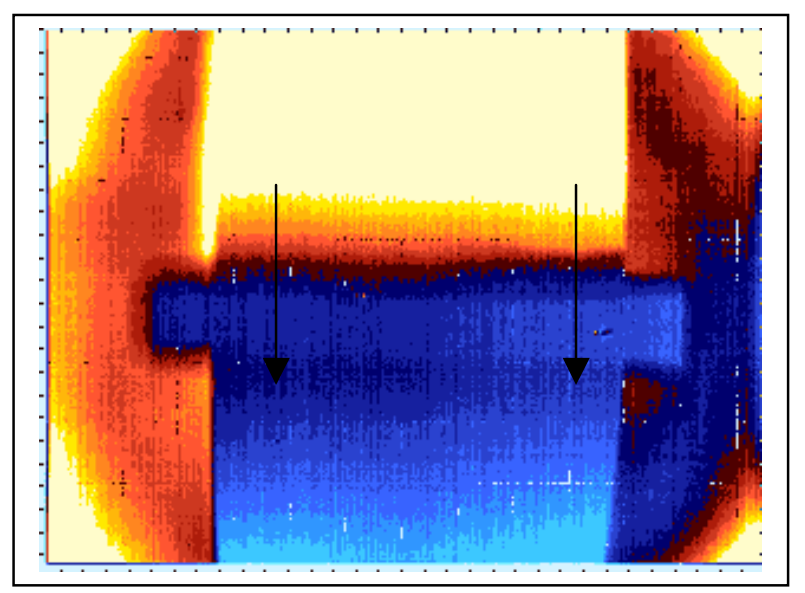

a) Thermal image

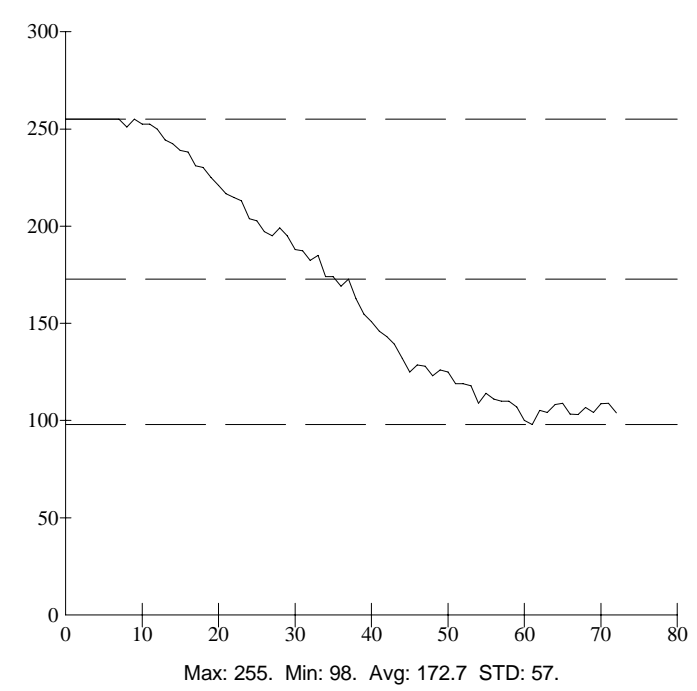

b) Thermal profile from the left line

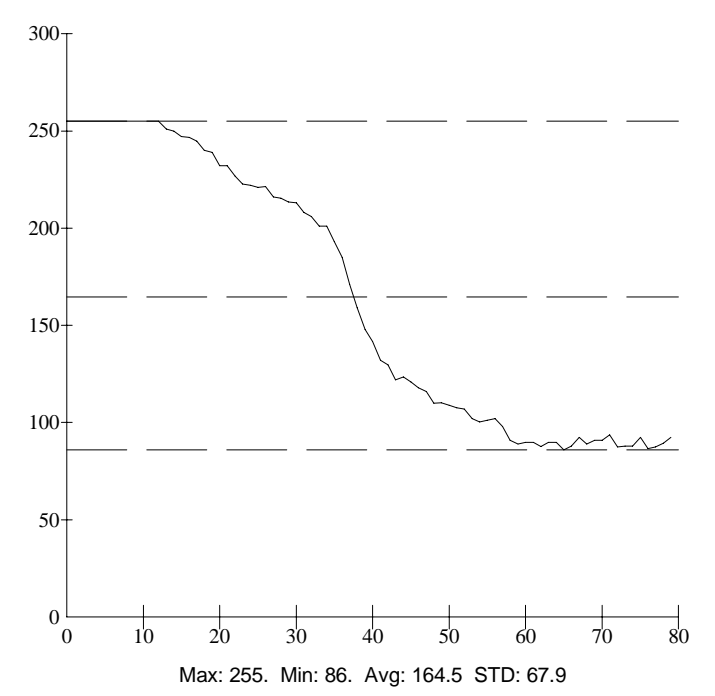

c) Thermal profile from the right line

Figure A.205 Top-heated thermal images of the Specimen WD-2 at 1,131,000 loading cycles. The heating time is 60 seconds. The delay time is 3 seconds. 


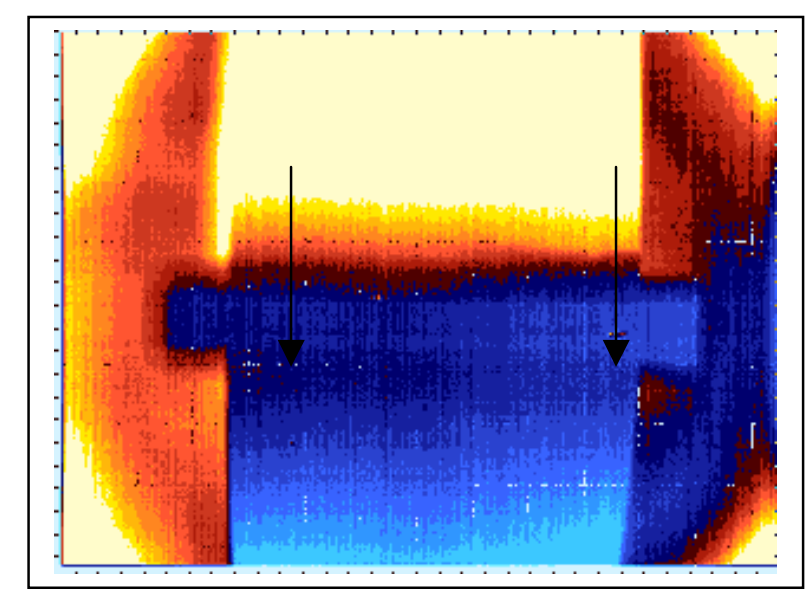

a) Thermal image

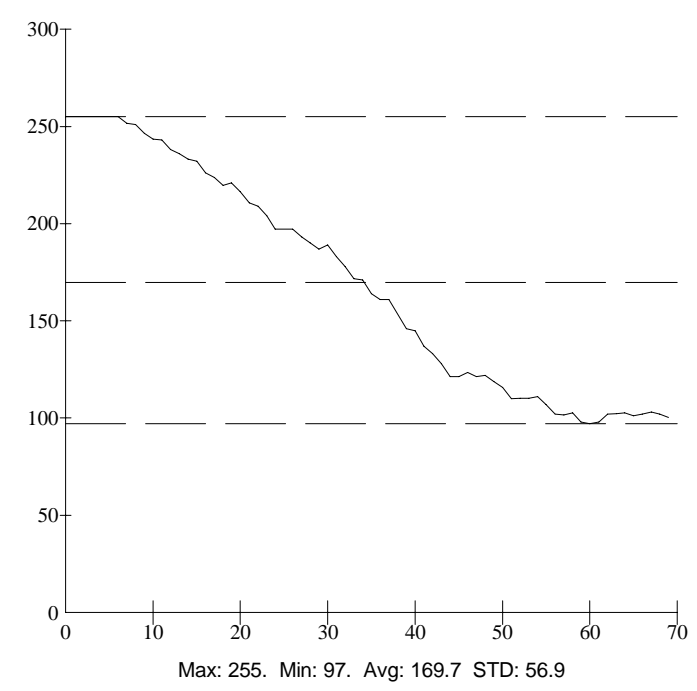

b) Thermal profile from the left line

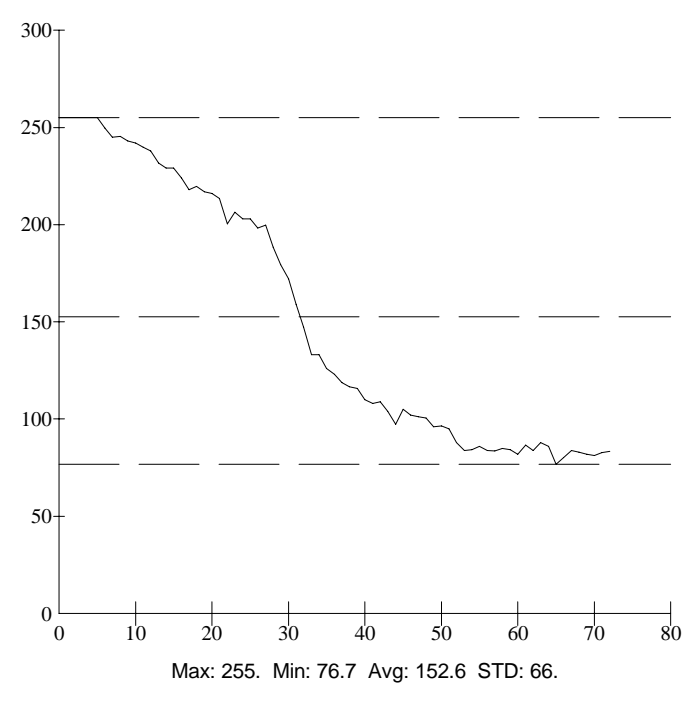

c) Thermal profile from the right line

Figure A.206 Top-heated thermal images of the Specimen WD-2 at 1,131,000 loading cycles. The heating time is 60 seconds. The delay time is 6 seconds. 


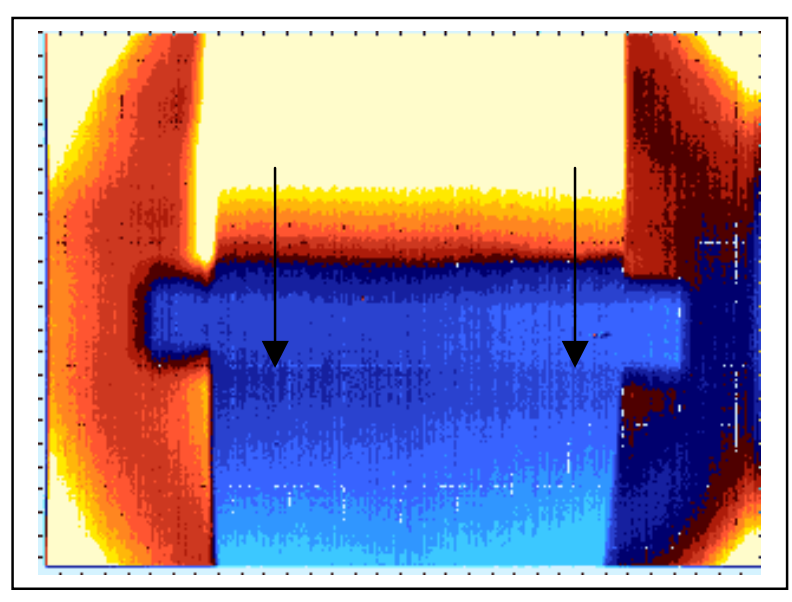

a) Thermal image

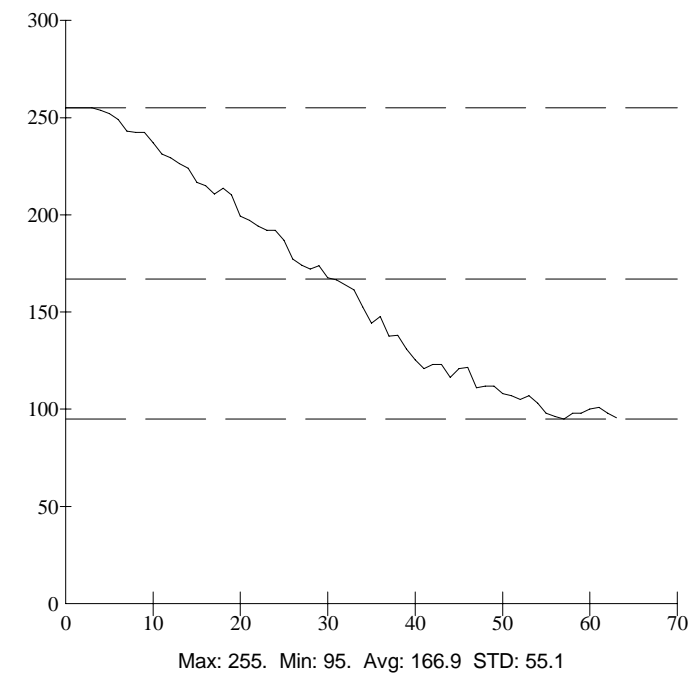

b) Thermal profile from the left line

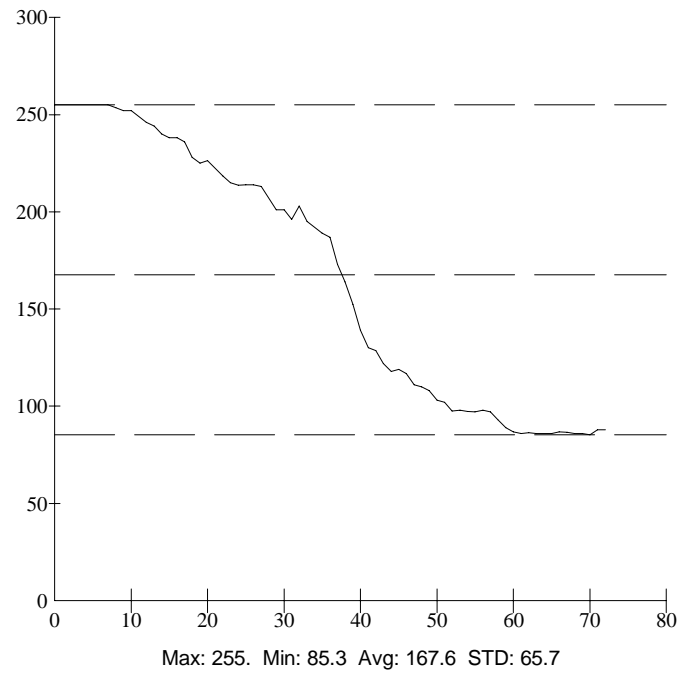

c) Thermal profile from the right line

Figure A.207 Top-heated thermal images of the Specimen WD-2 at 1,131,000 loading cycles. The heating time is 60 seconds. The delay time is 9 seconds. 


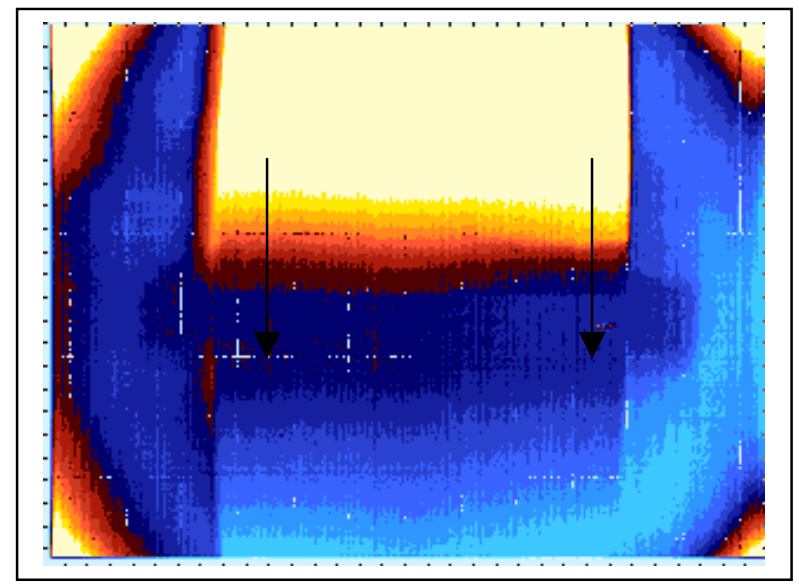

a) Thermal image

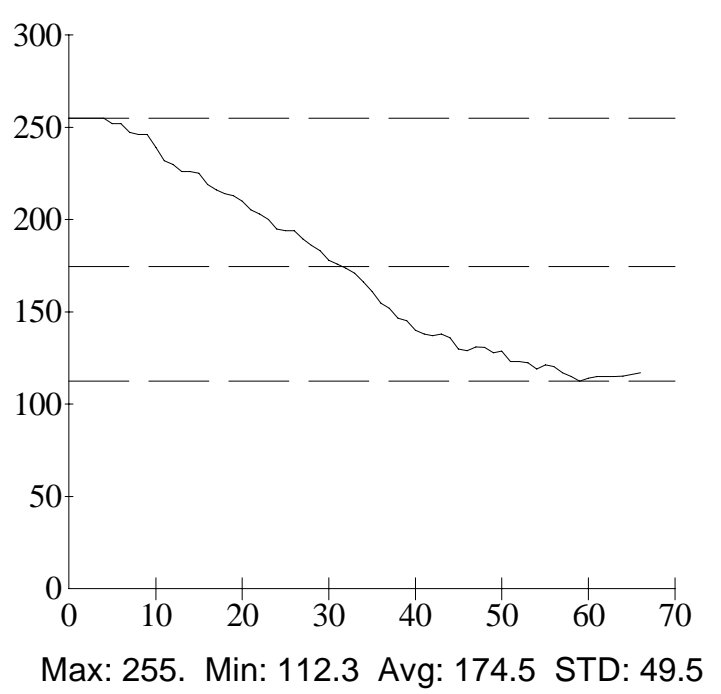

b) Thermal profile from the left line

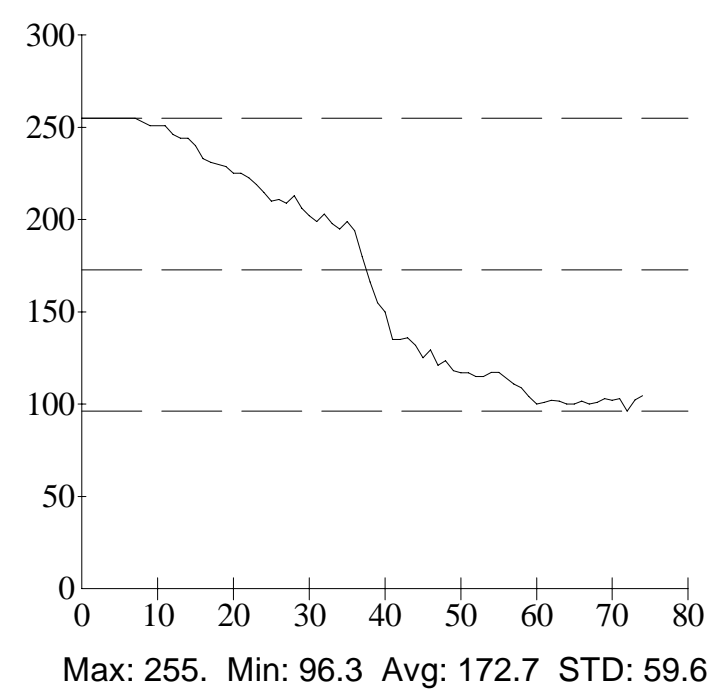

c) Thermal profile from the right line

Figure A.208 Top-heated thermal images of the Specimen WD-2 at 1,131,000 loading cycles. The heating time is 90 seconds. The delay time is 1 second. 


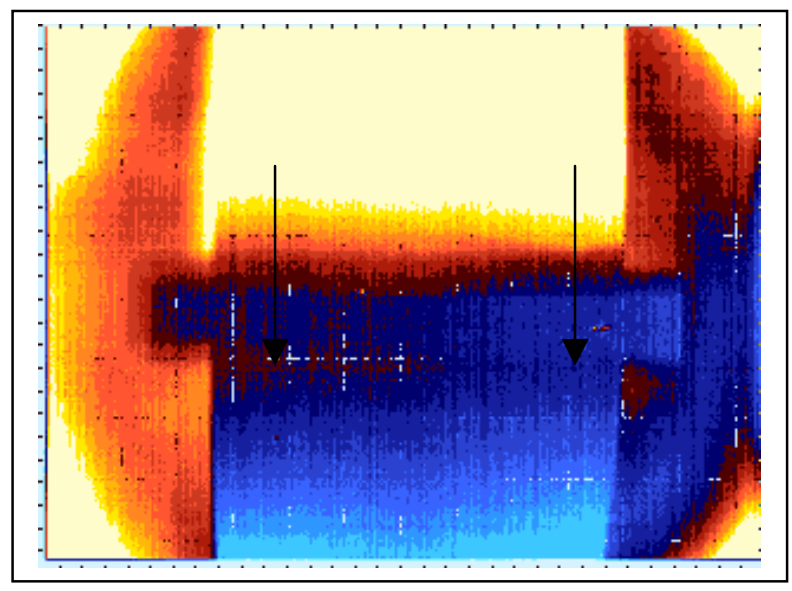

a) Thermal image
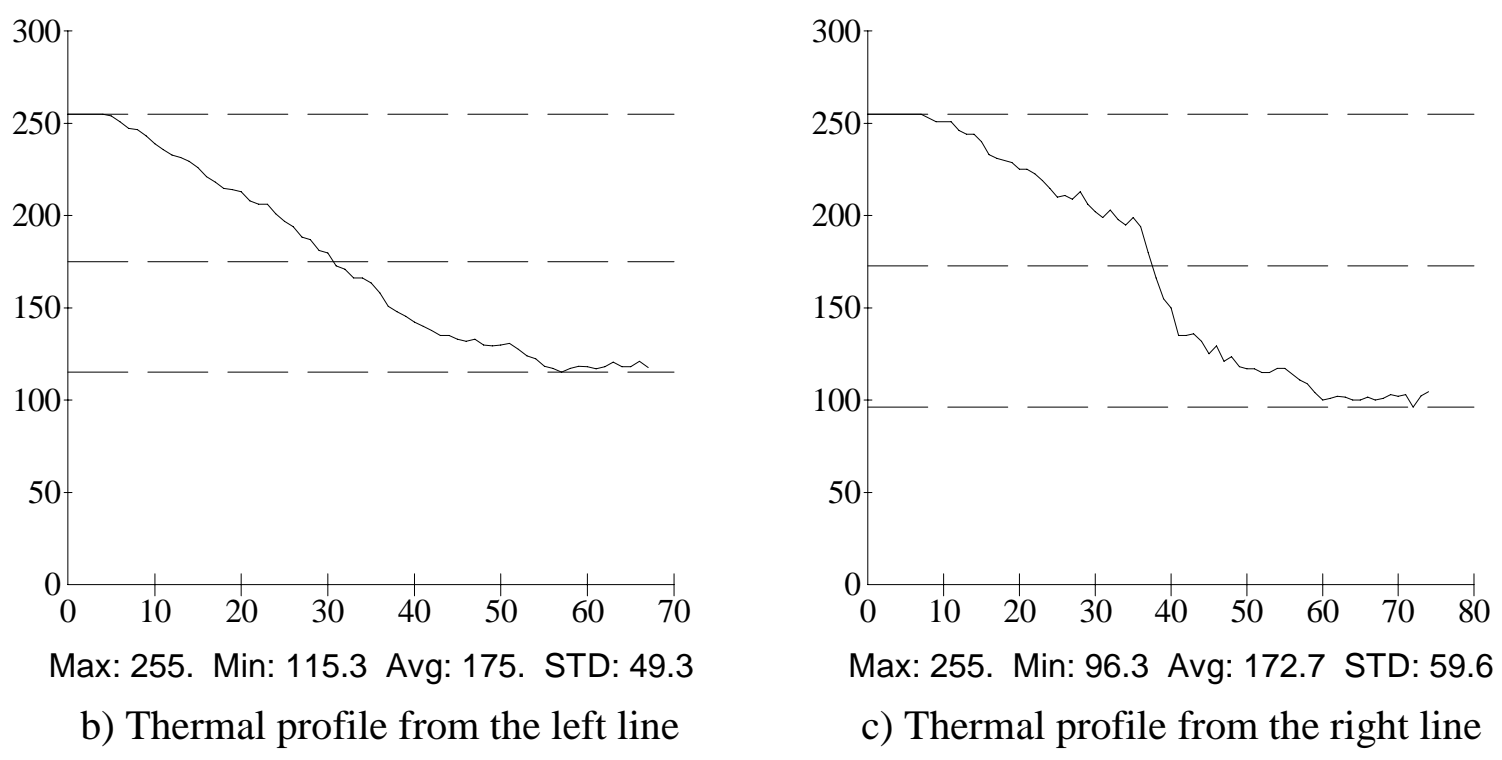

Figure A.209 Top-heated thermal images of the Specimen WD-2 at 1,131,000 loading cycles. The heating time is 90 seconds. The delay time is 3 seconds. 


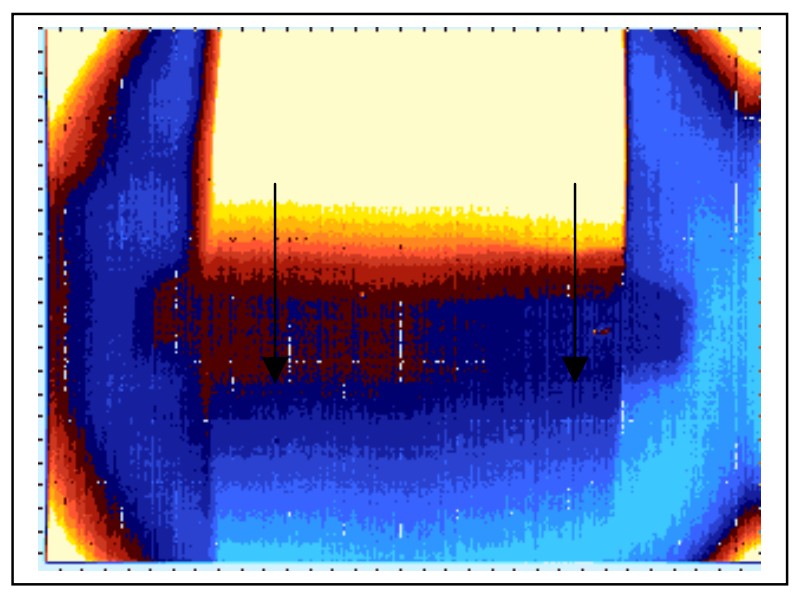

a) Thermal image

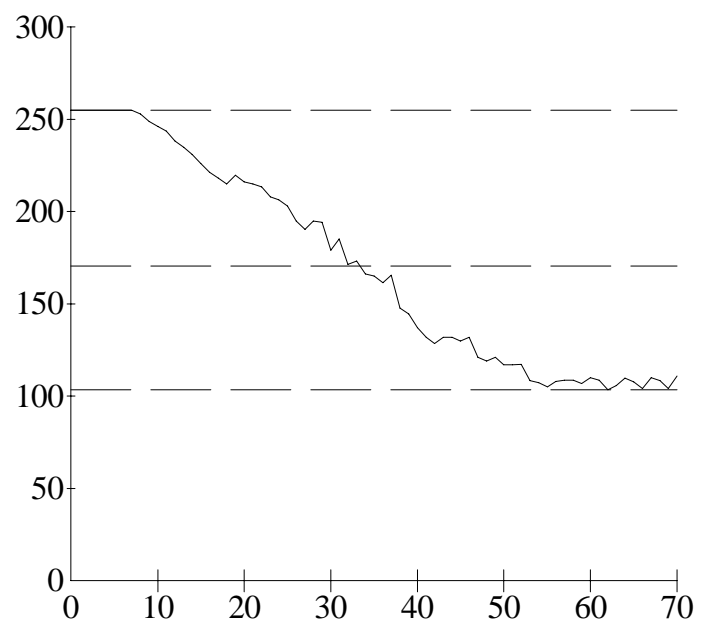

Max: 255. Min: 103.3 Avg: 170.5 STD: 55.3

b) Thermal profile from the left line

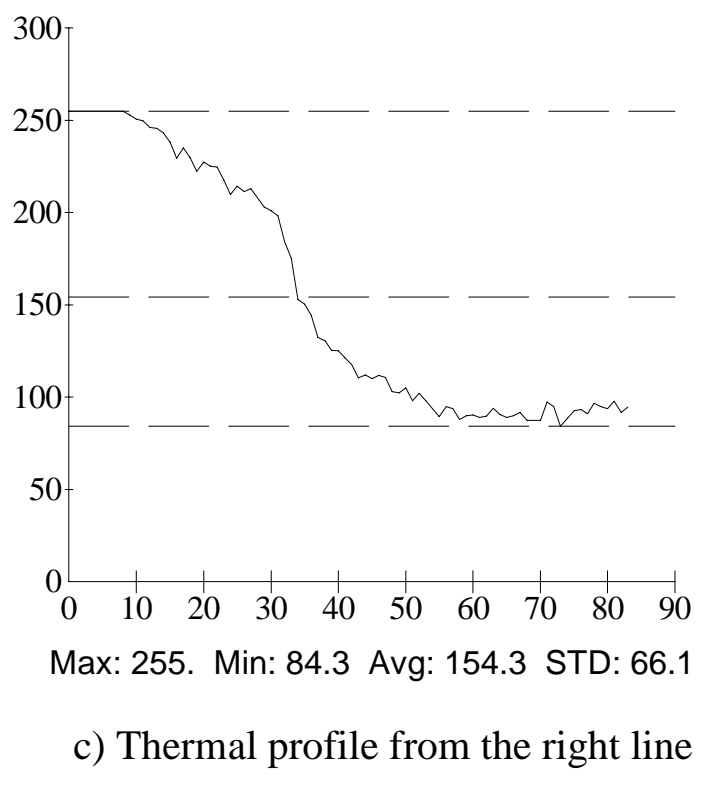

c) Thermal profile from the right line

Figure A.210 Top-heated thermal images of the Specimen WD-2 at 1,131,000 loading cycles. The heating time is 90 seconds. The delay time is 6 seconds. 


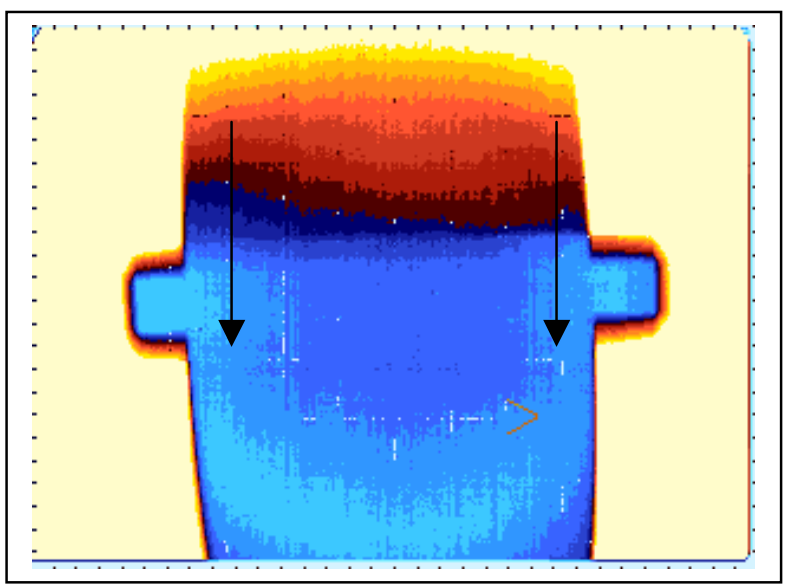

a) Thermal image

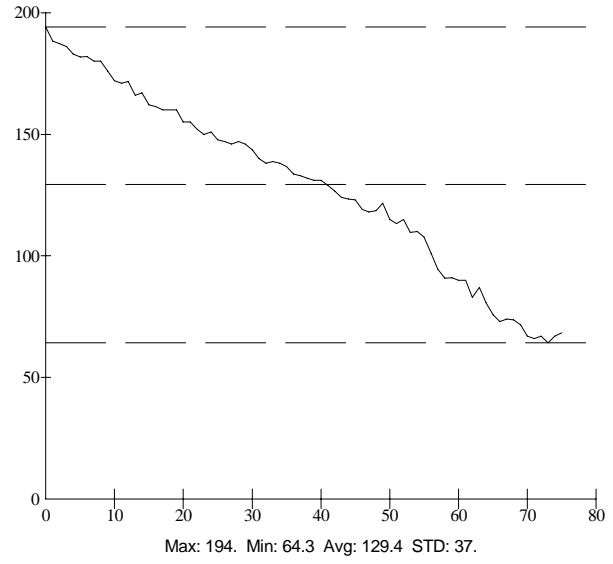

b) Thermal profile from the left line

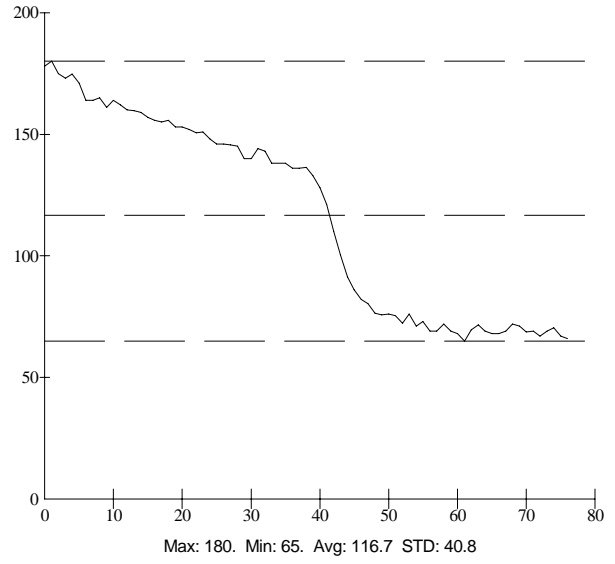

c) Thermal profile from the right line

Figure A.211 Top-heated thermal images of the Specimen WD-3 (coated with real color) at 1,735,550 loading cycles. The heating time is 30 seconds. The delay time is 1 second. 


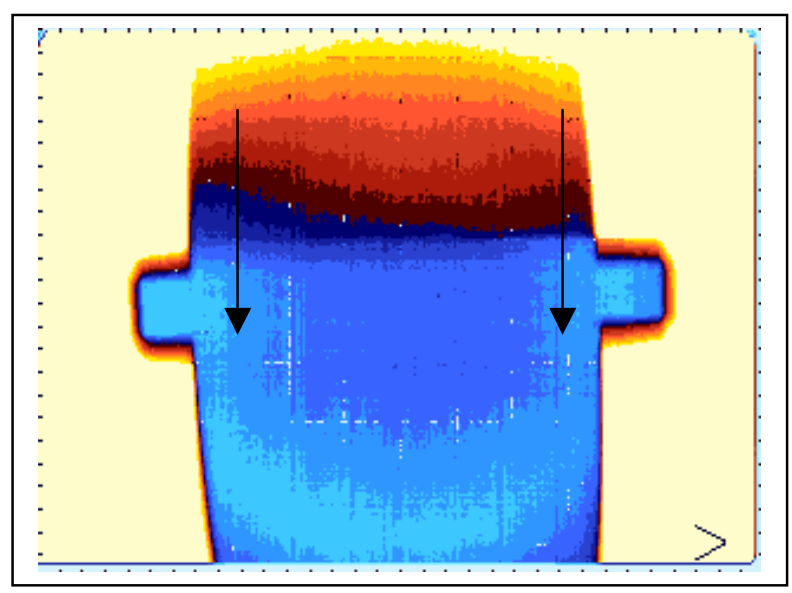

a) Thermal image

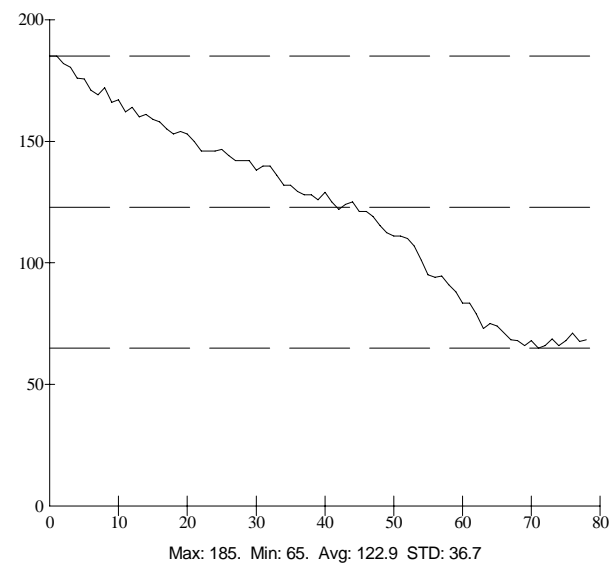

b) Thermal profile from the left line

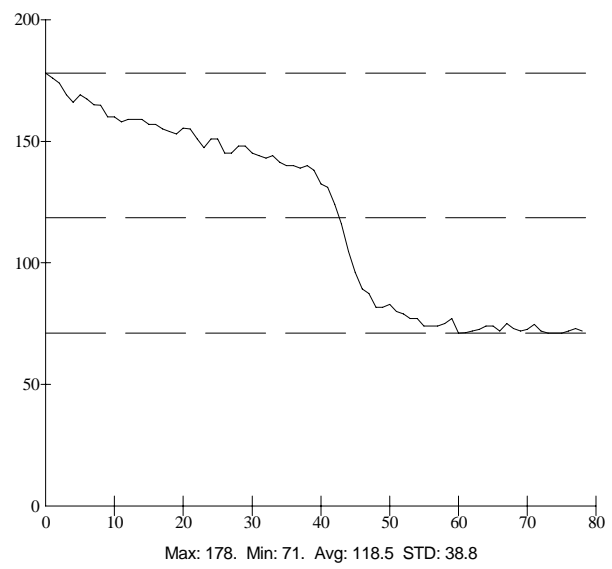

c) Thermal profile from the right line

Figure A.212 Top-heated thermal images of the Specimen WD-3 (coated with real color) at 1,735,550 loading cycles. The heating time is 30 seconds. The delay time is 3 seconds. 


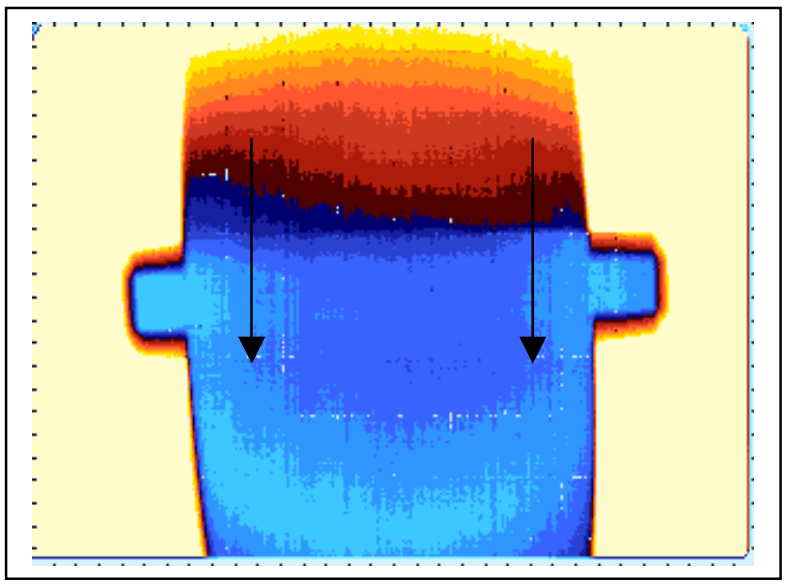

a) Thermal image

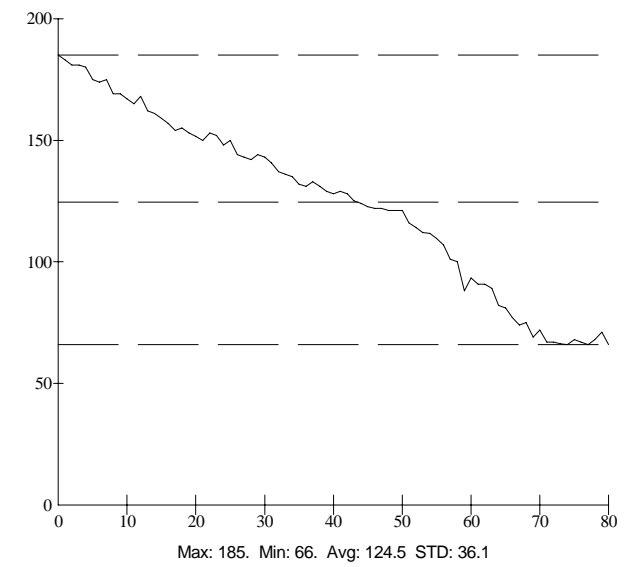

b) Thermal profile from the left line

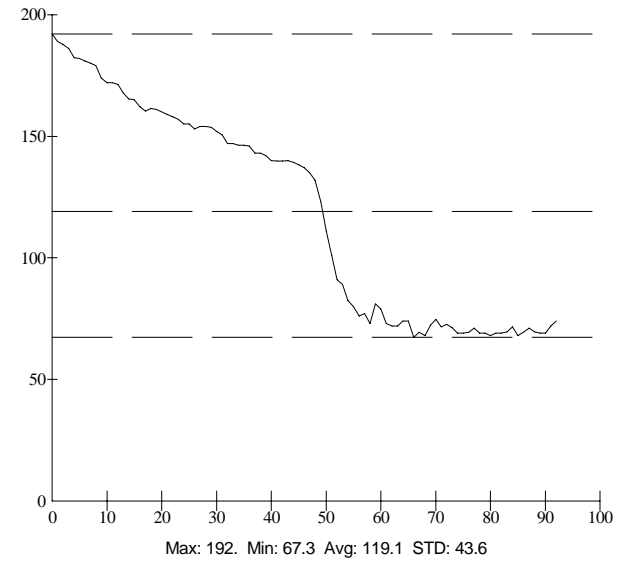

c) Thermal profile from the right line

Figure A.213 Top-heated thermal images of the Specimen WD-3 (coated with real color) at 1,735,550 loading cycles. The heating time is 30 seconds. The delay time is 6 seconds. 


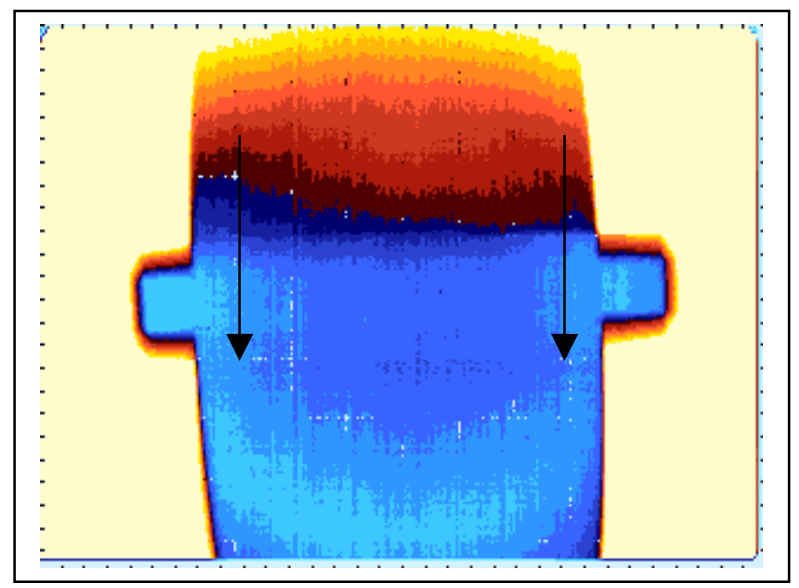

a) Thermal image

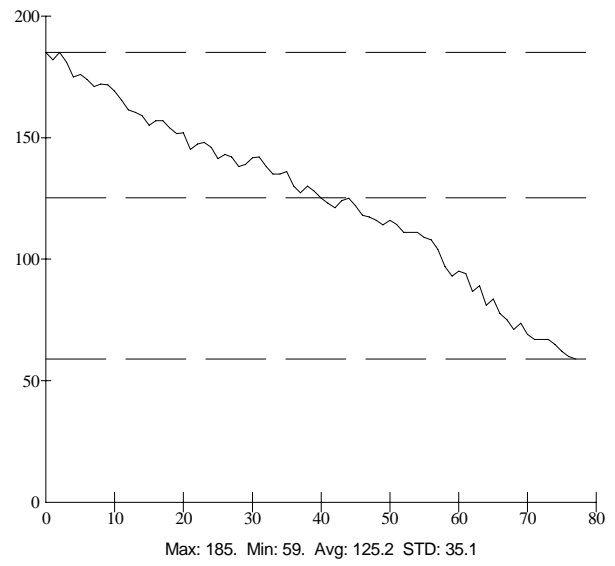

b) Thermal profile from the left line

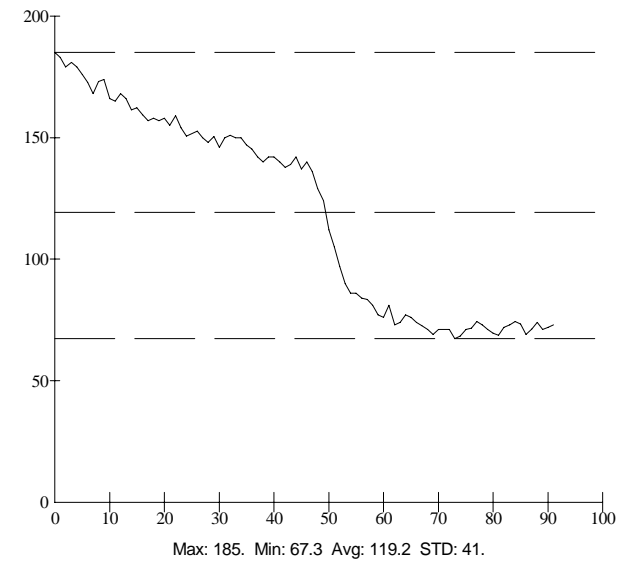

c) Thermal profile from the right line

Figure A.214 Top-heated thermal images of the Specimen WD-3 (coated with real color) at $1,735,550$ loading cycles. The heating time is 30 seconds. The delay time is 9 seconds. 


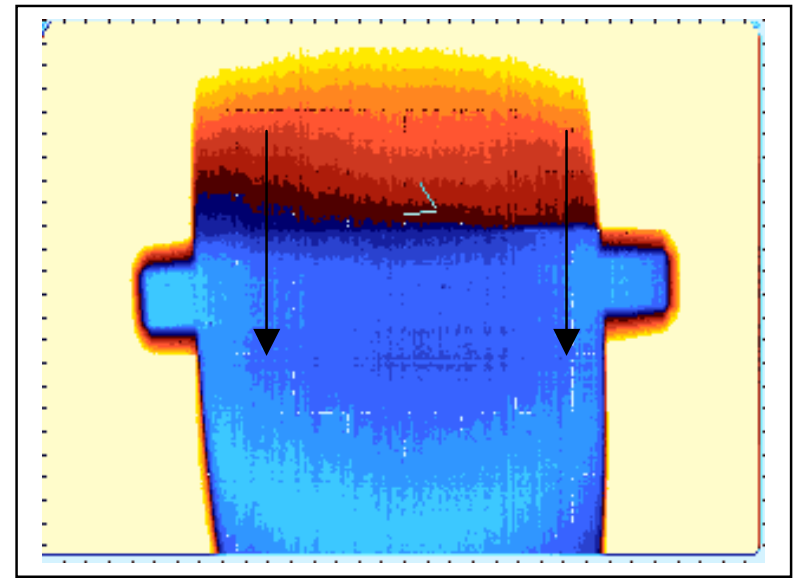

a) Thermal image

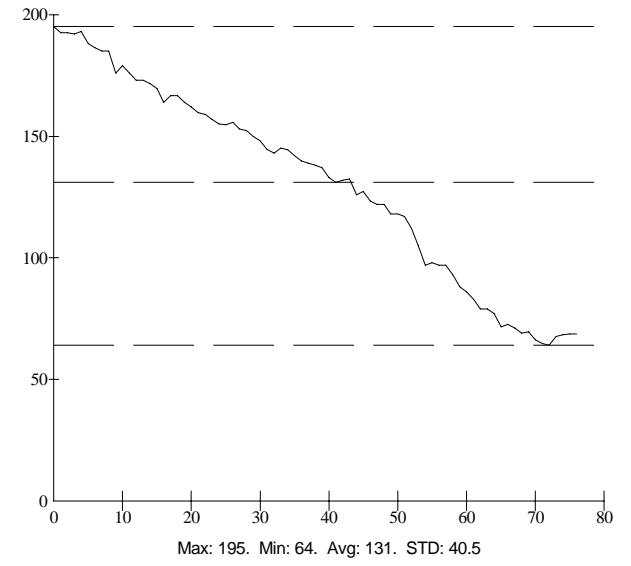

b) Thermal profile from the left line

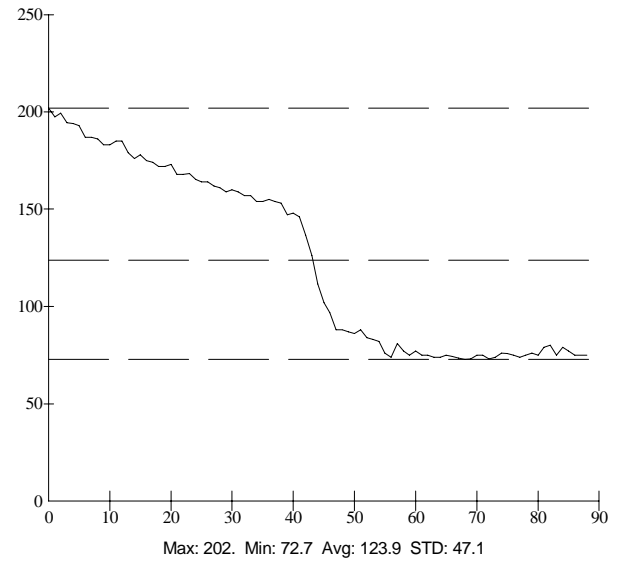

c) Thermal profile from the right line

Figure A.215 Top-heated thermal images of the Specimen WD-3 (coated with real color) at 1,735,550 loading cycles. The heating time is 60 seconds. The delay time is 1 second. 


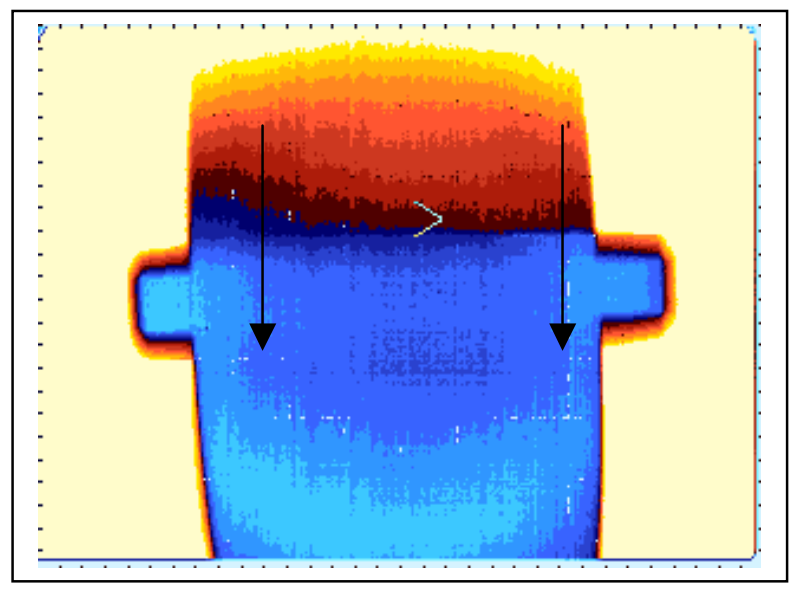

a) Thermal image

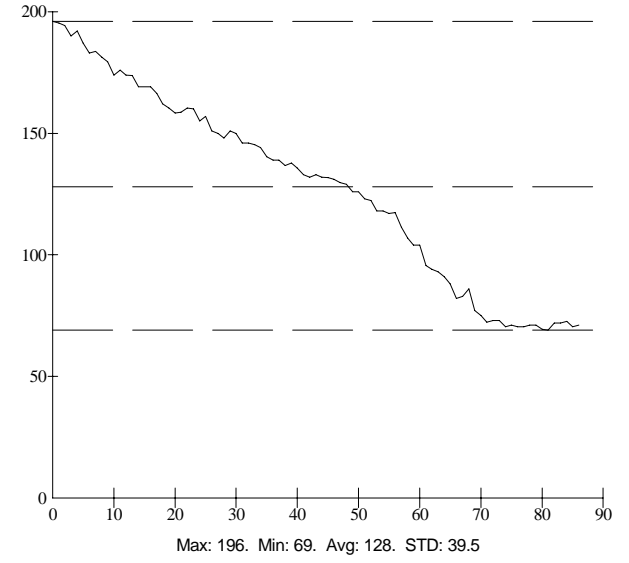

b) Thermal profile from the left line

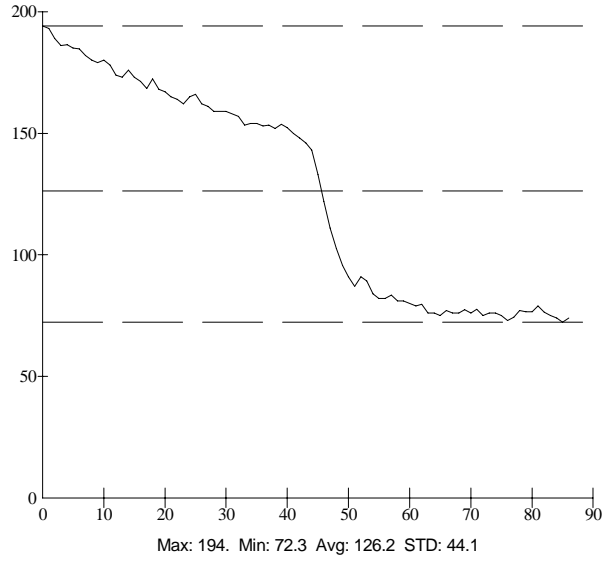

c) Thermal profile from the right line

Figure A.216 Top-heated thermal images of the Specimen WD-3 (coated with real color) at 1,735,550 loading cycles. The heating time is 60 seconds. The delay time is 3 seconds. 


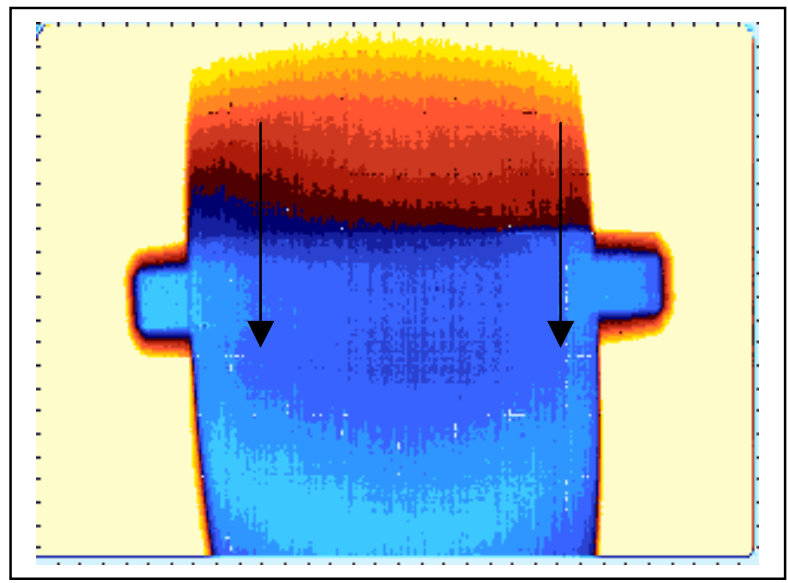

a) Thermal image

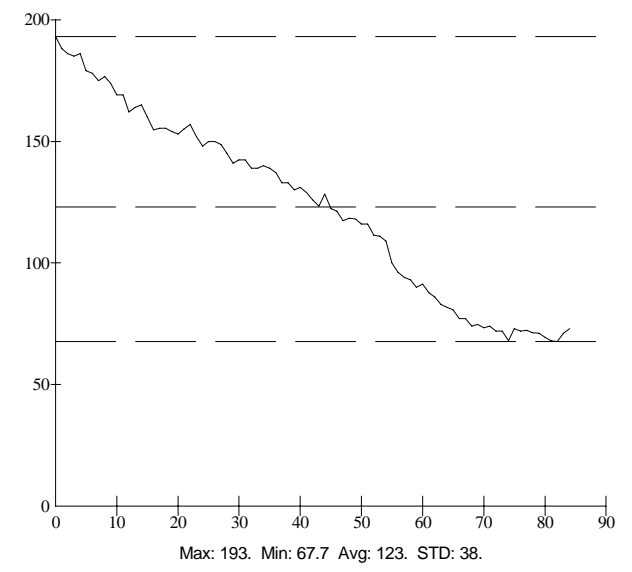

b) Thermal profile from the left line

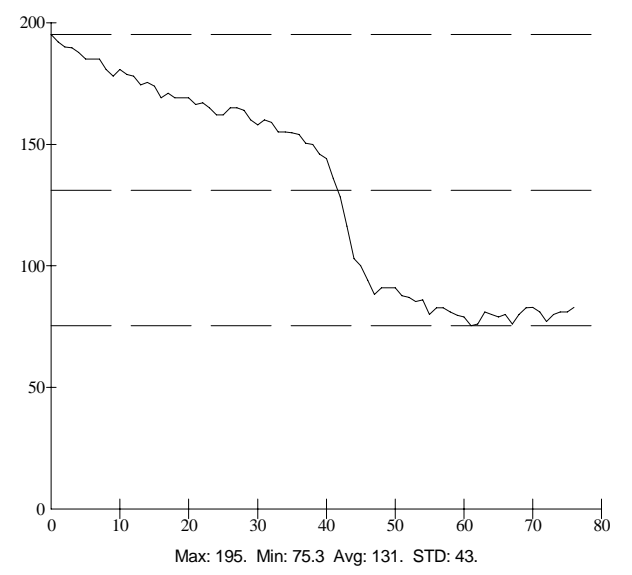

c) Thermal profile from the right line

Figure A.217 Top-heated thermal images of the Specimen WD-3 (coated with real color) at 1,735,550 loading cycles. The heating time is 60 seconds. The delay time is 6 seconds. 


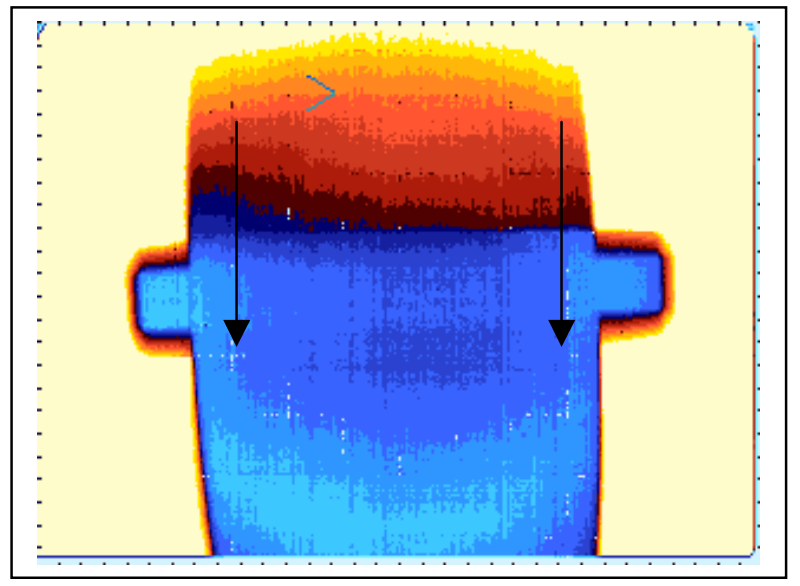

a) Thermal image

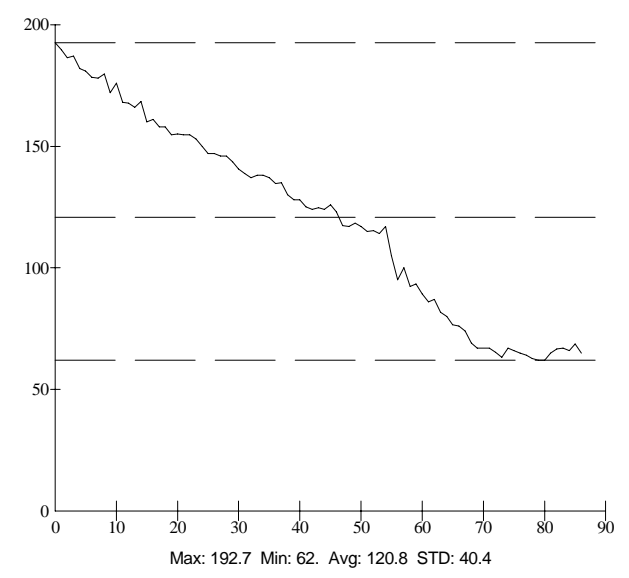

b) Thermal profile from the left line

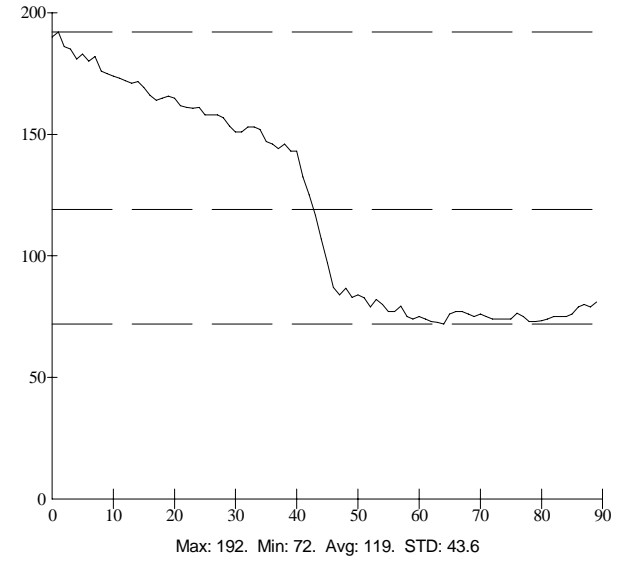

c) Thermal profile from the right line

Figure A.218 Top-heated thermal images of the Specimen WD-3 (coated with real color) at 1,735,550 loading cycles. The heating time is 60 seconds. The delay time is 9 seconds. 


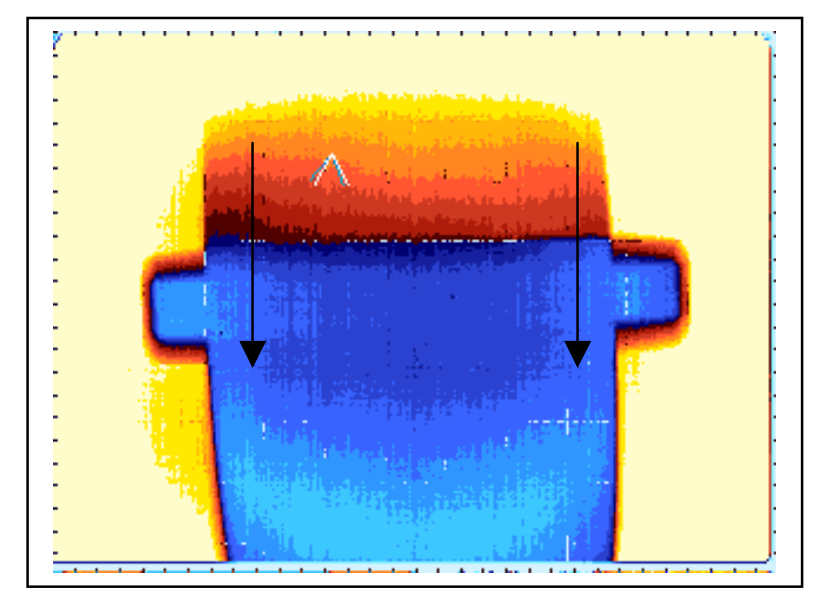

a) Thermal image

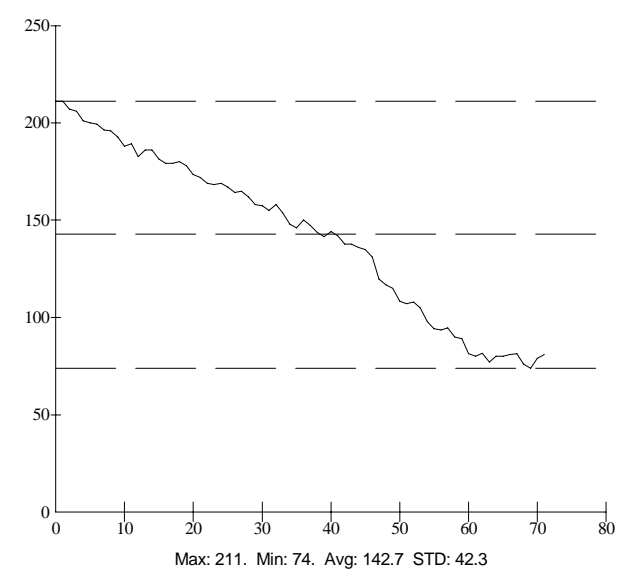

b) Thermal profile from the left line

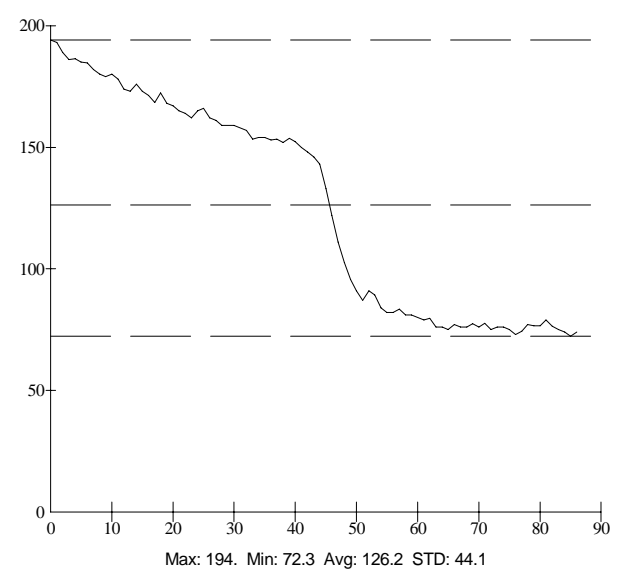

c) Thermal profile from the right line

Figure A.219 Top-heated thermal images of the Specimen WD-3 (coated with real color) at $1,735,550$ loading cycles. The heating time is 90 seconds. The delay time is 1 second. 


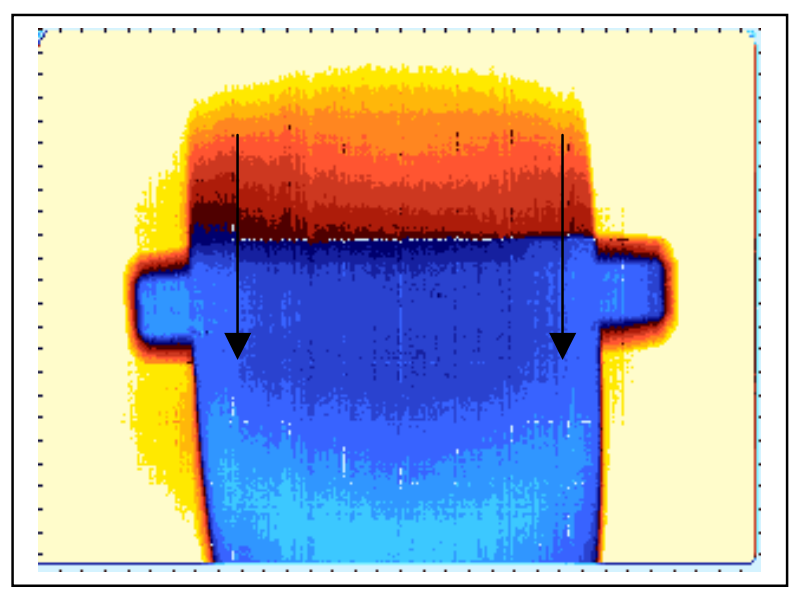

a) Thermal image

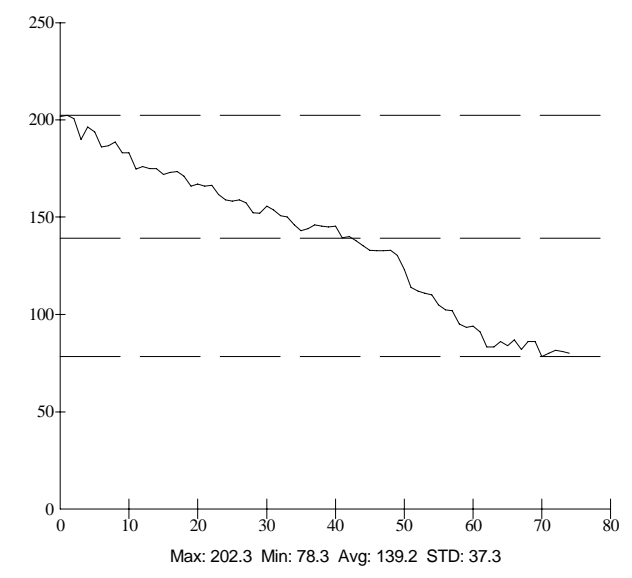

b) Thermal profile from the left line

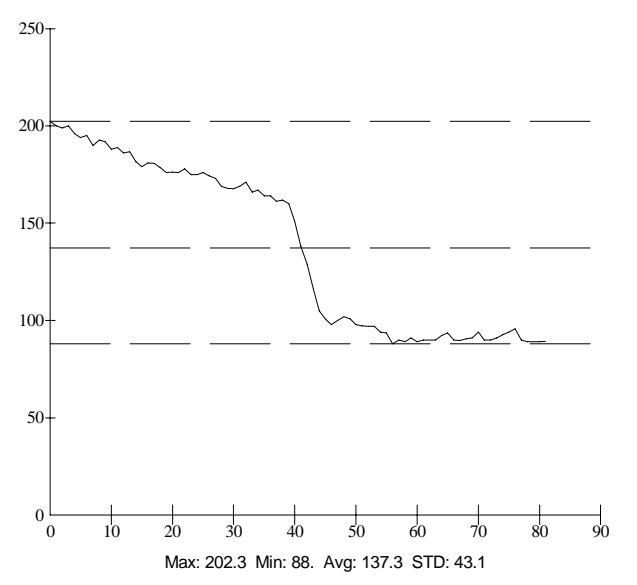

c) Thermal profile from the right line

Figure A.220 Top-heated thermal images of the Specimen WD-3 (coated with real color) at 1,735,550 loading cycles. The heating time is 90 seconds. The delay time is 3 seconds. 


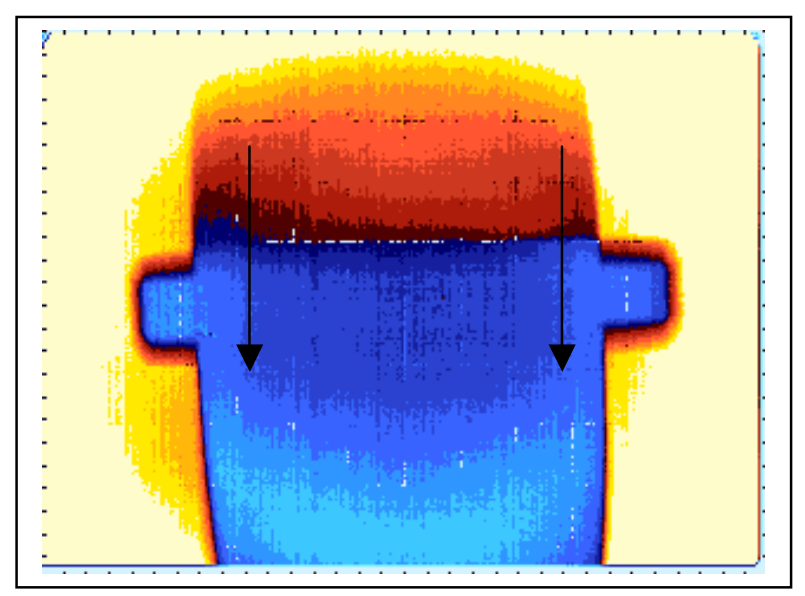

a) Thermal image

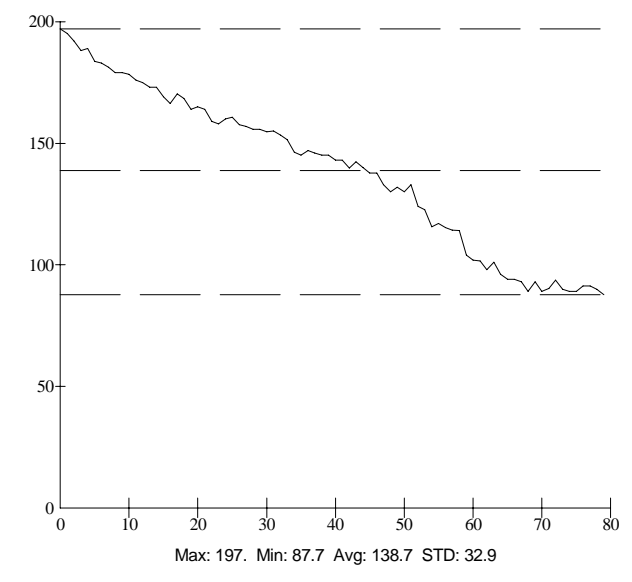

b) Thermal profile from the left line

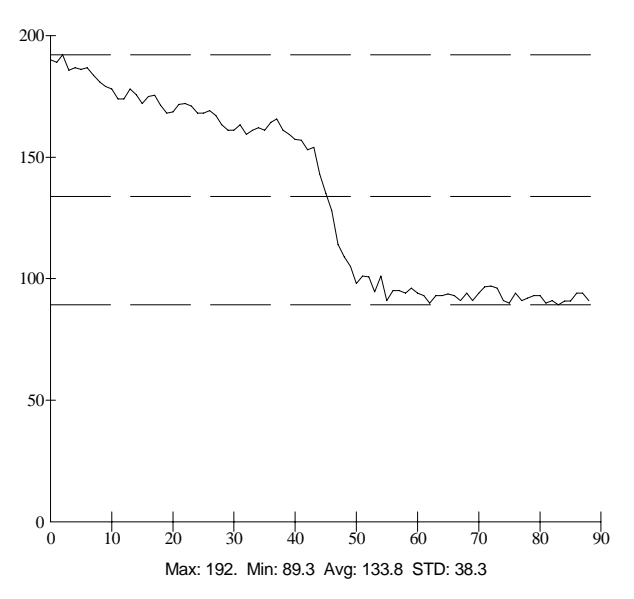

c) Thermal profile from the right line

Figure A.221 Top-heated thermal images of the Specimen WD-3 (coated with real color) at $1,735,550$ loading cycles. The heating time is 90 seconds. The delay time is 6 seconds. 


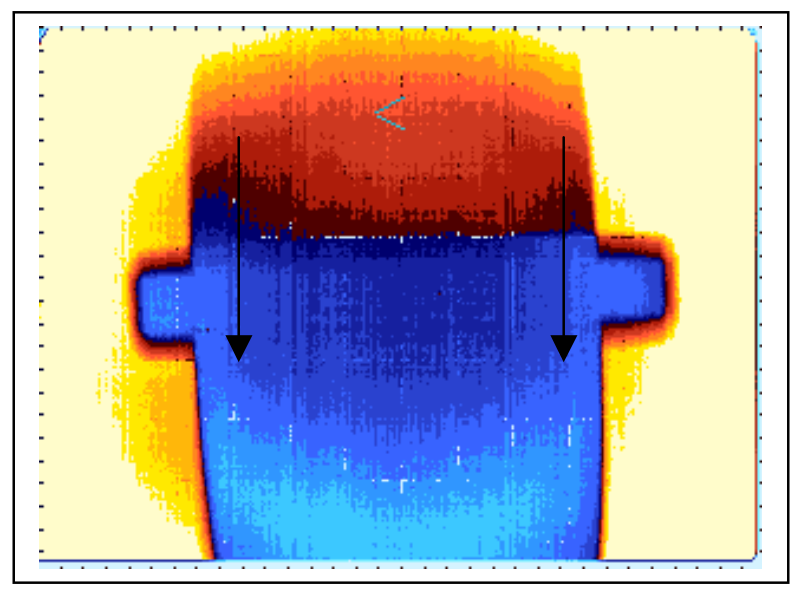

a) Thermal image

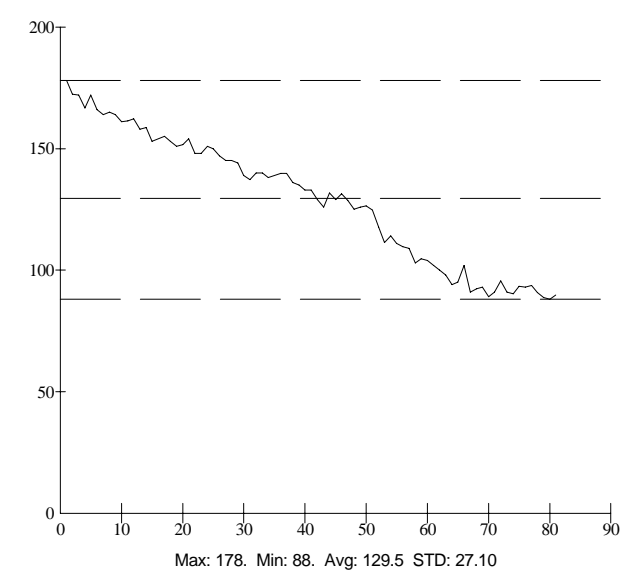

b) Thermal profile from the left line

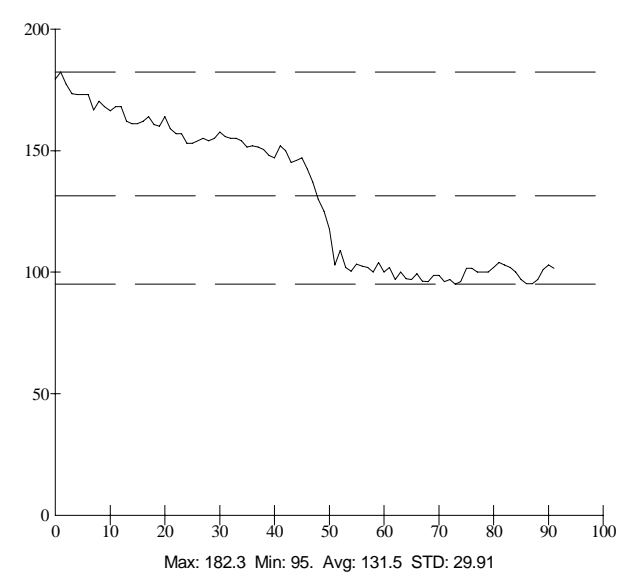

c) Thermal profile from the right line

Figure A.222 Top-heated thermal images of the Specimen WD-3 (coated with real color) at 1,735,550 loading cycles. The heating time is 90 seconds. The delay time is 9 seconds. 


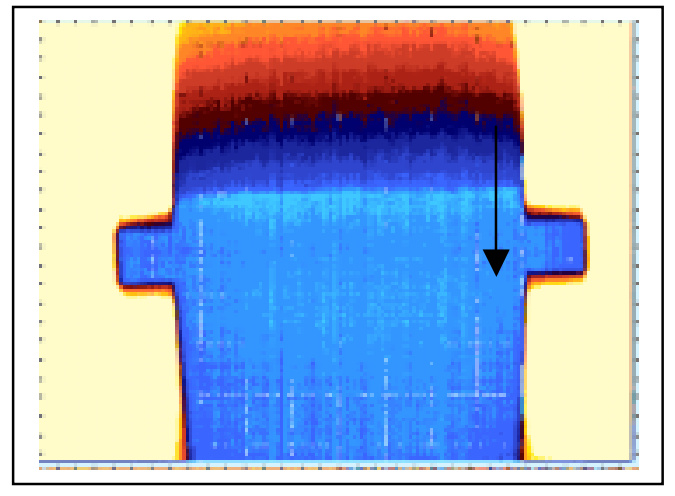

a) 1-second delay time

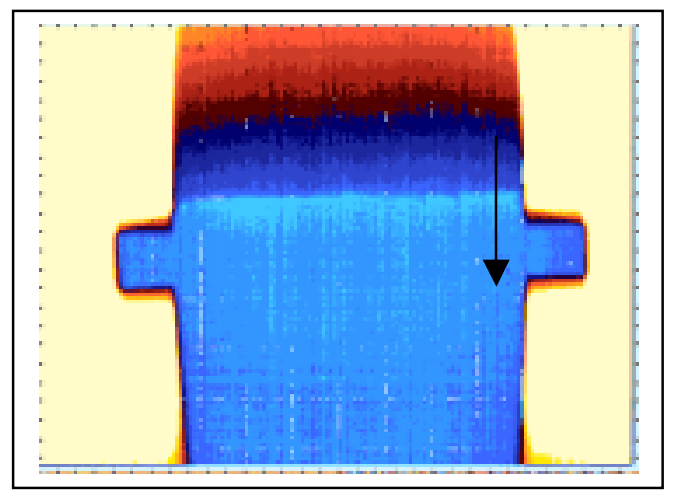

c) 6 second-delay time

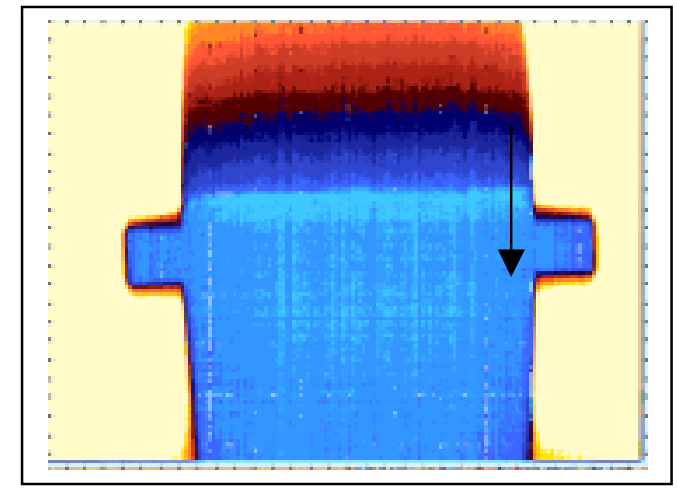

b) 3-second delay time

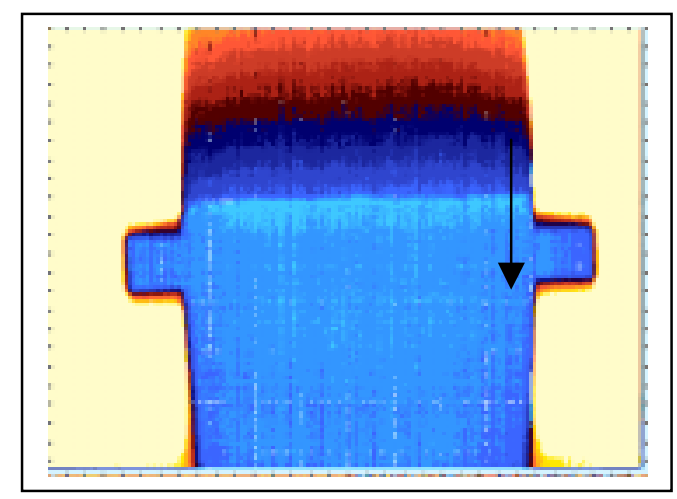

d) 9 second-delay time

Figure A.223 Top-heated thermal images of the Specimen WD-3 (coated with real color and tested under the outdoor condition) at 1,735,550 loading cycles. The heating time is 30 seconds. 


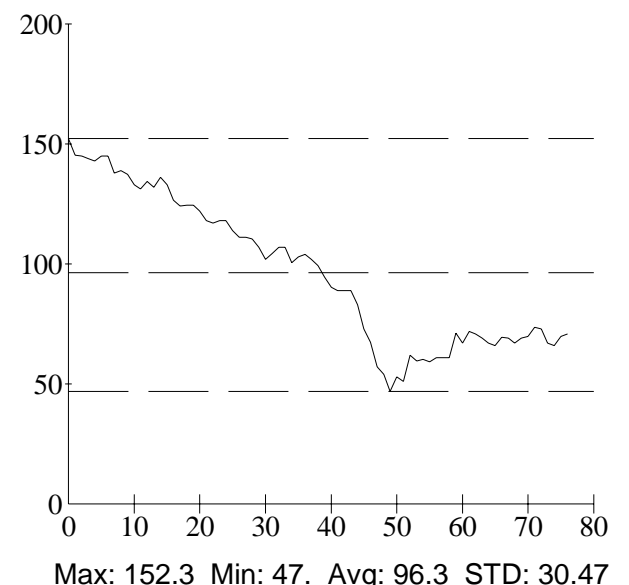

a) 1-second delay time

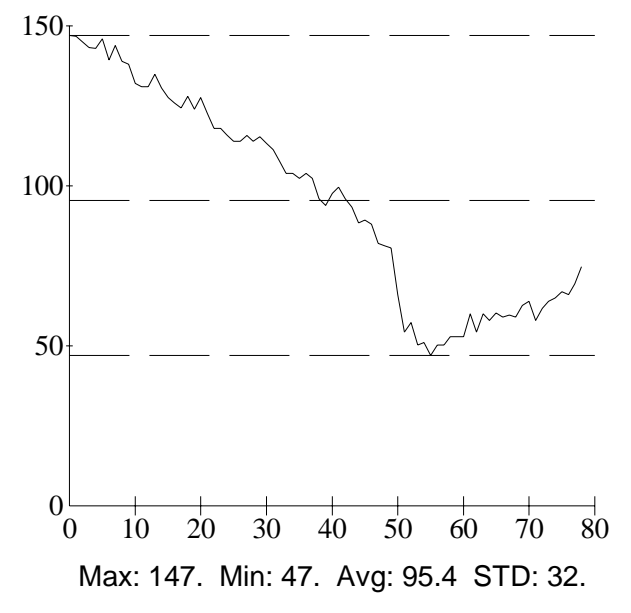

c) 6 second-delay time

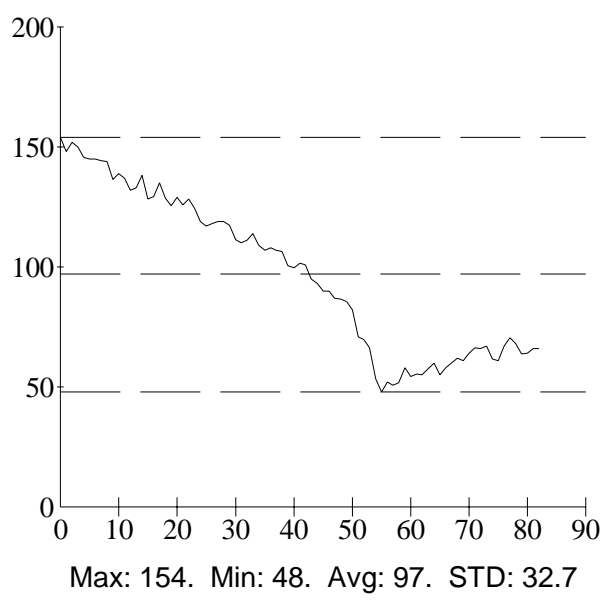

b) 3-second delay time

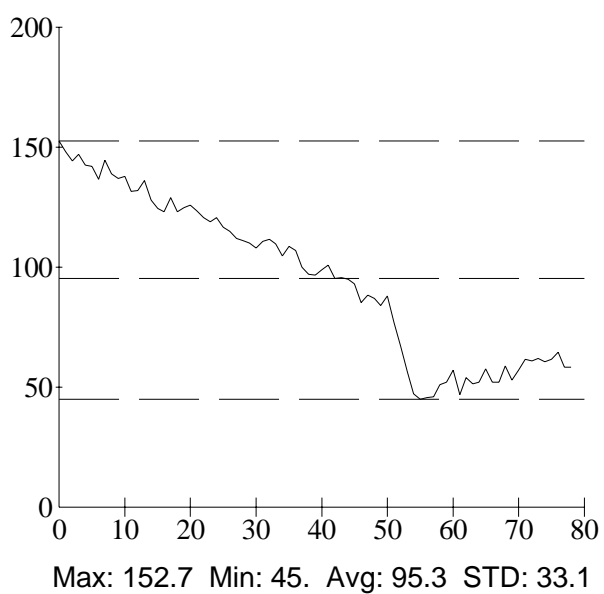

d) 9 second-delay time

Figure A.224 Thermal intensity profile along the line across the fatigue crack shown in Figure A.223. 


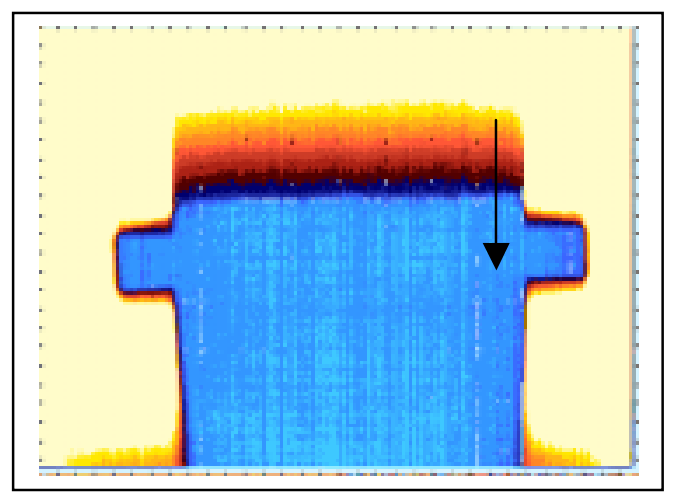

a) 1-second delay time

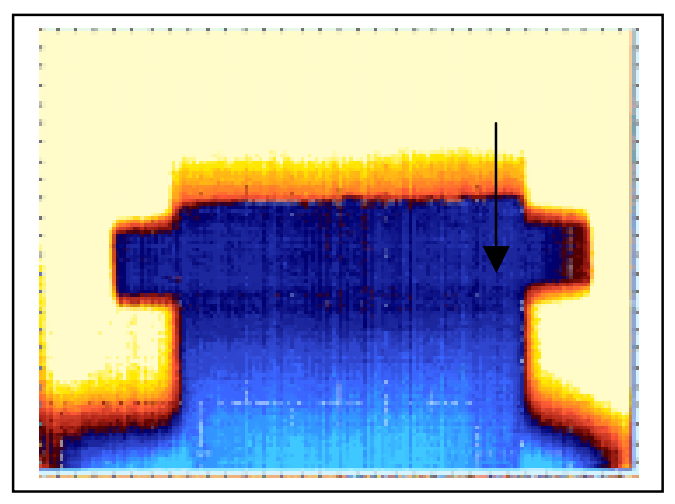

c) 6 second-delay time

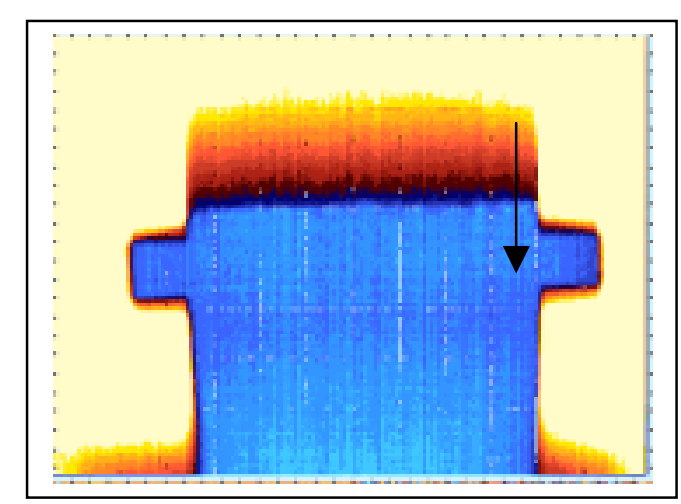

b) 3-second delay time

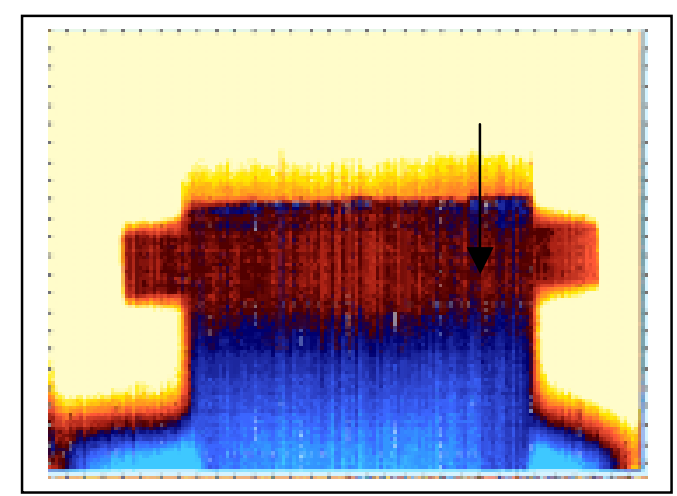

d) 9 second-delay time

Figure A.225 Top-heated thermal images of the Specimen WD-3 (coated with real color and tested under the outdoor condition) at 1,735,550 loading cycles. The heating time is 60 seconds. 


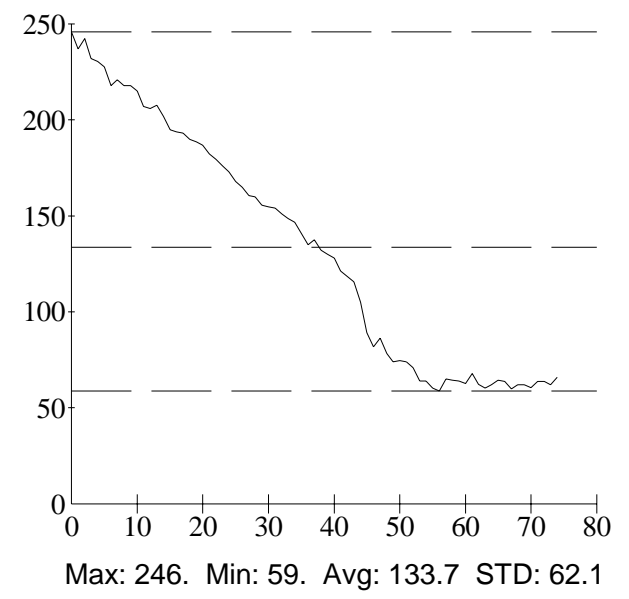

a) 1-second delay time

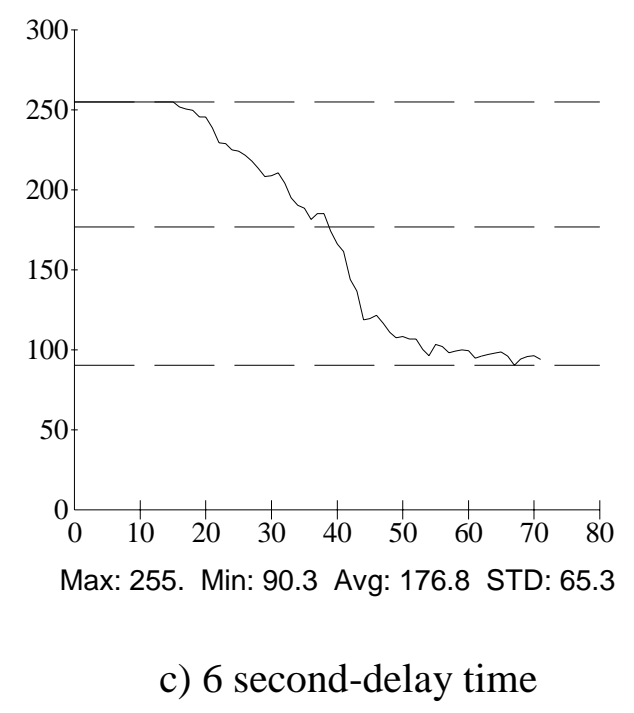

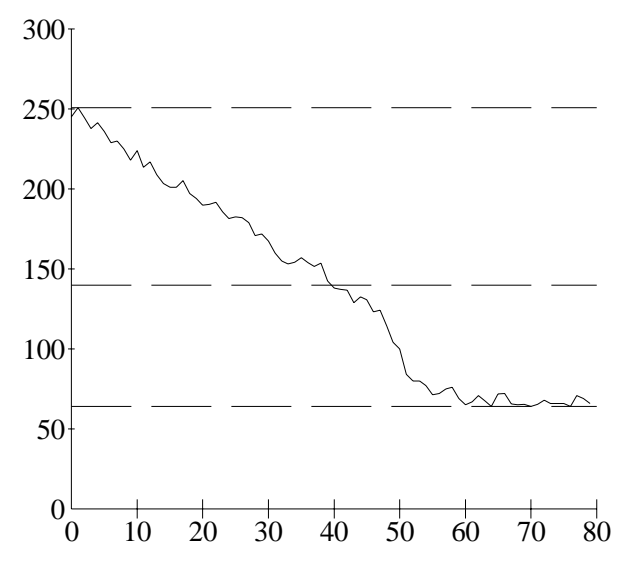

Max: 251. Min: 64. Avg: 139.9 STD: 61.9

b) 3-second delay time

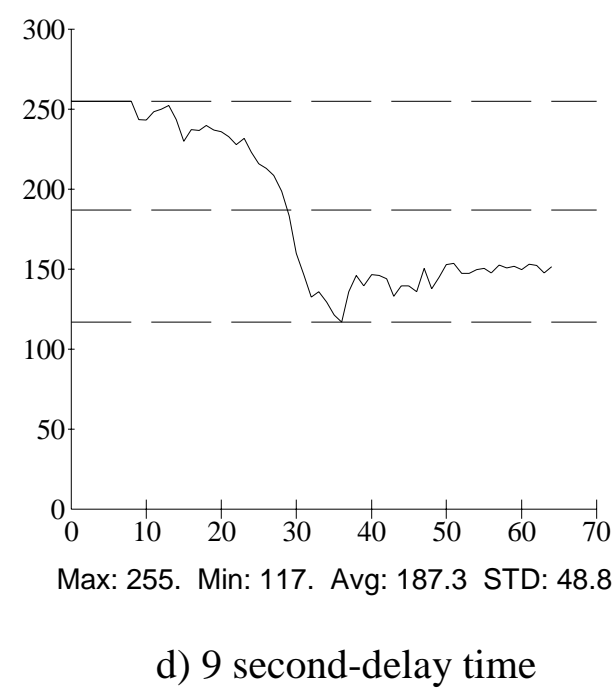

Figure A.226 Thermal intensity profile along the line across the fatigue crack shown in Figure A.225. 


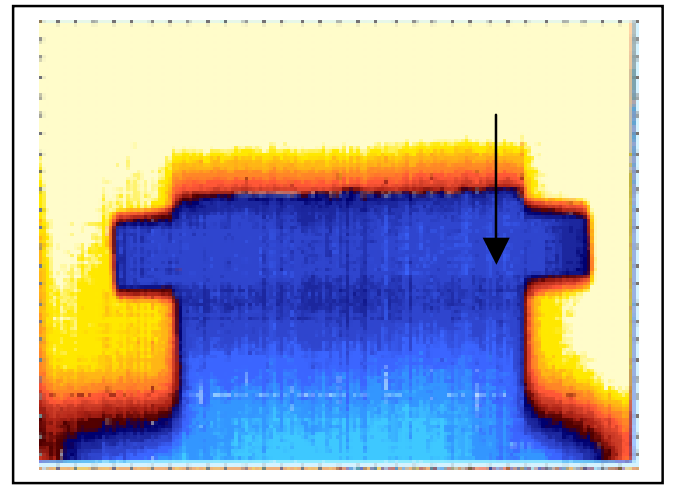

a) 1-second delay time

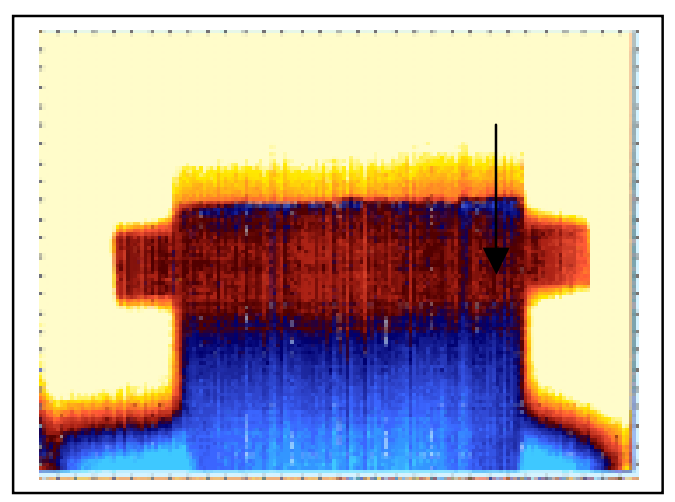

c) 6 second-delay time

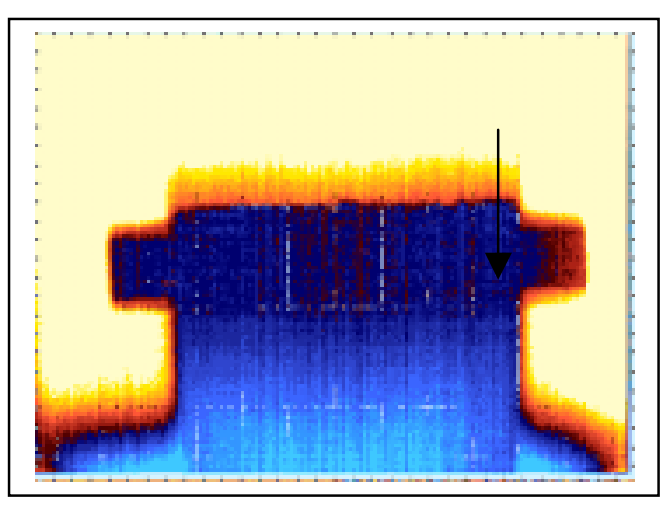

b) 3-second delay time

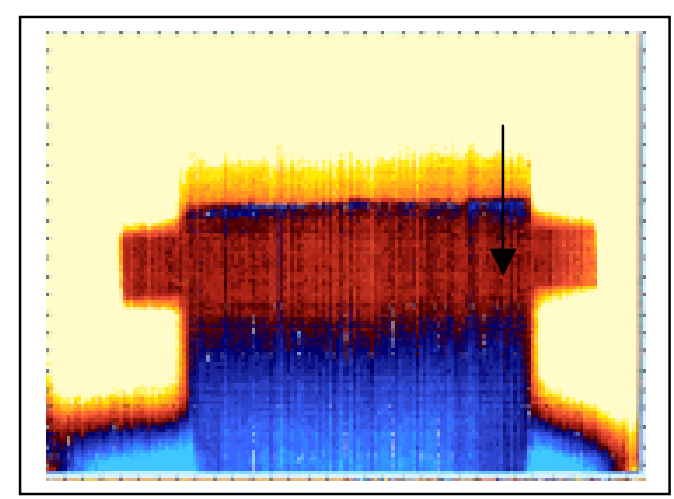

d) 9 second-delay time

Figure A.227 Top-heated thermal images of the Specimen WD-3 (coated with real color and tested under the outdoor condition) at $1,735,550$ loading cycles. The heating time is 90 seconds. 


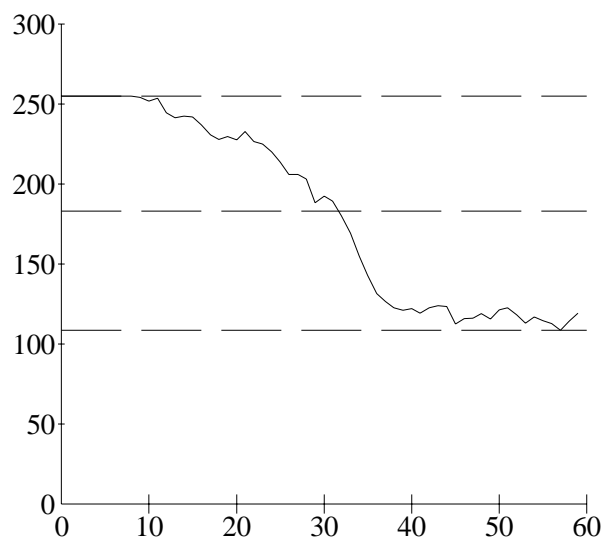

Max: 255. Min: 108.7 Avg: 183.1 STD: 57.6

a) 1-second delay time

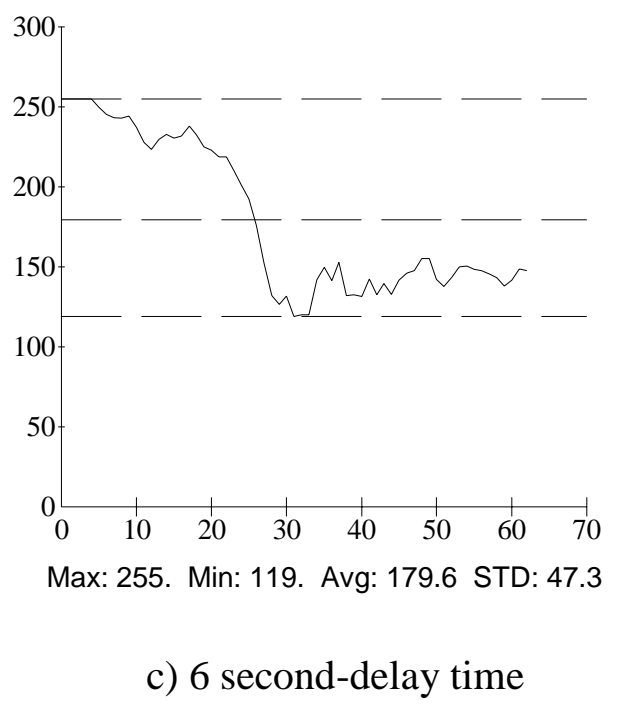

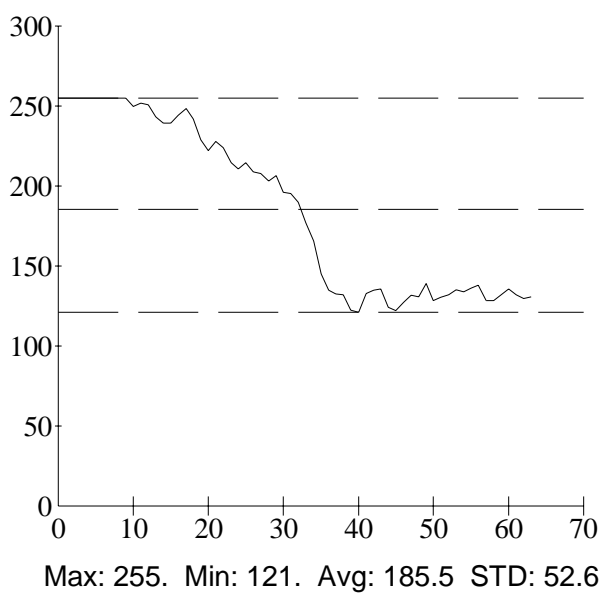

b) 3-second delay time

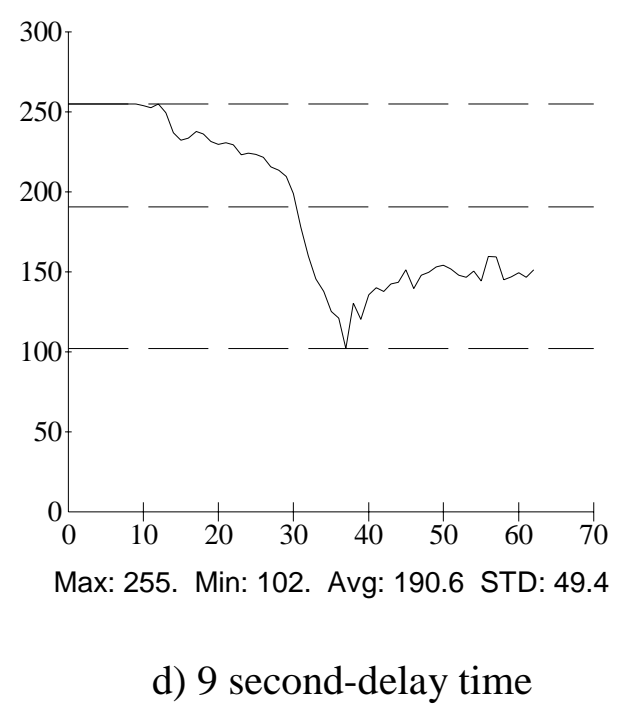

Figure A.228 Thermal intensity profile along the line across the fatigue crack shown in Figure A.227. 


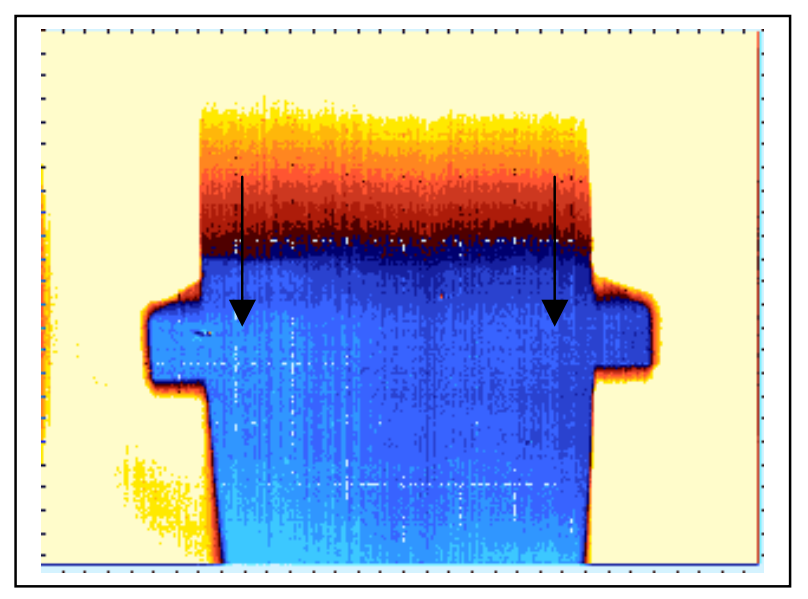

a) Thermal image

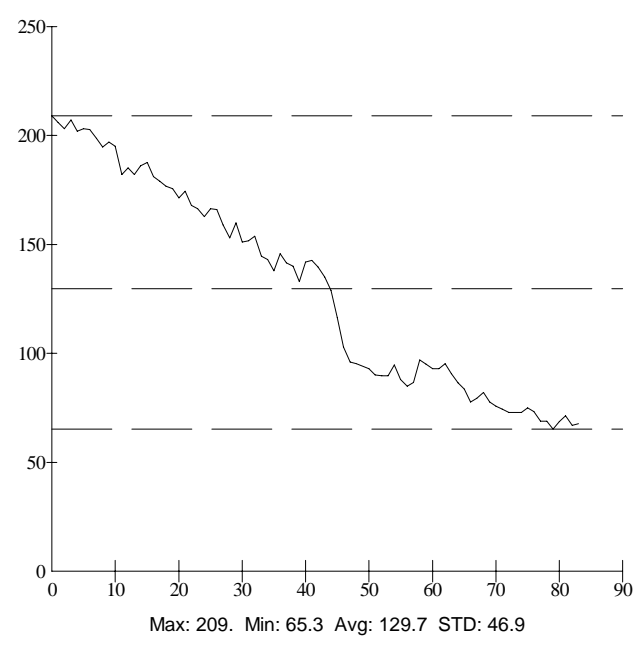

b) Thermal profile from the left line

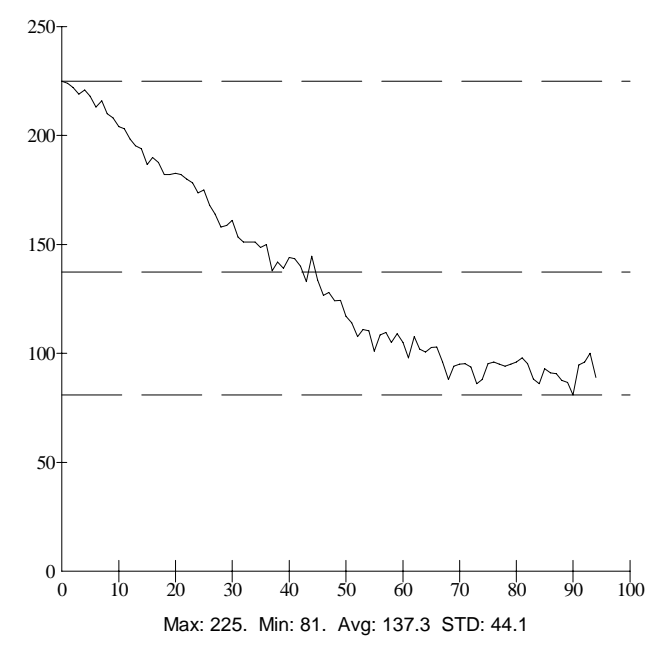

c) Thermal profile from the right line

Figure A.229 Top-heated thermal images of the Specimen WD-4 (coated with real color) at $1,845,500$ loading cycles. The heating time is 30 seconds. The delay time is 1 second. 


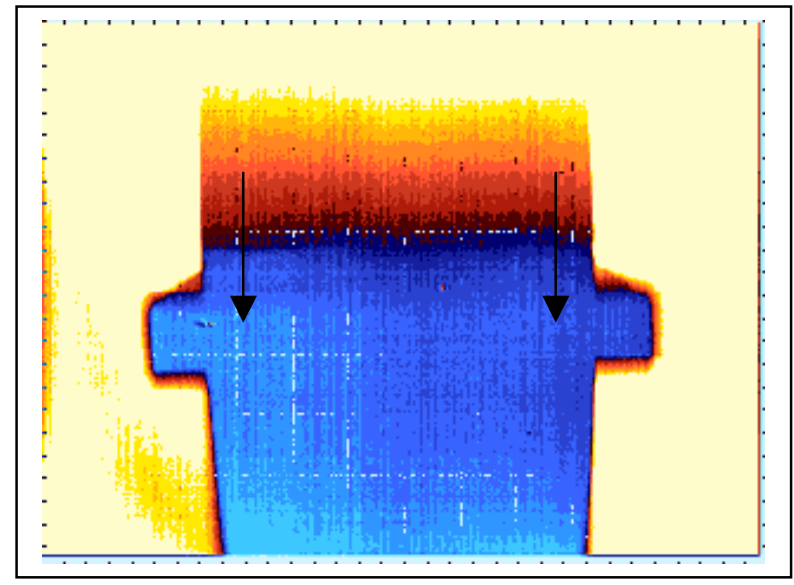

a) Thermal image

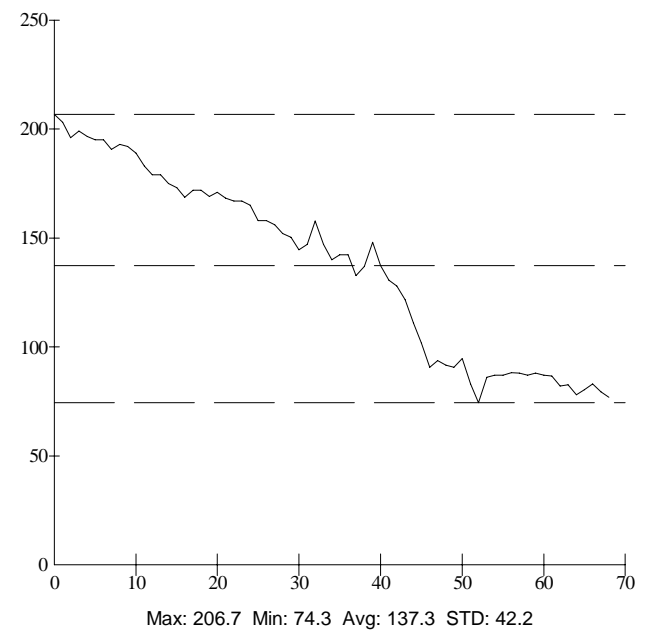

b) Thermal profile from the left line

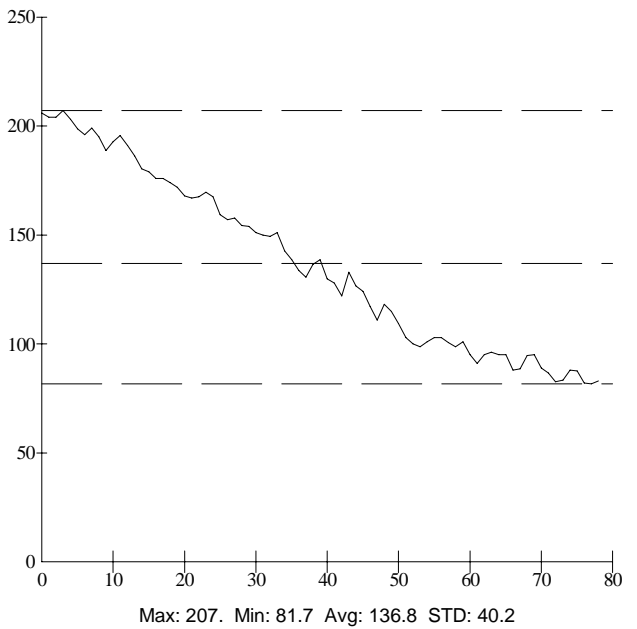

c) Thermal profile from the right line

Figure A.230 Top-heated thermal images of the Specimen WD-4 (coated with real color) at 1,845,500 loading cycles. The heating time is 30 seconds. The delay time is 3 seconds. 


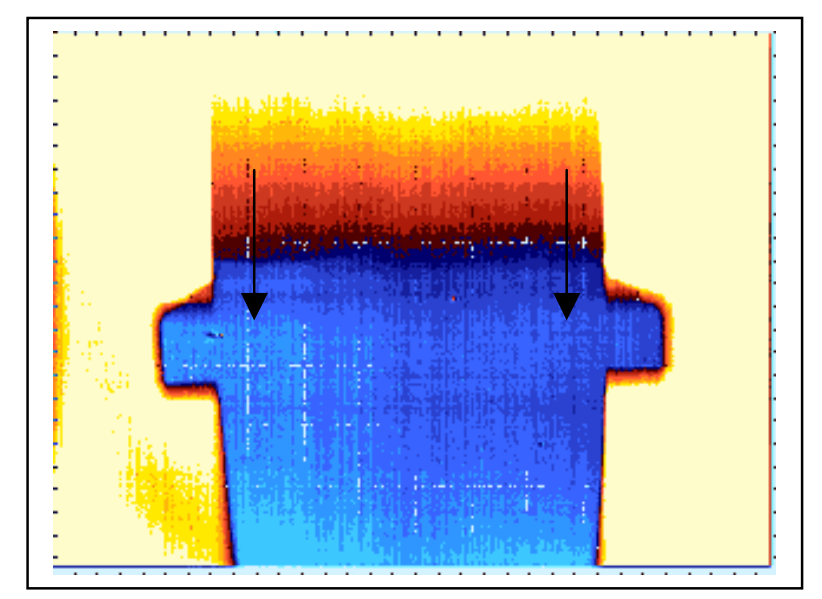

a) Thermal image

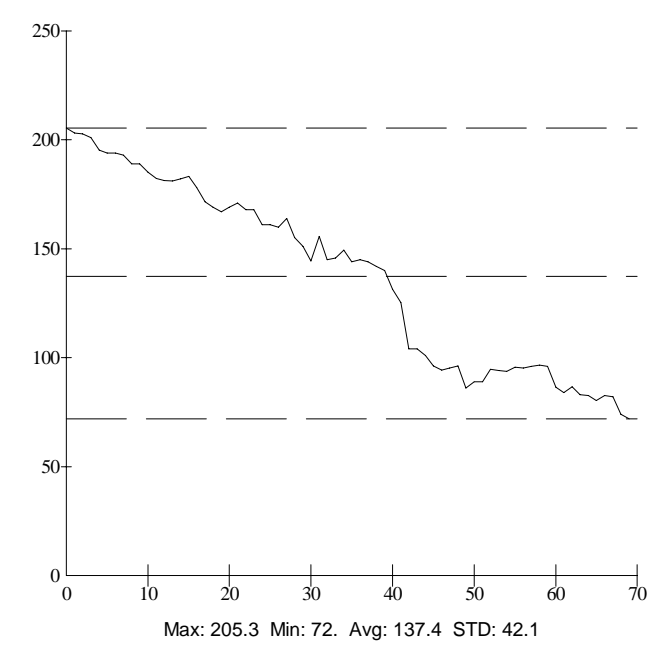

b) Thermal profile from the left line

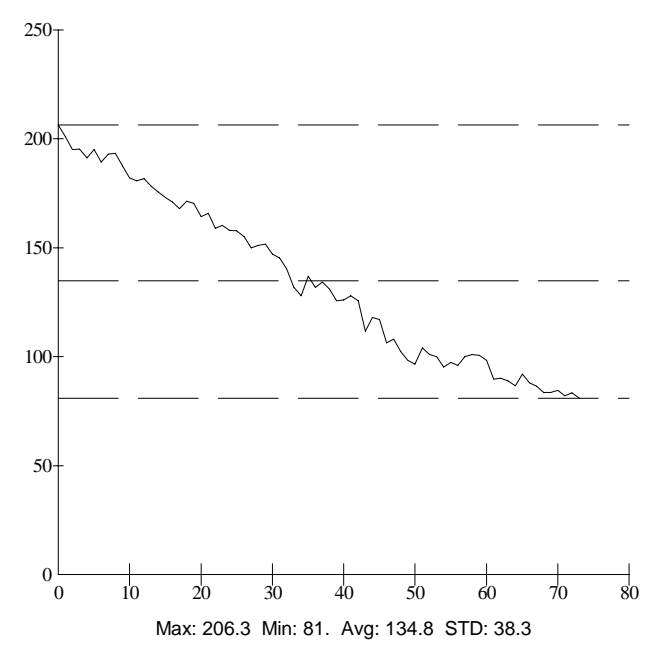

c) Thermal profile from the right line

Figure A.231 Top-heated thermal images of the Specimen WD-4 (coated with real color) at 1,845,500 loading cycles. The heating time is 30 seconds. The delay time is 6 seconds. 


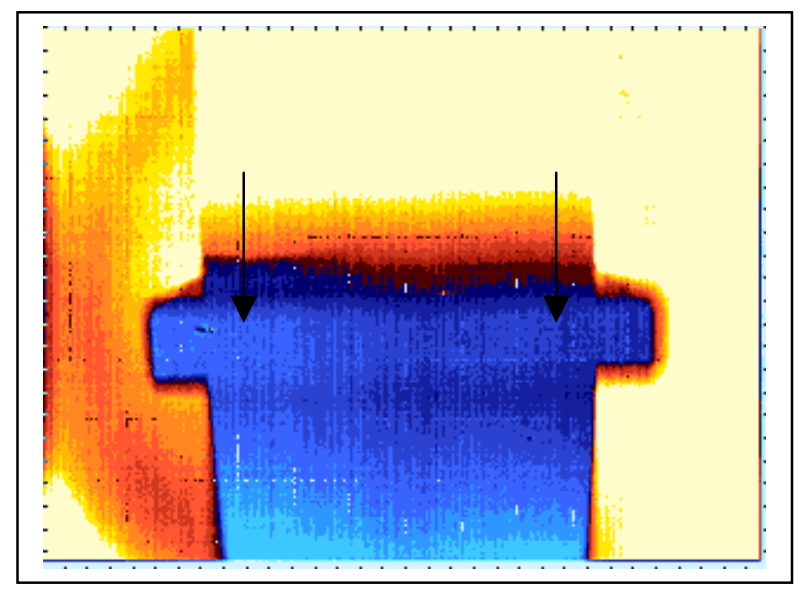

a) Thermal image

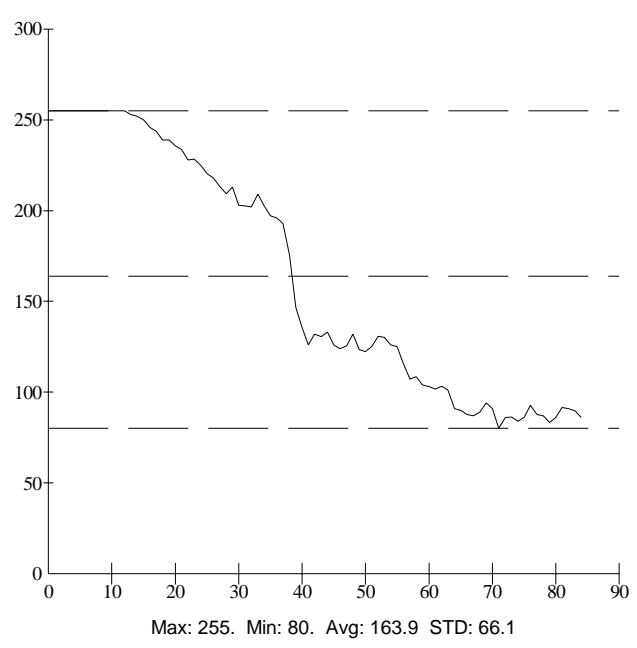

b) Thermal profile from the left line

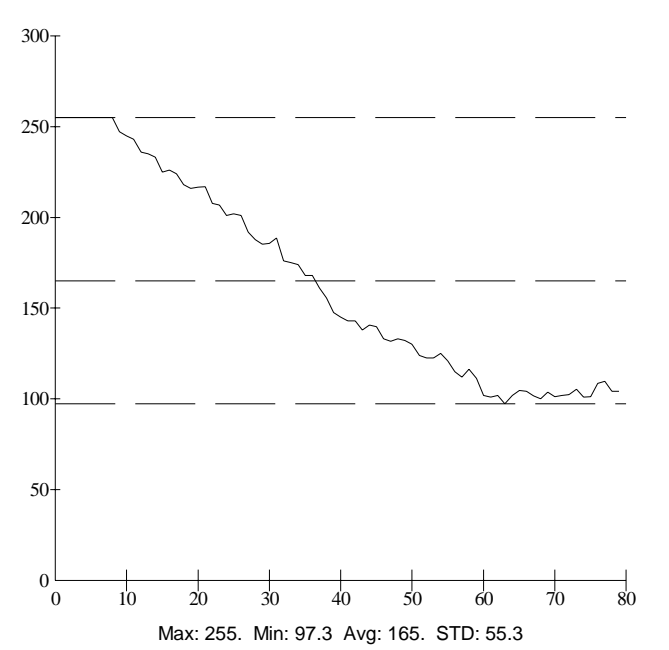

c) Thermal profile from the right line

Figure A.232 Top-heated thermal images of the Specimen WD-4 (coated with real color) at $1,845,500$ loading cycles. The heating time is 30 seconds. The delay time is 9 seconds. 


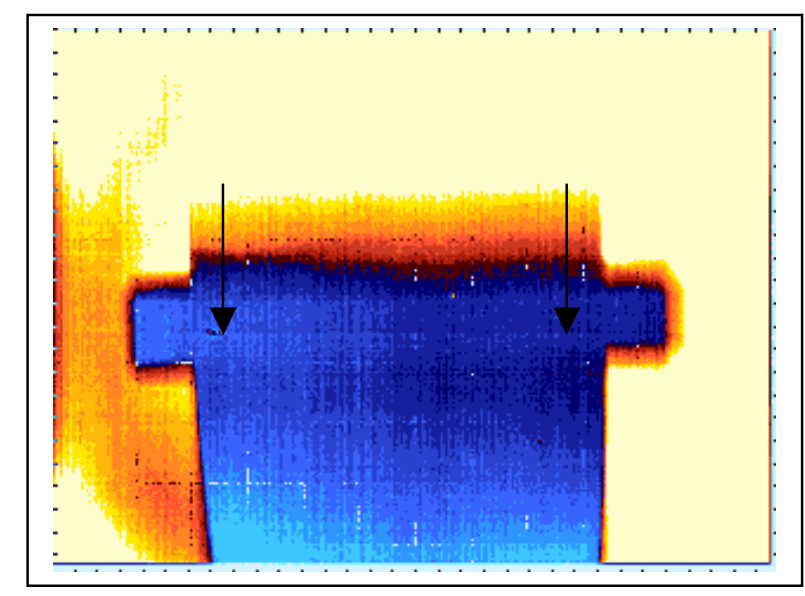

a) Thermal image

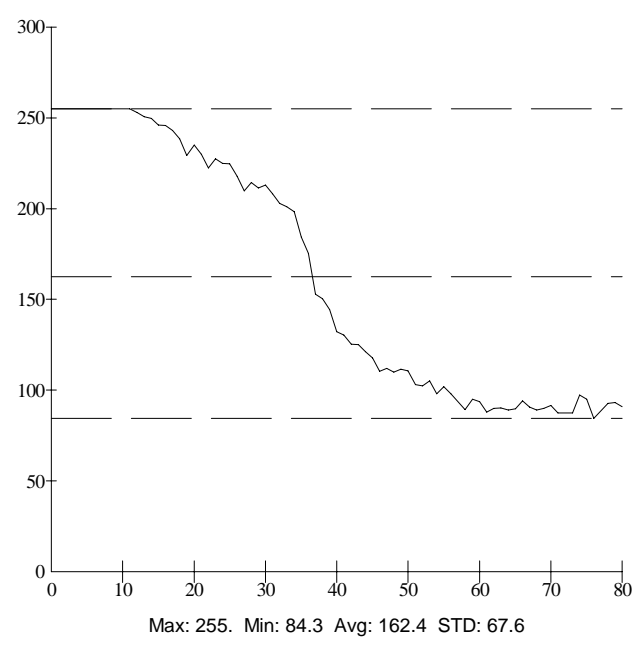

b) Thermal profile from the left line

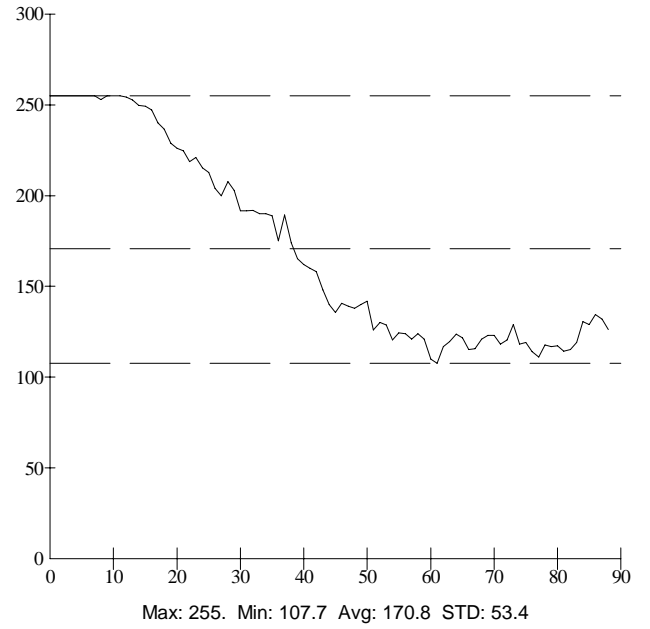

c) Thermal profile from the right line

Figure A.233 Top-heated thermal images of the Specimen WD-4 (coated with real color) at $1,845,500$ loading cycles. The heating time is 60 seconds. The delay time is 1 second. 


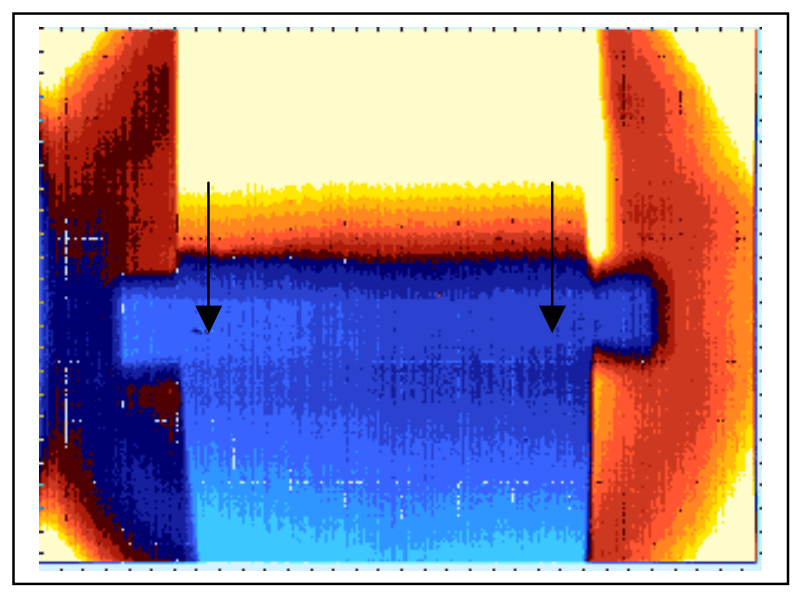

a) Thermal image

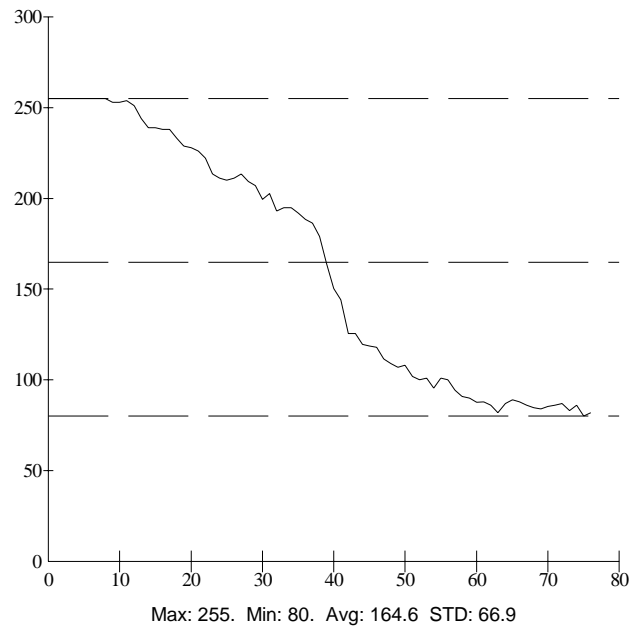

b) Thermal profile from the left line

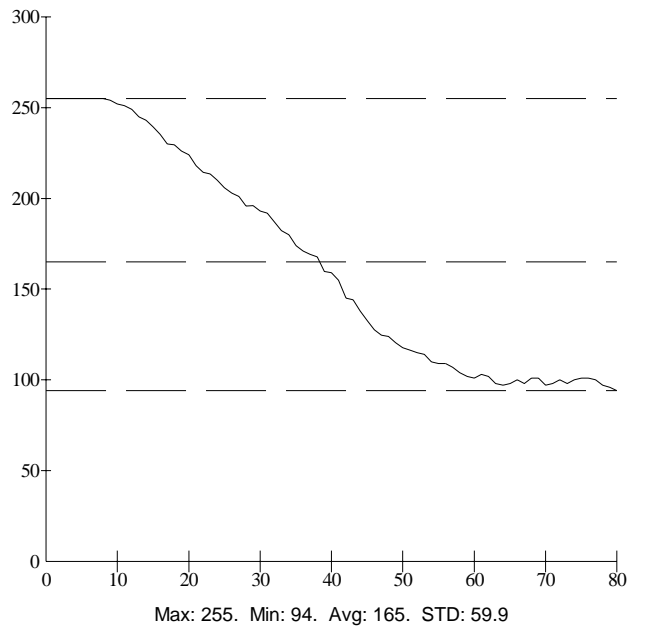

c) Thermal profile from the right line

Figure A.234 Top-heated thermal images of the Specimen WD-4 (coated with real color) at 1,845,500 loading cycles. The heating time is 60 seconds. The delay time is 3 seconds. 


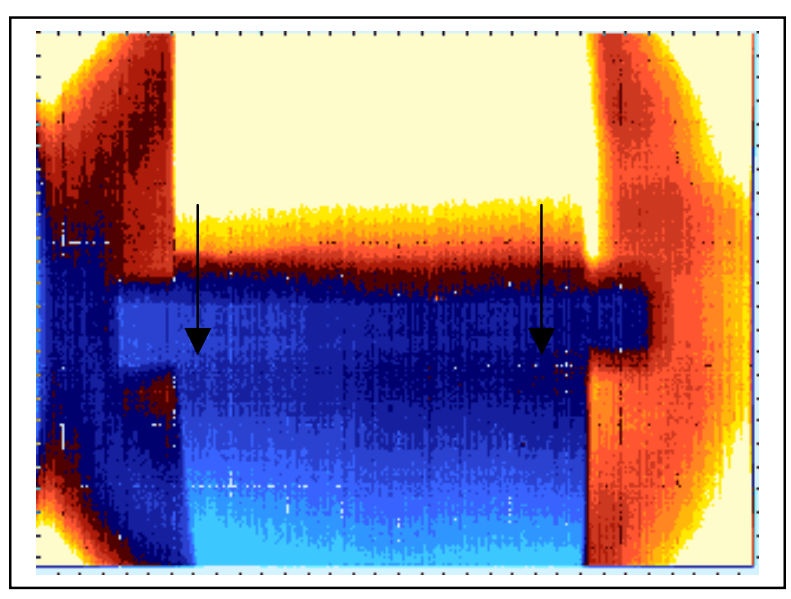

a) Thermal image

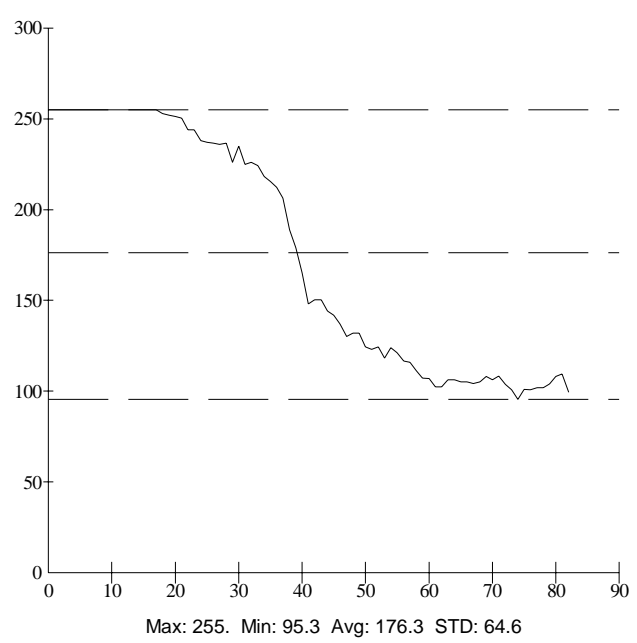

b) Thermal profile from the left line

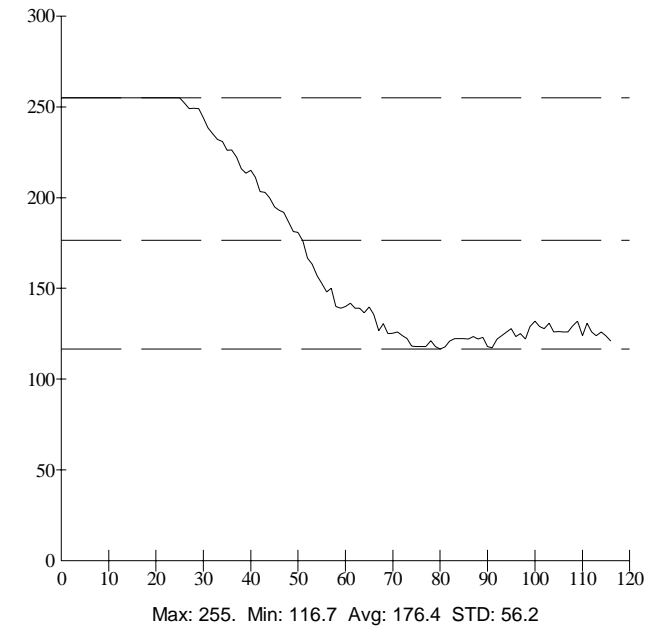

c) Thermal profile from the right line

Figure A.235 Top-heated thermal images of the Specimen WD-4 (coated with real color) at 1,845,500 loading cycles. The heating time is 60 seconds. The delay time is 6 seconds. 


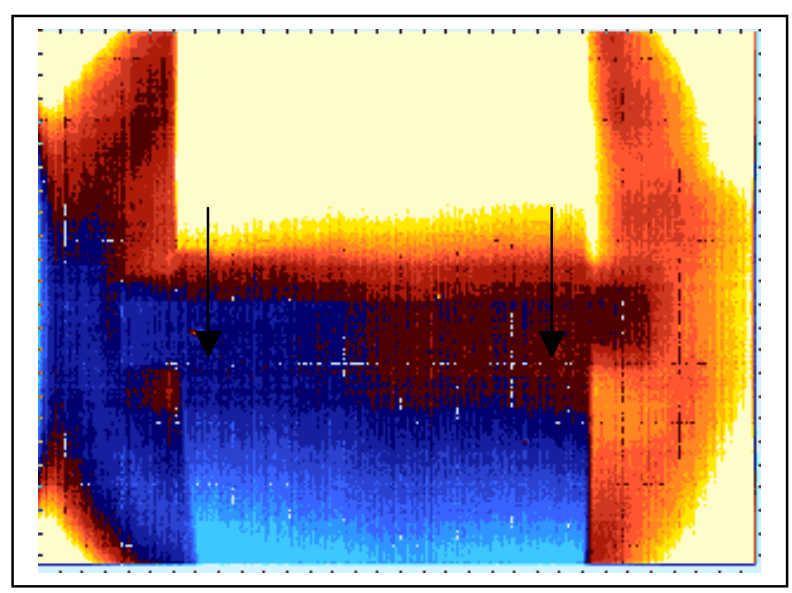

a) Thermal image

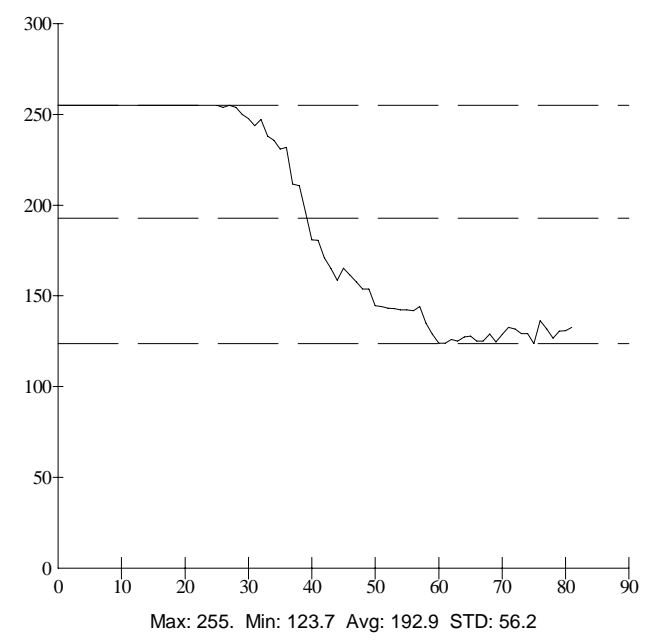

b) Thermal profile from the left line

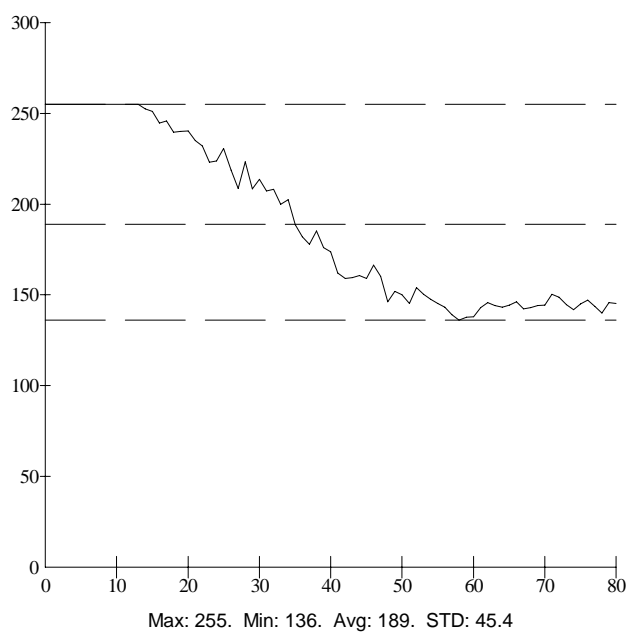

c) Thermal profile from the right line

Figure A.236 Top-heated thermal images of the Specimen WD-4 (coated with real color) at $1,845,500$ loading cycles. The heating time is 60 seconds. The delay time is 9 seconds. 


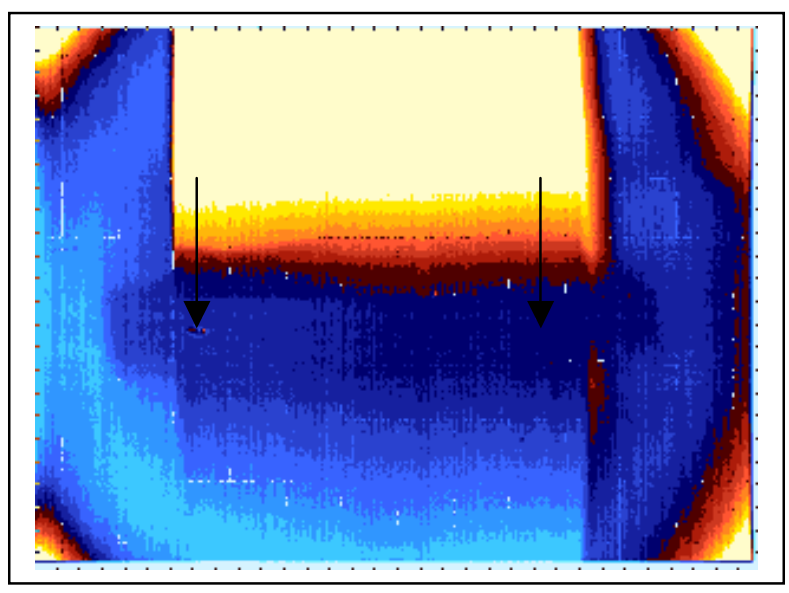

a) Thermal image

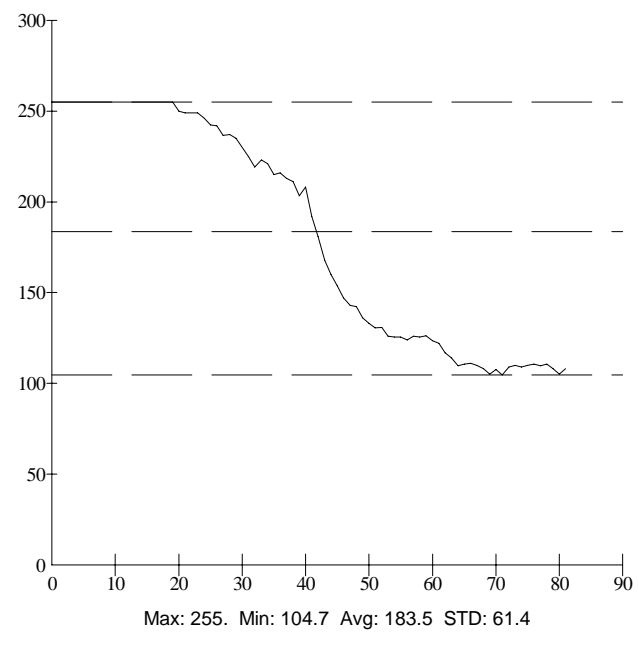

b) Thermal profile from the left line

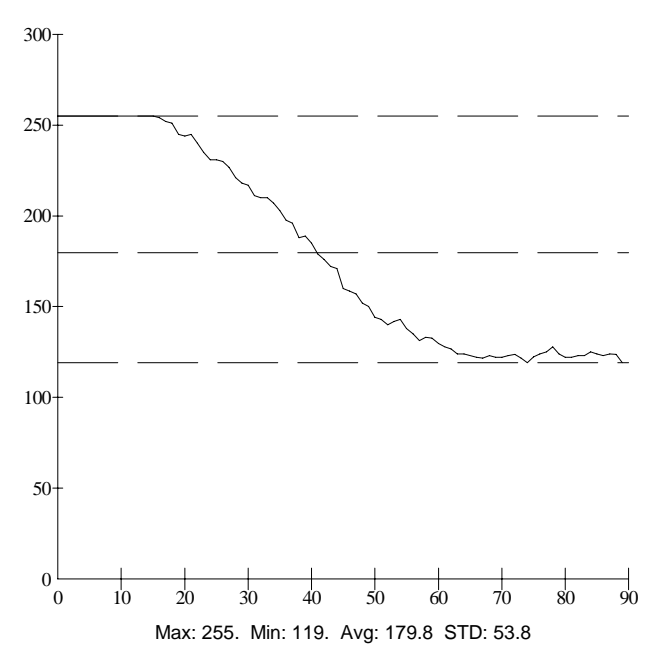

c) Thermal profile from the right line

Figure A.237 Top-heated thermal images of the Specimen WD-4 (coated with real color) at 1,845,500 loading cycles. The heating time is 90 seconds. The delay time is 1 second. 


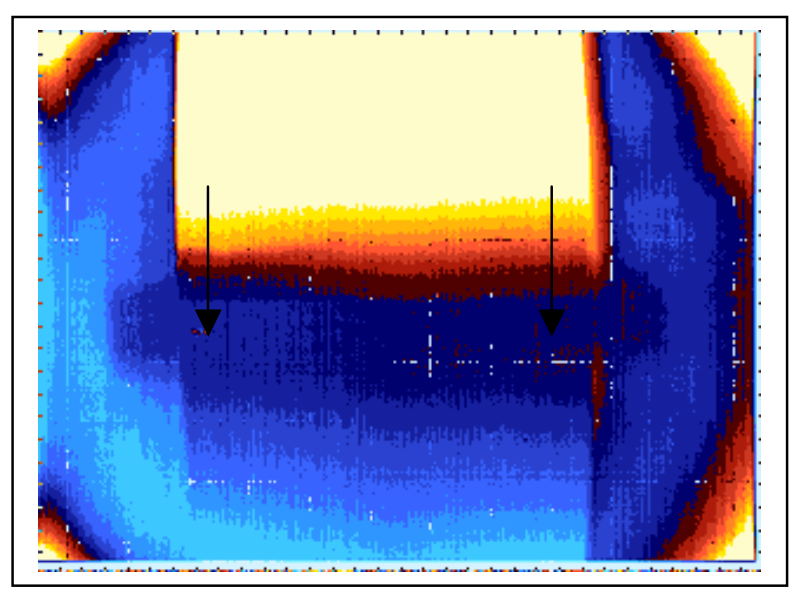

a) Thermal image

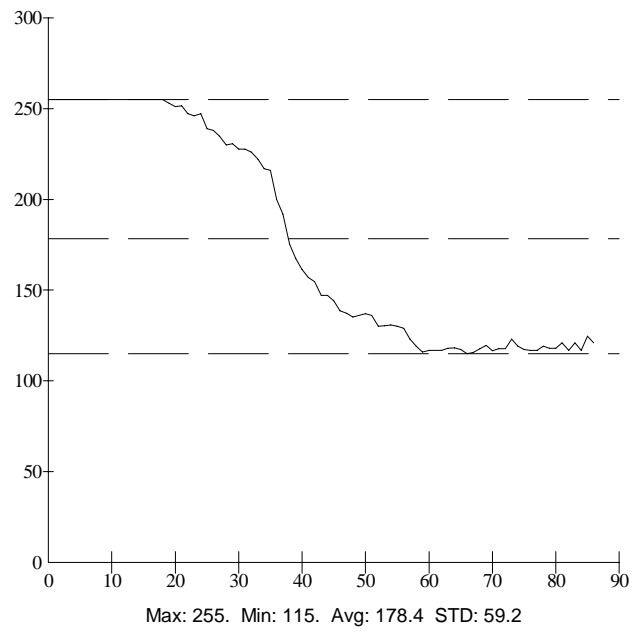

b) Thermal profile from the left line

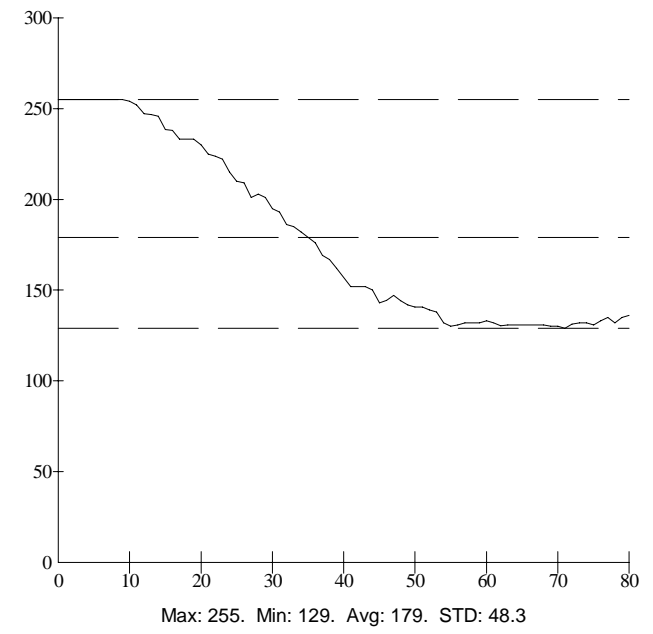

c) Thermal profile from the right line

Figure A.238 Top-heated thermal images of the Specimen WD-4 (coated with real color) at 1,845,500 loading cycles. The heating time is 90 seconds. The delay time is 3 seconds. 


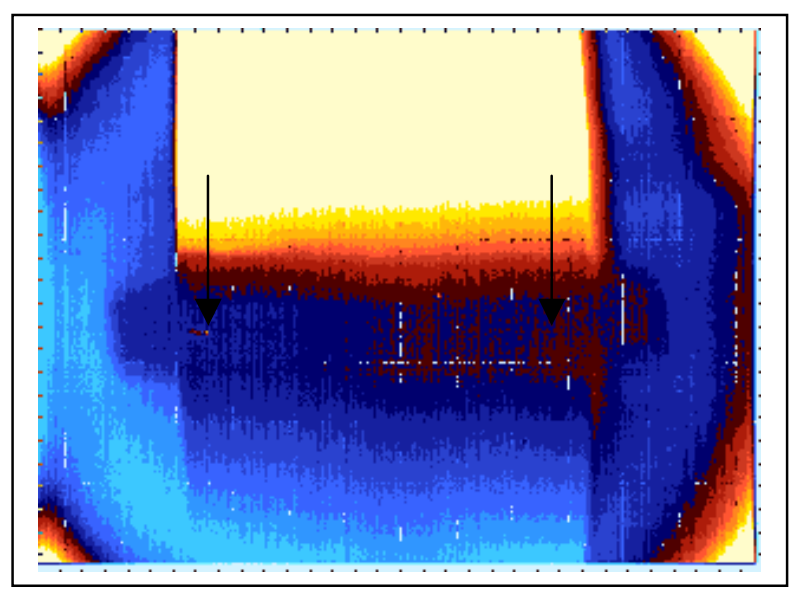

a) Thermal image

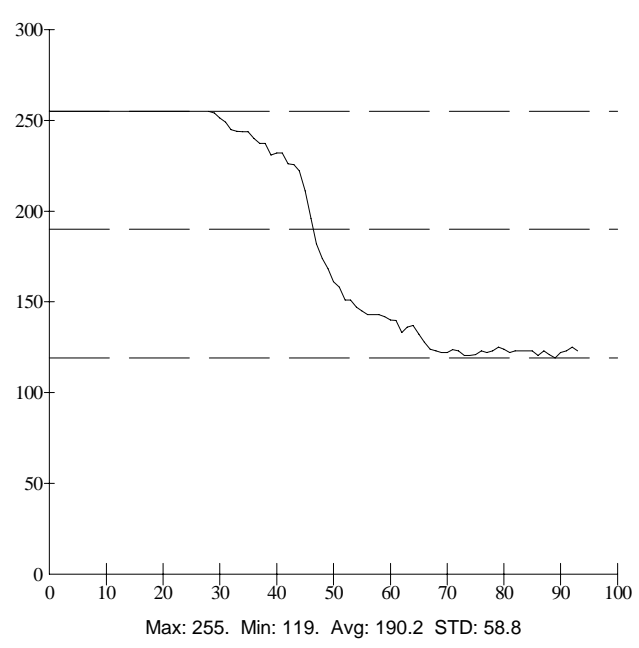

b) Thermal profile from the left line

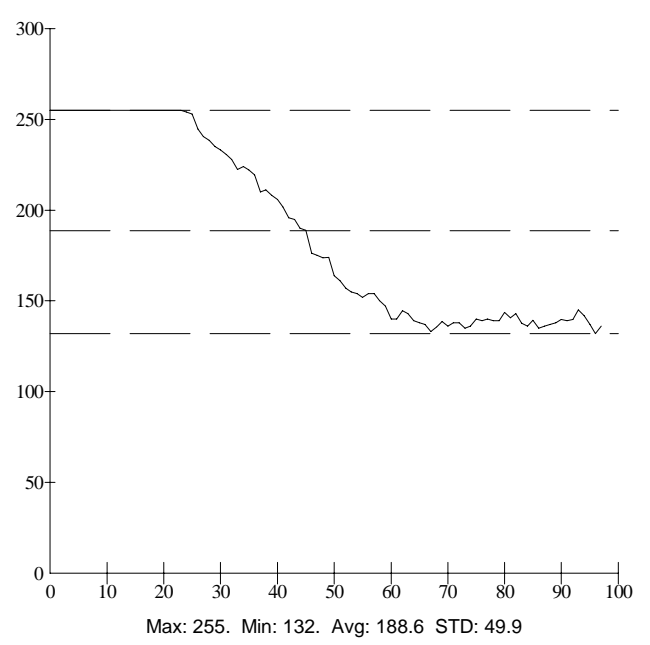

c) Thermal profile from the right line

Figure A.239 Top-heated thermal images of the Specimen WD-4 (coated with real color) at 1,845,500 loading cycles. The heating time is 90 seconds. The delay time is 6 seconds. 


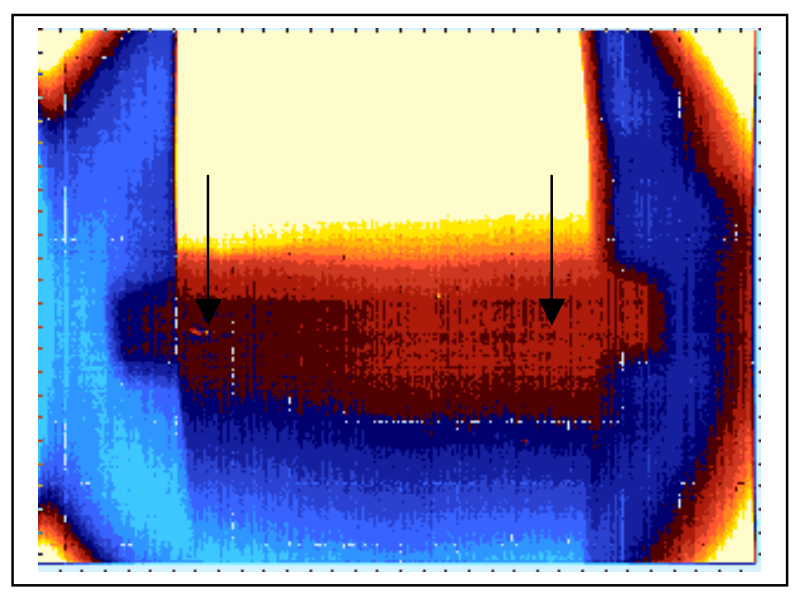

a) Thermal image

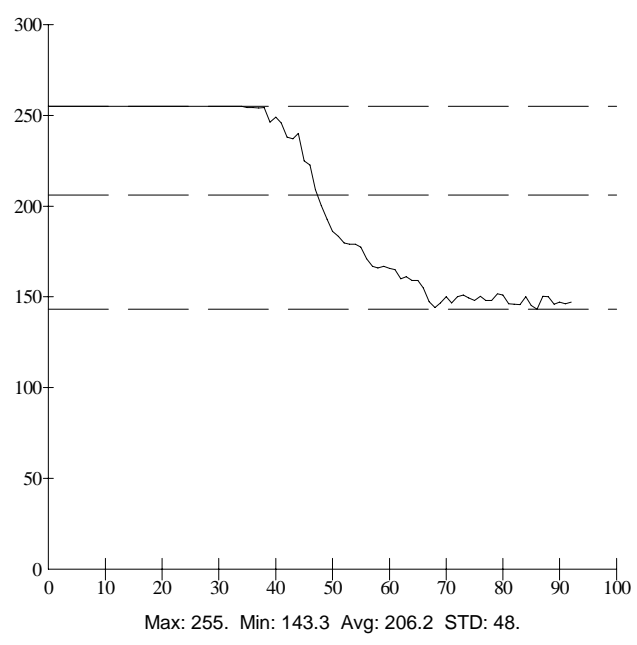

b) Thermal profile from the left line

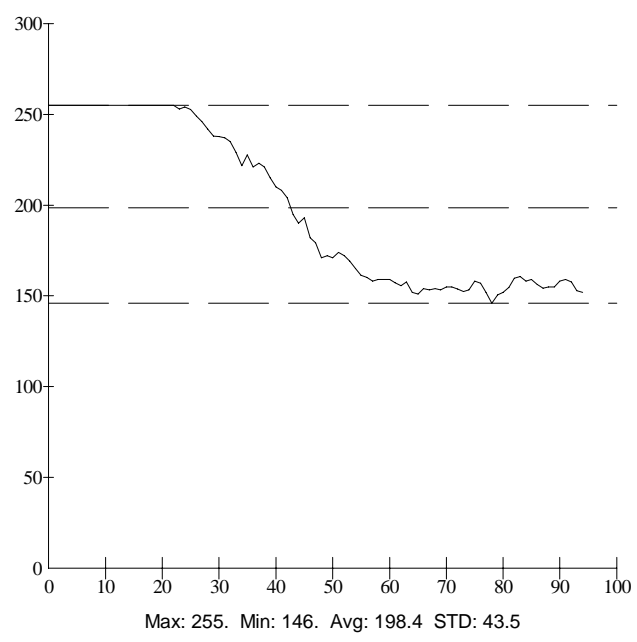

c) Thermal profile from the right line

Figure A.240 Top-heated thermal images of the Specimen WD-4 (coated with real color) at $1,845,500$ loading cycles. The heating time is 90 seconds. The delay time is 9 seconds. 


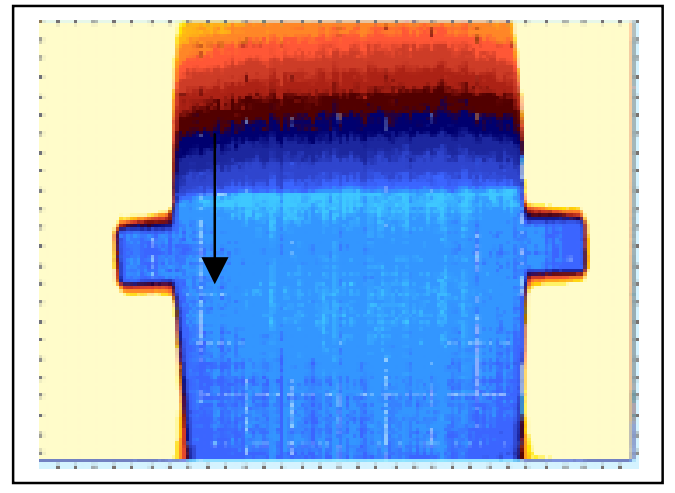

a) 1-second delay time

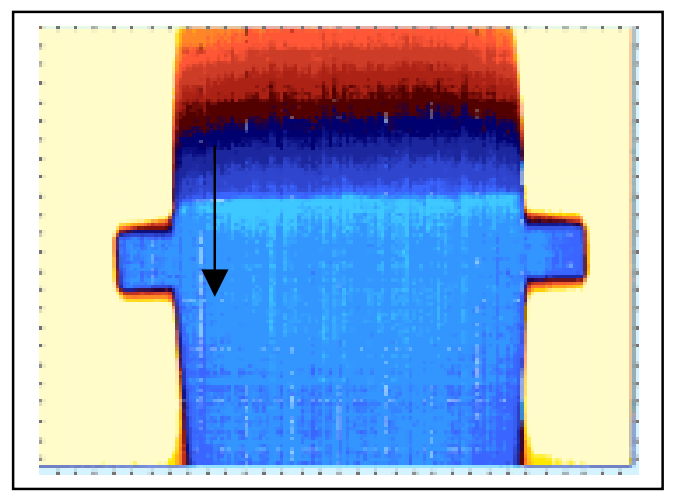

c) 6 second-delay time

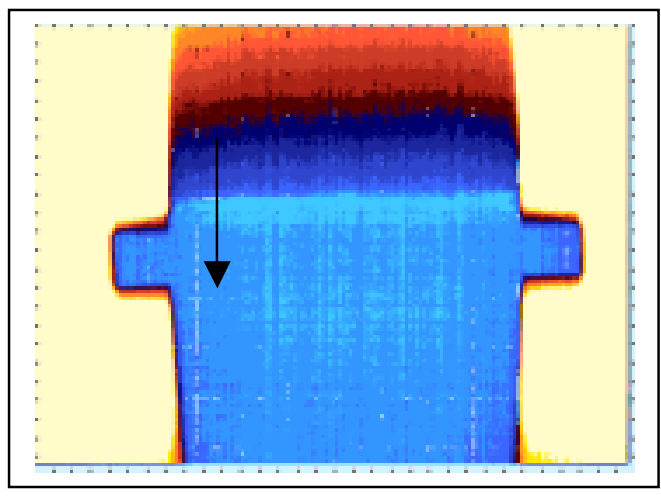

b) 3-second delay time

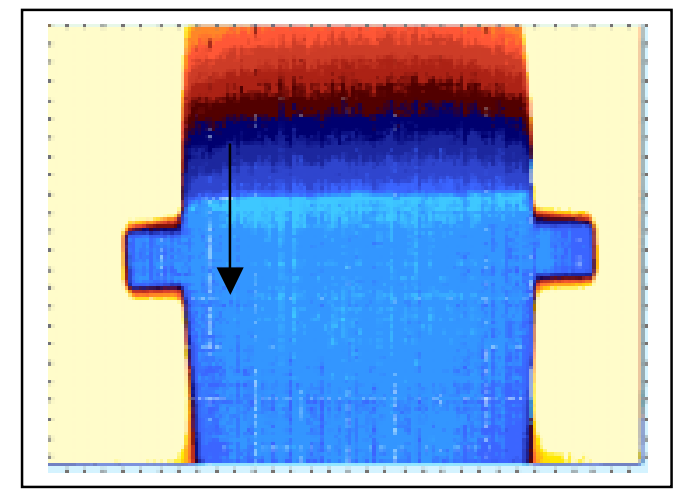

d) 9 second-delay time

Figure A.241 Top-heated thermal images of the Specimen WD-4 (coated with real color and tested under the outdoor condition) at 1,845,500 loading cycles. The heating time is 30 seconds. 


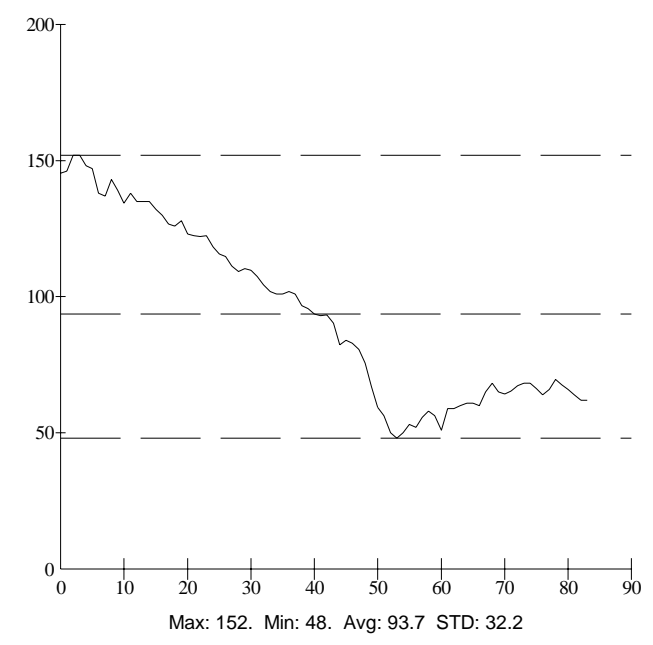

a) 1-second delay time

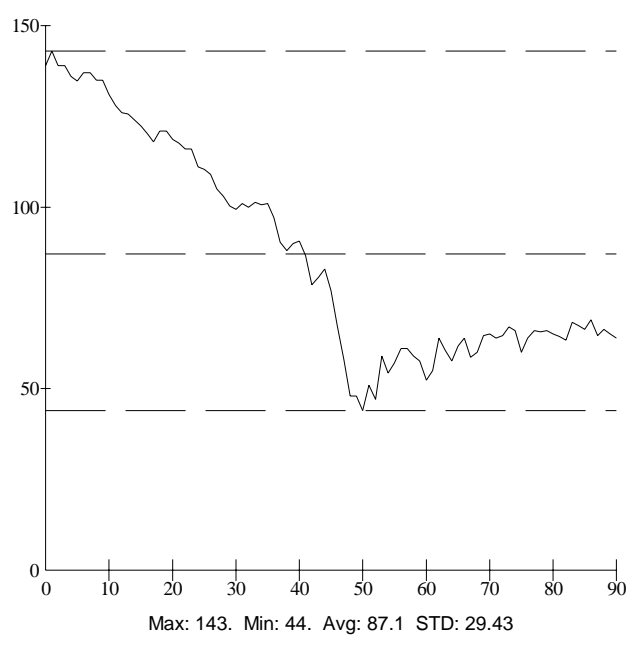

c) 6 second-delay time

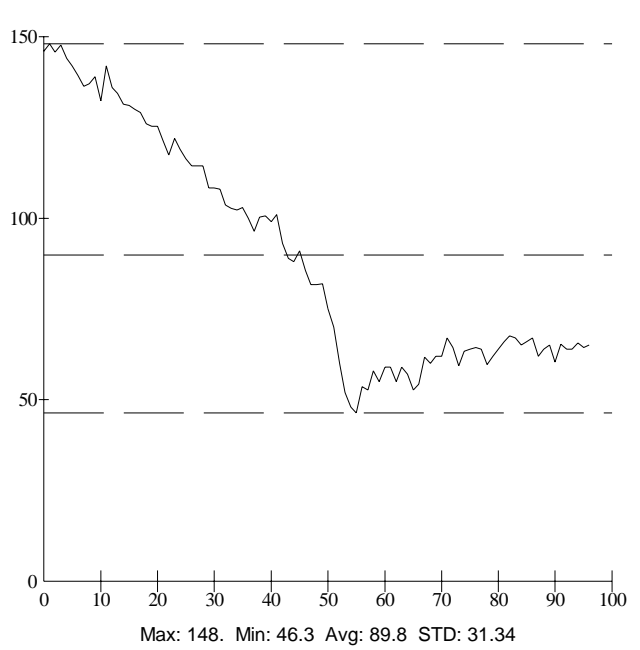

b) 3-second delay time

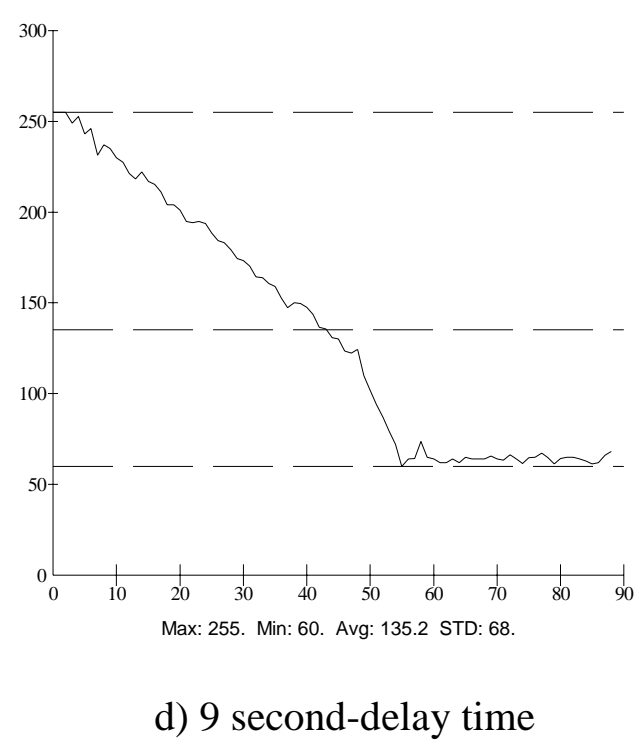

Figure A.242 Thermal intensity profile along the line across the fatigue crack shown in Figure A.241. 


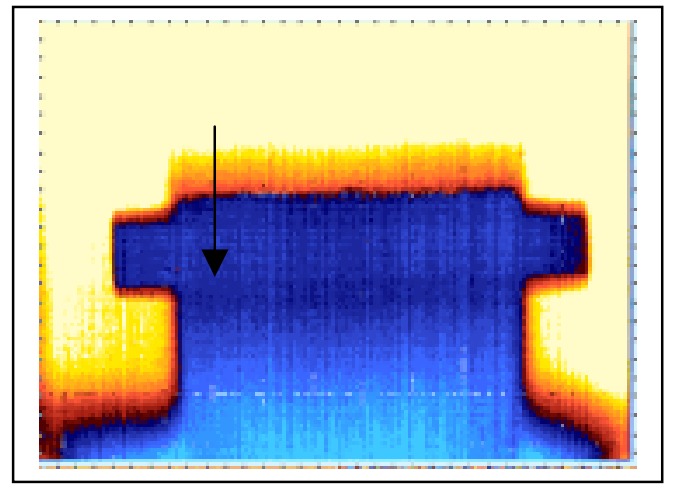

a) 1-second delay time

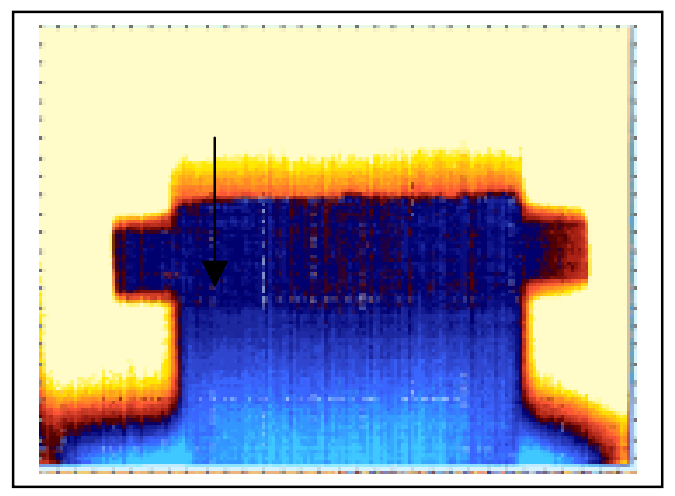

c) 6 second-delay time

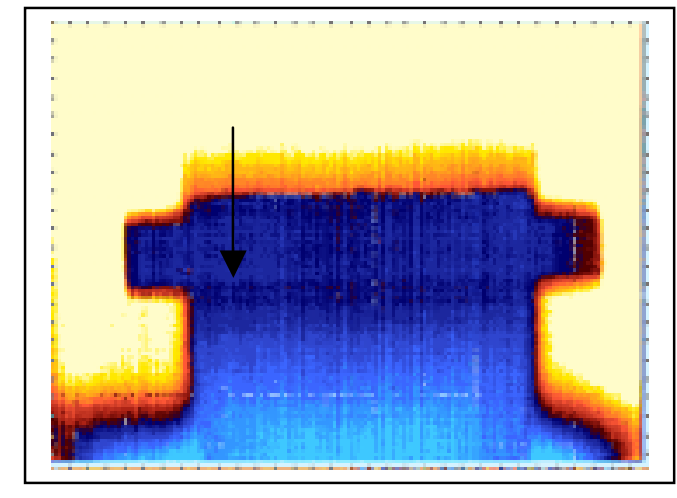

b) 3-second delay time

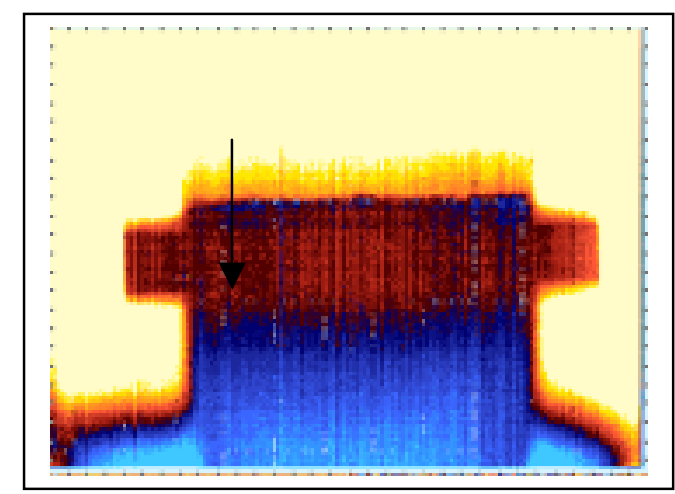

d) 9 second-delay time

Figure A.243 Top-heated thermal images of the Specimen WD-4 (coated with real color and tested under the outdoor condition) at 1,845,500 loading cycles. The heating time is 60 seconds. 


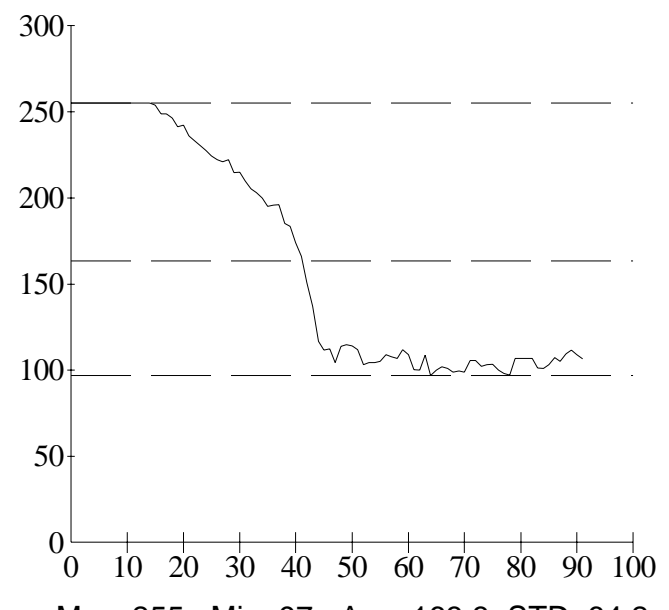

Max: 255. Min: 97. Avg: 163.3 STD: 64.2

a) 1-second delay time

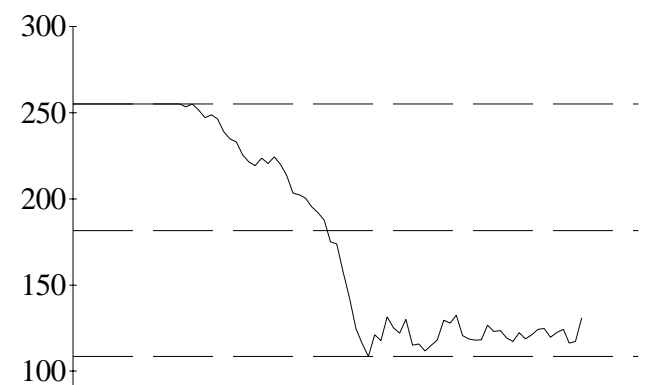

50

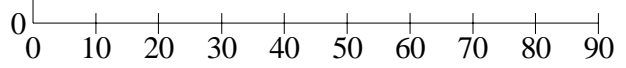

Max: 255. Min: 108.3 Avg: 181.5 STD: 59.1

c) 6 second-delay time

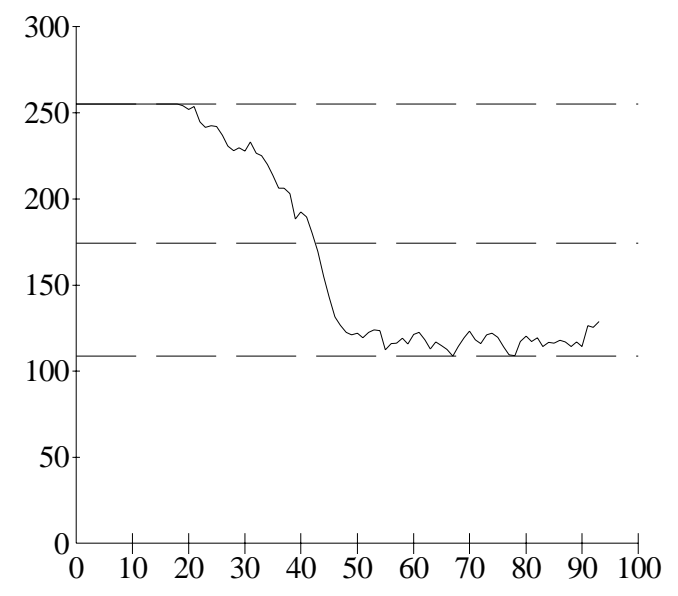

Max: 255. Min: 108.7 Avg: 174.2 STD: 60.6

b) 3-second delay time

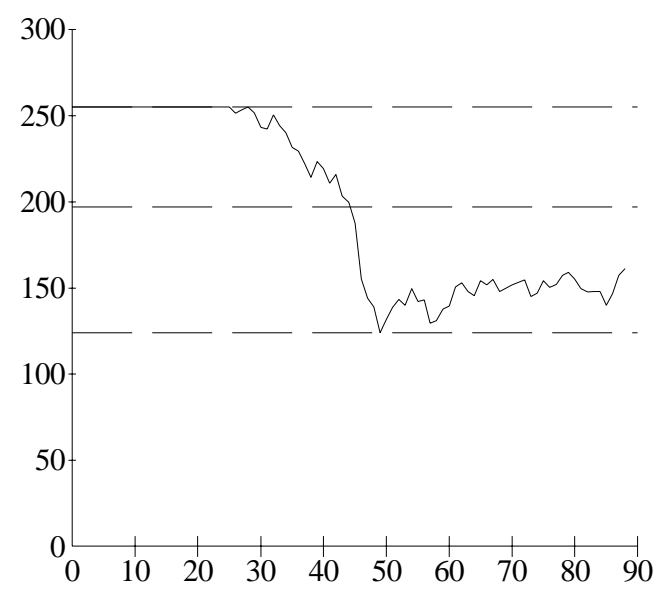

Max: 255. Min: 124. Avg: 197.1 STD: 50.4

d) 9 second-delay time

Figure A.244 Thermal intensity profile along the line across the fatigue crack shown in Figure A.243. 


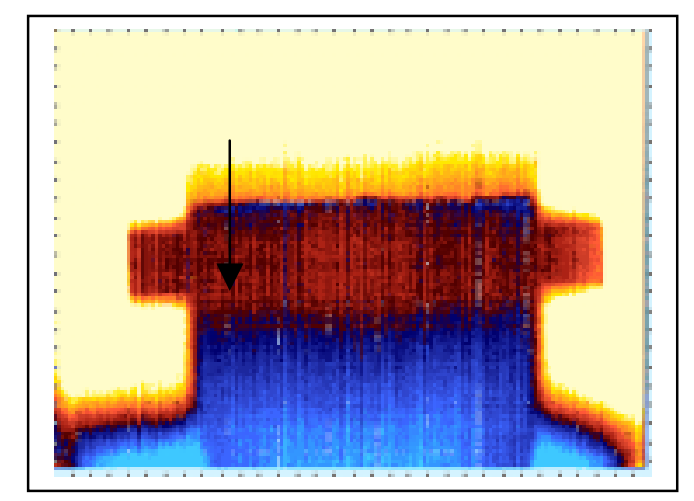

a) 1-second delay time

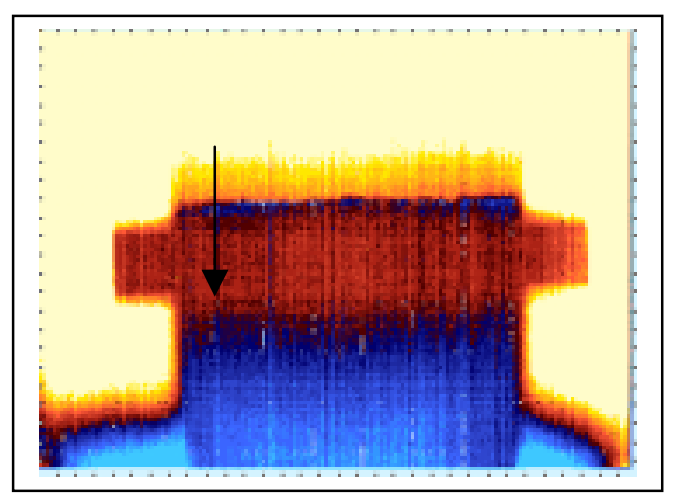

c) 6 second-delay time

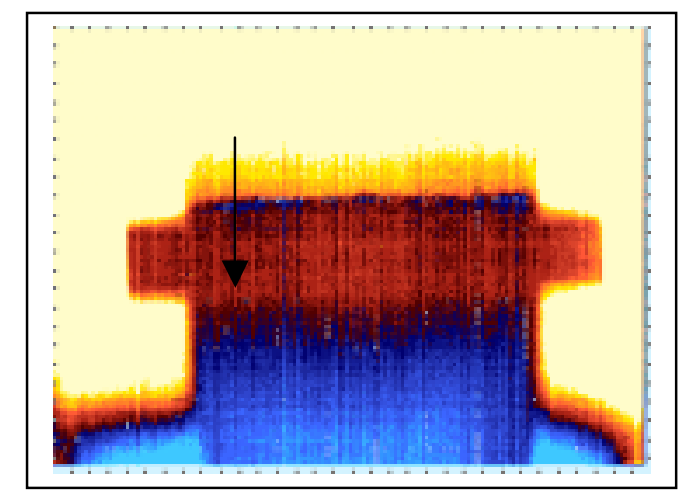

b) 3-second delay time

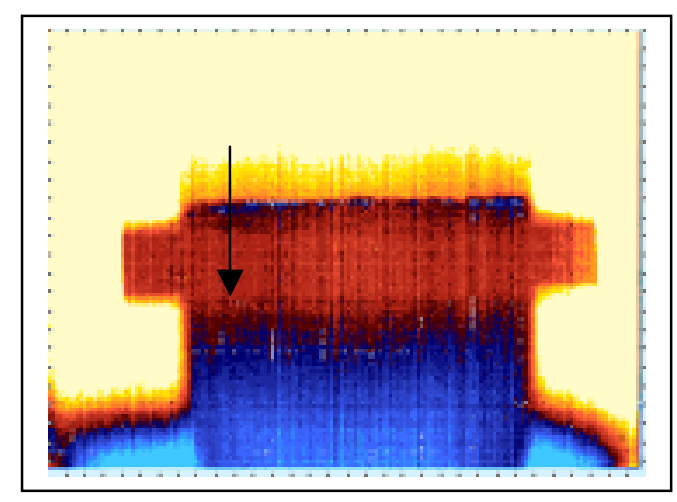

d) 9 second-delay time

Figure A.245 Top-heated thermal images of the Specimen WD-4 (coated with real color and tested under the outdoor condition) at 1,845,500 loading cycles. The heating time is 90 seconds. 


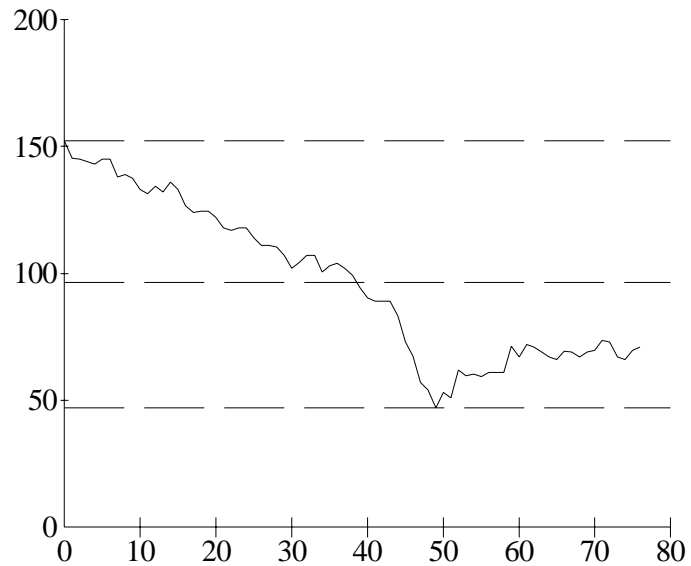
Max: 152.3 Min: 47. Avg: 96.3 STD: 30.47

a) 1-second delay time

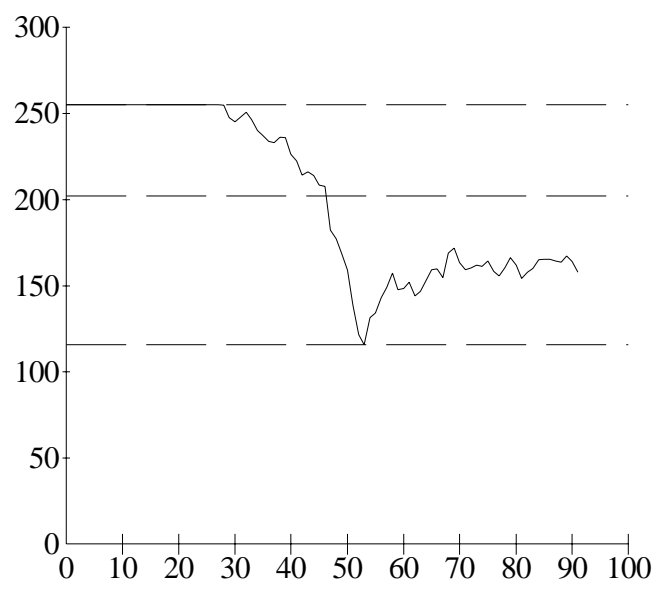

Max: 255. Min: 115.7 Avg: 202.2 STD: 46.7

c) 6 second-delay time

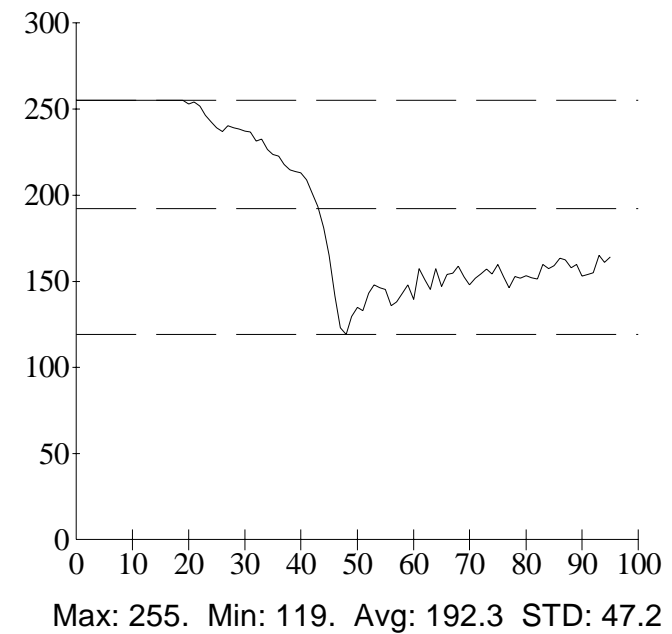

b) 3-second delay time

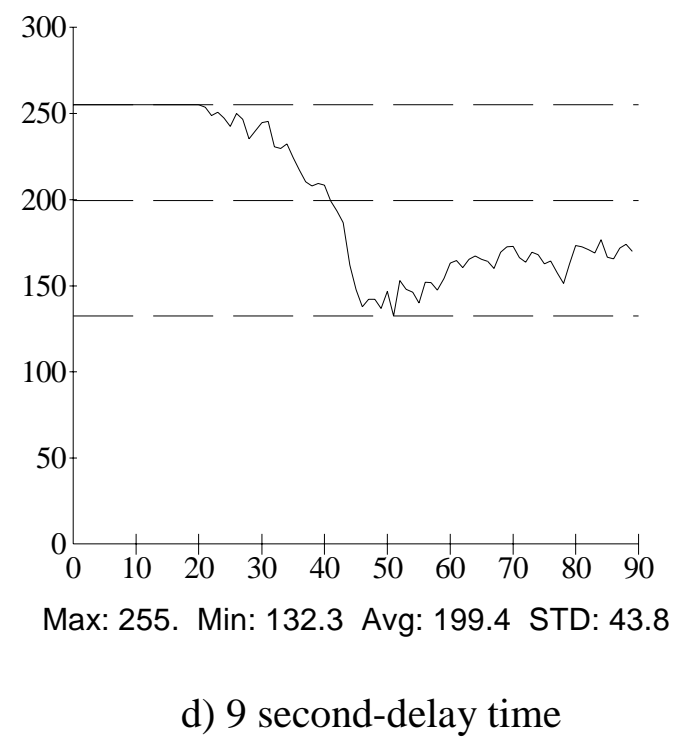

Figure A.246 Thermal intensity profile along the line across the fatigue crack shown in Figure A.245. 


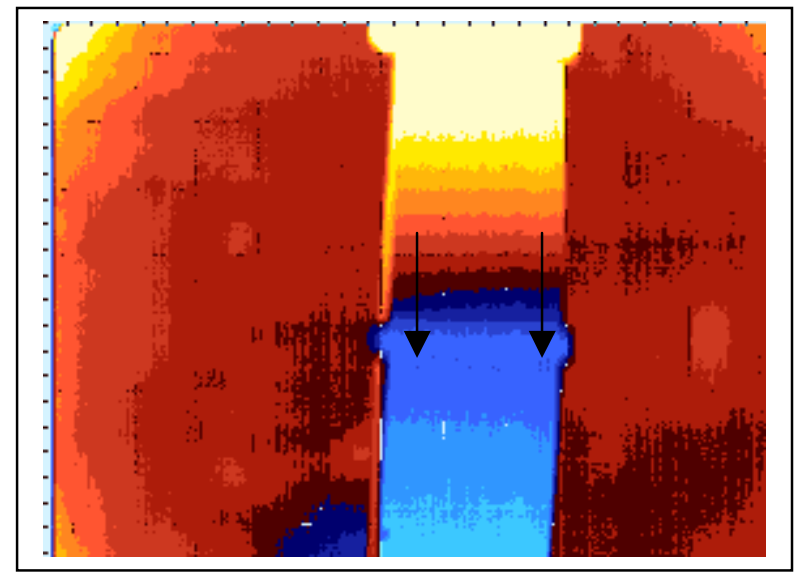

a) Thermal image
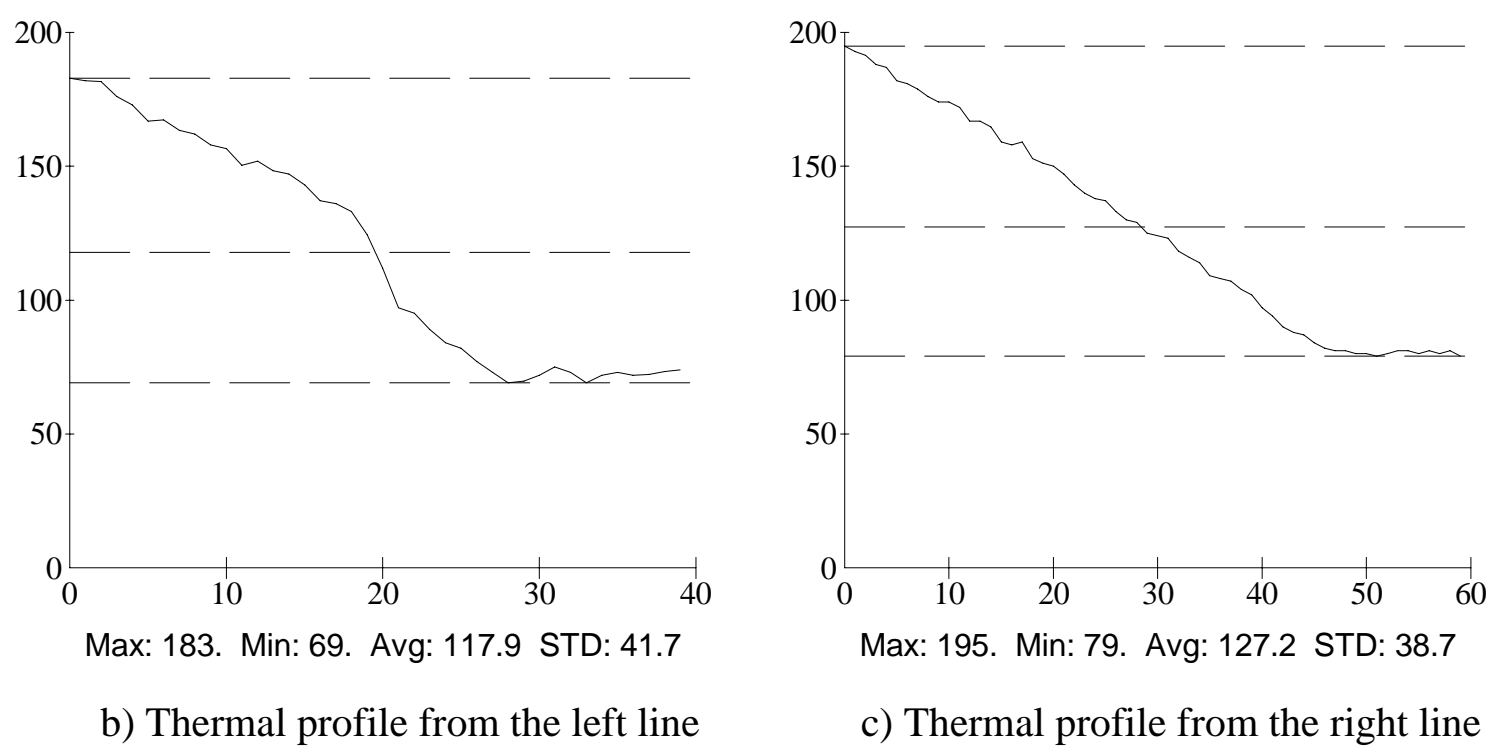

Figure A.247 Top-heated thermal images of the Specimen WD-1 at 1,336,000 loading cycles. The camera is at $450 \mathrm{~mm}$. from specimen. The heating time is 30 seconds. The delay time is 1 second. 


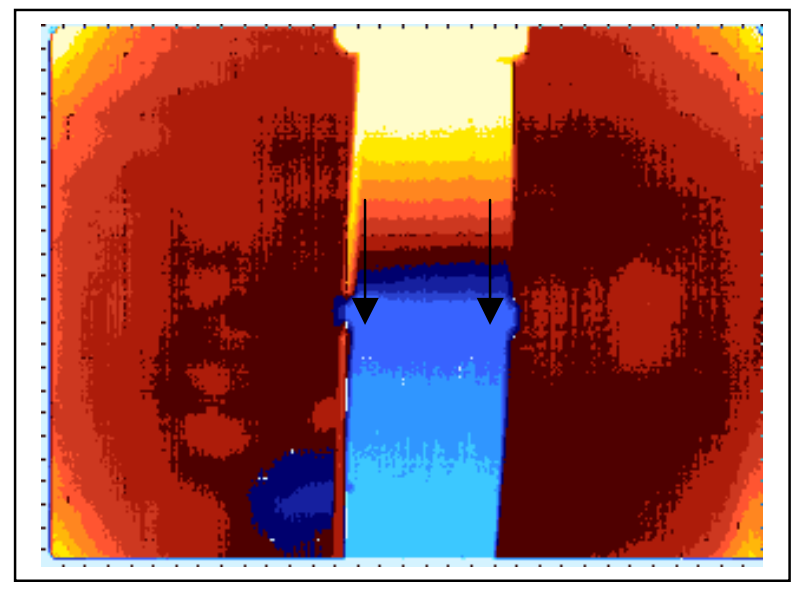

a) Thermal image
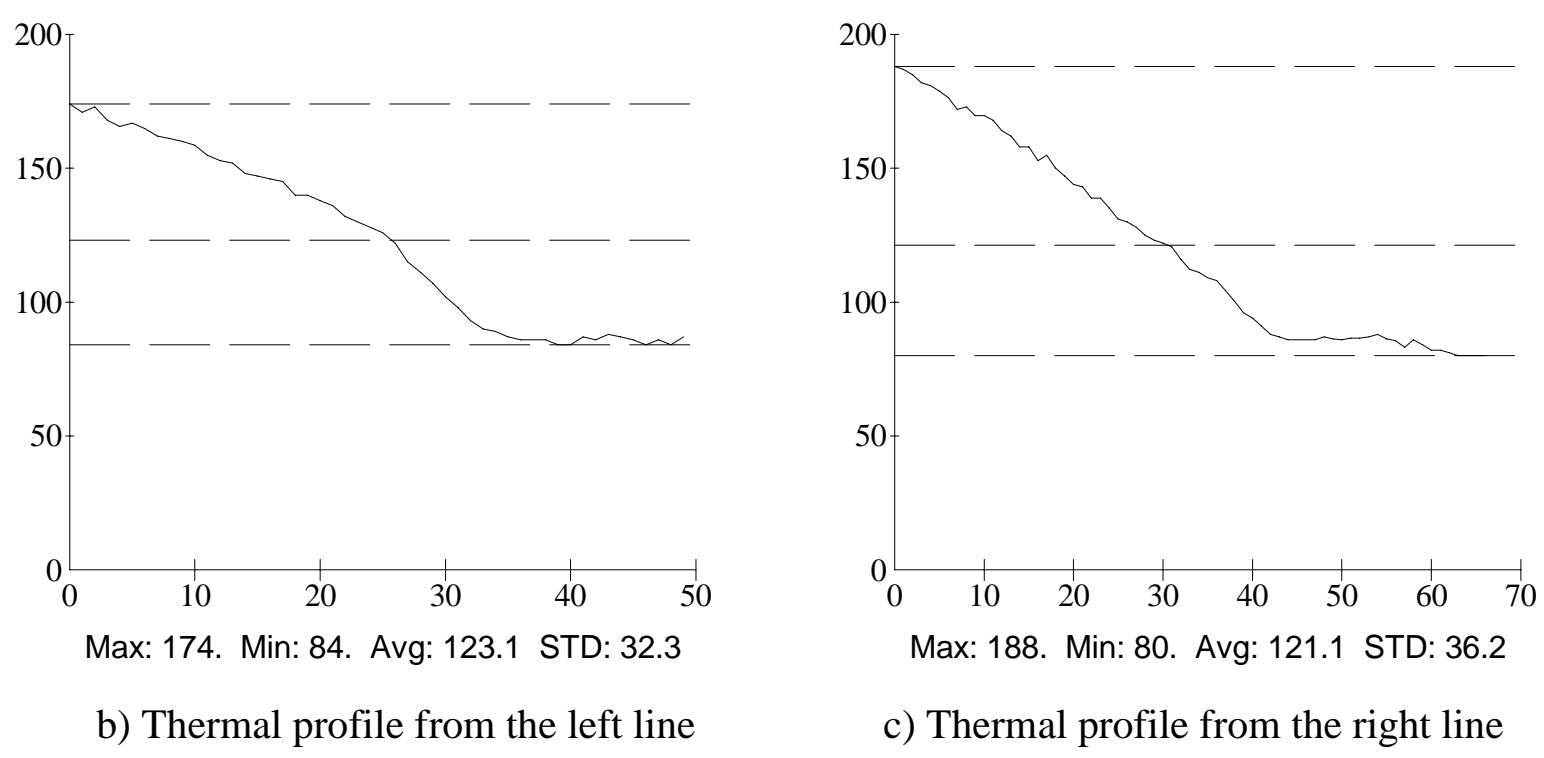

Figure A.248 Top-heated thermal images of the Specimen WD-1 at 1,336,000 loading cycles. The camera is at $525 \mathrm{~mm}$. from specimen. The heating time is 30 seconds. The delay time is 1 second. 


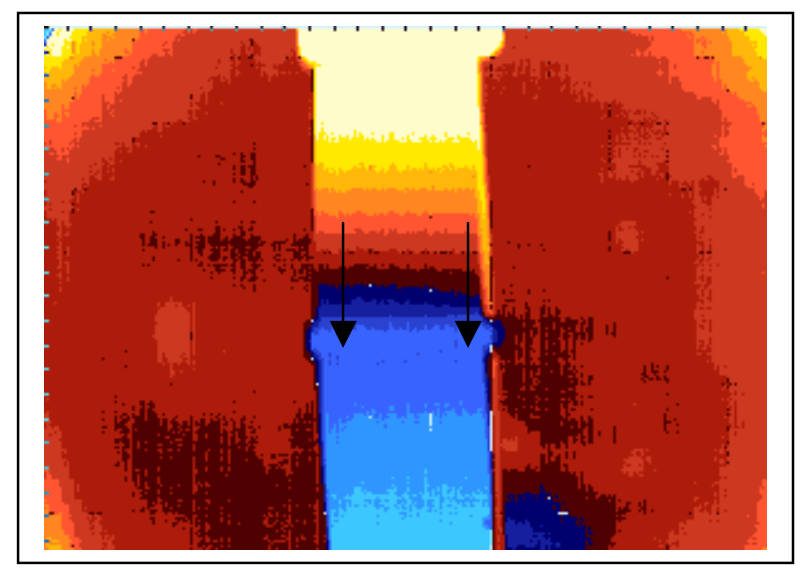

a) Thermal image

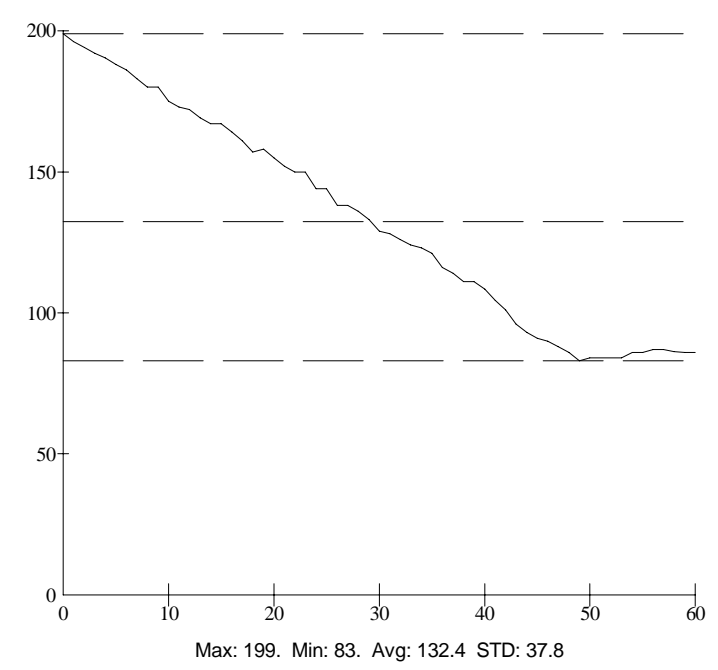

b) Thermal profile from the left line

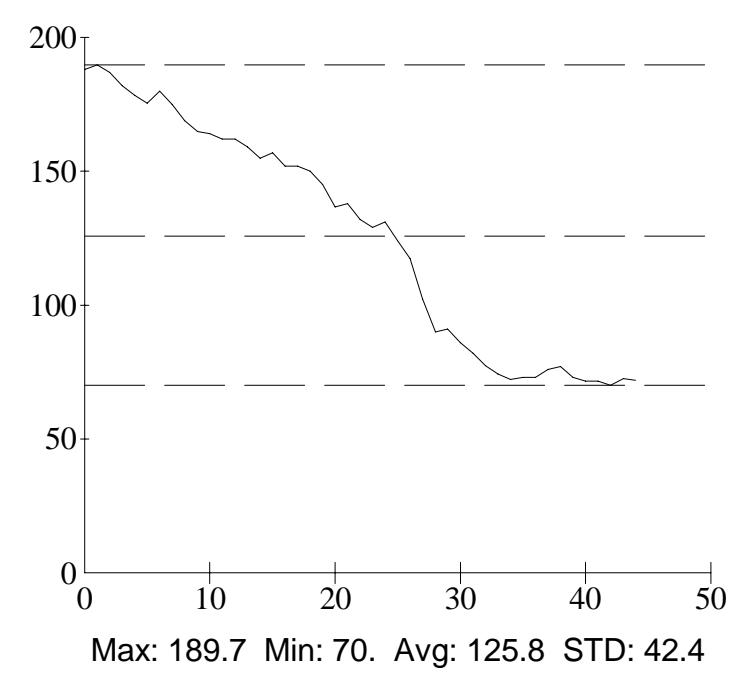

c) Thermal profile from the right line

Figure A.249 Top-heated thermal images of the Specimen WD-2 at 1,133,000 loading cycles. The camera is at $450 \mathrm{~mm}$. from specimen. The heating time is 30 seconds. The delay time is 1 second. 


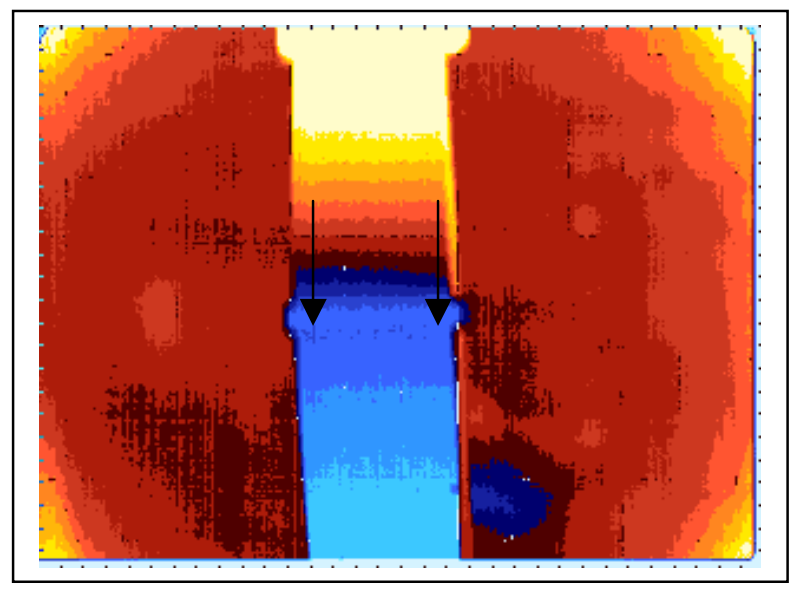

a) Thermal image

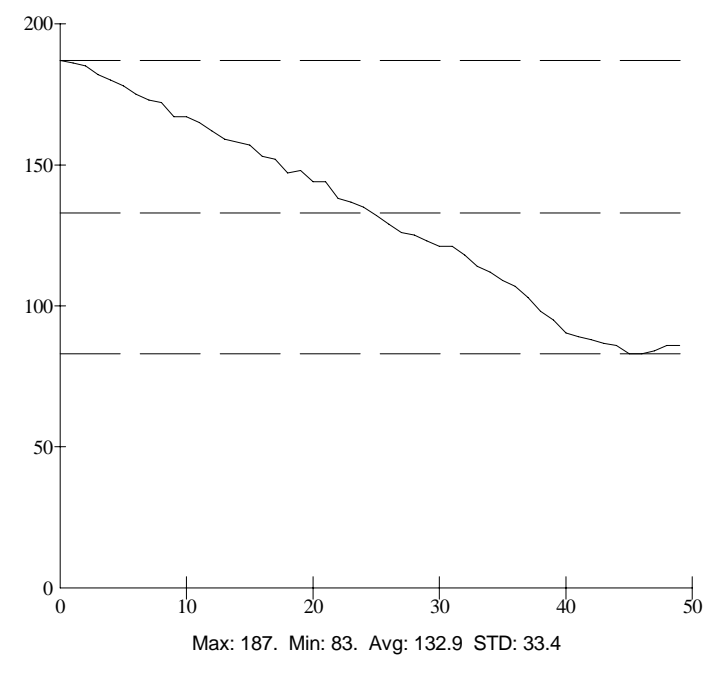

b) Thermal profile from the left line

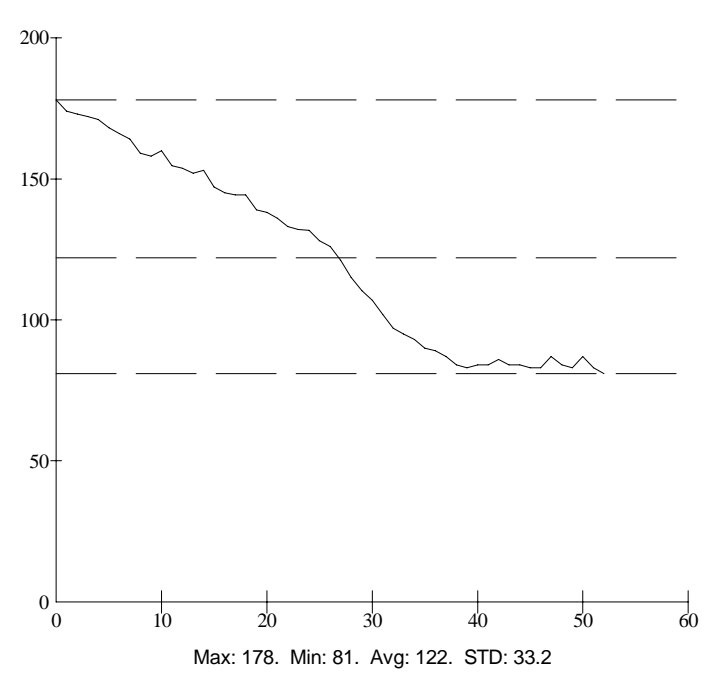

c) Thermal profile from the right line

Figure A.250 Top-heated thermal images of the Specimen WD-2 at 1,133,000 loading cycles. The camera is at $525 \mathrm{~mm}$. from specimen. The heating time is 30 seconds. The delay time is 1 second. 


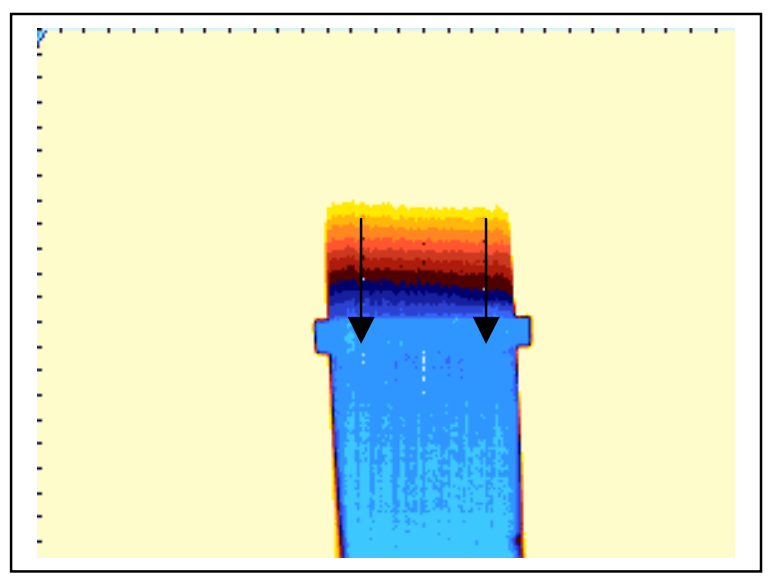

a) Thermal image

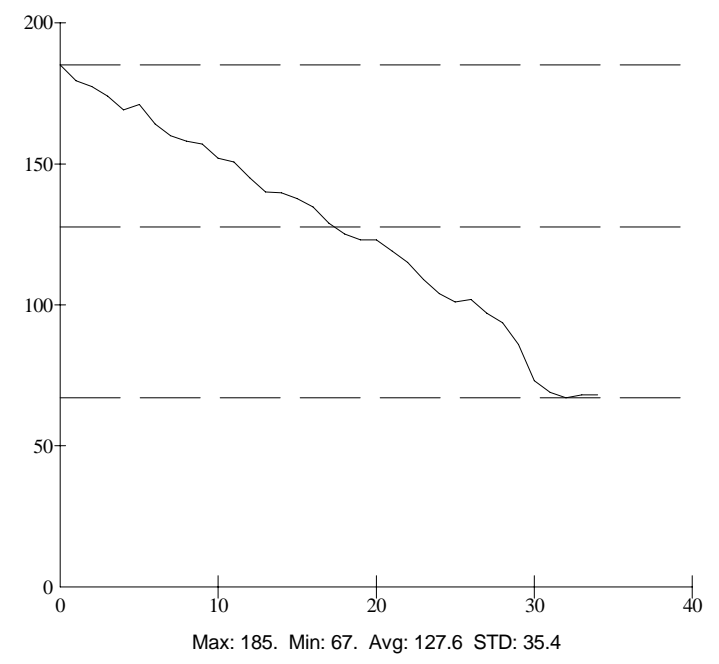

b) Thermal profile from the left line

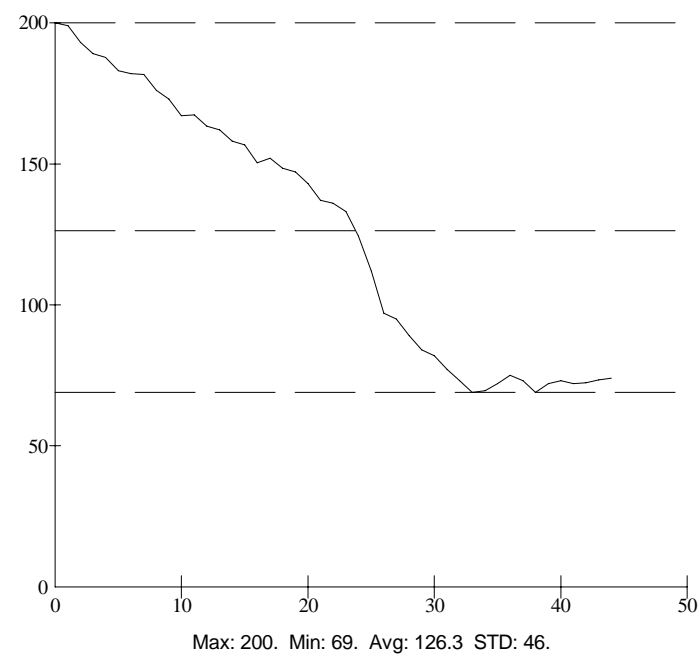

c) Thermal profile from the right line

Figure A.251 Top-heated thermal images of the Specimen WD-3 at 1,739,550 loading cycles. The camera is at $450 \mathrm{~mm}$. from specimen. The heating time is 30 seconds. The delay time is 1 second. 


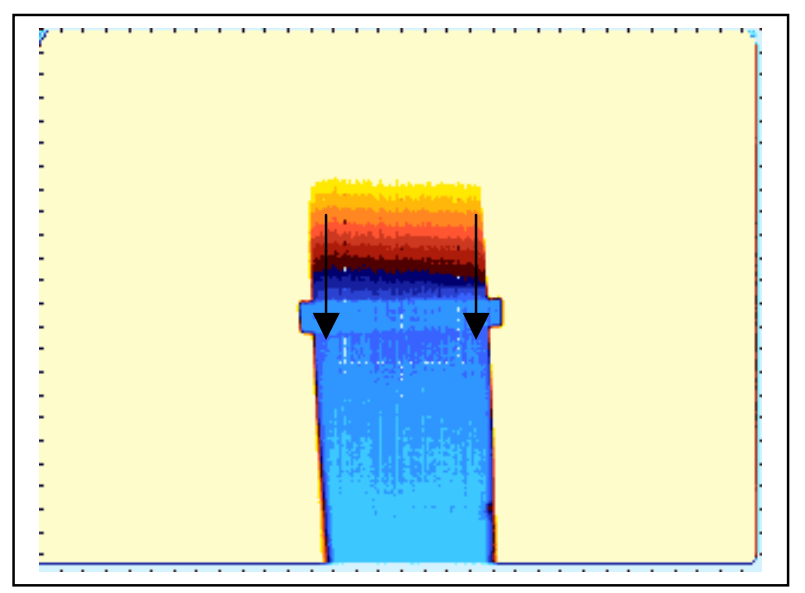

a) Thermal image

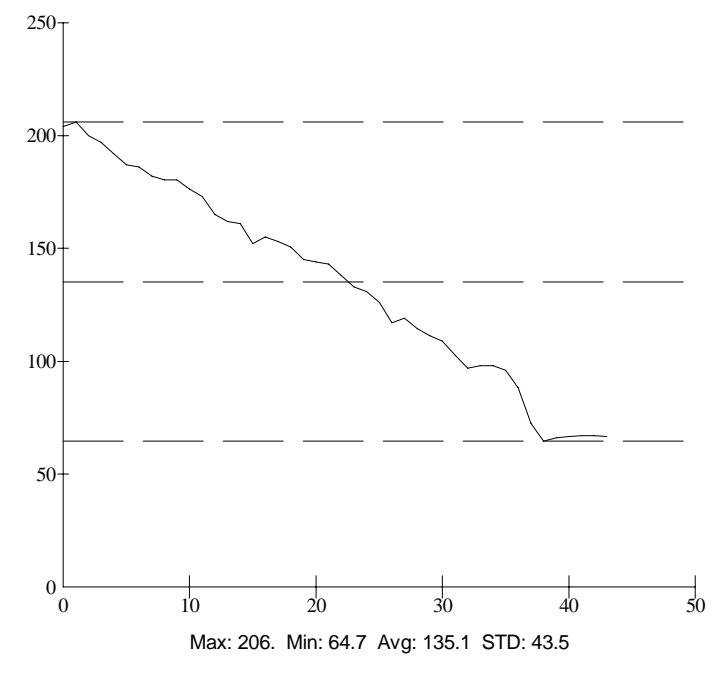

b) Thermal profile from the left line

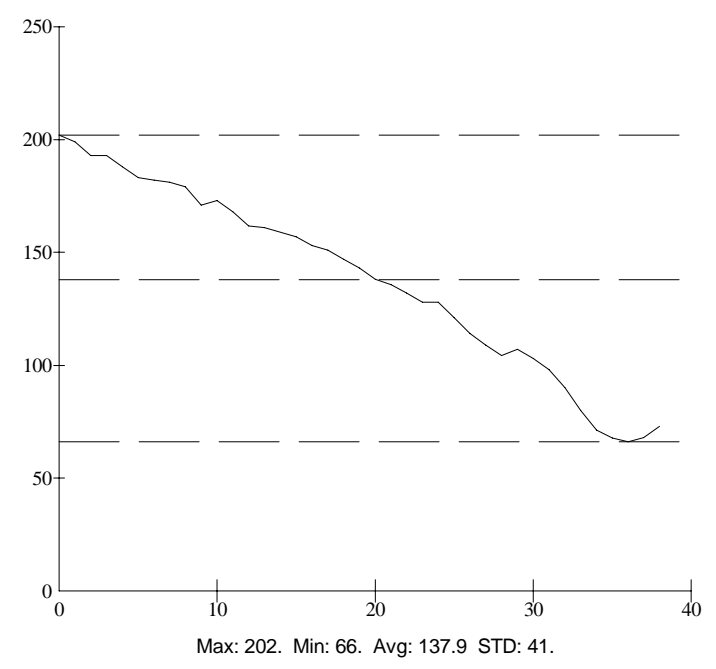

c) Thermal profile from the right line

Figure A.252 Top-heated thermal images of the Specimen WD-3 at 1,739,550 loading cycles. The camera is at $525 \mathrm{~mm}$. from specimen. The heating time is 30 seconds. The delay time is 1 second. 


\section{APPENDIX B \\ INFRARED CAMERA SET-UP}

This appendix describes the procedures used to set up the IR camera utilized in this work, including cable connection, calibration, image capturing, and control of the DeltaTherm Software (StressPhotonics, Inc., 1999), which is the software used to capture thermal images in this project.

\section{B.1 Cable Connection}

\section{B.1.1 Communication Cable}

The communication cable is a serial-port cable used to connect the IR camera with the computer, loaded with DeltaTherm Software, in order to send command signals. It is important to use a high quality cable for communications between the IR camera and the computer. The manufacturers recommend a cable that is marked "IEEE 1284". High-speed communications are sensitive to cable impedance, and IEEE 1284 cables are designed for high speed enhanced parallel port communications. The communication cable is shown as cable number 1 in Figure B.1.

\section{B.1.2 Video Signal Cable}

The video signal cable and video image card are the devices used to connect the IR camera with the computer, in order to show a real-time thermographic 
image on a computer 's monitor. The video signal cable and video image card are shown in Figure B.1 as cable number 2.

\section{B.2 Calibration}

The FPA (focal plane array) IR Camera used in this work contains a $128 \mathrm{x}$ 128 array of 16,384 infrared detectors, each of which measures infrared radiation at a specific point on the test object surface. The sensitivity of each detector varies slightly throughout the array, but the software used in this project provides calibration features to compensate for these variations. The calibration must be performed before capturing the thermal image. It can be controlled by using the calibration function as shown in Figure B.2. The two-point calibration is recommended because it will give better image results than the one-point calibration. The two-point calibration requires two calibration plates, each coated with a flat black surface and maintained at a slightly different temperature. The "cold" plate image is captured before the "hot" plate image. Then, the thermal differences between two plates are calculated and used as the lower and upper limits for capturing the thermal images. Figure B.3 shows how the IR camera is set up to perform the calibration. After calibration, then the camera can be aimed at the object to be tested and the focus adjusted. Next, the thermal image can be captured by setting the command on the DeltaTherm software. Software control details are briefly discussed in the next section.

\section{B.3 Software control}

The DeltaTherm software was developed with Microsoft Visual Basic, and as such it follows all of the same operating conventions as in most other Windows 
applications: windowed screen displays, icons, standardized menus, graphic "buttons," scroll bars, dialog boxes, and so forth. The main functions used to control the software are the followings.

\section{B.3.1 DeltaVision Control Panel}

A form in which the command for capturing the thermal image can be entered. The thermal image is captured when the capture button is placed. The thermal image will be automatically saved if the autosave function is selected. The DeltaVision Control Panel is shown in Figure B.4

\section{B.3.2 Data Viewer Window}

A data viewer window is a resizable window containing a DeltaTherm image, a color bar "legend" for the image, and text data reporting the thermal values within the image. The data viewer window is shown in Figure B.5.

- Color Bar: The Data Viewer color bar is a legend of the relative thermal intensities within the image. Different color schemes can reveal different details within the image, and it can be changed to an alternate color scheme by selecting it from the Color Bar Menu

- Interrogate Box: The Interrogate box, in the lower-left corner, reports the thermal values of individual pixels within the image array. To view the thermal value of a pixel, position the mouse pointer on that pixel and the value appears at the top of the Interrogate box, along with the $\mathrm{X}$ and $\mathrm{Y}$ coordinates of the targeted pixel. To define a line segment for interrogation, position the mouse pointer at one endpoint of the segment, click and drag the pointer to the other endpoint, and 
release the mouse button. The thermal profile of that line will appear. The example of the thermal intensity profile is shown in Figure B.6.

\section{B.3.3 Heat Source Control Function}

The Heat Source Control Function is the function to control the heating time and delay time by setting the program on the Controller. The Heat Source Control Function can be found by clicking Heat Source Control button (see Figure B.4).

\section{B.3.4 Image Control Function}

This is the form in which the command for analyzing the thermal image can be entered. The Image Control Function can be found by clicking Image Control button (see Figure B.5).

- Redraw: Redraws the image to conform to the current settings as entered in these Image Tool controls.

- Median: Applies a median filter to the image. A median filter can mask extraneous signal noise by assigning each pixel a new value equal to the median of its original value and those of the surrounding eight pixels. A median-filtered image looks "cleaner," but at the expense of some spatial resolution.

- Mean: Applies a mean filter to the image. A mean filter can mask extraneous signal noise by assigning each pixel a new value equal to the mean average of its original value and those of the surrounding eight pixels. A mean-filtered image looks "cleaner," but at the expense of some spatial resolution. 
- Invert: Converts the image to a negative image by multiplying the calibration factor for the data set by -1 .

- Bar Range: The Bar Range stretches or compresses the range of the color bar in the Data Viewer, by changing its upper and lower limits. Adjustments to the Bar Range controls can enhance detail and contrast in certain regions of the image.

- AutoScale: The AutoScale control specifies the scope of the data that will be considered when automatically optimizing the color bar range. The Image option optimizes the color bar range for the entire image. 


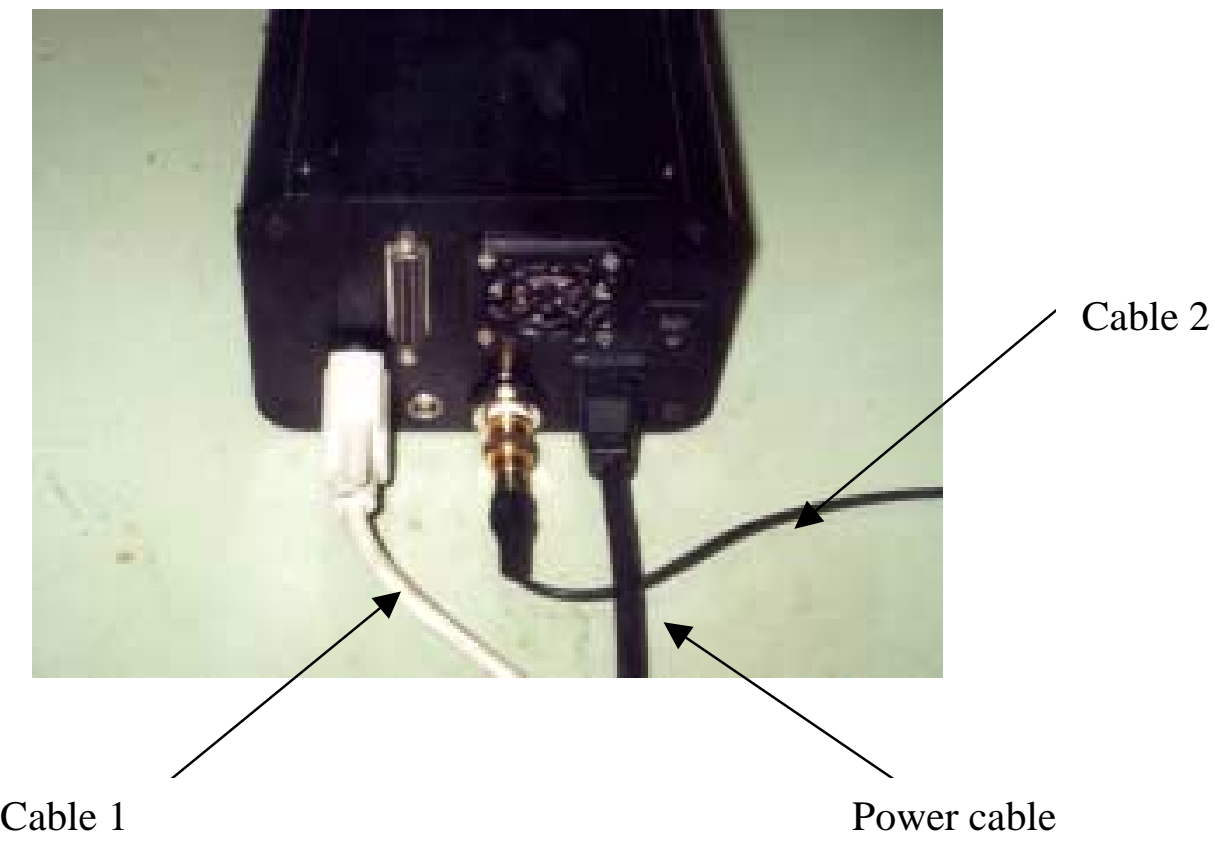

Figure B.1 Cable connection to control IR camera 


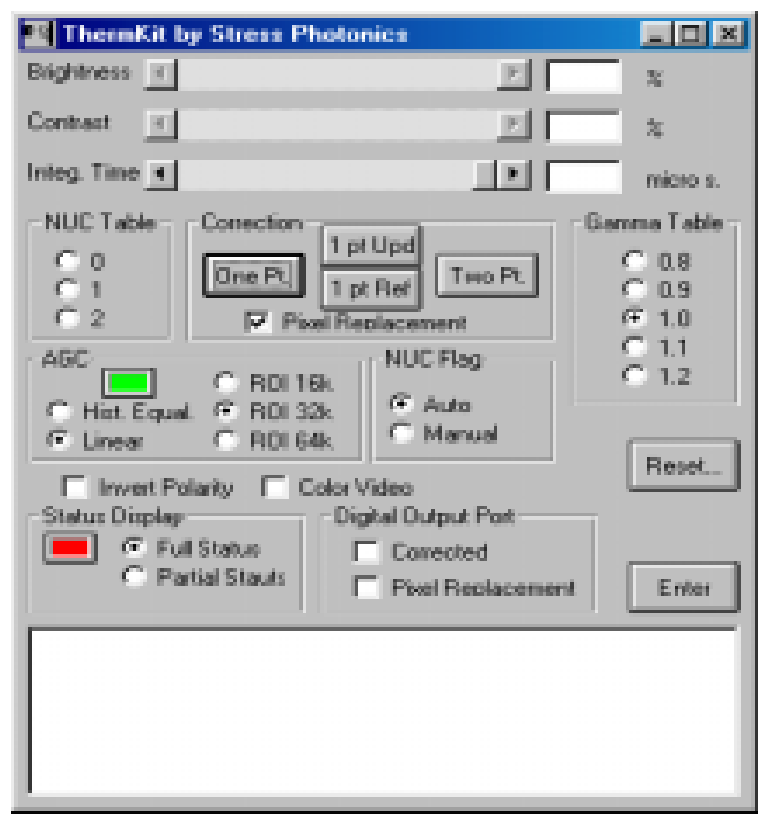

Figure B.2 Calibration window

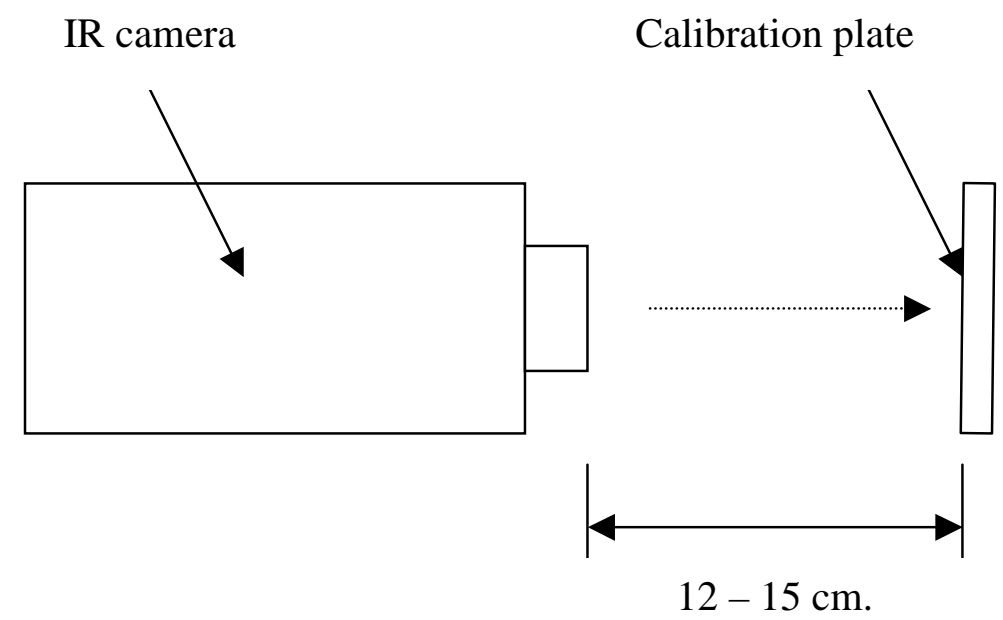

Figure B.3 Calibration set up 


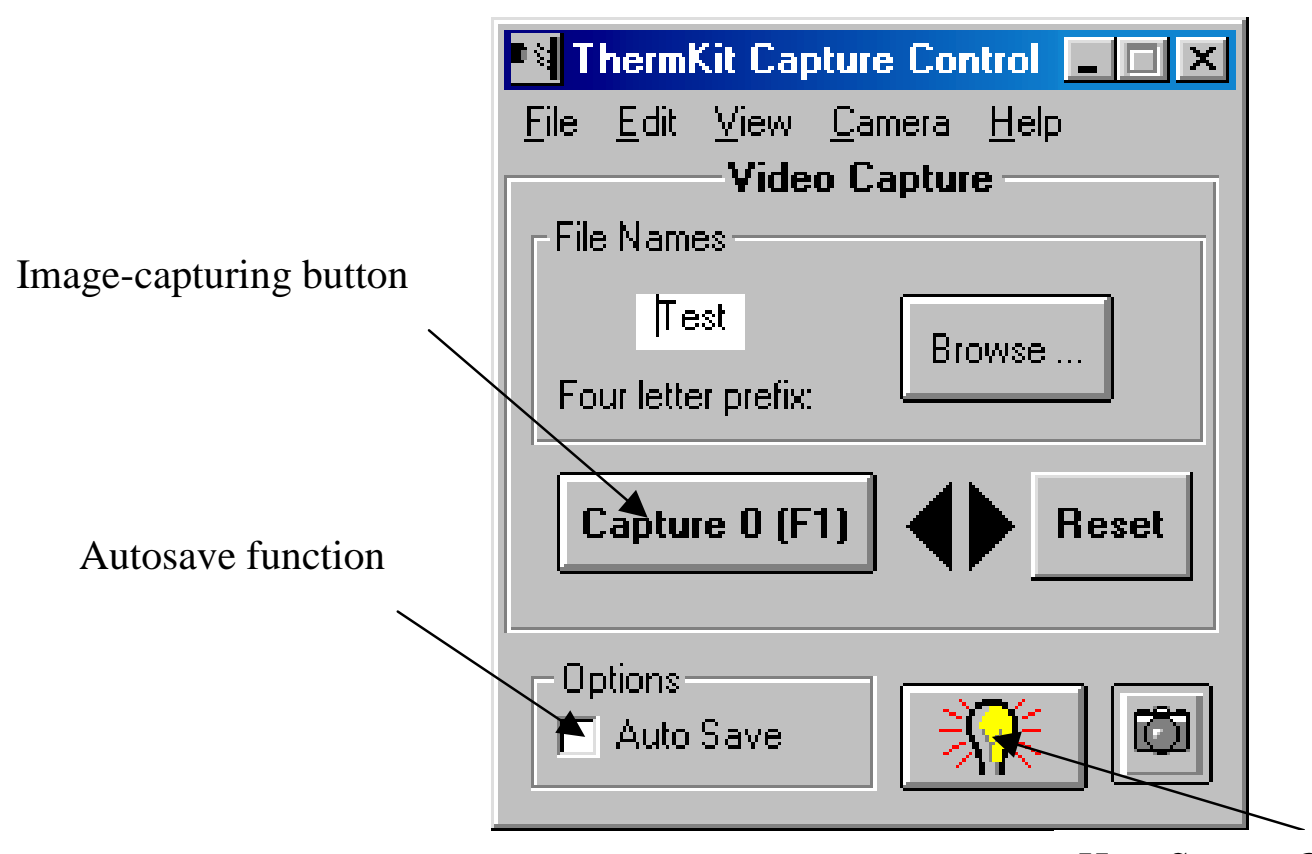

Figure B.4 The DeltaVision Control Panel

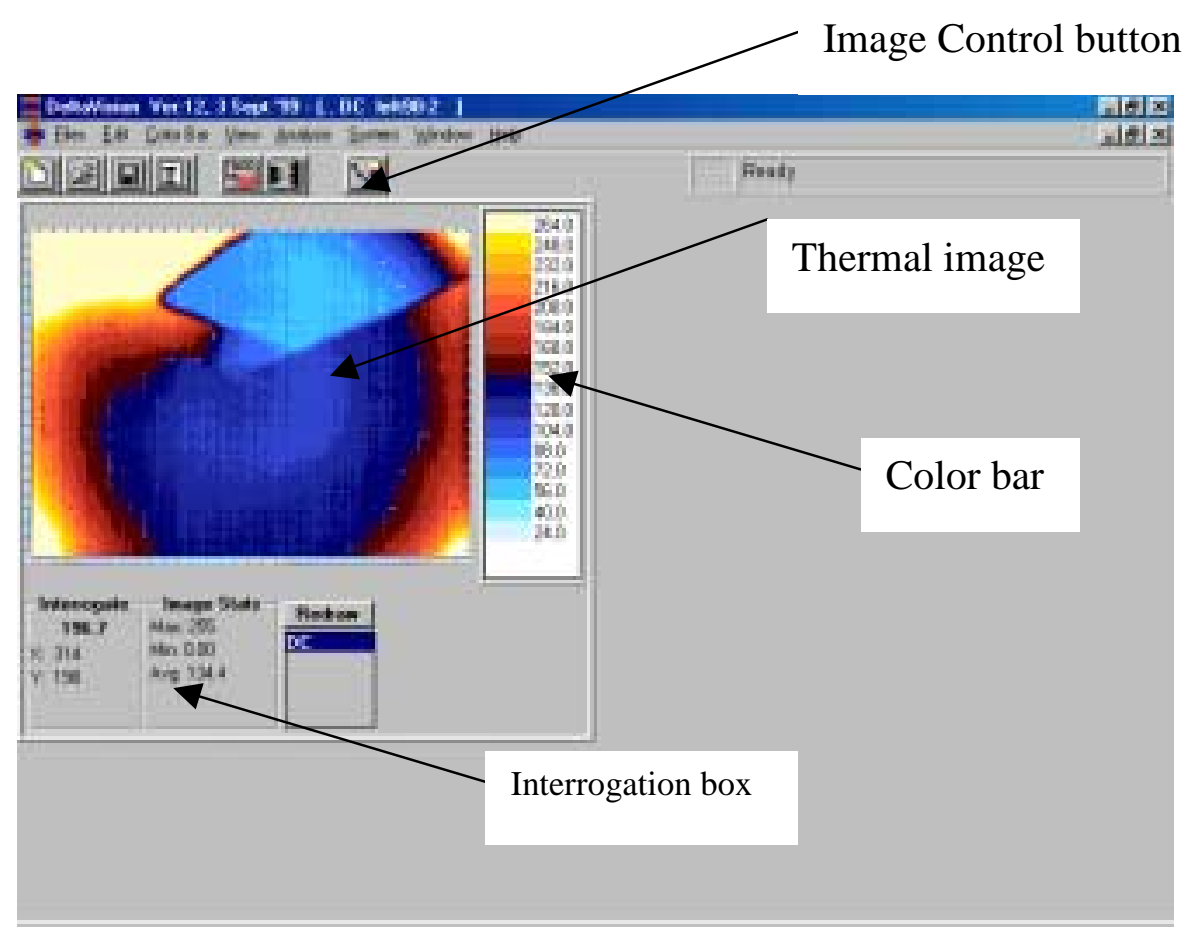

Figure B.5 The Data Viewer Window 

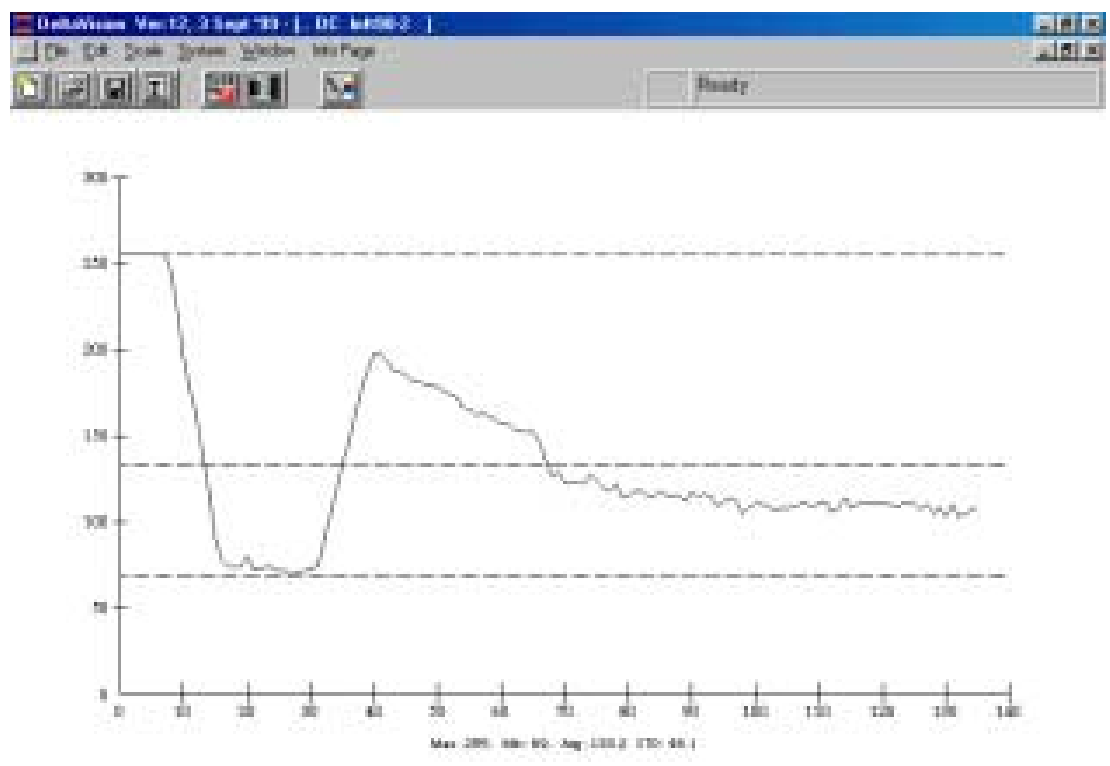

Figure B.6 Thermal intensity profile 